\title{
Eva Molitor
}

\section{Message électronique oder E-Mail?}

Einstellungen frankophoner Informatikerinnen und Informatiker zu offiziellen Ersatzwörtern für die Fachsprache des Internet und zur Sprachpolitik. Ergebnisse einer WWW-Befragung

\section{«causette» «bavardage»}

\section{«page d'accueil»}



Eva Molitor

Message électronique oder E-Mail? 
erschienen in der Reihe der Universitätsdrucke

des Universitätsverlages Göttingen 2004 
Eva Molitor

Message électronique

oder E-Mail?

Einstellungen frankophoner

Informatikerinnen und Informatiker

zu offiziellen Ersatzwörtern für die

Fachsprache des Internet und zur

Sprachpolitik: eine WWW-Befragung

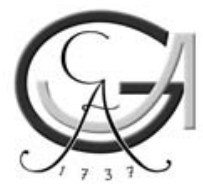

Universitätsdrucke Göttingen 2004 
Bibliografische Information Der Deutschen Bibliothek

Die Deutsche Bibliothek verzeichnet diese Publikation in der Deutschen Nationalbibliografie; detaillierte bibliografische Daten sind im Internet über $<$ http//dnb.ddb.de $>$ abrufbar.

(C) Alle Rechte vorbehalten, Universitätsverlag Göttingen 2004

Umschlaggestaltung: Margo Bargheer ISBN 3-930457-43-1 


\section{Danksagung}

Im Laufe dieser Arbeit haben mir viele Leute unendlich viel Geduld entgegengebracht, für die ich mich auf diesem Wege herzlich bedanken möchte.

Zunächst gilt mein besonderer Dank Prof. Dr. Günter Holtus, der die Arbeit betreut hat. Ohne sein Interesse am Fortgang der Forschungen, seine zahlreichen Anregungen und seine fachliche Kritik hätte die Arbeit weder in der vorliegenden Form entstehen noch in einem Zeitraum von drei Jahren abgeschlossen werden können.

Großer Dank gilt allen Personen, die mir durch ihre Ratschläge, ihr fachliches wie technisches Können weitergeholfen haben. Namentlich möchte ich nennen wenn ich auch leider sicherlich einige Personen vergessen habe - Prof. Dr. Petra Braselmann, Sandra Felix, Dr. Guillaume Garner, Holger Gutschmidt, Dr. Sylvie Mutet, Tanja Nemecek, Dr. Carsten Peust, Dirk Richter, Andreas Scholz, Anja vom Stein, Dr. Angela Weißhaar und last but not least die Zweitgutachterin Prof. Dr. Uta Helfrich.

Bedanken möchte ich mich natürlich noch bei allen Informanten, die sich die Zeit für das Ausfüllen des Fragebogens genommen haben. Ohne ihre Mithilfe wäre dieses Projekt nicht zu realisieren gewesen!

Ein Dankeschön gilt weiterhin den Mitgliedern der Göttinger Thesis-Gruppe, die mir alle viel Energie und Zuversicht gegeben haben.

Nicht unerwähnt lassen möchte ich aber auch das Stipendium nach dem niedersächsischen Graduiertenförderungsgesetz, das mir zwei Jahre finanziell unabhängigen Forschens ermöglicht hat. Ich hoffe sehr, dass trotz aktueller Sparmaßnahmen im Bildungssektor noch viele junge Forscherinnen und Forscher in den Genuss eines solchen Stipendiums kommen werden!

Göttingen, im Januar 2004 


\section{Inhaltsverzeichnis}

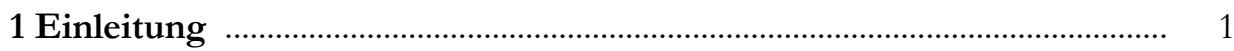

1.1 Gegenstand und Ziel dieser Arbeit .............................................................. 1

1.2 Methodik .................................................................................................

1.3 Kapitelüberblick ........................................................................................... 5

2 Einstellungsforschung ...............................................................................

2.1 Der Begriff der Einstellungen in der Sozialpsychologie und der

Linguistik ................................................................................................ 7

2.2 Einstellungsmessung …………………………………………………... 15

2.3 Einstellungsforschung in der Frankophonie: Frankreich, Belgien,

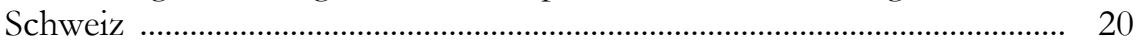

2.3.1 Die Rolle der Frankophonie .............................................................. 20

2.3.2 Frankreich ................................................................................. 24

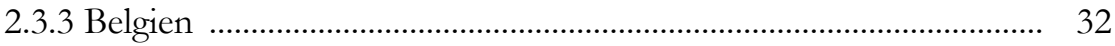

2.3.3.1 Soziolinguistische Situation ......................................................... 32

2.3.3.2 Einstellungen zum Französischen ........................................... 34

2.3.3.2.1 Das Verhältnis zwischen französisch- und
niederländischsprachigen Belgiern ........................................ 34

2.3.3.2.2 Das Verhältnis der frankophonen Belgier zum Französischen Frankreichs ...................................................... 35

2.3.3.2.3 Belgischer Purismus und Normierungsbestrebungen ......... $\quad 40$

2.3.3.2.4 Das Verhältnis der frankophonen Belgier zum Französischen Belgiens ........................................................... 42

2.3.3.3 Einstellungen zum Englischen und zu Anglizismen .................... 44

2.3.3.4 Zusammenfassung von 2.3.3 ........................................................ 47

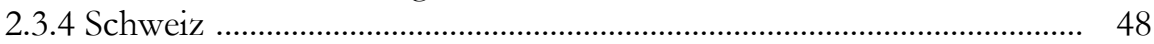

2.3.4.1 Soziolinguistische Situation ………………………………......... 48

2.3.4.2 Einstellungen zum Französischen ................................................ 51

2.3.4.2.1 Anpassung an Frankreich vs. Eigenständigkeit ................... 51

2.3.4.2.2 Das Verhältnis der Romands zum Französischen
Frankreichs und zum Französischen der Schweiz .............. 53

2.3.4.2.3 Ein eigenes Sprachbewusstsein? Lexikografie und Orthografie ............................................................................ 57

2.3.4.2.4 Sprachliche Unsicherheit bei Romands? ............................... 58

2.3.4.3 Einstellungen zum Englischen und zu Anglizismen ................... 61

2.3.4.4 Zusammenfassung von 2.3.4 ......................................................... 64

2.4 Zusammenfassung des 2. Kapitels ............................................................. 65

3 Sprachpolitische Maßnahmen zur Eindämmung angloamerikanischen Wortgutes in Frankreich, Belgien und der Schweiz

3.1 Sprachpolitik als Forschungsgebiet der Linguistik .................................... 67 
3.1.1 Terminologische Unterscheidungen: Sprachpolitik, Sprachplanung und Sprachpflege

3.1.2 Kloss' Unterscheidung zwischen Status- und Korpusplanung .......... 71

3.1.3 Vier Phasen der Sprachplanung …………………………………….... 75

3.1.4 Zusammenfassung von 3.1 ................................................................ 81

3.2 Sprachpolitik und Terminologiearbeit in Frankreich ................................. 82

3.2.1 Historischer Überblick: die Bekämpfung des franglais bis 1970 ......... 83

3.2.2 Von der Gründung der ersten Terminologiekommissionen bis

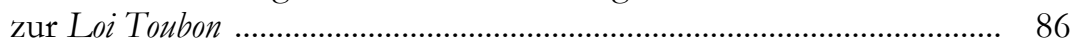

3.2.3 Die Loi Toubon und das Dekret vom 03. Juli 1996 ............................. 92

3.2.3.1 Die Loi Toubon ................................................................................ 92

3.2.3.2 Das Dekret vom 03. Juli 1996 ....................................................... 96

3.2.4 Verbreitung der Terminologie .............................................................. 101

3.2.4.1 Verbreitung der Terminologieerlasse ............................................ 101

3.2.4.2 Terminologiedatenbanken ................................................................ 104

3.2.5 Die Fachkommission zur Informatik-Terminologie ........................... 106

3.2.6 Möglichkeiten der Mitwirkung an der französischen

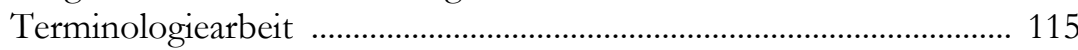

3.2.7 Zusammenfassung von 3.2 ............................................................... 116

3.3 Nationale und länderübergreifende Terminologiearbeit ............................. 117

3.3.1 Terminologiearbeit in Belgien ............................................................... 118

3.3.2 Terminologiearbeit in der Schweiz .................................................... 124

3.3.3 Länderübergreifende Terminologiearbeit .............................................. 131

3.3.3.1 Der Réseau International de Néologie et de Terminologie (Rint) und der Réseau international francophone d'aménagement linguistique

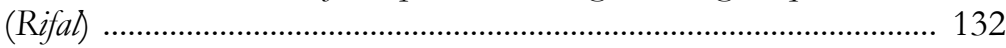

3.3.3.2 Der Réseau panlatin de terminologie (Realiter) ..................................... 135

3.3.4 Die in Frankreich, Belgien, der Schweiz und Québec gültige

Internet-Terminologie .......................................................................... 136

3.3.5 Zusammenfassung von 3.3 ................................................................... 147

4 Evaluation der französischen Sprachpolitik und Terminologie-

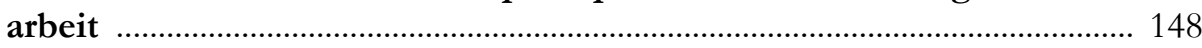

4.1 Begriffsklärung: Neologismus ........................................................................ 149

4.2 Verschiedene Typen empirischer Studien ................................................... 151

4.3 Empirische Studien zur Akzeptanz der französischen Sprachpolitik und Terminologiearbeit ............................................................................... 154

4.3.1 Studien zur Akzeptanz von Anglizismen, französischer

Sprachpolitik und Neologismen (1969-1997) ....................................... 157

4.3.2 Studien zur Akzeptanz offizieller Informatik-Neologismen .............. 168

4.3.3 Konsequenzen für die weitere empirische Forschung ........................ 173

4.4 Bewertung der französischen Sprachpolitik und Terminologiearbeit ....... 176

4.4.1 Bewertung der französischen Sprachpolitik und Terminologiearbeit aus linguistischer Perspektive ................................................... 176 
4.4.2 Bewertung der französischen Sprachpolitik durch die

Bevölkerung

4.4.2.1 Meinungsumfragen ........................................................................ 184

4.4.2.2 Reaktionen in der französischen Presse ....................................... 185

4.4.2.3 Reaktionen in der deutschsprachigen Presse ............................. 187

4.5 Zusammenfassung .............................................................................. 191

5 Akzeptanzkriterien, Analyse ausgewählter Internet-Neologismen und Arbeitshypothesen ............................................................................... 193

5.1 Kriterien der Akzeptanz ........................................................................ 194

5.2 Auswahl und Analyse der sechs Internet-Neologismen für den

WWW-Fragebogen ...................................................................................... 200

5.2.1 Selektion aufgrund formaler Kriterien .............................................. 204

5.2.2 Selektion aufgrund des Bekanntheitsgrades ...................................... 213

5.2.3 Analyse der ausgewählten französischsprachigen Internet-

Neologismen und Prognosen zu ihrer Akzeptanz .............................. 215

5.2.3.1 Analyse der ausgewählten französischsprachigen Internet-

Neologismen ................................................................................ 215

5.2.3.2 Prognosen zur Akzeptanz der ausgewählten französischsprachigen Internet-Neologismen .............................................. 219

5.3 Arbeitshypothesen ................................................................................... 223

5.3.1 Hypothesen zum Bekanntheits- und Akzeptanzgrad der französischsprachigen Neologismen .................................................. 224

5.3.2 Hypothesen zu Korrelationen zwischen sozialstatistischen Daten der Informanten und ihrem Sprachverhalten/ihren Einstellungen.... 225

5.3.3 Länderspezifische Hypothesen zur Bewertung der Sprachpolitik und Terminologiearbeit .................................................................... 227

5.3.3.1 Hypothesen zu Frankreich .......................................................... 228

5.3.3.2 Hypothesen zu Belgien .............................................................. 228

5.3.3.3 Hypothesen zur Schweiz ............................................................. 229

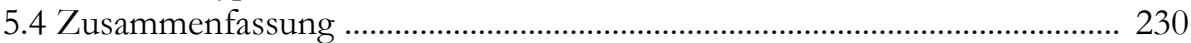

6 Die empirische Studie: Theoretische Vorüberlegungen zur

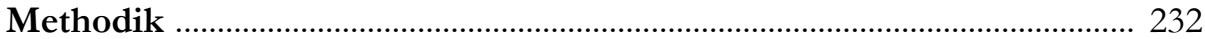

6.1 Das Internet als neues Umfragemedium ................................................. 233

6.2 Die verschiedenen Typen von Online-Befragungen ................................... 235

6.3 WWW-Befragungen und traditionelle (Papier-)Fragebögen im

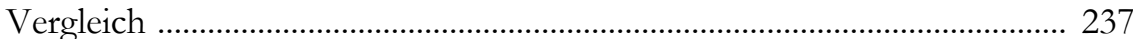

6.3.1 Nachteile von WWW-Befragungen und Lösungsansätze .................... 237

6.3.2 Vorteile von WWW-Befragungen .................................................... 244

6.4 Ankündigung eines WWW-Fragebogens (in Diskussionsforen) ............... 248

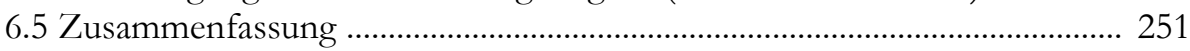


7.1 Der Aufbau des WWW-Fragebogens zur Internet-Terminologie und

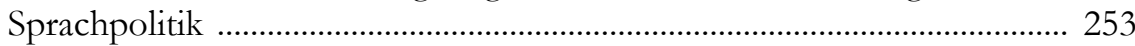

7.1.1 Zur Konzeption und Gestaltung von WWW-Befragungen ............... 253

7.1.1.1 Ein- und mehrteilige Fragebögen .................................................. 254

7.1.1.2 Fragetypen in WWW-Fragebögen ................................................. 256

7.1.1.3 Optische Gestaltung von WWW-Fragebögen .............................. 257

7.1.1.4 Technische Gestaltung von WWW-Fragebögen ........................... 259

7.1.2 Konzeption des Fragebogens zur Internet-Terminologie und Sprachpolitik ................................................................................... 260

7.1.2.1 Das erste Fragebogenmodul ....................................................... 264

7.1.2.2 Das zweite Fragebogenmodul ......................................................... 268

7.1.2.3 Das dritte Fragebogenmodul ....................................................... 270

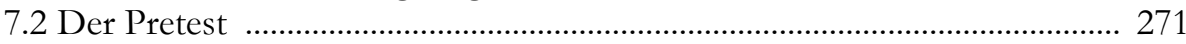

7.2.1 Funktion und Gestaltung eines Pretests ............................................... 271

7.2.2 Durchführung des Pretests zur Internet-Terminologie und

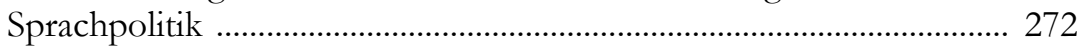

7.3 Zusammenfassung ...................................................................................... 274

8 Die Durchführung der WWW-Befragung und die Informanten ............. 276

8.1 Durchführung der WWW-Befragung zur Internet-Terminologie und Sprachpolitik 276

8.1.1 Ankündigung des WWW-Fragebogens in Diskussionsforen ............. 276

8.1.2 Charakterisierung der neun ausgewählten Diskussionsforen ............. 279

8.1.2.1 Das Forum fr.comp.divers …………………………………....... 280

8.1.2.2 Das Forum fr.soc.internet ............................................................. 280

8.1.2.3 Das Forum fr.comp.lang.general .................................................. 281

8.1.2.4 Das Forum fr.misc.bavardages.linux ........................................... 281

8.1.2.5 Das Forum fr.comp.developpement ............................................. 282

8.1.2.6 Das Forum fr.comp.lang.perl .......................................................... 283

8.1.2.7 Das Forum fr.comp.lang.java …………………………………..... 283

8.1.2.8 Das Forum fr.comp.lang.c .......................................................... 284

8.1.2.9 Das Forum fr.comp.lang.c ........................................................... 284

8.2 Biosoziale Angaben der Informanten .......................................................... 285

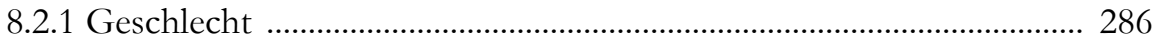

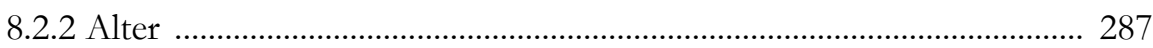

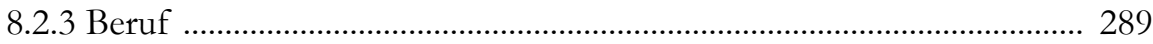

8.2.4 Höchster Bildungsabschluss ............................................................... 290

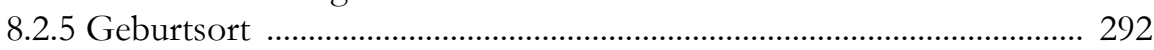

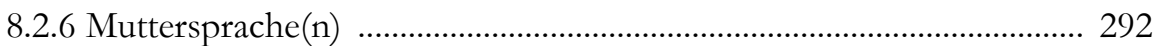

8.2.7 Wohnsitz (Land, Region/Kanton) ........................................................ 293

8.2.8 Englischkenntnisse .................................................................................. 294

8.2.9 Art und Dauer der Internetnutzung .................................................... 296

8.3 Zusammenfassung ....................................................................................... 299 
9.1 Erstes Fragebogenmodul: Auswertung der sechs ausgewählten

Lexemgruppen

9.1.1 Die Termini courrier électronique, message électronique, mél, courriel, messagerie électronique, lettre électronique, e-mail und mail

9.1.2 Die Termini page d'accueil, page d'introduction und homepage

9.1.3 Die Termini toile d'araignée mondiale, toile mondiale, toile, T.A.M., réseau mondial, World Wide Web und web

9.1.4 Die Termini causette, bavardage, conversation électronique und chat ........... 328

9.1.5 Die Termini pirate, fouineur und cracker .................................................. 335

9.1.6 Die Termini fournisseur d'accès, pourvoyeur d'accès und (access) provider ...... 341

9.1.7 Zusammenfassung und Schlussfolgerungen .......................................... 346

9.2 Zweites Fragebogenmodul: Auswertung der Kenntnis und Akzeptanz der aktuellen Sprachpolitik und Terminologiearbeit .................................. 350

9.2.1 Auswertung der Fragen 44-49 ................................................................... 350

9.2.2 Auswertung der länderspezifischen Hypothesen ............................... 355

9.3 Drittes Fragebogenmodul: Auswertung der Kommentare zur

Sprachpolitik und Terminologiearbeit .................................................... 357

9.4 Korrelationen zwischen biosozialen Faktoren und Sprachverhalten/

Einstellungen

9.4.1 Hypothese II.1: Vergleich zwischen Ablehnung der Anglizismen und der Ablehnung der Sprachpolitik

9.4.2 Hypothese II.2: Korrelation zwischen Alter und Sprachgebrauch/

Einstellungen

9.4.2.1 Korrelation zwischen Alter und Sprachgebrauch

9.4.2.2 Korrelation zwischen Alter und Einstellungen zur Sprach-

politik/Terminologiearbeit

9.4.3 Hypothese II.3: Korrelation zwischen Bildungsgrad und

Einstellungen

9.4.4 Hypothese II.4: Korrelation zwischen Beruf und Sprachgebrauch/ Einstellungen

9.4.5 Hypothese II.5: Korrelation zwischen Englischkenntnissen und Sprachgebrauch

9.4.6 Hypothese II.6: Korrelation zwischen Internetnutzung und Sprachgebrauch

\section{Auswertung der WWW-Befragung: das französischsprachige}

10.1 Erstes Fragebogenmodul: Auswertung der sechs ausgewählten

Lexemgruppen

10.1.1 Die Termini courrier électronique, message électronique, mél, courriel, messagerie électronique, lettre électronique, e-mail und mail

10.1.2 Die Termini page d'accueil, page d'introduction und homepage 
10.1.3 Die Termini toile d'araignée mondiale, toile mondiale, toile, T.A.M., réseau mondial, World Wide Web und web

10.1.4 Die Termini causette, bavardage, conversation électronique und chat ......... 400

10.1.5 Die Termini pirate, fouineur und cracker .............................................. 405

10.1.6 Die Termini fournisseur d'accès, pourvoyeur d'accès und (access) provider ... 411

10.1.7 Zusammenfassung und Schlussfolgerungen ..................................... 416

10.2 Zweites Fragebogenmodul: Kenntnis und Akzeptanz der aktuellen

Sprachpolitik und Terminologiearbeit ................................................... 418

10.2.1 Auswertung der Fragen 44-49 ................................................................ 418

10.2.2 Auswertung der länderspezifischen Hypothesen ............................. 421

10.3 Drittes Fragebogenmodul: Auswertung der Kommentare zur

Sprachpolitik und Terminologiearbeit ................................................. 421

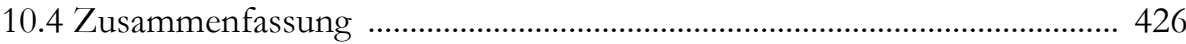

\section{Auswertung der WWW-Befragung: die französischsprachige}

Schweiz

11.1 Erstes Fragebogenmodul: Auswertung der sechs ausgewählten

Lexemgruppen

11.1.1 Die Termini courrier électronique, message électronique, mél, courriel, messagerie électronique, lettre électronique, e-mail und mail

11.1.2 Die Termini page d'accueil, page d'introduction und homepage................... 435

11.1.3 Die Termini toile d'araignée mondiale, toile mondiale, toile, T.A.M., réseau mondial, World Wide Web und web

11.1.4 Die Termini causette, bavardage, conversation électronique und chat .......... 446

11.1.5 Die Termini pirate, fouineur und cracker ................................................. 452

11.1.6 Die Termini fournisseur d'accès, pourvoyeur d'accès und (access) provider ... 457

11.1.7 Zusammenfassung und Schlussfolgerungen ....................................... 460

11.2 Zweites Fragebogenmodul: Kenntnis und Akzeptanz der aktuellen

Sprachpolitik und Terminologiearbeit ..................................................... 463

11.2.1 Auswertung der Fragen 44-48 ........................................................... 463

11.2.2 Auswertung der länderspezifischen Hypothesen ............................... 465

11.3 Drittes Fragebogenmodul: Auswertung der Kommentare zur

Sprachpolitik und Terminologiearbeit ................................................... 466

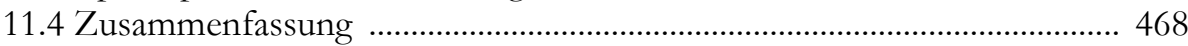

12 Vergleich der Ergebnisse: Frankreich, Belgien und die Schweiz ........ 470

12.1 Erstes Fragebogenmodul: Auswertung der sechs ausgewählten

Lexemgruppen 471

12.1.1 Die Termini courrier électronique, message électronique, mél, courriel, messagerie électronique, lettre électronique, e-mail und mail 472

12.1.2 Die Termini page d'accueil, page d'introduction und homepage .................. 475

12.1.3 Die Termini toile d'araignée mondiale, toile mondiale, toile, T.A.M., réseau mondial, World Wide Web und web

12.1.4 Die Termini causette, bavardage, conversation électronique und chat ......... 479 
12.1.5 Die Termini pirate, fouineur und cracker ............................................... 480

12.1.6 Die Termini fournisseur d'accès, pourvoyeur d'accès und (access) provider ... 483

12.1.7 Zusammenfassung und Schlussfolgerungen ....................................... 484

12.2 Zweites Fragebogenmodul: Kenntnis und Akzeptanz der aktuellen Sprachpolitik und Terminologiearbeit .

12.3 Drittes Fragebogenmodul: Auswertung der Kommentare zur

Sprachpolitik und Terminologiearbeit ....................................................... 495

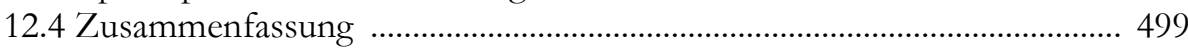

12.5 Exkurs: Sprachpolitik und Internet-Terminologie in Spanien,

Deutschland und Italien ............................................................................... 501

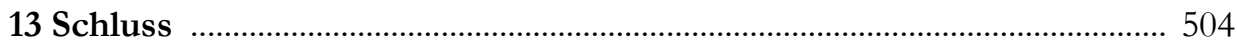

13.1 Ergebnisse und Ausblick ................................................................................ 504

13.2 Résumé et perspectives ………………………………………………….... 509

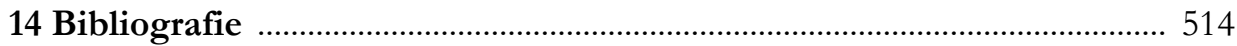

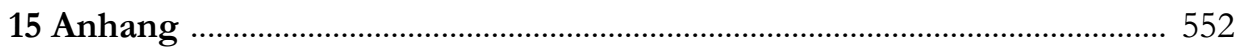

15.1 Internetseiten zur WWW-Umfrage ........................................................ 552

15.1.1 Eingangsseite der WWW-Umfrage ………………………………... 552

15.1.2 Internetseite mit weiterführenden Informationen ............................. 553

15.2.3 Endseite der WWW-Umfrage ........................................................ 555

15.2 Ankündigung des Fragebogens in den ausgewählten Diskussionsforen

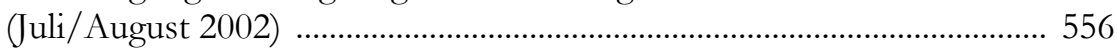

15.2.1 Ankündigung des Fragebogens .......................................................... 556

15.2.2 Erinnerungsschreiben (2. Erhebungswelle) ……………………….... 557

15.3 Der Fragebogen .................................................................................... 558

15.4 Biosoziale Daten (3. Fragebogenmodul) ………………………………... 574

15.4.1 Berufe der Informanten .................................................................. 574

15.4.2 Wohnsitz der Informanten .................................................................. 578

15.5 Textantworten (2. Fragebogenmodul) ....................................................... 581

15.5.1 Fragen 3, 10, 17, 24, 31 und 38 nach dem Bedeutungsunterschied 581

15.5.1.1 Frankreich .................................................................................... 581

15.5.1.1.1 Frage 3: Bedeutungsunterschiede zwischen courrier électronique / message électronique / mél / courriel / messagerie électronique / e-mail / mail (Frankreich) ................................... 581

15.5.1.1.2 Frage 10: Bedeutungsunterschiede zwischen page d'accueil / homepage (Frankreich) ........................................... 586

15.5.1.1.3 Frage 17: Bedeutungsunterschiede zwischen toile d'araignée mondiale / toile mondiale / toile / T.A.M. / web / World Wide Web (Frankreich) .............................................. 588

15.5.1.1.4 Frage 24: Bedeutungsunterschiede zwischen causette / bavardage / chat (Frankreich) ................................................ 589

15.5.1.1.5 Frage 31: Bedeutungsunterschiede zwischen pirate / 
cracker (Frankreich) ............................................................... 590

15.5.1.2 Belgien

590

15.5.1.2.1 Frage 3: Bedeutungsunterschiede zwischen courrier électronique / message électronique / mél / courriel / messagerie électronique / e-mail / mail (Belgien)

15.5.1.2.2 Frage 10: Bedeutungsunterschiede zwischen page d'accueil / homepage (Belgien)

15.5.1.2.3 Frage 17: Bedeutungsunterschiede zwischen toile d'araignée mondiale / toile mondiale / toile / T.A.M. / web / World Wide Web (Belgien)

15.5.1.2.4 Frage 24: Bedeutungsunterschiede zwischen causette / bavardage / chat (Belgien) .................................................... 592

15.5.1.3 Schweiz 592

15.5.1.3.1 Frage 3: Bedeutungsunterschiede zwischen courrier électronique / message électronique / mél / courriel / messagerie électronique / e-mail / mail (Schweiz)

15.5.1.3.2 Frage 10: Bedeutungsunterschiede zwischen page d'accueil / homepage (Schweiz)

15.5.1.3.3 Frage 24: Bedeutungsunterschiede zwischen causette / bavardage / chat (Schweiz)

15.5.1.3.4 Frage 31: Bedeutungsunterschiede zwischen pirate / cracker (Schweiz)

15.5.2 Kritik zur aktuellen Sprachpolitik (3. Fragebogenmodul) ................ 593

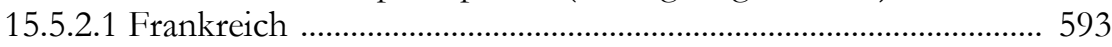

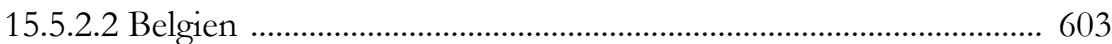

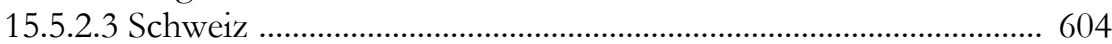

15.6 Präsenz verschiedener Sprachen im Internet ............................................... 605

15.7 Glossar der verwendeten Internet-Termini ................................................. 606

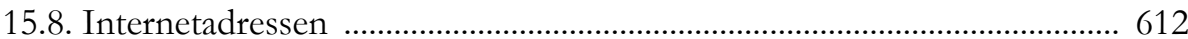

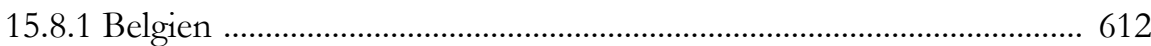

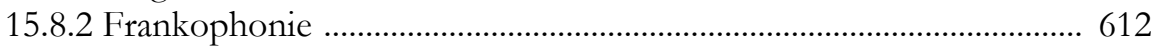

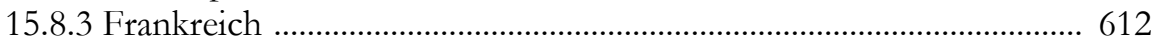

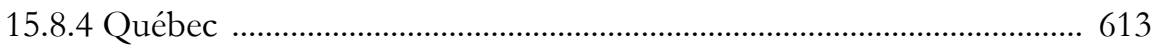

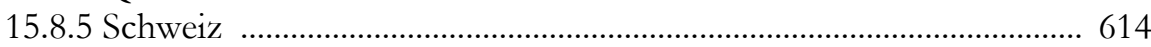

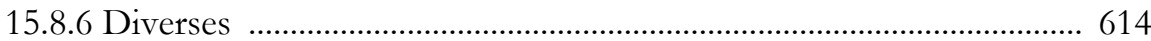

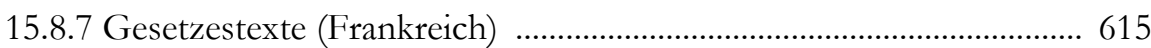

15.8.8 Terminologielisten und -datenbanken ............................................... 616

15.8.9 Jahresberichte der DGLF/DGLFLF und der Commission générale

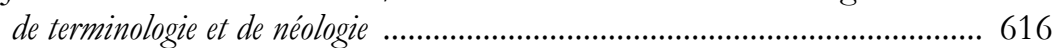

15.8.9.1 Die Jahresberichte der DGLF/DGLFLF .................................. 616

15.8.9.2 Die Jahresberichte der Commission générale de terminologie et de

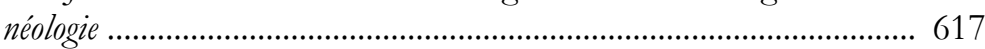

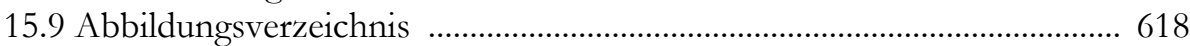

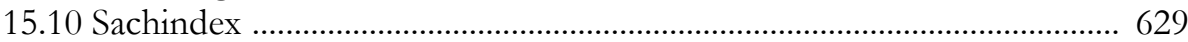




\section{Abkürzungsverzeichnis}

Abb.

ACCT

ADM

AFAL

AGULF

AILF

AIM

AFNOR

AFTERM

AISLF

ALF

APFA

Art.

ASCII

ASP

Bac

BEPC

BEP

bes.

BFS

BNQ

BSI

Bsp.

bzg1.

bzw.

ca.

CAP

CETMF

C.F.B.

CGI

CIDIF

CIIP

CILF

CMT

CNRS

COGETER

C.Q.F.D.

CRETTAL

CRITER
Abbildung

Agence de coopération culturelle et technique

Arbeitskreis Deutscher Markt- und Sozialforschungsinstitute

Association francophone d'amitié et de liaison

Association générale des usagers de la langue française

Association des Informaticiens de la Langue Française

AOL Instant Messenger

Association Française de Normalisation

Association de terminologie

Association internationale des navigants de langue française

Avenir de la langue française

Association pour la promotion du français des affaires

Artikel

American Standard Code for Information Interchange

Active Server Pages

Baccalauréat

Brevet d'études du premier cycle

Brevet d'études professionnelles

besonders

Bundesamt für Statistik (Schweiz)

Bureau de normalisation du Québec

British Standards Institution

Beispiel

bezüglich

beziehungsweise

cirka

Certificat d'aptitude professionnelle

Comité d'étude des termes médicaux français

Communauté française de Belgique

Common-Gateway-Interface

Centre international pour le développement de l'inforoute en français

Conférence intercantonal de l'instruction publique de la Suisse romande et du Tessin

Conseil international de la langue française

commissions ministérielles de terminologie

Centre national de la recherche scientifique

Commission générale de terminologie et de néologie

Cercle de qualité du français dynamique

Centre de Recherches et d'Études en Terminologie, Termatique et Aménagement des Langues

Corpus du Réseau Interministériel de Terminologie 
CST

CSTIC

CSTNT

CTN

CTOLF

DDC

Def.

DGCCRF

DGLF

DGLFLF

d.h.

DLF

DOM-TOM

DSR

dt.

ebd.

ed.

edd.

ellipt.

engl.

et al.

etc.

EU

evtl.

f.

FF

FRANTERM

franz.

ftp

ggf.

GPSR

GWDG

HTML

http

https

IBM

IEC commissions spécialisées de terminologie et de néologie

Commission Spécialisée de Terminologie et de Néologie de l'Informatique et des Composants Electroniques

Commission spécialisée de terminologie et de néologie des télécommunications

Centre de terminologie et de néologie

Commission de terminologie de l'Office de la langue française

Le Droit de comprendre

Definition

Direction Générale de la Concurrence, de la Consommation et de la Répression des Fraudes

Délégation générale à la langue française

Délégation générale à la langue française et aux langues de France

das heißt

Défense de la langue française (Frankreich), Délégation à la langue française (Schweiz)

Départements d'outre-mer - Territoires d'outre-mer

Dictionnaire suisse romand

deutsch

ebenda

edidit

ediderunt

elliptisch

englisch

et alii

et cetera

Europäische Union

eventuell

femininum/folgende

Francs français

Association pour la promotion de la Terminologie scientifique et technique en français

französisch

File Transfer Protocol

gegebenenfalls

Glossaire des patois de la Suisse romande

Gesellschaft für wissenschaftliche Datenverarbeitung $\mathrm{mbH}$ Göttingen

Hypertext Markup Language

Hypertext Transfer/Transmission Protocol

Hypertext Transfer Protocol Secure

International Business Machines

International Electrotechnical Commission 


\begin{tabular}{ll} 
ICQ & I Seek You \\
i.d.R. & in der Regel \\
INaLF & Institut National de la Langue Française \\
ink1. & inklusive \\
INS & Institut national de Statistique (Belgien) \\
INSEE & Institut National de la Statistique et des Études Économiques \\
& (Frankreich) \\
IP & Internet Protocol \\
IRANOR & Instituto Nacional de Racionalización y Normalización \\
IRC & Internet Relay Chat \\
ISO & International Organization for Standardization \\
IT & Information technology \\
ital. & italienisch \\
JDK & Java Development Kit \\
JO & Journal officiel de la République française \\
JVM & Java Virtual Machine \\
Kap. & Kapitel \\
katal. & katalanisch \\
LLI & Laboratoire de Linguistique Informatique \\
m. & maskulinum \\
m. E. & meines Erachtens \\
max. & maximal \\
min. & minimal \\
mind. & mindestens \\
Mio & Millionen \\
MOOSE & Markup Organization Of Survey Environments ${ }^{1}$ \\
MS & Microsoft \\
MSN & Microsoft Network \\
Nr. & Nummer \\
NTIC & Nouvelles technologies d'information et de communication \\
o.Ä. & oder Ähnliches \\
OFS & Office fédéral de la statistique \\
o.J. & ohne Jahr \\
OLF & Office québécois de la langue française \\
o.S. & ohne Seite \\
o.V. & ohne Verlag \\
OVF & Office du vocabulaire français \\
PAGSI & Le Programme d'Action Gouvernemental pour la Société de \\
PC & l'Information \\
P1. & Personal Computer \\
port. & Plural \\
PS & portugiesisch \\
\hline & Parti Socialiste \\
\hline
\end{tabular}

\footnotetext{
${ }_{1}^{1}$ Organisation von Umfragen durch Auszeichnungsbefehle
} 


\begin{tabular}{ll} 
Realiter & Réseau panlatin de terminologie \\
RIFAL & Réseau international francophone d'aménagement linguistique \\
RINT & Réseau international de néologie et de terminologie \\
RIOFIL & Réseau international des observatoires francophones de \\
& l'inforoute et du traitement informatique des langues \\
RPR & Rassemblement pour la République \\
rum. & rumänisch \\
s. & siehe \\
Sg. & Singular \\
SMTP & Simple Mail Transfer Protocol \\
SNCF & Société Nationale des Chemins de Fer Français \\
SNT & Service de néologie et terminologie \\
s.o. & siehe oben \\
sog. & so genannt \\
span. & spanisch \\
SPER & Syndicat professionnel des matériels électroniques et radio- \\
& électriques \\
s.u. & siehe unten \\
sog. & so genannt \\
SPSS & Statistical Program for Social Sciences \\
Syn. & Synonym \\
TERMDAT & Terminologiedatenbank der Bundesverwaltung (Schweiz) \\
TIC & technologies de l'information et de la communication \\
u.a. & und andere \\
u.Ä. & und Ähnliches \\
UDF & Union pour la Démocratie Française \\
UK & United Kingdom \\
URL & Uniform Resource Locator \\
usw. & und so weiter \\
u.U. & unter Umständen \\
v.a. & vor allem \\
vgl. & vergleiche \\
vs. & versus \\
WFG & WWW-Fragebogen-Generator \\
WWW & World Wide Web \\
XML & Extended Markup Language \\
z.B. & zum Beispiel \\
z.T. & zum Teil \\
& \\
\hline &
\end{tabular}


xviii 


\section{Einleitung}

\subsection{Gegenstand und Ziel dieser Arbeit}

Das Internet ist aus der heutigen Medienlandschaft nicht mehr wegzudenken. Es erfreut sich weltweit einer ständig wachsenden Zahl an Nutzern'1 Im Jahr 2002 nutzen 29\% der Spanier das Internet. In Frankreich sind es 37\%, in Italien und Großbritannien 38\%. Unter die Länder mit hoher Nutzungsrate fällt z.B. Belgien mit 44\%. Spitzenreiter sind die USA mit 62\% und Dänemark mit 63\% InternetNutzern (vgl. Taylor Nelson Sofres Interactive 2002, Folie 16).

Das Internet verbreitete sich in den 1990er Jahren in Frankreich und anderen frankophonen Staaten langsamer als in den anglophonen Staaten. Im Herbst 1998 überstieg die Anzahl der Internet-Nutzer in Frankreich erstmals die Millionengrenze. Die zögerliche und verspätete Verbreitung des Internet in Frankreich wird als „retard français“ bezeichnet.

Bis sich aber die neue Technologie ebenso durchsetzen wird wie z.B. das Fernsehen, wird noch einige Zeit vergehen. Das Fernsehen als das sozial bedeutendste Unterhaltungs- und Informationsmedium liegt immer noch weit vor allen anderen Medien wie Computern, aber auch Tageszeitungen und Hörfunk (vgl. Beck/ Glotz/Vogelsang 2000, 65f.).

Der Einsatz des Internet bringt eine fachspezifische Terminologie mit sich, die aus denjenigen Ländern stammt, in denen sich die wesentlichen Entwicklungen im Bereich EDV/Internet vollzogen haben und vollziehen. Dabei handelt es sich in

\footnotetext{
1 Wenn der Einfachheit halber im Folgenden nur die männliche Form verwendet wird, so sind Nutzerinnen, Linguistinnen etc. stets eingeschlossen.
} 
erster Linie um die USA. Entsprechend weist die internationale Internet-Terminologie viele Anglizismen ${ }^{2}$ auf. Die Dominanz der USA und des Englischen spiegelt sich auch in der sprachlichen Gestaltung der Internetseiten wider. Im September 1998 waren 75\% aller Internetseiten in englischer Sprache verfasst, nur 2,81\% in französischer Sprache. Einen ähnlich geringen Anteil machten InternetSeiten in anderen romanischen Sprachen aus. Inzwischen haben die romanischen Sprachen aufgeholt. Die englischsprachigen Internetseiten haben im Juni 2001 einen Anteil von 52\%, die französischsprachigen Seiten von 4,61\% (vgl. Étude Funredes/Union latine 2001, o.S.; vgl. auch für die anderen romanischen Sprachen 15.6). Analog zur Verteilung der Sprachen auf die Internetseiten verteilen sich die Sprachen auf die Internet-Nutzer: 40,2\% der Internet-Nutzer sind anglophon, 59,8\% nicht-anglophon. Von den nicht-anglophonen Sprachen machen das Französische 3,9\%, das Spanische 7,2\%, das Portugiesische 2,6\%, das Italienische 3,6\% und das Deutsche 6,8\% aus (vgl. Global Reach 2002, o.S.).

Dass der französische Staat seit Beginn der 1970er Jahre bemüht ist, die Anzahl an Anglizismen vor allem auf gesetzlichem Wege einzuschränken, ist allseits bekannt. Seit einigen Jahren wird auch das Internet in den Sprachpflegeprozess eingebunden, nicht nur in Frankreich, sondern auch in Belgien und der Schweiz. Diese drei frankophonen Länder stehen im Hinblick auf ihre Sprachpolitik und Terminologiearbeit - speziell die von ihnen erarbeitete Internet-Terminologie - im Zentrum dieser Arbeit. Eigentlich müssten in diesem Zusammenhang auch die in Québec gültigen Sprachgesetze sowie die frankokanadische Internet-Terminologie ins Blickfeld rücken, allerdings weichen die in Québec gültigen Termini so stark von den französischen, belgischen und schweizerischen Internet-Termini ab, dass ein Vergleich sich nicht als sinnvoll erweist (vgl. 3.3.4).

Für die (staatliche) französische Sprachpflege ist die dem Kultusministerium unterstellte Délégation générale à la langue française et aux langues de France (DGLFLF) zuständig. Die DGLFLF betreibt seit 1996 eigene Internetseiten, auf denen vielfältige Informationen zur aktuellen Sprachpolitik, zur Frankophonie, zur Terminologie und zu anderen Themen, die in den Zuständigkeitsbereich dieser Institution fallen, verfügbar sind. Unter anderem können die neuesten Gesetze, Erlasse und Dekrete zur Sprachpolitik bequem über das Internet abgerufen werden, beispielsweise die aktuellen Terminologieerlasse zum Internet-Vokabular vom 16. März 1999, vom 01. September 2000 und vom 08. Dezember 2002.

Ähnlich verhält sich die Situation in Bezug auf die Internet-Terminologie in Belgien und der Schweiz. Der Service de la langue française der Communauté française de Belgique bietet auf seinen Internetseiten vielfältige Informationen zur Sprachpolitik

\footnotetext{
2 An dieser Stelle bietet sich ein terminologischer Hinweis an: Wenn in dieser Arbeit von Anglizismen gesprochen wird, umfasst dieser Begriff sowohl (Anglo-)Amerikanismen als auch Anglizismen. Auf geografische Varianten der englischen Sprache wie z.B. das kanadische oder australische Englisch wird in dieser Arbeit nicht eingegangen. Die Herkunft der Begriffe ist im Einzelnen nur schwer nachzuweisen. Da sich jedoch die meisten Entwicklungen im Bereich des Internet in Amerika vollzogen haben und vollziehen, ist es wahrscheinlich, dass die Internet-Terminologie ausschließlich durch (Anglo-)Amerikanismen geprägt ist.

Eine Definition von „Anglizismus“ erfolgt in Kap. 2, Fußnote 34.
} 
in Belgien sowie eine Terminologie-Datenbank. Diese Datenbank umfasst neben anderen Fachgebieten auch eine Informatik-Terminologie, unter die auch die Internet-Termini fallen. In der Schweiz ist die Schweizerische Bundesverwaltung für terminologische Belange zuständig. Auf ihren Seiten befindet sich eine umfangreiche Tabelle zur Internet-Terminologie, die die entsprechenden Termini in den Sprachen Englisch, Französisch, Deutsch und Italienisch präsentiert.

Die Bereiche Terminologie bzw. Neologie lassen sich von zwei Seiten betrachten, von der Bildungsseite und von der Sprecherseite. Auf der Bildungsseite geht es um formal-linguistische Aspekte der Terminologie bzw. der Neologie und die Schaffung neuer Termini. Auf der Sprecherseite geht es um die Rezeption, d.h. die Einstellungen zu Termini bzw. Neologismen. Der Schwerpunkt dieser Arbeit liegt auf der Seite der Rezipienten. Es wird daher aus soziolinguistischer, nicht aus lexikologischer Perspektive an die Fragestellung herangegangen. Schließlich werden Sprachpolitik und die damit verbundenen Terminologieerlasse nicht nur von jemandem, sondern immer auch für jemanden gemacht.

Doch es stellt sich die Frage, inwieweit die Listen zur Internet-Terminologie sowie die in diesen Listen vorgeschlagenen französischen Neologismen, welche die unliebsamen Anglizismen ersetzen sollen, tatsächlich bekannt sind. Und, weiter gefragt, werden sie auch von den Internet-Nutzern verwendet? Wie werden die französischen Internet-Neologismen beispielsweise unter dem Blickwinkel der Ästhetik oder Nützlichkeit bewertet, welche Gründe sprechen für den Gebrauch der Anglizismen? Was halten die von den Sprachregelungen betroffenen Franzosen, Belgier und Schweizer von den staatlichen Maßnahmen zum Schutz der Sprache vor dem Einfluss des Angloamerikanischen? Unterscheiden sich die Akzeptanz der Termini und die Einstellungen zur Sprachpolitik von Land zu Land? Um diese Fragen beantworten zu können, ist es unabdingbar, den tatsächlichen Sprachgebrauch, aber auch die Einstellungen der Sprecher zur aktuellen Sprachpolitik zu kennen. Die hier vorliegende Studie soll klären, inwieweit die sprachpolitischen und insbesondere terminologischen Bemühungen auf Akzeptanz stoßen und welchen Einfluss sie auf das Denken und Handeln, d.h. auf die Einstellungen der jeweiligen Sprachgemeinschaft, genommen haben. Dabei geht es in dieser Arbeit nicht darum, die Legitimität von Sprachpolitik zu hinterfragen, sondern ihre Wirksamkeit zu ermitteln.

Zur französischen Sprachpolitik und speziell zur Akzeptanz einiger der gesetzlich vorgeschriebenen Ersatzwörter liegen bereits vereinzelte Studien vor. Ein Vergleich im Hinblick auf die Akzeptanz und Bekanntheit der sprachpolitischen und terminologischen Maßnahmen zwischen verschiedenen frankophonen Ländern fehlt bislang ${ }^{3}$.

Von der Internet-Terminologie sind in erster Linie Personen betroffen, die beruflich mit den Medien Computer und Internet zu tun haben. Insofern ist es sinnvoll, den Adressatenkreis der Befragung zur Internet-Terminologie und Sprachpolitik

3 Die einzige Ausnahme stellen vergleichende Studien zwischen Québec und Frankreich dar (vgl. 2.3.1). 
genau auf diesen Personenkreis einzugrenzen, nämlich auf Informatiker im weitesten Sinne4. Hinzu kommt, dass Umfragen umso aussagekräftiger und repräsentativer werden, je eingegrenzter die Zielgruppe ist, über die Aussagen getroffen werden sollen. Ein dritter Grund, der für die Befragung von Informatikern spricht, ist die aktuelle Forschungslage: Es sind bereits zwei Umfragen zum Etablierungsgrad informatischer Termini bzw. zur Einstellung von Informatikern zur staatlichen Terminologieplanung durchgeführt worden, nämlich von Le Guilly-Wallis (1991) und Gouadec (1993) (vgl. 4.3.2). Durch diese weitere Studie zur Internet-Terminologie und zur Sprachpolitik, die sich zwar mit dem Internet- und nicht mit dem Informatik-Wortschatz befasst, aber die gleiche Zielgruppe wie die beiden genannten Studien hat, ist eine Vergleichsmöglichkeit gegeben. Die Ergebnisse dieser weiteren Studie können Aufschluss darüber geben, ob sich der in den zu Beginn der 1990er Jahre veröffentlichten Studien festgestellte Trend fortsetzt oder ob es eine Richtungsänderung gibt. Für die Befragung zur Internet-Terminologie und Sprachpolitik ist neben der Eingrenzung der Zielgruppe auf Informatiker eine weitere Eingrenzung nötig. Diese betrifft die Untersuchungsländer, aus denen die Informanten stammen. Als Untersuchungsländer wurden Frankreich, Belgien und die Schweiz ausgewählt, da diese drei Länder über eine eigenständige Informatik- bzw. Internet-Terminologie verfügen.

Um eine entsprechende vergleichende Studie zur Sprachpolitik und Internet-Terminologie durchführen zu können, wurde eine in der Linguistik gänzlich neue Methodik verwendet, die WWW-Befragung.

\subsection{Methodik}

Die gesamte Wissenschaft profitiert von den Möglichkeiten, die sich durch das Internet eröffnen. Auch die Linguistik hat sich das Internet sehr schnell zu Forschungszwecken zu Eigen gemacht. Verschiedene Studien widmen sich der Sprache und den Sprachgewohnheiten im Netz und geben ein Abbild der in E-Mails, Chats oder anderen Textsorten verwendeten Sprache (vgl. als allgemeinen Einstieg z.B. Crystal 2001 und Runkehl/Schlobinski/Siever 1998, für die romanischen Sprachen z.B. Kattenbusch 2002 und speziell zum Französischen z.B. Anis 2001). Das Internet bietet somit auch für Linguisten viele neue Forschungsimpulse. Es lässt sich aber nicht nur als Forschungsobjekt, sondern auch als Forschungsinstrument heranziehen. In den Sozialwissenschaften oder den Wirtschaftswissenschaften sind Umfragen, die über das Internet geführt werden, keine Seltenheit mehr. Im Bereich der romanischen Linguistik und speziell im Hinblick auf die französische Linguistik betritt man in dieser Hinsicht Neuland. Lebsanft (1999) ist einer der wenigen Linguisten, die das Internet bislang als Forschungsinstrument

\footnotetext{
${ }^{4}$ Die Berufsbezeichnung „Informatiker“ steht in dieser Arbeit als Oberbegriff für eine Vielzahl an unterschiedlichen akademischen und nicht-akademischen Berufen. Unter Informatiker in diesem weiten Sinne werden Personen gefasst, die im Computer-/Internetbereich arbeiten, wie Programmierer, Programmentwickler, Netzwerkadministratoren, Informatiklehrer, Webdesigner etc.
} 
genutzt haben. Lebsanft führte eine Online-Befragung durch, indem er den Mitgliedern der spanischen Mailingliste „Apuntes“ einen E-Mail-Fragebogen mit Fragen zur spanischen Sprache und Sprachpflege schickte, der ihm ausgefüllt per E-Mail zurückgeschickt wurde.

Das Internet bietet dem Forscher aber auch andere Möglichkeiten der OnlineBefragung, z.B. E-Mail- und WWW-Befragungen. Die Studie zur Akzeptanz von Internet-Termini und Sprachpolitik basiert auf der Methode der WWW-Befragung. Online-Befragungen bieten gegenüber herkömmlichen Papier-Fragebögen viele Vorteile: Für den Untersuchenden kann mit geringem finanziellem Aufwand (keine Reisekosten, keine Papierkosten) ein disperses Publikum erreicht werden. Hinzu kommt bei einer Studie zur Internet-Terminologie, dass die Thematik der Befragung den Einsatz des Internet als Forschungsinstrument auch zur Teilnehmeransprache nahe legt: Das Internet lässt sich zur Rekrutierung von Informanten für jegliche Art von Befragungen nutzen. Zugleich findet bei einem derartigen Rekrutierungsverfahren zugleich automatisch eine Selektion statt. Bei einer Datenerhebung über das Internet werden nur diejenigen Personen angesprochen, die mit diesem Medium umgehen. Anhand der Ankündigung von Umfragen in bestimmten Diskussionsforen, die nur von speziellen Berufs- oder auch Interessengruppen gelesen werden, kann die gewünschte Informantengruppe gezielt kontaktiert werden.

\subsection{Kapitelüberblick}

Die Arbeit lässt sich in zwei große thematische Blöcke unterteilen ${ }^{5}$. Der erste Block, der die Kapitel 2 bis 5 umfasst, beschäftigt sich mit den linguistischen Grundlagen der Studie. Der zweite Block, bestehend aus den Kapiteln 6 bis 12, schildert die Methodik, Durchführung und Auswertung der Befragung.

Das zweite Kapitel widmet sich der ursprünglich aus der Sozialpsychologie stammenden Einstellungsforschung. Es wird erläutert, was Einstellungen sind, wie sie sich erforschen lassen und welche Studien auf diesem Gebiet bislang für Frankreich, Belgien und die Schweiz vorliegen. Der Schwerpunkt des dritten Kapitels liegt auf der Sprachpolitik und Terminologiearbeit in den drei Untersuchungsländern. Dieses Kapitel besteht aus drei Unterkapiteln: 3.1 befasst sich mit den Konzepten der Sprachpolitik und Sprachplanung und skizziert den Ablauf von sprachplanerischen Maßnahmen, 3.2 gibt einen Überblick über die Sprachpolitik und Terminologiearbeit in Frankreich seit den 1970er Jahren, 3.3 widmet sich der Terminologiearbeit in Belgien, der Schweiz und Québec, stellt aber auch länderübergreifend arbeitende Institutionen vor.

Alle bislang publizierten Studien zur Akzeptanz der Sprachpolitik und der Terminologie beziehen sich auf Frankreich; für Belgien und die Schweiz fehlen derartige

\footnotetext{
5 An dieser Stelle bieten sich zwei Bemerkungen zur formalen Gestaltung der vorliegenden Arbeit an: Der Text ist in neuer Rechtschreibung geschrieben; Zitate aus anderen, älteren Texten werden unverändert in der alten Rechtschreibung übernommen. Typografische Hervorhebungen in den Zitaten werden ebenfalls beibehalten.
} 
Untersuchungen. In Kapitel 4 werden die wichtigsten Studien zur Evaluierung der Wirksamkeit französischer Sprachpolitik und Terminologiearbeit vorgestellt. Dazu werden Studien herangezogen, bei denen Spezialisten, bestimmte Bevölkerungsgruppen oder auch breite Bevölkerungsschichten befragt wurden. Ferner wird ein Überblick über die verschiedenen Positionen gegeben, die in der französischen und deutschsprachigen Linguistik sowie in der Presse vertreten werden.

Eine Studie, die die Etablierung von Fachtermini ermitteln will, stellt einen enormen Aufwand dar, der zu einer Begrenzung des Arbeitsfeldes zwingt. Es muss nicht nur eine Eingrenzung auf ein spezifisches Wortfeld, d.h. den Arbeitsbereich einer Terminologiekommission erfolgen, sondern auf eine Auswahl zu prüfender Termini getroffen werden. Nachdem in 5.1 die Kriterien der Akzeptanz für Neologismen erörtert wurden, gibt 5.2 Aufschluss darüber, auf welche Weise die Anzahl der zu untersuchenden Internet-Termini von über 50 in Frage kommenden Lexemgruppen auf sechs reduziert wurde. In 5.3 werden die der WWW-Befragung zugrundeliegenden Hypothesen erläutert, die aus den in den Kapiteln 2 bis 5 dargestellten Sachverhalten abgeleitet wurden. Kapitel 5 schließt den sprachwissenschaftlichen Theorieteil ab, der der inhaltlichen Vorbereitung der in den Kapiteln 9 bis 12 präsentierten Befragungsergebnisse dient.

Kapitel 6 setzt sich mit der Methodik von Online-Befragungen und speziell WWW-Befragungen auseinander, da sich diese Methode in der linguistischen Forschung noch nicht hat etablieren können. Das siebte Kapitel erläutert die Konzeption des WWW-Fragebogens und schildert den für die definitive Studie durchgeführten Pretest. Kapitel 8 gibt einen Überblick über die befragten Informanten und schildert die Vorbereitung und den Verlauf der WWW-Befragung.

Die Kapitel 9 bis 12 widmen sich der Auswertung der Studie und der Überprüfung der Hypothesen. Kapitel 9 präsentiert die Ergebnisse für die französischen, Kapitel 10 für die belgischen und Kapitel 11 für die schweizerischen Informatiker. Kapitel 12 vergleicht die Ergebnisse im Hinblick auf mögliche länderspezifische Besonderheiten. Die Arbeit schließt mit einer Zusammenfassung der wesentlichen Ergebnisse sowie einem Ausblick auf Fragestellungen, denen im Rahmen dieser Arbeit nicht nachgegangen werden konnte und die weiterer Forschung bedürfen. 


\section{Einstellungsforschung}

Dieses Kapitel befasst sich zunächst mit der theoretischen Seite der Einstellungsforschung. 2.1 erläutert das aus der Sozialpsychologie stammende Einstellungskonzept und zeigt auf, in welchen Bereichen sich die Linguistik der Einstellungsforschung bedient. Da zur Theorie der Spracheinstellungen bereits umfassende Darstellungen vorliegen, wird dieser Abschnitt nur die wesentlichen Konzepte und Ansätze aufgreifen. 2.2 gibt einen Überblick über die verfügbaren empirischen Verfahren zur Einstellungsmessung.

Nach diesen beiden theoretisch ausgerichteten Teilen richtet sich der Fokus auf die Einstellungsforschung im frankophonen Sprachraum. Üblicherweise wird in empirischen Studien der Darstellung der eigentlichen Untersuchung eine Beschreibung der soziolinguistischen Situation des jeweiligen Untersuchungsgebietes vorangestellt. Dieses Verfahren erscheint mir auch für eine Arbeit angemessen, in deren Zentrum die Einstellungen von Sprechern dreier Staaten stehen. Entsprechend beginnen die Ausführungen zur Einstellungsforschung im frankophonen Belgien (2.3.3) und in der frankophonen Schweiz (2.3.4) mit je einem Unterkapitel zur soziolinguistischen Situation des jeweiligen Landes.

\subsection{Der Begriff der Einstellungen in der Sozialpsychologie und der Linguistik}

Der Begriff der Einstellung stammt ursprünglich aus der Sozialpsychologie und bezeichnet die emotionale, gedankliche und handlungsmäßige Disposition gegenüber bestimmten Aspekten der Umwelt, aus der die Bereitschaft für ein bestimmtes Verhalten (readiness for behavior) resultiert. Einstellungen sind seit den 1930er Jahren zentraler Gegenstand der amerikanischen sozialpsychologischen For- 
schung. In den darauf folgenden Jahrzehnten wurden analoge Forschungen ferner in anderen Bereichen der Psychologie und der Soziologie sowie in der Anthropologie, Geschichtsforschung, in den Erziehungswissenschaften und seit den 1960er Jahren auch in der Linguistik betrieben ${ }^{1}$.

Es herrscht in allen Fachrichtungen Konsens darüber, dass Einstellungen erlernt und implizit sind. Erlernt werden sie zunächst durch das elterliche Vorbild. Später kommen das weitere soziale Umfeld und die damit verbundenen Interaktionserfahrungen hinzu. Soziale Einstellungen tragen zur Orientierung des Individuums in seiner Umgebung bei (vgl. Werlen 1984, 140). Einmal erlernt, sind Einstellungen relativ stabil und im Menschen als überdauernde Verhaltensdispositionen verankert. Sie benötigen immer ein Objekt, auf das sie sich beziehen. Dies können einzelne Personen, soziale Gruppen (wie „die Franzosen“, „die frankophonen Belgier", Dialektsprecher), Gegenstände, Verhaltensweisen, Situationen oder abstrakte Ideen (wie Vorstellungen von Sprache) sein (vgl. Baker 1992, 10; Oppenheim 1992, 174). Einstellungen sind niemals neutral, sondern stets wertend.

Das Individuum wird in seinen Einstellungen in der Regel durch seine Zugehörigkeit zu einer sozialen Gruppe geprägt. Diese Prägung kann auch durch eine Sprachgruppe erfolgen. Die sozialpsychologische Forschung nimmt an, dass Einstellungen innerhalb definierter Gruppen relativ homogen sind. Sie geht sogar davon aus, dass sich Gruppen eher durch übereinstimmende Einstellungen als durch andere Faktoren formieren (vgl. Werlen 1984, 156). Diese Tatsache legitimiert es, Aussagen verschiedener Sprecher einer Gruppe auf die gesamte Gruppe zu übertragen, wie es in der Einstellungsforschung üblich ist.

Einstellungen spielen für den Status von Sprachen bzw. Varietäten (z.B. Dialekten) in mehrsprachigen Gesellschaften eine wichtige Rolle (vgl. Glück 2000, 178). Für die linguistische Forschung ist es daher von Interesse, mit Hilfe entsprechender Studien Aussagen darüber treffen zu können, welches Prestige ${ }^{2}$ eine bestimmte Sprache oder Varietät in einem definierten Umfeld genießt. Einstellungen richten sich jedoch nur selten auf die Sprache selbst, sondern vielmehr auf Spre-

\footnotetext{
${ }^{1}$ Einen Überblick über die Spracheinstellungsforschung in den 1960er Jahren bis heute geben Bradac/Cargile/Hallett (2001). Etwas älter, aber durchaus informativ ist auch die Darstellung bei Fasold (1985). Eine systematische Darstellung zur Theorie und Praxis Spracheinstellungsforschung, auf die in dieser Arbeit einige Male zurückgegriffen wird, bietet Baker (1992). Leider beziehen sich die meisten der in diesen Publikationen referierten Studien auf den anglophonen Sprachraum. In Bezug auf die Frankophonie fehlt eine entsprechende systematische Darstellung.

2 Prestige ist kein fester Bestandteil einer Sprache oder Varietät, sondern wird ihr von den Sprechern zugeschrieben. Das Prestige und der Status, die einer Sprache zugeschrieben werden, üben maßgeblichen Einfluss auf die Sprachwahl des Sprechers aus. Prestige steht in direkter Verbindung mit sozialem Ansehen, sozialer Geltung und Wertschätzung. Da stets bestimmte Werturteile an einen bestimmten Sprachgebrauch geknüpft werden, verfügt niemand neutral über Sprache (vgl. Haarmann 1990, 2). Die Wahl eines Sprachcodes wird in den meisten Fällen vielmehr unbewusst von Prestigewerten gesteuert. Möglich ist aber auch der bewusste Gebrauch der prestigebesetzten Sprache oder Varietät, weil sich der Sprecher daraus einen persönlichen Vorteil erhofft. Hier lässt sich z.B. an den Gebrauch des Französischen im Belgien früherer Jahrhunderte denken (vgl. 2.3.3.1) oder an das Ansehen, das das „Pariser Französisch" in Frankreich, v.a. aber auch im frankophonen Belgien und der französischsprachigen Schweiz genießt. Das Prestige einer Sprache lässt sich analog zu den Spracheinstellungen mit formalen Mitteln erforschen, z.B. mit Hilfe des semantischen Differentials (vgl. Haarmann 1990, 15-19, zum semantischen Differential vgl. Fußnote 13 und 7.1.2.1).
} 
cher oder die Sprachgemeinschaft, mit denen bestimmte Vorstellungen (Stereotype $^{3}$ ) verbunden werden (vgl. z.B. Fischer 1988, 88).

Im Rahmen der Einstellungsforschung sind zwei grundsätzliche Positionen voneinander zu unterscheiden, die behavioristische und die mentalistische Einstellungsforschung ${ }^{4}$. Innerhalb der behavioristischen Einstellungsforschung wird versucht Wissenselemente, Bewertungen und Verhalten(sabsichten) in ein Ursache-Wirkung-Verhältnis zu bringen. Der behavioristischen Einstellungsforschung liegt ein unidimensionales Modell zugrunde (vgl. Fishbein/Ajzen 1975). Klassische behavioristische Methoden stützen sich ausschließlich auf Reize (stimuli) und Reaktionen (responses) als objektiv beobachtbare Variablen. Mentalisten dagegen beziehen auch nicht direkt beobachtbare innere Prozesse in ihre Forschungen ein. Während die behavioristische Einstellungstheorie von einer einschichtigen Struktur ausgeht, liegt dem mentalistisch ausgerichteten Forschungszweig ein aus drei Komponenten bestehendes Einstellungssystem (nach Rosenberg/Hovland 1960) zugrunde. In der sprachwissenschaftlichen Forschungspraxis dominiert die mentalistische Position (vgl. z.B. Agheyisi/Fishman 1970, 139; Cichon 1998, 44f.; Glück 2000, 178; Stahlberg/Frey 1996, 220f.; Vandermeeren 1996, 692).

Das dreistufige mentalistische Einstellungsmodell setzt sich aus der kognitiven, affektiven und konativen Komponente zusammen. Erstere umfasst Wissenselemente wie Gedanken und Meinungen, die sich - z.B. durch gezieltes Nachfragen - in Form verbaler Meinungsäußerungen abrufen lassen. Die affektive oder evaluative Komponente bezieht sich auf Gefühle (wie Zuneigung oder Hass), die das Individuum dem Einstellungsobjekt entgegenbringt. Sie wird in der Linguistik in der Regel in Form verbaler Gefühlsäußerungen gemessen, wenngleich auch andere (physiologische) Messverfahren, wie die Messung der Pulsfrequenz, denkbar sind (vgl. 2.2). Bei der affektiven Bewertungskomponente der Einstellungen ist zwischen ihrer Richtung (im Sinne von Zu- oder Abwendung zum Einstellungsobjekt) und ihrer Intensität zu unterscheiden. Die Intensität der Zu- oder Abneigung zum Gegenstand ist mit Hilfe von Skalen messbar (vgl. 2.2). Die konative Dimension schließlich hat Einfluss auf die konkreten, beobachtbaren Handlungen (= Verhalten) sowie - weniger offensichtlich - die Handlungsbereitschaft (= Verhaltensabsichten). Während das Verhalten beobachtbar ist, lässt sich die

\footnotetext{
3 Stereotype stellen eine Unterkategorie der Einstellungen dar. Sie bilden sich vor allem dann heraus, wenn das Wissen, die Urteile und Meinungen über ein Objekt mehr auf Erfahrungen anderer als auf eigenen Erfahrungen beruhen. Im Extremfall führt dies zum Aufbau von Feindbildern oder auch Idealbildern (vgl. Deprez/Persoons 1987, 126). Bei Glück $(2000,690)$ wird Stereotyp definiert als Bezeichnung für „starre, gleichförmige, fest montierte Abläufe“. Ein Stereotyp bezeichnet in der Psychologie „ein relativ erfahrungsresistentes, gleichförmig über eine Gruppe verteiltes System von Ansichten, Anschauungen, Urteilen oder Werten, das die Trägergruppe entlastet und die Komplexität und Uneinheitlichkeit des stereotypisierten Sachverhaltes über Gebühr reduziert" (ebd.). Mit Quasthoff $(1973,28)$ kann man von Stereotypen als Einstellungsverbalisierungen sprechen, welche in ihrer Form relativ stabile, satzartige Gebilde darstellen und als ganze gelernt und reproduziert werden, wie etwa die stereotype Behauptung vieler frankophoner Belgier oder Schweizer „On parle moins bien que les Français“" (zur Abgrenzung der Konzepte Stereotyp, Meinung, Überzeugung und Einstellungen vgl. auch Şmit 1996, 28f.).

${ }_{4}$ Eine knappe Erörterung des behavioristischen und des mentalistischen Einstellungskonzeptes findet sich in Schlieben-Lange (1991, 108-111).
} 
Handlungsbereitschaft nur in Form verbaler Äußerungen bezüglich des Verhaltens ermitteln, wobei umstritten ist, inwiefern Einstellungen als Verhaltensprädiktoren fungieren können ${ }^{5}$. Die konative Komponente darf jedoch nicht pauschal mit realem Verhalten gleichgesetzt werden, sondern sie hat vielmehr erheblichen Einfluss auf die Entscheidung zu bestimmten Handlungen. In der sprachwissenschaftlichen Forschungspraxis wird meist nur die affektive, kaum jedoch die konative Dimension erfasst (vgl. Cichon 1988, 4; Kolde 1981, 342).

Die kognitive und die affektive Komponente stimmen nicht grundsätzlich überein, da die Wissensinhalte durch Gefühle und Erfahrungen, die mit der über die Sprache assoziierten Sprachgemeinschaft verbunden sind, negativ oder positiv beeinflusst werden können. Auch wenn die drei Komponenten in der theoretisch ausgerichteten Einstellungsforschung auseinander gehalten werden, spielen sie in der alltäglichen Praxis zusammen und lassen sich nicht so einfach isolieren.

In der linguistischen Forschung wurde lange Zeit der Wert von Äußerungen über die Sprache hinter die sprachlichen Äußerungen selbst gestellt. Äußerungen über sprachliche Phänomene von Laien galten als subjektiv und spekulativ und daher als wenig bedeutsam:

„Als ,objektive’ Daten galten in der Geschichte der modernen Linguistik zwar die sprachlichen Äußerungen der Informanten selbst, nicht aber ihre Äußerungen über Sprache, die von einem positivistischen Wissenschaftsverständnis aus als ,subjektive' Daten verpönt wurden. Skepsis bis strikte Ablehnung gegenüber solchen internen, angeblich nur spekulativ, als ,unwissenschaftlich’ faßbaren Größen wie Introspektion, Sprachgefühl, Meinungen über Sprache, Sprachbewußtsein wirken als strukturalistisches und behavioristisches Erbe noch bis in die Gegenwart fort" (Neuland 1993, 723).

Zwei Umstände führten zur Aufwertung metasprachlicher Urteile in der linguistischen Forschung. Zum einen gelang es Chomsky in den 1960er Jahren, die Be-

\footnotetext{
${ }^{5}$ Es ist Vorsicht geboten, Verhaltensabsichten und tatsächliches Verhalten automatisch gleichzusetzen. Häufig wird versucht mit Hilfe der Einstellungsforschung zukünftiges Verhalten vorauszusagen. Diese prognostischen Fragen werden als problematisch angesehen, da angegebenes und tatsächliches Verhalten nicht zwangsläufig übereinstimmen. Ein berühmtes Beispiel für die Divergenz zwischen Verhaltensabsicht und tatsächlichem Verhalten ist LaPiere's Untersuchung (1934). Ein chinesisches Ehepaar betrat insgesamt 251 Restaurants in den USA, um dort zu essen. Das Ehepaar wurde nur in einem dieser Restaurants nicht bedient. Sechs Monate später wurde ein Brief an jedes dieser Restaurants geschickt. Hierin wurde eine entsprechende Situation geschildert und um die Meinung der Restaurantbetreiber gebeten. Die Auswertung der Antworten hatte zum Ergebnis, dass $92 \%$ der Restaurantbetreiber angaben, sie würden einem chinesischen Ehepaar den Eintritt und die Bedienung verweigern. Diese Untersuchung zeigt eindeutig, wie stark tatsächliches Verhalten und geäuBerte Einstellungen voneinander abweichen können. Einstellungen beeinflussen zwar das Verhalten; jedoch ist das Verhalten weniger konsistent als die ihm zugrunde liegenden Einstellungen (vgl. Baker 1992, 15f.; Stahlberg/Frey 1996, 238-242). Die Divergenz zwischen Verhaltensabsicht und Verhalten lässt sich mit folgendem Ansatz erklären: Bei Aussagen zu eigenem gegenwärtigen oder zukünftigen Verhalten erfolgt häufig eine Anpassung der Antwort an das, was der Informant als sozial erwünscht bzw. als vom Interviewer intendiert erachtet (vgl. z.B. Stahlberg/Frey 1996, 226). Einstellungsforschung darf aus den genannten Gründen keinesfalls dazu verwendet werden, zukünftiges Verhalten prognostizieren zu wollen.
} 
deutung sprachlicher Intuitionen von Muttersprachlern für die Forschung herauszustellen (vgl. Chomsky 1969). Zum anderen trat Hoenigswald 1966 mit seiner Befürwortung einer eigenständigen Disziplin der „Volkslinguistik“6 für eine Rehabilitation der von Laien geäußerten intuitiven Sprecher- und Sprachurteile ein, indem er mit diesem Begriff überhaupt erst einmal die von Laien ausgehende Beschäftigung mit Sprache(n) rechtfertigte. Die Aufwertung von Sprechermeinungen führte zu einer Erweiterung des Gegenstandsbereichs der Linguistik um die Dimension der Einstellungsforschung. Der Grundstein für die Erforschung der Einstellungen von Sprechern gegenüber einem spezifischen Sprachgebrauch, der Sprachnorm und Sprachvarietäten war somit gelegt (vgl. Neuland 1993, 724).

Das obige Zitat von Neuland (ebd., 723) deutet bereits ein weiteres Charakteristikum von Einstellungen an: Einstellungen sind latent, d.h. nicht direkt beobachtbar. Sie spielen sich in Form von Gedanken, (stereotypen) Vorstellungen und Gefühlen im Kopf ab und bleiben als solche Außenstehenden verborgen. Jedoch lassen sich Einstellungen aus einem bestimmten Verhalten (bzw. Verhaltensabsichten) und entsprechenden Bewertungen rekonstruieren. Anders formuliert manifestieren sich Spracheinstellungen erst im konkreten Handeln bzw. sind in Form von Verbalisierungen (z.B. Meinungen) erfragbar und werden somit empirischer Betrachtung zugänglich. Es reicht jedoch nicht, sich zur Erforschung von Einstellungen allein auf das sichtbare Verhalten bzw. auf erfragbare Meinungen zu beziehen. Um Verhalten bzw. Meinungen und die ihnen zugrunde liegenden Einstellungen verstehen zu können, fordert Baker (1992, 16) die zusätzliche Beachtung persönlicher, interpersonaler und situativer Faktoren. Einstellungen werden von den folgenden persönlichen und kontextuellen Faktoren maßgeblich beeinflusst und/oder verändert: Alter, Geschlecht, Sprachfertigkeit/Beherrschung der Sprache, einschneidende Erlebnisse, sprachlicher Hintergrund (z.B. Sprachgebrauch in Familie und unter Gleichaltrigen, Sprache der Massenmedien etc.), kultureller Hintergrund (Religion, Status der Sprache etc.), Institutionen (z.B. Schule), wechselseitige Einflüsse zwischen Sprachgemeinschaften (vgl. Baker 1992, 41-45, 106-111). In der Regel sind sich die Informanten des Einflusses dieser Faktoren nicht bewusst, wenn sie bezüglich ihrer Einstellungen befragt werden.

Hinzu kommt, dass einige der genannten Variablen - insbesondere das Alter dynamisch sind und sich im Laufe der Zeit ändern. Entsprechend ändern sich

${ }^{6}$ Der Begriff Volkslinguistike bezieht sich auf „Intuitionen von Sprechern über ihre Spr[ache] und
deren Gebrauch, Struktur und Funktionieren. "...] Sprecher haben eine genaue Vorstellung von dem,
was sprachl[ich] richtig oder falsch, häßlich oder schön ist, was innerhalb einer Situation kontext-
angemessen ist oder nicht [...] ““ (Glück 2000, 782). Brekle (1985, 145) schlägt vor, dass als als Volks-
linguistik ,"...] all jene sprachlichen Ausdrücke bzw. Äußerungen [...] bezeichnet werden sollen, die
ihrerseits auf Sprachliches referieren oder die metakommunikativ fungieren, bzw. in denen explizit
oder implizit Eigenschaften sprachlicher Einheiten bzw. Kommunikationshandlungen verwendet
werden, um damit bei Kommunikationsteilnehmern bestimmte gesellschaftlich-praktisch relevante
Wirkungen hervorzubringen. Dabei sind solche Äußerungen über Sprachliches ausgeschlossen, die
in der Absicht hervorgebracht werden, ,nur’ einen Erkenntnisgewinn über Sprachliches um seiner
selbst willen auszudrücken; solche Äußerungen wären nämlich - legt man Minimalkritierien
zugrunde - schon als sprachwissenschaftliche Aussagen zu qualifizieren.“ Zur Abgrenzung der Konzepte Laien-Linguistik und Volkslinguistik vgl. besonders Antos (1996, 7-25). 
trotz der für Einstellungen angenommenen Konsistenz die mit den Variablen verknüpften Einstellungen. Das bedeutet, dass sich mit der ständigen Entwicklung und Veränderung des Individuums auch seine Einstellungen ändern, wenngleich dies zumeist ein langsam verlaufender Prozess ist (vgl. Baker 1992, 46). Genau bei dieser Veränderlichkeit und Veränderbarkeit von Einstellungen setzen Sprachpflege und Sprachpolitik an: Wären Einstellungen ein unveränderlicher Bestandteil des Individuums, würde jegliche Art der sprachlichen Beeinflussung fehlschlagen. Mit Hilfe gezielter sprachpolitischer Maßnahmen wie der Schaffung von Gesetzen oder der Androhung von Sanktionen bei Verstoß sollen die Einstellungen zur Sprache und der Umgang mit ihr verändert werden. Hierbei kann ein Staat versuchen seine Bürger durch offene Überzeugungsarbeit, aber auch z.B. durch Indoktrinierung oder subtile Methoden der Einflussnahme zu manipulieren (vgl. Baker 1992, 97).

Einstellungen können nicht isoliert von den Funktionen betrachtet werden, die sie für ein Individuum oder eine Gruppe haben. Hier sind vor allem die integrative und instrumentale Funktion zu nennen 7 . Der integrative bzw. emotionale Wert, den eine Varietät für die Sprecher haben kann, ist meist kulturell, sozial und/oder zwischenmenschlich beeinflusst. Er drückt sich durch den Wunsch aus, sich einer anderen Gruppe sprachlich anzupassen, um von ihr anerkannt zu werden und sich mit ihr identifizieren zu können. Der instrumentale Wert einer Sprache führt beispielsweise dazu, dass ein Sprecher die prestigeträchtigere Sprache lernt, um sozial - materiell und im Ansehen - aufsteigen zu können. Häufig werden Einstellungen, die zu bestimmten Sprachen geäußert werden, dem sozial erwünschten, prestigeträchtigeren Sprachmodell angepasst (vgl. Baker 1992, 31-36).

Einstellungen hängen nicht nur von persönlichen und interpersonalen Faktoren, sondern auch von äußeren Umständen, den situativen Faktoren, ab. Wichtige Einflussfaktoren sind bestimmte historische und/oder politische Schlüsselreize, die in wissenschaftlichen und populärwissenschaftlichen Arbeiten vertretenen Positionen, die Meinungen der Chroniqueurs der Tageszeitungen, aber auch die normative Konsultationsliteratur, zu der z.B. Anglizismenwörterbücher zählen (vgl. Beinke 1990, 28-33, 182-210).

\footnotetext{
7 Diese Funktion geht auf Katz (1960) zurück, der insgesamt vier motivationale Funktionen von Einstellungen unterscheidet, nämlich 1. die instrumentelle, utilitaristische oder Anpassungsfunktion (Ausdruck von bestimmten Einstellungen, um einem Bedürfnisziel näher zu kommen), 2. die IchVerteidigungsfunktion (Abwehrmechanismen wie Rationalisierung und Projektion zum Schutz einer Person z.B. vor negativen Gefühlen), 3. der Ausdruck eigener Werte/Selbstverwirklichung mit dem Ziel der Bestätigung des eigenen Selbstkonzeptes und 4. die Wissens- oder Ökonomiefunktion (Strukturierung bzw. Kategorisierung der Umwelt als Voraussetzung für ihr Verständnis und zur besseren Informationsverarbeitung) (vgl. Stahlberg/Frey 1996, 229-231).
} 
Im Rahmen der Beschäftigung mit Spracheinstellungen sind vor allem die folgenden Bereiche erforscht worden:

1. Einstellung zu Sprachvariation, Dialekt und Sprechstilen,

2. Einstellung zum Fremdsprachenerwerb,

3. Einstellung zu bestimmten Minderheitensprachen,

4. Einstellung zu sprachlichen Gruppen oder Minderheiten,

5. Einstellung zum Sprachunterricht,

6. Einstellung zum Gebrauch einer bestimmten Sprache,

7. Einstellung der Eltern gegenüber dem Spracherwerb und

8. Einstellung zu sprachlichen Vorlieben (vgl. Baker 1992, 29).

Die vorliegende Studie zur Akzeptanz der französischsprachigen Internet-Termini und zur Sprachpolitik fällt unter Punkt 6, teilweise auch unter Punkt 8 dieser Aufzählung.

Abschließend zu den theoretischen Ausführungen zum Einstellungsbegriff werden die eng mit der Einstellungsforschung verknüpften Begriffe Sprachwissen, Sprachbewusstsein und Vorstellungen von Sprache erläutert. Während der Einstellungsbegriff (engl. attitudes) aus der nordamerikanischen Forschung stammt, werden in der deutschsprachigen Linguistik oftmals die Termini Sprachwissen und Sprachbewusstsein verwendet. Inhaltlich sind die Termini annähernd identisch. Schlieben-Lange (1975) bevorzugt den Begriff Sprachwissen, während sich seit der Studie Scherfers (1983), der dieses Konzept in der Theorie erheblich vorangetrieben hat, vielfach auch der Begriff Sprachbewusstsein durchgesetzt hat. Es würde in diesem Kontext zu weit führen, diese beiden komplexen Begrifflichkeiten näher zu erörtern. Einstellungen können als ein Teilgebiet des Sprachwissens bzw. Sprachbewusstseins aufgefasst werden.

Des Weiteren ist zwischen Spracheinstellungen (franz. attitudes linguistiques) und Vorstellungen von Sprache (franz. représentations linguistiques) zu differenzieren, auch wenn sie im konkreten Fall nicht immer scharf voneinander getrennt werden können.

Der Terminus Repräsentation stammt aus den Humanwissenschaften (Geografie, Geschichte, Sozialpsychologie). Bezogen auf die Sprache wird von einem engen Zusammenhang zwischen der eigenen Sprachpraxis und den Vorstellungen bezüglich der Sprache ausgegangen. Francard (1993e, 39) beschreibt das Vorstellungskonzept wie folgt:

„Ces représentations sont des constructions mentales plus ou moins spontanées qui, dans le cas de la langue, font partie d'un 'imaginaire linguistique' dans lequel les locuteurs puisent lorsqu'il s'agit d'évaluer leurs propres productions linguistiques ou celles d'autres locuteurs, d'expliciter les normes qu'ils reconnaissent, de désigner les modèles qu'ils prétendent imiter ou rejeter, de hiérarchiser les variétés linguistiques, etc. Elles sont autant de normes subjectives qui servent à légitimer, à justifier, à minoriser; elles sont autant de stéreotypes qui exhibent toute la violence symbolique qui les soustend.“ 
Die Vorstellungen von einer Sprache sind Gueunier (1997, 247) zufolge vorwiegend konservativer Natur und äußern sich u.a. in der ablehnenden Haltung der Franzosen gegenüber jeglichen Reformen wie z.B. Orthografiereformen. Vorstellungen sind immer an Ideologien geknüpft, was aber nicht impliziert, dass sie zwangsläufig falsch sein müssten. In der Soziolinguistik konzentriert sich die Erforschung von Vorstellungen in erster Linie auf Sprachkontaktphänomene, Varietäten einer Sprache wie Regionalsprachen oder auch auf Sprachcodewechsel. Lange Zeit wurden die beiden Konzepte - Spracheinstellungen und Vorstellungen von Sprache - verwechselt bzw. als synonym betrachtet. Es gibt in der Tat Gemeinsamkeiten zwischen Spracheinstellungen und Vorstellungen von Sprache: Beide vereint der episprachliche ${ }^{8}$ (intuitive) Charakter, der sie vom Sprachgebrauch und von metasprachlichen Urteilen als bewussten und auf Theorien basierenden Analysen unterscheidet. Ein bedeutender Unterschied im Konzept der Vorstellungen von Sprache ist die Tatsache, dass sie weniger aktiv, d.h. im Gegensatz zu Einstellungen weniger handlungs- als diskursorientiert sind. Auch in der Methodik ihrer Erforschung unterscheiden sich Spracheinstellungen und Vorstellungen von Sprache voneinander. Vorstellungen von der Sprache sind im Unterschied zu Spracheinstellungen nur schwer über direkte Methoden wie die Befragung zu erfassen. Das bedeutet für die konkrete Forschungssituation, dass zur Erforschung von Einstellungen vorwiegend Tests und Fragebögen verwendet, zur Bestimmung von Repräsentationen möglichst natürliche Interaktionen analysiert werden (vgl. Gueunier 1997, 248). Einen Beitrag zur Erforschung sprachlicher Vorstellungen liefert das Konzept der sprachlichen Unsicherheit (vgl. Fußnote 27). Dieses Schlagwort fällt in der aktuellen Diskussion zu den in der peripheren Frankophonie vorherrschenden Spracheinstellungen und Vorstellungen von der Sprache sehr häufig, wie vor allem in den Abschnitten 2.3.2, 2.3.3 und 2.3.4 zu zeigen sein wird. Francard (1997a, 176) bezeichnet die sprachliche Unsicherheit als Schlüsselkonzept in der Erforschung sprachlicher Vorstellungen.

Die Analyse der Einstellungen und der Vorstellungen zu einem Gegenstand schließen sich in der linguistischen Forschung keineswegs aus. Die Analyse sprachlicher Repräsentationen wäre z.B. in hohem Maße geeignet, um die aus der Einstellungsforschung gewonnenen Erkenntnisse zur Orthografiereform, zur Loi Toubon oder zum Gebrauch von Anglizismen im Französischen zu ergänzen (vgl. Gueunier 1997, 249). Daher ist es in der Linguistik keinesfalls ausgeschlossen,

\footnotetext{
8 Der Begriff épilinguistique bzw. episprachlich wird vornehmlich in der romanistischen Linguistik verwendet. Dubois et al. (1994, 184) definieren ihn im Dictionnaire de linguistique wie folgt: „Le terme qualifie les jugements de valeur que les locuteurs portent sur la langue utilisée et les autres langues; les qualificatifs de ,beau', ,noble', ,clair', etc., appliqués à la langue, sont dénués de caractère scientifique, mais peuvent fournir des données importantes en cas de conflit entre langues." Baggionis Definitionsansatz ist insofern präziser, als er episprachliche von metasprachlichen Urteilen trennt. Mit episprachlich werde „un discours sur la langue (= métalangue) à caractère prescriptif non-théorisé (épilinguistique) du type jugement esthétique ou correctif sur les énoncés produits dans telle ou telle langue" bezeichnet. Demgegenüber hätten metasprachliche Urteile deskriptiven Charakter und seien zumeist theoretischer als episprachliche Urteile, was aber nicht ausschließe, dass sie zugleich präskriptiv sein können (vgl. Baggioni 1996, 18f., Fußnote 1).
} 
dass zu einem Bereich sowohl die Spracheinstellungen als auch die sprachlichen Vorstellungen analysiert werden.

\subsection{Einstellungsmessung}

Wie gezeigt wurde, wird das Thema Einstellungen von mehreren Disziplinen erforscht. Mit der theoretischen Bestimmung gingen auch methodische Überlegungen sowie die Entwicklung geeigneter Forschungsinstrumente einher. Die Forschungsinstrumente entstammen im Wesentlichen der (Sozial-)Psychologie und den Sozialwissenschaften. Durch ständige Erweiterung und Verfeinerung des zur Verfügung stehenden Instrumentariums ist es dem heutigen Einstellungsforscher möglich, in Abstimmung mit den Forschungsinteressen und -absichten zwischen einer Vielzahl von empirischen Methoden zu wählen.

Der Gliederungspunkt 2.2 dient in erster Linie der Klärung der folgenden drei Fragen:

1. Welche Verfahren bieten sich an, um Einstellungen zu messen?

2. Welche Verfahren sind in der Linguistik gängig und eignen sich für Fragebogenstudien?

3. Welche Schwächen weist die experimentelle Spracheinstellungsforschung auf?

Die heute zur Verfügung stehenden Methoden der Datengewinnung lassen sich auf mehrfache Weise unterscheiden. Manche Autoren differenzieren zunächst zwischen qualitativen und quantitativen Methoden, bevor sie weitere Klassifizierungen treffen. Qualitative und quantitative Methoden schließen sich jedoch nicht aus, sondern werden mitunter in der linguistischen Feldforschung sogar kombiniert (vgl. 4.3.2, Gouadec 1993). Deshalb erweist es sich als sinnvoll, diese Unterteilung erst an späterer Stelle zu vollziehen.

Stahlberg/Frey (1996, 223-229) unterscheiden in einem ersten Schritt zwischen direkten und indirekten Methoden ${ }^{9}$. Dabei ordnen sie die Selbsteinschätzungsmessungen den direkten Methoden und diejenigen Einstellungsmessungen, die nicht auf Selbsteinschätzungen beruhen, den indirekten Methoden zu. Unter den ersten Typus, d.h. unter die Selbsteinschätzungsmessungen, subsumieren sie die Ein-ItemRating-Skala ${ }^{10}$, die Likert-Skala ${ }^{11}$ und das semantische Differential. Zum zweiten Typus

\footnotetext{
9 Häufig ist auch die Rede von reaktiven und nicht-reaktiven Verfahren, wobei die Informanten bei reaktiven Verfahren wissen, dass sie befragt werden, indem sie auf einen Stimulus, die Frage, reagieren. Bei nicht-reaktiven Verfahren wie der teilnehmenden Beobachtung hingegen fehlt der Stimulus durch den Interviewer. Mitunter wissen auch die beobachteten Personen nichts von ihrer Funktion als Datenlieferanten (vgl. Stahlberg/Frey 1996, 227-229).

10 Zum Konzept der Ein-Item-Rating-Skala vgl. Fußnote 11. Im Deutschen hat sich für den aus dem anglo-amerikanischen Sprachraum stammenden Begriff Rating-Skala keine einheitliche Bezeichnung durchgesetzt. Als deutsche Entsprechungen sind Schätzskala, Beurteilungsskala, Rangordnungsskala, Einschätzskala, Skalafrage und Einstufungsskala gebräuchlich (vgl. Stier 1996, 65). Rating-Skalen sind sowohl für die Selbsteinstufung als auch für die Fremdeinstufung einsetzbar. Jäpel $(1985,121)$ schreibt dazu: „Man benutzt die Rating-Technik bei der Einstellungs-[,] Meinungs- und Imagemessung, bei der Beurteilung von Personal, der Kooperationsfähigkeit, der Attraktivität, der Führer-
} 
zählen sie physiologische Messungen wie Pupillenerweiterung, Puls, Hautreaktion und Gesichtsmuskelaktivität, die allesamt emotionale Reaktionen widerspiegeln, sowie Verhaltensbeobachtung, bei der die Einstellungen aus den beobachteten Verhaltensweisen abgeleitet werden. Die von Stahlberg/Frey im Rahmen eines sozialpsychologischen Lehrbuchs getroffene Unterteilung ist selbstverständlich als Grundlage für die psychologische Forschung besser geeignet als für die Linguistik. So gehören beispielsweise die aufwändigen physiologischen Messverfahren nicht zu den gängigen linguistischen Forschungsmethoden. Auch auf die Methode der Verhaltensbeobachtung dürfte sich nur ein sehr geringer Teil linguistischer Studien stützen. Es dürfte sehr lange dauern, bis die beobachteten Personen sich zufällig so äußern, dass über zum Ausdruck gebrachte Meinungen Rückschlüsse über ihre Spracheinstellungen gezogen werden können. Diese Methode bietet sich somit weniger für die Ermittlung von Spracheinstellungen an als z.B. für die Analyse von Gesprächsverhalten. In der nachfolgenden Tabelle wird daher eine Einteilung vorgeschlagen, die für linguistische Belange angemessener ist. Sie greift die von Stahlberg/Frey getroffene Differenzierung in direkte und indirekte Messverfahren auf, nennt aber nur die zur Ermittlung von Spracheinstellungen gängigen Verfahren ${ }^{12}$ :

Abb. 1: Direkte und indirekte Erhebungsverfahren in der linguistischen Einstellungsforschung

\begin{tabular}{|c|c|}
\hline Direkte Erhebungsverfahren & Indirekte Erhebungsverfahren \\
\hline Schriftliche Befragung (Fragebogen) & Matched-guise-Technik \\
\hline Mündliche Befragung (Interview) & $\begin{array}{l}\text { Beobachtungsverfahren (v.a. „teilneh- } \\
\text { mende Beobachtung") }\end{array}$ \\
\hline Gruppendiskussion & \\
\hline
\end{tabular}

schaft, bei der Charakter- und Persönlichkeitsmessung, um nur einige wenige Beispiele zu nennen und das Spektrum der Anwendungsmöglichkeiten aufzuzeigen."

11 Nach Stier (1996, 83) werden den Informanten bei der von Rensis Likert im Jahre 1932 entwickelten Skala im Normalfall Rating-Skalen mit je fünf Antwortkategorien vorgelegt. Die Antwortkategorien auf eine zu bewertende Aussage können wie folgt aussehen:

stimme stimme lehne lehne

$\begin{array}{llll}\text { stark } \mathrm{zu} & \mathrm{zu} & \mathrm{ab} & \text { stark } \mathrm{ab}\end{array}$

(5) (4) (3) (2) (1)

Möglich wären anstelle der genannten Kategorien „stimme stark zu“ etc. auch die Antwortkategorien „,sehr wichtig“, „ziemlich wichtig“, ,wichtig“, ,weniger wichtig“, „unwichtig“ oder Antworten in gänzlich anderem Wortlaut, je nach dem in der Frage formulierten Statement. Bei der Likert-Skala handelt es sich um ein eindimensionales Skalierungsmodell. Deshalb kann mit einer Skala auch nur die Einstellung zu einem Sachverhalt gemessen werden (vgl. Stier 1996, 84). Von der Likert-Skala, bei der die Informanten mit einer Batterie von Statements mit gleichem Antwortprinzip konfrontiert werden, ist die oben bereits erwähnte sog. Ein-Item-(Rating-)Skala zu unterscheiden. Bei dieser Skala liegt nur eine Frage bzw. ein zu bewertendes Statement vor anstelle einer Fragenbatterie wie bei der Likert-Skala. Weitere Informationen zur Verwendung der Likert-Skala in der Einstellungsforschung sind z.B. bei Oppenheim (1992, 195-200) und Stosberg (1980, 99-102) nachzulesen.

12 Weitere Methoden zur Einstellungsmessung, die sich nicht in eine derartige, auf die empirische Feldforschung ausgerichtete Tabelle einordnen lassen, sind die Dokumentenanalyse, Inhaltsanalyse, Autobiografie und Fallstudie (vgl. Baker 1992, 17). 
Die linke Spalte der Tabelle entspricht dem von Stahlberg/Frey genannten Verfahren der Selbsteinschätzung, ist aber um die Methode der Gruppendiskussion, bei der der Forscher involviert ist, ergänzt worden.

Zudem ist eine im Rahmen linguistischer Forschung entwickelte und speziell für die Erforschung von Spracheinstellungen geeignete Methode in die Tabelle aufgenommen worden, die matched-guise-Technik. Sie wurde von Lambert und seinen Mitarbeitern in den späten 1950er und 1960er Jahren eigens zur Erforschung von Spracheinstellungen entwickelt (vgl. Bauvois 1997, 202f.; Lambert et al. 1960; Lambert 1967). Bei dieser Methode arbeitet der Interviewer mit Tonbändern, die den Informanten mit der Bitte vorgelegt werden, den oder die zu hörende/n Sprecher/in im Hinblick auf verschiedene Merkmale (Charakter und Person) zu beurteilen. Aus den Unterschieden in der Beschreibung der gehörten Sprecher, nicht der Sprache selbst (!), werden Rückschlüsse auf die Einstellungen der Informanten zu den jeweils vorgespielten Sprachen gezogen. Deshalb wird diese Forschungsmethode zu den indirekten Erhebungsverfahren gezählt. Als früheste, auf dieser Forschungstechnik basierende Untersuchung zur französischen Sprache gilt die Arbeit Hoppes zur Verbindung von Aussprache und sozialem Status (Hoppe 1976; vgl. Fußnote 32).

Generell gilt als Vorteil direkter Verfahren, dass sie ökonomischer als die indirekten Verfahren sind. Dies ist sowohl auf die zur Durchführung der Verfahren benötigte Zeit bezogen als auch auf das Fehlen teurer Apparaturen wie Videogeräte. Nachteilig an direkten Verfahren, welche auf Selbsteinschätzung beruhen, ist die Tatsache, dass die Informanten nicht immer in der Lage sind, über ihre Einstellungen Auskunft zu geben bzw. dass sie ihre Aussagen willentlich fälschen können, um beispielsweise im Sinne sozialer Erwünschtheit zu antworten (vgl. Albert/Koster 2002, 8f.; Stahlberg/Frey 1996, 226; Fußnote 5).

Die klassische Untersuchungsmethode der empirischen Sozialforschung ist die Befragung. Sie eignet sich in besonderem Maße für die Einstellungsforschung. Dies zeigt sich auch in ihrer regen Anwendung: In der sozialpsychologischen, aber auch in der linguistischen Einstellungsforschung wird mehrheitlich mit Selbsteinschätzungsmessungen in Form von Fragebögen und Interviews gearbeitet.

Befragungen lassen sich nach dem Medium (schriftlicher Fragebogen oder mündliches Interview) sowie dem Grad der Standardisierung (geschlossene oder offene Fragen) unterscheiden. Interviews mit persönlichem Kontakt - d.h. Telefoninterviews ausgenommen - legen oftmals die Verwendung offener Fragen nahe sowie ein wenig direktes Interviewerverhalten (sog. Tiefeninterviews), während in schriftlichen Befragungen häufig geschlossene Fragen eingesetzt werden. Die formale Standardisierung durch den Einsatz geschlossener Fragen bietet dem Forschenden den Vorteil, dass die vergleichende Analyse verschiedener Antworten erleichtert wird. Zugleich liegt in der hochgradigen Formalisierung ein Nachteil: Durch den für jeden Informanten identischen Fragenkatalog sowie die vorgegebenen Antwortkategorien wird das Antwortverhalten des Informanten erheblich beeinflusst. 
Die in Abb. 1 präsentierten Verfahren lassen sich im Hinblick auf die zur Durchführung eingesetzten Techniken weiterhin präzisieren. Die Methode der Befragung gilt im Unterschied beispielsweise zur teilnehmenden Beobachtung zwar immer als eine direkte Form der Messung, jedoch lassen sich Einstellungen auch innerhalb eines Fragebogens direkt bzw. indirekt erforschen. Entgegen der von Stahlberg/Frey getroffenen Einordnung des semantischen Differentials als direkte Methode der Einstellungsmessung wird dieses Forschungsinstrument in linguistischen Arbeiten stets als eine indirekte Messmethode eingestuft. Die Methode wird deshalb als indirekt klassifiziert, weil es wie auch beim Einsatz der matched-guiseTechnik für die Informanten nicht ersichtlich wird, dass und inwiefern ihre Einschätzungen der vorgegebenen Adjektive direkte Rückschlüsse auf ihre Einstellungen, insbesondere auf die affektive Einstellungsdimension, zulassen ${ }^{13}$.

Zur direkten Einstellungsmessung werden üblicherweise Skalen verwendet ${ }^{14}$. Die bekanntesten Skalentypen sind die Likert-Skala, die Thurstone- bzw. Thurstone\& Chave-Skala ${ }^{15}$ und das Skalogramm von Guttman ${ }^{16}$. Bei den Skalenkonstruktionen werden die Einstellungen der Informanten zu Sprachen und Sprachverhalten anhand ihrer Reaktion (Zustimmung bzw. Ablehnung, Intensität der Zustimmung bzw. Ablehnung) auf die vorgelegten positiven oder negativen Behauptungen direkt ermittelt. Mit Hilfe dieser Skalen können in der Spracheinstellungsforschung z.B. die am Ende von 2.1 genannten acht Bereiche in ihrer gesamten Bandbreite von extrem positiv bis extrem negativ gemessen sowie Einschätzungen des eigenen Sprachgebrauchs der Informanten vorgenommen werden (vgl. Smit 1996, 45; Vandermeeren 1996, 696-699). Ein Vorteil der Skalen besteht darin, dass diese im Unterschied etwa zu freien Interviews, die eine qualitative Evaluation erfordern, quantitativ ausgewertet werden können.

Die verschiedenen allgemeinen sowie speziell linguistischen Messverfahren gelten als sehr gut erforscht und erprobt. Dennoch ist es nicht möglich, die Einstellung von Individuen hundertprozentig zu bestimmen, wie bereits im letzten Kapitel angedeutet wurde. Generell gilt die isolierte Betrachtung der im Rahmen der experimentellen Einstellungsforschung gemessenen Variablen als Nachteil, weil Ein-

\footnotetext{
13 Das von Osgood/Suci/Tannenbaum in den 1950er Jahren entwickelte semantische Differential hat sich als quantitatives Messinstrument in der Einstellungsforschung bewährt (vgl. Osgood/Suci/Tannenbaum 1957, 76-188). In seiner Weiterentwicklung durch Peter Hofstätter wird es auch als Polaritätenprofil bezeichnet. Das semantische Differential wurde in erster Linie konzipiert, um die konnotative, d.h. subjektive Bedeutung eines Begriffs messen zu können, und gilt als das meistverwendete Verfahren zur Analyse der Bewertung von Marken, Produkten, Firmen und Personen (vgl. z.B. Koschnick, „Semantisches Differential“, o.J., o.S.). Die Messung der Einstellung erfolgt in Form von meist siebenstufigen Skalen, an deren Endpunkten sich zwei inhaltlich entgegenstehende Adjektive (Antonyme) befinden, wie „gut" - „schlecht“. Informationen zur konkreten Gestaltung semantischer Differentiale in Fragebögen werden in 7.1.2.1 gegeben.

14 Zum Gebiet der Skalierung bieten sich als einführende Literatur Gediga (1998) und Borg/Staufenbiel (1997) an.

15 Detaillierte Informationen zur Verwendung der eindimensionalen Thurstone- bzw. Thurstone\& Chave-Skala in der Einstellungsforschung geben Oppenheim (1992, 190-195) und Stosberg (1980, 102-112).

16 Zur Anwendung der eindimensionalen Guttman-Skala in der Einstellungsforschung vgl. Oppenheim (1992, 201-205), Stosberg (1980, 112-115).
} 
stellungen und daraus resultierendes Verhalten immer Ausdruck eines komplexen Systems sind (vgl. Cichon 1998, 45). Eine der Komplexität des Einstellungskonzepts gerecht werdende Forschung müsste im Sinne der Forderung Bakers (1992, 16; vgl. 2.1) auch persönliche, interpersonale und situative Faktoren einbeziehen. Hier zeigt sich jedoch die Diskrepanz zwischen theoretischem Anspruch und forschungspraktischer Umsetzbarkeit.

Bakers Kritik an der aktuellen Einstellungsforschung bezieht sich konkret auf die folgenden fünf Mängel: Erstens gelte es zu bedenken, dass vorgegebenes und tatsächliches Verhalten bzw. vorgegebene und tatsächliche Einstellungen nicht zwangsläufig übereinstimmen müssen. Oftmals beeinflussten gesellschaftliche Gegebenheiten das Antwortverhalten, und es werde so geantwortet, wie es als sozial anerkannt gelte (vgl. auch 2.1, bes. Fußnote 5). Zweitens würden die Antworten durch eine Vielzahl personaler Faktoren determiniert, wie z.B. ethnische Zugehörigkeit, Geschlecht, sozialer Status und Alter ${ }^{17}$. Drittens könnten aber auch situative Faktoren aus dem Umfeld der Untersuchung, wie z.B. die Person des Untersuchungsleiters oder die räumliche Umgebung der Informanten, die Antworten beeinflussen. Viertens könne ein Forscher auch nach Durchführung eines Pretests bei der Formulierung geschlossener Fragen kaum die komplette Bandbreite an möglichen Antworten vorhergesehen haben. Fünftens sei es sehr schwierig, die Testpopulation so auszuwählen, dass sie als repräsentativ gelten könne (vgl. Baker 1992, 18-20).

Sicherlich lassen sich einige der Punkte, die Baker zu Recht an vielen bisherigen Einstellungsstudien bemängelt, auch in dieser Untersuchung nicht beheben. Die verzerrenden Faktoren sollen jedoch, soweit dies möglich ist, reduziert werden. Die Befürchtung der Informanten, sozial unerwünschte Antworten zu geben, wird mit der entsprechenden Erklärung im Eingangstext zum Fragebogen entkräftet: Der Fragebogen bleibe anonym und durch die Fragen würden nicht die Sprachkenntnisse der Informanten getestet, sondern die Wirksamkeit der französischen Sprachpolitik (vgl. 15.2.1). Der Tatsache, dass die Antworten von einer Vielzahl persönlicher Faktoren abhängen, wird im dritten Teil des Fragebogens Rechnung getragen, in dem um die Angabe persönlicher Daten (Alter, Geschlecht etc.) gebeten wird, welche in die anschließende Auswertung einfließen. Entsprechend bietet es sich in einer Studie über die englische bzw. französische Internet-Terminologie an, neben den klassischen biosozialen Daten wie Alter, Geschlecht, Wohn- und Geburtsort, Beruf bzw. Bildungsstand auch nach den Englischkenntnissen und Internet-Erfahrungen zu fragen. Natürlich kann nur eine Auswahl an personalen Faktoren herangezogen werden. Niemals können alle Faktoren, die die Einstellungen einer Person beeinflussen, berücksichtigt werden. Einflüsse durch das Umfeld der Untersuchung - der dritte, vor allem auf Interviewer bezogene Kritikpunkt - lassen sich bei einer WWW-Studie durch eine klare, sachliche Gestaltung des Fragebogens auf ein Minimum reduzieren. Bakers viertem Kritikpunkt ist kaum entgegenzutreten, da auch nach Durchführung eines Pretests nicht

17 Aufgrund der Tatsache, dass biografische Daten und Einstellungen häufig korrelieren, empfiehlt Baker (1992, 25f.) in der Auswertung stets auf diese Zusammenhänge einzugehen. 
alle Antwortmöglichkeiten antizipiert werden können, insbesondere bei einer Befragung von Informanten aus drei Ländern. Dieses Problem lässt sich jedoch weitestgehend durch die Einführung einer zusätzlichen Antwortkategorie beheben, der Kategorie „Sonstiges ... und zwar“/franz. „Autre, veuillez préciser“ (vgl. 7.1.1.2). Das fünfte Problem, die mangelnde Repräsentativität, kann auch in dieser Studie nicht behoben werden, jedoch wurde versucht, die Aussagekraft der Ergebnisse durch die Eingrenzung der Zielgruppe zu erhöhen ${ }^{18}$. In der Forschungspraxis müssen daher einige kleinere Mängel in Kauf genommen werden, um über eine direkte Befragung an brauchbares Datenmaterial zu gelangen.

\subsection{Einstellungsforschung in der Frankophonie: Frankreich, Belgien, Schweiz}

\subsubsection{Die Rolle der Frankophonie}

Die folgenden Ausführungen geben Aufschluss über das Frankophoniekonzept sowie die der Frankophonie angehörenden Länder. Hierbei wird unterschieden, welche Länder bzw. Sprechergruppen der zentralen Frankophonie und welche der Peripherie zugewiesen werden. Abschließend werden zwei entscheidende Desiderate in der gegenwärtigen, im Rahmen der Frankophonie betriebenen Einstellungsforschung aufgezeigt.

Seit den 1960er Jahren existiert ein Staatenbündnis, das unter dem Namen der Frankophonie ${ }^{19}$ alle französischsprachigen Länder vereint. Als Initiator gilt Léopold Sédar Senghor, der in einem 1962 veröffentlichen Manifest zur Frankophonie „die französische Sprache und Kultur zum gemeinsamen Erbe der frankophonen Staaten erklärt und eine, geistige Gemeinschaft' zwischen diesen Staaten heraufbeschwört" (Gahlen/Geisel 1999, 84). Auf diese Veröffentlichung folgten Zusammenkünfte und Konferenzen in den 1960er Jahren, in deren Folge es zur Gründung zahlreicher Frankophonieorganisationen ${ }^{20}$ sowie seit 1986 zur Austragung

\footnotetext{
18 Zum Problem der Repräsentativität in Online-Befragungen vgl. 6.3.1.

$19 \mathrm{Zu} \mathrm{Begriff}$ und Konzept der Frankophonie vgl. ausführlich Butzke-Rudzynski (1992, 21-53); Deniau (1998, 9-24, hier auch die Abgrenzung zum Konzept der francité); Pöll (1998, 5-8, 2001, 1924) und Schmitt (1990c). Einen guten Überblick über die Geschichte und die institutionelle Organisation der Frankophonie - wahlweise in Französisch, Englisch, Spanisch, Portugiesisch oder Arabisch, nicht aber in Deutsch - gibt die Internetseite des Ministère des Affaires Étrangères: http://www.france.diplomatie.fr/francophonie/index.html.

Walter (2001, 261) macht auf den Unterschied zwischen francophonie und Francophonie aufmerksam: „Depuis la création en 1986 des Sommets de la Francophonie, [...] une réelle confusion règne quant à la signification à accorder à ces termes. En fait, la francophonie (avec un f minuscule) correspond à l'ensemble des populations dont la langue est le français, tandis que la Francophonie (avec un F majuscule) désigne tous les pays qui, dans leurs échanges avec les autres pays de la Francophonie, ont le 'français en partage', mais dans lesquels la langue française ne jouit pas toujours d'un statut particulier. C’est que la Francophonie a une vocation plus générale, qui se traduit par une coopération culturelle, scientifique et technique concertée."

20 Als eine der wichtigsten Organisationen ist der 1969 gegründete Conseil international de la langue française (CILF) zu nennen (vgl. auch 4.2.1).
} 
der Frankophoniegipfel21 kam. Jedoch sagt das Frankophonie-Konzept nichts über die Einstellungen frankophoner Sprecher zur französischen Sprache aus, welche häufig nicht einmal ihre Muttersprache ist, sondern - v.a. in den frankophonen Staaten Nord- und Schwarzafrikas - nur die offizielle Landessprache.

Zur Erläuterung des Frankophonie-Konzeptes bietet es sich an, zwischen der Frankophonie im engeren und im weiteren Sinn zu differenzieren. Im Petit Robert (2000, 1085) wird Frankophonie definiert als „1. Ensemble constitué par les populations francophones (France, Belgique, Canada [...], Louisiane, Suisse, Afrique [...]" und „2. Mouvement en faveur de la langue française.“ In dieser Definition, die z.B. auch die französischsprachigen Staaten Afrikas einschließt, wird von einem weiten Frankophoniebegriff ausgegangen. Dieser spiegelt sich auch in der Definition von francophone, der zufolge auch als frankophon gilt, wer Französisch nicht als Muttersprache, sondern als Fremdsprache erworben hat, und sogar, wer lediglich in einem Land lebt, in dem Französisch die offizielle Sprache bzw. die Verkehrssprache ist:

„Qui parle habituellement le français, au moins dans certaines circonstances de la communication, comme langue première ou seconde. [...] (En parlant d'un groupe, d'une région) Dans lequel le français est pratiqué en tant que langue maternelle, officielle ou véhiculaire (même si les individus ne parlent pas tous le français [...])“ (ebd.).

Wesentlich enger gefasst ist die Definition Schmitts (1990c, 686):

„Zur Frankophonie gehören alle Gebiete, die das Französische als Muttersprache kennen oder infolge politischer Ereignisse [...], primär des Kolonialismus seit dem 16. Jahrhundert, das Französische als Schul- und Verwaltungssprache angenommen haben bzw. zu übernehmen gezwungen waren [...].“

Nach Angaben der Délégation générale à la langue française et aux langues de France (DGLFLF) gehören zur Zeit 49 Mitgliedsstaaten und drei Beobachterstaaten (Polen, Mazedonien und Albanien) zur Frankophonie. Insgesamt werden ihr 500 Millionen Personen zugerechnet. Jedoch sei es wichtig, zwischen tatsächlichen, d.h. permanenten, und gelegentlichen Frankophonen zu unterscheiden. Daher unterteilt die DGLFLF die Frankophonen in drei Gruppen:

21 Die Austragungsorte der Frankophoniegipfel waren Versailles (1986), Québec (1987), Dakar (Senegal, 1989), Paris (1991), Grand Baie (Mauritius, 1993), Cotonou (Benin, 1995), Hanoi (Vietnam, 1997) und Moncton (Nouveau-Brunswick, 1999). Der eigentlich für 2001 in Beirut (Libanon) geplante 9. Frankophoniegipfel wurde aufgrund politischer Ereignisse um ein Jahr verschoben und hat somit erst im Oktober 2002 stattgefunden (vgl. z.B. Deniau 1998, 60-67; Ministère des Affaires Étrangères 2002, o.S., 2003b, o.S.). 
1. 113 Millionen tatsächliche Frankophone, die Französisch als Erst- oder Zweitsprache haben 22 ,

2. 61 Millionen gelegentliche Frankophone, die zwar im frankophonen Sprachraum wohnen, jedoch nur rudimentäre Kenntnis von dieser Sprache haben,

3. 100-110 Millionen Personen, die Französisch außerhalb des frankophonen Sprachraums als Fremdsprache gelernt haben (vgl. DGLFLF o.J.f, o.S., Zahlen von 1997/98).

Somit stellt sich die Frage, wer überhaupt als frankophon im eigentlichen Sinne zu bezeichnen ist. Aus linguistischer Sicht dürfte es wenig sinnvoll sein, eine Person als frankophon zu bezeichnen, die Französisch als Fremdsprache gelernt hat und nicht im frankophonen Sprachraum wohnt (d.h. Gruppe 3). Unabhängig von dieser Einschätzung ist es wenig sinnvoll, Fremdsprachler zu den Einstellungen gegenüber einzelnen französischen bzw. angloamerikanischen Fachtermini sowie zur französischen, belgischen oder schweizerischen Sprachpolitik zu befragen. Zum einen wird nur Muttersprachlern das zur Bewertung bestimmter Termini benötigte Sprachgefühl zugesprochen (vgl. Abraham 1988, 319). Wer Französisch als Fremdsprache erworben hat, kennt zum anderen die französischen Fachtermini nicht so genau wie die von diesen Termini betroffenen Muttersprachler. Deswegen ist es zweckmäßig, ausschließlich Muttersprachler in eine entsprechende Studie zur Akzeptanz von französischsprachigen Fachtermini sowie zur Beurteilung der jeweils geltenden Sprachpolitik einzubeziehen.

Pöll $(1998,2)$ löst das Problem, eine Trennlinie zwischen der Frankophonie im engeren und im weiteren Sinn zu ziehen, indem er sein Hauptaugenmerk richtet

„[...] auf jene Gebiete, um deren frankophone Zukunft man sich wahrscheinlich keine allzu großen Sorgen machen muß und die sich durch eine spezifische Sprachenlage deutlich von Frankreich abheben: Die frankophonen europäischen Länder Schweiz, Belgien, Luxemburg, sowie Québec und Afrika (Schwarzafrika und Maghreb).“"

Pöll zufolge gehören demgegenüber Länder und Gegenden, in denen das Französische nur Zweitsprache ist, nicht zum Kern der Frankophonie, wie beispielsweise die ehemaligen Kolonialländer Kambodscha, Laos, Vietnam, Haiti. Aber auch auf den beiden Karibikinseln Martinique und Guadeloupe, die politisch als DOM (= départements d'outre-mer, überseeische Gebiete) zu Frankreich gehören, wird mehrheitlich Kreol gesprochen, obwohl Französisch die offizielle Amtssprache ist (vgl. ebd., 3) ${ }^{23}$.

\footnotetext{
22 Davon leben ca. 71 Millionen Sprecher in der Europäischen Union (Frankreich, Belgien, Schweiz und Luxemburg). Französisch ist nach Deutsch mit ca. 90 Millionen Sprechern die zweithäufigste Muttersprache in der EU und liegt somit vor dem Englischen mit ca. 61 Millionen Sprechern (vgl. Ministère des Affaires Étrangères 2003a, o.S.).

23 Neben Martinique und Guadeloupe gehören Französisch-Guyana und La Rémnion zu den DOM. Ferner gibt es die TOM (= territoires d'outre-mer), zu denen Französisch Polynesien, Wallis \& Futuna, Neukaledonien, die Französischen Südlichen und Antarktischen Länder sowie die sog. Collectivités territoriales St. Pierre-et-Miquelon und Mayotte gehören (vgl. Pöll 1998, 17).
} 
Als Alltags- und Standardsprache wird das Französische (bzw. eine geografische Varietät) nur in Frankreich, Wallonien, der Westschweiz und in den frankophonen Gebieten Kanadas und der USA gebraucht. Deshalb bezeichnet man diese Gebiete mitunter als die première francophonie (vgl. ebd., 20; Robillard 2000, 71).

Durand $(1997,439)$ zufolge gab es 1996 allein über 120 nichtstaatliche Organisationen, die sich um die Verbreitung des Französischen innerhalb und außerhalb der Frankophonie bemühten. Wenngleich die Frankophonie ein äußerst heterogenes und vielfältiges Gebilde darstellt, zählen die Verteidigung des Französischen und die Subvention der Brüderstaaten zu den wesentlichen Zielen und Aufgaben fast aller frankophonen Sprachpflegeorganisationen (vgl. Butzke-Rudzynski 1992, 31; Schmitt 2000, 66f.). Insbesondere bezüglich der Zielsetzung, das Französische vor fremden Einflüssen sowie in seinem Status zu verteidigen, ist in der frankophonen Sprachpolitik eindeutig eine Fortsetzung der französischen Sprachpolitik erkennbar.

Frankreich verstand und versteht sich seit Jahrhunderten als Träger einer universalen Sprachkultur und vertritt dieses Selbstbewusstsein auch innerhalb der Frankophonie. Frankreich begreift sich als Herzstück der Frankophonie. Entsprechend wird zumeist das hexagonale Französisch als Zielnorm für die gesamte Frankophonie betrachtet (vgl. Bourhis 1982, 34; Schmitt 1990c, 686). Ein Teil der frankophonen Länder akzeptiert diese selbstbeanspruchte Rolle Frankreichs jedoch nicht und versucht sich durch Schaffung eigener Sprachgesetze und einer vom Sprachideal des Hexagons z.T. abweichenden Norm zu emanzipieren (vgl. Neumann-Holzschuh 1995, 201f.; Schmitt 1990b, 379-385). Die höchste Unabhängigkeit von der Norm Frankreichs sowie die Ausbildung eines hohen Sprachbewusstseins dürften inzwischen in Québec erreicht sein. Dort ist seit den 1960er Jahren durch massiven Bevölkerungseinsatz ein Emanzipationsprozess in Gang gekommen, der ein wesentliches Ziel mit Festschreibung des Französischen als offizieller Sprache zunächst in der Déclaration du statut des langues (1969), dann im Rahmen der Charte de la langue française (1977) erreichte und für das Selbstverständnis vieler Québécois einschneidend war (vgl. Neumann-Holzschuh 1995, 202)24. Ein Ausdrucksmittel der Unabhängigkeit Québecs von Frankreich besteht in der Schaffung einer von der hexagonalen oftmals abweichenden Terminologie (vgl. 3.3.4). Belgien hingegen übernimmt nahezu ausnahmslos die von Frankreich vorgeschlagene Terminologie (vgl. 3.3.1). Drückt sich hierin die Abhängigkeit Belgiens von Frankreich aus? Oder verbirgt sich hinter der Übernahme der französischen Terminologie ein hohes Maß sprachlicher Unsicherheit? Oder steckt einfach nur die Einsicht dahinter, dass die Übernahme der französischen Terminologie der Communauté française de Belgique viele Kosten erspart? Und wie ist die Situa-

\footnotetext{
${ }^{24}$ Auf das hohe Sprachbewusstsein der Frankokanadier kann hier nicht weiter eingegangen werden. Der Ablösungsprozess der Frankokanadier vom dominierenden Englisch, das neue Selbstbewusstsein gegenüber ihrer eigenen Varietät sowie dem Französischen Frankreichs, aber auch ihre Einstellung zur Frankophonie und zum Englischen sind in zahlreichen Publikationen ausführlich dargestellt worden (vgl. z.B. Bagola 2000, Bourhis 1982, 1983, 1984, Bourhis 1994; Labrie 1991, Laporte 1995, Martel/Cajolet-Laganière 1996, Mauderer 1994, Maurais 1985b, 1993, Neumann-Holzschuh 1995, Pacquot 1991, Sarcher 1994, Wolf 1992).
} 
tion in der Westschweiz? Werden dort auch die in Frankreich gültigen Termini übernommen? Zur Klärung dieser Fragen werden besonders die Abschnitte 3.3.1 und 3.3.2 beitragen, in denen die Terminologiearbeit in Belgien und der Schweiz behandelt wird.

Die im Rahmen der französischen Sprache betriebene Einstellungsforschung weist zwei entscheidende Desiderate auf:

1. Es fehlen Studien über den Status und die Einstellung zum Französischen in vielen außereuropäischen frankophonen Staaten. Hierzu zählen nicht nur die frankophonen Staaten Afrikas, in denen dem Französischen der Rang einer Verkehrssprache zukommt, sondern beispielsweise auch die frankophonen kanadischen Regionen Akadien und Ontario. Des Weiteren fehlen entsprechende aktuelle Studien für die frankophonen Sprachinseln in den USA, wie die Neu-England-Staaten oder Louisiana, sowie für die DOM-TOM ${ }^{25}$. Einen Anfang bezüglich der in dieser Hinsicht bisher kaum erforschten frankophonen Staaten in Afrika macht die Studie von Gahlen/Geisel (1999), in der die Einstellungen von senegalesischen Sprechern zum Französischen und zum Frankophoniekonzept untersucht werden.

2. Die ländervergleichende Erforschung von Spracheinstellungen oder ähnlich gelagerten Konzepten wie Repräsentationen von Sprache oder Sprachbewusstsein steckt noch in den Anfängen. Die meisten der bislang durchgeführten Studien konzentrieren sich auf nur ein Untersuchungsgebiet, meistens auf ein in Frankreich gelegenes Territorium, in dem eine Minderheitensprache gesprochen wird (insbesondere auf das Okzitanische, vgl. 2.3.2). Befragungen in mehr als einem Untersuchungsgebiet sind derzeit äußerst selten. Eine löbliche Ausnahme stellen die Studien Schafroths (z.B. Schafroth 1992/1996) und Sarchers (1994) dar, in denen die Akzeptanz und das Sprachbewusstsein von Franzosen und Frankokanadiern in Bezug auf Regionalismen (Sarcher 1994) und Anglizismen (Sarcher 1994, Schafroth 1996), die Feminisierung der Berufsbezeichnungen (Sarcher 1994, Schafroth 1992) und die Orthografie (Sarcher 1994) kontrastiert werden ${ }^{26}$. Eine kontrastive empirische Studie, die wie in der vorliegenden Arbeit drei frankophone Länder bezüglich der dort vorherrschenden Einstellungen in den Mittelpunkt rückt, fehlt meines Wissens bisher völlig.

\subsubsection{Frankreich}

In diesem Abschnitt werden drei zentrale Studien zur Erforschung der französischen Spracheinstellungen bzw. des französischen Sprachbewusstseins vorgestellt,

\footnotetext{
25 Einen Überblick über die Einstellungsforschung in Frankreich, Belgien, der Schweiz, in den frankophonen Staaten Nordafrikas, im Libanon, in Süd-Ost-Asien, in den 24 frankophonen Staaten Schwarzafrikas, auf Haiti, Martinique und Guadeloupe, im anglophonen Kanada und in Québec bis zu Beginn der 1980er Jahre gibt Bourhis (1982). Die Einstellungen der Québécois gelten als von allen frankophonen Sprechern am besten erforscht.

${ }^{26}$ Lediglich die Regelungen zur Feminisierung von Berufsbezeichnungen in den Ländern Québec, Frankreich, Belgien und der Schweiz werden verglichen, nicht aber die dazugehörigen Einstellungen (vgl. Burr 2000, Gladischefski/Lieber 1998).
} 
nämlich die Arbeiten von Gueunier/Genouvrier/Khomsi (1978), von Paltridge/Giles (1984) und von Fischer (1988). Diese Studien zeigen, dass Einstellungen auch innerhalb eines Landes regionalen Differenzen unterliegen. Sie werden hier vorgestellt, um Parallelen zu den im frankophonen Belgien und in der frankophonen Schweiz durchgeführten Studien ziehen zu können. Dieses Kapitel kann keinen vollständigen Forschungsüberblick über alle bislang auf französischem Territorium durchgeführten Einstellungsstudien bieten, in denen das Verhältnis der Franzosen zu regionalen Varietäten bzw. Minderheitensprachen einerseits und das Verhältnis zur Standardsprache andererseits im Zentrum steht. In diesem Zusammenhang ist es unumgänglich, das Konzept der insécurité linguistique zu erläutern. Auf die Erforschung der Einstellungen von Dialektsprechern bzw. Sprechern von Minderheitensprachen wird nur kurz eingegangen.

Es ist bekannt, dass in Frankreich Sprache und Kultur sehr hoch eingeschätzt werden. Nicht nur sprachwissenschaftliche Studien bestätigen immer wieder den hohen Stellenwert, den Sprache und Kultur in Frankreich einnehmen, sondern auch Studien mit ganz anders gelagertem Schwerpunkt wie die folgende. Im November/Dezember 2000 wurde eine SOFRES-Umfrage zum Thema „Les attitudes des Français à l'égard de la science“ im Auftrag des Ministère de l'Éducation Nationale und der Usine Nouvelle durchgeführt. Dabei wurden insgesamt 1500 Franzosen mit einer Reihe von Fragen konfrontiert, von denen hier nur die in diesem Kontext relevante Frage zitiert sei: „A votre avis, dans la liste suivante, quelles sont les deux choses que vous estimez les plus importantes pour le prestige de la France dans le monde? Quelle est celle que vous citeriez en premier? [...]“. Als wichtigste Faktoren wurden genannt:

1. Sa langue et sa culture $(38 \%)$,

2. Ses traditions et son histoire $(18 \%)$,

3. Le niveau de vie de ses habitants $(17 \%)$,

4. Son développement économique (15\%),

5. Ses réalisations scientifiques $(8 \%)$,

6. Son armée $(3 \%)$,

7. Sans opinion (1\%) (vgl. Taylor Nelson Sofres 2000, o.S.).

Für 38\% der Befragten stehen die französische Sprache und Kultur an erster Stelle, wenn es um das Ansehen Frankreichs in der Welt geht. Das Ergebnis der SOFRES-Umfrage zeigt eindeutig, dass auch in Kontexten, in denen nicht primär Einstellungen zu Sprache und/oder Sprechern erforscht wird, die Wichtigkeit von Sprache und Kultur als Ausdruck nationaler Identität tief im französischen Nationalbewusstsein verankert sind.

Einstellungen werden im Rahmen sozialpsychologischer Forschung seit den 1920er Jahren, im Rahmen der nordamerikanischen Linguistik seit den 1950er Jahren erforscht. Die französische Soziolinguistik geht erst sehr spät auf die nordamerikanische Soziolinguistik (v.a. Labov 1966, 1972, 1976, 1978; Lambert et al. 1960) ein, da sich in Frankreich bereits eine soziolinguistische Tradition herausgebildet hat, die eng mit der Textlinguistik verschmolzen ist (vgl. Schlieben- 
Lange 1991, 55). Somit setzt die Erforschung von Spracheinstellungen unter Einsatz der in Nordamerika entwickelten Konzepte und Methoden in Frankreich erst in den 1970er Jahren ein. Die matched-guise-Technik findet beispielsweise Verwendung in der Studie Hoppes (1976, vgl. Fußnote 32), auf die hier nicht weiter eingegangen wird, sowie in der Befragung von Paltridge/Giles (1984). Das von Labov entwickelte Konzept der sprachlichen Unsicherheit (franz. insécurité linguisti$q u)^{27}$ liegt der Untersuchung von Gueunier/Genouvrier/Khomsi (1978) zugrunde. In den nachfolgenden Jahren wurde der Schwerpunkt in der soziolinguistischen Forschung auf die soziale Bewertung regionaler Varietäten (Dialekte und Patois) und Minderheitensprachen gelegt. Ohne im Detail auf die Inhalte eingehen zu können, seien vier dieser Arbeiten an dieser Stelle genannt: Fischers Studie zu den Einstellungen von Sprechern des Okzitanischen bzw. Bündnerromanischen zu ihrer Sprache (1993), Scherfers Untersuchungen zum Sprachbewußtsein der PatoisSprecher in der Franche-Comté von 1983, Cichons Studie zum Sprachbewusstsein von Okzitanischlehrern (1988) und die Arbeit Strohs zu Sprachkontakt und Sprachbewusstsein in Ost-Lothringen (1993). Als Ergebnis dieser Untersuchungen lässt

27 Labov hat dieses Konzept Mitte der 1960er Jahre im Zuge seiner Untersuchung zur sozialen Stratifikation der sprachlichen Variablen in New York entwickelt (Labov 1966). Den Begriff der sprachlichen Unsicherheit (engl. linguistic insecurity) hat er in seinem Buch Sociolinguistic Patterns eingeführt: „A great deal of evidence shows that lower-middle-class speakers have the greatest tendency towards linguistic insecurity, and therefore tend to adopt, even in middle age, the prestige forms used by the youngest members of the highest-ranking class. This linguistic insecurity is shown by the very wide range of stylistic variation used by lower-middle-class speakers; by their great fluctuation within a given stylistic content; by their conscious striving for correctness; and by their strongly negative attitudes towards their native speech pattern" (Labov 1972, 117). Labov betrachtet vor allem Hyperkorrekturen und die Abwertung der eigenen Sprechweise als Indikatoren sprachlicher Unsicherheit. Kritik am Labovschen Konzept äußern Baggioni (1996) und Robillard (1996). Während Baggioni Labovs Definition vorwirft, dass sie zirkulär und zu eng sei, entkräftet Robillard diesen Vorwurf berechtigterweise, indem er deutlich macht, dass das Konzept der sprachlichen Unsicherheit bei Labov nicht der Ausgangspunkt, sondern das Ergebnis seiner Untersuchungen gewesen sei und deshalb in seiner theoretischen Begründung nur unvollkommen sein könne. Zudem sei es nur ein Unterprodukt seiner Forschungen, nicht aber das zentrale Forschungsgebiet (vgl. Robillard 1996, 63f.). In Frankreich greift Bourdieu (1993, 38) das Konzept der sprachlichen Unsicherheit auf und folgt in seiner Definition Labov: Sprecher der nicht nur sprachlich, sondern oftmals auch wirtschaftlich unterdrückten Gruppe versuchen bewusst oder unbewusst, ihre Aussprache, ihr Vokabular sowie die Syntax an die dominierende Sprache anzupassen.

Francard, der dieses Konzept in Bezug auf das frankophone Belgien intensiv erforscht hat, definiert den Begriff der insécurité linguistique im Anschluss an die bereits zum frankophonen Belgien vorliegenden Untersuchungen wie folgt: ,[...] l'insécurité linguistique [est] la prise de conscience, par les locuteurs, d'une distance entre leur idiolecte (ou leur sociolecte) et une langue qu'ils reconnaissent comme légitime parce qu'elle est celle de la classe dominante, ou celle d'autres communautés où l'on parle un français 'pur', non abâtardi par les interférences avec un autre idiome, ou encore celle de locuteurs fictifs détenteurs de LA norme véhiculée par l'institution scolaire“ (Francard 1993a, 13). Kurz gesagt ergibt sich das Gefühl sprachlicher Unsicherheit aus dem Wissen bzw. der fälschlichen Annahme der Sprecher, dass ihr sprachlicher Ausdruck nicht der anerkannten Norm entspreche bzw. weit von ihr entfernt sei. Sprachliche Sicherbeit und spracbliche Unsicherbeit stehen nicht in bipolarer Opposition zueinander, sondern man hat sich die Begriffe als Endpunkte eines Kontinuums vorzustellen, auf dem diverse Zwischenstufen möglich sind (vgl. Francard 1997a, 172). Der Begriff (in seiner theoretischen Begründung) und die Ausprägungen sprachlicher (Un-)Sicherheit in unterschiedlichen Sprachgesellschaften wurden in verschiedenen empirischen Studien vertieft. Theoretisches zum Konzept der insécurité linguistique findet sich bei Swiggers (1994), Baggioni (1996) und Robillard (1996). Zur ausführlichen Lektüre zum Konzept der sprachlichen Unsicherheit sowie zu Studien im frankophonen Sprachraum vgl. Bavoux (1996) und Francard (1993b). 
sich festhalten, dass den Patois, die schon zur Zeit der Französischen Revolution staatlich bekämpft wurden, aber auch Minderheitensprachen wie dem Okzitanischen $^{28}$, heute keine hohe Bedeutung zukommt. Wenngleich die Sprecher ihrer Mundart affektiv verbunden sind, geben sie dieser jedoch kaum eine Überlebenschance. Patois gelten im Vergleich zum Standardfranzösischen als minderwertig. Vor allem bei der jüngeren Generation, die kaum noch über Kenntnis des jeweiligen Patois verfügt, wird - insbesondere auch im Hinblick auf wirtschaftliche Interessen - einzig die Beherrschung der Nationalsprache als erstrebenswert erachtet (vgl. Cichon 1988, 135f.; Fischer 1993, 103; Scherfer 1983, 165-169; Stroh 1993, 61-63, 116f, 180). Insgesamt lässt sich festhalten, dass der Substitutionsprozess der Patois bzw. Minderheitensprachen wie Okzitanisch durch das Französische ungehindert fortschreitet (vgl. Markhof 1987, 285).

In diesem Abschnitt jedoch sollen Frankreich und die dort betriebene Einstellungsforschung im Zentrum stehen. Gueunier/Genouvrier/Khomsi, die 1978 das Buch Les Français devant la norme veröffentlicht haben, sind die ersten Linguisten, die im frankophonen Sprachraum eine Studie auf dem Hintergrund des von Labov geprägten Konzeptes der sprachlichen Unsicherheit durchgeführt haben. Sie arbeiteten mit Tests, Fragebögen und Interviews. Für die Tests und Befragungen wurden Informanten in Tours, Lille, Limoges und Saint-Denis-de-la-Réunion herangezogen. Gueunier/Genouvrier/Khomsi ermitteln, inwiefern Sprecher aus Tours die Aussprachenorm (die Opposition von /e/ und / $\varepsilon /$ ) befolgen (Teil 1) und welche Einstellungen sie zur sprachlichen Norm vertreten (Teil 2 und 3). Als Ergebnis des zweiten Teils lässt sich festhalten, dass die 75 Informanten aus Tours, das als Milieu sprachlicher Sicherheit gilt ${ }^{29}$, in hohem Maße überzeugt sind von der Reinheit, d.h. Akzentlosigkeit der eigenen Varietät ${ }^{30}$. 44\% der Befragten (44\%) bejahen die Frage, ob sie ein gutes Französisch sprechen, 44\% verneinen sie (vgl. Gueunier/Genouvrier/Khomsi 1978, 86). Teil 3 zeigt auf, dass die Informanten aus Gebieten, die als „milieu d'insécurité linguistique“ gelten (Lille, Limoges und Saint-Denis-de-la-Réunion), davon überzeugt sind, kein gutes Französisch zu sprechen: Nur 19\% der Informanten aus Lille und 28\% der Befragten aus Saint-Denis geben an ein gutes Französisch zu sprechen (vgl. ebd., 133) ${ }^{31}$. Während in Tours nur 6,5\% der Befragten angeben einen Akzent zu haben, sind es in Lille schon 57\%, in Limoges $77 \%$ und in Saint-Denis 89\% (vgl. ebd. 144).

${ }^{28}$ Es fällt insgesamt auf, dass es sehr viele empirische Untersuchungen zum Okzitanischen gibt. Allein im Bereich der deutschsprachigen Linguistik lassen sich die jeweils als Monografien publizierten Studien von Cichon (1988), Fischer (1993), Markhof (1987), Meisenburg (1985) und Rogge (1987) anführen.

${ }^{29}$ Nach Genouvrier $(1986,49)$ hat die verbreitete Ansicht, in Tours spreche man das reinste Französisch, eine lange Tradition. Diese geht nicht zuletzt auf die bedeutenden Schriftsteller zurück, die mit Tours verbunden werden: „Une très ancienne tradition donne à la Touraine une vocation à la fois horticole et linguistique: 'Tours, jardin de la France et du beau langage...' Douceur du climat, région d'équilibre, lumière du fleuve Loire, séjour d'élection des rois de France, pays d'ancienne culture, lieu natif ou de prédilection de Rabelais et de Ronsard, de Balzac, d'A. France et de J. Romains... [...].“

30 88,5\% der Befragten verneinen die Frage, ob sie einen Akzent hätten, nur 6,5\% bejahen diese Frage (5\% Enthaltungen) (vgl. Gueunier/Genouvrier/Khomsi 1978, 82).

${ }^{31}$ Der Prozentwert für Limoges ist unbekannt. 
Des Weiteren beurteilen die Informanten aller drei Städte ihren eigenen Akzent als negativ (vgl. ebd., 148-152).

Seitdem Gueunier/Genouvrier/Khomsi in dieser Studie die Konzepte insécurité linguistique und sécurité linguistique auf den französischen Sprachraum übertragen haben, findet das Konzept auch in anderen frankophonen Ländern Anwendung und trägt maßgeblich zum Fortschritt der Einstellungsforschung im frankophonen Belgien bei (vgl. Francard in 2.3.3.2) und in der Westschweiz (vgl. Bayard/Jolivet 1984, Singy 1997 in 2.3.4.2.4).

Sehr interessant im Hinblick auf regionale Unterschiede ist auch die von Paltridge und Giles durchgeführte Studie, in der mit der matched-guise-Technik Sprechereinstellungen zu den Akzenten von Sprechern aus Paris, der Provence, der Bretagne und dem Elsass ermittelt wurden (Paltridge/Giles 1984). Der Akzent von Paris hat das höchste Ansehen, was das berufliche Erscheinungsbild (Eigenschaften wie Seriösität, Ehrgeiz, Vertrauenswürdigkeit, Fleiß), die Zuverlässigkeit und Macht betrifft. In Bezug auf die sozialen Qualitäten (Freundlichkeit, Geselligkeit etc.) steht Paris nur an dritter Position. Die Bretagne und die Provence liegen bei der Selbst- und Fremdeinschätzung im Mittelfeld. Sprecher dieser beiden Regionen schätzen sich selbst in Bezug auf soziale Qualitäten wesentlich besser ein, als sie z.B. Sprecher mit Pariser Akzent einschätzen. Diese Haltung lässt sich als eine Form der Loyalität gegenüber ihrem Akzent bewerten (vgl. Lafontaine 1991, 11). Das Elsass belegt in Bezug auf die Kriterien Beruf, soziale Qualitäten und Macht den vierten und letzten Platz ${ }^{32}$. Hierbei ist zu beachten, dass sich die Elsässer selbst viel negativer einschätzen, als sie von den Sprechern anderer Regionen beurteilt werden. Dieses Phänomen, die eigene Varietät gering zu schätzen, ist auch in anderen Gebieten großer sprachlicher Unsicherheit zu beobachten, z.B. bei den frankophonen Belgiern (vgl. 2.3.3.2.2) oder den frankophonen Schweizern (vgl. 2.3.4.2.4). Der eigene Akzent wird von den Sprechern der Provence als am stärksten empfunden, gefolgt von dem elsässischen und dem bretonischen Akzent. Paris erhält den niedrigsten Wert (vgl. Paltridge/Giles 1984, 75-78).

Doch wie bewerten Sprecher aus Paris, das ja vor allem von frankophonen Belgiern und Schweizern als Referenznorm angegeben wird, das aktuelle Französisch und ihre eigenen Sprachkenntnisse? In umfassender Weise befasst sich Fischer (1988) mit den Einstellungen von (Pariser) Sprechern zur Standardsprache und greift somit den Forschungsansatz von Gueunier/Genouvrier/Khomsi (1978) wieder auf. Ihre Untersuchung kann als die erste Untersuchung gelten, die die Einstellung von Muttersprachlern gegenüber der französischen Standardsprache zum Forschungsgegenstand hat. Fischer bekräftigt, dass die Sprache in Frankreich einen so hohen Stellenwert habe, dass sie nicht nur in den Medien thematisiert werde (vgl. z.B. Schwarze 1977 zu den Sprachchroniken), sondern auch den Gegenstand privater und öffentlicher Unterhaltungen bilde. Einen Grund für das

\footnotetext{
$32 \mathrm{Zu}$ dem Ergebnis, dass der elsässische Akzent allgemein schlechter bewertet wird als der südfranzösische Akzent der Provence, gelangt auch Hoppe (1976, bes. 129), die ebenfalls mit der matchedguise-Technik Sprechproben von Sprechern aus dem Elsass, der Bretagne, der Provence sowie Paris und Umgebung bewerten lässt.
} 
besondere Interesse der Franzosen an ihrer Sprache sieht Fischer darin, dass die Franzosen selbst den Umgang mit ihrer Sprache als problematisch empfinden. Entsprechend bringt Fischer die häufige Beschäftigung mit Sprachfragen mit der tiefen Verunsicherung in sprachlichen Dingen in Zusammenhang (vgl. Fischer 1988, 69-72)33. Alle von Fischer in Interviews befragten Personen gehen von der Existenz einer Idealnorm aus, einem idealen Sprachgebrauch, der allgemein verbindlich sein solle. Diese Idealnorm wird von den meisten Befragten als ,le bon français" bezeichnet (vgl. ebd., 76). Der aktuell praktizierte Sprachgebrauch wird von den Befragten generell negativ eingeschätzt. Dies drücke sich v.a. in einem ständig schlechten Gewissen bezüglich des eigenen Sprachgebrauchs aus (vgl. ebd., 162-165). Nur drei von insgesamt 34 befragten Sprechern schätzen ihren eigenen Sprachgebrauch als gut ein (vgl. ebd., 167). Diese schlechte Gesamteinschätzung sei Ausdruck einer tiefen sprachlichen Verunsicherung (vgl. ebd., 170), wie sie auch von Gueunier/Genouvrier/Khomsi (1978) für verschiedene Sprachregionen in Frankreich festgestellt wurde.

In Bezug auf die Sprachnorm untersucht Fischer insgesamt vier Bereiche: die phonetisch-phonologische Ebene (Artikulation, Aussprache), die syntaktische Ebene (hierunter fallen Phänomene wie der Gebrauch der Tempora und die Negation), die lexikalische Ebene (z.B. Reichtum des Wortschatzes, argot, franglais) und die semantische Ebene (Differenziertheit und Präzision im Ausdruck). Im Kontext dieser Arbeit interessieren natürlich besonders die Aussagen der Befragten in Bezug auf das franglais. Zwar bemerken viele Informanten den Einfluss des Englischen auf die Lexik, doch teilen sie keineswegs die Meinung von Anglizismengegnern wie Étiemble (vgl. Fischer 1988, 121)34. Die Befragten grenzen sich bewusst von sprachpuristischen Initiativen ab, wie zum Beispiel aus folgender Äußerung hervorgeht:

\footnotetext{
33 Die These Fischers fußt auf keiner neuen Erkenntnis. Schon Martinet $(1974,29)$ stellt provokant fest: „Les Français n'osent plus parler leur langue parce que des générations de grammairiens, professionnels et amateurs, en ont fait un domaine parsemé d'embûches et d'interdits."

34 An dieser Stelle bietet sich eine kurze Definition des Begriffs Anglizismus an. Eine zwar schon alte, aber immer noch gültige Definition des (Anglo-)Amerikanismus gibt Carstensen (1965, 30): „So wird im folgenden unter Amerikanismus verstanden die Übernahme von linguistischen Gegebenheiten aus dem AE [amerikanischen Englisch], die sich auf Laut, Wort, Satz und den ganzen Text erstrecken, d.h. es sind lautliche, morphologische, semantische, syntaktische, stilistische und Amerikanismen der Rechtschreibung zu unterscheiden. Bei entsprechender Beeinflussung durch das BE [britische Englisch] sprechen wir von Britizismen." Höfler (1982, Vf.) verzichtet auf eine terminologische Unterscheidung zwischen Anglizismen und Amerikanismen und versteht Anglizismus als Oberbegriff. Er (ebd., VI) unterscheidet zwischen Fremdwörtern, die als Lexeme mit eventuellen phonetischen Anpassungen übernommen wurden, und Lehnwörtern, die auf der Basis heimischer Elemente nach fremdsprachigem (englischsprachigem) Muster gebildet wurden (Bsp. engl. skysscraper, franz. gratte-ciel). In sein Wörterbuch wurden nur Wörter aufgenommen, bei denen sowohl das Zeichen als auch der Wortinhalt entlehnt wurden. Pergnier $(1989,19$ f.) nennt drei gängige Definitionen des Terminus, die er jeweils anschließend kurz kritisiert (Pergniers Kritik wird hier der Kürze halber ausgelassen): ,1) Un mot anglais ou une tournure anglaise que l'on rencontre occasionellement dans un énoncé en français. [...] 2) Un terme anglais, ou influencé par l'anglais, dont la fréquence d'utilisation est suffisamment élevée pour pouvoir être considéré comme étant intégré (bien ou mal) au lexique du français et donc être répertorié dans les dictionnaires et glossaires. [...] 3) Un mot (une tournure, un emploi d'un mot, etc.) anglais utilisé de manière fautive à la place du mot (de la tournure, de l'emploi d'un mot, etc.) français correct."
} 
,j'utilise le mot anglais lorsqu'il n'y a pas de correspondant rapide en français ... ça me gêne absolument pas ... je ne suis pas ... pour une défense à tout prix de la langue française“ (ebd., 122).

Die Informanten sehen im Einströmen englischer Termini keinerlei Gefahr für die französische Sprache. Vielmehr zeugen die Untersuchungsergebnisse von einer durchweg positiven Einstellung der Informanten gegenüber Anglizismen (vgl. ebd.). Fischer bezeichnet diese positive oder zumindest neutrale Einstellung gegenüber Anglizismen als überraschend, weil die Informanten bei zahlreichen anderen Phänomenen in ihren metasprachlichen Urteilen für eine Idealnorm des Französischen im Sinne des bon usage plädierten ${ }^{35}$. Die Autorin führt die positive Bewertung der Anglizismen darauf zurück, dass sich die Befragten in diesem Bereich stärker am tatsächlich in Frankreich praktizierten Sprachgebrauch als am restriktiven Sprachmodell des bon usage orientierten (vgl. ebd., 123). Interessant ist auch die Bewertung des Sprachstandards in den verschiedenen Regionen Frankreichs. Vor allem der Norden Frankreichs (Bretagne und Normandie) wird negativ bewertet. Paris und - mit Einschränkungen - Tours gelten als Orte, an denen am ehesten gutes Französisch gesprochen wird (vgl. ebd., 129f., 160).

Zusammenfassend liefert die Untersuchung Fischers ein anschauliches Beispiel für die starke Normorientierung der Franzosen. Da die Befragten sich ausschließlich am Schriftfranzösischen orientieren, gehen sie so weit zu behaupten, niemand beherrsche heutzutage mehr das gute Französisch (in phonetischer, syntaktischer, morphologischer, lexikalischer und semantischer Hinsicht). Im Umgang mit Anglizismen und in deren Bewertung erweisen sich die Befragten jedoch als äuBerst tolerant.

Die Ergebnisse von Fischers Studie decken sich insbesondere in einem Punkt mit denen von Gueunier/Genouvrier/Khomsi (1978): Bei der Mehrheit der Franzosen ist eine große Unsicherheit in Bezug auf die Korrektheit der eigenen Sprache bzw. des eigenen Sprechens festzustellen. Jedoch muss diese sprachliche Unsicherheit noch von Sprachregion zu Sprachregion differenziert werden. Einige Gebiete gelten als Zonen relativer sprachlicher Sicherheit (Paris, Tours). Zonen, in denen Dialekt gesprochen wird (vgl. Scherfer 1983 zur Franche-Comté, Stroh 1993 zu Lothringen), gelten als Zonen relativer sprachlicher Unsicherheit. Aber selbst in Zonen relativer sprachlicher Sicherheit sind die Sprecher überzeugt kein reines, gutes Französisch zu sprechen. Insbesondere die Studie Fischers deutet darauf hin, dass es im Bewusstsein französischer Sprecher eine Variante gibt, die oberhalb der Standardsprache anzusiedeln ist, nämlich die „langue légitime“ (Bourdieu 1993, 50), eine Art Prestigevariante. Sarter (1990, 201f.) versucht diese Variante näher zu charakterisieren:

\footnotetext{
35 Die Befragten empfinden typische Phänomene der gesprochenen Sprache, die im linguistischen Sinne nicht als falsch eingestuft werden, als Regelverletzungen. Entsprechend gilt die geschriebene Sprache im Unterschied zur gesprochenen Sprache, die man nicht eigens erlernen müsse, sondern von Kind an beherrsche, als schwer. Insgesamt wird dem schriftlich fixierten Text somit eine weitaus höhere Stellung zugeordnet als der gesprochenen Sprache (vgl. Fischer 1988, 157-159).
} 
„Die, langue légitime’, die Prestigevariante des Französischen, ist nicht identisch mit dem ,Hoch-Französisch', der Schriftsprache oder Standardsprache; sie ist auch nicht einfach deren Erweiterung. Sie ist vielmehr ein Elite-Idiom [...]. Mit ihr ist ein Gebrauch, ein Typus des Französischen gemeint, der - wiewohl von wenigen, zumeist bei seltenen Gelegenheiten, verwendet - Maßstab ist für den Begriff ,der' französischen Sprache. Sie ist, le bon usage' in Perfektion und besteht ebenso aus Regeln, die klären, wie zu sprechen ist, wie aus solchen, die bestimmen, wie nicht zu sprechen ist."

Lerat geht in seiner Überblicksdarstellung zur Sprachbewertung (Französisch) ${ }^{36}$ an mehreren Stellen auf die Bewertung von Anglizismen ein. Er nennt als Instanzen, die für Sprachbewertung zuständig sind, die Schule, Forscher (insbesondere Linguisten), die Akademien und Vereine (insbesondere die Académie française), die Presse (insbesondere die Sprachchroniken) und die Verwaltungen (inbesondere die Arbeit der Terminologiekommissionen) (vgl. Lerat 1990, 392f.). Anschließend deckt Lerat die politisch-ideologischen und die ästhetischen Gründe auf, die Sprachbewertung(en) maßgeblich beeinflussen (vgl. ebd., 393-396) ${ }^{37}$. Lerat macht auch auf historische Klischeevorstellungen aufmerksam, wie die Idee, das Französische sei sprachlichen Importen gegenüber rebellisch (vgl. ebd., 397). Er entgegnet dieser Vorstellung:

„Mais quelle langue moderne se révèle morphologiquement impropre à s'enrichir au contact des autres? Aucune! S'il existe des dictionnaires d'anglicismes du français, c'est précisément parce que les sujets parlants sont plus rebelles au dirigisme linguistique qu'aux importations" (ebd.).

Lerat ist also der Meinung, dass die Sprecher sich weniger den angloamerikanischen Fremdwörtern widersetzen als vielmehr jeglicher Form des (staatlichen) Einflusses auf die Lexik.

Der Ermittlung der Einstellungen französischer Sprecher zu Anglizismen bzw. der Akzeptanz der offiziellen Neologismen hat die Forschung bislang, wenn auch sehr vereinzelt und unsystematisch, weitaus mehr Beachtung geschenkt als der Erfor-

\footnotetext{
36 Spracbbewertung ist selbstverständlich kein typisch französisches Phänomen. Sprache wird in allen Gesellschaften bewertet, selbst in denjenigen, die keine Schrift und keine literarischen Kriterien kennen (vgl. Yaguello 1988, 93). Brumme $(1992,379)$ weist auf den engen Zusammenhang zwischen Sprachbewertungen und Sprachpolitik hin. Sie klassifiziert Sprachbewertungen als „ein grundlegendes Mittel, mit dem Sprachpolitik thematisiert, inszeniert und durchgesetzt wird." Jedoch werden Sprachbewertungen erst dann sprachpolitisch wirksam, wenn durch sie der tatsächliche Sprachgebrauch geregelt oder beeinflusst wird. Somit sind Sprachbewertungen im Sinne von Sprachpolitik immer an Sprecher, d.h. an eine Öffentlichkeit gebunden (vgl. ebd.).

${ }^{37}$ Hier sind v.a. die seit langem dem Französischen anhaftenden Werturteile wie universalité, clarté etc. zu nennen, die Albrecht $(2001,532)$ als intrinsische Qualitäten der Sprache bezeichnet. Das bedeutet, dass der Verbreitungsgrad einer Sprache nicht nur auf die günstigen historischen oder politischen Umstände zurückgeführt wird, sondern auch auf (vermeintlich) der Sprache inhärente Qualitäten (vgl. ebd.). Hinzu kommt die traditionell negative Bewertung fremdsprachlicher Einflüsse, die aus Sprachkontakt resultieren. Die Verwendung von Anglizismen wird nach Aussage von Lerat $(1990,395 f$.) in Frankreich mehrheitlich als Ausdruck von Snobismus angesehen.
} 
schung der Einstellungen französischer Sprecher zur Standardsprache. Aufgrund des größeren Umfangs, aber auch aufgrund zahlreicher methodischer Erkenntnisse, die sich aus den bereits durchgeführten Studien ableiten lassen, soll die Behandlung der Einstellungen französischer Sprecher zu Anglizismen bzw. zu offiziellen Ersatzwörtern in einem eigenständigen Kapitel, nämlich in Kapitel 4, erfolgen.

\subsubsection{Belgien}

\subsubsection{Soziolinguistische Situation}

In Belgien gibt es drei Sprachgemeinschaften, die flämische (niederländische), die französische und die deutsche, und vier Sprachregionen, die französischsprachige, die niederländischsprachige, die deutschsprachige und die bilinguale Region Brüssel (vgl. Art. 3bis der belgischen Verfassung von 1970 und Art. 3ter von 1980). Obwohl die Flamen den frankophonen Belgiern stets zahlenmäßig überlegen waren, dominierte auf dem Gebiet des heutigen Belgien die französische (Schrift)Sprache über Jahrhunderte hinweg. Das Französische ersetzte das Latein und war seit der Burgunderzeit, ab 1369, die Verwaltungssprache. Während der Herrschaft der Spanier und anschließend der Österreicher (ab 1714) verbreitete sich der französische Einfluss weiter, was dazu führte, dass das Französische die Sprache der Ober- und aufstrebenden Mittelschicht wurde (vgl. Willemyns 1997, 1123f.).

Bevor die österreichischen Niederlande, das heutige Belgien, 1795 von Frankreich annektiert wurden, hat es auf diesem Territorium keine sprachpolitischen Regelungen gegeben, was auf eine fehlende zentrale Regierung zurückzuführen ist (vgl. Willemyns 1996, 244). 1830 wurde Belgien zum Königreich und somit von Frankreich unabhängig. Französisch und Niederländisch wurden zwar als Nationalsprachen anerkannt, aber nur dem Französischen kam der Status einer offiziellen Sprache zu. Nach wie vor dominierte die französischsprachige Minderheit die niederländischsprachige Mehrheit, obwohl 1842 60,8\% der Einwohner Belgiens Niederländisch sprachen und nur 37,6\% Französisch ${ }^{38}$ (vgl. Francard 1998, 15). Die französische Sprache dominierte in allen gesellschaftlichen Bereichen. Sogar das flämische Bürgertum sprach Französisch. Die führende Position des Französischen und der Frankophonen lässt sich auf die stärkere Industrialisierung und somit größere politische Macht Walloniens zurückführen. Flandern hingegen galt als wirtschaftlich rückständig (vgl. Erfurt 1992, 6; Willemyns 1996, 244). Folglich lag in Belgien bis zum Ende des 19. Jahrhunderts eine paradoxe Situation vor: Die Mehrheit der Bewohner sprach zwar Niederländisch, doch verfügte ihre Sprache über keinerlei Prestige und war als Nationalsprache offiziell nicht anerkannt. Erst durch die sog. „Flämische Bewegung“ wurden die Rechte der Flamen geltend gemacht. Als Folge wurde 1898 das „Gleichheitsgesetz“ verabschiedet, welches die beiden Sprachen Französisch und Niederländisch zu offiziellen Staatssprachen

\footnotetext{
${ }^{38}$ Es wäre berechtigter, in diesem Falle von einer romanischen Regionalsprache zu sprechen, denn die in Wallonien und Brüssel gesprochenen Varietäten entsprachen nicht dem Standardfranzösischen (vgl. Francard 1998, 16).
} 
erklärte. Seitdem ist das Niederländische dem Französischen praktisch gleichgestellt. Alle Gesetze in Belgien werden fortan in diesen beiden Sprachen verabschiedet und verbreitet (vgl. Willemyns 1997, 1125) ${ }^{39}$.

In der Zeit nach 1950 vollzog sich auch ein wirtschaftlicher Wandel: In der Nähe der flämischen Häfen entstand eine moderne und leistungsfähige Wirtschaft. Die ökonomische Macht verlagerte sich in das vormals wirtschaftlich rückständige Flandern, während sich die wallonische Wirtschaft, v.a. die Schwerindustrie, in einer Krise befand (vgl. Erfurt 1992, 8f.). Umso mehr erhöhte sich der Druck der Flamen auf die Regierung, entsprechende Gesetze zum Schutz ihrer Sprache zu verabschieden. Mit dem Gesetz vom 08. November 1962 wurde in Belgien das Territorialitätsprinzip ${ }^{40}$ festgeschrieben und das Land in vier Sprachgebiete eingeteilt ${ }^{41}$ : in drei einsprachige Gebiete (niederländisch, französisch und deutsch ${ }^{42}$ ) und das zweisprachige Brüssel (französisch und niederländisch) ${ }^{43}$. Somit wurde der Grundstein für den seit 1994 auch verfassungsrechtlich festgeschriebenen belgischen Föderalismus gelegt. Das Territorialitätsprinzip besagt nicht anderes, als dass auf französischsprachigem Territorium (Wallonien) ${ }^{44}$ das Französische die offizielle Sprache ist, auf niederländischsprachigem Territorium (Flandern) ${ }^{45}$ das Niederländische, auf deutschsprachigem Territorium das Deutsche und in den zweisprachigen Regionen (Brüssel und angrenzende Kommunen) das Französische und das Niederländische ${ }^{46}$. Belgischer Föderalismus führt inzwischen zu einer fast ähnlichen Situation der Einsprachigkeit wie in Frankreich und in den meisten Kantonen der Schweiz. Von nun an richtet sich die Sprache des Bewoh-

\footnotetext{
${ }^{39}$ Eine ausführliche Darstellung der Geschichte des Französischen in Belgien befindet sich in Blampain et al. (1997, 81-152). Dem Französischen in Flandern, insbesondere von 1830 bis heute, widmet sich Willems (1997, 259-272).

${ }^{40}$ Eine kurze Erklärung des Begriffs gibt Pöll $(1998,23)$ : „Das bedeutet, daß die Sprachzonen [...] grundsätzlich einsprachig sind und anderssprachige Bürger [...] in diesen Gebieten keine wie immer gearteten Sonderrechte genießen (Assimiliationszwang)." Loubier (o.J.b, 2-4) stellt dem Territorialitätsprinzip (principe de la territorialitê) das Personalitätsprinzip (principe de la personnalité) gegenüber, das jeder Person das Recht auf den Gebrauch seiner Muttersprache garantiert.

${ }^{41}$ Zum Verlauf und zur historischen Entstehung der Sprachgrenzen vgl. z.B. Nelde/Weber (1995, 90f.).

${ }^{42}$ Die deutschsprachige Minderheit wurde erst nach dem Ersten Weltkrieg Teil Belgiens.

43 Während für Flandern und für Wallonien das Territorialitätsprinzip gilt, gibt es in Brüssel selbst keine klaren geografischen Sprachgrenzen. In Brüssel sind von ca. 1 Million Einwohner ca. 85\% frankophon. Jedoch weicht das „français bruxellois“, das auch „marollien“ genannt wird, stark von dem Französischen in der Wallonie ab. Das liegt zum einen sicherlich an der Trennung von Wallonien (Brüssel selbst liegt auf flämischem Gebiet), zum anderen aber auch daran, dass einige der in Brüssel lebenden Flamen sich das französische Idiom zu eigen machen wollen und als Resultat dieses Prozesses eine Art Hybridsprache entsteht (vgl. Francard 1998, 15).

${ }^{44}$ Wallonien besteht aus den Provinzen Liège/Lüttich, Namur, Hainaut, Luxembourg und der südlichen Hälfte von Brabant. Neun Kommunen der Provinz Liège/Lüttich sind jedoch deutschsprachiges Territorium.

${ }^{45}$ Flandern besteht aus den Regionen Antwerpen, Flämisch-Brabant (die nördliche Hälfte von Brabant), Limburg, Ostflandern und Westflandern.

46 Erst seit der Einführung des Territorialprinzips kann somit die Communauté francaise die französische Sprache in Belgien mittels Dekreten und anderer Verordnungen für die französischsprachigen Regionen Belgiens regeln. Eine rein auf das Französische bezogene Sprachpolitik existiert in Belgien folglich erst seit ca. 40 Jahren.
} 
ners eines bestimmten belgischen Dorfes oder einer Stadt nicht nach persönlichen Faktoren (wie beispielsweise die Sprache der Eltern), sondern nur danach, in welchem Gebiet sich der jeweilige Ort befindet (vgl. Willemyns 1996, 245). Von einer gesamtbelgischen Identität kann auf Grund dieser strengen Grenzziehung zwischen den einzelnen Sprachgemeinschaften keine Rede sein. Durch die getrennte Entwicklung der drei Sprachgruppen hat auch jede Gruppe zu einer eigenen Identität gefunden.

Nach Angaben des Institut national de Statistique (INS) und des Moniteur belge vom 28. Mai 2002 leben Anfang 2002 insgesamt 10.309.725 Menschen in Belgien. In Flandern leben 5.972.781 Einwohner, d.h. ca. 58\% der Bevölkerung, in Wallonien 3.358.560 Einwohner, d.h. ca. 33\% der Bevölkerung, und in der Region Brüssel 978.384 Einwohner, d.h. ca. 9\% der Bevölkerung. Die deutschsprachige Minderheit besteht aus nur ca. 70.000 Sprechern und entspricht damit einem Bevölkerungsanteil von weniger als 1\% (vgl. Pöll 1998, 43, Portail fédéral (Belgien) 2003, o.S.).

Über aktuelle Ereignisse in Wallonien informiert auch die Internetseite der Communauté française de Belgique (C.F.B.) unter http://www.cfwb.be.

\subsubsection{Einstellungen zum Französischen}

Die Schweiz und Belgien blicken zwar nicht auf eine mit Frankreich vergleichbare Tradition der Sprachpflege zurück. Sie waren und sind aber aufgrund der Sprachkontaktsituation im eigenen Land umso mehr dazu angehalten, sich eine eigenständige sprachliche und kulturelle Identität zu schaffen und diese zu bewahren.

Belgien hat v.a. im Ausland den Ruf der „terre des grammairiens“, und somit genießen die Belgier den Ruf, über ein ausgeprägtes Sprachnormenbewusstsein zu verfügen. Darf aber so pauschal von einem Zusammenhang zwischen dem mehrsprachigen Land Belgien und dem hohen Sprachnormenbewusstsein seiner Bewohner ausgegangen werden?

Soziolinguistische Untersuchungen haben in Belgien eine noch kürzere Tradition als in Frankreich. Forschungen belgischer Linguisten haben sich lange Zeit, bis in die 1980er Jahre, vorwiegend auf die Beschreibung phonetischer und lexikalischer Besonderheiten des in Belgien gesprochenen Französisch konzentriert. Entsprechend haben Forschungen zu Einstellungen, zum Sprachbewusstsein oder zu sprachlichen Vorstellungen im frankophonen Belgien eine sehr kurze Tradition. Erst seit den ausgehenden 1970er Jahren werden das Sprachbewusstsein der Belgier sowie ihre Einstellungen zu anderen Sprachen bzw. Varietäten erforscht (vgl. Lefevre 1978/1979), wobei seit Ende der 1980er Jahren der Begriff der sprachlichen Unsicherheit bei der Bestimmung des belgischen Sprachbewusstseins eine entscheidende Rolle spielt. Unter den neueren Arbeiten sind die mit sozialwissenschaftlichen Methoden durchgeführten Studien Francards, Garsous und Lafontaines von zentraler Bedeutung.

2.3.3.2.1 Das Verhältnis zwischen französisch- und niederländischsprachigen Belgiern

Das hohe Prestige des Französischen in Belgien lässt sich in erster Linie durch die integrative und instrumentale Funktion von Spracheinstellungen erklären (vgl. 
2.1). Bis ins 19. Jahrhundert passten sich die Flamen (insbesondere die Oberschicht) an die französischsprachigen Belgier an. Da die Wallonen der wirtschaftlich erfolgreicheren Gruppe angehörten und gleichzeitig Sprecher einer prestigeträchtigeren Sprache waren, versprachen sich die Flamen durch die Beherrschung dieser zweiten Sprache wirtschaftliche Vorteile (instrumentale Funktion), aber auch soziale Anerkennung (integrative Funktion).

Entsprechend war das Prestige des Niederländischen sehr niedrig, bis es Ende 1898 per Gesetz zu einer der beiden offiziellen Staatssprachen wurde. Durch die Festschreibung als offizielle Staatssprache und v.a. im Zuge des wirtschaftlichen Wachstums Flanderns in den 1950er Jahren und der parallel dazu stattfindenden Krise in Wallonien hat sich das Niederländische zu einer prestigeträchtigen Sprache entwickelt.

Während die Einstellungen zum Niederländischen aus französischer Perspektive traditionell negativ waren, sind die Einstellungen der niederländischsprachigen Bevölkerung zum Französischen trotz der jahrhundertelangen Unterdrückung relativ positiv:

„The Flemish population for one has a long tradition of linguistic frustrations since their linguistic rights and aspirations have been neglected and turned down for centuries. [...] Attitudes towards French however were not and are not only determined by the fact that it is the language of Wallonia but also of France, the prestigeous neighbour country, and remain therefore reasonably positive" (Willemyns 1988, 1256).

Zwar stehen die Wallonen und frankophonen Brüsseler der anderen Nationalsprache nicht unbedingt positiv gegenüber, jedoch haben sie trotz des Prestigegewinns des Niederländischen keinerlei Angst, dass das Französische durch das Niederländische zurückgedrängt werden könnte. Diese Sicherheit in Bezug auf den Status ihrer Sprache beziehen sie größtenteils aus der Jahrhunderte andauernden Phase der sprachlichen Ruhe („quiétude linguistique“, Francard 1993c, 67). Diese Ruhe haben sie in erster Linie der sprachlichen und kulturellen Vormachtstellung des mächtigen Nachbarn Frankreich zu verdanken, dessen Sprache sie mit einer großen internationalen Gruppe teilten. Das Französische in Belgien war weder bedroht, noch mussten die Wallonen und Brüsseler besondere Anstrengungen unternehmen, um sich sprachlich gegen die Flamen zu behaupten. Juristisch besiegelt wurde die Situation sprachlicher Ruhe und Sicherheit im Jahre 1962 durch die Einführung des Territorialitätsprinzips.

2.3.3.2.2 Das Verhältnis der frankophonen Belgier zum Französischen Frankreichs

Die frankophonen Belgier haben zwar in Bezug auf ihre Position gegenüber der niederländischsprachigen Bevölkerung viele Vorteile aus dem mächtigen Nachbarland Frankreich gezogen, hätten diese Ruhe in sprachlichen Angelegenheiten 
allerdings mit einem Defizit an Identität bezahlt (vgl. Francard 1993c, 67) ${ }^{47}$. Dieser Mangel an Identität sei auch heute noch sehr präsent bei den frankophonen Belgiern, und aus dem früheren Vorteil, die Sprache mit dem mächtigen Nachbarland zu teilen, sei heute eine für das franko-belgische Selbstverständnis nachteilige Situation entstanden. Da es in Belgien im Unterschied zu Frankreich zwei große Nationalsprachen gebe, aus denen auch kulturelle Unterschiede resultieren, habe sich in Belgien auch nicht das Gefühl einer einheitlichen Identität herausgebildet (vgl. ebd.). Vielmehr herrsche nach wie vor eine starke sprachliche und kulturelle Orientierung der frankophonen Belgier in Richtung Frankreich vor. Die sprachliche Vorherrschaft Frankreichs werde von den frankophonen Belgiern nicht ernsthaft in Frage gestellt (vgl. Francard 1993a, 28). Die Studie Francards bestätigt den Vorbildcharakter Frankreichs für die befragten frankophonen belgischen Schülerinnen und Schüler und zeigt deren reserviertes Verhalten gegenüber regionalen Varietäten auf (vgl. ebd., 38). Aus dem Wissen um die Verschiedenheit der eigenen Varietät von der in Paris gesprochenen Varietät, d.h. aus dem Aufeinandertreffen des Wissens über die Art und Weise, in der gesprochen werden müsste, und des Bewusstseins, diesem Ideal nicht zu entsprechen, resultieren bei den frankophonen Belgiern sprachliche Minderwertigkeitsgefühle, die sich im Gefühl sprachlicher Unsicherheit äußern.

Bereits vor der Durchführung und Veröffentlichung Francards umfangreicher Studien bezüglich der sprachlichen Unsicherheit der frankophonen Belgier haben Andrianne (1984) und Massion (1987) auf den belgischen Minderwertigkeitskomplex hingewiesen. Massion $(1987,57)$ hebt hervor, dass das Gefühl sprachlicher Minderwertigkeit besonders deutlich zum Vorschein komme, wenn sich die frankophonen Belgier außerhalb ihres vertrauten (belgischen) Umfeldes befänden:

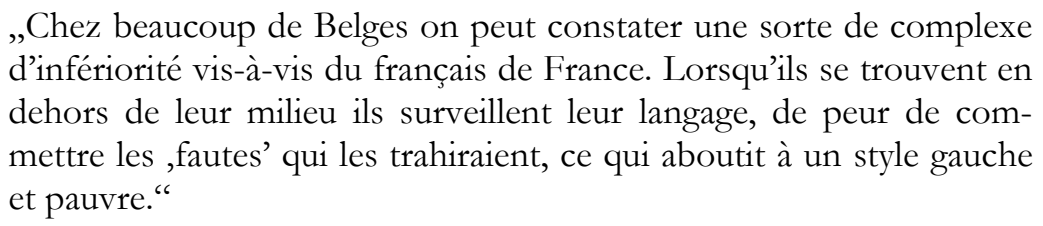

Francard (1993a, 13) setzt die sprachliche Unsicherheit in direkte Beziehung zum vergeblichen Streben nach sprachlicher Legitimation: „L'insécurité linguistique est la manifestation d'une quête non réussie de légitimité." Nach Francard (1993a, 19) lassen sich vier mögliche Ausdrucksformen der sprachlichen Unsicherheit festmachen:

\footnotetext{
47 Als Beispiel für einen umgekehrten Fall lässt sich Québec anführen. In mehrjähriger Auflehnung mussten sich die Frankokanadier gegen die Dominanz durch die anglophonen Kanadier behaupten. Es wird gemeinhin angenommen, dass diese ständige sprachliche Bedrohung sowie die unmittelbare geografische Nachbarschaft der Entwicklung eines eigenen Sprach- und Nationalbewusstseins überaus förderlich waren.
} 
1. Die Akzeptanz einer sprachlichen Abhängigkeit von Frankreich,

2. die Geringschätzung von Sprechweisen, die als nicht legitim (normgetreu) empfunden werden,

3. der Rückgriff auf Strategien, um die nicht legitimen Sprachweisen zu kompensieren, und

4. eine pessimistische Sicht der Zukunft des Französischen.

Konkret lässt sich sprachliche Unsicherheit zum Beispiel an den Vorstellungen vieler frankophoner Belgier ablesen, ein schlechtes Französisch zu sprechen, sowie an dem (z.T. latenten) Wunsch, sich der Pariser Varietät und der Kultur Frankreichs anzupassen ${ }^{48}$ (vgl. Francard 1993a, 37f.; Garsou 1991; Lafontaine 1986/1991/1997, 384).

Moreau (1999, 37) macht deutlich, dass die befragten Belgier den Sprachgebrauch der Franzosen pauschal als normkonform einordnen ohne zu bedenken, dass auch auf französischem Territorium verschiedene Varietäten gesprochen werden. Sprachliche Besonderheiten des belgischen Französisch setzten die befragten Belgier automatisch mit falschem Französisch gleich (vgl. ebd.). Ein weiterer Beweis für das Gefühl sprachlicher Minderwertigkeit und sprachlicher Unsicherheit sei der verstärkte Wunsch der frankophonen Belgier ihre Sprachkompetenzen zu verbessern (vgl. Garsou 1991, 24).

Sprachliche Unsicherheit ist jedoch nicht in gleichem Maße bei den Mitgliedern einer Sprachgesellschaft vorhanden, sondern hängt in starkem Maße vom Alter und vom Bildungsstand ab. Die Studien von Francard (1993a) und Garsou (1991, $22,31)$ zeigen, dass jüngere Leute (Schüler) tendenziell größere sprachliche Sicherheit manifestieren als die älteren Generationen. Francard (1989) versucht erstmals den Zusammenhang zwischen Schulbildung und sprachlicher Unsicherheit herauszuarbeiten und stellt dabei fest, dass die sprachliche Unsicherheit mit dem Grad der Schulbildung steigt. Dies bestätigen auch die Ergebnisse von Ledegens Befragung von Studenten an der Universität bzw. an der Pädagogischen Hochschule von Tours (Frankreich) und Louvain-la-Neuve (Wallonien). Sie zeigen, dass nicht primär die Zugehörigkeit zu einem frankophonen Land für den Grad der sprachlichen Unsicherheit ausschlaggebend ist, sondern das Bildungsniveau (vgl. Ledegen 1998, 48). Was den Einfluss des Bildungsniveaus auf das Gefühl der sprachlichen Unsicherheit betrifft, stellt Ledegen $(1998,48)$ bei Studenten der Universität zwar bessere Kenntnisse der Sprachnorm fest, zugleich aber auch eine höhere sprachliche Unsicherheit als bei den Studenten der pädagogischen Hochschule. Nach Swiggers (1993, 22f.) rangiert unter den Einflussfaktoren neben dem Bildungsniveau auch die Sprachpolitik (sowohl in Form der Statusals auch der Korpusplanung).

Wie Moreau/Brichard (1999, 12) ermittelt haben, sind viele frankophone Belgier der Auffassung, Belgier und Franzosen unterschieden sich nicht nur in der Qualität oder in der Richtigkeit ihrer Sprache, sondern Franzosen verfügten über größere sprachliche Gewandtheit, die sich u.a. in einem umfangreicheren Wort-

48 Insofern ordnet Francard (1993a, 14) Belgien in zweifacher Hinsicht der Peripherie zu: geografisch und kulturell, da Belgien sich sprachlich wie auch kulturell am Zentrum Frankreichs orientiere. 
schatz und im schnelleren und flüssigeren Sprechen niederschlage. Entsprechende Untersuchungen konnten diesen subjektiven Eindruck sprachlicher Unterlegenheit jedoch nicht bestätigen (vgl. ebd., 17f.). Goosse $(1995,271)$ beschreibt diese Orientierung am „großen Nachbarn“ als ein nahezu sentimentales Interesse für Frankreich, die französische Lebensart, Frankreichs Literatur, Theater, Kino, Fernsehen, Presse, die französische Politik etc.

Trotz ihrer Orientierung an der französischen Kultur und dem damit verbundenen Respekt, den die frankophonen Belgier den Franzosen zollten, sähen sie deren Verhalten kritisch. Sie bemängelten den sprachlichen Imperialismus Frankreichs und wünschten sich mehr Respekt gegenüber regionalen Varietäten von Seiten der Franzosen (vgl. Lafontaine 1997, 387f.).

In ihren Diskursen über Sprache bewegen sich die frankophonen Belgier zwischen zwei Extremen: Die Vertreter des einen Richtung (mowvement ,rattachiste") verneinen jeglichen Unterschied zwischen dem in Belgien und in Paris gesprochenen Französisch und betonen die kulturelle Nähe beider Länder, die Vertreter der anderen Seite betonen die sprachlichen und kulturellen Unterschiede zwischen Belgien und Frankreich (vgl. Francard 1993c, 68; Lenoble-Pinson 1997, 241). Auf der Suche nach größerer Legitimität ihrer Varietät haben die Belgier Francard (1993a, 14) zufolge zwei Möglichkeiten zur Auswahl: Entweder sie akzeptieren die Situation, indem sie das Prestige der dominierenden Varietät anerkennen, oder sie bringen die Wertehierarchie in der Weise zum Umsturz, dass sie ihre (dominierte) Varietät mit einigen Attributen der legitimen Varietät ausstatten.

Die Untersuchungen sprechen dafür, dass sich die erste der beiden Möglichkeiten durchgesetzt hat: Die Belgier erkennen die Legitimität der Pariser Varietät an. Dies bedeutet jedoch keinesfalls, dass sie dieser auch emotional verbunden sind. Die frankophonen Belgier identifizieren sich in hohem Maße mit ihrer jeweiligen belgischen Varietät und mit den sprachlichen Besonderheiten der belgischen Varietät(en). Ein Beispiel für diese sprachlichen Besonderheiten sind die bekannten Belgizismen ${ }^{49}$ septante, buitante/octante und nonante anstelle von franz. soixante-dix, quatre-vingt und quatre-vingt-dix (vgl. z.B. Lagerqvist 2001, 41). Von Pohl stammt der Ausdruck statalisme (Statalismus), den er am Ende seines Aufsatzes wie folgt definiert: „Tout fait de signification ou de comportement, observable dans un pays, et qui soit arrêté ou nettement raréfié au passage d'une frontière“" (Pohl 1984, 262). Ein Beispiel für einen solchen Statalismus, der eine typisch belgische Realität beschreibt und nur innerhalb des Landes verwendet wird, ist der belgische bourgmestre anstelle des franz. maire oder der belgische conseiller communal anstelle des franz. conseiller municipal (vgl. Wolf 1992, 103f.). Diesen regionalen Besonderheiten sind

\footnotetext{
49 Der Begriff belgicisme ist erstmals 1811 bei Poyart belegt (vgl. Wilmet 2000, 13). Der keineswegs unproblematische Begriff wird - auch in seiner Abgrenzung zum Regionalfranzösisch und zum Französischen Belgiens - bei Massion (1987, 56-64) diskutiert. Wie uneinheitlich das ist, was unter Belgizismus subsumiert wird, zeigt der unterschiedliche Umfang zweier Belgizismen-,„Listen“. Pirons (1973) Liste umfasst ca. 250 Einträge, während Massions Recherchen zu einem zweibändigen Wörterbuch mit 1150 Einträgen führen (vgl. Erfurt 1992, 22; Wolf 1992, 105). Die Wörterbücher Larousse und Robert öffnen sich seit den 1980er Jahren den regionalen Besonderheiten. So nimmt der Petit Larousse in seiner Ausgabe von 1989 fast 300 Belgizismen auf (vgl. Klinkenberg 2000, 706).
} 
die von Francard und Lafontaine befragten Belgier nicht nur emotional verbunden, sondern sie erachten sie zudem als schützenswert und oftmals sogar als präziser als den entsprechenden französischen Terminus (vgl. Francard 1993a, 30; Lafontaine 1986, 1991, 20). Dennoch sind nach wie vor viele frankophone Belgier der Meinung, dass sich ,guter" Sprachgebrauch gerade im Fehlen von Belgizismen manifestiere. Mit der Aussage „D’après-vous, bien utiliser la langue française c'est ne pas employer d'expressions typiquement belges, (belgicismes)“ erklärten sich $45,1 \%$ (ganz) einverstanden, jedoch waren auch 37,2\% (vollkommen) dagegen (vgl. Garsou 1991, 20). Aber auch das in Frankreich gesprochene Französisch, das gemeinhin von den Belgiern als normkonform angesehen wird, erfüllt in den Augen der von Garsou befragten Personen nicht die Voraussetzungen, um mit gutem Sprachgebrauch gleichgesetzt werden zu können: Fast 73\% antworteten auf diese Gleichsetzung negativ (vgl. ebd.).

Wie sehr die frankophonen Belgier ihrer jeweiligen Varietät emotional verbunden sind, zeigt die soziolinguistische Studie Lafontaines (1991). Die von ihr befragten Belgier empfinden nach eigenen Aussagen ihre eigenen Varietäten im Unterschied zum Französischen Frankreichs als natürlicher, spontaner und als insgesamt wärmer. Sie sind stolz auf ihre eigenen Varietäten, ordnen sie jedoch eher als schwer und grob ein. Den Franzosen hingegen bestätigen sie sprachliche Finesse. Die Pariser Varietät wird mehrheitlich als pedantisch, kalt und künstlich empfunden, nur mit der eigenen Varietät können sich die befragten Belgier identifizieren (vgl. ebd., 23). Anders ausgedrückt ist für die Belgier der Charme, den für sie das Familiäre, Unperfekte ihrer Sprache ausmacht, höherrangig als die Prestigevariante. Dem Standardfranzösischen zollten sie den nötigen Respekt, den man offiziellen Institutionen entgegenbringe (vgl. Lafontaine 1997, 387).

Diese Einschätzung bestätigt auch die Studie Garsous: Mit der Aussage, dass guter Sprachgebrauch gleichzusetzen sei mit „parler comme les Français“, erklären sich nur 14,9\% (vollkommen) einverstanden, 36,3\% sind dagegen (vgl. Garsou 1991, 20). In Francards Studie wird die Gleichsetzung von gutem und akzentfreiem Sprechen von $76 \%$ der befragten Jungen und 56\% der befragten Mädchen abgelehnt (vgl. Francard 1993a, 29). Jedoch trifft man nicht selten die Ansicht, dass gutes Sprechen sich gerade dadurch auszeichne, dass es keinen Akzent gebe. Francard (1993a, 30) zitiert in diesem Zusammenhang einen Schüler, der sagt: „Avoir un bel accent, c'est justement ne pas avoir trop d'accent.“

Die Aussagen der Befragten zu ihrem positiven Verhältnis gegenüber Belgizismen spiegeln sich auch in der belgischen Presse wider. Högstedt (1998, Kap. 5, o.S.) stellt bei ihrer Analyse der belgischen Pressesprache keinerlei Bemühungen von Seiten der Journalisten fest weniger Belgizismen zu verwenden oder sogar auf diese zu verzichten.

Trotz ihres Stolzes und ihrer Verbundenheit mit regionalen Besonderheiten wie den Belgizismen stehen die frankophonen Belgier der Varietät Frankreichs durchweg positiv gegenüber und sehen diese als erstrebenswert an. Umgekehrt jedoch zeigen sich die Franzosen den im Nachbarland gesprochenen französi- 
schen Varietäten gegenüber wenig tolerant und stehen dem belgischen Akzent misstrauisch gegenüber (vgl. Willemyns 1988, 1257).

\subsection{Belgischer Purismus und Normierungsbestrebungen}

Belgizismen werden in Belgien zwar größtenteils befürwortet, doch mangelt es in Belgien auch nicht an puristischen Bestrebungen. Purismus entwickelt sich Klinkenberg $(1985,124)$ und Lebouc $(1998,14 f$.$) zufolge aus der abwertenden Hal-$ tung der Sprecher gegenüber den nicht-legitimen Varietäten, aus sprachlicher Unsicherheit sowie aus dem Gefühl, das Französische insgesamt befinde sich in einer Krise ${ }^{50}$. Eine Ausdrucksform der puristischen Bestrebungen und zugleich Ausdruck des sprachlichen Minderwertigkeitskomplexes ist die Produktion zahlreicher Antibarbari ${ }^{51}$. Der Anfang der Ära von Belgizismen-Wörterbüchern, die in der Regel nach dem Schema „Ne dites pas... mais dites“ funktionieren, fällt in die Jahre nach 1830. Es wird nahezu ,Jagd“ gemacht auf Belgizismen und Wallonismen, die es als vom hochgeschätzten Pariser Sprachgebrauch abweichende sprachliche Eigenheiten zu eliminieren gelte. Beginnend mit Benoîts Belgicismes on les vices de langage et de prononciation les plus communs en Belgique (Benoît 1857) führt der Weg der normativen belgischen Lexikologie bis zum Verkaufsschlager Chasse aux belgicismes (Doppagne/Hanse/Bourgeois-Gielen 1971 - 34.000 verkaufte Exemplare in den ersten zwei Jahren nach Erscheinen; Neuauflage: Doppagne/Hanse/Bourgeois-Gielen, Nouvelle chasse aux belgicismes, 1974) ${ }^{52}$. Somit äuBert sich der belgische Purismus mehr als ein Jahrhundert lang in der Herausgabe von eindeutig gegen Belgizismen gerichteten, präskriptiven Wörterbüchern, die an das breite Publikum adressiert sind. Wilmet $(2000,20)$ bewertet die normative Arbeit belgischer Persönlichkeiten als Kompensierung eines allgemeinen schlechten Gewissens der Belgier gegenüber der französischen Mehrheit; die Grenzen zwischen Belgiern und Franzosen seien, wie er später ausführt, jedoch nur politischer, nicht aber sprachlicher Natur:

\footnotetext{
${ }^{50}$ Klinkenberg $(1985,135 f$ f.) sieht die Identität der frankophonen Belgier in einer schweren Krise: „Or le francophone de Belgique vit actuellement une grave crise d'identité: d'un côté, toute identité belge a disparu, mais de l'autre la 'Communauté française de Belgique' n'offre qu'un cadre artificiel, où les Wallons ne peuvent en tout cas pas se reconnaître." Garsou $(1991,25)$ konnte mit ihrer Studie ermitteln, dass eine knappe Mehrheit $(52 \%)$ der befragten frankophonen Belgier das Gefühl hatte, der Zustand der französischen Sprache verschlechtere sich. Jedoch wurde die Krise des Französischen weniger im eigenen Sprachgebrauch festgemacht als in der Sprache der anderen, da die Hälfte angab über bessere Sprachkenntnisse als die eigenen Eltern zu verfügen (vgl. ebd., 26).

51 Helfrich $(1993,248)$ bringt die Situation, wenngleich sie sich auf die französische Situation bezieht, auf den Punkt: „Sprachliche Neuerungen vermitteln sprachliche Unsicherheit. Allein das Wörterbuch als Instanz erscheint wie ein Fels in der Brandung in der Lage, sprachliche Sicherheit zu bieten." Im Hinblick auf die Terminologie macht Helfrich (ebd., 249) deutlich, dass die Sprecher „,vor dem Wörterbuch als normverwaltende Instanz“ größeren Respekt haben als vor Sprachgesetzen und den offiziellen Terminologielisten.

52 Einen Überblick über die bekanntesten neun Belgizismenwörterbücher vor 1945 von Benoit (1857) bis Brasseur (1939) und die bedeutendsten Arbeiten - nicht nur zu lexikalischen Besonderheiten des belgischen Französisch - nach 1945, endend mit Hanses Nouveau dictionnaire des difficultés du français moderne (1983), gibt Massion (1987, 77-84).
} 
„L'activité souvent glorifiée intra et extra muros des normaticiens belges (Grevisse, Hanse, Doppagne...) sublime la mauvaise conscience générale de nos concitoyens, francophones naturels mais fragilisés parce que minoritaires, et rien de plus.“

Doch in der zweiten Hälfte der 1970er Jahre kommt die Wende, und Belgizismen werden hoffähig. Dieser Umschwung im Denken wird bezeichnenderweise u.a. hervorgerufen durch Doppagne, selbst ehemaliger Purist, den Wolf $(1992,103)$ deshalb auch als „Wendehals“ bezeichnet. Nach der Hetzjagd auf Belgizismen

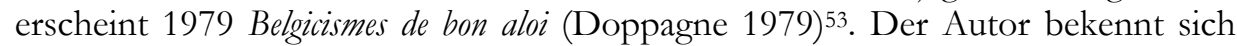
selbst im Vorwort zu der Wende, die jedoch nicht seinen eigenen Erkenntnissen entstamme, sondern vielmehr den in Frankreich festzustellenden Richtungswechsel nachvollziehe (vgl. Doppagne 1979, 12): Im Petit Robert und etwas später auch im Larousse werden verstärkt Belgizismen aufgenommen, nun aber nicht mehr mit dem Hinweis „régional, belgicisme“, sondern mit dem Hinweis Belg. (vgl. Wolf $1992,112)^{54}$.

In der Nachfolge Doppagnes (1979) erscheinen weitere sprachwissenschaftlichdeskriptiv ausgerichtete Belgizismen-Wörterbücher, die üblicherweise als dictionnaire oder inventaire bezeichnet werden. Allerdings lässt der erste Titel nicht unbedingt eine neutrale, beschreibende Haltung vermuten: Le français à la sauce anglaise (Doppagne/Lenoble-Pinson 1982), Dictionnaire de belgicismes (Massion 1987), Anglicismes et substituts français (Lenoble-Pinson 1991), Belgicismes. Inventaire des particularités lexicales du français en Belgique (Bal/ Doppagne/Goosse 1994) und Dictionnaire du français de Belgique (Delcourt 1998, 1999).

Belgizismen werden nach dieser Wende weder innerhalb noch außerhalb Belgiens als zu vermeidende regionale Varianten abklassifiziert, sondern erhalten den Status gleichberechtigter Lexeme, zumindest aus lexikologischer Sicht. Von der französischen Bevölkerung werden Belgizismen trotz ihrer offiziellen Anerkennung in Wörterbüchern immer noch belächelt oder mit Entsetzen gewürdigt (vgl. Wolf 1992, 112).

Belgischer Purismus zur Kompensierung des sprachlichen Minderwertigkeitskomplexes äußert sich bis in die 1970er Jahre aber nicht nur in der Herausgabe entsprechender Antibarbari, sondern auch in der Produktion von Grammatiken und Aussprachewörterbüchern (vgl. Hanse 1989, 313f.). Aufgrund ihrer Aktivitäten auf diesen Gebieten wird den Belgiern häufig von Außenstehenden vorgeworfen, noch „französischer“, d.h. sprachlich noch korrekter sein zu wollen als die Franzosen selbst. Und in der Tat haben die belgischen Grammatiker großen An-

\footnotetext{
53 Wie Massion $(1987,59 f$.$) zu Recht bemerkt, bleibt Doppagne jedoch nach wie vor der normativen$ Richtung verhaftet. Zwar würden Belgizismen jetzt akzeptiert und gelten nicht mehr grundsätzlich als schlechter Sprachgebrauch, jedoch sei das Werk Belgicismes de bon aloi insofern normativ ausgerichtet, als nur eine von Doppagne ausgewählte Anzahl von Belgizismen würdig sei, in ein solches Wörterbuch aufgenommen zu werden und somit offiziell in den französischen Wortschatz eingehen zu dürfen.

${ }^{54}$ Gleiches gilt auch für die Aufnahme lexikalischer Einheiten aus dem Französischen der Schweiz (vgl. Fußnote 74).
} 
teil an der grammatischen und lautlichen Normierung der französischen Sprache (vgl. Holtus 1992). Es sind dies namentlich Maurice Grevisse und sein Nachfolger André Goosse als Autoren des Bon Usage, Joseph Hanse als Verfasser des Dictionnaire des difficultés grammaticales et lexicologiques (11949, später: Nouveau dictionnaire des difficultés du français moderne, inzwischen ${ }^{42000)}$ und Warnant als Autor des Dictionnaire de la prononciation française dans sa norme actuelle (41987). Aber auch hier lässt sich, zumindest für den oftmals als präskriptiv eingeordneten Bon usage, eine Wende feststellen. Das Standardwerk zur französischen Grammatik hat unter Goosse (ab 1986) sehr viel von seinem normgebenden Anspruch verloren und bildet inzwischen fast wertneutral den aktuellen grammatischen Stand der französischen Sprache ab. Ausgehend von der ehrgeizigen Normierungsarbeit belgischer Grammatiker und Phonetiker kann nicht automatisch auf einen Zusammenhang zwischen der Mehrsprachigkeit Belgiens und dem hohen Sprachnormenbewusstsein seiner Bewohner geschlossen werden, um die zu Beginn von 2.3.3.2 gestellte Frage vorläufig zu beantworten. Schließlich ist es unzulässig, von Einzelleistungen einiger Lexikologen oder Grammatiker auf eine gesamte Bevölkerungsgruppe schließen zu wollen. Entsprechende Untersuchungen zu dieser Fragestellung fehlen bislang. Jedoch lässt einiges auf die Existenz eines Zusammenhangs schließen, der sich aber auch aus der Situation der Mehrsprachigkeit entwickelt haben kann, wie Holtus $(1992,62)$ bemerkt:

„In Belgien scheint sich das Bewußtsein für sprachliche Normierungsfragen besonders ausgeprägt entwickelt zu haben. Daß dieses Phänomen - wie etwa auch im Falle der viersprachigen Schweiz mit auf die im Lande existierende offizielle Mehrsprachigkeit und das Vorhandensein von deutlich getrennten Sprachgrenzgebieten mit ihren diversen nationalen, sozialen und individuellen Problemen zurückzuführen ist, erscheint naheliegend, müßte jedoch im Rahmen einer nicht nur sprachwissenschaftlich orientierten Studie detaillierter untersucht werden."

Viel mehr aber als die Mehrsprachigkeit ist vermutlich die Distanz Belgiens zum sprachlichen und kulturellen Zentrum Frankreich bzw. Paris und die damit einhergehende sprachliche Unsicherheit für das hohe Sprachnormenbewusstsein ausschlaggebend.

2.3.3.2.4 Das Verhältnis der frankophonen Belgier zum Französischen Belgiens Es wurde bereits auf das Phänomen der Belgizismen und Statalismen eingegangen. Es wäre jedoch falsch, aus der Existenz einiger, in allen frankophonen Regionen Belgiens verbreiteter Termini zu schließen, dass in Belgien ein einheitliches Französisch gesprochen werde, eine Art Regionalfranzösisch oder gar ein französischer Dialekt. Während Kasper (2001) das Wallonische als Regionalsprache klassifiziert und sich vehement gegen dessen Bezeichnung als Dialekt ausspricht, plädiert Hausmann (1986a, 3f.) bereits 1986 dafür, dass es sich beim Französischen Belgiens nicht um ein Regionalfranzösisch, sondern vielmehr um eine nationale Variante des Französischen handele. Dieser Diskussion soll jedoch an dieser 
Stelle nicht weiter nachgegangen werden. Fest steht, dass es Differenzen zwischen dem in Frankreich und dem in Belgien gesprochenen Französisch gibt, aber auch innerhalb beider Länder kein einheitliches Französisch gesprochen wird. Auch Lafontaine $(1991,22)$ hebt ausdrücklich die Verschiedenheit des belgischen vom Französischen Frankreichs hervor, spricht sich zugleich aber dagegen aus, eine einheitliche belgische Varietät einer genauso wenig existierenden einheitlichen französischen Varietät gegenüber stellen zu wollen:

„La grosse majorité des sujets interrogés évoquent le phénomène de l'accent comme un signe distinctif d'identité linguistique. Ils sont cependant nombreux à dénoncer parallèlement le mythe de l'accent belge véhiculé en France, où l'on assimile volontiers accent belge et accent bruxellois, au mépris de la diversité. Or, il n'y a pas un accent belge, mais des accents belges, de même qu'il y a en France une multiplicité d'accents régionaux (fait mentionné par un quart des sujets). Pour certains, on procède donc de manière excessivement caricaturale lorsqu'on oppose l'accent belge à l'accent français.“

Auch andere Studien haben gezeigt, dass die frankophonen Belgier sich in hohem Maße dessen bewusst sind, dass in Belgien kein einheitliches Französisch gesprochen wird, sondern vielmehr jede Region Walloniens sowie die zweisprachige Hauptstadt Brüssel über eine eigene Färbung („Akzent“) verfügt (vgl. Francard 1993a, 30; Lafontaine 1991, 23). Zudem gibt es Belgizismen, die überregional bekannt und verbreitet sind, während andere nur in sehr eng umgrenzten Gebieten benutzt werden (vgl. Lafontaine 1991, 16-21).

Regionale Akzente werden nicht generell negativ bewertet, sondern die Einstellungen hängen vielmehr vom jeweiligen Akzent ab, so wird der Brüsseler Akzent am schlechtesten bewertet (vgl. ebd., 24-29).

Welchen Platz räumen die frankophonen Belgier dem Französischen in der heutigen Gesellschaft ein? Wie bewerten sie ihre Sprache im Vergleich zum Französischen Frankreichs? Wie stehen die frankophonen Belgier politisch motivierten Eingriffen in die Sprache gegenüber? Dieser und anderen Fragen ist Garsou (1991) im Jahre 1986 nachgegangen, indem sie 800 französischsprachige Belgier befragt hat. Sie stellt fest, dass das Französische nach wie vor in den Bereichen Kultur, feine Küche und Mode als sehr wichtig und präsent erachtet wird. Jedoch stellt sie einen gewissen Fatalismus fest bezüglich des Französischen als Sprache der Wissenschaft und Technik: Wenngleich 63,1\% der Befragten dem Französischen einen (sehr) wichtigen Platz im wissenschaftlichen und technischen Bereich zuweisen, erklären sich 73\% der Befragten mit der Aussage einverstanden, dass es unvermeidlich sei, dass das Englische die hauptsächliche Sprache der Wissenschaft und Technik bleibe (vgl. Garsou 1991, 14, 19). In den Antworten wird das Altersgefälle deutlich: Nur 14,1\% der unter 30-Jährigen räumen dem Französischen in Wissenschaft und Technik eine bedeutende Rolle ein, während es bei den über 60Jährigen noch 40\% sind. Die entscheidende Frage, ob das Französische den modernen technischen Erfordernissen angepasst sei, bejaht eine knappe Mehrheit 
(56\%) (vgl. ebd., 18). Für 31\% der Informanten besteht die Sprache aus vielen offensichtlich erkennbaren Fremdwörtern, 30\% antworten neutral, 38,9\% sind der Meinung, es gebe nur wenige offensichtlich erkennbare Fremdwörter (vgl. ebd.).

Das ambivalente Verhältnis zum Französischen Frankreichs drückt sich in den Antworten auf die Behauptung ,les Belges parlent naturellement moins bien le français que les Français“" aus: 46\% der befragten Personen erklären sich mit dieser Aussage einverstanden, 43\% widersprechen ihr (vgl. ebd., 22). Dies deckt sich mit den Ergebnissen Lafontaines (1991), die ermittelt hat, dass die Belgier den Franzosen eine höhere sprachliche Finesse bescheinigen.

Im letzten Fragenkomplex Garsous geht es um staatliche Interventionen bezüglich der französischen Sprache in Belgien. Garsou dürfte damit die einzige Linguistin sein, die dieser Fragestellung mittels einer Befragung nachgeht. Die Auswertung ergibt, dass sich eine breite Mehrheit (82,5\%) für die Notwendigkeit der Verteidigung des Französischen ausspricht. In der Konsequenz wird auch die Frage nach möglichen Eingriffen in die Sprache von den Befragten mehrheitlich befürwortet. Den $70 \%$, die staatliche Eingriffe zur Verbreitung und Schutz der französischen Sprache befürworten, stehen nur 11\% gegenüber, die derartige Interventionen strikt ablehnen (vgl. ebd., 31). Insbesondere jüngere Belgier, Bewohner der Hauptstadt Brüssel und Informanten aus dem universitären Umkreis lehnen sprachliche Interventionen ab. Doch in welcher Form können diese staatlichen Eingriffe auf die Sprache ablaufen? Wie ist die Haltung der Befragten dazu?

Der Rückgriff auf Sprachgesetze wird nicht mehr so entschieden befürwortet wie die allgemeiner formulierte Frage nach sprachlichen Eingriffen von Seiten des Staates: Mit Sprachgesetzen erklären sich nur noch 50\% der Befragten einverstanden, während 26\% (vor allem Lehrer und andere Akademiker) dagegen sind (vgl. ebd.). Trotz ihrer positiven Haltung gegenüber sprachlichen Eingriffen kennen die Befragten die aktuell geltenden Sprachregelungen oder Sprachpflegeorganisationen gar nicht oder nur sehr rudimentär. Weniger als ein Viertel der Befragten gibt an private oder staatliche Initiativen zum Schutz oder zur Verbreitung der französischen Sprache zu kennen. Den Décret Spaak (vgl. 3.3.1) kennen nur 5\% der Befragten, nach Ansicht von Garsou $(1991,32)$ ein eindeutiger Hinweis darauf, dass Maßnahmen der Verteidigung der Sprache verstärkt in der Öffentlichkeit bekannt gemacht werden müssten.

\subsubsection{Einstellungen zum Englischen und zu Anglizismen}

Die französische Sprachgemeinschaft in Belgien hat sich fast zeitgleich mit Frankreich, nämlich 1978, der Eindämmung der Angloamerikanismen angenommen (vgl. 3.3.1). Alle zuvor in Belgien verabschiedeten Gesetze fallen unter den Bereich der Statusplanung (z.B. Gleichheitsgesetz von 1898, Festschreibung der Sprachgrenzen im Jahre 1962).

Generell ist davon auszugehen, dass das Französische Belgiens in gleichem Maße vom Angloamerikanischen beeinflusst wird wie das Französische Frankreichs. Der Rückgriff auf Anglizismen findet vor allem im Bereich der Wissenschaften (Publikationen), bei der Post, der Eisenbahn, am Flughafen, in Stellenanzeigen, in Werbeslogans und in den Aushängeschildern von Geschäften und Restaurants statt. 
Der Anteil der Anglizismen am Wortschatz liegt Lenoble-Pinson (1997, 246) zufolge unter $2 \%$, jedoch würden die Anglizismen so häufig gebraucht, dass dies bei vielen Belgiern den Eindruck einer angloamerikanischen Invasion hervorrufe (vgl. ebd.). Nach Dierickx (1997, 312f.) haben die Anglizismen am Wortschatz des belgischen Französisch einen Anteil von ca. 2,5\%, d.h. genauso viel wie im Französischen Frankreichs ${ }^{55}$. Dierickx (ebd., 313) geht allerdings davon aus, dass aufgrund ihres unterschiedlichen Temperaments die Reaktionen der Belgier auf diesen Einfluss weniger heftig ausfielen als die der Franzosen. Das bedeutet, dass entsprechend der Widerstand gegen angloamerikanisches Wortgut und gegen die englische Sprache in Belgien geringer als im Nachbarland ausfallen müsste. Anglophobie und Antiamerikanismus, der zu großen Teilen in der französischen Geschichte nach 1945 begründet liegt (vgl. 3.2.1), seien in Belgien weniger verbreitet als in Frankreich. Hinzu komme, dass Englisch in beiden großen Sprachgemeinschaften Belgiens ein hervorragendes Mittel darstelle, um die jeweils andere Sprache zurückzudrängen. Im frankophonen Belgien wählten Schüler als erste Fremdsprache vier Mal häufiger Englisch als Niederländisch. Brüssel sei insofern eine Ausnahme, als in Brüsseler Schulen Niederländisch als erste Fremdsprache für die Frankophonen verpflichtend sei (vgl. Dirickx 1997, 315).

Vielfach wird aber auch die Ansicht vertreten, das Französische in Belgien nehme leichter und schneller Anglizismen auf als das Französische Frankreichs. Exemplarisch sei hier verwiesen auf Klinkenberg (2000), Lebouc (1998) und Wynants (1993). Klinkenberg (2000, 704) vertritt die Ansicht, das Französische Belgiens widersetze sich dem Einfluss des Angloamerikanischen weniger als das Französische Frankreichs und nennt vier Gründe, warum das Angloamerikanische in Belgien besser habe Fuß fassen können als in Frankreich:

1. Die Verbreitung von Anglizismen sei eng an urbane Strukturen geknüpft. Da Belgien dichter besiedelt sei als Frankreich, hätten sich hier die Anglizismen auch schneller und einfacher verbreiten können.

2. Belgien habe dem wirtschaftlichen Einfluss der USA weniger Widerstand entgegengebracht als Frankreich. Insbesondere für ein Industrieland wie Belgien, das durch seinen Handel mit dem Ausland lebe, sei das Englische als Wirtschaftssprache unabdingbar.

3. Da es in Frankreich andere und v.a. mehr Institutionen mit sprachpflegerischem Impetus gebe, unterscheide sich das Sprachbewusstsein der Franzosen von dem der Belgier.

4. Das Englische diene in Belgien mitunter als Sprache des Kompromisses in der Verständigung zwischen den beiden großen Sprechergruppen (Niederlän-

\footnotetext{
55 Es liegen verschiedene Arbeiten, v.a. zur Pressesprache, vor, in denen die Anglizismenquote ermittelt wird (vgl. Kap. 4, Fußnote 2). Alle Untersuchungen gelangen jedoch zu dem Schluss, dass die Anglizismenquote unter 5\% liege und damit aus linguistischer Sicht nicht besorgniserregend sei. Rey-Debove (1987) hat bei einem Korpus von 59.000 Wörtern (Petit Robert 1) 1.500 Anglizismen ausgezählt, die alle der Allgemeinsprache zuzurechnen sind. Rey-Debove/Gagnon (1988, VI) gehen davon aus, dass die Anglizismen nur einen Anteil von 2,5\% am aktuellen Wortschatz ausmachen. Walter $(1997,45)$ gibt die Anglizismenquote mit Bezug auf eine Analyse von 60.000 Wörterbucheinträgen, bei der 2.500 Wörter englischer Herkunft ermittelt wurden, mit ca. $4 \%$ an.
} 
dischsprachige und Frankophone) und sei häufig die gemeinsame Sprache in großen Unternehmen (vgl. Klinkenberg 2000, 704f.).

Auch Lebouc $(1998,9)$ vertritt die These, dass die frankophonen Belgier in stärkerem Maße auf Anglizismen zurückgriffen als die Franzosen, und führt drei Argumente an:

1. Die Einwohner Belgiens befänden sich an der Sprachgrenze zwischen romanischen und germanischen Sprachen. Der Kontakt mit germanischen Sprachen erleichtere häufig das Erlernen von Fremdsprachen, darunter auch des Englischen.

2. Belgien befinde sich an der Schnittstelle der Diagonalen von Schweden bis Portugal und von Schottland bis Griechenland. Insbesondere in einer Zeit, in der die Europäische Union verstärkt zusammenwachse, liege Belgien somit an einer Art kommunikativem Knotenpunkt.

3. Englisch - und in diesem Punkt gibt es eine Überschneidung mit dem zweiten und vierten Apekt von Klinkenberg (2000) - sei die Sprache der Wirtschaft und infolgedessen auch in Belgien unverzichtbar. Hinter dem Gebrauch des Englischen im ökonomischen Kontext verstecke sich jedoch zweifellos der ewige Sprachkonflikt zwischen den beiden großen Sprachgemeinschaften des Landes. Um Konflikte zu vermeiden, werde in Kontaktsituationen auf die gewissermaßen „neutrale“ Sprache Englisch bzw. auf englische Fachtermini zurückgegriffen ${ }^{56}$.

Auch Wynants $(1993,52)$ vertritt die Auffassung, dass die frankophonen Belgier sich weniger gegen Anglizismen zur Wehr setzten, als dies z.B. in Frankreich der Fall sei:

„D’une part, il est bien connu qu'il peut s'agir d'une forme de snobisme: l'usage d'un jargon technique anglais permet de se distancier du simple profane. D'autre part, en Belgique, l'anglais continue à être ressenti comme une langue neutre [...]. Les francophones belges n'adoptent pas automatiquement une attitude défensive vis-à-vis de l'anglais, parce que leur passé collectif ne les a guère poussés à cultiver ce réflexe en face d'un quelconque danger (réel ou imaginaire) de domination linguistique."

Wynants nennt als Gründe für die Verwendung des Englischen bzw. englischer Termini zunächst den Wunsch nach Abgrenzung („,snobisme“). Er verweist dann wie Lebouc (1998) darauf, dass das Englische in Belgien als neutrale Sprache empfunden werde. Zuletzt greift er einen Aspekt auf, den Francard als „quiétude linguistique“ bezeichnet hat (vgl. 2.3.3.2.2), d.h. die seit Jahrhunderten fehlende Bedrohung der französischsprachigen Belgier durch eine andere Sprache.

\footnotetext{
56 Auch de la Guérivière (1994, 10) bewertet den Gebrauch des Englischen speziell in Brüssel als Konfliktvermeidungsstrategie: „Néanmoins, plusieurs facteurs spécifiques aggravent l'anglomanie universelle à Bruxelles. Peuplée à $85 \%$ de francophones et à $15 \%$ de néerlandophones, la capitale belge est officiellement bilingue. Le recours partiel à l'anglais est une façon d'esquiver certains choix délicats pour des entreprises travaillant dans les deux parties du pays.“
} 
Swiggers (1993, 25) stellt den Aspekt der sprachlichen Unsicherheit ins Zentrum und setzt die sprachliche Unsicherheit in Verbindung mit der Bewertung von Anglizismen. Im Unterschied zu Klinkenberg (2000), Lebouc (1998) und Wynants (1993) vertritt Swiggers die Auffassung, die sprachliche Unsicherheit ziehe bei den frankophonen Belgiern eine allergische Reaktion gegen das Englische nach sich:

„[...] Les résultats en [du manque de participation de la Belgique francophone au capital linguistique de France] sont: une insécurité linguistique qui se traduit de façon contradictoire, une réaction allergique contre l'anglais, une mauvaise conscience à propos de l'enseignement [...], une politique de la langue qui n'est qu'une politique de la crainte des interférences lexicales et de l'exaltation de la virtuosité orthographique, et qui veut bien ignorer la variété du français hexagonal.

L'image est sans doute trop peu nuancée, mais elle n'est pas caricaturale $[\ldots . . . " “$

Alle in diesem Abschnitt dargestellten Positionen sind lediglich als Hypothesen zu bewerten. Wissenschaftliche Studien, die die Einstellungen frankophoner Belgier zu Anglizismen untersuchen, liegen noch nicht vor.

\subsubsection{Zusammenfassung von 2.3.3}

Die Erforschung der Spracheinstellungen im frankophonen Belgien hat sich in den 1970er und 1980er Jahren fast nur auf die sprachlichen Vorstellungen vom Französischen Frankreichs/Paris im Unterschied zu den Vorstellungen von den Varietäten des Französischen Belgiens konzentriert. Erst die Einstellungsforschung der späten 1980er Jahre wurde unter einer etwas veränderten Perspektive betrieben, nämlich aus dem Blickwinkel der für diese Sprachgemeinschaft angenommenen sprachlichen Unsicherheit. Frankreich ist und bleibt der sprachliche und kulturelle Bezugspunkt der frankophonen Belgier. Auch wenn der Pariser Akzent negativ konnotiert ist, wird seine Position von den frankophonen Belgiern nicht in Frage gestellt. Diese Art zu sprechen gilt nach wie vor als erstrebenswert, d.h. die Pariser Varietät genießt ein hohes Prestige. Insofern ist es - um auf die am Ende von 2.3.1 aufgeworfene Fragestellung zurückzukommen - durchaus nicht nur als Ausdruck von Sparmaßnahmen zu deuten, sondern vielmehr als Ausdruck sprachlicher Unsicherheit und Orientierung am französischen Nachbarn, dass die frankophonen Belgier die in Frankreich gültige Terminologie weitestgehend übernehmen. Der starken Frankreichorientierung steht die emotionale Bindung der Belgier an die jeweilige Regionalsprache entgegen, wie Untersuchungen ergeben haben. Zu einem Teil ihrer frankobelgischen Identität gehören die Belgizismen, die die befragten Personen auch nicht aufgeben möchten, im Gegenteil sogar als erhaltenswert betrachten.

Was jedoch fehlt, ist die eingehende Untersuchung des Verhältnisses der frankophonen Belgier zum Englischen und zu Anglizismen. Es werden lediglich Hypothesen geäußert, die größtenteils dafür sprechen, dass die Belgier dem Englischen weniger ablehnend gegenüber stehen als ihre französischen Nachbarn. Dies wird 
in erster Linie mit der bedeutenden Rolle des Englischen im Wirtschafts- und Wissenschaftsleben erklärt. Außerdem fungiert das Englische im zweisprachigen Brüssel oder in Betrieben mit französisch- und niederländischsprachigen Beschäftigten oftmals als Verkehrssprache zwischen den Sprechern der beiden großen Sprachgemeinschaften.

Wie noch zu zeigen sein wird, reagiert die französische Sprachgemeinschaft in Belgien auf den Einfluss von Anglizismen ganz ähnlich wie der französische Staat: Mit Hilfe sprachpolitischer Regelungen, die ganz im Stil Frankreichs erfolgen, sollen die Verbreitung und der Gebrauch unerwünschter Anglizismen eingedämmt und statt dessen die offiziell vorgeschlagenen Ersatzwörter verwendet werden (vgl. 3.3.1).

\subsubsection{Schweiz}

$$
\text { „La Romandie n'existe pas“"57 }
$$

\subsubsection{Soziolinguistische Situation}

Die Schweiz hat seit 1848 drei und seit 1938, mit der Anerkennung des Rätoromanischen ${ }^{58}$, sogar vier offizielle Nationalsprachen: Deutsch, Französisch, Italienisch und Rätoromanisch. 63,6\% der schweizerischen Bevölkerung sprechen Deutsch, 19,2\% Französisch, 7,6\% Italienisch und 0,6\% Rätoromanisch (vgl. z.B. Pöll 1998, 25; Zahlen von 1990) ${ }^{59}$.

Seit 1996 sind alle vier Nationalsprachen zugleich Amtssprachen ${ }^{60}$. Von den vier Nationalsprachen ist Deutsch eindeutig die Sprache mit den höchsten Sprecher-

\footnotetext{
${ }^{57}$ So lautet der bekannte Buchtitel von Alain Pichard (1978). Die Bezeichnung Romandie bzw. Suisse romande umfasst die französischsprachigen Gebiete der Schweiz.

Der Buchtitel impliziert, dass es keinen wirklichen historischen, kulturellen, konfessionellen und wirtschaftlichen Zusammenhalt zwischen den französischsprachigen Kantonen der Schweiz gibt, sondern dass vielmehr jeder Kanton die eigenen Belange selbstständig und unabhängig von den anderen regelt (vgl. Kolde/Näf 1996, 390). Ob sich dennoch so etwas wie eine überkantonale Identität der Romands entwickelt hat, wird das Unterkapitel 2.3.4.2 klären.

58 In Bezug auf das Rätoromanische wird unterschieden zwischen der meistens als Bündnerromanisch bezeichneten gesprochenen Sprache und der als Rumantsch grischun bezeichneten Schriftsprache (vgl. Solèr 1997, 1879). Das erst 1982 geschaffene Rumantsch grischun gilt inzwischen als gut etabliert (vgl. Arquint 2000, 241).

59 Bei Lüdi $(1996,103)$ wird eine zeitliche Entwicklung der Anteile der einzelnen Nationalsprachen von 1900 bis 1990 aufgezeigt. Der Anteil der deutschsprachigen Bevölkerung ist um über 6\% zurückgegangen (von 69,8\% im Jahre 1900 auf 63,6\% im Jahre 1990), ebenso der der französischsprachigen (von 22\% auf 19,2\%) und der der rätoromanischsprachigen Bevölkerung (von 1,2\% auf $0,6 \%$ ). Einzig die italienischsprachige Bevölkerung hat anteilig leicht zugenommen (von 6,7\% auf 7,6\%). 1990 lebten in der Schweiz 1.246.000 Ausländer, was einem Anteil von 18,1\% der Gesamtbevölkerung entspricht. Insgesamt sprechen $8,9 \%$ der in der Schweiz lebenden Personen keine der vier Nationalsprachen als Muttersprache (vgl. Lüdi 1996, 105). Die Anzahl der im Jahre 2000 in der Schweiz lebenden frankophonen Schweizer beträgt einer Pressemitteilung des Bundesamtes für Statistik (BFS) vom 19. Dezember 2002 zufolge 1,49 Millionen (vgl. BFS 2002, 1).

60 Am 10. März 1996 wurde mit 76,1\% für die Änderung des Artikels 116 der Schweizerischen Bundesverfassung gestimmt (vgl. Le Culturactif Suisse 2003, o.S.; Pedretti 2000, 300-305). Während seit 1938 nur Deutsch, Französisch und Italienisch als Amtssprachen festgeschrieben waren, heißt es nun: „Amtssprachen des Bundes sind Deutsch, Französisch und Italienisch. Im Verkehr mit Personen rätoromanischer Sprache ist auch das Rätoromanische Amtssprache des Bundes. Das Gesetz regelt die Einzelheiten“ (Pedretti 2000, 305). Die neue Schweizerische Bundesverfassung, die in Art. 70 die Viersprachigkeit anerkennt, gilt seit dem 01. Januar 2000.
} 
zahlen, während nur ca. 20\% der Einwohner Französisch als Alltagssprache sprechen. In der Praxis ist die Schweiz jedoch eher als zweieinhalbsprachig zu bezeichnen (vgl. Maier 1995, 127). Nur dem Deutschen und dem Französischen kommt der Status „ganzer“ Sprachen zu. Das Italienische bekommt nur wenig Raum, und das Rätoromanische verschwindet im Vergleich zu den dominierenden Sprachen fast gänzlich, auch wenn es in den letzten Jahren merklich an Rechten und Bedeutung gewonnen hat ${ }^{61}$.

In 20 der 26 weitgehend souveränen schweizerischen Kantone und Halbkantone herrscht strikte Einsprachigkeit, in der Bevölkerung und in den Behörden. Sehr eindrucksvoll zeigt die Studie von Hauck (1993) die Diskrepanz zwischen dem Anspruch der schweizerischen Behörden, ein viersprachiger Nationalstaat zu sein, und der Realität. In der Bundesverwaltung und im Parlament wird die Schweiz dem theoretischen Anspruch der zu Beginn der 1990er Jahre noch geltenden Dreisprachigkeit nicht in ausreichendem Maße gerecht. Hauck $(1993,150)$ gelangt zu dem Ergebnis, dass mehr als ein Drittel der deutschsprachigen Beamten nur des Deutschen mächtig sei. Cichon $(1998,14)$ weist darauf hin, dass die vielgerühmte Mehrsprachigkeit der Schweiz sich auf klar festgelegte Verwendungsbereiche beschränkt: ,auf gesamtstaatliche Institutionen wie die Bundesverwaltung, das Militär, Bahn und Post sowie auf die mehrsprachigen Kantone Bern, Fribourg, Valais und Graubünden." Dass der Schweizer an sich mehrsprachig sei, nur weil er in einem mehrsprachigen Land lebe, muss als Mythos eingestuft werden (vgl. Cichon 1998, 14f.; De Pietro 1995, 225; Wunderli 2001). Jede Sprachregion führt vielmehr ihr Eigenleben, v.a. in administrativer und kultureller Hinsicht. Außer bei besonderen Gelegenheiten (z.B. Schüleraustausch, Militärdienst) oder bei gelegentlichen Arbeitskontakten kommt der durchschnittliche Schweizer nicht mit den Angehörigen anderer Sprachregionen in Kontakt. Der durchschnittliche Schweizer ist also in aller Regel einsprachig. Dennoch geben 67\% der Romands ${ }^{62}$ an, eine oder mehrere andere Sprachen als ihre Muttersprache regelmäßig zu gebrauchen, wie erstmals bei der Volkszählung 1990 ermittelt wurde (vgl. Kolde/Näf 1996, 388).

Eine Ausnahme von der Einsprachigkeit bildet die Situation in einigen zweisprachigen Regionen, z.B. in den Städten Biel/Bienne und Freiburg/Fribourg mit deutsch-französischer Zweisprachigkeit und in einigen Gemeinden in Graubünden mit deutsch-rätoromanischer Zweisprachigkeit63. Mit Ausnahme dieser Sprachkontakte leben die einzelnen Sprachgemeinschaften isoliert voneinander. Genau dieses sprachliche, aber auch politisch-historische und kulturelle Nebeneinander erklärt auch den von Außenstehenden so oft gepriesenen schweizeri-

${ }^{61}$ Für die Rechte der Rätoromanen setzt sich vor allem der Sprach- und Kulturverein Lia Rumantscha ein.

62 Nach Kolde/Näf $(1996,387)$ lautet die Eigenbezeichnung der Westschweizer, d.h. der Bewohner der Suisse romande, die auch kurz als Romandie bezeichnet wird, les Suisses romands oder les Romands. Die von den Deutschschweizern gebrauchten Bezeichnungen die Welschen, die welsche Schweiz, das Welschland o.Ä. werden von vielen Romands als pejorativ empfunden (vgl. ebd.).

${ }^{63} \mathrm{Da}$ Rätoromanisch für weniger als $1 \%$ der Schweizer die Muttersprache ist, sind alle Rätoromanen grundsätzlich zweisprachig rätoromanisch-deutsch. 
schen Sprachenfrieden, dem zufolge die Schweizer bezüglich sprachlicher Angelegenheiten als tolerant, ausgeglichen und harmonisch gelten (vgl. Kolde 1981, 63f.; Kolde/Näf 1996, 394). Pedretti (2000, 273) gelangt zu der These, dass die Schweiz nicht deswegen keine Sprachkonflikte kenne, weil ihre Bürger besonders tolerant und rücksichtsvoll gegenüber anderen Sprachen und Sprechern seien, sondern weil sie, mit Ausnahme der Situation an den Sprachgrenzen, nicht miteinander leben. Der Historiker Lüthy ist der Auffassung, dass die Schweiz das Problem der Mehrsprachigkeit nicht gelöst, sondern nur vermieden habe, es zu stellen (vgl. Kolde/Näf 1996, 394). Das vielzitierte Sprichwort „Les Suisses s’entendent bien parce qu'ils ne se comprennent pas“ ist somit nicht gänzlich aus der Luft gegriffen (vgl. ebd., 395).

Grund zu der Annahme, die Romands würden durch die deutschsprachige Mehrheit rechtlich unterdrückt oder in ihrer Anzahl weiter zurückgedrängt, besteht nicht. Die quantitative Verteilung der Schweizer Nationalsprachen ist über die Zeit relativ stabil geblieben, was Cichon (1998, 106f.) auf drei Grundprinzipien des schweizerischen Sprachenrechtes zurückführt:

- „der bundesstaatlichen Anerkennung von vier National- und drei Amtssprachen (Art. 116 der Bundesverfassung),

- der Sprachenfreiheit, d.h. dem Prinzip der freien Sprachwahl des Einzelnen,

- dem Territorialitätsprinzip, d.h. der Entscheidungshoheit der einzelnen Kantone über die amts- und schulsprachlichen Regelungen innerhalb eines Gebietes, wobei die entsprechende Praxis traditionell dem Leitziel territorialer Einsprachigkeit folgt ${ }^{\text {"6 } 64}$.

Die Schweiz lässt sich in vier territorial abgegrenzte, jeweils einsprachige Gebiete einteilen, für die das sog. Territorialitätsprinzip (vgl. Fußnote 40) gilt, auch wenn dies, ebenso wie das Prinzip der Sprachenfreiheit, nicht konstitutionell verankert ist (vgl. Cichon 1998, 107; Pöll 1998, 23). Das Territorialitätsprinzip hat in der Schweiz zur Folge, dass jede der vier Sprachen Deutsch, Französisch, Italienisch und Rätoromanisch jeweils in einem bzw. mehreren klar umgrenzten Gebieten gesprochen wird. Von den 23 Kantonen (+ drei Halbkantonen) sind die Kantone Genève, Jura ${ }^{65}$, Neuchâtel und Vaud französischsprachig. Drei Kantone sind zweisprachig (deutsch-französisch), jedoch mit unterschiedlicher Gewichtung der beiden Sprachen. In Bern wird mehrheitlich deutsch gesprochen; die französischsprachige Bevölkerung hat hier nur einen Anteil von 6-7\%. In Freiburg/Fribourg

\footnotetext{
64 Anmerkung zum ersten Grundprinzip: Inzwischen sind es vier Amtssprachen (vgl. Fußnote 60). Anmerkung zum zweiten Grundprinzip: Sprachenfreiheit bezieht sich auf das Recht, die eigene Muttersprache zu benutzen. Das bedeutet auch, dass sich jeder Schweizer in seiner Muttersprache an Bundesbehörden wenden und auch eine Antwort in der entsprechenden Sprache erwarten kann, sofern es sich dabei um eine der Amtssprachen handelt (vgl. Cichon 1998, 107).

${ }^{65}$ Für eine Abspaltung des Kantons Jura vom Kanton Bern wurde erst bei einer Volksabstimmung am 23. Juni 1974 gestimmt. Die Verfassung des neuen Kantons wurde von seinen Bewohnern am 20. März 1977 verabschiedet und von der Schweiz am 24. September 1978 ratifiziert.
} 
und im Wallis/Valais wird mehrheitlich französisch gesprochen, die Frankophonen stellen hier etwa zwei Drittel der Bevölkerung (vgl. Knecht/Py 1997, 1862; Pöll 1998, 23). Bei einer Gesamtbevölkerung von etwa 6,8 Millionen auf ca. 1,3 Millionen schätzen Knecht/Py $(1997,1862)$ die Zahl der Romands auf 1,5 Millionen, die sich prozentual wie folgt auf die Kantone der Romandie verteilen: Vaud $36 \%$, Genève 21\%, Valais 12\%, Fribourg 11\%, Neuchâtel 11\%, Jura 5\% und Berne 4\%.

Die Westschweizer brauchen weder sprachliche Unterdrückung noch eine mangelnde Versorgung mit französischsprachigen schweizerischen Medien zu befürchten. Es kann keine Rede von einem etwaigen Medienmangel sein, der die Westschweizer zwingen würde, auf französisches Fernsehen bzw. französische Zeitungen auszuweichen. Neben einer vielfältigen Presse verfügt die Westschweiz über eine selbstständige französischsprachige Radio- und Fernsehgesellschaft. Des Weiteren weist die Westschweiz ein reiches kulturelles Eigenleben auf: Sie verfügt über zahlreiche französischsprachige Institutionen wie Theater, Kinos, Verlage, vier Universitäten, Kirchen, Vereine etc. (vgl. Kolde/Näf 1996, 398, 405).

Während in diesem Abschnitt zur soziolinguistischen Situation in der Schweiz neben den Westschweizern auch die anderen Sprachgemeinschaften kurz behandelt wurden, beschränken sich die folgenden Unterkapitel 2.3.4.2 und 2.3.4.3, in denen es um die Einstellungen zum Französischen und zum Englischen geht, auf die frankophonen Schweizer.

\subsubsection{Einstellungen ₹um Franæösischen}

\subsection{Anpassung an Frankreich vs. Eigenständigkeit}

Während in Frankreich die Einheit von Sprache und Nation schon seit Jahrhunderten gegeben ist, erweist sich die Situation in der viersprachigen Schweiz als sehr viel komplexer. Die Orientierung an der Pariser Sprachnorm hat in der Romandie bereits im 16. Jahrhundert eingesetzt. Sie hat sich als einziger schweizerischer Sprachraum in ihrem gesamten Sprachverhalten dem ihre Schriftsprache bestimmenden Ausland angepasst. Die lokale Sprachtradition ist daher größtenteils verloren gegangen.

Sprachfragen werden nicht wie in Frankreich zentral, sondern kantonal geregelt. Dies führt zu einer Diversifizierung der Sprachweisen innerhalb der französischen Schweiz. Somit kann in der Romandie ebenso wenig wie in Wallonien von einem einheitlichen Französisch ausgegangen werden. Ähnlich wie für das französischsprachige Belgien gibt es auch einen schweizerischen Purismus, dessen Vertreter den Stil und die Lexik des welschen Französisch als dem hexagonalen Französisch unterlegen einschätzen. Der schweizerische Purismus, der sich gegen regionale Wortschöpfungen richtet, lässt sich bis ins 17. Jahrhundert zurückverfolgen. Die erste Barbarismen-Sammlung zum schweizerischen Französisch stammt aus dem Jahre 1691. Es handelt sich dabei um den Essai des remarques particulières sur la langue françoise pour la ville de Genève von De LaBarre. De LaBarre findet viele Nachahmer, die sich der Eigenheiten verschiedener französischsprachiger Kantone annehmen. Im 20. Jahrhundert verschwinden diese kantonal bezogenen Wortsammlungen. Die Sprachchroniken in der Presse und im Radio setzen sich durch (vgl. Thibault 
1998, 29-32). Heute jedoch finden sich kaum noch puristisch ausgerichtete Sprachchroniken in den Medien. Für Fragen des korrekten Sprachgebrauchs kann inzwischen eine andere Quelle konsultiert werden, die Défense du français. Bulletin édité par la section suisse de l'Union internationale des journalistes et de la presse de la langue française, von der jährlich 12 Ausgaben erscheinen (vgl. L'association suisse des journalistes de la langue française 2003, o.S.; Pochon 1999, o.S.; Rubattel 1985, 89f.).

Das Gefühl, dem hexagonalen Französisch unterlegen zu sein, geht so weit, dass der schweizerischen Verwaltung vorgeworfen wird, sie verbreite Texte in fehlerhaftem Französisch. Insbesondere werden die aus dem Deutschen übersetzten Texte der Bundesverwaltung als Einfallstor für Germanismen gesehen; das aus dem Deutschen übersetzte und von der Pariser Norm mitunter abweichende Amtsfranzösisch wird häufig abwertend als français fédéral bezeichnet (vgl. Kolde/Näf 1996, 394) ${ }^{66}$. Um die Situation zu verbessern, wird 1959 von schweizerischen Staatsbeamten die sprachpflegerische Initiative Fichier français de Berne begründet (zu Gründung und Aktivitäten des Fichier français de Berne vgl. Frey 2000, 235-237). Der Fichier français de Berne ist ein interner Informationsdienst von mehreren in der Schweizerischen Bundeskanzlei tätigen Übersetzern. Der Fichier français de Berne sieht seine Aufgabe vorwiegend in der Wahrung des guten französischen Sprachgebrauchs und im Angebot von Hilfe bei Schwierigkeiten der deutsch-französischen Übersetzung. In über vierzig Jahren sind mehr als 1.000 Datenblätter entstanden, die in Form grüner und weißer Datenblätter unterschiedliche Zielrichtungen verfolgen. Die grünen Datenblätter dienen der Übersetzung deutscher Termini ins Französische. Weiße Datenblätter, die allerdings weder veröffentlicht noch aktualisiert wurden, beziehen sich auf sprachliche Zweifelsfälle, d.h. greifen französische Termini auf, die häufig falsch verwendet werden, und klären den korrekten Sprachgebrauch. Diese Datenblätter sind in erster Linie für diejenigen bestimmt, die offizielle Texte verfassen oder übersetzen. Außerdem wird der Bericht Défense du français herausgegeben. Die Angriffspunkte dieser Vereinigung sind im Wesentlichen Germanismen, Anglizismen, Neologismen, aber auch Regionalismen (französische Helvetismen) und feminisierte Formen. Eines ihrer Hauptziele ist die Ersetzung von Entlehnungen aus dem Deutschen durch französische Wendungen. Aus der Arbeit des Fichier français de Berne resultieren Terminologieempfehlungen in Form von Datenblättern (vgl. Knecht 2000b, 721; Thibault 1998, 32f.). Inzwischen sind die Datenblätter des Fichier français durch internationale Datenbanken wie EURODICAUTOM abgelöst worden (vgl. 3.3.2).

\footnotetext{
${ }^{66}$ Die Bundesverwaltung setzt sich entsprechend der Sprachverteilung in der Bevölkerung zusammen. Aufgrund der deutschsprachigen Mehrheit ist die Amtssprache der Bundesverwaltung im Wesentlichen das Deutsche, so dass Gesetze und andere offizielle Texte zumeist auf Deutsch erarbeitet werden, bevor sie dann ins Französische und Italienische übertragen werden (vgl. Kolde/Näf 1996, 400). Da in den schweizerischen Bundesbehörden genauso wie in den französischen Behörden Muttersprachler arbeiten, ist sprachlich allerdings kein qualitativer Unterschied zur Sprache in französischen Behördentexten feststellbar.
} 
Den Helvetismen hingegen, mit denen analog zu den von Pohl als Statalismen bezeichneten Belgizismen schweizerische Einrichtungen in der Verwaltung, Wirtschaft, im Schulwesen etc. benannt werden, spricht kein Westschweizer ihre Existenzberechtigung ab. Hier zeigt sich bereits eine erste Parallele zu Belgien: Landestypische Bezeichnungen im Wortschatz werden weder in Belgien noch in der Schweiz in Frage gestellt.

\subsection{Das Verhältnis der Romands zum Französischen Frankreichs und zum}

Französischen der Schweiz

Um einen Überblick über die Einstellungen der frankophonen Schweizer zu ihrer Varietät und zum Französischen Frankreichs zu geben, ist die Arbeit Cichons (1998) hervorragend geeignet. Cichon widmet sich in umfassender Weise dem Sprachkontakt zwischen frankophonen Schweizern und Deutschschweizern ${ }^{67}$ und greift damit ein Thema auf, das 1981 von Kolde, 1992 von Windisch et al. und 1999 von Fuchs/Werlen behandelt wurde ${ }^{68}$. Ein Blick in die Arbeit Koldes ist auch heute noch vor allem wegen der Vielfalt an methodischen Herangehensweisen lohnend ${ }^{69}$. Problematisch ist allerdings die geringe Übertragbarkeit der Ergebnisse über die untersuchte Personengruppe hinaus, auf die der Autor selbst auch hinweist (vgl. Kolde 1981, 427f.). Da er nur das Sprachverhalten und die Einstellungen von Jugendlichen in den Städten Biel/Bienne und Freiburg/Fribourg erforscht, lassen sich die Ergebnisse nicht ohne weiteres auf alle Altersgruppen und die gesamte Westschweiz übertragen.

Im Folgenden sollen nur die Ergebnisse der Studie Cichons zu deutsch-französischen Sprachkontakten in der Schweiz eingehend dargestellt werden, da Cichons Arbeit die meisten Anhaltspunkte für die hier ins Zentrum gerückte Fragestellung bietet.

Cichon hat in mehr als 90 zwischen 1990 und 1993 durchgeführten Interviews insgesamt vier Gruppen frankophoner Sprecher in der Schweiz befragt ${ }^{70}$ :

\footnotetext{
${ }^{67}$ Die sprachlich-kulturelle, aber auch geografisch fixierte Grenze, die Deutschschweizer und Romands trennt, wird von den Romands als le Röstigraben oder la barrière ou fossé des röstis bezeichnet.

${ }^{68}$ Während die Untersuchung Koldes im Schwerpunkt linguistisch ausgerichtet ist - unter Zuhilfenahme sozialwissenschaftlicher Methoden - setzt sich die neunköpfige Forschergruppe um Windisch sowohl aus Linguisten als auch aus Soziologen zusammen. Die umfangreiche und ausgesprochen detaillierte Studie unter der Leitung Windischs, der selbst Soziologe ist, öffnet sich somit neben linguistischen auch kulturellen Fragestellungen. Insgesamt bestätigt auch diese Arbeit, wie die Arbeiten von Kolde (1981), Cichon (1998) und Apothéloz/Bysaeth (1981), die negative Einstellung der Romands zu den Deutschschweizern und ihrer Sprache.

${ }^{69}$ Kolde verwendet folgende Forschungsmethoden: Fragebögen, Interviews, teilnehmende Beobachtung bei Diskussionen, schriftliche Sprachtests und Spracheinstellungstests nach der matched-guiseTechnik.

${ }^{70}$ Der Autor betont, selbst Nichtschweizer zu sein. Dies ermögliche ihm, sich dem Gegenstand über die Außenperspektive mittels einer Befragung und deren Auswertung zu nähern (vgl. Cichon 1998, 23).
} 
1. französischsprachige Übersiedler in St. Gallen (d.h. in einer weitgehend monolingual deutsch geprägten Umgebung),

2. frankophone Einwanderer in Biel/Bienne (d.h. in einer zweisprachigen Stadt mit deutschsprachiger Mehrheit),

3. in Fribourg/Freiburg im Üchtland lebende Romands (d.h. in einer zweisprachigen Stadt mit französischsprachiger Mehrheit) und

4. Romands in Genève und Lausanne (d.h. in einer einsprachigen Umgebung) (vgl. Cichon 1998, 21f.).

Faktisch weicht das schweizerische Französisch als français régional nur wenig vom hexagonalen Französisch $\mathrm{ab}^{71}$. Andererseits variiert das français régional von Region zu Region so stark, dass kaum von einem kantonübergreifenden ,français suisse $e^{\text {" die }}$ Rede sein kann, ebenso wenig wie in den frankophonen Regionen Belgiens oder Kanadas ein einheitliches Französisch gesprochen wird (vgl. Cichon 1998, 100f.; Knecht 2000a, 165). In den Befragungen bringen die Informanten entsprechend dieser Feststellungen immer wieder zum Ausdruck, dass sie sich sowohl mit ihrer Region als auch mit Frankreich identifizieren, nicht aber mit der gesamten Romandie. Entsprechend ihrer Identifikation mit Frankreich fällt es den Romands auch schwer, die Vorstellung vom erstrebenswerten Pariser Französisch abzulegen (vgl. Cichon 1998, 101).

Cichon erfragt in den Interviews mit Informanten der vier genannten Sprechergruppen stets die gleichen Themenbereiche, um die Ergebnisse hinterher besser vergleichen zu können. Für dieses Kapitel ist relevant, dass alle Befragten um eine Einschätzung ihrer eigenen Identität und kulturellen Zugehörigkeit gebeten werden. Des Weiteren ermittelt Cichon in den Interviews, inwieweit eine Majorisierungsfurcht in Bezug auf die deutschsprachige Bevölkerung besteht (Unterdrückung durch die deutschsprachige Mehrheit) und wie die eigene Französischkompetenz eingeschätzt wird. Aus den Antworten leitet Cichon u.a. den Grad der Frankreichorientierung ab. Cichon stellt fest, dass bei den befragten St. Gallenern kaum Vereinnahmungsängste in Bezug auf Frankreich bestehen und somit auf Bemühungen um (kulturelle) Eigenprofilierung der Romands weitgehend verzichtet wird (vgl. ebd., 131). Des Weiteren kann festgehalten werden, dass sich die St. Galler Romands ebenso wie die Romands in Biel/Bienne als Ausgleich zur gesellschaftlichen Dominanz der Deutschen sprachlich und kulturell an Frankreich ausrichten und auch kaum kulturelle Divergenzen zwischen sich und den Franzosen sehen. Die Tatsache, dass sie in einer deutsch geprägten Umgebung leben, kompensieren sie somit in einer engen ideellen Anlehnung an das Nachbarland (vgl. ebd., 132, 209). Das sprachliche Selbstbewusstsein der St. Galler Romands und der Romands in Biel/Bienne ist allerdings nicht sehr ausgeprägt: Viele der Befragten werten die sprachliche Differenz zum Französischen Frankreichs als eigene Defizienz (vgl. ebd., 132, 222f.). Außerdem verneint die Mehrheit

\footnotetext{
71 Knecht/Rubattel (1985) stellen einige typische phonologische, syntaktische und lexikalische Besonderheiten des schweizerischen Französisch heraus. Sie betonen jedoch, dass das Französische der Schweiz kaum vom hexagonalen Französisch abweiche. Es sei lediglich etwas konservativer, was sie mit dem peripheren Status der Schweiz erklären (vgl. Knecht/Rubattel 1985, 144).
} 
der Befragten die über die gemeinsame Sprache hinausgehende und beispielsweise kulturelle Übereinstimmungen umfassende Existenz einer Suisse romande.

In Fribourg stellen die Romands die Bevölkerungsmehrheit und müssen sich aus diesem Grund nicht in dem Maße gegen die deutschsprachige Bevölkerung behaupten wie die Romands in St. Gallen oder Biel/Bienne. Analog zu den Ergebnissen für St. Gallen und Biel/Bienne identifizieren sich die Freiburger Romands mit Frankreich. Sie haben das Gefühl, den Franzosen kulturell und sprachlich unterlegen zu sein (vgl. ebd., 292, 312).

Die Bewohner der Städte Genf und in noch stärkerem Maße Lausanne orientieren sich eng an Frankreich, was z.B. den Medienkonsum betrifft. Das Verhältnis zu Frankreich wird jedoch in beiden Städten (wie auch in den beiden anderen Befragungsorten) nicht durchweg positiv beurteilt, da sich die Romands von den Franzosen oft geringschätzig behandelt fühlen (vgl. ebd., 321-326) ${ }^{72}$. Aufgrund ihrer geografischen und kulturellen Nähe zu Frankreich empfinden die Bewohner von Lausanne und Genf die französische Schweiz noch weniger als verbindende Einheit als die Befragten Romands in St. Gallen und Biel/Bienne (vgl. ebd., 357f.). Die Untersuchungsergebnisse können dahingehend zusammengefasst werden, dass für die Mehrheit der von Cichon befragten Informanten (aller vier Gruppen) Frankreich, nicht die französische Schweiz, den sprachlichen und kulturellen Bezugspunkt darstellt. Damit bestätigt die empirische Studie Cichons die Frankreichorientierung, die Knecht bereits 1979 mit den Worten ausdrückte, die Romandie sei „une France politiquement suisse ou une Suisse linguistiquement française“ (Knecht 1979, 249). Zwar verfügen die Romands über die nötige Infrastruktur, um unabhängig von französischen Medien ein kulturelles Eigenleben führen zu können, wie am Ende von 2.3.4.1 ausgeführt wurde, doch legen sie auf diese Eigenständigkeit offenbar keinen Wert. Dies bedeutet jedoch keinesfalls, dass sich die Westschweizer auch politisch mit dem Nachbarland identifizieren:

„Zwar teilt die Westschweiz mit Frankreich viele Vorlieben und Wertvorstellungen, was sich etwa am Abstimmungsverhalten gut aufzeigen läßt; staatspolitisch gesehen sind die Romands jedoch Erzföderalisten, die einen Zentralismus in der Art Frankreichs für sich selbst kategorisch ablehnen. Die meisten Westschweizer identifizieren sich denn auch vorbehaltslos mit dem schweizerischen Bundesstaat $^{\text {“ }}$ (Kolde/Näf 1996, 405).

Knecht (2000a, 139) weist darauf hin, dass sich die Bewohner der anderen drei schweizerischen Sprachregionen weitaus mehr sprachliche und kulturelle Eigenständigkeit bewahrt haben als die Westschweizer:

\footnotetext{
72 Diese Einschätzung unterstützt auch Knecht (2000a, 176), wenn er schreibt: „Dieses welsche Selbstverständnis stand jedoch bisher in Frankreich auf schwachem Fuß. Obwohl sich die welsche Schweiz nie als kulturelles Randgebiet betrachtet hat - davon zeugt ihr unbeirrter Integrationswille -, wurde sie von Frankreich bisher schon immer als solches behandelt. Daran wird sich jetzt, im Zuge einer neuen Frankophonie-Konzeption, sicher etwas ändern müssen.“
} 
„Im Gegensatz zu den drei anderen Sprachregionen ist in der französischsprachigen Schweiz die lokale Sprachtradition zum größten Teil verlorengegangen. Als einziger schweizerischer Sprachraum hat sie sich in ihrem gesamten Sprachverhalten fast völlig dem ihre Schriftsprache bestimmenden Ausland angepasst. Dies war, angesichts der streng zentralisierten Sprachlenkung, wie sie von Paris bisher ausgeübt wurde, gewissermaßen der Preis, den sie für ihre Zugehörigkeit zum französischen Sprachgebiet entrichten musste. Zu dieser Sprachlenkung gehören das unerbittliche Streben nach Sprachreinheit in Grammatik und Wortschatz, aber auch die Bekämpfung der Mundarten.

Allerdings wurde diese Anpassung von Paris nie ausdrücklich geforde $[\mathrm{r}] \mathrm{t}$ oder kontrolliert. Sie war und ist durchaus spontanen Ursprungs und hängt in erster Linie mit dem weltweiten Prestige zusammen, das die französische Sprache als Symbol raffinierter Kultur und Instrument des Fortschritts überhaupt seit dem 18. Jh. bis in die erste Hälfte des 20. Jhs. genoss. “

$\mathrm{Zu}$ einem ähnlichen Ergebnis gelangt auch De Pietro (1995, 230), wenn er schreibt:

„Les attitudes des Romands ne sont d'ailleurs pas homogènes et uniformes. Et l'ambigïité n'en est pas absente: parallèlement à une loyauté parfois très forte au français 'de France', doublée d'une légère gêne à l'égard de son propre parler, voire d'un rejet de tout ce qui est teinté d'accent régional, on peut rencontrer l'attitude opposée faite d'affirmation identitaire vis-à-vis du grand voisin.“

Das bedeutet, dass die Romands der gleichen Auffassung sind wie die frankophonen Belgier: Ihre Art zu sprechen sei der der Franzosen unterlegen. Das bringt auch die Romands in einem Zwiespalt zwischen der Bewunderung der Sprache und Kultur Frankreichs einerseits und dem Streben nach einer eigenen Identität in Abgrenzung zu Frankreich andererseits. Dieser Zwiespalt spiegelt sich auch in den Einstellungen der frankophonen Schweizer wider. Einerseits streben sie nach einer Norm, nach einem geregelten System (das es nicht gibt) und versuchen sich sprachlich an Frankreich anzupassen, andererseits fühlen sie sich emotional den lokalen Varietäten verbunden, erkennen den eigenen Wert der französisch geprägten Helvetismen an und fühlen sich dadurch eher als frankophone Schweizer bzw. als Bewohner einzelner frankophoner Kantone oder Städte (vgl. De Pietro 1995, 233f.). Aus diesem ambivalenten Verhältnis zu Frankreich und seiner Sprache resultiert, analog zur Situation in Belgien, das Gefühl sprachlicher Unsicherheit. 


\subsection{Ein eigenes Sprachbewusstsein? Lexikografie und Orthografie}

Für die Schaffung einer eigenen sprachlichen Identität wird von staatlicher wie auch von privater Seite wenig getan ${ }^{73}$. Probleme eigener (schweizerischer) Sprachbedürfnisse werden Knecht (2000a, 164) zufolge kaum öffentlich diskutiert, die Auseinandersetzung mit der französischen Sprache folge wiederum dem Beispiel Frankreichs: die Verteidigung des Französischen vor weiterem Geltungsverlust und der Wunsch nach Reinhaltung der Sprache. Hier gälten für die Romands jedoch nicht nur die Anglizismen als bedrohlich, sondern aufgrund der deutschfranzösischen Kontaktsituation in erster Linie der Einfluss des Deutschen. Eine weitere Abhängigkeit der Romands von Frankreich bestehe darin, dass sie kein Recht hätten, an der französischen Sprachlenkung mitzuwirken, obwohl Französisch ihre Muttersprache sei. Hinzu komme der Ausschluss aus der Académie française, in die nur französische Staatsbürger gewählt werden dürfen (vgl. ebd., 170f.). Das mangelnde Mitspracherecht im Bereich der Terminologieplanung werde von den Romands keineswegs als problematisch empfunden, da sie sich Wörter, die dem Französischen fehlten, selbst schüfen, diese aber nicht offiziell zu legitimieren versuchten. Diese spezifische Situation erkläre auch das Fehlen eines in der Schweiz entstandenen normativen Wörterbuchs, welches auch über die Schweiz hinaus Gültigkeit hätte (vgl. ebd., 171). Von einem gewissen Bewusstsein für lokale Eigenheiten zeugen Wörterbücher des schweizerischen Französisch. Seit 1997 liegt das sehr umfassende, deskriptiv angelegte Wörterbuch Dictionnaire suisse romand. Particularités lexicales du français contemporain (DSR) vor (vgl. Knecht 1997, 9-15; Thibault 1998, 36-40) ${ }^{74}$. Goosse $(1995,272)$ weist zu Recht darauf hin,

\footnotetext{
${ }^{73} \mathrm{Zu}$ den staatlichen Bemühungen im Bereich der schweizerischen Terminologieplanung vgl. 3.3.2.

${ }^{74} \mathrm{Im}$ DSR sind ungefähr 1000 Wörter aufgenommen worden, die alle auch Bestandteil der gesprochenen Sprache sind. Der DSR illustriert den aktuellen Wortgebrauch mit Hilfe vieler Textbeispiele wie Presseauszügen, administrativen Texten und Zitaten aus der westschweizerischen Gegenwartsliteratur. Das Wörterbuch ist zu einem großen Publikumserfolg geworden (vgl. Knecht 2000a, 173). Auf der Internetseite des Institut de dialectologie der Universität von Neuchâtel wird der DSR als erster wissenschaftlicher Versuch bezeichnet, ein Wörterbuch zum Französischen der gesamten französischsprachigen Schweiz seit dem Erscheinen des Wörterbuchs von William Pierrehumbert, dem Dictionnaire historique du parler neuchâtelois et suisse romand (1926), zu verfassen (vgl. Institut de dialectologie de l'Université de Neuchâtel 2003, o.S.). Wörterbücher mit Helvetismen hat es allerdings auch schon vor Pierrehumbert gegeben. Zunächst waren alle lexikologischen Veröffentlichungen des 19. Jahrhunderts, die hauptsächlich als Wortlisten („glossaires") erschienen, in erster Linie pädagogisch-didaktischen Zielen verpflichtet. Sie wollten den Romands ein Beispiel und Vorbild für ,gutes" Französisch sein, indem sie die in Frankreich übliche Lexik verbreiteten und regionale Besonderheiten stigmatisierten. Dagegen war und ist der 1898 gegründete Glossaire des patois de la Suisse romande (GPSR) pädagogischen und wissenschaftlichen Zielen verpflichtet, indem er die Vielfalt der französischen Sprache und Kultur in der französischsprachigen Schweiz abbilden will. Seit 2001 gibt es eine enge Zusammenarbeit zwischen dem GPSR und dem Centre de dialectologie et de français régional der Université von Neuchâtel (vgl. CIIP o.J., o.S.).

Außerhalb der Schweiz begann die wissenschaftliche Beschäftigung mit regionalen Varietäten des Französischen mit dem Erscheinen des Supplément zum Dictionnaire de la langue française von Littré im Jahre 1877. Littré war der erste, der Helvetismen wertneutral in sein Wörterbuch aufnahm (vgl. Knecht 1997, 11f.). Andere Wörterbücher zum Französischen folgten dem Beispiel Littrés erst ein Jahrhundert später. In den 1970er Jahren nahm der Trésor de la langue française die Westschweiz als Untersuchungsgebiet mit auf, dann folgten der Larousse 1980 und der Grand Robert 1985 (vgl. Knecht 2000a, 172). Das gleiche gilt für die Aufnahme von Belgizismen, wie bereits in 2.3.3.2.3 gezeigt wurde. In den Jahren vor der Veröffentlichung des DSR sind drei Wörterbücher zum Französischen der Schweiz erschienen, die Wörterbücher von Hadacek (1983), Nicollier (1990) und Pidoux (1984).
} 
dass andererseits die Produktion eigener Wörterbücher den Graben zu Frankreich insofern vertiefe, als die Franzosen dadurch glauben, dass es tatsächlich ein schweizerisches oder belgisches Französisch gebe, welches sich der - ebenso wenig existierenden - einen hexagonalen Varietät entgegenstelle.

Traditionell wurden die aus Paris stammenden Entscheidungen in sprachlichen Dingen von den Bewohnern der Romandie akzeptiert, nicht zuletzt, weil es in der Westschweiz kein eigenes Sprachpflegeinstitut gab. Die Gemüter erhitzten sich erst in dem Moment, als die französische Orthografiereform 1990 durchgesetzt wurde, ohne dass mit den frankophonen Schweizern - im Unterschied zu den entsprechenden Vertretern für Québec und Belgien - in irgendeiner Weise Rücksprache gehalten wurde (vgl. Knecht 1996, 766; 2000a, 173f.). Ein Grund für die fehlende Berücksichtigung der Schweiz ist genau darin zu sehen, dass es zur Zeit der Diskussion um die Orthografiereform in der Romandie keine eigenständige Akademie gab, die analog zur französischen oder belgischen Akademie als Ansprechpartner in Sprachenfragen gelten konnte. In der Schweiz übernahm die Konferenz der welschen Erziehungsdirektoren diese Aufgabe ${ }^{75}$. Nach diesem „Reinfall“, der auf das Fehlen einer qualifizierten Autorität für Sprachfragen zurückzuführen ist, wurde 1992 eine entsprechende Organisation, die Délégation à la langue française geschaffen (vgl. DLF 2003, o.S.; Knecht 2000b, 722) ) $^{76}$. Dass Frankreich hier wieder einmal Modell gestanden hat, ist in Anbetracht des Namens kaum zu übersehen.

\subsection{Sprachliche Unsicherheit bei Romands?}

Die bisherigen Ausführungen haben gezeigt, dass es für die Romands - ähnlich wie für die frankophonen Belgier - aufgrund ihrer mehrheitlichen Orientierung an Paris schwierig ist, zu einer eigenen sprachlichen und kulturellen Identität zu finden. Aus dem Bewusstsein heraus, das Französische Frankreichs sei der eigenen Varietät überlegen, müsste bei den Romands eine gewisse sprachliche Unsicherheit spürbar sein. Dieser These wird dieser Abschnitt nachgehen.

Die Einstellungen der Westschweizer zu ihrer jeweiligen Regionalsprache sowie der Grad der sprachlichen Unsicherheit variieren innerhalb der frankophonen

Die Tatsache, dass in den letzten 20 Jahren, vor allem durch das Erscheinen des DSR, allein vier namhafte Wörterbücher für das schweizerische Französisch erschienen sind, bezeugt das gesteigerte Interesse der Romands an ihrer eigenen Varietät. Der DSR weist einige Besonderheiten auf, die ihn von anderen (regional beschränkten) Wörterbüchern unterscheiden: Neben der genauen Beschreibung von französischen Helvetismen werden für alle Termini, die sich auf schweizerische Institutionen beziehen, auch Äquivalente in den drei anderen Landessprachen angegeben. Außerdem richtet sich der Blick auf das französischsprachige Ausland. Bei einigen Termini werden auch die Äquivalente für das Französische Frankreichs, Belgiens und Kanadas angegeben, z.B. entsprechen dem schweizerischen gymnase die Wörter lycée in Frankreich, athénée in Belgien und cégep in Québec (vgl. Thibault 1997, 436f.).

75 Knecht (2000a, 174) rechtfertigt das Verhalten Frankreichs damit, dass es für Frankreich nicht vorhersehbar war, dass die Konferenz der welschen Erziehungsdirektoren im Falle der Orthografiereform die Rolle übernehmen würde, die in anderen Staaten von den Akademien getragen wird.

76 Auf ihrer Internetseite werden folgende Arbeitsbereiche der DLF genannt: „langue française dans l'information scientifique et technique“, ,industries de la parole“, ,image et présence du français en Suisse et dans le monde“, ,,évolution du français en Suisse“, , ,place et usage du français dans un pays plurilingue“ und „rectifications de l’orthographe“ (vgl. DLF 2003, o.S.). 
Schweiz. Der waadtländer Akzent beispielsweise gilt als bäuerlich und derb, während die in Genf oder Neuchâtel gesprochenen Varietäten sogar in intellektuellen Kreisen ein hohes Prestige genießen (vgl. Knecht/Rubattel 1984, 145 und 1985, 150) ${ }^{77}$. Um den Einstellungen zu ihrer Sprache bzw. dem Grad der sprachlichen Unsicherheit nachzugehen, sind vereinzelt Studien durchgeführt worden. In diesem Kontext sind vor allem drei Arbeiten zu nennen:

1. die Studie von Bayard/Jolivet (1984),

2. die Studie von De Pietro/Matthey (1993/1995) und

3. die Studie von Singy (1997).

Die Untersuchung von Bayard/Jolivet mit dem Titel „Des Vaudois devant la

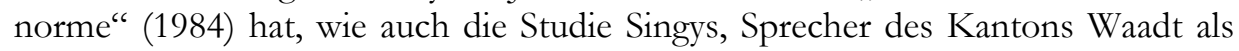
Zielgruppe.

Bayard/Jolivet untersuchen die Einstellungen von insgesamt 32 waadtländer Sprechern gegenüber ihrer regionalen Varietät. 18 Sprecher $(56 \%)$ haben den Eindruck kein gutes Französisch zu sprechen. 14 Informanten (44\%) halten ihr Französisch für gut (vgl. Bayard/Jolivet 1984, 153). Die Autoren vergleichen ihre Ergebnisse mit der Studie von Gueunier/Genouvrier/Khomsi (1978), bei der 44\% der befragten Bewohner von Tours angegeben hatten, gut zu sprechen, aber auch ebenso viele Informanten dies verneint hatten (vgl. 2.3.2). Insgesamt liegt also die sprachliche Sicherheit der Bewohner von Tours geringfügig über der der Sprecher des Kantons Waadt (vgl. Bayard/Jolivet 1984, 152f.). In Anbetracht der Tatsache, dass Tours als ein Milieu hoher sprachlicher Sicherheit gilt, in der eine Varietät gesprochen wird, die dem Pariser Standard sehr nahe kommt, erstaunt die hohe Selbsteinschätzung der waadtländer Sprecher, deren Akzent innerhalb der Romandie allgemein relativ schlecht angesehen wird. Üblicherweise schätzen Sprecher, die nicht in Paris (oder Tours) leben, sondern in französischen Dialektgebieten oder in französischsprachigen Regionen außerhalb Frankreichs - das Beispiel Belgiens, aber auch die vorangehenden Seiten haben es deutlich gezeigt ihre Varietät als der Pariser Varietät unterlegen ein und bringen, auch ohne diesen Bezugspunkt explizit zu nennen, ihr Minderwertigkeitsgefühl gegenüber Sprechern der Hochsprache und ihre eigene mangelnde Sprachbeherrschung deutlich zum Ausdruck. Die waadtländer Sprecher können aufgrund der Ergebnisse der Studie von Bayard/Jolivet (1984) als dem Pariser Modell gegenüber besonders kritisch bezeichnet werden.

De Pietro/Matthey befragten im Laufe des Jahres 1989 etwas mehr als 100 frankophone Sprecher aus Neuchâtel zu ausgewählten Lexemen. Mit Hilfe einer von 1 (= unakzeptabel) bis 7 (= vollkommen akzeptabel) reichenden Skala sollen zwei Ausdrücke des Standardfranzösischen (aider quelqu'un, trébucher), zwei Anglizismen (weekend, walkman), neun französischsprachige Regionalismen (septante, souper, s'encoubler, fricasse, cramine, frions, il a eu coupé, on a personne vu, il veut pleuvoir), sechs

\footnotetext{
$77 \mathrm{Zu}$ einem analogen Ergebnis gelangt auch Singy. Auf die Frage, wo in der französischsprachigen Schweiz das beste Französisch gesprochen werde, antworten 33,6\% der Befragten mit Genf, 29,7\% mit Neuchâtel und 12,7\% mit Lausanne (vgl. Singy 1997, 235).
} 
Germanismen bzw. typische Fehler im Französischen der Deutschschweizer (schuss, schwyzertütsch, benzine, visiter quelqu'un, s'intéresser pour und spielgruppe) und zwei nicht eindeutig einer Kategorie zuzuordnende Termini bzw. Konstruktionen (catelle und Je vais lui aider) eingeschätzt werden. Für jede bzw. jeden der vorgelegten Konstruktionen und Termini sollte der Akzeptabilitätsgrad für eine informelle Situation (Gespräch mit Freunden) und eine formelle Situation angegeben werden. Das Ergebnis lässt sich folgendermaßen zusammenfassen:

- Ausdrücken des Standardfranzösischen wird sowohl für formelle als auch für informelle Verwendungssituationen eine hohe Akzeptanz entgegengebracht.

- Auch die beiden Anglizismen weisen sehr hohe Akzeptanzwerte auf, insbesondere für informelle Gesprächssituationen: Der Begriff weekend erhält für informelle Situationen den durchschnittlichen Skalenwert 6,5, für formelle Situationen den Wert 5,3. Der Anglizismus walkman erhält für informelle Situationen den Wert 6,2, während er in formellen Situation nur mit 4,2 bewertet wird.

- Die Einschätzung der französischsprachigen Regionalismen muss differenziert betrachtet werden. Ihnen gegenüber ist die Einstellung weder durchweg positiv noch negativ (min. 1,5, max. 6,7 auf der Werteskala). Als Tendenz lässt sich festhalten, dass lexikalische Regionalismen in informellen Situationen höhere Akzeptanzwerte aufweisen als in formellen Situationen.

- Ausdrücke aus dem Deutschen bzw. Schweizerdeutschen werden deutlich schlechter als die französischsprachigen Regionalismen bewertet (min. 1,2, max. 5,6 auf der Werteskala) (vgl. De Pietro 1995, 239f.).

Ausgehend von der These, dass Sprecher in frankophonen Gebieten außerhalb Frankreichs dazu neigen, ihren Regiolekt gering zu schätzen, hat Singy im Jahre 1990606 Fragebögen an Sprecher im Kanton Waadt verteilt und anschließend ausgewertet. Das Ziel der Untersuchung ist die Klärung der Beziehung der Waadtländer zu ihrer Varietät. Die Auswertung der insgesamt 41 Fragen brachte teilweise überraschende Ergebnisse. Die sprachliche Unsicherheit der Befragten hat sich jedoch keinesfalls als so hoch erwiesen, wie dies zu erwarten war. Die Frage, ob sie einen Akzent haben, bejahen 83,1\% (vgl. Singy 1997, 139). 74\% der Befragten geben an ihren als recht ausgeprägt geltenden Akzent zu mögen (vgl. ebd., 141) ${ }^{78}$. Hierin zeigt sich deutlich die Loyalität der Waadtländer zu ihrer Regionalsprache ${ }^{79}$. Sie betrachten die Qualität des in der Romandie gesprochenen Französisch als durchschnittlich (54,9\%) oder gut (33,8\%) (vgl. ebd., 148). 75,4\% sind der Meinung, die Waadtländer könnten auf ihre Art zu sprechen stolz sein

\footnotetext{
78 Die Antworten auf die Frage, ob es Waadtländer gebe, die ihren Akzent zu verlieren versuchen, erscheinen auf den ersten Blick hierzu widersprüchlich: 79,3\% der Befragten antworten mit ,ja“ (vgl. Singy 1997, 152). Offensichtlich sind die Waadtländer der eigenen Varietät gegenüber positiver eingestellt, als sie dies von den anderen Sprechern dieser Varietät annehmen.

${ }^{79}$ Hiermit bestätigt die Studie Singys die Ergebnisse von Doise/Sinclair/Bourhis (1976, 248f.), die vor allem die identitätsstiftende Funktion der Regionalsprachen herausstellen: „Vaudois and Valaisan accents are very strong indeed. For both groups, accent is an important part of their social identity: it is the only way one can recognize members of these groups [...]."
} 
(vgl. ebd., 162). Bei der Frage, in welcher Situation sich ein Waadtländer befinde, wenn er mit einem sozial gleichgestellten Franzosen spreche, plädieren 65\% der Befragten für eine Gleichheit des Status. Den 3,3\%, die für eine Überlegenheit der Waadtländer gegenüber den Franzosen stimmen, stehen 30,5\% gegenüber, die die Waadtländer als den Franzosen unterlegen betrachten (vgl. ebd., 179). Die Tatsache, dass 30,5\% die Franzosen im Gespräch als überlegen betrachten, spricht für ein gewisses $\mathrm{Maß}$ an sprachlicher Unsicherheit. Eine andere Erklärungsmöglichkeit für dieses Ergebnis ist das Verhalten vieler Franzosen (insbesondere Pariser): ihre negative, nahezu herablassende Haltung gegenüber französischen Varietäten der Peripherie. 69,1\% der Informanten glauben, dass die Franzosen das Französisch der Westschweizer negativ beurteilen, nur 8,5\% trauen den Franzosen ein positives Urteil über das Französische in der Schweiz zu (vgl. ebd., 184).

Gegenüber frankophonen Belgiern fühlen sich 76,5\% der Befragten in einer Situation der Gleichheit, 2,8\% in einer Situation der Unterlegenheit, und 17,6\% fühlen sich ihnen überlegen (vgl. ebd., 182). Die 76,5\% sprechen eindeutig dafür, dass Sprecher nicht-hexagonaler französischer Varietäten ihre Sprechweise als nahezu gleichwertig betrachten. Allerdings ist das sprachliche Selbstbewusstsein der Waadtländer nicht gänzlich ungebrochen. Dies resultiert vielleicht aus der negativen Einstellung, welche die Franzosen der schweizerischen Varietät nach Ansicht der Waadtländer entgegenbringen. Zwar sind 54,6\% der Befragten der Meinung, dass die Waadtländer genauso gut sprechen wie die Franzosen, jedoch halten 41,9\% das regionale Französisch für schlechter als das in Frankreich gesprochene (vgl. ebd., 195). Frankreich (58,4\%) und Paris (11,5\%) bekommen die höchsten Werte bei der Frage, wo in der Welt das beste Französisch gesprochen wird (vgl. ebd., 99). 64,5\% bzw. 15,5\% der Informanten sind der Ansicht, in Frankreich bzw. Paris werde das beste Französisch gesprochen. Andererseits wird der Pariser Akzent zugleich von 36,9\% der Befragten als der unsympathischste Akzent eingeschätzt, gefolgt vom Brüsseler Akzent (24,5\%) - eine weitere Parallele zur Situation im frankophonen Belgien. Auf der Unbeliebtheitsskala folgen der Akzent von Québec (11,7\%) und der Akzent von Lausanne (6,4\%). Der Akzent von Marseille wird nur von 3,6\% der Befragten als unsympathisch bewertet (vgl. ebd., 111).

Im Gesamtbild ergibt sich eine Sprachgemeinschaft, die stolz ist auf ihre Varietät und überzeugt ist von ihrer Sprachkompetenz. Dennoch sprechen die Waadtländer französischen und insbesondere Pariser Sprechern eine gewisse Führungsposition zu. Singy beobachtet in Bezug auf die Waadtländer Sprecher das gleiche Paradoxon, das auch für die frankophonen Belgier festzustellen war. Einerseits sind sie stolz auf ihre Varietät(en), andererseits fühlen sie sich Frankreich in sprachlicher Hinsicht immer noch unterlegen (vgl. ebd., 258).

\subsubsection{Einstellungen zum Englischen und zu Anglizismen}

Das schweizerische Gesamtsprachenkonzept sieht vor, dass alle Schüler zusätzlich zur lokalen Landessprache mindestens eine zweite (fremde) Landessprache sowie Englisch lernen. Darüber hinaus sollen sie die Möglichkeit haben, eine weitere fremde Landessprache bzw. eine andere Fremdsprache zu erlernen (vgl. Arbeitsgruppe der Schweizerischen Konferenz der Kantonalen Erziehungsdirektoren 
2003, o.S.). Das bedeutet für alle Schulen der Westschweiz, dass Deutsch als erste Fremdsprache gelernt wird. Trotz dieser Regelung, die eindeutig das Erlernen der Landessprachen fördert, ist das Englische in den Schulen sehr gut etabliert. Seit Jahren wird in der Schweiz diskutiert, ob es nicht sinnvoller sei, das Englische automatisch als zweite Fremdsprache in den Schulen einzuführen, anstatt die Schüler eine zweite (fremde) Nationalsprache lernen zu lassen. Romands und Deutschschweizer fordern sogar das Englische als erste schulische Fremdsprache, was seit 1998 in Zürich möglich ist (vgl. Fußnote 81). Für die Verstärkung des Englischunterrichts in Schulen werden vor allem die folgenden Argumente vorgebracht:

- Größere Nützlichkeit des Englischen,

- weiterer Wirkungskreis des Englischen,

- einfacheres Erlernen sowie die Tatsache, dass

- Schweizer bei gemischtsprachigen Treffen ohnehin auf Englisch kommunizieren und nicht in einer der Nationalsprachen (vgl. Windisch 1998, 17).

Dem Englischen kommt nicht nur im Rahmen der Schulbildung, sondern auch außerhalb der Schulen eine wichtige Rolle zu. Beispielsweise seien Englischkenntnisse für viele Bundesbeamte in den letzten Jahren unabdingbar geworden (vgl. Hauck 2000, 199). Des Weiteren trage die angelsächsische Musik maßgeblich zur Verbreitung des Englischen und zur Erhöhung seines Prestiges bei (vgl. Knecht/Py 1997, 1868). Vom hohen Etablierungsgrad des Deutschen an westschweizerischen Schulen kann jedoch nicht auf eine positive Einstellung der Romands zu dieser Sprache geschlossen werden, wie die folgende Untersuchung zeigt.

Schülern eines Gymnasiums in Neuchâtel wurde ein Fragebogen zur Bewertung von sechs europäischen Sprachen vorgelegt, nämlich Englisch, Französisch, Spanisch, Schwyzerdütsch, Italienisch und Deutsch. Mittels des semantischen Differentials sollten die Sprachen jeweils im Hinblick auf die drei Aspekte „Ästhetik“, „Nützlichkeit““ und „Erlernbarkeit/Verständlichkeit“ bewertet werden. Englisch schneidet in allen drei Bereichen am besten ab. Es gilt im ästhetischen Bereich als musikalisch, schön und warm, wird im Bereich der Nützlichkeit als überaus wichtig und praktisch angesehen. Es wird als eine relativ unkomplizierte Sprache eingeschätzt und gilt somit als leicht erlernbar. Im Vergleich dazu wird das Standarddeutsche zwar hoch angesehen im Bereich der Nützlichkeit, gilt aber als überaus schwer erlernbar. Italienisch und Spanisch werden in ästhetischer Hinsicht positiv bewertet und gelten als leicht erlernbar. Das Schweizerdeutsche schneidet in allen drei Bereichen schlecht ab (vgl. Apothéloz/Bysaeth 1981, bes. 73-81) ${ }^{80}$.

Das umfassendste Zeugnis über die Bedeutung des Englischen in der Schweiz (v.a. als Fremdsprache im schulischen Bereich) liefert der Forschungsbericht von

\footnotetext{
${ }^{80} \mathrm{Zu}$ gleichen Ergebnissen gelangt auch Kolde (1981, 365): Die von ihm befragten Romands reagieren gegenüber dem Schriftdeutsch neutral. Das (gesprochene) Schweizerdeutsche hingegen beurteilt fast die Hälfte als hässlich.
} 
Murray/Wegmüller/Khan (2001). Die Autoren beginnen den Bericht, indem sie die drei wesentlichen Befürchtungen nennen, die in aktuellen schweizerischen Publikationen hinsichtlich der wachsenden Verbreitung des Englischen auftauchen:

Das Englische könnte auf Kosten der Nationalsprache zunehmend die erste (schulische) Fremdsprache werden.

Das Englische könnte zur Verkehrssprache unter den verschiedenen Sprachgemeinschaften der Schweiz werden und somit eine Mehrsprachigkeit der Schweizer gänzlich unnötig machen.

Der steigende Rückgriff auf englische Ausdrücke in den Medien und in der Werbung könnte das Französische oder Deutsche verdrängen (vgl. Murray/Wegmüller/Khan 2001, 3, 9).

Eine Befragung von 33.826 Rekruten der schweizerischen Armee im Jahre 1985 ergab, dass Englisch von mehr als der Hälfte der befragten Romands und Deutschschweizer als erste schulische Fremdsprache gelernt wurde (vgl. ebd., 15). Dies verwundert insofern, als das schweizerische Schulsystem eigentlich den Erwerb einer anderen Nationalsprache, nicht aber des Englischen, als erste Fremdsprache vorsieht.

Im September 2000 hat eine Befragung zum Englischen als Unterrichts- und Verkehrssprache sowie als Sprache für Pressekonferenzen signifikante Unterschiede zwischen Deutschschweizern und Romands ergeben. Bei der ersten Frage ging es darum, die Einführung des Englischunterrichts in der Primarstufe nach dem Modell Zürichs zu bewerten ${ }^{81}$. Mit der Züricher Entscheidung, Englisch in der Primarstufe einzuführen, erklären sich $45 \%$ der befragten Romands und $73 \%$ der befragten Deutschschweizer einverstanden. Entsprechend bewertet die Hälfte der befragten Romands diese Entscheidung negativ, während nur 24\% der befragten Deutschschweizer diese ablehnen (vgl. ebd., 16). Bei der zweiten Frage ging es um die Wahl der ersten Fremdsprache. 45\% der befragten Romands plädierten für Englisch als erste Fremdsprache, 48\% für Deutsch. 65\% der Deutschschweizer stimmten für das Englische und nur 29\% für das Französische (vgl. ebd.). Die Romands zeigen somit, wie es aufgrund ihrer zahlenmäßigen Unterlegenheit kaum anders zu erwarten war, ein ausgeprägtes Bewusstsein für die Wichtigkeit des Erlernens der anderen großen Nationalsprache, während die Deutschschweizer das Englische als erste Fremdsprache bevorzugen. Frage 3, bei der es um die Verkehrssprache zwischen Schweizern ging, ergab ein recht einheitliches Bild bei Deutschschweizern und Romands: Die Mitglieder beider Sprachgruppen plädierten mit 27\% bzw. 28\% für das Englische als Verkehrssprache (vgl. ebd., 16f.). Bezüglich der Sprachwahl in Pressekonferenzen, Frage Nr. 4, plädierten wiederum mehr Deutschschweizer als Romands für die Verwendung des Englischen (vgl. ebd., 17). Insgesamt zeigen die Ergebnisse der Studie, dass die Romands dem

\footnotetext{
81 Am 04. Februar 1998 wurde das „Schulprojekt 21“ von den Erziehungsdirektoren des Kantons Zürich verabschiedet. Nach diesem Projekt sollen die Schulkinder u. a. ab der ersten Primarklasse in die englische Sprache sowie in den Umgang mit dem Computer eingeführt werden (vgl. Bildungsdirektion des Kantons Zürich 2003, o.S.). Damit bricht das Gesetz die Tradition, der zufolge immer eine der Landessprachen als erste Fremdsprache gelernt wird (vgl. Hauck 2000, 196).
} 
Erlernen der anderen großen Nationalsprache wesentlich positiver gegenüber stehen als die Deutschschweizer. Dies drückt sich darin aus, dass die Romands bezüglich der ersten zu erlernenden Fremdsprache dem Deutschen den Vorzug vor dem Englischen geben. Die Situation in der deutschsprachigen Schweiz hingegen ist umgekehrt: Das Englische wird dem Französischen vorgezogen.

Ein weiterer interessanter Punkt, den der Bericht von Murray/Wegmüller/Khan (2001) hervorhebt, ist die Selbsteinschätzung der Schweizer bezüglich ihrer Fremdsprachenbeherrschung. Hierbei rangiert Englisch bei den befragten Romands und Deutschschweizern an erster Stelle, bei den italophonen Schweizern, für die Englisch normalerweise die dritte Fremdsprache darstellt, an dritter (und somit letzter) Stelle. 35\% der Romands geben an, Englisch gut bzw. perfekt zu sprechen, und 31\% behaupten das Gleiche in Bezug auf ihre Deutschkenntnisse. Von den befragten Deutschschweizern geben 46\% an, Englisch gut bzw. perfekt zu sprechen, etwas weniger (41\%) schätzen ihre französischen Sprachkenntnisse auf diesem Niveau ein (vgl. ebd., 21). Es ist auffällig, dass sowohl Romands als auch Deutschschweizer ihre Englischkenntnisse besser einstufen als die Kenntnisse in der jeweils anderen Nationalsprache.

In der Berufswelt wird Englisch von weniger als 20\% der Beschäftigten benutzt und hat somit nicht die Bedeutung, die ihm häufig für den beruflichen Sektor zugesprochen wird (vgl. ebd., 13, 28).

Wie bereits festgestellt wurde, folgen die Romands sprachlich und kulturell dem Vorbild Frankreichs, was nach Rubattel $(1985,87)$ auch die Übernahme der in Frankreich vorherrschenden Einstellung zu Anglizismen einschließt:

„Structurellement, le français de Suisse romande est très proche de la norme française. De plus, les normes culturelles françaises sont aussi bien enracinées que la langue française elle-même. S’il y a une crise de la langue, il est fort possible qu'elle soit perçue en grande partie à travers des représentations originaires de France. Par exemple, la Suisse romande a repris les protestations contre le franglais - bien que les différences institutionnelles empêchent évidemment l'adoption des directives ministérielles françaises frappant l'abus des anglicismes" (ebd.).

Im Unterschied zu Frankreich oder Belgien gab es in der Westschweiz bis zur Gründung der Délégation à la langue française im Jahre 1992 (vgl. 2.3.4.2.3 und 3.3.2) jedoch keine Institutionen, die sich der Anglizismenfrage widmeten.

\subsubsection{Zusammenfassung von 2.3.4}

Insgesamt lassen sich viele Parallelen zwischen den Einstellungen frankophoner Belgier und frankophoner Schweizer ziehen. Die Bewohner beider Sprachregionen orientieren sich sprachlich und kulturell an Frankreich. In beiden Ländern wird die eigene Sprechweise als der Varietät des ,großen Nachbarn“ unterlegen betrachtet. Für die Romands hat weiterhin das Französische Frankreichs das größte Prestige. Im expliziten Vergleich zu Frankreich äußert sich bei Romands 
das Gefühl sprachlicher Unterlegenheit und somit sprachlicher Unsicherheit. Ein Ausdruck dieser Unsicherheit ist beispielsweise die Kritik an der Behördensprache, dem sog. français fédéral. Trotz des Gefühls sprachlicher Unsicherheit hat sich auch in der Schweiz in den letzten Jahren und Jahrzehnten ein Bewusstsein für sprachliche Besonderheiten entwickelt, dem u.a. Rechnung getragen wird mit der Veröffentlichung von deskriptiven Wörterbüchern zum regionalen Französisch wie dem 1997 publizierten Dictionnaire suisse romand. Particularités lexicales du français contemporain (DSR). Die Schweizer stehen Regionalismen analog zu den Belgiern sehr positiv gegenüber.

Eine weitere Parallele zu Belgien ist die Tatsache, dass die Romands sprachlich in der Minderheit sind. Während die frankophonen Belgier zahlenmäßig von den niederländischsprachigen Belgiern dominiert werden, stellen in der Schweiz die Deutschschweizer den größten Bevölkerungsanteil. Die Position der französischen Sprache kann in der Schweiz durch das Territorialitätsprinzip sowie die kantonale Eigenständigkeit in Verwaltungsfragen (wie z.B. Sprachregelungen) als gesichert gelten.

In den schweizerischen Schulen hat Englisch als Fremdsprache mehr Zuspruch als Deutsch. Englisch läuft den anderen Nationalsprachen als erste Fremdsprache allmählich den Rang ab, obwohl das schweizerische Gesamtsprachenkonzept das Erlernen einer weiteren Nationalsprache vor dem Englischen propagiert. Englisch erfreut sich größerer Beliebtheit als die anderen Nationalsprachen, nicht zuletzt dient es häufig als Verkehrssprache zwischen Deutschschweizern und Romands.

Studien, die die Einstellungen der Romands zu Anglizismen ermitteln, stellen bislang ein Desiderat dar. Cichon (1998) hat herausgefunden, dass die Westschweizer in den aus dem deutschsprachigen Teil der Schweiz stammenden Germanismen eine größere Gefahr sehen als in den durch Werbung, Medien oder auf anderen Wegen in die Sprache gelangenden Anglizismen. Weitere Anhaltspunkte gibt die Untersuchung von De Pietro/Matthey (1993/1995). Hierbei erhielten die Anglizismen weekend und walkman auf einer Skala von 1-7, wobei 1 den negativen und 7 den positiven Pol repräsentiert, jeweils überdurchschnittlich hohe Akzeptanzwerte: für informelle Situationen 6,5 bzw. 6,2, für formelle Situationen 5,3 bzw. 4,2. Bezüglich der Einstellungsforschung zu Anglizismen ist erst ein Anfang gemacht worden, und es besteht in diesem Bereich noch dringender Forschungsbedarf.

\subsection{Zusammenfassung des 2. Kapitels}

In diesem Kapitel ging es darum, das Konstrukt der (Sprach-)Einstellungen vorzustellen und zu zeigen, mit welchen empirischen Methoden sich Spracheinstellungen ermitteln lassen. Einstellungen lassen sich als latente Verhaltensdispositionen von Individuen beschreiben, die nicht direkt beobachtbar sind und sich nur in speziellen Äußerungsformen (z.B. Handlungen und Meinungen) messen lassen. Die mentalistische Einstellungsforschung, die in der Wissenschaft dominiert, geht 
von einem Drei-Komponenten-Modell mit einer kognitiven, affektiven und konativen Einstellungsdimension aus.

Die Linguistik bedient sich zur Erforschung von Spracheinstellungen im Wesentlichen der Methoden, die in anderen Disziplinen wie der Sozialpsychologie oder den Sozialwissenschaften entwickelt wurden. Die zur Verfügung stehenden Methoden lassen sich zwei verschiedenen Bereichen zuordnen: 1) Selbsteinschätzung, 2) physiologische Messungen und Verhaltensbeobachtung. In der linguistischen Forschung wird vorwiegend mit den der Selbsteinschätzung zugeordneten Methoden gearbeitet. Hierzu zählen die schriftliche und mündliche Befragung, d.h. Fragebögen bzw. Interviews.

Seit den 1960er Jahren ist eine neue Ära der französischen Sprachpflege angebrochen, die nicht mehr nur auf Frankreich ausgerichtet ist, sondern mit der versucht wird, sich über die Ländergrenzen hinweg für die Verbreitung und Erhaltung der französischen Sprache und Kultur einzusetzen. Diese Bemühungen werden unter den Terminus Frankophonie subsumiert. Jedoch impliziert die alle französischsprachigen Länder oder Sprechergruppen verbindende Frankophonie weder eine einheitliche Sprachpolitik noch identische Einstellungen zum Französischen. Einen bislang wenig erforschten Bereich stellen 1. Einstellungsstudien in den Ländern der peripheren Frankophonie und 2. vergleichende Studien dar, in denen die Einstellung von Sprechern verschiedener frankophoner Länder zum gleichen Untersuchungsobjekt ermittelt werden. Ziel dieser Arbeit ist es, einen Beitrag zum zweiten der beiden genannten Bereiche zu leisten.

Studien zur Erforschung der französischen Spracheinstellungen bzw. des französischen Sprachbewusstseins, insbesondere die Arbeiten von Gueunier/Genouvrier/ Khomsi (1978), von Paltridge/Giles (1984) und von Fischer (1988), zeigen deutlich, dass Einstellungen auch innerhalb eines Landes regionalen Differenzen unterliegen. So werden unterschiedliche französische Dialekte in vielerlei Hinsicht schlechter bewertet werden als das sog. Pariser Französisch (vgl. Paltridge/Giles 1984). Paris und Tours gelten als Gebiete größerer sprachlicher Sicherheit als beispielsweise Lille, Limoges und Saint-Denis-de-la-Réunion.

Wie 2.3.3.2 und 2.3.4.2 zeigen, hat der Anspruch Frankreichs auf eine unantastbare Norm, den bon usage, auch erheblichen Einfluss auf das Sprachbewusstsein und die Einstellungen frankophoner Belgier und Schweizer. Dies äußert sich u.a. in der sprachlichen Unsicherheit (insécurité linguistique) und in dem häufig von frankophonen Belgiern und Schweizern zum Ausdruck gebrachten Gefühl, ihre eigene Sprachkompetenz sei der der Franzosen unterlegen.

Hinsichtlich der Einstellungen gegenüber Anglizismen fehlen für Belgien und die Schweiz mit wenigen Ausnahmen entsprechende Studien und es gibt nur Vermutungen. Das Englische dient in Belgien und der Schweiz oftmals als lingua franca im Kontakt zwischen Angehörigen unterschiedlicher Sprachgemeinschaften, was darauf schließen lassen könnte, dass Anglizismen in Belgien und der Schweiz auf weniger Ablehnung stoßen als in Frankreich. 


\section{Sprachpolitische Maßnahmen zur Eindämmung angloamerikanischen Wortgutes in Frankreich, Belgien und der Schweiz}

Dieses Kapitel besteht aus drei Teilen. Teil 3.1 behandelt den Forschungsgegenstand Sprachpolitik aus theoretischer Perspektive und umreißt die Konzepte und die Forschungsgeschichte von Sprachpolitik, Sprachpflege und Sprachplanung. Die Terminologieplanung ist eine spezifische Form der Sprachplanung. In welche einzelnen Schritte sie üblicherweise unterteilt wird und welche Rolle der Linguistik jeweils zukommt, beschreibt 3.1.3. 3.2 gibt einen Überblick über die moderne französische Sprachpolitik nach 1945, aus der die in den 1970er Jahren einsetzende staatliche Terminologiearbeit nicht mehr wegzudenken ist. 3.3 lenkt den Fokus auf die Sprachpolitik und die Terminologiearbeit in Belgien und der Schweiz. Außerdem werden länderübergreifend arbeitende Organisationen vorgestellt, die im Wesentlichen der Terminologiearbeit verpflichtet sind. Abschließend wird die in Frankreich, Belgien, der Schweiz und Québec gültige Internet-Terminologie verglichen.

\subsection{Sprachpolitik als Forschungsgebiet der Linguistik}

\subsubsection{Terminologische Unterscheidungen: Sprachpolitik, Sprach- planung und Sprachpflege}

Seit Einar Haugen (1968 [1959], 673) in einem Artikel zur sprachlichen Situation in Norwegen den Ausdruck language planning geprägt und damit der linguistischen Diskussion um Sprachplanung den Anstoß gegeben hat, erfreut sich dieses Thema in der Linguistik großer Beliebtheit. In den folgenden Jahren brachte die linguisti- 
sche Diskussion neben Sprachplanung eine Flut von Termini wie Sprachpolitike1, Sprachlenkung, Sprachpflege, Sprachkultur ${ }^{2}$ hervor, welche bis heute nicht eindeutig definiert worden sind. Labrie/Nelde $(1994,119)$ führen das terminologische Durcheinander zu einem Teil darauf zurück, dass Forscher verschiedener Disziplinen wie der Politikwissenschaften, der Sprachsoziologie, der Soziolinguistik, der Didaktik oder der Rechtswissenschaften sich dem Feld der Sprachplanung widmen - jede Disziplin mit ihren je eigenen Definitionen dieser Termini.

In der Linguistik ist erstens umstritten, wie die Termini Sprachpolitik, Sprachplanung, Sprachlenkung, Sprachpflege und andere definitorisch voneinander abzugrenzen sind, und zweitens, in welchem Verhältnis sie zueinander stehen. Ein Hauptproblem ist zweifelsohne die Mehrdeutigkeit der Termini (vgl. Greule/Ahlvers-Liebel 1986, 2). Verschiedene Autoren geben Definitionen für Sprachpolitik und Sprachplanung, diese Definitionen stimmen jedoch nicht immer überein. Wie die folgenden Ausführungen zeigen, ist das auch darauf zurückzuführen, dass die Grenzen zwischen den Termini fließend sind.

Wie unterschiedlich, z.T. auch durch Ländergrenzen beeinflusst, beispielsweise Sprachpolitik und Sprachplanung definiert werden, zeigen die folgenden Ausführungen. Gröschel $(1982,13)$ subsumiert unter Sprachplanung die Gesamtheit der Maßnahmen zur bewussten und zielgerichteten Steuerung sprachlicher Entwicklung. Demgegenüber entspricht Gröschels Definition von Sprachplanung bei Calvet (1999, 154f.) der Sprachpolitik, während dieser unter Sprachplanung vielmehr die Umsetzung der sprachpolitischen Entscheidungen fasst:

\begin{abstract}
„Nous considérerons la politique linguistique comme l'ensemble des choix conscients effectués dans le domaine des rapports entre langue et vie sociale, et plus particulièrement entre langue et vie nationale, et la planification linguistique comme la recherche et la mise en œuvre des moyens nécessaires à l'application d'une politique linguistique. [...]

Si la notion de planification linguistique implique donc celle de politique linguistique, la réciproque n'est pas vraie et l'on pourrait faire une longue liste des choix politiques en matière de langues qui n’ont jamais été appliqués." 3
\end{abstract}

\footnotetext{
${ }^{1}$ Neben Sprachpolitik gibt es auch noch den Terminus Sprachenpolitik. Es herrscht jedoch keine Einigkeit darüber, ob es sinnvoll ist, zwischen Sprach- und Sprachenpolitik, zu unterscheiden. Sprachpolitile bezeichnet üblicherweise die Politik im Rahmen einer Sprache bzw. Sprachgemeinschaft, während Sprachenpolitik das Verhältnis verschiedener Sprachen zueinander regelt (vgl. z.B. Bochmann 1993, 13).

2 Dieser Terminus wird im Folgenden nicht mehr aufgegriffen. Der Ausdruck Sprachkultur wurde von der Prager Schule geprägt. Inhaltlich ähneln sich Sprachkultur und Sprachpflege inzwischen sehr, allerdings verfügt die Sprachkultur über eine fundiertere Konzeption und eine entsprechende Methode. Sprachkultur kann zugleich als Ziel und Ergebnis erfolgreicher Sprachpflege aufgefasst werden, nämlich als Kultiviertheit des Sprachgebrauchs (vgl. Juhász 1984, 87; 1985, 33f.).

${ }^{3}$ Labrie $(1996,829)$ weist darauf hin, dass Sprachpolitik nicht nur das menschliche Eingreifen in die Sprache bezeichne, sondern auch die Disziplin, die sich für Sprachpolitik interessiere. In diesem Kontext darf auch der von Maas (1980) entwickelte Terminus Politische Spracbwissenschaft nicht uner-
} 
Ähnlich wie Calvet positionieren sich auch Baylon (1996), Corbeil (o.J.b) und Éloy (1994). Baylon $(1996,175)$ und Corbeil (o.J.b, 1) verstehen Sprachplanung als die konkrete (juristische) Umsetzung sprachpolitischer Erwägungen auf der Ebene der Institutionen (staatlich, regional, international), wofür ein gewisses $\mathrm{Ma} \beta$ an soziolinguistischen Kenntnissen vorauszusetzen sei. Éloy $(1994,103)$ betrachtet Sprachpolitik als übergeordneten, eher abstrakten Terminus, während Sprachplanung einen Unterbegriff darstelle, der auch konkrete sprachpolitische Handlungen impliziere:

„La politique linguistique, c'est cet ensemble complexe de réalités de tous ordres, de gestion de ces réalités, et d'action, en général trop complexe pour se résumer à un plan d'action; elle peut être implicite, voire obscure, et nécessite une approche large, sur le plan empirique et sur le plan théorique.

La planification linguistique est un sous-ensemble explicite, 'ciblé', de l'autre. C'est une action, censée consciente, et à ce titre elle demande aux linguistes des outils, des théories ad hoc, une démarche de science appliquée (ce qui n'est pas moins complexe, mais bien spécifique)."

Auch Arntz $(1998,17)$ sieht Sprachpolitik als den für die Sprachplanung notwendigen Rahmen an, weist zugleich aber darauf hin, dass sich die beiden Termini in der Praxis nicht immer eindeutig voneinander abgrenzen lassen:

„Aufgabe der Sprachplanung ist es, die von der Sprachpolitik vorgegebenen Richtlinien praktisch umzusetzen; dazu gehören insbesondere die Kodifizierung der Sprache und die Förderung ihrer gesellschaftlichen Verbreitung. Da allerdings die Politik vielfach auch den Sprachplanungsprozeß in mehr oder weniger starkem Maße beeinflußt, lassen sich Sprachpolitik und Sprachplanung nicht immer exakt trennen."

Neben dem von Calvet (1999) und Éloy (1994) verwendeten Terminus planification linguistique ist in französischsprachigen Texten oft auch von aménagement linguistique oder normalisation linguistique die Rede. Die drei Termini verbindet die Tatsache, dass sie sich - als Äquivalente des englischen language planning - auf den Vorgang des offiziellen Eingreifens in die Sprache beziehen. Sie werden in der Praxis oft synonym gebraucht, sind jedoch sehr unterschiedlich konnotiert. Der Terminus planification linguistique konnotiert in erster Linie einen sehr stark staatlich gelenkten Eingriff („dirigisme“), während das Konzept des aménagement linguistique vielmehr

wähnt bleiben (vgl. dazu Januschek 1986, 132f.; Maas 1989, bes. 16-65). Das Konzept der Politischen Sprachwissenschaft geht von den beiden Annahmen aus, dass erstens sprachliche Verhältnisse als politische Verhältnisse untersucht werden und zweitens diese Disziplin sich selbst als Moment der Entwicklung sprachlicher Verhältnisse begreift. Insofern müsse Politische Sprachwissenschaft sowohl von der Sprachwissenschaft als allgemeiner Disziplin als auch von den Termini Sprachpolitik und Sprachplanung abgegrenzt werden (vgl. Januschek 1986, 132). 
einen sozialen Konsens in Bezug auf das durchzuführende Projekt impliziert. Der dritte Terminus, die normalisation linguistique, suggeriert die Existenz einer nicht mehr den Erfordernissen angemessenen Situation, die wieder an die aktuellen Verhältnisse angepasst werden müsse (vgl. Daoust/Maurais 1987, 12).

Welcher dieser drei Termini verwendet wird, hängt nicht nur vom Kontext und der Intention des jeweiligen Autors ab, sondern oftmals auch von der Forschungstradition des jeweiligen Landes. In den Arbeiten der Québecer Schule hat sich die Bezeichnung aménagement linguistique durchgesetzt, die katalanischen Soziolinguisten haben jedoch die Bezeichnung normalisation linguistique populär gemacht. Wieder andere Linguisten, die in der Tradition Fishmans stehen, wählen eine vierte Bezeichnung, nämlich die von Fishman favorisierte codification. Seit 1986 taucht ein weiterer Terminus in der französischsprachigen Linguistik auf, der sich allmählich größerer Popularität erfreut: glottopolitique ${ }^{4}$ (vgl. Baylon 1996, 176f.; Kremnitz 1994, 34f.; Loubier o.J.a, 1f.).

Was genau umfasst der Terminus Sprachplanung? Eine brauchbare Definition gibt Jahr (1992, 12f.):

\begin{abstract}
„[O]rganized activity (private or official) which attempts to solve language problems within a given society, usually at the national level. Through LP [language planning], attempts are made to direct, change, or preserve the linguistic norm or the social status (and communicative function) of a given written or spoken language variety of a language. LP is usually conducted according to a declared program or a defined set of criteria, and with a deliberate goal - by officially appointed committees or bodies, by private organizations, or by prescriptive linguists working on behalf of official authorities. Its object is to establish norms (primarily written) which are validated by high social status; oral norms connected with these written standards follow."
\end{abstract}

Jahr nennt sowohl die Gründe für sprachplanerische Eingriffe („, to solve language problems") als auch das Ziel dieser Eingriffe (,to direct, change, or preserve the linguistic norm or the social status (and communicative function) of a given written or spoken language variety of a language“, „to establish norms"). Weiterhin weist Jahr darauf hin, dass Sprachplanung normalerweise von offizieller Seite, durch private Sprachpflegeinstitutionen oder auch durch präskriptive Linguisten betrieben werde. Es handelt sich nach Jahrs Verständnis bei Sprachplanung somit um eine praktische Tätigkeit, deren vorderstes Ziel in der Beseitigung von Sprach- und Kommunikationsproblemen liege ${ }^{5}$.

\footnotetext{
4 Dieser Terminus wurde von Guespin und Marcellesi (1986, 5) in die sprachwissenschaftliche Diskussion eingebracht und bezeichnet „les diverses approches qu'une société a de l'action sur le langage, qu'elle en soit ou non consciente $[\ldots]^{“ .}$.

5 Wiley (1996, 109) weist zu Recht darauf hin, dass die Bezeichnung Sprachprobleme keineswegs eindeutig sei. Vielmehr gelte es, genau festzulegen, wer darüber urteile, wann es sich um Sprachprobleme handele, inwiefern sprachliche Phänomene problematisch seien und für wen.
} 
Sprachplanung lässt sich häufig am einfachsten von ihren Initiatoren ausgehend beschreiben. Aus dieser Perspektive lässt sich die Sprachplanung am besten durch die Beantwortung der Frage klären: Wer plant welche sprachlichen Varianten unter welchen Bedingungen, mit welcher Autorität für wen und warum? Wird der Blick hingegen auf die von der Sprachplanung betroffenen Sprecher gelenkt, empfiehlt sich die folgende Fragestellung: Wer akzeptiert welche Planungsprodukte unter welchen Bedingungen von wem und für welchen Zweck? (vgl. Haarmann 1990b, 123; 1990c, 43). Wesentlich schwieriger als die Beantwortung dieser Fragen ist allerdings die Erklärung, warum manche Maßnahmen zur Sprachplanung glücken und andere nicht. Haarmann (1990c, 42f.) betont in diesem Kontext die Wichtigkeit der Sprechereinbindung und plädiert für eine stärkere Berücksichtigung der vom Sprecher vorgenommenen Wertungen. In diesem Zusammenhang spiele das Prestige eine zentrale Rolle (vgl. Kap. 2, Fußnote 2).

Ein im Vergleich zur Sprachplanung relativ alter Terminus ist die in der deutschsprachigen Literatur häufig genannte Sprachpflege. Wenngleich dieser Terminus nicht zuletzt durch seine zentrale Rolle in Mosers Dudenpreisrede von 1964 (vgl. Moser 1967, 23) in der germanistischen Linguistik Anerkennung gefunden hat, findet er sich kaum in anderen Sprachen wieder. In den romanischen Sprachen gibt es kein eindeutiges Pendant zur deutschen Sprachpflege. In der englischsprachigen Linguistik wird das Konzept der Sprachpflege durch language cultivation und language elaboration ausgedrückt.

Sprachpflege bezeichnet die Summe aller Aktivitäten zur Standarderhaltung, die v.a. durch die Verbesserung der Sprachkompetenz erzielt werden soll (vgl. Greule/Ahlvers-Liebel 1986, 54-72; Gröschel 1982, 19f.). Ergänzend dazu lässt sich auch die Definition von Schmitt (1998, 220) anführen: „Sprachpflege stellt [...] ein bewußtes, zielorientiertes Eingreifen in Sprechen und Sprache dar, sie dient der gelenkten Herausbildung, Entwicklung und Bewahrung der Gemeinsprache $[\ldots . .$. .“

Übereinstimmend wird Sprachpflege heute als ein Teilbereich der Sprachplanung angesehen.

Ein letzter Terminus, der in diesem Rahmen kurz angesprochen werden soll, ist die Sprachlenkung. Nach Diekmann (1980, 508) und Greule (1982, 278f.) fungiert Sprachlenkung als Oberbegriff für Sprachpolitik, Sprachplanung, Sprachpflege und Sprachnormierung. Unter Sprachlenkung werden alle Tätigkeiten gefasst, mit denen gezielt auf Sprache(n) oder Sprachverwendung Einfluss genommen wird mit dem Ziel, sie zu verändern bzw. Änderungen zu verhindern oder zu verzögern.

\subsubsection{Kloss' Unterscheidung zwischen Status- und Korpusplanung}

Sprachplanung stellt heute ein Teilgebiet der angewandten Sprachwissenschaft dar. In der Zeit des amerikanischen Strukturalismus wird Sprachplanung rigoros

Auf den Unterschied zwischen expliziter (de jure) und impliziter (de facto) Sprachplanung soll in dieser Arbeit nicht näher eingegangen werden. Eine Erklärung dieser Konzepte findet sich z.B. bei Kremnitz $(2001,493)$. 
abgelehnt, was am deutlichsten in Halls programmatischer Schrift Leave your language alone (1950) zum Ausdruck kommt ${ }^{6}$. Zudem ist zum damaligen Zeitpunkt die Frage der Planbarkeit von Sprachen überhaupt noch nicht geklärt. Entsprechenden Fragestellungen wendet man sich erst in den 1960er Jahren zu. Infolgedessen betiteln Rubin/Jernudd einen Sammelband mit der Frage Can language be planned? (1970), obwohl diese Frage spätestens seit den ersten Veröffentlichungen Haugens als beantwortet gelten kann - mit ,ja“7 . Ein weiterer wichtiger Schritt in der Ausdifferenzierung des Terminus Sprachplanung stellen die Arbeiten von Heinz Kloss dar. Auf Kloss geht u.a. die wichtige Unterscheidung zwischen Status- und Korpusplanung zurück (vgl. Kloss 1969) ${ }^{8}$. Der Grundgedanke dieser beiden Formen von Sprachplanung impliziert drei Tatsachen: 1. Sprache verändert sich, 2. Beziehungen zwischen Sprachen verändern sich bzw. können sich verändern, 3. der Mensch kann in die beiden ersten Punkte eingreifen und sowohl Sprache als auch die Beziehungen zwischen Sprachen verändern (vgl. Calvet 1999, 159; Coulmas 1985, 259-265).

Kloss schlägt den Terminus corpus planning (franz. planification du corpus, dt. Korpusplanung) für diejenigen Fälle vor, in denen eine Organisation, eine Einzelperson oder eine Gruppe von Personen eine Veränderung auf der Ebene der Sprachform herbeiführen will. Bei der Korpusplanung werden in erster Linie Lexikon, Grammatik oder Orthografie einer Sprache standardisiert, erweitert oder in anderer Form beeinflusst (vgl. Kloss 1969, 81). Der Terminus status planning (franz. planification du statut, dt. Statusplanung), bezieht sich auf Interventionen, die den sozialen Status der Sprache oder Varietät betreffen, d.h. ihren Status in Bezug auf andere Sprachen oder auf eine nationale Regierung (vgl. ebd.) ${ }^{9}$.

\footnotetext{
${ }^{6}$ Schmitt (1990a, 354) geht im LRL-Artikel zu Sprache und Gesetzgebung davon aus, dass heute immer noch diejenigen Linguisten überwiegen, die sich gegen jede Form von Sprachplanung aussprechen. In seinem im HSK-Band zur Kontaktlinguistik veröffentlichten Artikel zu Sprachpflege und Sprachreinigung macht Schmitt (1996, 877) seinen Standpunkt deutlich und zeigt auf, unter welchen Umständen Sprachplanung auch aus sprachwissenschaftlicher Perspektive zugestimmt werden kann: „Aus sprachwissenschaftlicher Warte wird man [...] einer gemäßigten Planung, Pflege und Reinigung deshalb zustimmen, weil man in der menschlichen Sprache nicht nur ein Kommunikationssystem, sondern auch eine soziale Einrichtung erkennt, deren Ziel es ist, über alle geographischen und gesellschaftlichen Barrieren hinweg Verständigung oder Gedankenaustausch zu ermöglichen, was nur bei weitgehend deckungsgleichem Kode möglich ist." Jedoch stellt er bezüglich der französischen Sprachpolitik bis einschließlich 1990 fest, dass kommunikationstheoretische Überlegungen im Bereich der Sprachplanung nur eine sehr periphere Rolle spielen (vgl. Schmitt 1990a, 371).

7 Mit der Frage nach der Planbarkeit der französischen Sprache befassen sich Schoeni, Bronckart und Perrenoud in ihrem Sammelband La langue française est-elle gouvernable? Normes et activités langagières (1988). Allerdings ist auch heute noch recht wenig über die gesetzliche Reglementierbarkeit von Sprachen und sprachlichem Verhalten bekannt (vgl. Kremnitz 2001, 500).

8 Anstelle von Korpus- und Statusplanung werden häufig auch die Termini Sprach- und Sprachenplanung verwendet (vgl. Fußnote 1).

${ }_{9}$ In jüngerer Zeit wurde das zweidimensionale Modell von Kloss ergänzt durch die Konzepte des acquisition planning (vgl. Cooper 1989) und des prestige planning (vgl. Haarmann 1990b). Acquisition planning meint alle Maßnahmen, die das Erlernen einer bestimmten Sprache fördern und somit die Anzahl an Sprechern einer bestimmten Sprache oder Varietät erhöhen sollen, während prestige planning diejenigen sprachplanerischen Aktivitäten umfasst, die eine positive Einstellung gegenüber einem bestimmten Korpus, Status und/oder dem Erlernen einer Sprache fördern (vgl. Deumert 2001, 645).
} 
Innerhalb Frankreichs spielen die staatliche Sprachpflegeinstitution Délégation générale à la langue française et aux langues de France (DGLFLF) und die private Académie française eine tragende Rolle sowohl bei der Statusplanung (Verhältnis des (Standard-)Französischen zu anderen, auf französischem Territorium oder außerhalb Frankreichs gesprochenen Sprachen oder Mundarten) als auch bei der Korpusplanung, insbesondere bei der im Rahmen dieser Arbeit zu evaluierenden Terminologieplanung.

Jedes Land regelt Statusfragen individuell. Oftmals greift die Politik erst nach massivem Einsatz der betroffenen Bevölkerung ein. Ein Beispiel für das späte Eingreifen der Politik in einen seit langem herrschenden Sprachkonflikt ist die Situation der flämischsprachigen Bevölkerung in Belgien. Erst 1898 wurde ein Gesetz erlassen, mit dem auch das Niederländische als offizielle Sprache anerkannt und dem Französischen gleichgestellt war (vgl. 2.3.3.1). Im Gegensatz zu Belgien als dreisprachigem Staat und der Schweiz als viersprachigem Staat ist Frankreichs Sprachpolitik eng an die Idee der Einsprachigkeit geknüpft ${ }^{10}$. Obwohl das Französische als offizielle Staatssprache erst seit 1992 in der Konstitution verankert ist, war und ist es seit Jahrhunderten erklärtes Ziel der französischen Sprachpolitik, das Französische vor dem Einfluss oder gar der Verdrängung durch andere Sprachen zu schützen und seinen Status in der Welt zu sichern ${ }^{11}$. Ein aktuelles Beispiel für die Statussicherung ist die staatliche Kontrolle darüber, dass das Französische in internationalen Organisationen wie der UNO oder UNESCO, aber auch bei den Olympischen Spielen in - aus französischer Perspektive - angemessenem Maße vertreten ist. Die jahrhundertelange Tradition, Mundarten und anderen Sprachen auf französischem Territorium den Kampf anzusagen, fällt ebenfalls unter Statusplanung. In diesem Sinne werden die Patois seit der Französischen Revolution bekämpft, obwohl diese die französische Sprache weder in ihrem Status noch in ihrer Form ernsthaft bedrohen. Eine weniger offensive Politik gegen Mundarten oder Minderheitensprachen beginnt erst mit der Verabschiedung der Loi Deixonne (1951) ${ }^{12}$. Dieses dennoch als sehr restriktiv geltende Gesetz wird 1992 von der Charte européenne des langues régionales ou minoritaires abgelöst ${ }^{13}$. Der

${ }^{10}$ In jedem mehrsprachigen Staat bedarf es jedoch, wie in 2.3.3.1 und 2.3.4.1 gezeigt wurde, besonderer Gesetze, die für eine friedliche Koexistenz der verschiedenen Sprachen sorgen. Diese Gesetze zur Regelung des Sprachfriedens fallen ebenfalls unter Statusplanung. Es ist nicht selten, dass sprachliche Regelungen in den Verfassungen der Staten festgeschrieben sind. Gauthier/Leclerc/Maurais (1993, XIII-XV) stellen fest, dass 130 der von ihnen insgesamt untersuchten 172 souveränen Staaten über konstitutionell festgelegte Regelungen zur Sprache verfügen. Diese Klauseln betreffen vor allem den Bereich der Erziehung/Bildung, die öffentliche Verwaltung, weiterhin die Rechte der sprachlichen Minderheiten (vgl. ebd., XV).

${ }^{11}$ Kleineidam (1990) spricht im Zusammenhang mit der französischen Sprachpolitik, die eng mit der Frankophonie verknüpft ist, von einer „Sprachverbreitungspolitik“.

12 Zur Stellung von Minderheitensprachen in Frankreich sowie zum Verhältnis zwischen französischem Staatsbewusstsein und dem Bewusstsein der Sprecher von Minderheitensprachen vgl. z.B. Kremnitz (1993, 430-432, 436-445).

13 Die Charte européenne des langues régionales ou minoritaires wird am 05 . November 1992 zur Unterzeichnung freigegeben, konnte aber erst in Kraft treten, nachdem sie von mindestens fünf Ländern ratifiziert wurde. Diese Voraussetzung wurde 1997 erreicht, so dass die Charte offiziell seit dem 01. März 1998 in Kraft ist. Frankreich unterzeichnete die Charte am 07. Mai 1999, die Ratifizierung steht noch aus. Die Schweiz ist eines von 16 Ländern, in denen die Charte offizielle Gültigkeit erlangt hat. Die 
Wandel zugunsten der Mundarten und Minderheitensprachen setzt sich in der November 2001 vollzogenen Umbenennung der Délégation générale à la langue française (DGLF) in Délégation générale à la langue française et aux langues de France (DGLFLF) fort. Seitdem hat es sich die DGLFLF zur Aufgabe gemacht, nicht nur das Französische auf nationalem und internationalem Territorium zu fördern und zu verbreiten, sondern auch die Mehrsprachigkeit als ein Garant kultureller Vielfalt zu unterstützen. Es ist ferner die Aufgabe der DGLFLF, die auf französischem Territorium beheimateten Regionalsprachen zu schützen und sich für eine für diese begünstigende Kulturpolitik einzusetzen (vgl. DGLFLF o.J.a, o.S.; Leclerc 2001, o.S.).

In dieser Arbeit geht es jedoch nicht um die Status-, sondern um die Korpusplanung. Dazu ist zunächst einmal die Beantwortung der Frage wichtig, wann und in welcher Form Sprachpolitik oder auch Sprachpflege eingreifen.

In jeder lebenden Sprache gibt es die Tendenz zur Variation und zum Sprachwandel (Dynamik). Genau hier setzen diejenigen sprachpflegerischen Bemühungen an, die zum Ziel haben, die Sprache in einer gegebenen Form zu erhalten und somit dem Sprachwandel entgegenzuwirken (Stasis) (vgl. Labrie 1996, 826). Sprachwandel kann zum Beispiel eine Folge von Sprachkontakt sein. Der Sprachkontakt verschiedener Einzelsprachen mit der englischen Sprache führt u.a. zur Aufnahme von Angloamerikanismen. Diesem Sprachkontaktphänomen versuchen einige Staaten mit Sprachgesetzen entgegenzuwirken, neben Frankreich und Belgien geschieht dies seit neuestem auch in Polen ${ }^{14}$. In Spanien und Italien gibt es jedoch keine derartigen Gesetze (vgl. 12.5) ${ }^{15}$. Die Sprachplaner versuchen im Falle Frankreichs, Belgiens oder auch Polens den Gebrauch von Anglizismen in denjenigen Bereichen, auf die der Staat Zugriffsmöglichkeiten hat, gesetzlich einzuschränken bzw. zu verbieten. In Frankreich und seit kurzem auch in Belgien werden französische Termini erarbeitet, welche anstelle der Anglizismen zu benutzen sind. Es handelt sich bei diesen Aktivitäten um Korpusplanung, genauer um Terminologieplanung ${ }^{16}$.

Hinter der aktuellen französischen Sprachpolitik steckt aber noch viel mehr als nur eine Form der Korpusplanung. Wenn vielerseits behauptet wird, das offizielle Argument für die sprachpolitischen Regelungen, der Verbraucherschutz, sei nur vorgeschoben und in Wahrheit ginge es um den Schutz und die Verbreitung des

Schweiz unterzeichnete die Charte am 08. Oktober 1993, ratifizierte sie am 23. Dezember 1997, so dass sie dort am 01. April 1998 in Kraft trat. Belgien hat bislang noch nicht unterzeichnet (vgl. Conseil de l'Europe 2000, o.S.).

14 In Polen ist seit dem 09. Mai 2000 das neue Gesetz zur Pflege und Verwendung der polnischen Sprache in Kraft. Das Gesetz bezieht sich auf Waren und Dienstleistungen (auch aus dem Ausland). Verstöße werden mit Geldbußen geahndet. Drei Paragraphen sind besonders wichtig: Gemäß Art. 7.1 sind alle Dokumente, die Rechtsgeschäfte in Polen betreffen (Rechnungen, Gebrauchsanweisungen etc.), in polnischer Sprache zu verfassen, Art. 8.1 schreibt die polnische Sprache für Verträge mit polnischen Vertragspartnern vor, und Art. 15.1 und 2 legen die Höhe des Strafmaßes auf bis zu 100.000 polnische Zloty (ca. 24.500 Euro) fest (vgl. UDT 1999, o.S.; Wistinghausen 1999, o.S.).

15 Zur Sprachpflege in Spanien vgl. ausführlich Lebsanft (1997).

16 Calvet (1989, 34) unterscheidet weiter in zwei Arten von Terminologieplanung: 1. „in vivo“, d.h. spontane Neologismenbildung durch Sprachbenutzer, 2. „in vitro“, d.h. Terminologie als Folge sprachplanerischer Maßnahmen, gewissermaßen Terminologieplanung am Schreibtisch. 
Französischen (vgl. z.B. Braselmann 1999a, 19-23), ist dies nicht zuletzt auf den engen Zusammenhang zwischen Status- und Korpusplanung zurückzuführen. Es handelt sich bei den Sprachgesetzen von 1975 und 1994 sowohl um Korpus- als auch um Statusplanung, denn die Gesetze setzen das Ringen um die verlorene Führungsposition des Französischen nun mit staatlichen Mitteln fort (vgl. Éloy 1997, 14f.). Wird angloamerikanischem Wortgut innerhalb der französischen Sprache der Kampf angesagt, wird damit insgesamt eine Ablehnung der englischen Sprache, aber auch der damit verbundenen US-amerikanischen Kultur ausgedrückt; der Kampf gegen die Angloamerikanismen symbolisiert in Wirklichkeit den Kampf gegen den amerikanischen Einfluss und gegen die USA im Allgemeinen (vgl. Trescases 1982, 126; zum Phänomen des französischen Antiamerikanismus vgl. Beinke 1990, 7-13, 28-44; Trescases 1982, 67-10817).

\subsubsection{Vier Phasen der Sprachplanung}

Der Sprachplanungsprozess lässt sich nach einem von Haugen bereits 1966 entworfenen Modell in vier chronologisch geordnete Phasen unterteilen: ,selection“, „codification“, „implementation“ und „elaboration“18 (vgl. Haugen 1983, 270; 1987). Dieses Modell wird im Laufe der Jahre modifiziert und differenziert (vgl. z.B. Depecker 2001a, 595-605; Labrie/Nelde 1994, 119) ${ }^{19}$. Um zu ermitteln, welcher Anteil der Linguistik in den einzelnen Phasen der Sprachplanung zukommt, erweist es sich als günstig, das von Haugen vorgeschlagene Viererschema in leicht modifizierter Form beizubehalten und von den folgenden vier Phasen auszugehen:

\footnotetext{
17 Trescases $(1982,70)$ spricht in diesem Zusammenhang von „événements catalyseurs“, die den französischen Antiamerikanismus begünstigt hätten. Beinke greift diesen Gedanken auf und weist darauf hin, dass es in der französischen Sprachpolitik - zumindestens nach dem 2. Weltkrieg offensichtliche Zusammenhänge zwischen politischen Schlüsselereignissen und staatlichen Interventionen gebe (vgl. Beinke 1995, 88). Staatliche Interventionen als Folge politischer Ereignisse äußern sich z.B. in Form von neugegründeten Sprachpflegeinstitutionen, aber auch in Form von Sprachgesetzen. Beinke (ebd.) nennt als Hintergrund des Sprachgesetzes von 1975 den EG-Beitritt Großbritanniens und als Schlüsselereignis im Fall der Loi Toubon die schwierigen europäisch-amerikanischen GATT-Verhandlungen. Dies bestätigt einmal mehr die oben formulierte These, dass es bei der französischen Sprachpolitik in erster Linie um die Behauptung und Verteidigung des Französischen gegen den angloamerikanischen Einfluss gehe, obgleich die sprachpolitischen Maßnahmen von offizieller Seite anders begründet werden.

18 Die vierte Etappe, elaboration, wird bei Haugen als Äquivalent zu Kloss' Terminus Ausbau verstanden. Die Sprache wird kontinuierlich modernisiert und somit den veränderten Anforderungen und Realitäten angepasst. Eine wichtige Rolle spielt in diesem Zusammenhang die Aktualisierung der Terminologien (vgl. Haugen 1987, 629-633).

${ }^{19}$ Labrie/Nelde $(1994,119)$ unterteilen den Prozess der Sprachplanung in die folgenden vier Einzelschritte: „l'analyse de la situation“, „la décision“, „l'application et l'arbitrage“, „l'observation et l'évaluation". Auger $(1994,53)$ entwirft für die Terminologieplanung ein sechsstufiges Schema mit den Phasen 1. „Recherche“, 2. „Normalisation“, 3. „Diffusion“, 4. „Implantation“, 5. „Évaluation et contrôle" und 6. „Mise à jour", von denen er Phase 4 für die wichtigste hält. Ein noch differenzierteres Schema legt Depecker (2001a, 595-605) vor, der den Terminologieplanungsprozess in acht Stufen unterteilt: 1. „définition des besoins“" 2. „étude socioterminologique“, 3. „traitement terminologique“, 4. „,choix du statut des termes“, 5. „publication et diffusion“, 6. „communication“, 7. „implantation“" und 8. „évaluation et mise à jour". Unabhängig davon, ob der Terminologieplanungsprozess in vier, sechs oder acht Stufen unterteilt wird, sind die Inhalte dieser Modelle nahezu identisch.
} 
1. Analyse der Situation und Normenauswahl,

2. Entscheidung und Kodifizierung/Gesetzentwurf,

3. Implementierung und

4. Evaluierung.

Die ersten beiden Schritte beziehen sich auf die Auswahl und Fixierung der Norm. In der ersten Phase werden das zu lösende Problem bestimmt sowie Entscheidungen bezüglich der anzuwendenden Normen getroffen. Die erste Phase entspricht daher einer Bestandsaufnahme, bei der u.a. folgende Fragen zu stellen sind: Wie ist die aktuelle Situation, wo muss mit welchen Mitteln und auf welche Weise etwas geändert werden? Geht es um die Festlegung einer bestimmten Varietät als Standard, findet in dieser Phase die Auswahl dieser Varietät statt. Als Ergebnis dieses Prozesses entsteht in der Regel ein Projektbericht, der die weiteren Schritte bestimmt.

Bei der zweiten Phase gilt es, eine Entscheidung über das weitere Vorgehen zu treffen. In dieser Phase werden die genauen Inhalte bestimmt (z.B. neue Regeln für Grammatik, Orthografie und Lexik) sowie die Gesetzesentwürfe erarbeitet, über die in der anschließenden Etappe abzustimmen sein wird. Während die Inhalte des jeweiligen Eingriffes durch offizielle oder private Organisationen bzw. präskriptive Linguisten festgelegt werden, sind die eigentlichen Entscheidungsträger in dieser Phase in der Regel Politiker. In diesem Stadium müssen die involvierten Sprachplaner bzw. Politiker darauf achten, dass die geplanten Maßnahmen nicht mit den vorherrschenden Gesetzen in Konflikt geraten, wie dies bei den Parlamentsdebatten um die Loi Toubon der Fall war (vgl. 3.2.3.1). In der dritten Phase erfolgt dann die Umsetzung der sprachplanerischen Maßnahmen durch die exekutiven und administrativen Staatsorgane. In dieser Phase geht es auch um die Verbreitung der neuen Norm(en) in der betroffenen Gesellschaft. Dies geschieht insbesondere durch die Massenmedien und Bildungsstätten. Die Verbreitung der Norm(en) wird meistens in der vierten und letzten Phase fortgesetzt.

In der vierten und letzten Phase schließlich, einer Art Effektivitätskontrolle, beobachten v.a. die Sprachplaner selbst, wie die Maßnahmen von der Bevölkerung bzw. vom betroffenen Personenkreis aufgenommen werden. Es handelt sich bei der Analyse sprachplanerischer Maßnahmen stets um einen interdisziplinären Forschungsgegenstand, der sich aus unterschiedlichen Perspektiven beleuchten lässt. Entsprechend kann der Erfolg der Maßnahmen von Forschern verschiedener Fachrichtungen mit Hilfe gezielter Untersuchungen evaluiert werden.

Im Rahmen einer linguistischen Arbeit stellt sich an dieser Stelle die Frage nach der Rolle der Linguisten in den vier dargestellten Phasen der Sprachplanung. In welchen Etappen der Sprachplanung - Identifikation des Problems, Konzeption und Umsetzung der Normierung, Evaluation der Ergebnisse - und in welcher Form kann die Linguistik einbezogen werden?

Auch wenn in der sprachpolitischen Praxis letztendlich der politische Wille über die durchzuführenden Maßnahmen entscheidet, hat die Linguistik ihre Aufgaben im komplexen Sprachplanungsprozess. Der Beitrag, den die Linguistik leisten kann, kann gerade dann für die Konzeption zukünftiger bzw. bei der Auswertung 
durchgeführter Aktivitäten von Vorteil sein, wenn Sprache in einem weiteren, nämlich dem sozio-kulturellen Kontext betrachtet wird und somit auch Faktoren in die Überlegungen einfließen, die nicht der Sprache inhärent sind. Da Linguisten und insbesondere Soziolinguisten am präzisesten über Sprachverhalten im jeweiligen soziokulturellen Kontext informiert sind, sollten sie auf jeden Fall beratende Funktion übernehmen (vgl. Baylon 1996, 183, 197f.; Christian 1988, 208). Beratende Funktion impliziert, dass sich die in den Sprachplanungsprozess einbezogenen Linguisten jeder Form von Direktionismus enthalten. Beratende Funktion schließt z.B. das Vorschreiben von Lösungen aus. Die Aufgabe der Linguisten ist es vielmehr, sich auf die Beobachtung des Sprachwandels und auf die Analyse der verschiedenen außer- und innersprachlichen Faktoren zu stützen, die diesen Wandel beeinflussen (vgl. Chansou 1981, 286).

Bereits im ersten Stadium der Sprachplanung, bei der Eruierung des Problems und einem ersten Nachdenken über entsprechende Maßnahmen, kann die Linguistik den Sprachplanern die in der Bevölkerung herrschenden Spracheinstellungen nahebringen. Es ist nicht unerheblich für den Erfolg oder Misserfolg politischer Regelungen, die vorherrschenden Spracheinstellungen zu kennen. Die Entscheidungen, die bezüglich einer Sprache oder Varietät zu treffen sind, müssen jedoch von den eigenen, d.h. subjektiven Einstellungen zu den von der bzw. den zukünftigen Regelungen betroffenen Sprache(n), Varietät(en) oder Sprechern getrennt werden. Linguisten können den Politikern helfen, den Blick eines Außenstehenden anzunehmen, um so objektiv entscheiden zu können (vgl. Baylon 1996, 181; Giles/Ryan 1982, 223).

Außerdem kann die Linguistik auf die Gefahr des Missbrauchs politischer Macht hinweisen: Wird beispielsweise unter Missachtung sprachlicher Minderheiten nur im Interesse der Mehrheit gehandelt, kann dies zur Unterdrückung von bestimmter Sprechergruppen führen. Auch der umgekehrte Fall ist denkbar: Eine Regierung berücksichtigt bei der Planung von Sprachgesetzen nicht die Interessen möglichst aller Betroffenen, sondern nur die einer speziellen Gruppe (vgl. Smit 1996, 19). Sprachpolitik kann, wie die beiden Beispiele zeigen, zur Stärkung, aber auch zur Schwächung bestimmter Sprechergruppen und ihrer Sprachen eingesetzt werden (vgl. Kremnitz 1994, 100). Optimal wäre es, wenn die Linguistik in dieser Phase einen Dialog zwischen Sprachplanern und den beteiligten Bevölkerungsgruppen in Gang setzen könnte, innerhalb dessen die Probleme und Konflikte gemeinsam evaluiert und Handlungsperspektiven reflektiert werden, bevor weitreichende Entscheidungen gefällt werden.

Auch die zweite Phase der Sprachplanung kann von der im Wesentlichen beratenden linguistischen Tätigkeit profitieren. Bei der Konzeption und Umsetzung stehen jedoch vorwiegend politische, juristische und andere außersprachliche Aspekte im Vordergrund.

Der Anteil der Linguistik in der dritten Phase, der Realisierung der erarbeiteten Konzepte, ist nicht eindeutig zu bestimmen. Im Rahmen des Gesetzgebungsverfahrens, ein durch die Volksvertreter vollzogener legislativer Akt, bietet sich Linguisten in der Regel keine Handlungsmöglichkeit, sofern sie nicht selbst zu den 
Volksvertretern gehören. Die konkrete Ausgestaltung der sprachpolitischen Regelungen kann jedoch durchaus in den Aufgabenbereich der Linguistik fallen. Wie der Abschnitt 3.2 zeigen wird, sind bei der französischen Terminologieplanung neben den Repräsentanten der betroffenen Berufs- und Interessengruppen auch Linguisten vertreten. Linguisten sind sowohl an der Erarbeitung neuer Vorschläge (im Rahmen der einzelnen Fachkommissionen) als auch an der Erarbeitung allgemeiner akzeptanzfördernder Kriterien (im Rahmen der Commission générale de terminologie et de néologie) beteiligt (vgl. 3.2.3.2 und 5.1).

In der vierten Phase vergleicht der Sprachplaner die konkreten Ergebnisse mit den anfänglichen Zielen und beurteilt daraufhin, ob es nötig ist, die Strategien zu ändern. Die Linguistik ist in dieser Phase insbesondere dann gefragt, wenn es darum geht, Kriterien aufzustellen, mit denen die Wirksamkeit sprachpolitischer Maßnahmen gemessen werden kann (vgl. Baylon 1996, 182; Otman 1995, 318f.) ${ }^{20}$. Die staatlichen Bemühungen, die Lexik zu normieren, werden jedoch bislang wesentlich weniger systematisch ausgewertet als die Regulierung von Phonetik/Phonologie, Morphosyntax oder Orthografie (vgl. Humbley 1997, 156). Dies ist auch daran abzulesen, dass es sehr wenige linguistische Studien gibt, die sich mit der Etablierung der staatlich vorgeschriebenen Neologismen auseinandersetzen (vgl. Kap. 4). Angesichts der Tatsache, dass es mittlerweile 18 Fachkommissionen zur Erarbeitung geeigneter Terminologielisten gibt, sind die zehn in 4.3 vorgestellten Studien (Chansou 1993, Fugger 1979/1980/1983a/1983b/1987, Gaudin 1991, Gaudin/Guespin 1993, Gouadec 1993, Goudaillier 1977/1982, Guilford 1997, Le Guilly-Wallis 1991, Rouges-Martinez 1992, Thoiron/Iwaz/Zaouche 1993), die sich gezielt mit der Evaluierung ausgewählter Terminologievorschläge befassen, ausgesprochen wenig.

Weitere Studien zu verschiedenen Terminologielisten sind nötig, um detaillierter Auskunft zu erhalten, inwieweit Sprache und sprachliches Verhalten sich mit Hilfe gesetzlicher Regelungen steuern lassen:

20 Die Evaluierung der Wirksamkeit sprachpolitischer Maßnahmen wird Gegenstand des nächsten Kapitels sein. 
„Trotz zahlreicher Arbeiten zur Sprachplanung ist über die gesetzliche Reglementierbarkeit von Sprachen und sprachlichem Verhalten noch recht wenig bekannt. Es dürfte offensichtlich sein, daß es sich dabei weniger um eine linguistische, als vielmehr um eine psychologische und politische, vielfach auch im weiteren Sinne wirtschaftliche Frage handelt. Für die meisten Sprachgemeinschaften scheint eine aktive Sprachpolitik, welche auch die Gesetzgebung miteinbezieht, unumgänglich, wenn sie sich der monopolisierenden Sogwirkung des Anglo-Amerikanischen nicht schutzlos aussetzen wollen. Allerdings mußten Sprachpolitiker schon oft die aus anderen Bereichen hinreichend bekannte Erfahrung machen, daß die angestrebten und wirklich erreichten Ziele einer Politik weit auseinanderklaffen; sprachliches Verhalten wird von komplexen Variablen bestimmt, die nur in unzureichendem Maße kalkulierbar sind“ (Kremnitz 2001, 500).

Kremnitz weist zu Recht darauf hin, dass das sprachliche Verhalten von vielen Variablen beeinflusst wird. Dies können neben Einflüssen, die von der Sprache selbst ausgehen (vgl. 5.1), auch außersprachliche Faktoren sein. Der Einfluss der außersprachlichen Faktoren, die den Entscheidungsprozess des Individuums für oder gegen ein bestimmtes Wort determinieren, ist (noch) nicht berechenbar. Auch aufgrund bisheriger Studienergebnisse können kaum verbindliche Prognosen für den Erfolg späterer sprachplanerischer Aktivitäten gegeben werden (vgl. Humbley 1997, 155; 4.3.3). Mit jeder zur Etablierung der Neologismen durchgeführten Studie wird jedoch deutlicher, unter welchen Umständen es wahrscheinlich ist, dass sich ein bestimmtes Ersatzwort etabliert, und welche Umstände die Beibehaltung eines Anglizismus begünstigen (vgl. 5.1).

Die Durchführung weiterer empirischer Studien zur Evaluation der französischen Terminologieplanung ist auch deshalb nötig, weil zum einen seit Beginn der 1990er Jahre in allen Bereichen neue Terminologielisten erschienen und zum anderen alte Terminologielisten einer gründlichen Revision unterzogen worden sind (vgl. 3.2.3.2 und 3.2.4.2).

Im Überblick sprechen vier Gründe für weitere Forschung zur Evaluierung der Terminologieplanung:

- die Vielzahl an Terminologiekommissionen, die zum Teil noch niemals einer Evaluation unterzogen worden sind,

- die Vielschichtigkeit sprachlicher und außersprachlicher Faktoren, die das sprachliche Verhalten determinieren,

- die veränderte Situation nach Überarbeitung der alten Terminologielisten und

- das kontinuierliche Erarbeiten neuer Terminologielisten, in die die Erfahrungen bisheriger Terminologiearbeit einfließen.

Die sprachwissenschaftliche Auswertung sprachplanerischer Aktivitäten erfolgt in erster Linie durch Umfragen. Aber auch andere Typen linguistischer Studien sind bislang zur Auswertung herangezogen worden. Welche Arten von Umfragen es 
gibt und welche Ergebnisse diese geliefert haben, wird Gegenstand des 4. Kapitels sein.

Bis jetzt wurde die Frage beantwortet, welche Rolle der Linguistik in den einzelnen Phasen der Sprach- bzw. Terminologieplanung zukommt. Doch bleibt noch präziser zu fragen, welche Rolle der deutschsprachigen Romanistik in der französischen Terminologieplanung zukommt. Da es wenig wahrscheinlich ist, dass deutschsprachige Linguisten im Vorfeld sprachplanerischer Aktivitäten oder währenddessen zu Rate gezogen werden, bleibt ihre Tätigkeit vorwiegend auf die vierte Phase beschränkt, auf die Evaluierung der Terminologieplanung. Wie Kramer $(2002,17)$ anmerkt, kann es sogar von Vorteil sein, wenn deutschsprachige Romanisten im Bereich der französischen Linguistik forschen, da sie als Nicht-Muttersprachler in kritischer Distanz zum Forschungsgegenstand stehen: „Arbeitsteilung ist ja gerade heute, im Zeitalter der explodierenden Wissensmenge, angesagt; machen wir als deutschsprachige Romanisten das, wo die Außensicht förderlich sein kann, und überlassen wir den Muttersprachlern das, wo es eher der Innensicht bedarf." In die vierte Phase des Sprachplanungsprozesses lässt sich auch die vorliegende Arbeit einordnen.

Es müssen aber auch die Grenzen der Linguistik im Rahmen staatlicher Terminologieplanung deutlich gemacht werden. Die Linguistik ist nur eine Disziplin, die in den komplexen Prozess der Sprachplanung involviert ist. Meistens werden sprachpolitische Entscheidungen in erster Linie von politischen, sozio-kulturellen und/oder wirtschaftlichen Faktoren beeinflusst und/oder herbeigeführt. Der Linguistik kommt derzeit in den ersten zwei bis drei Phasen des Sprachplanungsprozesses eine eher marginale Rolle zu. Ihre Rolle beschränkt sich, wie festgestellt wurde, oftmals auf die beratende Tätigkeit. Auf die Linguistik wird erst in der dritten und vierten Phase verstärkt zurückgegriffen. Für die Terminologieplanung werden Linguisten bereits in der dritten Phase einbezogen. Sie sind in den entsprechenden Kommissionen vertreten und an der konkreten Umsetzung der Gesetzesvorschriften beteiligt, indem sie die offiziell gültigen Neologismen sowie deren Definition festlegen.

Ein weiteres Feld, für das sich die Linguistik erst langsam öffnet bzw. das der Linguistik z.B. durch entsprechende Auftragsstudien erst langsam geöffnet wird, ist die Phase der Evaluation ${ }^{21}$. Unter Zuhilfenahme sozialwissenschaftlicher Methoden kann sich die Linguistik an der Evaluierung der staatlichen Maßnahmen beteiligen und aus den Ergebnissen wiederum Rückschlüsse für spätere sprachplanerische Maßnahmen ziehen.

Mit Otman (1995, 318f.) lässt sich der Beitrag der Linguistik in den vier Phasen der Terminologieplanung wie folgt zusammenfassen:

${ }^{21} \mathrm{Zu}$ den von der DGLF vergebenen Auftragsstudien Anfang der 1990er Jahre vgl. 4.3.1. 
„Le processus de normalisation terminologique est un processus délicat qui procède par étapes. Il y a d'abord une étape strictement linguistique d'observation et de recueil des usages terminologiques dans un domaine de spécialité: c'est l'activité d'analyse et de synthèse du terminologue (ou mieux de l'équipe terminologique). A cette étape succèdent une étape de sélection et de décision de ce qui peut et doit être normalisé et une étape de règlementation et de diffusion. Ces deux phases échappent au terminologue de terrain. Idéalement, une quatrième étape, dite de suivi, devrait être systématiquement instaurée. Elle ne l'est que rarement dans les faits. Elle consisterait à suivre dans les usages l'implantation ou le rejet des termes normalisés, d'essayer de déterminer les causes des succès et des échecs de normalisation afin d'en tirer des enseignements propres à alimenter les premières étapes du processus. Cette quatrième étape serait bien entendu du ressort des terminologues. Elle permettrait d'évaluer la réelle qualité des termes proposés (et de leurs définitions), la normalisation ne pouvant garantir à elle seule cette qualité."

Wenn Christian (1988, 202-208) herausstellt, dass derzeit Sprachwissenschaftler de facto kaum eine Rolle bei der konkreten Sprachplanung spielen, ist dies - zumindest bezogen auf Frankreich - nur für die Statusplanung der Fall. Es dürfte nicht zuletzt auf die entscheidende Rolle der DGLFLF bei der Sprachplanung zurückzuführen sein, dass sich die französische Sprachpolitik in den letzten zehn Jahren der Linguistik geöffnet hat und in vielen Fällen auf deren Kapazitäten zurückgreift.

\subsubsection{Zusammenfassung von 3.1}

Sprachpolitik kann als der abstrakte Oberbegriff für alle Arten menschlichen Eingreifens in die Sprache betrachtet werden. Zur Bezeichnung der konkreten Umsetzung von Sprachpolitik bietet sich der Begriff Sprachplanung an (franz. aménagement linguistique, planification linguistique, normalisation linguistique). Sprachpflege wird als Teilbereich der Sprachplanung aufgefasst und richtet sich in erster Linie auf eine Verbesserung oder zumindest Beibehaltung einer bestimmten Sprachverwendung. Haugen hat das Thema Sprachplanung im Jahre 1959 in die linguistische Diskussion eingebracht, aus der es mittlerweile nicht mehr wegzudenken ist. Kloss verdanken wir die Unterscheidung in Status- und Korpusplanung.

Haugen versuchte in den 1960er Jahren als erster eine Systematisierung des Sprachplanungsprozesses. Ihm folgend wird in dieser Arbeit in Bezug auf die Terminologieplanung von den folgenden vier Etappen ausgegangen:

1. Analyse der Situation und Normenauswahl,

2. Entscheidung und Kodifizierung/Gesetzentwurf,

3. Implementierung und

4. Evaluierung. 
Diese Arbeit ist in die vierte Phase des Terminologieplanungsprozesses einzuordnen, die Evaluierung. Hierbei kann insbesondere die Außensicht förderlich sein, während in den anderen Phasen der Terminologieplanung eher frankophone Linguisten involviert sind.

Die Linguistik kann innerhalb dieses komplexen vierstufigen Prozesses mindestens drei Aufgaben erfüllen:

1. Beratung im Vorfeld politischer Entscheidungen,

2. Unterstützung bei der Umsetzung sprachpolitischer Maßnahmen und

3. Bewertung des Erfolges der staatlichen Sprachplanung (vgl. Kap. 4).

Derzeit ist die Rolle der Linguisten bei der Terminologieplanung vor allem auf die Phase der Implementierung, d.h. die Unterstützung sprachpolitischer Maßnahmen sowie auf die Phase der Evaluation beschränkt. Die Bedeutung der Linguistik im gesamten Sprachplanungsprozess könnte noch verstärkt werden.

Das folgende Unterkapitel gibt einen Überblick über die moderne französische Sprachpolitik und die Terminologiearbeit seit 1970. Der Schwerpunkt liegt auf dem Sprachgesetz von 1994, dem Dekret vom 03. Juli 1996, das als wegweisend für die weitere Arbeit der Terminologiekommissionen gilt. Etwas detaillierter wird auf die verschiedenen (ministeriellen) Kommissionen zum Wortschatz der Informatik eingegangen, die sich seit 1997 auch der Französisierung der InternetTerminologie annehmen.

\subsection{Sprachpolitik und Terminologiearbeit in Frankreich}

Der Stellenwert, den die Franzosen ihrer Sprache auch heute noch beimessen, lässt sich nur aus der kulturellen und (sprach-)geschichtlichen Entwicklung Frankreichs erklären. Sprachpflege blickt in Frankreich auf eine lange Tradition zurück. Auf eine ausführliche Darstellung der französischen Sprachpolitik von den üblicherweise auf 1539 (Edikt von Villers-Cotterêts) datierten Anfängen bis heute wird in dieser Arbeit verzichtet. Der Schwerpunkt dieses Abschnittes liegt auf der französischen Sprachpolitik nach 1970. In der Konsequenz werden die ersten beiden großen Sprachgesetze von 1539 (Französisch als Sprache der Gerichtsbarkeit) und 1794 (Französisch als einzige offizielle Amtssprache)22 im Rahmen dieser Arbeit nicht näher behandelt. Zur frühen und neueren französischen Sprachpolitik sind gerade im Bereich der deutschsprachigen romanischen Sprachwissenschaft sehr viele Publikationen erschienen, die einen guten Überblick über die sprachpolitischen Maßnahmen und ihre historischen Hintergründe geben und auf die hier verwiesen $\operatorname{sei}^{23}$.

\footnotetext{
22 In vielen Publikationen wird die Loi 118 du 2 Thermidor, l'an II de la République française, das zweite große Sprachgesetz, auf das Jahr 1793 datiert. Naguschewski (2002, 38) weist nach, dass 1794 die korrekte Datierung ist.

${ }^{23} \mathrm{Zu}$ nennen sind hier v.a. Beinke (1990), Braselmann (1999a), Christmann (1986), Gebhardt (1981), Klare (1999), Schmitt (1990a/1998), Settekorn (1988) und Winkelmann (1990). Eine sehr gute französischsprachige Überblicksdarstellung ist der Aufsatz von Szulmajster-Celnikier (1996, bes. 37-49).
} 
Nach einem kurzen Abriss der Entwicklung der französischen Sprachpflege von 1945-1970, einer Hochphase der gegen Anglizismen und Amerika gerichteten Polemiken, werden die aktuelle französische Sprachpolitik seit den 1970er Jahren und insbesondere die Maßnahmen zur Terminologieplanung erörtert.

\subsubsection{Historischer Überblick: die Bekämpfung des franglais bis 1970}

Die Reinheit ihrer Sprache liegt den meisten Franzosen sehr am Herzen. Diese Grundhaltung ist nicht allein als Reaktion auf den vermehrten Einfluss von Angloamerikanismen nach dem Zweiten Weltkrieg zu erklären, sondern hat ihre Wurzeln bereits im 17. Jahrhundert. Weniger durch den ersten staatlichen Eingriff in die Sprache als v.a. durch die Gründung der Académie française (1635) sowie durch das Wirken bestimmter Einzelpersonen wie Vaugelas oder Rivarol sind bestimmte Vorstellungen von einer idealen Sprachform entstanden und gewachsen. Topoi, die sich durch die gesamte Sprachpflege hindurchziehen, sind - um nur einige zu nennen - universalité, génie de la langue, clarté, pureté, élégance, bon goût, bon usage (vgl. z.B. Beinke 1990, 16-21). Auch das heutige Denken der meisten Franzosen ist, wie Fischer (1988; vgl. 2.3.2) anschaulich zeigt, noch immer von diesen jahrhundertealten Wertvorstellungen geprägt.

Die Diskrepanz zwischen den Vorstellungen von der Idealnorm des Französischen, für die die (Literatur-)Sprache des 17. Jahrhunderts den Referenzpunkt bildet, und dem tatsächlichen Zustand des heutigen Französisch hat Ende des 19. und zu Beginn des 20. Jahrhunderts zu einer Art Krisenempfinden geführt (vgl. Bally 1930; Görtz 1990, zur Fremdwortdiskussion bes. 147-164; Settekorn 1988, 109f.; Söll 1983, Trabant 2002, 134f.). Das Krisenempfinden setzt sich auch in den folgenden Jahrzehnten fort und erstreckt sich auf verschiedene Bereiche der Sprache. Als Symptome werden neben der Diskrepanz zwischen dem sog. bon usage und dem tatsächlichen, aktuellen Sprachgebrauch zunehmend schlechtere Grammatikkenntnisse und nicht zuletzt das Einströmen anglo-amerikanischer Lehnwörter genannt (vgl. z.B. Müller 1975, 29-33; Plümer 2000, 35f.) ${ }^{24}$. Das Krisenbewusstsein erreicht mit dem Erscheinen von Étiembles Parlez-vous franglais (1964, 21973, 31991) einen Höhepunkt ${ }^{25}$. Die Befürchtung, das Französische würde durch Angloamerikanismen überfremdet und letzten Endes werde Frankreich politisch, wirtschaftlich und kulturell den USA unterjocht, ist weit verbreitet und schlägt sich in der Politik de Gaulles (1958-1969) deutlich nieder ${ }^{26}$. Die

\footnotetext{
${ }^{24}$ Polemiken gegen Fremdwörter haben in Frankreich Tradition. Vor allem in den Jahren 1550-1580 wurde massiv gegen die Italianismen und die von ihnen ausgehende vermeintliche Bedrohung polemisiert. Vierhundert Jahre später haben Sprachkritiker - nicht nur in Frankreich - einen neuen Angriffspunkt gefunden: die sprachliche Bedrohung durch Angloamerikanismen.

$25 \mathrm{Zu}$ Étiembles Anglizismenkritik vgl. ausführlich Beinke (1990, 118-134). Heute wird vielfach anstelle von franglais von franricain gesprochen. Franricain bezieht sich auf das, was zu Zeiten Étiembles als franglais bekannt war, jedoch betont diese neue Bezeichnung als Wortkreuzung von français und américain noch stärker den Einfluss des amerikanischen Englisch.

${ }^{26}$ Étiembles Parlez-vous franglais? (1964) gilt als ein auslösendes Moment der Sprachpolitik der 1960er und 1970er Jahre. Auf gesetzlichem Weg wird versucht den Zustrom an Anglizismen einzudämmen. Sprachpuristen wie Étiemble, die einen massiven Einfluss der Anglizismen zu verzeichnen glauben und die französische Sprache daher in besonderem Maße davor schützen wollen, stehen viele
} 
Krisenstimmung veranlasst die französische Regierung in den 1960er Jahren, Maßnahmen zur Stärkung der Frankophonie und zur organisierten Fremdwortbekämpfung durchzuführen (s.u.).

Die Abwehr der Anglizismen ist aber keineswegs nur auf das 20. Jahrhundert beschränkt. Schon im 19. Jahrhundert werden Stimmen zum franglais und zur anglomanie laut, deren Ursachen ins 18. Jahrhundert zurückgehen und vorwiegend politischer und kultureller Natur sind ${ }^{27}$. Es ist offensichtlich, dass es bei der französischen Sprachpolitik nicht nur um die Ausmerzung einzelner Anglizismen geht, sondern vor allem um die Kompensation des mit der zunehmend unbedeutenderen Rolle des Französischen als Sprache der Diplomatie, der Politik, der Philosophie, internationaler Gesetze, der Wirtschaft, der Wissenschaften etc. einhergehenden Identitäts- und Prestigeverlusts. Hinzu kommt das besondere Sendungsbewusstsein der französischen Elite (vgl. Braselmann 1999a, 5, 16; Éloy 1994, 406; Kremnitz 2001, 499; Schmitt 1990c, 687-690; Settekorn 1988, 110).

Der Höhepunkt der staatlichen Bekämpfung des angloamerikanischen Einflusses liegt im 20. Jahrhundert. Den heftigen Diskussionen folgen nach dem 2. Weltkrieg vermehrt sprachpolitische Maßnahmen. Sowohl in Frankreich als auch in anderen frankophonen Staaten wie v.a. in Belgien und Frankokanada werden zahlreiche private, halbstaatliche und staatliche Sprachpflegeorganisationen gegründet, die sich in erster Linie die Verteidigung des Französischen vor dem Einfluss der USA und die Statussicherung der französischen Sprache in der Welt auf die Fahnen geschrieben haben ${ }^{28}$. Die Zahl der Sprachpflegeorganisationen ist nahezu unübersehbar; der 1984 vom Commissariat général de la langue française herausgegebene Répertoire des organisations et associations francophones nennt mehr als 1000 Organisationen zur Verbreitung und Verteidigung der französischen Sprache (vgl. Commissariat général de la langue française 1984). Unmittelbar nach 1945 erreichen Frankreich besonders viele Angloamerikanismen, ausgelöst durch den übergroßen Einfluss der USA, der insbesondere auf den Marshallplan zurückzuführen ist. Die Reaktion auf die Anglizismen erfolgt prompt: Anfang der 1950er Jahre werden mehrere Kommitees zum Schutz der französischen Sprache gegründet, z.B. das Comité consultatif du langage scientifique im Jahre 1952, der Cercle de Presse Richelieu

\footnotetext{
Linguisten und andere neutrale Beobachter der Situation gegenüber. Einen vermittelnden Standpunkt vertritt Hagège. Er gibt in seinem Buch Le français et les siècles einen sehr guten Überblick über die Anglizismendebatte aus der Sicht eines Linguisten. Ohne jeglichen Purismus skizziert er die Bemühungen um die Verteidigung der französischen Sprache vor Anglizismen und macht vor allem darauf aufmerksam, dass der Einfluss der Anglizismen realiter nicht so massiv sei, wie es zahlreiche Sprachpuristen suggerierten.

${ }^{27}$ Einen Überblick zum Einfluss des Englischen auf das Französische vom 12. bis zum 20. Jahrhundert gibt Plümer (2000, 21-27).

28 Beinke $(1995,79)$ zählt zu den Instanzen der Sprachpflege nicht nur die verschiedenen Institutionen, sondern auch den Staat als Gesetzgeber. Die vorliegende Arbeit konzentriert sich auf die Rolle des Staates bei der Sprach- bzw. präziser Terminologieplanung. Einige private Organisationen werden zwar genannt, aber es würde den Rahmen dieses Kapitels sprengen, detailliert auf die zahlreichen halboffiziellen und privaten Institutionen einzugehen, die sprachpflegerisch tätig sind.
} 
(1953), das Comité d'étude des termes techniques français ${ }^{29}$ (1954) sowie die Défense de la langue française (DLF, 1958) ${ }^{30}$.

Die genannten privaten Organisationen sowie der 1957 gegründete staatliche Office $d u$ vocabulaire français (OVF) sind die entscheidenden Akteure des französischen Kampfes gegen die Angloamerikanismen in den 1950er und 1960er Jahren, bis die verschiedenen, kaum miteinander koordinierten Bemühungen im Jahre 1966 durch die Gründung des Haut Comité pour la défense et l'expansion de la langue française in einer einzigen offiziellen Organisation zentral zusammengeführt werden ${ }^{31} .1968$ wird der Conseil international de la langue française (CILF) ${ }^{32}$, die angesehenste internationale Vereinigung zur Terminologiearbeit, ins Leben gerufen. Der Kampf gegen die Anglizismen ist zwar nicht das einzige Ziel der genannten Organisationen, hat aber einen hohen Stellenwert.

Die Phase nach 1945 ist in Frankreich aber nicht nur sprachlich, sondern vor allem politisch von einer antiamerikanischen Stimmung geprägt (vgl. Fußnote 17). Nach dem Rücktritt de Gaulles (1969) geht der Antiamerikanismus in der Bevölkerung sowie in den privaten Sprachpflegegesellschaften etwas zurück, um dann allerdings ab 1970 von der Epoche des sogenannten ,dirigisme linguistique“ abgelöst zu werden (vgl. Depecker 2001a, 19). Mit der Schaffung von Terminologiekommissionen im Jahre 1970 ist der Kampf gegen Angloamerikanisches in der Sprache zur Staatsaffäre und Aufgabe seiner Beamten geworden (vgl. z.B. Schmitt 1995;

\footnotetext{
${ }^{29}$ Zu Gründung, Mitgliedern, Aufgaben und Zielsetzung des Comité vgl. Frey (2000, 273-284). Frey (ebd., 275-282) hebt besonders hervor, dass es sich beim Comité d'étude des termes techniques français um eine Institution handele, die von Anfang an mit Linguisten zusammen gearbeitet habe, auch wenn sich diese Kooperation aufgrund des deskriptiven Anspruchs vieler Linguisten oftmals sehr schwierig gestaltet habe.

$30 \mathrm{Zu}$ Gründung, Mitgliedern und Aktivitäten der Défense de la langue française (DLF) vgl. Frey (2000, 296-299); zur Bewertung der konkreten sprachpflegerischen Maßnahmen der DLF vgl. Schmitt (1998, 221-237). Schmitt (ebd., 235) beurteilt die Sprachpflege der DLF als „puristisch, ideologisch ausgerichtet, teilweise sogar nationalistischen Prinzipien verpflichtet“" und als „,rückwärts orientiert", da sie sich auf frühere Sprachsysteme beziehe und sprachlicher Evolution feindlich gegenüber stehe. Seine Hauptaufgabe sieht der Verein in der Herausgabe der gleichnamigen Zeitschrift, welche vier Mal jährlich erscheint.

${ }^{31}$ Das Haut Comité pour la défense et l'expansion de la langue française wird 1980 in Haut Comité de la langue française umbenannt, 1983 dann aufgelöst. An seine Stelle treten die drei durch den Premierminister Mauroy neu gegründeten Sprachinstitutionen: der Commissariat général de la langue française, das Comité consultatif de la langue française und der Haut Conseil de la francophonie. Zu Gründung, Aufgaben, Zielsetzung und Vorsitzenden des Commissariat général de la langue française vgl. Frey (2000, 215-229). Zu Gründung, Aufgaben, Zielsetzung und Mitgliedern des Comité consultatif de la langue française vgl. Frey (2000, 241-246). Zu Gründung, Aufgaben, Zielsetzung und Mitgliedern des Haut Conseil de la francophonie vgl. Frey (2000, 257-264). 1989 wird der Commissariat général de la langue française durch die Délégation à la langue francaise (DGLF) abgelöst. Die Ziele dieser mehrfach umbenannten und neugegründeten Organisation bleiben über die Jahre hinweg identisch: die Pflege und Verbreitung der französischen Sprache (vgl. Frey 2000, 230).

$32 \mathrm{Zu}$ Gründung, Mitgliedern und Aktivitäten des Conseil international de la langue française (CILF) vgl. Frey (2000, 289-292). Der CILF beschreibt seine Aufgaben auf seinen Internetseiten (http://www.cilf.org/) wie folgt: „Le Conseil international de la langue française a pour tâche d'enrichir la langue française et de favoriser son rayonnement en gérant les ressources de la langue française et de la francophonie et en organisant la communication avec les autres langues." Ein Hauptbetätigungsfeld des CILF liegt in der Terminologiearbeit. Neben verschiedenen Fachwörterbüchern gibt der CILF die Zeitschriften La Banque des Mots und Le Français Moderne heraus.
} 
Trescases 1982, 101)33. Ab 1973 ist das Haut Comité de la langue française für die Terminologiearbeit zuständig, ab 1984 übernehmen der Commissariat général de la langue française $e^{34}$ und das Comité consultatif de la langue française diese Aufgabe, bis es schließlich 1989 zur Gründung der Délégation générale à la langue française (DGLF) ${ }^{35}$ und des Conseil Supérieur de la langue française $e^{36}$ kommt. Nach Frey $(2000,271)^{37}$ sind die Délégation générale à la langue française, der Conseil Supérieur de la langue française und der Haut Conseil de la francophonie die wichtigsten französischen Sprachinstitutionen in den 1990er Jahren.

\subsubsection{Von der Gründung der ersten Terminologiekommissionen bis zur Loi Toubon}

Die französische Terminologiearbeit, die hauptsächlich englische durch französische Termini ersetzt ${ }^{38}$, beginnt nicht erst im Jahre 1970 mit der Einrichtung staatlicher Terminologiekommissionen. Vielmehr ist der Beginn der französischen Terminologiearbeit auf die 1930er Jahre zu datieren. Die erste Kommission wird

33 Die Formel: „Le franglais est une affaire d'État“ stammt von keinem anderen als von Étiemble (vgl. Trescases 1982, 104).

Detailliertere Informationen zum politischen Hintergrund der institutionalisierten französischen Sprachpflege von 1966 bis 1984 und zur Loi Bas-Lauriol gibt Hausmann (1986b, 88-93).

34 Zur Zusammenarbeit zwischen dem Commissariat général de la langue française und den Terminologiekommissionen vgl. Bidard (1988).

$35 \mathrm{Zu}$ den Zielen und Aufgaben sowie zu den ersten Vorsitzenden der DGLF vgl. Frey (2000, 232240) und die Informationen auf den Internetseiten der DGLFLF (vgl. DGLFLF o.J.a, o.S.). Seit November 2001 ist ihr offizieller Name Délégation générale à la langue française et aux langues de France (DGLFLF). Der Délégué général ist zurzeit Bernard Cerquiglini, sein Stellvertreter Claude Jean. Die DGLFLF sieht als eine ihre Aufgaben die Überwachung, aber auch die Förderung der Einhaltung der Loi Toubon an. Dazu greift sie in diejenigen Bereiche ein, in denen die Grundsteine für die Zukunft des Französischen gelegt werden: die Neologie und die neuen Technologien. Konkret bedeutet das die Koordinierung der einzelnen Terminologiekommissionen, die Verbreitung ihrer Arbeiten sowie die Übernahme des Sekretariats der Commission générale de terminologie et de néologie. Außerdem nimmt die DGLFLF an Aktivitäten zur Verbreitung des Französischen im Internet teil. Ferner sieht die DGLFLF ihre Aufgaben in der Bewahrung der Rolle des Französischen als Nationalsprache, aber auch als Sprache der internationalen Kommunikation (nach dem Englischen) sowie in der Anerkennung, im Schutz und der Förderung von Regionalsprachen, der sprachlichen Vielfalt und der Mehrsprachigkeit (vgl. DGLFLF o.J.a, o.S.).

$36 \mathrm{Zu}$ Gründung, Mitgliedern, Aufgaben und Zielsetzung des Conseil Supérieur de la langue française vgl. Frey $(2000,247-253)$.

${ }^{37}$ Frey verfolgt in ihrer Arbeit eine ähnliche Zielrichtung wie Bengtsson (1968). Allerdings geht ihre Darstellung zur aktuellen französischen Sprachpolitik von den Bemühungen der Académie française aus, zu der sie alle anderen Sprachpflegeorganisationen in Beziehung setzt.

38 Das hat sich bis heute nicht geändert: Hauptziel der Terminologieerlasse ist immer noch die Ersetzung von Angloamerikanismen durch französische Neologismen. Lazare (2000, 26) schildert in ihrem Artikel, dass in den zwischen 1996 und 2000 veröffentlichten Terminologieerlassen (am 22. September 2000 im Répertoire terminologique publiziert, vgl. 3.2.4.2) nur ein einziger Terminus enthalten ist, der nicht aus dem angloamerikanischen Sprachraum stammt, nämlich das deutsche Hinterland, das durch franz. arrière-pays zu ersetzen ist. Hinzu kommt allerdings noch ein weiteres Wort, nämlich die deutsche Infobahn, welche durch franz. autoroutes de l'information zu ersetzen ist (Erlass vom 16. März 1999). Auffällig ist, dass an der Bildung der offiziellen französischen Neologismen häufig lateinische oder griechische Elemente beteiligt sind. Offenbar werden englische Wörter als fremd empfunden, nicht aber Wörter mit lateinischen oder griechischen Wurzeln. Klare $(1999,37)$ mutmaßt: ,[...] diese gelten offenbar als Elemente aus der unmittelbaren Nachbarschaft und engerer sprachlicher Verwandtschaft [...].“ 
1933 im Rahmen der Académie française gegründet und hat den Auftrag, die für die Entwicklung der französischen Sprache notwendigen Termini zu schaffen (vgl. Humbley 2000, 320). 1937 übernimmt dann der neu gegründete Office de la langue française $^{39}$ die Terminologiearbeit und schlägt verschiedene Ersetzungsmöglichkeiten für Anglizismen vor, z.B. die Ersetzung von engl. wagon durch franz. vagon und von engl. container durch franz. conteneur (vgl. Depecker 2001a, 16). Des Weiteren nimmt seit den 1960er Jahren auch die Académie française am Kampf gegen die vermeintliche Überfremdung teil, denn einige ihrer Communiqués de mises en garde sprechen sich gegen die Verwendung bestimmter Anglizismen aus (vgl. Langenbacher 1980, 89f.40 ${ }^{41}$. Im Rahmen dieser Arbeit steht jedoch die staatliche Terminologiearbeit ab 1970 im Vordergrund, deren Wirken - ebenso wie die Bemühungen der genannten Sprachpflegeorganisationen - darauf abzielt, die französische Sprache an die Bedürfnisse der Wissenschaft und Technik anzupassen, um auf diese Weise zu zeigen, dass es durchaus möglich ist, mit französischem Wortgut für jeden Fachbereich eine eigenständige Terminologie zu schaffen.

Doch wie kommt es überhaupt zur Gründung der ersten Terminologiekommissionen zu Beginn der 1970er Jahre? Den Anstoß gibt eine vom Premierminister Pierre Messmer am 14. Januar 1970 unterzeichnete Anweisung, in der die Ministerien aufgefordert werden, Kommissionen zu bilden, deren Hauptaufgabe die Ersetzung von Anglizismen durch französische Termini ist. In den Jahren 1970 bis 1972 werden auf diese Weise mehr als zehn Terminologiekommissionen (commissions ministérielles de terminologie, CMT) innerhalb der verschiedenen Ministerien gegründet. Im April 1970 entsteht durch eine Ministerialentscheidung die erste Kommission, die Terminologiekommission zum Transportwesen. Im Juli 1970 folgt ein Erlass zur Gründung einer Kommission für die Terminologie der Erdölindustrie. Im September 1970 wird die Informatik-Kommission ins Leben gerufen (vgl. 3.2.5); 1971 kommt es zur Gründung einer Kommission zum Wortschatz der Wirtschaft und Finanzen. Im Jahre 1971 existieren insgesamt zehn

\footnotetext{
${ }^{39}$ Der (französische) Office de la langue francaise muss während des 2. Weltkrieges seine Arbeit einstellen und wird 1957 wieder als Office du vocabulaire français (OVF) ins Leben gerufen.

${ }^{40}$ Langenbacher $(1980,89)$ ermittelt in den zwischen 1964 und 1978 erschienenen Communiqués de mises en garde eine Anzahl von 28 Anglizismen bzw. Angloamerikanismen (wie doping, goal, indoor), deren Gebrauch von der Akademie ausdrücklich abgelehnt wird. Auf die Bewertung der englischsprachigen Lexeme in vier der fünf von Langenbacher untersuchten Wörterbüchern wirken sich die Empfehlungen der Akademie fast überhaupt nicht aus. In mehr als zwei Dritteln der Fälle werden die betreffenden Lexeme lediglich als mot angl. bzw. anglicisme markiert, nicht aber in irgendeiner Weise stigmatisiert. Das bedeutet, dass die französische Lexikografie in den 1960er und 1970er Jahren von der Arbeit der Akademie kaum Notiz nimmt.

${ }^{41}$ Die Akademie hat die ersten der von ihr seit 1964 in unregelmäßigen Abständen herausgegebenen Communiqués de mises en garde in einer Broschüre zusammengestellt (vgl. Académie française 1967). Die Herausgabe weiterer Communiqués de mises en garde hat die Akademie in den 1980er Jahren eingestellt (vgl. Frey 2000, 59f.). Den Bemühungen der Akademie um die Reinhaltung der Sprache wird mit der Einstellung ihrer Communiqués jedoch kein Ende gesetzt. Wie wichtig der Akademie der Schutz der französischen Lexik vor angloamerikanischem Lehngut ist, zeigt die von ihr 1985 ins Leben gerufene Académie des enfants, die sich zum Ziel gesetzt hat, Kinder nicht nur für die Wahrnehmung von Fremdwörtern in der Sprache empfänglich zu machen, sondern sie sogar an der Schaffung geeigneter französischer Ersatzwörter zu beteiligen (vgl. Braselmann 1999a, 7).
} 
Terminologiekommissionen zu den folgenden Bereichen: Kommunikationstechnik, Gebäude/öffentliche Arbeiten/Städtebau, Verteidigung, Wirtschaft und Finanzen, Informatik, Atomtechnik, Erdölindustrie, Sport, Raumfahrt und Transportwesen. Die Existenz dieser sowie die Schaffung weiterer ministerieller Terminologiekommissionen wird in Artikel 1 des Dekrets Nr. 72-19 vom 07. Januar 1972 legitimiert. Ferner werden in Artikel 2 des Dekrets die Aufgaben der Terminologiekommissionen festgelegt: Sie sollen für einen festgelegten Bereich die Lücken im französischen Wortschatz ermitteln und die notwendigen Termini vorschlagen, um diese Lücken zu füllen bzw. die unerwünschten Fremdwörter zu ersetzen. Artikel 3 des Dekrets legt die Zusammensetzung der Kommissionen fest, Artikel 4 gibt Aufschluss über die Art, wie die Ergebnisse publiziert werden sollen, die vom Haut Comité pour la défense et l'expansion de la langue française koordiniert werden. Artikel 5 sieht vor, dass die Terminologielisten vor ihrer Veröffentlichung vom Minister der Éducation nationale gegengezeichnet werden. Erst mit der Verabschiedung dieses Dekrets erhalten die bisher existierenden Terminologiekommissionen einen offiziellen Status, und es kann somit von Ministerialkommissionen (commissions ministérielles de terminologie, CMT) gesprochen werden (vgl. Depecker 2001a, 342-344) ${ }^{42}$.

Die Aufgabe der in den zentralen staatlichen Behörden und vor allem in den verschiedenen Ministerien eingesetzten Kommissionen besteht darin, für die im jeweiligen Tätigkeitsbereich auftretenden neuen (zumeist angloamerikanischen) Termini geeignete französische Neologismen zu schaffen. Ab 1973 werden in unregelmäßigen Abständen Erlasse mit entsprechenden Terminologielisten veröffentlicht, die die Verwendung bestimmter französischer Lexeme zwingend vorschreiben. Den juristischen Rahmen für diese Maßnahmen schafft die 1975 verabschiedete Loi Bas-Lauriol (s.u.) ${ }^{43}$. Im Januar 1973 erscheinen im Journal officiel de la République française (JO) die ersten sechs Terminologieerlasse (Kommunikationstechnik, Gebäude/öffentliche Arbeiten/Städtebau, Atomtechnik, Erdölindustrie, Raumfahrt und Transportwesen), zwei weitere erscheinen im November des gleichen Jahres (Wirtschaft und Finanzen, Informatik) (vgl. Depecker 2001a, 24f. $\left.{ }^{44}\right)$.

\footnotetext{
42 Das Dekret zur Bereicherung der französischen Sprache von 1972 wird in den Jahren 1983 und 1986 durch zwei weitere Dekrete abgelöst, die es inhaltlich etwas modifizieren und präzisieren, grundsätzlich aber in die gleiche Richtung weisen: das Dekret Nr. 83-243 vom 25. März 1983 (publiziert im Journal officiel vom 29. März 1983) und das Dekret Nr. 86-439 vom 11. März 1986 (publiziert im Journal officiel vom 16. März 1986). Die Unterschiede zwischen den einzelnen Dekreten sind als eher gering zu bezeichnen. Das Dekret von 1983 legt den Akzent stärker auf die Verbreitung der erarbeiteten Termini, als es im Dekret von 1972 der Fall ist. Im Dekret von 1986 wird die Einrichtung einer zusätzlichen Kommission, die die Arbeiten der einzelnen CMT koordinieren soll, beschlossen (vgl. ausführlich Depecker 2001a, 345-349). Eine große Veränderung stellt sich erst 1996 ein, als das Dekret von 1986 durch das Dekret vom 03. Juli 1996 abgelöst wird (vgl. 3.2.3.2).

43 Die sprachterminologischen Arbeiten beziehen sich jedoch nicht nur auf Frankreich, sondern Frankreich hofft darauf, dass auch andere Länder der Frankophonie, wie beispielsweise die schwarzafrikanischen Staaten, das vorgeschlagene Vokabular übernehmen (vgl. Gahlen/Geisel 1999, 94).

44 Zum Überblick über die Aktivitäten der Terminologiekommissionen in den Jahren 1970-1993 vgl. Depecker (2001a, 24-26). Zur Geschichte und den Arbeiten der einzelnen CMT vgl. ebd., 33-339.
} 
Die Terminologielisten werden darüber hinaus in Büchern, Zeitungen und Zeitschriften veröffentlicht, damit auch Privatpersonen von ihnen Kenntnis nehmen und die offiziellen Termini verwenden. Ein Beispiel dafür ist der 1985 vom Commissariat général de la langue française herausgegebene Guide des mots nouveaux (Commissariat général de la langue française 1985).

Mehrfach wird versucht, die Arbeiten der verschiedenen Institutionen zur Terminologie zu koordinieren. Neben den Terminologiekommissionen befassen sich auch noch die Association française de normalisation (AFNOR, 1926 gegründet), das Comité d'étude des termes techniques français (1954 gegründet ${ }^{45}$, der Centre d'étude du français moderne et contemporain und andere mit Terminologiefragen. 1975 wird zusätzlich die Association de terminologie (AFTERM, Teil der Organisation AFNOR) gegründet, die die Aufgabe hat, die verschiedenen Arbeiten zusammenzuführen. 1980 wird AFTERM durch eine neue Organisation, FRANTERM ${ }^{46}$, ersetzt. FRANTERM macht sich zum Ziel, die Arbeiten der Terminologiekommissionen zu koordinieren sowie an der Erstellung einer terminologischen Datenbank mitzuarbeiten. Auf diese Organisation geht der erste Dictionnaire des néologismes officiels (Fantapié/Brúle 1984) zurück. Während insbesondere die frühen Terminologieerlasse der Jahre 1973/1974 ein sehr uneinheitliches Format haben (die Bereiche, auf die sich die Termini beziehen, fehlen mitunter; Definitionen und Anmerkungen überlappen einander u.Ä.), bringt FRANTERM durch die Publikation aller bisher veröffentlichten Terminologielisten in einem einheitlichen Format etwas Ordnung in die Terminologiearbeit und beschreitet damit den Weg zu einem einheitlichen Modell für ein terminologisches Datenblatt. Aus der Arbeit der CMT leitet die AFNOR 1986 eine Norm ab, die sie „Fiche minimale de terminologie“ nennt (vgl. Depecker 2001a, 380f.).

Ende der 1980er Jahre verschwindet auch FRANTERM. Die Terminologiekommissionen, andere an der Terminologiearbeit beteiligte Organisationen wie die Académie des sciences und die AFNOR 47 sowie zahlreiche branchen- bzw.

${ }^{45}$ Das Hauptziel der Vereinigung besteht in der Verteidigung der französischen Sprache vor eindringenden Fremdwörtern (v.a. den aus dem angloamerikanischen Sprachraum stammenden technischen Fachtermini, „emprunts de nécessitéc), indem durch die Suche nach geeigneten Äquivalenten die französische Lexik selbst an die neuen technischen Gegebenheiten angepasst wird. Chansou untersucht in seiner Dissertation die Rolle des Comité d'étude des termes techniques français in der zeitgenössischen französischen Sprachplanung, die dort vorherrschenden Einstellungen gegenüber Fremdwörtern sowie die den Terminologievorschlägen des Comité zugrunde liegenden sprachlichen Auswahlkriterien (vgl. Chansou 1981, 64-67). Chansou (ebd., 36) weist auch darauf hin, dass einige Mitglieder des Comité auch in einigen der seit 1970 bestehenden ministeriellen Terminologiekommissionen mitarbeiten.

${ }^{46}$ FRANTERM steht für die Association pour la promotion de la Terminologie scientifique et technique en français.

47 Wissenschaftliche Fundierung der Arbeiten wird des Weiteren durch die Kooperation mit universitären Forschungseinrichtungen wie dem Institut National de la Langue Française (INaLF) oder dem am 01. September 1987 als Nachfolgeorganisation von FRANTERM gegründeten Centre de terminologie et de néologie (CTN) erreicht. Der CTN hängt sowohl vom Centre National de la Recherche Scientifique (CNRS) als auch vom Institut National de la Langue Française (INaLF) ab. Seit Januar 1993 gehört der CTN zum Laboratoire de Linguistique Informatique (LLI) und befindet sich seit Oktober 1993 in den Räumen der Universität Paris 13. Seit der Gründung des Service de néologie et terminologie (SNT) im September 1998 kommt dem CTN keine große Bedeutung mehr zu. Dem SNT, der wiederum dem $I N a L F$ angegliedert ist, kommt vor allem die Aufgabe zu, die Arbeit der Commission générale und 
berufsgruppenspezifischen Organisationen wie die Association des informaticiens de langue francaise (AILF), die Association internationale des navigants de langue française (AISLF), die Association pour la promotion du francais des affaires (APFA) oder das Comité d'étude des termes médicaux français (CETMF) bleiben im Wesentlichen auf sich selbst gestellt (vgl. Depecker 2001a, 28f.). Vor allem das Haut Comité de la langue française, zu dessen Aufgaben die Betreuung und die Koordinierung der CMT gehören, kümmert sich in nur ungenügendem Maße um die Arbeiten der einzelnen Terminologiekommissionen, so dass sich die Arbeiten zwischen 1973 und Beginn der 1980er Jahre sehr verlangsamen. In der Folge werden nur wenige Terminologieerlasse publiziert, und manche Kommissionen lösen sich sogar auf (vgl. Depecker 2001a, 350). Ein Versuch, die Arbeiten der einzelnen Kommissionen zu koordinieren, wird im Dekret Nr. 86-439 vom 11. März 1986 (publiziert im JO vom 16. März 1986) unternommen. Analog zum Modell der kanadischen Terminologiearbeit durch den Office québécois de la langue française, der bereits seit Jahren über eine die Terminologiearbeiten koordinierende Terminologiekommission verfügt, soll ein entsprechendes Organ nun auch für die französische Terminologieplanung eingerichtet werden. Unter der Bezeichnung commission générale de terminologie tritt diese Kommission 1986 ihre Arbeit an (vgl. Depecker 2001a, 348f.). Trotz dieser Versuche, die einzelnen Arbeiten besser zu koordinieren, stellt sich der Erfolg erst einige Jahre später ein, nach der Gründung der DGLF im Jahre 1989.

Rechtsgültig und somit verbindlich werden die Terminologielisten erst mit Inkrafttreten des unter dem damaligen Staatspräsidenten Valéry Giscard d'Estaing erlassenen Sprachgesetzes vom Dezember 1975, der Loi du 31 décembre 1975 relative à l'emploi de la langue française (im Folgenden nur noch als Loi Bas-Lauriol bezeichnet) am 01. Januar 1977. Das neue Gesetz wird offiziell mit dem Argument des Verbraucherschutzes sowie der Interessenvertretung des Arbeitnehmers begründet, weswegen sämtliche (englischen) Fremdwörter in der Werbung, auf Verpackungen, Gebrauchsanweisungen, Garantieurkunden, Arbeitsverträgen, Stellenanzeigen etc. durch die offiziell angeordneten französischen Lexeme ersetzt werden sollen, um dem Verbraucher bzw. Arbeitnehmer eine absolute Verständlichkeit zu garantieren.

Die Vorschriften haben bindenden Charakter insbesondere für Schulen und Behörden, aber auch in der Industrie und auf dem Arbeitsmarkt. Der Loi Bas-Lauriol zufolge sollen in Werbetexten, auf Verpackungen, Gebrauchsanweisungen, Garantieurkunden, in Stellenanzeigen, Arbeitsverträgen, den Medien, Schul- und Lehrbüchern sowie in Angelegenheiten der öffentlichen Hand anstelle von Anglizismen und anderen Fremdwörtern die staatlich vorgeschlagenen französischen Neologismen verwendet werden. Fremdsprachliche Ausdrücke dürfen nur dann verwendet werden, wenn kein entsprechendes französisches Wort vorhanden ist. Dies gilt nicht für nationale Spezialitäten wie beispielsweise engl. sandwich. Ver- 
stöße gegen das Gesetz sollen mit Geldbußen in Höhe von 600 bis 1300 FF geahndet werden ${ }^{48}$. Über die Einhaltung der gesetzlichen Bestimmungen, insbesondere auch für den nicht-staatlichen Bereich, wacht die 1976 durch Alain Guillermou gegründete Association générale des usagers de la langue française (AGULF) ${ }^{49}$. Ab 1977 werden von der AGULF einige Prozesse gegen eine Reihe von Personen eingeleitet, z.B. gegen Journalisten und Firmen (am bekanntesten: Prozess gegen British Airways), die jedoch ohne großes Echo bleiben ${ }^{50}$.

Weil sich aber die juristische Seite, d.h. die Ermittlung von Zuwiderhandlungen, die strafrechtlich geahndet werden können, als äußerst schwierig erweist, halten viele Sprachwissenschaftler das Gesetz für gescheitert (vgl. z.B. Ager 1996, 44; Chansou 1997, 3251; Christmann 1982, 280f.; Falter 1991; Gebhardt 1981, bes. 25 31; Goudaillier 1977/1982, Schmitt 1979). Der Jurist Haas äußert sogar die These, die französische Regierung habe Ende der 1980er/Anfang der 1990er Jahre eingesehen, dass mit gesetzgeberischen Maßnahmen keine wirkungsvolle Sprachpolitik $\mathrm{zu}$ betreiben sei, und würde sich folglich von der staatlichen Anglizismenbekämpfung abwenden (vgl. Haas 1991, 171) ${ }^{52}$. Das Scheitern der Loi Bas-Lauriol lässt sich konkret auf zwei Ebenen konstatieren: 1. in Bezug auf die fehlenden Sanktionen und die infolgedessen häufigen Verstöße gegen das Gesetz, 2. in Bezug auf die soziale Akzeptanz der neuen Termini bei frankophonen Sprechern (vgl. Kap. 4).

In den 1980er Jahren kommt aufgrund der Unzufriedenheit über die Wirksamkeit des Gesetzes wieder Bewegung in die französische Sprachpolitik. Für eine Novellierung und Verschärfung der Loi Bas-Lauriol vor allem im Hinblick auf die bei Verstoß geltenden Sanktionen treten in erster Linie die beiden Abgeordneten Pierre Bas (RPR) und George Sarre (PS) ein, die selbst für das Sprachgesetz verantwortlich sind. Der neue Gesetzentwurf findet jedoch keine Mehrheit, so dass weiterhin das Sprachgesetz von 1975 in Kraft bleibt (vgl. Plümer 2000, 47f.). Eine Novellierung der Sprachgesetzgebung erfolgt erst 1994 durch den von April 1993 bis Mai 1995 für Kultur und Frankophonie zuständigen Minister Jacques Toubon.

\footnotetext{
$48 \mathrm{Zu}$ den Inhalten der Loi Bas-Lauriol und ihrer praktischen Umsetzung vgl. ausführlich Plümer (2000, 40-54).

${ }^{49}$ Inzwischen musste die AGULF aufgrund finanzieller Engpässe ihre Arbeit einstellen (vgl. Plümer 2000, 50, Fußnote 222).

50 Wie gering die tatsächliche Sanktionierung der Verstöße ausfällt, zeigt die bei Plümer $(2000,52)$ für die Jahre 1977 bis 1984 abgedruckte Statistik. In den Jahren 1977 bis 1982 schwankt die Anzahl der Verurteilungen zwischen 19 und 53, nur 1981 kommt es zu keiner einzigen Verurteilung. Seitdem die DGLF für die Kontrolle der Verstöße gegen die Gesetzesvorschriften zuständig ist, steigt die Anzahl der Verurteilungen merklich: In den Jahren 1990 bis 1994 werden jeweils zwischen 85 und 165 Verhandlungen geführt (vgl. Plümer 2000, 54; vgl. hierzu auch Fußnote 60).

51 Obgleich Chansou $(1997,32)$ das Gesetz von 1975 als gescheitert betrachtet, hält er es aber trotz seiner Mängel in seinen wesentlichen Zielen für ein vernünftiges Gesetz: „La loi Bas-Lauriol, mal perçue, rencontre l'indifférence de ceux qui sont chargés de la faire respecter, et elle ne sera guère appliquée. Cependant, avec le recul du temps, elle peut apparaitre [sic!] malgré ses défauts comme une loi ,raisonnable' dont les objectifs essentiels, la protection des consommateurs et des salariés, répondaient véritablement à un besoin de la communauté sociale."

${ }^{52}$ Damit hat er allerdings nicht Recht behalten, wie in 3.2.3.1 gezeigt wird.
} 


\subsubsection{Die Loi Toubon und das Dekret vom 03. Juli 1996}

\subsubsection{Die Loi Toubon}

Am 23. Februar 1994 präsentiert der französische Minister für Kultur und Frankophonie, Jacques Toubon, einen Entwurf für ein neues Gesetz zum Schutz der französischen Sprache vor dem Ministerrat ${ }^{53}$. Die Loi du 4 août 1994 relative à l'emploi de la langue française, kurz: Loi Toubon, stellt einen zweiten Versuch dar, das Anglizismen-Problem wirksam in den Griff zu bekommen. Mit Plümer $(2000,56)$ kann man von einer ,erweiterte[n] Neuauflage der Loi Bas-Lauriok" sprechen. Der Anwendungsbereich des Gesetzes von 1975 wird erweitert, seine Bestimmungen werden verschärft. Hierbei hat sich der Schwerpunkt der Loi Toubon im Vergleich zum Vorgängergesetz etwas verlagert. Zwar werden beide Gesetze mit dem Verbraucherschutz begründet, und die Loi Toubon setzt den Kampf gegen das franglais fort, jedoch reagiert die Loi Toubon stärker auf die Gefahr des Eindringens der englischen Sprache in bestimmte Diskursdomänen und nimmt sich nicht mehr nur ausschließlich des Wortschatzes an (vgl. Trabant 1995b, 13, 2001, 12). Diese neue Zielrichtung, dass es nicht vornehmlich um englische Wörter, sondern um die Bewahrung des Französischen in bestimmten Kommunikationsbereichen wie bei Kongressen, in der Schule oder bei der Publikation wissenschaftlicher Texte geht, macht Toubon im Februar 1994 in einem in Le Monde erschienenen Artikel deutlich (vgl. Toubon 1994a, 2) 54 .

Am 14. April 1994 passiert der Gesetzentwurf den Senat, Anfang Mai wird er in erster Lesung von der Assemblée Nationale verabschiedet. Die endgültige Verabschiedung erfolgt in dritter Lesung am 30. Juni 1994. Bevor es jedoch zur Umsetzung des neuen Gesetzes kommt, wird der Gesetzentwurf als Versuch Toubons, den Bürgern per Gesetz vorschreiben zu wollen, welche Wörter sie zu benutzen haben, zunächst Gegenstand einer Verfassungsklage. Der ursprüngliche Gesetzentwurf sieht nämlich vor, diejenigen Anglizismen, für die entsprechende Ersatzwörter geschaffen worden sind, nicht nur in bestimmten Situationen des öffentlichen Sprachverkehrs, sondern auch in der Öffentlichkeit zu verbieten. Es wird vom Conseil constitutionnel (vergleichbar dem deutschen Verfassungsgericht) am 29. Juli 1994 unter Berufung auf Artikel 11 der Menschenrechtserklärung befunden, der Gesetzentwurf verstoße in der vorliegenden Form gegen das Recht der freien Meinungsäußerung. Aufgrund der Eingriffe des Verfassungsgerichts und nach vielen Parlamentsdebatten entsteht ein gegenüber dem Entwurf stark eingeschränktes Gesetz, welches am 04. August 1994 verabschiedet wird. Auf das Le-

\footnotetext{
53 Die Bemühungen um ein neues Sprachgesetz gehen zurück ins Jahr 1992. Nicht Toubon, der zu diesem Zeitpunkt auch noch nicht Minister für Kultur und Frankophonie war, sondern Catherine Tasca, Staatssekretärin für Frankophonie und internationale Kulturbeziehungen, bringt das Projekt zur Revision des Sprachgesetzes ins Rollen (vgl. Hagège 1996, 151-153).

${ }^{54}$ Das äußert sich zum Beispiel darin, dass fremdsprachige Publikationen nur durch den französischen Staat gefördert werden, wenn sie mit einem französischsprachigen Resümee versehen sind (vgl. Gesetz Nr. 94-665 vom 4. August 1994, Art. 7).
} 
ben der Normalbürger hat das neue Sprachgesetz kaum Auswirkungen (vgl. statt vieler Braselmann 1999a, 8-13)55.

Konkret legt die Loi Toubon den Gebrauch des Französischen für vier Bereichen als obligatorisch fest:

1. für jede Art schriftlicher oder mündlicher Information (Werbung, Schilder etc.) auf öffentlichen Plätzen, Straßen, in öffentlichen Transportmitteln etc. (vgl. Gesetz Nr. 94-665 vom 4. August 1994, Art. 2-5),

2. bei Veranstaltungen oder Kongressen, die auf französischem Territorium stattfinden (vgl. ebd., Art. 6),

3. im Arbeitsrecht: sämtliche den Arbeitnehmer betreffende Texte müssen auf Französisch verfasst sein (vgl. ebd., Art. 8-10),

4. im Unterricht: Französisch als ausschließliche Unterrichtssprache (vgl. ebd., Art. 11).

Neu im Vergleich zur Loi Bas-Lauriol sind in der Loi Toubon die folgenden Punkte: Französisch wird nun auch im Bereich des Arbeitsrechts sowie in den Schulen und an den Universitäten obligatorisch. Zudem muss Französisch Kongresssprache sein bei Veranstaltungen auf französischem Territorium, was zur Folge hat, dass bei englischen Vorträgen eine französische Übersetzung erfolgen muss. Nach wie vor müssen Gebrauchsanweisungen, Produktbeschreibungen, Rechnungen u.Ä. in französischer Sprache verfasst sein, ebenso wie mündlich und schriftlich übermittelte Werbetexte. Gleiches gilt auch weiterhin für Informationen, Anzeigen, Schilder, Wegweiser etc. Das bedeutet, dass jegliche in einem öffentlichen Ort oder Verkehrsmittel angebrachte Aufschrift oder Anzeige in französischer Sprache formuliert sein bzw. bei einem fremdsprachigen Text eine französische Übersetzung enthalten muss (vgl. ebd., Art. 2-4) ${ }^{56}$.

Die wesentliche Änderung des Gesetzes liegt in der verschärften Sanktionierung in Form von Bußgeldern und sogar Gefängnisstrafen ${ }^{57}$. Die beiden wichtigsten Kontrollinstanzen für die Einhaltung der Loi Toubon sind die DGLF/DGLFLF und die Direction Générale de la Concurrence, de la Consommation et de la Répression des Fraudes (DGCCRF). Seit dem 01. August 1996 besteht eine vertraglich vereinbarte Kooperation zwischen diesen beiden Organisationen. Des Weiteren unterstützen die in Artikel 1 des Erlasses vom 25. Juni 2001 genannten Organisationen

Association francophone d'amitié et de liaison (AFAL),

Avenir de la langue française (ALF) und

Défense de la langue française (DLF)

\footnotetext{
55 Zwar wird im Allgemeinen der 04. August 1994 als Tag für das Inkrafttreten des neuen Gesetzes genannt, jedoch werden die verschiedenen Bestimmungen des Gesetzes erst nach und nach wirksam, wie dies in Artikel 23 der Loi Toubon festgelegt ist. In ihrer Gesamtheit tritt die Loi Toubon somit erst im September 1995 in Kraft (vgl. ebd., Art. 23).

${ }^{56}$ Der Artikel 2 der Loi Toubon wird durch den Runderlass vom 20. September 2001 präzisiert. Anstelle eines französischsprachigen Textes bzw. eines fremdsprachigen Textes mit wörtlicher Übersetzung sind auch andere Mittel möglich, um den französischsprachigen Konsumenten zu informieren, nämlich die Verwendung von Zeichnungen, Symbolen oder Piktogrammen.

${ }^{57}$ Die Sanktionen auf Verstöße der Loi Bas-Lauriol fallen deswegen so niedrig aus, weil dieses Gesetz auf die Bestimmungen des Anti-Betrugsgesetzes aus dem Jahre 1905 rekurriert.
} 
die staatlichen Kontrollbemühungen. Für ihren Beitrag zur Sprachpflege werden diese fünf Organisationen finanziell von der DGLF unterstützt, wie dies am 03. Mai 1995 in einem Erlass des Ministers für Kultur und Frankophonie sowie des Justizministers festgeschrieben wurde. Für die Kontrolle der Einhaltung der Loi Toubon fühlt sich neben den fünf genannten auch die private Vereinigung Le Droit de comprendre (DDC) zuständig58. Die jeweiligen Jahresberichte der DGLF/ DGLFLF („Rapports au Parlement“), die über die Internetseiten der DGLFLF abzurufen sind ${ }^{59}$, bieten zahlreiche Statistiken zu den Verstößen gegen das Gesetz von 199460 .

Im Zuge der Erarbeitung und Verabschiedung der Loi Toubon gibt es einigen Wirbel, so dass die Mehrheit der Franzosen nicht umhin kommt, die Existenz dieses Gesetzes zur Kenntnis zu nehmen. Über den konkreten Inhalt des Gesetzes jedoch scheinen die Franzosen nicht bzw. kaum informiert zu sein, wie eine Umfrage des Meinungsforschungsinstitutes SOFRES zeigt, welche im Auftrag der Association Force Ouvrière Consommateurs und mit Unterstützung u.a. der DGLF durchgeführt wurde. Nur 34\% der Befragten kennen den Paragraphen des Gesetzes, der das Französische auf Etiketten von Verpackungen und Gebrauchsanweisungen für obligatorisch erklärt. 93\% der Befragten erachten diese Vorschriften jedoch als ziemlich bzw. sehr nützlich (vgl. Bericht der DGLFLF 2001, Teil 2, o.S.).

58 Diese Sprachpflegeorganisation wurde im Oktober 1994 durch die Initiative der Organisationen Avenir de la langue française und Défense de la langue française gegründet. Auf ihrer Internetseite (Le droit de comprendre o.J., o.S.) werden als ihre Aufgaben genannt:

- „,...] 'Le Droit de comprendre' a pour vocation de coordonner et de renforcer l'efficacité des moyens et des actions de toutes les associations qui œuvrent pour le développement de la francophonie et pour le droit à une information claire et loyale des consommateurs, et des usagers du service public.

- 'Le Droit de comprendre' soutient à cet effet toutes les initiatives visant à renforcer le rayonnement de la langue française et à faire respecter les droits linguistiques des citoyens sur le territoire national et en Europe dans le cadre de la législation en vigueur.

- $\quad$ 'Le Droit de comprendre' se prononce également en faveur du respect de toutes les langues nationales au sein de l'Union européenne et pour le développement d'un plurilinguisme équilibré dans les institutions européennes nécessaire à leur démocratisation."

Im Januar 1999 veröffentlicht der DDC einen ausführlichen Rechenschaftsbericht, „La langue française dans tous ses états“, der bislang einzige, im Internet zugängliche Bericht dieser Organisation (Le droit de comprendre 1999).

${ }^{59}$ Die Jahresberichte der DGLF/DGLFLF sowie der Commission générale de terminologie et de néologie befinden sich in 15.8.9.

${ }^{60}$ Insgesamt wird die Ahndung von Verstößen nach der Verabschiedung der Loi Toubon konsequenter durchgeführt als im Rahmen der Loi Bas-Lauriol. Als Vergleichswert: 1982 werden 266 Verstöße registriert, es kommt allerdings nur zu 42 Verurteilungen (vgl. Beinke 1990, 255). Demgegenüber präsentieren sich für die Jahre 1995ff. folgende Zahlen, die eindeutig belegen, dass die Anzahl der festgestellten Verstöße insgesamt gestiegen ist: 1995: 390 Verstöße (32 Verurteilungen), 1996: 1.091 Verstöße (56 Verurteilungen), 1997: 1103 Verstöße (127 Verurteilungen), 1998: 913 Verstöße (124 Verurteilungen), 1999: 1007 Verstöße (98 Verurteilungen), 2000: 826 Verstöße (80 Verurteilungen) (vgl. Bericht der DGLFLF 2001, Teil 2, o.S.). 
Versucht man eine Gesamtbewertung der Loi Toubon vorzunehmen, bleibt von dem ehrgeizigen Projekt, die Loi Bas-Lauriol von $1975 \mathrm{zu}$ novellieren, nicht viel mehr übrig als eine Verschärfung der Sanktionen, die auf die Verstöße gegen das Sprachgesetz erfolgen sollen. Das eigentliche Ziel der Loi Toubon, die Verankerung der offiziellen Bezeichnungen im allgemeinen Wortschatz, indem deren Verwendung für den öffentlichen wie auch für den privaten Sprachgebrauch verpflichtend gemacht wird, wird nicht erreicht.

Wie üblich in der französischen Gesetzgebung, gehen die Anwendungsbestimmungen weiter ins Detail als die Gesetze selbst und geben über deren konkrete Umsetzung Auskunft ${ }^{61}$.

Mehrere Dekrete und Erlasse präzisieren die Loi Toubon in ihrer konkreten Anwendung:

1. das Dekret vom 03. März 1995, in dem in erster Linie das Strafmaß für die verschiedenen Arten von Verstößen festgelegt wird;

2. der Erlass (circulaire) vom 19. März 1996, in dem die DGLF mit der Koordinierung, Förderung und Kontrolle der in der Loi Toubon festgeschriebenen Sprachpflege beauftragt wird;

3. der Erlass (circulaire) vom 15. Mai 1996, in dem verfügt wird, dass alle Internetseiten des französischen Staates (Verwaltungen/Ministerien) auf Französisch publiziert werden müssen, eine englische Übersetzung jedoch erlaubt sei, wenn mindestens eine weitere Übersetzung in einer anderen Sprache vorhanden sei;

4. das Dekret vom 03. Juli 1996 (s. 3.2.3.2);

5. das Dekret vom 01. Juli 1998, das das Dekret vom 03. März 1995 inhaltlich modifiziert und ablöst;

6. der Erlass (circulaire) vom 28. September 1999, der die Anwendung der Artikel 3 und 4 der Loi Toubon im Bereich des Transportwesens betrifft;

7. der Erlass vom 25. Juni 2001 bezüglich der Sprachpflegeorganisationen, die für die Überwachung der Verstöße gegen die Loi Toubon zuständig sind: Association francophone d'amitié et de liaison (AFAL), Avenir de la langue française (ALF), Défense de la langue française (DLF);

${ }^{61}$ Gesetze sind in ihren Formulierungen oft sehr allgemein und unpräzise gehalten. Deshalb werden die französischen Gesetze durch zahlreiche décrets, arrêtés und circulaires inhaltlich ausgestaltet und in ihrer Anwendung konkretisiert. Der Zusammenhang zwischen den Termini loi, décret, arrêté und circulaire ist für den juristisch Ungeschulten schwierig zu durchschauen. Generell ist festzuhalten, dass Gesetze gegenüber Verordnungen das höchste Prestige genießen und aufgrund der komplizierten Verfahren, die zu ihrer Verabschiedung führen, als relativ stabil gelten. Da sie aber in Bezug auf ihre Durchführung wenig konkrete Informationen enthalten, werden sie durch Verwaltungserlasse ergänzt. Verwaltungserlasse in Form von arrêtés oder circulaires gelten als die niedrigsten expliziten Formen der Sprachregelung (vgl. Kremnitz 2001, 499). Alle Terminologielisten werden in Form von arrêtés veröffentlicht und erhalten mit dem Tag ihrer Publikation im JO Gültigkeit. In circulaires, einer Art hausinterner Sprachregelung, die der Öffentlichkeit nicht bekannt sein müssen, werden beispielsweise die Umsetzungen und Anwendungsbereiche von Sprachgesetzen präzisiert. Das Dekret, stets vom Staatspräsidenten oder Premierminister erlassen, stellt eine Durchführungsverordnung eines Gesetzes dar. Entsprechend enthält das Dekret vom 03. Juli 1996 konkrete Bestimmungen zur Umsetzung der in der Loi Toubon formulierten Zielsetzungen (vgl. Braselmann 1999a, 19, Anmerkung 62). 
8. der Erlass (circulaire) vom 20. September 2001 bezüglich des Artikels 2 der Loi Toubon.

Von den sechs aufgeführten Dekreten bzw. Erlassen hat das Dekret Nr. 96-602 vom 03. Juli 1996 für die Umsetzung der in der Loi Toubon geforderten Verteidigung und Verbreitung der französischen Sprache und, spezieller noch, für die Terminologiearbeit, die weitreichendsten Folgen. Deshalb wird es im Folgenden ausführlich behandelt.

\subsubsection{Das Dekeret vom 03. Juli 1996}

Das Dekret Nr. 96-602, veröffentlicht im JO vom 05. Juli 1996, ist eine Folge des Urteils vom 29. Juli 1994, in dem das Verfassungsgericht dem Staat das Recht abspricht Privatpersonen den Gebrauch bestimmter Termini vorzuschreiben. Daraus resultiert eine neue Rolle des Staates: Dieser ist zwar weiterhin für die Initiierung und Koordinierung der Terminologiearbeiten zuständig, ist jedoch fortan von der Erarbeitung und Auswahl der offiziellen Terminologie ausgeschlossen.

Mit diesem Dekret werden die Schaffung einer allgemeinen, koordinierenden Terminologiekommission, der sog. Commission générale de terminologie et de néologie (im Folgenden der Kürze halber nur noch als Commission générale bezeichnet), die dem Premierminister untersteht, sowie die Einrichtung von Spezialkommissionen, den sog. commissions spécialisées de terminologie et de néologie (CST), beschlossen. Das Dekret gibt über die Zusammensetzung der Commission générale Auskunft, welche aus insgesamt 16 Personen bestehen soll, die für jeweils vier Jahre nominiert werden, wobei optional Experten zu Rate gezogen werden können (vgl. Dekret Nr. 96-602 vom 03. Juli 1996, Art. 2). Weiterhin werden im Dekret die Zusammensetzung der jeweiligen CST, die die bisherigen CMT ablösen, und deren Aufgaben festgelegt (vgl. ebd., Art. 6 und 7). Die folgenden vier Aufgaben der Fachkommission werden genannt:

$1^{\circ}$ „D’établir l'inventaire des cas dans lesquels il est souhaitable de compléter le vocabulaire français, compte tenu des besoins exprimés ;

$2^{\circ}$ De recueillir, analyser et proposer les termes et expressions nécessaires, notamment ceux équivalents à des termes et expressions nouveaux apparaissant dans les langues étrangères, accompagnés de leur définition ;

$3^{\circ}$ De veiller à l'harmonisation des termes, expressions et définitions proposés avec ceux des autres organismes de terminologie, de néologie et de normalisation et avec ceux des pays francophones et des organisations internationales dont le français est la langue officielle ou langue de travail ;

$4^{\circ}$ De concourir à la diffusion auprès des usagers des listes de termes, expressions et définitions publiées au Journal officiel"

(ebd., Art. 7). 
Das Dekret legt auch die Rolle der DGLF (bzw. seit 2001 DGLFLF) fest, welche für die Koordination der Arbeiten der verschiedenen Spezialkommissionen sowie die Verbreitung ihrer Ergebnisse zuständig ist (vgl. ebd., Art. 4). Des Weiteren sind im Dekret die Aufgaben der Commission générale festgeschrieben. Die Commission générale ist für die Kontrolle der von den Fachkommissionen erarbeiteten Termini, Redewendungen und Definitionen zuständig. Sie soll auf die Harmonisierung der erarbeiteten Termini und auf den beständigen Fortgang der Arbeiten in den einzelnen Kommissionen achten (vgl. ebd., Art. 8).

Erstmals kommt nun auch der Académie française eine entscheidende Rolle in der modernen Sprachpflege zu, denn ohne ihre Zustimmung darf nach Artikel 9 des Dekrets keine Terminologieliste veröffentlicht werden.

Artikel 10 legt fest, wie die Terminologieerlasse bekannt gemacht werden sollen. Wenn die Académie française ihr Einverständnis zu den Terminologievorschlägen gegeben hat, reicht die Commission générale diese Listen (mitsamt der Definitionen) zur Veröffentlichung an den JO weiter. Dort werden sie unter der Rubrik „Avis et communications" abgedruckt und sind vom Tag der Veröffentlichung an gültig für den öffentlichen Dienst sowie für alle Fälle, die in den Artikeln 5 und 14 der Loi Toubon festgelegt sind (vgl. ebd., Art. 11). Nach Publikation der Listen im JO obliegt den für ihre Erstellung verantwortlichen Ministerien die weitere Verbreitung $^{62}$. Außerdem sollen die Terminologielisten im Bulletin officiel des Ministère de l'Éducation nationale veröffentlicht werden (vgl. ebd., Art. 10).

Artikel 13 legt fest, dass im Laufe des ersten Jahres nach Gründung der Commission générale eine Revision aller in den Vorjahren veröffentlichten gültigen Listen erfolgen solle 63 .

Artikel 14 des Dekrets legt fest, dass jede Fachkommission vor dem 15. Januar jeden Jahres einen Jahresbericht über ihre Tätigkeiten sowie über die Verbreitung und den Gebrauch der Termini, Ausdrücke und Definitionen vorzulegen habe. Die Rechenschaftsberichte aller Kommissionen fließen dann in den Jahresbericht Commission générale ein ${ }^{64}$.

Durch das Dekret von 1996 kommt es zu einer Umstrukturierung der Terminologiearbeit. Es wird erneut eine die Arbeiten der einzelnen Fachkommissionen koordinierende Instanz, die Commission générale, geschaffen. Diese löst die 1986 gegründete Commission générale de terminologie ab. Für die konkrete Arbeit der Terminologiekommissionen ändert sich nicht viel: Die Struktur der Kommissionen mit

\footnotetext{
${ }^{62}$ Entsprechend zu diesem Artikel heißt es im Jahresbericht der DGLFLF (2001, Teil 5, o.S.): „La publication au Journal officiel des travaux de la Commission générale en constitue l'étape finale et entraîne l'obligation pour les services de l'État d'employer les équivalents français publiés à la place des termes étrangers correspondants. Il est donc important que cette publication s'accompagne d'un effort de diffusion tant auprès des administrations que des publics concernés et plus généralement de toutes les personnes intéressées.“

${ }^{63}$ Die Umsetzung dieses Artikels hat sich etwas verzögert, aber seit 2000 liegt das Ergebnis vor: der „Répertoire terminologique 2000“ (vgl. Commission générale 2000b/2000c; vgl. 3.2.4.2).

${ }^{64}$ Der jeweils aktuelle Jahresbericht der Commission générale kann auf der Seite der DGLFLF abgerufen werden (vgl. 15.8.9.2). Die Berichte der einzelnen Fachkommissionen sind leider nicht öffentlich einsehbar (persönliche Mitteilung von Florence Desmoulières (DGLFLF) vom 11. Februar 2002).
} 
jeweils zwischen 20 und 30 Mitgliedern bleibt weitestgehend erhalten, allerdings sorgt die Commission générale durch ihre koordinierenden Tätigkeiten für mehr Kontinuität in der Arbeit der einzelnen Kommissionen. Die Kontinuität der Arbeiten hängt nicht zuletzt von der Tatsache ab, dass jede Kommission bei der Commission générale einen jährlichen Rechenschaftsbericht über die Tätigkeiten der vergangenen zwölf Monate abzulegen hat. Die CST treffen sich durchschnittlich alle zwei Monate, die Commission générale trifft sich ca. einmal im Monat (vgl. Bericht der Commission générale von 1999 und 2001, Teil 1, o.S., Teil 3, o.S.).

Aus der Einrichtung der Commission génerale resultiert eine ergebnisreiche Terminologiearbeit in den Jahren 1997-2001, wie die folgende Übersicht über die in diesem Zeitraum veröffentlichten Terminologielisten zeigt ${ }^{65}$ :

\section{2}

8 décembre 2002 : Informatique et internet

26 mars 2002 : composants électroniques

2 mars 2002 : services de télécommunication

1er mars 2002 : polymères

\section{1}

28 juillet 2001 : vocabulaire de l'économie et des finances

18 avril 2001 : vocabulaire de la chimie

18 avril 2001 : défense

18 avril 2001 :vocabulaire de la stéréochimie

18 avril 2001 : vocabulaire des techniques spatiales

\section{0}

22 septembre 2000 : répertoire terminologique

1er septembre 2000 : vocabulaire de l'informatique et internet

3 août 2000 : vocabulaire de l'ingénierie nucléaire

12 mai 2000 : vocabulaire de l'économie et des finances

\footnotetext{
${ }^{65}$ Das bedeutet: In fünf Jahren (1997-2001) werden 17 Terminologielisten erstellt, d.h. durchschnittlich 3,4 Terminologielisten pro Jahr. Zum Vergleich: In den Jahren 1973-1995, also in 23 Jahren, sind insgesamt 53 Terminologielisten veröffentlicht worden, d.h. durchschnittlich 2,3 Terminologielisten pro Jahr. Das Bemühen der DGLF/DGLFLF sowie der einzelnen Fachkommissionen um die ständige Aktualisierung der Terminologielisten ist in den letzten Jahren deutlich zu spüren. Gerade die mangelnde Aktualität der Terminologielisten wurde der DGLF mehrfach zum Vorwurf gemacht, u.a. von Chansou (1993, 165; vgl. 4.3.1).
} 


\section{9}

23 octobre 1999 : vocabulaire de l'automobile

13 janvier 1999 : vocabulaire des carburants

16 mars 1999 : vocabulaire de l'informatique et internet

14 septembre 1999 : „Zone euro“

\section{8}

16 décembre 1998 : vocabulaire de l'architecture

14 août 1998 : vocabulaire de l'économie et des finances

10 octobre 1998 : vocabulaire de l'informatique

\section{7}

2 décembre 1997 : vocabulaire de la monnaie européenne, courrier électronique, sports, transports

(Commission générale, o.J, o.S.).

Durch das Dekret vom 03. Juli 1996 wird die Rolle des Staates bei der Terminologieplanung (vertreten durch die DGLF/DGLFLF) neu festgelegt: Dem Staat kommen bei der Terminologieplanung initiierende, unterstützende und koordinierende Aufgaben zu. Die DGLF/DGLFLF koordiniert den Austausch der Arbeiten zwischen der Commission générale, den einzelnen Fachkommissionen und der Académie française. Ferner trägt sie Sorge für die Publikation der Ergebnisse. Der Staat ist nun jedoch weder für die Auswahl der zu normierenden Termini noch für die Definitionen oder die Wahl der entsprechenden französischsprachigen Äquivalente verantwortlich (vgl. Depecker 1997a, XXXI) ${ }^{66}$.

In den Jahren 1996 und 1997 werden als Folge der Veröffentlichung des Dekrets weitere Erlasse publiziert, welche die Einrichtung einzelner Terminologiekommissionen verfügen bzw. die Zusammensetzung ihrer Mitglieder festlegen. Jede dieser Kommissionen setzt sich zusammen aus Vertretern des jeweiligen Ministeriums bzw. der jeweiligen Verwaltung, aus Vertretern der betroffenen Berufsgruppen sowie aus Linguisten.

Anfang des Jahres 2003 gibt es 18 Terminologiekommissionen, die von insgesamt zwölf Ministerien oder Unterabteilungen abhängen und sich wiederum in ca. 40

66 Entsprechend heißt es im Jahresbericht der DGLFLF (2001, Teil 5, o.S.): „Le dispositif d'enrichissement de la langue française, renforcé et modernisé par le décret du 3 juillet 1996, a pour objectif de mettre des termes de référence à la disposition des utilisateurs et en premier lieu des services de l'État pour qui leur usage est obligatoire. Il a poursuivi les tâches que lui confie ce texte : la veille néologique et la publication de listes de termes." 
Unterkommissionen aufspalten (vgl. DGLFLF o.J.c, o.S.; Jahresbericht der DGLFLF 2001, Teil 5, Teil 4, o.S.) ${ }^{67}$.

Da das Dekret von 1996 eine Festlegung der Amtszeit aller Kommissionen, d.h. sowohl der Commission générale als auch der Fachkommissionen, auf vier Jahre vorsieht, werden in den Jahren 2000 und 2001 weitere Erlasse verabschiedet, in denen die Zusammensetzung der Mitglieder der einzelnen Kommissionen neu festgelegt wird. Was die Commission générale betrifft, verlängert der Erlass vom 11. Januar 2001 die Präsidentschaft von Gabriel de Broglie um weitere vier Jahre.

Durch den Erlass vom 18. Dezember 2000 werden die folgenden Personen als Mitglieder der Commission générale für die Jahre 2001 bis 2004 festgelegt:

- Mme Hélène Magliano, Staatsanwältin;

- M. François Plaisant, französischer Botschafter;

- $\quad$ M. Salah Stetié, Schriftsteller;

- M. Alain Rey, Linguist;

- M. Marc Baconnet, Dekan der Staatsinspektion des Kultusministeriums für Französisch;

- M. Jacques Campet, Berater am Rechnungshof;

- M. Gérard Painchault, Staatsinspektor des Industrieministeriums;

- Mme Jacqueline Risset, Professorin an der Universität La Sapienza in Rom;

- M. Etienne Guyon, Universitätsprofessor;

- M. Daniel Prado, Linguist;

- M. Jack Robert, Universitätsprofessor;

- Mme Michèle Lenoble-Pinson, Professorin an den Universitätsinstituten Saint-Louis de Bruxelles;

- M. Maurice Pergnier, emeritierter Professor der Universität Paris-XII.

Neben den koordinierenden Aufgaben wie der Förderung des Datenaustauschs zwischen den Fachkommissionen, der Commission générale und der Académie française ist die Commission générale dem Dekret vom 03. Juli 1996 zufolge auch für die Harmonisierung der Ergebnisse zuständig. Um der Terminologiearbeit bereits im Vorfeld eine grundlegende Richtung zu geben, hat die Commission générale drei Kri-

67 Die einzelnen Ministerien sind: défense, économie et finances, emploi et solidarité (zwei CST), industrie (sechs CST), recherche, culture et communication, justice, agriculture et pêche, affaires étrangères, équipement, environnement, jeunesse et sports. Die jüngste Kommission ist die der Jugend und des Sports. Sie wurde durch einen Erlass vom 27. März 2001 gegründet und trat im Oktober 2001 erstmalig zusammen (s. Anhang, 15.8.7). 
terien - 1. Notwendigkeit eines Neologismus, 2. Transparenz der Bildung und 3. deren Systemadäquatheit - entwickelt, welche die einzelnen Fachkommissionen bei der Erarbeitung ihrer Vorschläge berücksichtigen sollten:

„La nécessité : la création d'un nouveau terme est-elle indispensable pour désigner la notion? La transparence : le terme est-il immédiatement associé à la réalité ou à la notion qu'il désigne ? La bonne formation: le terme respecte-t-il le système morphologique et syntaxique du français ?" (DGLFLF o.J.b, o.S.) ${ }^{68}$.

Ferner hat es sich die Commission générale zur Aufgabe gemacht, darauf zu achten, dass die Definitionen der Termini, gerade weil sie sich auch an die breite Masse und nicht nur an Fachleute richten, allgemein verständlich sind (vgl. ebd.).

\subsubsection{Verbreitung der Terminologie}

\subsubsection{Verbreitung der Teminologieerlasse}

Der französische Staat hat vor allem in den letzten Jahren nicht nur Wert gelegt auf die Schaffung neuer Termini, sondern auch auf deren wirkungsvolle Verbreitung. Schließlich ist es kaum effektiv, viel Geld in die Terminologiearbeit zu investieren, wenn die Ergebnisse dieser Arbeit kaum bekannt sind. Insbesondere die aus der Sprachwissenschaft stammenden Forschungsergebnisse von Goudaillier (1982) und Fugger (1979/1980/1983a,b/1987) machen deutlich, dass die Resultate der Terminologieplanung der Mehrheit der Bevölkerung und mitunter sogar dem von den Erlassen direkt betroffenen Personenkreis weitestgehend unbekannt sind (vgl. auch Gaudin 1991, 4.3.1). Die Veröffentlichung der Terminologielisten im JO allein bewirkt nichts, da diesen kaum jemand liest. Entsprechend werden in den 1990er Jahren die Maßnahmen zur Verbreitung der Terminologielisten verstärkt, woran die DGLF und die Möglichkeiten, die das Internet bietet, einen erheblichen Anteil haben. Inwiefern sich dies auf den Bekanntheitsgrad der gültigen Internet-Terminologielisten auswirkt, werden die in den Kapiteln 9 bis 12 beschriebenen Untersuchungsergebnisse zeigen.

Es muss somit eine wirksamere Lösung gefunden werden, als die Terminologie nur in staatlichen Publikationen zu verbreiten, z.B. die Veröffentlichung in Fachzeitschriften oder die Übersendung der Neologismen an die Universitäten mit der Bitte, sie in den einzelnen Laboratorien und Forschungsstellen zu verbreiten (vgl. Garsou in: „Comptes rendus des débats“ 1994, 74 - s. Bibliografie unter „Comptes rendus $[\ldots]^{\natural \bullet}$ ).

Die Ansicht, dass zu wenige Leute die Terminologielisten kennen, vertritt auch Depecker (ebd.). Er weist auf eine Studie des Ministère de l'Éducation nationale hin,

${ }^{6}$ Die für die Erarbeitung der Termini geltenden Kriterien haben sich im Laufe der Jahre nicht verändert. Im Bericht der Commission générale von 2001 (Teil 1, o.S.) heißt es: „En matière de néologie, la commission générale de terminologie a continué d'appliquer quelques principes dégagés à l'occasion de ses premiers travaux, ces principes étant principalement l'opportunité et la nécessité du nouveau terme, sa clarté et sa transparence par rapport à la notion qu'il doit désigner, et enfin sa conformité au système morphologique et syntaxique du français.“ 
der zufolge nur 5\% des Personals des entsprechenden Ministeriums den Bulletin Officiel des Ministère de L'Éducation nationale lesen. Depecker (ebd.) plädiert daher als wirksames Mittel für die Herausgabe von Pressecommuniqués.

Insgesamt werden die Terminologieerlasse derzeit auf vier verschiedene Arten verbreitet:

1. Veröffentlichung im Journal officiel,

2. Veröffentlichung auf den Internet-Seiten der DGLFLF (und auf anderen französischsprachigen Seiten zur Sprachpflege) ${ }^{69}$,

3. Veröffentlichung einzelner Heftchen (fascicules spécialisés) in einer Auflagenhöhe von 5.000 bis 60.000 Exemplaren,

4. Veröffentlichung im Bulletin officiel de l'Éducation nationale, einem „Amtsblatt“, das alle Lehrer erhalten.

Ein umfangreiches Zwischenergebnis der Terminologiearbeit, das allerdings mit dem Zeitpunkt seines Erscheinens bereits dem Veraltungsprozess unterworfen ist, stellt der ca. 3.600 Einträge umfassende Dictionnaire des termes officiels (DGLF 1994a) dar.

Die Auflagenhöhe der einzelnen Heftchen, die kostenlos verteilt werden, fällt von Bereich zu Bereich unterschiedlich aus. Sie schwankt zwischen 5.000 und 60.000 Exemplaren. 60.000 Exemplare wurden z.B. von der Internet-Terminologie II (2000) gedruckt und z.B. an Verwaltungen und Behörden, an die Medienanstalten, an Übersetzer, Verbände, im Ausland tätige Französischlehrer, auf Veranstaltungen zur französischen Sprache, wie die „Fête de l'Internet“ oder die „Semaine de la langue française et de la francophonie" ${ }^{\text {"70 }}$, aber auch auf individuelle oder kollektive Anfragen hin verteilt (vgl. Jahresbericht der DGLFLF 2001, Teil 5, o.S.).

Es stellt sich natürlich die Frage, ob die im Internet angebotenen Terminologielisten auch tatsächlich konsultiert werden. Die DGLFLF registriert die Anzahl der Zugriffe auf ihre Seiten und stellt für das Jahr 2001 fest, dass am häufigsten von allen auf ihren Internetseiten befindlichen Dokumenten auf die Terminologielisten zurückgegriffen worden ist (vgl. Jahresbericht der DGLFLF 2001, Teil 5, o.S. Für dieses Ergebnis sind hoffentlich nicht allein die Recherchen für die Erstellung dieser Arbeit verantwortlich.).

Das Internet bietet für die Publikation der Termini vielerlei Vorzüge gegenüber den traditionellen Printmedien. Erstens sind die im Internet veröffentlichten Terminologielisten mit wenig finanziellem und zeitlichem Aufwand aktualisierbar, während eine Änderung im Printmedienbereich einen Neudruck bedingt und von daher mit hohen Kosten und logistischem Aufwand (Distribution) verbunden ist. Zweitens können sich über das Internet unbegrenzt viele Leute die offiziellen Ersatzwörter ansehen, während sicherlich nur wenige Privatpersonen Zugriff auf den JO bzw. die entsprechenden Broschüren haben. Mit anderen Worten über-

\footnotetext{
${ }^{69}$ Lange Zeit, auch bereits vor der Verbreitung des Internet, war es möglich, die offiziellen Wortlisten über Minitel abzurufen.

${ }^{70}$ Die „Fête de l'Internet“ findet seit 1998 jährlich statt (vgl. Afi-Pythagore Médiation Communication 2003, o.S.), die „Semaine de la langue française et de la francophonie“ seit 1996.
} 
trifft der Wirkungskreis des Mediums Internet den der Printmedien. Drittens bietet das Internet die Möglichkeit schnell zu reagieren, während die Ausgabe von Printmedien durch staatliche Stellen immer eine gewisse Zeitverzögerung mit sich bringt. Entsprechend erhofft sich der französische Staat präventive Arbeit durch die rasche Publikation der Wortlisten bzw. einzelner Termini im Internet:

„Man kämpft damit gegen das auch der staatlichen Seite nur zu gut bekannte Problem, das immer wieder in den Medien angesprochen wird, dass ein französisierter Ausdruck sich um so leichter durchsetzt, je weniger bekannt der proskribierte Anglizismus ist. Schon in dem Moment, in dem ein neuer englischer Term erscheint, kann durch französische Äquivalente reagiert werden“ (Braselmann 1999a, 24).

Der französische Staat hat die Vorteile des Internet für eine wirkungsvolle Sprachpflege erkannt und scheut keine Kosten und Mühen seine sprachpflegerischen Aktivitäten der Öffentlichkeit über dieses Medium bekannt zu machen ${ }^{71}$. Die Internetseiten der DGLFLF befinden sich stets auf dem aktuellen Stand, da sie ständig aktualisiert und erweitert werden. Aktuelle Terminologieerlasse, die Jahresberichte der DGLFLF bzw. der Commission générale, aber auch Informationen über die neuesten Ereignisse rund um die französische Sprache werden mit wenig Zeitverzögerung von der DGLFLF über das Internet verfügbar gemacht.

De Broglie (2001, o.S.) stellt die Frage, ob diese Art der Verbreitung der Terminologiearbeiten ausreichend sei, und beantwortet diese Frage positiv, was das Fachpublikum anbelangt, negativ jedoch im Hinblick auf die breite Masse der Bevölkerung. De Broglie hält das Internet für die effektivste Methode der Datenverbreitung, wenngleich er einräumt, dass bezüglich der weiteren Bekanntmachung der offiziellen Termini noch einiges geschehen müsse. Verschiedene Maßnahmen zur Verbesserung der Verbreitung seien in Arbeit (vgl. ebd.).

Depecker (2001a, 593) betont, dass die weite Verbreitung der Termini allein nicht reiche, um deren Etablierung zu erwirken. Daher seien Depecker zufolge weitere Maßnahmen notwendig, um die Etablierung der Termini zu begünstigen und zu beschleunigen.

Folgende Maßnahmen erachtet Depecker (2001a, 588-593) für die Verbreitung der offiziellen Termini als erfolgversprechend:

1. regelmäßige Erstellung und Publikation von Listen, die alle bisher verabschiedeten Terminologieerlasse in einem Dokument zusammenfassen, wie dies im etwa 3.600 Termini umfassenden Dictionnaire des termes officiels von 1994 (DGLF 1994a) geschehen ist ${ }^{72}$;

2. Publikation der jeweiligen Fachterminologien in den einschlägigen Fachzeitschriften, die von den betroffenen Berufsgruppen gelesen werden;

\footnotetext{
${ }^{71}$ Der Etat für Terminologie, der der DGLFLF jährlich zur Verfügung steht, beträgt seit Anfang der 1990er Jahre mehr als 1 Million FF (= 152.000 Euro) (vgl. Depecker 1997b, o.S.).

72 Dieser Forderung wird zwar nicht für den Printbereich, dafür aber in Form der ständig aktualisierten Datenbank CRITER Rechnung getragen (vgl. 3.2.4.2).
} 
3. Publikation der Termini in Wörterbüchern und Fachwörterbüchern ${ }^{73}$;

4. verstärkte Stellungnahmen von Sprachpflegegesellschaften und insbesondere der DGLFLF in Form von Pressecommuniqués;

5. verstärkte Medienpräsenz und verstärkte Präsenz bei den Multiplikatoren für Sprache (z.B. durch das Erziehungsministerium und die Schulen).

\subsubsection{Terminologiedatenbanken}

Da die Verbreitung der Terminologielisten im Internet als die effektivste Methode gilt, die offiziellen Termini einer breiten Bevölkerungsschicht zugänglich zu machen, was nicht zuletzt die hohen Zugriffszahlen auf die entsprechenden Seiten belegen, wurden von der DGLFLF im Laufe der letzten Jahre verschiedene kostenlose Datenbanken angelegt.

Zunächst besteht die Möglichkeit, sämtliche seit 1997 vorliegende Terminologieerlasse einzeln auf der Seite der DGLFLF abzurufen (vgl. Commission générale o.J., o.S.).

Des Weiteren liegt seit dem 22. September 2000 der „Répertoire terminologique 2000“ vor, dessen Erarbeitung in Artikel 13 des Dekrets vom 03. Juli 1996 festgelegt wurde.

In die vierjährige Revisionsarbeit, an der neben den CST die Académie française sowie die DGLF beteiligt waren, flossen folgende Quellen ein:

- die 13 zwischen Juli 1994 und Juli 1996 publizierten Terminologielisten,

- $\quad$ der Dictionnaire des termes officiels von 1994.

Der Répertoire terminologique enthält insgesamt ca. 2.500 Termini verschiedenster Fachgebiete (Genetik, Raumfahrt, Ökonomie und Finanzen, Informatik etc.). Bei dieser Revision aller alten Termini wurden einige völlig aufgegeben, andere modifiziert; z.T. wurden auch die Definitionen erweitert oder eingegrenzt. Neben der inhaltlichen Anpassung der Termini wurde auch eine formale Vereinheitlichung angestrebt: alle zwischen 1973 und 1996 erarbeiteten und modernisierten französischsprachigen Termini sollten in einheitlicher Form und in einer einzigen Publikation versammelt $\operatorname{sein}^{74}$.

Der Répertoire terminologique lässt sich auf den Internetseiten der DGLFLF abrufen. Die einzelnen Einträge können sowohl nach den Anfangsbuchstaben der französischen Neologismen als auch nach den Anfangsbuchstaben der Fremdwörter

\footnotetext{
73 Depecker (2001a, 591) räumt diesbezüglich selbst ein, dass aufgrund der Zeitverzögerung bei der Erstellung von Wörterbüchern mehr Wert auf die Publikation der Termini in der Presse gelegt werden sollte.

${ }^{74}$ Vgl. Commission générale (2000d, o.S.). In der Einleitung des Répertoire terminologique heißt es:

„Cette révision répond à plusieurs objectifs :

- mettre à jour et harmoniser les travaux conduits de 1973 à 1996 par les différentes commissions ministérielles ;

- recueillir sur l'ensemble des termes ainsi révisés l'avis de l'Académie française ;

- insérer les listes antérieures dans le cadre juridique posé par le décret du 3 juillet 1996 ;

- présenter de façon homogène, dans une publication unique, l'ensemble des termes approuvés“ (ebd., o.S.).
} 
geordnet eingesehen werden ${ }^{75}$. Nicht zuletzt kann der Répertoire auch in der 192 Seiten umfassenden Druckversion bezogen werden (DGLF 2000b).

Während der Répertoire terminologique nur die überarbeiteten Wortlisten bis einschließlich 1996 umfasst, enthält die Datenbank CRITER (Corpus du Réseau Interministériel de Terminologie) ebenfalls alle von 1973 bis 1996, aber auch alle in den Jahren 1997ff. im JO publizierten Termini und Definitionen. CRITER existiert seit dem 02. Juli 2001 und umfasst ca. 3.000 französischsprachige Termini mit ihrer Definition und dem fremdsprachigen Ursprungswort.

Es ist geplant, CRITER beständig zu aktualisieren, indem neue Terminologieerlasse nach ihrer Publikation im JO in die Datenbank integriert werden. CRITER sieht verschiedene Abfragemöglichkeiten vor: nach den französischsprachigen oder fremdsprachigen Bezeichnungen, nach thematischen Bereichen sowie nach Fachkommissionen (vgl. DGLFLF o.J.d).

Einen Überblick über alle 65 im JO publizierten Terminologielisten von 1973 bis September 2000 (mit Angabe des Fachbereichs, z.B. „Agriculture“ und des Datums der Veröffentlichung im JO) gibt eine entsprechende Liste (vgl. Commission générale 2000b).

Die Rubrik „Néologie coopérative“ bzw. „Néologie“ in der Zeitschrift La Banque des Mots ist keine Datenbank im eigentlichen Sinne, sondern stellt eine weitere Fundgrube für Neologismen der verschiedensten Bereiche dar. In dieser Rubrik, die einige Seiten umfasst und in der Regel einmal jährlich erscheint, führt der CILF französische Neologismen auf, die v.a. in Zeitungen und Zeitschriften nachgewiesen werden konnten. Diese sind allerdings (noch) nicht Bestandteil einer der offiziellen Terminologielisten. Bei einem Blick in die Listen von 1999 und $2000^{76}$ fällt auf, dass die Neologismen der Informatik/des Internet diejenigen aller anderen Bereiche, wie z.B. der Medizin, überwiegen. 1999 werden für die Bereiche ,informatique“, „multimédia“ und „techniques de l'information“ insgesamt 29 Termini inkl. Wortartbestimmung, Definition und Quelle angegeben. In der Liste von 2000 wird zu den drei Kategorien des Vorjahres eine vierte Kategorie hinzugefügt: „toile“. Insgesamt werden in dieser Liste 24 neue Termini aufgeführt, z.B. cyberutopiste (Def.: „Personne imaginant que la télématique améliorera les conditions de la société.“, „Néologie coopérative 2000“ 2000, 35) und métamoteur (Def.: „Moteur de recherche sur Internet qui permet d'effectuer la même recherche sur plusieurs moteurs différents et de synthétiser les résultats“, ebd., 42).

Diese alljährlich erscheinende Neologismensammlung dürfte auch eine Fundgrube für die Terminologiekommissionen darstellen, die hier bereits einige mögliche französische Äquivalente für die zu ersetzenden Anglizismen finden können ${ }^{77}$.

\footnotetext{
75 Vgl. Commission générale (2000b), Achtung: lange Ladedauer für beide Listen.

76 Veröffentlicht unter „Néologie coopérative 1999“ in La Banque des Mots 58 (1999), 51-106, „Néologie coopérative 2000" in La Banque des Mots 59 (2000), 28-51 und „Néologie" in La Banque des Mots 61 (2001), 57-119 (s. Bibliografie unter Murcia/Joly 2001).

77 Depecker $(2000,116)$ hebt hervor, dass die Terminologiekommissionen insbesondere in den Jahren seit 1996 nur eine geringe Anzahl von Termini selbst schaffen, sondern sich vielmehr auf bereits existierende Termini stützen. So hätten die CMT nur ca. 200 Termini selbst kreiert, während mehr als 4000 der offiziellen Termini bereits zuvor existierten (vgl. ebd., 119).
} 


\subsubsection{Die Fachkommissionen zur Informatik-Terminologie}

Die Informatik ist eine relativ junge Disziplin, deren Geburtsjahr in Frankreich zumeist auf 1955 datiert wird, da in diesem Jahr die Bezeichnung ordinateur ${ }^{78}$ geprägt wird ${ }^{79}$. Die Bezeichnung ordinateur geht auf den im Ausbildungszentrum von IBM tätigen Linguisten Jacques Perret zurück (vgl. Otman 2000, 371f.). Mit der neuen Technologie wächst auch der fachspezifische Wortschatz in allen Industrieländern. Die ersten europäischen Terminologiesammlungen zur Informatik erscheinen Anfang der 1960er Jahre. Während die Geschichte der Informatik bereits geschrieben wurde, bleibt die Geschichte der informatischen Fachsprache noch zu schreiben: „Si l'histoire des origines de l'informatique est déjà écrite et connait ses historiens, l'histoire de la langue de l'informatique est un vaste chantier qui n’a pas encore été attaqué dans son ampleur"“ (Otman 2000, 396). Einen Anfang macht hier sicherlich das Kapitel Depeckers, in dem er die Geschichte der Informatik-Kommissionen von 1970 bis 1993 beschreibt (vgl. Depecker 2001a, 59-92).

Die Geschichte der Informatik-Kommission beginnt am 18. September 1970 mit einem Brief von M. Jean-Paul Costa, Beauftragter des Delegierten für Informatik im Industrieministerium (Ministère du Développement industriel et scientifique), adressiert an den General Ferré sowie an dessen Sekretär und den Sekretär des Syndicat professionnel des matériels électroniques et radioélectriques (SPER). Dieser Brief fordert zur Einrichtung einer Kommission zur Verteidung des Französischen im Bereich der Informatik auf. Es solle ein Vokabular für den Bereich Informatik geschaffen werden, das sowohl innerhalb der Behörden als auch in den Medien (Presse, Radio und Fernsehen), sowohl in Frankreich als auch in anderen frankophonen Ländern verwendet werden könne (vgl. Depecker 2001a, 59f.). Am 19. Oktober 1970 tritt unter Jean-Paul Costa erstmals die Commission de défense de la langue française en matière d'informatique zusammen, die sich umgehend an die Arbeit begibt. Bereits vier Monate später berichtet die Kommission in einem an die Mitglieder des CILF gerichteten Schreiben vom 21. Januar 1971 von ihrer Tätigkeit:

\footnotetext{
${ }^{78}$ Bis in die 1970er Jahre wurde im Französischen allerdings noch der englische Terminus computer verwendet. Mitunter wurde das englische Wort grafisch oder phonetisch an das Französische angepasst (z.B. computeur). Das französische Wort ordinateur wurde mit der Publikation eines entsprechenden Terminologieerlasses am 12. August 1976 im JO offiziell festgeschrieben (vgl. Bauer 1990, 42, Fußnote 7).

79 Die eigentlichen Wurzeln der Informatik sind einige Jahre älter. Die Informatik ist in den Kontext der Informations- und Kommunikationstechnologien eingebettet, deren Beginn auf 1948 datiert wird, als Norbert Wiener eine neue Definition für Kybernetik vorschlug, die dem heutigen Konzept der Informatik sehr nahe steht (vgl. Otman 2000, 371).
} 
„Sur décision du Premier ministre français, il a été constitué sous l'autorité de la Délégation à l'informatique une commission de spécialistes du langage de l'informatique qui comprend un certain nombre de personnalités parmi lesquelles l'inventeur du vocable informatique [il s'agit de M. Philippe Dreyfus, attesté par une note de sa part datée du 2 mai 1962 au Comité d'étude des termes techniques français, Zusatz von Depecker 2001a, 63]. Une des premières tâches de cette commission a été d'examiner les possibilités de traduction du couple hardware et software“ (zitiert nach Depecker 2001a, 63).

Nicht einmal einen Monat nach diesem Schreiben kann die Informatik-Kommission am 10. Februar 1971 bereits eine erste, zehn französische Termini umfassende Liste präsentieren. Unter den zehn Termini befinden sich auch matériel und logiciel als Übersetzungen für hardware und software. Aus dieser Liste geht dann zweieinhalb Jahre später, am 29. November 1973, nach einigen Schriftwechseln zwischen der Informatik-Kommission und der Kommission des Wörterbuchs der Académie française, die zunächst zu keinem einzigen der vorgelegten Neologismen ihr Einverständnis gibt, ein erster Terminologieerlass zur Informatik-Terminologie hervor. Dieser Erlass wird am 12. Januar 1974 im JO veröffentlicht und umfasst insgesamt 34 englische Informatik-Termini, ihre Definitionen sowie ihre französischsprachigen Äquivalente (vgl. Depecker 2001a, 61-70, 451-454)

Im Anschluss an diesen ersten Erlass bleibt es einige Jahre stumm um die Informatik-Terminologie, bis durch einen Erlass vom 07. September 1979 eine offizielle Informatik-Kommission im französischen Industrieministerium eingerichtet wird. Durch einen Erlass vom 13. November 1986 werden eine neue InformatikKommission sowie eine Kommission zum Vokabular der elektronischen Bauelemente gegründet (vgl. Schmitt 1990a, 366f.).

In den Jahren 1979 bis 1993 werden von den beiden Informatik-Kommissionen insgesamt fünf Erlasse zum Informatik-Vokabular im JO veröffentlicht, nämlich der Erlass vom 22. Dezember 1981 (54 Termini), vom 30. Dezember 1983 (36 Termini), vom 30. März 1987 (27 Termini), vom 27. Juni 1989 (15 Termini) und vom 19. Februar 1993 (42 Termini).

1997 wird die bisherige CMT in der Folge des Dekrets vom 03. Juli 1996 in commission spécialisée de terminologie et de néologie de l'informatique et des composants électroniques (CSTIC) umbenannt und durch den Erlass vom 05. August 1997 ins Leben gerufen. Die Geschäftsführung der CSTIC liegt bei der AFNOR. Parallel zu diesem Erlass wird im JO vom 23. August 1997 ein zweiter Erlass publiziert, in dem die Zusammensetzung der Mitglieder dieser Kommission festgelegt wird. Die Mitglieder der CSTIC werden zunächst für eine Amtsdauer von vier Jahren nominiert. Seit 2002 gibt es eine neu zusammengesetzte Kommission, in der neben dem Präsidenten nur zwei Mitglieder der alten Kommission (L. Depecker und A.

80 Vor allem die Arbeiten von Marcellesi (1971/1973) geben eine Momentaufnahme der InformatikTerminologie Anfang der 1970er Jahre. Bei einem Vergleich der früheren und der heutigen Informatik-Terminologie wird deutlich, dass die frühere Terminologie weitaus stärker anglisiert war als die heutige (vgl. Humbley 2000, 330). 
Roca) weiterarbeiten. Über die Zusammensetzung der beiden ab 1997 bzw. ab 2002 tätigen Informatik-Kommissionen gibt die folgende Abbildung Aufschluss:

Abb. 2: Zusammensetzung der Informatik-Kommission 1997-2001 und 20022005/2006

\section{Zusammensetzung der Mitglieder der Kom- mission nach ihren Funktionen}

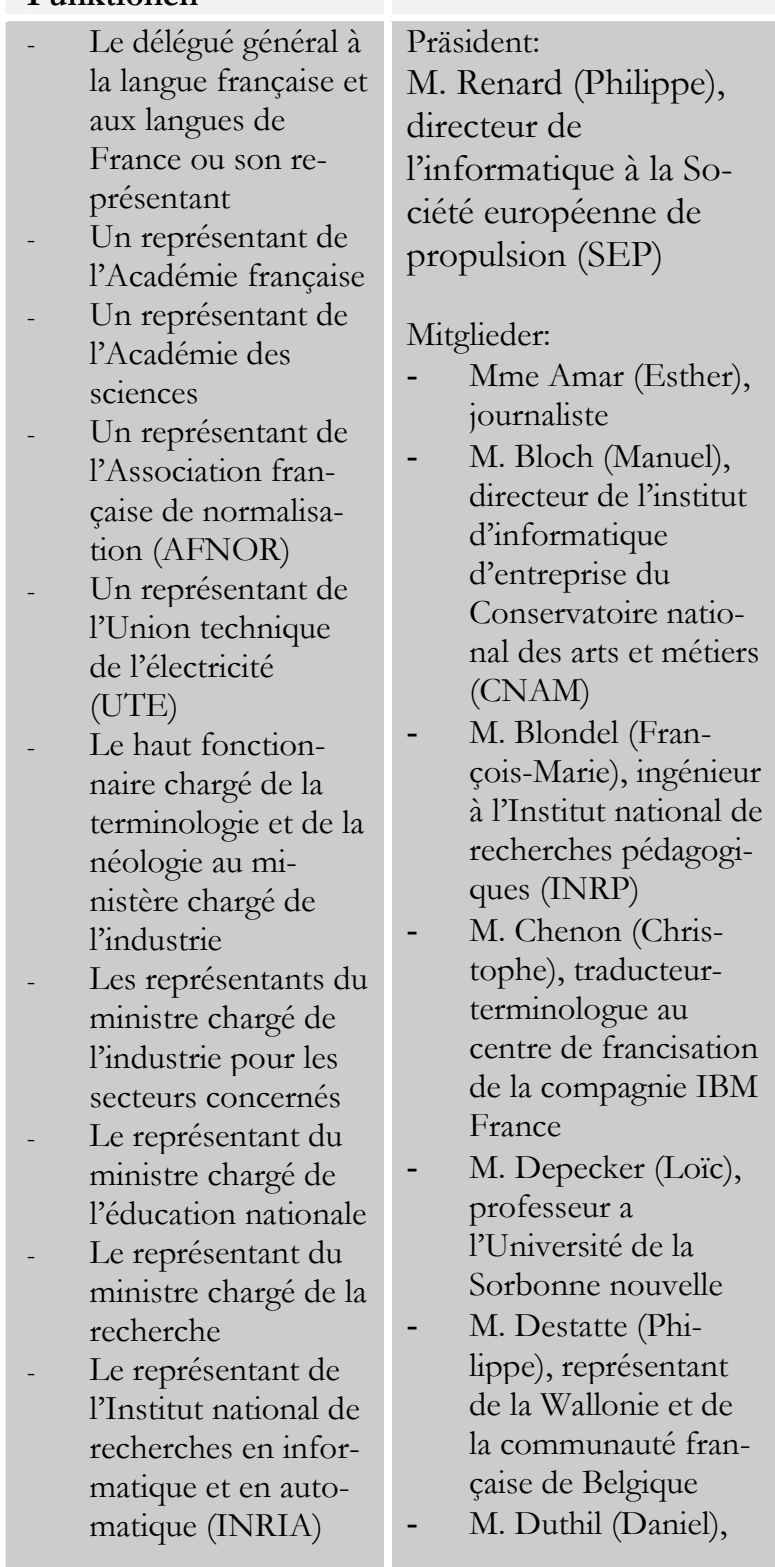

\section{Mitglieder der Infor- matik-Kommission (ab 2002)}

\author{
Präsident: \\ M. Renard (Philippe) \\ Mitglieder:
}

- $\quad$ M. Anis (Jacques), professeur de linguistique à l'université Paris$\mathrm{X}$ - Nanterre

- $\quad$ M. Bodin (Jacques), ingénieur

- M. Bourguignon (Bernard), ingénieur informaticien

- $\quad$ Mme Candel (Danielle), chercheuse en linguistique française au Centre national de la recherche scientifique (CNRS)

- M. Carteron (Thierry), contre-amiral (2e section)

- M. Chauvois (Bernard), inspecteur général honoraire de l'éducation nationale

- M. Depecker (Loïc), professeur à l'université de la Sorbonne nouvelle, président de la Société française de terminologie et de néologie

- Mme Guillerme (Hélène), chef de projet terminologie au centre de francisation d'IBM

- M. Hernandez (JeanAlain), enseignant- 


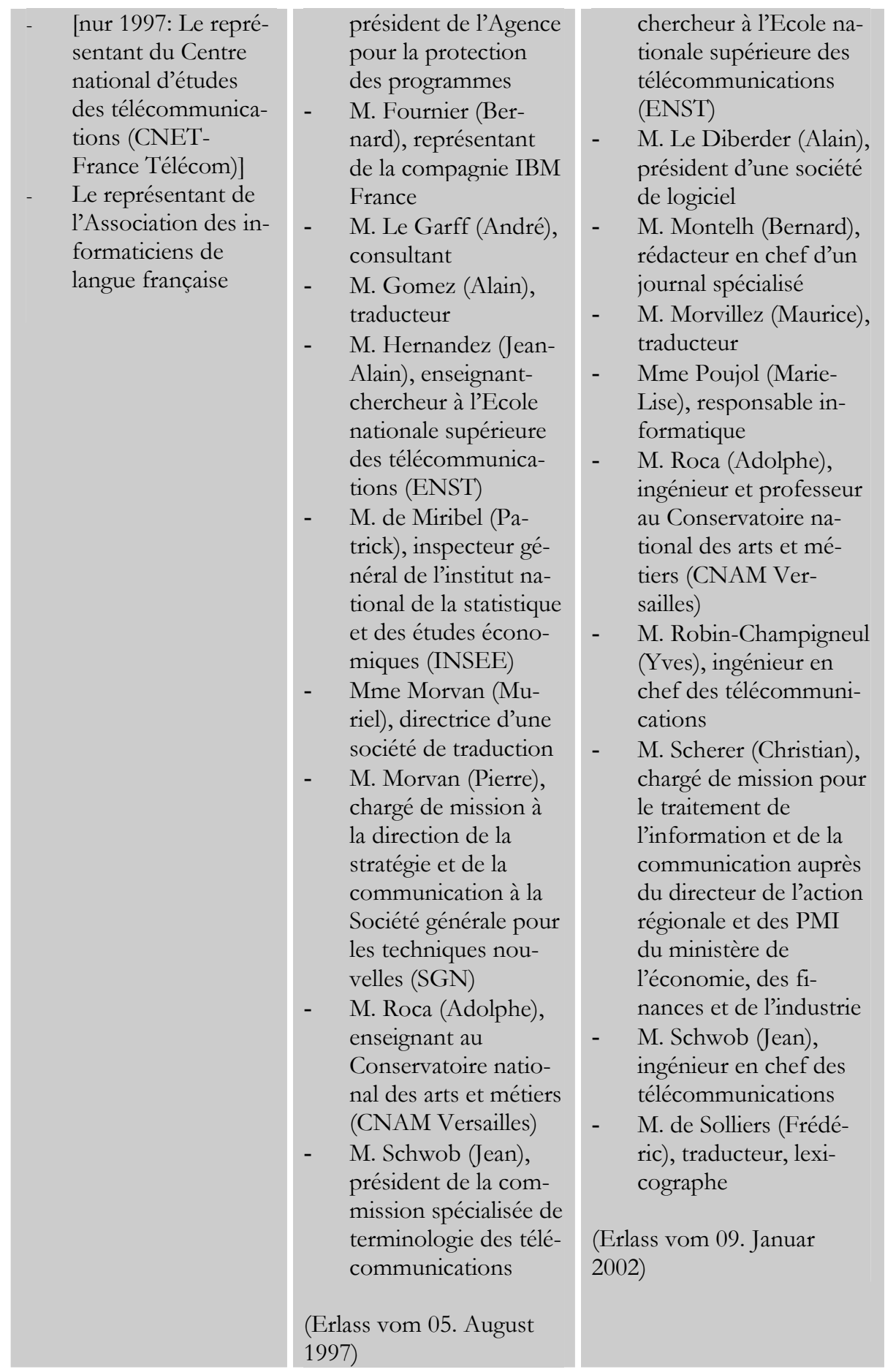


Über die Arbeit der seit 2002 nominierten Kommission kann an dieser Stelle noch keine Aussage getroffen werden. Die Ergebnisse der von 1997-2001 tätigen Informatik-Kommission sind auf jeden Fall beachtlich. Es ist anzunehmen, dass die Informatik-Kommission zumindest beratenden Anteil an dem von der Commission générale erarbeiteten Erlass vom 02. Dezember 1997 bezüglich der Äquivalente zu engl. e-mail hat. Am 10. Oktober 1998 wird ein insgesamt 37 Begriffspaare umfassender Erlass zur Informatik-Terminologie veröffentlicht. Ab 1998 konzentriert sich die Arbeit der CSTIC in der Folge einer Anfrage durch die Ministerin für Kultur und Kommunikation Mme Trautmann auf das Vokabular des Internet. Der Veröffentlichung der ersten Liste zur Internet-Terminologie gehen zahlreiche Vorarbeiten voraus. Neben der Möglichkeit zur Mitbestimmung der Termini (vgl. 3.2.6) ist auf der Seite der DGLF bereits viele Monate vor der Verabschiedung der offiziellen Internet-Terminologie ein (vorläufiges) „Glossaire des termes relatifs à Internet" abrufbar (vgl. Sachs 1998, 2. Teil, o.S.) ${ }^{81}$.

Die erste, 53 Begriffspaare umfassende Liste zum Internet-Vokabular wird im JO vom 16. März 1999 publiziert und anschließend in einer Broschüre der DGLF mit einer Auflagenhöhe von 50.000 Exemplaren (1. Auflage) abgedruckt und verteilt ${ }^{82}$. Über die Vorarbeiten zu dieser ersten Internet-Terminologie und v.a. zur Bildung der interministeriellen Arbeitsgruppe gibt der Jahresbericht 1998 der Commission générale Auskunft:

\footnotetext{
81 Die Internet-Terminologie der DGLF ist jedoch keineswegs der einzige Versuch, französischsprachige Internet-Termini festzulegen. Neben der seit 1999 offiziell gültigen Terminologie gab und gibt es noch andere im Internet zugängliche Wörterbücher zur Internet-Terminologie, z.B. den Lexique des néologismes Internet von Guy Brand und Jean-Pierre Kuypers (1997) oder die Datenbank des OLF (vgl. 3.3.3). Eine Aufstellung verschiedener online einsehbarer Verzeichnisse zur Internet-Terminologie gibt z.B. der Centre international pour le développement de l'inforoute en français (CIDIF, 1996-2001, o.S.).

82 Dabei kann die CSTIC auf bereits existierende Terminologie-Vorschläge zum Internet-Vokabular zurückgreifen. Ein Beispiel ist, neben einigen Wörterbüchern zur Informatik, die von Cosquer (1996, 92-114) in der Zeitschrift La Banque des Mots veröffentlichte Internet-Terminologie, bei der allerdings noch, wie die Autorin selbst einleitend bemerkt, die englischsprachigen Ausdrücke überwiegen. Es fällt bei Cosquers Terminologie im Vergleich zu der Terminologie vom März 1999 auf, dass für engl. browser noch kein eindeutiges französischsprachiges Synonym gefunden wurde, denn für engl. browser werden engl. browser und franz. butineur (vgl. ebd., 94), franz. feuilleteur (vgl. ebd., 96) und franz. fouineur (vgl. ebd., 97 - dieser Terminus gilt ab 1999 als Ersatzwort für engl. hacker (!)) angegeben. Für engl. chat fehlt ein französischsprachiges Äquivalent, so dass auf engl. chat zurückgegriffen wird (vgl. ebd., 94). Für andere englischsprachige Termini existieren jedoch bereits die französischsprachigen Äquivalente, die auch die Liste vom März 1999 vorsieht: franz. page d'accueil für engl. home page (vgl. ebd., 106), franz. signet für engl. bookmark (vgl. ebd., 109), franz. émoticône für engl. smiley (vgl. ebd.).
} 
„Le 16 janvier 1998, Mme Catherine TRAUTMANN, ministre de la culture et de la communication, a écrit au président de la commission générale de terminologie et de néologie, M. Gabriel de BROGLIE, pour demander à la commission générale de se consacrer en priorité à l'élaboration d'un vocabulaire français de l'informatique et de l'internet.

La commission générale de terminologie, qui dès le début de ses travaux avait fait du vocabulaire de l'internet un champ de travail prioritaire, a chargé M. Gérard PAINCHAULT, membre de la commission générale et haut fonctionnaire chargé de la terminologie et de la néologie au ministère de l'économie, des finances et de l'industrie, de constituer, autour des différentes commissions spécialisées de terminologie concernées par ce vocabulaire (à titre principal, la commission de l'informatique et celles des télécommunications, mais aussi les commissions spécialisées de l'économie et des finances et celle de la culture et de la communication), un groupe d'experts interministériel chargé d'effectuer la veille, de coordonner les travaux et de soumettre régulièrement à la commission générale des propositions d'équivalents français.

Ce groupe de travail a transmis à la commission générale une première liste de propositions comprenant les notions de base de l'internet. Cette liste a été examinée lors des réunions des mois de juin et de juillet et transmise à l'Académie française.

La liste adoptée par la commission générale, qui comporte une soixantaine de termes et définitions, a pu être publiée au Journal officiel, après avis définitif de l'Académie française, en mars 1999 pour la fête de l'internet et la semaine de la langue française et de la francophonie.

Par ailleurs, la liste des termes de l'informatique publiée au Journal officiel du 10 octobre 1998 constitue, avec les termes relatifs au courrier électronique publiés le 2 décembre 1997, le premier volet des publications de la commission générale dans le domaine des technologies de l'information et de la communication. Une deuxième liste de termes relatifs à l'internet est en cours de préparation“"

(Bericht der Commission générale von 1998, Teil 1, o.S.).

Im Jahresbericht 1998 wird bereits eine zweite Internet-Terminologie angekündigt. Zu deren Vorbereitung hält die CSTIC 1999 insgesamt fünf Treffen ab (8. Januar, 9. April, 11. Juni, 17. September und 3. Dezember) und reicht ihren Entwurf Anfang Dezember 1999 an die Commission générale weiter. Die Commission générale begutachtet diese Liste am 08. Dezember 1999. Die Publikation dieser zweiten, aus insgesamt zwölf Lexempaaren bestehenden Liste erfolgt im JO vom 01. September 2000 (vgl. AILF 2002, o.S.; DGLF 2000a, o.S.). 
Im Jahr 2000 beginnen sogleich die Arbeiten für die dritte Liste zur Internet-Terminologie. Parallel dazu wird an einer dritten Liste zur Informatik-Terminologie gearbeitet. Beide Listen werden im Laufe des Jahres 2001 zusammen mit fünf weiteren Terminologielisten anderer Fachkommissionen von der Commission générale, die sie überprüft hat, an die Académie française weitergereicht (vgl. Bericht der Commission générale von 2001, Teil 1, o.S.) ${ }^{83}$. Außerdem wird im Jahr 2001 eine Liste mit Empfehlungen herausgegeben, durch welche französischen Äquivalente das englische Präfix e- (z.B. e-mail, e-commerce) wiedergegeben werden kann. Diese Liste wird von der Commission générale in Zusammenarbeit mit den Fachkommissionen zur Telekommunikation und zur Informatik erstellt. Möglichkeiten zur Ersetzung des englischen Präfixes sind z.B. die französischen Präfixe cyber- und téléoder die Formulierung en ligne (vgl. Bericht der Commission générale von 2001, Teil 1, o.S.; De Broglie 2002, o.S.). Die dritte, aus neun Lexempaaren bestehende Liste zur Internet-Terminologie wird dann im JO vom 08. Dezember 2002 publiziert (vgl. DGLFLF 2002, o.S.).

Im Jahre 2001 richtet die CSTIC eine eigene Internetseite ein, auf der nicht nur Informationen zur Terminologiearbeit bereit gestellt werden, sondern auch die Möglichkeit zur Mitwirkung an der Terminologiefindung gegeben wird. Entsprechend heißt es im Bericht der Commission générale (2001, Teil 3, o.S.):

„La commission spécialisée de l'informatique a réalisé un site informatique (www.cstic.fr.st) qui, non seulement donne des informations diverses sur la commission, les textes de référence, les termes publiés dans le domaine de l'informatique et de l'internet, mais offre un espace d'information et de concertation réservé aux membres de la commission, ainsi qu'une possibilité de dialogue avec le public. La commission a institué un comité de rédaction responsable de la mise en place de ce site."

Konkret bedeutet das, dass auf der Seite der CSTIC (http://www.ensmp.fr/|industrie/igic/cstic/84) eine Rubrik „Participez aux études préparatoires“ vorhanden ist ${ }^{85}$. Von Januar bis Dezember des Jahres 2002 wurden ein französisches Äquivalent sowie eine Definition für den englischen Internet-Terminus $p \circ p$ и $p^{86}$ gesucht. Auf dieser Seite ist es möglich, einen eigenen Beitrag zu leisten, indem per E-Mail entweder eine Definition oder ein französischer Neologismus oder beides vorgeschlagen wird. Die Seite enthält sowohl die Bitte zur Teilnahme als auch einige (vorläufige) Angaben zum Terminus: einen Kommentar zur Bedeutung und zum Ursprung des englischen Terminus, eine vorläufige Definition

\footnotetext{
${ }^{83}$ Die Publikation der dritten Terminologieliste ist eigentlich in den letzten Monaten des Jahres 2001 vorgesehen (vgl. Bericht der DGLFLF 2001, Teil 5, Kap. 4), was aber nicht eingehalten wird.

${ }^{84}$ Zur Trennung von Internetadressen vgl. Bibliografie, Fußnote 1.

${ }^{85}$ Diese Terminologiekommission ist derzeit die einzige Kommission, die über eine Internetpräsenz verfügt, wie die Liste aller aktuell existierenden Terminologiekommissionen ausweist (vgl. DGLFLF o.J.c, o.S.).

86 Zur Erklärung der Termini pop up und peer to peer vgl. Glossar (Anhang, 15.7).
} 
sowie einen vorläufigen Vorschlag für ein französisches Äquivalent. Außerdem wird für pop up eine zeitliche Begrenzung genannt: „Fin de consultation: 15 mars 2002“, welche zunächst bis zum 30. April, dann bis zum 01. September 2002 und bis zum 01. Dezember 2002 verlängert wurde (vgl. http://ensmp.net/cstic/|etudes/). Im November 2002 kommt dann ein weiteres Kästchen für den informatischen Terminus peer to peer hinzu, und für beide wird zunächst der 06. Dezember 2002, dann der 31. Januar 2003 als Stichtag angegeben:

\section{Abb. 3: Beteiligung der Öffentlichkeit an der Terminologiearbeit der CSTIC}

Terme étranger (dont on cherche un équivalent) : pop up

Commentaires relatifs au concept : le verbe "to pop up" est, à l'origine, une onomato-

pée qui peut s'appliquer à un évènement survenant de façon inattendue, par exemple le bou-

chon qui surgit avec un bruit caractéristique du col d'une bouteille de champagne, ou encore un sous-marin américain qui émerge à l'improviste sous la quille d'un navire de pêche japonais!

avant-définition : Au niveau des interactions bomme-machine, désigne une zone d'affichage ou fenêtre qui apporte soudainement un élément nouveau.

avant-terme en français : Apparition.

Fin de consultation : 15 mars 2002 [6 décembre 2002, 31 janvier 2003]

Terme étranger (dont on cherche un équivalent) : peer to peer

Commentaires relatifs au concept : le concept s'applique à la situation d'un réseau dans lequel les ordinateurs communiquent entre eux sans l'intervention d'un serveur client. avant-définition : qualifie un logiciel permettant à des ordinateurs de coopérer entre eux au même niveau.

avant-terme en français : pair-à -pair

symbole : P2P.

Fin de consultation : 6 décembre 2002 [31 janvier 2003]

Es ist davon auszugehen, dass die beiden Termini Bestandteil der jeweils vierten Liste zur Internet- und Informatik-Terminologie sein werden.

Die Listen zur Internet-Terminologie werden zwar maßgeblich, aber nicht auschließlich von der CSTIC gestaltet. Neben der Mithilfe durch andere Organisationen wie die Association des Informaticiens de la Langue Française (AILF) beteiligen sich auch noch weitere Fachkommissionen an der Terminologiearbeit zum Internet-Vokabular. Im Bericht der DGLF von 1998 (Teil 1) wird noch von einer einer interministeriellen Arbeitsgruppe (,groupe interministériel pour le vocabulaire de l'internet") gesprochen, zu der die Fachkommissionen der Telekommunikation, der Wirtschaft und Finanzen und der Kultur gehören. Die Zusammenarbeit hat 
sich dann allerdings auf zwei Kommissionen reduziert, nämlich die InformatikKommission und die Kommission zum Wortschatz der Telekommunikation ${ }^{87}$.

Mehr als die anderen Fachkommissionen findet die Informatik-Kommission für ihre Arbeit in dem vom Premierminister am 16. Januar 1998 präsentierten „Programme d'Action Gouvernemental pour la Société de l'Information" (PAGSI) Rückhalt ${ }^{88}$. In diesem Programm wird vor allem die Bedeutung der ständigen Erarbeitung einer aktuellen französischsprachigen Informatik- und Internet-Terminologie für die Eingliederung Frankreichs in die Informations- und Kommunikationstechnologien hervorgehoben (vgl. DGLFLF, o.J.b, o.S.). Eine konkrete Umsetzung findet dieses Projekt in den drei 1999, 2000 und 2002 veröffentlichten Terminologie-Listen zum Internet-Vokabular, in den beiden Listen zum Informatik-Vokabular sowie in der vierten (Internet) bzw. dritten (Informatik) in Arbeit befindlichen Liste.

An der Erstellung der Informatik- und Internet-Terminologie hat sich neben den genannten Einrichtungen auch das Unternehmen IBM (v.a. in Frankreich, Belgien und Kanada) beteiligt. Anstatt den Mitarbeitern eine firmeneigene Terminologie aufzuerlegen, hat IBM sich kooperativ gezeigt und in Zusammenarbeit mit den Terminologiekommissionen eine umfassende französischsprachige Informatik/Internet-Terminologie erarbeitet. Das Ergebnis von IBM (Kanada) ist ein im Internet konsultierbares Wörterbuch, das inzwischen schon in der zweiten Version zugänglich ist. Der „Dictionnaire de l'internaute (commerce électronique, infographie, informatique, internet, micro-informatique, multimédia, réseautique, sécurité informatique, technologies de l'information, télécommunications) “ kann auf der Seite von IBM (Kanada) unter http://www.can.ibm.com/francais/dico/ eingesehen werden. Für die Koordinierung der Terminologiearbeit zwischen IBM (Frankreich) und der CSTIC ist Mme Hélène Guillerme zuständig, die auch Mitglied der aktuellen Informatik-Kommission ist (vgl. Abb. 2) ${ }^{89}$.

\footnotetext{
87 In einer Pressemitteilung der CSTIC wird lediglich auf die Zusammenarbeit mit der Kommission für die Kommunikationstechnik hingewiesen: „La Commission spécialisée de terminologie et de néologie de l'informatique et des composants électroniques (CSTIC) ainsi que la Commission spécialisée de terminologie et de néologie des télécommunications (CSTNT) élaborent des listes d'équivalents français aux termes étrangers de l'informatique et de l'internet“" (CSTIC 1999, o.S.). Auch im 3. Teil des Berichts der Commission générale von 1999 ist auch nur noch von diesen beiden Kommissionen die Rede.

88 Dieses Programm läuft auch unter dem Titel „Préparer l'entrée de la France dans la société de l'information". Ein Auszug dieses Programms ist im Bericht der Commission générale von 1998 (Anhang 6, o.S.) nachzulesen. Hier wird besonders auf die Vorreiterrolle Québecs verwiesen: „Le Québec, qui a montré la voie d'un engagement résolu en faveur de l'utilisation d'Internet, nous en donne l'exemple : la terminologie francophone s'adapte aisément au développement des termes propres à Internet. Surtout, parce que les technologies de l'information et de la communication deviennent un enjeu de société, il importe que la terminologie sur laquelle elles se fondent soit accessible au grand public, et donc compréhensible."

Über den Erfolg des Programms berichten Renonciat/Cours de Stéphane Cottin (o.J., o.S.).

89 Zur Kooperation von IBM (Frankreich) mit Organisationen wie AFNOR und den Terminologiekommissionen, aber auch mit IBM (Belgien) vgl. Oleffe (1994, 24f.).
} 


\subsubsection{Möglichkeiten der Mitwirkung an der französischen Termino- logiearbeit}

Unter dem Titel „Kooperative Neologismen (Internet)“ beschreibt Braselmann (1999a, 63-67), wie Terminologen, Übersetzer oder andere sprachinteressierte Personen bei der Suche nach den offiziellen Ersatzwörtern mitarbeiten können. Braselmann schildert ausführlich den Prozess der Ersatzwortfindung für die vier englischen Termini browser, computer ${ }^{00}$, home page“ und e-mail.

Um die Bevölkerung in den Prozess der Ersatzwortfindung einbeziehen zu können, gründet die DGLF 1995 für Fragen und Diskussionen zum Thema Terminologie den Internet-Dienst dglf@culture.fr (vgl. Depecker 1997a, XXXIV). Mitte der 1990er Jahre stellt die DGLF auf ihren Internetseiten drei Dienste zur Verfügung: 1. drei Mailinglisten zu den Themen Terminologie, Übersetzung und Neologie ${ }^{91}$, 2. eine Liste mit häufig zu diesem Thema gestellten Fragen (zusammengestellt aus früheren Beiträgen der Mailingliste) und 3. die online abrufbaren Terminologielisten (vgl. Depecker 1997b, o.S.). Da die Sprachbenutzer an der Entscheidung für bestimmte Ersatzwörter beteiligt werden, kann man hier mit Braselmann von einer modernen, kooperativen und demokratischen Form der Sprachpflege sprechen, die im Gegensatz zur traditionellen und nur von einer Elite betriebenen Sprachpflege breitere Bevölkerungsschichten miteinbeziehe (vgl. Braselmann 1999a, 65-67) 92 .

Die geschilderte Möglichkeit, bei der Ersatzwortfindung mitzuwirken, ist heute nur noch in sehr reduzierter Form möglich. In den Jahren 1998/1999 wird die Struktur des Internetangebots der DGLF grundlegend verändert und die Inhalte werden im Laufe der darauf folgenden Jahre um ein Vielfaches erweitert. Die drei Mailinglisten sind inzwischen stillgelegt. Insofern entfällt seit einigen Jahren die Möglichkeit, sich über die Internetseiten und Mailinglisten der DGLFLF an der Ersatzwortfindung zu beteiligen. Das bedeutet, dass die Entscheidung, ob die

\footnotetext{
${ }^{90}$ Diesem Wort wurde allerdings bereits im Erlass vom 30. Dezember 1983 ein offizielles Ersatzwort zugewiesen, nämlich ordinateur, das sich längst in Frankreich durchgesetzt hat (vgl. Fußnote 78). Gut zehn Jahre später wird der Versuch einer Revision dieses Terminus unternommen. Für engl. computer werden die französischen Termini ordinateur und bécane zur Auswahl gestellt, von denen sich wiederum ordinateur durchsetzt.

${ }^{91}$ Die Gestaltung der Internetpräsenz der DGLF/DGLFLF hat sich im Laufe der Jahre erheblich verändert. In der Zeit bis 1999 besteht die Internetseite der DGLF nur aus zwei Unterseiten, der Seite France langue und der Seite Ressources sur les langues (vgl. Petit 1999, 161). Den Aufbau der frühen Internetpräsenz der DGLF, speziell für den Dienst „France-Langue“, beschreiben für den Zeitraum von 1995-1999 z.B. Braselmann (1999a, 63-65), Depecker (2001b) und Petit (1999). Bis 1999 gab es auf der Seite France langue der DGLF eine allgemeine Liste, france_langue@culture.fr, die für alle Sprachbenutzer offen war. Des Weiteren gab es zwei Listen, die sich an professionelle Sprachbenutzer (Übersetzer, Terminologen, Wissenschaftler) richteten: france_langue_assistance@culture.fr und france_langue_technologies@culture.fr. An die Stelle dieser drei 1999 stillgelegten Mailinglisten ist ein neuer Dienst getreten: Auf der Seite „Des ressources sur la toile pour les traducteurs et les terminologues" (DGLFLF o.J.e) sind verschiedene Informationen u.a. in der Form eines FrageAntwort-Katalogs zusammengestellt, die für Übersetzer und Terminologen von Interesse sein könnten. Inzwischen betreibt die DGLFLF keine eigenen Mailinglisten mehr. An die Stelle von france_langue@culture.fr ist die neue Liste langue-fr@yahoogroupes.fr getreten.

92 Entsprechend unterteilt Braselmann (2001, 175f.) die seit 1970 vorgeschlagenen Ersatzwörter in drei Gruppen, 1. die „,künstlich“ geschaffenen Äquivalente, 2. die spontan entstandenen Äquivalente und 3. die kooperativen, experimentellen Neologismen.
} 
Öffentlichkeit in die Terminologiearbeit einbezogen werden soll, nun den einzelnen Kommissionen obliegt. Bezüglich der Informatik-/Internet-Terminologie ist eine Mitarbeit der Öffentlichkeit, wenn auch in sehr eingeschränktem Maße, möglich (vgl. 3.2.5).

Der Bereich Terminologie wurde in den letzten Jahren auf den Internetseiten der DGLFLF ausgebaut. Auf der Startseite der DGLFLF (http://www.culture.fr/|culture/dglf/) befindet sich die Rubrik „Vocabulaire et terminologie“. Diese Rubrik umfasst Informationen zur französischen Terminologiearbeit, die einzelnen Terminologielisten, den Répertoire terminologique sowie die Datenbank CRITER (vgl. 3.2.4.2). Aufgrund der vielen Texte, die die Terminologiearbeit, aber auch die übrigen Aktivitäten der DGLFLF dokumentieren, entfällt inzwischen die vor einigen Jahren noch existierende Rubrik mit den häufig gestellten Fragen.

Insgesamt kann Braselmann (1999a, 65) zugestimmt werden, wenn sie die neue Richtung, die die französische Sprachpolitik in der zweiten Hälfte der 1990er Jahre eingeschlagen hat, wie folgt charakterisiert: „Die französische Spachpolitik hat mit dem Internet ein Medium gefunden, mit dem es deskriptiv, präventiv, experimentell, demokratisch und kooperativ, d.h. unter Einbezug der Sprachbenutzer, französische Äquivalente für Anglizismen vorschlagen kann.“

Wenngleich inzwischen die Möglichkeiten für interessierte Bürger, an der Ersatzwortfindung mitzuwirken, sehr eingeschränkt sind, erreicht die DGLFLF durch die ausführliche Dokumentation ihrer sowie der Arbeit der Commission générale und der einzelnen Fachkommissionen (CST) eine große Transparenz. Die einzelnen Arbeitsschritte und die Ergebnisse bleiben für die interessierte Bevölkerung nachvollziehbar, und der Steuerzahler kann sehen, wo ein Teil seines Geldes hinfließt.

\subsubsection{Zusammenfassung von 3.2}

In der zweiten Hälfte des 20. Jahrhunderts hat die französische Sprachpolitik im Wesentlichen zwei Ziele: 1. die Verbreitung der französischen Sprache in der Welt („Frankophonie“, vgl. 2.3.1) und 2. die Verteidigung des Französischen vor Angloamerikanismen. Im Rahmen dieser Arbeit wird nur das zweite Ziel näher beleuchtet.

Seit der Gründung des Haut Comité de la langue française im Jahr 1966 werden in Frankreich verschiedene Verordnungen und Gesetze zum Schutz der französischen Sprache erlassen. Als wichtigste gesetzgeberische Maßnahmen gelten das Dekret vom 07. Januar 1972, welches die Existenz der Terminologiekommissionen legitimiert, die Sprachgesetze von 1975 und 1994 sowie das Dekret vom 03. Juli 1996.

Ein weiterer wichtiger Meilenstein in der Geschichte der staatlichen Terminologieplanung ist die Gründung der DGLF im Jahre 1989, die sich 2001 in DGLFLF umbenennt. Durch diese Sprachpflegeorganisation, durch die Einrichtung der Commission générale und durch weitere, im Dekret vom 03. Juli 1996 vorgesehene Regelungen erlebt die französische Terminologiearbeit seit einigen Jahren einen gewaltigen Aufschwung. Das Dekret von 1996 systematisiert die Terminologiearbeit durch die Einrichtung einer koordinierenden Stelle, der Commission générale, 
und legt eine Überarbeitung aller bisher veröffentlichten Terminologielisten fest. Als Ergebnis dieser Bemühungen wird im September 2000 der Répertoire terminologique veröffentlicht. Auf der Basis dieser Arbeit wird der Öffentlichkeit bereits ein Jahr später eine weitere Datenbank, CRITER, zur Verfügung gestellt.

Im Rahmen dieses Unterkapitels konnte nicht auf alle Terminologiekommissionen einzeln eingegangen werden. Vielmehr wurde versucht einen Eindruck von den seit 1970 stattfindenden Terminologiearbeiten zu vermitteln. Detaillierter wurden die Aktivitäten der Informatik-Kommissionen betrachtet, deren Mitglieder in Form einer interministeriellen Arbeitsgruppe auch für die Erstellung der Listen zur Internet-Terminologie zuständig sind. Es konnte gezeigt werden, wie vor allem die DGLFLF und die Informatik-Kommission das Internet in ihre Bemühungen einbeziehen. In diesem Bereich wird auch in der Zukunft noch einiges zu erwarten zu sein.

Eine Möglichkeit, einen systematischen Überblick über die Terminologiearbeit zu geben, zeigt Depecker (2001a, 24-29) auf, der die Terminologiearbeit in drei Phasen unterteilt: Die erste Phase umfasst den Zeitraum 1970-1973 und stellt die Phase der Konstituierung dar, die zweite Phase umfasst den Zeitraum 1978 bis Ende der 1980er Jahre. In dieser Phase werden die terminologischen Aktivitäten zunächst wieder aufgenommen und neue CMT geschaffen. Dieser Aufschwung verläuft dann allerdings allmählich mit dem Verschwinden von FRANTERM in der zweiten Hälfte der 1980er Jahre im Sande. Eine dritte Phase beginnt 1990 mit der Öffnung der Terminologiearbeit gegenüber intensiver Kooperation mit den Universitäten (besonders: Rennes-II, Rouen, Lyon-II, Toulouse-le-Mirail) und verschiedenen anderen Forschungsinstituten. Humbley (2000, 323) schließt an diese Einteilung eine vierte Phase der Terminologiearbeit an, die Phase nach 1996. Diese umfasst die Arbeiten, die sich aufgrund der Neustrukturierungen in der Folge des Dekrets vom 03. Juli 1996 ergeben haben.

\subsection{Nationale und länderübergreifende Terminologiearbeit}

In 3.2.3.2 wurde die oberste, in Frankreich für die Koordinierung der Terminologievorschläge zuständige Kommission vorgestellt, die Commission générale de terminologie et de néologie. Dieser Abschnitt widmet sich der Frage, ob es vergleichbare Institutionen, die ausschließlich für die Terminologiebildung bzw. für die Koordinierung der Ergebnisse einzelner Arbeitsgruppen zuständig sind, auch in den anderen Kernländern der Frankophonie gibt. Mit anderen Worten geht es darum, die in Belgien, in der Schweiz und in Québec für die Terminologiearbeit zuständigen Stellen und ihre Arbeitsweise vorzustellen. Des Weiteren ist zu fragen, wie die juristischen Rahmenbedingungen der Terminologiearbeit in den einzelnen Ländern aussehen: Gibt es in Belgien, der Schweiz und Québec auch Sprachgesetze zum Schutz der französischen Sprache? Besonders interessiert im Rahmen der folgenden Unterkapitel 3.3.1 und 3.3.2 natürlich, ob es für den Wortschatz des Internet auch belgische und schweizerische Neologismen gibt und welche dies sind. Außerdem soll der Frage nachgegangen werden, wie es mit Bemühungen 
aussieht, Terminologiefragen auch über Ländergrenzen hinweg zu diskutieren, und ob es eine übernationale Zusammenarbeit zwischen den einzelnen Terminologieinstituten der frankophonen Länder gibt (3.3.3). 3.3.4 schließlich gibt einen vergleichenden Überblick über die in Frankreich, Belgien, der Schweiz und Québec offiziell gültige Internet-Terminologie.

\subsubsection{Terminologiearbeit in Belgien}

Während in Frankreich die DGLF für Sprachpolitik generell und die Commission générale de terminologie et de néologie für die Koordinierung der Terminologiearbeiten zuständig sind, werden diese Aufgaben in Belgien vom Service de la langue française du Ministère de la Communauté française wahrgenommen. Auf der Internetseite des Service de la langue française, der vom Service Général des Lettres et du Livre abhängt, werden acht entscheidende Maßnahmen aufgezählt, die zum Schutz der französischen Sprache ins Leben gerufen wurden (vgl. Service de la langue française o.J.a, o.S.). Von Interesse ist in diesem Kontext die zweite Maßnahme, nämlich das Projekt „L'enrichissement de la langue française: néologie et terminologie“. In der Einführung zu diesem Projekt heißt es zur belgischen Sprach- und insbesondere Terminologiepolitik: „La France d'abord, la Communauté française de Belgique ensuite ont emboîté le pas au Québec pour tenter de définir les grands axes d'une politique terminologique pour la langue française“" (vgl. Service de la langue française o.J.b, o.S.). Es wird auf Québec und seine Vorreiterrolle in Terminologiebelangen verwiesen. Diesem Beispiel seien erst Frankreich, und dann auch seit 1978 Belgien gefolgt. Der Hintergrund der belgischen Terminologiearbeit sei aber - hiermit soll falschen Vorstellungen von den mit der Terminologiearbeit verbundenen Zielen vorgebeugt werden - nicht die Vertreibung der Anglizismen, sondern die Bereicherung des Französischen, um die Bedürfnisse nach französischen Bezeichnungen all derjenigen zu befriedigen, die beruflich auf Fachtermini zurückgreifen müssten:

„Le véritable objectif de la politique terminologique ne consiste donc pas à faire la chasse systématique au franglais. Il consiste plutôt à répondre à la demande des professionnels (surtout traducteurs) en créant les conditions nécessaires pour leur permettre de disposer d'un corpus de termes utilisables en français, dans les nombreuses langues de spécialitéc، (ebd.).

Am 12. Juli 1978 wird als Reaktion auf das französische Sprachgesetz von 1975 der „décret du 12 juillet 1978 sur la défense de la langue française“ erlassen und im Moniteur belge vom 09. September 1978 publiziert (vgl. Service de la langue française o.J.e $)^{93}$. Dieses Dekret folgt inhaltlich sehr eng dem französischen Vorbild, der Loi Bas-Lauriol. Gemäß Artikel 1 des Dekrets wird der Gebrauch des Französischen in öffentlichen Gebäuden, Arbeitsverträgen, Gebrauchsanweisungen, Wer-

\footnotetext{
${ }_{93}$ Der Vorschlag für dieses Dekret liegt bereits seit dem 21. Oktober 1975 vor. Weil es von u.a. von Madame Spaak verfasst und vertreten wurde, wird das Dekret auch als décret Spaak, mitunter auch als décret Spaak-Lagasse bezeichnet (vgl. Service de la langue française o.J.b, o.S.).
} 
bungen etc. verpflichtend. Artikel 2 verbietet den Fremdwortgebrauch in denjenigen Fällen, in denen ein offizieller französischer Neologismus existiert. Analog zur französischen Regelung sind die Bezeichnungen für regionale Spezialitäten von dieser Regelung ausgenommen (vgl. ebd.; Garsou 1997, 461)94. Mit der Verabschiedung des décret Spaak kommt in der französischen Sprachgemeinschaft auch das Bedürfnis auf, für die wissenschaftlichen und technischen Sektoren neue Termini zu schaffen (vgl. Garsou 1997, 470). Im Unterschied zur französischen Gesetzgebung sieht der Artikel 5 des Dekrets allerdings keine Strafen bei einem etwaigen Verstoß gegen die Anordnungen vor. Lediglich Organisationen, die gegen die Vorschriften verstoßen, sollen die staatlichen Subventionen entzogen werden.

Ab Mitte der 1980er Jahre beginnt in Belgien die Ära der Sprachpflegeorganisationen, hervorgerufen durch das Empfinden, das Französische befinde sich in einer Krise (vgl. Francard 1993d, 332; Klinkenberg 1985; Garsou 1991, 31)95. Seit 1983 gibt es den Cercle de qualité du français dynamique (C.Q.F.D.), der überwiegend aus Linguisten, Übersetzern und Lehrern besteht und sich v.a. die Beobachtung des aktuellen französischen Sprachgebrauchs (Neologismen, Belgizismen, grammatische Problemfälle) und die Suche nach französischen Ersatzwörtern für die sog. überflüssigen Anglizismen auf die Fahnen geschrieben hat ${ }^{96}$. Die Ergebnisse der dort betriebenen Terminologiearbeit werden zunächst in den Questions du français vivant (vgl. Lenoble-Pinson 1984-1987/1989-1992), seit 1993 in der vom Maison de la Francité herausgegebenen Zeitschrift Francité veröffentlicht (vgl. Lenoble-Pinson 1993-1996). Die ersten 120 überarbeiteten Datenblätter erscheinen 1991 in Form eines Buchs mit dem Titel Anglicismes et substituts français (Lenoble-Pinson 1991). 1985 werden der Service de la langue française und der Conseil de la langue française (1993 in Conseil supérieur de la langue française umbenannt) gegründet, zwei Organisationen, deren Aufgabe darin besteht, die Regierung der Communauté française über alle die Sprache und die Frankophonie betreffenden Fragen zu beraten sowie eine Politik der Verteidigung und der Bereicherung der Sprache zu initiieren. Die Leitung des Conseil supérieur de la langue française hat zunächst J. Hanse inne, dann J.-M. Klinkenberg und M. Wilmet. Der Conseil vertritt nicht nur die Welt der Linguistik und

\footnotetext{
94 Garsou (1997, 461) stellt weitere Parallelen zwischen Belgien und Frankreich heraus, was die Befolgung des Gesetzes betrifft: „En définitive, ce décret dépourvu de toute sanction pénale n’a jamais été réellement appliqué. Les listes de termes français obligatoires ou recommandés n'ont d'ailleurs été publiées qu'une seule fois au Moniteur en 1981. Ce décret a cependant permis une certaine sensibilisation à la langue française." Analog zu Frankreich fehlen auch in Belgien Strafen bei Verstößen gegen das Gesetz, was die Tendenz fördert, es nicht zu befolgen. Im Unterschied zu Frankreich, in dem jedes Jahr neue Terminologieerlasse erscheinen, wurde in Belgien jedoch nur ein einziges Mal, nämlich 1981, eine Liste mit Termini im Moniteur belge publiziert. Obwohl das Gesetz selbst von staatlicher Seite nicht befolgt wurde und wird, da jegliche Terminologiearbeiten bis zu Beginn der 1990er Jahre eingeschlafen sind und erst Ende der 1990er Jahre wieder aufgenommen wurden, kann als positiver Effekt betrachtet werden, dass durch das Gesetz die Sensibilität der frankophonen Belgier gegenüber ihrer Sprache gestiegen ist (vgl. Ernotte 1999, o.S.).

${ }^{95}$ Einen Überblick über sämtliche Sprach- und Kulturpflegeorganisationen gibt der „Répertoire des institutions et associations“ (2000, s. Bibliografie unter „Répertoire“).

${ }^{96}$ Der C.Q.F.D. wird auf der Internetseite der Maison de la Francité kurz beschrieben (vgl. Maison de la Francité o.J.b, o.S.).
} 
Philologie, sondern auch breitere Bereiche, die für die französischsprachige Gemeinschaft von Interesse sind, wie das Erziehungswesen, die Wirtschaft und die Wissenschaft/Forschung (vgl. Garsou 1997, 463-466; Klinkenberg 2000, 713; Service de la langue française o.J.c, o.S.).

Einen weiteren sprachpolitisch bedeutsamen Schritt stellt die Verabschiedung der Charte de la langue française ${ }^{97}$ durch den Conseil de la Communauté am 21. Juni 1989 dar. Mit der Charte werden insgesamt vier große Ziele verfolgt:

1. Anpassung des Französischen an die Erfordernisse der modernen Welt,

2. Verbesserung der Qualität der Sprache,

3. Sicherung der Präsenz des Französischen und

4. Verbreitung der französischen Sprache und belgischen Kultur.

Die mit der Charte verfolgte Sprachpolitik betrifft zwei Bereiche: das Korpus der französischen Sprache (Punkt 1 und 2) und ihren Status (Punkt 3 und 4) (zu den Termini Korpus- und Statusplanung vgl. 3.1.2). Die Charte ist keinesfalls als normativer Text oder als exhaustiver Katalog sämtlicher durchzuführender Maßnahmen anzusehen, sondern eher als Orientierungshilfe, wie sich sprachliche Fragen politisch lösen lassen (vgl. Garsou 1997, 468). Parallel zur vermehrten Aktivität der Sprachpflegeorganisationen steigt auch die Anzahl an Dekreten und Erlassen, die zum Schutz der französischen Sprache in Belgien sowie zum Schutz des Verbrauchers im französischsprachigen Landesteil verabschiedet werden ${ }^{98}$. Ein Beispiel ist die „Loi du 14 juillet 1991 sur les pratiques du commerce et sur l'information et la protection du consommateur"،, die im Moniteur belge vom 29. August 1991 veröffentlicht wurde. Das Gesetz schreibt für Etiketten, Gebrauchsanweisungen und Garantieurkunden die Sprache der jeweiligen Region vor.

Dem Service de la langue française kommt eine Reihe von Aufgaben zu, von denen hier nur diejenigen genannt werden, die die Terminologiearbeit betreffen:

\footnotetext{
${ }^{97}$ Der Text der Charte wird z.B. bei Garsou (1997, 468-469) abgedruckt, ist aber auch im Internet einsehbar (vgl. Service de la langue française o.J.d).

${ }^{98}$ Eine (noch unvollständige) Auflistung der zur französischen Sprache in Belgien verabschiedeten Dekrete, Erlasse und Gesetze befindet sich auf den Internetseiten der Maison de la Francité (Maison de la Francité o.J.a).
} 
- Koordination der erarbeiteten Terminologievorschläge und deren Verbreitung (innerhalb der jeweils dadurch betroffenen Bereiche),

- Teilnahme an den Treffen des Rint, dem Belgien 1986 beigetreten ist (vgl. 3.3.3.1),

- Teilnahme an den französischen (Spezial-)Terminologiekommissionen ${ }^{99}$,

- Einrichtung von belgischen Terminologiekommissionen, den sog. Comités expérimentaux de terminologie im Jahre $1991^{100}$ und

- finanzielle und logistische Unterstützung verschiedener Forschungsinstitutionen

(vgl. Service de la langue française o.J.b, o.S.).

Die obersten Ziele des Service de la langue française bestehen somit in der Erarbeitung einer speziell auf die Bedürfnisse der französischsprachigen belgischen Bevölkerung ausgerichteten Terminologie, deren Bekanntmachung und Verbreitung sowie in der internationalen Zusammenarbeit mit anderen Terminologieinstitutionen (vgl. ebd.).

Die Bestrebungen, den Sektor der Terminologiearbeit zu verstärken, werden in den folgenden Jahren fortgesetzt. Im November 1996 werden die folgenden sieben Empfehlungen zur belgischen Terminologiearbeit formuliert:

- „l'élaboration d'une terminologie officielle en Communauté française;

- la diffusion de la terminologie adaptée aux besoins de la Communauté française;

- l'officialisation de la terminologie en Communauté française de Belgique;

- l'adaptation du cadre législatif de la politique linguistique;

- la collaboration entre les différents niveaux de pouvoir de la Belgique fédérale;

- la collaboration internationale;

- les moyens du Service de la langue française“" (vgl. ebd.).

Diese Empfehlungen sehen konkret vor, dass die aus Frankreich stammende französische Terminologie überprüft und gegebenenfalls erweitert oder modifiziert wird (1. Empfehlung). Dann soll sie über die Internetseiten des Service de la langue française, aber auch in Form gedruckter Broschüren, die speziell für die von der Terminologie betroffenen Personengruppen sowie für staatliche Übersetzer-

\footnotetext{
${ }^{99}$ Hiermit sind die commissions spécialisées de terminologie im Unterschied zur koordinierenden Commission générale de terminologie et de néologie gemeint.

100 Mit der Einrichtung dieser Überprüfungs-Kommissionen wird das folgende Ziel verbunden: „Cette expérience, menée pendant trois ans, a jeté les bases d'une coopération plus étroite avec les Commissions spécialisées françaises de terminologie et a permis de mieux percevoir les besoins de la Communauté française en matière terminologique dans les domaines de l'environnement, de la pharmacie, de l'informatique et du tourisme“" (vgl. Service de la langue française o.J.b, o.S.).
} 
dienste angefertigt werden, verbreitet werden (2. Empfehlung). Ferner wird empfohlen, die französische Terminologie zunächst einer gründlichen Überprüfung zu unterziehen und sie anschließend in Form von Terminologielisten im Moniteur belge zu veröffentlichen, wie es das Dekret Spaak von 1978 vorsieht (3. Empfehlung). Die vierte Empfehlung sieht eine Überarbeitung des Dekrets Spaak nach dem Muster der Loi Toubon vor. Die Empfehlungen 4 und 5 sehen nationale (mit den zuständigen niederländisch- und deutschsprachigen Stellen) und internationale Zusammenarbeit in Terminologiefragen vor. Empfehlung 7 sieht eine Erhöhung des Budgets für die Terminologieplanung vor, um die Empfehlungen 1 bis 6 in die Praxis umsetzen zu können. Es spricht daher vieles dafür, dass die Übernahme der französischen Termini in erster Linie aus finanziellen Gründen erfolgt. Auch ist es günstiger, legislative Texte aus anderen Ländern zu übernehmen und lediglich auf ihre Tauglichkeit hin prüfen zu lassen als eigene Gesetzesentwürfe und/oder Dekrete zu erarbeiten.

Bis April 2002 konnte von diesen Empfehlungen aufgrund beschränkter finanzieller Möglichkeiten noch nichts in die Praxis umgesetzt werden, wie mir Nathalie Marchal vom Service de la langue française auf meine Anfrage hin mitteilte (persönliche Mitteilung vom 17. April 2002). Mme Marchal bestätigt, dass seit 1980 keine Terminologielisten mehr im Moniteur belge erschienen seien, da eine Veröffentlichung entsprechender Listen, um den rechtlichen Voraussetzungen zu genügen, eine Modifikation des Dekrets Spaak voraussetze. Andernfalls müssten zu jedem der zu verabschiedenden Termini das Parlament der Communauté française sowie der Conseil supérieur de la langue française ihr Einverständnis geben, wobei weder das Parlament noch der größte Teil des Conseil die fachliche Befähigung hätten. Bezüglich der Veröffentlichung zusätzlicher Broschüren verweist Mme Marchal auf das nach wie vor niedrige Budget des Service de la langue française, das es aktuell nicht erlaube, die belgische Terminologie in anderer Form als über die Datenbank zugänglich zu machen.

Im Folgenden wird erklärt, wie die Datenbank zur belgischen Terminologie aufgebaut ist. Zur Startseite der Datenbank („Banque de données terminologique“) gelangt man unter http://www.cfwb.be/franca/bd/bd.htm. Die einzelnen Datenblätter sind wie folgt strukturiert:

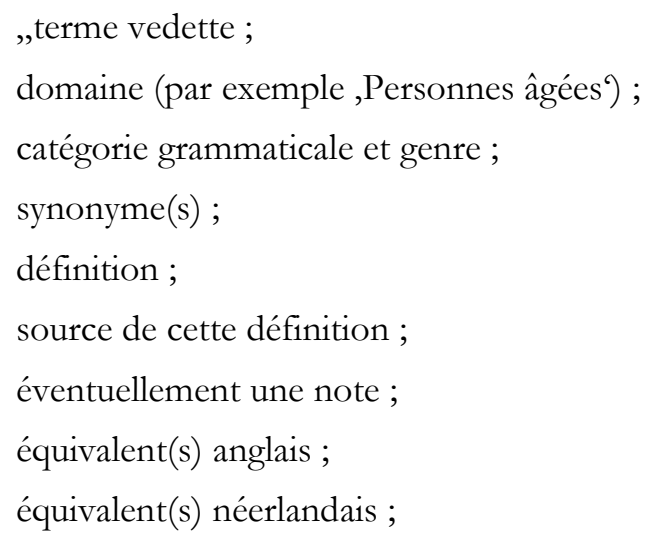


équivalent(s) allemand(s) ;

auteur de la fiche“ (Service de la langue française o.J.h, o.S.).

Der Benutzer der Datenbank kann wählen, ob die gewünschten Informationen unter den offiziellen französischen Bezeichnungen oder unter den englischen, niederländischen bzw. deutschen Bezeichnungen abgerufen werden sollen. Außerdem enthält die Datenbank ein ausführliches französisches Stichwortverzeichnis, das alle französischen Bezeichnungen und ihre Synonyme enthält, die auf den einzelnen Datenblättern erfasst sind.

Die belgische Terminologie orientiert sich eng an der von der DGLF vorgeschlagenen Terminologie, wie im Einleitungstext zur Datenbank zum Ausdruck gebracht wird (vgl. Service de la langue française 2002, o.S.). In dieser begleitenden Dokumentation wird eindeutig herausgestellt, dass die belgischen Terminologen auf die französischen Terminologievorschläge zurückgreifen ${ }^{101}$ :

- „Le champ vedette reprend, en principe, le terme de l'arrêté français. Des exceptions sont prévues lorsque ce terme n'a qu'une implantation médiocre ou nulle en Communauté française de Belgique (désormais C.F.B.).

- Le champ vedette ne reprend pas, en principe, d'anglicismes, et ce même s'ils bénéficient d'une bonne implantation en C.F.B“ (ebd.).

Auch die in den französischen Erlassen festgeschriebenen Zuordnungen der Termini zu bestimmten Wortfeldern, die Angabe der Synonyme, die Definitionen sowie die Anmerkungen werden zunächst durch die Experten der C.F.B. geprüft. Die Mitglieder der Expertenkommission „Terminologie“ sind Michèle LenoblePinson, Daniel Blampain, André Goosse und Michel Trousson (vgl. ebd.). Wenn der Gebrauch der von den französischen Kommissionen vorgeschlagenen Termini auch in Belgien belegt werden kann, wird der französische Neologismus für die offiziellen belgischen Terminologielisten übernommen. Als Quelle der Neologismen wird das Erscheinungsdatum des jeweiligen französischen JO angegeben, sofern dieses bekannt ist. Gegebenenfalls werden die französischen Termini an den in Belgien üblichen Sprachgebrauch angepasst. Ebenso können die Definitionen oder die Anmerkungen der Termini verändert werden (vgl. ebd.).

Wynants stellt bereits 1993 fest, dass sich die frankophonen Belgier bewusst aus der Terminologieplanung zurückziehen und diese Tätigkeiten dem sog. großen Bruder überlassen:

1011999 gab es zunächst ein Abkommen, dann ein Dekret zur Kooperation zwischen Frankreich und Belgien in sprachlichen und kulturellen Angelegenheiten sowie im Erziehungswesen und in der Wissenschaft (Accord du 22 mars 1999 de coopération linguistique, culturelle, éducative et scientifique entre le Gouvernement de la Communauté française de Belgique et le Gouvernement de la République française und Décret du 9 décembre 1999 du Parlement de la Communauté française portant assentiment à l'accord de coopération linguistique, culturelle, éducative et scientifique entre le Gouvernement de la Communauté française de Belgique et le Gouvernement de la République française, vgl. Maison de la Francité o.J.a, o.S.). Diese beiden Dokumente legen den Grundstein dafür, dass ein Großteil der von den französischen Terminologiekommissionen erarbeiteten Termini auch in Belgien offizielle Gültigkeit erhält. 
„La Belgique francophone ne se considère pas comme le principal dépositaire de la langue française. Elle se complait plutôt dans son rôle de 'petit frère' de la France et cette vision n'est pas dépourvue d'ambiguité. Les francophones belges trouvent normal que la France soit prioritairement investie du rôle créatif en terminologie et néologie, mais ils marquent généralement un instant d'hésitation avant d'adopter un nouveau terme préconisé par la France“" (Wynants 1993, 52).

Generell werden die französischen Terminologievorschläge in Belgien übernommen. Mitunter werden die französischen Terminologievorschläge durch weitere französische Neologismen ergänzt, die z.B. den in Québec gültigen Terminologielisten entnommen werden. Von insgesamt 24 vom Service de la langue française geplanten Bereichen sind bereits 20 von den belgischen Terminologieexperten bearbeitet worden und können mittels eines Mausklicks einzeln abgerufen werden. Diese Bereiche sind in der gleich folgenden Auflistung mit einem * gekennzeichnet worden. Die Ausarbeitung der Datenblätter für die restlichen vier Bereiche wird vermutlich in den nächsten Monaten erfolgen, da sie ja bereits in der Liste vorgesehen sind: „Affaires étrangères“, „Agriculture*“, „Audiovisuel et publicité"“*, „Chimie“, „Composants électroniques*“, „Défense*“, „Éducation*“", „Économie et finances“*, „Environnement", „Équipement“, „Génie génétique*“", „Informatique“**, „Mer“**, „Nucléaire“*, „Personnes âgées*“, „Pétrole“*, „Santé et médecine“**, „Sport"**, „Techniques spatiales*“, „Télécommunications“*, „Télédétection aérospatiale“**, ,Tourisme ${ }^{\text {“** }}$, „Transport" ${ }^{\text {"** }}$, „Urbanisme et logement"** (Service de la langue française o.J.f, o.S.; Stand: Januar 2003) ${ }^{102}$.

Im Rahmen der belgischen Terminologielisten gibt es keine eigenständige Rubrik zum Internet-Vokabular. Die Internet-Termini werden unter den InformatikWortschatz subsumiert. Es werden fast immer die von Frankreich vorgeschlagenen Internet-Termini übernommen, gelegentlich erfolgt auch der Rückgriff auf die in Québec gültigen Vorschläge, für franz. courrier électronique wird beispielsweise das vom Office québécois de la langue française (OLF) geschaffene courriel als Synonym angegeben, das in den französischen Listen zur Internet-Terminologie gänzlich fehlt. Einen tabellarischen Überblick über einige ausgewählte französische, belgische, schweizerische und frankokanadische Internet-Termini gibt 3.3.4.

\subsubsection{Terminologiearbeit in der Schweiz}

In den letzten Jahren haben sich im Bereich der Sprachpflege und Terminologiearbeit in der Schweiz einige wesentliche Entwicklungen vollzogen. Die Schweiz

\footnotetext{
102 Analog zur Situation in der Schweiz (s. nächster Abschnitt) kann man hier im Laufe kurzer Zeit große Fortschritte beobachten. Während im September 2001 erst 13 der 24 vorgesehenen Bereiche fertiggestellt waren, nämlich „Audiovisuel et publicité“, „Économie et finances“, „Informatique“, „Mer“, „Nucléaire“, „Pétrole“, „Santé et médecine“, „Sport“, „Télécommunications“, „Télédétection aérospatiale“, „Tourisme“, „Transport" und „Urbanisme et logement", sind es ein Jahr später, im September 2002, bereits 20. Es fehlen seitdem nur noch die Bereiche „Affaires étrangères“, „Chimie“, „Environnement" und „Équipement“ (vgl. Service de la langue française o.J.f, o.S.; Stand: September 2001 und September 2002).
} 
engagiert sich seit den 1980er Jahren im Rahmen ihrer Rolle als Mitglied der Frankophonie: 1987 wird im Département fédéral des affaires étrangères ein Service de la Francophonie eingerichtet, 1988 in der Schweizerischen Bundeskanzlei ein Service de terminologie multilingue. Seit 1989 nimmt auch die Schweiz an den seit 1986 stattfindenden Frankophoniegipfeln teil. 1995 wird die Schweiz Mitglied bei der Agence de Coopération Culturelle et Technique (ACCT) (vgl. Knecht 2000b, 720).

Terminologiearbeit ist in der Schweiz ein relativ junges Unterfangen. Obwohl die französischsprachigen Schweizer nach Ansicht der Académie française den französischen Wortschatz nicht erweitern dürfen (vgl. 2.3.4.2.3), gab und gibt es Bemühungen für eine Erweiterung und Vereinheitlichung der Terminologie. Erst 1982 nimmt die ein Jahr zuvor geschaffene Arbeitsgruppe „Terminologie“ der Schweizerischen Bundeskanzlei (auch „Behörden der Schweizerischen Eidgenossenschaft", „Confoederatio Helvetica“ bzw. auf französisch Chancellerie fédérale genannt) ihre Arbeit auf. Die Schweizer erkennen schnell, welch ungeheuren finanziellen Aufwand die Erarbeitung eigener, dreisprachiger Terminologielisten mit sich bringen würde. Daher beschließen sie keine eigene Datenbank anzulegen, sondern an eine bereits vorhandene Datenbank anzuknüpfen und in diesem Bereich zu kooperieren. Mehrere bekannte Datenbanken werden auf ihre Tauglichkeit hin überprüft, bis sich die schweizerische Arbeitsgruppe zur Zusammenarbeit mit der in Luxemburg von der Europäischen Union verwalteten Datenbank EURODICAUTOM entschließt. In einem Einigungsvertrag aus dem Jahre 1987 wird festgehalten, dass die Schweizerische Bundeskanzlei die Datenbank der Europäischen Union EURODICAUTOM unter dem Namen TERMDAT weiterführen darf ${ }^{103}$. Entsprechend übernimmt die Schweiz ab 1988 die bereits 1.400.000 Termini umfassende mehrsprachige Datenbank und erweitert diese um 115.000 schweizerische Datenblätter, vorwiegend in den Sprachen Deutsch, Französisch und Italienisch, seltener auch in Englisch und Rätoromanisch (vgl. Sektion Terminologie der Schweizerischen Bundeskanzlei o.J., o.S.).

Im Rahmen ihrer Terminologiearbeit, d.h. der Erweiterung der Datenbank EURODICAUTOM, konzentrieren sich die schweizerischen Terminologen vorwiegend auf den juristischen und administrativen Wortschatz, behalten aber auch die Fachwortschätze im Blick:

„L'objectif du projet TERMDAT est de saisir, sur la base d'EURODICAUTOM, l'ensemble de la terminologie juridique et administrative suisse, ainsi que les diverses terminologies spécialisées ressortissant au domaine public, dans les langues officielles de la Confédération, et de les mettre à disposition d'un large cercle d'usagers. Cet objectif ambitieux dépasse les moyens de l'Administration fédérale, c'est pourquoi ce programme a été conçu dès le départ pour être réalisé en coopération“ (ebd.).

${ }^{103}$ Für TERMDAT gibt es einen 70-seitigen „Leitfaden für die Erarbeitung von Datenbankeinträgen“" (vgl. Sektion Terminologie der Schweizerischen Bundeskanzlei 2002). 
Die bisherigen Ausführungen zeigen bereits, dass die schweizerische Terminologiearbeit erheblich von der französischen und frankokanadischen Terminologiearbeit abweicht. Es fließen weniger finanzielle Mittel in diesen Bereich, als dies in Frankreich und Québec der Fall ist. Außerdem fehlen die Terminologiearbeit und die erarbeiteten Termini legitimierende Sprachgesetze oder Dekrete, welche zudem die Verwendung der erarbeiteten Bezeichnungen in bestimmten Bereichen als obligatorisch erklären.

Dass in der Schweiz im Unterschied zu Frankreich und Belgien keine offensive Sprachpolitik betrieben wird, die sich gegen angloamerikanische Einflüsse richtet, kann auf verschiedene Faktoren zurückgeführt werden. 1. Es fehlte bis 1992 eine Sprachpflegeorganisation, die ähnliche Aufgaben wie die französische oder belgische Akademie wahrnimmt. Es gab zwar die Konferenz der welschen Erziehungsdirektoren, doch diese wurde insbesondere von Frankreich nicht als einer Akademie gleichwertig betrachtet (vgl. zum Streit um die Nichtbeachtung der Romands bei der französischen Rechtschreibreform 2.3.4.2.3). 2. Die schweizerischen Sprachgesetze waren v.a. auf den Status der Nationalsprachen ausgerichtet, damit der Sprachfrieden gewahrt werden konnte. 3. Die Romands sehen sich eher durch das in unmittelbarer Nachbarschaft gesprochene Deutsch gefährdet. Daher wird das Englische in der Schweiz nicht als so wichtiger Einflussfaktor bewertet wie in Frankreich. 4. Im Unterschied zu Frankreich leben die Schweizer in einem mehrsprachigen Staat. Entlehnungen aus dem (Schweizer-)Deutschen sind im schweizerischen Französisch keine Seltenheit. Möglicherweise sind sie aufgrund ihres viersprachigen Staates an Sprachkontakt gewöhnt und tolerant in sprachlichen Belangen, solange ihr Recht auf den Gebrauch ihrer Muttersprache nicht eingeschränkt wird ${ }^{104}$.

Was das Internet-Vokabular betrifft, wird man auf den fünfsprachig ${ }^{105}$ verfügbaren Internetseiten der Schweizerischen Bundeskanzlei fündig. Hier gibt es eine große, viersprachig (englisch, deutsch, französisch, italienisch) angelegte Tabelle zur Internet-Terminologie, der ein einleitender Text vorangestellt ist. In diesem Text werden die mit diesem Terminologieprojekt verbundenen Zielsetzungen und Arbeitsweisen erklärt:

\footnotetext{
104 Die Toleranz der Schweizer im Umgang mit der Mehrsprachigkeit im Unterschied zu Belgien und Kanada hebt auch Willemyns (1991, 5f.) hervor: „Belgium and Canada are reputed for linguistic unrest and trouble and have got a heavy linguistic legislation conceived to diminish linguistic tensions [...]. Switzerland on the other hand is often quoted as the example par excellence of various (linguistic) communities living very peacefully together."

105 Auf der Eingangsseite (http://www.admin.ch/ch/) kann der Besucher wählen, in welcher Sprache die Internetseiten dargestellt werden sollen. Zur Verfügung stehen die Sprachen Deutsch, Französisch, Italienisch, Rätoromanisch und Englisch.
} 
„New Public Management, provider, e-government : tout le monde sait-il de quoi il s'agit ? Pour la Confédération, et pour toutes les autres administrations publiques, il est vital que les textes destinés au grand public soient aisément compréhensibles. Ce n'est que de cette manière que les citoyens sauront quels sont leurs droits et leurs devoirs. De même, quiconque entend recourir aux services de l'administration, par exemple en voulant déposer une requête ou renouveler un passeport, doit savoir comment s'y prendre.

Tous les textes par lesquels l'administration s'adresse à la population - lois et ordonnances, messages, rapports, communiqués, modes d'emploi en ligne, etc. - doivent donc être rédigés dans une langue accessible à tous. Outre des phrases simples exprimant clairement la pensée de l'auteur, une construction logique, etc., le choix des mots contribue grandement à la compréhension d'un texte" (Zentrale Sprachdienste der Schweizerischen Bundeskanzlei o.J.a, o.S.).

Auf den ersten Blick unterscheidet sich die Intention der schweizerischen Arbeitsgruppe eindeutig von der der französischen Terminologiekommissionen. Der Leser gewinnt in den ersten Absätzen des Textes den Eindruck, dass es in der Schweiz im Unterschied zu Frankreich nicht darum gehe, den Bürgern die Benutzung bestimmter Bezeichnungen für ihren Sprachgebrauch vorzuschreiben. Vielmehr entsteht der Eindruck, die Listen hätten lediglich die Schaffung eines Wortschatzes zum Ziel, der es den staatlichen Institutionen ermöglichen solle, mit der Bevölkerung in den jeweiligen Landessprachen kommunizieren zu können. Weiter heißt es, dass zur Erreichung dieses Ziels eine Arbeitsgruppe gegründet worden sei, die sich mit diesem Problem befasst und Lösungen vorgeschlagen habe. Es seien eine Internetseite mit einer Terminologieliste erstellt sowie eine Reihe von Empfehlungen erarbeitet worden, wie mit Fremdwörtern am besten umzugehen sei (vgl. ebd.). In den Empfehlungen wird die Terminologiearbeit wie folgt begründet: 
„La Confédération fait face à des responsabilités et des exigences particulières en matière de langue:

- par souci démocratique, elle est tenue de s'adresser à la population dans une langue aisément compréhensible; la clarté du message s'impose comme tout premier principe dans les échanges avec ses partenaires;

- politiquement elle est tenue de respecter et de faire respecter les langues officielles; les textes officiels émanant de l'administration véhiculent certes un message, mais en même temps ils illustrent, et du même coup servent, la diversité linguistique du pays;

- en tant qu'agent de communication de premier plan elle se doit de participer à la réflexion collective sur la langue“"

(Zentrale Sprachdienste der Schweizerischen Bundeskanzlei o.J.d, o.S.).

Einige Absätze später wird als Argument für die Verwendung nationaler Termini vorgebracht, Anglizismen würden die Kommunikation erschweren:

„Là où les anglicismes prolifèrent librement, surtout lorsqu'il s'agit comme ici de la communication d'un État avec ses citoyens et du respect des langues officielles, on peut affirmer sans risque de se tromper que c'est au détriment de la clarté du message et de la langue. Dans ce contexte les anglicismes nuisent plus à la communication qu'ils ne la servent, et ils entravent l'action de l'État dans l'exercice de ses responsabilités envers les langues officielles“ (ebd.).

In diesem Fall deckt sich die offizielle Begründung für die schweizerische Terminologiearbeit mit derjenigen, die von französischer Seite vorgebracht wurde: Durch die Schaffung einer nationalsprachigen Fachterminologie wolle man möglichen, auf die englische Sprache zurückzuführenden Kommunikationsschwierigkeiten entgegentreten. Die Schweizerischen Behörden berufen sich zusätzlich auf den Respekt, der den offiziellen Landessprachen entgegenzubringen sei. Jedoch bleibt - analog zur Situation in Frankreich - die Frage offen, inwieweit die Anglizismen von der Bevölkerung eventuell besser verstanden werden als die Neubildungen in den jeweiligen Landessprachen und ob möglicherweise die offiziellen Neologismen Kommunikationsschwierigkeiten verursachen.

Insgesamt fällt die Terminologiearbeit in der Schweiz, die hier am Beispiel der Internet-Terminologie untersucht wird, im Vergleich zur französischen, belgischen und frankokanadischen Situation etwas aus dem Rahmen. Die Ziele und Ergebnisse der Terminologiearbeit werden nicht so präzise dargestellt, wie dies in den anderen untersuchten Ländern der Fall ist. Beispielsweise fehlen in der Terminologieliste die grammatischen Angaben zu den Neologismen ebenso wie Definitionen der Termini. Das Resultat fällt dadurch sicherlich sehr benutzer- 
freundlich aus, weil die Termini im Unterschied zu den belgischen Terminologielisten in einer einzigen langen und alphabetisch geordneten Tabelle abgedruckt sind und dadurch umständliches Hin- und Herklicken zwischen den einzelnen Datenblättern und verschiedenen Wortfeldern entfällt. Neben zahlreichen Internet-Termini enthält die schweizerische Terminologieliste vor allem Einträge aus dem wirtschaftlichen Bereich. Die schweizerischen Terminologievorschläge für das deutsche und das italienische Vokabular hinken derzeit noch etwas hinter den französischen Termini hinterher (s.u.).

Es ist davon auszugehen, dass hinter der Terminologiearbeit der Schweizerischen Bundeskanzlei auch der Gedanke steht, dass die von der Arbeitsgruppe erarbeiteten Neologismen, die offiziell nur für den öffentlichen Bereich (Umgang mit Behörden) gelten, auch in den privaten Sprachgebrauch der Bürger übergehen. Für den privaten Sprachgebrauch lassen sich allerdings weder in Frankreich, wie es ja 1994 mit dem Gesetzentwurf der Loi Toubon versucht wurde, noch in der Schweiz gesetzliche Vorschriften machen.

Ebenso wie der französische Staat muss sich auch die Schweizerische Bundeskanzlei bemühen, die von der Arbeitsgruppe erarbeiteten Termini in der Bevölkerung publik zu machen. Die entsprechenden Internetseiten sind in den letzten zwei Jahren ständig überarbeitet und erweitert worden, z.T. wurden Texte auch gänzlich geändert. Nun allerdings wird es Zeit, die entsprechenden Seiten bekannt zu machen. Bisher dürften nur wenige Personen durch Zufall die entsprechenden Internetseiten gefunden haben. Doch je später die französischen Neologismen bekannt gemacht werden, desto schwerer wird es sein, sie gegenüber den bereits im Sprachgebrauch etablierten Anglizismen durchzusetzen. Positiv an der schweizerischen Terminologiearbeit ist die Möglichkeit des Mitwirkens zu bewerten. Es gibt ein Formular, das allen Besuchern dieser Internet-Seiten ermöglicht, an der Terminologiearbeit mitzuwirken. Dieses Formular kann von der Eingangsseite zur Terminologiearbeit (vgl. Zentrale Sprachdienste der Schweizerischen Bundeskanzlei o.J.a) aus angesteuert werden; es ist die Rubrik „Vos questions et contributions“. Auf dieser Seite hat jeder Besucher die Möglichkeit, einen englischen Terminus zu nennen und dann in einige oder alle folgenden Felder Vorschläge für das Deutsche, Französische und/oder Italienische einzutragen. Außerdem enthält das Formular ein Textfeld für einen eventuellen Kommentar (vgl. Zentrale Sprachdienste der Schweizerischen Bundeskanzlei o.J.c).

Unter der Adresse http://www.admin.ch/ch/f/bk/sp/anglicismes/anglicismesfr-2.html (Zentrale Sprachdienste der Schweizerischen Bundeskanzlei o.J.b). sind die von der Arbeitsgruppe erarbeiteten Tabellen zur Terminologie einsehbar. Es handelt sich im Unterschied zu den zweisprachigen (Englisch-Französisch bzw. Französisch-Englisch) Wortlisten des französischen JO oder der belgischen Banque de données terminologique um eine viersprachige Tabelle (vgl. Zentrale Sprachdienste der Schweizerischen Bundeskanzlei o.J.b, o.S.). Die erste Spalte der Tabelle gibt jeweils die englischen Termini wieder, die zweite Spalte die deutschen, die dritte die französischen und die vierte Spalte die italienischen. Außerdem wird im Unterschied zu den französischen und belgischen Wortlisten auf eine Spalte 
mit den Definitionen der Termini verzichtet. Auch die schweizerischen Wortlisten sind wie die belgischen noch im Aufbau. Ebenso wie auch für Belgien lässt sich die Weiterarbeit an den schweizerischen Wortlisten bequem über das Internet verfolgen. Im Mai 2001 sind die Termini (63 Anglizismen mit entsprechenden französischen, teilweise italienischen und deutschen Ersatzwörtern) in vier thematisch voneinander getrennten Tabellen verzeichnet ${ }^{106}$. Die erste Tabelle umfasst den „Vocabulaire utilisé en cyberadministration“ (z.B. engl. e-government, email, e-petition), die zweite die „Expressions du commerce électronique“ (z.B. engl. customer relationship management, e-banking), die dritte ist unspezifiziert („Autres expressions“, z.B. engl. access provider, bookmark, browser) und die vierte verzeichnet das Vokabular der „Effets publicitaires ou graphiques“ (engl. e-ducation und egovernment) (vgl. Zentrale Sprachdienste der Schweizerischen Bundeskanzlei o.J.b, o.S.; Stand: Mai 2001). Alle Tabellen weisen zahlreiche Lücken in der Spalte mit den deutschen Terminologievorschlägen auf. Hinter den wenigen vorgeschlagenen deutschsprachigen Termini befinden sich zudem häufig Fragezeichen. Noch lückenhafter als in der Spalte zum Deutschen sieht es in der Spalte zum Italienischen aus. Einzig für den englischen Terminus superuser ist ein Vorschlag gemacht worden: collaboratore per l'assistenza agli utenti, der aufgrund seiner Länge wohl kaum eine Chance haben dürfte, sich im Sprachgebrauch durchzusetzen (vgl. 5.1).

Im September 2001 wird die Unterteilung in vier thematisch voneinander getrennte Tabellen zugunsten einer einzigen Tabelle aufgegeben. Diese neue Tabelle umfasst insgesamt 77 englischsprachige Bezeichnungen. Somit sind im Zeitraum von Mai bis September 2001 einige neue Einträge hinzugekommen. Wiederum ein Jahr später, im September 2002, ist die Liste auf 136 Einträge angewachsen. Es gibt mehr Einträge in der Spalte mit den italienischen Äquivalenten als mit den deutschen ${ }^{107}$. Die schweizerische Internet-Terminologie weicht in vielen Punkten von der französischen ab. Z.B. werden in umfassender Weise Ersatzwörter für Anglizismen mit dem Präfixoid $e$ - (für electronic) angeboten, nämlich für

\footnotetext{
106 Von diesen 63 Anglizismen sind 18 auch von der französischen Informatik-TerminologieKommission bearbeitet worden. In diesem Fällen greifen die schweizerischen Terminologen auf die in den beiden französischen Terminologielisten vorgeschlagenen Neologismen zurück.

${ }^{107}$ Für 104 der 136 englischsprachigen Termini liegen italienische Ersatzwörter, z.T. auch mehrere, vor. Für 72 der englischsprachigen Termini liegen deutsche Entsprechungen vor. Häufig wird im Falle der italienisch- oder deutschsprachigen Entsprechungen auch der Anglizismus beibehalten und somit als Internationalismus behandelt (vgl. Zentrale Sprachdienste der Schweizerischen Bundeskanzlei o.J.b, o.S.; Stand: September 2002).
} 


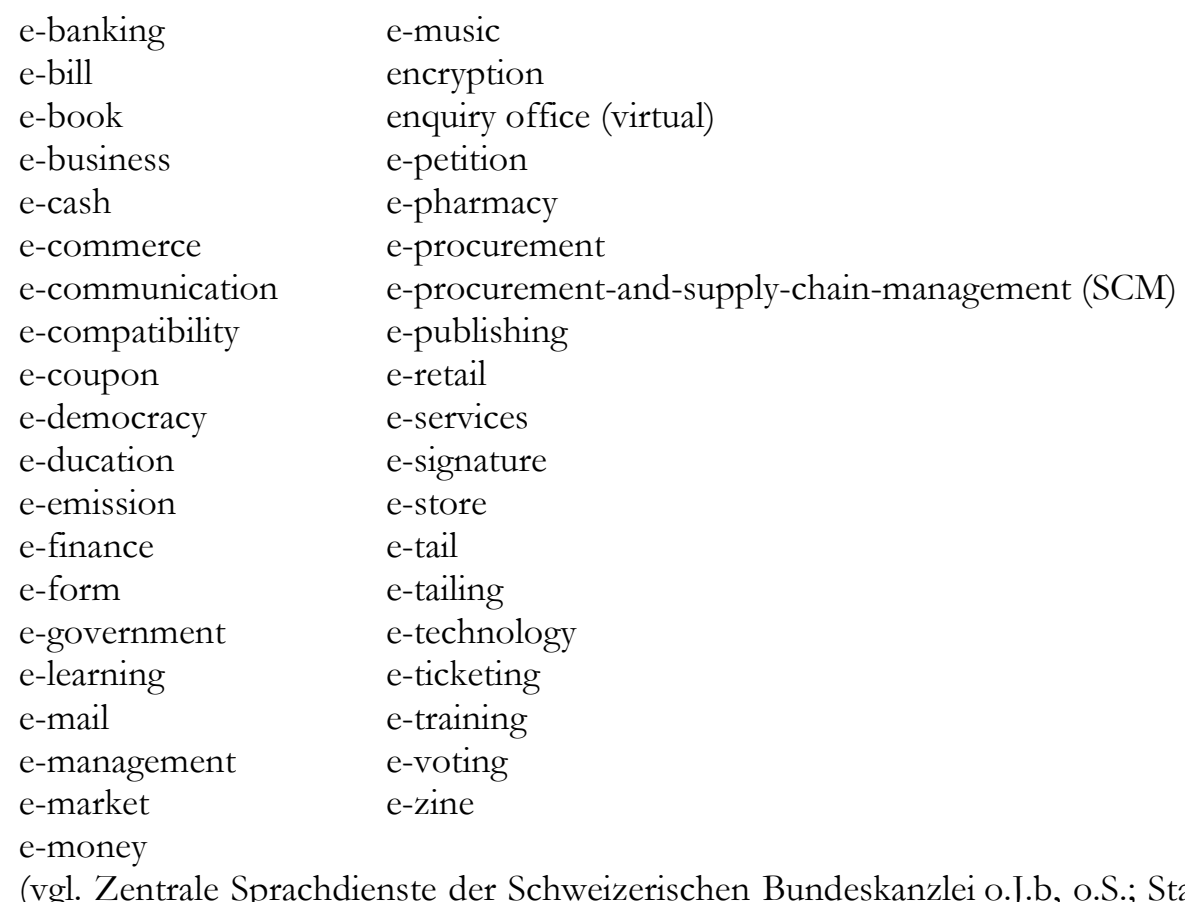
September 2002). Die Liste zur französischen Internet-Terminologie vom 16. März 1999 enthält demgegenüber keinen einzigen Terminus mit dem Präfixoid $e$ Die Commission générale hat stattdessen allgemeine Hinweise zum Umgang mit dem Präfixoid $e$ - erarbeitet, das sich nicht für alle Termini durch ein einheitliches französisches Wort ersetzen lasse (vgl. de Broglie 2002, o.S.; 3.2.5).

\subsubsection{Länderübergreifende Terminologiearbeit}

Heute betreiben etwa 60 Staaten systematische Terminologienormung. Für Frankreich wurde bereits die Association Française de Normalisation (AFNOR) genannt, in Großbritannien ist die British Standards Institution (BSI) und in Spanien das Instituto Nacional de Racionalización y Normalización (IRANOR) für Terminologienormung zuständig. Für die internationale Koordination der nationalen Terminologiearbeiten ist v.a. die ISO bzw. im Bereich der Elektrotechnik die IEC zuständig (vgl. Arntz/Picht 1991, 147).

Die wohl bekannteste frankophone Organisation für länderübergreifende Terminologiearbeit ist der 1986 gegründete Réseau international de néologie et de terminologie (Rint), der im Jahre 2000 vom Réseau international francophone d'aménagement linguistique (Rifal) abgelöst wurde.

Internationale Terminologieorganisationen gibt es schon vor der Gründung des Rint: 1970 wird in Paris die Agence de coopération culturelle et technique (ACCT) gegründet, deren Aufgabe vorwiegend darin besteht, die wirtschaftliche Entwicklung in den südlichen, d.h. afrikanischen Staaten voranzutreiben. 1974 wird ein Comité 
interministériel pour les affaires francophones eingerichtet, 1984 folgt der Haut Conseil de la francophonie, 1988 dann ein Secrétariat d'État à la francophonie (vgl. Humbley 2000, 323; 3.2.1). Trotz dieser Versuche länderübergreifender Terminologiearbeit behalten Frankreich und Québec in terminologischer Hinsicht ihre Vorreiterrolle bei.

Die nationale Terminologiearbeit wird weitaus intensiver betrieben als die übernationalen terminologischen Aktivitäten. Daher verstärken insbesondere auch Linguisten wie de Bessé $(1980,49)$ in den 1980er Jahren die Forderung nach einer effektiven länderübergreifenden Zusammenarbeit in Terminologiefragen. Dieser Einsicht, die Arbeiten der in den verschiedenen (nicht nur frankophonen) Staaten aktiven Terminologiekomitees und -organisationen zusammenzuführen, folgen seit Mitte der 1980er Jahre entsprechende Initiativen. Hinzu kommt, dass die internationale Anerkennung der Frankophonie als politische Vereinigung schließlich auch die internationale Zusammenarbeit in Terminologiefragen nach sich zieht (vgl. Depecker 1997b, o.S.). Frankreich beschränkt sich zunächst auf die Kooperation mit der Chancellerie fédérale de Berne, dem Secrétariat d'État du Canada, dem Office québécois de la langue française und dem Service de la langue française de la Communauté française de Belgique, die zusammen die Eckpfeiler des 1986 gegründeten Réseau International de Néologie et de Terminologie, kurz Rint genannt, bilden (vgl. Depecker 2001a, 465).

Neben dem für die Zusammenarbeit der verschiedenen frankophonen Institutionen zur Terminologie zuständigen Rint gibt es inzwischen auch länderübergreifend arbeitende Institutionen für alle Staaten, in denen eine romanische Sprache gesprochen wird. Im Folgenden werden zunächst der Rifal, anschließend der Rint und der Réseau panlatin de terminologie, kurz Realiter genannt, vorgestellt.

3.3.3.1 Der Réseau International de Néologie et de Terminologie (Rint) und der Réseau international francophone d'aménagement linguistique (Rifal)

Nach 14-jährigem Bestehen wird der Résean International de Néologie et de Terminologie (Rint) im Jahre 2000 von einer neuen Organisation, dem Réseau international francophone d'aménagement linguistique (Rifal) abgelöst ${ }^{108}$. Eine kurze Vorstellung des Rifal sowie ein Rückblick auf die Arbeit des Rint (1986-2000) gibt der ehemalige Generalsekretär des Rint und jetzige Generalsekretär des Rifal, Louis-Jean Rousseau (2000). Als Ziele des Rifal nennt Rousseau (2000, 4): ,contribuer à l'aménagement, la promotion, la consolidation, la valorisation et le développement de l'usage du français et des langues partenaires." Die ersten Sitzungen des Rifal finden im Juni 2000 in Paris beim Sitz der Agence intergouvernementale de la francophonie (AIF) statt, die den Rifal finanziert.

Seit März 2001 verfügt der Rifal über eine eigene Internetseite (http://www.rifal.org/), auf der die Aufgaben, die 21 Mitgliedsstaaten (Benin, Burundi, Kamerun, Kanada, Belgien, Kongo, Frankreich, Guinea, Haiti, Madagaskar, Mali, Marokko, Mauretanien, Niger, Québec, Zentralafrikanische Republik, Demokratische Republik Kongo, Rumänien, Ruanda, Republik Senegal, Schweiz)

108 Genauer gesagt löst der Rifal gleich zwei Organisationen ab, den Rint und den Réseau international des observatoires francophones de linforoute et $d u$ traitement informatique des langues (Riofil). Allerdings ist der Rint für die übernationale Terminologiearbeit wesentlich bedeutender gewesen. 
und der Aufbau der Organisation vorgestellt werden. Der Rifal wird wie seine Vorgängerorganisation Rint vom OLF in Québec verwaltet.

Das Ergebnis der terminologischen Koordinierungsbemühungen stellen der Inventaire ressources terminologiques und der Inventaire terminotique dar. Der Inventaire ressources terminologiques ist eine Datenbank, die terminologische Ressourcen wie Wörterbücher verzeichnet. Der Inventaire terminotique umfasst eine Datenbank zu entsprechenden Computerprogrammen sowie eine Bibliografie (vgl. Rifal o.J.). Die Besonderheit dieser Datenbanken besteht darin, dass Materialien aus allen frankophonen Ländern berücksichtigt werden.

Da der Rifal erst seit kurzer Zeit besteht, lassen sich zu diesem Zeitpunkt nur wenige Aussagen zu seinen Tätigkeiten machen. Es erweist sich als sinnvoller, kurz auf seine Vorgängerorganisation Rint (http://www.rint.org) einzugehen, an der sich der Rifal in seinem Aufbau und seinen Zielen orientiert.

Auf seiner Homepage stellt sich der Rint wie folgt vor:

\section{„Qu'est-ce que le Rint?}

Le réseau international de néologie et de terminologie est une organisation intergouvernementale francophone orientée vers le développement terminologique et vers la coopération internationale en matière d'aménagement linguistique. Créé en 1986 à l'occasion du premier sommet de la Francophonie, le Rint constitue un regroupement d'organismes à vocation terminologique officiellement mandatés par chacun des vingt pays et États membres suivants :

\begin{tabular}{|c|c|c|}
\hline • Bénin, & • Guinée, & • République \\
\hline - Burundi, & - Haïti, & centrafricaine, \\
\hline - Cameroun, & - Madagascar, & • République \\
\hline - Canada, & - Mali, & démocratique \\
\hline - Communauté & - Maroc, & du Congo, \\
\hline française de & - Mauritanie, & - Rwanda, \\
\hline Belgique & - Niger, & - Sénégal, \\
\hline - Congo, & • Québec, & - Tunisie \\
\hline - France, & & \\
\hline$[.]$. & & \\
\hline
\end{tabular}

Le Rint est ouvert à tout pays membre de l'Agence de la Francophonie et il peut également accueillir à titre de membre associé tout organisme international qui exerce une activité terminologique en langue française. Ainsi, l'Union latine fait également partie du Rint à titre de membre associé. 
L’Office de la langue française (Québec) assure le Secrétariat général du Rint" (Rint o.J.a, o.S.) ${ }^{109}$.

Es ist anzunehmen, dass die Institute der vier großen westlichen Staaten der Frankophonie (Frankreich, Belgien, Schweiz, Kanada/Québec) am einflussreichsten sind, nicht zuletzt, weil sie über erheblich bessere finanzielle Mittel verfügen als die frankophonen Staaten Afrikas. In Bezug auf die internationale Zusammenarbeit dürfte vor allem der Einfluss Québecs erheblich sein, denn die Geschäftsführung des Rint obliegt dem OLF in Québec, der auch für die Gestaltung der Internetseiten zuständig ist.

Depecker (2001a, 468) weist auf die enge Zusammenarbeit zwischen der Communauté française de Belgique und Frankreich hin, die er nicht zuletzt auf die geografische Nähe zurückführt: Es sei recht einfach, von Belgien aus zu Sitzungen nach Paris zu reisen. Außerdem habe das Kabinett des Ministerpräsidenten den Posten eines Terminologen bewilligt, dessen Hauptaufgabe darin besteht, die Arbeiten der französischen Terminologiekommissionen zu verfolgen. Weniger intensiv, aber dennoch vorhanden, seien Kooperationsbemühungen zwischen Frankreich, Québec und der Schweiz. Während die Kooperation zwischen Frankreich, Belgien, der Schweiz und Québec alles in allem funktioniere, sei die Zusammenarbeit mit den südlichen frankophonen Ländern verbesserungsbedürftig (vgl. ebd.).

Oberstes Anliegen des Rint ist die Behebung der Bezeichnungsbedürfnisse, die sich durch den rasanten technischen und wissenschaftlichen Fortschritt ergeben. Diese Bezeichnungslücken sollen durch moderne französische Termini ausgefüllt werden. Die wichtigste Aufgabe des Rint besteht in der Koordinierung der Arbeiten der einzelnen Terminologiekommissionen der frankophonen Länder. Die neu entstandenen Termini werden vom Rint aufgenommen und verbreitet. Der Rint will nicht nur die Terminologiearbeit koordinieren und vereinheitlichen, sondern auch die Etablierung der Termini im Rahmen der Frankophonie begünstigen. Außerdem sollen die Terminologiearbeit der südlichen Mitgliedsstaaten der Frankophonie beispielsweise durch eine entsprechende terminologische Ausbildung gefördert und ihre Arbeitsergebnisse stärker berücksichtigt werden (vgl. Rint o.J.a, o.S.). Diese Organisation arbeitet keineswegs präskriptiv in dem Sinne, dass der Gebrauch bestimmter Termini empfohlen wird, während von anderen abgeraten wird. Der Rint begreift sich vielmehr als eine Institution, die die verschiedenen frankophonen Terminologiebemühungen zusammenfasst. Dazu wurde die Datenbank Balnéo geschaffen (vgl. Lemeur/Depecker 1995; Petit 1999, 172-175).

Des Weiteren organisiert der Rint Seminare und Kolloquien zu zahlreichen Terminologiefragen, deren Ergebnisse in der halbjährlich erscheinenden Zeitschrift Terminologies nouvelles veröffentlicht werden, von der seit 1988 insgesamt 21 Hefte erschienen sind. Sie wird vom Service de la langue française der Communauté française de Belgique herausgeben, der sie in Zusammenarbeit mit der AIF erstellt. Die Zeitschrift Terminologies nouvelles erscheint zwei Mal jährlich und ist kostenlos. Die ein-

${ }^{109}$ Es ist festzustellen, dass es leichte Verschiebungen bei den Mitgliedsstaaten gegeben hat: An die Stelle Tunesiens sind nun Rumänien und die Schweiz getreten. Weiterhin ist die Union Latine assoziiertes Mitglied. 
zelnen Ausgaben dieser Zeitschrift, die sich ausschließlich der Terminologie und Terminologieplanung widmet, sind ab Nr. 14 (Dezember 1995) als pdf-Dokumente im Internet verfügbar (Rint o.J.b). Für die Nummern 1 (1989) bis 13 (1995) sind auf der angegebenen Seite lediglich die Inhaltsverzeichnisse einsehbar; die Texte selbst liegen nicht in digitalisierter Form vor. Inzwischen wurde die Zeitschrift Terminologies nouvelles eingestellt und durch die Zeitschrift Les cabiers du Rifal ersetzt. Für die Redaktion ist nach wie vor die Communauté française de Belgique verantwortlich. In der ersten Hälfte des Jahres 2002 ist die erste Ausgabe von Les cahiers du Rifal (Dezember 2001) erschienen. Sie trägt die Nummer 22, um auf diese Weise deutlich zu machen, dass Les cabiers du Rifal die direkte Nachfolge der Terminologies nouvelles antreten (vgl. Service de la langue française o.J.g). Allerdings erscheinen sie (noch) nicht so regelmäßig, wie es für die Zeitschrift Terminologies nouvelles üblich war.

\subsubsection{Der Réseau panlatin de terminologie (Realiter)}

Der 1993 in Paris gegründete Réseau panlatin de terminologie, kurz: Realiter, versteht sich als Zusammenschluss von Personen, Institutionen und Organisationen aus diversen romanischsprachigen Ländern zur länder- und sprachenübergreifenden Terminologiearbeit. Dabei sind in erster Linie die Sprachen Katalanisch, Spanisch, Französisch, Italienisch, Portugiesisch und Rumänisch vertreten. In diesen Sprachen sind auch alle Informationen auf den Internetseiten des Realiter (http://www.realiter.net/) abrufbar. Da Ziele, Strukturen, Mitglieder (Organisationen sowie Einzelpersonen $\left.{ }^{110}\right)$, Aktivitäten und die Protokolle vergangener Treffen auf den Internetseiten der Organisation sehr ausführlich dokumentiert werden, findet an dieser Stelle nur eine kurze Präsentation statt. Das allgemeine Ziel von Realiter wird wie folgt angegeben:

„Favoriser un développement harmonisé des langues latines, compte tenu de leur origine commune et du fait qu'elles ont recours à des modes de formation lexicale voisins et qu'elles utilisent des formants semblables" (Realiter 2002a, o.S.).

Das bedeutet im Einzelnen, dass methodische Leitlinien sowie mehrsprachige Terminologielisten für bestimmte Wortfelder und Referenzwerke zu erstellen sind. Ein weiteres Anliegen ist die Förderung der gegenseitigen Ausbildung von Studenten, der Austausch von Lehrern sowie die Entwicklung von didaktischem Material. Der Realiter besteht aus einer Generalversammlung, einem Komitee, der Geschäftsführung und verschiedenen Arbeitsgruppen (vgl. ebd.; Näheres zu den einzelnen Organen vgl. Realiter 2002b, o.S., Art. 12-16). Das Sekretariat des Realiter übernimmt die Union Latine. Im Komitee befindet sich für jede der Sprachen Katalanisch, Spanisch, Französisch, Italienisch, Portugiesisch und Rumänisch

\footnotetext{
110 Belgien wird durch den Centre de Terminologie de Bruxelles (Institut Libre Marie Haps) und den Service de la langue française der Communauté française de Belgique vertreten, Frankreich durch den Centre de Terminologie et de Néologie (INaLF, CNRS), den Laboratoire d'Ingéniérie Linguistique et de Linguistique Appliquée der Universität von Nice-Sophia Antipolis sowie die Universität Paris III. Die Schweiz wird durch keine Organisation oder Universität vertreten, sondern nur durch eine Einzelperson, nämlich Rolf Moos von den Zentralen Sprachdiensten der Schweizerischen Bundeskanzlei (vgl. Realiter 2001d, o.S.).
} 
mindestens ein Vertreter oder eine Vertreterin. Für die französische Sprache sind dies Loïc Depecker (Universität Paris III) und Louis-Jean Rousseau (OLF und Rifal, Québec). L. Depecker erfüllt aktuell zusätzlich die Funktion des Generalsekretärs von Realiter (vgl. ebd.).

Der Realiter hat in den letzten Jahren einige Projekte bereits realisiert, andere befinden sich gerade in der Phase der konkreten Umsetzung bzw. in Planung: Bereits in die Tat umgesetzt wurden drei Projekte: 1. die „Taula de formants cultes“, Informationen für Personen, die im Computerbereich arbeiten und auf die Verwendung mehrerer Sprachen angewiesen sind, 2. ein „Léxico Panlatino de Terminologia do Ambiente“, ein mehrsprachiges Wörterbuch zum Wortfeld Umwelt, sowie 3. ein „Lexique des termes de base de l'informatique“. Letzteres Projekt wurde von Depecker koordiniert und zeigt, dass es für alle Sprachen mit lateinischer Wurzel möglich ist, neue Termini zu schaffen und sie so an die Erfordernisse der modernen Technologien anzupassen. Das Glossar setzt sich aus 130 Konzepten zusammen, welche als die Grundbegriffe der Informatik gelten können. 1997 wurde es gedruckt, inzwischen stellt die Druckfassung einen Auszug des im Internet einsehbaren und erweiterten Dictionnaire panlatin des termes de base de l'informatique dar. Bezüglich seiner Konzeption und Entstehung gibt die ausführliche Dokumentation zum Dictionnaire Auskunft (vgl. Realiter 2002c, o.S.; CRETTAL 1996, o.S.). Das im Internet verfügbare Lexikon enthält Einträge in insgesamt sieben Sprachen: Englisch, Katalanisch, Spanisch, Französisch, Italienisch, Portugiesisch und Rumänisch. Das Informatik-Lexikon enthält auch einige Internet-Termini. Beispielsweise werden die engl. Termini electronic mail/electronic messaging/message handling/messaging (e-mail) übersetzt mit katal. correu electrònic, span. correo electrónico/e-mail/mensajería electrónica, ital. posta elettronica, port. correio eletrónico/correio eletrônico und rum. e-mail/posta electronica (vgl. CRET'TAL 1996, o.S.). Unter den fünf aktuell laufenden Projekten befindet sich ein von Louis Claude Tremblay (Kanada) koordiniertes Internet-Wörterbuch (Lexique panlatin d'Internet), welches mit 300 Einträgen die wichtigsten Internet-Konzepte enthält. Es soll im Internet publiziert und ständig aktualisiert werden und die Sprachen Französisch, Spanisch, Portugiesisch, Italienisch, Rumänisch, Katalanisch und Galizisch berücksichtigen (vgl. Realiter 2002c, o.S.).

\subsubsection{Die in Frankreich, Belgien, der Schweiz und Québec gültige Internet-Terminologie}

\section{Frankreich:}

Alle offiziellen, in Frankreich geltenden Termini lassen sich durch Eingabe des französischen oder englischen Terminus in die Suchmaske der Datenbank CRITER erfragen. Auf die Suchmaske gelangt man unter: http://www.cul|ture.gouv.fr/culture/dglf/terminologie/base-donnees.html. Jeder Terminus wird auf einer eigenen Seite dargestellt. Es ist auch möglich, in die Suchmaske den Namen der Kommission bzw. des Fachbereichs einzugeben. 
Die auf diese Weise einzeln abrufbaren Datenblätter enthalten die folgenden Angaben (die mit einem * gekennzeichneten Angaben sind in jedem Datenblatt enthalten):

- $\quad$ Terminus ${ }^{111}$,

- Kurzwort,

- *Nummer/Kürzel des Datenblatts,

- *Publikationsdatum,

- *Angabe der zuständigen Kommission,

- $\quad *$ Bereich $^{112}$,

- Unterbereich,

- französisches Synonym,

- $\quad *$ Definition ${ }^{113}$,

- Bemerkung/Kommentar,

- Beispiel ${ }^{114}$,

- *fremdsprachiges Äquivalent,

- fremdsprachiges Kurzwort,

- geografische Variante mit Quellenangabe ${ }^{115}$ und

- Verweise auf verwandte Einträge (vgl. ebd.).

Die Internet-Terminologie wurde von der CSTIC erarbeitet und im JO vom 16. März 1999 veröffentlicht (vgl. 3.2.5). Die zweite Liste zur Internet-Terminologie vom September 2000 wird in die WWW-Befragung nicht einbezogen, da diese Termini Mitte des Jahres 2002 sowohl von belgischer als auch von schweizerischer Seite noch nicht aufgegriffen worden waren. Eine Überprüfung des Etablierungsgrades dieser Neologismen wäre somit nur für Frankreich sinnvoll, nicht aber für Belgien und die Schweiz. Ebenso entfällt die Einbeziehung der dritten Liste zur Internet-Terminologie, da diese erst im Dezember 2002, d.h. einige Monate nach Durchführung der WWW-Befragung, erschienen ist.

\section{Belgien:}

Die belgische Informatik-Terminologie umfasst die Bereiche Telekommunikation, Informatik und Internet. Sie ist im Internet abrufbar unter: http://www.cfwb.|be/franca/bd/bd.htm (Service de la langue française o.J.f).

\footnotetext{
111 Angaben zur grammatischen Kategorie sind nicht systematisch vermerkt, mitunter aber sehr ausführlich (z.B. wird für toile „n.f.sg.“ angegeben). Bei Komposita wie barrière de sécurité oder serveur mandataire hingegen werden keinerlei grammatische Angaben gemacht.

112 Die Termini werden auf den einzelnen Datenblättern jeweils in Domaine (z.B. Informatique) und Sous-domaine (z.B. Internet) unterteilt.

113 Eine Definition fehlt allerdings bei den Termini page sur la toile und site (de la toile, sur la toile).

${ }^{114}$ Das Wort wird hier im Satzkontext präsentiert.

115 Z.B. wird für engl. e-mail das vom OLF vorgeschlagene courriel angegeben. Diesem Punkt wird aber nur sehr inkonsequent nachgegangen. Bei vielen Termini, zu denen es eine frankokanadische Variante gibt, fehlt jeglicher Verweis.
} 
„Les fiches terminologiques se présentent sous la forme suivante:

- terme vedette ;

- domaine (par exemple 'Personnes âgées') ;

- catégorie grammaticale et genre ;

- $\quad$ synonyme(s);

- définition ;

- $\quad$ source de cette définition;

- éventuellement une note ;

- équivalent(s) anglais ;

- équivalent(s) néerlandais ;

- équivalent(s) allemand(s) ;

- auteur de la fiche“ (Service de la langue française o.J.h).

\section{Schweiz:}

Die Terminologie, die von der Schweizerischen Bundeskanzlei vorgeschlagen wird, kann unter http://www.admin.ch/ch/f/bk/sp/anglicismes/anglicismes-fr1.html abgerufen werden (Zentrale Sprachdienste der Schweizerischen Bundeskanzlei o.J.a). Grammatische Angaben oder Definitionen fehlen, wie bereits in 3.3.2 angemerkt wurde.

Paradoxerweise werden zwar im Rahmen der Terminologie für den Anglizismus email entsprechende französische Äquivalente genannt, auf der französischsprachigen Startseite der Schweizerischen Bundeskanzlei (http://www.admin.ch/ch/|index.fr.html) heißt es jedoch: „Contactez-nous par e-mail ou par poste“, was nicht gerade für die konsequente Verwendung der französischsprachigen Terminologie spricht.

\section{Québec:}

Die umfangreiche Liste zur frankokanadischen Internet-Terminologie kann auf der Seite des OLF eingesehen werden: http://www.olf.gouv.qc.ca/ressources/|bibliotheque/dictionnaires/Internet/Index/ (OLF 2002c). Dort wird die Terminologie in sehr übersichtlicher Weise präsentiert. Im Index kann sowohl unter der englischen als auch unter der französischen Bezeichnung gesucht werden. Erstaunlich groß ist die Anzahl der Einträge. Allein für den Buchstaben „A“ gibt es im französischsprachigen Index 283 Einträge, wobei die Liste nicht nur Substantive, sondern auch Adjektive und Verben bzw. Phrasen enthält ${ }^{116}$.

Die folgende Abbildung 4 listet alle Termini auf, die bei einer Befragung zur Internet-Terminologie im Hinblick auf ihre Akzeptanz getestet werden könnten (zu

\footnotetext{
116 In die französische Liste vom 16. März 1999 sind weder Verben noch Phrasen aufgenommen worden. Die Liste enthält nur ein Adjektiv, nämlich bypertextuel.
} 
den Auswahlkriterien vgl. 5.2.1). Die Tabelle gibt die Internet-Terminologie von der angloamerikanischen Bezeichnung ausgehend in alphabetischer Reihenfolge wieder, nicht aber in der Reihenfolge des Bekanntheitsgrades (zum Bekanntheitsgrad der Termini vgl. 5.2.2).

\section{Abb. 4: Die Internet-Terminologie in Frankreich, Belgien, der Schweiz und Qué- bec: 21 Termini und Definitionen}

\begin{tabular}{|c|c|c|c|c|c|}
\hline $\begin{array}{l}\text { Engli- } \\
\text { scher } \\
\text { Termi- } \\
\text { nus }\end{array}$ & $\begin{array}{l}\text { Französi- } \\
\text { scher } \\
\text { Terminus } \\
\text { (Frank- } \\
\text { reich) }\end{array}$ & $\begin{array}{l}\text { Französi- } \\
\text { scher Ter- } \\
\text { minus } \\
\text { (Belgien) }\end{array}$ & $\begin{array}{l}\text { Französi- } \\
\text { scher } \\
\text { Terminus } \\
\text { (Schweiz) }\end{array}$ & $\begin{array}{l}\text { Französischer } \\
\text { Terminus } \\
\text { (Québec) }\end{array}$ & Definition $^{118}$ \\
\hline $\begin{array}{l}\text { (access) } \\
\text { provi- } \\
\text { der }\end{array}$ & $\begin{array}{l}\text { fournis- } \\
\text { seur } \\
\text { d'accès } \\
\text { (n.m.) }\end{array}$ & $\begin{array}{l}\text { fournisseur } \\
\text { d'accès } \\
\text { (n.m.) }\end{array}$ & $\begin{array}{l}\text { fournisseur } \\
\text { d'accès } 119\end{array}$ & $\begin{array}{l}\text { fournisseur de } \\
\text { services In- } \\
\text { ternet (n.m.) } \\
\text { Syn.: prestataire } \\
\text { de services } \\
\text { Internet (n.m.), } \\
\text { fournisseur } \\
\text { Internet } \\
\left(\text { n.m.) }{ }^{120}\right.\end{array}$ & $\begin{array}{l}\text { Organisme offrant à } \\
\text { des clients d'accéder } \\
\text { à l'internet, ou, plus } \\
\text { généralement, à tout } \\
\text { réseau de communi- } \\
\text { cation. }\end{array}$ \\
\hline applet & $\begin{array}{l}\text { appliquette } \\
\text { (n.f.) }\end{array}$ & $\begin{array}{l}\text { appliquette } \\
\text { (n.f.), Syn.: } \\
\text { applette } \\
\text { (n.f.) }\end{array}$ & [fehlt] & $\begin{array}{l}\text { applet (n.m.), } \\
\text { Syn.: appli- } \\
\text { quette (n.f.) }\end{array}$ & $\begin{array}{l}\text { Petite application } \\
\text { indépendante du } \\
\text { matériel et du logi- } \\
\text { ciel utilisés, qui est } \\
\text { téléchargée depuis } \\
\text { un serveur de la toile } \\
\text { mondiale et qui est } \\
\text { exécutée localement } \\
\text { au sein d'un logiciel } \\
\text { de navigation. }\end{array}$ \\
\hline $\begin{array}{l}\text { brow- } \\
\text { ser }\end{array}$ & $\begin{array}{l}\text { logiciel de } \\
\text { navigation } \\
\text { (n.m.), } \\
\text { Syn.: navi- } \\
\text { gateur }\end{array}$ & $\begin{array}{l}\text { logiciel de } \\
\text { navigation } \\
\text { (n.m.), Syn.: } \\
\text { navigateur }\end{array}$ & navigateur & $\begin{array}{l}\text { navigateur Web } \\
\text { (n.m.) }\end{array}$ & $\begin{array}{l}\text { Dans un environ- } \\
\text { nement de type } \\
\text { internet, logiciel qui } \\
\text { permet à à l'utilisa- } \\
\text { teur de rechercher et } \\
\text { de consulter des do- } \\
\text { cuments, et d'exploi- } \\
\text { ter les liens }\end{array}$ \\
\hline
\end{tabular}

117 Es werden nur Termini aus der Internet-Terminologie vom 16. März 1999 sowie engl. e-mail aufgenommen, für das bereits 1997 entsprechende französische Neologismen vorgeschlagen worden sind.

118 Die Definitionen wurden von der CSTIC erarbeitet und zusammen mit den französischen Neologismen im JO vom 16. März 1999 veröffentlicht (vgl. DGLF 1999, o.S.). Die Ersatzwörter und Definitionen zu engl. e-mail wurden bereits im JO vom 02. Dezember 1997 veröffentlicht (vgl. DGLF 1997, o.S.). Die belgischen Definitionen sind entweder mit den französischen identisch oder geben diese in verkürzter Form wieder.

${ }^{119}$ In den Tabellen der schweizerischen Behörden fehlen die entsprechenden grammatischen Angaben. Ebenso wenig werden hier Definitionen der Termini gegeben.

120 Unter der Rubrik „Entrée(s) additionnelle(s)“ finden sich weitere Alternativen: fournisseur d'accès à Internet (n.m.), fournisseur d'accès Internet (n.m.), FAI (n.m.), prestataire d'accès à Internet (n.m.), fournisseur d'accès (n.m.) und als Kurzwort: FSI (n.m.). 


\begin{tabular}{|c|c|c|c|c|c|}
\hline & & & & & $\begin{array}{l}\text { hypertextuels qu'ils } \\
\text { comportent. }\end{array}$ \\
\hline chat & $\begin{array}{l}\text { causette } \\
\text { (n.f. fam.) }\end{array}$ & $\begin{array}{l}\text { causette } \\
\text { (n.f.), bavar- } \\
\text { dage } \\
\text { (n.m.) }{ }^{121}\end{array}$ & [fehlt] & $\begin{array}{l}\text { bavardage- } \\
\text { clavier (n.m.) } \\
\text { Syn.: clavardage } \\
\text { (n.m.), cyberba- } \\
\text { vardage (n.m.), } \\
\text { bavardage en } \\
\text { ligne (n.m.), } \\
\text { bavardage } \\
\text { (n.m.) }\end{array}$ & $\begin{array}{l}\text { Communication } \\
\text { informelle entre } \\
\text { plusieurs personnes } \\
\text { sur l'internet, par } \\
\text { échange de messages } \\
\text { affichés sur leurs } \\
\text { écrans. }\end{array}$ \\
\hline cookie & $\begin{array}{l}\text { témoin (de } \\
\text { con- } \\
\text { nexion) } \\
\text { (n.m.) }\end{array}$ & $\begin{array}{l}\text { témoin (de } \\
\text { connexion) } \\
\text { (n.m.) } \\
\text { Syn.: mou- } \\
\text { chard }\end{array}$ & témoin & témoin (n.m.) & $\begin{array}{l}\text { Définition : 1. Ap- } \\
\text { pliquette envoyée } \\
\text { par un serveur de la } \\
\text { toile mondiale à un } \\
\text { utilisateur, parfois à } \\
\text { l'insu de celui-ci, au } \\
\text { cours d'une conne- } \\
\text { xion afin de caracté- } \\
\text { riser cet utilisateur. } \\
\text { 2. Par extension, } \\
\text { information que } \\
\text { l'appliquette peut } \\
\text { enregistrer sur le } \\
\text { disque de l'utilisateur } \\
\text { et à laquelle le ser- } \\
\text { veur peut accéder } \\
\text { ultérieurement. } \\
\text { Note: Dans cette } \\
\text { acception, on dit } \\
\text { aussi „mouchard“ } \\
\text { (n.m.) }\end{array}$ \\
\hline cracker & $\begin{array}{l}\text { pirate } \\
\text { (n.m.) }\end{array}$ & pirate (n.m.) & [fehlt] & [fehlt] & $\begin{array}{l}\text { Personne qui } \\
\text { contourne ou détruit } \\
\text { les protections d'un } \\
\text { logiciel, d'un ordi- } \\
\text { nateur ou d'un } \\
\text { réseau informatique. }\end{array}$ \\
\hline $\begin{array}{l}\text { cyber- } \\
\text { naut }\end{array}$ & $\begin{array}{l}\text { internaute } \\
\text { (n.) }\end{array}$ & $\begin{array}{l}\text { internaute } \\
\text { (n.), Syn.: } \\
\text { cybernaute } \\
\text { (n.) }\end{array}$ & [fehlt] & $\begin{array}{l}\text { internaute (n.), } \\
\text { Syn.: cybernaute } \\
\text { (n.) }\end{array}$ & $\begin{array}{l}\text { Utilisateur de } \\
\text { l'internet. }\end{array}$ \\
\hline $\begin{array}{l}\text { drag } \\
\text { and } \\
\text { drop }\end{array}$ & $\begin{array}{l}\text { glisser- } \\
\text { déposer } \\
\text { (n.m.) }\end{array}$ & $\begin{array}{l}\text { glisser-dépo- } \\
\text { ser (n.m.) }\end{array}$ & [fehlt] & [fehlt] & $\begin{array}{l}\text { Action par laquelle } \\
\text { l'utilisateur sé- } \\
\text { lectionne un objet à } \\
\text { l'écran, le déplace } \\
\text { jusqu'à une autre } \\
\text { position, puis le }\end{array}$ \\
\hline
\end{tabular}

121 Dieser Eintrag stammt aus dem Jahr 2001. Er ist in der Zwischenzeit aus der Datenbank entfernt worden. Jetzt gibt es keinen Eintrag mehr für engl. chat bzw. eines der französischsprachigen Ersatzwörter. 


\begin{tabular}{|c|c|c|c|c|c|}
\hline & & & & & $\begin{array}{l}\text { lâche pour déclen- } \\
\text { cher une action sur } \\
\text { cet objet. }\end{array}$ \\
\hline e-mail & $\begin{array}{l}\text { 1. adresse } \\
\text { de courrier } \\
\text { élec- } \\
\text { tronique } \\
\text { (n.f.) } \\
\text { 2. courrier } \\
\text { élec- } \\
\text { tronique } \\
\text { (n.m.) / } \\
\text { messagerie } \\
\text { électro- } \\
\text { nique (n.f.) } \\
\text { 3. message } \\
\text { élec- } \\
\text { tronique } \\
\text { (n.m.) } \\
\text { Kurzwort: } \\
\text { mél }\end{array}$ & $\begin{array}{l}\text { 1. courrier } \\
\text { électronique } \\
\text { (n.m.) } \\
\text { 2. courriel } \\
\text { (n.m.) } \\
\text { 3. message- } \\
\text { rie élec- } \\
\text { tronique }\end{array}$ & $\begin{array}{l}\text { courrier } \\
\text { électro- } \\
\text { nique, mes- } \\
\text { sagerie élec- } \\
\text { tronique, } \\
\text { message } \\
\text { électro- } \\
\text { nique }\end{array}$ & $\begin{array}{l}\text { courrier électro- } \\
\text { nique (n.m.) } \\
\text { Kurzwörter: } \\
\text { C.élec., CÉ, } \\
\text { Mél. } \\
\text { Syn.: courriel } \\
\text { (n.m.), mes- } \\
\text { sagerie électro- } \\
\text { nique (n.f.), } \\
\text { Mél. (n.m.) }\end{array}$ & $\begin{array}{l}\text { [1. courrier électro- } \\
\text { nique / messagerie } \\
\text { électronique:] } \\
\text { Service permettant } \\
\text { aux utilisateurs } \\
\text { habilités la saisie, la } \\
\text { consultation différée } \\
\text { et la transmission, } \\
\text { sur des ordinateurs } \\
\text { connectés en réseau, } \\
\text { de documents infor- } \\
\text { matisés, ou messages } \\
\text { électroniques. } \\
\text { [2. message électro- } \\
\text { nique:] Document } \\
\text { saisi, consulté ou } \\
\text { transmis au moyen } \\
\text { du courrier électro- } \\
\text { nique. }\end{array}$ \\
\hline \multicolumn{6}{|l|}{$\begin{array}{l}\text { emoti- } \\
\text { con } \\
\text { (s. smi- } \\
\text { ley) }\end{array}$} \\
\hline firewall & $\begin{array}{l}\text { barrière de } \\
\text { sécurité } \\
\text { (n.f.) } \\
\text { Syn.: pare- } \\
\text { feu }\end{array}$ & $\begin{array}{l}\text { barrière de } \\
\text { sécurité (n.f.) } \\
\text { Note: ,„[..] } \\
\text { on dit aussi } \\
\text { „pare-feu“" } \\
\text { (n.m.)"“ }\end{array}$ & pare-feu & $\begin{array}{l}\text { coupe-feu } \\
\text { (n.m.) } \\
\text { Syn.: pare-feu } \\
\text { (n.m.) } \\
\text { Entrée(s) addi- } \\
\text { tionnelle(s): } \\
\text { garde-barrière } \\
\text { (n.m.), barrière } \\
\text { de sécurité (n.f.) }\end{array}$ & $\begin{array}{l}\text { Dispositif informa- } \\
\text { tique qui filtre les } \\
\text { flux d'informations } \\
\text { entre un réseau in- } \\
\text { terne à un organisme } \\
\text { et un réseau externe } \\
\text { en vue de neutraliser } \\
\text { les tentatives de } \\
\text { pénétration en pro- } \\
\text { venance de l'exté- } \\
\text { rieur et de maittriser } \\
\text { les accès vers l'exté- } \\
\text { rieur. }\end{array}$ \\
\hline hacker & $\begin{array}{l}\begin{array}{l}\text { fouineur } \\
\text { (n.m.) }\end{array} \\
\text { Verweis } \\
\text { auf pirate } \\
\text { (als Ent- } \\
\text { sprechung } \\
\text { zu engl. } \\
\text { cracker) }\end{array}$ & $\begin{array}{l}\text { fouineur } \\
\text { (n.m.) }\end{array}$ & [fehlt] & [fehlt] & $\begin{array}{l}\text { Personne passionnée } \\
\text { d'informatique qui, } \\
\text { par jeu, curiosité, } \\
\text { défi personnel ou } \\
\text { par souci de noto- } \\
\text { riété, sonde, au } \\
\text { hasard plutôt qu'à } \\
\text { l'aide de manuels } \\
\text { techniques, les pos- } \\
\text { sibilités matérielles et } \\
\text { logicielles des } \\
\text { systèmes informati- } \\
\text { ques afin de pouvoir } \\
\text { éventuellement s'y }\end{array}$ \\
\hline
\end{tabular}




\begin{tabular}{|c|c|c|c|c|c|}
\hline & & & & & $\begin{array}{l}\text { immiscer. (source : } \\
\text { Office québécois de } \\
\text { langue française) }\end{array}$ \\
\hline $\begin{array}{l}\text { home- } \\
\text { page / } \\
\text { home } \\
\text { page }\end{array}$ & $\begin{array}{l}\text { page } \\
\text { d'accueil } \\
\text { (n.f.) }\end{array}$ & $\begin{array}{l}\text { page } \\
\text { d'accueil } \\
\text { (n.f.) }\end{array}$ & $\begin{array}{l}\text { page } \\
\text { d'accueil }\end{array}$ & $\begin{array}{l}\text { 1. page d'ouver- } \\
\text { ture (n.f.) } \\
\text { 2. page d'accueil } \\
\text { (n.f.) } \\
\text { Syn.: page de } \\
\text { démarrage } \\
\text { (n.f.), page de } \\
\text { départ (n.f.) }\end{array}$ & $\begin{array}{l}\text { 1. Page de présenta- } \\
\text { tion d'un site sur la } \\
\text { toile mondiale. } \\
\text { 2. Page de tête affi- } \\
\text { chée par un logiciel } \\
\text { de navigation. }\end{array}$ \\
\hline $\begin{array}{l}\text { infor- } \\
\text { mation } \\
\text { (super) } \\
\text { high- } \\
\text { way }\end{array}$ & $\begin{array}{l}\text { autoroutes } \\
\text { de l'infor- } \\
\text { mation }^{122} \\
\text { (n.f.pl.) }\end{array}$ & $\begin{array}{l}\text { autoroutes } \\
\text { de l'infor- } \\
\text { mation } \\
\text { (n.f.pl.) } \\
\text { Syn.: info- } \\
\text { route }\end{array}$ & [fehlt] & $\begin{array}{l}\text { autoroute de } \\
\text { l'information } \\
\text { (n.f.) } \\
\text { Syn.: inforoute } \\
\text { (n.f.), autoroute } \\
\text { électronique } \\
\text { (n.f.), autoroute } \\
\text { numérique } \\
\text { (n.f.), autoroute } \\
\text { informatique } \\
\text { (n.f.) }\end{array}$ & $\begin{array}{l}\text { Structure constituée } \\
\text { par des moyens de } \\
\text { télécommunication } \\
\text { et d'informatique } \\
\text { interconnectés, qui } \\
\text { permet d'offrir à un } \\
\text { très grand nombre } \\
\text { d'usagers de mul- } \\
\text { tiples services, en } \\
\text { général à débit élevé, } \\
\text { y compris des servi- } \\
\text { ces audiovisuels. } \\
\text { Note: On rencontre } \\
\text { aussi le terme,,info- } \\
\text { route“, qui n'est pas } \\
\text { recommandé. }\end{array}$ \\
\hline $\begin{array}{l}\text { news- } \\
\text { group }\end{array}$ & $\begin{array}{l}\text { forum } \\
\text { (n.m.) }\end{array}$ & $\begin{array}{l}\text { forum (n.m.) } \\
\text { Syn.: FAQ, } \\
\text { fichier des } \\
\text { questions } \\
\text { courantes, } \\
\text { questions } \\
\text { courantes }^{123}\end{array}$ & forum & $\begin{array}{l}\begin{array}{l}1 . \quad \text { forum } \\
\text { (n.m.) }\end{array} \\
\begin{array}{l}\text { 2. } \quad \begin{array}{l}\text { groupe de } \\
\text { nouvelles }\end{array} \\
\quad \text { (n.m.) }\end{array} \\
\text { Syn. zu 1: } \\
\text { forum de dis- } \\
\text { cussion (n.m.), } \\
\text { groupe de dis- } \\
\text { cussion (n.m.), } \\
\text { groupe de nou- } \\
\text { velles (n.m.) } \\
\text { Syn. zu 2: } \\
\text { groupe de nou- } \\
\text { velles Usenet } \\
\text { (n.m.), forum } \\
\text { Usenet (n.m.) }\end{array}$ & $\begin{array}{l}\text { Service permettant } \\
\text { discussions et } \\
\text { échanges sur un } \\
\text { thème donné : cha- } \\
\text { que utilisateur peut } \\
\text { lire à tout moment } \\
\text { les interventions de } \\
\text { tous les autres et } \\
\text { apporter sa propre } \\
\text { contribution sous } \\
\text { forme d'articles. }\end{array}$ \\
\hline
\end{tabular}

122 Dies ist kein Tippfehler. Autoroutes steht in der Terminologieliste im Plural.

${ }^{123}$ Hier liegt ein Fehler vor: Ein Diskussionsforum und die FAQ sind nicht identisch. Die Definition hingegen ist korrekt: „Service permettant l'échange et la discussion sur un thème donné : chaque utilisateur peut lire à tout moment les interventions de tous les autres et apporter sa propre contribution sous forme d'articles.“ 


\begin{tabular}{|c|c|c|c|c|c|}
\hline $\begin{array}{l}\text { proxy } \\
\text { server / } \\
\text { proxy }\end{array}$ & $\begin{array}{l}\text { mandataire } \\
\text { (n.m.) }\end{array}$ & [fehlt] & [fehlt] & $\begin{array}{l}\text { serveur man- } \\
\text { dataire (n.m.), } \\
\text { Syn.: manda- } \\
\text { taire (n.m.), } \\
\text { serveur man- } \\
\text { daté (n.m.), } \\
\text { logiciel manda- } \\
\text { taire (n.m.) }\end{array}$ & $\begin{array}{l}\text { Dispositif informa- } \\
\text { tique associé à un } \\
\text { serveur et réalisant, } \\
\text { pour des applica- } \\
\text { tions autorisées, des } \\
\text { fonctions de média- } \\
\text { tion, telle que le } \\
\text { stockage des docu- } \\
\text { ments les plus fré- } \\
\text { quemment deman- } \\
\text { dés ou l'établisse- } \\
\text { ment de passerelles. }\end{array}$ \\
\hline $\begin{array}{l}\text { pull } \\
\text { techno- } \\
\text { logy }\end{array}$ & $\begin{array}{l}\text { recherche } \\
\text { indivi- } \\
\text { duelle } \\
\text { (n.f.) }\end{array}$ & $\begin{array}{l}\text { recherche } \\
\text { individuelle } \\
\text { (n.f.) }\end{array}$ & [fehlt] & $\begin{array}{l}\text { technologie du } \\
\text { tirer (n.f.), Syn.: } \\
\text { tirer (n.m.) }\end{array}$ & $\begin{array}{l}\text { Technique utilisée } \\
\text { sur la toile mondiale } \\
\text { lorsque l'internaute } \\
\text { recherche des don- } \\
\text { nées par une dé- } \\
\text { marche active au } \\
\text { moyen de son logi- } \\
\text { ciel de navigation, } \\
\text { qui lui présentera } \\
\text { ensuite le résultat de } \\
\text { cette recherche. }\end{array}$ \\
\hline $\begin{array}{l}\text { push } \\
\text { techno- } \\
\text { logy }\end{array}$ & $\begin{array}{l}\text { distribu- } \\
\text { tion sélec- } \\
\text { tive (n.f.), } \\
\text { diffusion } \\
\text { sélective } \\
\text { (n.f.), } \\
\text { distri- } \\
\text { bution } \\
\text { personna- } \\
\text { lisée (n.f.) }\end{array}$ & $\begin{array}{l}\text { diffusion } \\
\text { sélective } \\
\text { (n.f.), Syn.: } \\
\text { distribution } \\
\text { sélective } \\
\text { (n.f.), distri- } \\
\text { bution } \\
\text { personnali- } \\
\text { sée (n.f.) }\end{array}$ & [fehlt] & $\begin{array}{l}\text { technologie du } \\
\text { pousser (n.f.), } \\
\text { Syn.: pousser } \\
\text { (n.m.) }\end{array}$ & $\begin{array}{l}\text { Technique utilisée } \\
\text { pour faire bénéficier } \\
\text { automatiquement un } \\
\text { utilisateur de la toile } \\
\text { mondiale, à sa de- } \\
\text { mande, d'un envoi } \\
\text { de données d'un } \\
\text { type choisi. }\end{array}$ \\
\hline smiley & $\begin{array}{l}\text { frimousse } \\
\text { (n.f.) }\end{array}$ & $\begin{array}{l}\text { frimousse } \\
\text { (n.f.) } \\
\text { Syn.: binette } \\
\text { (n.f.) }\end{array}$ & [fehlt] & $\begin{array}{l}\text { binette (n.f.) } \\
\text { zu vermeiden: } \\
\text { émoticône, } \\
\text { souriant, souri- } \\
\text { ard }\end{array}$ & $\begin{array}{l}\text { Dans un message, } \\
\text { association facé- } \\
\text { tieuse de quelques } \\
\text { caractères typogra- } \\
\text { phiques qui évo- } \\
\text { quent un visage ex- } \\
\text { pressif. }\end{array}$ \\
\hline viewer & $\begin{array}{l}\text { visionneur } \\
\text { (n.m.) }\end{array}$ & $\begin{array}{l}\text { visionneur } \\
\text { (n.m.) }\end{array}$ & visionneur & $\begin{array}{l}\text { visualiseur (n. } \\
\mathrm{m} .)\end{array}$ & $\begin{array}{l}\text { Logiciel permettant } \\
\text { d'afficher un docu- } \\
\text { ment sans disposer } \\
\text { du logiciel qui a servi } \\
\text { à le produire. }\end{array}$ \\
\hline $\begin{array}{l}\text { World } \\
\text { Wide } \\
\text { Web }\end{array}$ & $\begin{array}{l}\text { toile } \\
\text { d'araignée } \\
\text { mondiale } \\
\text { (n.f.) } \\
\text { Kurzwör- } \\
\text { ter: toile } \\
\text { mondiale, }\end{array}$ & $\begin{array}{l}\text { toile } \\
\text { d'araignée } \\
\text { mondiale } \\
\text { (n.f.) } \\
\text { Syn.: toile } \\
\text { mondiale, } \\
\text { toile, T.A.M. }\end{array}$ & [fehlt] & $\begin{array}{l}\text { Web (n.m.) } \\
\text { Syn.: W3 (n.m.) } \\
\text { Entrée(s) addi- } \\
\text { tionnelle(s): } \\
\text { toile d'araignée } \\
\text { mondiale (n.f.), } \\
\text { toile mondiale }\end{array}$ & $\begin{array}{l}\text { Dans l'internet, } \\
\text { système, réparti } \\
\text { géographiquement et } \\
\text { structurellement, de } \\
\text { publication et de } \\
\text { consultation de } \\
\text { documents faisant }\end{array}$ \\
\hline
\end{tabular}




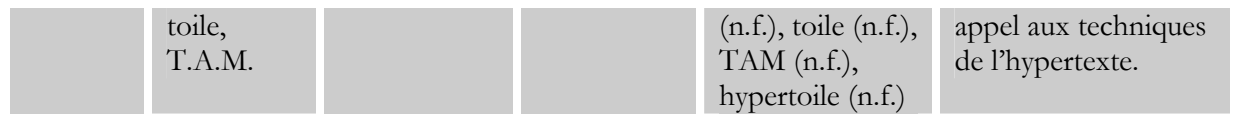

Bei einem Vergleich der in der vorangehenden Tabelle aufgeführten französischen, belgischen, schweizerischen und frankokanadischen Termini fallen die Parallelen zwischen den Vorschlägen der französischen, belgischen und schweizerischen Arbeitsgruppe auf. Dies ist im Falle Belgiens auf das Abkommen und das Dekret von 1999 zurückzuführen, die eine weitestgehende Übernahme der französischen Terminologie vorsehen (vgl. Fußnote 101).

Die kanadische Internet-Terminologie weicht nicht nur im Umfang, sondern auch in der Form der vorgeschlagenen Neologismen erheblich von der französischen Terminologie ab. Exemplarisch lassen sich die unterschiedlichen Resultate der frankokanadischen im Gegensatz zur französischen, belgischen und schweizerischen Terminologiearbeit anhand des Terminus e-mail demonstrieren. Während in Frankreich und der Schweiz courrier électronique, messagerie électronique und message électronique gelten, wird in Québec die Bezeichnung courriel verwendet. Die belgische Terminologie lässt beides zu, franz. courrier électronique und messagerie électronique sowie das kanadische courriel.

Diese Abweichung zwischen den in Québec und den in Frankreich, Belgien und der Schweiz erarbeiteten Internet-Termini kann auf mindestens zwei Faktoren zurückgeführt werden:

1. Mangelnde Kooperation bzw. Uneinigkeit in Terminologiefragen zwischen Québec und den europäischen frankophonen Staaten und

2. zeitliche Verzögerung der französischen, belgischen und schweizerischen Terminologiearbeit im Unterschied zu Québec.

Die zeitliche Verzögerung liegt eindeutig auf europäischer Seite, wo es sehr lange dauert, bis die französische Terminologiekommission zur Informatik Vorschläge entwickelt und diese im JO veröffentlicht werden. 1999, als die erste französische Liste zur Internet-Terminologie publiziert wurde, war ein Großteil der kanadischen Internet-Neologismen bereits verabschiedet.

Die Veröffentlichung der französischen Terminologielisten beeinflusst dann wiederum die belgischen und schweizerischen Terminologieentscheidungen. Belgien entwickelt im Gegensatz zu den drei anderen betrachteten frankophonen Staaten keine eigenen Neologismen, sondern übernimmt weitestgehend die französischen Vorschläge. Die Arbeitsgruppe der Schweizerischen Eidgenossenschaft arbeitet kontinuierlich an einer entsprechenden Tabelle weiter, berücksichtigt allerdings im Unterschied zu Frankreich und Québec vier Sprachen.

Für die sechs für den Fragebogen ausgewählten Neologismen ergibt sich im tabellarischen Überblick folgendes Bild (die Kriterien der Auswahl werden in Kapitel 5.2.1 und 5.2.2 erläutert): 
Abb. 5: Die sechs ausgewählten Internet-Termini und ihre französischen Äquivalente

\begin{tabular}{|c|c|c|c|c|}
\hline $\begin{array}{l}\text { Inter- } \\
\text { natio- } \\
\text { nalismus }\end{array}$ & Frankreich & Belgien & Schweiz & Québec \\
\hline e-mail & $\begin{array}{l}\text { courrier } \\
\text { électro- } \\
\text { nique }{ }^{124} \text {, } \\
\text { message } \\
\text { électro- } \\
\text { nique, mél }\end{array}$ & $\begin{array}{l}\text { courrier élec- } \\
\text { tronique, } \\
\text { courriel, mes- } \\
\text { sagerie élec- } \\
\text { tronique }\end{array}$ & $\begin{array}{l}\text { courrier } \\
\text { électro- } \\
\text { nique, mes- } \\
\text { sagerie élec- } \\
\text { tronique, } \\
\text { message } \\
\text { électronique }\end{array}$ & $\begin{array}{l}\text { courrier électro- } \\
\text { nique, C.élec., CÉ, } \\
\text { Mél, courriel, messa- } \\
\text { gerie électronique }\end{array}$ \\
\hline homepage & $\begin{array}{l}\text { page } \\
\text { d'accueil }\end{array}$ & page d'accueil & $\begin{array}{l}\text { page } \\
\text { d'accueil }\end{array}$ & $\begin{array}{l}\text { page d'ouverture, } \\
\text { page d'accueil, page } \\
\text { de démarrage, page } \\
\text { de départ }\end{array}$ \\
\hline $\begin{array}{l}\text { World } \\
\text { Wide } \\
\text { Web/web }\end{array}$ & $\begin{array}{l}\text { toile } \\
\text { d'araignée } \\
\text { mondiale, } \\
\text { toile mon- } \\
\text { diale, toile, } \\
\text { T.A.M. }\end{array}$ & $\begin{array}{l}\text { toile } \\
\text { d'araignée } \\
\text { mondiale, } \\
\text { toile mon- } \\
\text { diale, toile, } \\
\text { T.A.M. }\end{array}$ & ---- & $\begin{array}{l}\text { Web, W3, toile } \\
\text { d'araignée mondiale, } \\
\text { toile mondiale, toile, } \\
\text { TAM, hypertoile }\end{array}$ \\
\hline chat & causette & $\begin{array}{l}\text { causette, } \\
\text { bavardage }^{125}\end{array}$ & ---- & $\begin{array}{l}\text { bavardage-clavier, } \\
\text { clavardage, cyber- } \\
\text { bavardage, bavar- } \\
\text { dage (en ligne), ba- } \\
\text { vardage }\end{array}$ \\
\hline cracker & pirate & pirate & ---_126 & ---- \\
\hline $\begin{array}{l}\text { (access) } \\
\text { provider }\end{array}$ & $\begin{array}{l}\text { fournisseur } \\
\text { d'accès }\end{array}$ & $\begin{array}{l}\text { fournisseur } \\
\text { d'accès }\end{array}$ & $\begin{array}{l}\text { fournisseur } \\
\text { d'accès }\end{array}$ & $\begin{array}{l}\text { fournisseur (de ser- } \\
\text { vices) Internet, } \\
\text { prestataire de ser- } \\
\text { vices }\end{array}$ \\
\hline
\end{tabular}

Unter diesen Umständen wäre ein WWW-Fragebogen 1. aufgrund der Vielzahl an zu vermerkenden französischen Äquivalenten noch länger und für die Informanten sehr unübersichtlich und 2. wenig aussagekräftig. Es ist m.E. nicht sinnvoll,

${ }^{124}$ Der Terminus adresse de courrier électronique wird weggelassen, weil sein Inhalt dem englischen e-mailadress entspricht.

125 Causette und bavardage waren im Jahr 2001 als französische Ersatzwörter für engl. chat angegeben (vgl. Abb. 4).

126 Cracker gibt es nicht nur im Bereich des Internet, sondern dieser Terminus bezieht sich auf jede Form von Computernetzen. Dies könnte ein Grund dafür sein, dass cracker weder in die schweizerische noch in der frankokanadische Internet-Terminologie eingegangen ist. 
Informanten aus Québec in die Untersuchung einzubeziehen, wenn die Ergebnisse aller Voraussicht nach so stark von denen der französischen, belgischen und schweizerischen Informanten abweichen werden, dass keine Vergleichbarkeit mehr gegeben ist. Es wäre allerdings interessant zu erforschen, inwiefern es sich im Hinblick auf die Akzeptanz auswirkt, wenn so viele französischsprachige Neologismen angeboten werden, wie es im Falle der frankokanadischen Terminologie der Fall ist. Wahrscheinlich stiftet eine Vielzahl von Bezeichnungen für eine Sache bzw. ein Konzept unter den Sprechern nur unnötige Verwirrung, welchen der vorgeschlagenen Termini sie benutzen sollten, um verstanden zu werden.

Québec würde aufgrund der Vielzahl der von dort stammenden Neologismen im Rahmen der Untersuchung, deren Ausgangspunkt die französische Internet-Terminologie darstellt, ein zu großes Gewicht bekommen. Zwar wäre durch eine Korrelation der gewählten Neologismen und der im dritten Fragebogenteil angegebenen Wohnsitze möglich herauszustellen, inwiefern die Franzosen der französischen Terminologie und die Frankokanadier der in Québec geltenden Terminologie folgen, doch entspricht dies nicht der mit dieser Studie verfolgten Zielsetzung. Insofern wird sich die Studie auf die Überprüfung beschränken, inwieweit die Franzosen, Belgier und Schweizer die in ihren Ländern geltenden InternetNeologismen kennen und verwenden.

\subsubsection{Zusammenfassung von 3.3}

Nicht nur in Frankreich, sondern auch in anderen frankophonen Staaten wird systematische Sprachplanung in Form von Terminologiearbeit betrieben. Die Parallelen zwischen den vier betrachteten frankophonen Staaten sind eindeutig. Zumindest in Frankreich, Wallonien und Québec wird eine offensive Sprachpolitik betrieben, die die Rolle des Französischen gegenüber dem Englischen stärken soll. In der Schweiz gibt es keine eigenständige Sprachpolitik für das Französische, möglicherweise ändert sich die Situation in den nächsten Jahren durch die Aktivitäten der 1992 neu gegründeten Sprachpflegeorganisation Délégation à la langue française (DLF).

Die Situation für Frankreich wurde bereits in 3.2 ausführlich behandelt, in 3.3 ging es um die Sprachpolitik und insbesondere die Terminologiearbeit in Belgien und der Schweiz und Québec, aber auch um übernationale terminologische Bemühungen.

In allen drei in 3.3 betrachteten Staaten gibt es Institutionen, denen die Terminologiearbeit obliegt. In Belgien überprüft die Expertenkommission „Terminologie“ der Communauté française de Belgique die in Frankreich verabschiedeten Termini im Hinblick auf ihre Eignung für die frankophonen Sprecher Belgiens. Die meisten der französischen Terminologievorschläge werden von den Belgiern übernommen. Die Datenbank des belgischen Service de la langue française umfasst Terminologielisten zu mehreren Wortfeldern, die Internet-Neologismen sind Bestandteil der Informatik-Terminologie. Auch die deutschen und niederländischen Bezeichnungen sind, sofern vorhanden, in die Datenbank aufgenommen worden. In der 
Schweiz ist die Arbeitsgruppe Terminologie der Schweizerischen Bundeskanzlei für die Terminologiearbeit zuständig. Die Schweiz hat keine eigene TerminologieDatenbank erstellt, sondern greift auf die europäische Datenbank EURODICAUTOM zurück und erweitert diese im Hinblick auf die schweizerischen Terminologiebedürfnisse. Im Bereich der Internet-Terminologie gibt es jedoch eine Besonderheit. Die seit 1981 bestehende Arbeitsgruppe hat unter Berücksichtigung der Vorschläge von schweizerischen Bürgern eine viersprachig angelegte Tabelle entworfen, die für englische Internet-Termini französische, deutsche und italienische Äquivalente vorschlägt. In Québec ist die Terminologiekommission des OLF für die Schaffung von Neologismen zuständig. Die in Québec vorgeschlagenen französischsprachigen Neologismen weichen jedoch erheblich von den in Frankreich, Belgien und der Schweiz gültigen Termini ab, wie Abb. 4 verdeutlicht. Deshalb wird darauf verzichtet, Québec als Untersuchungsland in die Befragung einzubeziehen. Die belgischen und schweizerischen Termini (sofern die Schweizer für das entsprechende englische Wort eine französische Bezeichnung geschaffen haben) hingegen stimmen weitgehend mit der französischen Terminologie überein. Die terminologischen Parallelen sind sicherlich zu einem großen Teil darauf zurückzuführen, dass das Pariser Französisch in Wallonien und in der Romandie noch immer als die Standardsprache und die somit erstrebenswerte Varietät angesehen wird (vgl. 2.3.3.2.2 und 2.3.4.2.2). Ein anderer Grund liegt aber auch im finanziellen Bereich: Terminologiearbeit ist ein teures Unterfangen. Der belgische und der schweizerische Staat sind nicht bereit, in diesem Bereich so große Summen zu investieren wie Frankreich.

Auch die länderübergreifende Terminologiearbeit wird in den letzten Jahren verstärkt. Die bedeutendste Terminologieorganisation im frankophonen Sprachraum ist der 1986 gegründete Réseau International de Néologie et de Terminologie (Rint), der im Jahre 2000 durch den Réseau international francophone d'aménagement linguistique (Rifal) abgelöst wurde. Für die terminologische Kooperation zwischen den romanischsprachigen Ländern ist der 1993 gegründete Réseau panlatin de terminologie (Realiter) zuständig. 


\section{Evaluation der französischen Sprachpolitik und Terminologiearbeit}

In diesem Kapitel wird versucht einen Überblick über die bisherige Evaluation der französischen Sprachpolitik und Terminologiearbeit zu geben. Dafür werden die Ergebnisse, aber auch die Methodik von Studien vorgestellt, die die Akzeptanz von Anglizismen bzw. deren offiziellen Ersatzwörtern ermittelt haben.

Nachdem zunächst der Begriff Neologismus geklärt und die verschiedenen Typen empirischer Studien erörtert werden, werden in den Abschnitten 4.3.1 und 4.3.2 die Ergebnisse von insgesamt 13 empirischen Studien vorgestellt, die mit Ausnahme der Studie Chansous (1993) auf einer Befragung, d.h. auf Interviews bzw. Fragebögen basieren. Im Zentrum dieser Studien steht nicht der tatsächliche Anglizismenanteil an der französischen Sprache, sondern wie Anglizismen bzw. französische Neologismen von französischen Sprechern rezipiert werden. Entsprechende Studien, die über die Akzeptanz von Neologismen bzw. über die Einstellungen zu Sprachgesetzen die Wirksamkeit der aktuellen französischen Sprachpolitik evaluieren, liegen zu Frankreich und Québec vor, nicht aber zu Belgien oder der Schweiz.

Es wäre sicherlich sinnvoll, im Rahmen einer umfassenden Auswertung politischer Eingriffe in die Lexik der französischen Sprache auch die in Québec betriebene Forschung zu beachten. Die systematische Auswertung sprachpolitischer und terminologischer Bemühungen ist bezogen auf Québec wesentlich fortgeschrittener als bezogen auf Frankreich. Da Québec allerdings nicht zu den in dieser Studie untersuchten Ländern gehört, wird an dieser Stelle nur auf den Artikel Humbleys (1997) verwiesen, der einen Überblick über derzeit u.a. für 
Québec vorliegende Arbeiten gibt und auf weiterführende Literatur hinweist ${ }^{1}$. Aus den genannten Gründen wird sich dieses Kapitel nur mit der Evaluation der französischen Sprachpolitik und Terminologiearbeit beschäftigen.

Abschnitt 4.4 gibt schließlich einen Überblick, wie französische und deutschsprachige Linguisten, die französische Bevölkerung sowie die französische und deutschsprachige Presse die moderne französische Sprachpolitik bewerten. In Abschnitt 4.4 fließen auch vereinzelt Ergebnisse von Studien ein, in denen die Anglizismenquote ermittelt wurde (z.B. Plümer 2000); jedoch steht auch hier weniger die tatsächliche Anglizismenquote im Vordergrund als vielmehr sich daraus ableitende Schlussfolgerungen zur Wirksamkeit der französischen Sprachpolitik ${ }^{2}$. In dieser Arbeit fallen häufig die Termini Neologismus und Anglizismus. Eine Definition des Anglizismus wurde bereits im 2. Kapitel, Fußnote 34, gegeben, dem Neologismus widmet sich der folgende Abschnitt.

\subsection{Begriffsklärung: Neologismus}

Aufgrund von Helfrichs ausführlicher Auseinandersetzung mit der Forschung zur Neologismenproblematik (vgl. Helfrich 1993, 4-52), erweist sich eine eingehende Beschäftigung mit dem theoretischen Konzept in dieser Arbeit als unnötig. Somit werden im Folgenden nur zwei Definitionen des Terminus Neologismus vorgestellt. Helfrich (1993, 19f.) definiert diesen Terminus wie folgt:

\footnotetext{
1 Der Titel des Aufsatzes lautet: „Paramètres d'observation de l'aménagement de la langue“ (s. Bibliografie).

Im Unterschied zu Frankreich wurden in Québec die Erfolge der Sprachpolitik bereits kurz nach der Einführung der entsprechenden Gesetze in den 1970er Jahren (Gesetz 22 von 1974 und Gesetz 101 von 1977) evaluiert. Studien zur Evaluation der offiziellen Terminologie werden seit den späten 1970er Jahren durchgeführt. Die ersten Arbeiten befassen sich im Wesentlichen mit zwei Fragen: 1. Inwieweit ist das Französische in ausgewählten Betrieben vertreten (in Abgrenzung zum Englischen) und 2. inwieweit wird die offizielle Terminologie verwendet. Einen Überblick über die neueren Studien zum Sprachgebrauch in Québec geben Cajolet-Laganière/Martel (1995). Sie zeigen, dass sich die Qualität des in öffentlichen Institutionen in Québec gesprochenen Französisch insbesondere in Bezug auf die Verwendung der französischen Terminologie verbessert hat. Das gilt auch für private Firmen, jedoch bleibt der Sprachgebrauch der Arbeiter unzureichend (vgl. Cajolet-Laganière/Martel 1995, 92f.). Martin (1997) zeigt am Beispiel der Commission de terminologie de l'éducation, welche Schwierigkeiten bei der Etablierung neuer Terminologievorschläge auftreten (können). Cormier/St-Pierre $(1996,92)$ halten es für äußerst schwierig, allgemeine Aussagen über den Etablierungsgrad der Terminologievorschläge zu treffen. Die Evaluation der Bemühungen des OLF, die französische Terminologie im öffentlichen Sektor sowie in Betrieben zu etablieren, wird insgesamt als Erfolg gewertet, wenngleich es weiterhin gilt, die Bemühungen fortzusetzen und sogar noch zu verstärken (vgl. Fortin 1993, 25-29).

2 Studien zur Anglizismenquote in ausgewählten Zeitschriften und Zeitungen stammen z.B. von Forgue (1980), Goosen (1980) und Plümer (2000). Zum Anglizismenanteil im Petit Robert vgl. ReyDebove/Gagnon (1986, VI) und Rey-Debove (1987), zum Anteil der Anglizismen am Wortschatz des Grand Robert vgl. Gebhardt (1975). Mit der Anglizismenquote in belgischen Tageszeitungen befassen sich Doppagne/Lenoble-Pinson (1982) und Högstedt (1998). Ein Vergleich zwischen der Anglizismenquote in französischen und belgischen Printmedien findet sich in Klein/Lienart/Ostyn (1997).
} 


\begin{abstract}
„Übereinstimmend wird heute ein Wort als Neologismus bezeichnet hinsichtlich seiner Neuheit in bezug auf das bestehende Lexikon einer Sprache. Neologismen dienen der Erweiterung oder auch der Erneuerung des Wortschatzes (enrichissement lexical). Ein Bedarf an Neuwörtern ergibt sich infolge neuer Bezeichnungsbedürfnisse, aber auch zum Zwecke der Informationsverdichtung, Präzision und Originalität. Der Form nach kann ein solches Bezeichnungsbedürfnis sowohl durch ,autochthone' Neubildung wie auch durch Übernahme aus anderen Sprachen oder Varietäten, z.B. als Entlehnung, Lehnübersetzung oder auch aus einem anderen Register derselben Sprache, gedeckt werden. Diese werden als lexikalische Neologismen bezeichnet. Daneben stehen die semantischen Neologismen, d.h. vorhandene Wörter, die mit neuer Bedeutung versehen werden“" (Helfrich 1993, 19f.).
\end{abstract}

Die Definition Helfrichs lässt sich auch auf die französischen Neologismen übertragen, die von den Terminologiekommissionen vorgeschlagen werden. Allerdings liegt hierbei weniger ein grundsätzliches Bezeichnungsbedürfnis vor (dieses ist ja bereits durch den fremdsprachigen Terminus gedeckt), sondern der Wunsch nach einem aus französischem Wortmaterial und nach französischen Wortbildungsregeln geschaffenen Terminus. Neben diesen lexikalischen Neologismen bringen die Kommissionen auch semantische Neologismen hervor, indem vorhandene Wörter einfach mit neuer Bedeutung versehen werden. Ein Beispiel aus dem Bereich der Internet-Terminologie ist franz. toile für engl. web, das in diesem Kontext einen Teil des Internet, nämlich das World Wide Web, bezeichnet, während es vorher nur eine bestimmte Verarbeitungsform von Textilien bezeichnete.

Herberg $(2001,92)$ geht in seiner Definition stärker auf die Rezipientenseite ein, ein von der früheren Neologismenforschung vernachlässigter Aspekt:

„Ein Neologismus ist eine lexikalische Einheit bzw. eine Bedeutung, die in einem bestimmten Abschnitt der Sprachentwicklung in einer Kommunikationsgemeinschaft aufkommt, sich ausbreitet, als sprachliche Norm allgemein akzeptiert und in diesem Entwicklungsabschnitt von der Mehrheit der Sprachbenutzer über eine gewisse Zeit hin als neu empfunden wird.“

Ob Neologismen als „allgemein akzeptiert“ gelten können, wie die Formulierung Herbergs unterstellt, ist in Bezug auf die offiziellen französischen Ersatzwörter fraglich. Wie die in 4.3.1 und 4.3.2 vorgestellten Studien zeigen, werden die französischen Neologismen nicht immer von den Sprachbenutzern akzeptiert. Zwar sind die in den französischen Terminologielisten erscheinenden französischen Neologismen für bestimmte Geltungsbereiche zur Norm erhoben worden, aber dies impliziert nicht automatisch ihre allgemeine Akzeptanz in der Bevölkerung. 
Die Neologismenbildung ist meistens ein natürlicher Prozess, und jeder Sprachbenutzer kann zum Produzenten von Neologismen werden. Die créativité lexicale ${ }^{3}$ tritt immer dann ein, wenn Sprecher ein akutes Bezeichnungsbedürfnis verspüren und eine offizielle Bezeichnung bislang fehlt (vgl. Helfrich 1993, 21). Der Neologismenbildung als natürlichem Prozess stehen die von den Terminologiekommissionen teilweise künstlich geschaffenen Neologismen gegenüber. Sie gehen nicht aus einem spontan empfundenen Bezeichnungsbedürfnis hervor, sondern stellen eine Art Auftragsarbeit dar, nämlich für ein begrenztes (Fach-)Gebiet die englische Terminologie aufzulisten und dafür französische Termini vorzuschlagen. Wie Depecker (2000) nachweist, hat sich in dieser Hinsicht inzwischen ein Wandel vollzogen: Die Terminologiekommissionen haben bis Mitte der 1990er Jahre wesentlich mehr Termini selbst kreiert, als dies in der zweiten Hälfte der 1990er Jahre der Fall war. In den letzten Jahren wurden in erster Linie bereits existierende Neologismen durch die Aufnahme in die entsprechenden Terminologielisten nur offiziell bestätigt. Insofern ist davon auszugehen, dass die auf natürliche Weise entstandenen offiziellen französischen Neologismen auf mehr Akzeptanz stoßen werden als die künstlich geschaffenen. In die gleiche Richtung weist auch die Argumentation von Éloy $(1995,412)$ :

„Au-delà, et même au sein, de ces emplois contraints, le succès de cette terminologie officielle, élaborée par des commissions réunies par les différents ministères, dépend non seulement du mode de proposition ou d'imposition, mais aussi de la qualité des propositions: les termes normalisés par arrêtés que l'on trouve effectivement en usage sont souvent ceux qui étaient déjà installés avant l'arrêté ministériel.“

Im Bereich der Neologismen ist es somit sinnvoll, nicht nur morphologisch zwischen ,autochthonen' Bildungen und Fremdwörtern sowie generell zwischen lexikalischen und semantischen Neologismen zu unterscheiden, sondern auch zwischen spontan entstandenen und systematisch geschaffenen Neologismen (z.B. zur Über- und Ersetzung eines Fremdwortes).

\subsection{Verschiedene Typen empirischer Studien}

Die den empirischen Studien zugrunde liegenden Fragestellungen und Methoden sind von Untersuchung zu Untersuchung unterschiedlich. Feste Vorgaben oder ein Katalog mit entsprechenden Anhaltspunkten für derartige Arbeiten fehlen bislang. In der bisherigen Forschung wurde mit ganz unterschiedlichen Methoden versucht, den Etablierungsgrad von Lexemen zu ermitteln. Was die Möglichkeiten einer empirischen Evaluierung der offiziellen Sprachpolitik betrifft, drängen sich verschiedene Fragen auf: Sollte eher eine Befragung stattfinden oder ein Korpus an Texten als Basis verwendet werden? Sollte bei Fragen nach der Bekanntheit

${ }^{3}$ Zur créativité lexicale vgl. in erster Linie Guilbert (1975). 
eines Terminus eher ein onomasiologischer oder ein semasiologischer Ansatz gewählt werden? Sollte der tatsächliche Sprachgebrauch als Ausgangspunkt gelten oder sollte man sich auf die diesbezüglichen Aussagen der Informanten verlassen? Ab wann kann ein Terminus als etabliert gelten: bereits, wenn er bekannt ist, oder erst, wenn er auch aktiv benutzt wird? Welche Bedingungen müssen eingehalten werden, damit die Ergebnisse stichhaltig sind? (vgl. Depecker 2001a, 525).

Humbley (1997, 156) unterscheidet drei Typen von Umfragen, die bislang zur Evaluation der Terminologiearbeit vorliegen: 1. Untersuchungen zum Sprachkorpus, 2. metalinguistische und 3. epilinguistische Studien ${ }^{4}$ :

- „sondage linguistique, qui se fonde sur un corpus primaire: un échantillon de discours employé dans une situation naturelle; il s'agit, dans le corpus retenu, de déterminer si les formes préconisées sont employées, ou leur concurrentes;

- sondage métalinguistique, qui consiste à interroger des locuteurs/scripteurs sur leur emploi des formes préconisées et des formes concurrentes;

- $\quad$ sondage épilinguistique, qui sollicite ou recueille des opinions de locuteurs/scripteurs sur les formes préconisées ou des formes concurrentes, et, plus généralement sur les initiatives de planification linguistique et les phénomènes de contact linguistique."

Es gibt aber auch andere Möglichkeiten, die Wirksamkeit französischer Terminologie-Vorschläge zu überprüfen. Anstelle einer Befragung wären die Analyse verschiedener allgemeiner Wörterbücher und/oder Fachlexika sowie die Analyse von Fachzeitschriften für ein breites Publikum (wie z.B. Computerzeitschriften) zu nennen. Für die Informatik-Terminologie liegen bereits entsprechende Studien vor. Humbley (1990) beispielsweise untersucht, ob und inwiefern die 1981 und 1983 im Journal officiel publizierten Informatik-Neologismen in sieben französische Informatik-Wörterbücher (darunter zwei zweisprachige) Eingang gefunden haben. Er stellt fest, dass die offiziellen Termini weitestgehend in diesen Wörterbüchern auffindbar sind, sich zugleich aber auch viele Anglizismen nachweisen lassen, für die es teilweise (noch) keine offiziellen französischen Bezeichnungen gibt. Bezüglich der Untersuchung von Zeitschriftenkorpora verweist Humbley auf eine 1986 durchgeführte Studie, die zu ähnlichen Ergebnissen kommt: Die 1981 und 1983 veröffentlichten französischen Informatik-Termini sind in den untersuchten Computerzeitschriften nachzuweisen ${ }^{5}$.

Bei seinen Überlegungen, inwiefern die Wörterbücher und Zeitschriften den tatsächlichen Sprachgebrauch widerspiegeln, weist Humbley auf die stets zu treffende Unterscheidung hin, ob es sich bei der Textquelle um einen redaktionellen

${ }^{4} \mathrm{Zu}$ den Termini „,metasprachliche“/,métalinguistique“ und „episprachlich“/,épilinguistique“ vgl. Kap. 2, Fußnote 8.

${ }^{5}$ Eine ähnliche Studie hat Langenbacher (1980) durchgeführt. Sie überprüft allerdings, inwiefern die Communiqués de mises en garde der Académie française in verschiedenen allgemeinsprachlichen Wörterbüchern Eingang finden (vgl. Kap. 3, Fußnote 40). 
oder einen Werbetext, einen gesprochenen oder einen geschriebenen Text handelt (vgl. Humbley 1990, 246). Mit diesem Hinweis trägt Humbley u.a. der Tatsache Rechnung, dass die im Bereich der Werbung zu konstatierende Anglizismenquote in den meisten Fällen über der in der Alltagssprache nachzuweisenden Anglizismenquote liegen dürfte.

Walter (1997) analysiert das von Morvan (1996) bei Larousse publizierte Wörterbuch zur Informatik ${ }^{6}$. Es enthält insgesamt 1649 Einträge. Unter diesen 1649 Einträgen befinden sich 174 Ausdrücke und Termini, die von den Terminologiekommissionen zur Informatik empfohlen worden sind. Auffällig hoch ist die Anzahl von englischen und französischen Akronymen. Das Korpus weist 309 Akronyme auf, davon sind 228 Akronyme englisch und nur 81 französisch, d.h. 74\% der im Wörterbuch publizierten Akronyme sind englisch. Von den Akronymen abgesehen, stehen im Korpus 44 englische Termini 1296 französischen Termini gegenüber, d.h. die Anglizismenquote liegt bei nur 0,3\% - ein unerwartet niedriges Ergebnis für einen Bereich, den man gänzlich als vom Englischen durchdrungen ansieht (vgl. Walter 1997, 46-50). Dies ändert sich, wenn die 44 englischen Lexeme und die 228 Siglen auf englischer Basis addiert werden. Die Addition ergibt einen Gesamtwert von 272 englischen Wörterbucheinträgen, was einer Anglizismenquote von 16,5\% entspricht. Walter weist selbst darauf hin, dass ihre Studie auf einem sehr eingegrenzten Korpus basiert, in dem viele wichtige Computertermini wie scanner oder driver fehlen (Walter 1997, 50; 2001, 279). Sie macht deutlich, dass einer aussagekräftigeren Untersuchung ein repräsentativeres Korpus zugrunde liegen müsse, und plädiert dafür, Informatiker selbst zu befragen, um zu ermitteln, wie hoch der tatsächliche Einfluss des Englischen in der Fachsprache der Informatik sei:

„Il faudrait maintenant mener une enquête auprès des informaticiens eux-mêmes et des utilisateurs non spécialistes. Lorsque cette enquête auprès des usagers aura été réalisée, on pourra évaluer plus exactement les atteintes à l'intégrité du français par la langue anglaise, mais la question qui se posera alors sera celle de savoir, sur un plan plus général, à partir de quel pourcentage de mots étrangers on peut dire que le lexique d'une langue est en danger" (Walter 2001, 279).

Eine weitere Analyse zur Häufigkeit von Informatik-Anglizismen bzw. deren offiziellen Ersatzwörtern, dieses Mal für den Bereich der französischen Fachpresse, legen Ahlers/Holtus (1999) vor. Sie ermitteln die Häufigkeit von 46 offiziellen Neologismen bzw. deren englischen Äquivalenten in verschiedenen Computerzeitschriften und stellen fest, dass in vielen Fällen ausschließlich die offizielle französische Form nachzuweisen ist. Dies bedeute jedoch nicht, dass es in den sechs untersuchten Fachzeitschriften keine Anglizismen gebe. Vielmehr decken Ahlers/Holtus (1999, 307) einen Zusammenhang auf zwischen der Anglizismenfrequenz und dem Publikum, an das sich die Zeitschrift richtet: Mit steigendem

\footnotetext{
${ }^{6}$ Bei Walter (2001, 276-279) wird eine knappe Zusammenfassung der Studie gegeben.
} 
Anspruchsniveau der Zeitschrift und damit einhergehendem steigenden Grad des Fachwissens der Leser steige auch die Anglizismenrate nachweisbar.

Dieser kleine Exkurs zu Humbley (1990), Walter (1997) und Ahlers/Holtus (1999) zeigt, dass die Möglichkeiten, den Erfolg der französischen Sprachpolitik zu messen, nicht auf Umfragen in Form von Interviews und/oder Befragungen beschränkt sind. Sichtet man die Literatur zur Evaluierung verschiedener Terminologien (Wirtschaft, Sport etc.), wird deutlich, dass es weit mehr Studien gibt, die sich auf Zeitungstexte, Zeitschriften etc. stützen, als entsprechende Befragungen. Bei Studien, die die Anglizismenquoten in ausgewählten Medien bestimmen, ist es sinnvoll, stets kritisch zu hinterfragen, inwieweit Wörterbücher und Pressetexte Sprachgebrauch und somit den tatsächlichen Anglizismeneinfluss realistisch wiedergeben.

\subsection{Empirische Studien zur Akzeptanz der französischen Sprachpolitik und Terminologiearbeit}

Die Arbeiten, die zur Evaluation der französischen Sprachpolitik sowie zu den Einstellungen französischer Informanten gegenüber Anglizismen vorliegen, werden in zwei Gruppen unterteilt. Hierbei werden verschiedene Arbeiten berücksichtigt, die in unmittelbarem Kontext der durch Étiemble und andere in den 1960er Jahren hervorgerufenen Anglizismendebatte und der entsprechenden Sprachpolitik seit Beginn der 1970er Jahre (vgl. 3.2.1) stehen.

Die elf Arbeiten der ersten Gruppe werden in 4.3.1 vorgestellt. Die beiden ersten Arbeiten befassen sich mit den Einstellung zum franglais sowie der Kenntnis und dem Gebrauch von Anglizismen (vgl. Butterworth 1980, Cartier 1977). Bei diesen beiden frühen Arbeiten zur Akzeptanz von Anglizismen findet noch keine Evaluierung der französischen Sprachpolitik statt, da das erste Sprachgesetz zum Schutz der französischen Sprache erst zum 01. Januar 1977 wirksam wurde. In den Studien Goudailliers (1982), Fuggers (1979/1980/1983a,b/1987) und Gaudins (1991) werden Kenntnis und Gebrauch einiger der in den Terminologieerlassen vorgeschriebenen französischen Neologismen ermittelt. Während Goudaillier und Fugger den Bekanntheitsgrad einiger zur Ersetzung von Anglizismen geschaffener Neologismen überprüfen, erforscht Gaudin, inwieweit französische Verwaltungsbeamte Kenntnis von den französischen Ersatzwörtern zu ausgewählten Archaismen, Latinismen und Anglizismen haben. Die Studie Helfrichs (1993) fällt insofern etwas aus dem Rahmen, als es nicht um die Ermittlung der Akzeptanz offizieller Neologismen geht, sondern um die Bewertung von Neologismen, die aus einem Zeitschriftenkorpus isoliert wurden. Diese Studie hat eine etwas anders gewichtete Zielrichtung, nämlich die Erarbeitung eines allgemein gültigen Akzeptanzmodells für Neologismen (vgl. auch 5.1). Zusätzlich zum Akzeptanzmodell ist Helfrichs Studie für die Themenstellung der vorliegenden Arbeit relevant im Hinblick auf die zur Beurteilung der Neologismen verwendete Methodik, das semantische Differential (vgl. 7.1.2.1). 
Anschließend werden vier Studien vorgestellt, die 1991 von der DGLF in Auftrag gegeben wurden 7 . Diese Studien verfolgen das Ziel, die Etablierung der offiziellen Neologismen in den vier Bereichen Gentechnologie, Gesundheit/Medizin, Fernerkundung des Luftraums sowie audiovisuelle Medien/Werbung und somit den Erfolg der französischen Sprachpolitik zu ermitteln. In diesen vier Studien wird der Etablierungsgrad ausgewählter offizieller Neologismen aus den entsprechenden Fachwortlisten eruiert.

Abschließend wird die Untersuchung Guilfords (1997) vorgestellt, in der es um die Einstellung junger Franzosen zu Anglizismen geht.

Der Übersichtlichkeit halber werden die elf in 4.3.1 vorzustellenden Arbeiten hier im Überblick präsentiert:

- die Studie von Joan Butterworth zur Einstellung zum franglais (Orléans, 1969), (vgl. Butterworth 1980),

- die Untersuchung von Anne Cartier zu Kenntnis und Gebrauch von Anglizismen (Paris, 1972-74) (vgl. Cartier 1977),

- die Studie von Jean-Pierre Goudaillier zum Bekanntheitsgrad von Anglizismen und deren offiziellen Ersatzwörtern (Paris und Leon) (vgl. Goudaillier 1977, 1982),

- die Studie von Bernd Fugger zur Einstellung der Franzosen zur Sprachpolitik und dem Ministerialerlass vom 01. Januar 1977 (Ostfrankreich, 1978-1983) (vgl. Fugger 1979/1980/1983a/1983b/1987),

- die Studie von François Gaudin zur Beachtung der Terminologieerlasse bezüglich der Verwendung von Archaismen, Latinismen und Anglizismen (vgl. Gaudin 1991),

- die Untersuchung von Uta Helfrich zur Akzeptanz von Neologismen (vgl. Helfrich 1993),

- die von François Gaudin und Louis Guespin geleitete Studie zum Vokabular der Gentechnologie (1993, in: Depecker 1997a, 1-45)

\footnotetext{
7 Die Evaluierung der staatlichen Terminologiearbeit durch Vergabe von Auftragsstudien hat erst eine kurze Tradition. Da das Dekret vom 03. Juli 1996 (vgl. 3.2.3.2) vorsieht, dass die Commission générale den tatsächlichen Gebrauch der von ihr publizierten Termini überprüft, wird die Vergabe von entsprechenden Aufträgen auch weiterhin praktiziert. Nachdem Anfang der 1990er Jahre fünf Aufträge erteilt wurden, wurden im September 2000 von der DGLF und der Commission générale zwei weitere Studien in Auftrag gegeben, eine zur Evaluierung der Terminologielisten zu Wirtschaft und Finanzen und eine zur Evaluierung des Internet-Vokabulars (vgl. Bericht der Commission générale 2000, Teil 1). Die Studie zur Terminologie der Wirtschaft und Finanzen wurde vom CNRS (Centre National de la recherche scientifique, http://www.cnrs.fr/accueil.html) übernommen und soll den Gebrauch der Termini in öffentlichen Organisationen, aber auch in der Bevölkerung sowie in Fachkreisen untersuchen. Die Studie zur Internet-Terminologie wurde vom INaLF durchgeführt. Eine erste Bilanz zur Internet-Terminologie wurde bereits im Juni 2001 gezogen: Viele der französischen Neologismen des Internet-Vokabulars finden in der Öffentlichkeit Beachtung. Die Ergebnisse der Studie werden im Laufe des Jahres 2002 erwartet (vgl. Bericht der Commission générale 2001, Teil 1 und der DGLFLF 2001, Teil 5).

8 Diese Studie sowie die Studien von Thoiron/Iwaz/Zaouche (1993), Fossat (= Rouges-Martinez 1997), Chansou (1993) und Gouadec (1993) werden hier nach Depecker (1997a) zitiert. Dort ist jeweils ein ausführlicher Forschungsbericht abgedruckt. In der Zeitschrift Terminologies nowvelles 12 vom Dezember 1994 sind die Studienergebnisse ebenfalls publiziert, allerdings in einer wesentlich kürzeren Fassung als in Depecker (1997a).
} 
- die Untersuchung von Philippe Thoiron, Jean Iwaz und Nadine Zaouche zu Neologismen aus dem Wortschatz der Gesundheit und Medizin (1993, in: Depecker 1997a, 47-95),

- Jean-Louis Fossats Expertenbefragung zum Wortschatz der Fernerkundung des Luftraums (1992, vgl. Rouges-Martinez in: Depecker 1997a, 97-132),

- die qualitative Studie von Michel Chansou zur Etablierung der Neologismen im Bereich der audiovisuellen Medien und der Werbung (Januar 1993, in: Depecker 1997a, 133-233) und

- die Untersuchung von Jonathon Guilford zur Einstellung junger französischer Studenten zu Anglizismen (vgl. Guilford 1997)9.

Alle in 4.3.1 und 4.3.2 vorgestellten empirischen Arbeiten weisen inhaltliche und/oder methodische Schnittstellen zu der in dieser Arbeit präsentierten WWWBefragung auf.

Das Unterkapitel 4.3.2 befasst sich ausführlich mit zwei Studien zum Wortschatz der Informatik. Le Guilly-Wallis (1991) hat in zwei von ihr durchgeführten Befragungen nicht nur ermittelt, welche der offiziell gültigen Neologismen von den befragten Informatikern tatsächlich gebraucht werden, sondern auch, welche Gründe und situativen Umstände für den Gebrauch der Neologismen bzw. der Anglizismen sprechen. Die Forschungsgruppe von Gouadec (1993) verfolgt neben dem inhaltlichen Interesse, welche Neologismen sich im Französischen etabliert haben, auch ein methodisches Interesse: Auf welche Weise lässt sich der Etablierungsgrad offizieller Termini ermitteln?

\footnotetext{
9 In diesem Kapitel werden die Studien von Thogmartin (1991), Gasquet/Villebrun (1994) und Straßner (1997) nicht berücksichtigt. Thogmartin untersucht mittels eines Fragebogens insgesamt zwölf Anglizismen und deren offizielle Ersatzwörter (Termini aus der Allgemeinsprache), jedoch ist seine Stichprobe mit 27 Informanten relativ gering. Seine Ausführungen ergeben, dass insbesondere die von den Terminologiekommissionen neu kreierten Termini nur auf eine sehr geringe Akzeptanz stoßen, und bestätigen damit die Ergebnisse Goudailliers und Fuggers. Gasquet/Villebrun folgen dem Aufruf der DGLF und führen erst eine schriftliche, dann eine mündliche Befragung zu 54 Fachtermini der Metallindustrie durch. Dabei ermitteln sie die Kenntnis und Häufigkeit des Gebrauchs der Termini, deren Definitionen, die Gebrauchssituationen sowie semantische und morphologische Aspekte der Termini. Insgesamt ist ihre Untersuchung jedoch zu speziell für eine Darstellung in diesem Kapitel, zumal sie im Vergleich zu den hier behandelten Studien keine neuen methodischen Aspekte aufweist. Straßner untersucht im Rahmen einer Magisterarbeit mittels einer Fragebogenstudie mit 320 Teilnehmern den Bekanntheitsgrad der Loi Toubon und ihrer Inhalte sowie die Einstellungen zu diesem Gesetz. Des Weiteren wird überprüft, ob die Informanten in der Lage sind, 40 Anglizismen den entsprechenden offiziellen Ersatzwörtern zuzuordnen. Straßner stellt fest, dass sich nur wenige der offiziellen Ersatzwörter haben etablieren können (vgl. Straßner 1997, 128). Die Gruppe der unter 30-jährigen Informanten war jedoch fast ausnahmslos in der Lage die jeweiligen Anglizismen den empfohlenen offiziellen Neologismen zuzuordnen (vgl. ebd., 211). Die passive Akzeptanz der offiziellen Neologismen beurteilt Straßner als gut, warnt aber davor, daraus Rückschlüsse auf die aktive Akzeptanz zu ziehen, d.h. auf den Gebrauch dieser Lexeme (vgl. ebd., 151). Interessant ist, dass Straßner (ebd., 220) bei der jüngeren Generation eine breitere Akzeptanz der französischen Neologismen feststellt als bei der Generation der über 30-Jährigen. Auch wenn für einen Anglizismus oft 20-30 verschiedene französische Lexeme genannt wurden, scheint die französische Terminologieplanung allmählich Früchte zu tragen (vgl. ebd., 232). Die Ergebnisse bezüglich der Loi Toubon werden in 9.2 als Vergleichswerte herangezogen.
} 
Im Überblick umfasst 4.3.2:

- die Untersuchung von Anne Le Guilly-Wallis zum Gebrauch der für den Informatik-Bereich offiziell vorgeschlagenen Neologismen (vgl. Le GuillyWallis 1991) und

- die mehrstufige Untersuchung von Daniel Gouadec zu Lexemen aus dem Bereich der Informatik (1993, in: Depecker 1997a, 235-493).

\subsubsection{Studien zur Akzeptanz von Anglizismen, französischer Sprach- politik und Neologismen (1969-1997)}

Für die Präsentation sämtlicher oben genannter empirischer Studien in diesem und im folgenden Kapitel gelten die folgenden Kriterien - sofern sie aus den Arbeiten hervorgehen - als eine Art Leitfaden:

- Zeitraum der Erhebung,

- Ort der Erhebung,

- Anzahl und Auswahl der Informanten,

- Zielsetzung der Erhebung,

- Methode und

- kurze Charakterisierung der Ergebnisse.

Dieses Verfahren wird aus Gründen der besseren Vergleichbarkeit der Studien gewählt, soll aber zugleich auch die Parallelen und Differenzen zu der in den Kapiteln 8-12 präsentierten WWW-Befragung deutlich machen. Leider fehlt in vielen Texten die Angabe des Ortes, an dem die jeweilige Untersuchung stattgefunden hat. Je nach Anlage der Untersuchung können weitere Aspekte hinzukommen, doch die genannten sechs Aspekte bilden eine Art Gerüst für die Darstellung.

Mit ca. 150 französischen Informanten im Alter von 17 bis 70 Jahren hat Butterworth im Jahre 1969 in Orléans jeweils 37 Fragen umfassende Interviews zur Ermittlung von Sprachbewertungen durchgeführt. Dabei handelte es sich um zufällig befragte Personen. Aufgrund der biosozialen Daten wurden 90 dieser Interviews ausgewertet. Eine dieser Fragen bezieht sich speziell auf die Einstellung zum franglais: „Que pensez-vous du franglais? Est-ce que vous êtes pour, contre ou indifférent? Pourquoi?" (Butterworth 1980, 125). Die Auswertung zeigt, dass über $30 \%$ der Befragten noch nie etwas von dem Wort franglais gehört haben. Insgesamt sprechen sich $20 \%$ gegen und 17\% für franglais aus, $50 \% 0^{10}$ sind nicht explizit dagegen, 13\% enthalten sich einer Antwort.

Cartier hat sich mit ihrer von 1972-74 in Paris durchgeführten Fragebogen-Studie das Ziel gesetzt, die passive und aktive Kenntnis (genauer: das Verständnis, den Gebrauch und die Aussprache) von 41 häufig im Französischen gebrauchten Anglizismen zu ermitteln. Sie befragte dafür 111 Franzosen, die seit mindestens zwei Jahren ihren Wohnsitz in Paris hatten. Als Ergebnis ihrer Studie ist festzu-

${ }^{10}$ Hier dürften sich vor allem diejenigen Personen eingeordnet haben, die das Wort franglais vor der Befragung noch nie gehört haben. 
halten: Die Fähigkeit, die abgefragten Wörter aktiv zu benutzen, ist prozentual geringer als die passive Kenntnis der Wörter. Wörter, die verstanden werden, werden nicht zwangläufig im eigenen Sprachgebrauch verwendet.

Goudaillier hat Ende der 1970er Jahre 54 Einwohner der Städte Paris und Leon befragt. Alle haben als Muttersprache Französisch angegeben. Mittels eines Fragebogens ermittelt Goudaillier den Bekanntheitsgrad von sieben offiziellen Neologismen aus der Allgemeinsprache, wie beispielsweise transbordeur ('Fähre', anstelle des Anglizismus ferry-boat) und cuisinette ('Kochecke', anstelle des Anglizismus kitchenette). Die Befragung ergibt, dass prozentual immer mehr Personen das franglaisWort, d.h. den Anglizismus, als das empfohlene Ersatzwort kennen. Aus der ungenügenden Verbreitung der offiziellen Neologismen leitet Goudaillier (1982, 35) die folgenden Überlegungen ab:
„Schon diese ersten Ergebnisse erlauben die Feststellung, daß Fran- kophone gewisse von den Erläßen [sic!] empfohlene Vokabeln nicht annehmen werden und man kann wiederum fragen, ob die veröf- fentlichten Listen überhaupt zweckmäßig sind, in welchem Maße das Gesetz auf alle Vokabeln, die darin empfohlen sind, angewendet werden kann, da es sprachlich tief eingewurzelten Gewohnheiten wi- derspricht, und da eine verhältnismäßig hohe Zahl anfangs rein technischer Wörter immer leichter in den alltäglichen Gebrauch des französischen Volkes übergehen.“

Die bekannteste von allen in diesem Abschnitt genannten Untersuchungen ist die Studie Fuggers. Sie wird fast in jeder deutschsprachigen Publikation erwähnt, die sich mit der Wirksamkeit der französischen Sprachpolitik befasst. Fugger legt im Zeitraum von 1978 bis 1983 insgesamt etwas mehr als 2.000 Personen in Lothringen einen Fragebogen vor. Die Informanten sind Lehrer, Beamten im öffentlichen Dienst, Journalisten und Beschäftigte in der Tourismusbranche und somit von den Spracherlassen direkt betroffene Sprecher. Fugger intendiert mit der Studie die Klärung folgender drei Fragen:

1. Inwieweit sind die vom Sprachgesetz (1976) betroffenen Personen über dessen Existenz und über Sprachpolitik allgemein informiert?

2. Welche der betroffenen Lexeme sind bekannt? ${ }^{11}$

3. Was halten die betroffenen Personen von Sprachpolitik im Allgemeinen und den Spracherlassen im Besonderen?

$\mathrm{Da}$ die Ergebnisse Fuggers in verschiedenen Publikationen (v.a. Fugger 1979/1983a/1987) ausführlich erörtert und auch in anderen Texten, die sich mit der aktuellen französischen Sprachpolitik befassen, immer wieder genannt werden, werden im Folgenden nur drei Tendenzen wiedergegeben:

\footnotetext{
11 Es handelt sich um die folgenden zehn Wortpaare, bei denen jeweils erst der französische Neologismus, dann der Anglizismus genannt wird: industrie de spectacle - show business, palmarès bitparade, publipostage - mailing, animateur - disk-jockey, franc-jeu - fair-play, postsonorisation - play-back, récepteur de poche - pocket-radio, surjeu - play-back, message (publicitaire) - spot, cadreur-cameraman.
} 
1. Die Existenz einer französischen Sprachpolitik ist $85 \%$ (83\%) der Befragten ${ }^{12}$ bekannt. 90\% (70\%) der Befragten geben an, den Inhalt der Ministerialerlasse vom 01. Januar $1977 \mathrm{zu}$ kennen.

2. Die Ersatzwörter werden von den Informanten oftmals als semantisch zu weit empfunden, so dass die Informanten nicht in der Lage sind, den genauen Inhalt des Anglizismus wiederzugeben.

3. Sprachplanung wird von $47 \%(25 \%)$ der befragten Personen als überflüssig bewertet, von $23 \%(25 \%)$ als unbedingt nötig erachtet.

Das Urteil über die französische Sprachpolitik und speziell über die Terminologieerlasse, zu dem Fugger aufgrund der Ergebnisse seiner Studie gelangt, fällt negativ aus:

„S'il doit exister une planification de la langue, elle doit être faite dans un cadre suprarégional, même international et pas sous la forme d'une xénophobie, d'un nationalisme mal compris comme cela nous semble être le cas avec les arrêtés ministériels“ (Fugger 1983a, 170)13.

Gaudin hat in den 1980er Jahren sämtliche Verwaltungsbeamte zweier Berufungsgerichte, d.h. insgesamt 235 Verwaltungsbeamte, angeschrieben und ihnen je einen Fragebogen zugesandt. Von den angeschriebenen Personen antworten 75 Personen, d.h. ein knappes Drittel. Gaudins oberstes Ziel besteht darin zu überprüfen, inwiefern die französischen Erlasse zur Verwaltungssprache bekannt sind und beachtet werden. Dieses Hauptziel unterteilt Gaudin (1991, 59f.) in vier Unterziele:

1. „Le monde judiciaire connaît-il l'existence des arrêtés terminologiques et du Dictionnaire des néologismes officiels qui les rassemble?

2. Est-il parfois reproché aux magistrats qui méconnaîtraient ces textes de ne pas s'y conformer dans leur pratique professionnelle?

3. Savent-ils quels termes techniques du langage juridique doivent être évités?

4. Connaissent-ils les équivalents français censés remplacer des emprunts?"

Um den vierten Punkt beantworten zu können, wählt Gaudin einige Termini aus dem Runderlass vom 15. Dezember 1977 aus. In dieser Vorschrift wird festgelegt, welche Latinismen und Archaismen in Zukunft zwecks Vereinfachung der Verwaltungssprache zu vermeiden seien.

\footnotetext{
12 Die erste Zahl betrifft die befragten Journalisten, die zweite, in Klammern genannte Zahl diejenigen Informanten, die im Tourismus beschäftigt sind (vgl. Fugger 1987).

13 Weitere Informationen zur Zielsetzung Fuggers und zur Struktur des seiner Studie zugrunde liegenden Fragebogens sind in 7.1.1 nachzulesen.
} 
Das Ergebnis der Studie ist eher ernüchternd. Obwohl seit mehr als 15 Jahren regelmäßig Terminologieerlasse im JO publiziert werden, ist die Existenz dieser Erlasse nur 62,6\% der Befragten bekannt. Von den 62,6\%, die von der Existenz dieser Erlasse wissen, können wiederum nur 61,7\% angeben, dass sich die Listen in zwei Kategorien unterteilen, in denen angegeben wird, ob der Gebrauch des jeweiligen Terminus obligatorisch ist oder nur empfohlen wird. Obwohl die Beamten aufgrund ihrer eigenen Schreibpraxis auf die Vorschriften zurückgreifen müssten, kennen jedoch nur 4\% der Befragten den Dictionnaire des néologismes officiels, mit dessen Hilfe offizielle Texte vorschriftsmäßig verfasst werden können. Diese niedrige Quote verwundert nicht, denn der Dictionnaire steht in keinem der beiden Gerichtshöfe zur Verfügung ${ }^{14}$.

Als Ergebnis der Studie bleibt festzuhalten, dass nur ein Drittel der Verwaltungsbeamten die offizielle Terminologie kennt. Diese Unkenntnis wirft für Gaudin die Frage auf, inwiefern die Ministerialerlasse überhaupt nützlich sind (vgl. ebd., 66). Er vergleicht die Ergebnisse seiner Studie mit denen aus Fuggers Studie. Der Vergleich ergibt, dass die Quote für die Kenntnis der Ersatzwörter bei Fugger um ein Zweifaches höher ausfällt als bei Gaudin. Daraus folgert Gaudin, dass erstens die Bekanntheit der Texte mit der Zeit nicht ansteigt und sie zweitens auch bei demjenigen Personenkreis, der die offiziellen Ersatzwörter nicht nur kennen, sondern sie selbst auch verwenden müsste, nicht besser ist als bei Leuten, die nicht unmittelbar von den Erlassen betroffen sind (vgl. ebd.).

Helfrich hat mit ihrer 1991 in Wissembourg durchgeführten Fragebogenstudie die Akzeptanz von insgesamt 80 Neologismen aus den Zeitschriften L'Express und Le Nouvel Observateur des Jahres 1990 überprüft, um daraus allgemeine Kriterien für den Prozess der Akzeptanz von Neologismen ableiten zu können (vgl. Helfrich 1993, 185). 46 ausgewählte französische und englische Neologismen sollten mittels des semantischen Differentials beurteilt werden ${ }^{15}$. Helfrich legte ihren Fragebogen insgesamt 40 Personen (20 Schülern und 20 Informanten im Alter von mind. 50 Jahren) vor. Der ebenfalls in den Fragebogen integrierte Wortalternativentest zeigt, dass etablierte Anglizismen wie sponsoriser, overdose, superwoman mehrheitlich den französischen Entsprechungen patronner, surdose und surfemme vorgezogen werden. Aus den Ergebnissen ihrer Befragung leitet Helfrich ein Akzeptanzmodell ab, das aus zwei Filtern besteht: Im ersten Filter geht es um die Zugriffsmöglichkeit (= passive Akzeptanz) mit den Kriterien ,Gebräuchlichkeit', ,Bekanntheit', ,Einfachheit', ,Verständlichkeit', im zweiten Filter um die Benutzbarkeit (= aktive Akzeptanz) mit den Kriterien ,Nützlichkeit', ,Adäquatheit', ,Korrektheit', ,Ästhetische Qualitäten’ und ,Normalität' (vgl. ebd., 288-291). Somit hängt die Akzeptanz oder Nicht-Akzeptanz von Neologismen weniger vom

14 Diese Studie bezieht sich auf den 1984 von Fantapié/Brúle herausgegebenen Dictionnaire des néologismes officiels (vgl. Fantapié/Brulé 1984). Über den Dictionnaire von 1984 informiert 3.2.2. In 3.2.4.1 wurde kurz auf das Nachfolgewerk aus dem Jahr 1994 eingegangen.

15 Das von Helfrich verwendete semantische Differential zur Ermittlung der Akzeptanz von Lexemen wird in leicht modifizierter Form auch in dem Fragebogen zur Akzeptanz der Internet-Termini eingesetzt. 
Bildungstyp (z.B. Derivation als produktives Wortbildungsverfahren) als von bestimmten Qualitäten des jeweiligen Wortes ab. Helfrich stellt ferner heraus, welche Desiderate im Bereich der Neologismenforschung bestehen, nämlich die Erforschung der Rezeption, Akzeptanz und Diffusion von Neologismen (vgl. ebd., 21).

Im Folgenden werden vier der von der DGLF Anfang der 1990er Jahre initiierten Studien vorgestellt. Insgesamt fünf von der DGLF veranlasste Studien zur Akzeptanz der offiziellen Neologismen werden in dem 1997 von Depecker herausgegebenen Buch La mesure des mots. Cinq études d'implantation terminologique (Rouen 1997) zusammengefasst. Die fünf Studien widmen sich den Wortfeldern (d.h. Terminologielisten) „Génie génétique“, „Santé et médecine“, „Télédétection aérospatiale“, „Audiovisuel et publicité" und „Informatique“ und wurden alle in den Jahren 1991 bis 1993 durchgeführt.

In seinem ausführlichen Vorwort stellt Depecker fest, dass es noch keine ausgearbeitete Methodik zur Überprüfung der Etablierung von Termini gibt:

„Malgré le besoin ressenti, il n’y avait jamais eu de véritables enquêtes menées sur des bases scientifiques, sur la manière dont les termes traités et élaborés par ces commissions étaient passés ou passaient dans l'usage réel“" (Depecker 1997a, VII).

Da auch von der DGLF keinerlei methodische Vorgaben zur Bearbeitung der jeweiligen Wortfelder gemacht wurden, fällt die den einzelnen Untersuchungen zugrunde liegende Methodik sehr unterschiedlich aus. Insofern stellen alle in dem Buch zusammengefassten Studien Versuche dar, die staatliche Terminologiearbeit $\mathrm{zu}$ evaluieren ${ }^{16}$. So unterschiedlich die Herangehensweisen der einzelnen Forschungsgruppen sind, so unterschiedlich fallen auch der Aufbau der einzelnen Studien und deren Ergebnisse aus, wie im Folgenden zu zeigen sein wird. Einige Studien stellen Textkorpora in den Mittelpunkt, anhand derer die Vorkommenshäufigkeit der offiziellen Ersatzwörter bestimmt wird, andere führen Informantenbefragungen mit Hilfe von Interviews bzw. Fragebögen durch. Es wurden jeweils ausgewählte Termini aus den Terminologieerlassen auf ihre Bekanntheit und ihre tatsächliche Verwendung hin getestet. Allerdings fehlen weiterreichende Fragen - wie sie beispielsweise bei Fugger gestellt wurden -, die die Akzeptanz der französischen Sprachpolitik selbst betreffen und somit über die Fragen nach der Bekanntheit der vorgeschriebenen Ersatzwörter hinausgehen.

Die beiden zentralen Themen des Buchs, die sich wie ein roter Faden durch alle Beiträge ziehen, lassen sich folgendermaßen formulieren:

\footnotetext{
${ }^{16}$ Aline Francoeur (1998, o.S.) bezeichnet das Buch in ihrer Rezension als Präzedenzfall: „Il s'agissait là d'un précédent, puisque l'usage réel des termes traités et proposé par ces commissions ministérielles n'avait auparavant fait l'objet d'une étude scientifique." Zwar gibt es bereits erste Studien z.B. von Fugger und Goudaillier, welche das Ziel verfolgen, den Erfolg der französischen Sprachpolitik zu eruieren, aber die in Depecker (1997a) behandelten Terminologielisten wurden mit Ausnahme älterer Listen zu audiovisuellen Medien bislang noch keiner empirischen Studie unterzogen.
} 
1. Welche Tragweite haben in Frankreich die von den Terminologiekommissionen getroffenen Entscheidungen?

2. Wann kann ein Terminus als im Sprachgebrauch etabliert gelten? Und wie lässt sich der Grad der Etablierung eines Terminus messen (vgl. Depecker 1997a, VII; Francoeur 1998; Rouges-Martinez 1992, 99)?

Als erste der fünf Studien wird bei Depecker (1997a) die Untersuchung zu 41 Termini aus dem Bereich Gentechnologie abgedruckt, welche aus dem Ministerialerlass vom 14. November 1990 hervorgehen ${ }^{17}$. Die Studie wurde unter der Regie von Louis Guespin durchgeführt. Sie stützt sich auf schriftliche und mündliche Quellen ${ }^{18}$. Ergänzt wird die Korpusstudie durch freie Gespräche mit zwei Wissenschaftlern des Fachs (vgl. Gaudin/Guespin 1993, 23-27). Die Notwendigkeit mündlicher Quellen sowie einer Befragung in Form eines geleiteten Gesprächs begründen die Autoren wie folgt:

- „d'une part, ,l'oral de la science“ constitue une part importante des pratiques langagières [...]. C'est pourquoi nous avons choisi d'enregistrer des productions orales pédagogiques (cours) et de recherche (séminaire);

- d'autre part, c'est à l'oral que nous pouvions le mieux saisir des pratiques spontanées et des positions métalinguistiques (de type définititoires) ou épilinguistiques (relevant de jugements sur la langue): c'était l'objet de notre guide d'entretien“ (ebd., 11f.) ${ }^{19}$.

Die Autoren wollen folglich durch die Aufnahme von Gesprächen eine stärkere Berücksichtigung der Gesprächssituation und des entsprechenden Sprachverhaltens (Wissenschaftskontext, mündliche Kommunikation) erreichen. Durch die gezielten Befragungen erhoffen sie sich weitere Manifestationen spontanen Sprechens, aber vor allem auch metasprachliche Aussagen und Bewertungen.

Die Interviews zeigen, dass den Befragten viele der offiziellen französischen Formen unbekannt sind (vgl. ebd., 26f.). Das ist insofern erstaunlich, als die untersuchten Zeitschriften der Jahrgänge 1991 und 1992, die nach der Veröffentlichung des Erlasses publiziert wurden, sich weitgehend an die offiziellen Formen halten und diese somit verbreiten.

Die weite Verbreitung der englischen Termini wird von den Autoren auch darauf zurückgeführt, dass gerade ausländische Benutzer den englischen Termini immer eine Monosemie unterstellten, die de facto gar nicht gegeben sei. Der Grund für

\footnotetext{
17 Dieses Vokabular bezieht sich speziell auf die mit der Landwirtschaft und ihren Erzeugnissen verbundene Gentechnologie (vgl. Gaudin/Guespin 1993, 3). Die mit dem Erlass vorgelegte Terminologieliste umfasst 381 Einträge, so dass die Autoren eine Auswahl treffen mussten (vgl. ebd., 7).

18 Als schriftliche Quellen werden Fachwörterbücher, Zeitungen, Fachtexte, aber auch Texte, die sich an die breite Masse richten, sowie Vorlesungsskripte und Doktorarbeiten konsultiert. Als mündliches Korpus dienen Aufnahmen aus Vorlesungen und Seminaren sowie halbgeleitete Gespräche mit den Forschern der Arbeitsgruppe selbst.
}

${ }^{19} \mathrm{Zu}$ den Termini métalinguistique und épilinguistique vgl. Kap. 2, Fußnote 8. 
diese Fehleinschätzung liege auf der Hand: Es seien die mangelhaften Englischkenntnisse der Wissenschaftler. Die Autoren veranschaulichen ihre These durch folgendes Beispiel:

„Les termes anglais du génie génétique parviennent trop aisément, pour un Français, à la monosémie terminologique postulée par E. Wüster; trop aisément parce que par défaut. Pour un médiocre anglicisant, cap est monosémique parce qu'il ne lit pas de romans anglais; sinon, il n'aurait pu manquer les school caps" (ebd., 37f.).

Gaudin/Guespin gelangen zu dem Schluss, dass es nicht reiche, Terminologieempfehlungen auszusprechen und zu erwarten, dass diese befolgt werden. Vielmehr müssten den Betroffenen die Notwendigkeit von Terminologie deutlich gemacht, mögliche Lösungsmuster gegeben sowie Gründe für die Auswahl der vorgeschriebenen Neologismen genannt werden. Es gehe darum zu überzeugen, nicht vorzuschreiben. Gaudin/Guespin fordern eine stärkere Einbeziehung der Zielgruppen schon bei der Erarbeitung der offiziellen Termini sowie deren Sensibilisierung für den Gebrauch dieser Neologismen. Darin sehen die Autoren die aussichtsreichste Perspektive für eine erfolgreiche Sprachpolitik (vgl. ebd., 39f.).

Die zweite Studie des Sammelbandes befasst sich mit 31 Termini aus den Bereichen Gesundheit und Medizin. Sie bezieht sich auf die beiden am 02. Januar 1975 und 07. Dezember 1978 verabschiedeten Terminologielisten. Bei dieser Studie unter der Leitung von Philippe Thoiron wurde besonderes Augenmerk auf die Methodik gelegt (vgl. Francoeur 1998, o.S.). Auch liegt den Autoren sehr daran, zwischen Kenntnis und Gebrauch eines Terminus zu trennen, nicht nur in der Theorie, sondern auch in der Forschungspraxis ${ }^{20}$. Ihrer Meinung nach sei es zu einfach, nur herauszuarbeiten, ob ein Terminus bekannt ist oder nicht. Vielmehr gebe es verschiedene Stufen der Bekanntheit und verschiedene Strategien, um den Bekanntheitsgrad eines Terminus zu ermitteln (vgl. Thoiron/Iwaz/Zaouche 1993, 50).

Der Studie liegen ein schriftliches Korpus ${ }^{21}$ und halbgeleitete Gespräche zugrunde. Die Gespräche wurden mit 30 Fachärzten, zehn Allgemeinmedizinern und 20 Medizinstudenten geführt. Um die Kenntnis der offiziellen Neologismen zu ermitteln, wurde den Versuchspersonen lediglich die Definition der Neologismen gegeben. Die Reaktionen werden in die folgenden vier Kategorien aufgeteilt:

\footnotetext{
${ }^{20}$ Die Autoren begründen ihre differenzierte Sichtweise wie folgt: „Pour la connaissance du terme, il faut envisager plusieurs niveaux. Il est simpliste de dire qu'un terme est connu ou non, même d'un spécialiste. Il existe des degrés et nous avons cherché ici à mettre en œuvre diverses stratégies d'accès permettant d'appréhender le niveau de familiarité avec le terme" (Thoiron/Iwaz/Zaouche 1993, 50).

${ }_{21}$ Das Korpus besteht aus 249 Titeln verschiedener Jahrgänge und eröffnet somit auch eine diachronische Betrachtungsmöglichkeit. Es handelt sich bei den konsultierten Texten um Fachtexte aus dem biologischen und pharmazeutischen Sektor.
} 
1) der offizielle Terminus wurde anhand der Definition gefunden,

2) der offizielle Terminus wurde durch die Nennung des englischen Äquivalents gefunden,

3) der offizielle Terminus wurde nicht gefunden,

4) der offizielle Terminus wurde weder gefunden noch wiedererkannt (vgl. ebd., 53).

Entsprechend dieser Einteilung werden auch die Termini in vier Gruppen unterteilt:

1) „les termes bien implantés“

2) „les termes mal implantés“"

3) „les termes connus mais non employés“

4) „les termes peu connus mais employés assez fréquemment“(ebd., 67).

Als generelles Fazit aus den Gesprächen leiten die Autoren ab, dass die Allgemeinmediziner anglophiler seien als die beiden anderen befragten Personengruppen, da sie erklärten, häufig die englischen Termini zu benutzen (vgl. ebd., 66). Das (fach-)sprachliche Ausdrucksvermögen der Fachärzte erweise sich demgegenüber als wesentlich differenzierter. Die Fachärzte geben mehrheitlich an eher die französischen Termini zu verwenden. Allerdings kennen sie trotz der Bevorzugung der französischen Termini die entsprechenden Erlasse in völlig unzureichender Weise. Insgesamt ist der Umgang mit den vorgeschlagenen Termini sehr frei. Manche Arztgruppen wie die befragten Radiologen erklären, dass sie sich in keiner Weise nach den offiziellen Wortlisten richteten (die sie eventuell auch gar nicht kennen), sondern nur nach den Termini, die ihnen durch die Fachpresse nahegebracht würden (vgl. ebd.). Die Unterschiede zwischen den Allgemeinmedizinern und den Fachärzten sind evident und veranlassen die Autoren zu dem Fazit: „La dichotomie généralistes-spécialistes [...] semble donc correspondre à une réelle opposition pour ce qui concerne l'adoption d'une terminologie française" (ebd., 67).

In ihrem Schlusswort betonen die Autoren, dass es sehr schwer sei, allgemeine Regeln für die Akzeptanz von Neologismen zu geben. Termini, die aufgrund ihrer morphologischen Struktur eigentlich hätten akzeptiert werden müssen, konnten sich nicht durchsetzen. Hier habe ihrer Ansicht nach das irrationale Moment seinen Platz gefunden:

„On ne peut échapper, au terme d'une enquête de ce genre, à un sentiment de frustration. Des termes, formés selon les canons de la morphologie, n'ont pas pu s'implanter. [...] Il faut admettre que pour l'implantation des termes, comme pour d'autres faits linguistiques, l'irrationnel sait parfois trouver sa place. Faut-il alors aller jusqu'à demander aux commissions de terminologie de faire un peu de poésie?“" (ebd., 72) 22 .

\footnotetext{
22 Hieran wird ersichtlich, wie schwierig es ist, Prognosen zu diesem Bereich abzugeben. Vielleicht gehört Sprachprognostik auch deshalb nicht zu den kanonisierten Forschungsbereichen der Linguistik. Holtus $(1994,7 f$.) zufolge begegnen viele Linguisten dem Vorhaben, Sprachentwicklungen vorhersagen zu wollen, eher ablehnend.
} 
Die dritte Studie wurde unter der Leitung von Jean-Louis Fossat (Universität von Toulouse-le-Mirail) durchgeführt. Sie erstreckt sich auf 59 Termini (53 offizielle Termini sowie sechs von der Forschungsgruppe hinzugefügte Synonyme) der Terminologieliste zur Fernerkundung des Luftraums (télédétection spatiale), die 1980 im JO erschienen ist. Im Unterschied zu den beiden vorigen Studien verzichtet Fossat zugunsten einer systematischen zweistufigen Befragung auf eine Korpusstudie. Befragt wurden zwölf auf dem Gebiet der Fernerkundung des Luftraums tätige Professoren und Forscher sowie acht Fachleute, die in der Produktion bzw. im Vertrieb beschäftigt waren. Somit handelt es sich um eine reine Befragung von Fachleuten. Die Befragung fand in der Region Toulouse statt. Die Informanten wurden gebeten einen Fragebogen auszufüllen, in dem es darum ging, das eigene Sprachverhalten in Bezug auf den Gebrauch der Termini zu charakterisieren. Nach der Rückgabe des ausgefüllten Fragebogens wurde mit den Informanten sogleich ein Interview geführt, in dem näher auf die im Fragebogen gegebenen Antworten eingegangen wurde. Mit Hilfe dieser Interviews konnte bei den entscheidenden, kritischen Punkten ,nachgehakt" werden, insbesondere in den Fällen, in denen die Befragten einen offiziell vorgeschlagenen Terminus abgelehnt oder bei der Beantwortung der Frage gezögert hatten. Die Informanten wurden dann gebeten, die von ihnen bevorzugten Termini zu nennen, sofern sie diese nicht schon auf dem Fragebogen vermerkt hatten. Dieser Prozess, zusätzlich zu den vorgegebenen Termini einen weiteren Terminus vorzuschlagen, nämlich denjenigen Terminus, den die Befragten üblicherweise benutzen, wird hier als Substitution bezeichnet. Die Reaktionen der Befragten werden wie in der Studie Thoirons (s.o.) in vier Kategorien eingeteilt:

1. Gebrauch des Terminus,

2. Ablehnung des Terminus,

3. Zögern bei der Antwort ${ }^{23}$ und

4. Substitution (vgl. Rouges-Martinez 1992, 100).

Der Grad der Etablierung wird anhand einer Dreiteilung ermittelt. Die erste Klasse (A) enthält diejenigen Termini, von denen 91,1\% bis 70\% der Informanten angegeben haben, diese zu benutzen, die zweite Klasse (B) enthält Termini mit einer Benutzungsrate von 70\%-30\% und in die dritte Klasse (C) werden diejenigen Termini eingeordnet, die nur von 30\%-3,6\% der befragten Personen gebraucht werden. Die Begriffe der Klasse C können aufgrund ihres schwachen Gebrauchs als kaum etabliert gelten. Diese Termini gelten aufgrund der hohen Ablehnungsquote und der Vielzahl an vorgeschlagenen Substitutionen als „bedroht“ („en danger") (vgl. ebd., 103). Die untersuchten Termini werden somit nach ihrer Benutzungsfrequenz eingeteilt in einen starken, einen mittleren und einen schwachen Etablierungsgrad.

\footnotetext{
23 Als Gründe für das Zögern werden drei Faktoren genannt: 1. die mangelhafte Kenntnis der exakten Vokabeln, 2. die ungenügende Präzision des Terminus selbst, 3. der Versuch, die Benutzung der offiziellen Neologismen zu umgehen, die als falsch erachtet werden (vgl. Rouges-Martinez 1992, 106).
} 
Das Ergebnis der Befragung lässt sich folgendermaßen zusammenfassen: Von den 59 getesteten Termini haben sich 30 ( $=50,8 \%$ des Korpus $)$ bereits etabliert oder sind auf dem Weg dahin, 17 Termini weisen eine mittlere Gebrauchsfrequenz auf und bei 12 Termini ist die Gefahr groß, dass sie sich nicht durchsetzen werden (vgl. ebd., 104).

Bei den Fachleuten ist ein großes Interesse an Terminologiefragen festzustellen. Ihr Sprachgebrauch ist gekennzeichnet durch eine große Bandbreite an Verhaltensmöglichkeiten in Bezug auf die Fachterminologie. Interessant für weitere Studien sind vor allem die Termini mittlerer Gebrauchsfrequenz. Rouges-Martinez (1992, 129) bezeichnet diese Termini als ,zone d'incertitude“, da sie weder als allgemein akzeptiert noch abgelehnt gelten können. Hier wäre eine zweite, spätere Messung nötig, um zu sehen, ob der Gebrauch der Termini ab- bzw. zunimmt.

Die vierte, von Michel Chansou durchgeführte Studie bezieht sich auf 41 ausgewählte Termini aus den Ministerialerlassen vom 24. Januar 1983 und vom 10. Oktober 1985 zum Wortschatz der audiovisuellen Medien und der Werbung (Vocabulaire de l'audiovisuel et de la publicité) ${ }^{24}$. Der Autor erklärt mit Nachdruck, dass für die Evaluation der aktuellen Sprachpolitik die Beschreibung des Gebrauchs unverzichtbar sei:

„Dans le domaine de la langue, il paraît difficile d'évaluer les effet directs d'une action de politique linguistique, c'est-à-dire d'établir un lien de causalité objectif entre les décisions prises et les implantations néologiques dans l'usage. [...]

Une recherche d'évaluation dans le domaine de la politique linguistique se limitera, de ce point de vue, à une simple description de l'usage. Mais cette description de l'usage nous est apparue comme la base nécessaire de notre recherche, et d'autant plus importante qu'il s'agit d'un vocabulaire très largement répandu“" (Chansou 1993, 137).

Chansou hat zur Evaluierung des Wortschatzes der audiovisuellen Medien und der Werbung insgesamt zwei Studien durchgeführt. In der ersten Studie analysiert er anhand eines umfangreichen Textkorpus den schriftlichen Sprachgebrauch, in der zweiten Studie befragt er Lehrer und im Bereich der Öffentlichkeitsarbeit beschäftigte Personen. Leider werden sowohl in dem in Depecker (1997a) als auch in dem in der Zeitschrift Terminologies nouvelles (1994) veröffentlichten Aufsatz nur die Ergebnisse der ersten Studie präsentiert. Die Ergebnisse der für die Zwecke dieses Kapitels wesentlich interessanteren zweiten Studie sind offensichtlich nicht publiziert worden.

Daher können an dieser Stelle nur die Ergebnisse von Chansous erster Studie vorgestellt werden. Der Ausgangspunkt der Untersuchung ist ein umfangreiches ${ }^{24}$ Es wurden nur Termini ausgewählt, die sowohl der Fach- als auch der Gemeinsprache angehören
(vgl. Chansou 1993, 138). 
und durch die Vielfalt der betrachteten Textsorten sehr breit gestreutes Korpus ${ }^{25}$. Es geht Chansou um eine systematische Betrachtung des schriftlichen Sprachgebrauchs mit Blick auf die verschiedenen Kommunikationsniveaus (vgl. ebd.). Auf die quantitative Bestimmung des Etablierungsgrades der Termini wird verzichtet. Statt dessen wird für jeden der 41 Termini in einer alphabetisch geordneten Liste (von boomer bis walkman) aufgeschlüsselt, in welchen Wörterbüchern er $\mathrm{zu}$ finden ist und in welchem Zusammenhang er in den verschiedenen analysierten Textgattungen gebraucht wird (vgl. ebd., „Annexe“, 167-231).

Als Fazit zum methodischen Vorgehen stellt der Autor fest, dass die Präsentation qualitativer Daten zwar sehr aufschlussreich sei, aber kaum signifikante Aussagen ermögliche, denn die offiziellen Termini könnten in den untersuchten Wörterbüchern mehrheitlich nachgewiesen werden, in denen sie in der Regel als „recommandation officielle" markiert seien. Auch die betrachteten Texte wiesen alle offiziellen Termini auf, allerdings in unterschiedlicher Frequenz. Dennoch könnten nur zwei Termini als vollkommen im Sprachgebrauch etabliert gelten, nämlich baladeur und scripte (vgl. ebd., 164). Der Autor weist zu Recht darauf hin, dass eine ständige Aktualisierung der Terminologielisten durch die jeweils zuständige Kommission wünschenswert und nötig sei, denn die 1983 und 1985 erstellten Vorschläge bedürften inzwischen (1993) dringend einer Aktualisierung, die dem Sprachwandel Rechnung trage (vgl. ebd., 165). Aus der fehlenden ständigen Aktualisierung leitet sich Chansous (ebd., 166) Fazit zur Arbeit der Terminologiekommissionen ab: „Il apparaît bien [...] que le système rigide et les dispositions réglementaires des arrêtés s'appliquent mal à la réalité de la langue et qu'ils ne tiennent pas suffisamment compte des conditions sociales de la communication." Chansou (vgl. ebd.) befürwortet vielmehr eine Verlagerung der Rolle der Terminologiekommissionen hin zu einer Instanz, die zur Reflexion anrege, Vorschläge mache, Anstöße gebe und auf diese Weise in der Bevölkerung ein Bewusstsein für Terminologiebildung schaffe, ohne jedoch in der bisherigen Manier Vorschriften zu machen. Dass die DGLF/DGLFLF sich seit dem Dekret vom 03. Juli 1996 bemüht, in der geforderten Weise zu arbeiten, hat das Unterkapitel 3.2.3 zeigen können.

Guilford (1997) legt im Januar 199435 in Paris eingeschriebenen Studierenden im Grundstudium der Humanwissenschaften einen Fragebogen vor, der die Überprüfung des Bekanntheitsgrades von Anglizismen und den offiziell empfohlenen Ersatzwörtern zum Ziel hat. Außerdem soll die Einstellung der befragten Studierenden zu Anglizismen und ihren französischen Äquivalenten erforscht werden. In einem zweiten Schritt legt Guilford 33 weiteren Studierenden (ebenfalls im Grundstudium der Humanwissenschaften) einen weiteren Fragebogen vor, in dem zwölf Anglizismen ihren zwölf französischen Entsprechungen zugeordnet werden

${ }^{25}$ Das Korpus setzt sich u.a. zusammen aus allgemeinen Nachschlagewerken, Fachwörterbüchern, Datenbanken, Verwaltungstexten, Handbüchern, Lehrbüchern und Texten aus der allgemeinen Presse sowie aus der Fachpresse der Jahre 1989 bis 1992. 
sollen. Des Weiteren werden die Informanten nach ihrem eigenen Sprachgebrauch gefragt.

Die Auswertung des ersten Fragebogens ergibt, dass die Anglizismen generell bekannter sind als ihre französischen Entsprechungen. Die Anglizismen werden häufiger verwendet als die Ersatzwörter. 89,6\% der französischen Neologismen werden als französisch empfunden, aber nur 68,3\% der Anglizismen als englisch. Mit anderen Worten werden die Anglizismen von vielen Informanten nicht als Fremdkörper betrachtet. Die Analyse des zweiten Fragebogens zeigt, dass 90,7\% der befragten Studierenden in der Lage sind, die Anglizismen den entsprechenden Ersatzwörtern richtig zuzuordnen. Auf die Frage nach dem eigenen Sprachgebrauch geben 73\% der Befragten an, die Anglizismen den französischen Neologismen vorzuziehen.

\subsubsection{Studien zur Akzeptanz offizieller Informatik-Neologismen}

Le Guilly-Wallis und Gouadec nehmen eine Evaluation der Wirksamkeit der von der commission spécialisée de terminologie et de néologie de l'informatique et des composants électroniques (CSTIC) bzw. der von ihrer Vorgängerkommission (vgl. 3.2.5) erarbeiteten Terminologievorschläge vor.

In der Studie von Le Guilly-Wallis werden Informatiker zu ihrem Sprachgebrauch und ihrem Verhältnis zu Anglizismen und deren offiziellen Ersatzwörtern befragt. Gouadec erprobt in seiner breit angelegten Studie verschiedene methodische Ansätze, um die Bekanntheit und Akzeptanz der offiziellen Informatik-Terminologie zu ermitteln.

Le Guilly-Wallis beschäftigt sich mit den Informatik-Neologismen der vier zwischen 1981 und 1989 verabschiedeten Terminologieerlasse. Insgesamt wurden zwei Befragungen durchgeführt, von denen sich die erste Befragung im Jahre 1984 an die Erlasse von 1981 und 1983 und die zweite im Jahre 1990 an die Erlasse von 1987 und 1989 angeschlossen hat. Le Guilly-Wallis möchte erforschen, ob und inwiefern sich die befragten Informatiker durch den kontinuierlichen Einfluss des Englischen auf ihr Fachgebiet betroffen fühlen, worin sie die Gründe des anhaltenden Einflusses des Englischen sehen und wie diesem Einhalt geboten werden könnte.

Die Untersuchung von Le Guilly-Wallis verläuft in drei Schritten: Der erste Schritt besteht aus einem fragebogengestützten, halbgeleiteten Gespräch. In einem zweiten Schritt wird untersucht, welche der in den Terminologieerlassen vorgeschriebenen Neologismen die Informanten aktiv verwenden. Der dritte und letzte Schritt besteht aus einer freien Diskussion, die Aufschluss über die Einstellungen und Vorstellungen der Informanten geben soll, insbesondere über die Bedeutung der englischen Sprache innerhalb der Informatik und über den Sprachgebrauch der Informanten selbst (vgl. Le Guilly-Wallis 1991, 117, 126).

Als Ergebnis des ersten Untersuchungsschrittes, der halbgeleiteten Interviews, kann festgehalten werden: 15 der insgesamt 21 befragten Personen wissen von der Existenz der vier Terminologieerlasse zur Informatik; von diesen haben aber nur 
vier Personen diese Texte auch im Detail gelesen (vgl. ebd., 118). Von den 18 Personen, die angeben weiterhin die englischen Informatik-Termini zu benutzen, werden im Wesentlichen die folgenden drei Gründe genannt:

1. Das Englische sei präziser als das Französische ${ }^{26}$.

2. Die Dokumentationen zu Computern seien auf Englisch verfasst.

3. Das Englische sei die internationale Verkehrssprache. Folglich führe eine Aufgabe des Englischen zu einer Abkapselung Frankreichs von der aktuellen Informatik (vgl. ebd.).

Werden von den befragten Informatikern französische Termini verwendet, so sind dies mehrheitlich Termini, die von den offiziellen Vorschlägen abweichen (vgl. ebd., 119).

Im zweiten Schritt der Studie wird die Benutzungsfrequenz ausgewählter Informatik-Anglizismen ermittelt. Die Benutzungsfrequenz ist sehr unterschiedlich und variiert je nach Terminus und Kontext zwischen 8,5\% und 80\%. Die französischen Termini werden vorwiegend im Bereich der Lehre sowie bei Kontakten mit nicht-spezialisierten Computernutzern verwendet. Englische Termini werden häufig zwischen den Technikern in Unternehmen während ihrer täglichen Arbeit gebraucht sowie bei Treffen und Kolloquien von Informatikern (selbst wenn diese in Frankreich stattfinden). Außerdem werde man bei der Verwendung von Computerprogrammen, Dokumentationen etc. häufig mit englischen Termini konfrontiert (vgl. ebd., 122).

Beim dritten Untersuchungsschritt, der Diskussion, wurde insbesondere deutlich, inwiefern sich die Einstellungen der in der Privatwirtschaft Beschäftigten von denen der im öffentlichen Dienst Beschäftigten unterscheiden. Während die in der Privatwirtschaft tätigen Personen die Terminologieerlasse eher als Einschränkung erachten, die sie im Verhältnis zu nicht-französischsprachigen Kollegen benachteiligen, betrachten die Angestellten im öffentlichen Dienst den Einfluss des Englischen auf die französische Sprache mit Besorgnis. Den Diskussionen der Informatiker lassen sich sowohl Argumente für die englische als auch für die französische Terminologie entnehmen. Nach Meinung der Gesprächsteilnehmer gelte beispielsweise ein Informatiker als wenig kompetent, der die englische Terminologie nicht kenne bzw. nicht benutze. Dieses Faktum bewirkt, dass selbst diejenigen Informatiker, die eigentlich den französischen Äquivalenten positiv gegenüberstehen, diese auf Kongressen und im Gespräch mit Kollegen nicht verwenden (vgl. ebd., 119, 123). Für die französische Terminologie spreche, dass es mittlerweile für zahlreiche Anglizismen geeignete Neologismen gebe, so dass es als Ausdruck von Snobismus interpretiert werde, wenn Anglizismen um jeden Preis verwendet würden (vgl. ebd., 124).

Abschließend verweist die Autorin auf ein Problem, das von allen Befragten einstimmig gesehen wird: Bestimmte französische Termini, die entweder lächerlich wirkten oder nicht zu rechtfertigen seien, würden sich niemals bei französischsprachigen Informatikern durchsetzen. Einige Vorschläge wie franz. bogue/déboguer

26 Beispielsweise wird das französische mémoire vive als semantisch weiter empfunden als sein englisches Pendant RAM (vgl. Le Guilly-Wallis 1991, 119). 
und spoule (für engl. bug/debug und spool) zeugten von einer nahezu zwanghaften Französisierung, welche auf Kosten der sinnvollen und guten Ersatzwortvorschläge gehe, deren Glaubwürdigkeit und Etablierung unter den schlecht gewählten Neologismen leiden könnte (vgl. ebd.). Insgesamt plädiert Le Guilly-Wallis für eine weitere Verbreitung der offiziellen französischen Neologismen v.a. in und durch die zahlreich erscheinenden Computer-Zeitschriften. Damit solle eine ernsthaft betriebene Überzeugungsarbeit einhergehen, die sich auch auf Privatpersonen erstrecke, die sich mit Computern beschäftigen. Als noch wichtiger für die weitere Verbreitung der französischen Termini schätzt die Autorin den Unterricht ein. Nur wenn die Lehrkräfte selbst die französischen Termini benutzten, hätten diese auch die größten Chancen, von späteren Informatikergenerationen verwendet zu werden (vgl. ebd., 125).

Die von der DGLF Anfang der 1990er Jahre initiierte und unter der Leitung von Daniel Gouadec durchgeführte Studie hat die Überprüfung von 136 Termini aus dem Bereich der Informatik zum Ziel, deren offizieller Status mit den Erlassen vom 22. Dezember 1981, 30. Dezember 1983, 30. März 1987 und 27. Juni 1989 festgeschrieben wurde. Die Studie Gouadecs besteht aus fünf Untersuchungsschritten, welche alle unterschiedliche Fragestellungen verfolgen.

Mit dem Ziel, die tatsächliche Akzeptanz der offiziellen Ersatzwörter zu ermitteln, führt Gouadec zunächst eine Korpus-Studie durch, deren Ergebnis allerdings relativ unbefriedigend ausfällt: 132 der 136 untersuchten Termini und somit nahezu alle offiziellen Termini lassen sich in beliebigen (Presse-)Texten nachweisen und können somit als etabliert gelten (vgl. Gouadec 1993, 247). Jedoch können aufgrund der ersten Korpusstudie keinerlei Aussagen dazu getroffen werden, ob die englischen Formen ernstzunehmende Konkurrenten für die französischen Neologismen darstellen oder nicht.

In einem zweiten Schritt geht es darum zu prüfen, wie viele und welche Anglizismen bzw. wie viele und welche offiziellen Ersatzwörter in verschiedenen Textsorten, Diskurs- oder Kommunikationstypen nachzuweisen sind. Erwartungsgemäß ergibt dieser Teil der Untersuchung, dass die Benutzung englischer bzw. französischer Termini von den Anwendungsgebieten, dem (Ziel-)Publikum und den verwendeten Textsorten abhängt. Entsprechend ist der Anteil von Anglizismen sehr hoch im Bereich der Computerspiele und in den Dokumentationen zu Computerspielen bzw. -programmen, relativ hoch im Bereich der Übersetzung und im Verkauf, mittel im Bereich der Ausbildung, in Computerzeitschriften, im juristischen Bereich und in der Herstellung und Vermarktung von Computern (Hardware) und Programmen (Software), schwach hingegen im Bereich der Fachpresse (vgl. ebd., 290). Ganz generell lässt sich auch sagen, dass sich das französische Wort besonders in der mündlichen Rede und in informellen Gesprächen nicht gegen den englischen Terminus behaupten kann (vgl. ebd., 274).

Im dritten, im Hinblick auf die WWW-Befragung zum Wortschatz des Internet interessanten Teil der Studie steht die Ermittlung der Kenntnis der offiziellen Termini und ihrer Bedeutung im Vordergrund. Hierzu wurde 50 Informatikern 
zunächst ein Fragebogen mit den Definitionen für 20 offizielle Informatik-Termini vorgelegt. Zu den gegebenen Definitionen sollen jeweils die entsprechenden französischen Termini genannt werden ${ }^{27}$. Der zweite Fragebogen geht die Fragestellung genau aus der entgegengesetzten Perspektive an: 20 offizielle Neologismen werden vorgegeben, die von den Informanten definiert bzw. erklärt werden sollen. Die Ergebnisse unterteilt Gouadec $(1993,301)$ in drei Gruppen, denen zufolge die jeweiligen französischen Termini entweder 1. stark etabliert, 2. mittelmäßig etabliert oder 3. schwach etabliert sind.

Die Auswertung der beiden Befragungen fällt im Hinblick auf die tatsächliche Etablierung der offiziell vorgeschlagenen Ersatzwörter keineswegs so positiv aus, wie es die Ergebnisse der ersten Teilstudie vermuten lassen. Als Ergebnis des ersten Fragebogens lässt sich festhalten, dass nur gut die Hälfte (57\%) der Termini, die die Befragten zu den Definitionen nennen, französische bzw. französisierte Termini sind. Zudem stimmen nur 15\% der genannten französischen Termini mit den jeweiligen offiziellen französischen Neologismen überein, was auch insofern verschwindend wenig ist, als die Befragten durchschnittlich vier Termini pro Definition nennen (vgl. ebd., 302). Die Auswertung des zweiten Fragebogens, in dem die vorgelegten offiziellen Ersatzwörter definiert werden sollten, zeigt, dass mehr als die Hälfte der Befragten die vorgelegten Termini nicht kennen und daher auch nicht definieren können (vgl. ebd., 302-305).

Aufgrund dieser Ergebnisse fällt auch Gouadecs Fazit negativ aus:

„Il faut donc conclure la présente étude par questionnaire sur une note pessimiste: les termes officiels sont mal connus ou inconnus. Le constat demeure quel que soit le sens dans lequel on prend la question. Il faudra sans doute de grandes forces d'information et de persuasion pour faire évoluer les choses auprès de l'ensemble de la collectivité، (ebd., 306).

Die vierte Untersuchungsetappe bezieht sich auf ein Korpus aus französischenglischen Fachwörterbüchern der Informatik. Hier kann für 15 Termini exemplarisch festgestellt werden, dass die offiziellen Neologismen nicht systematisch als Äquivalente der englischen Termini zitiert werden. Wie auch schon im dritten Teil der Untersuchung ist auffällig, dass sich die offiziellen Termini in sehr unterschiedlichem Maße im Sprachgebrauch etabliert haben. Gleiches gilt für den Nachweis der offiziellen Termini in Fachwörterbüchern. Welche Termini nachzuweisen sind, schwankt von Wörterbuch zu Wörterbuch. In den Fällen, in denen die offiziellen Termini in Fachwörterbüchern eingetragen sind, ist auch immer mindestens ein nicht offizieller französischer Terminus vermerkt (vgl. ebd., 312).

Der fünfte und letzte Schritt der umfangreichen Studie zur Informatik-Terminologie besteht wiederum aus einem Fragebogen. Mit dieser Befragung soll ermittelt werden, welche Faktoren den Prozess der Französisierung bzw. die Etablierung der offiziellen Termini fördern bzw. bremsen (vgl. ebd., 313). Wieder werden die

27 Gouadec verwendet somit das gleiche Testverfahren, wie es unter der Leitung von Thoiron in der Studie zum Wortschatz der Gesundheit und Medizin angewendet wurde (s.o.). 
50 Informanten befragt, die auch die anderen beiden Fragebögen ausgefüllt haben. Dieses Mal werden sie um ihre Meinung zur Französisierung und Normierung des Informatik-Vokabulars aus zwei Perspektiven gebeten. Zum einen sollen sie aus der Sicht der Akteure der Terminologienormierung antworten ${ }^{28}$, zum anderen aus der Sicht der Benutzer des Informatik-Wortschatzes.

Es ist unmöglich, die Ergebnisse des 16 Fragen umfassenden Fragebogens, welche sich teilweise noch in mehrere Unterfragen aufgliedern, hier darzustellen. Bei Gouadec (ebd., 325-355) werden alle Fragen detailliert ausgewertet, so dass es hier reicht, allgemeine Antworttendenzen wiederzugeben. Grundsätzlich lassen sich unter den Befragten zwei Gruppen voneinander unterscheiden: 1. Vertreter einer laisser-faire-Haltung in Bezug auf die Sprache und 2. Befürworter des Sprachschutzes (vgl. ebd., 356). Als Antwort auf die Frage, ob sich das Französische als Sprache der Informatik eigne, gibt die Mehrheit der Befragten (60\%) dem Englischen als Sprache der Informatik den Vorzug (vgl. ebd., 325, 356). Aufgrund der Konkurrenzsituation zwischen englischen und französischen Termini komme es bei den Computernutzern (i.d.R. interessierten Laien) vor allem in den folgenden Bereichen zu großer Verwirrung:

- Installation und Benutzung von Computerprogrammen (Software),

- Verständnis der mitgelieferten Dokumentation,

- Lektüre von Fachpresse,

- Kontakt mit Forschern und

- Installation der Hardware (vgl. ebd., 358).

Obwohl das Englische als die geeignete Sprache der Informatik gesehen wird, wird eine Französisierung der Termini nur in den Bereichen der Wartung (Reparatur, technische Betreuung) und in der Forschung für überflüssig gehalten (vgl. ebd., 359). Die Französisierung wird in den Bereichen der Software (33\% der Befragten), der zu den Computerprogrammen mitgelieferten Dokumentationen (30\%) und der Produktinformation (25\%) als besonders notwendig erachtet (vgl. ebd.). Die meisten der befragten Informatiker stehen der Schaffung französischer Informatik-Termini hoffnungsvoll gegenüber. Nur 22\% der Befragten betrachten die Französisierung der Anglizismen als einen schon im voraus verlorenen Kampf (vgl. ebd., 361). Nach Aussagen der Befragten begünstigen vor allem die folgenden Faktoren den Gebrauch der französischen Termini:

- Schaffung französischer Termini, sobald die Anglizismen in die französische Sprache gelangen $(84 \%)$,

- Verstärkung der Übersetzungstätigkeit (81\%),

- Entwicklung französischer Produkte und entsprechender Dienstleistungen $(76 \%)$,

- Gebrauch der Sprache des Kunden (65\%) ${ }^{29}$ (vgl. ebd., 361).

\footnotetext{
${ }^{28}$ Damit ist gemeint, dass die Befragten ja auch selbst Neologismen schaffen und diese (und/oder andere) in ihrem beruflichen Umfeld verbreiten (vgl. Gouadec 1993, 313).

${ }^{29} \mathrm{Die}$ in Klammern gesetzten Prozentwerte entsprechen der anteiligen Nennung durch die Befragten.
} 
Das Fazit, das Gouadec aus der Befragung zieht, ist im Sinne der aktuellen französischen Sprachpolitik und für die Arbeit der Terminologiekommissionen als durchaus positiv zu bewerten. Die Französisierung wird als eine sinnvolle Arbeit erachtet: ,[...] franciser, c'est favoriser la compréhension [...]“ (ebd., 363). Auch die Normierung im Sinne einer klaren Terminologiebildung wird von den Befragten trotz der häufigen Kritik und Karikierung der sprachpolitischen Bestrebungen in den Medien - mehrheitlich positiv bewertet. Nach Ansicht der Befragten sei Terminologienormung nicht gleichzusetzen mit Verboten, sondern bedeute vielmehr die Vermeidung von Mehrdeutigkeiten, die Vermeidung von Anglizismen und zugleich eine Französisierung, die die Kommunikation vereinfache (vgl. ebd., 364). Nur wenige der Befragten halten eine Intervention des Staates für absolut notwendig. Die Mehrheit derer, die sich zu dieser Frage äußern, beurteilen ein Eingreifen des Staates als wünschenswert, sprechen sich jedoch gegen Geldstrafen bei Verstoß gegen die Regelungen aus (vgl. ebd., 365). Aus den Antworten geht zudem hervor, dass die befragten Informatiker die Terminologiekommissionen kaum kennen und die Resultate von deren Arbeit noch weniger (vgl. ebd., 366). Diese Unkenntnis erscheint in Anbetracht ihres Plädoyers für die Schaffung französischer Termini paradox. Die Gründe für die auf den ersten Blick paradoxe Situation - die Befragten sind für eine französische Terminologie, kennen aber die französischen Termini nicht - liegen auf der Hand: Die offiziellen InformatikTermini sind kaum verbreitet. Der Staat und die für die Sprachpflege zuständigen Organisationen, aber auch die Medien müssten sich stärker für die Verbreitung und Bekanntmachung der Terminologielisten in der Bevölkerung einsetzen. Nur in der weiteren Verbreitung der Wortlisten lägen die größten Chancen für die weitere Etablierung dieser Termini im allgemeinen Sprachgebrauch (vgl. Depecker 1997a, XXIX).

Gouadec (1994, 143) nennt vier Gründe, weswegen sich das Französische im Informatikbereich kaum gegen das Englische durchsetzen könne:

- Verbreitungsgrad angelsächsischer Produkte und ihrer Bezeichnungen,

- häufige Vermischung zwischen dem Englischen und den Programmiersprachen,

- schnelle Assimilierung englischer Bezeichnungen (z.B. Siglen), deren Ursprung nicht mehr sichtbar oder nachvollziehbar ist, und

- $\quad$ zu späte bzw. unzutreffende Übersetzung.

\subsubsection{Konsequenzen für die weitere empirische Forschung}

Es ist ein wachsendes Interesse festzustellen, die Bekanntheit und Wirksamkeit sprachpolitischer Regelungen zu ermitteln. Während sich dieses Interesse in den 1970er und 1980er Jahren auf die Linguistik beschränkt, zieht der Wunsch nach einer Evaluation der Sprachpolitik in den 1990er Jahren weitere Kreise. Auch bei der für die Koordination und Verbreitung der sprachpolitischen Maßnahmen zuständigen Organisation, der DGLF/DGLFLF, ist ein Bedürfnis festzustellen, die Wirksamkeit sprachpolitischer Regelungen zu ermitteln. In diesem Punkt folgt die DGLF den frankokanadischen Vorreitern, denn der OLF führt seit vielen 
Jahren regelmäßig Studien zur Ermittlung der Wirksamkeit der Sprachpolitik durch oder fördert entsprechende Studien. Auf dieses neu erwachte Interesse, nicht nur sprachpolitische Maßnahmen vorzubereiten und durchzusetzen, sondern auch ihren Erfolg zu messen, sind die 1991 von der DGLF vergebenen Forschungsaufträge zurückzuführen, mit deren Hilfe der Verbreitungsgrad der offiziell vorgeschriebenen Neologismen eruiert werden soll. Gaudin/Guespin $(1993,4)$ heben dieses neue Problembewusstsein der DGLF mit den folgenden Worten hervor: „Que la France commence à se poser ce problème: 'suffit-il d'édicter pour faire dire?' c'est un fait à marquer d'une pierre blanche."

Dem Aufruf der DGLF sind lediglich sechs Forscher bzw. Forschungsgruppen gefolgt. Von ihnen wurden Anfang der 1990er Jahre Studien für sechs verschiedene Bereiche vorgelegt ${ }^{30}$. Trotz dieser ersten Detailstudien steht für alle anderen Bereiche, für die auch Neologismen geschaffen und verabschiedet wurden, sowie für die bereits erforschten Bereiche, in denen seit 1991 auch neue Terminologielisten erstellt wurden, weiterhin die Frage im Raum, ob die Neologismen weit verbreitet sind (passive Akzeptanz) und von den jeweils durch die Fachwortschätze betroffenen Personen verwendet werden (aktive Akzeptanz). Sämtliche Studien haben ergeben, dass der Bekanntheitsgrad des Anglizismus in der Regel den des offiziellen französischen Ersatzwortes übersteigt. Das schließt allerdings nicht aus, dass sich der französische Terminus nicht etabliert habe. Oftmals lassen sich sowohl der Anglizismus als auch sein französisches Pendant in Texten nachweisen (vgl. Chansou 1993, Gouadec 1993).

Generelle Regeln formulieren zu wollen, wann ein Terminus als etabliert gelten könne, ist nahezu unmöglich. Bei vielen Neologismen kann bereits aufgrund ihrer sprachlichen Form eine Hypothese abgegeben werden, ob sich dieses Wort wird etablieren können oder nicht (vgl. 5.1). Da verlässliche Prognosen jedoch nur sehr schwer zu treffen sind - Thoiron/Iwaz/Zaouche $(1993,72)$ sprechen in diesem Kontext vom irrationalen Moment -, bleibt es letzten Endes empirischen Studien überlassen aufzuzeigen, in welchen Fällen häufiger der französische und in welchen Fällen häufiger der englische Terminus benutzt wird. Natürlich variiert der Sprachgebrauch von Person zu Person, so dass in diesem Bereich ohnehin nur von Tendenzen die Rede sein kann. Hinzu kommt, dass in den durchgeführten Studien oftmals auch nur ein sehr eingeschränktes Publikum ins Blickfeld gerät, wie z.B. Informatiker zur Evaluierung der Informatik-Termini, nicht aber breitere Bevölkerungsschichten. Die Entscheidung, ob sich ein Terminus auf dem Wege der Durchsetzung oder vielmehr auf dem Weg des Vergessenwerdens befindet, würde somit eine Vielzahl empirischer Studien voraussetzen. Problematisch erweisen sich insbesondere diejenigen Termini, die einen mittleren Bekanntheitsgrad aufweisen (vgl. z.B. Gouadec 1993, Rouges-Martinez 1992). In diesem Fall ist dann der zeitliche Faktor entscheidend, d.h. bei diesen Neologismen kann nur eine diachrone Betrachtungsweise in Form einer weiteren, mit zeitlichem Abstand

\footnotetext{
30 Neben den fünf in 4.3.1 und 4.3.2 vorgestellten Studien ist noch die Studie von Gasquet/Villebrun (1994) zu nennen (vgl. Fußnote 9).
} 
durchgeführten Studie den gewünschten Aufschluss über ihren Etablierungsgrad geben.

Aus den empirischen Studien, deren Inhalte und Ergebnisse in 4.3.1 und 4.3.2 skizziert worden sind, lassen sich einige Punkte als Fazit für die Gestaltung weiterer Studien zur Akzeptanz der offiziellen Terminologie sowie der in den Kapiteln 7-12 vorgestellten WWW-Befragung zur französischen Internet-Terminologie ableiten:

- Der Erfolg von Terminologieplanung lässt sich nicht in allgemeingültiger Form messen. Der Etablierungsgrad der offiziellen Termini kann nur im Rahmen einzelner Studien zu je einem Bereich, für den Terminologielisten vorliegen, ermittelt werden.

- Terminologielisten umfassen oftmals fünfzig und mehr englische Termini und ihre französischen Äquivalente. Nicht alle auf einer Terminologieliste stehenden Termini können im Rahmen einer Befragung auf ihren Bekanntheitsgrad hin geprüft werden, sondern es muss eine wie auch immer geartete Auswahl erfolgen.

- Da universitäre Studien mit begrenzten Mitteln es meist nicht ermöglichen, Repräsentativerhebungen durchzuführen, die Rückschlüsse auf die gesamte Bevölkerung erlauben, ist es sinnvoll, sich bei einer Befragung auf eine Personengruppe zu beschränken. Naheliegend ist dabei, wie es vor allem in den Studien von Fugger (1979/1980/1983a,b/1987), Gaudin (1991), Le GuillyWallis (1991), Gaudin/Guespin (1993), Thoiron/Iwaz/Zaouche (1993), Fossat (Rouges-Martinez 1992) und Gouadecs (1993) geschehen ist, dass nur der jeweils von dem Terminologieerlass direkt betroffene Personenkreis befragt wird.

- Die Entscheidung für die Verwendung eines französischen Neologismus bzw. eines Anglizismus hängt nicht allein vom Terminus selbst bzw. seinem Akzeptanzgrad ab. Die Situation (formell vs. informell), aber auch das Medium (mündlicher vs. schriftlicher Sprachgebrauch) üben entscheidenden Einfluss auf die Wahl der Lexik aus.

- Der Anteil an französischen bzw. englischen Termini hängt von den betrachteten Textsorten ab. In Wörterbüchern und Lehrwerken ist der Anteil an französischen Termini in der Regel höher als beispielsweise in Fachtexten.

- Korpusstudien (v.a. mit schriftlichen Quellen) und Befragungen führen nicht automatisch zu gleichen Ergebnissen. Besonders bei Gouadec (1993) wird dieser Unterschied deutlich: Die Ergebnisse der 1. Teilstudie weichen signifikant von denen der dritten und fünften Teilstudie ab. Anders formuliert bedeutet dies: Termini, die sich in Textkorpora nachweisen lassen, werden nicht unbedingt von der Mehrheit der Sprachbenutzer gekannt oder aktiv verwendet.

- Es ist schwieriger, aus qualitativen Daten signifikante Aussagen abzuleiten als aus quantitativen Daten (vgl. Chansou 1993). 
- Ein methodischer Zugang reicht allein nicht aus, um den tatsächlichen Erfolg der Sprachpolitik ermessen zu können. Eine Korpusstudie sollte im Optimalfall durch eine Befragung ergänzt werden und umgekehrt.

- Als Fazit aus allen Studien lässt sich festhalten, dass sich Neologismen bezüglich ihres Etablierungsgrades zweckmäßigerweise in die folgenden drei Kategorien einteilen lassen:

I) „Termes implantés ou en bonne voie d'implantation

II) Termes en équilibre entre leur forme française et leur équivalent anglais $^{31}$

III) Termes non implantés“ (Depecker 1997a, XII).

An dieser Stelle sei das Fazit Depeckers zu den fünf von ihm herausgegebenen Studien wiedergegeben, in dem er den Schritt der DGLF, die Nachhaltigkeit ihrer offiziellen Neologismenlisten überprüfen zu lassen, befürwortet. Depecker weist nachdrücklich darauf hin, dass es irrig sei zu glauben, Termini etablierten sich von allein, sobald sie im JO oder an anderer Stelle (z.B. auf der Internet-Seite der DGLF) festgeschrieben seien: „Implanter reste donc dans les faits bien distinct de s'implanter. C'est dire tout ce que ces études et celles à venir sont susceptibles d'apporter à l'aménagement linguistique et terminologique“" (Depecker 1997a, XXXIV).

\subsection{Bewertung der französischen Sprachpolitik und Termi- nologiearbeit}

\subsubsection{Bewertung der französischen Sprachpolitik und Terminologie- arbeit aus linguistischer Perspektive}

Dieser Abschnitt stellt eine Zusammenschau kritischer Stimmen von Linguisten zur Sprachpolitik (Loi Bas-Lauriol und Loi Toubon) und zur Terminologiearbeit dar. Die französische Sprachpolitik und Terminologiearbeit dürfen nicht nur isoliert im Hinblick auf ihre Wirksamkeit innerhalb Frankreichs betrachtet werden, sondern müssen auch im globalen Kontext gesehen und bewertet werden. Im Zeitalter der Globalisierung ist es alles andere als ratsam, dass sich ein Land sprachlich oder auf andere Weise zu sehr isoliert. In diesem Zusammenhang ist zu fragen: Wie vollzieht sich angesichts der modernen Sprachpolitik die Verständigung im Bereich der Wissenschaften? Blockiert eine Französisierung des Wortschatzes gerade im Bereich der Wissenschaften und der Wirtschaft nicht vielmehr die in-

\footnotetext{
31 Wie dieser Etablierungsgrad in der Praxis aussehen kann, lässt sich sehr gut am Informatik-Wortschatz demonstrieren. Im Informatikbereich bleibt in vielen Fällen der Anglizismus neben dem französischen Neologismus bestehen. Die Textanalyse, der erste Schritt von Gouadecs Studie, zeigt, dass bei den folgenden Wortpaaren sowohl die französischen als auch die englischen Bezeichnungen im untersuchten Korpus nachzuweisen sind: boule de commande / joystick, codet / code element, de secours / back up, déboguer / debug (to), dévideur / spooler, en ligne / on line, invite / prompt, mémoire morte / ROM, mémoire vive / RAM, microprogramme / firmware, numériser / digitaliser, progiciel / package, relancer / reboot, spoule / spool, test de performance / benchmark, traitement par lots/ traitement batch (vgl. Gouadec 1993, 250f.).
} 
ternationale Verständigung, als dass sie französischsprachigen Wissenschaftlern und Ökonomen dienlich ist? Stellt eine Französisierung des Fachwortschatzes die betroffenen Personen nicht vor das Problem, sich mit anderssprachigen Kommunikationspartnern nicht mehr austauschen zu können? Anders ausgedrückt, treibt die Französisierung des Wortschatzes Frankreich auf Dauer nicht sogar in die Isolation (vgl. z.B. Beinke 1995, 88; Braselmann 1999a, 97f.; Hagège 1987, 249)? Hagège (1987, 249) warnt vor einer Isolierung und Abschottung gegenüber der englischen Sprache, die einer Abwendung der Sprache vom internationalen Niveau gleichkomme:

\begin{abstract}
„Si le français ne s’industrialise pas, ses chances de se maintenir au niveau d'une langue internationale iront en s'amenuisant, du fait de la pression croissante qu'exerceront, dans tout type de communication industrielle, commerciale et scientifique, les ordinateurs capables de manipuler l'anglais, c'est-à-dire la langue des ingénieurs qui construisent actuellement le plus d'ordinateurs.“
\end{abstract}

Aber auch andere Argumente als die mögliche (wirtschaftliche) Isolierung werden gegen die aktuelle französische Sprachpolitik vorgebracht. Braselmann (1999b, 277-279; 2000, B2) hält den Nutzen der aktuellen französischen Sprachpolitik im Verhältnis zu den enormen Kosten, die sie erfordert, für eher fragwürdig. Sie nennt fünf Argumente, deren drittes auch das Globalisierungsargument aufgreift:

1. Englisches schleiche sich auch in den staatlichen Ersatzwörtern ein (z.B. entsprechen franz. payer-prendre für engl. cash and carry und franz. prépayé anstelle des plausibleren franz. payé d'avance für engl. prepaid eher den englischen als den französischen Wortbildungsregeln);

2. Ersatzwörter stießen bei Sprechern, in den Medien und bei Lexikografen nur auf eine geringe Akzeptanz;

3. die sprachpolitischen Maßnahmen trügen insofern anti-europäische Züge, als sie Internationalismen ${ }^{32}$ verböten;

4. im Werbebereich würden aus Gründen des gesteigerten Werbeeffekts häufig die verbotenen Anglizismen eingesetzt, wofür die vergleichsweise geringen Geldstrafen gerne in Kauf genommen würden;

5. es werde mit Kanonen auf Spatzen geschossen, da die Anglizismenquote sogar in besonders anglizismenverdächtigen Texten wie Sportberichten und Jugendzeitschriften lediglich bei zwei bis drei Prozent liege.

\footnotetext{
32 Internationalismen bezeichnen sprachliche Gemeinsamkeiten in den Wortschätzen verschiedener Sprachen und somit den übernationalen Charakter von bestimmten Wörtern. Zum Begriff des Internationalismus vgl. besonders Braun (1990), Bruns (2001, 114-123) und Schaeder (1990). Braun $(1990,32)$ weist darauf hin, dass Internationalismen sowohl die Allagskommunikation zwischen Menschen verschiedener Muttersprachen erleichtern als auch als Wortschätze einer möglichen europäischen Integration betrachtet werden können. Nicht alle Termini aus dem Computerbereich sind als Internationalismen anzusehen. So entwickelte Frankreich für engl. software, hardware, computer und andere Termini eigene Bezeichnungen. Die deutsche Sprache bringt im Vergleich zum Französischen weniger eigensprachliche Bezeichnungen im Computerbereich hervor wie z.B. Rechner für engl. computer.
} 
Andererseits wird dem Sprachgesetz - insbesondere von französischer Seite immer wieder zugute gehalten, dass es möglicherweise eine Steigerung des Sprachbewusstseins mit sich bringe, indem es die Bevölkerung für das Anglizismenproblem sensibilisiere. Der französische Linguist Claude Hagège, der Sprachplanung als solcher durchaus positiv gegenüber steht, antwortet dem Journalisten Gsteiger in einem Zeit-Interview auf die Frage, was er von dem neuen Gesetz halte: „Wenn das Gesetz dazu beiträgt, daß Medien, aber auch die Wirtschaft und besonders die Werbung die Sprache wieder bewußter verwenden und nicht völlige Anarchie herrschen lassen, erfüllt es vielleicht gar einen Zweck“ (Gsteiger 1994b, 26). Insgesamt erachtet Hagège die ständige Sorge um den Sprachverfall als „Panikmache“. Eine konkrete Gefahr für die französische Sprache durch Angloamerikanismen bestehe nicht.

Die deutschsprachigen Linguisten äußern sich zur französischen Sprachpolitik eindeutig negativ. Die Loi Toubon wird in der deutschsprachigen Romanistik in der Regel als eine Fortführung der Sprachpolitik der 1970er Jahre bewertet, wenngleich sich der Schwerpunkt etwas verlagert habe. Die offiziellen Zielsetzungen der französischen Sprachpolitik, vor allem das Argument des Verbraucherschutzes und die - unberechtigte - Sorge um den möglichen Untergang des Französischen, werden häufig als vorgeschoben enttarnt (vgl. Beinke 1990, 231, 237; 1995, 81-87; Braselmann 1999a, 19-23; Schmitt 1990a, 365; 1996, 875; 1997, 875). Der aktuellen französischen Sprachpolitik ab 1994 wird vorgehalten, dass sie in erster Linie auf die Stärkung des Französischen in diversen Diskursdomänen abziele.

Als Ergebnis ihres Vergleich zwischen deutschen und französischen Tageszeitungen sowie Fernsehsendungen hält Plümer (2000, 274) fest, dass die seit den 1960er Jahren geführte Diskussion um das franglais und die französische Sprachgesetzgebung zwar das Bewusstsein der Franzosen für die Verwendung eigensprachlicher Ausdrücke gefördert hätten, aber kaum von einer wirklich erfolgreichen französischen Sprachpolitik die Rede sein könne:

„Trotz der oben genannten Zahlen, nach denen im Deutschen weitaus mehr unterschiedliche Anglizismen festgestellt wurden als im Französischen, kann man wohl kaum von einem durchschlagenden Erfolg der modernen französischen Sprachpolitik sprechen. Zieht man beispielsweise in Betracht, daß sich die untersuchten französischen Medien in 21 von 39 Fällen über die von den Terminologiekommissionen erarbeiteten Ersatzwörtern hinwegsetzten und statt dessen weiterhin die proskribierten Anglizismen benutzten, so kann man schon von einer gewissen Mißachtung, zumindest aber von einer Gleichgültigkeit gegenüber der Gesetzgebung sprechen. Als schwierig beziehungsweise nahezu unmöglich scheint es darüber hinaus, den nicht-staatlichen Bereich, also die alltäglich gesprochene Sprache, zu kontrollieren. Der Bürger wird sich wohl kaum vorschreiben lassen, welche Wörter er benutzen darf und welche nicht." 
Neben der Kritik an der Wirksamkeit der französischen Sprachgesetzgebung wird häufig auch Kritik an den Resultaten laut, v.a. an den Ersatzwörtern selbst. In 5.1 wird ausführlich auf die Kriterien eingegangen, welche die Akzeptanz von Ersatzwörtern begünstigen oder verhindern können. Um diesen Ausführungen nicht vorwegzugreifen, werden an dieser Stelle nur kurz die häufigsten Kritikpunkte bezüglich der Ersatzwörter skizziert.

Von verschiedenen Sprachwissenschaftlern wird immer wieder kritisiert, dass viele der französischen Ersatzwörter nicht so klar und verständlich seien wie die Angloamerikanismen und somit dem offiziellen Ziel der Sprachpolitik, die Verständigung zu sichern anstatt Kommunikationsbarrieren zu schaffen, nicht gerecht würden (vgl. Beinke 1995, 84f.) ${ }^{33}$. Hierzu schreibt Plümer (2000, 70):

„Obwohl sich der französische Staat - insbesondere in Form des modifizierten Sprachgesetzes von 1994 und der Sprachpflegeorganisation DGLF - seit Anfang der 90er Jahre wieder verstärkt um die französische Sprache (und damit auch um die Abwehr von Anglizismen) kümmert, hat sich an den grundlegenden Prinzipien dieser Aktivitäten nichts [E]ntscheidendes geändert. Die von den Terminologiekommissionen erarbeiteten Neologismen erfüllen nach wie vor nur in den seltensten Fällen die Anforderung, klarer und leichter verständlich zu sein als die zu ersetzenden Anglizismen. Positiv zu beurteilen ist jedoch das Bemühen der Terminologiekommissionen, ihrer Tätigkeit mehr Transparenz zu verleihen, indem sie ihre Terminologiearbeit bereits während der Erarbeitungsphase für Wissenschaftler und andere Interessenten im Internet öffentlich zugänglich machen. Auf diese Weise wird die Zeit zwischen dem Auftauchen eines neuen fremdsprachlichen Ausdrucks und den ersten eigensprachlichen Ersetzungsvorschlägen erheblich verkürzt. Möglicherweise kann dieses Vorgehen ja dazu beitragen, daß sich die neukreierten französischen Ersatzlexeme künftig schneller und besser verbreiten und somit auch von großen Teilen der Bevölkerung akzeptiert und benutzt werden." 34

\footnotetext{
33 Beinke $(1995,83)$ nennt hier Neologismen wie franz. spationef (für engl. space craft), franz. chouquage (für engl. chugging) oder franz. oriel (für engl. bow windows). Zudem weist sie darauf hin, dass in einer Reihe von Fällen für einen Anglizismus mehrere Ersetzungen vorgeschlagen würden, z.B. für space craft die gleichrangig einzustufenden Ersatzwörter astronef und spationef, was der vielgerühmten clarté des Französischen sicherlich nicht zuträglich sei (vgl. Beinke 1995, 85).

${ }^{34}$ In der Tat liegt in dem im Dekret vom 03. Juli 1996 formulierten Auftrag an die Kommissionen, präventiv zu arbeiten, eine große Chance, die Akzeptanz der Ersatzwörter zu erhöhen. Präventives Arbeiten bedeutet in diesem Fall das Erarbeiten und Publizieren von französischen Neologismen, bevor sich die entsprechenden angloamerikanischen Bezeichnungen im Sprachgebrauch etabliert hätten (vgl. Braselmann 2001, 169). Was die Form der Ersatzwörter selbst betrifft, hat sich in den letzten Jahren eine deutliche Besserung eingestellt. Dies ist v.a. auf die koordinierende Arbeit der Commission générale und die von ihr aufgestellten Kriterien zurückzuführen, mit denen bereits im Vorfeld unrealistische Ersatzwortbildungen verhindert werden sollen. Depecker (2001a, 442) versucht die Arbeit der Terminologiekommissionen gegenüber dem ihr mehrfach entgegengebrachten Vorwurf der mitunter technokratischen, künstlichen Ersatzwörter zu rechtfertigen. Er weist darauf hin, dass die Künstlichkeit mitunter daraus resultiere, dass die Kommissionsmitglieder eine mög-
} 
Inwieweit die in der Folge der Loi Toubon veränderte Terminologiearbeit jedoch bewirkt, dass die Ersatzwörter auf eine breitere Akzeptanz bei der Bevölkerung stoßen, muss auch Plümer offen lassen. Neben der von Plümer geäußerten Kritik lassen sich in der Literatur weitere Kritikpunkte ausmachen, die sich nach Beinke (1995, 83-86) und Gebhardt $(1981,28)$ wie folgt benennen lassen:

- Es fehlten einheitliche Kriterien für die Entscheidung zwischen Ersetzung und grafisch-phonischer Französisierung, was zu inkonsequenten Entscheidungen führe (Bsp.: pipeline hat sich gegenüber dem auch morphologisch französisierten Wort oléoduc durchgesetzt, obwohl es andere Neologismen auf der Basis der Morphems oléo gibt wie oléoprise, oléoréseau, oléoserveur).

- Der Integrationsgrad eines Anglizismus werde nicht berücksichtigt (Bsp.: walkman wurde durch franz. baladeur ersetzt, obwohl der Terminus walkman bereits seit Jahren im französischen Wortschatz verankert war).

- Die Ersatzwörter seien teilweise nicht bedeutungsgleich mit den entsprechenden Anglizismen (Bsp.: disk-jockey und das Ersatzwort animateur, vgl. Kap. 5, Fußnote 1).

- Ersatzwörter seien mitunter „zu lang, zu aufwendig, system- und informationsunökonomisch" (Gebhardt 1981, 28) (Bsp.: franz. (de) baut de gamme für engl. standing).

- Ersatzwörter widersprächen morphologisch oder syntaktisch mitunter ästhetischen und/oder grammatischen Regeln (Bsp.: der adverbiale Gebrauch von Adjektiven im Fall von couper sec oder die Schaffung von Siglen und Kontaminationen nach englischem Wortbildungsmuster wie docudrame).

- Es sei unpräzise, wenn für einen Anglizismus mehrere gleichberechtigte Ersatzwörter vorgeschlagen würden (Bsp.: franz. message électronique, courrier électronique, messagerie électronique oder mél für engl. e-maið ${ }^{35}$.

- Bei den Sprachbenutzern würde durch neue Erlasse, die alte Erlasse zum gleichen Wortschatz außer Kraft setzten, Unsicherheit erzeugt. Das bedeutet, dass die Sprachbenutzer nicht immer sicher sein könnten, sich terminologisch wirklich auf dem neuesten Stand zu befinden.

Aus sprachwissenschaftlicher Perspektive ist somit ernsthaft zu fragen, ob die Ersetzung ausgewählter Anglizismen durch französische Neologismen wirklich die Kommunikation verbessert oder diese nicht vielmehr unnötig erschwert.

\footnotetext{
lichst große Distanz zum angloamerikanischen Ursprungswort schaffen wollten: „Peut-être y a-t-il là quelques éléments de nature à alimenter le reproche qui peut être fait à ces CMT de créer un néofrançais, fait de termes à résonance anglaise, technocratique, voire artificielle. Mais dans leur immense majorité, les termes officiels comptent, comme on l'a vu, peu de formes créées de toutes pièces, et il est difficile [...] de donner des désignations populaires à des concepts que les spécialistes ont besoin de nommer rigoureusement. Et si les limites de la correction et de la rigueur furent parfois atteintes, on peut considérer que c'était là le prix à payer [...] pour tenir à distance l'anglicisme, même s'il pouvait arriver à celui-ci de se refléter dans la désignation française retenue."

35 Stehen mehrere Ersatzwörter zur Verfügung, kann dies bei in Terminologiefragen Rat suchenden Sprechern zur Verstärkung der sprachlichen Unsicherheit führen. Wie Depecker (1997a, XXVIf.) als Fazit der von ihm herausgegebenen Studien feststellt, wollten die Befragten nur einen französischen Terminus, nicht mehrere. Sonst sähen sie sich vor das Problem gestellt, unter mehreren Bezeichnungen eine ihrer Meinung nach passende auswählen zu müssen.
} 
Auf Seiten der französischen Kritiker lässt sich in Bezug auf die Terminologiearbeit keine eindeutige Position ausmachen. Während De Broglie (2001), Hagège (1987) und Mortureux (1997, 121f.) eine weitgehend positive Bilanz ziehen, zeigen sich z.B. de Bessé (1990), Lerat/Sourioux (1990) und de Schaetzen (1993) eher enttäuscht, weil die praktische Umsetzung der Terminologiearbeit die Erwartungen nicht erfüllt habe.

Der immer wieder an den Ersatzwortvorschlägen geäußerten Kritik hält de Broglie als Präsident der Commission générale eine positive Bilanz entgegen. De Broglie (2001, o.S.) hebt vor allem den Nutzen der Terminologiearbeit hervor und betont die Aktualität von Terminologiearbeit. Sie verfehle keinesfalls ihre Wirkung, wie es das Beispiel der Internet-Terminologie zeige:

„En conclusion, les travaux terminologiques ne sont nullement des travaux d'arrière-garde, ni dans leur conception, ni dans l'attente du public auquel ils s'adressent. Ils ne sont pas dépassés par l'évolution technologique, l'exemple du vocabulaire de l'internet le prouve. Les travaux ne peuvent pas être présentés comme un combat perdu d'avance."

Goudaillier kritisiert in seinem Aufsatz von 1987 in erster Linie, dass bei der Schaffung von Neologismen der tatsächliche Sprachgebrauch nur ungenügende Beachtung finde und während der Erarbeitung der neuen Termini keinerlei linguistische Studien (z.B. Befragungen) stattfänden (vgl. Goudaillier 1987, 361). Insbesondere in diesem Punkt kann man der Terminologiearbeit nach 1996 einen Wandel zum Positiven bescheinigen: Viele der offiziellen Termini waren bereits vor ihrer Publikation in den Terminologielisten verbreitet und werden durch die Aufnahme in die Listen lediglich offiziell bestätigt, wie Depecker (2000; vgl. 4.1) nachweist.

Goudaillier (1987, 363) weist darauf hin, dass die offiziellen Termini bis 1987 oft wenig erfolgreich waren. Er mutmaßt, dass entsprechende Studien im Vorfeld der Publikation der Listen den Misserfolg dieser Termini hätten verhindern können. Als ein Beispiel für gelungene Terminologiearbeit nennt Goudaillier (ebd.) die im März 1986 ins Leben gerufene Kommission zur Feminisierung der Berufs- und anderer Bezeichnungen. Insgesamt plädiert Goudaillier (ebd., 364) dafür, bei der Terminologiearbeit das tatsächliche Sprachverhalten und die Einstellungen der Sprecher stärker zu berücksichtigen: „Les commissions de terminologie [mit Ausnahme der Kommission zur Feminisierung der Berufs- und anderer Bezeichnungen, E.M.] semblent avoir œuvré jusqu'à présent malgré les usagers et non pas avec eux, pour eux, avec leur langue, pour leur langue ... pour notre langue."

Ein weiterer, von einigen Sprachwissenschaftlern vorgebrachter Kritikpunkt besteht darin, dass sich die staatliche Terminologieplanung eigentlich nur auf die Fachsprachen konzentrieren solle, wie frühe Texte zur Terminologiearbeit belegen (vgl. z.B. Feyry 1973, 47f.). Bei näherer Betrachtung der Terminologielisten wird immer wieder deutlich, dass auch die Allgemeinsprache betroffen ist, denn es werden vielfach allgemein bekannte und geläufige Anglizismen durch französische 
Neologismen ersetzt. Auf diese Erweiterung des Gegenstandsbereichs der CMT weist Fugger bereits 1983 hin:

„Die ab 1972 offiziell eingesetzten Terminologiekommissionen und die Sprachpflegeorganisationen schießen wie Pilze aus dem Boden und beschränken sich schon lange nicht mehr auf die, langue scientifique et technique, sondern berühren nun auch Bereiche, die ohne weiteres der ,langue commune’ zuzuordnen sind [...]“ (Fugger 1983b, 130).

Nach Braselmann (2002b, 207) entstammen ca. 12\% der zu ersetzenden Anglizismen nicht der Fach-, sondern der Allgemeinsprache.

Auch Gebhard $(1981,26)$ moniert, dass die Opposition zwischen Fach- und Gemeinsprache in dem Gesetz von 1975 übersehen werde, beide Bereiche sogar stillschweigend gleichgesetzt würden. Vielfach sind die Grenzen zwischen Fachund Allgemeinsprache allerdings fließend, und etliche Termini aus den Fachsprachen sind inzwischen auch Teil der Allgemeinsprache geworden. So werden viele Termini des Wortfeldes Internet (homepage, e-mail, server etc.) nicht nur von Spezialisten benutzt, sondern sind in die Allgemeinsprache eingegangen. Ein anderes prominentes Beispiel aus dem Bereich der audiovisuellen Medien ist der baladeur, der in den 1980er Jahren zur Ersetzung des engl. walkman geschaffen wurde und auf beiden Seiten des Rheins für viel Furore gesorgt hat.

Die empirische Untersuchung der Sprechereinstellungen, genauer der Akzeptanz der vorgeschriebenen Ersatzwörter, stellt noch immer ein Forschungsdesiderat dar. Schmitt macht darauf bereits 1990 aufmerksam:

„[...] dabei wäre es angebracht, sich gestützt auf systemlinguistische und pragmatische Kriterien sowie auf empirische Analysen der tatsächlichen aktualisierten Sprache zu fragen, ob im je gegebenen Fall für den Legislator ein Handlungsbedarf gegeben ist, ob ein ermittelter Xenismus tatsächlich beim sprachlichen Handeln ein Hindernis bildet und, vor allem, ob das vorgeschlagene Ersatzwort tatsächlich eine akzeptable Lösung und keine Verschlimmbesserung darstellt“ (Schmitt 1990a, 371).

In die gleiche Richtung wie die Forderung Schmitts zielt auch Kremnitz (2001, 500), der die Interdisziplinarität des Forschungsgegenstandes betont:

„Trotz zahlreicher Arbeiten zur Sprachplanung ist über die gesetzliche Reglementierbarkeit von Sprachen und sprachlichem Verhalten noch recht wenig bekannt. Es dürfte offensichtlich sein, daß es sich dabei weniger um eine linguistische, als vielmehr um eine psychologische und politische, vielfach auch im weiteren Sinne wirtschaftliche Frage handelt. Für die meisten Sprachgemeinschaften scheint eine aktive Sprachpolitik, welche auch die Gesetzgebung miteinbezieht, unumgänglich, wenn sie sich der monopolisierenden Sogwirkung des Anglo-Amerikanischen nicht schutzlos aussetzen wollen. Allerdings mußten Sprachpolitiker schon oft die aus anderen Bereichen hinrei- 
chend bekannte Erfahrung machen, daß die angestrebten und wirklich erreichten Ziele einer Politik weit auseinanderklaffen; sprachliches Verhalten wird von komplexen Variablen bestimmt, die nur in unzureichendem Maße kalkulierbar sind.“

Gerade weil sprachliches Verhalten von sehr vielen sprachinternen und -externen Faktoren gesteuert wird und weder vollständig zu prognostizieren noch zu reglementieren ist, muss dem tatsächlichen Sprachgebrauch Rechnung getragen und dieser überprüft werden. In diesem Sinne befürwortet Depecker (1997a) nicht nur Neologismen zu schaffen und ihren Gebrauch offiziell zu verabschieden, sondern auch die tatsächliche Kenntnis und Benutzung dieser Wörter zu ermitteln. Bezeichnungen „von oben“ vorzuschreiben sei kein Garant für deren Etablierung im französischen Wortschatz (vgl. Depecker 1997a, XXXIV; 4.3.3).

Auch Ahlers/Holtus (1999) beenden ihren Aufsatz „Lassen sich Anglizismen verbieten?" mit dem Impetus, weitere Forschungen zur Ermittlung der Etablierung der Informatik bzw. Internet-Neologismen anzustellen:

„Ausgehend von den vorliegenden Ergebnissen sollen weiterführende Studien zunächst verläßliche statistische Aussagen zur Verwendung von Anglizismen und Ersatzwörtern des Bereichs Informatik liefern. Da diese erst auf der Basis eines weit größeren Korpus mit erheblich mehr Belegen pro Lexem möglich sind, sollte der zu allgemeine Ansatz zugunsten einer eingegrenzten Perspektive aufgegeben werden. Beispielsweise könnte untersucht werden, wie sich der noch junge Bereich Internet weiterentwickelt, da einerseits die wachsende Zahl der Nutzer in Frankreich eine Bildung verständlicher französischer Termini begünstigt, durch die globale Vernetzung andererseits ein noch stärkerer Sprachaustausch möglich ist. Genauso wäre eine strenge Beschränkung auf den Wortschatz der Spracherlasse unter Betrachtung diachroner Aspekte ein lohnendes Forschungsfeld, dennoch gibt es keine definitiven Aussagen darüber, ob sich der Zeitfaktor zugunsten der Anglizismen oder zugunsten der Ersatzwörter auswirkt“" (Ahlers/Holtus 1999, 309).

\subsubsection{Bewertung der französischen Sprachpolitik durch die Bevölke- rung}

Wie im letzten Abschnitt gezeigt wurde, stehen Sprachwissenschaftler dem Gesetz von 1994 sowie der gesamten neueren Sprachpolitik durchweg kritisch gegenüber. Die Ansichten in der französischen Bevölkerung sind durchaus gespalten, was sich vor allem darin niederschlägt, dass verschiedene Befragungen zu völlig unterschiedlichen Ergebnissen gelangen. Nicht zuletzt gibt es Paradoxien wie das in 3.2.3.1 geschilderte Umfrageergebnis, dem zufolge die Loi Toubon zwar generell befürwortet wird, den Informanten ihr genauer Inhalt jedoch mehrheitlich unbekannt ist. Auf diese Paradoxie weist auch Schmitt $(1996,876)$ hin: 
„Daher ist es auch nicht verwunderlich, daß z.B. die überwiegende Mehrheit der Franzosen in bezug auf die Spracherlasse, deren Inhalt ihnen meist nur vage bekannt ist, einerseits grundsätzl[i]ch dafür ist, daß die französische Sprache geschützt wird und dass man sich von offizieller Seite Gedanken über die weitere Entwicklung des Französischen in Frankreich und der immer wichtiger werdenden Frankophonie $[\ldots]$ macht, andererseits aber die inzwischen vorliegenden Produkte sprachplanerischer Tätigkeit vielfach ablehnt und im Grunde nicht bereit ist, sich in ihrer Sprachverwendung an die vorgegebenen Regeln zu halten.“

Auch bei Sokol (2001, 206f.) wird die Kluft zwischen der Befürwortung der Sprachpolitik einerseits und der Unkenntnis ihrer Inhalte andererseits deutlich, wenn sie schreibt:

„Die Veröffentlichung der Listen mit den Néologismes et termes officielles [sic!] im Journal officiel erregt jedes Mal kollektives Aufsehen, wobei man sie in der Regel ebenso kollektiv ignoriert. Obwohl die Distanznorm heute kaum noch jemand beherrscht, steht allerdings die Mehrheit der Franzosen der Sprachpolitik der Regierung und anderer Organisationen positiv gegenüber; hierzu Befragte sind jederzeit bereit, ihre eigene Art zu sprechen als, unrichtig' und ,minderwertig' zu qualifizieren."

Inwieweit diese Paradoxie auch für die Internet-Terminologie Gültigkeit hat, wird die Auswertung der WWW-Befragung (vgl. Kap. 9-12) klären. Im Fragebogen wird getrennt danach gefragt, ob die vorgeschlagenen französischen Neologismen von den Informanten selbst verwendet werden und ob die offizielle(n) Liste(n) zur Internet-Terminologie bekannt ist/sind.

\subsubsection{Meinungsumfragen}

Der Staat kann seinen Bürgern aufgrund des Urteils vom 29. Juli 1994 nicht vorschreiben, wie sie zu sprechen haben. Dennoch besteht von offizieller Seite die Hoffnung, dass die Terminologievorschläge auch bei Privatleuten Wirkung zeigen. Über die Anwendung des Gesetzes im offiziellen Bereich geben entsprechende Statistiken in den Jahresberichten der DGLF/DGLFLF Auskunft. Doch wie sieht es im privaten Bereich aus, in der geschriebenen und gesprochenen Alltagssprache, die sich der staatlichen Kontrolle weitestgehend entzieht?

Welche Position die Bevölkerung in Bezug auf die Loi Toubon vertritt, wird vor allem in Meinungsumfragen deutlich. Aufschlussreich ist auch die Lektüre von Presseartikeln zur Sprachpolitik, wenngleich diese Informationsquelle wenig repräsentativ ist, da die Meinung einzelner Journalisten keinerlei Rückschlüsse auf die Ansichten der Gesamtbevölkerung zulässt. Anfang 1994 werden zwei Meinungsumfragen zur Rezeption des Gesetzentwurfs von Toubon durchgeführt, die sehr unterschiedliche Ergebnisse aufweisen.

Zunächst ist die vom französischen Meinungsforschungsinstitut SOFRES durchgeführte Befragung zu nennen, die den Titel „Les Français et la défense de la lan- 
gue française" trägt. Bei der vom Ministère de la Culture et de la Francophonie in Auftrag gegebenen Studie werden am 4. und 5. März 1994 insgesamt 1.000 Franzosen über 18 Jahre befragt. Das Ergebnis lässt sich wie folgt zusammenfassen:

- 52\% (gegenüber 44\%) der befragten Personen stehen Fremdwörtern zur Bereicherung der französischen Sprache positiv gegenüber.

- $\quad 97 \%$ der Franzosen erklären sich ihrer Muttersprache verbunden, 70\% sind stolz auf die Existenz der Frankophonie, der mittlerweile ca. 50 Länder angehören. $81 \%$ bis $92,5 \%$ aller befragten Franzosen sprechen sich - je nach Gesetzesartikel - für das Sprachgesetz aus.

- $\quad 90 \%$ halten die Verteidigung der französischen Sprache in Frankreich sowie im Ausland für ein wichtiges politisches Ziel.

- $65 \%$ glauben an ein Gelingen solcher sprachpolitischer Maßnahmen (vgl. DGLF 1994b; Péroncel-Hugoz 1994b, 20).

Eine zweite Umfrage wird bei Braselmann (1999a, 14) präsentiert: Im April 1994 führt die Zeitschrift Globe Hebdo eine Telefonumfrage durch. Zu diesem Zeitpunkt ist zwar die Loi Toubon noch nicht verabschiedet worden, dafür aber soeben (16. März 1994) eine neue Auflage des Dictionnaire des termes officiels erschienen. Die Frage an die 826 französischen Informanten lautet, ob sie aufgrund von Vorschriften ihre Art zu sprechen und zu schreiben ändern würden. Das Ergebnis ist kein gutes Omen für die Wirksamkeit der Loi Toubon, denn nur 3\% der Befragten bejahen die Frage uneingeschränkt, 9\% antworten mit „peut-être“, während 79\% eine künftige Veränderung ihrer Sprech- und Schreibgewohnheiten völlig ablehnen (vgl. Braselmann 1999a, 14).

Braselmann (1999a, 14f.) unterteilt die Reaktionen auf den Gesetzentwurf in drei Gruppen: 1. eindeutig pro, 2. eindeutig contra und 3. differenziert, wobei Angehörige der Terminologiekommissionen und anderer staatlicher Institutionen sowie die Mehrheit der RPR- und UDF-Vertreter dem Gesetz prinzipiell positiv gegenüberstehen, während die Sozialisten und, wie die Telefonumfrage zeigt, der Großteil der Bevölkerung diesem kritisch gegenüberstehen.

\subsubsection{Reaktionen in der französischen Presse}

Nicht nur Bevölkerungsumfragen, sondern auch Artikel in Tageszeitungen geben ein Bild von der öffentlichen Meinung. Vor allem im Jahr 1994 thematisieren zahlreiche Artikel in französischen Tageszeitungen das neue Gesetz bzw. den ihm vorangehenden Entwurf. Insbesondere in der Tageszeitung Le Monde wird ein breites Meinungsspektrum vertreten, das sich zwischen vollständiger Ablehnung und vollständiger Befürwortung bewegt.

Ganz offen wird in einigen Artikeln die Ansicht geäußert, es handele sich bei dem Vorhaben Toubons um einen Abwehrkampf gegen den amerikanischen Kulturimperialismus. Aus diesem Motiv macht auch Toubon selbst keinen Hehl, wenn er in Le Monde vom 24. Februar 1994, 2 schreibt: 
„Les pays anglo-saxons, loin de se contenter de la rente de situation anglaise, en particulier dans les industries culturelles, déploient des efforts considérables, comme l'ont montré les récentes négociations multilatérales, pour que leur langue commune conserve ses positions et conquière de nouveaux espaces."

Auch Plenel (in: Le Monde vom 04. Mai 1994, 10) sieht in dem Gesetzentwurf einen weiteren (nostalgischen) Versuch Frankreichs, die ehemalige Weltgeltung der französischen Sprache wieder zu erlangen:

„Suffit-il de défendre notre langue pour prétendre avoir quelque chose à dire au monde? [...] Au lieu de courir vainement, par le détour de la bataille linguistique, après une puissance défunte, ne faudrait-il pas plutôt regarder la réalité en face: une France devenue puissance moyenne, qui se crispe au lieu de s'ouvrir?"36

Demgegenüber wird der Gesetzentwurf beispielsweise von Péroncel-Hugoz (1994a) befürwortet. Dieser sieht darin die Gewährleistung, dass die französische Sprache vor allem im Dienstleistungssektor erhalten bleibe. Außerdem begrüßt er, dass die Regelungen auch für den Bereich der Werbung gelten sollen. Seine positive Haltung bringt Péroncel-Hugoz auch in zwei späteren Le Monde-Artikeln vom 10. März und vom 03./04. Juli 1994 zum Ausdruck. Im März-Artikel macht Péroncel-Hugoz deutlich, dass der Staat mit dem Gesetz keineswegs intendiere fortan alle Wörter fremden Ursprungs aus der französischen Sprache zu verbannen. Vielmehr sei es das Ziel des neuen Gesetzes, den Gebrauch der französischen Sprache z.B. bei Kolloquien, auf Schildern und in Gebrauchsanweisungen zu gewährleisten (vgl. Péroncel-Hugoz 1994b, 20). Auch im Artikel vom Juli 1994 bewertet Péroncel-Hugoz das Gesetz nochmals als wichtigen Beitrag zum Verbraucherschutz und misst ihm eine wichtige Rolle für die Bewahrung des Französischen in bestimmten Diskursdomänen zu:

„Le texte du 30 juin n'a pas pour but de chasser l'Hexagone des cultures ou même des mots allogènes mais simplement de faire en sorte que le français ne soit pas exclu en France dans des circonstances en constante extension depuis deux ou trois lustres (recherche, colloques, recrutement, contrats, prospectus, publicités, etc.); que toute personne puisse ici, partout, si elle le désire, et hormis les exceptions allant de soi, être entendue, servie, informée, enseignée, diplômée, recrutée uniquement à l'aide du français" (Péroncel-Hugoz 1994c).

\footnotetext{
36 Diesen Standpunkt teilen auch andere Autoren. Dupuy $(1994,3)$ bewertet den Gesetzentwurf in erster Linie als einen patriotisch motivierten Akt: „Tout semble programmé pour qu'il reste surtout de cette loi un beau geste patriotique et une affirmation d'autorité pour l'autorité [...].“Auch der französische Linguist Hagège $(1996,116)$ bewertet den Kampf um die Reinhaltung der französischen Sprache als einen politisch und kulturell motivierten Akt: „C'est assez dire qu'aujourd'hui comme hier, la lutte pour le français est politique autant que culturelle."
} 
Als zweites Ziel des neuen Gesetzes nennt Péroncel-Hugoz im weiteren Verlauf des Artikels die Neologismenbildung mit eigensprachlichen Mitteln.

Die Arbeit der Terminologiekommissionen sieht Toubon keinesfalls als der sprachlichen Evolution entgegenstehend oder gar als präskriptiv an. Den sprachlichen Fortschritt verhinderten vielmehr diejenigen, die weiterhin fremdsprachliche Ausdrücke verwendeten:

„En vérité, les adversaires de l'évolution de la langue française ne sont pas ceux qui, depuis des siècles, font l'effort d'inventer des mots pour désigner des réalités nouvelles (logiciel, ordinateur, oléoduc, cadreur) mais bien les prescripteurs qui emploient systématiquement les termes étrangers et se refusent donc à créer de nouveaux mots français“" (Toubon, Le Monde vom 04. August 1994, 16).

Während in den französischen Artikeln durchaus auch die positiven Seiten des Gesetzentwurfs hervorgehoben werden wie z.B. die Sicherung des Französischen in verschiedenen Diskursdomänen, wird in der deutschsprachigen Presse über den Gesetzentwurf weitgehend geschmunzelt.

\subsubsection{Reaktionen in der deutschsprachigen Presse}

Das in der deutschsprachigen Presse vertretene Meinungsspektrum bewegt sich im Großen und Ganzen zwischen Skepsis und leichtem Spott.

Braselmann (2002a, 296-304) teilt die Reaktionen auf den Gesetzentwurf und die Verabschiedung der Loi Toubon in deutschsprachigen Zeitungen in drei Phasen ein: 1. die Phase der Bekanntgabe des Gesetzentwurfes (Februar bis Juni 1994), 2. der Zeitraum der Verfassungsklage und der Verabschiedung des modifizierten Gesetzes (Juli/August 1994) und 3. die Diskussion um ein deutsches Sprachschutzgesetz (seit Januar 2001).

Die erste Phase erstreckt sich über den Zeitraum von Februar bis Juni 1994 und erfasst die ersten Reaktionen auf den Gesetzentwurf. In diese erste Phase fällt z.B. der Artikel in der Frankefurter Allgemeinen Zeitung vom 28. Februar 1994, in dem es einleitend heißt:

„Da in Frankreich der Kampf für die Landessprache besonders entschieden geführt wird, zugleich aber auch Einhelligkeit darüber besteht, daß le ridicule tue, daß Lächerlichkeit tödlich wirkt, ist das Ringen um ein reines Französisch besonders diffizil. Die Frankophonie, für die es ein eigenes Ministerium gibt, war immer ein Gebiet für Verrenkungskünstler. Es lebe das Französische: Wenn Gelehrte, Politiker und Bürokraten dies rufen, meinen sie oft: Nieder mit dem Englischen“ (Hanimann 1994, 33).

Ein in der Tageszeitung vom 28. Februar 1994 erschienener Artikel trägt den aussagekräftigen Titel „Parlez français - oder zahlen!“ (Hahn 1994, 20). In der Frankfurter Rundschau vom 11. März 1994 wird gemutmaßt, dass sich die Sprache kaum mittels eines Gesetzes regulieren lasse und dieses nach kurzer Zeit ohnehin in 
Vergessenheit geraten und im Sande verlaufen werde. Daher heißt es am Ende: „Deshalb kann man allzu Besorgten getrost auf Neufranzösisch den Rat geben: Restez cool." (Edl/Matz 1994, 8). Der am 16. April 1994 in der Frankfurter Allgemeinen Zeitung erschienene Artikel „Statt Airbag soll es künftig heißen: Aufblasbarer Sack“ (Altwegg 1994, 30) zielt insbesondere auf die vielfach als lächerlich empfundenen französischen Ersatzwörter ab. Auch in der Frankfurter Rundschau vom 06. Mai 1994 wird der Gesetzentwurf ins Lächerliche gezogen:

„Es fällt schwer, über die Bemühungen des französischen Kulturministers Jacques Toubon, die Sprache Voltaires vor der Flut linguistischer Importe aus dem anglo-amerikanischen Sprachraum zu schützen, nicht zu lächeln. Doch nun ist das , Gesetz über den Gebrauch der französischen Sprache' verabschiedet, was wird es also bewirken? Nicht viel“ (s. Bibliografie unter: „Die Ächtung der Sprachsünde").

In die gleiche Richtung zielt auch ein in der Zeit vom 27. Mai 1994 veröffentlichter Artikel. Hier wird mit Blick auf einige der Ersetzungsvorschläge angemerkt, dass das neue Gesetz „an vielen Stellen gut für Lacherfolge“ sei (Siegele 1994, 39). Gleichermaßen wird in einem Artikel in Die Welt vom 04. Juli 1994 bereits im Titel durch die Verballhornung des Namens „Toubon“ eindeutig Stellung bezogen. Dort heißt es „Mr. Allgood kämpft gegen Hollywood“ (Lorey 1994, 8) ${ }^{37}$. In dieser ersten Phase macht sich die deutsche Presse fast durchgängig lustig über den Gesetzentwurf.

Die zweite Phase bezieht sich auf das Urteil des Verfassungsgerichtes und das Inkrafttreten der modifizierten Loi Toubon (Juli/August 1994). Mit merklicher Genugtuung registriert die deutschsprachige Presselandschaft das Urteil des Verfassungsgerichtes, dem zufolge der Gesetzentwurf gegen das Recht auf freie Meinungsäußerung verstoße. Dies bezeugen beispielsweise Artikel in der Süddeutschen Zeitung vom 01. August 1994 (s. Bibliografie unter „Niederlage für französische Puristen“), in Die Welt vom 01. August 1994 („Frankreichs Sprachhüter müssen ,Franglais' dulden“, s. Bibliografie unter Welt-Nachrichtendienst 1994) und in der Neuen Zürcher Zeitung vom 03. August 1994 (s. Bibliografie unter „Verfassungsrat gegen staatliche Zwangsterminologie"). Im Rheinischen Merkur vom 05. August 1994 wird die Schadenfreude über die Niederlage Jacques Toubons am deutlichsten: „Frankreichs Sprachschützer kollidierten mit den Idealen von 1789. Gescheitert, Monsieur Allgood!“ (Wahl 1994, 2).

Insgesamt wird von den großen deutschen Tageszeitungen das Geschehen in Frankreich aufmerksam verfolgt. Allerdings richtet sich die Berichterstattung vorwiegend gegen den Gesetzentwurf und die später verabschiedete Loi Toubon. Häufig ist die Berichterstattung auch fehlerhaft. So stimmen die in dem ZeitArtikel vom 15. Juli 1994 dargestellten Fakten zwar mit der Realität überein, doch

\footnotetext{
${ }^{37} \mathrm{Mr}$. Allgood ist die Verballhornung von M. Toubon (tout bon $=$ all good) .
} 
wird nirgends erwähnt, dass nicht alle Anglizismen von dem Verbot betroffen sind, sondern nur diejenigen, für die es entsprechende offizielle Ersatzwörter gibt:

„Französisch soll fortan von ausländischem Vokabular befreit werden, und zwar unter Androhung von Bußen bis zu 50000 Francs (15 000 Mark) oder sechs Monaten Haft. Werbung, Wissenschaftskongresse, Stellenanzeigen, Fernsehsendungen, Gebrauchsanweisungen - alles ist nunmehr im Visier [...]“" (Gsteiger 1994a, 26).

Den gleichen Unterlassungsfehler stellt man auch bei der Lektüre des Artikels in der Süddeutschen Zeitung vom 01. August 1994 (s. Bibliografie unter „Niederlage für französische Puristen") fest. Auch wird oft in den Artikeln nicht deutlich zum Ausdruck gebracht, dass nur bestimmte Bereiche der Sprache und bestimmte Berufsgruppen betroffen sind, keineswegs aber dem normalen Bürger auf der Straße Vorschriften für seine Wortwahl gemacht werden. Einige Fehler in der Berichterstattung haben sich auch in einem Spiegel-Artikel (s. Bibliografie unter „Mireille statt Guns N’ Roses“) eingeschlichen, wie Trabant (1995c, 175f.) aufzeigt. Dem französischen Gesetz wird mit großer Skepsis begegnet. Entsprechend heißt es: „Viele Franzosen fühlen sich durch die Strafandrohung brüskiert und durch Toubons Katalog mit 3500 Ersatzwörtern für Franglais der Lächerlichkeit preisgegeben“ („Mireille statt Guns N’ Roses“, 170).

Insbesondere die Idee, englische Bezeichnungen durch französische Termini ersetzen zu wollen, trifft in der deutschen Presse auf großen Spott. So schreibt Altwegg in der Frankfurter Allgemeinen Zeitung vom 16. April $1994 \mathrm{zu}$ den im Dictionnaire des termes officiels von 1994 veröffentlichten Terminologievorschlägen: „Einleuchtend ist kaum eines der 3500 Beispiele, die meisten sind peinlich, ja lächerlich.“ Um das Ganze noch weiter ins Lächerliche zu ziehen, geht Altwegg am Ende des Artikels auf die Belustigung ein, die die französische Gesetzgebung auch aus den eigenen Reihen erntet: So habe Mitterrand einmal einen englischen Ausdruck benutzt und kurz daraufhin gefragt, ob er nun ins Gefängnis müsse. Auch Chirac hätte sich für den Gebrauch des Wortes marketing entschuldigt, für das selbst Toubon das offizielle Ersatzwort nicht kannte und fälschlicherweise promotion gemutmaßt habe (vgl. Altwegg 1994).

Im Rheinischen Merkur vom 05. August 1994 erfährt der Leser dann endlich, wie das offizielle französische Wort zu marketing denn nun heißt, und auch sonst nimmt der Artikel den Leser nicht gerade für die französische Sprachpolitik ein: 
„Aus marketing hatte mercantique zu werden, aus airbag ein sac gonflable, aus software ein Plural namens logiciels. Frankreich reagierte auf Minister „Allgood“, wie Toubon rasch verspottet wurde, mit Witz und Wut. Ob der hot dog künftig chien chaud zu nennen sei? [...] Die meisten Franzosen reagierten gelassen: ,Das geht wie mit dem Rauchverbot.' In den Bistros qualmen weiter die höheren Orts gebannten Zigaretten. [...] Frankreich lacht über Toubon-Allgood. Demnächst, so ulken Kommentatoren, müsste Monsieur ein Wörterbuch in der Tasche haben, wenn er Beamte im Wirtschaftsministerium besuche“ (Wahl 1994, 2).

Eine dritte Phase lässt sich auf die Monate Januar bis März 2001 datieren. Die Diskussion um das französische Sprachgesetz flammt in Deutschland wieder auf, als Eckhard Werthebach, damaliger Innensenator von Berlin, Ende Januar 2001 den Vorschlag macht, auch die deutsche Sprache mittels eines Sprachgesetzes vor Anglizismen zu schützen. Werthebach erntet für seinen Vorschlag von der Presse reichlich Hohn und Kritik (vgl. Molitor 2001, 70-74).

Der Gesetzentwurf wird nicht nur in der französischen und deutschsprachigen Presse kommentiert, sondern natürlich auch in anderen europäischen Ländern. Z.B. wird in der italienischen Presse auch über den französischen Gesetzentwurf sowie über das Urteil des Verfassungsgerichtes berichtet. Der Corriere della sera berichtet am 24. Februar 1994 in neutralem Ton vom französischen Gesetzentwurf „Parigi contro l'inglese/l'inglesese. Multe a chi ne abusa“ (s. Bibliografie unter „Parigi contro l'inglese [...]"). Im Corriere della sera vom 31. Juli 1994 hingegen wird eindeutig Stellung zu dem geplanten Vorhaben bezogen. Dem Artikel ist der Triumph des Autors, dass dem Gesetzentwurf in der geplanten Form nicht zugestimmt wurde, deutlich anzumerken. So beginnt der Artikel mit dem Titel „In nome della libertà d'espressione il consiglio costituzionale sancisce il permesso di usare le parole straniere. La Francia dice, oui' all'inglese. Liberata da Bastiglia lessicale: via la legge che proibiva, weekend' et ,topless“" mit den Worten:

La grande anima di Voltaire, ieri, doveva essere idealmente piena di luce e bagliori. [...] ,Allons enfants', si dica pure gioiosamente weekend, corner, sandwich, air bag, topless e scoop. Usateli serenamente nelle conversazioni correnti, nei dialoghi cinematografici e televisivi, nelle insegne e negli spot pubblicitari. Nessun poliziotto [...] potrà affibiarvi delle multe salate $\mathrm{e}$, in casi di recidiva reiterata $\mathrm{e}$ di proteste, mandarvi addirittura in prigione per sei mesi.

Un soffio di libertà in una Francia che, democraticamente', afflige i suoi cittadini con astute e perfide misure repressive“ (Munzi 1994, 6). 


\subsection{Zusammenfassung}

Die linguistische Forschung hat sich verschiedener Methoden bedient, um die Wirksamkeit der französischen Sprachpolitik bzw. Terminologiearbeit zu evaluieren. Neben Korpusstudien, in denen die Verbreitung französischer bzw. englischer Termini in verschiedenen Textsorten wie Zeitungsartikeln, Fachzeitschriften, Lehrbüchern, Wörterbüchern etc. ermittelt wird, liegen auch einige Studien vor, denen eine oder mehrere (Experten-)Befragungen zugrunde liegen.

Die Befragungen zeigen, dass das Thema franglais Ende der 1960er und bis in die 1980er Jahre hinein in der Öffentlichkeit nicht so weite Wellen schlägt, wie es die Polemiken Étiembles u.a. nahe legen. Aus den verschiedenen Studien zum Etablierungsgrad der Neologismen in unterschiedlichen Fachbereichen geht hervor, dass viele der französischen Neologismen sich nicht haben durchsetzen können und vielfach nicht einmal bekannt sind. Dies ist sowohl in den Fachsprachen wie der Gentechnologie (vgl. Gaudin/Guespin 1993/1994), Medizin (Thoiron/Iwaz/Zaouche 1993/1994) und Informatik (vgl. Gouadec 1993/1994), als auch bei Wörtern der Allgemeinsprache der Fall (vgl. Goudaillier 1982, Fugger 1979/1980/1983a,b/1987 und Guilford 1997). Etwas positivere Ergebnisse bringt die Studie Fossats (Rouges-Martinez 1992) zur Terminologie der Fernerkundung des Luftraums: Etwa die Hälfte der getesteten französischen Neologismen kann als etabliert gelten.

Die Studien Fuggers (1979/1980/1983a,b/1987) und Gaudins (1991) weichen in ihren Ergebnissen bezüglich des Bekanntheitsgrades der Terminologieerlasse erheblich voneinander ab. Daraus lässt sich schließen, dass die Einstellung gegenüber der französischen Sprachpolitik keine Konstante ist. Sie hängt sicherlich maßgeblich von der befragten Personengruppe ab, aber auch die zeitliche Nähe bzw. der zeitliche Abstand zwischen der Befragung und der Verabschiedung der Sprachgesetze dürfte einen entscheidenden Einfluss ausüben: Fuggers Studie fand Ende der 1970er Jahre, Gaudins Studie Ende der 1980er Jahre statt. Um in diesem Bereich etwas mehr Klarheit zu gewinnen, könnte sich eine zu Beginn des neuen Jahrtausends stattfindende Umfrage, die neben der Kenntnis und dem Gebrauch offizieller Neologismen auch die Kenntnis und Akzeptanz der gegenwärtigen Sprachpolitik erfragt, als durchaus aufschlussreich erweisen.

In 4.3.2 wurden die Ergebnisse zweier Studien präsentiert, in denen die Akzeptanz der offiziellen Informatik-Terminologie ermittelt wird. Diese beiden Studien werden in einem eigenständigen Unterkapitel behandelt, weil sie sich wie die dieser Studie zugrunde liegende WWW-Befragung auf die Arbeit der InformatikKommission beziehen. Sie geben wertvolle Anhaltspunkte für die Durchführung weiterer Studien zum Wortschatz der Informatik bzw. Informatiker und ermöglichen erste Hypothesen zum Ausgang entsprechender Studien.

Einstellungen hängen, wie in 2.1 ausgeführt wurde, von vielen Variablen ab. Die Einstellungen zu Anglizismen und ihr Gebrauch werden in entscheidendem Maße durch den situativen Kontext, z.B. das berufliche Umfeld, beeinflusst. Insbesondere in Informatikerkreisen gilt es, wie die Umfrage von Le Guilly-Wallis (1991) zeigt, als geradezu laienhaft, sich des französischsprachigen Informatik-Vokabu- 
lars zu bedienen. Neben dem Einfluss durch das berufliche Umfeld spielt auch der Adressatenbezug eine große Rolle. Die Befragten sprechen sich dafür aus, dass in Lehrbüchern, aber auch in den Dokumentationen von Computerprogrammen verstärkt französische Neologismen benutzt werden. Für das Gespräch unter Fachleuten werden hingegen die englischen Termini bevorzugt.

Die geltende Sprachpolitik und die Terminologieerlasse, die ohnehin nur wenigen Personen im Einzelnen bekannt sind, haben nicht dazu geführt, dass die französischen Neologismen die Anglizismen aus dem Sprachgebrauch verdrängen konnten. Es ist daher zu vermuten, dass die Entscheidung, ob sich ein Neologismus im Sprachgebrauch durchsetzen wird, weniger von außersprachlichen Motiven wie den geltenden sprachpolitischen Vorschriften abhängt als vielmehr von Faktoren, die mit dem jeweiligen Neologismus selbst und mit der Situation verknüpft sind.

Die öffentliche Meinung zur französischen Sprachpolitik lässt sich keineswegs als einhellig bezeichnen. Während die deutschsprachige Romanistik sowie die deutschsprachige Presse sich nahezu ausnahmslos gegen die Ziele und die Wirksamkeit französischer Sprachpolitik aussprechen, gibt es unter den frankophonen Romanisten sowohl enttäuschte als auch optimistische Stimmen. Analog zur französischsprachigen Romanistik ist auch die französische Presse nicht einstimmig für oder gegen den Gesetzentwurf und das Gesetz von 1994 eingestellt. 


\section{Akzeptanzkriterien, Analyse ausgewählter Inter- net-Neologismen und Arbeitshypothesen}

Bevor die Auswertung des Fragebogens die Antwort darauf gibt, welche der sechs ausgewählten Internet-Neologismen sich de facto etabliert haben und welche nicht, wird sich dieses Kapitel der Fragestellung aus theoretischer Perspektive annehmen.

In 5.1 wird ein Überblick gegeben, welche sprachlichen und außersprachlichen Faktoren der Akzeptanz eines Neologismus förderlich und welche ihr hinderlich sind. Ferner wird deutlich gemacht, inwiefern diese akzeptanzfördernden bzw. -hemmenden Faktoren Eingang in den dieser Arbeit zugrunde liegenden WWWFragebogen gefunden haben.

In 5.2 wird zunächst das Auswahlverfahren für die zu testenden Internet-Neologismen erörtert. Dabei wird erläutert, nach welchen Kriterien die sechs Lexemgruppen aus der insgesamt 53 Einträge umfassenden Terminologieliste vom 16. März 1999 ausgewählt wurden. In einem zweiten Schritt werden die ausgewählten französischen Neologismen nach dem von Braselmann (1999a) entworfenen Wortbildungsschema für Ersatzwörter analysiert und kommentiert. Anschließend werden anhand der in 5.1 vorgestellten akzeptanzfördernden bzw. -hemmenden Kriterien Prognosen zur Akzeptanz der ausgewählten französischen Neologismen formuliert.

5.3 schließlich nennt die Arbeitshypothesen, auf die sich die WWW-Befragung stützt und die insbesondere aus den Kapiteln 2, 4 sowie aus 5.1 abgeleitet werden. 


\subsection{Kriterien der Akzeptanz}

Hypothesen, welche Faktoren die Akzeptanz von Neologismen begünstigen, wurden schon vor der Publikation von Helfrichs Arbeit (1993) oder der Publikation der fünf im Auftrag der DGLF durchgeführten Einzelstudien (vgl. Depecker 1997a; 4.3) formuliert. Nachdem die Arbeit der Terminologiekommissionen, welche bereits seit Anfang der 1970er Jahre die Wortlisten erarbeiten (vgl. 3.2.2), mit der Verabschiedung der Loi Bas-Lauriol im Rahmen eines Gesetzes legitimiert und ihre Vorschläge für bestimmte Bevölkerungsgruppen sowie für die Industrie bindend wurden, machten sich einige Linguisten unverzüglich daran, die Bekanntheit und Akzeptanz dieser offiziellen Maßnahmen zu evaluieren. Die bekanntesten Studien stammen von Fugger (1979) und Goudaillier (1977/1982). Sie wurden bereits in 4.3.1 vorgestellt. Aus den Ergebnissen dieser und anderer empirischer Studien wurden Faktoren abgeleitet, welche die Akzeptanz begünstigen bzw. behindern.

Bécherel nennt bereits 1981 mit Bezug auf die Ergebnisse Cartiers (1977), Goudailliers (1977) und Fuggers (1979 et al.) die folgenden akzeptanzbegünstigenden Merkmale für offizielle Neologismen:

1. größte morphologische Ähnlichkeit mit dem Fremdwort (Bsp.: conteneur anstelle von container),

2. verständnisfördernde Ersetzungen (Bsp.: bilan de santé anstelle von check up) und

3. Ersetzungen zur Vermeidung einer vor allem für Laien komplizierten Aussprache (Bsp.: ingénierie anstelle von engineering, billeterie anstelle von ticketing) (vgl. Bécherel 1981, 129f.).

Demgegenüber gibt es auch Faktoren, die die Akzeptanz eines Lehnwortes begünstigen, wie

1. Kürze (insbesondere die Einsilbigkeit bei Anglizismen) (Bsp.: engl. spot anstelle von franz. message publicitaire),

2. inhaltlich fragwürdige Übersetzung (Bsp.: franz. animateur für engl. disc jockey ${ }^{1}$ ) und

3. Gewöhnung an das Fremdwort (vgl. Bécherel 1981, 130).

Der dritte Faktor ist für Bécherel $(1981,130)$ am gewichtigsten, da der Faktor Gewöhnung das Sprachverhalten weitaus mehr beeinflusse als beispielsweise die sprachliche Form des Ersatzwortes.

\footnotetext{
${ }^{1}$ Im Petit Robert $(2000,95)$ werden mehrere Definitionen für animateur, -trice gegeben: Unter I gibt es zwei Definitionen: „1. Qui anime, insuffle la vie. [...] 2. Personne qui anime une collectivité par son ardeur et son allant." Unter II werden drei Definitionen gegeben, deren erste sich auf das französische Pendant zum engl. disc jockey bezieht: „1. Personne qui présente et commente un spectacle (music-hall) ou une émission (radio, télévision)." Des Weiteren wird vermerkt, dass es sich um die offizielle Empfehlung handelt. Demgegenüber wird disc jockey im Webster's $(2001,223)$ wie folgt definiert: „one who selects and plays recordings on a radio program or at a discotheque“. Beim Vergleich beider Definitionen ist offenkundig, dass das englische disc jockey semantisch wesentlich enger gefasst ist als das französische animateur, -trice, da es nur eine der Bedeutungen des französischen Terminus hat.
} 
Hagège $(1987,133)$ hält die Verwendung des Fremdwortes in den folgenden drei Fällen für sehr wahrscheinlich:

1. bei einer breiten Verteilung des Fremdwortes in der Masse der Benutzer,

2. wenn die Form des Wortes den artikulatorischen und akustischen Gewohnheiten der Zielsprache nicht zu sehr entgegengehe ${ }^{2}$ und

3. wenn der Sinn des Wortes auf ein Bezeichnungsbedürfnis eingehe und dieses beantworte (d.h. die bezeichnete Sache durfte vorher noch keine Bezeichnung haben).

Natürlich lassen sich noch weitere Gründe nennen, die bestimmte Sprecher dazu bewegen, anstelle eines bereits existierenden und verbreiteten muttersprachlichen Wortes ein Fremdwort zu benutzen, wie z.B. das Bedürfnis, sich besonders international geben zu wollen („Imponiergehabe“), oder der Wunsch, der Rede ein bestimmtes Lokalkolorit zu verleihen (vgl. dazu ausführlich Pfitzner 1978). Lagueux $(1988,95)$ bezieht sich auf die Jugendlichen Frankreichs und Québecs und begründet ihren Anglizismengebrauch mit ihrer Schwärmerei für die USA. Für die Jugend sei das Englische weitaus mehr Ausdruck einer freizügigen als einer repressiven Kultur. Aber auch Lagueux (ebd., 96) nennt als Motiv Snobismus. Die von Pfitzner und Lagueux in diesem Kontext genannten Motive für den Gebrauch von Fremdwörtern treffen auf die Verwendung von Anglizismen in der Alltagssprache zu.

Anders verhält es sich aber in den Fachsprachen. In den Fachsprachen und hier beispielhaft im Bereich der neuen Technologien wie Internet lassen sich hinter der Verwendung von Anglizismen jedoch andere Motive als Imponiergehabe, Snobismus, der Wunsch nach Lokalkolorit oder die Bewunderung für die USA und ihre Kultur vermuten.

Das Internet ist zu großen Teilen in Amerika entwickelt worden ${ }^{3}$. Dort wurden mit der technischen Innovation auch die entsprechenden Fachtermini geprägt. Mit der wachsenden Vernetzung und steigenden Anzahl an Internetanschlüssen in den verschiedenen Industrienationen gelangen die Internet-Termini zunächst als Angloamerikanismen in nahezu alle Sprachen der technisch hochentwickelten Länder und finden dort vorübergehend oder dauerhaft als Fremdwörter Eingang. Einige Termini werden im Laufe der Zeit durch autochthone Bildungen ersetzt, andere Termini verbleiben als Internationalismen in der jeweiligen Sprache. Der ursprünglich englische Terminus wird von den Sprechern in der Regel als die präziseste, eindeutigste Bezeichnung empfunden (vgl. Lagueux 1988, 94). Mit der jährlich wachsenden Zahl an Internet-Nutzern wächst auch die Verbreitung der entsprechenden Fachterminologie. Das Internet wird Mitte der 1990er Jahre zu einem Massenmedium in allen industrialisierten Ländern. Konzepte aus der

\footnotetext{
2 Dieses Kriterium ähnelt dem 3. Punkt von Bécherel (s.o.).

3 Der Teil des Internet, den wir als das World Wide Web bezeichnen und der mit http- bzw. httpsProtokolle funktioniert, wurde 1992 in der Schweiz entwickelt (vgl. Glossar).
} 
(Fach-)Sprache des Internet wie e-mail, homepage, World Wide Web, chat und cracker ${ }^{4}$ kennt inzwischen (fast) jeder, der sich mit diesem Medium und somit auch mit seiner spezifischen Terminologie auseinandersetzt, sei es nun in Form der Anglizismen bzw. Internationalismen oder in Form nationaler Äquivalente. Aufgrund der Popularisierung des Mediums, das anfänglich fast ausschließlich im universitären Kontext genutzt wurde, sind auch die mit dem Internet verbunden Termini von der Fach- in die Alltagssprache übergegangen. Daher ist die Sprache des Internet heute keine Fachsprache im streng definierten Sinne mehr ${ }^{5}$.

Doch nun zurück zur Situation in Frankreich, Belgien und der Schweiz. In Frankreich hat das Internet bereits einen breiten Nutzerkreis, als die amerikanische Terminologie auf staatlichem Weg französisiert wird. Zunächst wird nur ein einziger Terminus, der Anglizismus e-mail, von der Commission générale ersetzt. Für e-mail werden die französischen Äquivalente message électronique, messagerie électronique und courrier électronique vorgeschlagen (vgl. DGLF 1997, o.S.). Nach mehr als einjähriger Pause erscheint dann eine ausführliche Terminologieliste zum Internet-Vokabular (März 1999), der im September 2000 und im Dezember 2002 zwei weitere, recht kurze Listen folgen. Analoge Entwicklungen vollziehen sich, mit einiger Verzögerung, im frankophonen Belgien und der Schweiz (vgl. 3.3.1 und 3.3.2).

Inwieweit aber ist es wahrscheinlich, dass sich die französischsprachigen Neologismen durchsetzen werden, oder, differenzierter gefragt: Bei welchen Neologismen ist die Wahrscheinlichkeit groß, dass sie von der frankophonen InternetNutzerschaft akzeptiert werden, und welche werden sich möglicherweise nicht etablieren können? Um diese Frage beantworten zu können, ist es zunächst notwendig, alle akzeptanzbegünstigenden bzw. -hemmenden Faktoren aufzulisten. In einem zweiten Schritt muss dann von Fall zu Fall entschieden werden, welche der Kriterien auf bestimmte Termini zutreffen und welche nicht.

Ganz offensichtlich wirkt sich die relativ späte Publikation der Terminologielisten hemmend auf die Akzeptanz der französischen Neologismen aus (Faktor Gewöhnung, vgl. Bécherel 1981, 130; Beinke 1995, 84; Braselmann 1999a, 24). Diese Problematik wird von vielen Linguisten angesprochen, erstmals von Bengtsson (1968, 197). Bislang fehlt jedoch eine empirische Überprüfung dieser (logischen) Annahme. In Bezug auf die Internet-Terminologie ist es somit fraglich, ob sich ein

\footnotetext{
${ }^{4}$ Neben cracker existiert der sehr ähnliche Terminus backer. Beide Wörter sind sich zwar phonetisch und semantisch ähnlich, dürfen aber nicht verwechselt werden. Sie werden entsprechend auch durch unterschiedliche französische Termini ersetzt: cracker - pirate, hacker - fouineur. Cracker bezeichnet jemanden, ,[...] der unbefugt in Computersysteme wie Internet-Server [...] oder Bankenrechner eindringt und dort Änderungen am Programmcode vornimmt. [...] Im Gegensatz zu Hackern (hacker) handeln Cracker in der Regel eigennützig oder gegen Bezahlung im Auftrag“ (Networds, 1997-2002, o.S.). Im Unterschied dazu wird als Hacker bezeichnet: „Computer-Enthusiast, der sein Können und Wissen u. a. dazu nutzt, unbefugt in geschlossene Computersysteme einzudringen. [...] Hacker selbst grenzen sich betont von so genannten ,Cybervandalen' und ,Crackern' [...] ab [...]“ (ebd.).

${ }^{5}$ Eine sehr präzise Definition von Fachsprache gibt Figge (1989, 302): „Sie [die Fachsprache] ist eine Varietät einer Standardsprache, besteht aus einer spezifischen Menge häufig normierter lexikalischer Elemente und einer spezifischen Menge (morphologisch-)syntaktischer Regeln, wird von Individuen gekonnt, die auf einem spezifischen Gebiet Fachleute sind, und dient der Manifestation von Fachwissen über dieses Gebiet zum Zwecke der Kommunikation unter diesen Fachleuten.“
} 
frankophoner Internet-Nutzer, der sich seit Mitte der 1990er Jahre im Internet bewegt, aufgrund dieser offiziellen Erlasse umgewöhnen wird, wenn er nicht schon vorher automatisch ein bzw. zufällig genau das vorgeschriebene französische Wort benutzt hat. Dass sich die Commission générale sehr wohl dessen bewusst ist, dass gerade im Bereich der Internet-Terminologie schnelles Handeln hinsichtlich der Schaffung und Verbreitung französischer Internet-Neologismen unabdingbar ist, zeigt folgende Äußerung ihres Präsidenten:

„Le besoin terminologique s'évalue aussi dans le temps en termes d'urgence. Les notions nouvelles apparaissent vite et les termes pour les désigner là où elles naissent, immédiatement.

Ce fut le cas de l'informatique. C'est aujourd'hui le cas de l'internet. On assiste à une course de vitesse entre la diffusion des termes américains et l'adoption d'un terme français, sa diffusion et son usage.

[...] La course de vitesse est rarement gagnée. Mais on peut réduire le retard entre l'apparition de réalités nouvelles et leur désignation approuvée en français grâce à une veille terminologique “ (de Broglie 2001, o.S.).

Welche weiteren Kriterien können der Akzeptanz hinderlich sein?

Braselmann (1999a, 113) teilt die Kriterien, die ihrer Meinung nach für die Akzeptanz von Neologismen ausschlaggebend seien, in drei Gruppen ein:

1. die Art und Weise der Bildungen,

2. die Bedingungen der Akzeptanz und

3. ihre Verbreitung.

Diese drei Kriterien können nicht unabhängig voneinander gesehen werden. Helfrich (1993, 289f.) kommt in ihrer Studie zu dem Ergebnis, dass der Bildungstyp für die Akzeptanz der Ersatzwörter weniger relevant ist als rezeptive Faktoren wie Gebräuchlichkeit, Einfachheit und Benutzbarkeit.

Aufgrund einiger Studien (Ahlers/Holtus 1999, Chansou 1993, Gaudin/Guespin 1993, Gouadec 1993, Helfrich 1993, Le Guilly-Wallis 1991, Rouges-Martinez 1992, Thoiron/Iwaz/Zaouche 1993) gibt es bereits erste Anhaltspunkte dafür, unter welchen Umständen ein Ersatzwort gute Chancen hat, akzeptiert zu werden und sich somit im Wortschatz zu etablieren. Nach Ansicht von Ahlers/Holtus (1999, 308) werden folgende Faktoren für die Durchsetzung der Ersatzwörter gegenüber den Anglizismen als günstig angesehen:

1. Ersatzwörter, die kürzer als die unerwünschten Anglizismen sind,

2. Ersatzwörter, die den gleichen Wortstamm wie die entsprechenden Anglizismen, jedoch die französischen Derivationsmorpheme besitzen,

3. metaphorischer Charakter der Ersatzwörter,

4. Kürze und Nähe zum Vorbild und

5. offizielle Bestätigung der Ersatzwörter. 
Depecker (1997a) hat aus den fünf in seinem Buch versammelten Einzelstudien eine Reihe von Faktoren zusammengestellt, welche die Akzeptanz von Neologismen begünstigen können. Er stellt sie in seiner Einleitung vor:

die (semantische) Motiviertheit des französischen Terminus, die Möglichkeit der Paradigmenbildung ${ }^{6}$,

die exakte Abdeckung des gemeinten Konzepts durch die französische Bezeichnung ${ }^{7}$,

die Einfachheit und Eingängigkeit des französischen Terminus ${ }^{8}$,

die Transparenz der Bezeichnungen (gilt für Zusammensetzungen/Komposita),

die Kürze des französischen Terminus,

- $\quad$ die phonetische und grafische Nähe des französischen Terminus zum englischen Vorbild (Bsp.: franz. moniteur für engl. monitor),

übereinstimmende Konnotationen und

Termini ohne englischsprachigen Konkurrenten (Bsp.: franz. coloscope) (vgl. Depecker 1997a, XXIV-XXVI).

Diese recht umfangreiche Liste zeigt bereits, welche Fortschritte die Forschung in den Jahren zwischen 1981 (Bécherel) und 1997 (Depecker) gemacht hat. Während Bécherel (1981) nur drei akzeptanzbegünstigende Faktoren nennt, sind es bei Depecker (1997a) bereits neun Kriterien. Es folgt nun eine Zusammenstellung der akzeptanzbegünstigenden Faktoren nach der von Braselmann (1999a, 113) vorgeschlagenen Dreiteilung. In diese Liste fließen die von Ahlers/Holtus (1999), Bécherel (1981), Depecker (1997a) und Hagège (1987) genannten Kriterien sowie ein eigener Vorschlag ein:

Art und Weise der Bildungen

(Semantische) Motiviertheit,

Möglichkeit der Paradigmenbildung,

exakte Abdeckung des gemeinten Konzepts,

Einfachheit und Eingängigkeit,

Transparenz (gilt für Zusammensetzungen/Komposita),

Kürze,

\footnotetext{
6 Als Beispiel für Paradigmenbildung nennt Depecker (1997a, XXIV) ,parrain/parraineur/parrainage/parrainer".

${ }^{7}$ Es ist ein generelles Problem bei Ersatzwortvorschlägen, dass der Anglizismus und das entsprechende Ersatzwort nicht synonym sind. Sie sind es oftmals hinsichtlich des Konzeptes, nicht aber bezüglich der Assoziationen und Konnotationen. Ein extremes Beispiel für die mangelnde Übereinstimmung der Konzepte ist das offizielle französische Ersatzwort animateur, welches das engl. discjockey ersetzen soll (vgl. Fußnote 1).

${ }^{8}$ Bande vidéo promotionnelle ist zwar semantisch motiviert, aber nicht so leicht und eingängig wie die englische Bezeichnung clip (vgl. Depecker 1997a, XXIV).
} 
phonetische und grafische Nähe zum angloamerikanischen Vorbild (z.B. identischer Wortstamm mit entsprechendem Anglizismus, aber französische Derivationsmorpheme $)^{9}$ und metaphorischer Charakter.

\section{Bedingungen der Akezeptanz.}

(Semantische) Motiviertheit,

Fehlen eines englischsprachigen Konkurrenten ${ }^{10}$,

Füllen eines Bezeichnungsbedürfnisses (der Neologismus darf vorher noch keine (französische) Bezeichnung haben) ${ }^{11}$,

Fehlen von französischsprachigen Konkurrenten ${ }^{12}$, übereinstimmende Konnotationen und

einfachere Aussprache im Vergleich zum angloamerikanischen Ursprungswort.

\section{Verbreitung}

Offizielle Bestätigung der Ersatzwörter und

breite Verteilung der Ersatzwörter in der Masse der Benutzer.

Dieses dreigeteilte Schema wird in modifizierter Form in den Fragebogen einflieBen. In denjenigen Fällen, in denen die Informanten den Anglizismus dem französischen Neologismus vorziehen, wird nach den konkreten Gründen gefragt. Dabei werden die Kriterien aus dem obenstehenden Schema zur Auswahl gestellt, ohne dass sich jedoch die Dreiteilung im Fragebogen niederschlägt. Für den jeweiligen Informanten sollte es mit einigem Nachdenken möglich sein anzugeben, aus welchem der genannten Gründe er lieber den Anglizismus benutzt. Er wird aber als Nicht-Linguist kaum in der Lage sein, zwischen morphologischen und anderen akzeptanzfördernden Faktoren zu trennen.

Die verschiedenen oben aufgeführten kontextunabhängigen Variablen ermöglichen es, Prognosen zu treffen, ob ein Ersatzwort reelle Chancen hat, sich gegenüber dem Anglizismus durchzusetzen oder nicht. Neben der Anwendung dieser Kriterien auf die zu analysierenden Termini bleibt jedoch zu bedenken, dass Spra-

\footnotetext{
${ }^{9}$ Dieser Punkt entspricht, um die Schreibgewohnheiten erweitert, dem Kriterium Hagèges, dass die Form des Wortes den artikulatorischen und akustischen Gewohnheiten der Zielsprache nicht zu sehr entgegengehen dürfe (s.o.).

${ }^{10}$ Im Falle der französischen Neologismen, die zur Ersetzung der vorwiegend englischsprachigen Termini geschaffen werden, existiert immer ein - meist englischsprachiger - Konkurrent.

11 Dieser Punkt ist besonders problematisch. Oft haben sich zu einem Anglizismus im Laufe der Jahre mehrere französische Entsprechungen gebildet, bevor dann, Jahre später, eine Bezeichnung von der entsprechenden Terminologiekommission festgesetzt wird. Wenn diese Kommission wie z.B. im Fall der Ersetzung von e-mail mehrere französischsprachige Äquivalente vorschlagen, wird es für den Sprachbenutzer besonders verwirrend.

12 Erstaunlicherweise wird dieses Kriterium in der Literatur nicht genannt. Das Phänomen, dass für einen Anglizismus mehrere französische Ersatzwörter geschaffen wurden, tritt bei der frankokanadischen Terminologie besonders deutlich zu Tage: Für einen Anglizismus werden mitunter bis zu sechs französische Äquivalente vorgeschlagen (vgl. Kap. 3, Abb. 4).
} 
che niemals isoliert verwendet wird, sondern immer in einem situativen Kontext steht. Sprachliches Handeln steht immer auch im Zusammenhang mit der Situation (z.B. formeller Anlass oder informelles Gespräch), mit dem Medium (schriftlicher oder mündlicher Sprachgebrauch), mit dem Sprecher und dessen persönlichen Merkmalen (Alter, Geschlecht, Bildungsstand, Fremdsprachenkenntnisse etc.) und Intentionen sowie mit seinem bzw. seinen Adressaten (persönliche Merkmale des bzw. der Adressaten) ${ }^{13}$. Was in 2.1 bezüglich der Einstellungen ausgeführt wurde - Abhängigkeit von persönlichen, interpersonalen und situativen Faktoren - gilt selbstverständlich für jede Form sprachlichen Handelns.

Des Weiteren fällt die Existenz einer offenkundigen Diskrepanz zwischen der Produktion und der Diffusion von Neologismen auf, d.h. die Produktionsrate ist höher als die Aufnahmerate. Gründe dafür sind der begrenzte lexikalische Aufnahmebedarf in der Sprachgemeinschaft und die begrenzte Erinnerbarkeit der Teilnehmer der Sprachgemeinschaft. Letztendlich reguliert der Sprachgebrauch den Markt, und somit sind bei der Durchsetzung von Neologismen die Einstellungen der Sprecher von entscheidender Bedeutung (vgl. Helfrich 1993, 292). Wenn das Ersatzwort beispielsweise der Norm entspricht, der Anglizismus aber verbreiteter ist und die betreffende Person zudem glaubt, bei der Verwendung eines französischen Neologismus als weniger kompetent zu gelten (vgl. Le GuillyWallis 1991; 4.3.2), ist es äußerst unwahrscheinlich, dass sich das französische Wort durchsetzt. In diesem Fall determinieren die persönlichen Einstellungen der Sprachbenutzer die Akzeptanz bzw. Ablehnung bestimmter Termini.

\subsection{Auswahl und Analyse der sechs Internet-Neologismen für den WWW-Fragebogen}

Die Liste zur französischen Internet-Terminologie vom 16. März 1999 umfasst insgesamt 53 Ersatzwörter und ihre englischsprachigen Äquivalente (vgl. DGLF 1999, o.S.). Nachfolgend ist sie in leicht veränderter Form abgedruckt. Es fehlt die mittlere Spalte, in der die Zuordnung zu einem Wortfeld (Informatik, Internet, Telekommunikation) angegeben ist. Dafür wurde eine weitere Spalte hinzugefügt, in der jeder Lexemgruppe nach einem eigens dafür konzipierten und in 5.2.1 erläuterten Prinzip eine Kategorie zugeordnet wurde:

\footnotetext{
13 Soll dem Adressaten z.B. ein bestimmtes Vokabular vermittelt werden (Lehrbuchsprache), wird i.d.R. das französische Vokabular verwendet. Soll aber der Adressat gar nicht in den Verstehensprozess einbezogen werden, kann er durch die gezielte Verwendung von Fremdwörtern aus der Kommunikation ausgeschlossen werden.
} 
Abb. 6: Die offizielle Terminologieliste zum Vokabular des Internet vom 16. März 1999

\begin{tabular}{|c|c|c|}
\hline Terme étranger & Équivalent français & Kategorie \\
\hline access provider & fournisseur d'accès & Fragebogen \\
\hline applet & appliquette $n . f$. & 8 \\
\hline $\begin{array}{l}\text { asymetric (bit rate) di- } \\
\text { gital subscriber line } \\
\text { (ADSL) }\end{array}$ & $\begin{array}{l}\text { raccordement numérique asymétri- } \\
\text { que, RNA, liaison numérique à débit } \\
\text { asymétrique }\end{array}$ & 1 \\
\hline backbone & dorsale n. f. & 4 \\
\hline bookmark & signet $\mathrm{n} . \mathrm{m}$. & 4 \\
\hline browser & $\begin{array}{l}\text { logiciel de navigation, navigateur } n \text {. } \\
\mathrm{m} \text {. }\end{array}$ & Fragebogen \\
\hline chat & causette n. f., fam. & Fragebogen \\
\hline cookie & $\begin{array}{l}\text { témoin (de connexion), mouchard n. } \\
\text { m. }\end{array}$ & 8 \\
\hline cracker & pirate n. m. & Fragebogen \\
\hline cybernaut & internaute $\mathrm{n}$. & 8 \\
\hline $\begin{array}{l}\text { Digital Versatile Disk } \\
\text { (DVD) }\end{array}$ & disque numérique polyvalent & 1,3 \\
\hline domain & domaine n. m. & 6 \\
\hline $\begin{array}{l}\text { domain name system } \\
\text { (DNS) }\end{array}$ & $\begin{array}{l}\text { système d'adressage par domaines, } \\
\text { annuaire des domaines }\end{array}$ & 1 \\
\hline drag and drop & glisser-déposer n. m. & 8 \\
\hline emoticon & frimousse n. f. fam. & 8 \\
\hline Extranet & extranet n. f. & 5 \\
\hline firewall & barrière de sécurité, pare-feu n. m. & 8 \\
\hline frame & cadre n. m. & 4 \\
\hline $\begin{array}{l}\text { frequently asked } \\
\text { questions (file) (FAQ) }\end{array}$ & $\begin{array}{l}\text { foire aux questions, FAQ, fichier des } \\
\text { questions courantes, questions cou- } \\
\text { rantes }\end{array}$ & 1 \\
\hline gateway & passerelle n. f. & 4 \\
\hline hacker & fouineur $\mathrm{n} . \mathrm{m}$. & 8 \\
\hline hotlist & liste de signets & 7 \\
\hline homepage & page d'accueil & Fragebogen \\
\hline hub & concentrateur n. m. & 7 \\
\hline hypertext & hypertexte n. m., hypertextuel adj. & 6 \\
\hline Infobahn (all.) & autoroutes de l'information & $2+$ Germanismus \\
\hline information highway & autoroutes de l'information & 8 \\
\hline $\begin{array}{l}\text { information super- } \\
\text { highway }\end{array}$ & autoroutes de l'information & 2 \\
\hline $\begin{array}{l}\text { Internet network, } \\
\text { Internet }\end{array}$ & internet n. m. sg. & 5 \\
\hline
\end{tabular}




\begin{tabular}{|c|c|c|}
\hline intranet & intranet $\mathrm{n} . \mathrm{m}$. & 5 \\
\hline middleware & logiciel médiateur & 3 \\
\hline Net & internet n. m. sg. & keine Kategorie ${ }^{14}$ \\
\hline netcasting & $\begin{array}{l}\text { diffusion systématique sur la toile, } \\
\text { diffusion réticulaire systématique, } \\
\text { diffusion sur la toile, diffusion réti- } \\
\text { culaire }\end{array}$ & 7 \\
\hline newsgroup & forum n. m. & 8 \\
\hline news article & article de forum, contribution $\mathrm{n} . \mathrm{f}$. & 2 \\
\hline news item & article de forum, contribution n. f. & 2 \\
\hline news posting & article de forum, contribution n. $\mathrm{f}$. & 2 \\
\hline on-line data service & serveur n. m. & 3 \\
\hline plug-in & module d'extension & 7 \\
\hline proxy server, proxy & serveur mandataire, mandataire n. m. & 8 \\
\hline pull technology & recherche individuelle & 8 \\
\hline push technology & $\begin{array}{l}\text { distribution sélective, diffusion sélec- } \\
\text { tive, distribution personnalisée }\end{array}$ & 8 \\
\hline server & serveur n. m. & 6 \\
\hline smiley & frimousse n. f. fam. & 8 \\
\hline thread & fil (de la discussion) & 4 \\
\hline $\begin{array}{l}\text { uniform resource } \\
\text { locator (URL) }\end{array}$ & adresse universelle, adresse réticulaire & 1 \\
\hline $\begin{array}{l}\text { universal resource } \\
\text { locator (URL) }\end{array}$ & adresse universelle, adresse réticulaire & 1 \\
\hline viewer & visionneur $\mathrm{n} . \mathrm{m}$. & 8 \\
\hline webcasting & $\begin{array}{l}\text { diffusion systématique sur la toile, } \\
\text { diffusion réticulaire systématique, } \\
\text { diffusion sur la toile, diffusion réti- } \\
\text { culaire }\end{array}$ & 7 \\
\hline webmaster & administrateur de site, de serveur & 7 \\
\hline webpage, web page & page sur la toile & 7 \\
\hline website, web site & site (de la toile, sur la toile) & 6 \\
\hline window & fenêtre n. f. & 4 \\
\hline World Wide Web & $\begin{array}{l}\text { toile d'araignée mondiale, toile mon- } \\
\text { diale, toile n. f. sg., T.A.M. }\end{array}$ & Fragebogen \\
\hline
\end{tabular}

Im Rahmen einer Umfrage ist es nicht möglich, alle 53 Lexemgruppen zu testen, da es die Geduld der Informanten überstrapazieren würde, wenn sie zu jedem der 53 Wortpaare mehrere Fragen beantworten müssten. Zudem gibt es für viele der in der französischen Terminologie-Liste enthaltenen Termini keinen belgischen oder schweizerischen Terminologievorschlag. Deshalb sollen Termini ausgewählt

\footnotetext{
${ }^{14}$ Mit Net liegt zwar auch ein Kurzwort vor, aber es fällt nicht unter die Kategorie der Akronyme, da es nicht aus Initialen gebildet ist. Bei Net handelt es um die Kurzform (Rumpfwort) zu internet.
} 
werden, von denen anzunehmen ist, dass sie als Anglizismus oder französischer Neologismus mittlerweile Bestandteil der Allgemeinsprache sind (vgl. die Konzeption der Studien Goudailliers 1982 und Chansous 1993 in 4.3.1). Damit der Fragebogen nicht zu umfangreich wird, sollen nur sechs der insgesamt 53 Lexemgruppen der Liste ausgewählt werden. Die Anzahl der Lexemgruppen wurde deswegen auf sechs - und nicht etwa auf zehn oder acht - reduziert, weil die Bearbeitungszeit des Fragebogens bei sechs Lexemgruppen ca. 20 Minuten beträgt, was m.E. die zeitliche Obergrenze für eine freiwillige und unbezahlte Befragung ist, die einen möglichst hohen Rücklauf erzielen soll. In einer früheren Version des Fragebogens erschienen noch acht Lexemgruppen, allerdings war die Bearbeitungsdauer auf diese Weise zu lang.

Das Auswahlverfahren erfolgt in zwei Stufen: Eine erste Selektion wird von linguistischen Kriterien geleitet, da bei bestimmten Ersatzwörtern eine Akzeptanz so wahrscheinlich ist, dass eine Überprüfung dieser Ausdrücke überflüssig wird (s.u.). Die zweite Auswahl, die ohne weitere Studien nicht vorgenommen werden kann, betrifft den Bekanntheitsgrad der nach der ersten Selektion verbleibenden Termini. Aus linguistischer Sicht ist die Beantwortung der Frage problematisch, welche der in der Liste aufgenommenen Anglizismen nebst Ersatzwörtern (z.B. engl. chat und franz. causette, engl. (access) provider und franz. fournisseur d'accès) den potenziellen Informanten überhaupt geläufig sind. Zwei Möglichkeiten bieten sich an, um zu ermitteln, welche Anglizismen bzw. französischen Neologismen französische, belgische und schweizerische Informanten aktiv verwenden oder zumindest kennen ${ }^{15}$. Zum einen wäre eine Korpusanalyse denkbar, in der Zeitschriften, Zeitungen oder andere Texte ausgewertet werden bezüglich der in ihnen enthaltenen Termini. Zum anderen könnte eine Befragung mit möglichst vielen Franzosen, Belgiern und Schweizern durchgeführt werden, in der ihnen sämtliche englische und französische Internet-Termini vorgelegt werden und sie die ihnen bekannten Termini angeben sollen. Beide Verfahren sind nicht nur sehr aufwändig, sondern haben auch je einen schwerwiegenden Nachteil. Bei einer Korpusanalyse mit einem umfangreichen Korpus lassen sich meist alle Termini nachweisen (vgl. Chansou 1993, Gouadec 1993; 4.3), was im Hinblick auf ein durchzuführendes Auswahlverfahren nicht besonders hilfreich ist. Bei einer Befragung frankophoner Sprecher besteht die, wenn auch sehr geringe Gefahr, dass möglicherweise die gleichen Leute an der ersten und an der zweiten Befragung teilnehmen. Dies sollte bei empirischen Studien zum gleichen Thema unbedingt vermieden werden, da in der sozialwissenschaftlichen Methodenforschung davon ausgegangen wird, dass die Teilnahme an der ersten Umfrage den Informanten im Hin-

\footnotetext{
15 Es geht in diesem Fall weniger um die Kenntnis der einzelsprachlichen Bezeichnungen als vielmehr um die dahinter stehenden Konzepte. Unabhängig davon, ob jemand, der ein Mailprogramm benutzt, dazu engl. e-mail, dt. E-Post oder franz. message, messagerie bzw. courrier électronique sagt, kennt er das hinter dem entsprechenden Terminus stehende Konzept.
} 
blick auf seine Antworten in einer weiteren Umfrage zum gleichen Thema beeinflusst ${ }^{16}$.

Um herauszufinden, welche Internet-Termini von einem breiten Informantenkreis als am bekanntesten eingeschätzt werden, ohne damit allerdings der späteren Studie mit einem frankophonen Fachpublikum vorauszugreifen, wurde im Frühjahr 2001 eine entsprechende Studie mit Informanten im deutschsprachigen Raum durchgeführt (vgl. Molitor 2001/2002). Hierauf wird in 5.2.2 zurückzukommen sein. Zunächst erfolgt die erste Eingrenzung der Lexemgruppen aufgrund formaler Kriterien.

\subsubsection{Selektion aufgrund formaler Kriterien}

Zunächst fallen drei Gruppen von Termini aus der engeren Auswahl heraus: 1. Akronyme, 2. Unterbegriffe zu anderen, in der Liste enthaltenen Termini und 3. Termini, die in der offiziellen Terminologieliste dem Wortfeld Informatik zugeordnet werden.

\section{Kategorie 1: Akronyme}

Bei Akronymen werden zwei grundlegende Fälle und ein Spezialfall unterschieden: 1. die amerikanischen Akronyme werden beibehalten und nur auf der Ebene der Aussprache französisiert, Bsp.: ASCII, CD, CD-ROM, DVD, GSM, HTML, $L A N$, URL, PC, BASIC und andere Namen von Programmiersprachen.

2. die Akronyme werden aus französischen Termini gebildet, Bsp.: franz. DOC als Akronym zu disque optique compact (für engl. CD-ROM) oder franz. SID $A$ für engl. $A I D S$. Der zweite Fall tritt seltener auf und ist bezüglich seiner Etablierung tendenziell nicht so erfolgreich wie der erste: $D O C$ konnte sich gegen $C D-R O M$ nicht durchsetzen, SID $A$ gegen AIDS hingegen schon.

Neben diesen beiden Fällen existiert noch eine weitere Form der Französisierung: Das angloamerikanische Akronym wird beibehalten, der Gesamtwortlaut jedoch französisiert. Ein Beispiel ist die unterschiedliche Vollform des im englisch- und französischsprachigen Raum geltenden FAQ, das im anglophonen Sprachraum durch frequently asked questions und im frankophonen Sprachraum durch foire aux questions bzw. forum aux questions wiedergegeben wird (vgl. Bauer 1990, 38f.; Otman $2000,387)^{17}$.

\footnotetext{
${ }^{16}$ In der Literatur zur empirischen Sozialforschung wird stets darauf hingewiesen, dass diejenigen Informanten, die am Pretest teilgenommen haben, für die definitive Studie als Informanten ausfallen müssen, um ein verlässliches Untersuchungsergebnis zu erhalten (vgl. 7.2.1).

17 De Schaetzen $(1993,35)$ weist darauf hin, dass die fremdsprachigen Akronyme üblicherweise leichter zu memorieren seien als ihre Übersetzungen. Humbley $(2000,326)$ zeigt am Beispiel der Kommission zum Transportwesen, dass üblicherweise versucht werde, das englische Akronym beizubehalten. Unter Beibehaltung der ursprünglichen Initialen werde dann versucht für die englischen Akronyme eine französische Bezeichnung zu schaffen, da die Erfahrung gezeigt habe, dass ins Französische übertragene Akronyme oftmals nicht akzeptiert werden. Beispielsweise habe sich AGETAC (Accord général sur les tarifs douaniers et le commerce) nicht gegenüber dem englischen Akronym GATT durchsetzen können. Âhnliches dürfte für T.A.M. (toile d'araignée mondiale) gelten, während $F A Q$ als englisches Akronym mit französischer Vollform als eine erfolgversprechende Lösung betrachtet werden kann.
} 
Unabhängig ihres Bildungstyps sind Akronyme nur sehr schwer im Hinblick auf ihre Akzeptanz zu überprüfen, da sie sich den gängigen in 5.1 genannten Kriterien entziehen. Hinzu kommt, dass die französischen Ersatzwörter im Fragebogen mit Hilfe des semantischen Differentials (vgl. 7.1.2.1) im Hinblick auf verschiedene, z.B. ästhetische Kriterien beurteilt werden sollen, was sich für Akronyme kaum als praktikabel erweist ${ }^{18}$.

Die Terminologieliste zum Internet-Vokabular vom 16. März 1999 enthält die folgenden Akronyme:

engl.: asymetric (bit rate) digital subscriber line $=A D S L-$ franz.: raccordement numérique asymétrique $=$ RNA,

engl. Digital Versatile Disk = DVD - franz.: disque numérique polyvalent, engl.: domain name system = DNS - franz.: système d'adressage par domaines, annuaire des domaines,

engl.: frequently asked questions (file) $(\mathrm{F} A Q)$ - franz.: foire aux questions, $\mathrm{F} A Q$, fichier des questions courantes, questions courantes,

engl.: uniform resource locator (URL), universal resource locator (URL) - franz.: adresse universelle, adresse réticulaire und

engl.: World Wide Web - franz.: toile d'araignée mondiale, toile mondiale, toile, T.A.M.

Es fällt auf, dass nur für zwei englischsprachige Akronyme französische Formen und entsprechende Akronyme gebildet wurden, engl. ADSL wurde zu franz. RN $A$ und engl. $W W W$ zu franz. T.A.M. In Bezug auf das engl. F $A Q$ wurde eine geschickte Ersetzung für die Vollform gewählt, in der die für das ursprünglich englischsprachige Kurzwort verwendeten Initialen im Französischen erhalten bleiben. Die restlichen drei englischsprachigen Akronyme DVD, DNS und URL gelten auch für das Französische.

\section{Kategorie 2: Unterbegriffe}

Weitere Termini scheiden aus der Liste aus, weil es sich um Unterbegriffe handelt: Information superhighway ist ein Unterbegriff von information highway, da superhighway lediglich eine Spezifizierung von highway ist. Beide Termini, information highway und information superhighway, werden unabhängig von der durch das vorangestellte super

\footnotetext{
Neben den drei genannten Fällen verweist Bauer (1990, 38f.) auf einen vierten Fall, der insofern aber aus diesem Bereich herausfällt, als es nicht zur Bildung eines französischen Akronyms kommt: Für ein englisches Akronym existiere im Französischen kein Pendant, wohl aber eine Übersetzung des englischsprachigen Terminus, Bsp. engl. LCD (liquid crystal display) wird im Französischen zu affichage à cristanx liquides.

18 Helfrich $(1993,92)$ und Bauer $(1990,41)$ weisen in diesem Zusammenhang darauf hin, dass nicht jedem Sprecher die Auflösung der Akronyme bekannt sei und ihm daher das Verständnis für das entsprechende Kurzwort fehle. In der Konsequenz werde dann oftmals das internationale Akronym beibehalten. Bauer $(1990,41)$ führt aus: „Hinter den Akronymen verstecken sich meist lange und auch komplizierte technische Definitionen, die auf den ersten Blick oft nicht einmal dem Muttersprachler geläufig sind. Die onomasiologische Komplexität solcher Definitionen führt schließlich auch zu deren Reduzierung auf Abkürzungen, die früher in Umlauf geraten [...] als der ihnen zu Grunde liegende Gesamtwortlaut. So gesehen ist die Beibehaltung internationaler Akronyme (englischsprachiger Herkunft) in französischen - wie überdies auch in deutschen oder etwa italienischen - Werbetexten wiederum leicht verständlich.“
} 
ausgedrückten Bedeutungsnuance mit dem französischen Terminus autoroutes de l'information (im Plural) wiedergegeben ${ }^{19}$.

Als Unterbegriffe zu engl. newsgroup (Diskussionsforum), das mit dem franz. forum wiedergegeben wird, zählen:

engl.: news article - franz.: article de forum, contribution,

engl.: news item - franz.: article de forum, contribution und

engl.: news posting - franz.: article de forum, contribution.

Da die drei englischen Termini news article, news item und news posting, die einen Beitrag in einem Diskussionsforum bezeichnen, allesamt mit dem französischen Ausdruck article de forum bzw. contribution übersetzt werden, ist eine differenzierte Überprüfung hier nicht notwendig. Sofern das franz. forum für engl. newsgroup akzeptiert wird, ist davon auszugehen, dass auch die zusammengesetzten Unterbegriffe, die ebenfalls das Wort forum enthalten, angenommen werden. Für die Akzeptanz des Neologismus forum sprechen seine Kürze sowie die Bedeutung des ursprünglich lateinischen Wortes ${ }^{20}$.

\section{Kategorie 3: Zugehörigkeit zum Wortfeld Informatik}

Da sich die WWW-Umfrage auf Termini aus dem Wortfeld Internet konzentriert, sollen die folgenden Lexempaare, welche nur dem Wortfeld Informatik zugeordnet werden, nicht in den Fragebogen aufgenommen werden:

engl.: Digital Versatile Disk (DVD) - franz.: disque numérique polyvalent (s. auch Kategorie 1), engl.: middleware - franz.: logiciel médiateur,

engl.: on-line data service - franz.: serveur,

engl.: server - franz.: serveur ${ }^{21}$ und

engl.: window - franz.: fenêtre.

Alle anderen 48 Lexemgruppen werden entweder dem Wortfeld „Informatique/Internet“ oder "Télécommunications/Internet“ zugeordnet (vgl. DGLF 1999, o.S.).

Nach dieser ersten Selektion nach den Kategorien „Akronyme“, „Unterbegriffe“ und „Zugehörigkeit zum Wortfeld Informatik“" scheiden bereits die oben ge-

\footnotetext{
${ }^{19}$ Bezüglich des Terminus information bighway ist zudem problematisch, dass es mehrere englische und sogar ein deutsches Synonym für diesen Ausdruck gibt (engl. information highway, dt. Infobahn, aber auch engl. data bighway - der letzte Terminus erscheint allerdings nicht auf der Liste vom 16. März 1999). Alle drei in der Liste aufgeführten Termini engl. information bighway, engl. information superbighway und dt. Infobahn werden im Französischen mit autoroutes de l'information übersetzt.

20 Das aus dem Lateinischen stammende forum bezeichnet einen öffentlichen Platz. Dies kann entweder der Marktplatz sein oder der Platz, auf dem Volksversammlungen abgehalten und öffentliche Angelegenheiten diskutiert wurden (vgl. Petit Robert 2000, 1070). Da auch die Diskussionsforen Plätze sind, an denen Meinungen über verschiedene Gegenstände ausgetauscht werden, ist die Bezeichnung forum, die in Bezug auf das Internet metaphorischen Charakter hat, sehr treffend gewählt.

${ }^{21}$ Dieses und das voranstehende Lexempaar werden in der offiziellen Terminologieliste zwar dem Wortfeld Informatik zugeordnet, gehören m.E. aber auch zum Wortfeld Internet.
} 
nannten Lexemgruppen - mit Ausnahme der Äquivalente zu engl. World Wide $W e b$, für das es nur im Französischen, nicht aber im Englischen ein offizielles Akronym gibt - aus der Liste der zu untersuchenden Termini aus. Es folgen drei weitere Kategorien, bei denen es wahrscheinlich ist, dass sich bei den ihnen zugeordneten Lexemgruppen der französische Neologismus durchsetzen wird. Somit kann für die in den Kategorien 4-6 genannten Termini eine Überprüfung mittels eines Fragebogens als überflüssig erachtet und somit die Anzahl potenziell zu testender Lexemgruppen weiterhin reduziert werden:

Kategorie 4: eindeutige 1:1-Übersetzung, bei der das französische Wort vorher, wenn auch mit anderer Semantik, bereits existierte und nun eine Bedeutungserweiterung erfahren hat ${ }^{22}$. Voraussetzung für die Akzeptanz ist hierbei, dass die französische Bezeichnung einfach und eingängig ist sowie das mit dem englischen Terminus bezeichnete Konzept exakt abdeckt, d.h. nicht semantisch weiter oder enger ist. Ferner könnte es der Akzeptanz entgegenstehen, wenn der französische Neologismus bedeutend länger ist bzw. mehr Silben aufweist als das englische Ursprungswort (vgl. die in 5.1 genannten akzeptanzfördernden Kriterien: „Einfachheit und Eingängigkeit“, „Exakte Abdeckung des gemeinten Konzepts“ und „Kürze“).

Kategorie 5: grafische Übereinstimmung zwischen Anglizismus und Ersatzwort. Mit der Übernahme der Grafie geht im Regelfall eine Anpassung der Aussprache an das phonetische System des Französischen einher.

Kategorie 6: Anpassung des Anglizismus an das morphologische und/oder phonetische System des Französischen. Hierbei kann es sich z.B. um das Hinzufügen von Akzenten handeln oder auch um die Ersetzung der Endung, Bsp.: engl. -ing zu franz. -age u. ̈̈. (vgl. das in 5.1 genannte Kriterium „Nähe der phonetischen und grafischen Form zum angloamerikanischen Vorbild“).

Die unter Kategorie 4 formulierten Bedingungen treffen für die folgenden Lexemgruppen zu und lassen somit die Akzeptanz des französischen Neologismus als recht wahrscheinlich erscheinen:

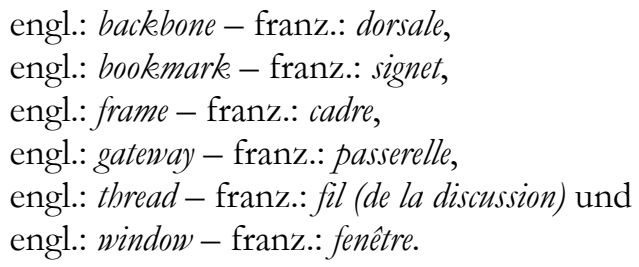

\footnotetext{
22 Problematisch ist mitunter die Übersetzung englischer Komposita, da sie im Französischen oftmals länger und umständlicher als das Ausgangswort sind, wenn es keinen kurzen, treffenden Ausdruck dafür gibt. Ein Beispiel ist die Ersetzung des engl. webcasting durch franz. diffusion systématique sur la toile. In diesen Fällen ist es äußerst zweifelhaft, ob das vorgeschlagene Ersatzwort mehrheitlich akzeptiert wird, so dass in diesem Fall eine empirische Überprüfung sinnvoll wäre.
} 
Zur Kategorie 5 gehören die folgenden drei Wortpaare:

engl.: Extranet - franz.: extranet, engl.: Internet (Network) - franz.: internet und

intranet - intranet ${ }^{23}$.

In die Kategorie 6 sind einzuordnen:

engl.: domain - franz.: domaine,

engl.: bypertext - franz.: bypertexte,

engl.: server - franz.: serveur ${ }^{24}$ und

engl.: website, web site - franz.: site (de la toile, sur la toile) ${ }^{25}$.

Es ist wahrscheinlich, dass sich bei den Lexemgruppen, die den Kategorien 4-6 zugeordnet sind, das französische Ersatzwort durchsetzt. Demgegenüber ist es bei Termini, die der folgenden Kategorie zugeordnet werden, unwahrscheinlich, dass sich die Neologismen gegen die Anglizismen durchsetzen:

Kategorie 7: Das französische Ersatzwort ist bedeutend länger als der Anglizismus.

Diese Kategorie leitet sich aus dem in 5.1 genannte Kriterium der Kürze ab, das in vielen Fällen als ausschlaggebend für die Akzeptanz betrachtet werden kann. Diese Kategorie ist insbesondere auch dann aufschlussreich für prognostische Zwecke, wenn zu einem Anglizismus zwei oder mehr französische Ersatzwörter offizialisiert wurden, z.B. werden für die engl. Termini browser und firewall je zwei französische Neologismen angegeben, die allerdings unterschiedlich lang sind. In diesen beiden Fällen (s. nachfolgende Liste) erfüllt das jeweils kürzere der beiden französischen Ersatzwörter alle akzeptanzbegünstigenden Kriterien. Daher ist es wahrscheinlich, dass es sich gegen den anderen Neologismus sowie gegen den Anglizismus durchsetzen kann:

engl.: browser - franz.: logiciel de navigation, navigateur (Hier ist es wahrscheinlich, dass sich das kürzere navigateur durchsetzt.),

engl.: firewall - franz.: barrière de sécurité, pare-feu (Hier ist es wahrscheinlich, dass sich das kürzere pare-feu durchsetzt.),

engl.: hotlist - franz.: liste de signets,

engl.: hub - franz.: concentrateur,

engl.: middleware - franz.: logiciel médiateur (s. auch Kategorie 3),

engl.: netcasting - franz.: diffusion systématique sur la toile, diffusion réticulaire systématique, diffusion sur la toile, diffusion réticulaire,

\footnotetext{
${ }^{23}$ Die Groß- und Kleinschreibung der englischen Bezeichnungen wird in der Terminologieliste vom 16. März 1999 sehr uneinheitlich gehandhabt (vgl. Abb. 6).

${ }^{24}$ Zur Ersetzung des englischen Suffix -er durch die französischen Suffixe -eur (m.) und -euse (f.) vgl. Feyry $(1973,53)$.

25 In diesem Fall ist es sehr wahrscheinlich, dass sich franz. site (ohne die in Klammern gesetzte Präzisierung) aufgrund der Nähe zum englischen Vorbild durchsetzen wird.
} 
engl.: plug-in - franz.: module d'extension ${ }^{26}$,

engl.: webcasting - franz.: diffusion systématique sur la toile, diffusion réticulaire systématique, diffusion sur la toile, diffusion réticulaire,

engl.: webmaster - franz.: administrateur de site, de serveur ${ }^{27}$,

engl.: webpage, web page - franz.: page sur la toile ${ }^{28}$ und

engl.: World Wide Web - franz.: toile d'araignée mondiale, toile mondiale, toile, T.A.M. (T.A.M.: vgl. Kategorie 1; die Bezeichnung toile d'araignée mondiale ist zu lang; demgegenüber ist es wahrscheinlicher, dass toile mondiale oder das noch kürzere toile akzeptiert werden).

Diese erste Selektion, die aufgrund formaler Eigenschaften erfolgt ist, hat die Liste der für den Fragebogen in Betracht kommenden Lexemgruppen bereits erheblich eingeschränkt. Die Kategorien 1, 2 und 3 enthalten Akronyme, Unterbegriffe bzw. der Informatik zugeordnete Termini und scheiden aus den oben erörterten Gründen aus. Was die französischen Neologismen der Kategorien 4 bis 6 betrifft, ist es aufgrund der in 5.1 dargestellten Faktoren sehr wahrscheinlich, dass sie sich etabliert haben. Gegen die Etablierung der meisten Neologismen der Kategorie 7 spricht vor allem ihre Länge, die im Allgemeinen die Akzeptanz der französischen Neologismen gegenüber den kürzeren Anglizismen erschwert.

Die Anzahl der Lexemgruppen hat sich nun von 53 auf 20 reduziert. Diese 20 Lexemgruppen fallen nun unter die Kategorie 8: potenziell zu testende Lexemgruppen (links des Schrägstrichs die englischsprachige, rechts des Schrägstrichs die französische Bezeichnung bzw. die französischen Bezeichnungen):

1. (access) provider/fournisseur d'accès,

2. applet/appliquette,

3. browser/navigateur,

4. chat/causette,

5. cookie/témoin (de connexion), mouchard,

6. cracker/pirate,

7. gybernaut/internaute,

8. drag and drop/glisser-déposer,

9. emoticon/frimousse,

10. firewall/pare-feu,

11. hacker/fouineur,

12. homepage/page d'accueil,

13. information highway/autoroutes de l'information,

${ }_{26}$ Die vom OLF (2002c, o.S.) vorgeschlagene Terminologie sieht hier das analog zu logiciel und anderen Computer-Termini, die auf -iel enden, gebildete plugiciel vor und nennt als Synonyme module d'extension und module externe.

${ }^{27}$ Im Unterschied zum französischen, belgischen und schweizerischen administrateur de site schlägt der OLF (2002c, o.S.) webmestre vor.

${ }^{28}$ Hier ist es wahrscheinlich, dass sich nur page durchsetzt und es aus dem Kontext klar wird, dass es sich um eine Seite im World Wide Web handelt. Der OLF (2002c, o.S.) schlägt wiederum etwas anderes vor, nämlich document $W e b$, eine Hybridbildung aus einem französischen und einem englischen Bestandteil. 
14. newsgroup/forum,

15. proxy server, proxy/mandataire,

16. pull technology/ recherche individuelle,

17. push technology/distribution sélective, diffusion sélective, distribution personnalisée,

18. smiley/frimousse,

19. viewer/visionneur ${ }^{29}$ und

20. World Wide Web/toile d'araignée mondiale, toile mondiale, toile, T.A.M.

Zusätzlich zu diesen 20 Termini wird der Erlass vom 02. Dezember 1997 (vgl. DGLF 1997, o.S.) mit den französischen Neologismen für den englischen Terminus e-mail (address) in die engere Auswahl einbezogen, da auch dieser Terminus zentraler Bestandteil des Internet-Vokabulars ist:

engl.: E-mail address, E-mail - franz.: adresse de courrier électronique, ellipt. adresse électronique, Symbol: mél,

engl.: electronic mail, E-mail - franz.: courrier électronique, messagerie électronique, Symbol: mél und

engl.: E-mail- franz.: message électronique (vgl. DGLF 1997, o.S.).

Die Einteilung schafft auf den ersten Blick eher Verwirrung als Klarheit, da für Email sowohl courrier électronique und messagerie électronique als auch message électronique angegeben werden. Während bei vielen Wortfeldern sonst eine entsprechende Tabelle ausreichend ist, um sich über die offizielle Terminologie zu informieren, bedarf es in diesem Falle der Definitionen der einzelnen Termini. Diese geben Aufschluss über die unterschiedlichen Verwendungsweisen der Neologismen:

1. Adresse de courrier électronique (ellipt.: adresse électronique) wird definiert als: „Désignation conventionnelle permettant l'identification d'un utilisateur du courrier électronique et l'acheminement des messages qui lui sont destinés.“

2. Courrier électronique wird definiert als „Service permettant aux utilisateurs habilités la saisie, la consultation différée et la transmission, sur des ordinateurs connectés en réseau, de documents informatisés, ou messages électroniques.“

3. Für messagerie électronique wird keine Definition gegeben, aber diese dürfte der von courrier électronique entsprechen, da beide Termini als Ersatzwörter zu engl. electronic mail und E-mail eingetragen sind.

4. Message électronique wird definiert als „Document saisi, consulté ou transmis au moyen du courrier électronique“" (ebd.).

Courrier électronique und messagerie électronique werden somit als der Dienst bzw. das System verstanden, mit dem am Computer elektronische Dokumente oder EMails konsultiert und übermittelt werden können. Adresse (de courrier) électronique bezeichnet die konkrete E-Mail-Adresse. Die nach dieser Tabelle und den angegebenen Definitionen einzig gültige Bezeichnung für die E-Mail (als Nachricht) ist message électronique.

In einer Anmerkung wird darauf hingewiesen, dass Mél., als Kurzwort für messagerie électronique, z.B. in Briefköpfen oder auf Visitenkarten vor der Angabe der E-

\footnotetext{
${ }^{29}$ Hierbei scheint es sich um einen Neologismus zu handeln. Im Petit Robert (2000) gibt es keinen Eintrag für visionneur. Eingetragen ist lediglich das Substantiv visionnaire: „Personne qui a ou croit avoir des visions, des révélations surnaturelles, ou qui a des idées folles, extravagantes“" (ebd., 2685).
} 
Mail-Adresse stehen kann analog zu Tél. vor Telefonnummern. Mél. solle aber nicht als Substantiv gebraucht werden ${ }^{30}$.

Die Verunsicherung darüber, welches französische Wort zur Substitution von engl. e-mail am angemessensten sei, war bereits einige Male Gesprächsthema im Diskussionsforum zur französischen Sprache fr.lettres.langue.francaise. In den monatlich im Diskussionsforum veröffentlichten häufig gestellten Fragen („FAQ“311), die der Verantwortliche dieses Forums, Luc Bentz, in Zusammenarbeit mit den Forenmitgliedern erstellt hat und die von Zeit zu Zeit überarbeitet werden, heißt es unter Punkt 08:

„08. Adresse électronique (Courriel, E-mail, etc.)

ニニニニニニニニニニニニニニニニニニニニニニニニニニニニニニニニニニニニニニニニ

EN UN MOT :

'L'ÉMAIL AU DENTISTE, LE MAIL AU PROMENEUR !'

L'anglais 'E-mail' est l'abréviation de 'electronic mail' (adresse électronique, poste électronique, courrier électronique). Il figure dans le 'Petit Larousse illustré' et dans 'Le Petit Robert', mais y est signalé comme anglicisme.

'Courriel', contraction de 'courrier électronique' est une invention québécoise -- elle-même mentionnée dans les deux dictionnaires courants précités. De nombreux utilisateurs francophones ont repris à leur compte 'courriel'.

'Mél.' a un emploi très restreint. C'est l'équivalent de l'abréviation 'Tél.' avec le même usage (papier à en-tête, prospectus, carte de visite). On ne dit pas 'Je vais te passer un tél' ; il n'y a pas lieu de dire 'Je vais t'envoyer un mél'.

On peut d'ailleurs se passer aujourd'hui, dans l'indication d'une adresse électronique (lettre, brochure, papier à en-tête) de la mention 'Mél' (comme d'ailleurs d"E-mail'), puisque la présentation particulière toto@fournisseur.com est très largement reconnue.

\footnotetext{
30 „Le symbole : Mél., pour 'messagerie électronique', peut figurer devant l'adresse électronique sur un document (papier à lettres ou carte de visite, par exemple), tout comme Tél. devant le numéro de téléphone. 'Mél.' ne doit pas être employé comme substantif"' (vgl. DGLF 1997, o.S.).

${ }^{31}$ Das Diskussionsforum zur französischen Sprache besteht seit dem 15. April 1998. Es ist in vielen Foren üblich, dass einmal monatlich eine oder zwei E-Mails mit Informationen über das Forum sowie mit einer Auflistung an Fragen, die bereits im Forum behandelt worden sind, an das betreffende Forum sowie - bei französischsprachigen Diskussionsforen - an das Forum fr.usenet.reponses gesendet werden. Dahinter steht die Überlegung, dass neue Leser sich in die Gepflogenheiten des jeweiligen Forums einfinden können und keine Fragen stellen, die bereits diskutiert wurden. Bei dem Forum zur französischen Sprache gibt es sowohl eine monatliche E-Mail mit den „Conseils d'utilisation“ als auch eine monatliche E-Mail mit den „FAQ“, d.h. den bereits diskutierten Fragen.
} 
La dénomination officielle est 'adresse, message, messagerie électronique' (selon les usages). Elle ne s'applique obligatoirement, en France, qu'aux administrations publiques (loi du 4 août 1994).

Quelques suggestions ('adrel, adèle', etc.) n'ont pas suscité l'enthousiasme ('courriel' est parfois employé pour désigner un message ou l'adresse électronique), mais il n'y a pas d'usage francophone fixé.

Les mots 'mail, émail, é-mail' (avec ou sans majuscule initiale) relèvent du franglais (et non de l'anglais 'importé'). 'Mail' conduit à des contresens dans un échange avec des Anglo-Saxons : pour eux, il ne s'agit que du courrier ordinaire, postal et non de l'electronic mail'.

Les verbes 'émailler', 'mailer' ou ,mailler' (dans le sens d'envoyer un courrier électronique) doivent être proscrits.

Détails :

$<$ http://www.culture.fr/culture/dglf/terminologie/base-don |nees.html>

$<$ http://www.granddictionnaire.com/>"

(Bentz, „[FAQ] fr.lettres.langue.francaise“, in: fr.lettres.langue.|francaise/ fr.usenet.reponses vom 02. Januar 2003).

Der Anglizismus e-mail ist sogar in die neueste Ausgabe des Petit Robert eingegangen. Alain Rey (2001, o.S.) äußert sich dazu in einem Interview mit der Internetbuchhandlung amazon.fr wie folgt:

„Amazon.fr: On trouve dans Le Grand Robert 'profileur/euse', mot français qui remplace le mot anglais 'profiler'. Mais on trouve aussi 'e-mail', directement en anglais...

Alain Rey: Nous avons gardé e-mail, parce que la très grande majorité des internautes utilisent ce mot - et même le verbe 'e-mailer' que nous n'avons pas mis dans le dictionnaire. Ce qui ne nous empêche pas de dire que l'on préfère 'courriel', utilisé par les Québécois. Je trouve particulièrement détestable le préfixe qui s'écrit 'e' et qui se dit 'i' ; abréger électronique en 'e' n'est pas dans les habitudes du français. Passent encore 'e-mail' et 'e-book', qui sont des mots anglais, mais 'e-commerce', 'e-économie', c'est du charabia. Pourtant, si tout le monde parle de 'e-commerce' en France, ce mot sera dans Le Grand Robert."

In den Fragebogen werden neben engl. E-mail die französischen Äquivalente courrier électronique, message électronique und messagerie électronique aufgenommen. Des Weiteren wird das häufig vor allem in der gesprochenen Sprache für e-mail verwendete mail zu den oben genannten Termini hinzugefügt. E-mail address und seine 
beiden französischen Äquivalente sind wiederum Unterbegriffe zu E-mail (entsprechend der oben genannten Kategorie 2) und werden deshalb nicht in den Fragebogen aufgenommen.

Insgesamt ergibt sich nach dieser ersten Selektion aufgrund formaler Kriterien eine 21 Lexemgruppen umfassende Liste.

\subsubsection{Selektion aufgrund des Bekanntheitsgrades}

Es würde die Geduld eines durchschnittlichen Informanten überstrapazieren, wenn er 21 Lexemgruppen bewerten müsste. Somit ist es unerlässlich, in einem zweiten Schritt aus der oben stehenden Liste von 20 Lexemgruppen (Kategorie 8) sowie zu engl. e-mail und seinen Äquivalenten eine weitere Auswahl zu treffen. Deshalb wird ein weiteres Kriterium herangezogen, der Bekanntheitsgrad. Es ist zum einen von größerem allgemeinen Interesse, Termini zu testen, die auch in der Allgemeinsprache verwendet werden, zum anderen soll auf diese Weise sicher gestellt werden, dass die Informanten die zu bewertenden Termini auf jeden Fall kennen und selbst verwenden. Zur Ermittlung des Bekanntheitsgrades der Termini wird in Ermangelung anderer, aussagekräftiger Quellen auf die Ergebnisse einer im Frühjahr 2001 mit deutschsprachigen Informanten durchgeführten WWW-Befragung zurückgegriffen (vgl. Molitor 2001/2002). Eine Korpusstudie mit Zeitungen oder Zeitschriften wäre nicht nur sehr aufwändig, sondern birgt zusätzlich das von Humbley (1990, 246; vgl. 4.2) genannte Problem, dass der Sprachgebrauch in den Printmedien nicht unbedingt den tatsächlichen Sprachgebrauch widerspiegelt.

Die Annahme, dass Konzepte, die im deutschsprachigen Raum bekannt sind, dies auch im französischsprachigen Raum sind, ist methodisch sicherlich in mehrfacher Hinsicht problematisch:

1. Es ist zweifelhaft, ob französischsprachige Internet-Nutzer die gleichen Konzepte kennen wie die befragten deutschsprachigen Informanten, zumal den deutschsprachigen Informanten in Ermangelung verbindlicher deutschsprachiger Ersatzwörter ausschließlich die englischen Termini vorgelegt wurden. Somit ist es nicht auszuschließen, wenngleich unwahrscheinlich, dass den deutschsprachigen Informanten zwar das Konzept, nicht aber der englischsprachige Terminus bekannt war und dadurch das Ergebnis verfälscht wurde.

2. Die Studie mit deutschsprachigen Informanten richtete sich an ein breites Publikum, wohingegen die in den Kapiteln 7 bis 12 präsentierte WWW-Befragung nur an Informatiker bzw. an Personen, die beruflich im Bereich des Internet tätig sind, adressiert ist.

Es ist nicht ausschlaggebend für den Aussagewert der Studie, ob die ausgewählten Termini in Frankreich, Belgien und der Schweiz genauso bekannt sind wie im deutschsprachigen Raum. Schließlich besteht das Zielpublikum der WWW-Umfrage ausschließlich aus Fachleuten, denen ohnehin alle 53 Konzepte der französischen Liste bekannt sein sollten. Es stellt sich in diesem Zusammenhang natürlich die Frage, ob es nicht sinnvoll wäre, eine entsprechende Studie zur Ermittlung des Bekanntheitsgrades der französischsprachigen Internet-Termini auch in Frank- 
reich, Belgien und der Schweiz durchzuführen. Zwei Punkte erweisen sich jedoch als problematisch:

1. Es ist zu diesem Zeitpunkt noch nicht geklärt, ob in frankophonen Ländern eher der Internet-Anglizismus oder der entsprechende französische Neologismus bzw. die entsprechenden französischen Neologismen verbreitet sind. Deswegen müsste immer nach allen - den englischen und den französischen - Bezeichnungen gefragt werden.

2. Es könnte passieren, dass sich z.T. die gleichen Informanten an dieser ersten wie auch der zweiten Studie beteiligen, was aufgrund der sehr ähnlichen Thematik das Ergebnis verzerren könnte (s.o., Beginn von 5.2).

Trotz der getroffenen Einschränkungen und in Ermangelung anderer Quellen beschränkt sich die Staffelung der Termini nach ihrem Bekanntheitsgrad einzig auf die Ergebnisse der Anfang 2001 durchgeführten Befragung. Im Folgenden werden die 21 potenziell zu überprüfenden Lexemgruppen entsprechend der Untersuchungsergebnisse in der Reihenfolge ihrer Bekanntheit angegeben (links des Schrägstrichs die englische, rechts des Schrägstrichs die französische Bezeichnung bzw. die französischen Bezeichnungen):

1. e-mail/ courrier électronique, message électronique, messagerie électronique, mél,

2. homepage/page d'accueil,

3. World Wide Web/toile d'araignée mondiale, toile mondiale, toile, T.A.M.,

4. chat/causette,

5. hacker/fouineur,

6. access provider/fournisseur d'accès,

7. browser/navigateur,

8. smiley/frimousse,

9. cookie/témoin (de connexion), mouchard,

10. newsgroup/forum,

11. firewall/pare-feu,

12. drag and drop/glisser-déposer,

13. information highway/autoroutes de l'information,

14. viewer/visionneur,

15. proxy server, proxy/mandataire,

16. emoticon/frimousse,

17. applet/appliquette,

18. cracker/pirate,

19. cybernaut/internaute,

20. push technology/distribution sélective, diffusion sélective, distribution personnalisée und

21. pull technology/recherche individuelle.

Da in den Fragebogen nur sechs Termini mit ihren jeweiligen Äquivalenten aufgenommen werden, um den Fragebogen in einer zumutbaren Länge und dadurch die Abbrecherquote möglichst gering zu halten, wurden nur die ersten sechs Lexemgruppen dieser Liste in den Fragebogen aufgenommen. Außerdem wurden zu den ausgewählten Lexemgruppen auch noch die in Belgien und der Schweiz gülti- 
gen französischsprachigen Neologismen hinzugefügt. Die ausgewählten Termini gehören sowohl der Allgemein- als auch der Fachsprache an, wofür der hohe Bekanntheitsgrad unter den Informanten bürgt. Unter den Befragten befanden sich sowohl technisch versierte Laien als auch Fachleute.

\subsubsection{Analyse der ausgewählten französischsprachigen Internet- Neologismen und Prognosen zu ihrer Akzeptanz}

\subsubsection{Analyse der ausgewählten französischsprachigen Internet-Neologismen}

In der linken Spalte von Abbildung 8 sind die bezüglich ihrer Akzeptanz zu testenden französischen Neologismen (gültig in Frankreich, Belgien und/oder der Schweiz) aufgeführt. Die rechte Tabellenspalte umfasst die Wortartbestimmung sowie die Bestimmung des Bildungstyps nach Braselmann (1999a, 68-95). Kommentare zu den Termini bzw. ihren Bildungsverfahren befinden sich in den Fußnoten.

Zur besseren Verständlichkeit und Nachvollziehbarkeit der Bestimmung des Bildungstyps wird vorab das Schema Braselmanns abgedruckt. Braselmann (1999a, 95) unterteilt die Ersatzwörter zunächst in künstlich geschaffene und spontan entstandene Ersatzwörter (vgl. Kap. 3, Fußnote 92). Außerdem unterscheidet Braselmann (1999a, 70-75; 2002b, 205f.) zwischen äußerem Lehngut (das fremde Wort wird importiert), innerem Lehngut (franz. calque, das fremde Wort wird mit Mitteln der eigenen Sprache substituiert), Lehnschöpfung (es werden Bezeichnungen gewählt, die sprachlich unabhängig vom Fremdwort sind) und dem Sonderfall der Scheinentlehnung bzw. des Pseudoanglizismus (das entsprechende Wort existiert im Englischen nicht). Von den letztgenannten vier Kategorien fließen das äußere und innere Lehngut in das Wortbildungsschema von Ersatzwörtern ein. Braselmann (2002b, 207) weist darauf hin, dass äußeres Lehngut sehr selten von den Terminologiekommissionen zugelassen werde. Zumeist werde es dann zumindest formal an die französische Grafie angepasst (franz. boum statt engl. boom, franz. serveur statt engl. server). 
Abb. 7: Schema zur Bestimmung der Wortbildung bei Ersatzwörtern

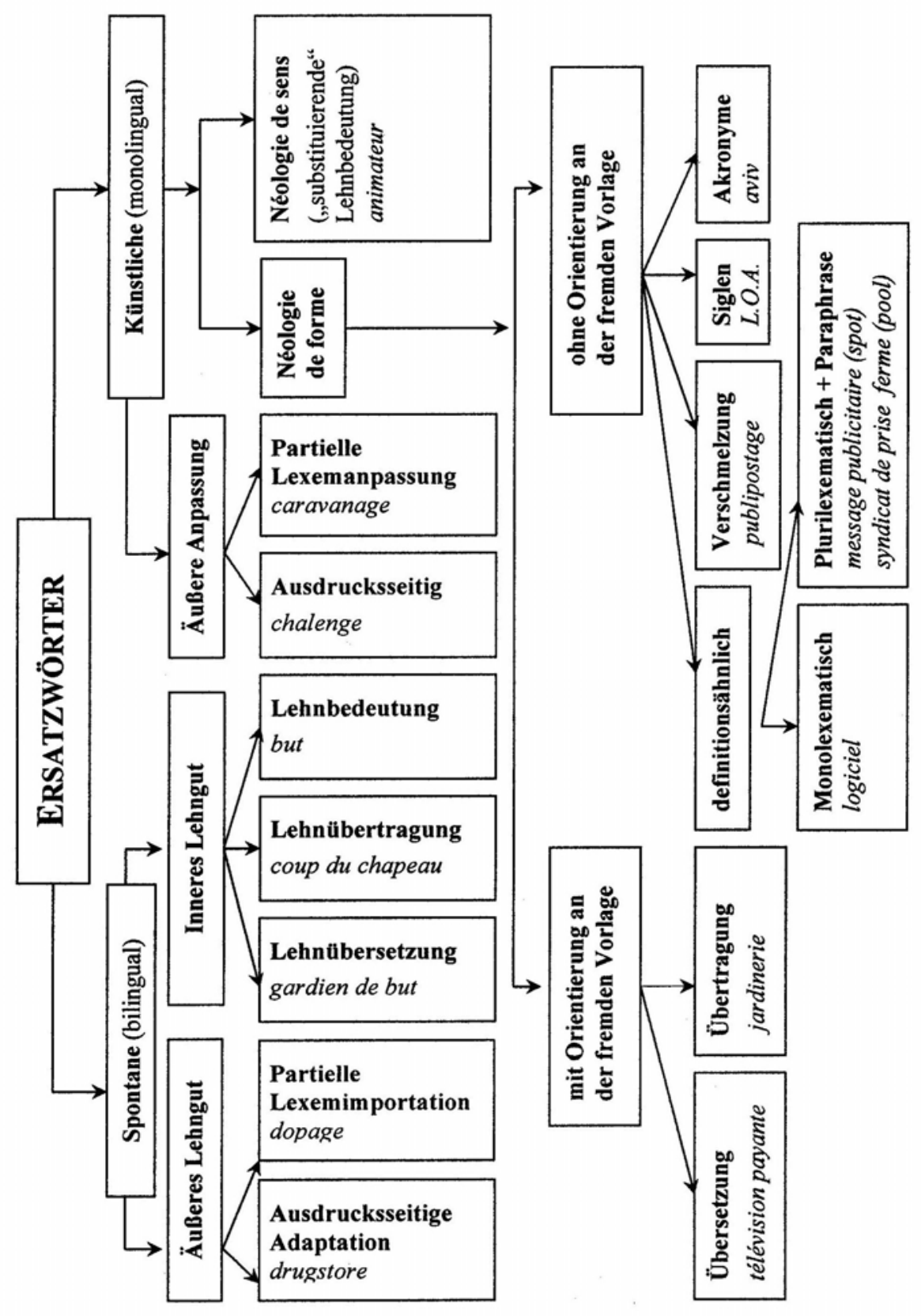

aus: Petra Braselmann, Sprachpolitik und Sprachbewnsstsein in Frankreich heute, Tübingen, Niemeyer, 1999, Seite 95 (= 1999a). 


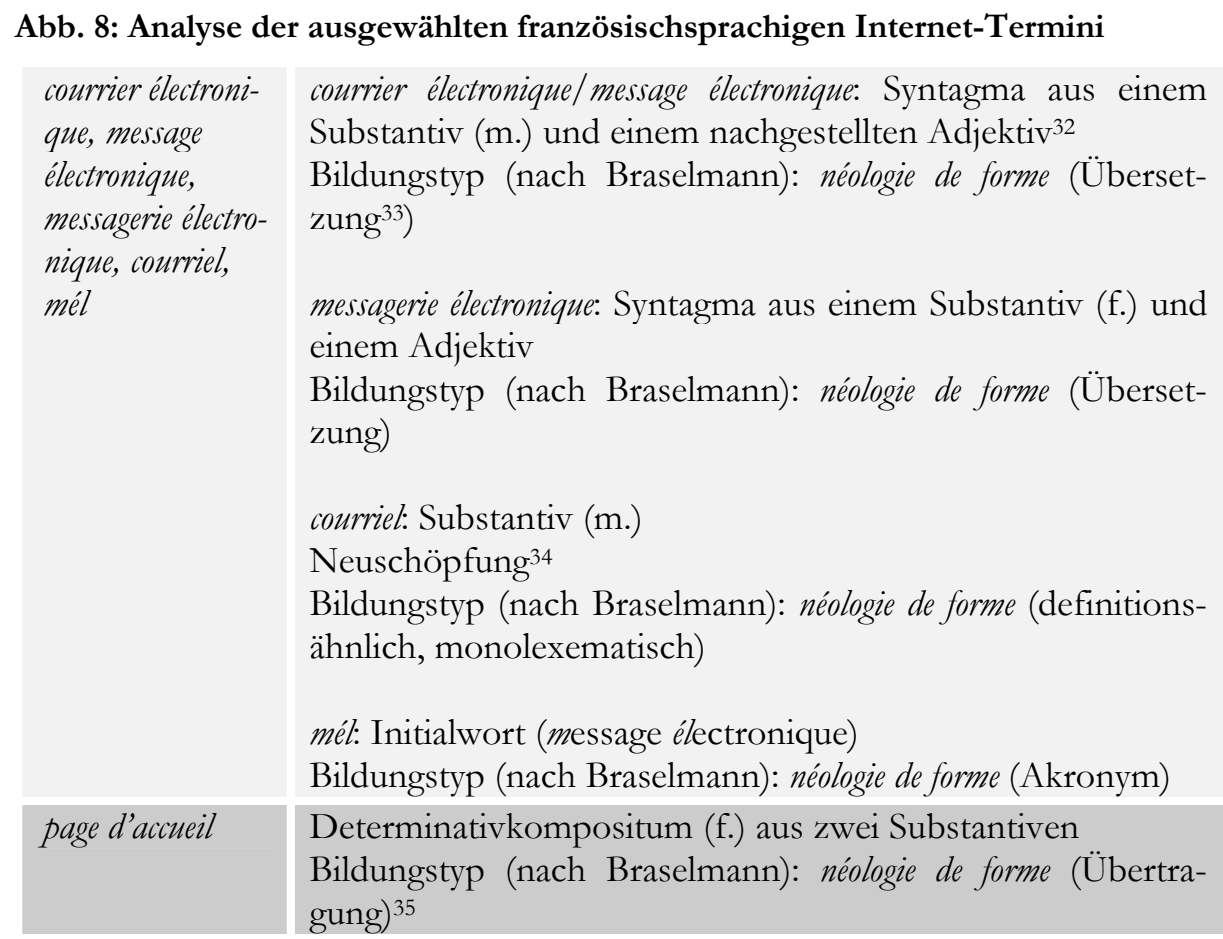

32 Bei der Übersetzung des englischen Terminus e-mail wurde das Präfix e-, das als Initiale für das Adjektiv electronic steht, in seiner Vollform ins Französische übersetzt (électronique) und als Adjektiv dem Substantiv courrier bzw. message nachgestellt. In auch in anderen französischen Bezeichnungen, deren angloamerikanisches Ursprungswort das Präfix $e$ - aufweist, findet sich das nachgestellte Adjektiv électronique. Beispiele sind engl. e-cash - franz. argent électronique, engl. e-żine - franz. magaźine électronique, engl. e-business - franz. commerce électronique und engl. e-pub - franz. publicité électronique (vgl. Otman 2000, 384).

33 Die von Braselmann vorgenommene Unterteilung in Lehnübersetzung und Lehnübertragung entspricht auch dem bei Bußmann $(2002,194)$ abgebildeten Schema. Die Lehnübertragung ist eine freie Übersetzung der einzelnen Glieder des Ursprungswortes, deren Reihenfolge üblicherweise den in der Zielsprache geltenden Wortbildungsregeln angepasst wird (Bsp. engl. skyscraper, dt. Wolkenkratzer, franz. gratte-ciel). Demgegenüber erfordert die Lehnübersetzung eine Glied-für-Glied-Übertragung des Wortes von der Ausgangs- in die Zielsprache (Bsp. dt. Halbwelt. franz. demi-monde, dt. Torbüter, franz. gardien de but).

34 Nach de Broglie (2001, o.S.) gibt es insbesondere im Bereich der Internet-Terminologie Fälle, in denen eine Übertragung ins Französische - z.B. durch morphologische und phonetische Anpassung des Terminus an das französische System - zu vermeiden sei. De Broglie hält in manchen Fällen die amerikanische Bezeichnung nicht für gelungen und befürwortet daher, dass für das Französische ein gänzlich neues Wort geschaffen werde. Als Beispiele für Neuschöpfungen nennt er franz. mouchard (engl. cookie), franz. frimousse (engl. smiley), franz. causette (engl. chat), franz. octet (engl. byte) u.a.

35 Das Determinativkompositum besteht aus einem wörtlich aus dem Englischen übersetzten Determinans page (= zweiter Bestandteil des engl. Determinativkompositums und erster Bestandteil des französischen Determinativkompositums) und einem französischen Determinatum accueil, welches keine wörtliche Übersetzung des englischsprachigen Ursprungswortes home darstellt. Dadurch wird ein neues, vorher nicht existentes französisches Determinativkompositum geschaffen: Aus zwei unabhängig voneinander existierenden französischen Substantiven wird ein mit ,,de“ verbundener neuer Terminus.

Bei einer wörtlichen Übersetzung des englischen Determinativkompositums homepage hätte der französische Neologismus *page-maison (nach dem Bildungsmuster von waggon-lit) bzw. *page de la 


$\begin{array}{ll}\text { toile d'araignée } & \text { toile d'araignée mondiale: Syntagma aus einem Determinativ- } \\ \text { mondiale, } & \text { kompositum } \\ \text { toile mondiale, } & \text { Bildungstyp (nach Braselmann): néologie de forme (Übertra- } \\ \text { toile, } & \text { gung) }\end{array}$

T.A.M.

causette

toile mondiale: Syntagma aus einem Substantiv (f.) und einem
nachgestellten Adjektiv
Bildungstyp (nach Braselmann): néologie de forme (Übertra-
gung)
toile: Substantiv (f.), Lehnübertragung des engl. web bzw.
Kurzwort zu toile (d'araignée) mondiale
Bildungstyp (nach Braselmann): néologie de sens (neuer Sinn
für ein bereits existierendes Wort)
$\begin{aligned} & \text { T.A.M.: Kurzwort (Initialwort) } \\ & \text { Bildungstyp (nach Braselmann): néologie de forme (Akronym) }\end{aligned}$
causette: Substantiv (f.)
Bildungstyp (nach Braselmann): néologie de sens (neuer Sinn
für ein bereits existierendes Wort)

maison heißen müssen. Das Wort page d'accueil ist semantisch durchsichtiger als der englische Ausdruck bomepage, da bereits in der Semantik des Kompositums enthalten ist, dass mit der page d'accueil nur die erste Seite, d.h. die Haupt- bzw. Startseite mehrerer miteinander verknüpfter Seiten gemeint ist. Diese Differenzierung, die das englische Wort zwar definitorisch auch enthält, die aber nicht durch das Kompositum bomepage selbst transparent wird, wird im Deutschen oftmals mit dem Terminus Startseite (neben dem engl. Homepage) bezeichnet. Anglizismen werden oft als eindeutiger angesehen als ihre französischen Äquivalente. Sie sind es aber nicht, sondern beim Vorgang des Entlehnens findet lediglich eine Reduktion der Polysemie statt: „La première constatation que l'on doit faire est que - contrairement à l'opinion courante - emprunter un mot à une langue étrangère n'est pas emprunter globalement le signifiant et le signifié de ce mot. [...] Cela consiste à emprunter un signifiant avec une de ses désignations (acceptions) et un seule, et dans un seul champ sémantique“ (Pergnier 1988b, 114). So bezeichnet z.B. das franz. vedette nur einen „Star“ im Sinne einer 'Berühmtheit', die zweite, astronomische Bedeutung des engl. star ist in vedette nicht enthalten (vgl. Pergnier 1989, 54).

36 Bei dem französischen Determinativkompositum toile d'araignée handelt es sich um ein bereits vorher im Französischen vorhandenes Wort. Als Bezeichnung für 'Spinnennetz' war dieses Wort bislang der Tierwelt zugeordnet. Es gibt mehrere Beispiele für Tiermetaphorik in der informatischen Fachsprache, neben franz. toile d'araignée gibt es noch franz. souris (dt. Maus), franz. puce (dt. Floh, in der Sprache der Informatik: Chip), franz. virus (dt. Virus) und franz. Cheval de Troie (dt. Trojanisches Pferd) (vgl. Otman 2000, 374-376). Das engl. bug, das soviel wie 'kleines, lästiges Insekt' bedeutet, verliert durch die französische Wiedergabe mit bogue seinen metaphorischen Charakter und wird vielleicht deshalb von den von Le Guilly-Wallis (1991) befragten Informanten abgelehnt (vgl. Ahlers/Holtus 1999, 302).

Toile d'araignée erhält durch den adjektivischen Zusatz mondiale eine ganz neue Bedeutung. Erst dieser Zusatz bewirkt die Zugehörigkeit des Terminus zum Wortfeld Internet. Toile d'araignée mondiale ist eine Erweiterung des engl. World Wide Web im metaphorischen Sinne, denn bei web kann es sich auch um andere Netze oder Gewebe handeln als um Spinnennetze (Spinnennetz = engl. spider web).

${ }^{37}$ Unter den genannten Varianten entspricht toile mondiale am ehesten dem engl. Word Wide Web; toile entspricht dem engl. web. 


\begin{tabular}{|l|l} 
pirate & pirate: Substantiv (m.) \\
& $\begin{array}{l}\text { Bildungstyp (nach Braselmann): néologie de sens (neuer Sinn } \\
\text { für ein bereits existierendes Wort }\end{array}$ \\
\hline fournisseur d'accès & $\begin{array}{l}\text { Determinativkompositum (m.) aus zwei Substantiven } \\
\text { Bildungstyp (nach Braselmann): néologie de forme (Überset- } \\
\text { zung) }\end{array}$
\end{tabular}

\subsubsection{Prognosen zur Akzeptanz der ausgewäblten französischsprachigen Internet- Neologismen}

De Broglie (2001, o.S.) gibt eine Gesamteinschätzung der positiven und negativen Seiten der Terminologiearbeit. Als positiv ordnet er ein, dass es in einigen Kreisen der Gesellschaft, z.B. bei Radio- und Fernsehjournalisten, zu einer Gewöhnung an die Verwendung des französischsprachigen Wortes anstelle des häufig schwer versteh- und artikulierbaren englischen Terminus gekommen sei. Des Weiteren hätten sich in bestimmten Bereichen wie der Raumtechnik, der Atomkraft, der Chemie, dem Internet und der Telekommunikation bestimmte französische Neologismen etabliert. Für den Bereich Internet/Telekommunikation nennt de Broglie die folgenden Termini: en ligne, hors ligne, toile, portail, forum, site, cadre, pirate, internaute, serveur und $p a g e^{40}$. Da jedoch keine Quelle für diese Aussage zitiert wird, ist zu vermuten, dass es sich um eine subjektive Einschätzung des Autors handelt. Es ist allerdings aufgrund der in 5.1 genannten Kriterien durchaus wahrscheinlich, dass sich die Termini toile, forum, site, cadre, pirate, internaute und serveur (aus dem Erlass vom 16. März 1999) etabliert haben.

Im Folgenden wird kurz eine Prognose bezüglich der Akzeptanz zu jedem der ausgewählten Lexeme der sechs Lexemgruppen gegeben. Es fällt zunächst auf, dass es für engl. e-mail sehr viele französische Entsprechungen gibt, wobei sich zwei dieser Ersatzwörter auf das System und ein Ersatzwort auf die elektronische Nachricht selbst beziehen. Daneben gibt es noch das als Symbol eingeordnete Kurzwort mél. Die vielen parallel existierenden französischen Neologismen scheinen auch Muttersprachlern Probleme zu bereiten, denn die französischen Äquivalente für engl. e-mail waren bereits häufiger Diskussionsgegenstand in dem französischsprachigen Diskussionsforum fr.lettres.langue.francaise (vgl. 5.2.1).

\footnotetext{
${ }^{38}$ Das Wort pirate gab es im Französischen bereits vor Einführung der Internet-Terminologie, in der Bedeutung 'Seeräuber'. Im Rahmen der Internet-Terminologie ist pirate die sinngemäße Übersetzung des engl. cracker. Im Deutschen lässt sich engl. cracker neben dem Anglizismus Hacker auch als Computereindringling übersetzen (vgl. LEO, „English-German-dictionary“, 1995-2003, o.S.; vgl. Glossar im Anhang).

${ }^{39}$ Durch die Übersetzung der einzelnen Bestandteile des englischen Determinativkompositums access provider ins Französische wird ein neues französisches Determinativkompositum aus bereits unabhängig voneinander im Französischen existierenden Komponenten geschaffen.

${ }^{40}$ Das Wort page gibt es ohne Zusatz im Bereich des offiziellen Internet-Vokabulars nicht. Entweder handelt es sich um page d'accueil (für engl. homepage) oder, was wahrscheinlicher ist, um eine Abkürzung von page sur la toile (für engl. webpage).
} 
Für die Bevorzugung des englischsprachigen Terminus e-mail, seiner Kurzform mail und des französischen Kurzwortes mél, das eigentlich ja nur für Briefköpfe und Visitenkarten vorgesehen ist, spricht die Kürze. Gegen mél sprechen allerdings seine Grafie, seine pseudoenglische Aussprache und die Tatsache, dass mél gegen die morpho-phonologischen Regeln des Französischen verstößt ${ }^{41}$. E-mail bzw. mail und mél bestehen aus je einer oder zwei Silben, während message électronique, messagerie électronique und courrier électronique aus sechs und mehr Silben bestehen. Diese drei Neologismen dürften nicht nur zu lang, sondern auch zu schwerfällig sein, als dass sie sich bei Benutzern eines so schnellen und modernen Mediums wie des Internet etablieren könnten. Yaguello $(1998,140)$ spricht sich gegen courrier électronique oder mél und für den Neologismus courriel aus, der ihrer Meinung nach ohnehin der auch in Frankreich am weitesten verbreitete Terminus sei. Sie bedauert, dass courriel nicht von der französischen Terminologiekommission gewählt worden sei:

„Or, parmi les usagers du courrier électronique, en particulier en milieu universitaire, se répand depuis un certain temps déjà un usage à mon avis infiniment mieux venu, qui est celui du néologisme courriel. Pourquoi la commission n'a-t-elle pas retenu ce dernier terme?"“ (ebd.)

Yaguello $(1998,142)$ ist der Ansicht, courriel würde sich gerade aufgrund der Suffigierung durch -iel harmonisch in die Reihe von Neologismen einfügen, die auf diese Weise im Bereich der neuen Technologien entstanden seien.

Der Neologismus page d'accueil ist nur eine Silbe länger als das angloamerikanische Ursprungswort. Da die Bezeichnung aber im Vergleich zur englischen Bezeichnung homepage den Inhalt transparenter werden lässt und somit vielen frankophonen Sprechern eindeutiger erscheinen dürfte (ohne es de facto zu sein, denn das engl. homepage bezeichnet per definitionem auch nur die erste Seite eines Internetangebots), dürfte sich bei frankophonen Sprechern insgesamt der französische Terminus durchgesetzt haben (vgl. Fußnote 35).

Es ist aufgrund seiner Länge unwahrscheinlich, dass sich das in Québec geschaffene toile d'araignée mondiale durchsetzen wird. Die Bezeichnung toile mondiale und vor allem das noch kürzere toile dürften mehr Zuspruch erhalten. Am bekanntesten ist nach Ausseil (1998, 42) das englische Kurzwort web, welches in der Regel mit französischen Artikel verwendet werde: le web. Auch Lazare und Otman äuBern die Vermutung, dass web mehr Zuspruch erhalten werde als seine französischsprachigen Äquivalente. Bei Lazare (2000, 26) heißt es: „L'internaute préfère

\footnotetext{
41 Nach Yaguello $(1998,141 \mathrm{f}$ ) handelt es sich hierbei um einen durch die Grafie maskierten Anglizismus. Es sei unmöglich, mél mit einem geschlossenen [e] auszusprechen, wie es die grafische Realisierung nahe legt. Vielmehr werde das <é> offen ausgesprochen $([\varepsilon])$, was - wenngleich ungewollt - auf eine pseudoenglische Aussprache schließen lasse.

Die Schreibweise mél verstößt gegen die morpho-phonologischen Regeln des Französischen, weil der accent aigu nur in offenen, niemals aber in geschlossenen Silben auftritt.
} 
travailler sur le ' $W e b$ ' que sur la 'Toile' [...], y pratiquer le 'chat [...] plutôt que d'y faire un brin de 'causette'. " Und Otman (2000, 392f.) schreibt mit Blick auf diverse, nicht nur offizielle französische Neologismen:

„On peut s'interroger aujourd'hui sur les chances d'implantation de cette dernière forme [toile d'araignée mondiale]. En quelque cinq années d'existence effective du Web [...] Web a pratiquement supplanté toutes les autres, $W 3$ et $W$ cube ayant totalement disparu de l'usage. Plusieurs raisons au succès de l'appellation Web: elle est brève (monosyllabique) et facile à prononcer par un francophone. $W W W$, typographiquement bref, correspond en revanche à neuf syllabes orales. De plus, $W e b$ est la seule forme utilisée en combinaison: pages $W e b$, navigateur $W e b$, serveur $W e b$, site $W e b \ldots$ Quelles chances le terme Toile a-t-il de concurrencer $W e b$ ? $،$

Hinzu kommen die negativen Konnotationen, die toile hervorrufe, während diese bei web fehlten:

„Le mot toile est déjà connoté en français. Dans le domaine des médias, il renvoie familièrement au cinéma (se faire une toile). De plus, il faut savoir que le mot anglais web désigne plus précisément la toile d'araignée ou la toile textile. La première toile est une toile dangereuse dans laquelle on est pris au piège et dont on ne peut plus se dépêtrer. La toile textile renvoie au tissu, qui, dans le domaine de la communication humaine, évoque des images négatives comme 'tissu de mensonges'. Web ne présente pas ces inconvénients connotatifs" (ebd., 393).

$W^{3}, W^{3}$ und $W$ cube seien inzwischen völlig aus dem Sprachgebrauch verschwunden (vgl. ebd.).

Aufgrund dieser Ausführungen ist es wahrscheinlich, dass sowohl der aus dem Angloamerikanischen stammende Terminus web (mit französischem Artikel) als auch das inhaltlich analoge französische Wort toile unter frankophonen Sprechern sehr verbreitet sind, jedoch web der Vorzug gegeben wird. Dass sich das Akronym T.A.M. gegen die weltweit geläufige Abkürzung $W W W$ durchsetzen wird bzw. schon durchgesetzt hat, ist insofern eher unwahrscheinlich. Der Gebrauch von T.A.M. würde voraussetzen, dass den frankophonen Internet-Nutzern auch die entsprechende Vollform (toile d'araignée mondiale) geläufig ist.

Gegen den Terminus causette sprechen zwei Faktoren: Zum einen ist es länger als das engl. chat, zum anderen bezeichnet causette auch ein privates Gespräch ${ }^{42}$. Im Unterschied zu toile d'araignée (mondiale) erhält dieser Terminus keine metaphorische Dimension, die seine Verwendung im Internet-Kontext begünstigen könnte. Es ist daher davon auszugehen, dass sich das kurze und prägnante chat durchgesetzt hat.

42 Im Petit Robert (2000, 362) wird für causette folgende Definition gegeben: „Petite causerie, entretien familier." Als Synonym wird „bavarder familièrement" genannt. 
Hier ist es möglich, dass - ähnlich wie bei homepage - mit der Entlehnung zugleich eine Reduktion der Polysemie stattgefunden hat. Im ursprünglichen Sinn bezeichnet chat sowohl das private Face-to-Face-Gespräch als auch die virtuelle Kommunikation im Internet. Für die Akzeptanz von causette spricht wiederum, dass es keinerlei Unsicherheiten bezüglich seiner Aussprache geben dürfte, wohingegen bei frankophonen Sprechern Unsicherheit herrschen könnte, wie das englische Wort chat ([t $\left.\left.\int \mathfrak{x t}\right]\right)$ korrekt auszusprechen sei.

Über die genannten Gründe hinaus hat das engl. chat viele andere französischsprachige Synonyme, beispielsweise die in Québec gültigen Neologismen bavardageclavier, clavardage, cyberbavardage und bavardage (en ligne) (vgl. 3.3.5) sowie andere Termini, die dem offiziellen Neologismus causette semantisch und morphologisch ähnlich sind, wie causerie. Sehr häufig findet sich auf französischsprachigen Internetseiten die Bezeichnung bavardage ${ }^{43}$. Da sich dieser Terminus im frankophonen Sprachraum größerer Beliebtheit zu erfreuen scheint als die offiziell in Frankreich und Belgien gültige Bezeichnung causette (in der schweizerischen Liste wurde dieser Terminus nicht berücksichtigt, vgl. 3.3.5) und zudem eine gewisse Zeit lang auch in der belgischen Internet-Terminologie verzeichnet war, wurde bavardage zusätzlich $\mathrm{zu}$ chat und causette in den Fragebogen aufgenommen. Es ist aufgrund der Vielzahl an existierenden französischsprachigen Äquivalenten sowie aufgrund der Kürze von engl. chat wahrscheinlich, dass sich chat gegenüber den beiden französischen Termini durchgesetzt hat.

Eine weitere Bezeichnung, die aber in keinem der Untersuchungsländer offiziell ist und daher auch nicht in den Fragebogen aufgenommen wird, aber vielfach auf französischsprachigen Internetseiten auftaucht (z.B. bei Yahoo! France, http://help.yahoo.com/help/fr/chat/), ist tchatche. Das entsprechende Verb lautet tchatcher.

Pirate bietet gegenüber dem Anglizismus cracker den Vorteil, dass es sich analog zu page d'accueil um eine semantisch durchsichtige Bezeichnung handelt. Das französische Wort pirate ist sehr anschaulich und drückt bildlich das illegale Handeln der betreffenden Person aus. Für die Etablierung des Terminus cracker spricht dessen lange Existenz als Fachterminus in der Computersprache, denn bereits vor dem Entstehen des Internet gab es Menschen, die sich beispielsweise zu Spionagezwecken in andere Computernetze Zugang verschafft haben. Daher ist davon auszugehen, dass viele Leute bereits seit etlichen Jahren mit dem englischen Wort cracker vertraut sein dürften und es entsprechend fraglich ist, ob sie ihren Sprachgebrauch aufgrund der offiziellen Terminologie ändern. Hier dürfte somit der Faktor Gewöhnung eine entscheidende Rolle spielen und durchaus die Akzeptanz des französischen Neologismus pirate erschweren, wenngleich diese Bezeichnung m.E. eine gelungene Ersetzung ist.

\footnotetext{
43 Dieses Substantiv war ebenso wie causette bereits vor der Erfindung des Internet und der damit verbundenen Terminologie Bestandteil der französischen Allgemeinsprache. Der Bildungstyp (nach Braselmann) lautet daher auch néologie de sens (neuer Sinn für ein bereits existierendes Wort).
} 
Die Akzeptanzquote von fournisseur d'accès dürfte in etwa der von page d'accueil entsprechen. Fournisseur d'accès ist zwar wesentlich länger als das englische Wort provider (das gebräuchlicher ist als das in der Liste angegebene längere access provider), in diesem Fall dürfte aber die Tatsache, dass die Aussprache des Fremdwortes erheblich von der französischen Aussprache abweicht, die Akzeptanz des französischen Neologismus bei Sprechern begünstigen, die des Englischen kaum oder gar nicht mächtig sind: Sowohl das $<\mathrm{i}>$ in provider, das korrekt [ai] ausgesprochen wird, als auch die Endung -er, die üblicherweise durch -eur französisiert wird (wie z.B. engl. server $>$ franz. serveur), weichen von den französischen Aussprachegewohnheiten $\mathrm{ab}$.

Diese soeben vorgenommene Einschätzung zur Akzeptanz der französischen Neologismen bezieht sich nur auf das erste Fragebogenmodul (zum Aufbau des Fragebogens vgl. Kap. 7). Die getroffenen Prognosen leiten sich von formalen Aspekten der Wörter, ihren phonetischen und grafischen Eigenschaften sowie ihrem semantischen Gehalt ab. Die Einschätzung der Termini bezieht sich auf alle drei Untersuchungsländer, da ihr die Annahme zugrunde liegt, dass die Akzeptanz eines Ersatzwortes weniger von staatlichen Vorschriften oder dem jeweils unterschiedlichen soziolinguistischen Umfeld abhängt, sondern von den dem Wort selbst inhärenten Eigenschaften wie dem Bildungstyp, der Nähe des Neologismus zum angloamerikanischen Vorbild, seiner Kürze etc.

Die in diesem Abschnitt vorgenommenen Prognosen werden im folgenden Abschnitt in Form von Arbeitshypothesen (5.3.1) zusammengefasst. Hinzu kommen weitere Hypothesen, die dem Zusammenhang von Sprachverwendung und Personendaten Rechnung tragen, sowie Hypothesen zur Bewertung der Sprachpolitik und Terminologiearbeit in den drei Untersuchungsländern.

\subsection{Arbeitshypothesen}

Die Konzeption des WWW-Fragebogens, die im Einzelnen in Kapitel 7 erläutert wird, ist das Resultat zahlreicher Hypothesen und methodischer Überlegungen, die größtenteils aus den Kapiteln 2 bis 6 dieser Arbeit abgeleitet werden.

Aufgrund der in 5.1 dargestellten Kriterien ist davon auszugehen, dass die Akzeptanz in allen drei Ländern in erster Linie von den Termini und ihrer Verbreitung selbst abhängt. Es ist anzunehmen, dass die Nationalität der Befragten sowie der jeweilige Grad der sprachlichen Sicherheit bzw. Unsicherheit keinen Einfluss auf die Kenntnis der Termini und nur einen geringen Einfluss auf den Sprachgebrauch ausüben.

Zusätzlich zu dieser Bewertung ist es wünschenswert, die Daten in Abhängigkeit von den persönlichen Eigenschaften der sie beurteilenden Sprachbenutzer, den Informanten, auszuwerten. Die personenbezogenen Parameter, die bei der Aus- 
wertung dieser Studie von Belang sind, sind Wohnort (Land), Alter, Bildungsgrad, Englischkenntnisse und Vertrautheit mit dem Medium Internet ${ }^{44}$.

Das zweite Fragebogenmodul befasst sich mit dem Bekanntheits- und Akzeptanzgrad der Sprachpolitik, der Terminologielisten und der Internet-Terminologie. In diesem Teil unterscheiden sich die Fragebögen für die französischen, belgischen und schweizerischen Informanten voneinander. Hier können vor allem unter Zuhilfenahme der Ausführungen des zweiten Kapitels sowie des Unterkapitels 3.3 Hypothesen für jedes der drei Untersuchungsländer formuliert werden.

Es ergeben sich drei Gruppen von Hypothesen:

1. Hypothesen zum Bekanntheits- und Akzeptanzgrad der französischsprachigen Neologismen (länderübergreifend),

2. Hypothesen zu Korrelationen zwischen biosozialen Daten der Informanten und ihrem Sprachverhalten/ihren Einstellungen,

3. länderspezifische Hypothesen zur Bewertung der jeweils vorherrschenden Sprachpolitik und Terminologiearbeit.

\subsubsection{Hypothesen zum Bekanntheits- und Akzeptanzgrad der franzö- sischsprachigen Neologismen}

Mit Bezug auf die in 5.2.3.2 getroffenen Prognosen werden bezüglich der Kenntnis und/oder Akzeptanz der sechs ausgewählten Lexemgruppen folgende Hypothesen aufgestellt:

I.1 Da es sich bei den Informanten um Informatiker handelt, wird die Mehrheit der Termini (mit Ausnahme der erfundenen Testwörter, vgl. 7.1.2.1) als bekannt angegeben.

I.2 Die Termini e-mail und mail werden aufgrund ihrer Kürze häufiger verwendet als message électronique, messagerie électronique oder courrier électronique. Mél wird aufgrund der pseudoenglischen Aussprache sicherlich seltener verwendet als die beiden englischen Termini.

I.3 Die Neologismen page d'accueil und fournisseur d'accès werden einen höheren Akzeptanzwert erhalten als die entsprechenden Anglizismen homepage und (access) provider.

I.4 Toile wird aufgrund seiner Kürze erheblich öfter gebraucht als die alternativ möglichen französischen Neologismen toile d'araignée mondiale und toile mondiale. Populärer als toile ist jedoch der Anglizismus web.

\footnotetext{
${ }^{44}$ Der Faktor Geschlecht darf eigentlich in keiner soziolinguistischen Studie fehlen. Jedoch ist es bei einer Studie, die sich an Informatiker und im Internet-Sektor tätige Personen richtet, nicht anzunehmen, dass beide Geschlechter in einem ausgewogenen Verhältnis antworten. Hinzu kommt nicht nur, dass weniger Frauen in den entsprechenden Bereichen arbeiten, sondern auch die Tatsache, dass die meisten Diskussionsforen derzeit überwiegend von Männern genutzt werden. Viele Frauen nutzen insbesondere die Diskussionsforen wenig bis gar nicht (zum unterproportionalen Frauenanteil vgl. Eimeren/Gerhard/Frees 2002, 348; vgl. Kap. 6, Fußnote 10 und Kap. 8, Fußnote 8). Es ist davon auszugehen, dass der Anteil an teilnehmenden Frauen unter $20 \%$ liegen wird. Es ist fraglich, ob bei einem so ungleichen Verhältnis ein Vergleich sinnvoll sein kann.
} 
I.5 Chat wird aufgrund seiner Kürze und aufgrund der doppeldeutigen französischen Äquivalente häufiger verwendet als die französischen Neologismen causette und bavardage.

I.6 Cracker wird aufgrund seiner langen Existenz als Computer-Terminus einen höheren Bekanntheits- und Verwendungsgrad aufweisen als pirate.

I.7 Die persönliche Präferenz stimmt nicht prinzipiell mit dem eigenen aktiven Sprachgebrauch überein.

Die siebte und letzte Hypothese leitet sich nicht aus den vorangehenden Ausführungen ab, sondern rekurriert auf einen in 2.1 dargestellten Sachverhalt: Der eigene Sprachgebrauch hängt nicht nur von affektiven Einstellungen $a b$, sondern auch von zahlreichen externen Faktoren, wie z. B. die Anpassung an das sozial gewünschte bzw. prestigeträchtigere Sprachmodell. Das bedeutet, dass der Sprachgebrauch zahlreichen (auch unbewussten) Kontrollmechanismen unterliegt. Auf den Unterschied zwischen Wortkenntnis und Wortverwendung wies Carstensen bereits in den 1960er Jahren hin:

„[...] der ,Durchschnittsleser' von Zeitungen und Zeitschriften lernt zwar eine relativ große Menge engl. Fremd- und Lehnwörter kennen, aber das bedeutet natürlich keineswegs, daß er sie versteht und vor allem nicht, daß er sie auch selbst verwenden würde" (Carstensen $1965,21)^{45}$.

\subsubsection{Hypothesen zu Korrelationen zwischen biosozialen Daten der Informanten und ihrem Sprachverhalten/ihren Einstellungen}

Die Thesen in diesem Abschnitt sind länderübergreifend und beziehen sich auf die Korrelationen zwischen den in der Soziolinguistik gängigen personenspezifischen Parametern (drittes Fragebogenmodul) und den Daten des ersten und zweiten Fragebogenmoduls. Die in dieser Gruppe aufgestellten Hypothesen werden im Wesentlichen aus den Ergebnissen anderer soziolinguistischer Studien abgeleitet.

Den folgenden sechs Hypothesen liegt die Annahme zugrunde, dass die Akzeptanz eines Ersatzwortes bzw. sprachpolitischer Maßnahmen weniger durch die Nationalität der Informanten gesteuert wird als durch deren persönliche Eigenschaften. Die personenbezogenen Parameter, die bei der Auswertung dieser Studie von Belang sind, sind Alter, Bildungsgrad, Beruf, Englischkenntnisse und Vertrautheit mit dem Medium Internet.

\footnotetext{
45 Entsprechend weist Carstensen $(1979,324)$ am Ende seines Aufsatzes „Zur Intensität und Rezeption des englischen Einflusses" auf die Dringlichkeit der Erforschung von Wortkenntnis und Wortverwendung hin: „Das Problem von ,Angebot und Nachfrage‘, d.h. dem, was in Pressepublikationen einschließlich Fernsehen (häufig oder selten) an Anglizismen geboten wird, und dem, was der ,Durchschnittssprecher des Deutschen', eine ebenso problematische Größe, aus der Fülle des Angebotenen tatsächlich (,richtig' oder ,falsch') verwendet, bedarf viel dringender einer Klärung als die Frage, wieviele Anglizismen pro Zeitungsseite aufzufinden sind.“
} 
Hypothese II.1: Sprecher sind gegenüber der angloamerikanischen Lexik weniger negativ eingestellt als gegenüber dem staatlichen Einfluss auf diese Fremdwörter.

Diese These entstammt der Äußerung von Lerat (1990, 397, zitiert am Ende von 2.3.2). Konkret bedeutet dies, dass die Ablehnung der Anglizismen niedriger ausfallen dürfte als die Ablehnung der staatlichen Maßnahmen, nach denen im zweiten Fragebogenmodul gefragt wird.

Hypothese II.2: Es gibt generationsspezifische Unterschiede: Die älteren Informanten werden eher die französische Internet-Terminologie bevorzugen als die jüngeren.

Bekanntermaßen sind Alter und Geschlecht maßgebliche Faktoren, die sowohl Einstellungen als auch Handlungen beeinflussen. Studien zeigen, dass jüngere Sprecher in Bezug auf die Sprache eine progressivere Einstellung aufweisen (vgl. z.B. Garsou 1991; Goudaillier 1982; Guilford 1997; Helfrich 1993, 76, 151-158, 293; Müller 1975, 14146). Unter der Voraussetzung, dass Anglizismen als ein neueres Phänomen und Ausdruck einer progressiveren Sprecherhaltung und die Verwendung genuin französischer Ausdrücke als konservativeres Sprachverhalten betrachtet werden, werden jüngere Informanten mehrheitlich die vorgeschlagenen Anglizismen präferieren und eine Einmischung des Staates in sprachpolitische Fragen mehrheitlich als unnötig erachten. Der Prozentsatz der Informanten, die Neologismen bevorzugen und sprachpolitische Eingriffe für sinnvoll halten, dürfte in der älteren Generation höher sein als in der jüngeren.

Hypothese II.3: Je höher der Bildungsgrad der Informanten, desto höher die Ablehnung von sprachpolitischen Maßnabmen und den daraus resultierenden Vorschriften.

Diese Hypothese stützt sich vor allem auf die Ergebnisse der Studien von Garsou (1991, vgl. 2.3.3.2.4), die nachweist, dass Lehrer und andere Akademiker sich in höherem Maße gegen staatliche Sprachlenkung aussprechen als die Restbevölkerung.

\section{Hypothese II.4: Informatiker lehnen die französischen Termini mehrheitlich ab.}

Diese These leitet sich aus den Ergebnissen der Studie von Le Guilly-Wallis (1991) ab, der zufolge ein Informatiker, der nicht die englische Terminologie verwendet, von seinen Kollegen als weniger kompetent eingeschätzt wird ${ }^{47}$.

\footnotetext{
46 Bereits 1975 schrieb Müller (1975, 141): „Die ältere Generation verhält sich sprachlich konservativer; die jüngere, jeweils der Träger der meisten Neuerungen, repräsentiert im Querschnitt ein fortgeschrittenes Stadium, eine weitere Etappe in der immerwährenden Entwicklung."“

$47 \mathrm{Um}$ dem Einfluss des beruflichen Umfeldes auf die Verwendung von Terminologie nachgehen zu können, sind weitere Untersuchungen nötig, bei denen eine identische oder ähnliche Befragung mit anderen Berufsgruppen durchgeführt wird. Auf diese Weise kann ermittelt werden, welche Unterschiede im Sprachgebrauch auf den Beruf der Informanten zurückzuführen sind. Im Falle der Internet-Terminologie könnte es bereits interessant sein, die Ergebnisse der hier befragten Fachleute den Ergebnissen einer Befragung von interessierten Computerlaien (d.h. Leuten, die sich nicht beruflich mit Computern oder dem Internet beschäftigen) gegenüberzustellen.
} 
Hypothese II.5: Je besser die Englischkenntnisse der Informanten ausfallen, desto eher werden Anglizismen verwendet.

Viele Anglizismen, die sich (noch) nicht etabliert haben, führen bei frankophonen Personen, die des Englischen nicht oder nur rudimentär mächtig sind, zu Unsicherheiten bezüglich der korrekten Aussprache. Wer einmal im französischsprachigen Ausland war, dürfte gemerkt haben, dass frankophone Sprecher die Aussprache englischer Wörter meistens an das französische Lautsystem anpassen, sofern dies möglich ist. Relativ selten werden englische Lehnwörter in korrekter englischer Lautung realisiert, weil das insbesondere unter Franzosen als snobistisch gilt (vgl. Kap. 2, Fußnote 37).

Wer jedoch die englische Sprache beherrscht und aus der Wortform zugleich auch ihre Bedeutung ableiten kann, wird weniger Scheu davor haben, das englische Wort zu verwenden. Hinzu kommt, dass in technischen Bereichen wie der Informatik solide Englischkenntnisse Voraussetzung sind, da dort viele Informationen ohnehin nur in englischer Sprache verfügbar sind.

Hypothese II.6: Wer länger als seit 1999 das Medium Internet benutzt, wird eher die InternetAnglizismen als die entsprechenden Neologismen verwenden.

Diese Hypothese beruht auf der Überlegung, dass Personen, die sich schon vor der Einführung der ersten Terminologieliste zum Internet-Vokabular mit diesem Medium auseinandergesetzt haben und Sachverhalte in Ermangelung französischer Neologismen zunächst mit den englischen Termini bezeichnet haben, sich nicht umgewöhnen wollen bzw. nicht bereit sind, ihren Sprachgebrauch aufgrund eines Erlasses zu ändern. Die Ablehnung der Neologismen dürfte proportional zur Anzahl der Jahre, die die Informanten bereits das Internet und die entsprechende Terminologie nutzen, steigen. Wer also bereits seit drei Jahren von homepage und provider spricht, wird diese Gewohnheit kaum aufgrund eines Erlasses ändern ${ }^{48}$. Eine Ausnahme stellen die Termini message électronique und courrier électronique dar, weil für den Anglizismus e-mail bereits Ende 1997 entsprechende französische Neologismen geschaffen wurden.

Dabei darf allerdings nicht vergessen werden, dass die meisten französischen Neologismen nicht erst mit der Konzeption der Terminologielisten geschaffen wurden, sondern bereits vor der Verabschiedung der Erlasse (in diesem Fall: 1997 und 1999) kursierten und daher den Internet-Nutzern auch schon vor dem Erscheinen der offiziellen Terminologielisten bekannt waren.

\subsubsection{Länderspezifische Hypothesen zur Bewertung der Sprachpoli- tik und Terminologiearbeit}

Die hier vorzustellenden Hypothesen werden aufgrund der drei befragten Sprechergruppen und des entsprechend unterschiedlich konzipierten zweiten Fragebo-

\footnotetext{
48 Es ist anzunehmen, dass Informatiker und Personen, die im Internet-Sektor beschäftigt sind, ohnehin vor der Publikation des ersten Erlasses zur Internet-Terminologie bereits mit dem Medium vertraut waren. Insofern ist es möglich, dass dieser Punkt sich bei der Auswertung der Studie als überflüssig erweist.
} 
genmoduls in drei Gruppen unterteilt. Die in 5.3.3.1, 5.3.3.2 und 5.3.3.3 aufgeführten Hypothesen beziehen sich nur auf das zweite Fragebogenmodul zur Sprachpolitik, da die Hypothesen zum ersten Fragebogenmodul bereits in 5.3.1 und 5.3.2 erörtert wurden. Gruppe 1 enthält die frankreichspezifischen Hypothesen, Gruppe 2 bezieht sich auf Belgien, Gruppe 3 auf die Schweiz.

\subsubsection{Hypothesen zu Frankreich}

Hypothese F1: Mehr als die Hälfte der befragten Franzosen bält Sprachpolitik für notwendig49.

Diese die Einstellung der Informanten zur Notwendigkeit von Sprachlenkung und Sprachpolitik betreffende Hypothese wird im Anschluss an die Ergebnisse Gouadecs (1993; vgl. 4.3.2) entwickelt, welcher feststellt, dass die befragten Informatiker ein Eingreifen des Staates (jedoch ohne Sanktionen bei Verstößen) mehrheitlich für wünschenswert halten. Es wird davon ausgegangen, dass das Bedürfnis nach Sprachpolitik gestiegen ist. Zum Vergleich: Die Befragung Fuggers (1979/1983a) ergab, dass Sprachpolitik von 47\% der befragten Personen als überflüssig bewertet und nur von $23 \%$ als unbedingt nötig erachtet wurde.

Die Akzeptanz der konkreten Umsetzung der Sprachpolitik, nämlich die Verabschiedung von Terminologie-Erlassen, dürfte jedoch auf wesentlich weniger Zustimmung stoßen als das abstrakte Konzept der Sprachpolitik (vgl. Garsou 1991; 2.3.3.2.4).

Hypothese F2: Die Existenz der Terminologieerlasse zur Internet-Terminologie sowie deren Inhalt ist der Mehrheit der Informatiker bekannt.

Auf den ersten Blick erscheint es abwegig davon auszugehen, dass die Mehrheit der Informanten über die Internet-Terminologie informiert sein soll, da insbesondere die Studien Fuggers (1979 et al.), Gaudins (1991) und Gouadecs (1993) gezeigt haben, dass die von ihnen befragten Informanten über die Inhalte der einzelnen Erlasse kaum informiert waren. Jedoch hat sich die Verbreitung der Ergebnisse der einzelnen Terminologiekommissionen durch die Arbeit der DGLF/DGLFLF seit 1996 enorm verbessert: Die Wortlisten erscheinen nicht mehr nur in Form von Printmedien, sondern sind seit einigen Jahren auch im Internet einsehbar (vgl. 3.2.4). Hinzu kommt, dass die französische Sprachpolitik durch den Wirbel um die Loi Toubon im Jahre 1994 häufig in den Nachrichten und der Presse thematisiert wurde und insofern auch lange Zeit öffentliches Gesprächsthema war.

\footnotetext{
49 An dieser Stelle ist auf die mit einer so pauschal formulierten Hypothese verbundenen Schwierigkeiten hinzuweisen. Einstellungen hängen, wie in 2.1 gezeigt wurde, sehr eng von den persönlichen Eigenschaften der Personen ab. Eine Befragung beispielsweise unter Französischlehrern, die in Bezug auf Sprachfragen allein von Berufswegen die Norm vertreten und somit tendenziell am Erhalt eines bestimmten Sprachstandes festhalten (müssen), hat mit Sicherheit ein ganz anderes Ergebnis zur Folge als eine Untersuchung unter Informanten, die im naturwissenschaftlich-technischen Bereich beschäftigt sind und die aktuelle Sprachentwicklung in der Regel etwas pragmatischer und nüchterner sehen.
} 


\subsubsection{Hypothesen ₹u Belgien}

Hypothese B1: Die Mehrheit der befragten Belgier wird sprachpolitische Maßnahmen zur Eindämmung der Anglizismen befürworten ${ }^{50}$.

Die Untersuchung von Garsou (1991) hat deutlich gezeigt, wie große Chancen die frankophonen Belgier sprachpolitischen Maßnahmen zur Förderung und Verteidigung des Französischen einräumen. Über 80\% der von Garsou Befragten sprechen sich für die Verteidigung der französischen Sprache aus, 70\% befürworten diesbezügliche staatliche Maßnahmen. Sogar die Erarbeitung konkreter Gesetze befürworten immerhin noch $50 \%$ (vgl. 2.3.3.2.4).

Hypothese B2: Im Vergleich zum Bekanntheitsgrad der offiziellen französischen Internet-Terminologie in Frankreich fällt der Bekanntheitsgrad der im Internet abrufbaren belgischen Internet-Terminologieliste niedriger aus.

Diese These leitet sich aus zwei Umständen ab: Zum einen sind die Inhalte der belgischen Sprachpolitik offensichtlich kaum bekannt ${ }^{51}$, zum anderen wird die belgische Terminologie nur über die im Internet zugängliche Datenbank verbreitet, nicht aber über andere Medien wie Amtsblätter oder Broschüren.

\subsubsection{Hypothesen zur Schweiz.}

Hypothese S1: Die Anzahl der Romands, die sprachpolitische Vorschriften begrüßen, ist geringer als die der Franzosen und frankophonen Belgier.

Die Schweizer gelten in Sprachfragen als recht tolerant, solange sie sich nicht in ihrem Recht bedroht fühlen, sich in ihrer Muttersprache verständigen zu können. Außerdem hat Korpusplanung in der französischen Schweiz kaum Tradition. Bisher in der Schweiz verabschiedete Gesetze erstrecken sich nur auf den Status und die Verbreitung der jeweiligen Sprachen, nicht aber auf die französische Sprache selbst. Hinter dieser Hypothese steht somit auch die Erfahrung, dass sprachpolitische Vorschriften in Ländern, in denen Sprachpolitik keine Tradition hat, nicht so gut angenommen werden wie beispielsweise in Frankreich, das auf mehr als vier Jahrhunderte sprachpolitischer Eingriffe zurückblicken kann ${ }^{52}$.

Hypothese S2: Die schweizerische (Internet-)Terminologie ist nur wenigen Informanten bekannt. Die schweizerische (Internet-)Terminologie ist nicht so leicht zugänglich wie die französische, für die es auch andere Distributionsformen gibt. Außerdem ist sie im Netz nicht so leicht zu finden wie die belgische Terminologiedatenbank, da der

\footnotetext{
50 Auch hier gilt das in der vorangehenden Fußnote Angemerkte.

51 Zur Erinnerung: Die von Garsou (1991) befragten Informanten plädieren zwar mehrheitlich für politische Maßnahmen zum Schutz des Französischen, jedoch wissen nur 5\% über die Existenz des décret Spaak Bescheid. Einschränkend ist zu sagen, dass zwischen dessen Verabschiedung (1978) und der Befragung Garsous im Jahre 1986 acht Jahre vergangen sind, der gleiche Abstand übrigens, wie zwischen der Verabschiedung der Loi Toubon (1994) und der WWW-Befragung (2002).

52 Ein Beispiel ist die deutsche Rechtschreibreform, die immer noch heftig diskutiert wird und weder in allen Bundesländern noch von allen Zeitungen angenommen wird. In Schleswig-Holsteins Schulen wird auch weiterhin in der alten Rechtschreibung unterrichtet, und die Frankfurter Allgemeine Zeitung hat die Umstellung auf die neue Rechtschreibung nach vehementen Leserprotesten rückgängig gemacht.
} 
sprachinteressierte Bürger möglicherweise nicht auf den Seiten der Schweizerischen Eidgenossenschaft nach entsprechenden Initiativen suchen würde, sondern eher auf den Internetseiten schweizerischer Sprachpflegegesellschaften oder Sprachvereine. Außerdem gibt es für die schweizerische Terminologie, zumindest solange diese noch nicht vollständig ist, keine anderen Distributionsformen als die Internet-Publikation.

\subsection{Zusammenfassung}

5.1 zeigt anhand der Ergebnisse bisher durchgeführter Akzeptanzstudien auf, welche sprachlichen und außersprachlichen Faktoren der Etablierung eines offiziellen Neologismus förderlich und welche ihr hinderlich sind. 5.2 stellt dar, wie aus der insgesamt 53 Einträge umfassenden Terminologieliste vom 16. März 1999 (zuzüglich engl. e-mail und seine französischen Ersatzwörter aus der Terminologieliste vom 02. Dezember 1997), sechs zu testende Lexemgruppen ausgewählt wurden. Um die Anzahl der für den Fragebogen in Frage kommenden Termini einzuschränken, wurden alle Termini, die einem der folgenden sieben Kriterien untergeordnet werden konnten, für die Untersuchung ausgeschlossen, da sie entweder im Rahmen von Akzeptanzstudien nur sehr schwer zu verwerten sind (Kriterium 1), zur Peripherie der Internet-Terminologie zählen (Kriterium 2 und 3), ihre Akzeptanz aufgrund der in 5.1 genannten Kriterien als sehr wahrscheinlich (Kriterium 4, 5 und 6) bzw. sehr unwahrscheinlich (Kriterium 7) anzusehen ist:

1. Akronyme,

2. Unterbegriffe,

3. Termini, die nur dem Wortfeld Informatik zugeordnet sind,

4. eindeutige 1:1-Übersetzung,

5. grafische Übereinstimmung zwischen Anglizismus und Ersatzwort,

6. Anpassung des Anglizismus an das morphologische und/oder phonetische System des Französischen und

7. ein im Vergleich zum Anglizismus bedeutend längeres französisches Ersatzwort.

Diese erste Selektion reduzierte die Anzahl der potenziell zu testenden Lexemgruppen auf 20. In einem zweiten Schritt wurden die Ergebnisse einer im Frühjahr 2001 durchgeführten WWW-Befragung herangezogen, in der die Bekanntheit der verschiedenen Internet-Begriffe ermittelt wurde. Die sechs bekanntesten Termini wurden ausgewählt und nach einem von Braselmann (1999a) entworfenen Modell zur Wortbildung von Neologismen analysiert. Anschließend wurden Prognosen geäußert, in welchen Fällen sich wahrscheinlich der englischsprachige und in welchen Fällen sich wahrscheinlich der französischsprachige Terminus durchsetzen wird. Im Anschluss an die Prognosen, die mit Hilfe des ersten Fragebogenmoduls überprüft werden sollen (vgl. 7.1.2.1), werden in 5.3 weitere Hypothesen aufgestellt, die vor allem aus den vorangehenden Kapiteln abgeleitet wurden und sich 1. auf den Bekanntheitsgrad und die Akzeptanz der einzelnen Neologismen, 2. auf den Zusammenhang zwischen den biosozialen Daten der Befragten und 
ihrem Sprachverhalten bzw. ihren Einstellungen und 3. auf mögliche länderspezifische Unterschiede zwischen den Einstellungen der Informanten beziehen. Die in 5.3 formulierten Arbeitshypothesen sind grundlegend für die WWW-Befragung und werden in den Auswertungskapiteln 9-12 an entsprechender Stelle wieder aufgegriffen.

Kapitel 6 wird den Bogen von der Linguistik zur sozialwissenschaftlichen Methodenforschung schlagen. Wie in der Einleitung dargelegt wurde, findet die Methodik der Online-Befragung in der Linguistik bisher kaum Anwendung. Sie bietet allerdings gegenüber den klassischen Papier-Fragebögen viele Vorteile und stellt daher auch für die Linguistik ein zukunftsträchtiges Forschungsinstrument dar, das nicht länger ignoriert werden darf. 


\section{Die empirische Studie: Theoretische Vorüber- legungen zur Methodik}

In diesem Kapitel wird die der Studie zugrunde liegende Methodik erörtert. Bereits der Titel der Arbeit gibt Aufschluss über das Forschungsinstrument, das World Wide Web (WWW). Doch wie kann das World Wide Web für Forschungszwecke und speziell für Befragungen genutzt werden? Welche Typen von OnlineBefragungen gibt es und welcher Typ wird für diese Studie verwendet?

Fragebogenstudien werden in der Soziolinguistik und insbesondere in der Einstellungsforschung häufig eingesetzt (vgl. 2.2). Zur Erstellung von Umfragen greift die Linguistik nach wie vor auf die Methoden und die Methodenforschung der Sozialwissenschaften zurück. Speziell linguistische Erhebungsmethoden (wie etwa die in 2.2 erwähnte matched-guise-Technik) oder für die Linguistik verfasste Methodenwerke wie das Buch Empirische Sprachwissenschaft von Schlobinski (1996) und Empirie in Linguistik und Sprachlehrforschung von Albert/Koster (2002) bleiben die Ausnahme.

Die Methodik der Papier-Bleistift-Befragung ${ }^{1}$ kann im Rahmen der sozialwissenschaftlichen Forschung als hinreichend beschrieben gelten. Seit einigen Jahren konzentriert sich die Methodenforschung auf das noch sehr junge Messinstrument der WWW-Befragung. Doch inwiefern unterscheiden sich die beiden Befragungsformen der Papier-Bleistift- und der WWW-Befragung voneinander, und wo weisen sie Parallelen auf? Wann und warum wird die neue Methode eingesetzt, oder anders gefragt, was rechtfertigt den Einsatz dieser neuen Methode gegenüber der

\footnotetext{
1 In der neueren Umfrageforschung wird häufig von Papier-Bleistift-Befragungen bzw. „Paperpencil“"-Fragebögen bzw. „Paper-pencil“-Befragungen gesprochen, um den Unterschied zu elektronischen Fragebögen deutlich zu machen.
} 
herkömmlichen? Was ist zu beachten, wenn die potenziellen Informanten in einem Anschreiben auf die Umfrage hingewiesen werden?

Einschränkend zu der in diesem Kapitel zitierten Literatur ist anzumerken, dass diese den Forschungsstand von Anfang 2002 widerspiegelt. Somit werden nur Forschungsergebnisse berücksichtigt, die in die Erstellung und Durchführung der Fragebogenstudie Eingang finden konnten. Durch die zahlreichen technischen und methodenwissenschaftlichen Fortschritte, die sich auf diesem Gebiet vollziehen, wird sich das Erscheinungsbild des Internet sowie der Forschungsstand zu Online-Befragungen in den nächsten Jahren erheblich verändern.

\subsection{Das Internet als neues Umfragemedium}

Die Welt der Umfrageforschung ist heute durch die Entwicklung neuer Informations- und Kommunikationstechnologien vielfältiger und bunter als vor 20 Jahren (vgl. Kaase 1999, 97-99). Heutzutage sind Hunderte Millionen Menschen weltweit über das Internet erreichbar, weswegen es sich ausgezeichnet für die Datengewinnung eignet. Für die Erhebung von Daten werden vor allem drei Internet-Dienste genutzt, nämlich das World Wide Web, E-Mail und die Diskussionsforen ${ }^{2}$ (vgl. Theobald 2000a, 2).

WWW-Befragungen, d.h. Umfragen im World Wide Web, erfreuen sich steigender Beliebtheit und dominieren derzeit im Bereich der Online-Forschung ${ }^{3}$. Die Vorteile von Online-Umfragen liegen auf der Hand: Mit geringem finanziellen Aufwand lassen sich über weite Gebiete innerhalb kurzer Zeit Umfragen realisieren, die vergleichsweise hohe Teilnehmerzahlen aufweisen (vgl. Bandilla/Hauptmanns 1998, 36; Theobald 2000a, 3).

WWW-Befragungen eignen sich insbesondere zur Durchführung quantitativer Studien. Quantitativ ausgerichtete Befragungen bestehen vorwiegend aus geschlossenen Fragen, die ein automatisches Auswerten ermöglichen. Qualitative Daten über WWW-Befragungen zu erhalten, dürfte weitaus schwieriger sein. Dies würde Fragebögen mit offenen Fragen bedingen, die aufgrund des hohen Zeitund Denkaufwandes bei den Befragten nicht unbedingt positiv bewertet werden

\footnotetext{
2 Während E-Mail und das World Wide Web inzwischen fast allen Internet-Nutzern bekannt sind, haben die Diskussionsforen einen geringeren Bekanntheitsgrad. In Diskussionsforen, auch Newsgruppen, Netnews oder Newsgroups genannt, können Leute aus aller Welt ihre Meinung zu bestimmten Themen kundtun. Es gibt viele Tausend Diskussionsforen, die nach Regionen, Sprachen und/oder Themen gegliedert sind. Häufig wird dieser Internetdienst auch Usenet genannt, die Abkürzung für User Network.

3 In der Methodenforschung ist auch der englische Terminus Online Research sehr verbreitet. Das Internet wird v.a. als Instrument zur Durchführung sog. self administered surveys genutzt, d.h. der Befragte antwortet auf die gestellten Fragen allein am Computer. Neben dieser Befragungsform, bei der der Informant auf sich selbst gestellt ist, wird das WWW auch für moderierte Befragungen sowie die teilnehmende Beobachtung eingesetzt. Diese beiden Formen, die moderierte Befragung sowie die teilnehmende Beobachtung, werden z.B. über die IRC-Technologie (Chat) realisiert. Auf diese Formen der Datengewinnung wird dieses Kapitel nicht eingehen, sondern sich ausschließlich den unmoderierten Befragungsformen via Internet widmen.
} 
und somit hohe Ausfallquoten (durch Abbruch) nach sich ziehen ${ }^{4}$. Zur Erhebung qualitativer Daten sind daher die moderierten Formen der Befragung bzw. die teilnehmende Beobachtung besser geeignet (vgl. Fußnote 3).

Bisher existiert noch kein systematisches Wissen über die Durchführung von WWW-Umfragen, was darauf zurückzuführen ist, dass dieses Medium erst seit Mitte der 1990er Jahre für die Forschung genutzt werden kann (vgl. Gräf 1999, 159). Einen ersten, bedeutenden Schritt in diese Richtung stellt die 2000 erschienene Dissertation Das World Wide Web als Befragungsinstrument von Axel Theobald dar. Theobald geht eingangs auf die Besonderheiten dieses neuen Umfragetyps im Vergleich $\mathrm{zu}$ den herkömmlichen Befragungsinstrumenten (Telefonbefragung, Interview und schriftliche Befragung) ein und skizziert die Vor- und Nachteile von WWW-Befragungen. Im Folgenden setzt sich Theobald ausführlich mit den Aspekten der Teilnehmeransprache, der Teilnehmermotivation und der Teilnehmerkontrolle bei WWW-Umfragen auseinander. Er vergleicht, inwiefern WWWBefragungen den v.a. aus sozialwissenschaftlicher Perspektive gestellten Anforderungen („Gütekriterien“) gerecht werden können. Der Arbeit Theobalds folgt 2001 die Dissertation von Batinic, der im Wesentlichen zwei Fragestellungen nachgeht: 1. die Qualität der bei Internet-Fragebögen gewonnenen Daten zu untersuchen und 2. dem Leser das nötige Umsetzungswissen zu vermitteln, damit dieser selbst eine solche Studie durchführen könne.

Um repräsentative Bevölkerungsumfragen zu den verschiedensten Lebensbereichen durchführen zu können, ist das Internet (noch) nicht das richtige Medium, da bestimmte Bevölkerungsschichten (insbesondere die Generation der über 40Jährigen sowie Frauen) nicht in dem Maße im Internet repräsentiert sind, wie es ihrem Bevölkerungsanteil entspricht (vgl. für Deutschland z.B. Eimeren/Gerhard/Frees 2002) $)^{5}$. Online-Befragungen wurden deshalb in der zweiten Hälfte der

\footnotetext{
${ }^{4}$ Zur generellen Unterscheidung zwischen quantitativen und qualitativen Befragungen in der Sprachwissenschaft schreibt Schlobinski (1996, 15): „Quantitative und qualitative Methoden in den Sprachund Sozialwissenschaften bezeichnen unterschiedliche Vorgehensweisen, Daten zu gewinnen, zu beschreiben und zu erklären. Quantitative Verfahren sind solche, bei denen das Operieren mit Zahlen eine zentrale Rolle spielt, qualitative sind solche, bei denen der Interpretationsprozeß im Vordergrund steht und die sich auf der Folie hermeneutischer Verfahren entwickelt haben. Quantitative Verfahren sind letztlich statistische Verfahren, qualitative sind - zumindest in den Sprachwissenschaften - solche, bei denen Texte oder Diskurse nach einer bestimmten Methodik interpretativ analysiert werden." Quantitative und qualitative Datenerhebung schließen sich keineswegs aus. Zum einen sind zweistufige Untersuchungen denkbar, die sich aus einem Fragebogen mit ausschließlich geschlossenen Fragen (quantitative Methode) und anschließenden Interviews, in denen die Antworten hinterfragt werden (qualitative Methode), zusammensetzen. In 4.3.2 wurde die fünfstufige Studie zur Informatik-Terminologie unter der Leitung von Gouadec vorgestellt, in der quantitative und qualitative Methoden kombiniert worden sind. Zum anderen ist es aber auch möglich, innerhalb eines Fragebogens beide Methoden zu verbinden, indem nicht nur geschlossene Fragen, sondern auch halboffene Fragen bzw. offene Fragen eingesetzt werden, bei denen die Befragten aufgefordert sind, selbst eine Antwort zu formulieren.

${ }^{5}$ Kaase $(1999,13)$ definiert den Terminus Repräsentativerbebung bzw. -befragung wie folgt: „Mit dem Ausdruck Repräsentativerbebung oder -befragung ist gemeint, daß auf der Basis einer dem statistischen Zufallsprinzip folgenden Auswahl der zu Befragenden aus der Gesamtpopulation ein Scbluß von der Stichprobe auf die Gesamtheit möglich ist [...]. Dabei kommt es entscheidend darauf an, daß jedes Element der Zielpopulation eine berechenbare Chance hat, in die Stichprobe aufgenommen zu werden." Die Zielpopulation ist mit der sog. Untersuchungsgesamtheit gleichzusetzen, d.h. mit allen Personen, über die
} 
1990er Jahre hauptsächlich in internetverwandten Branchen bzw. bei internetaffinen Zielgruppen eingesetzt (vgl. z.B. Spintig 1999, o.S.). Für Fragestellungen, die das Internet selbst betreffen, sind die Vorteile von Online-Umfragen evident: Auf einfachem Weg erreicht der Untersuchungsleiter die für derartige Befragungen interessante, interessierte und kompetente Bevölkerungsschicht. Seit der Jahrtausendwende hat es hier aber, wie Theobald (2000b, 298) feststellt, einen Wandel gegeben:

„Die Einsatzmöglichkeiten des WWW zur Primärdatengewinnung per Befragung gehen jedoch über die Erhebung von internetspezifischen Daten hinaus. Es wird mittlerweile auch als Erhebungsinstrument in sozialwissenschaftlichen Umfragen und Experimenten zu verschiedensten Themen verwendet, und es existieren umfangreiche Verzeichnisse bzgl. WWW-Befragungen [...] bzw. WWW-Experimenten $[\ldots]$..“

Trotz der vielen, mit Online-Befragungen verbundenen Vorteile scheuen sich viele Wissenschaftler, dieses Medium zu Forschungszwecken zu verwenden. Batinic/Puhle/Moser (1999, 93f.) führen das zurück auf die doppelte Anforderung, die eine Online-Umfrage an den Untersuchungsleiter stelle: Neben fachlichen Kenntnissen benötige der Untersuchungsleiter Kenntnisse der Informatik und der Sozialwissenschaften (vgl. 6.3.1, „Hohe Anforderungen an den Untersuchungsleiter $\left.{ }^{6}\right)$, wobei einschränkend anzumerken ist, dass Kenntnisse der Sozialwissenschaften die Voraussetzung für jede Art von Befragung sind.

\subsection{Die verschiedenen Typen von Online-Befragungen}

Nach der Einteilung des ADM et al. (2000, 1) schließt der Begriff Online-Befragung die folgenden drei Befragungsformen ein, bei denen die Informanten den Fragebogen

- , ,auf dem Server des Forschungsinstituts oder eines Providers mittels Internet online ausfüllen,

- vom Server mittels Internet herunterladen und per E-Mail zurücksenden oder

\footnotetext{
Aussagen gemacht werden sollen (vgl. ebd., 16). Es ergeben sich somit zwei Voraussetzungen für eine korrekt gezogene Zufallsstichprobe: 1. alle Mitglieder der ausgewählten Untersuchungsgesamtheit müssen bekannt sein, 2. alle müssen die gleiche Chance haben, gezogen zu werden. Beides ist bei Internet-Umfragen derzeit noch nicht möglich, da 1. die Grundgesamtheit der Internet-Nutzer nicht bekannt ist und 2. es noch keine Verfahren gibt, die eine Auswahl ermöglichen, bei der alle Mitglieder die gleiche Chance haben, von der Umfrage Kenntnis zu erlangen. Einen Ausnahmefall stellt die Befragung durch die Ankündigung über eine Mailingliste dar, weil in diesem Fall zumindest dem Betreiber der jeweiligen Liste alle Mitglieder bekannt sind.
} 
- in eine E-Mail integriert zugeschickt bekommen und auf die gleiche Weise zurücksenden." 6

Allen drei Verfahren ist gemeinsam, dass auf den Einsatz eines Interviewers verzichtet wird. Als einfachste Variante zählen die Befragungen per E-Mail. Hierbei wird an ausgewählte E-Mail-Adressen je ein Fragebogen gesandt, der am Computer ausgefüllt und via E-Mail an den Absender (Forscher) zurückgesendet werden soll (vgl. Bandilla/Hauptmanns 1998, 37f.). Die beliebteste und am häufigsten genutzte Umfragemöglichkeit ist jedoch die WWW-Befragung. Aufgrund zahlreicher grafischer Möglichkeiten (Einsatz typografischer Mittel, Einsatz von Farben und Bildern), multimedialer Elemente (Bild- und Tondokumente) und erweiterten technischen Möglichkeiten (Formulare mit verschiedenen Antwortvorgaben oder leeren Textfeldern, automatische Filterführung) sind WWW-Befragungen für die Internet-Nutzer attraktiver als ein per E-Mail versandter Fragebogen (vgl. Bandilla/Hauptmanns 1998, 38).

Mit der Erstellung eines Online-Fragebogens ist die Arbeit für den Untersuchungsleiter jedoch noch längst nicht beendet. Damit der Forscher die benötigten Daten erhält, muss der Fragebogen vom potenziellen Umfrageteilnehmer erst einmal gefunden werden. Es bieten sich mehrere Möglichkeiten an, auf eine Befragung aufmerksam zu machen ${ }^{7}$ :

- Ankündigung in Diskussionsforen oder Mailinglisten (vgl. 6.4),

- Links, die von möglichst vielen Internetseiten auf die Befragung hinweisen,

- Platzierung von Werbebannern auf häufig besuchten WWW-Seiten (Kostenfrage!) und

- Anmeldung des Fragebogens bei verschiedenen Suchmaschinen ${ }^{8}$.

Es ist zu beachten, dass die Art und Weise, in der die Informanten auf die Umfrage aufmerksam gemacht werden, direkten Einfluss auf die Zusammensetzung der Stichprobe hat, da nur diejenigen Internet-Nutzer, die von der Umfrage erfahren, auch die Möglichkeit haben, an ihr teilzunehmen (vgl. Theobald 2000b, 300). Insbesondere die Ankündigung eines Fragebogens in Diskussionsforen erreicht nur einen sehr beschränkten Personenkreis innerhalb der Internet-Nutzer, nämlich nur diejenigen, die sich regelmäßig an den Diskussionen in dem entsprechenden Forum beteiligen bzw. die Beiträge zumindest rezipieren oder zufällig zu dem Zeitpunkt der Ankündigung die in der entsprechenden Gruppe aufgeführten Beiträge lesen.

\footnotetext{
${ }^{6}$ Batinic 2001 (17-23) unterteilt die verschiedenen schriftlichen Befragungsformen im Internet etwas anders: 1. „Befragungen per E-Mail“, 2. „Befragungen per NetNews“ (d.h. Fragebogen wird in eine E-Mail integriert und an ein Diskussionsforum gesandt) und 3. „Befragungen per WWW“. Bei der in der Einleitung genannten Studie von Lebsanft, die über die spanische Mailingliste „Apuntes“ geschickt wurde, handelt es sich um eine Befragung per E-Mail, d.h. die dritte Möglichkeit nach der Einteilung des ADM bzw. die zweite Möglichkeit in der Einteilung von Batinic.

7 Theobald (2000a) stellt ausführlich dar, wie die Teilnehmeransprache über das Internet (ebd., 2944) oder über andere Medien (ebd., 44-47) erfolgen kann.

${ }^{8}$ Es wird allerdings verschiedentlich darauf hingewiesen, dass kaum jemand in einer Suchmaschine gezielt nach Umfragen suchen wird. Es empfehlen sich deshalb weitere inhaltliche Bestimmungen der Umfrage über inhaltliche Stichwörter, damit diese auch über Suchmaschinen gefunden werden kann.
} 
Von den drei in diesem Kapitel vorgestellten Befragungsformen - 1. Fragebogen auf dem Server online ausfüllen, 2. Fragebogen vom Server herunterladen und als E-Mail zurücksenden und 3. Befragung via E-Mail - wird für diese Studie die erste Form ausgewählt, die im Folgenden als $W W W$-Befragung bezeichnet wird. Bei der WWW-Befragung liegt ein Fragebogen auf einem Server bereit, der auf einer Internetseite online ausgefüllt werden kann. Um auf den WWW-Fragebogen zur Internet-Terminologie und Sprachpolitik aufmerksam zu machen, wurde dieser in verschiedenen Diskussionsforen (vgl. 6.4 und 8.1.1) angekündigt.

Die Methodik der WWW-Befragung ist, wie oben bereits erwähnt, noch recht neu. Da im Bereich der linguistischen Feldforschung Papier-Fragebögen bereits auf eine längere Tradition zurückblicken können und diese Methode vielen Linguisten bekannt sein dürfte, bietet es sich an, die neue der traditionellen Befragungsform gegenüberzustellen und auf diese Weise die Unterschiede zwischen dem WWW-Fragebogen und der klassischen Papier-Variante herauszuarbeiten. Es ist insbesondere für den Untersuchungsleiter wichtig, die zwischen diesen beiden Befragungsformen bestehenden Unterschiede zu kennen, um bei der Fragebogenkonstruktion und -verteilung unnötige Fehler vermeiden. Die folgenden Seiten werden somit die mit dem neuen Forschungsinstrument verbundenen Vor- und Nachteile, aber auch seine Besonderheiten vorstellen und einen Überblick über die Verfahrensweisen bei der Durchführung von WWW-Befragungen geben.

\subsection{WWW-Befragungen und traditionelle (Papier-) Frage- bögen im Vergleich}

\subsubsection{Nachteile von WWW-Befragungen und Lösungsansätze}

WWW-Befragungen bieten gegenüber den traditionellen Papier-Fragebögen viele Vorteile, von denen einige bereits in 6.1 genannt wurden. Gleichzeitig weisen sie aber auch einige Nachteile auf, die insbesondere für die wissenschaftliche Verwertbarkeit entsprechend durchgeführter Studien problematisch sein können. Um diese problematischen Bereiche soll es im Folgenden gehen, bevor in 6.3.2 die Vorteile von WWW-Befragungen erörtert werden.

Die im Zusammenhang mit WWW-Befragungen auftretenden Nachteile lassen sich im Überblick wie folgt darstellen:
Kosten auf Seiten der Informanten, selbstselektierende Stichprobe anstelle einer Repräsentativerbebung,
bäufiger Befragungsabbruch bzw. wablloses Durchklicken,
Gefahr von Mehrfachantworten und
bohe Anforderungen an den Untersuchungsleiter.

\section{Kosten auf Seiten der Informanten}

Für die Informanten entstehen durch Telefon- und/oder Providergebühren Kosten, weil die Zeit des Ausfüllens einer Umfrage in der Regel Online-Zeit ist. Wenn der Befragte nicht über einen kostenfreien Zugang verfügt, z.B. am Arbeits- oder 
Ausbildungsplatz, muss er ein erhebliches Interesse an der Umfrage haben, um bereit zu sein, diese Kosten zu tragen (vgl. Bandilla/Hauptmanns 1998, 39).

\section{Selbstselektierende Stichprobe anstelle einer Repräsentativerhebung}

Online-Befragungen eignen sich zurzeit (noch) nicht zur Durchführung repräsentativer Umfragen. Es fehlt eine allgemein gültige Definition des Internet-Nutzers 9 . Mit der Definitionsproblematik ist eng verbunden, dass die Grundgesamtheit der Internet-Nutzer nicht präzise angegeben werden kann ${ }^{10}$.

Aber nicht nur die fehlende definitorische Festlegung dessen, was einen InternetNutzer als solchen kennzeichnet, verhindert die Festlegung der Grundgesamtheit, sondern auch die Tatsache, dass es kein Verzeichnis von WWW- oder InternetNutzern gibt, mit Hilfe dessen die Informanten analog zur Auswahl ihrer Telefonnummern aus einem Telefonbuch bestimmt werden können. Ebenso wenig existieren Internetseiten, deren Besucherstrukturen für die der Internet-Nutzer insgesamt repräsentativ sind. Des Weiteren sind noch immer Teile der Gesamtbevölkerung aufgrund technischer oder finanzieller Hürden von diesem Medium ausgeschlossen. Fast alle WWW-Befragungen beziehen sich daher nicht auf die Gesamtbevölkerung, sondern auf die Grundgesamtheit der Internet-Nutzer (vgl. ADM et al., 2001, Kap. C, 1; Bandilla/Hauptmanns 1998, 42; Hauptmanns 1999, 22; Theobald 2000b, 309). Das bedeutet für die Durchführung einer WWWBefragung, dass die Ziehung einer echten, d.h. repräsentativen Zufallsstichprobe, die Verallgemeinerungen auf eine Grundgesamtheit zulässt, für diesen Umfragetyp

\footnotetext{
${ }^{9}$ Das Problem ist wie folgt gelagert: In verschiedenen Studien zur Internet-Nutzerschaft wird der Internet-Nutzer unterschiedlich definiert. Es fehlt u.a. aufgrund der verschiedenen Nutzungsmöglichkeiten der Internet-Dienste (z.B. World Wide Web, Diskussionsforen, E-Mail) eine Einigung darüber, wie der klassische Internet-Nutzer zu definieren ist. Gilt nur als Nutzer, wer über einen eigenen Zugang verfügt? Zählen auch diejenigen Personen als Nutzer, die nur einen der Internet-Dienste, z.B. E-Mail oder Home-Banking, benutzen, aber beispielsweise niemals WWW-Seiten aufrufen, oder wird nur als Nutzer bezeichnet, wer regelmäßig auf alle drei oben genannten großen Internet-Dienste zurückgreift? Zählt als Nutzer, wer sich selbst so bezeichnet, weil er überhaupt schon einmal gesurft hat, oder gibt es objektive Daten, dass nur als Nutzer zählt, wer regelmäßig einen oder mehrere Internet-Dienste nutzt (vgl. Bandilla/Hauptmanns 1998, 40-42)? Ferner stellt sich hier die Frage des Alters. Manche Studien zur Ermittlung der Internet-Aktivitäten befragen Personen ab 14 Jahren, andere beziehen nur volljährige Personen in ihre Studien ein. Wie werden Kinder gewertet? Es gibt verschiedene Definitionsversuche des Internet-Nutzers. Taylor Nelson Sofres Interactive (2002, Folie 6) schlagen vor: „someone who has personally used the Internet in the past month (at the time of the interview)". Eine ähnlich weite Definition schlägt auch Hauptmanns (1999, 22) vor: Als Internet-Nutzer solle jeder angesehen werden, „der Zugang zu den Diensten des Internet hat und zumindestens einen dieser Dienste auch nutzt.“

10 Theobald (2000b, 309) nennt dieses Phänomen die „Unbestimmbarkeit einer Grundgesamtheit". Daraus ergibt sich für die Durchführung einer Befragung ein weiteres Problem. Anhand der bei der Umfrage ermittelten Parameter wie Alter, Geschlecht etc. kann kaum auf die Grundgesamtheit hochgerechnet werden (vgl. Bandilla/Hauptmanns 1998, 40). Bekannt ist jedoch, dass die Altersverteilung bei den Teilnehmern von WWW-Befragungen nicht der tatsächlichen Altersverteilung von WWW-Nutzern entspricht: „Das WWW ist unter den jungen Internetteilnehmern außerordentlich beliebt, seine Nutzungsintensität nimmt mit steigendem Alter allerdings kontinuierlich ab. Dadurch wird erklärbar, warum z.B. ältere Internet-Nutzer in WWW-Befragungen unterrepräsentiert sind“" (Bandilla/Hauptmanns 1998, 48). Hinzu kommt, dass Frauen in Befragungen über das Internet in der Regel unterrepräsentiert sind (vgl. Bandilla/Hauptmanns 1998, 49).
} 
(noch) nicht möglich ist (vgl. Fußnote 5). Somit ist der Einsatz von Online-Befragungen v.a. für bevölkerungsrepräsentative Studien nicht geeignet.

„Nach der mathematisch statistischen Definition von Repräsentativität könnten Befragungen im World Wide Web nur dann Resultate erzielen, die für eine bestimmte Population repräsentativ sind, wenn

ein zentrales Verzeichnis der Population verfügbar wäre,

alle Mitglieder der Population über das World Wide Web antworten könnten und

keine Verzerrungen durch Nichtteilnehmer auftreten würden“ (Theobald 2000a, 121).

Deshalb weisen der ADM et al. (2001, Kap. C, 1) darauf hin, dass sich Repräsentativität bei Online-Befragungen nur dann erreichen lasse, wenn als Zielgruppe der Untersuchung entweder die gesamte Internet-Nutzerschaft, bestimmte Gruppen von Internet-Nutzern oder aber nur die Besucher bestimmter Internetseiten bestimmt würden ${ }^{11}$.

Das größte Manko von WWW-Befragungen lässt sich unter dem Stichwort der Selbstselektion zusammenfassen ${ }^{12}$. Eine starke Selbstselektion wird durch den für WWW-Befragungen typischen fehlenden direkten Kontakt zwischen Forscher und Informant gefördert; der Forscher spricht mit der von ihm gewählten Art der Fragebogenankündigung eine anonyme Masse an. Entsprechend kann nur eingeschränkt etwas über die jeweils angesprochene Zielgruppe ausgesagt werden. Es ist technisch zwar kein Problem, die Zugriffe auf die Startseite zu zählen und die Anzahl der Zugriffe mit der Anzahl der ausgefüllten Fragebögen (Rücklauf) zu vergleichen. Was jedoch fehlt, sind biosoziale Angaben über diejenigen, die

a) entweder von der Umfrage Kenntnis erlangt haben, aber nicht reagiert haben, oder

b) von ihr Kenntnis erlangt haben und auf die vorangehenden Erklärungen oder auf den Fragebogen selbst zugegriffen, diesen aber nicht ausgefüllt haben, oder

c) Kenntnis von der Umfrage erlangt, auf sie zugegriffen und einige Fragen beantwortet haben, dann jedoch abgebrochen haben.

Daneben gibt es eine vierte Kategorie: Informanten, die

d) Kenntnis von der Umfrage erlangt, den Fragebogen aufgerufen, ausgefüllt und abgeschickt haben (vgl. Hauptmanns 1999, 22; Theobald 2000a,

\footnotetext{
11 Auch Bandilla/Hauptmanns $(1998,41)$ weisen darauf hin, dass zwar keine verlässlichen Daten zur Gesamtheit der Internet-Nutzer gegeben werden können, dass es aber möglich wäre, sich auf definierbare Teilmengen innerhalb dieser Grundgesamtheit zu beziehen, wie „alle Teilnehmer einer Mailing-Liste“.

12 Zum Problem der für WWW-Umfragen typischen Selbstselektion und der daraus resultierenden mangelnden Repräsentativität der Umfrageergebnisse äußert sich ausführlich Theobald (2000a, 26, 89-93, 121-129).
} 
72/2000b, 304)13. Für diese Gruppe liegen i.d.R. die benötigten biosozialen Angaben vor.

Bei WWW-Befragungen ist die Stichprobe in aller Regel selbstselektierend, eine aktive Stichprobenziehung findet nicht statt ${ }^{14}$. Bei dieser Form der Befragung ist die zahlenmäßige Differenz zwischen Personen, die von der Umfrage wissen, an ihr aber nicht teilnehmen, und Personen, die an ihr teilnehmen, als ca. doppelt so hoch einzuschätzen wie bei einem entsprechenden Papier-Fragebogen (vgl. Batinic 2001, 67). Nach Stier (1996, 200) ist die Stichprobe in diesen Fällen keine Stichprobe mehr aus der definierten Erhebungsgesamtheit, sondern nur noch aus der „Teil-Grundgesamtheit der Antwortbereiten“. Dieses Phänomen wird im Fachjargon als Selbstselektionsrate bezeichnet. Der Umstand, dass sich nicht alle Mitglieder einer Zufallsstichprobe an einer Untersuchung beteiligen, führt zu einer Verzerrung der Stichprobe (vgl. Kaase 1999, 17; Theobald 2000b, 303, 307). Theobald (2000b, 307) bezeichnet das Auswahlverfahren trotz der genannten Nachteile als gängig, „da es mitunter die einzige sinnvolle Möglichkeit zur Teilnehmergewinnung darstellt." Batinic $(2001,11)$ hebt hervor, dass viele experimentelle Studien nur in geringem Maße auf eine repräsentative Stichprobe angewiesen seien, um ihre Hypothesen zu überprüfen.

\section{Häufiger Befragungsabbruch bzw. wablloses Durchklicken}

Die Hemmschwelle, eine Befragung abzubrechen, ist aufgrund der unpersönlichen Teilnehmerrekrutierung bei WWW-Umfragen geringer als bei anderen Befragungsformen wie Interviews, bei denen ein persönlicher Kontakt zwischen Interviewer und Informant besteht (vgl. Knapp/Heidingsfelder 2001, 1). Befragungsabbrüche, die sog. Drop-Outs, können aufgrund technischer Umstände erfolgen ${ }^{15}$ oder benutzerabhängig sein. Bei benutzerabhängigen Ausfällen sinkt die Motivation des Befragten so weit ab, dass er die Befragung abbricht. Als Ursachen sind denkbar:

\footnotetext{
13 Theobald (2000b, 305) rät davon ab, in Analogie zu Papier-Fragebögen auch für WWW-Befragungen eine Rücklaufquote zu ermitteln: „Aufgrund der medienspezifischen Eigenschaften von WWW-Umfragen erscheint die Definition nur einer Rücklaufquote wie z.B. bei schriftlichen Befragungen nicht sinnvoll. Diese scheitert bereits an der schwierigen Messung der Teilmenge $n_{1}\left[n_{1}\right.$ entspricht der ersten Gruppe, also der Anzahl derer, die von der WWW-Umfrage Kenntnis erlangen ohne zu reagieren, E.M.]. Nur den Quotienten der aufgerufenen und ausgefüllten Fragebögen zu messen, greift gleichfalls zu kurz."

14 Während bei einem klassischen Papier-Fragebogen (ebenso wie bei der Telefon-Befragung oder dem Interview) vom Forscher eine Zufallsauswahl getroffen werden kann, handelt es sich bei WWW-Umfragen immer um selbstselektierende Stichproben, weil sich in der Regel nur ein Teil der Internet-Nutzer, die von der Umfrage erfahren, zur Teilnahme entschließt (vgl. Bandilla/Hauptmanns 1998, 40).

15 Abbrüche aufgrund technischer Schwierigkeiten können beispielsweise bei Neulingen im Internet erfolgen, da diese mit WWW-Befragungen in der Regel nicht so gut zurechtkommen wie mit den herkömmlichen Papierfragebögen (vgl. Utz 1999, 314). Die Wahl des Mediums sollte somit auch in Abhängigkeit vom intendierten Zielpublikum erfolgen. Das geschilderte Problem ist für eine Studie, die sich an Informatiker im weiten Sinne richtet, nicht zu erwarten, da es sich bei diesen im Regelfall nicht um Internet-Neulinge handelt.
} 
mangelnde Motivation des Befragten ${ }^{16}$, ein zu langer Fragebogen,

keine Angabe, an welcher Stelle sich der Informant aktuell befindet, kein Splitten des Fragebogens auf mehrere Seiten $=>$ unkomfortables ständiges Scrollen, uninteressante und unübersichtliche optische Gestaltung der Befragung => Langeweile auf Seiten des Befragten, unklar formulierte Fragen, sensible (d.h. heikle bzw. sehr persönliche) Fragen und zu lange Ladezeiten (vgl. Bosnjak/Batinic 1999; Gräf 1999, 163f.; Knapp/Heidingsfelder 2001, 2; Theobald 2000b, 302).

Aufgrund der unpersönlichen Teilnehmerrekrutierung bei WWW-Befragungen besteht im Unterschied zu traditionellen Fragebögen immer die Gefahr, dass viele Informanten sich einfach wahllos „durchklicken“: Die Anonymität des Mediums kann Unaufrichtigkeit begünstigen (vgl. z.B. Batinic 2001, 57; Gräf/Heidingsfelder 1999, 120) ${ }^{17}$. Dieser medienbedingten Gefahr, welche aber auch bei traditionellen Papierfragebögen nicht völlig auszuschließen ist, lässt sich z.B. nachträglich mit einer Plausibilitäts- und Konsistenzprüfung entgegentreten. Dem Problem kann aber auch bereits im Vorfeld der Befragung durch das Einbauen von Kontrollfragen in den Fragebogen begegnet werden. So weisen z.B. inhaltliche Mängel in den Antworten, die in der Regel über die Kontrollfragen ermittelt werden können, auf unseriös antwortende Informanten hin; entsprechende Datensätze sollten aus dem Fragebogen entfernt werden. Gänzlich ausschließen lässt sich das Problem der unseriösen Antworten aber auch mit diesen Verfahren nicht.

\section{Gefahr von Mehrfachantworten}

WWW-Umfragen machen es leicht, mehrfach an einer Befragung teilzunehmen und somit das Ergebnis zu verzerren. Während der Informant bei einem PapierFragebogen normalerweise nur über ein einziges Exemplar verfügt, kann er beliebig oft auf eine WWW-Seite gehen und mehrfach den dort befindlichen Fragebogen abrufen und ausfüllen.

Gründe für die Mehrfachteilnahme sind oft zu hohe Belohnungen, im Fachjargon Incentives genannt. Daher sollten zu hohe Incentives vermieden werden. Nach Angaben des ADM et al. (2001, Kap. D) sollen Incentives lediglich eine Aufwandsentschädigung sein, um den monetären und zeitlichen Aufwand der Teilnehmer zu kompensieren. Sog. „professionellen Incentivejägern“ dürften keine

${ }_{16} \mathrm{Zu}$ den verschiedenen Arten der Motivation vgl. ausführlich Bosnjak/Batinic (1999) und Theobald (2000a, 49-65). Generell lassen sich drei Hauptaspekte der Teilnahmebereitschaft unterscheiden: 1. altruistische Gründe (z.B. einen Beitrag für die Forschung leisten wollen), 2. befragungsbezogene Gründe (z.B. Neugier) und 3. persönliche Gründe (z.B. Selbstkenntnis, materieller Anreiz) (vgl. Bosnjak/Batinic 1999, 145, 148).

17 Diesem von Batinic als „Spaßteilnahme“ bezeichneten Phänomen steht positiv entgegen, dass die Anonymität andererseits zu größerer Offenheit der Teilnehmer führt. Es ist somit damit zu rechnen, dass weniger im Sinne der sozialen Angemessenheit (vgl. 2.1) geantwortet wird als bei traditionellen Befragungsverfahren (vgl. Batinic 2001, 57). 
attraktiven Teilnahmebedingungen, wie z.B. die Aussicht auf die Teilnahme an einer Verlosung, geschaffen werden. Dies würde zu unnötigen Verzerrungen führen und damit die Reliabilität und die Validität der Ergebnisse einschränken, da davon auszugehen sei, dass diese Informanten die Fragen nicht gewissenhaft beantworteten, sondern sich möglichst schnell durch den Fragebogen klickten und möglicherweise nicht einmal der gewünschten Zielgruppe entsprächen (vgl. Batinic 2001, 57). Wenn als Belohnung hingegen die Zusendung der Ergebnisse zugesichert werde bzw. diese direkt am Ende der Befragung in Form einer Echtzeitstatistik präsentiert werde, ergäben sich kaum Verzerrungen durch Incentivejäger (vgl. Gräf/Heidingsfelder 1999, 121-124). Auf diese Weise könne sichergestellt werden, dass nur Personen an der Befragung teilnehmen, die sich wirklich für das Thema interessieren.

Für die WWW-Befragung zur Internet-Terminologie und Sprachpolitik wurde daher auf materielle Anreize verzichtet und den Teilnehmern stattdessen versprochen, dass ihnen vier Wochen nach Abschluss der Studie die Untersuchungsergebnisse zugesendet würden (was auch geschehen ist).

Es ist auf technischem Weg relativ schwierig, Mehrfachantworten zu verhindern. Eine Möglichkeit besteht darin, die IP-Adressen ${ }^{18}$ der Computer zu speichern, von denen die Fragebögen abgesendet wurden. Auf diese Weise kann nachvollzogen werden, ob von einem Rechner mehrfach Fragebögen abgesendet wurden (vgl. z.B. Theobald 2000a, 69-71). Jedoch ist hierbei zu bedenken, dass es öffentliche Rechner mit Internet-Anschluss gibt, die von mehreren Personen genutzt werden. Auch verfügen viele Firmen nur über einen Außenanschluss, was bedeutet, dass automatisch für alle vernetzten Computer dieser Firma nur eine einzige IP-Adresse gesendet wird. Insofern ist davon abzuraten, bei der Auswertung generell alle Datensätze, die unter der gleichen IP-Adresse versendet wurden, zu löschen.

Eine andere, häufig genutzte Möglichkeit bestehe darin, ein Cookie in der sog. Cookie-Datei auf dem Computer des Informanten zu setzen, mit dem verhindert werde, dass von einem Computer ein zweites Mal auf die entsprechende Seite zugegriffen werde (vgl. Batinic 2001, 28) ${ }^{19}$. Da sich jedoch Cookies jeweils auf der Festplatte des Informanten installierten und sich dort problemlos aufspüren lieBen, könnten findige Computernutzer diese auch jederzeit selbst wieder entfernen, womit die Teilnahmesperre wieder aufgehoben sei (vgl. Bamert/Heidingsfelder 2001, 177).

18 Die Termini Banner, CGI-Skript, Cookie, HTML, IP-Adresse, Mailingliste und Pop-up-Fenster, die im Rahmen dieser Ausführungen verwendet werden, werden im Glossar (15.7) erklärt.

19 Bei einem Cookie handelt es sich um eine kleine Textdatei, die beim Besuch einer Internetseite (z.B. eines WWW-Fragebogens) auf dem Rechner des Besuchers (hier: Informanten) abgelegt wird und in der gewisse Informationen über dessen Rechner dokumentiert werden. Das Setzen von Cookies ist aus datenschutzrechtlichen Gründen bedenklich, weil der Informant identifizierbar wird, ohne dies womöglich zu wissen. Daher empfiehlt der ADM et al. (2001, Kap. D): „,...] das Setzen von ,Cookies' [ist] nur zulässig, wenn sie zum Erreichen des Forschungszwecks der Online Befragung unerlässlich sind. Die Befragten müssen gegebenenfalls darüber vor Beginn des Interviews hinreichend informiert werden und darin einwilligen." 
Aufgrund der genannten Schwierigkeiten lässt sich die Gefahr von Mehrfachantworten mit technischen Mitteln nicht auf befriedigende Weise verhindern. Am vielversprechendsten ist es somit, keine Kontrollmechanismen im Vorfeld der Umfrage zu aktivieren, sondern vielmehr bei der Auswertung der Ergebnisse besonderes Augenmerk auf die übermittelten IP-Adressen zu legen. Treffen mehrere Fragebögen mit der gleichen IP-Adresse ein, so sind die Datensätze mittels der oben genannten Kontrollverfahren zu überprüfen. Weisen Datensätze die gleiche IP-Adresse auf und ähneln sich auch bezüglich der eingegebenen Antworten, könnte dies auf eine Mehrfachteilnahme hindeuten. In diesem Fall empfiehlt es sich, die Datensätze genau zu überprüfen und gegebenenfalls die doppelten Datensätze zu löschen.

\section{Hohe Anforderungen an den Untersuchungsleiter}

Die Erstellung einer WWW-Umfrage stellt hohe Anforderungen an den Untersuchungsleiter. Dieser benötigt, wenn er nicht auf Programme zur Fragebogenkonstruktion wie den kostenlosen WWW-Fragebogen-Generator (WFG) (vgl. Batinic 2001, 31-44; Batinic/Puhle/Moser 1999) oder den kostenpflichtigen InternetRogator zurückgreift (vgl. Gräf/Heidingsfelder 1999, Rogator Software AG 2002, o.S.), hohes technologisches Hintergrundwissen, da er mit HTML und CGISkripten (zur Datenübermittlung und -verarbeitung) vertraut sein sollte ${ }^{20}$.

Des Weiteren muss er für jede Art von Befragung (bei Papier-Fragebögen ebenso wie bei elektronischen Fragebögen) über hohes methodisches Wissen verfügen, um eine Umfrage nach wissenschaftlichen Maßstäben gestalten zu können. Die Aneignung der sozialwissenschaftlichen Forschungsmethoden stellt gerade für Forscher, die nicht selbst Sozialwissenschaftler bzw. Psychologen sind und somit in ihrer Ausbildung keinerlei Kontakt zur Methodenforschung hatten, einen besonderen Mehraufwand dar. Das bedeutet konkret: Neben der fachlichen Qualifikation benötigt der Wissenschaftler Kenntnisse in zwei weiteren Disziplinen, der Informatik und den Sozialwissenschaften (vgl. Batinic 2001, 31; Batinic/Puhle/ Moser 1999, 93f.). Zuletzt benötigt der Forscher für die Auswertung der Umfrage statistisches Grundlagenwissen, um die Daten adäquat interpretieren und darstellen zu können. Kenntnisse in entsprechenden Programmen wie z.B. SPSS und MS Excel sind auch hier von Vorteil, wenn nicht sogar unerlässlich.

\section{Fazit}

Unter den genannten Faktoren gilt das Problem der Selbstselektion bei WWWBefragungen als der gravierendste Faktor, da auf diese Weise die Repräsentativität der Umfrage weiter eingeschränkt wird. Selbst wenn der Adressatenkreis der Umfrage bekannt ist (z.B. die Mitglieder einer Mailingliste), kann der Faktor der Selbstselektivität die Ergebnisse derart verzerren, dass eine Verallgemeinerbarkeit

\footnotetext{
20 Bei der Verwendung von Umfragetools sind Kenntnisse in HTML wünschenswert, jedoch nicht unbedingt nötig. Auch Programmierkenntnisse sind nicht erforderlich, da die entsprechenden CGISkripte oder andere Datenübermittlungsverfahren wie MS Active Server Pages (ASP) bereits programmiert sind.
} 
der Ergebnisse für die gesamte Mailingliste nicht mehr möglich ist. Im Sinne der Theorie der repräsentativen Stichprobenziehung müsste bei jeder Befragung, unabhängig vom Medium, eine aktive Auswahl der Teilnehmer erfolgen. Das bedeutet, dass die Teilnehmer für WWW-Befragungen aktiv über bestimmte Verzeichnisse ausgewählt und angesprochen werden müssten. Dies ist jedoch in Ermangelung entsprechender Verzeichnisse nicht möglich. Der Hinweis auf den Fragebogen in Form von Werbung als Pop-up-Fenster bzw. als Banner oder die Ankündigung der Umfrage in Diskussionsforen, Mailinglisten ${ }^{21}$ oder in Suchmaschinen gelten als passive Auswahlverfahren und genügen aufgrund der hohen Selbstselektivität den methodischen Anforderungen an eine wissenschaftliche Befragung nicht. Daher können Ergebnisse von WWW-Befragungen, deren Teilnehmer nicht aufgrund anderer Hilfsmittel wie Telefonlisten, Mitgliedsverzeichnissen o. Ä. ermittelt wurden, derzeit nur Tendenzen wiedergeben. Sie dürfen aber nicht vorbehaltlos auf größere Gruppen oder gar die Gesamtbevölkerung übertragen werden.

Theobald (2000a, 121) weist einschränkend darauf hin, dass auch mit herkömmlichen Befragungsmethoden kaum den Anforderungen an die Qualität einer Stichprobe entsprochen werden könne. Für die anderen Nachteile von WWW-Befragungen mit Ausnahme des ersten Punktes, den Online-Gebühren, lassen sich Lösungen finden, mit denen sich die Nachteile überwinden lassen. So kann dem wahllosen Durchklicken, einer erhöhten Quote von Befragungsabbrüchen oder der Mehrfachteilnahme im Vor- bzw. Nachfeld der Befragung mit den oben skizzierten Maßnahmen wie beispielsweise dem Verzicht auf materielle Belohnungen gezielt entgegengewirkt werden.

\subsubsection{Vorteile von WWW-Befragungen}

Trotz der im vorigen Abschnitt genannten Nachteile, die sich bei WWW-Umfragen ergeben und u.a. zu einer eingeschränkten Repräsentativität der Ergebnisse führen, bietet dieser Umfragetypus im Unterschied zum traditionellen (Papier)Fragebogen eine Reihe von Vorteilen für den Untersuchungsleiter und für die Befragten. Die folgende Auflistung zeigt im Überblick die Vorteile, die WWWBefragungen gegenüber traditionellen Fragebögen aufweisen:

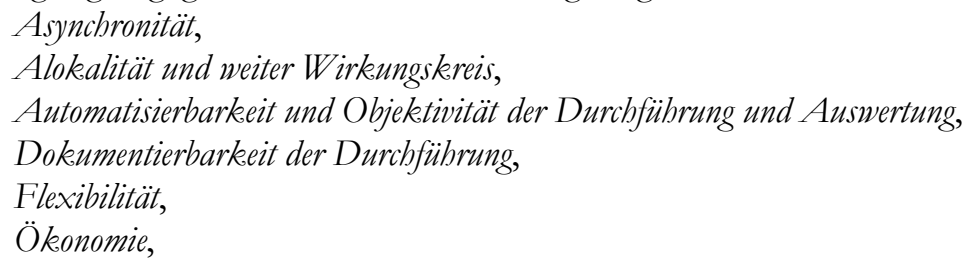

${ }^{21}$ Die Termini IP-Adresse, Pop-up-Fenster, Mailingliste und Cookie werden im Glossar (15.7) erklärt. Der Vorteil der Ankündigung des Fragebogens in Mailinglisten gegenüber Diskussionsforen liegt darin begründet, dass die Anzahl der Mitglieder von Mailinglisten bekannt ist bzw. in Erfahrung gebracht werden kann, während bei Diskussionsforen nur Schätzungen möglich sind, da zwar bei bekannteren Gruppen sehr viele Leute die Beiträge lesen, sich selbst aber an den Diskussionen nie oder nur sehr selten beteiligen und deswegen nicht als „Mitglied“ des Forums ins Erscheinung treten. 


\author{
bohe Attraktivität, \\ bohe Akzeptanz und \\ automatische Filterführung22.
}

\title{
Asynchronität
}

Dem Informanten sei es laut Dillman $\left(2000,81^{23}\right)$ völlig freigestellt, wann er den Fragebogen im WWW abrufe und ausfülle. Er sei zeitlich vom Interviewer unabhängig, sowohl was die Tageszeit des Ausfüllens als auch die insgesamt dafür aufgewendete Zeit betreffe. Der Informant könne sich Zeit nehmen über jede Frage in Ruhe nachzudenken. Bei Papierfragebögen, die persönlich verteilt werden, warte der Interviewer oftmals, während der Fragebogen ausgefüllt wird, um ihn wenig später ausgefüllt wieder mitzunehmen, wodurch beim Ausfüllenden das Gefühl von Zeitdruck entstehen könne. Bei einem Interview ist der Informant bezüglich des zeitlichen Rahmens und der Zeit, die er für das Nachdenken über die Fragen hat, noch eingeschränkter als bei Fragebogenstudien.

\section{Alokalität und weiter Wirkungskreis}

Bei Befragungen über das Internet können Teilnehmer unterschiedlicher Regionen und Länder unabhängig vom Aufenthaltsort des Untersuchungsleiters angesprochen werden, sofern sie über einen Internet-Zugang verfügen. Ländergrenzen spielen keine gravierende Rolle mehr. Demgegenüber sind die geografische Reichweite (Entfernung des Untersuchungsortes vom Wohnort des Forschers) bzw. der Verbreitungsgrad (Anzahl der Regionen, aus denen Teilnehmer rekrutiert werden) bei einem Papier-Fragebogen im Regelfall sehr viel begrenzter (Reisebzw. Portokosten auf Seiten des Untersuchungsleiters).

\section{Automatisierbarkeit und Objektivität der Durchführung und Auswertung24}

Aufgrund fehlender Interaktion zwischen Untersuchungsleiter und Informanten benötigt die Durchführung der Befragung keinen Interviewer vor Ort, der Fragebögen austeilt, einsammelt sowie bei der Befragung auftretende Fragen klärt ${ }^{25}$.

\footnotetext{
22 Die Auflistung erfolgt in Anlehnung an Batinic (2001, 12-14), Batinic/Puhle/Moser (1999, 93), Dillman (2000), Gadeib $(1999,109)$ und Theobald (2000a, bes. Kap. 1 und 4/2000b).

23 Das Werk Dillmans (2000) gilt als eines der komplexesten Bücher, die zurzeit zur konkreten Gestaltung von Online-Umfragen (WWW-Befragungen und E-Mail-Befragungen) auf dem Markt sind. Der Autor erläutert ausführlich, wie ein idealer (elektronischer) Fragebogen und das dazugehörige Anschreiben aussehen sollten. Er demonstriert anhand vieler Ausschnitte aus Modellfragebögen, wie man es besser nicht machen sollte, und gibt stattdessen die seiner Meinung nach optimale Lösung an. Insofern liest sich das äußerst komplexe Buch fast wie eine Art Gebrauchsanweisung zur Gestaltung von Online-Umfragen. Dillman vertritt die Grundidee, dass ein attraktives Fragebogendesign und ein angemessener Kontakt des Forschers zu den Informanten die Rücklaufquote automatisch erhöhten.

${ }^{24}$ Häufig wird in der Literatur zu Online-Befragungen die Objektivität der Auswertung im Unterschied zu anderen Befragungsverfahren hervorgehoben. Die objektive Auswertung ist aber keineswegs nur auf WWW-Befragungen beschränkt. Auch Daten, die manuell in Datenbanken und -verarbeitungsprogramme wie SPSS, SAS, STATISTICA oder SYSTAT eingegeben wurden, können aufgrund der mit diesen Programmen schnell und einfach durchzuführenden statistischen Verfahren objektiv ausgewertet werden.
} 
Auch die Datenspeicherung erfolgt automatisch, wohingegen Papier-Bleistift-Befragungen meist manuell ausgewertet wurden und werden (Ausnahme: Lochkarten oder Lesegeräte für die automatische Datenaufnahme aus Fragebögen, wie sie in großen Marktforschungsinstituten vorhanden sind). Bei der manuellen Auswertung, d.h. der manuellen Eingabe der Daten aller Fragebögen in eine Datenbank, können leicht Fehler unterlaufen. Anders ist es bei WWW-Fragebögen. Hier geben die Informanten selbst ihre Daten in den HTML-Fragebogen ein, in dessen Hintergrund, für den Informanten nicht sichtbar, Datenübertragungsprogramme wie CGI-Skripte oder Active Server Pages (ASP) laufen. Diese Datenübertragungsprogramme übermitteln die eingegebenen Werte vollautomatisch an den Server, auf dem der Fragebogen liegt. Dort werden sie in eine Datenbank oder ein entsprechendes Verzeichnis geschrieben. Durch diesen Automatisierungsprozess bei der Durchführung und Auswertung entfällt der Forscher als möglicher verzerrender Faktor bzw. als Fehlerquelle.

\section{Dokumentierbarkeit der Durchfübrung}

Die einzelnen Phasen der Durchführung lassen sich leichter dokumentieren, da automatisch mitgezählt wird, wie viele Personen auf den Fragebogen zugreifen, wie viele Personen diesen zurücksenden und wann dies geschieht. Anhand der von den meisten Umfragegeneratoren übermittelten Daten ist feststellbar, an welchem Datum und zu welcher Uhrzeit das Ausfüllen des Fragebogens begonnen und wann dieser abgeschickt wurde (vgl. Batinic 2001, 82f.).

Bei der Verteilung traditioneller Papierfragebögen muss der Forscher selbst genau über die einzelnen Schritte der Untersuchung Buch führen. Hinzu kommt, dass bei postalischen Umfragen nicht genau ermittelbar ist, wann der Fragebogen ausgefüllt wurde, sondern nur feststeht, wann der Fragebogen beim Untersuchungsleiter eintrifft.

\section{Flexibilität}

Der WWW-Fragebogen ist nicht nur auf Text beschränkt, sondern es können multimediale bzw. interaktive Elemente wie Grafiken, Bilder und sogar Anwendungsprogramme unter einer Oberfläche integriert werden. Auf diese Weise lässt sich die WWW-Befragung flexibel an die jeweilige Aufgabenstellung und das entsprechende Publikum anpassen.

\section{Ökonomie}

WWW-Umfragen lassen sich bezogen auf den zeitlichen und materiellen Aufwand in der Regel kostengünstiger durchführen als andere Befragungstypen, sofern der Forscher die technische Durchführung der Umfrage selbst besorgt und die entsprechenden Leistungen nicht extern einkaufen muss (vgl. z.B. Batinic 2001, 14; Dillman 2000, 352f.). Beim traditionellen Papier-Fragebogen entstehen zum einen die bei der Vervielfältigung anfallenden Druck- bzw. Kopierkosten, zum anderen

25 Sofern die Fragen klar formuliert sind, sind Benutzerfehler beim WWW-Fragebogen durch den Einsatz von Filtern so gut wie ausgeschlossen (s.u.). 
muss der Fragebogen den Informanten übermittelt werden. Dies kann entweder auf postalischem Weg geschehen (Portokosten), oder aber der Forscher reist in die ausgewählten Untersuchungsgebiete, wo er die Fragebögen persönlich verteilt (Fahrt- und Unterbringungskosten). Die persönliche oder postalische Übermittlung der Fragebögen an die Informanten nimmt mehr Zeit in Anspruch als die Veröffentlichung und Ankündigung des Fragebogens über das Internet.

\section{Hohe Attraktivität}

Ein traditioneller Fragebogen enthält in erster Linie Text, kann aber optisch durch die Einbindung von Bildern, Fotos o.Ä. aufgelockert werden. Aufgrund hoher Druckkosten für farbig bedruckte Bögen liegen wissenschaftlich angelegte Fragebögen in der Regel nur als Schwarz-Weiß-Kopien vor. WWW-Umfragen lassen sich durch den Einsatz von Bildern, Grafiken, Farben etc. ohne Mehrkosten attraktiver und abwechslungsreicher gestalten als Papier-Fragebögen. Das Ausfüllen einer WWW-Umfrage kann somit für den Befragten motivierend sein und für ihn zudem einen unterhaltsamen Zeitvertreib darstellen.

\section{Akreptanz.}

Auf klassische Erhebungsformen wie Papier-Fragebögen oder Interviews reagieren potenzielle Teilnehmer häufig abweisend. Demgegenüber stoßen Online-Erhebungen aufgrund ihres Neuheitswertes auf eine größere Akzeptanz.

\section{Automatische Filterführung}

Hier stellt sich zunächst die Frage: Warum müssen in einem Fragebogen, unabhängig davon, ob er in der Papierversion oder in elektronischer Form vorliegt, überhaupt Filter integriert werden?

Bei manchen Fragen eines Fragebogens ist es nicht sinnvoll, dass diese von allen Informanten beantwortet werden. Durch einen Filter erhält der Befragte bei einem traditionellen Papierfragebogen die Anweisung, bei Nennung einer bestimmten Antwort einige Fragen zu überspringen und die Befragung an einer späteren, durch den Filter angegebenen Stelle fortzusetzen (vgl. Porst 1998, 33). Bei einem WWW-Fragebogen wird der Filter so an die Antwortmöglichkeiten geknüpft, dass im Fragebogen automatisch die nächste, für den jeweiligen Informanten relevante Seite aufgerufen wird. Da die Filter unsichtbar sind, merkt der Befragte überhaupt nicht, an welchen Stellen ein Filter vorgelegen hat.

Die manuelle Filterführung in Papier-Fragebögen arbeitet mit Verweisen wie „Bitte weiter mit Frage X“, die hinter den betreffenden Antwortmöglichkeiten abgedruckt sind. Es besteht die Gefahr, dass der Informant sich durch diese Anweisungen verwirren lässt, Fehler macht oder schlimmstenfalls die Befragung abbricht. Durch die in WWW-Umfragen standardmäßig integrierte automatische Weiterleitung zur nächsten Frage wird das Ausfüllen des Fragebogens für den Benutzer erleichtert, und Benutzerfehler werden vermieden. Außerdem wird durch Filter die Zufriedenheit der Informanten erhöht, da sie nur Fragen beantworten müssen, die auf ihre Merkmalkombination zutrifft (vgl. Arbeitsgemein- 
schaft Informationsgesellschaft o.J., o.S.; Gräf 1999, 172; Gräf/Heidingsfelder 1999, 117). Aus den genannten Gründen wurden auch in den WWW-Fragebogen für die französischen, belgischen und schweizerischen Informanten an mehreren Stellen Filter integriert (vgl. 7.1.2).

Fazit

Aufgrund der zahlreichen Vorteile, die WWW-Umfragen gegenüber traditionellen Papier-Fragebögen sowohl für den Informanten als auch für den Untersuchungsleiter bieten, ist das World Wide Web trotz der in 6.1.3 dargestellten Nachteile in hohem Maße geeignet, Befragungen zur Datengewinnung durchzuführen. WWWUmfragen sind eine attraktive, preisgünstige, zeitgemäße sowie Benutzer- und Interviewerfehler reduzierende Möglichkeit, von einem breiten Publikum Daten zu einem bestimmten Thema zu erhalten.

Für eine Befragung, die sich an Informanten aus drei Ländern richtet und die Internet-Terminologie zum Gegenstand hat, ist das Internet als Umfragemedium dem Papierfragebogen vorzuziehen. Zum einen lassen sich Informatiker über das Medium Computer bzw. Internet besonders leicht ansprechen. Zum anderen senkt die WWW-Befragung nicht nur die für die Durchführung der Befragung anfallenden Kosten, sondern auf diese Weise können mehr potenzielle Informanten über die Umfrage informiert werden, als dies beispielsweise über den Postweg zu realisieren wäre.

Weiterhin bietet die WWW-Befragung die Möglichkeit, den Fragebogen farbig und damit optisch attraktiver zu gestalten und Grafiken zu integrieren. Von diesen Möglichkeiten wurde bei der WWW-Befragung zur Internet-Terminologie und zur Sprachpolitik ebenfalls Gebrauch gemacht. Nicht zuletzt bedeutet die Automatisierung der Datenübertragung von den ausgefüllten Fragebögen in die Datenbank eine große Zeitersparnis und verhindert mögliche, bei der manuellen Dateneingabe entstehende Fehler.

\subsection{Ankündigung eines WWW-Fragebogens (in Diskus- sionsforen)}

Jedem Fragebogen sollte, unabhängig davon, ob es sich um einen Papier- oder einen Online-Fragebogen handelt, ein Anschreiben vorausgehen. Dieses Anschreiben diene hauptsächlich dazu, die Befragten über den Zweck sowie die Verwendung der Daten zu informieren. Ferner könne durch ein gut aufgebautes und informatives Anschreiben die Rücklaufquote positiv beeinflusst werden (vgl. Dillman 2000, 135, 162, 180). Nach Batinic (1997), Dillman (2000, 162), Friedrichs (1990, 238) und den Qualitätsrichtlinien des ADM et al. (2000, 2/2001, Kap. D) sollte das Anschreiben im Idealfall die folgenden Informationen enthalten: 
- Name und Adresse des Untersuchers bzw. des die Untersuchung durchführenden Instituts (Bei Online-Befragungen empfiehlt sich zusätzlich die Einrichtung eines entsprechenden Hyperlinks auf das Forschungsinstitut.),

- Anliegen des Untersuchungsleiters,

- Gründe für die Auswahl der Informanten, evtl. Darlegung des Zusammenhanges von Thema, Verwertungsziel und Interessen des Befragten,

- Informationen über das (wissenschaftliche) Untersuchungsziel / Thema der Untersuchung,

- Nützlichkeit der Umfrage,

- Hinweis auf die Anonymität des Befragten sowie die Verwendung der Angaben ausschließlich in anonymisierter Form und nur für Forschungszwecke,

- Hinweis auf die Freiwilligkeit der Teilnahme,

- Angaben über die für die Untersuchung benötigte Zeit,

- Anreiz für das Ausfüllen des Fragebogens ${ }^{26}$,

- Nachfragemöglichkeit in Form einer E-Mail-Adresse oder Telefon-Hotline anbieten, die bei inhaltlichen oder technischen Problemen in Anspruch genommen werden kann (Hiermit signalisiert der Untersuchungsleiter den potenziellen Informanten die Bereitschaft, mögliche Fragen von Seiten der Informanten zu beantworten.),

- Nennung eines Rücksendetermins, d.h. Angabe zur Laufzeit des Fragebogens,

- Dankesformel und

- Unterschrift

Obwohl, wie aus der Auflistung zu ersehen ist, viele Punkte zu beachten sind, ist ein relativ kurzes Anschreiben anzustreben ${ }^{27}$. Bei der Ankündigung in einem Diskussionsforum sollte der Text auf der Basis von ASCII geschrieben sein. Ferner sollte keine Zeile mehr als 65 Zeichen enthalten, um ungünstige Zeilenumbrüche zu vermeiden, die vom System willkürlich gesetzt werden. Erklärungen sollten lieber bei der Umfrage selbst gegeben werden, damit der potenzielle Informant nicht bereits bei der Ankündigung der Untersuchung von einer Fülle an Informationen „erschlagen“ wird. Der Titel der Ankündigung, d.h. die BetreffZeile der E-Mail, sollte dem Leser bereits zeigen, dass es sich um einen Fragebogen handelt, damit dieser gleich entscheiden kann, ob er die Ausführungen lesen möchte oder nicht. Fragebogenankündigung sollten nur in sechs bis acht thematisch wichtigen Gruppen erfolgen, da „Massensendungen“ (cross posting) gegen die Netzregeln, die sog. Netiquette verstoßen ${ }^{28}$. Hierdurch wird verhindert, dass Abon-

\footnotetext{
${ }^{26}$ In Online-Befragungen wird zur Steigerung der Teilnahmebereitschaft häufig angeboten, dass die Teilnehmer nach Abschluss der Studie die Auswertungsergebnisse erhalten. Genauso wird auch in der WWW-Befragung zur Internet-Terminologie und Sprachpolitik verfahren.

${ }^{27}$ Als Regel für Anschreiben gilt: Je länger der Text, desto weniger Teilnehmer (vgl. Batinic 2000, o.S.).

${ }^{28}$ Neben dem Versenden eines Beitrages an viele Diskussionsforen wird es als Verstoß gegen die Netiquette aufgefasst, wenn in einem Diskussionsforum ein Beitrag veröffentlicht wird, der thematisch nicht zu den Diskussionen dieser Gruppe passt. Zur Definition von Netiquette, das sich in etwa mit „Netz-Etikette“ übersetzen lässt, und cross posting vgl. Glossar. Die wichtigsten Netzregeln, die beim Verfassen und Versenden von E-Mails bzw. bei der Teilnahme in Diskussionsforen zu beachten sind, sind in Batinic (2001, 116-124) abgedruckt oder finden sich bei Kunze (2000).
} 
nenten verschiedener Diskussionsforen mehrfach mit dem gleichen Beitrag konfrontiert werden. Außerdem sollten Umfragen nur in denjenigen Diskussionsforen angekündigt werden, deren Diskussionsgegenstände zu dem Thema des Fragebogens passen. Es sollte mit anderen Worten einen inhaltlichen Bezug geben zwischen dem Thema des Fragebogens und den Themen, die in dem jeweiligen Diskussionsforum behandelt werden (vgl. Batinic 2001, 21). Auf die Umfrage selbst sollte am besten ein in den Ankündigungstext integrierter Hyperlink verweisen, so dass der Empfänger des Anschreibens beim Anklicken dieses Links direkt von der Nachricht auf die Einführungsseite des Fragebogens gelangt.

Bei der Formulierung des Anschreibens für die WWW-Befragung zur InternetTerminologie und Sprachpolitik wurde versucht, den in dem Katalog aufgezählten Kriterien Rechnung zu tragen (vgl. Anhang, 15.2.1).

Jedoch dürfe auch die Gefahr, die die Bekanntmachung einer Umfrage in Diskussionsforen berge, nicht übersehen werden. Der Fragebogen könne in den Foren, in denen er angekündigt werde, öffentlich diskutiert und kritisiert werden, wodurch die gesamte weitere Entwicklung der Umfrage beeinflusst werde (vgl. Batinic 2001, 22; Starsetzki 2001, 46).

Für den weiteren Verlauf der Befragung gilt das Prinzip der Wellen. Dies Prinzip dient im Wesentlichen der Erhöhung der Rücklaufquote (vgl. Dillman 2000; Stier 1996, 202). Bei diesem Prinzip wird der (Papier- oder Online-)Fragebogen in drei Wellen angekündigt. Ca. eine Woche nach dem ersten, ausführlichen Anschreiben, für das die genannten Kriterien gelten, erhalten die potenziellen Teilnehmer ein Erinnerungsschreiben. In diesem Schreiben werden alle, die bislang den Fragebogen noch nicht ausgefüllt haben, nochmals zur Teilnahme aufgefordert. Dieser Vorgang wird wiederum eine Woche später noch einmal wiederholt. Bei der 2. und 3. Welle dürfe der Hinweis nicht fehlen, dass die erneute Aufforderung zur Teilnahme nicht für diejenigen Personen gelte, die den Fragebogen bereits ausgefüllt und zurückgesandt hätten (vgl. Friedrichs 1990, 239).

Bei einer Fragebogen-Ankündigung über Diskussionsforen sollte mit einer zweimaligen Erinnerung vorsichtig umgegangen werden. Ein zu penetrantes Verweisen auf eine Umfrage könnte auch ablehnende Reaktionen hervorrufen, die sich auf die Rücklaufquote keinesfalls positiv auswirken. Auch wird davon abgeraten, in zu kurzen Abständen zu erinnern. Die Erinnerung sollte vielmehr in Abhängigkeit der Speicherkapazitäten der entsprechenden Foren geschehen. Man kann davon ausgehen, dass nach ein bis zwei Monaten alle Nachrichten eines Diskussionsforums gelöscht werden und somit von Internet-Nutzer nicht mehr gelesen werden können. Batinic (1997) empfiehlt somit ein erstes Erinnerungsschreiben erst nach vier Wochen.

Bei der WWW-Umfrage zur Internet-Terminologie wurde nur eine Erinnerung pro Diskussionsforum verschickt. Da in den meisten der einbezogenen Diskussionsforen die Nachrichten schon nach ein bis zwei Wochen gelöscht werden, wurde bereits nach einigen Tagen eine Erinnerungs-E-Mail verschickt (vgl. 8.1.1). 


\subsection{Zusammenfassung}

Dieses Kapitel dient dazu, einen Einblick in die von der Sprachwissenschaft bislang noch relativ selten genutzten Möglichkeiten der Online-Forschung zu geben und das dieser Arbeit zugrunde liegende Forschungsinstrument der WWW-Befragung in seiner Methodik und seinen Besonderheiten vorzustellen. Ein ganz entscheidender Punkt, der viele Wissenschaftler von der Durchführung von OnlineBefragungen und speziell von WWW-Befragungen abhält, sind die hohen Anforderungen, die derartige Untersuchungen an den Forschenden stellen. Dieser muss neben fachlichen und sozialwissenschaftlichen Kenntnissen auch ein zumindest rudimentäres informatisches Wissen sowie Internet-Erfahrung mitbringen, um einen dem Forschungsgegenstand adäquaten Fragebogen erstellen zu können. Dieser Mehraufwand mag sicherlich den einen oder anderen Wissenschaftler von der Durchführung derartiger Studien abschrecken. Damit das Untersuchungsinstrument der WWW-Befragung auch in der Linguistik eine häufigere Anwendung finden kann, wäre daher ein auf die Bedürfnisse von Linguisten zugeschnittener Leitfaden für die Erstellung von Online-Befragungen wünschenswert. Dieses und das folgende Kapitel (bes. 7.1.1) können daher als ein erster Einstieg in diese Thematik betrachtet werden. Folglich ist dieses Kapitel bis auf einige Hinweise, wie die angesprochenen Faktoren in dem WWW-Fragebogen zur InternetTerminologie und Sprachpolitik umgesetzt wurden, sehr allgemein gehalten.

Es wurde zunächst aufgezeigt, welche drei Typen der Online-Befragung unterschieden werden: 1. der WWW-Fragebogen, der online ausgefüllt wird, 2. ein Fragebogen, der über das Internet heruntergeladen werden kann und per E-Mail zurückgeschickt wird und 3. ein über E-Mail übermittelter und zurückgesendeter Fragebogen. Dieser Studie liegt der erste Typ zugrunde, die WWW-Befragung. Dabei wird ein HTML-Fragebogen auf einem Server abgelegt. Dieser wird von den Informanten aufgerufen und online ausgefüllt. WWW-Befragungen bieten gegenüber traditionellen Befragungsformen wie dem Papier-Fragebogen, der in der soziolinguistischen Forschung durchaus verbreitet ist, viele Vor-, aber auch Nachteile. Es wurde gezeigt, dass sich die Nachteile bis auf die ersten beiden Faktoren beheben lassen können.

\section{Abb. 9: Vor- und Nachteile von WWW-Befragungen}

Vorteile
Asynchronität
Alokealität und weiter Wirkungskreis
Automatisierbarkeit und Objektivität der
Durchführung und Auswertung
Dokeumentierbarkeit der Durchführung
Flexibilität
Ökonomie
Hohe Attraktivität
Ak:zeptan₹
Automatische Filterführung

Nachteile

Kosten auf Seiten der Informanten Selbstselektierende Stichprobe anstelle einer Repräsentativerhebung Häufiger Befragungsabbruch bzw. wablloses Durchklicken Gefahr von Mehrfachantworten Hohe Anforderungen an den Untersuchungsleiter 
Der Faktor der Selbstselektivität ist bei WWW-Befragungen viel ausgeprägter als in anderen Befragungsformen. Dies bedeutet im Hinblick auf WWW-Studien, dass mit den Ergebnissen im Regelfall keine Repräsentativität beansprucht werden darf. Dies ist für eine linguistische Arbeit nicht so problematisch wie bei Untersuchungen großer Marktforschungsunternehmen, bei deren Studien Repräsentativität angestrebt wird. Aus Forschersicht sprechen vor allem die pragmatischen Faktoren Asynchronität, Alokalität, Automatisierbarkeit und Objektivität der Durchführung und Auswertung sowie Ökonomie für den Einsatz von WWWBefragungen. Aus Sicht der Informanten ist die Attraktivität von WWW-Befragungen in der Regel höher als die von Papier-Bleistift-Fragebögen. Außerdem stoßen WWW-Befragungen aufgrund ihrer Neuheit auf relativ hohe Akzeptanz. Zusätzlich erleichtert die in elektronischen Fragebögen übliche automatische Filterführung das Ausfüllen des Fragebogens. Hinzu kommt, dass gerade Informatiker, die die Zielgruppe der WWW-Befragung zur Internet-Terminologie und Sprachpolitik darstellen, besonders gut über dieses Medium zu erreichen sind. Bei der Formulierung eines Anschreibens, in welchem auf die Umfrage hingewiesen und zur Teilnahme aufgefordert wird, sollten bestimmte Informationen gegeben und einige technische Einzelheiten beachtet werden. Wie die konkrete Umsetzung dieser Punkte aussieht, zeigen v.a. die Kapitel 7 und 8. 


\section{Der Aufbau des Fragebogens und der Pretest}

Im 6. Kapitel wurde die Methodik der WWW-Befragung vor allem in Abgrenzung zur klassischen schriftlichen Befragung mittels Papier-Fragebögen erläutert.

Der folgende Abschnitt 7.1.1 wird Aufschluss geben über die Gestaltungsmöglichkeiten von WWW-Fragebögen. Welches sind die Vorteile einteiliger, welches sind die Vorteile mehrteiliger Fragebögen? Wie lassen sich zum Beispiel die aus Papier-Fragebögen bekannten Fragetypen in WWW-Befragungen übertragen? Ferner geben 7.1.1.3 und 7.1.1.4 Auskunft über bestimmte optische und technische Faktoren, deren Beachtung für die Durchführung einer erfolgreichen und in ihren Ergebnissen so wenig wie möglich verzerrten WWW-Befragung unverzichtbar ist. Im Abschnitt 7.1.2 wird der Aufbau des WWW-Fragebogens zur InternetTerminologie und Sprachpolitik nachgezeichnet. 7.2 schließlich erläutert den letzten Schritt, der vor der definitiven Datenerhebung zu beachten ist: die Durchführung eines Pretests, der die Probe aufs Exempel darstellt.

\subsection{Der Aufbau des WWW-Fragebogens zur Internet-Ter- minologie und Sprachpolitik}

\subsubsection{Zur Konzeption und Gestaltung von WWW-Befragungen}

Vor der konkreten Erstellung eines Fragebogens ist eine Vielzahl von Punkten zu beachten. Dieses Unterkapitel versucht dafür eine Hilfestellung zu geben. Zugleich sollen aber auch die Voraussetzungen für das Verständnis des Abschnittes 7.1.2 geschaffen werden, indem die zur Gestaltung von WWW-Befra- 
gungen grundlegenden technischen Möglichkeiten und Fachtermini eingeführt werden.

Der Markt stellt eine Vielzahl von teils kostenpflichtigen, teils kostenfreien Fragebogengeneratoren zur Verfügung. Die Auswahl eines Fragebogengenerators sollte nicht allein unter dem Aspekt erfolgen, welcher Generator die meisten technischen Möglichkeiten bietet. Mitunter ist ein Zuviel an Technik eher hinderlich, wie die folgenden Ausführungen zeigen werden.

\subsubsection{Ein- und mehrteilige Fragebögen}

WWW-Fragebögen können ein- oder mehrteilig sein. Bei einem einteiligen Fragebogen erfolgt kein Seiten- bzw. Bildschirmwechsel, sondern der gesamte Fragebogen wird durch seitliches Scrollen an einem Stück bearbeitet und erst am Ende, wenn alle Fragen beantwortet sind, abgeschickt. Dieses Verfahren bietet den Vorteil, dass Onlinekosten gespart werden können: Der vollständige Fragebogen kann heruntergeladen, offline bearbeitet und dann online abgeschickt werden. Ein Nachteil einteiliger Fragebögen ist, dass der Informant die Möglichkeit hat, sich zunächst den gesamten Fragebogen anzusehen, bevor er mit dessen Bearbeitung beginnt. Falls er dies tut, besteht die Gefahr, dass das Wissen um spätere Fragen sein Antwortverhalten beeinflusst und somit die Ergebnisse verzerrt.

Ein mehrteiliger Fragebogen besteht aus mehreren nacheinander erscheinenden Seiten, die miteinander verknüpft sind. Der Extremfall ist hierbei, dass eine Seite einer Frage entspricht (Prinzip: „Eine Frage - ein Bildschirm“). Hierbei muss jede ausgefüllte Seite durch Anklicken des entsprechenden Versendefeldes (häufig mit engl. „Submit“ oder „Send“ gekennzeichnet) einzeln verschickt werden. Dieses Verfahren ist bei kurzen Umfragen durchaus sinnvoll, um zu verhindern, dass die Informanten sich bereits die folgenden Fragen ansehen. Bei einem mehrseitigen Fragebogen können die Informanten nicht bis zum Ende des Fragebogens vorscrollen. Dadurch wird zum einen verhindert, dass sie in ihrem aktuellen Antwortverhalten durch spätere Fragen beeinflusst werden. Zum anderen wird verhindert, dass die Informanten von Anfang an auf das Ausfüllen des Fragebogens verzichten, wenn ihnen die Fragen uninteressant erscheinen (vgl. Theobald 2000a, 83f.).

Ferner kann bei mehrteiligen Fragebögen mit Filtern gearbeitet werden (vgl. 6.3.2). Das bedeutet, dass sich die nächste Seite jeweils in Abhängigkeit der angekreuzten Antworten aufbaut. Gadeib (1999, 196) warnt davor, die geringe Transparenz mehrteiliger Fragebögen dahingehend zu missbrauchen, den Fragebogen zu sehr in die Länge zu ziehen („Endlosbefragung“). Es empfiehlt sich somit, die Informanten stets darüber in Kenntnis zu setzen, wie viele Fragen noch auszufüllen sind. Es bieten sich zwei Möglichkeiten an, die Befragten darüber zu informieren, an welchem Punkt in der Gesamtuntersuchung sie sich gerade befinden. Zum einen lässt sich im oberen Bereich der Fragebogenseite ein Fortschrittsanzeiger in Form einer Grafik einbauen, zum anderen ist es möglich, dem Befragten ständig die Nummer der jeweiligen Frage und die Anzahl der Fragen insgesamt mitzuteilen. Auf diese Weise können die Informanten abschätzen, wie viel Prozent des 
Fragebogens sie bereits ausgefüllt haben und wie viel Zeit sie noch für die Befragung aufwenden müssen.

Ein gravierender Nachteil bei längeren, mehrteiligen Fragebögen ist die Wartezeit, die Zeit, die sich zwischen dem Absenden der einzelnen Fragebogenseiten und dem Laden der nächsten Seite ergibt.

Wovon sollte die Entscheidung für einen ein- oder mehrteiligen Fragebogen abhängen? Sind Mischformen möglich?

Insgesamt scheint es sinnvoll, bei kurzen Fragebögen das „Ein-Bildschirm-EineFrage-Prinzip“ einzusetzen, das ein Vorscrollen verhindert und das Ausfüllen trotz der Ladezeiten in einem zeitlich zumutbaren Rahmen hält. Den gesamten Fragebogen auf einer einzigen Seite darzustellen, bietet sich an, wenn

die Reihenfolge der Beantwortung der Fragen sich nicht verzerrend auf das Untersuchungsergebnis auswirkt, die Umfrage übersichtlich gestaltet ist,

der Fragebogen nicht zu lang ist und aufgrund der Fragen und des Layout motivierend wirkt und

Filterführung an keiner Stelle nötig ist.

Ein Kompromissmodell sollte dann eingesetzt werden, wenn der Fragebogen sehr lang ist und Filterführung unabdingbar ist. Gegen das „Ein-Bildschirm-EineFrage-Prinzip“ spricht bei längeren Fragebögen mit mehr als 20 Fragen die Ladedauer der einzelnen Seiten. Die Informanten würden ungeduldig, wenn sie nach jeder Frage einige Sekunden auf die neue Frage warten müssten. Insofern bietet es sich bei längeren Befragungen an, mehrere Fragen auf einer Bildschirmseite anzuordnen, wobei in die jeweils letzte Frage auf einer Seite ein Filter integriert werden kann, so dass die Beantwortung dieser Frage über die als nächste aufzurufende Fragebogenseite entscheidet. Auf diese Weise ist es durchaus möglich, dass die Befragten mehrere Fragen auf einer Bildschirmseite beantworten, wodurch viele Daten in relativ kurzer Zeit eingegeben und übermittelt werden.

Problematisch ist bei dieser Lösung in erster Linie die praktische Umsetzung, da fertige Umfragegeneratoren oftmals keine Mischformen, d.h. keine freie Verteilung der Fragen auf beliebig viele Bildschirmseiten, erlauben. So beruhen beispielsweise der Fragebogen-Generator der Rogator Software AG und der WWWFragebogen-Generator (WFG) von Batinic auf dem „Ein-Bildschirm-Eine-FragePrinzip“. Andere Umfragetools wie das kostenlose Programm MOOSE und andere Programme der Firma Globalpark ermöglichen die hier vorgeschlagene Kompromisslösung ${ }^{1}$.

Der WWW-Fragebogen zur Internet-Terminologie und Sprachpolitik beruht auf einer Mischform. Auf den Seiten des ersten Fragebogenmoduls befinden sich jeweils eine oder zwei Fragen, der zweite und dritte Fragebogenteil befindet sich

\footnotetext{
1 MOOSE ist die kostenlose Vorversion eines nur käuflich zu erwerbenden Umfragegenerators. Entsprechend ist die Vorversion noch mit kleineren Makeln behaftet, die aber mit Hilfe fachkundiger Informatiker behoben bzw. umgangen werden können (vgl. auch Kap. 8, Fußnote 1). Der aktuelle Fragebogengenerator wird von Globalpark - Software und Consulting für Online-Marktforschung: Online-Panel und Online-Umfragen (http://www.globalpark.de/) vertrieben.
} 
jedoch nur auf zwei Seiten bzw. auf einer Seite, wodurch das Beantworten der letzten Teile besonders schnell erfolgen kann.

\subsubsection{Fragetypen in WWW-Fragebögen}

Bei WWW-Befragungen bietet es sich an, weitgehend geschlossene Fragen mit entsprechenden Antwortvorgaben zu verwenden ${ }^{2}$. Für den Untersuchungsleiter, aber auch für die Befragten ist der Einsatz dieses Fragentyps am ökonomischsten. Quantitative Auswertungen sind schneller und leichter durchzuführen, weil sie im Unterschied zu qualitativen Evaluationen vollständig automatisiert werden können. Zudem entfällt bei geschlossenen Fragen eine nachträgliche Kategorisierung der von den Informanten frei formulierten Antworten. Geschlossene Fragen erleichtern den Benutzern die Beantwortung, weil diese sich nicht selbst eine Antwort ausdenken und diese eingeben müssen, sondern aus den angebotenen Möglichkeiten die zutreffende(n) Antwort(en) auswählen und anklicken können. Da ein Erkennen vorgegebener Antworten den Informanten i.d.R. leichter fällt und schneller geht als eigenes Formulieren, erweist sich der Einsatz geschlossener Fragen für die Informanten als motivierend. Offene Fragen führen zu höheren Abbruchquoten, wie Knapp/Heidingsfelder (2001) nachweisen. Der Königsweg dürften halboffene Fragen, sog. Hybridfragen, sein, in denen es neben verschiedenen Antwortmöglichkeiten die Option gibt, eine eigene, von den Vorgaben abweichende Antwort einzugeben. Diese zusätzliche Kategorie wird meistens mit „Sonstiges ... und zwar“ überschrieben.

„Darüber hinaus werden bei geschlossenen Fragen die Verzerrungen, die durch unterschiedliche Artikulationsfähigkeiten der Befragten entstehen können, reduziert. In vielen Befragungen sind auch Hybridfragen $\mathrm{zu}$ finden. Sie stellen eine Kombination aus offener und geschlossener Struktur dar und ermöglichen dem Befragten über die festgelegten Antwortoptionen hinaus eigene Angaben zu machen" (vgl. Arbeitsgemeinschaft Informationsgesellschaft o.J., o.S.).

Analog zu Papier-Fragebögen lassen sich auch in WWW-Umfragen die folgenden Skalentypen verwenden:

dichotome Items (Bsp.: „Kennen Sie die Bezeichnung E-Post?“ - ja/nein), Likert-Skala (5er bzw. 7er Skala) ${ }^{3}$,

Multiple Choice (mit einer möglichen Antwort, realisierbar über sog. RadioButtons oder die platzsparenden Drop-down-Menüs ${ }^{4}$ ),

\footnotetext{
${ }^{2}$ Es empfiehlt sich, unter den Antwortmöglichkeiten einer geschlossenen Frage auch die Kategorie „Weiß nicht“ anzubieten, um keinen Befragten zum Ankreuzen einer Kategorie, die eventuell auf ihn gar nicht zutrifft, zu zwingen (vgl. Stier 1996, 178).

3 Zur Likert-Skala vgl. Kap. 2, Fußnote 11.

${ }^{4}$ Die Bezeichnung dieses Auswahlfeldes ist leider nicht einheitlich. Neben Drop-down-Menüs wird auch häufig der Terminus Pull-down-Menüs oder Selectfelder verwendet. Drop-down-Menüs sind Felder, bei denen der Informant eine Antwort aus mehreren Antwortmöglichkeiten wählen kann, die auf einen Mausklick hin gewissermaßen aufklappen. Von der Funktion sind Selectfelder mit RadioButtons gleichzusetzen: Es kann nur eine aus den vorgegebenen Antwortmöglichkeiten ausgewählt werden. Der Vorteil dieser Formulare liegt eindeutig darin begründet, dass sie im Normalzustand sehr platzsparend sind, da sie nur eine Zeile einnehmen und sich erst auf einen Mausklick hin öff-
} 
Multiple Choice (mit mehreren möglichen Antworten, realisierbar über sog. Checkboxen),

halboffene Fragen (d.h. ein ein- oder mehrzeiliges Eingabefeld in Verbindung mit einer der beiden Möglichkeiten der Multiple Choice-Fragen) und

offene Fragen (ein- oder mehrzeiliges Eingabefeld) (vgl. Batinic/Puhle/Moser 1999, 101; Theobald 2000a, 81f.).

Für WWW-Befragungen bietet HTML verschiedene technische Möglichkeiten, um die Antwortkategorien zu gestalten. Mit dem Formular der Radio-Buttons (O) kann pro Antwortbatterie immer nur eine einzige Möglichkeit markiert werden $(\odot)$. Radio-Buttons stellen somit eine Entweder-Oder-Möglichkeit dar. Wenn sich der Informant für eine andere als die anfangs von ihm gegebene Antwort entscheidet und ein anderes Feld anklickt, wird das neue Feld markiert und die Markierung des zuvor gewählten Feldes verschwindet wieder. Der Einsatz von RadioButtons bietet sich immer dann an, wenn nur eine einzige Antwort gewünscht wird, z.B. bei der Angabe des Geschlechts.

Für Fragen, die die Wahl mehrerer Antwortvorgaben ermöglichen, bietet sich der Einsatz von Checkboxen $(\square)$ an. Diese werden durch Klicken aktiviert und erhalten einen Haken $(\square)$, und lassen sich durch ein zweites Klicken wieder deaktivieren. Checkboxen werden z.B. bei der Frage nach Freizeitaktivitäten eingesetzt, weil es durchaus wahrscheinlich ist, dass auf die Befragten mehrere der angebotenen Antwortalternativen zutreffen.

Werden sehr viele Antwortalternativen dargeboten, von denen aber nur eine einzige Antwort ausgewählt werden soll, empfiehlt Dillman (2000, 354) den Einsatz sog. Drop-down-Menüs. Bei den entsprechenden Menüs soll auf alle Fälle eine neutrale Position im Ausgangsfenster stehen, wie z.B. „Click Here“/„Bitte auswählen“. Dillman $(2000,393)$ rät davon ab, bereits eine der Antwortmöglichkeiten vorzuselektieren, um Verzerrungen zu vermeiden.

Der Fragebogen zur Internet-Terminologie und Sprachpolitik enthält die verschiedensten Fragetypen, zumeist jedoch geschlossene Multiple Choice-Fragen, die entweder eine oder mehrere Antwortmöglichkeiten zulassen (vgl. 7.1.2).

\subsubsection{Optische Gestaltung von WWW-Fragebögen}

Besonderes Augenmerk ist nicht nur auf die inhaltliche Gestaltung des Fragebogens zu richten (v.a. auf den Einsatz interessanter und verständlicher Fragen), sondern auch auf den optischen Eindruck eines Fragebogens. Die optische Gestaltung eines Fragebogens beeinflusst die Rücklaufquote entscheidend. Ein Fragebogen sollte deshalb generell ansprechend und motivierend gestaltet werden. Eine benutzerfreundliche und grafisch ansprechende Gestaltung des Fragebogens erhöht nicht nur die Antwortquote, sondern verhindert auch, dass einzelne Fragen übersehen und somit nicht beantwortet (der sog. nonresponse-error) oder aber bewusst ausgelassen werden. So geht Dillman (2000, 80f.) davon aus, dass Benutzer aufgrund des Layouts beurteilen, welche Teile des Fragebogens für sie wichtig

nen. Der Nachteil dieser Menüs besteht darin, dass die Informanten keinen eigenen Text im Sinne einer halboffenen Frage eingeben können. 
sind, d.h. gelesen und beantwortet werden sollen. Oftmals sind die Gestaltungsmöglichkeiten aufgrund des verwendeten Fragebogengenerators allerdings sehr eingeschränkt.

Für Fragebögen, welche die Grundlage wissenschaftlicher Studien bilden, empfiehlt sich ein seriöses Erscheinungsbild, da die Ernsthaftigkeit der Umfrage in erster Linie am Layout gemessen wird. In der Literatur zur Erstellung von WWWBefragungen werden folgende Punkte genannt, die es bei der Konzeption eines elektronischen Fragebogens zu beachten gelte (vgl. Batinic/Puhle/Moser 1999, 101; Dillman 2000, 23, 99-112, 115, 373, 385-390; Gräf 1999, 165; Theobald 2000a, 76-81):

- klare Arbeitsanweisungen, da keine unmittelbaren Rückfragen an einen Interviewer möglich sind ${ }^{5}$,

Filterführung,

Nummerierung der einzelnen Fragen,

Einsatz von Fettdruck und Schattierungen sowie übersichtliche Anordnung der Fragen in Spalten,

klare Absetzung der einzelnen Fragen voneinander,

- Verzicht auf Werbebanner oder andere Formen der Werbung in der Umfrage, modernes Erscheinungsbild, welches hohen ästhetischen Anforderungen genügen kann,

Verzicht auf aufwändige (animierte) Grafiken, Tondokumente, Applets u.Ä., welche die Ladezeiten erhöhen ${ }^{6}$,

Verzicht auf übermäßigen Einsatz von Farben,

keine zu kleine Schrift für den Fragetext,

unter Umständen besondere Hervorhebung des Fragetextes zur besseren Abgrenzbarkeit der einzelnen Fragen,

möglichst geringe Textmengen und

Beachtung verschiedener möglicher Bildschirmauflösungen, damit der Fragebogen auch bei geringerer Auflösung in seiner gesamten Breite dargestellt werden kann, ohne dass horizontales Scrollen nötig wird ${ }^{7}$.

\footnotetext{
${ }^{5}$ Arbeitsanweisungen zum konkreten Beantworten der einzelnen Fragen sollen nach Dillman (2000) immer direkt bei den jeweiligen Fragen eingefügt werden und nicht außerhalb der Fragen stehen. Abzuraten ist nach Meinung des Autors ebenfalls von separaten Büchern (bzw. im Falle einer WWW-Befragung: online lesbaren Dokumenten), welche die Arbeitsanweisungen enthalten. Beides verkompliziere nach Dillman das Ausfüllen des Fragebogens für den Informanten nur unnötig (vgl. Dillman 2000, 118, 120). Besser sei es, für einzelne Fragen die Möglichkeit von Pop-up-Fenstern zu eröffnen, durch welche Anweisungen bei Bedarf aufgerufen werden können. So greifen nur diejenigen Informanten darauf zurück, die Erklärungen zur jeweiligen Frage wünschen, der Fragebogen selbst wird jedoch durch diese Erklärungen nicht unnötig in die Länge gezogen (vgl. Dillman 2000, 354). Von diesem Verfahren konnte leider für die WWW-Befragung mit französischsprachigen Informanten kein Gebrauch gemacht werden, da das verwendete Programm MOOSE diese Option nicht bietet. Daher werden die Erklärungen direkt bei den jeweiligen Fragen vermerkt.

${ }^{6}$ Lange Ladezeiten rufen zumeist Verärgerung bei den Informanten hervor. Außerdem lenken zu viele Grafiken und andere multimediale Elemente vom Wesentlichen ab und verlängern das Ausfüllen des Fragebogens somit unnötig.

7 Scrollen wird von Nutzern meistens nicht geschätzt und sollte deswegen auf ein Mindestmaß beschränkt werden. Damit längere Fragen nicht über den Bildschirmrand hinaus gehen, was Scrollen
} 
Es kommt zusammenfassend darauf an, die zur Verfügung stehenden optischen Mittel sinnvoll und maßvoll zur Gestaltung des Fragebogens einzusetzen. Das oberste Ziel sollte ein benutzerfreundlicher und übersichtlicher Fragebogen sein, der den Informanten sowohl zum Durchhalten motiviert als auch vermeiden hilft, dass dem Informanten Fehler bei der Bearbeitung des Fragebogens unterlaufen.

Das Layout des WWW-Fragebogens zur Internet-Terminologie und Sprachpolitik ist schlicht gestaltet. Die Fragebogenseiten haben alle einen hellgelben Hintergrund. Die Eingangs- und Endseite wurden durch jeweils eine Grafik aufgelockert. Es wurde v.a. im Bereich der Schriftgröße und Schriftfarben variiert, um die Fragen von Arbeitsanweisungen deutlich abzusetzen und wiederum die zu beurteilenden Termini besonders hervorzuheben. Die Fragen wurden nummeriert. Vertikales Scrollen war nur bei sechs Fragen des ersten Fragebogenmoduls sowie für den zweiten und dritten Fragebogenteil notwendig. Horizontales Scrollen war an keiner Stelle des Fragebogens notwendig. Die Verständlichkeit der Fragen und Arbeitsanweisungen wurde im Pretest (vgl. 7.2) überprüft.

\subsubsection{Technische Gestaltung von WWW-Fragebögen}

Oberste Regel bei der Erstellung von WWW-Fragebögen ist, dass kein potenzieller Informant aufgrund technischer Probleme von der Umfrage ausgeschlossen werden darf. Vermieden werden soll beispielsweise, dass ein durch die Ankündigung aufmerksam gewordener, potenzieller Informant die Umfrage aufrufen will, diese jedoch aufgrund fehlender oder auf dem betreffenden Computer deaktivierter Programme nicht öffnen kann.

Um derartige ungewollte Ausschlussverfahren zu verhindern, sollten bei der technischen Gestaltung des Fragebogens die folgenden Punkte beachtet werden:

Verzicht auf Java-Script und Java Applets, da viele Nutzer die Java-SkriptFunktion aus Datenschutzgründen und/oder zwecks Zeitersparnis ${ }^{8}$ auf ihrem Computer deaktiviert haben,

Verzicht auf den Einsatz von Active-X (Active-X setzt MS-Windows als Betriebssystem voraus und schließt damit Unix-Nutzer aus; zudem birgt es ein hohes Sicherheitsrisiko),

Kompatibilität des Fragebogens mit allen gängigen Browsern (z.B. Netscape Communicator, Microsoft Internet Explorer oder Opera, auch mit jeweils älteren Programmversionen), d.h. plattform- und vom Endgerät des Nutzers unabhängige Gestaltung?,

Auswahl kurzer Ladezeiten, so dass auch bei Verwendung eines langsamen Modems der Fragebogen in akzeptabler Zeit geladen werden kann,

Verzicht auf den Einsatz der Frame-Technologie und

bedingen würde, müssen ggf. Zeilenumbrüche eingefügt bzw. ein kleinerer Schrifttyp gewählt werden. Dies erleichtert den Befragten merklich das Ausfüllen des Fragebogens.

${ }^{8}$ Das Laden dieser Applets ist oft sehr zeitintensiv.

9 So kann der Fragebogen unabhängig vom jeweils verwendeten Browser geöffnet und sogar mit älteren Programmen (und Computern) bearbeitet werden, ohne dass Personen der Zielgruppe aus technischen Gründen von der Beantwortung ausgeschlossen werden. 
möglichst wenig Wechsel zwischen Mausbedienung und Tastatureingaben (vgl. ADM et al. 2001, Kap. D; Batinic/Puhle/Moser 1999, 101f.; Gräf 1999, 169, 171; Theobald 2000a, 75).

Bei der Erstellung des WWW-Fragebogens zur Internet-Terminologie und Sprachpolitik wurde allen genannten Punkten Rechnung getragen. Die Kompatibilität des Fragebogens mit den gängigen Browsern und unter den beiden Betriebssystemen MS-Windows und Unix wurde an verschiedenen Computern erprobt. Die Ladedauer war jeweils kurz, meistens nur eine Sekunde.

\subsubsection{Konzeption des Fragebogens zur Internet-Terminologie und Sprachpolitik}

Der WWW-Fragebogen zur Internet-Terminologie und Sprachpolitik dient der Überprüfung der in 5.3 formulierten Hypothesen. Er wurde mit dem kostenlos verfügbaren Fragebogengenerator MOOSE erstellt (vgl. Fußnote 1). Dieses von Dorthe Lübbert entwickelte Programm wurde ausgewählt, weil es alle Anforderungen erfüllt, die für eine optimale Umsetzung des Fragebogens nötig sind:

Verwendung aller Fragetypen von geschlossenen über halboffene bis zu offenen Fragen,

Wahl zwischen Einfach- und Mehrfachnennungen (Radio Buttons, Drop-downMenüs, Checkboxen),

Filterführung,

freie Verteilung der Fragen auf Bildschirmseiten: Auf jedem Bildschirm können eine oder auch mehrere Fragen stehen ${ }^{10}$,

Kompatibilität der erstellten Fragebögen mit allen gängigen Browsern,

keine Java-, Active-X- oder Frame-Technologie,

Export der Daten nach MS Excel oder SPSS.

Nachdem die technischen Voraussetzungen geklärt sind, folgen einige Erläuterungen zur Struktur und zum Inhalt des Fragebogens.

$\mathrm{Da}$ es sich erstens nicht um einen ausgedruckten Papier-Fragebogen handelt und zweitens bei der Erstellung des WWW-Fragebogens mit Filtern gearbeitet wurde, ist es kaum möglich anzugeben, wie viele Seiten und wie viele Fragen der Fragebogen umfasst. Es muss vielmehr angeführt werden, wie viele verschiedene Bildschirmseiten bei der Bearbeitung des mehrteiligen Fragebogens aufgebaut werden. Hier kann die Anzahl der aufgebauten Bildschirme und entsprechend die Anzahl der Fragen je nach Antwortverhalten des Informanten variieren. Werden z.B. alle Termini einer Lexemgruppe als unbekannt eingestuft - was in Anbetracht der befragten Zielgruppe sehr unwahrscheinlich ist -, werden mit Hilfe der Filtertechnik alle weiteren Fragen zu dieser Lexemgruppe übersprungen, und der Informant wird direkt zum nächsten Fragenkomplex weitergeleitet. Es ist insofern sinnvoll, bei der Angabe der Anzahl aufgerufener Bildschirme und der davon abhängenden

\footnotetext{
${ }^{10}$ Es wäre theoretisch mit MOOSE auch möglich, einen einteiligen Fragebogen zu konstruieren. Das von vielen Generatoren geforderte „Ein-Bildschirm-Eine-Frage-Prinzip“ ist mit MOOSE ebenfalls möglich, aber nicht zwingend (vgl. 7.1.1.1).
} 
Anzahl von Fragen mit einem Minimal- und einem Maximalwert zu arbeiten. Beantwortet ein Informant alle Fragen inklusive der Unterfragen ${ }^{11}$ so, dass keine Frage übersprungen wird, umfasst der Fragebogen 40 Bildschirmseiten mit insgesamt 59 Fragen (= Maximalwert). Davon entfallen 36 Seiten mit insgesamt 42 Fragen auf den ersten Fragebogenteil. Falls ein Informant in diesem ersten Teil alle Termini als unbekannt einstuft, was wie gesagt sehr unwahrscheinlich ist, werden dem betreffenden Informanten im ersten Teil nur sechs Bildschirmseiten mit jeweils einer Frage angezeigt (= Minimalwert ${ }^{12}$ ). Es folgt der zweite Fragebogenteil, der in seiner konkreten Ausgestaltung vom Wohnort des jeweiligen Informanten abhängt. Teil II umfasst die Seite 38 mit den Fragen 44-48 und die Seite 39, die aber nur bei bestimmten Antworten auf die Frage 48 erscheint. Auf dieser Seite 39 steht nur eine einzige Frage, die Frage Nr. 49. Teil III entspricht der 40. Fragebogenseite. Dieser Teil enthält insgesamt zehn Fragen und zwei Kommentarfelder auf einer einzigen Bildschirmseite. Während das erste Fragebogenmodul viele Filter enthält, weist das zweite Modul nur noch einen einzigen Filter auf. Das dritte und letzte Modul enthält keinen Filter und ist mit Ausnahme der Bildungsabschlüsse und der Wohnorte für die Informanten aller drei Untersuchungsgebiete identisch (vgl. Fragebogen im Anhang 15.3).

Damit die Informanten jederzeit wissen, an welcher Stelle der Umfrage sie sich befinden, wird bei jeder Frage angezeigt, um die wievielte Frage von insgesamt 59 Fragen es sich handelt. Zusätzlich wurde zum Erhalt der Motivation nach der 30. Frage ein Kommentar eingefügt, dass die Informanten bereits die Hälfte des Fragebogens ausgefüllt hätten und der zweite Teil schneller gehen werde als der erste.

Es wurde versucht, die Fragebogenseiten so zu gestalten, dass die Informanten möglichst alle Fragen und Antwortoptionen auf einen Blick sehen. Natürlich ist dies nicht immer möglich, insbesondere wenn eine große Anzahl von Antwortoptionen zu einer Frage bzw. viele Fragen auf einer Bildschirmseite untergebracht sind. In diesen Fällen muss die Bildschirmseite durch die vertikale Scrollfunktion etwas nach oben geschoben werden. Der mangelnde Komfort (v.a. im zweiten und dritten Modul) verkürzt dafür die für das Ausfüllen des Fragebogens benötigte Zeit, da nicht ständig neue Seiten geladen werden müssen. Horizontales Scrollen ist jedoch an keiner Stelle des Fragebogens nötig.

Bei der inhaltlichen Konzeption des Fragebogens kann auf Vorbilder zurückgegriffen werden. Inhaltlich und methodisch lehnt sich diese Untersuchung eng an die von Fugger und Helfrich erstellten Fragebögen an (vgl. 4.3.1). Das mit dieser Arbeit verfolgte Forschungsinteresse kommt insbesondere den Zielsetzungen Fuggers sehr nahe, wenngleich dieser einen anderen Adressatenkreis ausgewählt

\footnotetext{
11 Als Unterfrage wird das Textfeld gewertet, das immer dann erscheint, wenn auf die jeweils zweite Frage in den sechs Fragenkomplexen, ob die angegebenen Termini synonym seien, mit „Non, ils ont un sens différent." geantwortet wird. In diesem Textfeld sollen die Informanten dann den Bedeutungsunterschied erklären.

${ }^{12}$ Es werden in diesem Fall nur die Seiten 1 (= Frage 1), 7 (= Frage 8), 13 (= Frage 15), 19 (= Frage 22), 25 (= Frage 29) und 31 (= Frage 36) des ersten Fragebogenmoduls angezeigt.
} 
hat. Außerdem bezieht sich seine Studie auf das damals aktuelle Sprachgesetz, die Loi Bas-Lauriol, und auf einen anderen Terminologieerlass, nämlich auf die Terminologie de l'audio-visuel (vgl. Fugger 1979/1980/1983a,b/1987). In dieser Studie werden analog zu Fuggers Befragung nicht nur die Einstellungen zu ausgewählten Neologismen, sondern auch die Einstellungen zur französischen Sprachpolitik und Terminologiearbeit im Allgemeinen erforscht. Für die konkrete Umsetzung des dieser Arbeit zugrunde liegenden Forschungsinteresses in einen Fragebogen bietet sich daher ein Blick auf die Vorgehensweise Fuggers an.

Fugger (1979, 158f.) untergliedert den Fragebogen entsprechend seiner Forschungsziele in drei Teile:

1. Ermittlung der Kenntnis von Sprachpolitik und Sprachpflegeinstitutionen im Allgemeinen und der Erlasse vom 01. Januar 1977 im Speziellen,

2. Ermittlung des inhaltlichen Bekanntheitsgrades von zehn durch die Erlasse betroffenen Lexempaaren aus dem Bereich der Gemeinsprache sowie deren Bewertung im Hinblick auf ihre Bedeutungsäquivalenz,

3. Ermittlung der Bewertung (und Akzeptanz) der französischen Sprachpolitik im Allgemeinen und der Erlasse vom 01. Januar 1977 im Speziellen.

Mit der WWW-Umfrage zur Internet-Terminologie und Sprachpolitik werden ebenfalls drei Ziele verfolgt, die sich wie folgt in den einzelnen Fragebogenmodulen widerspiegeln:

1. Ermittlung der Kenntnis der offiziellen Ersatzwörter (1. Fragebogenmodul);

2. Ermittlung des Sprachgebrauchs der Informanten. Werden die französischen Neologismen oder die Anglizismen verwendet? Aussagen über die Verwendung von Anglizismen bzw. Neologismen entsprechen der konativen Einstellungsdimension. Welche Gründe gibt es für den jeweiligen Sprachgebrauch? Im Falle der Verwendung von Neologismen wird mit Hilfe des semantischen Differentials die affektive Einstellungskomponente ermittelt. Im Falle der Verwendung der Anglizismen werden die diesem Verhalten zugrunde liegenden kognitiven und affektiven Einstellungen ermittelt (1. Fragebogenmodul);

3. Ermittlung der Einstellungen zur staatlichen Regulierung des Anglizismengebrauchs und der Bekanntheit der entsprechenden Verordnungen (2. Fragebogenmodul). Wie wird die Notwendigkeit von Sprachpolitik beurteilt (affektive Einstellungsdimension)? Ist die Existenz von Terminologieerlassen und speziell der Erlasse zur Internet-Terminologie bekannt (kognitive Einstellungsdimension)? Werden die Terminologievorschriften befolgt (konative Einstellungsdimension)? ${ }^{13}$

Aufgrund der engen Orientierung dieser Befragung an der Studie Fuggers ist es angebracht, auf die in seinem Fragebogen formulierten Fragen im Einzelnen einzugehen.

\footnotetext{
13 Bei dem WWW-Fragebogen zur Internet-Terminologie und Sprachpolitik handelt es sich ausgehend von der Einteilung Humbleys (1997, 156; vgl. 4.2) in 1. Untersuchungen zum Sprachkorpus, 2. metalinguistische und 3. epilinguistische Studien sowohl um eine metalinguistische als auch um eine epilinguistische Studie, da sich manche Fragen sich auf metalinguistisches, andere auf epilinguistisches Wissen beziehen.
} 
Fuggers erstes Fragebogenmodul beinhaltet die folgenden drei Fragen zur Kenntnis der französischen Sprachpolitik:

„Que savez-vous de la politique du Gouvernement Français en ce qui concerne la défense de la langue française?",

„Connaissez-vous des institutions en France qui s'occupent de la pureté et, le cas échéant, de la défense de la langue française? Pouvez-vous les nommer?",

„Avez-vous déjà entendu parler des Arrêtés Ministériels qui sont entrés en vigueur le $1^{\text {er }}$ janvier 1977 et qui remplacent certains mots d'origine anglaise par des mots d'origine française?" (Fugger 1987, 233f.).

Im zweiten Teil seines Fragebogens wird nach der Bedeutung der genannten Lexeme gefragt („Que signifient les mots suivants?“, ebd., 234). Hiermit will Fugger den semantischen Bekanntheitsgrad ermitteln, um daraus abzuleiten, ob die Befragten eher den Anglizismus oder das offizielle Ersatzwort kennen. Um festzustellen, inwieweit für die Sprachbenutzer der Anglizismus und das entsprechende Ersatzwort wirklich als bedeutungsäquivalent eingeschätzt werden, formuliert Fugger die folgende Frage, die für alle zehn von ihm ausgewählten Lexempaare zu beantworten ist: „Existe-t-il une différence de sens entre les couples de mots suivants? Laquelle?" (ebd., 237). Zuletzt wird in diesem Teil danach gefragt, welches Wort die Informanten bevorzugen: „Quel mot préféreriez-vous dans l'usage de la langue? Pourquoi?"“ (ebd., 239).

Im dritten Modul ermittelt Fugger mit Hilfe der drei nachstehend aufgeführten Fragen die Einstellung der Sprecher zur Sprachpolitik und speziell zu den Terminologieerlassen vom 01. Januar 1977:

„Une direction et une planification de la langue, est-elle à votre avis?" („en tout cas nécessaire“, „désirable“, „,inutile“),

„Que pensez-vous des Arrêtés Ministériels du $1^{\text {er }}$ janvier 1977?" (,utiles“, „rien“, „trop inconnus“, „,ridicules“, „,inutiles"),

„Vous conformerez-vous aux dispositions des Arrêtés Ministériels?" („oui“", „selon le cas“, „non“) (ebd., 240).

Im Unterschied zu Fugger umfasst der Fragebogen zur Internet-Terminologie und zur aktuellen Sprachpolitik nur zwei Module, die sich mit der Kenntnis und Akzeptanz der Sprachpolitik und Terminologiearbeit auseinandersetzen. Das erste dient der Bewertung der ausgewählten Internet-Lexeme, während sich das zweite der Einschätzung der Sprachpolitik sowie der Bekanntheit der Resultate der staatlichen Terminologieplanung widmet. Das dritte Modul schließlich umfasst Fragen zur Person der Informanten (biosoziale Daten). 


\subsubsection{Das erste Fragebogenmodul}

Das erste Fragebogenmodul orientiert sich hinsichtlich der Formulierung der Fragen eng an der Untersuchung von Fugger (1979/1980/1983a,b/1987) und bezüglich der Ausgestaltung der analog aufgebauten Fragen 6, 13, 20, 27, 34 und 41 an der Fragebogenstudie von Helfrich (1993).

Nachdem die Informanten sich zur Teilnahme entschlossen haben und auf den ersten Bildschirm des Fragebogens gelangt sind, wird ihnen zunächst ein Satz präsentiert: 1. Pour entrer en contact avec quelqu'un on peut lui envoyer un/une courrier électronique / message électronique / lettre électronique / mél / courriel / messagerie électronique / e-mail / maill4. Anschließend werden sie in der 1. Frage des ersten Fragebogenmoduls aufgefordert anzugeben, welche oder welchen der aufgeführten Internet-Termini (courrier électronique, message électronique, lettre électronique, mél, courriel, messagerie électronique, e-mail; d.h. französische und englische Termini) sie kennen ${ }^{15}$. Bei dieser Frage handelt es sich um eine geschlossene Multiple ChoiceFrage (vgl. 7.1.1.2.1), bei der mehrere der angebotenen Antwortmöglichkeiten gewählt werden können. Ein Textfeld für die Eingabe weiterer Termini ist nicht vorgesehen. Auch die folgenden Fragen 2 bis 6 beziehen sich auf die gleiche Lexemgruppe, bevor nach deren Beantwortung zur nächsten Lexemgruppe (page d'accueil, page d'introduction, homepage) vorgegangen wird und so fort. Zu Beginn der Fragen zu jeder der sechs Lexemgruppen werden die ausgewählten Termini im Kontext eines Satzes präsentiert.

Um die Ernsthaftigkeit der Antworten und damit die Glaubwürdigkeit der Informanten zu überprüfen, wurde jeweils ein äußerst ungebräuchliches oder aus einem anderen Kontext entnommenes französisches Ersatzwort unter die vorgegebenen Termini gemischt ${ }^{16}$. Fragebögen, in denen Informanten angeben, dass sie dieses Wort selbst häufig oder in der Mehrheit der Fälle verwenden, sind besonders kritisch zu bewerten und bei weiteren Ungereimtheiten von der Auswertung auszuschließen. Einen Überblick über die in den Fragebogen aufgenommenen Lexeme - inkl. der Testwörter - gibt die nachfolgende Tabelle:

${ }^{14}$ Der gesamte Fragebogentext ist im Anhang unter 15.3 abgedruckt.

15 Bei der Formulierung der konkreten Fragen wurden die zu diesem Thema von der empirischen Sozialforschung bzw. empirischen Sprachwissenschaft bereitgestellten Hinweise berücksichtigt. Verschiedene Werke geben Hilfestellung zur konkreten Frageformulierung, wie z.B. Dillman (2000, 32-78), Mayntz/Holm/Hübner (1978, 106-111), Schlobinski (1996, 40), Stier (1996, 180f.). Es herrscht dahingehend Übereinstimmung, dass die Fragen zur Vermeidung verzerrter Antworten

- nicht suggestiv,

- nicht hypothetisch,

- $\quad$ kurz und präzise sein sollten,

- $\quad$ keine doppelten Verneinungen, keine Fremdwörter, keine sog. „belasteten“ Wörter enthalten und

nicht aufeinander abfärben sollten.

Des Weiteren sei wichtig, dass pro Frage nur ein Sachverhalt erfragt werde.

16 Es ist durchaus üblich, Testwörter unter die Auswahl offizieller Neologismen zu mischen. Dieser Technik bedient sich auch Fossat, der die Terminologie der Fernerkundung des Luftraums untersucht (vgl. 4.3.1). 


\begin{tabular}{|c|c|c|}
\hline $\begin{array}{l}\text { Englischsprachige } \\
\text { Lexeme }\end{array}$ & $\begin{array}{l}\text { Französischsprachige Lexeme } \\
\text { (Frankreich, Belgien, Schweiz) }\end{array}$ & Testwörter \\
\hline e-mail, maill17 & $\begin{array}{l}\text { courrier électronique, message électro- } \\
\text { nique, mél, courriel, messagerie électro- } \\
\text { nique }\end{array}$ & $\begin{array}{l}\text { lettre électronique (an- } \\
\text { dere Bedeutung) }\end{array}$ \\
\hline homepage & page d'accueil & $\begin{array}{l}\text { page d'introduction } \\
\text { (nur in Québec } \\
\text { üblich }{ }^{19} \text { ) }\end{array}$ \\
\hline $\begin{array}{l}\text { World Wide Web, } \\
W W W, W e b\end{array}$ & $\begin{array}{l}\text { toile d'araignée mondiale, toile mondiale, } \\
\text { toile, T.A.M. }\end{array}$ & $\begin{array}{l}\text { réseau mondial (an- } \\
\text { derer Kontext) }\end{array}$ \\
\hline chat & causette, bavardage 21 & $\begin{array}{l}\text { conversation électroni- } \\
\text { que (selten, nicht } \\
\text { offiziell) }{ }^{22}\end{array}$ \\
\hline cracker & pirate & $\begin{array}{l}\text { fouineur (offizielles } \\
\text { Ersatzwort zu } \\
\text { engl. hacker) }\end{array}$ \\
\hline (access) provider & fournisseur d'accès & $\begin{array}{l}\text { pourvoyeur d'accès } \\
\text { (selten, nicht } \\
\text { offiziell) }^{23}\end{array}$ \\
\hline
\end{tabular}

Analog zu Fuggers Befragung wird mit der zweiten Frage, einer geschlossenen Multiple Choice-Frage mit einer möglichen Antwort, überprüft, ob die Anglizismen und die für sie geschaffenen Neologismen von den Informanten als synonym beurteilt werden ${ }^{24}$. Stellen die Befragten einen Bedeutungsunterschied fest, werden

17 Mail ist zwar nicht Bestandteil der offiziellen Internet-Terminologie, wird jedoch (nicht nur) im frankophonen Raum viel häufiger verwendet als das längere Wort e-mail. Darauf wiesen die Informanten während des Pretests hin, so dass dieser Terminus zusätzlich zu den in der offiziellen Terminologieliste verzeichneten Termini in den Fragebogen aufgenommen wurde.

${ }^{18}$ Lettre électronique hat vielmehr die Bedeutung eines elektronischen Informationsbriefes, der via EMail an alle Abonnenten versendet wird (engl. newsletter).

19 Page d'introduction ist aber weder in Québec noch in Frankreich, Belgien oder der Schweiz die offizielle Bezeichnung für engl. homepage (für Québec vgl. OLF 2002c, o.S.).

${ }^{20}$ Réseau mondial existiert als Bezeichnung für ein weltweites Netzwerk. Réseau mondial ist aber weder Bestandteil der offiziellen Internet-Terminologie noch an das Medium Internet geknüpft.

${ }^{21}$ Vgl. Kap. 3, Fußnote 124.

22 Der Terminus conversation électronique lässt sich nur auf wenigen Internetseiten nachweisen. Er ist weder Bestandteil der offiziellen Terminologie, noch scheint er sehr gebräuchlich zu sein.

23 Ebenso wie conversation électronique lässt sich pourvoyeur d'accès nur auf wenigen Internetseiten nachweisen. Es ist davon auszugehen, dass es sich dabei um einen sehr ungebräuchlichen Terminus handelt. Pourvoyeur d'accès ist die wörtliche Übersetzung von engl. (access) provider.

${ }^{24}$ Einschränkend ist anzumerken, dass es aus linguistischer Sicht keine absolute Synonymie gibt. Ein französischer Neologismus kann zwar das Konzept des entsprechenden Anglizismus wiedergeben, nicht aber die mit ihm verbundenen Konnotationen und Assoziationen (vgl. z.B. Braselmann 2002a, 293). Da sich der Fragebogen allerdings an Informatiker und nicht an Linguisten richtet, ist davon auszugehen, dass die Befragten in erster Linie überprüfen werden, ob die Konzepte der französischen und englischen Termini übereinstimmen. 
sie gebeten, diesen im Folgenden mittels einer Textantwort zu präzisieren (Frage 3). In der vierten Frage, wiederum eine geschlossene Multiple Choice-Frage (vgl. 7.1.1.2), bei der Mehrfachnennungen möglich sind, geht es um den persönlichen Geschmack der Informanten: Sie werden gebeten, maximal zwei aus den angebotenen Termini auszuwählen, die sie bevorzugen. Die persönliche Präferenz muss jedoch nicht automatisch, entsprechend der Hypothese I.6 (vgl. 5.3.1), mit dem eigenen aktiven Sprachgebrauch übereinstimmen: Einen Terminus/Neologismus zu kennen heißt nicht zwangsläufig, ihn auch zu benutzen (vgl. Martin 1994, 35). Deshalb soll die fünfte Frage, wie auch die zweite Frage eine geschlossene Multiple Choice-Frage mit einer möglichen Antwort, klären, welche der aufgelisteten französischen oder englischen Bezeichnungen die Informanten immer bzw. am häufigsten gebrauchen ${ }^{25}$. Kreuzen die Informanten an, immer oder hauptsächlich einen der vorgegebenen französischen Termini (inkl. der Testwörter) zu benutzen, dann werden sie mittels Filterführung zur sechsten Frage weitergeleitet, in der dieses Lexem mit Hilfe des semantischen Differentials beurteilt werden soll. Dieses Verfahren, mit dem in diesem Fragebogen die Einstellungen zu den ausgewählten französischen Neologismen gemessen werden sollen, fördert nicht nur die ästhetisch-affektive (in den Merkmalpaaren: beau - laid, artificiel - normal), sondern auch die instrumental-kognitive Einstellungsdimension (in den Merkmalpaaren: connu inconnu, comprébensible - incomprébensible, utile - inutile, adéquat - inapproprié, établi nouveau, normal - artificiel, simple - complexe, correct - incorrect) zu Tage.

Bevor es mit den Erläuterungen zur siebten Frage des Fragebogens weitergeht, erfolgt an dieser Stelle ein kurzer Exkurs zur konkreten Gestaltung des semantischen Differentials in Fragebögen.

Das semantische Differential ermöglicht es, Einstellungen zu bestimmten Termini, Sachverhalten o.Ä. quantitativ zu erfassen und statistisch auszuwerten. Semantische Differentiale bestehen aus fünf bzw. siebenstufigen Skalen, deren Endpunkte durch bipolare Adjektive wie „gut" - ,schlecht" markiert werden (vgl. Kap. 2, Fußnote 13). Jedes Gegensatzpaar wird als ein Kontinuum betrachtet, welches in mehrere Stufen unterteilt ist. Für die Durchführung einer aussagekräftigen Befragung ist wichtig, dass die Gegensatzpaare von den Informanten semantisch auch als solche empfunden werden, damit der Abstand zum neutralen Mittelpunkt von beiden Skalenenden gleich ist (vgl. Stier 1996, 73, 100). Der Informant soll die Angemessenheit der Adjektive auf einer fünf bzw. siebenstufigen Rating-Skala beurteilen. Hier stellt sich die Frage, ob die fünf oder die sieben Kategorien umfassende Rating-Skala vorzuziehen ist. Generell gilt, dass Skalen mit relativ vielen Kategorien die Befragten hinsichtlich ihres Differenzierungsvermögens überfordern und somit bei der nicht-akademischen Bevölkerung auf wenig

25 Leider kann diese Studie keine Unterscheidung zwischen formellem und informellem Sprachgebrauch vornehmen, wie dies beispielsweise in der Befragung von De Pietro/Matthey (1993/1995) der Fall ist (vgl. 2.3.4.2.4). Es bedarf zusätzlicher Erklärungen oder Beispiele, um dem Informanten den Unterschied zwischen formellem und informellem Sprachgebrauch zu verdeutlichen. Somit ist eine derartige Fragestellung eher für ein Interview geeignet als für einen Fragebogen, der ohne jegliche fremde Hilfe auszufüllen ist. 
Resonanz stoßen (vgl. ebd., 70). Deshalb sollte, um möglichst keine Bevölkerungsschicht auszulassen, eine Skala mit fünf Kategorien gewählt werden. Dies kann Missverständnissen vorbeugen helfen, denn gerade bei einem WWW-Fragebogen besteht aufgrund des fehlenden Interviewers keine direkte Rückfragemöglichkeit bei Bearbeitungsproblemen. Ferner wird dazu angeraten, auch innerhalb des semantischen Differentials niemanden zu einer Antwort zu zwingen und deshalb eine Ausweichkategorie (z.B. „weiß nicht“, „keine Angabe“) vorzusehen. Diese sollte optisch von den übrigen Kategorien getrennt sein (vgl. Dillman 2000, 394; Stier 1996, 71) ${ }^{26}$. Außerdem sollte sie nicht in der Mitte der Skala stehen, sondern am Ende (d.h. am Rand), denn diese Ausweichkategorie sei keinesfalls mit der neutralen Kategorie gleichzusetzen (vgl. Dillman 2000, 59).

Für diese Umfrage wurde eine Likert-Skala ${ }^{27}$ mit fünf Kategorien gewählt. Jeder französische Neologismus soll anhand von insgesamt neun Adjektivpaaren, d.h. in neun untereinander stehenden Rating-Skalen bewertet werden. Die Gestaltung der Skalen orientiert an dem Modell Helfrichs (1993) ${ }^{28}$. Helfrich lässt bei ihrer Umfrage die ausgewählten Neologismen anhand von neun Skalen bewerten, an deren beiden Endpunkten jeweils die Adjektivpaare connu/inconnu, beau/laid, compréhensible/incomprébensible, utile/superflu, adéquat/inapproprié, nouveau/établi, artificiel/normal, complexe/simple, correct/peu correct stehen. Die Gegensatzpaare Helfrichs werden mit zwei kleinen Änderungen übernommen ${ }^{29}$ und das Layout des semantischen Differentials wird an die Gepflogenheiten von WWW-Umfragen angepasst. Die Informanten sollen den jeweiligen französischen Neologismus mittels neun 5-stufigen Skalen bewerten. Die zur Verfügung stehenden Möglichkeiten reichen von voll-

\footnotetext{
${ }^{26}$ Nach Stier $(1996,71)$ werden Rating-Skalen, die über eine Ausweichkategorie verfügen, als nichtforcierte Ratings bezeichnet, während Skalen, bei denen keine Möglichkeit des Ausweichens besteht und der Infomant zu einem Urteil ,gezwungen“ wird, als forcierte Ratings bezeichnet werden.

${ }^{27} \mathrm{Zu}$ allgemeinen Informationen zur Likert-Skala vgl. Kap. 2, Fußnote 11. Im Fall des für diesen Fragebogen gewählten semantischen Differentials werden die Informanten gebeten, die Adjektive im Hinblick auf das zu beurteilende Objekt, den französischen Neologismus, auf den neun RatingSkalen einzustufen. Hier können sie sowohl die Richtung ( $\mathrm{Zu}$ welchem der beiden Extrempole tendieren sie?) als auch die Intensität (Nähert sich ihr Urteil eher dem neutralen Mittelpunkt oder eher dem Extrempol?) bestimmen (vgl. Stier 1996, 100).

28 Bezüglich der Gestaltung der Skalen wird in der sozialwissenschaftlichen Forschungsliteratur zwischen generalisierten und auf das Thema spezifizierten Skalen unterschieden. Da die Forschungsgegenstände viel zu spezifisch sind, als dass ein generelles Raster mit festgelegten Adjektivpaaren dem Untersuchungsgegenstand gerecht werden könnte, wurde schon in den 1950er Jahren von den generalisierten Skalen immer mehr abgerückt (vgl. Osgood/Suci/Tannenbaum 1957, 195198; Stier 1996, 100-102).

29 Zum einen wird zur Verstärkung der Gegensätzlichkeit der Adjektive anstelle von ,peu correct* , incorrect" und anstelle von ,superflu“ ",inutile“" verwendet, zum anderen wird bei der Anordnung der Skalen etwas variiert: Während bei Helfrich die positive Eigenschaft des Neologismus immer auf der linken Seite der Skala steht und die negative Eigenschaft entsprechend auf der rechten, wird dies bei den Adjektivpaaren établi/nouveau, normal/artificiel und simple/complexe vertauscht, so dass in diesen drei Fällen im Fragebogen am linken Skalenende die negativ konnotierte und am rechten Skalenende die positiv konnotierte Eigenschaft steht. Bezüglich der Werte ändert sich jedoch nach dieser kleinen Veränderung nichts, die positiven Konnotationen erhalten niedrige Zahlenwerte (1 und 2), die negativen Konnotationen höhere Zahlenwerte (4 und 5), während die Mitte mit dem Zahlenwert 3 als neutral einzustufen ist. Durch diese Umstellung kann bei WWW-Umfragen das mechanische Durchklicken verhindert werden, indem bei geringen inhaltlichen Unterschieden in den Antworten aus Bequemlichkeit die untereinander stehenden Werte angeklickt werden.
} 
ständiger Zustimmung über tendenzielle Zustimmung zu dem am linken Skalenende vermerkten Terminus über einen neutralen Punkt (weder das eine noch das andere Adjektiv trifft zu), zur tendenziellen und vollständigen Zustimmung zum anderen Adjektiv am anderen Skalenende. An der von den Informanten vorgenommenen Bewertung der Neologismen im Hinblick auf die neun vorgegebenen Adjektivpaare wird erkennbar, welche Eigenschaften der jeweiligen Neologismen von den Informanten als positiv bzw. als störend bewertet werden. Diese Faktoren wären entsprechend für die Schaffung weiterer Ersatzwörter bzw. im Falle einer Revision bestehender Neologismenlisten zu berücksichtigen.

Nach diesen ausführlichen Erläuterungen zur sechsten Frage folgt diese Darstellung nun wieder der Chronologie des Fragebogens. Haben die Informanten bei der fünften Frage angegeben meistens oder immer den englischen Terminus zu verwenden, werden sie direkt zur siebten Frage weitergeleitet. Hier werden sie nach den Gründen für die Bevorzugung des Anglizismus gefragt. Es handelt sich bei dieser Frage um eine halboffene Frage: Den Informanten werden 16 Antwortmöglichkeiten, die Option ,Je ne sais pas.“ sowie ein Textfeld angeboten, in das weitere Gründe für die Bevorzugung des englischsprachigen Terminus eingetragen werden können. 16 Antwortoptionen sind relativ umfangreich für eine Multiple Choice-Frage, jedoch sollte der Vollständigkeit halber auf keinen der Gründe verzichtet werden, die in der Forschungsliteratur für die geringe Akzeptanz von Neologismen genannt werden (vgl. Kap. 5.1).

Auf den letzten Seiten wurde ausführlich die Gestaltung der ersten sieben Fragen des ersten Fragebogenmoduls geschildert. Mit der Beantwortung der sechsten Frage (bei Benutzung eines französischen Terminus) bzw. der siebten Frage (bei Benutzung eines englischen Terminus) ist der erste Fragenkomplex zur ersten Lexemgruppe (e-mail etc.) abgeschlossen. Es folgt nun der wiederum aus sieben Fragen bestehende zweite Fragenkomplex, der sich den Termini page d'accueil, page d'introduction und homepage widmet. Es folgen dann nach dem gleichen Schema noch ein dritter, vierter, fünfter und sechster Fragenkomplex, in denen jeweils alle Termini abgefragt werden, die in Abb. 10 aufgeführt sind.

Bevor die Informanten nach Beantwortung der sechs Fragenkomplexe zum zweiten Fragebogenmodul gelangen, müssen sie ihren Wohnort angeben (Frankreich, Belgien, Schweiz, anderes Land ${ }^{30}$ ). Dieser Filter steuert den Übergang zum zweiten Fragebogenmodul.

\subsubsection{Das zweite Fragebogenmodul}

Während der erste Teil des Fragebogens viele Filter enthält, reduziert sich deren Anzahl im zweiten Modul erheblich. Entsprechend der drei für die Untersuchung relevanten Länder Frankreich, Belgien und die Schweiz gibt es auch drei Versio-

\footnotetext{
${ }^{30} \mathrm{Da}$ nur französischsprachige Informanten aus Frankreich, Belgien und der Schweiz in die Studie einbezogen werden, worauf bereits das Ankündigungsschreiben eindeutig hinweist, muss bei Informanten, die als Wohnort ein anderes Land angeben, bei der Auswertung geprüft werden, ob die anderen Angaben dem Anforderungsprofil entsprechen. Schließlich ist es denkbar, dass ein eigentlich in der Schweiz wohnhafter Informatiker ein Jahr in Québec verbringt.
} 
nen des zweiten Moduls. Die Konzeption eines für alle drei Länder gültigen Fragenkatalogs ist nicht möglich, weil in jedem der drei Länder unterschiedliche sprachpolitische Voraussetzungen gegeben sind (vgl. 3.2 und 3.3). Die Fragen sind jeweils länderspezifisch ausgerichtet, ähneln sich aber inhaltlich sehr. Der Fragentyp ist identisch: Es handelt sich bei allen Fragen um geschlossene Multiple-ChoiceFragen, bei denen nur jeweils eine Antwortmöglichkeit gewählt werden kann. In der Version für die Franzosen und Belgier beantworten die Informanten zunächst fünf Fragen hintereinander. Mit der fünften Frage ist ein Filter verknüpft. Bei Kenntnis der Listen zur Internet- bzw. Informatik-Terminologie werden sie zu einer weiteren, sechsten Frage weitergeleitet (s.u.). Bei Unkenntnis der Liste zur Internet- bzw. Informatik-Terminologie (= Frage 5 des zweiten Moduls) werden die Informanten direkt zum dritten und letzten Fragebogenteil weitergeleitet, in dem sie um Angaben zu ihrer Person gebeten werden. In der Version für die schweizerischen Informanten gibt es mehr Filter, da hier sowohl nach der Kenntnis der schweizerischen als auch der französischen Internet-Terminologie gefragt wird und bei negativer Antwort die jeweils daran anknüpfenden Fragen übersprungen werden. Die in Frankreich wohnhaften Informanten werden gefragt,

1. ob sie über die aktuelle Sprachpolitik informiert sind,

2. wie sie die aktuelle Sprachpolitik einschätzen,

3. wie sie die Terminologielisten insgesamt einschätzen,

4. ob sie sich nach den in den Terminologielisten gemachten Vorschlägen richten,

5. ob sie die französischsprachige offizielle Internet-Terminologie kennen,

6. ob sie die offizielle Internet-Terminologie benutzen.

Die frankophonen Belgier sollen Auskunft darüber geben,

1. ob sie über die aktuelle belgische Sprachpolitik bezüglich der Anglizismenregulierung informiert sind,

2. wie sie die aktuelle Sprachpolitik einschätzen,

3. wie sie die in der entsprechenden Internet-Datenbank veröffentlichten Terminologielisten insgesamt einschätzen,

4. ob sie sich nach den in den Terminologielisten gemachten Vorschlägen richten,

5. ob sie offizielle belgische Informatik-Terminologie kennen

6. ob sie die offizielle belgische Informatik-Terminologie benutzen.

Die Romands schließlich werden gefragt,

1. wie sie generell sprachpolitische Maßnahmen zur Anglizismenregulierung beurteilen,

2. ob sie die im Internet veröffentlichte schweizerische Internet-Terminologie kennen,

3. ob sie sich nach dieser offiziellen Terminologie richten,

4. ob sie über die aktuelle französische Sprachpolitik informiert sind,

5. ob sie die in Frankreich gültigen Terminologievorschläge befolgen. 
Wie der Auflistung der Fragen zu entnehmen ist, wird in dem dieser Studie zugrunde liegenden WWW-Fragebogen analog zu Fuggers Vorgehen zwischen Kenntnis der Gesetze, deren Beurteilung und deren Befolgung unterschieden.

Es mag verwundern, dass die Schweizer, nicht aber die Belgier nach der Kenntnis der französischen Sprachpolitik gefragt werden. Primär ging es bei der Konzeption dieses Fragebogenmoduls darum zu erfahren, inwiefern die Informanten über die landesspezifischen sprachpolitischen Maßnahmen informiert sind. In Ermangelung entsprechender Regelungen für die französischsprachige Schweiz wurde in diesem Fall nach der Kenntnis der französischen Sprachpolitik gefragt, da diese dann - wenn überhaupt - der einzige Bezugspunkt für die französischsprachigen Schweizer darstellen dürfte. Sicherlich wäre eine entsprechende Fragestellung auch im Falle der französischsprachigen Belgier durchaus interessant, jedoch steht diese Thematik nicht im Zentrum der Untersuchung.

\subsubsection{Das dritte Fragebogenmodul}

Das dritte Fragebogenmodul dient der Aufnahme der biosozialen Daten, um mehr Informationen über den persönlichen Hintergrund der Informanten zu erhalten. Zunächst werden die standardisierten (soziolinguistischen) Parameter erfragt, wie

1. Geschlecht,

2. Alter,

3. Beruf,

4. höchster berufsqualifizierender Abschluss,

5. Geburtsland,

6. Muttersprache,

7. Wohnsitz (Region/Kanton).

Darüber hinaus werden die Informanten um weitere Daten gebeten:

1. Einschätzung ihrer Englischkenntnisse,

2. Art und Dauer der Internet-Nutzung ${ }^{31}$.

Dieser Teil ist für die Informanten insofern am uninteressantesten, als sie im Unterschied zu den beiden ersten Fragebogenmodulen wenig bis gar nichts über sich selbst erfahren und die Fragen sehr routiniert beantworten werden. Es empfiehlt sich, diesen Fragebogenteil ans Ende zu stellen, weil die Befragten nach Ausfüllen einer Reihe von Fragen zu ermüden beginnen, Angaben zu ihrer Person ihnen in der Regel aber keine Mühe machen und wenig bis keinen Denkaufwand erfordern (vgl. z.B. Diekmann 2002, 415).

\footnotetext{
31 Gerade bei Informatikern oder Personen in internetaffinen Berufen wird davon ausgegangen, dass sie keine Neulinge auf dem Gebiet der Internetnutzung sind. Entsprechend sollten Personen, die länger als ein Jahr das Internet nutzen, die meisten der im Fragebogen vorkommenden Termini kennen. Die sehr unwahrscheinliche Angabe, dass den Informanten bestimmte Lexempaare gänzlich unbekannt sind, ließe sich somit aufgrund der in diesem Modul angegebenen kurzen Dauer der Internetnutzung erklären.
} 


\subsection{Der Pretest}

\subsubsection{Funktion und Gestaltung eines Pretests}

Der folgende Abschnitt gibt einen kurzen Überblick über die verschiedenen Möglichkeiten, wie ein am Schreibtisch entworfener Fragebogen im Hinblick auf seine Praxistauglichkeit überprüft werden kann.

Es ist allem theoretischen Vorwissen zum Trotz unmöglich, einen guten Fragebogen ausschließlich am Schreibtisch zu konstruieren. Autoren erkennen die Probleme eines Fragebogens selbst nur selten. Andere Personen jedoch, die nicht an der Entwicklung des Fragebogens beteiligt waren, bemerken Schwächen und Unzulänglichkeiten schnell. Deshalb sollte jeder Fragebogen mit einem entsprechenden Prototyp getestet werden (vgl. Gräf 1999, 172f.; Porst 1998, 34f.). Aufgabe eines derartigen Pretests ist es somit, das aus Vorüberlegungen zusammengestellte Forschungsinstrument, in diesem Fall den Fragebogen, empirisch zu prüfen und daraufhin zu optimieren (vgl. z.B. Friedrichs 1990, 245; Porst 1998, 35).

Einerseits ist es sinnvoll, den Fragebogen an einige Personen aus der Zielgruppe zu schicken, damit diese ihn probeweise ausfüllen und Rückmeldung über die Verständlichkeit des Fragebogens, seine Benutzerfreundlichkeit etc. geben. Andererseits ist zu bedenken, dass die Pretest-Gruppe für die Erhebung mit der Finalversion des Fragebogens verloren ist. Durch die Auseinandersetzung mit dem Thema sind die Informanten der Pretest-Gruppe sensibilisiert worden und würden bei einer erneuten Befragung das Ergebnis verzerren. Wer einen Fragebogen entworfen hat, der sich an eine relativ kleine Zielgruppe richtet, sollte für den Pretest besser Informanten auswählen, die gerade nicht der intendierten Zielgruppe angehören, um die Anzahl der potenziellen Teilnehmer für die Finalversion nicht allzu sehr einzuschränken.

Welche Methoden gibt es, um einen Pretest durchzuführen?

Prüfer/Rexroth (2000) empfehlen das sog. Zwei-Phasen-Pretesting, eine Kombination aus dem alten Verfahren (Standard-Pretest ${ }^{32}$ ) und kognitiven Techniken. Diese neuen kognitiven Techniken wurden vor allem in der nordamerikanischen Forschungsliteratur beschrieben und erst ab Mitte der 1980er Jahre in die deutsche Pretest-Forschung einbezogen. Konkret bedeutet das Zwei-Phasen-Pretesting, dass in der ersten Phase einzelne Fragen mittels eines Evaluationsinterviews getestet werden, in der zweiten Phase der Fragebogen dann mittels eines Standard-Pretests geprüft wird (vgl. Prüfer/Rexroth 2000, 3). Als kognitive Techniken für die Erprobung eines Fragebogens bieten sich v.a. die folgenden vier an:

- Probing: Hinterfragen von Antworten (mit vier Varianten),

- Think Aloud ${ }^{33}$ : Methode des lauten Denkens (mit zwei Varianten),

32 Zu den Eigenschaften des Standard-Pretests vgl. z.B. Prüfer/Rexroth (1996, 98; 2000, 14).

33 Nach Prüfer/Rexroth $(1996,105)$ ist die Think Aloud-Technik die zentrale kognitive Technik: „Der Befragte wird aufgefordert, ,laut zu denken’ und dabei sämtliche Gedankengänge zu for- 
- Paraphrasing: Wiederholung des Fragetextes (in eigenen Worten) durch den Befragten und

- Confidence Rating: Nachträgliche Bewertung des Verlässlichkeitsgrades der eigenen Antwort durch den Befragten - meist mittels einer Skala (vgl. Prüfer/Rexroth 2000, 7f.).

Es empfiehlt sich, den Befragten vor dem sog. Evaluationsinterview auf den besonderen Charakter des Interviews hinzuweisen und ihm zu vermitteln, dass er keine klassische Befragtenrolle übernehme, sondern vielmehr als „Mithelfender“ des Untersuchenden fungiere und durch seine Hilfe der Fragebogen optimiert werden solle (vgl. Prüfer/Rexroth 2000, 13).

\subsubsection{Durchführung des Pretests zur Internet-Terminologie und Sprachpolitik}

Mitte Juni 2002 wurde der Fragebogen auf dem WWW-Server der Gesellschaft für wissenschaftliche Datenverarbeitung mbH Göttingen (GWDG, http://www.|gwdg.de ${ }^{34}$ ) installiert.

Nach einigen Testläufen, die sicherstellen sollten, dass alle Filter funktionieren und die Datenübermittlung von verschiedenen Browsern (Netscape, Opera, Microsoft Internet Explorer) problemlos funktionierte, konnte mit dem Pretest begonnen werden ${ }^{35}$. Mit Hilfe des Pretests sollten in erster Linie die Logik des Fragebogenaufbaus, die Frageformulierungen und der Fragebogenumfang geprüft werden. Insbesondere bei halboffenen Fragen und Skalen besteht die Gefahr, dass sie mitunter nicht richtig verstanden werden (vgl. Beck/Glotz/Vogelsang 2000, $21)^{36}$.

Das von Prüfer/Rexroth (2000) vorgeschlagene Zwei-Phasen-Pretesting (vgl. 7.2.1) erfordert den persönlichen Kontakt zwischen Informant und Untersuchungsleiter. Um den Zeit- und Kostenaufwand zu minimieren, wurde auf die Durchführung eines Pretests mit Informanten der Zielgruppe (französische, belgische und schweizerische Informatiker) verzichtet, was eine Reise in jedes der drei Untersuchungsländer erfordert hätte. Der Pretest wurde stattdessen mit französischsprachigen Studierenden verschiedener Fächer durchgeführt. Dafür wurden Mitte Juni 2002 alle Erasmus-Studierenden aus Frankreich, dem französischspra-

mulieren, die zur Antwort führen bzw. führten. Ziel dieser Vorgehensweise ist, aus den Äußerungen der Befragten Hinweise darüber zu erhalten, wie die ganze Frage oder einzelne Begriffe verstanden wurden“ (Prüfer/Rexroth 1996, 105).

34 Die GWDG fungiert als Rechen- und Kompetenzzentrum für die Max-Planck-Gesellschaft und die Universität Göttingen.

35 Bei WWW-Umfragen ist es besonders wichtig, den Fragebogen nicht nur bezüglich des Inhaltes, sondern auch bezüglich seiner technischen Funktionsfähigkeit zu überprüfen. So muss u.a. sichergestellt werden, dass Fragebögen plattformunabhängig ausgefüllt werden können und die einzelnen Fragebogenseiten möglichst kurze Ladezeiten aufweisen (vgl. 7.1.1.4). Ein weiterer wichtiger Punkt, der nicht den Informanten, sondern den Untersuchungsleiter betrifft, ist die Gewährleistung, dass sich die erzeugten Datensätze problemlos mittels entsprechender Statistikprogramme auswerten lassen (vgl. Kap. 8, Fußnote 1).

36 Bei dem Fragebogen zur Internet-Terminologie und Sprachpolitik können Verständnisprobleme v.a. bei den Fragen auftreten, in denen um eine Beurteilung des französischen Neologismus mittels des semantischen Differentials gebeten wird (s. Frage 6, 13, 20, 27, 34 und 41 im Anhang 15.3). 
chigen Teil Belgiens und aus dem französischsprachigen Teil der Schweiz, die im Sommersemester 2002 im Göttinger Erasmus-Büro gemeldet waren, angeschrieben und zur Teilnahme am Pretest eingeladen. Die Pretests fanden in den letzten beiden Wochen im Juni 2002 sowie in der ersten Juliwoche 2002 an den mit dem Internet verbundenen Computern in der Göttinger Staats- und Universitätsbibliothek statt. Es nahmen insgesamt 20 Studierende (14 Franzosen, vier frankophone Belgier und zwei frankophone Schweizer) am Pretest tei ${ }^{37}$. Da sich unter den Studierenden Vertreter aller drei Untersuchungsländer befanden, konnte auf diese Weise sichergestellt werden, dass alle Fragen des Fragebogens nicht nur die französische Situation, sondern auch die Situation in Belgien und der Schweiz korrekt abbilden. Gerade weil es zur belgischen und schweizerischen Sprachpolitik wenig Literatur gibt, ist eine Überprüfung der Plausibilität der Fragen im zweiten Teil besonders wichtig. Unter den insgesamt 20 Informanten befanden sich zwei Informatik-Studenten, so dass beim Pretest auch die Zielgruppe der Finalerhebung vertreten war.

Die Pretests wurden mit je einem bzw. zwei Studierenden zeitgleich durchgeführt. Bevor den Informanten die Startseite der Umfrage gezeigt wurde, wurden sie gebeten, besonders darauf zu achten, ob die Fragen eindeutig formuliert seien und ob mögliche Antwortoptionen fehlten. Gelangten die Informanten auf die Seite mit dem semantischen Differential (Fragen 6, 13, 20, 27, 34 und 41), wurden sie um eine Paraphrasierung der Arbeitsanweisung gebeten, damit sichergestellt werden konnte, dass die Aufgabenstellung verstanden wurde. An Stellen, an denen die Informanten zögerten, wurden sie aufgefordert, laut zu denken, damit ersichtlich wurde, was ihnen Probleme bereitete (Methode des Think Aloud, s.o.). Parallel zum Ausfüllen des Fragebogens wurde die dafür benötigte Zeit protokolliert. Nachdem die Informanten den Fragebogen ausgefüllt und abgeschickt hatten, erfolgte ein kurzes Gespräch über den Fragebogen. Es wurde nachgefragt, wie die Länge des Fragebogens beurteilt wurde, ob die Arbeitsanweisungen verständlich waren und ob bestimmte Fragebogenelemente als besonders schwierig empfunden wurden. Die Bearbeitungszeit des Fragebogens lag bei durchschnittlich 22 Minuten, wobei einschränkend anzumerken ist, dass in diese Zeit auch kurze Nachfragen und Diskussionen zu bestimmten Formulierungen und entsprechenden Verbesserungsmöglichkeiten fielen. Im Anschreiben für die definitive Befragung wurde aufgrund dieses Erfahrungswertes eine Bearbeitungszeit von ca. 15 Minuten angegeben.

Die Informanten gaben während des Ausfüllens und im anschließenden Gespräch viele Anregungen für kleinere Veränderungen - teilweise waren es Formulierungsvorschläge, teilweise Vorschläge für zusätzliche Antwortoptionen, die nach Abschluss jeder Befragung direkt in den Fragebogen integriert wurden. Auf diese Weise konnte wiederum die nächste Person, die den Fragebogen ausfüllte, gezielt auf diese Veränderung angesprochen und aufgrund ihrer Reaktion entschieden werden, ob es sich um eine sinnvolle Veränderung handelte oder nicht.

${ }^{37}$ Die Auswertung des ersten Teils dieser Befragung ist nachzulesen in Molitor (in Vorbereitung). 
Was wurde am Fragebogen verändert? Insgesamt wurde der Fragebogenaufbau von den Informanten bestätigt und als sinnvoll beurteilt. An einigen Stellen wurde der Fragetext geringfügig geändert, an anderen Stellen wurde eine weitere Antwortoption angeboten. Die Informanten machten auf zwei Fachtermini aufmerksam, néologisme und désignation, die zugunsten einer höheren Allgemeinverständlichkeit durch terme ersetzt wurden. Wie vermutet, bereitete das Ausfüllen des semantischen Differentials vielen Informanten Schwierigkeiten, so dass zu dieser Frage eine ausführliche Erklärung formuliert sowie ein Ausfüllbeispiel gegeben wurden (vgl. Fragebogen im Anhang, 15.3, Frage 6).

\subsection{Zusammenfassung}

Für WWW-Umfragen gelten die gleichen Fragetypen, wie sie auch für traditionelle Umfragen bekannt sind: offene, geschlossene und halboffene Formen. Der Unterschied liegt jedoch darin, dass sich diese Fragetypen in WWW-Fragebögen auf unterschiedliche Arten realisieren lassen. Für die Frageformulierung gelten die gleichen Regeln wie für Papierfragebögen, jedoch muss immer bedacht werden, dass die Lesekapazitäten sowie das Lesetempo am Bildschirm deutlich geringer ausfallen als bei gedruckten Texten.

Anders ist es bei der grafischen und technischen Umsetzung von WWW-Fragebögen. Zwar bietet das Medium Internet zahlreiche audiovisuelle Gestaltungsmöglichkeiten (Einsatz von Farben, Grafiken, Filmsequenzen und Hörtexten/Musik), jedoch sollte immer darauf geachtet werden, dass der Fragebogen nicht auf Kosten kurzer Ladezeiten und der Übersichtlichkeit überladen wird. Die technischen Möglichkeiten sollten so einfach wie möglich gehalten werden, damit keine potenziellen Informanten ausgeschlossen werden, nur weil sie die benötigten Programme bzw. Funktionen nicht auf ihrem Computer installiert oder aktiviert haben. Außerdem sollte jeder WWW-Fragebogen mit allen gängigen Internet-Browsern kompatibel sein. Für die Erstellung des WWW-Fragebogens wurde der kostenlose Umfragegenerator MOOSE der Firma Globalpark gewählt.

Der Fragebogen umfasst in seiner Maximalversion 40 Bildschirmseiten mit insgesamt 59 Fragen. Durch den Einsatz von Filtern werden allerdings nicht von jedem Informanten alle Fragen beantwortet. Der erste Teil des Fragebogens enthält Fragen zu den sechs ausgewählten Lexemgruppen. Das zweite Fragebogenmodul fällt unterschiedlich für jede der drei Zielgruppen (französische, belgische und schweizerische Informatiker) aus. Es werden zunächst die Bekanntheit und die Akzeptanz der aktuellen Sprachpolitik zum Schutz der französischen Sprache ermittelt. Weitere Fragen beziehen sich auf die Kenntnis und den Gebrauch der offiziellen französischsprachigen Internet-Terminologie. Das dritte Modul schließlich dient der Aufnahme biosozialer Daten der Informanten und bietet die Möglichkeit, einen Kommentar zum Fragebogen bzw. zur Sprachpolitik und/oder Terminologiearbeit zu verfassen.

Um die für das Ausfüllen des Fragebogens benötigte Zeit, die Verständlichkeit der Fragen und Arbeitsanweisungen sowie die Vollständigkeit und Logik der Ant- 
wortoptionen zu überprüfen, wurde mit 20 frankophonen Erasmus-Studierenden ein Pretest durchgeführt, der zu kleineren Modifikationen des Fragebogens führte. Das Durchführen eines Pretests ist bei WWW-Umfragen nicht nur aufgrund möglicher inhaltlicher und konzeptioneller Unzulänglichkeiten nötig, sondern vor allem, um technischen Problemen rechtzeitig entgegentreten zu können. Dieses Kapitel hat wie das vorangehende sechste Kapitel gezeigt, dass bei der Konzeption eines WWW-Fragebogens die Berücksichtigung sozialwissenschaftlicher Erkenntnisse und technischer Sachverhalte unumgänglich ist, um nicht nur zuverlässige Daten zu erhalten, sondern auch potenzielle Informanten nicht von der Befragung auszuschließen oder zu verärgern. 


\section{Die Durchführung der WWW-Befragung und die Informanten}

Dieses Kapitel beschreibt, wie und in welchen Diskussionsforen die WWW-Befragung angekündigt wurde. Anschließend werden die neun Diskussionsforen, deren Leser zur Teilnahme aufgefordert wurden, kurz charakterisiert. 8.2 gibt einen Überblick über die Teilnehmer der Studie anhand ihrer biosozialen Daten und stellt somit die Auswertung des dritten Fragebogenmoduls dar.

\subsection{Durchführung der WWW-Befragung zur Internet-Ter- minologie und Sprachpolitik}

\subsubsection{Ankündigung des WWW-Fragebogens in Diskussionsforen}

Die im Folgenden präsentierte Studie hat zum Ziel, die aktive und passive Akzeptanz ausgewählter französischer, belgischer und schweizerischer InternetTermini sowie den Bekanntheits- und Akzeptanzgrad der offiziellen Sprach- und Terminologieplanung zu ermitteln. Die Zielgruppe sind französische, belgische und schweizerische Informatiker, die mittels eines WWW-Fragebogens befragt werden. Um auf die Befragung aufmerksam zu machen, wurde der Fragebogen in neun französischsprachigen Diskussionsforen angekündigt, die sich alle thematisch der Informatik bzw. dem Internet widmen. Durch die Ankündigung in ausgewählten Diskussionsforen konnte die erwünschte Zielgruppe gezielt und mit wenig Aufwand erreicht werden. Am 22. Juli 2002 wurde der Fragebogen in der Final-Version auf dem WWW-Server der GWDG installiert. Die Umfrage wurde 
in insgesamt drei Erhebungsphasen, die sich jeweils in zwei Erhebungswellen unterteilten, vom 25. Juli bis zum 31. August 2002 durchgeführt ${ }^{1}$.

In der ersten Erhebungsphase wurde der Fragebogen im Diskussionsforum fr.comp.divers angekündigt. In dem Anschreiben, das in nahezu identischer Form an alle Diskussionsforen geschickt wurde, wurde versucht, den Hinweisen für die Formulierung von Anschreiben (vgl. 6.4) Rechnung zu tragen. Entsprechend wurden alle Teilnehmer auf das Thema und den Zweck der Untersuchung, die Adresse, unter der der Fragebogen ausgefüllt werden kann, die gewünschte Zielgruppe, die Bearbeitungszeit des Fragebogens, die Freiwilligkeit der Teilnahme und die anonyme Verwertung der Daten hingewiesen. Außerdem wurde die Teilnahmemöglichkeit auf Ende August 2002 befristet. Als Belohnung wurde den Teilnehmern die Zusendung der Ergebnisse im September 2002 in Aussicht gestellt (s. Anschreiben im Anhang 15.2.1). Fünf Tage nach der Ankündigung des Fragebogens wurde an das gleiche Forum eine E-Mail verschickt, in der den bisherigen Teilnehmern für ihre Mühe gedankt wurde und alle weiteren Leser daran erinnert wurden, dass die Umfrage noch bis Ende August 2002 laufe und weitere Teilnehmer erwünscht seien. Dieses Verfahren der Erhebungswellen, wie es in 6.4 beschrieben wurde, hat eine möglichst hohe Ausschöpfungsquote, d.h. einen hohen Rücklauf, zum Ziel. Die zweite Erhebungswelle hat jeweils noch einige Informanten zur Teilnahme motivieren können, wie den mit den Datensätzen mitgelieferten Informationen (Zeitpunkt des Ausfüllens des Fragebogens) zu entnehmen war. Das Verfahren der Erhebungswellen hat sich auch in dieser Umfrage bewährt. Nach diesem Verfahren wurde auch in Bezug auf die Ankündigung der Umfrage in den anderen acht ausgewählten Diskussionsforen vorgegangen.

In der zweiten Erhebungsphase wurde der Fragebogen in vier Diskussionsforen angekündigt, die zwar Informatik bzw. das Internet zum Gegenstand haben, aber in ihren Inhalten sehr offen gestaltet werden:

- fr.soc.internet,

- fr.comp.lang.general,

- fr.misc.bavardages.linux und

- fr.comp.developpement.

\footnotetext{
${ }^{1}$ Für die Einteilung der Studie in drei Erhebungsphasen gibt es verschiedene Gründe. Zunächst wurde der Fragebogen nur in einem einzigen, sehr allgemeinen frankophonen Diskussionsforum zum Thema "Computer/Informatik“ angekündigt, um die generelle Reaktion auf eine solche Ankündigung abzuwarten und auf diese Weise eventuelle Fehler bei der Ankündigung in weiteren Diskussionsforen vermeiden zu können. Ein weiterer Grund für das gewählte Vorgehen ist technischer Natur. Der Umfragegenerator MOOSE verursacht Probleme, wenn zu viele Informanten zeitgleich einen Fragebogen ausfüllen. MOOSE schreibt zwar für jeden Fragebogen eine eigene Datei, die die übermittelten Datensätze enthält, die interne Nummerierung ist jedoch nicht korrekt. Werden beispielsweise parallel sieben Fragebögen ausgefüllt, so erhalten zwar alle Fragebögen verschiedene Startzahlen (z.B. die laufenden Nummern 47, 48, 49, 50, 51, 52 und 53) und werden in sieben verschiedene Dateien geschrieben, innerhalb der Fragebögen wechseln dann allerdings die Nummern. Die Daten sind zwar korrekt, jedoch muss die interne Nummerierung aller Datensätze innerhalb der einzelnen Dateien nachträglich von Hand korrigiert werden, damit die Datensätze korrekt ins Statistikprogramm SPSS eingelesen werden. Um dieses Problem etwas einzugrenzen, wurde es vorgezogen, die Untersuchung in drei Wellen durchzuführen, um die Zahl der Überschneidungen und die damit verbundenen Nachbesserungen auf diese Weise zu minimieren.
} 
Für die dritte Erhebungsphase stellt sich die Frage, in welchen Foren der Fragebogen angekündigt werden kann, ohne dass dies als Verstoß gegen die Netiquette aufgefasst wird ${ }^{2}$. Außer dem allgemeinen Forum zu Computersprachen fr.comp.lang.general, in dem der Fragebogen bereits in der zweiten Erhebungswelle angekündigt wurde, existieren zwölf weitere Diskussionsforen zu verschiedenen Programmiersprachen. Diese zwölf Diskussionsforen sind in der folgenden Aufzählung nach der Anzahl der in ihnen in der Zeit vom 26. Juli bis 01. August 2002 veröffentlichten Beiträge geordnet:

- fr.comp.lang.c++: 273 Beiträge,

- fr.comp.lang.java: 215 Beiträge,

- fr.comp.lang.c: 151 Beiträge,

- fr.comp.lang.perl: 150 Beiträge,

- fr.comp.lang.basic: 78 Beiträge,

- fr.comp.lang.tcl: 51 Beiträge,

- fr.comp.lang.pascal: 36 Beiträge,

- fr.comp.lang.ada: 33 Beiträge,

- fr.comp.lang.python:25 Beiträge,

- fr.comp.lang.lisp: 7 Beiträge,

- fr.comp.lang.caml: 1 Beitrag und

- fr.comp.lang.postcript: 0 Beiträge.

Es wäre unhöflich im Sinne der Netiquette, den Fragebogen in allen zwölf Diskussionsforen anzukündigen. Also wurde die Anzahl auf vier Diskussionsforen begrenzt. Für die dritte Erhebungsphase wurden die vier Foren fr.comp.lang.c++, fr.comp.lang.java, fr.comp.lang.c und fr.comp.lang.perl ausgewählt. Das Auswahlkriterium ist in diesem Fall der Grad der Benutzeraktivität. Je mehr Leute über ein Forum erreicht werden können, umso höher dürfte auch die Rücklaufquote ausfallen. Inhaltliche Kriterien lassen sich aus linguistischer Sicht (und in Ermangelung informatischen Fachwissens) an Diskussionsforen zur Informatik, in denen Fachleute diskutieren, ohnehin nicht anlegen.

Vor der Ankündigung der WWW-Umfrage wurde sichergestellt, dass es möglichst wenig bis keine Überschneidungen bei den aktiven Teilnehmern der vier ausgewählten Foren gibt, um zu verhindern, dass bestimmte Teilnehmer die Ankündigung der Umfrage in drei oder vier verschiedenen Foren lesen. Dies könnten sie zu Recht als Belästigung empfinden.

Insgesamt gab es 211 Rückläufe, davon sind 165 Fragebögen vollständig und 46 unvollständig ausgefüllt. Von den 165 Fragebögen (128 von Franzosen, 18 von Belgiern und 19 von Schweizern) können fünf Fragebögen nicht berücksichtigt werden, da sie nicht der Zielgruppe Informatiker angehören: ein Fragebogen aus

\footnotetext{
2 Zum Begriff der Netiquette vgl. Kap. 6, Fußnote 28, und Glossar (15.7). Die ersten fünf Foren behandeln relativ allgemeine Fragen aus den Bereichen Informatik/Internet, so dass sich hier problemlos eine Umfrage ankündigen lässt. Demgegenüber befassen sich die acht Foren zu den einzelnen Programmiersprachen mit so spezifischen Fragestellungen, dass eine Umfrage zur Internet-Terminologie auf jeden Fall aus dem Rahmen fällt. Deshalb wurde der Ankündigung der Umfrage in diesen speziellen Foren ein entsprechender entschuldigender Kommentar angefügt (vgl. 15.2.1).
} 
Belgien stammt von einem Pfarrer, drei Fragebögen aus Frankreich stammen von Schülern (Collège und Lycée) und ein Fragebogen aus Frankreich von einem Seemann.

Einen Überblick über die 160 Informanten, deren Fragebögen berücksichtigt wurden, gibt 8.2. Zuvor werden die neun französischsprachigen Diskussionsforen $\mathrm{zu}$ den Themen Informatik/Internet, in denen die Umfrage angekündigt wurde, kurz vorgestellt.

Insgesamt wurde der Fragebogen positiv aufgenommen, wie aus den Kommentaren, die am Ende des Fragebogens in ein entsprechendes Textfeld eingetragen werden konnten, ersichtlich wurde. Gelobt wurden vor allem das Thema und die Struktur des Fragebogens, Kritik gab es vereinzelt zur technischen Umsetzung.

\subsubsection{Charakterisierung der neun ausgewählten Diskussionsforen}

Im Usenet werden Diskussionsforen zumeist nicht nach Ländern, sondern nach Sprachen und Themen unterteilt. Alle Gruppen, die sich der französischen Sprache bedienen, beginnen somit mit dem Kürzel fr. Die französischsprachigen Foren, die ein informatisches Thema behandeln, beginnen mit fr.comp. Es gibt insgesamt 86 Diskussionsforen unter fr.comp ${ }^{3}$. In Belgien gibt es 13 Diskussionsforen $\mathrm{zu}$ Computerfragen: be.comp. be.comp.games, be.comp.hardware, be.comp.internet, be.comp.internet.design, be.comp.internet.irc, be.comp.|networking, be.comp.os.linux, be.comp.os.unix, be.comp.os.windows, be.comp.|programming, be.comp.security, be.comp.sys.mac. Allerdings sind nahezu alle Beiträge in diesen Foren in niederländischer Sprache verfasst. Französischsprachige Beiträge stellen die Ausnahme dar. Für die Schweiz gibt es insgesamt vier Diskussionsforen zu Computerfragen: ch.comp, ch.comp.networks, ch.comp.|os.linux und ch.comp.os.ms-windows. Diese Foren enthalten jedoch nur deutschsprachige Beiträge und scheiden somit - ebenso wie die belgischen Computerforen - für diese Umfrage aus.

Im Folgenden werden kurz alle neun Diskussionsforen charakterisiert, in denen die Umfrage angekündigt wurde.

Zur besseren Vergleichbarkeit werden jeweils folgende Eckdaten genannt:

- Gründungsdatum,

- Kurzbeschreibung der Diskussionsinhalte des Forums und

- Benutzerfrequenz für die Woche vom 26. Juli bis 01. August $2002^{4}$.

Im Unterschied zu Mailinglisten, bei denen die Anzahl der Abonnenten genau feststeht, ist die Zahl der Leser bei Diskussionsforen nicht zu ermitteln. Viele Personen verfolgen die Beiträge, ohne selbst aktiv zu werden und eigene Beiträge

\footnotetext{
3 Vgl. Mailgate 2003 (http://www.mailgate.org/). Mailgate ist ein kostenloser Internetdienst, der es ermöglicht, Beiträge in Diskussionsforen zu lesen, selbst zu verfassen und zu versenden. Auf der Eingangsseite sind alle Foren nach ihren Kürzeln geordnet (at. für Österreich, be. für Belgien, bit. für BitNet, ch. für die Schweiz, biz. für „Business“, comp. für Computer, de. für Deutschland etc.). Beim Anklicken der entsprechenden Kürzel werden alle sich hierarchisch unter diesen Kürzeln befindlichen Foren angezeigt und können eingesehen werden.

${ }^{4} \mathrm{Da}$ E-Mails in den hochfrequentierten Gruppen schnell gelöscht werden (hängt vom jeweiligen Provider ab), sind die Möglichkeiten, Zeiteinteilungen festzulegen, eingeschränkt.
} 
zu verfassen. Andere stellen nur einmal eine Frage an das Forum, ohne die Diskussionen des Forums jedoch längerfristig mitzuverfolgen. Da die Anzahl der Leser der verschiedenen französischsprachigen Diskussionsforen nicht ermittelbar ist, wird stattdessen die Anzahl der Beiträge innerhalb einer Woche festgesetzt, um den Grad der Aktivität des Forums zu bestimmen.

\subsubsection{Das Forum fr.comp.divers}

Zu diesem Forum gibt es keine „Charte“ bzw. keine „Conseils d'utilisation“, d.h. eine Internetseite bzw. ein News-Beitrag, in dem die Diskussionsinhalte und Verhaltensregeln für dieses Forum beschrieben sind. Üblicherweise wird zu Beginn jedes Monats automatisch ein entsprechender Beitrag im jeweiligen Forum sowie in dem Forum fr.usenet.reponses veröffentlicht. Eine andere Möglichkeit, sich mit den Benutzerhinweisen eines französischsprachigen Forums vertraut zu machen, besteht auf der Seite „Index of /pub/usenet/control/fr/“ (ftp://ftp. |isc.org/pub/usenet/control/fr/). Auf dieser Seite können alle „Chartes“ der französischsprachigen Diskussionsforen aufgerufen werden, sofern die Initiatoren der Foren ein entsprechendes Dokument verfasst haben. In Ermangelung einer entsprechenden Informationsquelle für das Forum fr.comp.divers kann an dieser Stelle nur das Gründungsdatum des Forums genannt werden, welches aus dem „Index of / pub/usenet/control/fr/“ hervorgeht, der 04. Juni 1996. Es handelt sich damit um eines der ältesten französischsprachigen Diskussionsforen. Diesem Index lässt sich ebenfalls entnehmen, dass die allerersten französischsprachigen Diskussionsforen im April 1996 gegründet wurden. Das Diskussionsforum fr.comp.divers wird, wie alle Foren, in denen der Fragebogen angekündigt wurde, nicht moderiert ${ }^{5}$.

Auf der Seite „Liste des groupes fr“ (http://www.fr.net/news-fr/liste.html) werden nur einzeilige Kurzbeschreibungen der verschiedenen Foren gegeben. Hier heißt es zum Forum fr.comp.divers: „Discussions diverses sur l'informatique“.

Da der Gegenstand des Forums nicht sonderlich eingegrenzt ist, finden hier die verschiedensten Beiträge Platz. Entsprechend hoch ist auch die Benutzerfrequenz: In der Woche vom 26. Juli bis 01. August 2002 (7 Tage) wurden 253 Beiträge an das Forum geschickt und dort veröffentlicht.

\subsubsection{Das Forum fr.soc.internet}

Das Diskussionsforum fr.soc.internet wurde am 15. November 1997 gegründet. Es handelt sich um ein nicht-moderiertes Forum, das die soziokulturellen Aspekte des Internet zum Gegenstand hat. In den von Bernadette Wernert verfassten „Conseils d'utilisation“, die jeden Monatsanfang in diesem Forum sowie im Forum fr.usenet.reponses veröffentlicht werden, werden die Diskussionsgegenstände wie folgt umrissen:

\footnotetext{
${ }^{5}$ Es gibt moderierte und nicht-moderierte Foren. Bei unmoderierten Foren kann jede Person direkt einen Beitrag an das Forum schicken, der wenige Sekunden später bereits für alle Abonnenten lesbar ist. Bei moderierten Foren werden die Beiträge an die sog. Moderatoren geschickt, welche die Beiträge auf ihre Adäquatheit hin überprüfen und erst dann in das Forum stellen.
} 
„Tous les débats au niveau social, politique, économique et culturel sur l'Internet et son avenir, en France ou ailleurs, peuvent être abordés. Il peut s'agir des conséquences sociales d'une nouvelle technologie, d'un débat sur un projet de réglementation de l'Internet, sur la francophonie et l'Internet, ... Bref tout débat/commentaire sur les aspects socioculturels, socio-éducatifs, socio-politiques, sociolinguistiques de l'Internet sont les bienvenus. Tous les événements du réseau peuvent donc être commentés dans ce forum pour autant qu'il s'agisse d'un commentaire au niveau social, politique, économique ou culturel“" (Wernert, „[Conseils d'utilisation] fr.soc.internet“, in: fr.soc.internet/fr.usenet.reponses vom 02. August 20026).

Die Benutzerfrequenz ist in diesem Forum jedoch nicht sehr hoch. In der Woche vom 26. Juli bis 01. August 2002 wurden im Forum fr.soc.internet nur acht Beiträge veröffentlicht.

\subsubsection{Das Forum fr.comp.lang.general}

Das unmoderierte Diskussionsforum fr.comp.lang.general wurde am 16. Dezember 1996 gegründet und befasst sich mit den „Generalités et questions diverses sur la programmation“. Unter dem Stichwort „Charte du groupe“ schreibt Sylvain Nierveze: „Ce groupe contient les discussions diverses sur les langages de programmations, en particulier ceux qui n'ont pas de groupe dédié [...]“ (Nierveze, „[Conseils d'utilisation] fr.comp.lang.general“, in: fr.comp.lang.general/fr.use |net.reponses vom 02. August 2002).

Die Anzahl der in diesem Forum veröffentlichten Beiträge ist mit 15 Beiträgen in der Woche vom 26. Juli bis 01. August 2002 als eher gering einzustufen.

\subsubsection{Das Forum fr.misc.bavardages.linux}

Das unmoderierte Diskussionsforum fr.misc.bavardages.linux wurde am 26. September 1998 gegründet. Es geht in diesem Forum um nicht-technische Diskussionen rund um das Betriebssystem Linux.

In den Benutzerinformationen, die monatlich an dieses Forum sowie an das Forum fr.usenet.reponses geschickt werden, präzisiert Thomas Nemeth die Diskussionsinhalte:

„Les sujets couverts (liste non exhaustive) sont les suivants :

- Discussions diverses sur les initiatives locales et nationales en rapport avec Linux (LUG, bouffes, conférences, démonstrations...)

- Commentaires humoristiques divers faisant suite à des fils de discussions initiés dans les groupes techniques et qui seraient du bruit dans ces groupes.

\footnotetext{
${ }^{6}$ Es wird auf eine aktuellere Inhaltsbeschreibung verzichtet, da gezeigt werden soll, welches die inhaltlichen Schwerpunkte zu dem Zeitpunkt waren, zu dem die WWW-Umfrage in den neun ausgewählten Foren angekündigt wurde. Im Übrigen ändern sich die Beschreibungen von Gruppen, die bereits seit einigen Jahren existieren, in der Regel nur noch geringfügig.
} 
- Evolution et devenir des familles Torvalds, Daniels...

- Recherche de partenariat pour la rédaction et/ou mise à jour de documentations.

- Avis/Commentaires personnels d'ouvrages ne prêtant pas à polémique.

- Revues de presse (sommaire de revues spécialisées, annonce d'articles de la presse généraliste...).

- Annonces, critiques ou publication (1) de fictions qui mettraient en scène des acteurs de Linux et des logiciels libres (réels ou imaginaires), ou dont le système Linux serait un des éléments moteurs de l'intrigue.

(Nemeth, „[Conseils d'utilisation] fr.misc.bavardages.linux“, in: fr.misc.bavardages. linux/fr.usenet.reponses vom 02. August 2002 vom 02. August 2002)

Das Forum wird häufig frequentiert. In der Woche vom 26. Juli bis 01. August 2002 wurden dort insgesamt 66 Beiträge veröffentlicht.

\subsubsection{Das Forum fr.comp.developpement}

Das unmoderierte Forum fr.comp.developpement wurde am 29. April 1999 gegründet. Es gibt leider keine monatlich im Forum veröffentlichten „Conseils d'utilisation“, dafür sind sämtliche Informationen unter dem „Index of /pub/usenet/control/fr/ abrufbar. Als Gegenstand wird angegeben:

„Le forum fr.comp.developpement a pour objet de rassembler les discussions relatives au développement informatique, et qui ne sont pas spécifiques à une architecture, un langage ou un système d'exploitation donnés.

Parmi les sujets couverts par ce groupe, on citera :

- le génie logiciel (tout ce qui touche à la gestion et la direction d'un projet informatique)

- les choix structurels (par exemple, dans le cas du développement d'un système d'exploitation, les discussion sur les avantages comparés des micro-noyaux et des noyaux monolithiques)

- les problèmes d'algorithmique

- les problèmes de portabilité du code entre architectures (les problèmes spécifiques à un langage particulier doivent être traité dans le groupe fr.comp.lang.* approprié) “"

(„Index of /pub/usenet/control/fr/“, ftp://ftp.isc.org/pub/use|net/control/fr/). 
In der Woche vom 26. Juli bis 01. August 2002 wurden in fr.comp.developpement 58 Beiträge veröffentlicht.

\subsubsection{Das Forum fr.comp.lang.perl}

Wie für das Forum fr.comp.lang.general ist auch für das unmoderierte Diskussionsforum fr.comp.lang.perl Sylvain Nierveze zuständig. Gegründet wurde fr.comp.lang.perl zeitgleich mit dem Forum fr.comp.lang.general am 16. Dezember 1996. Die Diskussionen im Forum beziehen sich auf die Programmiersprache Perl. In den ,[Conseils d'utilisation] fr.comp.lang.perl“ heißt es:

On y trouvera par exemple :

- des échanges de point de vue, de techniques de programmation, des sources, des commentaires.

- des questions précises résolues éventuellement par les usagers du groupe. Questions issues soit de personnes compétentes visant à résoudre des problèmes très pointus, mais aussi des questions de débutants visant à améliorer ou approfondir leurs connaissances.

- des informations générales sur les langages de programmation (adresses de sites, critique de produits commerciaux).

- des initiations aux différents langages assurées par des experts de bonne volonté.

(Nierveze, „[Conseils d'utilisation] fr.comp.lang.perl“, in: fr.comp.|lang.perl/ fr.usenet.reponses vom 02. August 2002).

Dieses Forum weist mit 150 Beiträgen in der Woche vom 26. Juli bis 01. August 2002 ein hohes Aktivitätsniveau auf.

\subsubsection{Das Forum fr.comp.lang.java}

Das am 18. Juni 1996 gegründete, nicht-moderierte Forum fr.comp.lang.java hat, wie der Name bereits indiziert, die Programmiersprache Java zum Diskussionsgegenstand. Der Begründer des Forums, Laurent Pellisier, präzisiert die Inhalte wie folgt:

Ce groupe est ouvert à toute discussion qui traite de Java. Ceci inclut :

- discussion sur les problèmes de développement rencontrés et les solutions proposées.

- discussion sur les outils connexes à Java (compilateur et environnement de développement, JDK, serveur HTTP et client HT'TP/HTML supportant Java, processeurs Java, compilateur Just In Time,...).

- discussion sur les problèmes de sécurités liés à Java et aux différentes versions des JVM. 
- annonce de produits (compilateur, débuggeur, environnement de développement, bibliothèque de classes, ordinateur Java, ...) en respectant si possible le caractère non commercial des messages postés ailleurs que dans fr.biz.*.

(Pellisier, „[Conseils d'utilisation] fr.comp.lang.java“, in: fr.comp.|lang.java/ fr.usenet.reponses vom 02. August 2002).

Mit 215 Beiträgen in der Woche vom 26. Juli bis 01. August 2002 handelt es sich um ein Forum mit sehr aktiven Teilnehmern.

\subsubsection{Das Forum fr.comp.lang.c ++}

Das Forum fr.comp.lang.c ++ wurde wie die Foren fr.comp.lang.general und fr.comp.lang.perl von Sylvain Nierveze ins Leben gerufen. Das unmoderierte Forum existiert seit dem 21. April 1997. Der Diskussionsgegenstand ist die Programmiersprache c++. Nähere Auskünfte zu den genauen Inhalten sind den „[Conseils d'utilisation] fr.comp.lang.c ++ “ zu entnehmen, die monatlich in den Foren fr.comp.lang.c ++ und fr.usenet.reponses veröffentlicht werden. Mit 273 Beiträgen in der Woche vom 26. Juli bis 01. August 2002 gehört auch dieses Forum zu den häufig frequentierten informatischen Diskussionsforen.

\subsubsection{Das Forum fr.comp.lang.c}

Wie die Diskussionsforen fr.comp.lang.c ++ , fr.comp.lang.general und fr.comp.lang.perl wurde auch fr.comp.lang.c von Sylvain Nierveze gegründet. Das unmoderierte Diskussionsforum fr.comp.lang.c entstand zeitgleich mit fr.comp.lang.general und fr.comp.lang.perl am 16. Dezember 1996. In diesem Forum wird über die Programmiersprache c sowie über verwandte Programmiersprachen diskutiert. Entsprechend lautet die Beschreibung der Inhalte dieses Forums:

On trouvera par exemple dans fr.comp.lang.c :

- des échanges de point de vue, de techniques de programmation, des sources, des commentaires.

- des questions précises résolues éventuellement par les usagers du groupe. Questions issues soit de personnes compétentes visant à résoudre des problèmes très pointus, mais aussi des questions de débutants visant à améliorer ou approfondir leurs connaissances.

- des informations générales sur les langages de programmation (adresses de sites, critique de produits commerciaux).

- des initiations aux différents langages assurées par des experts de bonne volonté.

(Nierveze, „[Conseils d'utilisation] fr.comp.lang.c“, in: fr.comp.|lang.c/ fr.usenet.reponses vom 02. August 2002).

In der Woche vom 26. Juli bis 01. August 2002 gab es in diesem Forum 151 Beiträge. Damit ist die Aktivität der Teilnehmer als hoch einzuordnen. 


\subsection{Biosoziale Angaben der Informanten}

Die Umfrage richtet sich an in Frankreich, Belgien oder der Schweiz lebende französischsprachige Informatiker sowie im Bereich des Internet Beschäftigte. Bei der Auswertung der Daten ist wichtig, dass jeweils Französisch als Muttersprache angegeben wurde. Um von der Stichprobe Rückschlüsse auf die Gesamtheit der frankophonen Informatiker der drei Untersuchungsländer ziehen zu können, ist es notwendig, den Sprachgebrauch von Muttersprachlern zu kennen. Insbesondere in Bezug auf die Verwendung von Anglizismen kann ein Nicht-Muttersprachler kein valides Zeugnis für den Sprachgebrauch der Zielgruppe der Untersuchung liefern. Auch für die Erforschung der Einstellungen zur französischen Sprache von in Frankreich, Belgien und der Schweiz lebenden Informatikern ist es unabdingbar, dass es sich bei der Stichprobe um Muttersprachler handelt. Insbesondere im Hinblick auf die ästhetische Dimension der eigenen Sprache (affektive Einstellungsdimension) beurteilen Muttersprachler das Französische sicherlich anders und haben eine andere Beziehung zu dieser Sprache als jemand, der Französisch als Fremdsprache erworben hat.

Es ist generell aussagekräftiger - wenn Vollerhebungen aus finanziellen oder zeitlichen Gründen nicht möglich sind -, Studien mit klar eingegrenzten Zielgruppen durchzuführen ${ }^{7}$. Die Gründe für die Beschränkung auf die drei genannten Länder sind in 3.3 nachzulesen. Eine Beschränkung auf die Berufsgruppe derjenigen, die im Bereich Informatik/Internet tätig sind, empfiehlt sich v.a. deswegen, weil sie von der entsprechenden Fachterminologie betroffen ist und nahezu täglich mit dieser konfrontiert wird. Angehörige dieser Berufsgruppe können daher am kompetentesten entscheiden, inwiefern die französischen Neologismen dem Gegenstand angemessen sind oder nicht. Eine weitere Einschränkung erfährt die Zielgruppe durch die Art und Weise der Ankündigung der Befragung. Die Umfrage wurde in neun französischsprachigen Diskussionsforen zu den Themen Informatik/Internet (vgl. 8.1.2) angekündigt. Das bedeutet natürlich zugleich, dass nicht alle französischen, belgischen und schweizerischen Informatiker/im InternetBereich Beschäftigten von der Umfrage Kenntnis erlangt haben und somit die Möglichkeit hatten, an ihr teilzunehmen, sondern nur diejenigen, die regelmäßig mindestens eines der genannten Diskussionsforen frequentieren.

Trotz der expliziten Eingrenzung der Zielgruppe der Befragung in Bezug auf den Beruf, den Wohnort und die Muttersprache ist es nicht auszuschließen, dass auch Informanten den Fragebogen ausfüllen, die nicht zu der intendierten Zielgruppe gehören. Entsprechende Fragebögen können aufgrund der biosozialen Daten (Beruf, Wohnort, Muttersprache) im dritten Teil des Fragebogens nachträglich herausgefiltert werden. Dabei muss darauf vertraut werden, dass diese Angaben ebenso wie die Antworten auf die einzelnen Fragen des ersten und zweiten Fragebogenmoduls - wahrheitsgemäß gemacht wurden. Die folgenden Abschnitte cha-

\footnotetext{
7 Bei einer WWW-Untersuchung, die sich auf die Gesamtbevölkerung bezieht, ist es derzeit noch nicht realisierbar, dass auch jedes Mitglied dieser Grundgesamtheit von der Studie erfährt oder auf andere Weise die gleiche Chance hat, an der Befragung teilzunehmen (vgl. zur Repräsentativität 6.1 und 6.3.1).
} 
rakterisieren die 160 Informanten, die ihre Fragebögen vollständig ausgefüllt haben und bezüglich ihres Geschlechtes, Alters, ihres Berufs/Ausbildung, des höchsten Bildungsabschlusses, ihres Geburtsortes, ihrer Muttersprache(n), des Wohnsitzes, ihrer Englischkenntnisse und der Art und Dauer der Internetnutzung der intendierten Zielgruppe entsprechen.

Alle statistischen Berechnungen wurden mit dem Programm SPSS for Windows (10.0) durchgeführt, die Grafiken in den Kapiteln 9-11 wurden mit MS Excel erstellt.

\subsubsection{Geschlecht}

Im Rahmen der Hypothesen zu Korrelationen zwischen biosozialen Daten der Informanten und ihrem Sprachverhalten bzw. ihren Einstellungen wurde auf die Formulierung einer Hypothese, die den Merkmalen ,männlich'/,weiblich' Rechnung trägt, verzichtet, da zu vermuten ist, dass die Anzahl an Informatikerinnen weit unter der der Informatiker liegen wird (vgl. 5.3.2).

Die Auswertung des Merkmals Geschlecht bestätigt diese Annahme:

Abb. 11: Geschlecht der Informanten (absolute Häufigkeit)

\begin{tabular}{|l|r|r|r|r|}
\hline Land & $\begin{array}{l}\text { Anzahl } \\
\text { insgesamt }\end{array}$ & Männlich & Weiblich & $\begin{array}{l}\text { Keine } \\
\text { Angabe }\end{array}$ \\
\hline Frankreich & 124 & 113 & 8 & 3 \\
\hline Belgien & 17 & 17 & 0 & 0 \\
\hline Schweiz & 19 & 17 & 2 & 0 \\
\hline Insgesamt & 160 & 147 & 10 & 3 \\
\hline
\end{tabular}

Um die Tabelle übersichtlich zu gestalten, werden die absoluten Häufigkeiten (Anzahl der Informanten) und die prozentualen Häufigkeiten (Prozentwert) in zwei getrennten Tabellen dargestellt. Die relative Verteilung der Geschlechter sieht wie folgt aus:

Abb. 12: Geschlecht der Informanten (prozentuale Häufigkeit)

\begin{tabular}{|l|r|r|r|}
\hline Land & Männlich (\%) & Weiblich (\%) & $\begin{array}{l}\text { Keine An- } \\
\text { gabe (\%) }\end{array}$ \\
\hline Frankreich & 91,1 & 6,5 & 2,4 \\
\hline Belgien & 100,0 & 0,0 & 0,0 \\
\hline Schweiz & 89,5 & 10,5 & 0,0 \\
\hline
\end{tabular}

Wie sich der Tabelle entnehmen lässt, ist die Anzahl an weiblichen Informanten mit zehn von 160 so gering, dass es nicht sinnvoll ist, in den Auswertungskapiteln 9, 10 und 11 eine geschlechterspezifische Auswertung vorzunehmen. Bei einem derart geringen Frauenanteil, welcher im Hinblick auf die Zielgruppe Informatiker und die derzeit noch zu konstatierende Männerdominanz bei der Nutzung von 
Computernetzen (vgl. Beck/Glotz/Vogelsang 2000, 418) nicht anders zu erwarten war, können keine validen Aussagen über das Sprachverhalten von Informatikerinnen getroffen werden. Um zu ermitteln, ob es bezüglich der Wortbenutzung oder bezüglich der Spracheinstellungen geschlechtsspezifische Unterschiede gibt, müsste eine entsprechende Untersuchung durchgeführt werden, die ein ausgewogenes Geschlechterverhältnis aufweist. Hinzu kommt, dass in der neueren Forschung zu geschlechtsspezifischen Sprachunterschieden davor gewarnt wird, die Geschlechter als Dichotomien zu betrachten. Dies sei eine künstliche Trennung und eine nicht zulässige Vereinfachung (vgl. Coates/Johnson 2001, 453, 460f.). Daher empfehlen Coates/Johnson (2001, 455, 460f.), die Variable Geschlecht immer im Kontext der Situation zu untersuchen, nicht jedoch isoliert von der Interaktion und anderen Variablen.

\subsubsection{Alter}

Beim Faktor Alter werden die absolute und die prozentuale Häufigkeit in einer Tabelle dargestellt. Für jedes der drei Untersuchungsländer Frankreich, Belgien und die Schweiz wird der besseren Übersichtlichkeit halber eine eigene Tabelle erstellt:

Abb. 13: Alter der Informanten (Frankreich)

\begin{tabular}{|c|c|c|}
\hline Kategorien & $\begin{array}{l}\text { Absolute } \\
\text { Häufigkeit }\end{array}$ & $\begin{array}{l}\text { Prozentuale } \\
\text { Häufigkeit }\end{array}$ \\
\hline$\leq 20$ Jahre & 5 & 4,0 \\
\hline 21-30 Jahre & 75 & 60,5 \\
\hline 31-40 Jahre & 28 & 22,6 \\
\hline 41-50 Jahre & 9 & 7,3 \\
\hline 51-60 Jahre & 6 & 4,8 \\
\hline$\geq 60$ Jahre & 1 & 0,8 \\
\hline Keine Angabe & 0 & 0,0 \\
\hline Insgesamt & 124 & 100,0 \\
\hline
\end{tabular}

\footnotetext{
8 Beck/Glotz/Vogelsang $(2000,96)$ prognostizieren jedoch, dass sich das derzeitige Ungleichgewicht in einigen Jahren aufheben werde: ,Zu einer relativen Angleichung der Nutzungsintensität wird es, wie bereits heute tende[n]ziell zu beobachten, zwischen Frauen und Männern kommen: Knapp die Hälfte der Experten nimmt an, dass im Jahre 2010 mehr als 50\% der Frauen Computernetze regelmäßig zur persönlichen Kommunikation nutzen werden, 70,7\% der Befragten schätzen, über die Hälfte der Männer würden dies tun [...].“
} 
Abb. 14: Alter der Informanten (Belgien)

\begin{tabular}{|l|r|r|}
\hline Kategorien & $\begin{array}{l}\text { Absolute } \\
\text { Häufigkeit }\end{array}$ & $\begin{array}{l}\text { Prozentuale } \\
\text { Häufigkeit }\end{array}$ \\
\hline < 20 Jahre & 2 & 11,8 \\
\hline 21-30 Jahre & 9 & 52,8 \\
\hline 31-40 Jahre & 2 & 11,8 \\
\hline 41-50 Jahre & 2 & 11,8 \\
\hline 51-60 Jahre & 2 & 11,8 \\
\hline 2 60 Jahre & 0 & 0,0 \\
\hline Keine Angabe & 0 & 0,0 \\
\hline Insgesamt & 17 & 100,0 \\
\hline
\end{tabular}

Abb. 15: Alter der Informanten (Schweiz)

\begin{tabular}{|l|r|r|}
\hline Kategorien & $\begin{array}{l}\text { Absolute } \\
\text { Häufigkeit }\end{array}$ & $\begin{array}{l}\text { Prozentuale } \\
\text { Häufigkeit }\end{array}$ \\
\hline < 20 Jahre & 3 & 15,8 \\
\hline 21-30 Jahre & 9 & 47,4 \\
\hline 31-40 Jahre & 6 & 31,6 \\
\hline 41-50 Jahre & 1 & 5,2 \\
\hline 51-60 Jahre & 0 & 0,0 \\
\hline$\geq$ 60 Jahre & 0 & 0,0 \\
\hline Keine Angabe & 0 & 0,0 \\
\hline Insgesamt & 19 & 100,0 \\
\hline
\end{tabular}

Die meisten Befragten sind zwischen 21 und 30 Jahren alt. Die zweithäufigste Kategorie ist die der 31-40-Jährigen. Von 160 Informanten sind nur 21 älter als 40 Jahre. Dies bedeutet im Hinblick auf die Ergebnisse auch, dass sich der Gültigkeitsbereich der Aussagen im Wesentlichen auf Informatiker zwischen 20 und 40 Jahren beschränkt. Für ältere Informatiker lassen sich keine zuverlässigen Aussagen treffen. Dennoch soll in 9.1.3 analysiert werden, ob das Alter einen Einfluss auf die Verwendung der Lexik (d.h. den eigenen Sprachgebrauch) und die Einstellungen zur Sprachpolitik ausübt. Allerdings wird dann eine Trennung in die beiden Gruppen derer, die 30 Jahre und jünger, und derer, die älter als 30 Jahre sind, vorgenommen.

Das weitgehende Fehlen von Informanten, die über 40 Jahre alt sind, ist insofern nicht ungewöhnlich, als das Internet in der jüngeren Generation verbreiteter ist als in der älteren. Außerdem ist die Informatik noch eine recht junge Disziplin, die in der Öffentlichkeit seit den 1980er Jahren einen enormen Aufschwung erfahren 
hat. Im Informatikbereich als einem vergleichsweise jungen Berufszweig sind sehr viele jüngere Leute beschäftigt.

Wie der folgende Abschnitt aufzeigt, führt nicht zuletzt der hohe Anteil an Studierenden zu der hohen Anzahl an jüngeren Informanten.

\subsubsection{Beruf}

Die Fragen 52 und 53 des dritten Fragebogenmoduls befassen sich mit der beruflichen Situation der Informanten. Im Anschreiben, das dem Fragebogen vorausging, wurde eindeutig darauf hingewiesen, für welche Zielgruppe der Fragebogen bestimmt ist.

In Frage 52 sollen sich die Befragten in eine der vorgegebenen Berufsgruppen einordnen, in Frage 53 (offenes Textfeld) werden sie gebeten, ihre genaue Berufsbezeichnung einzugeben. Dies dient zum einen als zusätzliche Kontrolle, dass nur die gewünschte Zielgruppe an der Befragung teilgenommen hat. Zum anderen ist die übliche Unterteilung in Berufsgruppen, wie sie in Frage 52 vorgenommen wird, in Bezug auf die verschiedenen Berufsfelder im Informatikbereich zu ungenau.

Wie bereits in 8.1.1 erwähnt, wurden vier der von den französischen Informanten und einer der von den belgischen Informanten ausgefüllten Fragebögen aus dem Datensatz entfernt. Alle 19 von den Schweizern ausgefüllten Fragebögen fließen in die Auswertung ein.

Die am häufigsten von den befragten Franzosen (47,6\%), Belgiern (29,4\%) und Schweizern (31,6\%) bei der Frage 52 gewählte Kategorie ist „Cadre et professions intellectuelles supérieures“. Danach folgt, außer in Belgien, die Kategorie „Étudiant(e): Université, Grande École“. Dies lässt auf eine relativ hohe soziale Situierung der Befragten schließen. Diesem Punkt wird der folgende Abschnitt näher nachgehen.

Die in Frage 53 formulierten Berufsbezeichnungen wurden geordnet und in drei länderspezifischen Listen zusammengefasst. Bei den französischen Informatikern lauten die häufigsten Berufsbezeichnungen Ingenieur (32 Informanten, 26,2\%), Informatiker (14 Informanten, 11,3\%) und Student (12 Informanten, 9,7\%). Bei den belgischen Informatikern sind es entsprechend Student (4 Informanten, 23,5\%), Informatiker (4 Informanten, 23,5\%) und Analyst-Programmierer (3 Informanten, 17,6\%) und bei den schweizerischen Informatikern Student (4 Informanten, 21\%), Lehrer (3 Informanten, 15,7\%) und Ingenieur (3 Informanten, 15,7\%). Bei manchen Berufen wie z.B. „Cadre SNCF“, „Chargé de cours“, „Chef d'entreprise“ oder „Électronicien“ ist aus der Berufsbezeichnung nicht direkt zu ersehen, dass es sich um Informatiker bzw. im Internet-Bereich tätige Personen handelt. Hier muss, wie im Übrigen bei allen biosozialen Angaben, auf die Ehrlichkeit der Informanten vertraut werden. Das gleiche gilt für die 17 Informanten, die das Textfeld mit der genauen Berufsbezeichnung nicht ausgefüllt haben. Unter den schweizerischen Informanten sind auch einige im Internetbereich tätig („Internet Content Manager", „Web Developper“ und „Webpublisher"). 
Mit der Auswertung der Fragen 52 und 53 und der daraufhin vorgenommenen Reduktion des Datensatzes um fünf Fragebögen kann es als wahrscheinlich angesehen werden, dass alle französischen, belgischen und schweizerischen Informanten der gewünschten Zielgruppe Informatiker angehören.

Die Auflistung aller in den Fragen 52 und 53 aufgeführten Berufsgruppen und Berufsbezeichnungen ist im Anhang (15.4.1) nach Ländern getrennt nachzulesen.

\subsubsection{Höchster Bildungsabschluss}

Die Hypothese II.3 aus 5.3.2 bezieht sich auf den Bildungsgrad der Informanten (,Je höher der Bildungsgrad der Informanten, desto höher die Ablehnung von sprachpolitischen Maßnahmen und den daraus resultierenden Vorschriften."). Um zu sehen, ob es sinnvoll ist, dieser Hypothese nachzugehen, bietet sich ein Blick auf die Bildungsabschlüsse der Informanten an.

Abb. 16: Höchster Bildungsabschluss der französischen Informanten

\begin{tabular}{|l|r|r|}
\hline Kategorie & $\begin{array}{l}\text { Absolute } \\
\text { Häufigkeit }\end{array}$ & $\begin{array}{l}\text { Prozentuale } \\
\text { Häufigkeit }\end{array}$ \\
\hline BEPC & 1 & 0,8 \\
\hline $\mathrm{BEP} / \mathrm{CAP}$ & 1 & 0,8 \\
\hline $\mathrm{Bac}$ et équivalent & 8 & 6,5 \\
\hline $\mathrm{Bac}+2$ & 32 & 25,8 \\
\hline $\mathrm{Bac}+3,+4$ & 22 & 17,7 \\
\hline $\mathrm{Bac}+5$ et plus & 58 & 46,8 \\
\hline Keine Angabe & 2 & 1,6 \\
\hline Insgesamt & 124 & 100,0 \\
\hline
\end{tabular}

98,4\% der befragten französischen Informanten hat das Abitur gemacht ${ }^{9}$. Fast die Hälfte aller Befragten (46,8\%) hat ein Studium abgeschlossen. Das Bildungsniveau der Befragten ist somit als relativ hoch anzusehen.

\footnotetext{
9 1,6 Prozent haben die Pflichtschule (entspricht BEPC) absolviert bzw. einen Ausbildungsberuf (entspricht BEP/CAP) gelernt.
} 
Abb. 17: Höchster Bildungsabschluss der belgischen Informanten

\begin{tabular}{|l|r|r|}
\hline Kategorie & $\begin{array}{l}\text { Absolute } \\
\text { Häufigkeit }\end{array}$ & $\begin{array}{l}\text { Prozentuale } \\
\text { Häufigkeit }\end{array}$ \\
\hline \begin{tabular}{l|r|} 
École primaire \\
École professionnelle / École \\
technique
\end{tabular} & 0 & 0,0 \\
\hline $\begin{array}{l}\text { Baccalauréat / Diplôme de } \\
\text { l'Enseignement Supérieur }\end{array}$ & 0 & 0,0 \\
\hline Candidature & & 35,3 \\
\hline Licence & 3 & 17,6 \\
\hline $\begin{array}{l}\text { Doctorat } \\
\text { Insgesamt }\end{array}$ & 7 & 41,2 \\
\hline
\end{tabular}

Alle befragten Belgier haben das Abitur, 41,2\% ein abgeschlossenes Studium. Damit liegt das Bildungsniveau der belgischen Informanten sehr hoch.

Abb. 18: Höchster Bildungsabschluss der schweizerischen Informanten

\begin{tabular}{|l|r|r|}
\hline Kategorie & $\begin{array}{l}\text { Absolute } \\
\text { Häufigkeit }\end{array}$ & \multicolumn{1}{|c|}{$\begin{array}{l}\text { Prozentuale } \\
\text { Häufigkeit }\end{array}$} \\
\hline École obligatoire & 0 & 0,0 \\
\hline Maturité professionnelle & 1 & 5,3 \\
\hline $\begin{array}{l}\text { Maturité / Baccalauréat et } \\
\text { équivalent }\end{array}$ & 6 & 31,5 \\
\hline Demi-licence & 3 & 15,8 \\
\hline Licence & 5 & 26,3 \\
\hline Doctorat & 3 & 15,8 \\
\hline Keine Angabe & 1 & 5,3 \\
\hline Insgesamt & 19 & 100,0 \\
\hline
\end{tabular}

18 der 19 befragten Schweizer haben das Abitur, acht ein abgeschlossenes Studium, davon drei einen Doktortitel. Analog zu den französischen und belgischen Informanten ist auch das Bildungsniveau der befragten Schweizer überdurchschnittlich hoch. Eine Überprüfung der Hypothese durch eine Gegenüberstellung von Informanten mit einem höheren (z.B. mindestens Abitur) und Informanten mit einem niedrigeren Bildungsniveau erweist sich bei dieser Verteilung nicht als sinnvoll, da nur drei der 160 Informanten kein Abitur haben. Für eine Analyse der Korrelation zwischen Bildungsniveau und Einstellungen zur Sprachpolitik müsste ein ausgeglicheneres Zahlenverhältnis vorliegen. 


\subsubsection{Geburtsort}

Zwar gibt es keine Hypothesen, die sich auf den Geburtsort beziehen, aber dieser sollte der Vollständigkeit halber auch in die Beschreibung der Informanten aufgenommen werden.

Abb. 19: Geburtsort der französischen Informanten

\begin{tabular}{|l|r|r|}
\hline Kategorie & $\begin{array}{l}\text { Absolute } \\
\text { Häufigkeit }\end{array}$ & $\begin{array}{l}\text { Prozentuale } \\
\text { Häufigkeit }\end{array}$ \\
\hline Frankreich (inkl. DOM-TOM) & 122 & 98,4 \\
\hline Kanada & 1 & 0,8 \\
\hline Deutschland & 1 & 0,8 \\
\hline Insgesamt & 124 & 100,0 \\
\hline
\end{tabular}

Abb. 20: Geburtsort der belgischen Informanten

\begin{tabular}{|l|r|r|} 
Kategorie & $\begin{array}{l}\text { Absolute } \\
\text { Häufigkeit }\end{array}$ & $\begin{array}{l}\text { Prozentuale } \\
\text { Häufigkeit }\end{array}$ \\
\hline Belgien & 16 & 94,1 \\
\hline Luxemburg & 1 & 5,9 \\
\hline Insgesamt & 17 & 100,0 \\
\hline
\end{tabular}

Abb. 21: Geburtsort der schweizerischen Informanten

\begin{tabular}{|l|r|r|} 
Kategorie & $\begin{array}{l}\text { Absolute } \\
\text { Häufigkeit }\end{array}$ & $\begin{array}{l}\text { Prozentuale } \\
\text { Häufigkeit }\end{array}$ \\
\hline Schweiz & 18 & 94,7 \\
\hline Keine Angabe & 1 & 5,3 \\
\hline Insgesamt & 19 & 100,0 \\
\hline
\end{tabular}

Mit drei Ausnahmen (und einer fehlenden Angabe) sind alle Informanten in Frankreich, Belgien oder der Schweiz geboren.

\subsubsection{Muttersprache(n)}

Mit der Frage nach der oder den Muttersprachen der Informanten sollte sichergestellt werden, dass wirklich nur Muttersprachler den Fragebogen bearbeitet haben, da 1. andernfalls keine Übertragbarkeit der Ergebnisse auf andere Muttersprachler möglich ist und 2. insbesondere die Fragen 6, 13, 20, 27, 34 und 41, in denen die Informanten mittels des semantischen Differentials den gewählten französischen Terminus im Hinblick auf u.a. ästhetische Kriterien beurteilen sollen, nur von Muttersprachlern adäquat bearbeitet werden können. 
Für die französischen Informanten ergibt sich die folgende Verteilung:

Abb. 22: Muttersprache(n) der französischen Informanten

\begin{tabular}{|l|r|}
\hline Kategorie & $\begin{array}{l}\text { Absolute } \\
\text { Häufigkeit }\end{array}$ \\
\hline Französisch & 124 \\
\hline Deutsch & 2 \\
\hline Englisch & 1 \\
\hline Niederländisch & 0 \\
\hline Italienisch & 0 \\
\hline Andere & 0 \\
\hline Keine Angabe & 0 \\
\hline
\end{tabular}

Französisch ist die Muttersprache aller Informanten. Drei Informanten sind zweisprachig, zwei französisch-deutsch, einer französisch-englisch. Es ist wahrscheinlich, dass ein Zusammenhang zum Geburtsort besteht, der in der vorhergehenden Frage ermittelt wurde. Bei dem in Deutschland geborenen Informanten könnte es sich um eine der drei zweisprachigen Personen (französisch-deutsch) handeln, bei dem in Kanada geborenen Informanten um eine weitere (französisch-englisch).

Alle belgischen und schweizerischen Informanten haben als Muttersprache Französisch angegeben. Insofern entfällt für diese beiden Länder die tabellarische Darstellung.

\subsubsection{Wohnsitz (Land, Region/Kanton)}

Wie bereits die Frage nach der Muttersprache sicherstellen konnte, sind alle Informanten französischsprachig. Mit Ausnahme von sechs Informanten leben alle befragten Informatiker in Frankreich, Belgien oder der Schweiz. Die exakten Wohnorte werden in den Kapiteln 9-12 allerdings nicht berücksichtigt, da es bei der Auswertung nicht um regionale Differenzen geht. Interessant wäre in diesem Zusammenhang sicherlich die Frage, ob Unterschiede zwischen Stadt- und Landbevölkerung festzustellen sind oder ob diese Unterscheidung in Bezug auf das Internet hinfällig ist. Allerdings ist eine detaillierte Unterteilung der Kategorie ,Wohnsitz' für die der Arbeit zugrunde liegende Fragestellung und bezüglich der Arbeitshypothesen irrelevant.

Es ist davon auszugehen, dass auch diejenigen Informanten, die nicht in Frankreich leben, zumindest über die Medien - in erster Linie vermutlich über das Internet selbst - regelmäßig mit der französischen (bzw. englischen) Internet-Terminologie konfrontiert werden. 55,6\% der französischen Informanten leben im Großraum Paris. Fast die Hälfte der belgischen Informanten lebt in Brüssel. In diesen Fällen ist es möglich, dass die in dieser Stadt gegebene Sprachkontaktsitua- 
tion mit den niederländischsprachigen Belgiern die Wahl der Terminologie beeinflusst $^{10}$. Die meisten der befragten Schweizer leben in Genf (52,6\%).

Die genaue Verteilung der Informanten auf die verschiedenen Regionen bzw. Kantone ist im Anhang 15.4.2 nachzulesen.

\subsubsection{Englischkenntnisse}

Es ist davon auszugehen, dass Personen, die der englischen Sprache mächtig sind, häufiger Anglizismen gebrauchen als Personen, die diese Sprache nicht beherrschen. In einer Studie, die ermitteln will, ob bestimmte Anglizismen oder deren französische Ersatzwörter häufiger verwendet werden, erweist es sich somit als sinnvoll, nach den Englischkenntnissen zu fragen.

Um ihre Englischkenntnisse einzustufen, wurden den Informanten sechs Kategorien zur Auswahl gegeben, von „keine Englischkenntnisse“ bis hin zu ,guten Englischkenntnissen“.

Aucune.

Très rudimentaires (à l'oral et à l'écrit).

Seulement bien à l'écrit.

Seulement bien à l'oral.

Bonnes connaissances (à l'écrit et à l'oral).

Je ne sais pas.

Abb. 23: Englischkenntnisse der französischen Informanten

\begin{tabular}{|l|r|r|}
\hline Kategorie & $\begin{array}{l}\text { Absolute } \\
\text { Häufigkeit }\end{array}$ & $\begin{array}{l}\text { Prozentuale } \\
\text { Häufigkeit }\end{array}$ \\
\hline Keine Englischkenntnisse & 0 & 0,0 \\
\hline Geringe Englischkenntnisse & 1 & 0,8 \\
\hline Mittlere Englischkenntnisse & 25 & 20,2 \\
\hline Gute Kenntnisse im Schriftlichen & 15 & 12,1 \\
\hline Gute Kenntnisse im Mündlichen & 2 & 1,6 \\
\hline Gute Englischkenntnisse & 79 & 63,7 \\
\hline Weiß nicht & 1 & 0,8 \\
\hline Keine Angabe & 1 & 0,8 \\
\hline Insgesamt & 124 & 100,0 \\
\hline
\end{tabular}

10 Vergleiche hierzu den Kommentar eines Belgiers (Anhang, 15.5.2.2, B7). 
Abb. 24: Englischkenntnisse der belgischen Informanten

\begin{tabular}{|l|r|r|}
\hline Kategorie & $\begin{array}{l}\text { Absolute } \\
\text { Häufigkeit }\end{array}$ & $\begin{array}{l}\text { Prozentuale } \\
\text { Häufigkeit }\end{array}$ \\
\hline Keine Englischkenntnisse & 0 & 0 \\
\hline Geringe Englischkenntnisse & 2 & 11,8 \\
\hline Mittlere Englischkenntnisse & 5 & 29,4 \\
\hline Gute Kenntnisse im Schriftlichen & 4 & 23,5 \\
\hline Gute Kenntnisse im Mündlichen & 0 & 0,0 \\
\hline Gute Englischkenntnisse & 6 & 35,3 \\
\hline Weiß nicht & 0 & 0,0 \\
\hline Insgesamt & 17 & 100,0 \\
\hline
\end{tabular}

Abb. 25: Englischkenntnisse der schweizerischen Informanten

\begin{tabular}{|l|r|r|}
\hline Kategorie & $\begin{array}{l}\text { Absolute } \\
\text { Häufigkeit }\end{array}$ & $\begin{array}{l}\text { Prozentuale } \\
\text { Häufigkeit }\end{array}$ \\
\hline Keine Englischkenntnisse & 0 & 0,0 \\
\hline Geringe Englischkenntnisse & 2 & 10,5 \\
\hline Mittlere Englischkenntnisse & 6 & 31,6 \\
\hline Gute Kenntnisse im Schriftlichen & 1 & 5,3 \\
\hline Gute Kenntnisse im Mündlichen & 0 & 0,0 \\
\hline Gute Englischkenntnisse & 10 & 52,6 \\
\hline Weiß nicht & 0 & 0,0 \\
\hline Insgesamt & 19 & 100,0 \\
\hline
\end{tabular}

Wenn man die Selbsteinschätzung in Bezug auf die Englischkenntnisse in den drei befragten Ländern vergleicht, fällt auf, dass mehr als die Hälfte der französischen und schweizerischen Informanten ihre Englischkenntnisse als gut einstuft. Dies ist insbesondere für Frankreich nicht unbedingt zu erwarten gewesen. Gerade in Frankreich dürfte sich bei repräsentativen Befragungen, die Aussagen über die gesamte Bevölkerung ermöglichen, die Mehrheit bezüglich ihrer Englischkenntnisse eher als schlecht einstufen. Entsprechendes mutmaßt zumindest Truchot (1994b, 22), wenn er schreibt:

„Si l'on établissait un profil général de la connaissance de l'anglais par la population française, on constaterait probablement une différence entre une minorité connaissant relativement bien l'anglais et une majorité dont la connaissance est nettement moins développée.“

Die überdurchschnittlich guten Englischkenntnisse verwundern in mehrsprachigen Ländern wie Belgien und der Schweiz weniger als in Frankreich. In Belgien und der Schweiz stellt Englisch zumeist die ,neutrale“ Sprache für die Kommuni- 
kation z.B. zwischen französisch- und niederländischsprachigen Belgiern oder deutsch- und französischsprachigen Schweizern dar. Insgesamt lassen sich die guten Englischkenntnisse (insbesondere auch im Schriftenglischen) der Informanten in Beziehung setzen zum überdurchschnittlich hohen Bildungsniveau (vgl. 8.2.4) sowie zu den Gepflogenheiten der Informatikbranche, wo vielfach Dokumente nur auf Englisch zugänglich sind und Englisch zudem als Verkehrssprache fungiert.

Die Daten bezüglich der Englischkenntnisse ermöglichen eine Analyse, die zeigen kann, ob es einen Zusammenhang zwischen den Englischkenntnissen der Informanten und einer möglichen Bevorzugung der englischen Terminologie gibt. Das hieße im Umkehrschluss: Wer kein oder nur rudimentäres Englisch beherrscht, bevorzugt die französischen Termini (vgl. Hypothese II.5, 5.3.2). Allerdings erweist sich eine entsprechende Gegenüberstellung in dieser Studie nicht als sinnvoll, da im Falle Frankreichs, Belgiens und der Schweiz 0,8\%, 10,8\% und 11,5\% Informanten mit geringen Englischkenntnissen 97,6\%, 88,2\% und 89,5\% mit mittleren bzw. guten Englischkenntnissen gegenüberstehen. Für eine aussagekräftige Analyse müsste ein ausgeglicheneres Zahlenverhältnis vorliegen.

\subsubsection{Art und Dauer der Internetnutzung}

Die offizielle Internet-Terminologie wurde für Frankreich im März 1999 verabschiedet. Die belgische und die schweizerische Terminologie folgten erst später. Den Terminologiekommissionen wird häufig vorgeworfen, ihre Terminologielisten kämen zu spät, d.h. nachdem sich die englischen Bezeichnungen bereits etabliert hätten. Entsprechend wurde in 5.3.2 die Hypothesen II.6 formuliert: „Wer länger als seit 1999 das Medium Internet benutzt, wird eher die InternetAnglizismen als die entsprechenden Neologismen verwenden." Das bedeutet in Bezug auf die biosozialen Angaben, dass in den Fällen, in denen die Informanten angeben die Dienste World Wide Web und E-Mail länger als drei Jahre zu nutzen, davon auszugehen ist, dass sie mit den englischen Bezeichnungen in Kontakt kamen, bevor eine entsprechende französische Terminologie verabschiedet war. Nichtsdestotrotz kursierten natürlich einige der seit 1997 bzw. seit 1999 offiziellen französischen Bezeichnungen bereits vorher und wurden von den Terminologiekommissionen lediglich aufgegriffen und offizialisiert.

Die Auswertung erfolgt wiederum getrennt für die drei Untersuchungsländer. 
Abb. 26: Internetnutzung der französischen Informanten

\begin{tabular}{|c|c|c|c|c|c|c|}
\hline \multirow[b]{2}{*}{$\begin{array}{l}\text { Katego- } \\
\text { rie }\end{array}$} & \multicolumn{2}{|c|}{$\begin{array}{l}\text { Dauer der E- } \\
\text { Mail-Nutzung }\end{array}$} & \multicolumn{2}{|c|}{$\begin{array}{l}\text { Dauer der } W W W- \\
\text { Nutzung }\end{array}$} & \multicolumn{2}{|c|}{$\begin{array}{l}\text { Dauer der Nut- } \\
\text { zung von Diskus- } \\
\text { sionsforen }\end{array}$} \\
\hline & $\begin{array}{l}\text { Absolu- } \\
\text { te Häu- } \\
\text { figkeit }\end{array}$ & $\begin{array}{l}\text { Prozen- } \\
\text { tuale } \\
\text { Häufig- } \\
\text { keit }\end{array}$ & $\begin{array}{l}\text { Absolute } \\
\text { Häufig- } \\
\text { keit }\end{array}$ & $\begin{array}{l}\text { Prozen- } \\
\text { tuale } \\
\text { Häufig- } \\
\text { keit }\end{array}$ & $\begin{array}{l}\text { Absolu- } \\
\text { te Häu- } \\
\text { figkeit }\end{array}$ & $\begin{array}{l}\text { Prozen- } \\
\text { tuale } \\
\text { Häufig- } \\
\text { keit }\end{array}$ \\
\hline Gar keine & 0 & 0,0 & 0 & 0,0 & 1 & 0,8 \\
\hline$<1 \mathrm{Jahr}$ & 1 & 0,8 & 1 & 0,8 & 6 & 4,8 \\
\hline$<3$ Jahre & 3 & 2,4 & 4 & 3,2 & 22 & 17,7 \\
\hline > 3 Jahre & 118 & 95,2 & 116 & 93,6 & 92 & 74,3 \\
\hline $\begin{array}{l}\text { Weiß } \\
\text { nicht }\end{array}$ & 2 & 1,6 & 2 & 1,6 & 2 & 1,6 \\
\hline $\begin{array}{l}\text { Keine } \\
\text { Angabe }\end{array}$ & 0 & 0,0 & 1 & 0,8 & 1 & 0,8 \\
\hline Insgesamt & 124 & 100,0 & 124 & 100,0 & 124 & 100,0 \\
\hline
\end{tabular}

Mehr als 90\% der Informanten nutzen die Internetdienste E-Mail und WWW seit mehr als drei Jahren. Auch Diskussionsforen werden von den Befragten mehrheitlich $(74,3 \%)$ seit mehr als drei Jahren frequentiert. Ein Informant gibt an, niemals Diskussionsforen zu nutzen. Da die Umfrage über ein Forum angekündigt wurde, ist davon auszugehen, dass die betreffende Person von einem Bekannten oder Arbeitskollegen auf den Fragebogen hingewiesen wurde.

Abb. 27: Internetnutzung der belgischen Informanten

\begin{tabular}{|c|c|c|c|c|c|c|}
\hline \multirow[b]{2}{*}{$\begin{array}{l}\text { Katego- } \\
\text { rie }\end{array}$} & \multicolumn{2}{|c|}{$\begin{array}{l}\text { Dauer der E- } \\
\text { Mail-Nutzung }\end{array}$} & \multicolumn{2}{|c|}{$\begin{array}{l}\text { Dauer der } W W W- \\
\text { Nutzung }\end{array}$} & \multicolumn{2}{|c|}{$\begin{array}{l}\text { Dauer der Nut- } \\
\text { zung von Diskus- } \\
\text { sionsforen }\end{array}$} \\
\hline & $\begin{array}{l}\text { Absolu- } \\
\text { te Häu- } \\
\text { figkeit }\end{array}$ & $\begin{array}{l}\text { Prozen- } \\
\text { tuale } \\
\text { Häufig- } \\
\text { keit }\end{array}$ & $\begin{array}{l}\text { Absolute } \\
\text { Häufig- } \\
\text { keit }\end{array}$ & $\begin{array}{l}\text { Prozen- } \\
\text { tuale } \\
\text { Häufig- } \\
\text { keit }\end{array}$ & $\begin{array}{l}\text { Absolu- } \\
\text { te Häu- } \\
\text { figkeit }\end{array}$ & $\begin{array}{l}\text { Prozen- } \\
\text { tuale } \\
\text { Häufig- } \\
\text { keit }\end{array}$ \\
\hline Gar keine & 0 & 0,0 & 0 & 0,0 & 0 & 0,0 \\
\hline$<1 \mathrm{Jahr}$ & 1 & 5,9 & 1 & 5,9 & 3 & 17,6 \\
\hline$<3$ Jahre & 1 & 5,9 & 2 & 11,8 & 3 & 17,6 \\
\hline$>3$ Jahre & 15 & 88,2 & 14 & 82,3 & 11 & 64,8 \\
\hline $\begin{array}{l}\text { Weiß } \\
\text { nicht }\end{array}$ & 0 & 0,0 & 0 & 0,0 & 0 & 0,0 \\
\hline $\begin{array}{l}\text { Keine } \\
\text { Angabe }\end{array}$ & 17 & 100,0 & 17 & 100,0 & 17 & 100,0 \\
\hline Insgesamt & 0 & 0,0 & 0 & 0,0 & 0 & 0,0 \\
\hline
\end{tabular}


Analog zur Situation der französischen Informanten geben auch mehr als 80\% der befragten Belgier an, E-Mail und das World Wide Web seit mehr als drei Jahren $\mathrm{zu}$ nutzen. Diskussionsforen werden von weniger Informanten, nämlich von 64,8\%, seit mehr als drei Jahren genutzt.

Abb. 28: Internetnutzung der schweizerischen Informanten

\begin{tabular}{|c|c|c|c|c|c|c|}
\hline \multirow[b]{2}{*}{$\begin{array}{l}\text { Katego- } \\
\text { rie }\end{array}$} & \multicolumn{2}{|c|}{$\begin{array}{l}\text { Dauer der E- } \\
\text { Mail-Nutzung }\end{array}$} & \multicolumn{2}{|c|}{$\begin{array}{l}\text { Dauer der } W W W- \\
\text { Nutzung }\end{array}$} & \multicolumn{2}{|c|}{$\begin{array}{l}\text { Dauer der Nut- } \\
\text { zung von Diskus- } \\
\text { sionsforen }\end{array}$} \\
\hline & $\begin{array}{l}\text { Absolu- } \\
\text { te Häu- } \\
\text { figkeit }\end{array}$ & $\begin{array}{l}\text { Prozen- } \\
\text { tuale } \\
\text { Häufig- } \\
\text { keit }\end{array}$ & $\begin{array}{l}\text { Absolute } \\
\text { Häufig- } \\
\text { keit }\end{array}$ & $\begin{array}{l}\text { Prozen- } \\
\text { tuale } \\
\text { Häufig- } \\
\text { keit }\end{array}$ & $\begin{array}{l}\text { Absolu- } \\
\text { te Häu- } \\
\text { figkeit }\end{array}$ & $\begin{array}{l}\text { Prozen- } \\
\text { tuale } \\
\text { Häufig- } \\
\text { keit }\end{array}$ \\
\hline Gar keine & 0 & 0,0 & 0 & 0,0 & 2 & 10,5 \\
\hline$<1 \mathrm{Jahr}$ & 0 & 0,0 & 0 & 0,0 & 0 & 0,0 \\
\hline$<3$ Jahre & 2 & 10,5 & 2 & 10,5 & 3 & 15,8 \\
\hline$>3$ Jahre & 17 & 89,5 & 17 & 89,5 & 14 & 73,7 \\
\hline $\begin{array}{l}\text { Weiß } \\
\text { nicht }\end{array}$ & 0 & 0,0 & 0 & 0,0 & 0 & 0,0 \\
\hline $\begin{array}{l}\text { Keine } \\
\text { Angabe }\end{array}$ & 19 & 100,0 & 19 & 100,0 & 19 & 100,0 \\
\hline Insgesamt & 0 & 0,0 & 0 & 0,0 & 2 & 10,5 \\
\hline
\end{tabular}

Fast 90\% der befragten Schweizer nutzen die Dienste E-Mail und WWW seit mehr als drei Jahren. Diskussionsforen werden von mehr als 70\% der schweizerischen Informanten seit mehr als drei Jahren genutzt. Zwei Informanten geben aber auch an, diesen Dienst niemals zu nutzen. In diesem Fall liegt es wie auch in dem oben genannten Fall nahe, dass die Informanten von Bekannten oder Kollegen über die Umfrage in Kenntnis gesetzt wurden.

Insgesamt nutzen 88-95\% aller Informanten seit mehr als drei Jahren den E-MailDienst und mehr als 82\% das World Wide Web. 64-74\% der Befragten nutzen seit mehr als drei Jahren die Diskussionsforen. Die meisten Internet-Fachtermini treten im Kontext des WWW auf. Im Falle dieser Umfrage stammen fünf der sechs Begriffe aus diesem Umfeld (bomepage, web, chat, cracker, (access) provider). Nur der Terminus e-mail bezeichnet den gleichnamigen Dienst und ist auch insofern ein Sonderfall, als die französischen Ersatzwörter zu engl. e-mail bereits Ende 1997 veröffentlicht wurden. Bezüglich der fünf im Kontext des WWW auftretenden Begriffe ist davon auszugehen, dass sie den $82-93 \%$ der Befragten, die diesen Dienst seit mehr als drei Jahren nutzen, bereits vor der Veröffentlichung der ersten Terminologielisten (in Frankreich März 1999, in Belgien und der Schweiz ein bis zwei Jahre später) vertraut waren. In diesen Fällen dürfte die offizielle Terminologie zu spät kommen, sofern sie nicht die französischen Termini für offiziell gültig erklärt, die ohnehin neben den englischen mehrheitlich benutzt wurden. 
Da in Bezug auf den E-Mail-Dienst und das World Wide Web nur wenige Informanten angeben diese weniger als drei Jahre zu nutzen (E-Mail: Franzosen: 3,2\%, Belgier: 11,8\%, Schweizer: 10,5\%; WWW: Franzosen: 4\%, Belgier: 17,7\%, Schweizer: $10,5 \%$, ist es nicht sinnvoll zu ermitteln, ob es signifikante Unterschiede in der Verwendung der Terminologie zwischen denjenigen Informanten gibt, die E-Mail und WWW seit mehr als drei Jahren, und denjenigen, die die beiden Dienste seit weniger als drei Jahren nutzen. Aufgrund des niedrigen Prozentsatzes an Informanten, die E-Mail und WWW erst seit vergleichsweise kurzer Zeit benutzen, würden derartige Vergleiche wenig aussagekräftig ausfallen.

\subsection{Zusammenfassung}

In 8.1 wurde zunächst erläutert, mit welcher Methodik und in welchen Diskussionsforen der WWW-Fragebogen zur Internet-Terminologie und Sprachpolitik angekündigt wurde. Die Bekanntmachung der Umfrage vollzog sich in drei Erhebungsphasen, die sich jeweils aus einer Ankündigung und einer späteren Erinnerung zusammensetzten. Die Ankündigung wurde an neun ausgewählte Diskussionsforen geschickt, die alle Gegenstände aus der Informatik oder das Internet thematisieren. Die neun Foren fr.comp.divers, fr.soc.internet, fr.comp.lang.|general, fr.misc.bavardages.linux, fr.comp.developpement, fr.comp.lang.perl, fr.comp.lang.java, fr.comp.lang.c ++ , fr.comp.lang.c wurden nach den Kriterien Gründungsdatum, Kurzbeschreibung der Diskussionsinhalte des Forums und ihrer Benutzerfrequenz für die Woche vom 26. Juli bis 01. August 2002 kurz charakterisiert. Das gewählte Ankündigungsverfahren steht insofern mit der sog. Netiquette im Einklang, als weitestgehend ausgeschlossen werden kann, dass eine Person die Ankündigung mehrmals in verschiedenen Foren gelesen hat.

Der Rücklauf an vollständig ausgefüllten Fragebögen belief sich nach Abschluss der Erhebungsphase, die von Juli bis Ende August 2002 dauerte, auf 165. Von diesen vollständig ausgefüllten Fragebögen mussten fünf ausgeschlossen werden, da die Informanten nicht der gewünschten Zielgruppe entsprachen. In die Auswertung (Kap. 9-12) sowie in die Vorstellung der Informanten nach ihren biosozialen Daten fließen die Angaben von 124 französischen, 17 belgischen und 19 schweizerischen Informatikern ein.

8.2 gibt einen Überblick über die biosozialen Daten der Informanten. Bei der Auswertung der 160 Fragebögen wurden die Kriterien Geschlecht, Alter, Beruf/Ausbildung, höchster Bildungsabschluss, Geburtsort, Muttersprache(n), Wohnsitz, Englischkenntnisse sowie Art und Dauer der Internetnutzung berücksichtigt. Die Verteilung innerhalb der einzelnen Kategorien war jedoch bezüglich des Geschlechtes, des höchsten Bildungsabschlusses, der Englischkenntnisse und der Art und Dauer der Internetnutzung so ungleich, dass sich eine Auswertung der in 5.3.2 in Bezug auf diese Kriterien formulierten Hypothesen (Korrelationen) nicht als sinnvoll erweist. Anhand der Kriterien Beruf/Ausbildung und Muttersprache(n) konnte weitestgehend sichergestellt werden, dass die Informanten der für diese Untersuchung festgelegten Zielgruppe entsprechen. 


\section{Auswertung der WWW-Befragung: Frankreich}

In diesem Kapitel werden die Daten der 124 französischen Informatiker ausgewertet, die an der Befragung teilgenommen und den Fragebogen vollständig ausgefüllt haben.

Wie bereits in Kapitel 6.3.1 ausgeführt, können WWW-Umfragen nicht den Anforderungen an repräsentative wissenschaftliche Studien genügen, wenn keine aktive Teilnehmerrekrutierung erfolgt. Aus drei Gründen ist es problematisch, die in diesem Kapitel dargestellten Ergebnisse auf alle französischen Informatiker zu übertragen: 1. aufgrund der passiven und somit nicht repräsentativen Teilnehmerrekrutierung, 2. aufgrund der für Online-Befragungen typischen hohen Selbstselektivität und 3. weil über die Ankündigung des Fragebogens in neun ausgewählten Diskussionsforen zu den Bereichen Informatik und Internet nicht alle in Frankreich tätigen Informatiker erreicht werden können, sondern nur diejenigen, die in diesen Foren aktiv sind. Die Interpretationsmöglichkeiten der Forschungsergebnisse sind somit durch Mängel im Auswahlverfahren eingeschränkt (vgl. ADM et al. 2001, Kap. E; 6.3.1). Aus den Fragebögen lassen sich jedoch Tendenzen zum Etablierungsgrad der ausgewählten Internet-Termini sowie zur Einstellung französischer Informatiker gegenüber der aktuellen französischen Sprachpolitik ableiten.

Bei der Auswertung wird der Chronologie des Fragebogens gefolgt. Zunächst wird in 9.1 das erste Fragebogenmodul ausgewertet, d.h. alle Fragen, die sich auf die sechs ausgewählten Lexemgruppen beziehen. Anschließend werden in 9.2 Fragen zur Kenntnis und Akzeptanz der französischen Sprachpolitik und Terminologiearbeit sowie zur Internet-Terminologie ausgewertet und mit den beiden in 5.3.3.1 formulierten Hypothesen verglichen. In 9.3 schließlich geht es um die Evaluation der frei formulierten Kommentare, für die am Ende der Befragung im 
dritten Fragebogenmodul ein entsprechendes Textfeld vorgesehen war. AbschlieBend werden zur Klärung der in 5.3.2 formulierten Hypothesen in Abschnitt 9.4 die biosozialen Daten aus dem dritten Fragebogenmodul mit den Daten aus dem ersten und zweiten Fragebogenteil korreliert, soweit dies möglich ist und sinnvoll erscheint ${ }^{1}$.

\subsection{Erstes Fragebogenmodul: Auswertung der sechs aus- gewählten Lexemgruppen}

In den sechs Abschnitten 9.1.1 bis 9.1.6 werden alle Fragen ausgewertet, die sich mit der Bekanntheit, Synonymie, Präferenz, dem Gebrauch und der Bewertung der französischen Neologismen bzw. mit den Gründen für die Bevorzugung der englischsprachigen Termini befassen (Fragen 1-42). Dabei wird für die Antworten auf die quantitativ ausgerichteten Fragen jeweils der Mittelwert (arithmetisches Mittel) errechnet. Fragen, auf die von den Informanten eine Antwort frei formuliert wurde, wurden durch Kategorienbildung ausgewertet. Dies betrifft die Fragen nach dem Bedeutungsunterschied zwischen den Lexemen. In die Auswertung der Lexemgruppen fließen auch die in 5.3.1 genannten Arbeitshypothesen ein.

\subsubsection{Die Termini courrier électronique, message électronique, mél, courriel, messagerie électronique, lettre électronique, e-mail und mail}

Die ersten sieben Fragen des ersten Fragebogenmoduls widmen sich engl. e-mail bzw. mail und den französischsprachigen Äquivalenten.

Mit der ersten Frage soll ermittelt werden, wie hoch der Bekanntheitsgrad der acht Lexeme (inkl. des Testwortes lettre électronique) ist. Bei dieser Frage waren beliebig viele Nennungen möglich. Für die Auswertung sind zwei Abbildungen vorgesehen. In der ersten Abbildung werden die absoluten Werte (= Anzahl der Nennungen) angegeben. Der Maximalwert, den ein Terminus erreichen kann, ist 124. Dies entspricht der Anzahl der französischen Informatiker, deren Fragebögen in die Evaluation eingegangen sind. In der zweiten Abbildung wird die Anzahl der Nennungen pro Terminus in Prozent angegeben. Jeder Terminus kann maximal 100 Prozent erreichen. Außerdem sind die acht Termini in der zweiten Abbildung nach der Häufigkeit der Nennungen geordnet. Die Umrechnung der Anzahl der Nennungen in Prozent ermöglicht in Kapitel 12 einen Vergleich des Bekanntheitsgrades der Termini zwischen den drei Untersuchungsländern².

\footnotetext{
1 Aufgrund der Fülle an Daten wird im Rahmen der Auswertung insbesondere im Bereich der Korrelationen gekürzt. Viele der theoretisch möglichen Korrelationen erweisen sich im Rahmen der hier erhobenen Daten als wenig sinnvoll (vgl. 8.2).

2 Die Abkürzung von électronique als él. im Diagramm ist nötig, um die Beschriftung der einzelnen Balken lesbar zu gestalten. Leider täuscht die Balkenlänge im Diagramm: Die Balken wirken etwas kürzer, als sie sein müssten. Dies ist ein durch das Programm MS Excel bedingter Fehler.
} 
Abb. 29: Frage 1, Bekanntheitsgrad der Termini courrier électronique, message électronique, mél, courriel, messagerie électronique, lettre électronique, e-mail und mail (absolute Häufigkeit, Frankreich)

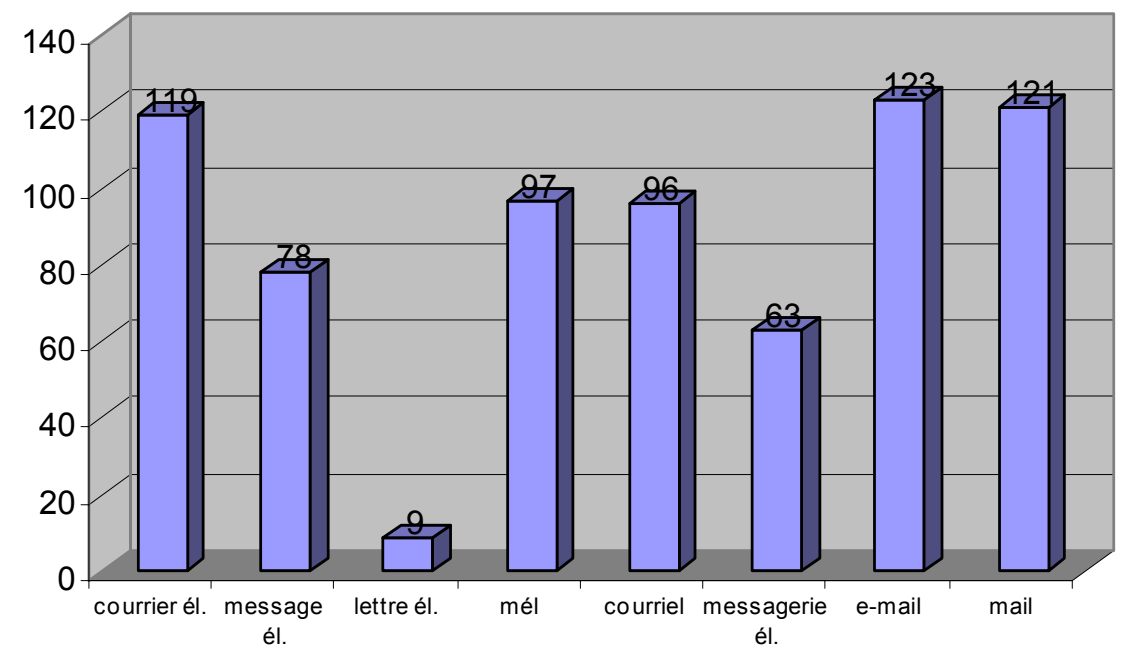

Abb. 30: Frage 1, Bekanntheitsgrad der Termini courrier électronique, message électronique, mél, courriel, messagerie électronique, lettre électronique, e-mail und mail (prozentuale Häufigkeit, Frankreich)

\begin{tabular}{|l|r|}
\hline Termini & $\mathbf{\%}$ \\
\hline E-mail & 99,2 \\
\hline Mail & 97,6 \\
\hline Courrier électronique & 96,0 \\
\hline Mél & 78,2 \\
\hline Courriel & 77,4 \\
\hline Message électronique & 63,0 \\
\hline Messagerie électronique & 50,8 \\
\hline Lettre électronique & 7,3 \\
\hline
\end{tabular}

Von allen aufgeführten Termini sind die beiden englischsprachigen die bekanntesten. 99,2 bzw. 97,6\% der Befragten kennen e-mail bzw. mail. Von den französischsprachigen Termini wird courrier électronique von $96 \%$ der Informanten als bekannt angegeben. Mél, das gemäß der offiziellen Terminologieliste nur in Briefköpfen u. Ä. verwendet werden soll, kennen 78,2\%. Immerhin noch 50,8\% kennen messagerie électronique. Das Testwort lettre électronique wird erwartungsgemäß nur von sehr wenigen Informanten (7,3\%) als bekannt angegeben.

Um die in Abb. 30 aufgeführten Werte in allgemeinere Kategorien einordnen zu können, bietet sich ein Blick in vergleichbare Studien an. Gasquet/Villebrun 
(1994, 117) unterteilen den Etablierungs- bzw. den Bekanntheitsgrad in vier Kategorien:

1. Termini, die $100 \%$ der Befragten bekannt sind,

2. Termini, die $80-100 \%$ der Befragten bekannt sind,

3. Termini, die $50-80 \%$ der Befragten bekannt sind, und

4. Termini, die weniger als 50\% der Befragten bekannt sind.

Entsprechend gelten Termini als sicher etabliert, die von mehr als 80\% der Befragten als bekannt eingestuft werden, Termini als unsicher bzw. mehr oder weniger etabliert, die von 50-80\% der Befragten als bekannt eingestuft werden, und Termini als schwach bzw. kaum etabliert, die von weniger als 50\% der Befragten gekannt werden. Bezogen auf die Termini e-mail, mail, courrier électronique, mél, courriel, message électronique und messagerie électronique bedeutet dies, dass e-mail, mail und courrier électronique als sicher etabliert gelten können. Die restlichen vier Termini gelten als mehr oder weniger etabliert, wobei mél und courriel als nahezu etabliert betrachtet werden können, während dies insbesondere für messagerie électronique fraglich ist.

Bei der Frage, ob die angegebenen Termini (mit Ausnahme des Testwortes) synonym seien, ergibt sich folgendes Bild:

Abb. 31: Frage 2, Synonymie der Termini courrier électronique, message électronique, mél, courriel, messagerie électronique, e-mail und mail (Frankreich)

\begin{tabular}{|l|r|r|}
\hline & $\begin{array}{l}\text { Absolute } \\
\text { Häufigkeit }\end{array}$ & $\begin{array}{l}\text { Prozentuale } \\
\text { Häufigkeit }\end{array}$ \\
\hline Synonym & 61 & 49,2 \\
\hline $\begin{array}{l}\text { Bedeutungs- } \\
\text { unterschied }\end{array}$ & 63 & 50,8 \\
\hline Insgesamt & 124 & 100,0 \\
\hline
\end{tabular}

Die Frage nach der Synonymie fällt nahezu unentschieden aus. 61 Informanten $(49,2 \%)$ sind der Meinung, die Termini seien synonym, 63 Informanten (50,8\%) stellen einen Bedeutungsunterschied fest. Nur wer einen Bedeutungsunterschied feststellte, wurde zur anschließenden dritten Frage weitergeleitet, in der die Informanten gebeten wurden, den Bedeutungsunterschied zu erläutern. Wer die Termini als synonym einschätzte bzw. sich für die Kategorie ,Je ne connais pas tous les mots./Je ne sais pas." entschied, die in diesem Fall von niemandem gewählte wurde, wurde direkt zur vierten Frage weitergeleitet (Filter).

Von den 63 Informanten, die einen Bedeutungsunterschied feststellen, füllten 60 das leere Textfeld der nachfolgenden Frage aus, bei der sie um eine Begründung ihrer Meinung gebeten wurden. Die 60 frei formulierten Begründungen wurden inhaltlich klassifiziert und zu insgesamt 13 Kategorien zusammengefasst. In der folgenden Tabelle werden die einzelnen Kategorien in der Häufigkeit ihrer Nennungen aufgeführt. Bei gleicher Anzahl an Nennungen werden die Kategorien alphabetisch geordnet. Die Kategorien befinden sich in der linken Spalte. In der mittleren Spalte befinden sich Kombinationen aus Buchstaben und Zahlen, die die 
jeweiligen Informanten bezeichnen, deren Textantworten dieser Kategorie zugeordnet wurden. Manche Antworten konnten auch mehreren Kategorien zugeordnet werden. Die genaue Auflistung der Informanten dient der besseren Nachvollziehbarkeit der Zuordnung zu den jeweiligen Kategorien. Die Textantworten der Informanten können im Anhang 15.5.1.1.1 nachgelesen werden.

Abb. 32: Frage 3, Bedeutungsunterschiede zwischen courrier électronique, message électronique, mél, courriel, messagerie électronique, e-mail und mail (Frankreich)

\section{Kategorie}

Bedeutungsunterschied zwischen messagerie électronique und den anderen Termini (message électronique, courrier électronique, courriel, mél, e-mail und mail: messagerie électronique ist das System (wie MS Outlook oder Netscape Messenger), die anderen Termini sind die einzelnen Nachrichten, die über das System übermittelt werden.
Message électronique ist allgemeiner als die anderen Termini (courrier électronique, courriel, mél, e-mail, mail) und bezieht sich auf jede Form von elektronisch übermittelten Nachrichten (z.B. auch Nachrichten im Usenet oder Chatraum).

Bedeutungsunterschied zwischen messagerie électronique und den anderen Termini (message électronique, courrier électronique, courriel, mél, e-mail und mail): ohne weitere Spezifizierung.

Unterschied zwischen e-mail und mail. Ersteres bezeichnet die elektronische Post, Letzteres die normale (Brief-)Post.

Bezug auf lettre électronique ${ }^{3}$.

E-mail und mail geben die E-Mail-

\section{Informanten}

F1.1, F1.2, F1.3, F1.4,

F1.5, F1.6, F1.7, F1.8,

F1.9, F1.10, F1.13, F1.14,

F1.15, F1.16, F1.17,

F1.18, F1.19, F1.21,

F1.23, F1.24, F1.25,

F1.26, F1.32, F1.33,

F1.34, F1.35, F1.36,

F1.37, F1.38, F1.39,

F1.40, F1.41, F1.43,

F1.44, F1.45, F1.46,

F1.47, F1.48, F1.50,

F1.51, F1.52, F1.57,

F1.58, F1.59

F1.8, F1.12, F1.20, F1.22,

F1.26, F1.28, F1.29
Anzahl

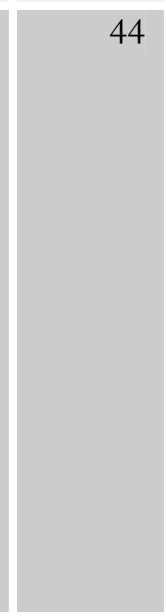

7

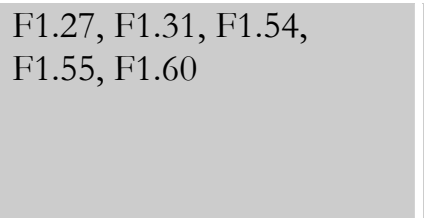

F1.11, F1.22, F1.23,

4

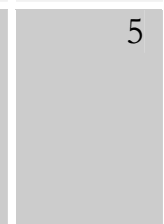

F1.49

F1.2

F1.56 
Adresse an.

\begin{tabular}{l|l|l|}
$\begin{array}{l}\text { Einige der Termini haben keine Bedeu- } \\
\text { tung. }\end{array}$ & F1.3 & 1 \\
\hline $\begin{array}{l}\text { Mél darf nicht zur Bezeichnung einer } \\
\text { Nachricht verwendet werden. Es darf } \\
\text { nur in einem Text verwendet werden, } \\
\text { um die E-Mail-Adresse einer Person } \\
\text { anzugeben. }\end{array}$ & F1.46 & 1 \\
\hline $\begin{array}{l}\text { Mél und courriel werden mehr und mehr } \\
\text { in Zeitschriften verwendet, so dass sich } \\
\text { ihr Gebrauch langsam etabliert. }\end{array}$ & F1.50 & 1 \\
\hline $\begin{array}{l}\text { Messagerie électronique bezeichnet die Ge- } \\
\text { samtheit der messages électroniques, courriers } \\
\text { électroniques, courriels, méls, e-mails und } \\
\text { mails. }\end{array}$ & F1.42 & 1 \\
\hline $\begin{array}{l}\text { Messagerie électronique ist inhaltlich weiter } \\
\text { als courrier électronique. }\end{array}$ & F1.53 & 1 \\
\hline $\begin{array}{l}\text { Message électronique und messagerie électro- } \\
\text { nique beziehen sich auf firmeninterne }\end{array}$ & F1.30 & 1 \\
\hline $\begin{array}{l}\text { Netze (Intranet). } \\
\text { Unterschiedlicher Artikel: un courrier } \\
\text { électronique vs. une messagerie électronique. }\end{array}$ & F1.9 & 1 \\
\hline
\end{tabular}

Die meisten Informanten weisen auf einen Bedeutungsunterschied zwischen messagerie électronique und den übrigen Termini hin. Messagerie électronique wird als das System oder Programm verstanden, mit dem elektronische Nachrichten empfangen und versendet werden. Alle übrigen Termini bezeichnen nach Auffassung der 44 Informanten, die dieser Kategorie zuzuordnen sind, die Nachrichten selbst. Insgesamt stellen 51 Informanten einen Bedeutungsunterschied fest zwischen courrier électronique, message électronique, mél, courriel, e-mail, mail einerseits und messagerie électronique andererseits ${ }^{4}$.

Sieben Informanten weisen darauf hin, dass message électronique weiter gefasst sei als die anderen Termini. Message électronique sei der Oberbegriff zur Bezeichnung jeder Form von elektronischen Nachrichten. Unter diesen Terminus fallen nach Meinung der Informanten auch elektronische Nachrichten, die nicht mit einem EMail-Programm versendet werden.

In 4.3.1 wurde erwähnt, dass sich die weite Verbreitung der englischen Termini auch darauf zurückführen lässt, dass gerade Nicht-Muttersprachler den englischen

\footnotetext{
${ }^{4}$ Die Unterscheidung zwischen messagerie électronique und message électronique gibt es nicht nur im Rahmen des Internet. Bereits bei dem älteren französischen System Minitel wurde zwischen messagerie und message unterschieden (vgl. z.B. Anis 1998, 115-120). Daher dürfte vielen Informanten die Unterscheidung zwischen dem System, das die Nachrichtenübermittlung erlaubt, und den Nachrichten selbst weder neu noch erst mit der Verbreitung des Internet bekannt geworden sein.
} 
Termini automatisch Monosemie unterstellen. Mitunter erhält der Anglizismus im Zuge seiner Entlehnung auch eine andere Bedeutung oder wird in seiner Bedeutungsvielfalt reduziert. Der Grund für diese Fehleinschätzung bzw. für die Bedeutungsänderung des englischsprachigen Terminus liegt auf der Hand: Es sind zumeist die mangelhaften Englischkenntnisse der Sprecher. Die Englischkenntnisse der hier befragten Informatiker sind jedoch überdurchschnittlich gut. Dafür spricht nicht nur die Selbsteinschätzung (vgl. 8.2.8), sondern auch, dass von vier Informanten auf den zwischen engl. e-mail und engl. mail bestehenden Bedeutungsunterschied hingewiesen wird ${ }^{5}$.

Ein Informant weist explizit auf die nach dem offiziellen Erlass vom Dezember 1997 einzig korrekte Verwendungsform des Kurzwortes mél hin. Wie verhält es sich mit den Definitionen der Termini, wie sie im Erlass vom 02. Dezember 1997 festgehalten sind? Den Definitionen der Terminologieliste zufolge beziehen sich sowohl courrier électronique als auch messagerie électronique auf das System bzw. E-MailProgramm. Die einzig gültige Bezeichnung für die E-Mail (als Nachricht) ist message électronique. Mél sollte nur als Symbol z.B. in Briefköpfen verwendet werden (vgl. ausführlicher 5.2.1). Courriel ist kein in Frankreich offiziell zugelassener Terminus, sondern eine geografische Variante, nämlich die in Québec offizielle französische Bezeichnung für engl. e-mail. Courriel ist auch im Rahmen der belgischen Informatik-Terminologie neben den französischen Termini courrier électronique und messagerie électronique als Synonym für engl. e-mail angegeben.

Es ist auffällig, dass sich die offiziellen Definitionen nur teilweise mit den Definitionen decken, die die befragten Informatiker den einzelnen Termini zuweisen.

Bei der vierten Frage geht es um die persönlichen Präferenzen der Informanten. Bei dieser Frage konnten bis zu zwei Termini ausgewählt werden. Die Antworten werden zunächst in absoluter Häufigkeit dargestellt, d.h. mit der Anzahl ihrer Nennungen. Hier sind wiederum 124 Stimmen das Maximum, das ein Terminus erreichen kann. Die zweite Abbildung zeigt die Termini in prozentualer Häufigkeit und nach ihrer Bekanntheit geordnet.

\footnotetext{
${ }^{5}$ Der Terminus mail steht nicht in der offiziellen Terminologie, sondern wurde im Zuge des Pretests auf mehrfachen Teilnehmerwunsch hinzugefügt. Die Anglizismen e-mail und engl. mail werden nicht nur im französischsprachigen Raum - häufig als Synonyme betrachtet, obwohl sie dies eigentlich nicht sind. Mail ist die allgemeine Bezeichnung für Post (auch Briefpost), während e-mail die elektronische Post bezeichnet.
} 
Abb. 33: Frage 4, persönliche Präferenz(en): courrier électronique etc. (absoute Häufigkeit, Frankreich)

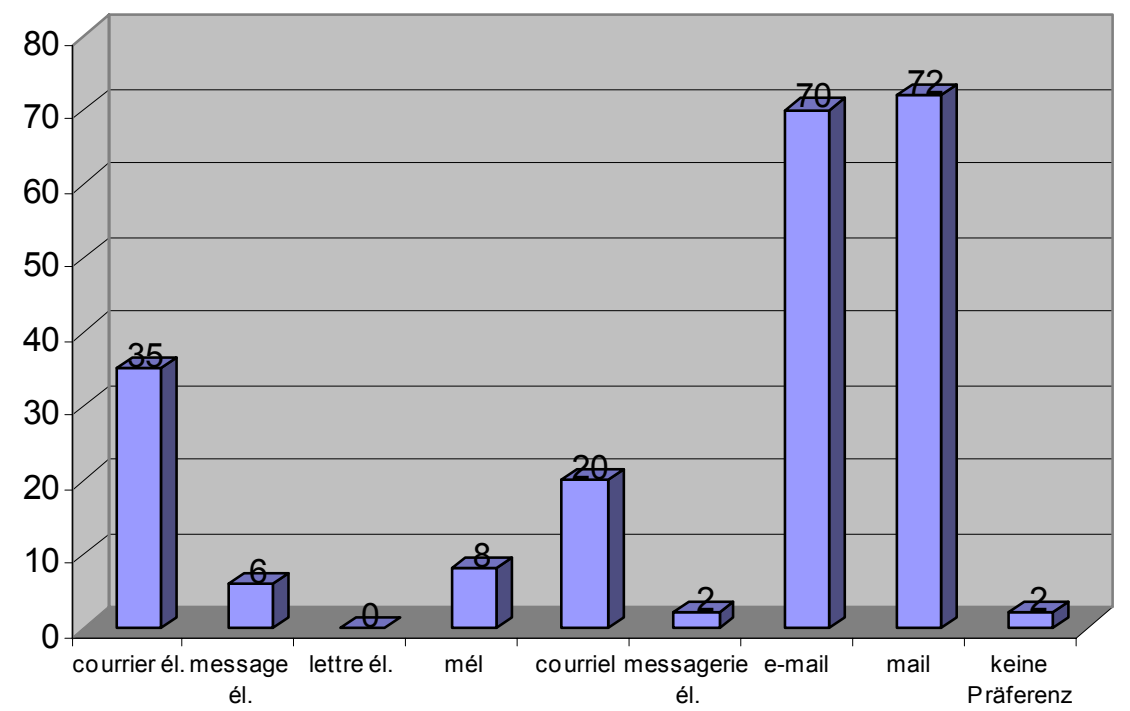

Abb. 34: Frage 4, persönliche Präferenz(en): courrier électronique etc. (prozentuale Häufigkeit, Frankreich)

\begin{tabular}{|l|r|}
\hline Termini & $\mathbf{0}$ \\
\hline Mail & 58,0 \\
\hline E-mail & 56,5 \\
\hline Courrier électronique & 28,2 \\
\hline Courriel & 16,1 \\
\hline Mél & 6,5 \\
\hline Message électronique & 4,8 \\
\hline Messagerie électronique & 1,6 \\
\hline Lettre électronique & 0,0 \\
\hline Keine Präferenz & 1,6 \\
\hline
\end{tabular}

Die beiden Abbildungen zeigen, dass die Anglizismen mail und e-mail, die auch den höchsten Bekanntheitsgrad aufweisen (vgl. Frage 1), mit 58\% und 56,5\% vorn liegen. Courrier électronique, das von 96\% der Informanten in der ersten Frage als bekannt angegeben wurde und damit fast ebenso bekannt ist wie die beiden Anglizismen, wird jedoch nur von 28,2\% der Informanten als persönliche Präferenz angegeben. An vierter Position folgt courriel, das immerhin noch von 16,1\% der Befragten als Präferenz genannt wird. Unter 10\% liegen die Termini mél, message électronique, messagerie électronique. Das Testwort lettre électronique wird von niemandem als Präferenz angegeben. 
Mit der nächsten, fünften Frage wird der persönliche Sprachgebrauch ermittelt. Die Darstellung der Ergebnisse erfolgt aufgrund der Vielzahl der gewählten Antwortoptionen in tabellarischer Form, weil eine Grafik in Form eines Kreisdiagramms in diesem Falle zu unübersichtlich wäre. Die Antwortoptionen sind in der Häufigkeit ihrer Nennung angeordnet.

Abb. 35: Frage 5, eigener Sprachgebrauch: courrier électronique etc. (Frankreich)

\begin{tabular}{|l|r|r|}
\hline Meistens mail & $\begin{array}{c}\text { Absolute } \\
\text { Häufigkeit }\end{array}$ & $\begin{array}{l}\text { Prozentuale } \\
\text { Häufigkeit }\end{array}$ \\
\hline Meistens e-mail & 47 & 37,9 \\
\hline Immer mail & 27 & 21,8 \\
\hline Immer e-mail & 21 & 16,9 \\
\hline Meistens courrier électronique & 10 & 8,1 \\
\hline Meistens mél & 5 & 4,0 \\
\hline Meistens message électronique & 3 & 2,4 \\
\hline Meistens courriel & 2 & 1,6 \\
\hline Je nach Kontext & 1 & 0,8 \\
\hline Insgesamt & 8 & 6,5 \\
\hline
\end{tabular}

Anders als bei der Einteilung von Gasquet/Villebrun (1994, 117), deren Kategorien sich auf den Bekanntheitsgrad beziehen, werden in der Studie Thoirons zur Fernerkundung des Luftraums drei Klassen gebildet, die sich auf die Gebrauchsfrequenz beziehen:

Klasse A: Gebrauchsfrequenz von mehr als 70\% - gute Etablierung, Klasse B: Gebrauchsfrequenz von 70-30\% - mittlere Etablierung und Klasse C: Gebrauchsfrequenz unter 30\% - schwacher Gebrauch/Termini in Gefahr, sich nicht zu etablieren (vgl. Rouges-Martinez 1992, 125f.; 4.3.1).

Dieser Einteilung zufolge kann nur mail mit einer Gebrauchsfrequenz von fast $55 \%$ bezüglich seines häufigen bzw. ausschließlichen Gebrauchs als mittelmäßig etabliert gelten, alle anderen Termini als schwach etabliert. 29,9\% der Informanten geben an, meistens oder immer e-mail zu verwenden. Damit steht dieser Terminus bezüglich seiner Verwendung auf der Schwelle zwischen schwacher und mittlerer Etablierung ${ }^{6}$.

Der Hypothese I.7 in 5.3.1 zufolge muss die persönliche Präferenz nicht zwangsläufig mit dem aktiven Sprachgebrauch übereinstimmen. Um dieser Hypothese

\footnotetext{
${ }^{6}$ Einschränkend zu der Übertragung des von Thoiron aufgestellten Schemas auf die InternetAnglizismen ist anzumerken, dass die Aussage der Informanten, einen der Termini meistens zu verwenden, die Verwendung der anderen Termini nicht automatisch ausschließt. Die Mehrheit der Informanten hat angegeben, einen der aufgeführten Termini mehrheitlich zu verwenden, was die Verwendung der anderen Termini und damit deren Etablierung nicht ausschließt. Um das Schema optimal auf die Internet-Anglizismen übertragen zu können, müsste für jeden Internet-Terminus einzeln gefragt werden, ob er von den Informanten verwendet wird oder nicht.
} 
nachzugehen, bietet sich der Vergleich zwischen den Antworten auf die Frage 4 nach der persönlichen Präferenz und den Antworten auf die Frage 5 nach dem eigenen Sprachgebrauch an.

Bezüglich der persönlichen Präferenzen erhält mail 58\% Zustimmung, e-mail 56,5\% . 28,2\% geben als eine von zwei möglichen persönlichen Präferenzen courrier électronique an. Bei der eigenen Sprachverwendung liegt mail mit 54,8\% nur ganz knapp (3,2\%) unter dem für die persönliche Präferenz angegebenen Prozentsatz. Mit einer Differenz von 26,7\% ist der Abstand zwischen der Präferenz und der Verwendung des Terminus e-mail erheblich größer, als dies bezüglich mail der Fall ist. Courrier électronique bleibt sowohl im Hinblick auf die persönliche Präferenz als auch bezüglich des Sprachgebrauchs, der aktiven Akzeptanz, an dritter Stelle. Jedoch geben nur 4\% der Informanten an, diesen Terminus meistens zu verwenden. Damit liegt der Wert für die aktive Akzeptanz um 24,2\% unter der persönlichen Präferenz (28,2\%). Die Prozentzahlen für e-mail und courrier électronique zeigen, dass der Prozentsatz für die Präferenz eines Terminus über der aktiven Akzeptanz liegt. Das liegt zum einen daran, dass bei der Präferenz bis zu zwei Nennungen möglich waren, während bezüglich der aktiven Akzeptanz nur eine einzige Antwort möglich war. Zum anderen lässt das Ergebnis darauf schließen, dass Sprachbenutzer mehr als einen Terminus kennen und auch bevorzugen. Dafür spricht auch, dass die Mehrheit der Befragten angegeben hat, meistens mail oder $e$ mail zu verwenden. Diese Antwort lässt die Verwendung anderer Termini zu. Dieser Punkt wurde im Fragebogen nicht weiter vertieft, da es wohl nur wenigen Sprechern möglich sein dürfte, noch präzisere Angaben zum eigenen Sprachgebrauch zu machen.

Es bleibt festzuhalten, dass sehr viele der angegebenen Termini bekannt sind, allen voran engl. e-mail, engl. mail und franz. courrier électronique. Bezüglich der eigenen Vorlieben und des eigenen Sprachgebrauchs bleibt diese Reihenfolge auch erhalten, jedoch wird - auch aufgrund der immer eingeschränkteren Anzahl an möglichen Antworten von unbegrenzter Anzahl (Frage 1), auf zwei Antworten (Frage 4), auf eine Antwort (Frage 5) - immer mehr zu Gunsten der englischen Termini entschieden.

Die Ergebnisse bestätigen die bereits 1998 von Saluden et al. geäußerte Vermutung:

„La Commission générale de terminologie et de néologie a choisi l'expression 'messagerie électronique'. C'est donc l'appellation française officielle. L'abréviation recommandée est Mél. (avec un point). Néanmoins, un grand nombre de personnes ont déjà l'habitude de dire mail ou email, courrier électronique, etc. Il est probable que l'introduction du terme arrive un peu tard [...]“ (Saluden et al. 1998, 141).

sowie die in 5.3.1 formulierte Hypothese I.2:

Die Termini e-mail und mail werden aufgrund ihrer Kürze häufiger verwendet als message électronique, messagerie électronique oder courrier 
électronique. Mél wird aufgrund der pseudoenglischen Aussprache sicherlich seltener verwendet als die beiden englischen Termini.

Die englischen Termini werden von insgesamt 85\% der Informanten meistens oder immer verwendet. Nur 2,5\% der Informanten geben an, meistens mél zu verwenden.

Insbesondere Linguisten plädieren für die Verwendung von courriel. Beispielsweise spricht sich Yaguello (1998, 140; vgl. 5.2.3.2) gegen courrier électronique oder mél und für courriel aus. Ihrer Annahme, dass courriel der auch in Frankreich am weitesten verbreitete Terminus sei, kann aufgrund der hier dargestellten Ergebnisse vorsichtig widersprochen werden 7 : courriel ist zwar 77,4\% der Informanten bekannt und $16,1 \%$ geben es als ihre persönliche Präferenz an, jedoch wird courriel von nur von $0,8 \%$ der Informanten meistens verwendet. Ähnlich wie Yaguello urteilt auch Burr (2000, 125f.). Sie zeigt auf, in welcher Form engl. e-mail als Lehnprägung in andere europäische Sprachen (Dänisch, Finnisch, Italienisch, Niederländisch, Polnisch, Schwedisch und Spanisch) Eingang gefunden hat. Sie bescheinigt der französischen Sprachpolitik insbesondere deshalb einen nationalen Alleingang, weil sie andere Termini ausgewählt habe als courriel, das sich bereits etabliert habe.

Nur elf der insgesamt 124 Informanten (8,8\%) haben angegeben meistens einen der französischen Termini courrier électronique (fünf Informanten), mél (drei Informanten), message électronique (zwei Informanten) und courriel (ein Informant) zu verwenden. Aufgrund dieser geringen Quote, die sich zudem auf verschiedene französische Termini bezieht, entfällt die Auswertung der sechsten Frage, in der es darum geht, wie die französischen Termini bewertet werden. Daher wird direkt zur Auswertung der siebten Frage übergegangen, in der nach den Gründen für die Bevorzugung der englischsprachigen Termini mail und e-mail gefragt wurde.

Bei dieser Frage wurden insgesamt 16 Antwortmöglichkeiten sowie die Option „weiß nicht“ und ein Textfeld für eine andere, von den Vorschlägen abweichende Antworten angeboten. Es war möglich, bei dieser Frage so viele Antwortoptionen auszuwählen, wie als zutreffend erachtet wurden. Die gewählten Antwortoptionen werden in der nachfolgenden Tabelle in der Reihenfolge ihrer Nennungen aufgeführt. Die frei formulierten Antworten werden in der Tabelle als unterste Kategorie aufgeführt. Sie sind orthografisch an die Standardsprache angepasst worden, da im Rahmen dieser Studie der Inhalt der Antworten und nicht etwa sprachliche Besonderheiten im Vordergrund stehen soll. Haben zwei oder mehr Antwortoptionen die gleiche Anzahl an Stimmen erhalten, werden sie in einem Kasten aufgeführt. Dies ist in der folgenden Tabelle zum Beispiel für die beiden Antworten der Fall, die an neunter Stelle genannt wurden.

\footnotetext{
${ }^{7}$ Vorsichtig deshalb, weil nur Informatiker befragt wurden, nicht aber Personen aus verschiedenen Bevölkerungsschichten und Berufsgruppen. Es kann nicht mit Sicherheit davon ausgegangen werden, dass sich die von den Informatikern bezüglich des Bekanntheitsgrades und des eigenen Sprachgebrauchs gemachten Angaben auf die gesamte französische Bevölkerung übertragen lassen. Die unter den befragten Informatikern am weitesten verbreiteten Termini müssen nicht auch automatisch diejenigen Termini sein, die in der gesamten Bevölkerung am bekannten sind.
} 


\section{Abb. 36: Frage 7, Gründe für die Bevorzugung der englischsprachigen Termini e- mail und mail (Frankreich)}

\begin{tabular}{|c|c|c|c|}
\hline Nr. & Begründung & $\begin{array}{l}\text { Absolute } \\
\text { Häufigkeit }\end{array}$ & $\begin{array}{l}\text { Prozentuale } \\
\text { Häufigkeit }\end{array}$ \\
\hline 1 & Le terme anglais est plus bref. & 55 & 52,4 \\
\hline 2 & Je me suis déjà habitué(e) à utiliser le terme anglais. & 54 & 51,4 \\
\hline 3 & En utilisant le terme anglais, je suis sûr(e) d'être compris(e). & 48 & 45,7 \\
\hline 4 & Presque tout le monde utilise le terme anglais. & 45 & 42,9 \\
\hline 5 & Le terme anglais est plus international. & 38 & 36,2 \\
\hline 6 & Les termes français ne sont pas assez connus. & 21 & 20,0 \\
\hline 7 & Les formulations des termes français sont trop compliquées. & 11 & 10,5 \\
\hline 8 & $\begin{array}{l}\text { Les connotations des termes français ne correspondent pas } \\
\text { aux connotations qui sont liées au terme anglais. }\end{array}$ & 10 & 9,5 \\
\hline 9 & $\begin{array}{l}\text { - Il y a trop d'équivalents français pour un seul terme } \\
\text { anglais. } \\
\text { - La signification des termes français n'est pas claire. }\end{array}$ & 8 & 7,6 \\
\hline 10 & Je n'aime pas suivre les propositions officielles. & 7 & 6,7 \\
\hline 11 & $\begin{array}{l}\text { La signification des termes français ne correspond pas à celle } \\
\text { du terme anglais. }\end{array}$ & 5 & 4,8 \\
\hline 12 & $\begin{array}{l}\text { - Je ne connais pas les termes français. } \\
\text { - Les termes français ne sont pas assez proches du terme } \\
\text { anglais. }\end{array}$ & $\begin{array}{l}3 \\
3\end{array}$ & $\begin{array}{l}2,9 \\
2,9\end{array}$ \\
\hline 13 & $\begin{array}{l}\text { Il n'est pas possible de créer des termes dérivés (du type: } \\
\text { logiciel, progiciel, ludiciel). }\end{array}$ & 1 & 0,8 \\
\hline 14 & $\begin{array}{l}\text { Autre : } \\
\text { - Courriel sonne mal à l'oreille, et mél, c'est moche visuelle- } \\
\text { - } \quad \text { Estht. C'est du mêtique déplorable (mé) } \text {. } \\
\text { - } \quad \text { Je travaille dans un environnement très international } \\
\text { dans lequel j’utilise } 4 \text { langues différentes pour communi- } \\
\text { quer. E-mail est le terme le plus commun à ces } 4 \text { langues } \\
\text { et réduit les risques d'incompréhension. } \\
\text { Je trouve idiot de chercher à remplacer des termes usuels } \\
\text { juste parce qu'ils sont anglais !!! } \\
\text { Je trouve que le terme de courriel est ridicule. } \\
\text { La francisation sauvage à base de cédérom et de mél en- } \\
\text { traine plus d'incompréhension que d'interêt. } \\
\text { La traduction française mél est une francisation phoné- } \\
\text { tique, elle n'a (à ma connaissance) aucun sens. Idem } \\
\text { pour les termes comme bogue (bug). } \\
\text { Le terme anglais est à la fois bref et [...] il ne nécessite } \\
\text { pas de préciser 'électronique', même si c'est un peu } \\
\text { paradoxal! Il n'y a pas d'ambiguité entre mail et courrier } \\
\text { postal. Enfin, le terme mél est encore peu utilisé et } \\
\text { correspond encore trop à mon goût au furieux besoin de } \\
\text { nos chers amis le l'académie française de franciser tout } \\
\text { ce qu'ils trouvent sans faire preuve d'originalité : tant } \\
\text { qu'à prononcer mél, autant l'écrire à l'anglaise. } \\
\text { Le terme français a peut-être été proposé trop tard. } \\
\text { Mél et courriel ne sont pas des vrais mots, mais ont été } \\
\text { inventés par des académiciens stupides. } \\
\text { Terme anglais plus joli. }\end{array}$ & 11 & 10,5 \\
\hline
\end{tabular}


Die am häufigsten genannte Kategorie, „Le terme anglais est plus bref“, bezieht sich auf ein den Termini e-mail und insbesondere mail inhärentes Kriterium, die Kürze. Dieses ist somit für den Großteil der Informanten ein die Entscheidung für den englischen Terminus maßgeblich beeinflussendes Kriterium. Am zweithäufigsten wird die Gewöhnung an den englischen Terminus genannt. Auch dieser Faktor scheint für die Sprachbenutzer äußerst wichtig zu sein. Damit wird die oben geäußerte Vermutung Saludens et al. (1998) bestätigt. An dritter bis fünfter Stelle werden pragmatische Kriterien genannt, die sich in erster Linie auf die nationale und internationale Kommunikation beziehen: a) die Sicherheit, bei Verwendung des englischsprachigen Terminus verstanden zu werden, b) die Tatsache, dass der englischsprachige Terminus am weitesten verbreitet und zugleich c) am internationalsten ist. Hieran ist deutlich zu ersehen, dass für die befragten Informatiker neben der Kürze des Terminus und der eigenen Gewohnheit die problemfreie Kommunikation mit anderen Personen einen hohen Stellenwert hat. Dass die befragten Informatiker die nationale und internationale Kommunikation durch die Verwendung der französischen Neologismen als gefährdet ansehen, zeigen auch die Kommentare zur Terminologiearbeit (vgl. 9.3). Unter den frei formulierten Antworten in Frage 7 fällt auf, dass die französischen Termini in ästhetischer Hinsicht kritisiert werden (v.a. courriel und mé). Aber auch das Argument, die Verwendung der englischen Terminologie vereinfache die internationale Kommunikation, wird genannt.

\subsubsection{Die Termini page d'accueil, page d'introduction und homepage}

Der zweite Fragenkomplex befasst sich mit engl. homepage und seinen französischen Äquivalenten. Da die Fragen 8-14 analog zu den ersten sieben Fragen aufgebaut sind und analog zu diesen ausgewertet werden, wird im Folgenden auf methodische Erklärungen verzichtet. Es gelten die methodischen Hinweise aus 9.1.1.

Frage 8 befasst sich mit dem Bekanntheitsgrad von homepage, seinem französischen Ersatzwort page d'accueil sowie dem Testwort page d'introduction. 
Abb. 37: Frage 8, Bekanntheitsgrad der Termini page d'accueil, page d'introduction und homepage (absolute Häufigkeit, Frankreich)

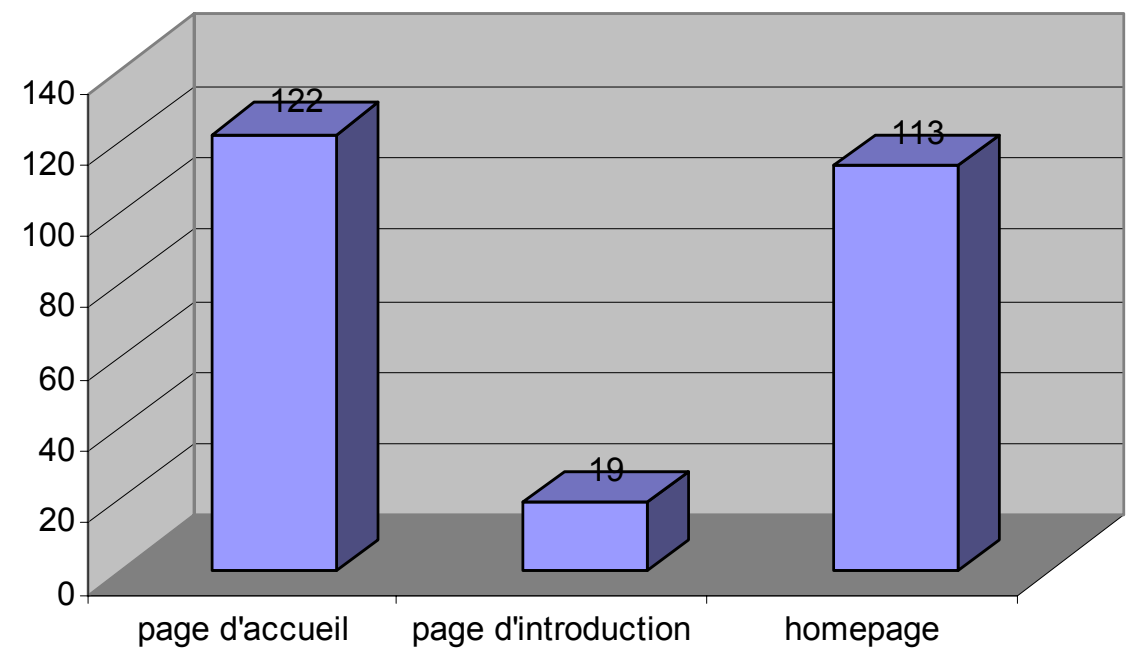

Abb. 38: Frage 8, Bekanntheitsgrad der Termini page d'accueil, page d'introduction und homepage (prozentuale Häufigkeit, Frankreich)

\begin{tabular}{|l|r|}
\hline Termini & $\mathbf{\%}$ \\
\hline Page d'accueil & 98,4 \\
\hline Homepage & 91,1 \\
\hline Page d'introduction & 15,3 \\
\hline
\end{tabular}

Nach den vier von Gasquet/Villebrun $(1994,117)$ aufgestellten Kategorien, um den Etablierungs- bzw. Bekanntheitsgrad anzugeben, bedeuten die in Abb. 38 dargestellten Prozentwerte, dass die beiden Termini page d'accueil und homepage mit einem Bekanntheitsgrad von über $90 \%$ als sicher etabliert gelten können, wobei das französische Wort etwas verbreiteter ist als sein englisches Pendant. Das Testwort page d'introduction kommt 15,3\% der Informanten bekannt vor, was insofern nicht weiter verwunderlich ist, als es aufgrund des Wortbildungsverfahrens (Determinativkompositum) und seiner Semantik durchaus in diesen Verwendungszusammenhang passt.

Auf die Frage nach der Synonymie zwischen dem englischsprachigen Terminus und seinem offiziellen französischen Ersatzwort page d'accueil wurde wie folgt geantwortet: 
Abb. 39: Frage 9, Synonymie der Termini page d'accueil und homepage (Frankreich)

\begin{tabular}{|l|r|r|}
\hline & $\begin{array}{l}\text { Absolute } \\
\text { Häufigkeit }\end{array}$ & $\begin{array}{l}\text { Prozentuale } \\
\text { Häufigkeit }\end{array}$ \\
\hline Synonym & 98 & 79,0 \\
\hline $\begin{array}{l}\text { Bedeutungs- } \\
\text { unterschied }\end{array}$ & 25 & 20,2 \\
\hline $\begin{array}{l}\text { Termini un- } \\
\text { bekannt / } \\
\text { Weiß nicht. }\end{array}$ & 1 & 0,8 \\
\hline Insgesamt & 124 & 100,0 \\
\hline
\end{tabular}

Fast 80\% der Informanten betrachten die beiden Termini als Synonyme. 25 Informanten $(20,2 \%)$ stellen einen Bedeutungsunterschied zwischen den beiden Termini fest, den sie wie folgt begründen:

Abb. 40: Frage 10, Bedeutungsunterschiede zwischen page d'accueil und homepage (Frankreich)

\begin{tabular}{|c|c|c|}
\hline Kategorie & Informanten & Anzahl \\
\hline $\begin{array}{l}\text { Page d'accueil bezeichnet die erste Seite } \\
\text { eines Internetangebots, auf der sich } \\
\text { auch der Index befindet, homepage eine } \\
\text { private Internetseite. }\end{array}$ & 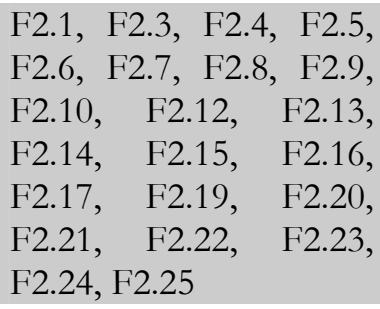 & 23 \\
\hline Bezug auf page d'introduction ${ }^{8}$. & F2.18 & 1 \\
\hline $\begin{array}{l}\text { Homepage entspricht eher einer Startseite } \\
\text { als page d'accueil. }\end{array}$ & F2.11 & 1 \\
\hline $\begin{array}{l}\text { Im Französischen wird homepage zur } \\
\text { Bezeichnung einer privaten Internet- } \\
\text { seite verwendet, im Englischen bezeich- } \\
\text { net homepage die erste Seite eines Inter- } \\
\text { netangebots (z.B. Unternehmen). }\end{array}$ & F2.2 & 1 \\
\hline
\end{tabular}

Die Meinungen derer, die einen Unterschied feststellen, gehen eindeutig in die gleiche Richtung. Für 23 Informanten bezeichnet page d'accueil die erste Seite eines (mehrseitigen) Internetangebots, während homepage für eine private Internetseite

\footnotetext{
8 Die Unterschiede, die in Bezug auf das Testwort réseau mondial festgestellt wurden, werden hier nicht weiter benannt. In der Frage nach der Synonymie der Termini wurde réseau mondial nicht erwähnt. Einige Informanten haben sich jedoch gemerkt, dass dieser Terminus zwei Fragen zuvor aufgeführt war.
} 
stehe. Interessanterweise ist die Bedeutung 'private Internetseite' weder in homepage enthalten, noch geht diese semantische Differenzierung aus der Definition hervor, die die Informatik-Kommission für page d'accueil gibt (vgl. Kap. 3, Abb. 4). Das bedeutet, dass dem Terminus homepage in Frankreich eine neue Bedeutung zugewiesen wird, die er eigentlich in der englischen Sprache gar nicht hat. Es ist durchaus möglich, dass bei dieser neuen Bedeutung der erste Bestandteil des Kompositums, home, eine entscheidende Rolle spielt: home wird von einer nicht unerheblichen Anzahl von Personen in diesem Verwendungskontext ausschließlich als 'privat' verstanden. In Abb. 8 in 5.2.3.1 wurde bereits darauf hingewiesen, dass page d'accueil als Übertragung des engl. homepage semantisch durchsichtiger ist als das Ursprungswort. Vielleicht liegt hierin die Ursache dafür, dass viele der befragten Franzosen hinter den beiden Termini unterschiedliche Bedeutungen vermuten. In der Tat bezeichnet aber auch homepage - trotz des für Nicht-Muttersprachler irreführenden Namens -, gemeinhin die erste Seite eines Internetangebots, sowohl von Firmen als auch von privaten Internetseiten (s. Glossar unter homepage).

Die Erklärungen sprechen dafür, dass in Frankreich beide Termini, page d'accueil und homepage, nicht nur parallel existieren, sondern auch von vielen Leuten zur Bezeichnung von zwei unterschiedlichen Sachverhalten verwendet werden. Insofern wäre es in diesem Fall sicherlich für viele Informatiker ein Verlust an Präzision, gänzlich auf den Anglizismus verzichten zu müssen.

Ein Informant verweist auf die semantische Entwicklung, die der Terminus homepage in Frankreich vollzogen habe, wenn er feststellt, dass homepage im Englischen die gleiche Bedeutung habe wie page d'accueil im Französischen, homepage im Französischen jedoch eine andere Bedeutung erhalten habe als im Englischen. In Bezug auf dieses Lexempaar wäre es angemessen, dass die französische InformatikKommission ihre Terminologie-Vorschläge von 1999 auch bezüglich der Definitionen überarbeitet.

Bei der Frage nach der Bedeutungsgleichheit wird nicht nur auf den Unterschied zwischen privater und nicht-privater Internetseite hingewiesen, sondern auch darauf, dass page d'accueil generell die erste Seite eines Internetangebots bezeichne, während diese Bedeutung in homepage nicht enthalten sei.

Page d'accueil wird von der französischen, belgischen und schweizerischen Terminologiekommission einhellig definiert als „Page de présentation d'un site sur la toile mondiale“ und „Page de tête affichée par un logiciel de navigation“. Die zweite Definition macht deutlich, dass man auf die homepage gelangt, wenn man ein Internetangebot über eine Suchmaschine gefunden hat.

Im Rahmen des Internet-Vokabulars des OLF (2002c, o.S.; vgl. 3.3.4) wird deutlich gemacht, dass allerdings auch innerhalb der englischen Sprache und analog dann auch im Französischen differenziert wird bzw. werden kann: Home page verfügt in der Datenbank des OLF über zwei Einträge. Beim ersten Eintrag werden als Synonyme zu engl. home page engl. start page und engl. startup page angegeben. Die französische Bezeichnung lautet in diesem Fall page d'ouverture, ihre Synonyme page de démarrage und page de départ. Page d'ouverture wird definiert als „Page d'accueil 
d'un document Web qui est automatiquement affichée quand on lance un navigateur Web“. Unter Bemerkungen heißt es:

„La page d'ouverture par défaut est souvent la page d'accueil de la compagnie qui a conçu le navigateur Web utilisé, ou celle du fournisseur d'accès, mais l'internaute peut la configurer selon ses goûts ou ses besoins.

Certains ne font pas de différence entre la page d'ouverture et la page d'accueil (qui est la première page de n'importe quel document Web affiché à l'écran) et nomment ces deux types de pages page d'accueil.،

Beim zweiten Eintrag zu engl. home page wird als Definition angegeben:

„Première partie d'un document Web qui est affichée à l'écran et qui contient généralement une présentation de ce document et d'autres informations sous forme d'images et de liens hypertextes (ou de liens hypermédias)“.

Mit dieser zweiten Definition wird eine Art Indexseite bezeichnet, auf der ein Übersichtsplan zu den entsprechenden, mit dieser Seite verknüpften Unterseiten zu finden sei. Unter Bemerkungen wird nach der bereits beim ersten Eintrag genannten Einschränkung, dass einige Leute keinen Unterschied zwischen page d'accueil und page d'ouverture machen, auf zwei nach Ansicht der kanadischen Terminologen überflüssige Termini hingewiesen: „Les termes page de bienvenue et page d'entrée font une concurrence inutile au terme page d'accueil qui est beaucoup plus attesté."

Der definitorische Unterschied zwischen franz. page d'accueil und page d'ouverture geht aus diesen Definitionen nicht besonders deutlich hervor. Keine der beiden Definitionen der kanadischen Terminologen bringt jedoch bome page mit einer privaten Internetseite in Verbindung. Umso interessanter ist die Beobachtung, dass in Frankreich eine terminologische Entwicklung stattgefunden hat, die zu einer Umdeutung des semantischen Gehaltes des englischen Terminus geführt hat. Das franz. page d'accueil hat nun die Bedeutung von engl. homepage übernommen und wird einstimmig als die erste Seite eines mehrseitigen (z.B. kommerziellen) Internetangebots verstanden; engl. homepage wurde vielfach eine neue Bedeutung zugeschrieben, nämlich die einer privaten (nicht-kommerziellen) Seite.

Die nächste Frage ermittelt wiederum die persönlichen Präferenzen der Befragten, die zunächst in absoluter und anschließend in prozentualer Häufigkeit dargestellt werden: 
Abb. 41: Frage 11, persönliche Präferenz(en): page d'accueil, page d'introduction, homepage (absolute Häufigkeit, Frankreich)

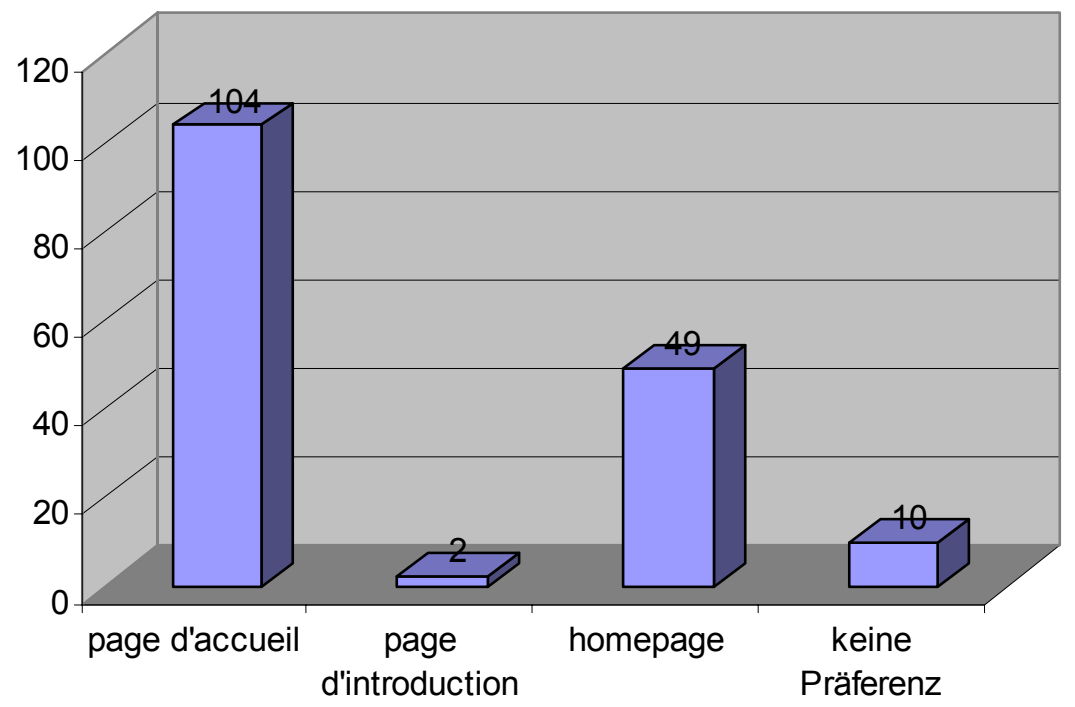

Abb. 42: Frage 11, persönliche Präferenz(en): page d'accueil, page d'introduction, homepage (prozentuale Häufigkeit, Frankreich)

\begin{tabular}{|l|r|}
\hline Termini & $\mathbf{0}$ \\
\hline Page d'accueil & 83,9 \\
\hline Homepage & 39,5 \\
\hline Page d'introduction & 1,6 \\
\hline Keine Präferenz & 8,1 \\
\hline
\end{tabular}

Während beide Termini, page d'accueil und homepage, über 90\% der Befragten bekannt sind (vgl. Frage 8) und als etabliert gelten können, kristallisiert sich bei der Frage nach der Präferenz bereits heraus, welcher Terminus auch bezüglich der aktiven Akzeptanz favorisiert wird. Page d'accueil erhält bezüglich der Präferenz mehr als doppelt so viele Stimmen wie homepage; der Unterschied zwischen beiden Termini beträgt über $40 \%$.

Die Bevorzugung des französischen Terminus schlägt sich noch deutlicher im Sprachgebrauch nieder: 
Abb. 43: Frage 12, eigener Sprachgebrauch: page d'accueil, page d'introduction, homepage (Frankreich)

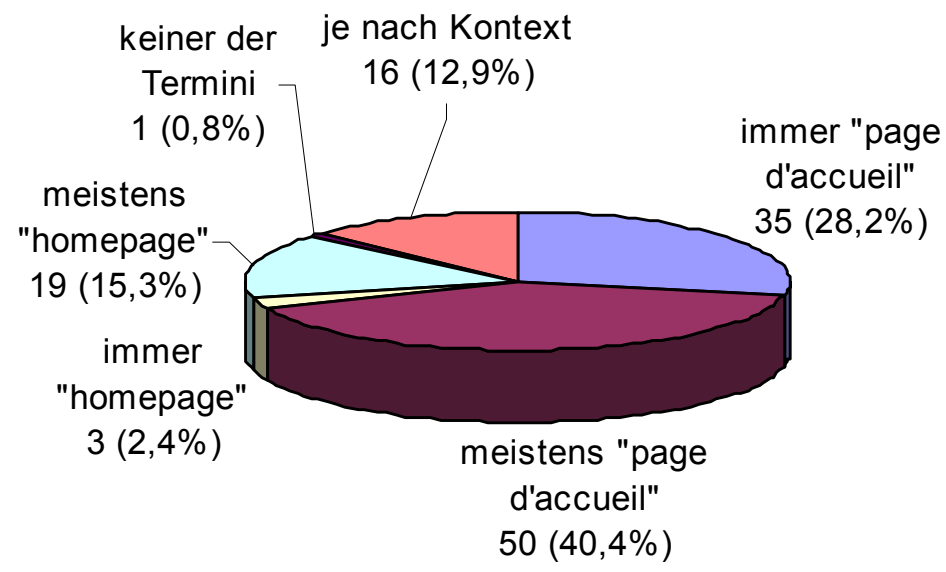

68,6\% der Informanten verwenden das franz. page d'accueil. Damit kann diesem Terminus bezüglich seiner Gebrauchsfrequenz ein guter Etablierungsgrad bescheinigt werden. Nur 17,7\% der Informanten verwenden meistens oder immer das engl. homepage, was nach dem Schema Thoirons als schwacher Etablierungsgrad einzustufen ist (Klasse C, vgl. Rouges-Martinez 1992, 125f.). 12,9\% der Informanten legen sich auf keinen der Termini fest, sondern machen ihre Entscheidung vom Kontext abhängig.

Auch hier zeigen sich die Parallelen zwischen der persönlichen Präferenz und dem eigenen Sprachgebrauch. Der französische Terminus ist doppelt so beliebt wie der englische. Bezüglich seiner Verwendungshäufigkeit wird vier Mal häufiger für den französischen als für den englischen Terminus plädiert. Allerdings ist einschränkend anzumerken, dass nur 28\% angeben, immer page d'accueil zu verwenden. $41 \%$ verwenden meistens diesen Terminus, was auch bedeuten kann, dass sie mitunter den englischsprachigen oder einen ganz anderen Terminus gebrauchen.

Es erweist sich auch deshalb als unmöglich, eine konkrete Aussage zu machen, ob eher der französische oder eher der englische Terminus verwendet wird, weil viele Informanten die Termini nicht als synonym erachten. Sie verwenden dementsprechend nicht nur einen Terminus, sondern je nach Aussageabsicht - erste Seite eines Internetangebots oder private Internetseite - mal den einen und mal den anderen Neologismus.

Die in 5.2.3.2 geäußerte Vermutung, dass sich der französische Terminus auch deshalb durchsetzt, weil er als präziser erachtet wird (ohne es zu sein), kann hiermit nur teilweise bestätigt werden. Vielmehr hat in Frankreich eine Ausdifferenzierung der Inhalte stattgefunden, was dazu führt, dass beide Termini ihre Da- 
seinsberechtigung haben und auch verwendet werden, wie die Antworten auf die zehnte Frage deutlich zeigen.

Bei der zwölften Frage haben 85 Informanten (68,6\%) angegeben, immer oder meistens das franz. page d'accueil zu verwenden. Aufgrund dieser Verteilung lohnt sich die Auswertung der 13. Frage, in der es um die Beurteilung des französischen Terminus geht.

Bei der 13. Frage liegt ein semantisches Differential vor. Die Auswertung des semantischen Differentials gibt Aufschluss darüber, wie die französischen Neologismen im Akzeptanzvotum der Sprecher abschneiden und wie sich der jeweilige Akzeptanzwert konstituiert (vgl. Helfrich 1993, 82). Bei dem semantischen Differential handelt es sich um ein sehr komplexes Erhebungsinstrument. Entsprechend komplex sind auch seine Auswertungsmöglichkeiten. Neben der Berechnung des arithmetischen Mittels sind auch die Berechnung der Standardabweichung (Streuung), des Medians, die Berechnung der jeweiligen Differenzen zwischen den Extremwerten, die Durchführung einer Faktorenanalyse ${ }^{9}$ etc. denkbar. Um erstens dem semantischen Differential jedoch nicht mehr Raum in der Auswertung zu geben, als der Frage selbst im Rahmen des Fragebogens zukommt, und da zweitens die genannten statistischen Verfahren im Hinblick auf die Überprüfung der in 5.3 formulierten Arbeitshypothesen nicht wesentlich weiterhelfen, beschränkt sich die Auswertung des semantischen Differentials auf die Ermittlung der Mittelwerte für die einzelnen Items. Aus den Mittelwerten lässt sich ableiten, welcher der sechs Termini das höchste Votum erhalten hat und bezüglich welcher Eigenschaften ein Terminus gut abschneidet und bezüglich welcher weniger.

Bei der folgenden Häufigkeitsverteilung werden die Mittelwerte für die einzelne Dichotomien (Items) ermittelt. Die folgende Tabelle gibt die durchschnittlichen Akzeptanzwerte der 85 Informanten an, die für die Verwendung des Terminus page d'accueil plädiert haben. Die Informanten konnten bei dieser Frage auf insgesamt neun Likert-Skalen jeweils einen Punkt markieren. Jedem Punkt ist ein Wert zwischen 1 und 5 zugeordnet. Da der positiven Eigenschaft wie ,bekannt', ,schön', ,verständlich', ,nützlich' etc. immer der Wert 1 und der negativen Eigenschaft wie ,unbekannt', ,hässlich', ,unverständlich', ,unnötig' etc. immer der Wert 5 zugeordnet ist, bedeutet ein Wert zwischen 1 und 2,9, dass der Neologismus bezüglich dieses Merkmals positiv bewertet wird. Konkret bedeutet bezüglich des dichotomen Merkmals ,Bekanntheit' ein Wert, der kleiner als 3 ist (1-2,9), dass die Infor-

\footnotetext{
9 Bei Stier (1996, 283) wird die Faktorenanalyse wie folgt erklärt: „Die Faktorenanalyse kann als eine statistische Prozedur angesehen werden, die versucht, Variablen so zu gruppieren, daß Variablen, die untereinander stark korrelieren, je in der selben Gruppe sind, während sich Variablen, die nur schwach oder gar nicht miteinander korrelieren, in verschiedenen Klassen befinden. Eine derartige Klassifikation legt die Annahme nahe, daß jede Gruppe von Variablen ein jeweils zugrunde liegendes Konstrukt (oder Faktor) repräsentiert, das (bzw. der) die beobachteten Korrelationen der Variablen ,erzeugt' hat.“ Der Hauptzweck der Faktorenanalyse liegt darin begründet, Variablen untereinander zu korrelieren und korrelierende Variablen zu Faktoren zusammenzufassen, um so ihre Anzahl zu reduzieren. So könnten dem Faktor ästhetischer Wert beispielsweise die Dichotomien „schön hässlich“, „plump - elegant“, , ungehobelt - vornehm“, ,kultiviert - primitiv“, , anmutig - schwerfällig“" etc. zugeordnet werden (vgl. z.B. Werlen 1984, 186-188, 266f.). Da im Fragebogen zur Internet-Terminologie und Sprachpolitik nur insgesamt neun Variablen vorgegeben waren, lohnt es sich nicht, diese zu Faktoren zusammenzufassen.
} 
manten den Neologismus als bekannt einordnen, ein Wert zwischen 3,1 und 5, dass der Terminus als (eher) unbekannt eingeschätzt wird. Wie der folgende tabellarische Überblick zeigt, sind sämtliche Durchschnittswerte der neun Items kleiner als 3 und liegen damit im positiven Bereich:

\begin{tabular}{|c|c|c|}
\hline Kriterium & $\begin{array}{l}\text { Skalenendpunkte im } \\
\text { Fragebogen }\end{array}$ & $\begin{array}{l}\text { Durchschnittlicher } \\
\text { Akzeptanzwert }\end{array}$ \\
\hline $\begin{array}{l}\text { Bekanntheit (Bekanntheit } \\
\text { vs. Unbekanntheit) }\end{array}$ & $\begin{array}{l}\text { соппи - іпсоппи } \\
1-5\end{array}$ & 1,28 \\
\hline $\begin{array}{l}\text { Schönheit (Schönheit vs. } \\
\text { Hässlichkeit) }\end{array}$ & $\begin{array}{l}\text { beau-laid } \\
1-5\end{array}$ & 2,26 \\
\hline $\begin{array}{l}\text { Verständlichkeit (Ver- } \\
\text { ständlichkeit vs. Unver- } \\
\text { ständlichkeit) }\end{array}$ & $\begin{array}{l}\text { compréhensible }- \text { in- } \\
\text { compréhensible } \\
1-5\end{array}$ & 1,26 \\
\hline $\begin{array}{l}\text { Nützlichkeit (Nützlichkeit } \\
\text { vs. Nutzlosigkeit) }\end{array}$ & $\begin{array}{l}\text { utile - inutile } \\
1-5\end{array}$ & 1,79 \\
\hline $\begin{array}{l}\text { Adäquatheit (Adäquatheit } \\
\text { vs. Inadäquatheit) }\end{array}$ & $\begin{array}{l}\text { adéquat-inapproprié } \\
1-5\end{array}$ & 1,38 \\
\hline $\begin{array}{l}\text { Etabliertheit (Altbestand } \\
\text { des Lexikons vs. Neuheit) }\end{array}$ & $\begin{array}{l}\text { établi- nouvean } \\
1-5\end{array}$ & 1,63 \\
\hline $\begin{array}{l}\text { Natürlichkeit (Normalität } \\
\text { vs. Künstlichkeit) }\end{array}$ & $\begin{array}{l}\text { normal-artificiel } \\
1-5\end{array}$ & 1,54 \\
\hline $\begin{array}{l}\text { Komplexität (Einfachheit } \\
\text { vs. Kompliziertheit) }\end{array}$ & $\begin{array}{l}\text { simple-complexe } \\
1-5\end{array}$ & 1,52 \\
\hline $\begin{array}{l}\text { Korrektheit (Korrektheit } \\
\text { vs. Unkorrektheit) }\end{array}$ & $\begin{array}{l}\text { correct-incorrect } \\
1-5\end{array}$ & 1,39 \\
\hline
\end{tabular}

Den besten Wert hat page d'accueil bezüglich seiner Adäquatheit $(1,26)$ erhalten, den schlechtesten bezüglich seiner ästhetischen Qualitäten $(2,26)$. Als durchschnittlicher Akzeptanzwert aus der Summe aller neun Werte ergibt sich der Wert von 1,56 auf der Likert-Skala. Das bedeutet, dass page d'accueil im Akzeptanzvotum der befragten Informatiker, die diesen Terminus meistens oder immer verwenden, überaus positiv abschneidet.

Bei der zwölften Frage haben nur 22 Informanten (17,7\%) angegeben, immer oder meistens den englischen Terminus homepage zu verwenden. Dementsprechend wurde die 14. Frage, in der nach den Gründen für die Bevorzugung des Anglizismus gefragt wurde, auch nur von diesen 22 Informanten beantwortet. Aufgrund der verhältnismäßig geringen Anzahl an Stimmen wird auf eine ausführliche Tabelle verzichtet. Es werden nur die häufigsten drei Gründe für die Bevorzugung des englischsprachigen Terminus genannt, die von den Informanten angegeben wurden. $13 \mathrm{Mal}$ werden die Gewöhnung an den englischen Terminus, 
elf Mal die Kürze des englischen Terminus und acht Mal die Gewissheit, bei Benutzung des englischen Terminus verstanden zu werden, als Grund angegeben.

Die in 5.3.1 geäußerte Hypothese I.4 („Die Neologismen page d'accueil und fournisseur d'accès werden einen höheren Akzeptanzwert erhalten als die entsprechenden Anglizismen homepage und (access) provider") lässt sich bezüglich des Neologismus page d'accueil bestätigen. Sowohl bezüglich der passiven Akzeptanz (Frage 8) als auch der aktiven Akzeptanz (Frage 12) liegt der französische Neologismus vor dem entsprechenden Anglizismus. Einschränkend zu dieser Aussage ist hinzuzufügen, dass page d'accueil und homepage von vielen Befragten nicht als synonym erachtet werden, sondern zur Bezeichnung unterschiedlicher Sachverhalte verwendet werden.

\subsubsection{Die Termini toile d'araignée mondiale, toile mondiale, toile, T.A.M., réseau mondial, World Wide Web und web}

Der dritte Fragenkomplex des ersten Moduls hat den englischsprachigen Terminus World Wide Web und seine französischsprachigen Äquivalente zum Gegenstand.

Abb. 45: Frage 15, Bekanntheitsgrad der Termini toile d'araignée mondiale, toile mondiale, toile, T.A.M., réseau mondial, World Wide Web und web (absolute Häufigkeit, Frankreich)

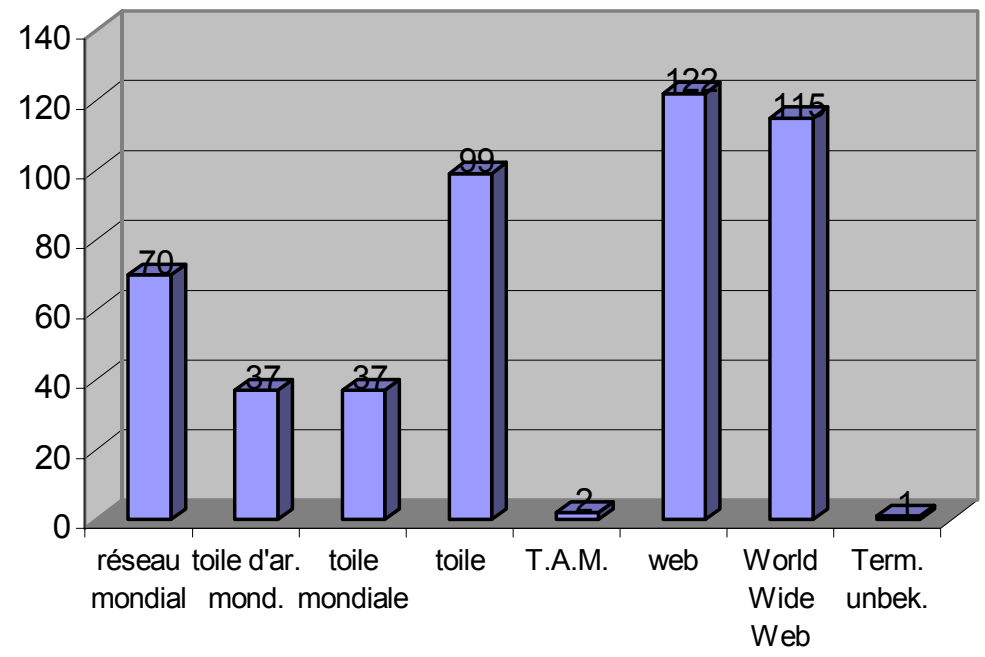


Abb. 46: Frage 15, Bekanntheitsgrad der Termini toile d'araignée mondiale, toile mondiale, toile, T.A.M., réseau mondial, World Wide Web und web (prozentuale Häufigkeit, Frankreich)

\begin{tabular}{|l|r|}
\hline Termini & $\mathbf{0}$ \\
\hline Web & 98,4 \\
\hline World Wide Web & 92,7 \\
\hline Toile & 79,8 \\
\hline Réseau mondial & 56,5 \\
\hline Toile d'araignée mon- & 29,8 \\
\hline diale & \\
\hline Toile mondiale & 29,8 \\
\hline T.A.M. & 1,6 \\
\hline Termini unbekannt & 0,8 \\
\hline
\end{tabular}

Wie bereits für die Fragen 1 und 8 geschehen, wird auch für web und seine Äquivalente angegeben, inwieweit sie nach der von Gasquet/Villebrun $(1994,117)$ entworfenen Einteilung als etabliert gelten können. Engl. web und World Wide Web sowie franz. toile können als sicher etabliert eingeordnet werden, da sie von mehr als $80 \%$ bzw. ca. 80\% als bekannt angegeben werden. Die beiden französischen Neologismen toile d'araignée modiale und toile mondiale haben sich nicht etablieren können. Ihr Bekanntheitsgrad liegt knapp unter 30\%, wobei bereits Termini, die weniger als 50\% der Befragten bekannt sind, als schwach oder kaum etabliert gelten. Der schlechte Etablierungsgrad der von der Terminologiekommission in Québec geschaffenen Termini toile d'araignée modiale und toile mondiale bestätigt die in 4.1 geäußerte Vermutung, dass die auf natürliche Weise entstandenen offiziellen französischen Neologismen auf mehr Akzeptanz stoßen dürften als die künstlich geschaffenen.

Das Testwort réseau mondial, das es zwar gibt, das allerdings inhaltlich umfassender ist als World Wide Web und die anderen Äquivalente, befindet sich im mittleren Bereich und kann als unsicher bzw. mehr oder weniger etabliert gelten. Den geringsten Bekanntheitsgrad hat das Kurzwort T.A.M., das nur zwei Informanten $(1,6 \%)$ als bekannt angeben. Wie in 5.2.3.2 bereits erwähnt, setzt das Kurzwort T.A.M. voraus, dass die entsprechende Vollform toile d'araignée mondiale verbreitet und bekannt ist, was bei einem Bekanntheitsgrad von knapp 30\% nicht der Fall ist ${ }^{10}$.

Der Informant, der angegeben hat, dass ihm die Termini unbekannt seien, wurde direkt zum nächsten Lexemkomplex (Frage 22) weitergeleitet, so dass für die Fragen 16-21 die Antworten von jeweils 123 statt 124 Informanten ausgewertet werden.

\footnotetext{
${ }^{10}$ Helfrich $(1993,94)$ stellt fest, dass sich die Informanten gegenüber Wortkürzungen in der Regel wenig aufgeschlossen zeigen.
} 
Mit der Frage 16 soll ermittelt werden, ob die Termini toile d'araignée mondiale, toile mondiale, toile, T.A.M., World Wide Web und web, d.h. alle Termini mit Ausnahme des Testwortes réseau mondial, als synonym erachtet werden.

Abb. 47: Frage 16, Synonymie der Termini toile d'araignée mondiale, toile mondiale, toile, T.A.M., World Wide Web und web (Frankreich)

\begin{tabular}{|l|r|r|} 
& $\begin{array}{l}\text { Absolute } \\
\text { Häufigkeit }\end{array}$ & $\begin{array}{l}\text { Prozentuale } \\
\text { Häufigkeit }\end{array}$ \\
\hline Synonym & 98 & 79,7 \\
\hline $\begin{array}{l}\text { Bedeutungs- } \\
\text { unterschied }\end{array}$ & 13 & 10,6 \\
\hline $\begin{array}{l}\text { Termini un- } \\
\text { bekannt / } \\
\text { Weiß nicht. }\end{array}$ & 12 & 9,7 \\
\hline Insgesamt & 123 & 100,0 \\
\hline
\end{tabular}

$79,9 \%$ halten die angegebenen Termini für synonym, 10,6\% der Befragten stellen einen Bedeutungsunterschied fest und fast ebenso viele, 9,7\% der Befragten, geben an, nicht alle Termini zu kennen bzw. diese Frage nicht beantworten zu können. Die 13 Informanten (10,6\%), die einen Bedeutungsunterschied feststellen, wurden in der folgenden Frage gebeten, diesen zu präzisieren.

Abb. 48: Frage 17, Bedeutungsunterschiede zwischen toile d'araignée mondiale, toile mondiale, toile, T.A.M., World Wide Web und web (Frankreich)

\section{Kategorie}

Toile d'araignée mondiale, toile mondiale, T.A.M. und toile bezeichnen das gesamte Internet, $W W W$, World Wide Web und web bezeichnen nur den auf http- und https-Protokollen basierenden Teil des Internet.

Definition von réseau mondial11.

Toile d'araignée mondiale hat eine andere Konnotation als web/World Wide Web.

Toile d'araignée mondiale ist ein anschaulicher Terminus, aber nicht so eindeutig wie z.B. réseau mondial.

Web bezeichnet alles, was mit dem http-Protokoll in Zusammenhang steht, während World Wide Web eher die Gesamtheit der (Internet-)Dienste bezeichnet.

\begin{tabular}{|l|r|}
\hline Informanten & Anzahl \\
\hline F3.1, F3.2, & 11 \\
F3.3, F3.4, \\
F3.5, F3.6, \\
F3.8, F3.9, \\
F3.10, F3.11, \\
\hline F3.12 \\
\hline F3.4 \\
\hline F3.7 \\
\hline F3.9 \\
\hline
\end{tabular}

\footnotetext{
11 Auf die Definition des Testwortes réseau mondial wird hier nicht weiter eingegangen.
} 
Ähnlich wie bei der Frage 10 nach dem Bedeutungsunterschied zwischen page d'accueil und homepage weist ein Großteil der Antworten (elf von 15 genannten Begründungen) in die gleiche Richtung. Die drei englischen Termini $W W W, W$ orld Wide $W e b$ und web werden als ein Teil des Internet aufgefasst, der auf http- bzw. auf https-Protokollen basiere. Die französischen Termini toile d'araignée mondiale, toile mondiale, T.A.M. und toile bezeichneten nach Meinung der Informanten demgegenüber das gesamte Internet, das neben dem World Wide Web z.B. auch den EMail-Dienst und die Diskussionsforen umfasse. Das bedeutet, dass toile d'araignée mondiale und seine kürzeren Äquivalente nicht als Ersatzwörter für engl. World Wide $W e b$ gesehen werden, sondern als Ersatzwörter für Internet.

Ein Informant grenzt das Testwort réseau mondial von den anderen Termini ab, ein anderer gibt eine Definition des Terminus réseau mondial. Weiterhin wird darauf hingewiesen, dass toile d'araignée eine andere Konnotation habe als web/World Wide $W e b^{12}$. Schließlich wird noch web von $W$ orld Wide $W e b$ abgegrenzt.

Die Frage 18 nach den persönlichen Präferenzen ergibt folgendes Bild:

Abb. 49: Frage 18, persönliche Präferenz(en): toile d'araignée mondiale etc. (absolute Häufigkeit, Frankreich)

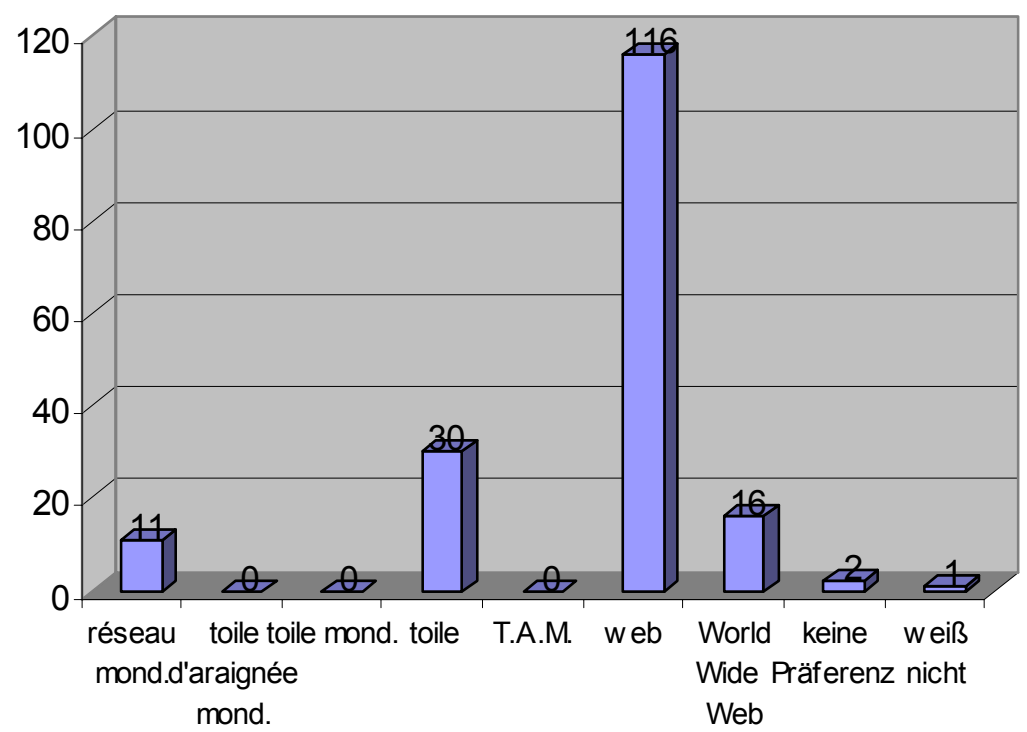
12 In 5.2 .3 .2 wurde bereits darauf hingewiesen, dass toile im Unterschied zu web negative Konnota-
tionen hervorrufen kann. 


\begin{abstract}
Abb. 50: Frage 18, persönliche Präferenz(en): toile d'araignée mondiale etc. (absolute Häufigkeit, Frankreich)
\end{abstract}

\begin{tabular}{|l|r|}
\hline Termini & $\mathbf{\%}$ \\
\hline Web & 94,3 \\
\hline Toile & 24,4 \\
\hline World Wide Web & 13,0 \\
\hline Réseau mondial & 8,9 \\
\hline \begin{tabular}{l|r} 
Toile d'araignée mon- \\
diale
\end{tabular} & 0,0 \\
\hline Toile mondiale & 0,0 \\
\hline T.A.M. & 0,0 \\
\hline Keine Präferenz & 1,6 \\
\hline Weiß nicht & 0,8 \\
\hline
\end{tabular}

In diesem Fall zeigt sich, dass die beiden bekanntesten Termini web und World Wide Web (vgl. Frage 15) nicht unbedingt die bevorzugten Termini sind. Toile, das mit 79,8\% hinter web $(98,4 \%)$ und World Wide Web (92,7\%) an dritter Stelle bezüglich des Bekanntheitsgrades steht, steht in Bezug auf die persönliche Präferenz an zweiter Stelle. Web wird von nahezu allen Befragten (94,3\%) der Vorzug gegeben, World Wide Web folgt erst an dritter Stelle mit 13\%. Die französischen Termini toile d'araignée mondiale und toile mondiale werden von keinem der Informanten genannt. Aufgrund dieser Ergebnisse erscheint es sehr wahrscheinlich, dass die Länge der Termini maßgeblichen Einfluss auf ihre Akzeptanz hat. Der längere Terminus World Wide Web schneidet bezüglich der persönlichen Präferenz weitaus schlechter $\mathrm{ab}$ als das kürzere web, toile d'araignée mondiale und toile mondiale schneiden schlechter $\mathrm{ab}$ als das kürzere toile. Die englischen Termini werden bei annähernd gleicher Länge den französischen Termini vorgezogen, so erhält web mehr Stimmen als toile und World Wide Web mehr Stimmen als toile d'araignée mondiale und toile mondiale.

Entgegen der in 5.2.3.2 geäußerten Vermutung, die Bezeichnung toile mondiale dürfte mehr Zuspruch erhalten als das längere toile d'araignée mondiale, machen die Informanten weder bezüglich des Bekanntheitsgrades (Frage 15) noch bezüglich der persönlichen Präferenz einen Unterschied zwischen toile d'araignée mondiale und toile mondiale.

Das französische Kurzwort T.A.M., das in Frage 15 nur von zwei Informanten als bekannt angegeben wird, erhält keine Stimmen. De Schaetzen und Humbley behalten Recht bezüglich ihrer Vermutungen zu französischen Akronymen: 1. Fremdsprachige Akronyme seien leichter zu memorieren als ihre Übersetzungen und 2. ins Französische übertragene Akronyme würden üblicherweise nicht akzeptiert (vgl. Kap. 5, Fußnote 17).

Frage 19 dient der Ermittlung der aktiven Akzeptanz und fragt somit nach dem Sprachgebrauch der Informanten. Da insgesamt neun verschiedene Antwortkategorien angegeben wurden, erweist sich eine Darstellung in Form eines Diagramms 
als zu unübersichtlich. Die Antworten werden daher in der Reihenfolge ihrer Nennungen in einer Tabelle aufgeführt.

Abb. 51: Frage 19, eigener Sprachgebrauch: toile d'araignée mondiale etc. (Frankreich)

\begin{tabular}{|l|r|r|}
\hline & $\begin{array}{l}\text { Absolute } \\
\text { Häufigkeit }\end{array}$ & $\begin{array}{l}\text { Prozentuale } \\
\text { Häufigkeit }\end{array}$ \\
\hline Immer web & 64 & 52,1 \\
\hline Meistens web & 43 & 35,0 \\
\hline $\begin{array}{l}\text { Keiner der Ter- } \\
\text { mini }\end{array}$ & 6 & 4,9 \\
\hline Meistens toile & 3 & 2,4 \\
\hline $\begin{array}{l}\text { Meistens World } \\
\text { Wide Web }\end{array}$ & 2 & 1,6 \\
\hline Je nach Kontext & 2 & 1,6 \\
\hline $\begin{array}{l}\text { Immer World } \\
\text { Wide Web }\end{array}$ & 1 & 0,8 \\
\hline $\begin{array}{l}\text { Immer réseau } \\
\text { mondial }\end{array}$ & 1 & 0,8 \\
\hline Weiß nicht & 1 & 0,8 \\
\hline Insgesamt & 123 & 100,0 \\
\hline
\end{tabular}

$87,1 \%$ der Informanten geben an, meistens oder immer web zu verwenden. Damit hat sich web bezüglich seiner Gebrauchsfrequenz eindeutig etabliert (Klasse A nach Rouges-Martinez 1992, 125f.). In diesem Fall stimmen auch die passive Akzeptanz (Bekanntheitsgrad), die persönliche Präferenz und die aktive Akzeptanz (eigener Sprachgebrauch) überein.

Der französische Terminus toile, den 79,8\% der Informanten als bekannt (Frage 15) und $24,4 \%$ als persönliche Präferenz bzw. eine ihrer beiden persönlichen Präferenzen angegeben haben, wird von nur 2,4\% der befragten Informatiker mehrheitlich verwendet. Für toile ist somit festzuhalten, dass seine passive Akzeptanz mit fast 80\% sehr hoch, seine aktive Akzeptanz mit 2,4\% jedoch sehr gering ausfällt (Klasse C, schwacher Gebrauch nach Rouges-Martinez 1992, 125f.). Auch engl. World Wide Web erhält bezüglich seiner passiven Akzeptanz einen niedrigen Wert: Nur 2,4\% der Informanten geben an diesen Terminus meistens oder immer zu verwenden.

$4,9 \%$ geben an, keinen der angegebenen Termini zu verwenden. Es ist wahrscheinlich, dass hierunter diejenigen Informanten fallen, die toile (d'araignée mondiale) als Synonym zu Internet ansehen und daher Internet bzw. Net verwenden (s. Frage 21, Rubrik „Autre“).

Nur vier der insgesamt 123 Informanten, die diese Frage beantwortet haben, geben an, meistens einen der französischen Termini toile (drei Informanten) und réseau mondial (ein Informant) zu verwenden. Die Auswertung der Frage 20 (se- 
mantisches Differential), in der die französischen Termini bewertet wurden, entfällt aufgrund dieser geringen Anzahl.

Als Gründe für die Bevorzugung der englischsprachigen Termini web und World Wide Web werden folgende Gründe angeführt:

\section{Abb. 52: Frage 21, Gründe für die Bevorzugung der englischsprachigen Termini web und World Wide Web (Frankreich)}

\begin{tabular}{|c|c|}
\hline Nr. & Begründung \\
\hline 1 & $\begin{array}{l}\text { - } \quad \text { Je me suis déjà habitué(e) à utiliser le terme anglais. } \\
\text { - } \quad \text { Le terme anglais est plus bref. }\end{array}$ \\
\hline 2 & Presque tout le monde utilise le terme anglais. \\
\hline 3 & En utilisant le terme anglais, je suis sûr(e) d'être compris(e). \\
\hline 4 & Le terme anglais est plus international. \\
\hline 5 & Les termes français ne sont pas assez connus. \\
\hline 6 & $\begin{array}{l}\text { - Les connotations des termes français ne correspondent } \\
\text { pas aux connotations qui sont liées au terme anglais. } \\
\text { Les formulations des termes français sont trop compli- } \\
\text { quées. }\end{array}$ \\
\hline
\end{tabular}

Absolute

Häufigkeit Häufigkeit

\begin{tabular}{|r|r|}
\hline 59 & 53,6 \\
\hline 59 & 53,6 \\
\hline 53 & 48,2 \\
\hline 42 & 38,2 \\
\hline 32 & 29,1 \\
\hline 28 & 25,5 \\
\hline 20 & 18,2 \\
\hline 20 & 18,2 \\
\hline & \\
\hline 18 & 16,4 \\
\hline 11 & 10,0 \\
\hline & \\
\hline 6 & 5,5 \\
\hline 4 & 3,6 \\
\hline 3 & 2,7 \\
\hline 2 & 1,8 \\
\hline 2 & 1,8 \\
\hline & \\
\hline & 0,9 \\
\hline 8 & 7,3 \\
\hline
\end{tabular}
7 La signification des termes français n'est pas claire.
8 La signification des termes français ne correspond pas à celle du terme anglais.

9 Je ne connais pas les termes français.

10 Il y a trop d'équivalents français pour un seul terme anglais.

11 Je n'aime pas suivre les propositions officielles.

12 - Il n'est pas possible de créer des termes dérivés (du type: logiciel, progiciel, ludiciel).

- Les termes français ne sont pas assez proches du terme anglais.

13 Pour paraitre compétent, il faut se servir de la terminologie anglaise.

14 Autre :

- C'est premier terme 'consacré'.

- En général, je dis «sur internet», mot qui n'est pas présent sur la liste de termes de la page précédente.

- internet

- L'abréviation $W W W$ vient de l'anglais.

- La toile qui correspond pour moi à l'ensemble des pages internet, est relativement peu utilisée : si j'explique à des amis que j'ai passé ma soirée sur «la toile», ils vont s'interroger avant de comprendre, car ça n'est pas naturel. Avec le web, qui qui fait partie du langage courant, ils comprendront tout de suite; ça fait partie du langage courant, où je vis. [...] Pour terminer, je soulignerai le fait que réseau mondial désigne plutôt internet [...], à la différence du web désigne plutôt l'ensemble des pages sur lesquelles on surfe.

- Les termes français sont laids.

- $\quad W W W$ est concis et connu.

- $\quad$ Y a aussi « le net ». 
Am häufigsten werden als Gründe für die Benutzung der englischsprachigen Termini die Gewöhnung an den englischen Terminus, die Kürze (gilt nur für web), die Verbreitung des Terminus, die Sicherheit, verstanden zu werden, sowie seine internationale Verwendung genannt. Die Parallele zu den Gründen, die für e-mail und mail angeführt wurden (1. Kürze, 2. Gewöhnung, 3. Sicherheit, verstanden zu werden, 4. Verbreitung des englischen Terminus, 5. Internationalität), ist nicht zu übersehen. Wie wichtig die Kürze eines Terminus für die Akzeptanz ist, wurde bereits bei der Frage nach den persönlichen Präferenzen deutlich. Auch die Gewöhnung an den Terminus beeinflusst die Entscheidung für einen bestimmten Terminus und zugleich gegen andere Termini maßgeblich. Die Argumente 3 bis 5 beziehen sich auf die nationale und internationale Kommunikation. Erst an sechster Stelle wird darauf verwiesen, dass a) die französischen Formulierungen sehr kompliziert seien, wobei insbesondere das in Québec geschaffene toile d'araignée mondiale gemeint sein dürfte, und dass b) die Konnotationen der englischsprachigen nicht mit denen der französischen Termini übereinstimmten. Dies passt zu der Angabe eines Informanten auf die Frage nach dem Bedeutungsunterschied, dass toile d'araignée mondiale anders konnotiert sei als die englischsprachigen Äquivalente.

Die unter „Autre“ angegebenen Begründungen machen nochmals deutlich, dass toile (d'araignée mondiale) und World Wide Web/web nicht von jedem Informanten als synonym angesehen werden, sondern toile vielmehr engl. Internet entspreche. Das englische Kurzwort $W W W$ hat sich im Unterschied zu T.A.M. etablieren können, denn es wird, wie die frei formulierten Begründungen zeigen, von einigen Informanten aktiv verwendet.

Zusammenfassend zeigen die Fragen 15 bis 21 folgende Tendenzen auf: Bezüglich des Bekanntheitsgrades liegen die Termini web, World Wide Web und toile vorne. Bereits bei der Frage nach den persönlichen Präferenzen zeichnet sich deutlich ein Plädoyer für engl. web ab, das auch in der Frage nach dem eigenen Sprachgebrauch bestätigt wird. Wie in 5.2.3.2 und in der Hypothese I.3 („,Toile wird aufgrund seiner Kürze erheblich öfter gebraucht als die alternativ möglichen französischen Neologismen toile d'araignée mondiale und toile mondiale. Populärer als toile ist jedoch der Anglizismus web.") vermutet, sind sowohl engl. web als auch franz. toile sehr verbreitet, web wird jedoch bevorzugt und ihm wird auch bezüglich des Sprachgebrauchs mit weitem Abstand vor toile der Vorzug gegeben. Das Kurzwort T.A.M. kann sich nicht durchsetzen.

\subsubsection{Die Termini causette, bavardage, conversation électronique und chat}

Die erste Frage zu der Lexemgruppe causette, bavardage, conversation électronique und chat widmet sich dem Bekanntheitsgrad dieser Termini: 
Abb. 53: Frage 22, Bekanntheitsgrad der Termini causette, bavardage, conversation électronique und chat (absolute Häufigkeit, Frankreich)

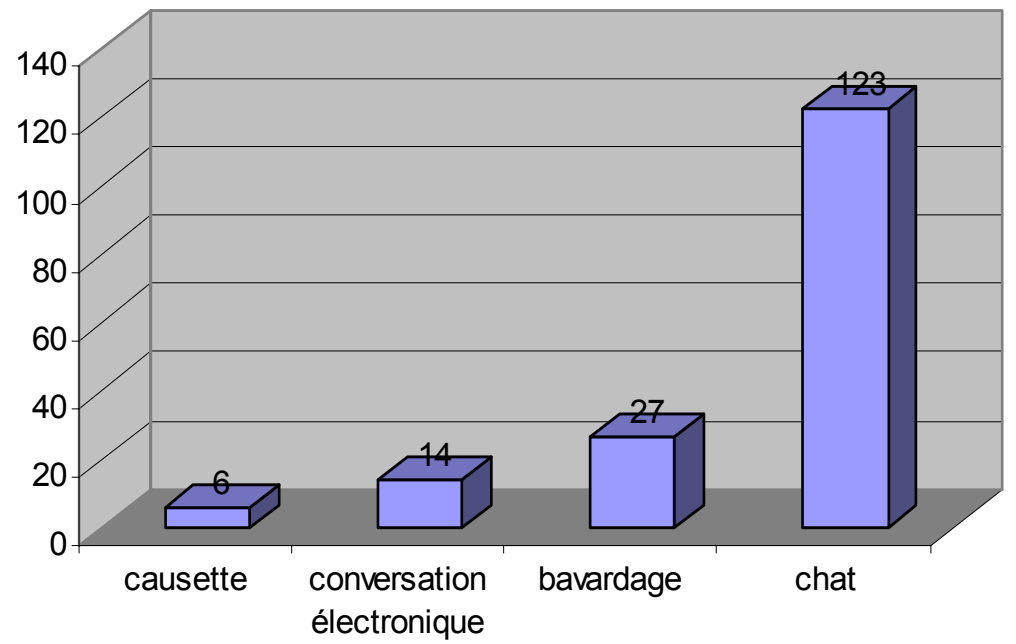

Abb. 54: Frage 22, Bekanntheitsgrad der Termini causette, bavardage, conversation électronique und chat (prozentuale Häufigkeit, Frankreich)

\begin{tabular}{|l|r|}
\hline Termini & $\mathbf{\%}$ \\
\hline Chat & 99,2 \\
\hline Bavardage & 21,8 \\
\hline Conversation électronique & 11,3 \\
\hline Causette & 4,8 \\
\hline
\end{tabular}

Nur engl. chat kann nach den von Gasquet/Villebrun (1994, 117) aufgestellten Kategorien als etabliert gelten. Bavardage und causette haben sich nicht etablieren können. Das einzige offizielle französische Ersatzwort, causette, schneidet dabei noch schlechter ab als das Testwort conversation électronique, das weder in Frankreich noch in Belgien, Kanada oder der Schweiz offiziellen Status hat.

Als nächstes wurde nach der Synonymie der Termini causette, bavardage und chat gefragt: 
Abb. 55: Frage 23, Synonymie der Termini causette, bavardage und chat (Frankreich)

\begin{tabular}{|l|r|r|}
\hline & $\begin{array}{l}\text { Absolute } \\
\text { Häufigkeit }\end{array}$ & $\begin{array}{l}\text { Prozentuale } \\
\text { Häufigkeit }\end{array}$ \\
\hline Synonym & 77 & 62,1 \\
\hline $\begin{array}{l}\text { Bedeutungs- } \\
\text { unterschied }\end{array}$ & 20 & 16,1 \\
\hline $\begin{array}{l}\text { Termini un- } \\
\text { bekannt / } \\
\text { Weiß nicht. }\end{array}$ & 27 & 21,8 \\
\hline Insgesamt & 124 & 100,0 \\
\hline
\end{tabular}

62,1\%, d.h. mehr als die Hälfte der Befragten, halten die drei angegebenen Termini für synonym. 16,1\% stellen zwischen den Termini einen Bedeutungsunterschied fest. 21,8\% geben an, entweder nicht alle Termini zu kennen oder die Frage nicht beantworten zu können.

Die 16,1\%, die einen Bedeutungsunterschied feststellen, begründen diesen wie folgt:

Abb. 56: Frage 24, Bedeutungsunterschiede zwischen causette, bavardage und chat (Frankreich)

\section{Kategorie}

Nur chat impliziert eine (virtuelle) Diskussion im Internet, causette und bavardage beziehen sich auf Diskussionen in verschiedenen anderen Kontexten der realen Welt.

Causette: Kommunikation in der realen Welt, chat: virtuelle Kommunikation im WWW oder IRC, $b a$ vardage: Kommunikation in der realen Welt oder in E-Mails und Diskussionsforen.

Nur der Terminus chat ist bekannt.

Bavardage (in Diskussionsforen) ist asynchron, während chat synchron ist.

Causette impliziert eine Face-to-Face-Kommunikation.

Causette und bavardage können auch über andere Wege (als IRC) erfolgen, z.B. telefonisch oder über E-Mail.

Chat impliziert ein Gespräch auf Distanz, causette und bavardage den direkten Kontakt (face-to-face).

Chat impliziert eine Diskussion im WWW, causette den direkten Kontakt (face-to-face), bavardage eine
Informanten Anzahl

F4.2, F4.4, F4.5, F4.7, F4.10, F4.11, F4.16, F4.19

F4.5, F4.13 2 F4.14, F4.15 2 F4.13

F4.9

F4.8

1

F4.1

F4.6 
Diskussion zwischen Personen, die nicht zwangsläufig in direktem (Augen-)Kontakt stehen.

\begin{tabular}{l|l|l|}
\hline $\begin{array}{l}\text { Chat ist der umfassendste Terminus und beinhaltet } \\
\text { mehr als nur die Diskussion. }\end{array}$ & F4.17 & 1 \\
\hline $\begin{array}{l}\text { Chat ist präziser als bavardage. } \\
\text { Definition von conversation électronique }{ }^{13} \text {. }\end{array}$ & F4.3 & 1 \\
\hline $\begin{array}{l}\text { Die Termini bavardage und causette bezeichnen keine } \\
\text { schriftliche Konversation. }\end{array}$ & F4.12 & F4.18 \\
\hline
\end{tabular}

Die Antworten fallen nicht so eindeutig aus wie bezüglich des Bedeutungsunterschiedes zwischen den Termini page d'accueil/homepage bzw. toile d'araignée mondiale/toile mondiale/T.A.M./toile/WWW/World Wide Web/web.

Während bezüglich der Bedeutung von chat relative Einigkeit herrscht (Konversation im IRC, virtuell, schriftlich, räumliche Distanz, synchron ${ }^{14}$ ), sind die Ansichten bezüglich der Bedeutungen von causette und bavardage gespalten. Bavardage und causette bewerten die meisten Informanten als Bezeichnung für Gespräche in der realen Welt (mit oder ohne Augenkontakt) ${ }^{15}$. Mitunter wird aber auch eingeräumt, dass sich bavardage auf andere Kommunikationsformen im Internet als IRC beziehen könne, z.B. auf E-Mails oder Diskussionsforen. Causette wird nur von einem Informanten auch auf die Kommunikation im Internet (E-Mail) bezogen, sonst nur für die Kommunikation in der realen Welt mit Augenkontakt (z.B. Gespräch auf der Straße, in der Cafeteria) oder ohne (z.B. Gespräch am Telefon).

Für manche Informanten impliziert chat im Unterschied zu causette und/oder bavardage automatisch ein Gespräch auf Distanz oder die schriftliche Form. Dies ist jedoch in der ursprünglichen Bedeutung von chat keineswegs enthalten. In 4.3.1 und in 9.1.1 wurde erwähnt, dass ausländische Benutzer den englischen Termini mitunter Monosemie unterstellen. Dies ist nicht nur der Fall bei e-mail/mail, sondern auch bei chat. Chat bezeichnet im angloamerikanischen Sprachraum sowohl ein mündliches Geplauder in einer Face-to-Face-Situation als auch das schriftliche Geplauder in einem Chatraum. Die Reaktionen der Informanten zeigen deutlich, dass chat in Frankreich fast ausschließlich als Bezeichnung für die virtuelle Unterhaltung im Internet bekannt ist.

Die folgende Frage 25 ermittelt die persönlichen Präferenzen der Informanten.

\footnotetext{
13 Auf die Definition des Testwortes conversation électronique wird hier nicht weiter eingegangen.

${ }^{14}$ Die Unterscheidung zwischen synchroner Kommunikation (IRC) und asynchroner Kommunikation (Diskussionsforen und Mailinglisten) findet sich auch bei Crystal (2001), der beide Kommunikationsformen im Kapitel „The language of chatgroups“ (ebd., 129-170) behandelt und chat somit weiter definiert, als dies in deutschsprachigen Publikationen üblicherweise der Fall ist.

15 Im Erlass vom 16. März 1999 wird causette nur als Bezeichnung für die virtuelle Kommunikation definiert: „Communication informelle entre plusieurs personnes sur l'internet, par échange de messages affichés sur leurs écrans."
} 
Abb. 57: Frage 25, persönliche Präferenz(en): causette, bavardage, conversation électronique, chat (absolute Häufigkeit, Frankreich)

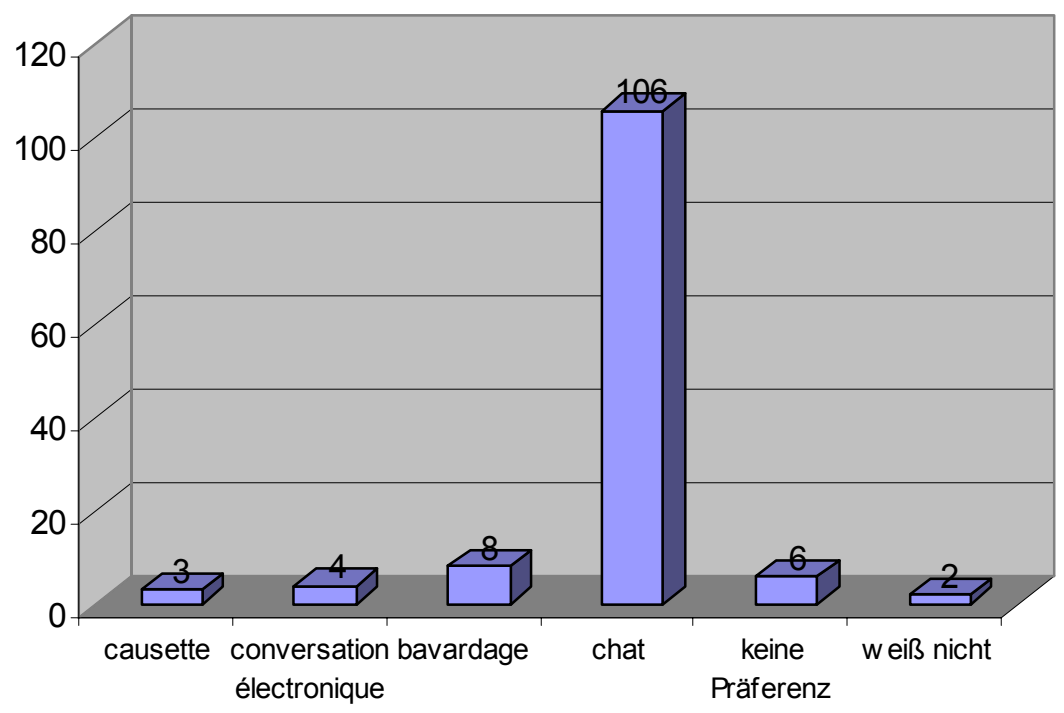

Abb. 58: Frage 25, persönliche Präferenz(en): causette, bavardage, conversation électronique, chat (prozentuale Häufigkeit, Frankreich)

\begin{tabular}{|l|r|}
\hline Termini & $\mathbf{\%}$ \\
\hline Chat & 85,5 \\
\hline Bavardage & 6,5 \\
\hline Conversation électronique & 3,2 \\
\hline Causette & 2,4 \\
\hline Keine Präferenz & 4,8 \\
\hline Weiß nicht & 1,6 \\
\hline
\end{tabular}

Es ergibt sich ein sehr ähnliches Bild wie bei Frage 22. Chat liegt mit weitem Abstand vor bavardage, gefolgt von conversation électronique und causette.

Die persönliche Präferenz deckt sich dieses Mal annähernd mit dem eigenen Sprachgebrauch: 
Abb. 59: Frage 26, eigener Sprachgebrauch: causette, bavardage, conversation électronique, chat (Frankreich)

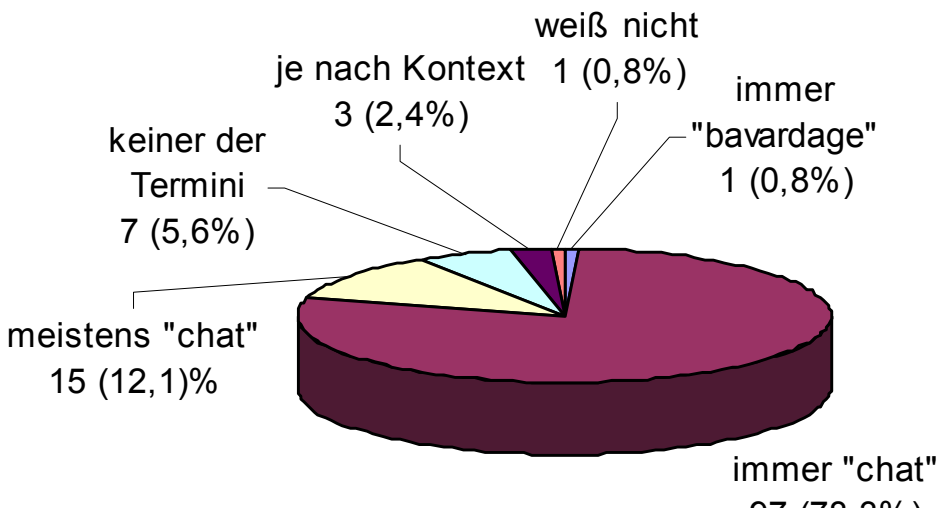

$97(78,3 \%)$

90,4\% der Informanten geben an, meistens oder immer chat zu verwenden. Damit kann chat als gut etabliert gelten (Klasse A nach Rouges-Martinez 1992, 125f.). Die Termini causette und conversation électronique werden gar nicht und bavardage nur von einem Informanten genannt und weisen damit keine oder nur eine äußerst schwache Gebrauchsfrequenz auf (Klasse C, vgl. ebd.). 5,6\% der Informanten geben an, keinen der angegebenen Termini zu verwenden; es wäre denkbar, dass sie z.B. das englische Akronym IRC verwenden.

Wie auch bei den vorangehenden Lexempaaren verstärkt die Frage nach dem eigenen Sprachgebrauch die Differenz zwischen den einzelnen Termini. In diesem Fall wird noch entschiedener zu Gunsten des englischen Terminus chat entschieden. Conversation électronique und causette, die bei der Frage nach der persönlichen Präferenz zusammen sieben Stimmen erhalten haben, werden von keinem der Befragten mehrheitlich oder immer verwendet.

112 der insgesamt 124 Informanten verwenden meistens oder immer den Terminus chat. Da nur ein Informant angibt immer bavardage zu verwenden, entfällt die Auswertung bezüglich der Bewertung der französischen Termini.

Folgende Gründe werden für die Bevorzugung von chat aufgeführt: 


\section{Abb. 60: Frage 28, Gründe für die Bevorzugung des englischsprachigen Terminus chat (Frankreich)}

Nr. Begründung

$1 \quad$ Je me suis déjà habitué(e) à utiliser le terme anglais.

2 Presque tout le monde utilise le terme anglais.

3 Le terme anglais est plus bref.

4 En utilisant le terme anglais, je suis sûr(e) d'être compris(e).

5 Les termes français ne sont pas assez connus.

6 Le terme anglais est plus international.

7 La signification des termes français n'est pas claire.

8 Je ne connais pas les termes français.

9 Les connotations des termes français ne correspondent pas aux connotations qui sont liées au terme anglais.

10 Les formulations des termes français sont trop compliquées.

11 La signification des termes français ne correspond pas à celle du terme anglais.

12 Les termes français ne sont pas assez proches du terme anglais.

13 Il y a trop d'équivalents français pour un seul terme anglais.

14 - Je n'aime pas suivre les propositions officielles.

- Il n'est pas possible de créer des termes dérivés (du type: logiciel, progiciel, ludiciel).

15 Pour paraitre compétent, il faut se servir de la terminologie anglaise.

16 Autre :

- Appelons un chat un chat...

- Clavardage

- J'utilise chat ou dialogue en direct.

- J'utilise aussi salon de discussion (en direct) [...] !

C’est moins rapide à prononcer mais ça présente l'avantage d'être plus compréhensible pour les novices $[\ldots]$.

- Les termes français sont laids.

- $\quad$ Proche de «Tchacher».

- Utiliser le terme anglais dans la langue française permet d'associer au mot la notion d'Internet, sans plus d'explications. Bavardage ne le permet pas.

17 Je ne sais pas.

\section{Absolute Prozentuale \\ Häufigkeit Häufigkeit}

\begin{tabular}{|l|}
\hline 51 \\
\hline 44 \\
\hline 41 \\
\hline 40 \\
\hline \\
\hline 34 \\
\hline 32 \\
\hline 25 \\
\hline 24 \\
\hline 15 \\
\hline
\end{tabular}

13

11,6

11 
Bezüglich der Gründe ergibt sich im Vergleich zu den Fragen 7 (mail/e-mail) und 21 (web/World Wide Web) ein leicht verändertes Bild. Am häufigsten werden 1. die Gewöhnung, 2. die weite Verbreitung des englischen Terminus, 3. die Kürze, 4. die Sicherheit, verstanden zu werden, und 5. die mangelnde Bekanntheit der französischen Termini genannt. Während die Kürze bei den Fragen 7 und 21 an erster Stelle steht, nimmt sie hier mit zehn Stimmen Abstand zur Gewöhnung den dritten Platz ein. Die Argumente, der englische Terminus sei weiter verbreitet als das/die französische/n Äquivalent/e und gewähre die Sicherheit, verstanden zu werden, stehen bei allen drei Fragen (7, 21 und 28) an den ersten fünf Positionen. Neu ist hier im Vergleich zu den Fragen 7 und 21 der Verweis auf die mangelnde Bekanntheit der französischen Termini. Dieser Punkt ist in der Tat auffällig, wie insbesondere die Auswertung der Frage 22 (vgl. Abb. 53 und 54) gezeigt hat, in der causette von nur sechs Informanten als bekannt angegeben wird.

In den unter „Autre“ frei formulierten Begründungen schlagen drei Informanten weitere französische Neologismen vor: Clavardage, dialogue en direct und salon de discussion (en direct), ein Informant macht auf die Nähe zum (Franglais-)Verb tchacher aufmerksam.

Die Auswertung der Fragen 22 bis 28 zeigt, dass chat sowohl bezüglich der passiven als auch der aktiven Akzeptanz weit vor den französischen Äquivalenten causette und bavardage liegt. Das offizielle französische Ersatzwort causette ist kaum bekannt. Der in 5.3.1 formulierten Hypothese „Chat wird aufgrund seiner Kürze und aufgrund der doppeldeutigen französischen Äquivalente häufiger verwendet als die französischen Neologismen causette und bavardage" kann bezüglich der häufigeren Verwendung von chat zugestimmt werden. Entscheidender als die Kürze des Terminus ist in diesem Fall jedoch die Gewöhnung der Befragten an den englischsprachigen Terminus.

\subsubsection{Die Termini pirate, fouineur und cracker}

Bevor die Fragen zu dieser Lexemgruppe ausgewertet werden, seien einige definitorische Erläuterungen vorangestellt. Im allgemeinen Verständnis liegen die englischen Termini hacker und cracker im frankophonen Sprachraum sehr eng beieinander. Im Deutschen hat Hacker sogar die negative Bedeutung, die eigentlich der englischsprachige Terminus cracker innehat (vgl. Kap. 5, Fußnote 4; Glossar). Im Rahmen der offiziellen französischen Internet-Terminologie gibt es zwei Einträge, einen für engl. hacker, einen für engl. cracker. Während hacker durch das französische Wort fouineur ersetzt wird, wird engl. cracker durch das französische Wort pirate ersetzt. Dass die Übergänge zwischen den Termini hacker und cracker fließend sind, zeigt auch die Tatsache, dass fouineur den Verweis auf pirate enthält:

„Définition: Personne passionnée d'informatique qui, par jeu, curiosité, défi personnel ou par souci de notoriété, sonde, au hasard plutôt qu'à l'aide de manuels techniques, les possibilités matérielles et logicielles des systèmes informatiques afin de pouvoir éventuellement s’y immiscer. 
(Source : Office de la langue française du Québec)

Voir aussi : pirate.

Équivalent étranger : hacker“ (Erlass vom 16. März 1999, vgl. DGLF 1999, o.S.).

Da kein anderes Wort gefunden werden konnte, das pirate inhaltlich ähnelt und in diesen Kontext passt, wurde als Testwort fouineur ausgewählt.

Die Frage 29 nach dem Bekanntheitsgrad der Termini wurde wie folgt beantwortet:

Abb. 61: Frage 29, Bekanntheitsgrad der Termini pirate, fouineur und cracker (absolute Häufigkeit, Frankreich)

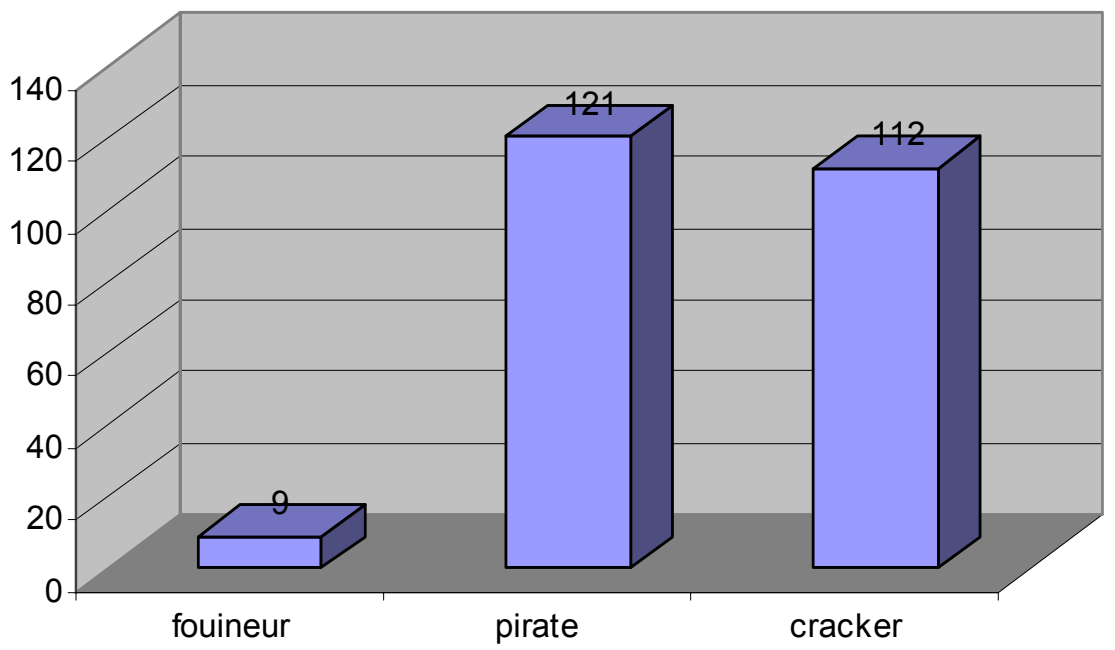

Abb. 62: Frage 29, Bekanntheitsgrad der Termini pirate, fouineur und cracker (prozentuale Häufigkeit, Frankreich)

\begin{tabular}{|l|r|}
\hline Termini & $\mathbf{\%}$ \\
\hline Pirate & 97,6 \\
\hline Cracker & 90,3 \\
\hline Fonineur & 7,3 \\
\hline
\end{tabular}

Sowohl pirate als auch cracker können nach den von Gasquet/Villebrun $(1994,117)$ aufgestellten Kategorien als sicher etabliert eingestuft werden. Dabei ist der französische Terminus bekannter als der englische. Hingegen kennen nur sehr wenige der Informanten franz. fouineur, das offizielle Ersatzwort zu engl. hacker, weswegen es nicht als etabliert gelten kann.

Es folgte die Frage, ob es einen Bedeutungsunterschied zwischen pirate und cracker gebe. 
Abb. 63: Frage 30, Synonymie der Termini pirate und cracker (Frankreich)

\begin{tabular}{|l|r|r|} 
& \multicolumn{1}{|c|}{$\begin{array}{l}\text { Absolute } \\
\text { Häufigkeit }\end{array}$} & $\begin{array}{l}\text { Prozentuale } \\
\text { Häufigkeit }\end{array}$ \\
\hline Synonym & 109 & 87,9 \\
\hline $\begin{array}{l}\text { Bedeutungs- } \\
\text { unterschied }\end{array}$ & 1 & 0,8 \\
\hline $\begin{array}{l}\text { Termini un- } \\
\text { bekannt / } \\
\text { Weiß nicht. }\end{array}$ & 14 & 11,3 \\
\hline Insgesamt & 124 & 100,0 \\
\hline
\end{tabular}

Nur ein Informant hält die beiden Termini nicht für synonym und begründet dies damit, dass sich nur cracker eindeutig auf den informatischen Kontext beziehe, wohingegen pirate ohne den Zusatz informatique eine weitere Bedeutung habe ${ }^{16}$.

Die Frage nach den persönlichen Präferenzen verstärkt den Abstand zwischen engl. cracker und franz. pirate:

Abb. 64: Frage 32, persönliche Präferenz(en): pirate, fouineur, cracker (absolute Häufigkeit, Frankreich)

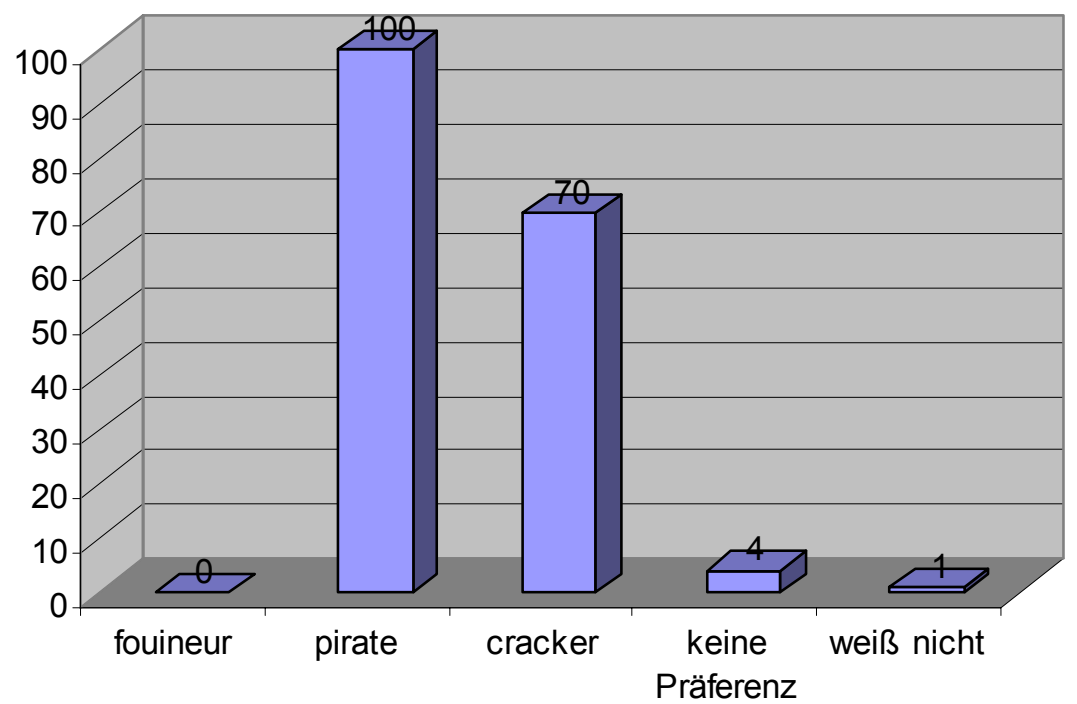

16 Die wörtliche Antwort lautet: „Cracker $=$ pirate informatique. Pirate $=$ sens plus large.“ 
Abb. 65: Frage 32, persönliche Präferenz(en): pirate, fouineur, cracker (prozentuale Häufigkeit, Frankreich)

\begin{tabular}{|l|r|}
\hline Termini & $\mathbf{0}$ \\
\hline Pirate & 80,6 \\
\hline Cracker & 56,5 \\
\hline Fouineur & 0,0 \\
\hline Keine Präferenz & 3,2 \\
\hline Weiß nicht & 0,8 \\
\hline
\end{tabular}

Der Bekanntheitsgrad beider Termini, franz. pirate und engl. cracker, liegt bei über 90\%. Der französische Terminus wird jedoch eindeutig vorgezogen. Nur etwas mehr als die Hälfte der Befragten plädieren für cracker, über $80 \%$ für pirate. Für das Testwort fouineur stimmt keiner der Informanten.

Die anschließende Frage klärt den eigenen Sprachgebrauch. Die Darstellung erfolgt in tabellarischer Form, da ein Kreisdiagramm aufgrund der Vielzahl der gewählten Antwortoptionen ziemlich unübersichtlich ausfällt.

Abb. 66: Frage 33, eigener Sprachgebrauch: pirate, fouineur, cracker (Frankreich)

\begin{tabular}{|l|r|r|}
\hline & $\begin{array}{l}\text { Absolute } \\
\text { Häufigkeit }\end{array}$ & $\begin{array}{l}\text { Prozentuale } \\
\text { Häufigkeit }\end{array}$ \\
\hline Meistens pirate & 37 & 29,9 \\
\hline Meistens cracker & 24 & 19,4 \\
\hline Immer pirate & 23 & 18,5 \\
\hline Je nach Kontext & 19 & 15,3 \\
\hline Immer cracker & 16 & 12,9 \\
\hline Weiß nicht & 3 & 2,4 \\
\hline Keiner der Termini & 2 & 1,6 \\
\hline Insgesamt & 124 & 100,0 \\
\hline
\end{tabular}

Der Abstand zwischen dem französischen und dem englischen Terminus, der sich zwischen der Frage nach dem Bekanntheitsgrad und der nach der persönlichen Präferenz vergrößert hat, wird bei der Frage 33 nach der aktiven Akzeptanz wieder geringer. Weder franz. pirate noch engl. cracker können als gut etabliert gelten. Vielmehr weisen beide Termini mit 48,4\% (pirate) bzw. 32,3\% (cracker) der Stimmen eine mittlere Gebrauchsfrequenz auf (Klasse B nach Rouges-Martinez 1992, 125f.). Der französische Terminus wird immer noch bedeutend häufiger verwendet als der englische Terminus. 15,3\% der Informanten machen ihre Entscheidung für einen der beiden Termini vom Kontext abhängig.

Es fällt bei den Fragen 29, 32 und 33 auf, dass der Bekanntheitsgrad, die Präferenz und die aktive Akzeptanz von pirate über der des englischsprachigen Äquivalents liegen. Allerdings ist der Unterschied zwischen dem französischen und dem 
englischsprachigen Terminus nicht so groß wie beispielsweise zwischen franz. page d'accueil und engl. bomepage: page d'accueil wird von fast $70 \%$ und der englische Terminus nur von knapp 18\% der Befragten verwendet (vgl. Frage 12).

Auch bezüglich der Lexeme pirate und cracker kann die Hypothese bestätigt werden, dass die persönliche Präferenz nicht zwangsläufig mit dem eigenen Sprachgebrauch übereinstimmt. Der Abstand zwischen der Präferenz der Termini pirate und cracker liegt bei 24,1\%, während der Abstand bezüglich des eigenen Sprachgebrauchs nur noch bei 16,1\% liegt. Generalisierend lässt sich aber feststellen, dass der Terminus, der die höchste Quote bei der persönlichen Präferenz erzielt, auch immer häufiger verwendet wird als der/die andere/n.

Da die Differenz zwischen der Verwendungshäufigkeit der beiden Termini mit $16,1 \%$ nicht so eindeutig ausfällt wie bei den vier vorangegangenen Lexempaaren und keiner der beiden Termini als gut etabiert gelten kann, werden im Folgenden sowohl die Antworten auf die Frage 34 als auch auf die Frage 35 ausgewertet.

Die folgende Abbildung zeigt, wie die insgesamt 60 Informanten (48,4\%), die angegeben haben meistens oder immer den französischen Terminus pirate zu verwenden, diesen bewerten.

\section{Abb. 67: Frage 34, Bewertung des französischen (Internet-) Neologismus pirate (Frankreich)}

\begin{tabular}{l|l|l|}
\hline Kriterium & $\begin{array}{l}\text { Skalenendpunkte } \\
\text { im Fragebogen }\end{array}$ & $\begin{array}{l}\text { Durchschnittlicher } \\
\text { Akzeptanzwert }\end{array}$ \\
\hline $\begin{array}{l}\text { Bekanntheit (Bekanntheit } \\
\text { vs. Unbekanntheit) }\end{array}$ & $\begin{array}{l}\text { connu-inconnu } \\
1-5\end{array}$ & 1,27 \\
\hline $\begin{array}{l}\text { Schönheit (Schönheit vs. } \\
\text { Hässlichkeit) }\end{array}$ & $\begin{array}{l}\text { beau-laid } \\
1-5\end{array}$ & 2,35 \\
\hline $\begin{array}{l}\text { Verständlichkeit (Verständ- } \\
\text { lichkeit vs. Unverständlich- } \\
\text { keit) }\end{array}$ & $\begin{array}{l}\text { compréhensible-in- } \\
1-5\end{array}$ & 1,34 \\
\hline $\begin{array}{l}\text { Nützlichkeit (Nützlichkeit } \\
\text { vs. Nutzlosigkeit) }\end{array}$ & $\begin{array}{l}\text { utile - inutile } \\
1-5\end{array}$ & 1,82 \\
\hline $\begin{array}{l}\text { Adäquatheit (Adäquatheit } \\
\text { vs. Inadäquatheit) }\end{array}$ & $\begin{array}{l}\text { adéquat-inapproprié } \\
1-5\end{array}$ & 1,58 \\
\hline $\begin{array}{l}\text { Etabliertheit (Altbestand } \\
\text { des Lexikons vs. Neuheit) }\end{array}$ & $\begin{array}{l}\text { établi-nouveau } \\
1-5\end{array}$ & 1,45 \\
\hline $\begin{array}{l}\text { Natürlichkeit (Normalität } \\
\text { vs. Künstlichkeit) }\end{array}$ & $\begin{array}{l}\text { normal-artificiel } \\
1-5\end{array}$ & 1,70 \\
\hline $\begin{array}{l}\text { Komplexität (Einfachheit } \\
\text { vs. Kompliziertheit) }\end{array}$ & $\begin{array}{l}\text { simple-complexe } \\
1-5\end{array}$ & 1,34 \\
\hline $\begin{array}{l}\text { Korrektheit (Korrektheit } \\
\text { vs. Unkorrektheit) }\end{array}$ & $\begin{array}{l}\text { correct-incorrect } \\
1-5\end{array}$ & 1,63 \\
\hline
\end{tabular}


Bezüglich seiner Bekanntheit erhält pirate den besten Wert, bezüglich seiner ästhetischen Qualitäten den schlechtesten, der mit einem Wert von 2,35 allerdings immer noch eher zur Schönheit (1) als zur Hässlichkeit (5) tendiert. Werden alle neun Werte zusammengefasst, liegt die Bewertung bei durchschnittlich 1,61 Punkten und ist damit als überaus günstig für den französischen Terminus einzustufen. Damit schneidet franz. pirate fast so gut in der Bewertung der Informanten ab wie page d'accueil, das einen durchschnittlichen Akzeptanzwert von 1,56 erhält.

40 Informanten $(32,3 \%)$ haben angegeben meistens oder immer den englischen Terminus cracker zu verwenden. Sie begründen ihre Entscheidung wie folgt:

Abb. 68: Frage 35, Gründe für die Bevorzugung des englischsprachigen Terminus cracker (Frankreich)

\begin{tabular}{|c|c|c|c|}
\hline Nr. & Begründung & $\begin{array}{l}\text { Absolute } \\
\text { Häufigkeit }\end{array}$ & $\begin{array}{l}\text { Prozentuale } \\
\text { Häufigkeit }\end{array}$ \\
\hline 1 & $\begin{array}{l}\text { - En utilisant le terme anglais, je suis } \\
\text { sûr(e) d'être compris(e). } \\
\text { - Je me suis déjà habitué(e) à utiliser } \\
\text { le terme anglais. }\end{array}$ & 20 & 50,0 \\
\hline 2 & Le terme anglais est plus international. & 14 & 35,0 \\
\hline 3 & $\begin{array}{l}\text { Presque tout le monde utilise le terme } \\
\text { anglais. }\end{array}$ & 13 & 32,5 \\
\hline 4 & $\begin{array}{l}\text { Les connotations des termes français } \\
\text { ne correspondent pas aux connotations } \\
\text { qui sont liées au terme anglais. }\end{array}$ & 12 & 30,0 \\
\hline 5 & $\begin{array}{l}\text { La signification des termes français } \\
\text { n'est pas claire. }\end{array}$ & 7 & 17,5 \\
\hline 6 & $\begin{array}{l}\text { Les termes français ne sont pas assez } \\
\text { proches du terme anglais. }\end{array}$ & 6 & 15,0 \\
\hline 7 & $\begin{array}{l}\text { La signification des termes français ne } \\
\text { correspond pas à celle du terme anglais. }\end{array}$ & 3 & 7,5 \\
\hline 8 & $\begin{array}{l}\text { - Il n'est pas possible de créer des } \\
\text { termes dérivés (du type: logiciel, } \\
\text { progiciel, ludiciel). } \\
\text { - Les termes français ne sont pas } \\
\text { assez connus. } \\
\text { - Pour paraittre compétent, il faut se } \\
\text { servir de la terminologie anglaise. }\end{array}$ & 1 & $\begin{array}{l}2,5 \\
2,5\end{array}$ \\
\hline 9 & $\begin{array}{l}\text { Autre : } \\
\text { - J'utilise pirateur. }\end{array}$ & 1 & 2,5 \\
\hline
\end{tabular}

Die am häufigsten genannten Gründe sind 1. die Sicherheit, verstanden zu werden, sowie die Gewöhnung an den englischsprachigen Terminus, 2. die Internationalität und 3. die weite Verbreitung des englischsprachigen Terminus. Am 
vierthäufigsten wird angeführt, dass die Konnotationen des französischen Terminus nicht denen des englischsprachigen Terminus entsprächen. Dieser Grund könnte darauf anspielen, dass franz. pirate auch außerhalb des Wortfeldes Computer/Internet existiert (vgl. Frage 31 nach dem Bedeutungsunterschied).

Die in 5.3.1 fomulierte Arbeitshypothese „Cracker wird aufgrund seiner langen Existenz als Computer-Terminus einen höheren Bekanntheits- und Verwendungsgrad aufweisen als pirate" kann nicht bestätigt werden. Das französische Wort pirate liegt sowohl bezüglich der passiven als auch bezüglich der aktiven Akzeptanz vor seinem englischsprachigen Konkurrenten. Allerdings ist der Abstand nicht so groß wie beispielsweise zwischen page d'accueil und homepage.

\subsubsection{Die Termini fournisseur d'accès, pourvoyeur d'accès und (access) provider}

Die Frage nach dem Bekanntheitsgrad der Termini der sechsten und letzten Lexemgruppe wurde wie folgt beantwortet:

Abb. 69: Frage 36, Bekanntheitsgrad der Termini fournisseur d'accès, pourvoyeur d'accès und (access) provider (absolute Häufigkeit, Frankreich)

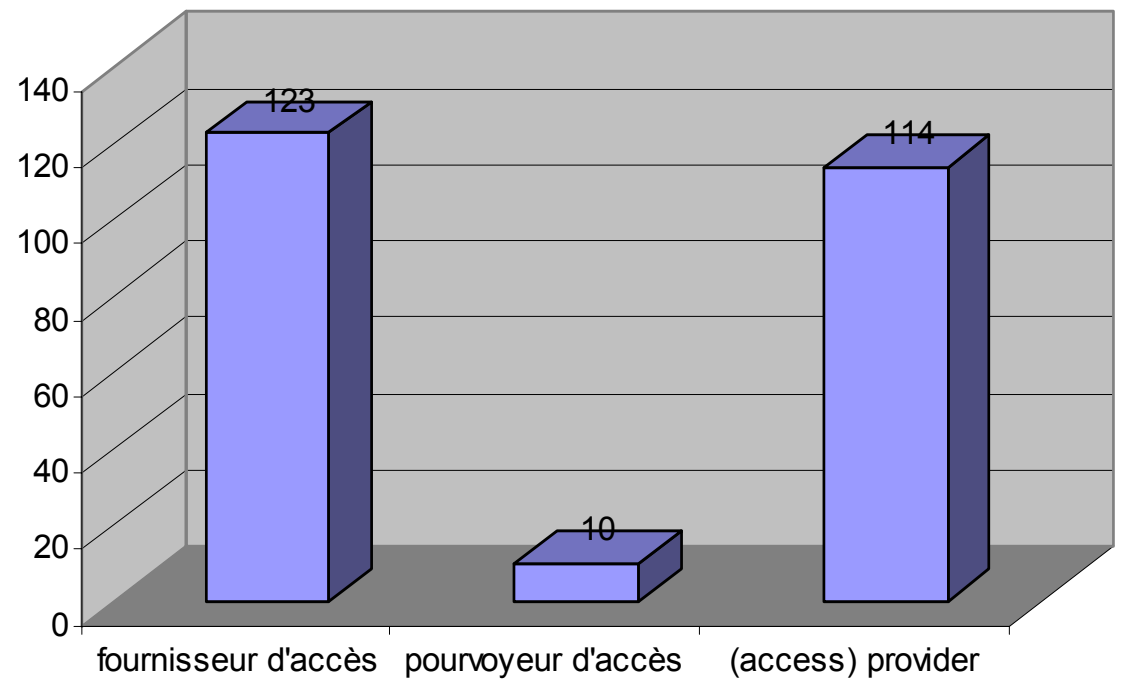

Abb. 70: Frage 36, Bekanntheitsgrad der Termini fournisseur d'accès, pourvoyeur d'accès und (access) provider (prozentuale Häufigkeit, Frankreich)

\begin{tabular}{|l|r|}
\hline Termini & $\mathbf{0}$ \\
\hline Fournisseur d'accès & 99,2 \\
\hline (Access) provider & 91,9 \\
\hline Pourvoyeur d'accès & 8,1 \\
\hline
\end{tabular}


Über 90\% der Befragten kennen die beiden Termini franz. fournisseur d'accès und engl. (access) provider. Wie auch im Falle von page d'accueil und pirate ist der französische Terminus einige Prozentpunkte bekannter als der englische. Sowohl foumisseur d'accès als auch (access) provider können nach dem von Gasquet/Villebrun (1994, 117) aufgestellten Schema als sicher etabliert gelten. Das erfundene Testwort pourvoyeur d'accès meinen $8,1 \%$ zu kennen.

Ein eindeutiges Bild ergibt die Frage nach der Synonymie der Termini:

Abb. 71: Frage 37, Synonymie der Termini fournisseur d'accès und (access) provi$\operatorname{der}$ (Frankreich)

\begin{tabular}{|l|r|r|} 
& $\begin{array}{l}\text { Absolute } \\
\text { Häufigkeit }\end{array}$ & $\begin{array}{l}\text { Prozentuale } \\
\text { Häufigkeit }\end{array}$ \\
\hline Synonym & 122 & 98,4 \\
\hline $\begin{array}{l}\text { Bedeutungs- } \\
\text { unterschied }\end{array}$ & 0 & 0,0 \\
\hline $\begin{array}{l}\text { Termini un- } \\
\text { bekannt / } \\
\text { Weiß nicht. }\end{array}$ & 2 & 1,6 \\
\hline Insgesamt & 124 & 100,0 \\
\hline
\end{tabular}

Keiner der Befragten stellt einen Bedeutungsunterschied zwischen fournisseur d'accès und (access) provider fest. Insofern entfällt die Auswertung der Frage 38.

Bei der Frage nach den persönlichen Präferenzen vergrößert sich wiederum der Abstand zwischen dem französischen und dem englischsprachigen Terminus:

Abb. 72: Frage 39, persönliche Präferenz(en): fournisseur d'accès, pourvoyeur d'accès, (access) provider (absolute Häufigkeit, Frankreich)

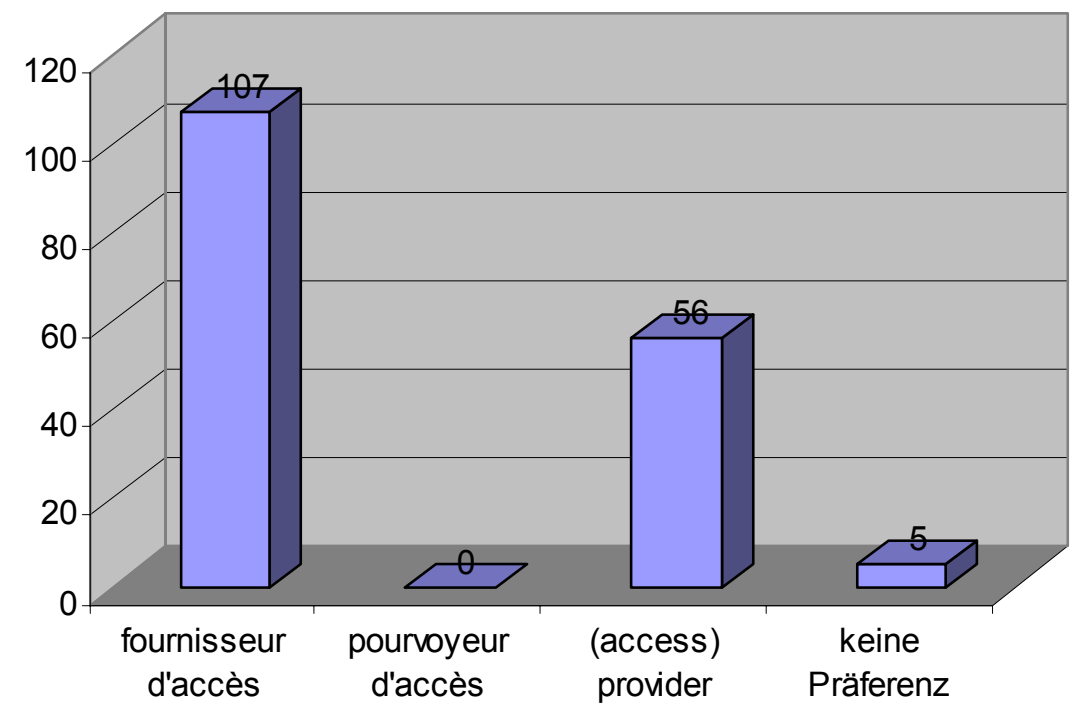


Abb. 73: Frage 39, persönliche Präferenz(en): fournisseur d'accès, pourvoyeur d'accès, (access) provider (prozentuale Häufigkeit, Frankreich)

\begin{tabular}{|l|r|}
\hline Termini & $\mathbf{0}$ \\
\hline Fournisseur d'accès & 86,3 \\
\hline (Access) provider & 45,2 \\
\hline Pourvoyeur d'accès & 0,0 \\
\hline Keine Präferenz & 4,0 \\
\hline
\end{tabular}

Bezüglich der Präferenzen verhält es sich hier ähnlich wie bei den Lexempaaren page d'accueil/homepage und pirate/cracker. Der Bekanntheitsgrad, d.h. die passive Akzeptanz aller Termini, liegt über 90\%, wobei der französische Terminus jeweils etwas bekannter ist als der englische. Bei den Präferenzen jedoch fällt die englische Bezeichnung jeweils hinter der französischen zurück. Franz. page d'accueil und pirate werden von 83,9\% bzw. 80,6\% der Informanten bevorzugt, engl. bomepage und cracker von 39,5\% bzw. 56,5\%. In diese Reihe lässt sich auch das Lexempaar fournisseur d'accès/ (access) provider einordnen. Die französische Bezeichnung wird von $86,3 \%$ als Präferenz angegeben, die englische nur von $45,2 \%$.

Dass franz. fournisseur d'accès beliebter ist als engl. (access) provider bestätigt und verstärkt die Auswertung der folgenden Frage:

Abb. 74: Frage 40, eigener Sprachgebrauch: fournisseur d'accès, pourvoyeur d'accès, (access) provider (Frankreich)

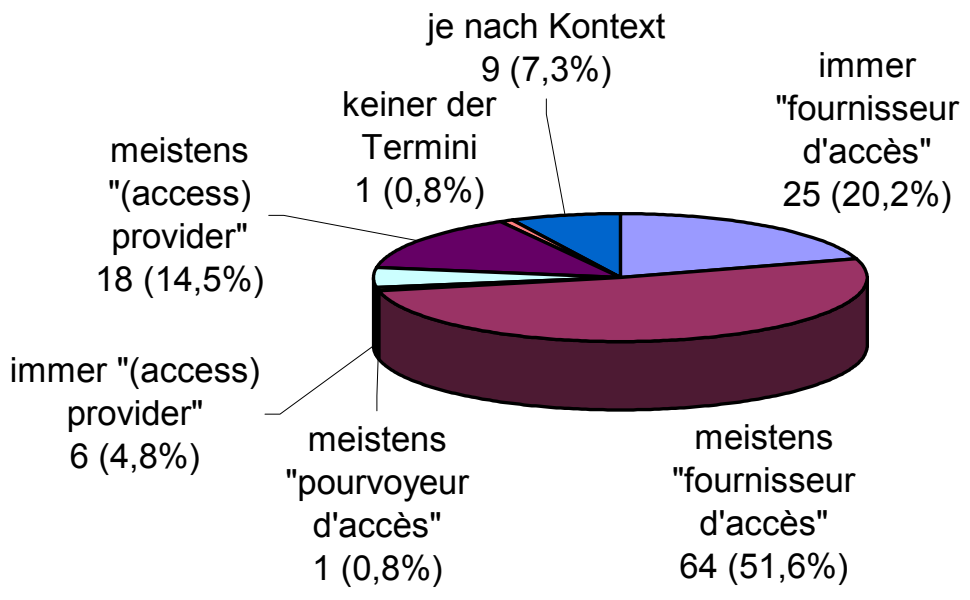

$71,8 \%$ geben an, meistens oder immer das franz. fournisseur d'accès zu verwenden. Für das engl. (access) provider sprechen sich nur 19,3\% aus. Ein Informant gibt sogar an, meistens das Testwort pourvoyeur d'accès zu verwenden, das von niemandem als 
persönliche Präferenz angegeben wird - ein Flüchtigkeitsfehler? 7,3\% entscheiden in Abhängigkeit vom jeweiligen Kontext, welchen der Termini sie verwenden. Nach dem dreistufigen Schema zur Bestimmung des Etablierungsgrades kann fournisseur d'accès als im Sprachgebrauch gut etabliert gelten, während (access) provider mit unter 30\% als schwach etabliert gilt (vgl. Rouges-Martinez 1992, 125f.).

Im Hinblick auf die Sprachverwendung, die aktive Akzeptanz, verhält sich das Lexempaar fournisseur d'accès/ (access) provider wie die anderen Lexempaare. Die aktive Akzeptanz des französischen Neologismus liegt jeweils etwas unterhalb der persönlichen Präferenz ${ }^{17}$. Die aktive Akzeptanz von fournisseur d'accès liegt bei $71,8 \%$. Damit liegt sie 14,5 Prozentpunkte unter der persönlichen Präferenz (86,3\%), die wiederum um 12,9 Prozentpunkte unter dem Bekanntheitsgrad (99,2\%) liegt.

Da 89 Informanten (71,8\%) für die Verwendung von fournisseur d'accès und nur 24 Informanten (19,3\%) für die Verwendung von (access) provider plädiert haben, wird im Folgenden nur die Frage 41 nach der Bewertung des französischen Neologismus ausgewertet. Auf die Auswertung der Bewertung des Testwortes pourvoyeur d'accès, das ein Informant eigenen Angaben zufolge meistens verwendet, wird verzichtet.

\footnotetext{
${ }_{17}$ Bei mail liegt die Verwendungsquote mit 54,8\% nur ganz knapp (3,2\%) unter dem hinsichtlich der persönlichen Präferenz errechneten Prozentsatz. Bei franz. page d'accueil beträgt die Differenz zwischen der Präferenz (83,9\%) und der aktiven Akzeptanz (68,6\%) 15,3 Prozentpunkte. Ähnlich knapp wie bei mail ist mit 7,2 Prozentpunkten auch die Differenz zwischen der Präferenz (94,3\%) und der aktiven Akzeptanz (87,1\%) von web. Bei chat beträgt die Differenz 4,9 Prozentpunkte, bei pirate fällt sie mit 32,2 Prozentpunkten Differenz am größten aus. Pirate hat sich im Unterschied zu page d'accueil und fournisseur d'accès (noch) nicht sicher im Sprachgebrauch etablieren können.
} 
Abb. 75: Frage 41, Bewertung des französischen Neologismus fournisseur d'accès (Frankreich)

\begin{tabular}{|l|r|r|}
\hline Kriterium & $\begin{array}{l}\text { Skalenendpunkte } \\
\text { im Fragebogen }\end{array}$ & $\begin{array}{l}\text { Durchschnittlicher } \\
\text { Akzeptanzwert }\end{array}$ \\
\hline $\begin{array}{l}\text { Bekanntheit (Bekanntheit } \\
\text { vs. Unbekanntheit) }\end{array}$ & $\begin{array}{l}\text { connu-inconnu } \\
1-5\end{array}$ & 1,45 \\
\hline $\begin{array}{l}\text { Schönheit (Schönheit vs. } \\
\text { Hässlichkeit) }\end{array}$ & $\begin{array}{l}\text { beau - laid } \\
1-5\end{array}$ & 2,61 \\
\hline $\begin{array}{l}\text { Verständlichkeit (Ver- } \\
\text { ständlichkeit vs. Unver- } \\
\text { ständlichkeit) }\end{array}$ & $\begin{array}{l}\text { compréhensible - in- } \\
\text { compréhensible }\end{array}$ & 1,46 \\
\hline $\begin{array}{l}\text { Nützlichkeit (Nützlichkeit } \\
\text { vs. Nutzlosigkeit) }\end{array}$ & $\begin{array}{l}\text { utile - inutile } \\
1-5\end{array}$ & 1,72 \\
\hline $\begin{array}{l}\text { Adäquatheit (Adäquatheit } \\
\text { vs. Inadäquatheit) }\end{array}$ & $\begin{array}{l}\text { adéquat-inapproprié } \\
1-5\end{array}$ & 1,36 \\
\hline $\begin{array}{l}\text { Etabliertheit (Altbestand } \\
\text { des Lexikons vs. Neuheit) }\end{array}$ & $\begin{array}{l}\text { établi-nouveau } \\
1-5\end{array}$ & 1,93 \\
\hline $\begin{array}{l}\text { Natürlichkeit (Normalität } \\
\text { vs. Künstlichkeit) }\end{array}$ & $\begin{array}{l}\text { normal-artificiel } \\
1-5\end{array}$ & 1,75 \\
\hline $\begin{array}{l}\text { Komplexität (Einfachheit } \\
\text { vs. Kompliziertheit) }\end{array}$ & $\begin{array}{l}\text { simple- complexe } \\
1-5\end{array}$ & 2,15 \\
\hline $\begin{array}{l}\text { Korrektheit (Korrektheit } \\
\text { vs. Unkorrektheit) }\end{array}$ & $\begin{array}{l}\text { correct-incorrect } \\
1-5\end{array}$ & 1,49 \\
\hline
\end{tabular}

Bezüglich der Ästhetik schneidet der französische Neologismus am schlechtesten ab $(2,61)$, jedoch nähert sich dieser Wert eher dem positiven als dem negativen Pol. Am besten schneidet fournisseur d'accès bezüglich seiner Adäquatheit ab $(1,36)$. Als durchschnittlicher Wert für alle neun Bewertungskategorien ergibt sich 1,77.

Damit schneidet fournisseur d'accès etwas schlechter ab als die Termini page d'accueil $(1,56)$ und pirate $(1,61)$.

Auf eine ausführliche Auswertung der Frage 42 wird verzichtet. Die folgenden beiden Gründe für den Gebrauch von (access) provider wurden am häufigsten genannt: 1. Gewöhnung an den englischsprachigen Terminus (14 Informanten) und 2. seine Kürze (13 Informanten).

Zusammenfassend lässt sich hinsichtliches des Lexempaares fournisseur d'accès/ (access) provider feststellen, dass sich beide Termini in der Fachwelt etabliert haben und dort allgemein bekannt sind. Hinsichtlich der aktiven Akzeptanz liegt fournisseur d'accès weit vor dem englischsprachigen Terminus (access) provider. Die in 5.3.1 formulierte Arbeitshypothese „Die Neologismen page d'accueil und fournisseur d'accès werden einen höheren Akzeptanzwert erhalten als die entsprechenden Anglizismen homepage und (access) provider" kann bezüglich der aktiven Akzeptanz auch für fournisseur d'accès bestätigt werden. 


\subsubsection{Zusammenfassung und Schlussfolgerungen}

Folgende sechs Lexemgruppen wurden von den insgesamt 124 französischen Informatikern hinsichtlich ihres Bekanntheitsgrades (passive Akzeptanz), ihrer Synonymie, der persönlichen Präferenzen der Befragten, ihrer Verwendung (aktive Akzeptanz), ihrer Charakterisierung (bei französischen Termini) und den Gründen für ihre Verwendung (bei englischsprachigen Termini) beurteilt:

- courrier électronique, message électronique, mél, courriel, messagerie électronique, lettre électronique, e-mail und mail,

- page d'accueil, page d'introduction und homepage,

- toile d'araignée mondiale, toile mondiale, toile, T.A.M., réseau mondial, World Wide Web und web,

- causette, bavardage, conversation électronique und chat,

- pirate, fouineur und cracker und

- fournisseur d'accès, pourvoyeur d'accès und (access) provider.

In den folgenden Ausführungen werden die Testwörter nicht berücksichtigt.

Von den Termini courrier électronique, message électronique, mél, courriel, messagerie électronique, e-mail und mail setzen sich die beiden Anglizismen e-mail und vor allem mail durch. Von den beiden Lexemen page d'accueil und homepage schneidet der französische Terminus besser ab. Bei der Lexemgruppe toile d'araignée mondiale, toile mondiale, toile, T.A.M., World Wide Web und web setzt sich wiederum der Anglizismus web gegenüber den anderen Termini durch. Von den Termini causette, bavardage und chat setzt sich engl. chat mit großem Abstand vor den anderen Termini durch. Etwas ausgeglichener ist es bei pirate und cracker. Beide Termini werden verwendet, pirate jedoch häufiger als sein englischsprachiger Konkurrent. Beim Lexempaar fournisseur d'accès und (access) provider erhält der französische Terminus das höhere Votum. Bezüglich der aktiven Akzeptanz setzen sich somit drei französische Neologismen und drei Anglizismen durch. Dieses Ergebnis zeigt, dass die befragten Informatiker nicht generell die englische Terminologie bevorzugen, sondern von Fall zu Fall, d.h. von Lexem zu Lexem, entscheiden. Viele Informanten entscheiden sich aber auch in Abhängigkeit vom Kontext und passen ihren Sprachgebrauch dem situativen Kontext an. Dies zeigt eine große Flexibilität im Umgang mit der Terminologie.

Häufig werden die Termini einer Lexemgruppe nicht als synonym erachtet. Bezüglich der ersten Lexemgruppe gibt ca. die Hälfte der Informanten an, dass es einen Bedeutungsunterschied gebe. Viele Informanten halten auch die Termini page d'accueil und homepage, toile d'araignée mondiale (und seine kürzeren Formen) und World Wide Web/web, bavardage/causette und chat nicht für synonym. Wenn man sich vor Augen führt, dass terminologische Aktivitäten ursprünglich die Erarbeitung eindeutiger, klar definierter Termini zum Ziel haben, kann hinsichtlich der Tätigkeit der Informatik-Kommission nicht von einer durchweg erfolgreichen Terminologiearbeit gesprochen werden. Nur ein einziger französischer Neologismus, nämlich fournisseur d'accès, wird als wirklich synonym mit seinem englischsprachigen Pendant (access) provider eingeschätzt. Dass Bedeutungsunterschiede zwischen dem Anglizismus und dem französischen Neologismus gesehen werden, lässt sich oft 
auch darauf zurückführen, dass viele ausländische Benutzer englischen Termini fälschlicherweise Monosemie unterstellen. Der Anglizismus wird in diesen Fällen in seiner Bedeutungsvielfalt reduziert. Diese Situation ist bei chat gegeben. Chat bezeichnet ursprünglich sowohl ein mündliches Geplauder in einer Face-to-FaceSituation als auch das schriftliche Geplauder in einem Chatraum. Die Antworten der Informanten bezüglich des Bedeutungsunterschiedes zwischen den französischen und englischen Bezeichnungen zeigen deutlich, dass chat in Frankreich nach Ansicht vieler Leute nur die virtuelle Unterhaltung im Internet bezeichnet. Mitunter erhält der Anglizismus auch eine andere Bedeutung, als er ursprünglich in der Gebersprache hat. Dies ist der Fall bei mail. Vielfach wird mail synonym zu email verwendet, obwohl mail die (Brief-)Post und e-mail die elektronische Post bezeichnet. Der Grund liegt auf der Hand: mail ist kürzer als e-mail. Der Kontext, in dem mail benutzt wird, macht deutlich, dass e-mail gemeint ist. Es handelt sich hierbei zugleich um Sprachökonomie. In anderen Fällen kann das Fremdwort in der Nehmersprache eine neue Bedeutung erhalten, die von der ursprünglichen abweicht. Dies konnte bei der Frage nach dem Bedeutungsunterschied zwischen engl. homepage und franz. page d'accueil gezeigt werden. Homepage wurde von vielen Informanten als Bezeichnung einer privaten Internetseite verstanden (ohne diese Bedeutung im anglophonen Sprachraum zu haben), während mit page d'accueil die erste Seite eines Internetangebots verbunden wurde.

Werden französische Termini den Anglizismen vorgezogen, erhalten sie überaus positive Werte auf der von 1-5 reichenden Likert-Skala: page d'accueil wird mit durchschnittlich 1,56, pirate mit 1,61 und fournisseur d'accès mit 1,77 bewertet.

Die Akzeptanz eines Neologismus hängt von sehr vielen Faktoren ab, so dass es schwierig ist, Prognosen zur Akzeptanz oder Nicht-Akzeptanz zu machen. Für Kunstwörter wie das in Québec geschaffene toile d'araignée mondiale und für französische Kurzwörter wie T.A.M. konnte eine geringe Akzeptanz festgestellt werden. Es ist davon auszugehen, dass diese Termini in Frankreich nicht verbreitet waren, als die Informatik-Kommission sie in ihre Liste aufgenommen hat (vgl. 4.1). Positive Beispiele sind page d'accueil, pirate und fournisseur d'accès. Die Gewöhnung der Sprecher an bestimmte Termini darf somit nicht unterschätzt werden. Daher gilt es im Sinne erfolgreicher Terminologiearbeit nicht nur, Termini in die Listen aufzunehmen, die ohnehin schon im Sprachgebrauch verbreitet sind, sondern auch schnell zu handeln, bevor sich die Sprecher an die Anglizismen gewöhnen konnten.

Unter den Gründen, die für die Verwendung der Anglizismen mail/e-mail, web/World Wide web und chat sprechen, werden am häufigsten

- die Sicherheit, bei Verwendung des englischsprachigen Terminus verstanden zu werden,

- der hohe Verbreitungsgrad des englischsprachigen Terminus,

- die Kürze des englischsprachigen Terminus,

- die Gewöhnung an den englischsprachigen Terminus und

- $\quad$ seine internationale Verwendung 
genannt. Persönliche Gründe wie die Gewöhnung oder sprachökonomische Gründe wie die Kürze stehen hinter den beiden ersten Argumenten zurück, die sich eindeutig auf die Kommunikation mit anderen beziehen. Für die befragten Informanten ist es folglich sehr wichtig, mit anderen (Fach-)Leuten so kommunizieren zu können, dass das Verständnis nicht durch die Verwendung nationaler Termini gefährdet wird.

Ähnlich wie die hier befragten Informanten argumentieren auch die von Le Guilly-Wallis befragten Informatiker. Sie begründen die Wahl der Anglizismen wie folgt:

1. Das Englische sei präziser als das Französische.

2. Die Dokumentationen zu Computern seien auf Englisch verfasst.

3. Das Englische sei die internationale Verkehrssprache. Folglich führe eine Aufgabe des Englischen zu einer Abkapselung Frankreichs von der aktuellen Informatik (vgl. Le Guilly-Wallis 1991, 119; 4.3.2).

Bei Gouadec (1994, 143; 4.3.2) werden vier Gründe aufgezählt, weswegen sich das Französische im Informatikbereich kaum gegen das Englische durchsetzen könne. Auch hier zeigen sich einige Parallelen zu den Argumenten, die von den in der WWW-Studie befragten Informatikern angeführt wurden:

1. Verbreitungsgrad angelsächsischer Produkte und ihrer Bezeichnungen,

2. häufige Vermischung zwischen dem Englischen und den Programmiersprachen,

3. schnelle Assimilierung englischer Bezeichnungen (z.B. Siglen), deren Ursprung nicht mehr sichtbar oder nachvollziehbar ist,

4. zu späte bzw. unzutreffende Übersetzung.

Welcher Stellenwert dem Englischen als Verkehrssprache im Bereich der neuen Technologien zukommt, zeigen insbesondere die Kommentare zur Sprachpolitik, die ausführlich in 9.3 ausgewertet werden.

Die Feststellung Plümers (2000) kann aufgrund dieser Ergebnisse nicht bestätigt werden. Plümer $(2000,273)$ schreibt: „Der größte Vorteil von Anglizismen scheint jedoch in deren Kürze zu liegen. Verglichen mit dem Deutschen und dem Französischen verfügt die englische Sprache über sehr viele kurzsilbige Wörter.“ Zwar sind mail/e-mail, web und chat kurze Wörter, aber trifft das nicht auch auf die französische Bezeichnung toile zu? Würde die Entscheidung für einen bestimmten Terminus überwiegend von seiner Kürze bestimmt werden, hätte sich neben engl. web auch das ebenfalls kurze französische Wort toile durchsetzen müssen.

Des Weiteren konnte festgestellt werden, dass sich der Bekanntheitsgrad (passive Akzeptanz) und der eigene Sprachgebrauch (aktive Akzeptanz) in allen Fällen gegenseitig bedingen. Die Lexeme, die von den meisten Informanten als bekannt angegeben werden, weisen in der Regel auch die höchste Verwendungsrate auf. Am größten ist die Differenz zwischen der passiven und aktiven Akzeptanz bei franz. courrier électronique: Es wird von 96\% der Befragten als bekannt angegeben, doch nur $4 \%$ geben an es mehrheitlich zu verwenden. Eine große Diskrepanz besteht auch zwischen der passiven und aktiven Akzeptanz von homepage (91,1\% vs. $17,7 \%$ ) und (access) provider ( $91,9 \%$ vs. $19,3 \%)$. 
An dieser Stelle bietet es sich an, der in 5.3.1 formulierten Hypothese I.1 nachzugehen („Da es sich bei den Informanten um Informatiker handelt, wird die Mehrheit der Termini als bekannt angegeben."). In das nachfolgende Schema fließen alle getesteten Termini mit Ausnahme der Testwörter ein. Sie werden 1. zeilenweise nach ihren Prozentwerten und 2. spaltenweise nach ihrer Sprache unterteilt. Innerhalb der einzelnen Felder sind sie alphabetisch geordnet. In die äußerste, rechte Spalte fließen die vier von Gasquet/Villebrun $(1994,117)$ vorgeschlagenen Kategorien zur Bestimmung des Etablierungsgrades ein.

Abb. 76: Bekanntheits- und Etablierungsgrad aller französischen und englischsprachigen Termini in \% (Frankreich)

Bekanntheitsgrad der Termini

Etablierungsgrad

\begin{tabular}{|c|c|c|c|}
\hline & $\begin{array}{l}\text { Französische } \\
\text { Neologismen }\end{array}$ & $\begin{array}{l}\text { Englischsprachige } \\
\text { Termini }\end{array}$ & \\
\hline $100 \%$ & -- & -- & $\begin{array}{l}\text { 100\% oige Etablie- } \\
\text { rung }\end{array}$ \\
\hline $\begin{array}{l}90- \\
99,9 \%\end{array}$ & $\begin{array}{l}\text { courrier électronique, } \\
\text { fournisseur d'accès, page } \\
\text { d'accueil, pirate }\end{array}$ & $\begin{array}{l}\text { (access) provider, chat, } \\
\text { cracker, e-mail, homepage, } \\
\text { mail, web, World Wide } \\
\text { Web }\end{array}$ & \multirow[t]{2}{*}{$\begin{array}{l}\text { sicherer Etablie- } \\
\text { rungsgrad }\end{array}$} \\
\hline $\begin{array}{l}80- \\
89,9 \%\end{array}$ & -- & -- & \\
\hline $\begin{array}{l}70- \\
79,9 \%\end{array}$ & courriel, mél, toile & -- & \multirow[t]{3}{*}{$\begin{array}{l}\text { unsicherer } \\
\text { Etablierungsgrad }\end{array}$} \\
\hline $\begin{array}{l}60- \\
69,9 \%\end{array}$ & message électronique & -- & \\
\hline $\begin{array}{l}50- \\
59,9 \%\end{array}$ & messagerie électronique & -- & \\
\hline $\begin{array}{l}40- \\
49,9 \%\end{array}$ & -- & -- & \multirow[t]{4}{*}{$\begin{array}{l}\text { schwacher } \\
\text { Etablierungsgrad }\end{array}$} \\
\hline $\begin{array}{l}30- \\
39,9 \%\end{array}$ & -- & -- & \\
\hline $\begin{array}{l}20- \\
29,9 \%\end{array}$ & $\begin{array}{l}\text { bavardage, toile } \\
\text { d'araignée mondiale, } \\
\text { toile mondiale }\end{array}$ & -- & \\
\hline $\begin{array}{l}\text { Weniger } \\
\text { als } 20 \%\end{array}$ & causette, T.A.M. & -- & \\
\hline
\end{tabular}

Es ist augenfällig, dass alle englischen Termini einen sicheren Etablierungsgrad aufweisen, da sie von jeweils mehr als 90\% der Befragten als bekannt angegeben werden. Bei den französischen Ersatzwörtern variiert der Etablierungsgrad von 
sicherer Etablierung (courrier électronique, fournisseur d'accès, page d'accueil, pirate) über unsichere Etablierung (d.h. ein mittlerer Etablierungsgrad: courriel, mél, message électronique, messagerie électronique, toile) bis hin zu einem (extrem) schwachen Etablierungsgrad (bavardage, causette, T.A.M., toile d'araignée mondiale, toile mondiale). Die Hypothese I.1 kann somit bestätigt werden. Die Mehrheit der Termini, 17 französische und englische Termini, sind mindestens der Hälfte der Befragten bekannt, die Mehrheit dieser Termini kann sogar als sicher etabliert gelten. Demgegenüber weisen nur fünf französische Termini einen Bekanntheitsgrad von weniger als $30 \%$ auf und müssen als weitgehend unbekannt eingeordnet werden.

\subsection{Zweites Fragebogenmodul: Auswertung der Kenntnis und Akzeptanz der aktuellen Sprachpolitik und Termi- nologiearbeit \\ 9.2.1 Auswertung der Fragen 44-49}

Bei der Auswertung des zweiten Fragebogenmoduls soll vor allem geklärt werden,

1. welchen Bekanntheitsgrad die aktuelle Sprachpolitik hat und wie sie beurteilt wird,

2. ob bekannt ist, dass es $\mathrm{zu}$ verschiedenen Wortfeldern offizielle Terminologielisten gibt, und ob diese befolgt werden und

3. ob die offizielle Internet-Terminologie (Terminologielisten vom März 1999 und September 2000) bekannt ist.

Einschränkend muss bereits im Vorfeld darauf hingewiesen werden, dass es sich bei den Antworten der Informanten um Selbsteinschätzungen handelt. Diese sind weder objektiv messbar, noch stimmt das von den Informanten angegebene eigene Verhalten in jedem Fall mit dem tatsächlichen Verhalten überein (vgl. Kap. 2, Fußnote 5). Andererseits besteht wenig Grund zur Annahme, dass die Informanten absichtlich unehrlich antworten, da erstens die Fragen weder prekär noch sehr persönlich sind noch anhand der Fragestellung ersichtlich wird, was sozial erwünscht ist bzw. der Norm entspricht ${ }^{18}$. Zweitens ist ein über das Internet ausgefüllter Fragebogen im Unterschied zu einem persönlich ausgehändigten Fragebogen oder einem Interview nahezu ein Garant für die Anonymität der Befragten.

In 9.2.2 werden die Ergebnisse mit den in 5.3.3.1 zur Bewertung der französischen Sprachpolitik und Terminologiearbeit formulierten Hypothesen verglichen.

Die erste Frage des zweiten Fragebogenmoduls erfragt die Kenntnis der aktuellen Sprachpolitik und bezieht sich somit auf die kognitive Einstellungsdimension.

\footnotetext{
18 Albert/Koster $(2002,8)$ nennen das Beispiel, dass Sprecher des Deutschen gefragt wurden, welches Tempus sie zur Bezeichnung von zukünftigen Ereignissen verwendeten. Fast alle Befragten gaben an das Futur zu verwenden. Eine spätere Untersuchung zu ihrer tatsächlichen Sprachproduktion ergab, dass sie allerdings nur in ca. $5 \%$ der Fälle das Futur verwendeten (vgl. zur Diskrepanz zwischen angegebenem und tatsächlichem Verhalten auch das Beispiel in Kap. 2, Fußnote 5).
} 
Abb. 77: Frage 44, Kenntnis der aktuellen Sprachpolitik (Frankreich)

\begin{tabular}{|l|r|r|}
\hline & $\begin{array}{l}\text { Absolute } \\
\text { Häufigkeit }\end{array}$ & $\begin{array}{l}\text { Prozentuale } \\
\text { Häufigkeit }\end{array}$ \\
\hline Oui. & 30 & 24,2 \\
\hline Oui, j’en ai entendu parler. & 67 & 54,0 \\
\hline Non. & 26 & 21,0 \\
\hline Je ne sais pas. & 1 & 0,8 \\
\hline Insgesamt & 124 & 100,0 \\
\hline
\end{tabular}

Nur 24\% der Informanten beantworten die Frage, ob ihnen die aktuelle französische Sprachpolitik zum Schutz der Sprache vor Anglizismen bekannt sei, mit einem uneingeschränkten ,ja“. Die Befragten schränken ihre Antwort mehrheitlich $(54 \%)$ dahingehend ein, dass sie bereits davon gehört hätten, was jedoch nicht impliziert, dass sie auch über die Inhalte informiert sind.

$21 \%$ geben an über die aktuelle Sprachpolitik nicht informiert zu sein.

Es ist somit festzuhalten, dass der Wirbel um die Loi Toubon ganz offensichtlich bleibende Spuren hinterlassen hat: 78,2\% der Befragten wissen zumindest, dass es eine offizielle Sprachpolitik gibt; ein gewisser Teil von ihnen ist sogar über die Inhalte informiert.

An diese Frage nach der Kenntnis der aktuellen Sprachpolitik schließt sich die Frage nach deren Beurteilung an:

Abb. 78: Frage 45, Beurteilung der aktuellen Sprachpolitik (Frankreich)

\begin{tabular}{|l|r|r|}
\hline & $\begin{array}{c}\text { Absolute } \\
\text { Häufigkeit }\end{array}$ & $\begin{array}{l}\text { Prozentuale } \\
\text { Häufigkeit }\end{array}$ \\
\hline Absolument nécessaire. & 7 & 5,6 \\
\hline Souhaitable. & 65 & 52,4 \\
\hline Inutile. & 47 & 37,9 \\
\hline Je ne sais pas. & 5 & 4,1 \\
\hline Insgesamt & 124 & 100,0 \\
\hline
\end{tabular}

Nur 5,6\% der befragten Informatiker halten politische Maßnahmen zum Schutz der französischen Sprache für notwendig. 52,4\% halten derartige Maßnahmen jedoch für wünschenswert. 37,9\% betrachten Sprachpolitik als unnötig.

Bei Fuggers Studie (vgl. 4.3.1) hat sich gezeigt, dass je nach befragter Personengruppe Sprachplanung von 47\% (bzw. 25\%) der Informanten als überflüssig und von 23\% (bzw. 25\%) als unbedingt nötig eingeschätzt wird. Wie man sieht, hängt die Einschätzung, ob Sprachpolitik überflüssig sei, stark vom befragten Personenkreis ab. Unter den befragten Informatikern halten 37,9\% sprachpolitische Maßnahmen für überflüssig. Dieser Prozentsatz liegt ziemlich genau in der Mitte zwischen den beiden von Fugger - je nach befragtem Personenkreis - ermittelten Werten. Hinsichtlich Fuggers zweitem Wert (23\% bzw. 25\% halten Sprachpolitik 
für unbedingt nötig) kann eine deutliche Abweichung nach unten festgestellt werden: Nur 5,6\% der im Sommer 2002 befragten Informatiker halten sprachpolitische Maßnahmen für nötig. Möglicherweise haben die Erfolglosigkeit des ersten Sprachgesetzes sowie die Diskussion um die Verabschiedung der Loi Toubon die öffentliche Meinung inzwischen dahingegend verändert, dass Sprachpolitik nicht mehr als wirkungsvoll und dem zufolge nicht mehr als unbedingt notwendig erachtet wird.

Die folgende Frage 46 ist etwas konkreter als die beiden vorangehenden Fragen und bezieht sich auf die Beurteilung der Terminologielisten. Die Informanten haben die Möglichkeit, eine aus sechs vorgegebenen Antworten auszuwählen.

\section{Abb. 79: Frage 46, Beurteilung der Terminologielisten (Frankreich)}

\begin{tabular}{|l|r|r|}
\hline & $\begin{array}{l}\text { Absolute } \\
\text { Häufigkeit }\end{array}$ & $\begin{array}{l}\text { Prozentuale } \\
\text { Häufigkeit }\end{array}$ \\
\hline Utiles. & 10 & 8,1 \\
\hline Souhaitables. & 15 & 12,1 \\
\hline Pas assez connues. & 38 & 30,6 \\
\hline Inutiles. & 42 & 33,9 \\
\hline Je ne les connais pas. & 14 & 11,3 \\
\hline Rien/Je ne sais pas. & 5 & 4,0 \\
\hline Insgesamt & 124 & 100,0 \\
\hline
\end{tabular}

20,2\% der Informanten befürworten Terminologielisten und beurteilen sie als nützlich bzw. wünschenswert. 30,6\% der Informanten bemängeln, dass die Terminologielisten nicht bekannt genug seien. 33,9\% halten Terminologielisten für überflüssig. 11,3\% geben an, diese nicht zu kennen und geben insofern kein Urteil zu den Listen ab.

Der Prozentsatz derjenigen, die Sprachpolitik ablehnen (37,9\%, vgl. Frage 45), deckt sich fast mit dem Prozentsatz derjenigen, die Terminologielisten ablehnen $(33,9 \%)$.

Lassen sich Parallelen aufdecken zwischen der Bewertung von Terminologielisten und deren Befolgung? Dies soll die nächste Frage klären.

Abb. 80: Frage 47, Befolgen der Terminologielisten (Frankreich)

\begin{tabular}{|l|r|r|}
\hline & $\begin{array}{l}\text { Absolute } \\
\text { Häufigkeit }\end{array}$ & $\begin{array}{l}\text { Prozentuale } \\
\text { Häufigkeit }\end{array}$ \\
\hline Oui. & 3 & 2,4 \\
\hline Non. & 52 & 42,0 \\
\hline Partiellement. & 48 & 38,7 \\
\hline Je ne les connais pas. & 20 & 16,1 \\
\hline Je ne sais pas. & 1 & 0,8 \\
\hline Insgesamt & 124 & 100,0 \\
\hline
\end{tabular}


Nur 2,4\% der Informanten geben an die Terminologielisten in jedem Fall zu befolgen. 38,7\% befolgen sie nach eigenen Aussagen teilweise, 42\% der Befragten überhaupt nicht. 16,1\% geben an, die Listen nicht zu kennen bzw. diese Frage nicht beantworten zu können. Dies deckt sich in etwa mit dem Prozentsatz derer, die in Frage 46 angegeben haben, die Listen nicht zu kennen bzw. die Frage nicht beantworten zu können (15,3\%).

Aus der Zahlenverteilung lässt sich kein eindeutiges Urteil ableiten. Die Anzahl an Informanten, die angeben den Vorschlägen zumindest teilweise Folge zu leisten $(41,1 \%)$, deckt sich annähernd mit der Anzahl derer, die angeben die Listen nicht $\mathrm{zu}$ befolgen (42\%). Dieses ausgeglichene Verhältnis zwischen Befolgen und Nicht-Befolgen spiegelt das Verhältnis bezüglich der Akzeptanz der französischen Termini wider: Von den sechs getesteten Lexemgruppen haben sich in drei Lexemgruppen die französischen Neologismen gegenüber den Anglizismen durchsetzen können (page d'accueil, pirate und fournisseur d'accès). In den anderen drei Fällen liegen die Anglizismen vorn. Dieses ausgeglichene Verhältnis zwischen Akzeptanz und Nicht-Akzeptanz der französischen Neologismen ist ein deutliches Indiz dafür, dass die Angaben der Informanten plausibel sind. Anstelle sich kategorisch für ein Befolgen der französischen Termini zu entscheiden, entscheiden sie von Terminus zu Terminus.

Interessant ist hierbei ein Vergleich mit den Ergebnissen des ersten Fragebogenmoduls. Die Auswertung hat ergeben, dass bestimmte Termini, wie insbesondere page d'accueil und fournisseur d'accès, von der Mehrheit der Informanten passiv (Bekanntheitsgrad) und aktiv (eigener Sprachgebrauch) akzeptiert werden. Andererseits haben $42 \%$ der Informanten angegeben, die offiziellen Terminologielisten niemals zu befolgen. Daraus lässt sich zweifelsohne der Schluss ziehen, dass es vielen Informanten nicht bewusst ist, dass es sich bei Termini wie page d'accueil, pirate und fournisseur d'accès um die offizielle Terminologie handelt. Die Terminologielisten sind offensichtlich nicht nur in unzureichendem Maße bekannt, sondern haben auch ein so negatives Ansehen, dass es 42\% der Befragten kategorisch ablehnen, Vorschläge dieser Listen zu befolgen.

Inwiefern die Befragten die Terminologielisten zur Internet-Terminologie kennen, wird die folgende Frage klären. Bei dieser Frage konnten die Informanten zwischen sieben verschiedenen Antwortvorgaben wählen. 
Abb. 81: Frage 48, Kenntnis der offiziellen Internet-Terminologie (Frankreich)

\begin{tabular}{l|r|r|}
\hline & $\begin{array}{c}\text { Absolute } \\
\text { Häufigkeit }\end{array}$ & $\begin{array}{l}\text { Prozentuale } \\
\text { Häufigkeit }\end{array}$ \\
\hline \begin{tabular}{l|r|} 
Oui, je les connais bien. \\
Oui, je les connais un peu.
\end{tabular} & 0 & 0 \\
\hline $\begin{array}{l}\text { Oui, mais je connais seulement la liste de } \\
1999 .\end{array}$ & 1 & 0,1 \\
\hline $\begin{array}{l}\text { Oui, mais je connais seulement la liste de } \\
\text { 2000. }\end{array}$ & 0 & 0 \\
\hline $\begin{array}{l}\text { J'en ai déjà entendu parler. } \\
\text { Non, pas du tout. }\end{array}$ & 47 & 37,9 \\
\hline Je ne sais pas. & 53 & 42,8 \\
\hline Insgesamt & 3 & 2,4 \\
\hline
\end{tabular}

Keiner der Informanten behauptet von sich, die beiden Listen gut zu kennen. 16,1\% meinen jedoch, die Listen ein wenig zu kennen, und 37,9\% räumen ein, von den Listen gehört zu haben, ohne sie aber inhaltlich zu kennen. Dies entspricht in etwa der Antwortoption „Oui, j'en ai entendu parler“ in Frage 44, in der es um die Kenntnis der französischen Sprachpolitik ging und die von 54\% der Befragten gewählt wurde. Ein Informant gibt an die 1999 publizierte Liste zu kennen.

Den Antworten auf die Frage 48 ist zu entnehmen, dass die Sprachpolitik und die Terminologiearbeit zwar in den Medien oder auf anderen Wegen bekannt gemacht werden, aber die genauen Inhalte entweder nicht besonders verbreitet oder aber von den meisten Leuten aus Desinteresse oder anderen Motiven überlesen werden. Da den Franzosen ein allgemein hohes Interesse für Sprachfragen nachgesagt wird, ist es wahrscheinlicher, dass konkrete Fakten zur Sprachpolitik, wie die Inhalte des Sprachgesetzes und vor allem die Inhalte der verschiedenen Terminologieerlasse, nur ungenügend bekannt gemacht werden. Dafür spricht des Weiteren, dass 42,8\% der befragten Informatiker angeben, die Internet-Terminologie nicht zu kennen, obwohl gerade sie aufgrund ihres Berufes von diesen Termini betroffen sind.

Die folgende Frage hat nur denjenigen Informanten vorgelegen, die auf die Frage 48 mit „Oui, je les connais un peu“ (20 Informanten) bzw. „Oui, mais je connais seulement la liste de 1999“" (ein Informant) geantwortet haben. 
Abb. 82: Frage 49, Gebrauch der offiziellen Internet-Terminologie (Frankreich)

\begin{tabular}{|l|r|r|}
\hline & $\begin{array}{l}\text { Absolute } \\
\text { Häufigkeit }\end{array}$ & $\begin{array}{l}\text { Prozentuale } \\
\text { Häufigkeit }\end{array}$ \\
\hline Non, jamais. & 5 & 23,8 \\
\hline Partiellement. & 15 & 71,4 \\
\hline Je ne sais pas. & 1 & 4,8 \\
\hline Insgesamt & 21 & 100,0 \\
\hline
\end{tabular}

Fünf Informanten geben an niemals die offizielle Internet-Terminologie zu verwenden. Ein Blick in die Datenbank zeigt, dass sie im ersten Fragebogenmodul auf die Fragen nach dem eigenen Sprachgebrauch (5, 12, 19, 26, 33 und 40) Folgendes angegeben haben:

- $\quad$ Frage 5: Alle fünf Informanten verwenden meistens oder immer mail bzw. email,

- Frage 12: Drei Informanten verwenden meistens page d'accueil, einer meistens homepage, einer entscheidet je nach Kontext,

- Frage 19: Alle fünf Informanten verwenden meistens oder immer web,

- Frage 26: Alle fünf Informanten verwenden immer chat,

- Frage 33: Ein Informant verwendet immer, einer meistens pirate, ein Informant verwendet immer, zwei meistens cracker,

- $\quad$ Frage 40: Drei Informanten verwenden meistens fournisseur d'accès, einer immer und einer meistens (access) provider.

Obwohl sie der Meinung sind, niemals die offizielle Terminologie zu verwenden, verwenden drei der Informanten page d'accueil und fournisseur d'accès. Zwei Informanten verwenden pirate. Die Informanten sind sich folglich nicht der Tatsache bewusst, dass es sich bei den Termini page d'accueil, pirate und fournisseur d'accès um die offizielle Internet-Terminologie handelt ${ }^{19}$.

Die 15 Informanten, die eigenen Aussagen zufolge teilweise den Terminologielisten Folge leisten, haben größtenteils für page d'accueil, pirate und fournisseur d'accès plädiert und sind damit - möglicherweise unbewusst - den Terminologielisten gefolgt. Bezüglich der drei anderen Lexemgruppen haben sie dann mehrheitlich für die Anglizismen mail/e-mail, web und chat gestimmt.

\subsubsection{Auswertung der länderspezifischen Hypothesen}

Abschließend sollen die beiden in 5.3.3.1 formulierten Hypothesen zur Bewertung der französischen Sprachpolitik und Terminologiearbeit aufgegriffen werden.

\footnotetext{
${ }_{19}$ Le Guilly-Wallis (1991, 118; vgl. 4.3.2) stellt ebenfalls Unterschiede zwischen metasprachlichen Aussagen über das eigene Sprachverhalten und dem tatsächlichen Sprachverhalten fest: Beispielsweise habe ein von ihr befragter Mitarbeiter der humanwissenschaftlichen Fakultät in Straßburg behauptet, er wisse nicht einmal von der Existenz der Terminologieerlasse, habe in der eigenen Sprachpraxis aber $80 \%$ der vorgeschlagenen Ersatzwörter verwendet.
} 
Die erste Hypothese lautet: „Mehr als die Hälfte der befragten Franzosen hält Sprachpolitik für notwendig." Sie beruht vor allem auf den in 4.3.2 vorgestellten Ergebnissen der Studie Gouadecs (1993). Die von Gouadec befragten Informatiker halten ein Eingreifen des Staates mehrheitlich für wünschenswert, sofern Verstöße gegen die vorherrschende Sprachpolitik nicht sanktioniert werden. Die Antworten auf Frage 45 des zweiten Fragebogenmoduls zeigen, dass auch die Mehrheit der im August 2002 befragten Informatiker sprachpolitischen Maßnahmen positiv gegenüber steht: $58 \%$ der Befragten befürworten sprachpolitische Maßnahmen. Hierbei darf allerdings nicht vergessen werden, dass sich immerhin auch 37,9\% gegen die Sprachpolitik aussprechen ${ }^{20}$.

Die mehrheitliche Befürwortung sprachpolitischer Maßnahmen bedeutet jedoch nicht automatisch, dass sich die Informanten für die konkreten Terminologievorschläge interessieren und diese auch (wissentlich) befolgen, wie die Überprüfung der folgenden Hypothese deutlich macht.

Die zweite Hypothese lautet: „Die Existenz der Terminologieerlasse zur InternetTerminologie sowie deren Inhalt ist der Mehrheit der Informatiker bekannt." Zwar legen die Ergebnisse anderer Studien nicht gerade den Schluss nahe, dass die Terminologielisten in der Öffentlichkeit sonderlich bekannt seien, jedoch wurde bei der Formulierung dieser Hypothese davon ausgegangen, dass insbesondere Leute, die viel mit dem Internet zu tun haben und aus beruflichem Interesse mit der offiziellen Terminologie vertraut sein sollten, auf die entsprechenden Internetseiten mit der offiziellen Internet-Terminologie gestoßen sind. Hinzu kommt die Annahme, dass viele Franzosen aufgrund des Wirbels um die Loi Toubon im Jahre 1994 zumindest von der Existenz der Terminologiekommissionen wissen. Frage 46 macht jedoch deutlich, dass die Terminologielisten noch weiterer Verbreitung und Bekanntmachung bedürfen. 30,6\% der Befragten beurteilen sie als zu wenig bekannt. Auch bezüglich der Kenntnis der Internet-Terminologie kann die Hypothese keineswegs bestätigt werden. Keiner der Informanten behauptet von sich, die beiden Listen zur Internet-Terminologie gut zu kennen. Insgesamt haben nur etwas mehr als 50\% der Informanten eine vage Vorstellung von der offiziellen Internet-Terminologie. Sie wissen somit von der Existenz dieser Terminologieliste(n), kennen aber die genauen Inhalte nicht. Dass jedoch nur ein einziger von 124 befragten französischen Informatikern überhaupt eine der Listen inhaltlich zu kennen meint, liegt weit hinter den Erwartungen zurück, auf denen die Hypothese beruht.

\footnotetext{
${ }^{20}$ In diesem Zusammenhang lohnt es sich, den Standpunkt von Hagège (1987) zum Vergleich heranzuziehen. Hagège lehnt - wie viele der Befragten auch - jegliche Art der künstlichen Sprachpflege ab, die unter der Prämisse steht, das Französische verteidigen zu wollen. Stattdessen setzt er auf den Selbstschutz der Sprache: „Mais le français le plus courant se défend mieux qu'on n'aime à croire“ (Hagège 1987, 93). Die hohe passive und aktive Akzeptanz der Termini page d'accueil, pirate und fournisseur d'accès zeigt, dass der Selbstschutz der Sprache in der Tat nicht zu unterschätzen ist. Es handelt sich deswegen um einen Selbstschutz, weil viele der befragten Informatiker Sprachpolitik und Terminologielisten ablehnen bzw. ihre Inhalte nicht genau kennen und daher in ihrer Entscheidung für die Verwendung der französischen Termini nicht von äußeren Zwängen wie der Sprachpolitik geleitet werden.
} 


\subsection{Drittes Fragebogenmodul: Auswertung der Kommen- tare zur Sprachpolitik und Terminologiearbeit}

Am Ende des Fragebogens bestand nach der Eingabe der biosozialen Daten wie Geschlecht, Alter etc. die Möglichkeit, einen Kommentar zur Sprachpolitik bzw. Terminologiearbeit zu verfassen. Das Verfassen eines Kommentars war optional, wie aus der Formulierung der Anweisung hervorgeht: „Vous pouvez noter ici ce que vous pensez de la politique linguistique (terminologie) !“ 73 der insgesamt 124 französischen Informanten haben von dieser Möglichkeit Gebrauch gemacht.

Bei der Auswertung der Kommentare steht der Inhalt im Vordergrund. Die Auswertung zielt nicht darauf ab zu ermitteln, in wie vielen Kommentaren für und in wie vielen gegen Sprachpolitik und Terminologiearbeit argumentiert wird. Dies war bereits Gegenstand des zweiten Fragebogenmoduls. Hier geht es vor allem um die Argumente, warum Sprachpolitik und/oder Terminologiearbeit befürwortet oder abgelehnt werden. Somit ist die quantitative Dimension zweitrangig, d.h. die Frage, wie viele Personen einen bestimmten Standpunkt vertreten. Daher erfolgte die Auswertung zunächst unter qualitativen Gesichtspunkten: Es wurden inhaltliche Kategorien für die in den Kommentaren enthaltenen Aussagen gebildet. In einem zweiten Schritt wurden alle Kommentare nochmals durchgegangen, die jeweils in ihnen enthaltenen Aussagen isoliert und den entsprechenden Kategorien zugeordnet.

Die Kategorisierung vieler Kommentare ist insofern problematisch, als in einem Kommentar oftmals eine ambivalente Position bezogen wird, wie z.B. beim Sprecher F1:

F1: Elle [la terminologie] arrive beaucoup trop souvent TROP TARD, après que les habitudes aient largement consacré l'usage de mots ou expressions courantes. De plus, elle génère des néologismes qui frisent souvent le ridicule (mél, cédérom, ...). Inversement, quand elle est suffisamment à l'avant-garde de la technique, et cohérente avec l'existant, elle peut donner de très bons résultats (p.ex. le mot logiciel, adopté sans problème par les communautés francophones, en particulier grâce à l'existence de son antonyme matériel).

De plus, elle doit faciliter la tâche des utilisateurs. Si un mot anglais, court, universellement compris et prononcé par tout le monde, existe déjà, à quoi bon se compliquer la vie en créant un nouveau terme qui ne sera compris et utilisé que par quelques pédants.

Dieser Kommentar enthält Aspekte, die sowohl für als auch gegen Sprachpolitik und Terminologiearbeit sprechen. Wichtig ist im Rahmen der Auswahl jedoch nicht der Standpunkt des einzelnen Informanten, sondern welche Argumente für eine bestimmte Position angeführt werden. Dieser Kommentar konnte fünf verschiedenen inhaltlichen Kategorien zugewiesen werden, nämlich den Kategorien „Terminologiearbeit bringt auch gute Ergebnisse hervor [...]“, „Französische Termini kommen häufig zu spät, wenn sich die engl. Termini etabliert und sich die Sprecher an diese gewöhnt haben“, „Französische Neologismen sind häufig lä- 
cherlich“, „Französische Terminologie ist lächerlich, wenn es sich bei den Neologismen lediglich um Französisierungen der Anglizismen handelt [... “ und „Kommunikation: [...] Die Verwendung der englischen Terminologie erleichtert die Kommunikation weltweit und unter frankophonen Sprechern." Mit diesem Verfahren kann hoffentlich etwas mehr Klarheit in dem Bereich erzielt werden, aus welchen Gründen die französische Sprachpolitik bzw. Terminologiearbeit von so vielen Personen kritisiert wird, aber auch, welche Aspekte der Sprachpolitik und Terminologiearbeit positiv bewertet werden.

Zur Auswertung wurden sechs große Kategorien gebildet:

1. Befürwortung der Sprachpolitik,

2. Ablehnung der Sprachpolitik,

3. Pro \& contra Sprachpolitik,

4. Befürwortung der Terminologiearbeit,

5. Ablehnung der Terminologiearbeit,

6. Pro \& contra Terminologiearbeit.

Für jede dieser großen Kategorien wurde eine Tabelle erstellt, die die verschiedenen Argumente enthält, die dieser Kategorie zugeordnet werden konnten. Die Argumente sind in den einzelnen Tabellen nach der Häufigkeit ihrer Nennung geordnet. Bei gleicher Anzahl an Nennungen sind sie alphabetisch sortiert.

In der linken Spalte jeder Tabelle sind die verschiedenen Unterkategorien (Argumente) aufgeführt. In der mittleren Spalte erfolgt die Angabe der Sprechernummern, die den jeweiligen Unterkategorien zugeordnet wurden. Die Angabe der Sprechernummern dient der besseren Nachvollziehbarkeit, welchen Kategorien die Kommentare jeweils zugeordnet wurden. Die 73 von den französischen Informanten formulierten Kommentare sind im Anhang 15.5.2.1 nachzulesen. Die nachträgliche Quantifizierung der einzelnen Kategorien in der rechten Tabellenspalte impliziert keinesfalls Repräsentativität, sondern zeigt nur, ob ein bestimmtes Argument von einem oder von mehreren Informanten genannt wurde. Die Tatsache, dass manche Argumente von mehreren Informanten genannt wurden, lässt allerdings Rückschlüsse auf deren Stellenwert zu.

Zunächst werden die Kommentare ausgewertet, die sich auf die Sprachpolitik beziehen und diese befürworten. 
Abb. 83: Argumente für die Befürwortung der Sprachpolitik (Frankreich)

\section{Befürwortung der Sprachpolitik}

\begin{tabular}{|c|c|c|}
\hline Kategorie & Informanten & Anzahl \\
\hline $\begin{array}{l}\text { Sprachpolitik ist notwendig, wünschens- } \\
\text { wert und nützlich, sollte aber nur in } \\
\text { Maßen vollzogen werden. }\end{array}$ & $\begin{array}{l}\text { F5, F9, F24, } \\
\text { F26, F42, F54, } \\
\text { F68 }\end{array}$ & 7 \\
\hline $\begin{array}{l}\text { Sprachpolitik ist zu befürworten, darf aber } \\
\text { nicht verpflichtend werden. }\end{array}$ & F43, F53, F62 & 3 \\
\hline $\begin{array}{l}\text { Sprachpolitik ist zu befürworten, } \\
\text { allerdings ist eine nur auf Frankreich } \\
\text { bezogene Sprachpolitik wenig sinnvoll. }\end{array}$ & F6 & 1 \\
\hline $\begin{array}{l}\text { Sprachpolitik ist zu befürworten, riskiert } \\
\text { aber, ins Lächerliche abzurutschen. }\end{array}$ & $\mathrm{F} 4$ & 1 \\
\hline $\begin{array}{l}\text { Uneingeschränkte Befürwortung der } \\
\text { Sprachpolitik zum Schutz der französi- } \\
\text { schen Sprache. }\end{array}$ & F40 & 1 \\
\hline
\end{tabular}

Nur ein Informant plädiert uneingeschränkt für sprachpolitische Maßnahmen zum Schutz der französischen Sprache. Sieben Informanten stehen sprachpolitischen Maßnahmen zwar positiv gegenüber, plädieren aber für eine moderate Durchführung entsprechender Maßnahmen. Drei Informanten stimmen für eine Form der Sprachpolitik, die Maßnahmen vorschlage, ohne sie aber vorzuschreiben, und damit auf freiwilliger Basis bleibe.

Die Informanten, die sich gegen sprachpolitische Maßnahmen aussprechen, führen die folgenden Argumente an: 
Abb. 84: Argumente für die Ablehnung der Sprachpolitik (Frankreich)

2. Ablehnung der Sprachpolitik

\begin{tabular}{|c|c|c|}
\hline Kategorie & Informanten & Anzahl \\
\hline $\begin{array}{l}\text { Natürliche Sprachentwicklung / Sprach- } \\
\text { politik kann die natürliche Sprachentwick- } \\
\text { lung nicht aufhalten. }\end{array}$ & $\begin{array}{l}\text { F28, F39, } \\
\text { F41, F46, } \\
\text { F50, F54 }\end{array}$ & 6 \\
\hline $\begin{array}{l}\text { Sprachgebrauch lässt sich nicht allein durch } \\
\text { Sprachpolitik ändern, vielmehr sollten die } \\
\text { französische Sprachkultur und die Beherr- } \\
\text { schung der französischen Sprache gefördert } \\
\text { werden. }\end{array}$ & F46, F54, F55 & 3 \\
\hline Sprachpolitik ist überflüssig. & $\mathrm{F} 41, \mathrm{~F} 45, \mathrm{~F} 50$ & 3 \\
\hline Sprachpolitik ist lächerlich. & F13, F38 & 2 \\
\hline Sprachpolitik ist zu arbeitsaufwändig. & F14 & 1 \\
\hline Sprachpolitik ist protektionistisch. & F46 & 1 \\
\hline $\begin{array}{l}\text { Vergleich mit der Konkurrenzsituation } \\
\text { zwischen dem Lateinischen und Französi- } \\
\text { schen. }\end{array}$ & F50 & 1 \\
\hline
\end{tabular}

Sechs Informanten argumentieren, dass die natürliche Sprachentwicklung sich nicht durch sprachpolitische Maßnahmen aufhalten lasse. Als eine andere Möglichkeit, den Sprachgebrauch zu lenken und möglicherweise zu ändern, wird von drei Informanten die Förderung der Sprachkultur vorgeschlagen.

Ein Argument lässt sich nicht eindeutig pro oder contra Sprachpolitik zuordnen, greift aber eine Antwortoption aus dem zweiten Fragebogenmodul auf, die dort in Bezug auf die Terminologiearbeit angeboten wurde (Frage 46, Beurteilung der Terminologielisten):

Abb. 85: Argumente pro \& contra Terminologiearbeit (Frankreich)

\section{Pro \& contra Sprachpolitik}

\begin{tabular}{|l|l|r|}
\hline Kategorie & Informant(en) & Anzahl \\
\hline Sprachpolitik ist nicht bekannt genug. & F63 & 1
\end{tabular}

Insgesamt beziehen sich die meisten Kommentare jedoch nicht auf die Sprachpolitik, sondern bewerten die Terminologiearbeit und ihre Resultate. Hier werden zunächst die Argumente dargestellt, die aus Sicht der Informanten für die Terminologiearbeit sprechen bzw. aufzeigen, unter welchen Umständen Terminologiearbeit zu befürworten ist. 
Abb. 86: Argumente für die Befürwortung der Terminologiearbeit (Frankreich)

4. Befürwortung der Terminologiearbeit

\begin{tabular}{|c|c|c|}
\hline Kategorie & Informanten & Anzahl \\
\hline $\begin{array}{l}\text { Terminologiearbeit ist zu befürworten, } \\
\text { wenn die französischen Termini kurz, prä- } \\
\text { zise und ästhetisch befriedigend sind. Au- } \\
\text { Berdem müssen sie den Sinn des } \\
\text { englischen Terminus korrekt wiedergeben. }\end{array}$ & $\begin{array}{l}\text { F27, F51, } \\
\text { F58, F66, } \\
\text { F67, F69, } \\
\text { F72 }\end{array}$ & 7 \\
\hline $\begin{array}{l}\text { Terminologiearbeit ist nützlich / kann } \\
\text { nützlich sein. }\end{array}$ & $\begin{array}{l}\text { F12, F19, } \\
\text { F22, F70 }\end{array}$ & 4 \\
\hline $\begin{array}{l}\text { Terminologiearbeit ist zu befürworten, } \\
\text { wenn keine Termini erfunden werden, } \\
\text { sondern die etablierten Termini (englische } \\
\text { wie französische) übernommen werden } \\
\text { und diese sinngemäß passen. }\end{array}$ & $\begin{array}{l}\text { F7, F32, F52, } \\
\text { F66 }\end{array}$ & 4 \\
\hline $\begin{array}{l}\text { Terminologiearbeit bringt auch gute Er- } \\
\text { gebnisse hervor (Bsp.: logicied). }\end{array}$ & F1, F21, F72 & 3 \\
\hline $\begin{array}{l}\text { Nur schwere Grafien sollten französisiert } \\
\text { werden (Bsp.: engl. packed boat }=>\text { franz. } \\
\text { paquebot, engl. roasted beef }=>\text { franz. rosbif). }\end{array}$ & F23 & 1 \\
\hline $\begin{array}{l}\text { Terminologiearbeit ist zu befürworten, } \\
\text { wenn schnell französische Neologismen } \\
\text { vorgeschlagen werden, bevor sich die } \\
\text { Anglizismen etablieren können. }\end{array}$ & F73 & 1 \\
\hline
\end{tabular}

Von 20 Informanten wird die Terminologiearbeit befürwortet, aber immer nur mit Einschränkungen. Dabei wird am häufigsten angeführt, dass Terminologiearbeit nur dann zu befürworten sei, wenn die erarbeiteten Bezeichnungen kurz, präzise, ästhetisch befriedigend seien und den Sinn des Ursprungswortes korrekt wiedergäben.

Die meisten der angeführten Argumente richten sich jedoch gegen die Terminologiearbeit und heben insbesondere die Nachteile französischer Terminologiearbeit hervor. 
Abb. 87: Argumente für die Ablehnung der Terminologiearbeit (Frankreich)

\section{Ablehnung der Terminologiearbeit}

Kategorie
Französische Terminologie ist lächerlich,
wenn es sich bei den Neologismen lediglich
um Französisierungen der Anglizismen
handelt, wie bei den französischen Neolo-
gismen cédérom und mél für engl. CD-ROM
und e-mail.

Französische Neologismen sind häufig lächerlich, insbesondere weil sie zu spät kommen, wenn sich die englischen Termini bereits etabliert und die Sprecher sich an diese gewöhnt haben.

Sprachgebrauch darf nicht durch den Staat vorgeschrieben werden, sondern der Gebrauch soll über die Termini entscheiden („Darwinismus“).

Kommunikation:

Englisch als die dominierende Sprache und die lingua franca im Bereich der neuen Technologien wie Informatik/Internet.

Die Verwendung der englischen Terminologie erleichtert die Kommunikation weltweit und unter frankophonen Sprechern.

Sprache lebt und verändert sich, dieser Prozess ist durch Terminologiearbeit nicht zu stoppen.

Französische Neologismen sind häufig unpassend, zu kompliziert bzw. entsprechen inhaltlich nicht dem zu ersetzenden Anglizismus.

Französische Neologismen sind überflüssig und lächerlich für den Bereich der neuen Technologien wie Informatik.

Die Vielzahl der französischen Termini bzw. die Termini selbst sind verwirrend und kompliziert.

Französische Terminologiearbeit steht der Globalisierung entgegen.

Frankreich sollte die Termini anderer frankophoner Nationen (Québec) übernehmen

\section{Informanten}

F1, F13, F17, F19,

Anzahl

F20, F24, F26,

F27, F29, F36,

F37, F43, F54,

F66, F67, F68,

F70, F71, F72

F1, F7, F13, F15,

F18, F30, F33,

F34, F35, F48,

F51, F52, F55,

F58, F64, F70

F10, F23, F25,

F27, F28, F39,

F53, F55, F61,

F62, F65, F73

F1, F2, F12, F22,

10

F28, F32, F35,

F41, F55, F72

F41, F46, F54,

7

F61, F62, F65,

F72

F24, F30, F31,
F37, F56, F57

F3, F7, F16, F41,

5

F60

F28, F31, F47,

4

F49

F7, F8, F12, F31

4

F18, F24, F29,

F36 


\begin{tabular}{|c|c|c|}
\hline $\begin{array}{l}\text { / Québec als positives Beispiel für Termi- } \\
\text { nologiearbeit. }\end{array}$ & & \\
\hline $\begin{array}{l}\text { Die Terminologievorschläge sollten von } \\
\text { Spezialisten gemacht werden. }\end{array}$ & F11, F20, F62 & 3 \\
\hline Entlehnung als sprachliche Bereicherung. & F54, F55 & 2 \\
\hline $\begin{array}{l}\text { Französische Neologismen sind häufig } \\
\text { künstlich. }\end{array}$ & F52, F66 & 2 \\
\hline $\begin{array}{l}\text { Französische Neologismen sind kaum be- } \\
\text { kannt. }\end{array}$ & F18, F64 & 2 \\
\hline $\begin{array}{l}\text { Französische Neologismen sind mitunter } \\
\text { überflüssig. }\end{array}$ & F15, F55 & 2 \\
\hline Französische Neologismen sind zu lang. & F59, F72 & 2 \\
\hline $\begin{array}{l}\text { Entlehnung ist ein natürlicher Prozess in } \\
\text { allen Sprachen. }\end{array}$ & F23 & 1 \\
\hline $\begin{array}{l}\text { Terminologiearbeit ist überflüssig, da die } \\
\text { Sprache in Québec viel anglisierter ist als in } \\
\text { Frankreich. }\end{array}$ & F66 & 1 \\
\hline $\begin{array}{l}\text { Kommunikation: } \\
\text { Kommunikationsprobleme zwischen } \\
\text { Anfängern, die die französischen Termini } \\
\text { lernen, und älteren Informatikern, die die } \\
\text { englischen Termini benutzen. }\end{array}$ & F33 & 1 \\
\hline
\end{tabular}

19 Informanten beurteilen Terminologiearbeit dann als lächerlich, wenn die Terminologiekommissionen sich darauf beschränken, bestimmte Anglizismen lediglich bezüglich ihrer Schreibung zu französisieren. Als Beispiel für diese Art misslungener Neologismenbildung werden vor allem drei Neologismen genannt: cédérom (für engl. CD-ROM), mél (für engl. e-maii) und bogue (für engl. bug) ${ }^{21}$. Über die Entstehung und Verwendung von mél wurden bereits in 5.2.3.1, 5.2.3.2 und 9.1.1 einige Informationen gegeben. Cédérom war der zweite Versuch, ein geeignetes französisches Ersatzwort für das engl. CD-ROM zu finden. Der erste Versuch bestand in der Schaffung des Akronyms DOC für Disque optique compact (vgl. JO vom 16. September 1989). Das aus dem französischen Terminus gebildete Akronym $D O C$ konnte sich allerdings gegen engl. $C D-R O M$ nicht durchsetzen. In einem zweiten Anlauf schlug die Académie française im Juni 1996 die Grafie cédérom vor. Aber auch dieses Ersatzwort konnte sich nicht durchsetzen, weil sich die meisten Frankophonen bereits an CD-ROM gewöhnt hatten (vgl. Otman 2000, $387)$.

\footnotetext{
${ }^{21}$ Der Vorschlag, engl. bug durch franz. bogue zu ersetzen, wurde bereits 1990 von den von Le GuillyWallis befragten Informatikern kritisiert (vgl. 4.3.2). Ahlers/Holtus $(1999,302)$ mutmaßen, dass es möglicherweise abgelehnt werde, weil engl. bug bei der Übertragung ins Französische seinen metaphorischen Charakter verliere (vgl. Kap. 5, Fußnote 36).
} 
16 Informanten finden die Neologismen größtenteils deshalb lächerlich, weil sie viel zu spät kämen, nämlich zu einem Zeitpunkt, zu dem sich die englischen Termini längst im Sprachgebrauch etabliert hätten. Zwölf Informanten verweisen auf die Rolle des Sprachgebrauchs und sind der Meinung, dass dieser im Gegensatz zu sprachpolitischen Maßnahmen dafür ausschlaggebend sein solle, welche Neologismen sich durchsetzten und welche nicht. Das Prinzip der natürlichen Auslese im Sinne der Darwinschen Definition - dieser Name fällt bei einem Informanten (F10) - solle sich auch auf die Terminologie erstrecken.

Zehn Informanten führen das pragmatische Argument der vereinfachten nationalen und internationalen Kommunikation an. Englisch sei nicht nur die dominierende Sprache und die lingua franca im Bereich der neuen Technologien wie Informatik/Internet, sondern die ausschließliche Verwendung der englischen Terminologie erleichtere zugleich die Kommunikation weltweit und unter frankophonen Sprechern und helfe, Missverständnisse zu vermeiden. In der Tat findet der internationale Austausch unter Experten (z.B. bei Konferenzen) häufig auf Englisch statt. Das Englische ist die lingua franca der heutigen Wissenschaften, und insbesondere bei Wissenschaftlern technischer und/oder naturwissenschaftlicher Fächer lässt sich ein beruflicher Bilinguismus beobachten. Gaudin $(1996,51)$ zufolge rufe dieser Bilinguismus in beruflichen Angelegenheiten bei den Forschern sprachliche Unsicherheit hervor. Die Wissenschaftler hätten eine negative Wahrnehmung der französischen Termini, benutzten infolgedessen anstelle eines französischen Neologismus den englischen Terminus, wobei sie aber zugleich das Bedürfnis empfänden, diesem eine lange französische Definition anzufügen. Hinzu komme, dass die meisten Wissenschaftler nicht dafür ausgebildet seien, englische Bezeichnungen ins Französische zu übersetzen und somit neue Termini zu schaffen, ,[...] et le poids du purisme français a plutôt tendance à inhiber leur créativité lexicale" (ebd., 51) 22 .

Sieben Informanten weisen auf die natürliche Sprachevolution hin und sind der Ansicht, dass sich dieser Prozess nicht durch Terminologiearbeit aufhalten lasse dieses Argument überschneidet sich mit der in Abb. 84 bezüglich der Sprachpolitik angeführten Kategorie „Natürliche Sprachentwicklung / Sprachpolitik kann die natürliche Sprachentwicklung nicht aufhalten“. Sechs Informanten erachten die französischen Neologismen als häufig unpassend, als zu kompliziert bzw. als inhaltlich nicht mit dem zu ersetzenden Anglizismus übereinstimmend. Fünf Informanten halten französische Neologismen zumindest im Bereich der neuen Technologien wie der Informatik für überflüssig und lächerlich. Vier Informanten verweisen darauf, dass die Vielzahl an französischen Termini für Verwirrung sorge bzw. mitunter die französischen Termini selbst sehr kompliziert seien. Von vier

\footnotetext{
22 Gaudin nennt noch eine weitere Situation sprachlicher Unsicherheit: Die Forscher bzw. Techniker werden mit neuen angloamerikanischen Termini konfrontiert, deren Bedeutung und/oder französische Übersetzung sie nicht kennen. Die Unsicherheit hat zwei mögliche Folgen: 1. spontane Neologismenbildung (,,francisations 'sauvages"), wobei sich in der Folgezeit erst zeigen wird, ob sich diese Neubildungen auf dem sprachlichen Markt durchsetzen werden oder nicht, 2. Rückgriff auf das Lehnwort, ohne den Versuch, eine französische Entsprechung dafür zu finden (vgl. Gaudin 1996, $52)$.
} 
weiteren Informanten wird das Argument genannt, dass die nationale französische Terminologiearbeit der Globalisierung entgegenstehe. Dieser Punkt wird auch von verschiedenen Linguisten angemerkt, da es im Zeitalter der Globalisierung alles andere als ratsam sei, dass sich ein Land sprachlich oder auf andere Weise zu sehr isoliere (vgl. 4.4.1; Beinke 1995, 88; Braselmann 1999a, 97f.; Hagège 1987, 249). In eine ähnliche Richtung geht der von ebenfalls vier Informanten angeführte Vorschlag, Frankreich solle die Termini anderer frankophoner Nationen wie Québec übernehmen. Québec gilt einigen Franzosen als positives Beispiel für Terminologiearbeit, allerdings dürfte den meisten Informanten nicht bekannt sein, dass z.B. die Termini toile d'araignée mondiale und bavardage (allerdings mit einem spezifizierenden Zusatz) aus der frankokanadischen Terminologiedatenbank stammen.

Ein weiteres Argument betrifft wiederum die Kommunikation: Englisch sei die dominierende Sprache im Bereich der neuen Technologien wie Informatik und Internet. Diese Aussage impliziert, dass die Schaffung französischer Neologismen unnötig, wenn nicht gar sinnlos ist. Auch Lagueux $(1988,95)$ weist darauf hin, dass in Wissenschaft und Technik die Verwendung der englischen Termini inzwischen eine Notwendigkeit geworden sei. Zwar seien die französische Sprache und Terminologie in Wissenschaft und moderner Technik weitgehend vom Englischen verdrängt worden, jedoch sei die sprachliche Verdrängung keinesfalls gleichbedeutend mit einer Verdrängung der Forschung in diesen Bereichen:

„L'emprunt de plus en plus fréquent de mots anglais - luxe pour les terminologues des organismes de normalisation, nécessité pour les hommes de science ou les techniciens - nous amène inévitablement à constater la place de plus en plus ténue du français dans les sciences et les techniques modernes dont les assises reposent fréquemment sur des facteurs, socio-économiques ou autres, n'ayant rien à voir avec la recherche technique ou scientifique en tant que telle.“

Drei Informanten sprechen sich dafür aus, dass die Terminologiearbeit nur von Spezialisten durchgeführt werden sollte. Diese Aussage impliziert die (falsche) Vorstellung, dass sich die derzeit bestehenden Terminologiekommissionen aus Laien zusammensetzten. Diese Annahme macht zugleich deutlich, dass bezüglich der konkreten Terminologiearbeit noch ein deutlicher Informationsbedarf seitens der Bevölkerung besteht. Andererseits bedeutet dies auch, dass die Ersatzwortvorschläge (insbesondere vor den Neuerungen, die das Dekret vom 03. Juli 1996 bewirkt hat) nicht als fachlich korrekt erachtet werden. De Bessé (1990, 260) weist auf die Notwendigkeit hin, fachliche und terminologische Kompetenz zusammenzuführen: 
„On observe que la plupart des définitions terminographiques sont rédigées par les spécialistes du domaine. Il est vrai que le terminographe, et à plus forte raison le lexicographe, n'a pas toujours une connaissance du domaine lui permettant de rédiger lui-même les définitions appropriées. Le concours du spécialiste est presque toujours indispensable. Mais le spécialiste n'entend pas se substituer au terminographe. En général, il n'a pas la prétention d'avoir des compétences terminographiques particulières, et accepte volontiers de collaborer à un travail terminographique. À la différence du travail lexicographique, le travail terminographique est nécessairement multidisciplinaire."

Es reicht somit nicht, nur Lexikologen oder andere Leute, die sich beruflich mit Sprache auseinander setzen, in den Kommissionen zu beschäftigen, sondern es muss ein Ausgleich zwischen Personen mit fachlicher Kompetenz und Personen mit terminografischer Kompetenz geschaffen werden, wie es in den beiden seit 1997 bzw. seit 2002 existierenden Fachkommissionen zur Informatik versucht wurde (vgl. 3.2.5).

Im Unterschied zur Haltung der Befragten in der Untersuchung Goudecs (vgl. 4.3.2) wird eine Französisierung der Termini von den in der WWW-Befragung befragten Informatikern tendenziell abgelehnt, zumindest für die Sprache der neuen Technologien wie Internet und Informatik. Das Fazit, das sich aus den Kommentaren ziehen lässt, stimmt infolgedessen nicht überein mit dem Fazit Gouadecs. Gouadec $(1993,363)$ entnimmt den Aussagen der von ihm befragten Informatiker, dass sie die Französisierung als eine sinnvolle Arbeit erachten, da die Französisierung das Verständnis begünstige (vgl. 4.3.2) ${ }^{23}$. Aus den Kommentaren der im Sommer 2002 befragten Informatiker spricht vielmehr, dass sie nur in sehr eingeschränktem Maße für eine Französisierung durch Terminologiekommissionen sind, nämlich nur, wenn die Terminologiekommissionen französische Neologismen aufnähmen bzw. erarbeiteten, die kurz, präzise, treffend und ästhetisch akzeptabel seien. Die mittels des WWW-Fragebogens befragten Informanten plädieren somit weniger für eine Französisierung durch entsprechende Kommissionen, die sie zum Teil als wenig kompetent erachten, sondern vielmehr für eine natürliche Sprachentwicklung und infolgedessen für eine natürliche Terminologiebildung: Termini sollten sich aus dem fachlichen Kontext heraus ergeben, d.h. von der Bevölkerung eingebracht werden. Der Sprachgebrauch solle dann entscheiden, ob sie sich durchsetzen können oder nicht. Die Terminologiekommissionen sollten dann alle Termini bestätigen, die sehr verbreitet sind (u.U. auch die Anglizismen).

\footnotetext{
23 Allerdings wird bei der WWW-Befragung nicht zwischen den einzelnen Verwendungsbereichen unterschieden wie Kundendienst, Produktinformation, Kommunikation unter Technikern etc. In den genannten Bereichen ist eine Französisierung in unterschiedlichem Maße nötig, für den Kontakt mit Kunden in weitaus höherem Maße als für die Kommunikation unter Spezialisten, die ohnehin meistens die englische Terminologie verwenden.
} 
Sehr wichtig ist den Befragten eine reibungslose Kommunikation, die nicht durch Kommunikationsbarrieren wie die Verwendung französischer oder anderer nationaler Termini eingeschränkt werden solle: Französische Termini werden bezüglich der nationalen wie internationalen Verständigung eher als hinderlich eingeschätzt. Analog zur Klassifizierung der Kommentare bezüglich der Sprachpolitik sprechen manche Argumente zur Terminologiearbeit weder eindeutig für noch gegen sie.

\section{Abb. 88: Argumente pro \& contra Terminologiearbeit (Frankreich)}

\section{Pro \& contra Terminologiearbeit}

\begin{tabular}{|c|c|c|}
\hline Kategorie & Informanten & Anzahl \\
\hline $\begin{array}{l}\text { Bei der Terminologie sollte weder mit der } \\
\text { Französisierung noch mit der Verwen- } \\
\text { dung englischer Termini übertrieben wer- } \\
\text { den. }\end{array}$ & F14 & 1 \\
\hline $\begin{array}{l}\text { Im Informatikbereich gelten diejenigen als } \\
\text { konservativ, die französische Termini ver- } \\
\text { wenden. }\end{array}$ & F72 & 1 \\
\hline $\begin{array}{l}\text { Im Informatikbereich werden Anglizismen } \\
\text { häufig aus Faulheit verwendet. }\end{array}$ & F72 & 1 \\
\hline $\begin{array}{l}\text { Ob die Terminologie gelungen ist, ent- } \\
\text { scheidet sich von Fall zu Fall. }\end{array}$ & F21 & 1 \\
\hline $\begin{array}{l}\text { Unterschiedlicher Gebrauch von Termini } \\
\text { im Geschriebenen und Gesprochenen. }\end{array}$ & F72 & 1 \\
\hline
\end{tabular}

Sehr aufschlussreich ist der Hinweis eines Informanten auf den Fremdwortgebrauch aus Faulheit. Damit ist sicherlich impliziert, dass viele Sprachbenutzer sich nicht mehr die Mühe machen nach Bezeichnungen in der Muttersprache zu suchen, sondern einfach die (fremdsprachige) Bezeichnung verwenden, die ihnen gerade einfällt.

\subsection{Korrelationen zwischen biosozialen Faktoren und Sprachverhalten/Einstellungen}

Im dritten Teil des Fragebogens wurden die in der Soziolinguistik gängigen personenspezifischen Parameter Alter, Geschlecht, Beruf/Ausbildung, höchster Bildungsabschluss, Geburtsort, Muttersprache(n), Wohnsitz, Englischkenntnisse, Art und Dauer der Internetnutzung erhoben (vgl. 8.2). Im Prinzip kann jedes dieser Merkmale mit der Akzeptanz (1. Fragebogenmodul) und den Einstellungen (2. Fragebogenmodul) korreliert werden.

Die Korrelation zwischen Geburtsort bzw. Wohnort (Land) und Sprachgebrauch entspricht in etwa der in dieser Arbeit vorgenommenen getrennten Auswertung zwischen den befragten französischen, belgischen und schweizerischen Informatikern (Kapitel 9-11), da fast alle Informanten in dem Land leben, in dem sie auch 
geboren sind. Als Muttersprache wurde von allen Informanten Französisch angegeben. Dieser Faktor hatte im Rahmen des Fragebogens Kontrollfunktion, um sicherzugehen, dass nur Fragebögen der gewünschten Zielgruppe ausgewertet werden.

Entsprechend verbleiben für eine weitere Analyse die Parameter Alter, Beruf, höchster Bildungsabschluss, Englischkenntnisse, Art und Dauer der Internetnutzung. Der Faktor Geschlecht wurde bereits in 5.3.1 ausgeschlossen (vgl. Kap. 5, Fußnote 44).

In 5.3.2 wurden sechs Hypothesen zu Korrelationen zwischen biosozialen Daten der Informanten und ihrem Sprachverhalten bzw. ihren Einstellungen formuliert. Diesen länderübergreifend formulierten Thesen wird im Folgenden einzeln nachgegangen.

\subsubsection{Hypothese II.1: Vergleich zwischen Ablehnung der Anglizismen und der Ablehnung der Sprachpolitik}

Hypothese II.1: Sprecher sind gegenüber der angloamerikanischen Lexik weniger negativ eingestellt als gegenüber dem staatlichen Einfluss auf diese Fremdwörter.

Diese Hypothese zielt auf einen Vergleich zwischen der Akzeptanz der Lexik (erstes Fragebogenmodul) und den Einstellungen gegenüber Sprachpolitik und Terminologiearbeit (zweites Fragebogenmodul) ab. Da sich von den sechs Lexemgruppen in drei Fällen die französischen Neologismen durchgesetzt haben, kann von einer generellen Ablehnung der englischen Termini keine Rede sein, was die Hypothese bestätigen würde. In den in 9.3 ausgewerteten Kommentaren sind andererseits viele Argumente enthalten, die für die Verwendung englischer Termini sprechen. Insgesamt zeichnen sich die befragten Informatiker durch eine tolerante Haltung gegenüber der Terminologie aus, befürworten aus pragmatischen Gründen jedoch die englischen Termini. Was die Einstellungen zum staatlichen Einfluss betrifft, so werden Terminologielisten sowie eine Befolgung ihrer Inhalte von mehr als einem Drittel abgelehnt (vgl. Frage 46 und 47). Insofern kann der Auffassung von Lerat (1990, 397; vgl. 2.3.3), dass sich französische Sprecher weniger den angloamerikanischen Fremdwörtern widersetzen als vielmehr jeglicher Form (staatlichen) Einflusses auf die Lexik, im Großen und Ganzen zugestimmt werden.

\subsubsection{Hypothese II.2: Korrelation zwischen Alter und Sprach- gebrauch/Einstellungen}

Hypothese II.2: Es gibt generationssperifische Unterschiede: Die älteren Informanten werden eher die französische Internet-Terminologie bevorzugen als die jüngeren.

Häufig wird in empirischen Studien eine Verbindung zwischen Alter und Sprachgebrauch konstatiert. In 5.3.2 wurde bereits herausgestellt, dass die jüngere Generation als sprachlich progressiver gilt. Helfrich (1993, 151-158 und 165-168) zeigt im Zuge der Auswertung der semantischen Differentiale zu den von ihr untersuchten Neologismen auf, dass es zwischen den Generationen einen offensichtlichen Unterschied im Hinblick auf die Bewertung von Neologismen gibt, aller- 
dings variieren die Akzeptanzwerte wiederum von Neologismus zu Neologismus. Allgemein ist den bei Helfrich veröffentlichten Abbildungen zu entnehmen, dass die Werte der älteren Generation immer etwas mehr zum negativen Bereich tendieren als die der jüngeren Generation (vgl. ebd., 165-168). Oder anders formuliert: Jüngere Sprecher bewerten Neologismen besser als Sprecher der älteren Generation. Entsprechend schreibt Helfrich (ebd., 293) in ihrer Zusammenfassung:

„Sprachliche Innovationen begegnen, wie Neues überhaupt, einer Unsicherheit, die generationsspezifisch unterschiedliche Reaktionen provoziert. Sprecher der älteren Generation sind in der Regel stärker auf Gewohntes fixiert und Neuem oder Fremdem gegenüber weniger aufgeschlossen als Sprecher der jüngeren Generation. Die Reaktionen der älteren Generation Neologismen gegenüber reichen von ablehnend-gleichgültig bis feindlich-puristisch. Hingegen dominiert bei der jüngeren Generation Toleranz als Reaktion auf die Neuwörter. L'habitude fait l'usage."

Generell stellt Helfrich die weitreichendsten Unterschiede bezüglich der Akzeptanz und der Sprachbewertungen zwischen den Generationen fest (im Unterschied zu anderen Faktoren wie z.B. Geschlecht, vgl. ebd., 183). Es bietet sich im Rahmen der Auswertung an nachzuprüfen, ob auch bei den befragten Informatikern altersbezogene Unterschiede festzustellen sind.

\subsubsection{Korrelation zwischen Alter und Sprachgebrauch}

Es wird mit Helfrich (1993) von einem altersspezifisch unterschiedlichen Sprachgebrauch ausgegangen. Allerdings wird im Unterschied zur Studie Helfrichs nicht überprüft, ob die Neologismen von den Generationen unterschiedlich bewertet werden. Da diese Arbeit in erster Linie der Frage nachgehen will, ob die englischen oder französischen Termini verwendet werden, und nicht die Fragestellungen vertiefen will, die sich im Hinblick auf die französischen Termini ergeben, wird im Folgenden darauf verzichtet, die Bewertung der französischen Neologismen (semantisches Differential) im Hinblick auf die beiden Generationen auszuwerten.

Um festzustellen, ob es generationsspezifische Unterschiede bezüglich des Gebrauchs von englischen oder französischen Termini gibt, wurde für jede Lexemgruppe ermittelt, wie viel Prozent der unter 30-Jährigen und wie viel Prozent der über 30-Jährigen bei den Fragen nach dem eigenen Sprachgebrauch (5, 12, 19 , 26, 33 und 40) für einen der französischen bzw. einen der englischsprachigen Neologismen gestimmt haben. Aus den sechs Gegenüberstellungen lassen sich allerdings keine klaren Tendenzen ableiten, die die Hypothese bestätigen könnten, dass Sprecher der älteren Generation eher die französischen Neologismen bevorzugen würden als Sprecher der jüngeren. Bezüglich eines häufigeren Gebrauchs des französischen Neologismus konnte nur in zwei von sechs Fällen ein signifikanter Unterschied zwischen den Informanten der älteren und der jüngeren Generation festgestellt werden. Ein im Vergleich zur jüngeren Generation etwas höherer Prozentsatz der Informanten der älteren Generation plädiert 
für die Verwendung von franz. courrier électronique, message électronique, mél, courriel und von franz. fournisseur d'accès.

Die Ergebnisse legen nahe, dass aus der von Helfrich festgestellten größeren sprachlichen Progressivität der jüngeren Generation und der positiveren Bewertung von Neologismen nicht in jedem Fall darauf geschlossen werden kann, dass die jüngere Generation auch Anglizismen generell positiver gegenüber steht und diese entsprechend häufiger verwendet als die ältere Generation. Bei den befragten Informatikern beider Generationen ist eine ähnlich hohe Toleranz gegenüber französischen und v.a. englischen Neologismen feststellbar. Insofern kann der Hypothese nicht zugestimmt werden, dass die älteren Informanten eher die französische Internet-Terminologie bevorzugen als die jüngeren. Die befragten Informatiker beider Generationen bevorzugen in einigen Fällen die französischen, in anderen Fällen die englischen Termini. Vermutlich üben diesbezüglich der Beruf und das berufliche Umfeld einen größeren Einfluss auf das Sprachverhalten und die Einstellungen aus als personenspezifische Merkmale wie das Alter.

Wie oben bereits angedeutet, lassen das Sprachverhalten und die Einstellungen der befragten Informatiker keine direkten Rückschlüsse auf andere Bevölkerungsgruppen zu. Es ist aber davon auszugehen, dass andere Berufsgruppen, die im Berufsleben häufig mit der englischen Sprache konfrontiert werden und diese auch für die tägliche Kommunikation bzw. das Verständnis von Texten benötigen, Anglizismen ähnlich aufgeschlossen gegenüber stehen wie die hier befragten Informatiker.

\subsubsection{Korrelation zwischen Alter und Einstellungen zur Sprachpolitik und Termino- logiearbeit}

Im Folgenden wird anhand ausgewählter Fragen des zweiten Fragebogenmoduls überprüft, ob es einen Zusammenhang zwischen dem Alter und den Einstellungen zur Sprachpolitik und Terminologiearbeit gibt. Zu diesem Zweck werden die Antworten der beiden Generationen in Form von Kreuztabellen gegenübergestellt. Zuvor werden jedoch die Ergebnisse einer weiteren empirischen Studie vorgestellt, in der z.T. ähnliche Fragen wie in der vorliegenden WWW-Befragung formuliert wurden. Es handelt sich um die Magisterarbeit Straßners von 1997, die in erster Linie die Evaluierung der Wirksamkeit der Loi Toubon zum Gegenstand hat.

Straßner (1997) hat insgesamt 320 Fragebögen ausgewertet, davon 60 von Informanten, die der Generation der über 30-Jährigen angehören, und 240 von Informanten, die der Generation der unter 30-Jährigen angehören. 91,7 \% der über 30Jährigen geben an, die Loi Toubon zu kennen, nur 6,7\% kennen sie nicht. Für 1,7\% der Befragten über 30-Jährigen liegt keine Angabe vor (vgl. Straßner 1997, 70). Bei den unter 30-Jährigen geben 95,8\% an, die Loi Toubon zu kennen, nur 3,8\% kennen sie nicht (vgl. ebd., 165). Ca. 90\% der jüngeren Generation sind sogar in der Lage, die Inhalte des Gesetzes zu erklären (vgl. ebd., 166). Die Fehlinterpretationen und die Fehlinformationen bezüglich der Loi Toubon fallen somit bei den Befragten recht gering aus (vgl. ebd., 167). 
Die Frage, ob sie sprachlichen Eingriffen positiv gegenüber ständen, beantworten $35 \%$ der über 30-Jährigen mit ja, 50\% mit nein, und 5\% mit teils/teils $(10 \%$ ohne Angabe; vgl. ebd., 78). Die Ablehnung sprachlicher Eingriffe ist bei der jüngeren Generation noch ausgeprägter: Den 31,2\%, die eine positive Haltung zu sprachlichen Eingriffen haben, stehen $62,7 \%$ gegenüber, die dagegen sind $(1,2 \%$ antwortet mit teils/teils, 5\% ohne Angabe; vgl. ebd., 171). Bezüglich der Interpretation dieser Ergebnisse warnt Straßner $(1997,226 f$.) vor falschen Schlussfolgerungen:

„Es wäre jedoch falsch, angesichts der oben skizzierten Umfrageergebnisse zu dem Schluß zu kommen, daß die jüngere Generation dem Schutze des Französischen weniger Bedeutung beimißt [...]. Die Ablehnung der Informanten aus Gruppe 2 [= jüngere Generation, E.M.] richtet sich nicht zwingend gegen die Zielsetzung des Schutzes der französischen Sprache, sondern lediglich gegen die Tatsache, daß ein Sprachgesetz den Französischsprachigen nicht freie Handhabe in der Auswahl der lexikalischen Elemente läßt.“

Für die WWW-Befragung zur Internet-Terminologie und Sprachpolitik ergibt sich bezüglich der altersspezifischen Auswertung der Kenntnis der aktuellen Sprachpolitik folgendes Bild ${ }^{24}$ :

\section{Abb. 89: Kreuztabelle: Korrelation zwischen Alter und Einstellung (Kenntnis der aktuellen Sprachpolitik)}

\begin{tabular}{|l|r|r|r|}
\hline & \multicolumn{2}{c|}{ Alter } & Insgesamt \\
\hline & $\begin{array}{l}\text { Jünger als } \\
\text { 30 (inkl. } \\
\text { 30) Jahre }\end{array}$ & $\begin{array}{l}\text { Älter als } \\
\text { 30 Jahre }\end{array}$ & \\
\hline Oui. & $25(31,3 \%)$ & $5(11,3 \%)$ & $30(24,2 \%)$ \\
\hline Oui, j'en ai entendu parler. & $41(51,2 \%)$ & 26 & $67(54,0 \%)$ \\
\hline Non. & $14(17,5 \%)$ & $(59,1 \%)$ & $26(21,0 \%)$ \\
\hline Je ne sais pas. & & $(27,3 \%)$ & 12 \\
\hline Insgesamt & $80(100,0 \%)$ & $1(2,3 \%)$ & $1(0,8 \%)$ \\
\hline
\end{tabular}

$82,5 \%$ der jüngeren und 70,4\% der älteren Generation geben an das Gesetz zu kennen oder zumindest von seiner Existenz zu wissen. Die Prozentwerte fallen jedoch niedriger aus als in der Befragung Straßners, in der 95,8\% der Informanten

\footnotetext{
${ }^{24}$ Die in den einzelnen Tabellenzellen aufgeführten Zahlen beziehen sich auf die Anzahl der Informanten (absolute Häufigkeit), die in den Klammern aufgeführten Zahlen auf die prozentuale Häufigkeit. Aufgrund der unterschiedlichen Anzahl an Informanten der jüngeren und der älteren Generation wird die prozentuale Häufigkeit verglichen.
} 
der jüngeren und 91,7\% der Informanten der älteren Generation angeben, die Loi Toubon zu kennen. Möglicherweise ist dies darauf zurückzuführen, dass Straßners Untersuchung zu einem Zeitpunkt stattgefunden hat, als die Loi Toubon noch verhältnismäßig aktuell war und viel stärker in den Medien diskutiert wurde als acht Jahre nach ihrer Verabschiedung. Im Jahre 2002 ist die Diskussion um dieses Gesetz abgeebbt und damit möglicherweise auch wieder aus vielen Köpfen verschwunden.

Bezüglich der Einstellungen zur Sprachpolitik ist insbesondere die folgende Frage aufschlussreich:

Abb. 90: Kreuztabelle: Korrelation zwischen Alter und Einstellung (Beurteilung der aktuellen Sprachpolitik)

\begin{tabular}{|l|r|r|r|}
\hline & \multicolumn{2}{|c|}{ Alter } & Insgesamt \\
\hline & $\begin{array}{l}\text { Jünger als } \\
\text { 30 (ink1. } \\
\text { 30) Jahre }\end{array}$ & $\begin{array}{l}\text { Älter als } \\
\text { 30 Jahre }\end{array}$ & \\
\hline Nécessaire dans tous les cas. & $2(2,5 \%)$ & $5(11,4 \%)$ & $7(5,7 \%)$ \\
\hline Souhaitable. & $41(51,2 \%)$ & 24 & $65(52,4 \%)$ \\
\hline Inutile. & $34(42,5 \%)$ & $134,6 \%)$ & $47(37,9 \%)$ \\
\hline Je ne sais pas. & $3(3,8 \%)$ & $2(4,5 \%)$ & $5(4,0 \%)$ \\
\hline Insgesamt & 80 & 44 & 124 \\
\hline
\end{tabular}

Nur 2,5\% der unter 30-Jährigen und 11,4\% der über 30-Jährigen halten die aktuelle Sprachpolitik für notwendig. Die Hälfte der befragten Informanten beider Generationen (51,2\% bzw. 54,6\%) hält die aktuelle Sprachpolitik für wünschenswert. Für überflüssig halten sie $42,5 \%$ der Informanten der jüngeren Generation und 29,5\% der Informanten der älteren Generation. Damit ist die Ablehnung sprachpolitischer Maßnahmen bei der jüngeren Generation etwas ausgeprägter als bei der älteren Generation.

Die Ergebnisse weichen erheblich von denen Straßners ab. Sprachpolitik wird in der Befragung Straßners von 62,7\% der unter 30-Jährigen und 50\% der über 30Jährigen abgelehnt. Von den im Sommer 2002 befragten Informatikern lehnen $42,5 \%$ (jüngere Generation) und 29,5\% (ältere Generation) sprachpolitische Maßnahmen ab. Es zeigt sich bei den von Straßner Befragten wie auch bei den befragten Informatikern, dass die Sprachpolitik bei den über 30-Jährigen auf geringere Ablehnung trifft als bei den unter 30-Jährigen. Insgesamt fällt die Ablehnung der Sprachpolitik bei den befragten Informatikern jedoch geringer aus als bei den von Straßner befragten Informanten. Dies könnte sich entweder auf die bereits mehrfach konstatierte höhere Toleranz auf Seiten der Informatiker zurückführen lassen (bei Straßner wurden im Unterschied dazu Personen ganz verschiedener Berufsgruppen befragt), oder aber es könnte wiederum dem Zeitfaktor zuzu- 
schreiben sein. Letztere Annahme würde bedeuten, dass der Widerstand gegen die Loi Toubon und gegen Sprachpolitik allgemein geringer geworden ist, nachdem sich die Wogen um die Loi Toubon geglättet haben.

Spiegelt sich die generationsspezifische Ablehnung bzw. Befürwortung der Sprachpolitik auch in der Bewertung der Terminologielisten wider? Dies kann mit Hilfe der folgenden Tabelle geklärt werden:

Abb. 91: Kreuztabelle: Korrelation zwischen Alter und Einstellung (Beurteilung der Terminologielisten)

\begin{tabular}{|c|c|c|c|}
\hline & \multicolumn{2}{|c|}{ Alter } & \multirow[t]{2}{*}{ Insgesamt } \\
\hline & $\begin{array}{l}\text { Jünger als } 30 \\
\text { (inkl. 30) } \\
\text { Jahre }\end{array}$ & $\begin{array}{l}\text { Älter als } 30 \\
\text { Jahre }\end{array}$ & \\
\hline Utiles. & $6(7,5 \%)$ & $4(9,1 \%)$ & $10(8,1 \%)$ \\
\hline Souhaitables. & $9(11,3 \%)$ & $6(13,6 \%)$ & $15(12,1 \%)$ \\
\hline Pas assez connues. & $22(27,5 \%)$ & $16(36,4 \%)$ & $38(30,6 \%)$ \\
\hline Inutiles. & $30(37,5 \%)$ & $12(27,3 \%)$ & $42(33,9 \%)$ \\
\hline Je ne les connais pas. & $8(10,0 \%)$ & $6(13,6 \%)$ & $14(11,3 \%)$ \\
\hline Rien/Je ne sais pas. & $5(6,3 \%)$ & 0 & $5(4,0 \%)$ \\
\hline Insgesamt & $80(100,0 \%)$ & $44(100,0 \%)$ & $\begin{array}{r}124 \\
(100,0 \%)\end{array}$ \\
\hline
\end{tabular}

$37,5 \%$ der unter 30-Jährigen und ca. 10\% weniger, nämlich $27,3 \%$, der über 30 Jährigen halten Terminologielisten für überflüssig. Die Informanten der älteren Generation bemängeln vielmehr $(36,4 \%)$, dass die Terminologielisten nicht bekannt genug seien, was nur 27,5\% der Informanten der jüngeren Generation angeben.

Bedeutet der höhere Prozentsatz an Informanten der älteren Generation, die sprachpolitischen und terminologischen Maßnahmen zustimmen, zugleich auch eine konsequentere Befolgung der Terminologielisten? Dies wird die altersspezifische Auswertung der Frage nach der Befolgung der Terminologielisten zeigen. 
Abb. 92: Kreuztabelle: Korrelation zwischen Alter und Einstellung (Befolgen der Terminologielisten)

\begin{tabular}{|l|r|r|r|}
\hline & \multicolumn{2}{|c|}{ Alter } & Insgesamt \\
\hline & $\begin{array}{l}\text { Jünger als 30 } \\
\text { (inkl. 30) Jahre }\end{array}$ & $\begin{array}{l}\text { Älter als } \\
\text { 30 Jahre }\end{array}$ & \\
\hline Oui. & $2(2,5 \%)$ & $1(2,3 \%)$ & $3(2,4 \%)$ \\
\hline Non. & $35(43,7 \%)$ & 17 & $52(42 \%)$ \\
\hline Partiellement. & $28(35,0 \%)$ & $\begin{array}{r}(38,6 \%) \\
(45,5 \%)\end{array}$ & $48(38,7 \%)$ \\
\hline Je ne les connais pas. & $14(17,5 \%)$ & $6(13,6 \%)$ & $20(16,1 \%)$ \\
\hline Je ne sais pas. & $1(1,3 \%)$ & 0 & $1(0,8 \%)$ \\
\hline Insgesamt & $80(100,0 \%)$ & 44 & 124 \\
\hline
\end{tabular}

Hinsichtlich der Beachtung der Terminologielisten ergibt sich ein ähnliches Bild wie bei den beiden vorangegangenen Tabellen: 43,7\% der unter 30-Jährigen und 38,6 der über 30-Jährigen lehnen deren Befolgung kategorisch ab. Der Grad der partiellen Befolgung der Terminologielisten ist bei den Sprechern der älteren Generation höher: 45,5\% der Informanten der älteren Generation geben an, diese zu befolgen, während dies nur auf 35\% der Informanten der jüngeren Generation zutrifft.

Insgesamt konnten generationsspezifische Unterschiede bezüglich der Einstellungen zur Sprachpolitik und Terminologiearbeit festgestellt werden. Der Grad der Befürwortung sprachpolitischer und terminologischer Maßnahmen liegt in der älteren Generation höher als in der jüngeren. Auch geben mehr Informanten der älteren als der jüngeren Generation an die in den Terminologielisten publizierten Termini zumindest teilweise zu verwenden.

\subsubsection{Hypothese II.3: Korrelation zwischen Bildungsgrad und Ein- stellungen}

Hypothese II.3: Je höher der Bildungsgrad der Informanten, desto höher die Ablehnung von sprachpolitischen Maßnabmen und den daraus resultierenden Vorschriften.

Bei den Informanten wurde ein überdurchschnittlich hohes Ausbildungsniveau festgestellt. Die Anzahl der Informanten ohne Abitur ist mit zwei von 124 Informanten zu gering, als dass es sich lohnen würde, den Sprachgebrauch von Sprechern mit Abitur bzw. abgeschlossenem Studium denjenigen gegenüberzustellen, die kein Abitur gemacht haben. Insofern muss die Überprüfung dieser Hypothese entfallen. 


\subsubsection{Hypothese II.4: Korrelation zwischen Beruf und Sprach- gebrauch/Einstellungen}

Hypothese II.4: Informatiker lehnen die französischen Termini mehrheitlich ab.

Bezüglich des Merkmals Beruf handelt es sich bei den Befragten um eine recht homogene Gruppe, da nur die Fragebögen von Informatikern ausgewertet wurden. Auf eine noch differenziertere Auswertung, bei der z.B. Unterschiede in den Akzeptanzurteilen von Ingenieuren oder Programmiern herausgearbeitet werden, wird verzichtet. Die Übergänge zwischen den einzelnen Berufsgruppen können mitunter fließend sein, so dass eine derartige Spezifizierung wenig aussagekräftig ist.

Die Ergebnisse des ersten Fragebogenmoduls zeigen, dass keine generellen Aussagen dahingehend möglich sind, dass französische Neologismen von den Befragten mehrheitlich abgelehnt werden. Die Termini page d'accueil und fournisseur d'accès setzen sich eindeutig gegen ihre englischsprachigen Konkurrenten durch und auch pirate liegt mit einigem Abstand vor engl. cracker. Auch die Antworten auf die Frage nach der Befolgung der Terminologielisten (vgl. 9.2) zeigen, dass die französische Terminologie nicht unbedingt von den Informatikern abgelehnt wird. Aufgrund der Ergebnisse kann die Hypothese nicht bestätigt werden, dass die befragten französischen Informatiker die französischen Termini mehrheitlich ablehnen.

\subsubsection{Hypothese II.5: Korrelation zwischen Englischkenntnissen und Sprachgebrauch}

Hypothese II.5: Je besser die Englischkenntnisse der Informanten ausfallen, desto eher werden Anglizismen verwendet.

Eine Korrelation zwischen Sprachgebrauch einerseits und guten bzw. schlechten Englischkenntnissen andererseits muss deshalb entfallen, weil die meisten Informanten nach eigenen Angaben über mittlere bis gute Englischkenntnisse verfügen. Nur ein Informant hat angegeben über geringe Englischkenntnisse zu verfügen (vgl. 8.2.8). Insofern muss auf die Überprüfung der Hypothese verzichtet werden.

Die Auswertung der Gründe, die für die Benutzung der Anglizismen genannt wurden (erstes Fragebogenmodul), und die Kommentare zur Terminologiearbeit (drittes Fragebogenmodul) haben jedoch gezeigt, dass der Rang des Englischen als Verkehrssprache in der Informatik- bzw. Internetbranche unangefochten ist. Die durchgängige Verwendung der englischen Terminologie wird als Vereinfachung der nationalen und internationalen Kommunikation bewertet. 


\subsubsection{Hypothese II.6: Korrelation zwischen Internetnutzung und Sprachgebrauch}

Hypothese II.6: Wer länger als seit 1999 das Medium Internet benutzt, wird eher die InternetAnglizismen als die entsprechenden Neologismen verwenden.

Mit dem letzten Faktor, der Art und Dauer der Internetnutzung, soll überprüft werden, ob die Informanten bereits vor der Veröffentlichung der Internet-Terminologie mit dem Medium und dem entsprechenden Wortschatz vertraut waren oder nicht. Alle sechs im Fragebogen überprüften Lexemgruppen beziehen sich auf den E-Mail-Dienst bzw. das World Wide Web. Daher könnte es aufschlussreich sein zu ermitteln, ob es Unterschiede im Sprachgebrauch zwischen Personen gibt, die den E-Mail-Dienst und das World Wide Web weniger als drei Jahre nutzen, und Personen, die diese beiden Dienste länger als drei Jahre nutzen. Eine Korrelation zwischen der Internetnutzung und dem Sprachgebrauch entfällt im Rahmen der Auswertung allerdings deshalb, weil über 80\% der Informanten angeben, den E-Mail-Dienst und das WWW seit mehr als drei Jahren zu nutzen (vgl. 8.2.9). Deshalb ist es ebenfalls nicht möglich, die Hypothese II.6 zu überprüfen.

\subsection{Zusammenfassung}

Im ersten Teil des Fragebogens antworteten 124 französische Informatiker auf Fragen zum Bekanntheitsgrad (passive Akzeptanz), zur Synonymie, zu persönlichen Präferenzen und zum eigenen Sprachgebrauch (aktive Akzeptanz). Diese Fragen bezogen sich auf sechs ausgewählte Internet-Lexemgruppen. Außerdem charakterisierten die Informanten die französischen Termini bezüglich ihrer Eigenschaften bzw. gaben bei Bevorzugung des englischsprachigen Terminus die Gründe an, die für dessen Gebrauch sprechen.

Von den sechs im ersten Fragebogenmodul überprüften Lexemgruppen erhalten in drei Fällen die französischen Neologismen und in drei Fällen die englischsprachigen Termini das höhere Akzeptanzvotum: e-mail/ mail, web und chat setzen sich gegen die französischen Neologismen und page d'accueil, pirate und fournisseur d'accès gegen die englischsprachigen Konkurrenten durch. Vielfach wird die Wahl eines Terminus auch in Abhängigkeit vom Kontext entschieden, was für eine große Flexibilität im Umgang mit der Fachterminologie spricht.

Nicht in allen Fällen werden die Anglizismen und die entsprechenden Ersatzwörter als synonym betrachtet. Die von den Informanten genannten Bedeutungsunterschiede weisen häufig Parallelen auf. Es erstaunt umso mehr, dass relativ viele Informatiker bei den ersten vier Lexemgruppen Bedeutungsunterschiede feststellen, als in der Informatik-Kommission neben Linguisten und Vertretern anderer Berufsgruppen auch Informatiker sitzen, die eigentlich mit den Termini und ihren Definitionen bestens vertraut sein sollten. Schließlich sollte das Ziel der Terminologiearbeit nicht nur darin bestehen, die ungeliebten Anglizismen auszumerzen, sondern auch französische Neologismen zu schaffen, die genau den Sinn des zu 
ersetzenden Terminus wiedergeben. Um derartige Fehler zu vermeiden, erweist es sich als durchaus sinnvoll, vor der Verabschiedung entsprechender Terminologielisten weitere Spezialisten zur Beurteilung der Lexempaare heranzuziehen, wenngleich dies mit erheblichem Aufwand und Kosten verbunden ist.

Bei den Gründen, die für die Verwendung der Anglizismen mail/e-mail, web/World Wide Web und chat sprechen, werden am häufigsten Argumente genannt, die sich auf die Kommunikation beziehen. Die Kommunikation werde nach Ansicht der befragten Informatiker durch den Einsatz von Anglizismen vereinfacht, weil alle (Fach-)Leute die englischen Termini kennen würden und die Sprecher daher sicher sein könnten, von ihrem Gegenüber richtig verstanden zu werden. Persönliche Gründe wie die Gewöhnung an den Anglizismus oder sprachökonomische Gründe wie die Kürze folgen erst an zweiter Stelle.

Im zweiten Fragebogenmodul ging es um die Kenntnis und Akzeptanz der Sprachpolitik und Terminologielisten. 97 von 124 Befragten (78,2\%) wissen, dass es eine offizielle Sprachpolitik gibt. Ein Drittel der Informanten ist sogar über die Inhalte informiert. Etwas mehr als die Hälfte der befragten Informatiker hält politische Maßnahmen zum Schutz der französischen Sprache für notwendig bzw. wünschenswert. Demgegenüber beurteilen 37,9\% Sprachpolitik als unnötig. Die ermittelten Werte decken sich annähernd mit den von Fugger (1979/1983a) ermittelten Prozentzahlen. Die Bekanntheit der Sprachpolitik in der Bevölkerung hat somit im Laufe von etwas mehr als 20 Jahren weder signifikant ab- noch zugenommen.

Der Anteil der Informanten, die die Terminologielisten für überflüssig halten, ist größer als der der Befürworter. Ein Drittel der Informanten bemängelt, dass die Terminologielisten nicht bekannt genug seien. Die Zahl der Informanten, die angeben, die Terminologielisten zu befolgen, deckt sich annähernd mit der jener, die sie nach eigenen Angaben nicht befolgen.

Was die Listen zur Internet-Terminologie betrifft, so behauptet keiner der Informanten, diese gut zu kennen. 54\% haben von den Listen gehört oder kennen sie ein wenig. 15 der 21 Informanten, die die Listen bzw. eine der Listen ein wenig kennen, geben an, sie teilweise auch zu befolgen. Dieses Ergebnis macht deutlich, dass es zwar einerseits nötig wäre, die erarbeiteten Terminologielisten in der Bevölkerung und insbesondere unter den betroffenen Berufsgruppen weiterhin bekannt zu machen, dass sich andererseits aber zumindest die Hälfte der befragten Informatiker in ihrer Entscheidung für oder gegen einen Anglizismus nicht von sprachpolitischen Maßnahmen beeinflussen lässt. Dieser Standpunkt wird auch bei der Auswertung der Kommentare (9.3) deutlich: Einzig der Sprachgebrauch solle darüber bestimmen, welche Termini sich etablieren können und welche nicht. Die Aufgaben der Terminologiekommissionen werden hingegen darin gesehen, Terminologievorschläge zu verbreiten und Denkanstöße zu geben, inwiefern eine französische Terminologie überhaupt sinnvoll und nützlich sein könne (vgl. auch Chansou 1993, 166; 4.3.1). Vielleicht ließe sich auf diese Weise der Widerstand, der der Arbeit der Kommissionen spürbar entgegengebracht wird, deutlich reduzieren. Dass die Terminologiekommissionen nach wie vor eine Daseins- 
berechtigung haben, zeigen andere Kommentare aus dem dritten Fragebogenteil: Trotz vielfacher Kritik an den Ersatzwörtern (insbesondere vom Typ mél oder cédérom) befürworten mehrere Informanten eine französische Terminologie, wenn die vorgeschlagenen französischen Termini kurz, präzise, ästhetisch befriedigend und inhaltlich korrekt seien. Die Tatsache, dass französische Termini nicht per se abgelehnt werden, darf bezüglich der Arbeit der Terminologiekommissionen und der Sinnhaftigkeit der Ersatzwortfindung durchaus als positives Signal interpretiert werden. Insbesondere im Bereich der neuen Technologien wird es als wichtig erachtet, dass die (fachliche) Kommunikation nicht durch die Verwendung nationaler Termini gefährdet werde.

In 9.4 konnte aufgrund der Datenlage nur eine einzige Korrelation zwischen biosozialen Daten und dem Sprachgebrauch einerseits und den Einstellungen andererseits vorgenommen werden. Als einzige sinnvolle Korrelation erweist sich aufgrund des vorhandenen Datensatzes neben der länderspezifischen Evaluation, der die Kapitel 9-11 sowie das vergleichende Kapitel 12 Rechnung tragen, die Korrelation zwischen Alter und Sprachverhalten bzw. Einstellungen. Aus den Daten war kein gravierender Unterschied im Sprachgebrauch der unter 30-Jährigen und der über 30-Jährigen ersichtlich. Die befragten Informatiker beider Altersgruppen bevorzugen in einigen Fällen die französischen, in anderen Fällen die englischen Termini. Die Entscheidung für einen französischen oder einen englischen Terminus scheint bei den Informatikern nicht so sehr vom Alter als von anderen Faktoren wie dem beruflichen Umfeld abzuhängen. Allerdings können generationsspezifische Unterschiede bezüglich der Einstellungen zur Sprachpolitik und Terminologiearbeit festgestellt werden. Die Informatiker, die älter als 30 Jahre sind, stehen sprachpolitischen und terminologischen Maßnahmen weniger ablehnend gegenüber als die unter 30-jährigen Informanten. Dieses Ergebnis allein reicht allerdings noch nicht aus, um daraus eine in sprachlicher Hinsicht konservativere Haltung der älteren Generation abzuleiten, denn sie verwenden Anglizismen fast genauso häufig wie die jüngere Generation. 


\section{Auswertung der WWW-Befragung: das franzö- sischsprachige Belgien}

Die Auswertung der 17 Fragebögen, die von belgischen Informatikern ausgefüllt wurden, erfolgt analog zur Auswertung in Kapitel 9. Bezüglich der Übertragbarkeit der Ergebnisse auf die Gesamtheit der frankophonen belgischen Informatiker gelten die am Anfang von Kapitel 9 getroffenen Einschränkungen. Hinzu kommt die relativ geringe Teilnehmerzahl.

Die Fragen werden in der Reihenfolge ihres Auftretens im Fragebogen ausgewertet. In 10.1 werden alle Fragen des ersten Fragebogenmoduls ausgewertet, d.h. Fragen zur Akzeptanz, Synonymie und Bewertung der ausgewählten InternetTermini. Im Anschluss an die Auswertung der Fragen zu jeder Lexemgruppe werden die in 5.3.1 formulierten Arbeitshypothesen aufgegriffen und überprüft. Das erste Fragebogenmodul, das von den belgischen Informatikern bearbeitet wurde, weicht nicht von der Version ab, die den französischen Informanten vorgelegen hat. 10.2 dient der Auswertung der Fragen zur Kenntnis und Akzeptanz der belgischen Sprachpolitik, Terminologiearbeit und speziell der InternetTerminologie. Das zweite Fragebogenmodul weicht nur insofern von der französischen Version ab, als die Fragen an die belgischen Verhältnisse angepasst wurden. In 10.3 schließlich stehen die frei formulierten Kommentare zur Sprachpolitik und Terminologiearbeit aus dem dritten Fragebogenmodul im Zentrum. Auf eine Korrelation der Daten aus den ersten beiden Fragebogenmodulen mit den biosozialen Daten, um wie in 9.4 die in 5.3.2 formulierten Arbeitshypothesen zu überprüfen, wird in Anbetracht der geringen Anzahl an Informanten und der ungünstigen Datenlage verzichtet: Alle Informanten sind männlich, elf Informanten sind unter 30 Jahre alt, sechs sind älter als 30 Jahre. Alle Befragten haben das Abitur, einige ein abgeschlossenes Studium. Zwei Informanten haben geringe, 
fünf mittlere und zehn gute Englischkenntnisse. Nur zwei Informanten nutzen den E-Mail-Dienst und drei das World Wide Web seit weniger als drei Jahren, 15 bzw. 14 Informanten seit mehr als drei Jahren. Aufgrund dieser jeweils sehr unausgeglichenen Verteilungen ist es nicht sinnvoll, zwei Gruppen zu bilden und einander gegenüberzustellen. Daher entfällt eine Auswertung bezüglich der Faktoren Geschlecht, Alter, Bildungsniveau, Englischkenntnisse oder Dauer der Internetnutzung.

\subsection{Erstes Fragebogenmodul: Auswertung der sechs aus- gewählten Lexemgruppen}

Die Auswertung erfolgt analog zur Auswertung der Fragebögen der französischen Informatiker. Daher wird in diesem Kapitel weitestgehend auf methodische Erklärungen verzichtet.

\subsubsection{Die Termini courrier électronique, message électronique, mél, courriel, messagerie électronique, lettre électronique, e-mail und mail}

Bezüglich der Bekanntheit der Termini courrier électronique, message électronique, mél, courriel, messagerie électronique, lettre électronique, e-mail und mail ergibt sich - sowohl in absoluter (Abb. 93) als auch in relativer Häufigkeit (Abb. 94) dargestellt - folgendes Bild:

Abb. 93: Frage 1, Bekanntheitsgrad der Termini courrier électronique, message électronique, mél, courriel, messagerie électronique, lettre électronique, e-mail und mail (absolute Häufigkeit, Belgien)

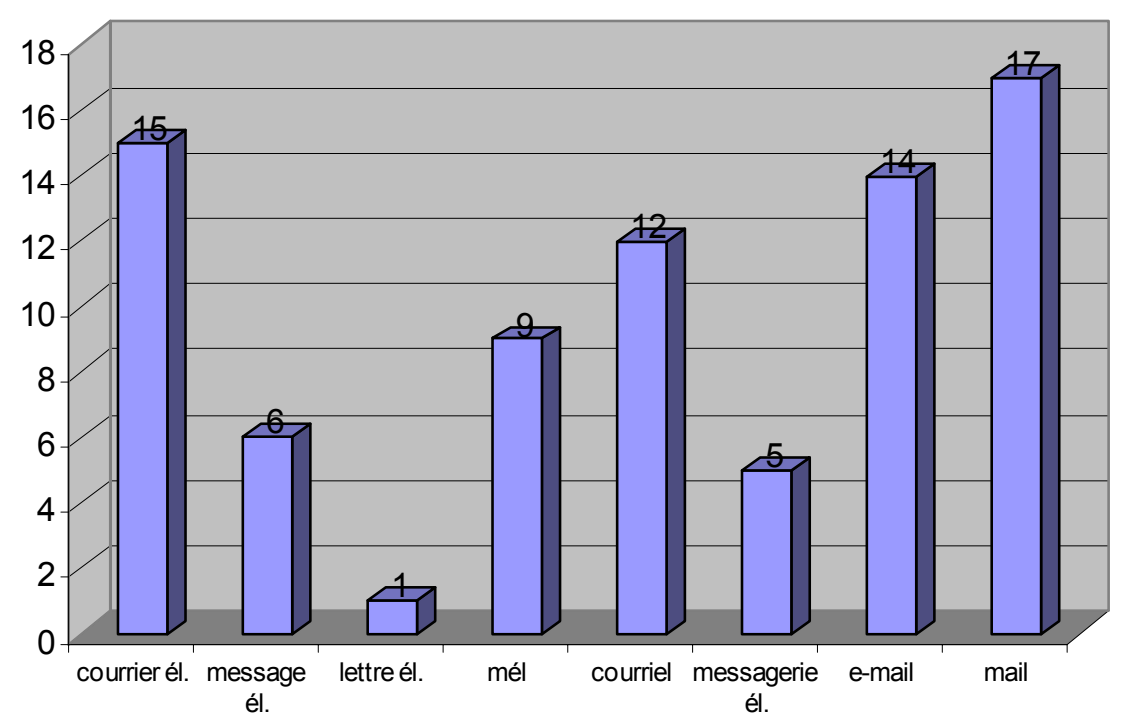




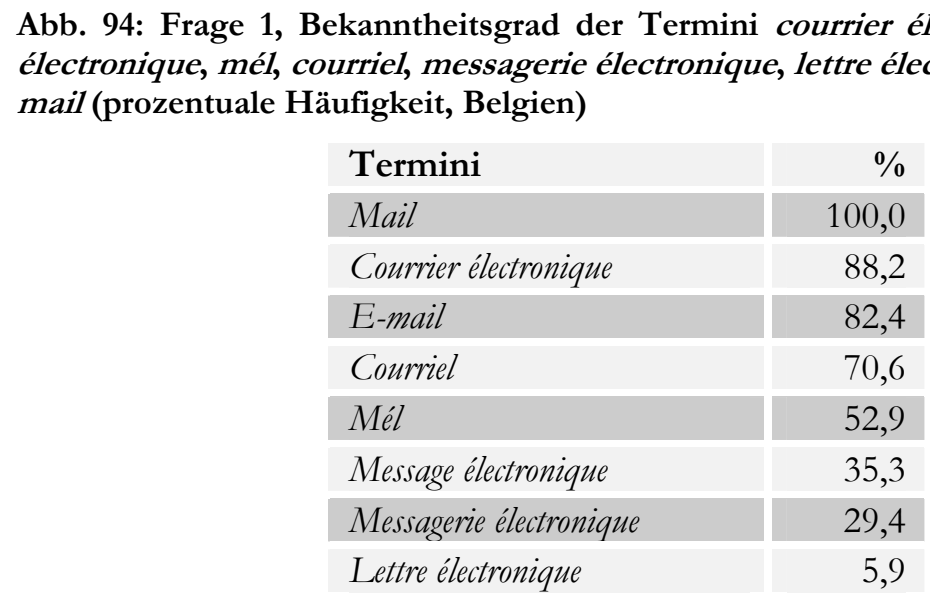

Alle Informanten kennen engl. mail, an zweiter Stelle steht mit fast 90\%igem Bekanntheitsgrad franz. courrier électronique. Erst an dritter Stelle folgt e-mail mit einem Bekanntheitsgrad von 82,4\%, an vierter Stelle das v.a. in Québec gebräuchliche courriel mit einem Bekanntheitsgrad von 70,6\%. Die Hälfte der Befragten kennt das Kurzwort mél, 35,3\% kennen message électronique, etwas weniger, 29,4\%, kennen messagerie électronique. Das Testwort lettre électronique wird von nur 5,9\% der Informanten als bekannt angegeben.

Wie auch in Kapitel 9.1.1 sollen die in Abb. 94 aufgeführten Werte in allgemeinere Kategorien eingeordnet werden, um den Etablierungsgrad bestimmen zu können. Hierfür wird wieder das von Gasquet/Villebrun (1994, 117) entworfene Schema herangezogen, in dem der Etablierungs- bzw. Bekanntheitsgrad in vier Kategorien unterteilt wird (vgl. 9.1.1). Entsprechend gelten Termini als sicher etabliert, die von mehr als $80 \%$ der Befragten als bekannt eingestuft werden, Termini als unsicher bzw. mehr oder weniger etabliert, die von 50-80\% der Befragten als bekannt eingestuft werden, und Termini als schwach bzw. kaum etabliert, die weniger als $50 \%$ der Befragten kennen.

Bezogen auf die im ersten Fragebogenkomplex überprüften Lexeme bedeutet dies: mail gilt als 100\%ig etabliert, da dieser Terminus allen Befragten bekannt ist. Als sicher etabliert gelten franz. courrier électronique und engl. e-mail. Einen mittleren Etablierungsgrad weisen courriel und mél auf. Als unsicher bis schwach etabliert können message électronique, messagerie électronique und lettre électronique eingestuft werden.

Werden diese Termini mit Ausnahme des Testwortes lettre électronique auch als Synonyme betrachtet? Dies klärt die folgende zweite Frage. 
Abb. 95: Frage 2, Synonymie der Termini courrier électronique, message électronique, mél, courriel, messagerie électronique, e-mail und mail (Belgien)

\begin{tabular}{|l|r|r|}
\hline & $\begin{array}{l}\text { Absolute } \\
\text { Häufigkeit }\end{array}$ & $\begin{array}{l}\text { Prozentuale } \\
\text { Häufigkeit }\end{array}$ \\
\hline Synonym & 6 & 35,3 \\
\hline $\begin{array}{l}\text { Bedeutungs- } \\
\text { unterschied }\end{array}$ & 9 & 52,9 \\
\hline $\begin{array}{l}\text { Termini un- } \\
\text { bekannt / } \\
\text { Weiß nicht }\end{array}$ & 2 & 11,8 \\
\hline Insgesamt & 17 & 100,0 \\
\hline
\end{tabular}

Für eine knappe Mehrheit der Informanten (52,9\%) besteht ein Bedeutungsunterschied zwischen den Termini, 35,3\% halten die Termini für synonym. Die von den Informanten frei formulierten Begründungen wurden analog zur Vorgehensweise in Kapitel 9.1.1 in verschiedene Kategorien eingeteilt. Die Begründungen können im Wortlaut im Anhang 15.5.1.2.1 nachgelesen werden. Die folgende Tabelle gibt Aufschluss über die von den Informanten genannten Bedeutungsunterschiede. Die einzelnen Kategorien werden nach der Häufigkeit ihrer Nennungen geordnet. Bei gleicher Anzahl an Nennungen werden die Kategorien alphabetisch geordnet.

Abb. 96: Frage 3, Bedeutungsunterschiede zwischen courrier électronique, message électronique, mél, courriel, messagerie électronique, e-mail und mail (Belgien)

\begin{tabular}{|c|c|c|}
\hline Kategorie & Informanten & Anzahl \\
\hline $\begin{array}{l}\text { Bedeutungsunterschied zwischen messagerie } \\
\text { électronique und den anderen Termini (message } \\
\text { électronique, courrier électronique, courriel, mél, e-mail } \\
\text { und mail): messagerie électronique ist das System } \\
\text { (wie MS Outlook oder Netscape Messenger), } \\
\text { die anderen Termini sind die einzelnen Nach- } \\
\text { richten, die über das System übermittelt wer- } \\
\text { den. }\end{array}$ & $\begin{array}{l}\mathrm{B} 1.2, \mathrm{~B} 1.5 \\
\mathrm{~B} 1.6, \mathrm{~B} 1.7\end{array}$ & 4 \\
\hline $\begin{array}{l}\text { Message électronique ist semantisch weiter als } \\
\text { courrier électronique, e-mail, courriel und mél. Mes- } \\
\text { sage électronique ist auch die Bezeichnung für } \\
\text { Beiträge in Diskussionsforen. }\end{array}$ & B1.3, B1.6 & 2 \\
\hline $\begin{array}{l}\text { Courriel ist der kanadische Terminus, mél ist } \\
\text { das französische Pendant. }\end{array}$ & B1.3 & 1 \\
\hline
\end{tabular}


Gebrauch der Termini wechselt von Person

B1.1

zu Person: Ein informatischer Laie würde

z.B. mél verwenden.

Message électronique, courrier électronique, courriel, mél, e-mail und mail sind synonym. Messagerie électronique hat eine weitere Bedeutung.

Unterschied zwischen e-mail und mail: Erste-

res bezeichnet die elektronische Post, Letzteres die normale (Brief-)Post.

Vier Informanten weisen auf den Unterschied zwischen messagerie électronique einerseits und den übrigen Termini andererseits hin. Messagerie électronique bezeichne das System, während die anderen Termini die Nachrichten als solche bezeichneten. Das nicht näher begründete Argument, messagerie électronique habe eine weitere Bedeutung als die anderen Termini, weist in eine ähnliche Richtung wie die Aussagen der vier Informanten, die messagerie électronique im Unterschied $\mathrm{zu}$ den anderen Termini als das System charakterisiert haben. Zwei Informanten halten den Terminus message électronique für semantisch weiter als die Termini courrier électronique, email, courriel und mél, da mit message électronique nicht nur Nachrichten bezeichnet würden, die mit einem E-Mail-Programm versendet und empfangen würden, sondern auch Beiträge in Diskussionsforen.

Die folgenden beiden Abbildungen zeigen, welche Termini von den Befragten bevorzugt werden:

Abb. 97: Frage 4, persönliche Präferenz(en): courrier électronique etc. (absolute Häufigkeit, Belgien)

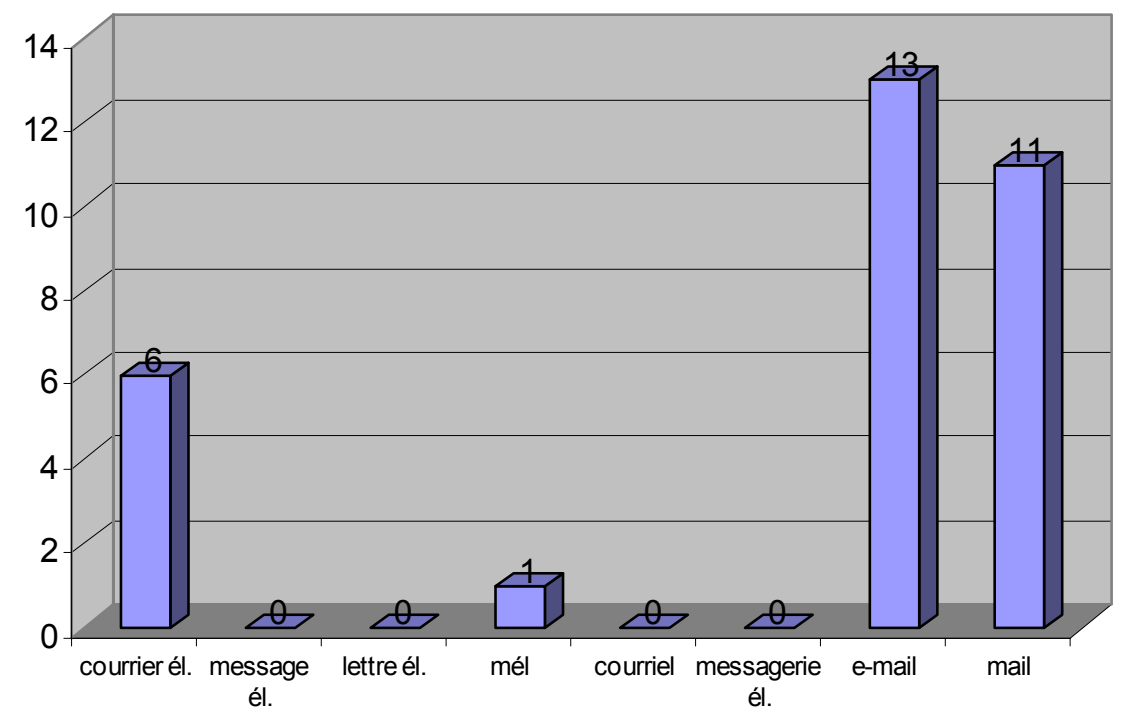


Abb. 98: Frage 4, persönliche Präferenz(en): courrier électronique etc. (prozentuale Häufigkeit, Belgien)

\begin{tabular}{|l|r|}
\hline Termini & $\mathbf{\%}$ \\
\hline E-mail & 76,5 \\
\hline Mail & 64,7 \\
\hline Courrier électronique & 32,3 \\
\hline Mél & 5,9 \\
\hline Courriel & 0,0 \\
\hline Message électronique & 0,0 \\
\hline Messagerie électronique & 0,0 \\
\hline Lettre électronique & 0 \\
\hline
\end{tabular}

Aus der Grafik wird ersichtlich, dass der in Frage 1 (vgl. Abb. 93 und 94) ermittelte Bekanntheitsgrad und die Präferenz der Termini keineswegs übereinstimmen. Während $100 \%$ der Befragten mail kennen, bevorzugen es jedoch nur 64,7\%. Demgegenüber weist e-mail einen Bekanntheitsgrad von nur 82,4\% auf. Allerdings bevorzugen diesen Terminus nahezu alle Informanten, die ihn auch als bekannt angegeben haben, nämlich 76,5\%. Courrier électronique, das von $88,2 \%$ der Informanten als bekannt angegeben wurde, wird nur von 32,3\% der Befragten als eine der persönlichen Präferenzen angegeben. Hinsichtlich dieses Terminus ist die Differenz zwischen dem Bekanntheitsgrad und der Präferenz mit 55,9 Prozentpunkten sehr groß. Ein Informant (5,9\%) hat als Präferenz auch mél angegeben, das bezüglich des Bekanntheitsgrades erst an fünfter Stelle, hinter courriel, steht. Die Termini courriel, message électronique, messagerie électronique und lettre électronique werden von keinem der Befragten als Präferenz genannt.

Die Präferenzen spiegeln sich in der Frage nach dem eigenen Sprachgebrauch wider. 
Abb. 99: Frage 5, eigener Sprachgebrauch: courrier électronique etc. (Belgien)

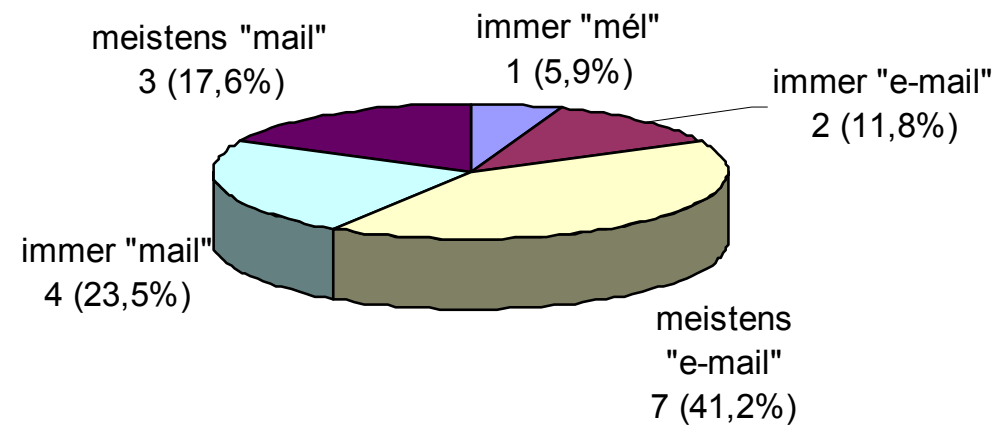

Neun von 17 Informanten (53\%) verwenden meistens oder immer e-mail. Sieben Informanten $(41,1 \%)$ geben an meistens oder immer mail zu verwenden. Insgesamt werden die englischen Termini somit von 16 Informanten (94,1\%) verwendet.

Um die Gebrauchsfrequenz in allgemeinere Kategorien einordnen zu können, wird auf das bereits in 9.1 verwendete Schema Thoirons zurückgegriffen, mithilfe dessen jeder Terminus einer der folgenden drei Klassen zugeordnet werden kann (vgl. 9.1.1).

Jeder der beiden englischsprachigen Termini mail und e-mail weist mit 41,1\% bzw. $53 \%$ für sich genommen einen mittleren Etablierungsgrad auf. In Abgrenzung zu den französischen Termini kann den englischen Termini mit einer zusammengenommen über 90\% liegenden Gebrauchsfrequenz ein guter Etablierungsgrad bescheinigt werden.

Da nur ein Informant angibt, immer mél zu verwenden, entfällt die Auswertung der sechsten Frage, wie die französischen Neologismen bewertet werden, und es wird direkt zur nächsten Frage übergegangen.

Folgende Gründe werden für die Verwendung der englischsprachigen Termini genannt: 
Abb. 100: Frage 7, Gründe für die Bevorzugung der englischsprachigen Termini email und mail (Belgien)

Nr. Begründung

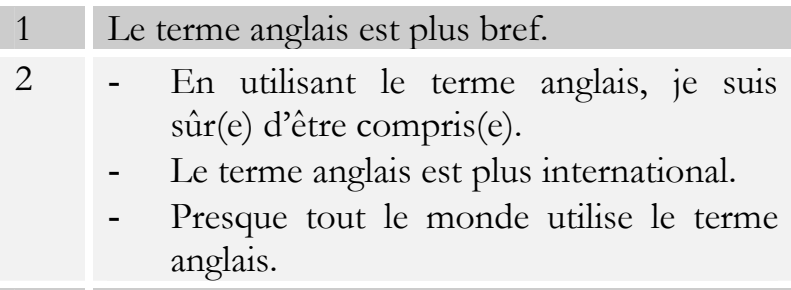

3 Je me suis déjà habitué(e) à utiliser le terme anglais.

$4 \quad$ Il y a trop d'équivalents français pour un seul terme anglais.

\begin{tabular}{|c|c|c|c|}
\hline 5 & $\begin{array}{l}\text { - La signification des termes français n'est } \\
\text { pas claire. } \\
\text { - Les formulations des termes français } \\
\text { sont trop compliquées. }\end{array}$ & 3 & 18,8 \\
\hline 6 & $\begin{array}{l}\text { Les termes français ne sont pas assez } \\
\text { connus. }\end{array}$ & 2 & 12,5 \\
\hline 7 & $\begin{array}{l}\text { - Il n'est pas possible de créer des termes } \\
\text { dérivés (du type: logiciel, progiciel, ludi- } \\
\text { ciel). } \\
\text { - Je n'aime pas suivre les propositions } \\
\text { officielles. } \\
\text { - La signification des termes français ne } \\
\text { correspond pas à celle du terme anglais. } \\
\text { - Les connotations des termes français ne } \\
\text { correspondent pas aux connotations qui } \\
\text { sont liées au terme anglais. }\end{array}$ & 1 & $\begin{array}{l}6,3 \\
6,3 \\
6,3 \\
6,3\end{array}$ \\
\hline 8 & $\begin{array}{l}\text { Autre : } \\
\text { - Courrier (tout simplement). } \\
\text { - Je travaille dans une société américaine } \\
\text { :-) De plus, utilisant Lotus Notes, le } \\
\text { terme note est aussi employé, mais perso, } \\
\text { j'aime pas car c'est trop général. }\end{array}$ & 2 & 12,5 \\
\hline
\end{tabular}

\begin{tabular}{|r|r|}
$\begin{array}{l}\text { Absolute } \\
\text { Häufigkeit }\end{array}$ & $\begin{array}{l}\text { Prozentuale } \\
\text { Häufigkeit }\end{array}$ \\
\hline 12 & 75,0 \\
\hline 8 & 50,0 \\
\hline & \\
8 & 50,0 \\
8 & 50,0 \\
\hline
\end{tabular}

\begin{tabular}{|r|r|}
\hline 6 & 37,5 \\
\hline 5 & 31,3 \\
\hline
\end{tabular}

\section{,8} 8,8 2,5 
Verbreitung des englischsprachigen Terminus. An dritter Stelle wird die Gewöhnung an den jeweiligen englischsprachigen Terminus genannt. Die Tatsache, dass es zu viele französische Äquivalente zu dem Anglizismus e-mail bzw. seiner (inoffiziellen) Kurzform mail gibt, steht an vierter Stelle und wird von fünf Informanten genannt. Auf die ausführliche Auflistung weiterer Gründe, die von je drei oder weniger Informanten angegeben wurden, wird an dieser Stelle verzichtet. Diese sind in der obenstehenden Tabelle nachzulesen.

Interessant sind die beiden Kommentare, die unter „Autre“ vermerkt wurden. Ein Informant schlägt als Alternative courrier vor, was dem engl. mail entspricht, da der französische Terminus sich ebenso wie der englische auf die (Brief-)Post bezieht, jedoch nicht im eigentlichen Sinne auf die elektronische Post (s. auch Frage 3). In dem zweiten Kommentar wird darauf hingewiesen, dass es neben den genannten Termini auch die Bezeichnung note gebe, die von dem Informanten selbst jedoch nicht verwendet werde, da sie zu allgemein sei.

Aufgrund der Ergebnisse kann die Hypothese I.2 („Die Termini e-mail und mail werden aufgrund ihrer Kürze häufiger verwendet als message électronique, messagerie électronique oder courrier électronique. Mél wird aufgrund der pseudoenglischen Aussprache sicherlich seltener verwendet als die beiden englischen Termini.“) bestätigt werden. Zwar wird der Terminus courrier électronique von 15 Informanten und e-mail nur von 14 Informanten als bekannt angegeben, jedoch bezüglich der aktiven Akzeptanz (eigener Sprachgebrauch) liegen die Anglizismen an erster Position. Der einzige französische Terminus, der von einem der Informanten nach eigenen Angaben verwendet wird, ist mél.

\subsubsection{Die Termini page d'accueil, page d'introduction und home- page}

Der zweite Fragenkomplex widmet sich den Termini franz. page d'accueil und engl. homepage sowie dem Testwort page d'introduction. 
Abb. 101: Frage 8, Bekanntheitsgrad der Termini page d'accueil, page d'introduction und homepage (absolute Häufigkeit, Belgien)

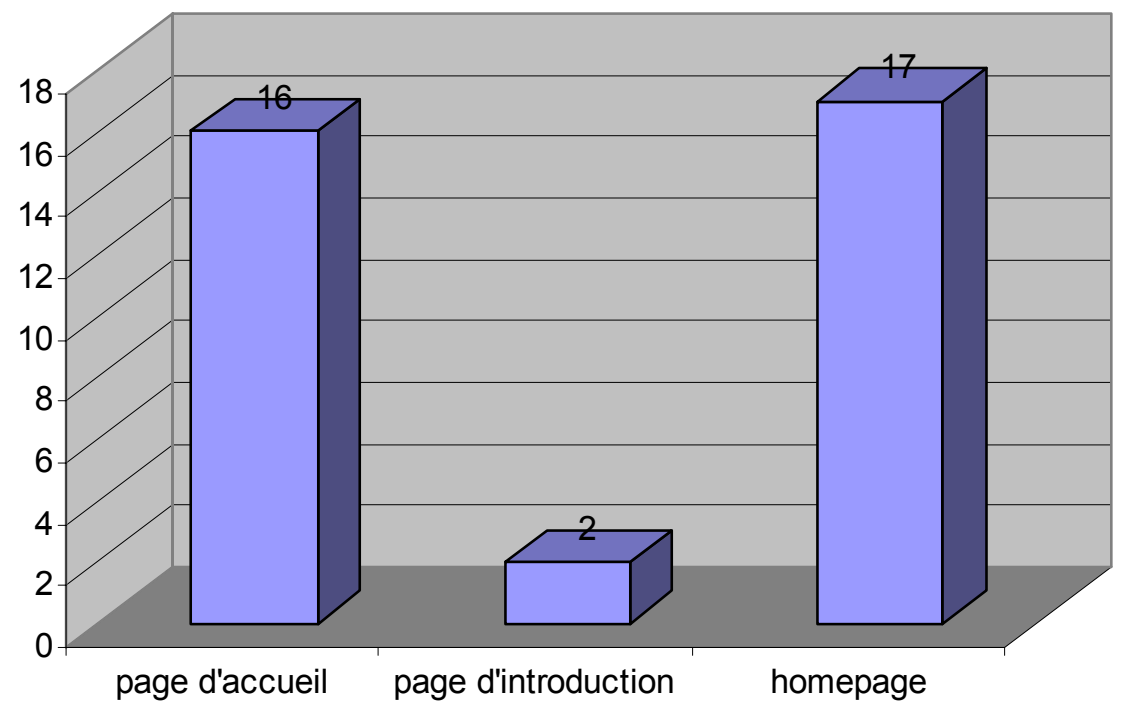

Abb. 102: Frage 8, Bekanntheitsgrad der Termini page d'accueil, page d'introduction und homepage (prozentuale Häufigkeit, Belgien)

\begin{tabular}{|l|r|}
\hline Termini & $\mathbf{\%}$ \\
\hline Homepage & 100,0 \\
\hline Page d'accueil & 94,1 \\
\hline Page d'introduction & 11,8 \\
\hline
\end{tabular}

Alle Informanten kennen den englischsprachigen Terminus homepage. Das französische Pendant page d'accueil kennen 16 von 17 Informanten (94,1\%). Das Testwort page d'introduction wird von zwei Informanten als bekannt angegeben. Nach dem Schema von Gasquet/Villebrun (1994, 117) weist bomepage einen 100\%igen Bekanntheitsgrad auf, page d'accueil gilt als sicher etabliert. Page d'introduction hat sich nur sehr schwach etabliert.

Mit der folgenden Frage wird geklärt, ob die Termini page d'accueil und homepage als synonym erachtet werden. 
Abb. 103: Frage 9, Synonymie der Termini page d'accueil und homepage (Belgien)

\begin{tabular}{|l|r|r|} 
& $\begin{array}{l}\text { Absolute } \\
\text { Häufigkeit }\end{array}$ & $\begin{array}{l}\text { Prozentuale } \\
\text { Häufigkeit }\end{array}$ \\
\hline Synonym & 15 & 88,2 \\
\hline $\begin{array}{l}\text { Bedeutungs- } \\
\text { unterschied }\end{array}$ & 2 & 11,8 \\
\hline Insgesamt & 17 & 100,0 \\
\hline
\end{tabular}

15 von 17 Informanten halten die Termini für synonym, zwei Informanten konstatieren einen Bedeutungsunterschied.

Die beiden Informanten, die einen Bedeutungsunterschied feststellen, führen folgende Begründungen an:

Abb. 104: Frage 10, Bedeutungsunterschiede zwischen page d'accueil und homepage (Belgien)

\begin{tabular}{|l|l|l|}
\hline Kategorie & Informanten & Anzahl \\
\hline $\begin{array}{l}\text { Homepage bezeichnet das gesamte Internetangebot, } \\
\text { während page d'accueil nur die erste Seite eines Inter- } \\
\text { netauftritts bezeichnet. }\end{array}$ & B2.1 & 1 \\
\hline $\begin{array}{l}\text { Page d'accueil bezeichnet die erste Seite eines Internet- } \\
\text { angebots, auf der sich auch der Index befindet, } \\
\text { homepage bezeichnet eine private Internetseite. }\end{array}$ & B2.2 & 1 \\
\hline
\end{tabular}

Bereits in 9.1.2 wurde bezogen auf die französischen Informanten festgestellt, dass von vielen Informanten ein Unterschied zwischen page d'accueil und homepage gemacht wird, wobei dem engl. homepage eine Bedeutung zugesprochen wird, die es in seiner ursprünglichen Verwendungsweise (im angloamerikanischen Sprachraum) gar nicht oder nicht ausschließlich hat. In Bezug auf dieses Lexempaar wäre es angemessen, dass die belgische Terminologiekommission ebenso wie die französische Terminologiekommission dem Sprachgebrauch Rechnung trägt und ihren Datenbankeintrag dahingehend überarbeitet, dass auch die Bedeutung von homepage als 'private Internetseite' aufgenommen wird.

Bezüglich der Präferenzen ergibt sich ein ausgeglichenes Bild zwischen page d'accueil und homepage: 
Abb. 105: Frage 11, persönliche Präferenz(en): page d'accueil, page d'introduction, homepage (absolute Häufigkeit, Belgien)

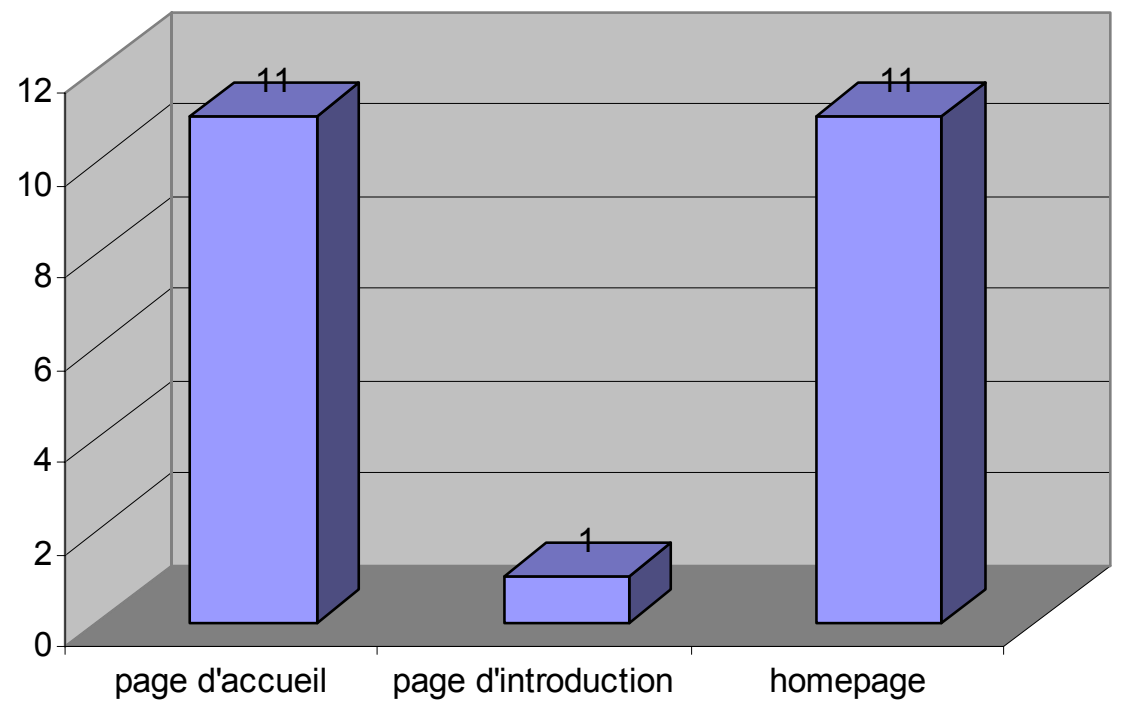

Abb. 106: Frage 11, persönliche Präferenz(en): page d'accueil, page d'introduction, homepage (prozentuale Häufigkeit, Belgien)

\begin{tabular}{|l|r|}
\hline Termini & \% \\
\hline Homepage & 64,7 \\
\hline Page d'accueil & 64,7 \\
\hline Page d'introduction & 5,9 \\
\hline
\end{tabular}

Bei dieser Frage waren maximal zwei Nennungen möglich, wovon insgesamt sechs der 17 Informanten Gebrauch gemacht und zwei Termini angegeben haben. Jeweils elf Informanten (64,7\%) geben page d'accueil oder homepage als ihre persönliche Präferenz an. Fünf Informanten geben die beiden Termini, franz. page d'accueil und engl. homepage, als ihre Präferenzen an. Ein Informant nennt neben page d'accueil auch page d'introduction. Dieser Informant bevorzugt zwar in diesem Fall die französischen Termini, tut dies aber nicht generell, denn in Frage 4 hat er, wie die Datenbank zeigt, als einzige Präferenz e-mail genannt. Entsprechend hat er in Frage 6 bezüglich des eigenen Sprachgebrauchs angegeben meistens e-mail zu verwenden.

Bei der Frage nach dem eigenen Sprachgebrauch zeigt sich eine mehrheitliche Bevorzugung des englischsprachigen Terminus: 
Abb. 107: Frage 12, eigener Sprachgebrauch: page d'accueil etc. (Belgien)

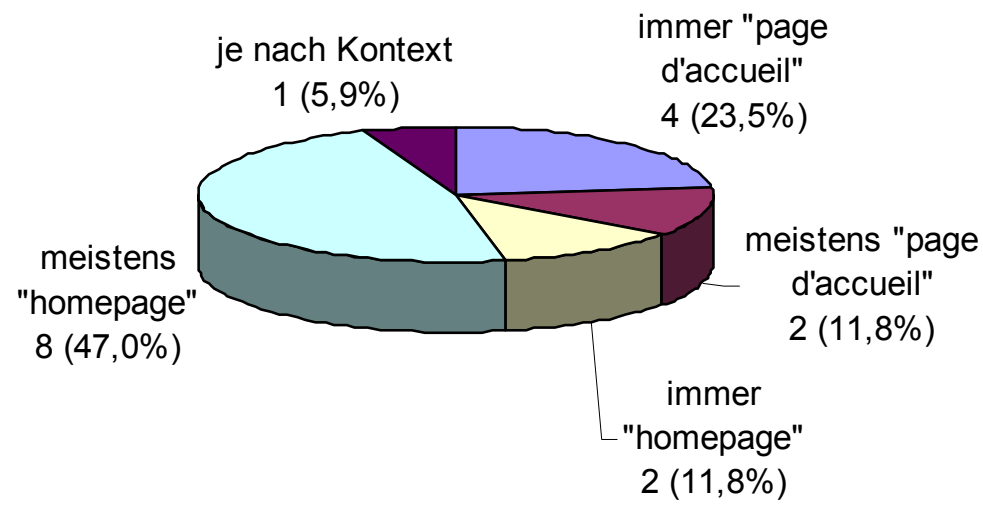

Der englische Terminus wird von zehn Informanten (58,8\%) meistens oder immer verwendet. Demgegenüber geben sechs Informanten (35,3\%) an immer oder meistens den französischen Terminus zu verwenden. Ein Informant entscheidet je nach Kontext.

Nach dem bei Rouges-Martinez (1992, 125f.) abgedruckten Schema weisen damit beide Termini einen mittleren Etablierungsgrad (70-30\%) auf, wobei sich homepage im oberen Drittel und page d'accueil am unteren Rand befindet.

Die sechs Informanten, die für den Gebrauch von page d'accueil plädieren, bewerten diesen Terminus bezüglich der Merkmale Bekanntheit, Schönheit, Verständlichkeit, Nützlichkeit, Adäquatheit, Etabliertheit, Natürlichkeit, Komplexität und Korrektheit wie folgt ${ }^{1}$ :

\footnotetext{
${ }^{1}$ Hinweise zum Auswertungsverfahren des semantischen Differentials wurden in 9.1.2 gegeben.
} 
Abb. 108: Frage 13, Bewertung des französischen Neologismus page d'accueil (Belgien)

\begin{tabular}{|c|c|c|}
\hline Kriterium & $\begin{array}{l}\text { Skalenendpunkte im } \\
\text { Fragebogen }\end{array}$ & $\begin{array}{l}\text { Durchschnittlicher } \\
\text { Akzeptanzwert }\end{array}$ \\
\hline $\begin{array}{l}\text { Bekanntheit (Bekanntheit } \\
\text { vs. Unbekanntheit) }\end{array}$ & $\begin{array}{l}\text { соппи - inсоппи } \\
1-5\end{array}$ & 1,33 \\
\hline $\begin{array}{l}\text { Schönheit (Schönheit vs. } \\
\text { Hässlichkeit) }\end{array}$ & $\begin{array}{l}\text { beau-laid } \\
1-5\end{array}$ & 2,50 \\
\hline $\begin{array}{l}\text { Verständlichkeit (Ver- } \\
\text { ständlichkeit vs. Unver- } \\
\text { ständlichkeit) }\end{array}$ & $\begin{array}{l}\text { compréhensible }- \text { in- } \\
\text { compréhensible } \\
1-5\end{array}$ & 1,50 \\
\hline $\begin{array}{l}\text { Nützlichkeit (Nützlichkeit } \\
\text { vs. Nutzlosigkeit) }\end{array}$ & $\begin{array}{l}\text { utile - inutile } \\
1-5\end{array}$ & 2,17 \\
\hline $\begin{array}{l}\text { Adäquatheit (Adäquatheit } \\
\text { vs. Inadäquatheit) }\end{array}$ & $\begin{array}{l}\text { adéquat-inapproprié } \\
1-5\end{array}$ & 1,83 \\
\hline $\begin{array}{l}\text { Etabliertheit (Altbestand } \\
\text { des Lexikons vs. Neuheit) }\end{array}$ & $\begin{array}{l}\text { établi-nouveau } \\
1-5\end{array}$ & 1,50 \\
\hline $\begin{array}{l}\text { Natürlichkeit (Normalität } \\
\text { vs. Künstlichkeit) }\end{array}$ & $\begin{array}{l}\text { normal-artificiel } \\
1-5\end{array}$ & 1,50 \\
\hline $\begin{array}{l}\text { Komplexität (Einfachheit } \\
\text { vs. Kompliziertheit) }\end{array}$ & $\begin{array}{l}\text { simple-complexe } \\
1-5\end{array}$ & 1,33 \\
\hline $\begin{array}{l}\text { Korrektheit (Korrektheit } \\
\text { vs. Unkorrektheit) }\end{array}$ & $\begin{array}{l}\text { correct-incorrect } \\
1-5\end{array}$ & 1,83 \\
\hline
\end{tabular}

Am besten schneidet page d'accueil bezüglich seiner Bekanntheit und Komplexität ab (1,33), wird also nahezu von allen Informanten als sehr bekannt und sehr einfach bewertet. Den schlechtesten Wert mit 2,5 Punkten auf der Likert-Skala erhält page d'accueil bezüglich seiner ästhetischen Qualitäten; aber auch dieser Wert liegt noch oberhalb des neutralen Mittelwertes 3,0 und tendiert damit noch zur positiven Seite. Aus allen Werten ergibt sich ein durchschnittlicher Wert von 1,72. Dieses Ergebnis bedeutet auf einer von 1-5 reichenden Skala ein gutes Akzeptanzvotum für page d'accueil.

Zehn Informanten haben in Frage 12 für die Verwendung des englischsprachigen Terminus plädiert. Die Gründe, die ihrer Meinung nach für homepage sprechen, werden in der folgenden Tabelle aufgeführt: 
Abb. 109: Frage 14, Gründe für die Bevorzugung des englischsprachigen Terminus homepage (Belgien)

Nr. Begründung

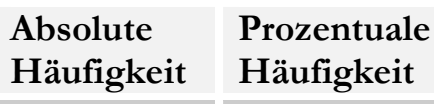

1 En utilisant le terme anglais, je suis sûr(e) d'être compris(e).

2 - Je me suis déjà habitué(e) à utiliser le terme anglais. Le terme anglais est plus bref.

- Presque tout le monde utilise le terme anglais.

\begin{tabular}{|c|c|c|c|}
\hline 3 & $\begin{array}{l}\text { - La signification des termes français n’est } \\
\text { pas claire. } \\
\text { - La signification des termes français ne } \\
\text { correspond pas à celle du terme anglais. } \\
\text { - Les connotations des termes français ne } \\
\text { correspondent pas aux connotations qui } \\
\text { sont liées au terme anglais. } \\
\text { - Les termes français ne sont pas assez } \\
\text { connus. }\end{array}$ & 2 & $\begin{array}{l}20,0 \\
20,0 \\
20,0\end{array}$ \\
\hline 4 & $\begin{array}{l}\text { - Il n'est pas possible de créer des termes } \\
\text { dérivés (du type: logiciel, progiciel, ludi- } \\
\text { ciel). } \\
\text { - Pour paraittre compétent, il faut se servir } \\
\text { de la terminologie anglaise. }\end{array}$ & 1 & 10,0 \\
\hline 5 & $\begin{array}{l}\text { Autre: } \\
\text { - En général, j'utiliserai le mot le plus } \\
\text { approprié en fonction de mon interlo- } \\
\text { cuteur. } \\
\text { - Toujours, déformation professionelle. }\end{array}$ & 2 & 20,0 \\
\hline
\end{tabular}

Fünf der zehn Informanten (50\%), die diese Frage beantwortet haben, nennen als Begründung für die Wahl des englischsprachigen Terminus die Sicherheit, bei dessen Gebrauch verstanden zu werden. Am zweithäufigsten werden die Gewöhnung und die weite Verbreitung des englischsprachigen Terminus genannt. Unter den selbstformulierten Gründen („Autre“) weist ein Informant explizit daraufhin, dass er nicht generell den französischen oder generell den englischen Terminus verwende, sondern die Wahl des entsprechenden Terminus von seinem Gesprächspartner abhängig mache. Mit der Äußerung „,Toujours, déformation professionelle“ wird vermutlich darauf angespielt, dass die Verwendung der englischsprachigen Termini eng an den Beruf des Informatikers geknüpft sei. 
Der in 5.3.1 formulierten Hypothese, dass page d'accueil einen höheren Akzeptanzwert erhalte als der entsprechende Anglizismus homepage, kann in Bezug auf die belgischen Informanten nicht zugestimmt werden. Zwar erhalten die beiden Termini bezüglich der Präferenz gleiche Werte, bezüglich der aktiven Akzeptanz schneidet der englische Terminus jedoch etwas besser ab als sein französisches Äquivalent.

\subsubsection{Die Termini toile d'araignée mondiale, toile mondiale, toile, T.A.M., réseau mondial, World Wide Web und web}

Hinsichtlich der Bekanntheit der Termini toile d'araignée mondiale, toile mondiale, toile, T.A.M., réseau mondial, World Wide Web und web ergibt sich folgende Verteilung:

Abb. 110: Frage 15, Bekanntheitsgrad der Termini toile d'araignée mondiale, toile mondiale, toile, T.A.M., réseau mondial, World Wide Web und web (absolute Häufigkeit, Belgien)

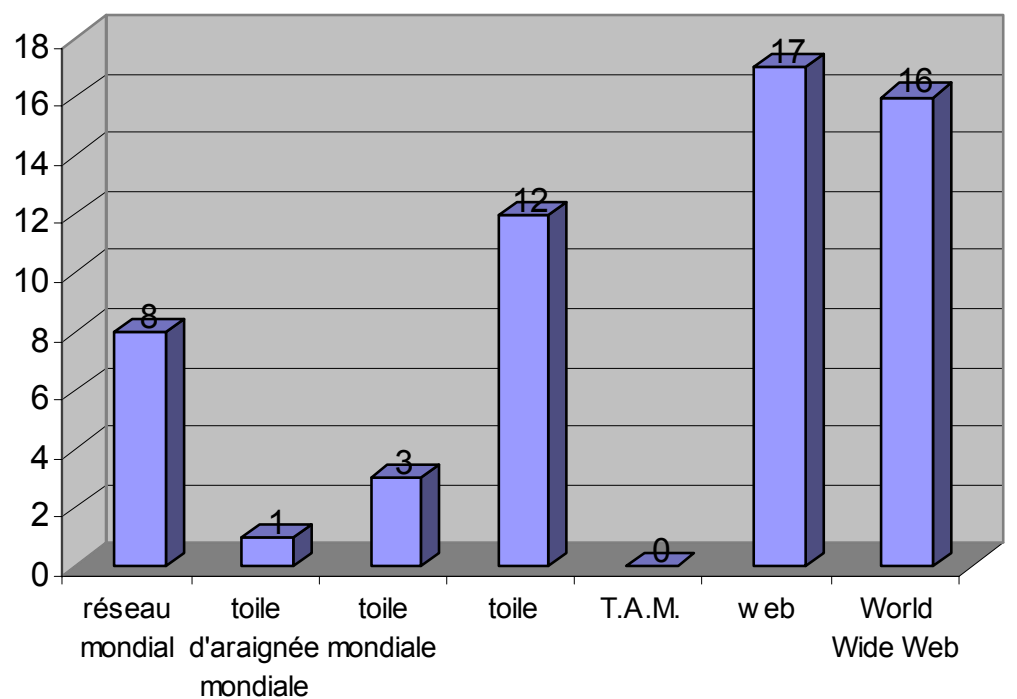


Abb. 111: Frage 15, Bekanntheitsgrad der Termini toile d'araignée mondiale, toile mondiale, toile, T.A.M., réseau mondial, World Wide Web und web (prozentuale Häufigkeit, Belgien)

\begin{tabular}{|l|r|}
\hline Termini & $\mathbf{\%}$ \\
\hline Web & 100,0 \\
\hline World Wide Web & 94,1 \\
\hline Toile & 70,6 \\
\hline Réseau mondial & 47,1 \\
\hline Toile mondiale & 17,6 \\
\hline Toile d'araignée mondiale & 5,9 \\
\hline T.A.M. & 0,0 \\
\hline
\end{tabular}

Alle Informanten kennen das engl. web, 16 Informanten (94,1\%) kennen das engl. World Wide Web. Immerhin zwölf Informanten (70,6\%) kennen das französische toile. Knapp die Hälfte der Befragten kennt das Testwort réseau mondial, das allerdings semantisch weiter ist als die anderen angegebenen Termini. Toile mondiale wird von drei Informanten (17,6\%) und toile d'araignée mondiale von einem Informanten $(5,9 \%)$ als bekannt angegeben. Das aus toile d'araignée mondiale abgeleitete Kurzwort T.A.M. kennt keiner der Informanten.

Wird das von Gasquet/Villebrun $(1994,117)$ entworfene Schema auf die Termini angewendet, ergibt sich für web ein 100\%iger Bekanntheitsgrad, World Wide Web gilt als sicher etabliert und fällt damit in die zweite Kategorie (Termini, die 80$100 \%$ der Befragten bekannt sind). In die dritte Kategorie mit Termini, deren Etablierung als ungewiss einzuschätzen ist, fällt toile. Réseau mondial gilt mit einem Bekanntheitsgrad von weniger als 50\% als unsicher bzw. schwach etabliert. Toile mondiale und toile d'araignée mondiale sind nur schwach etabliert. T.A.M. hat sich in Belgien gar nicht etablieren können.

Mit der nächsten Frage wird ermittelt, ob die Termini nach Ansicht der Befragten synonym sind.

Abb. 112: Frage 16, Synonymie der Termini toile d'araignée mondiale, toile mondiale, toile, T.A.M., World Wide Web und web (Belgien)

\begin{tabular}{|l|r|r|} 
& \multicolumn{1}{|c|}{$\begin{array}{l}\text { Absolute } \\
\text { Häufigkeit }\end{array}$} & \multicolumn{1}{c|}{$\begin{array}{l}\text { Prozentuale } \\
\text { Häufigkeit }\end{array}$} \\
\hline Synonym & 11 & 64,7 \\
\hline $\begin{array}{l}\text { Bedeutungs- } \\
\text { unterschied }\end{array}$ & 4 & 23,5 \\
\hline $\begin{array}{l}\text { Termini un- } \\
\text { bekannt / } \\
\text { Weiß nicht. }\end{array}$ & 2 & 11,8 \\
\hline Insgesamt & 17 & 100,0 \\
\hline
\end{tabular}


Die Termini werden mehrheitlich $(64,7 \%)$ als synonym eingeschätzt. Vier Informanten $(23,5 \%)$ stellen einen Bedeutungsunterschied fest, den sie wie folgt begründen:

Abb. 113: Frage 17, Bedeutungsunterschiede zwischen toile d'araignée mondiale, toile mondiale, toile, T.A.M., World Wide Web und web (Belgien)

\begin{tabular}{l|l|r|}
\hline Kategorie & Informanten & Anzahl \\
\hline $\begin{array}{l}\text { Toile d'araignée mondiale, toile mondiale, T.A.M. und } \\
\text { toile bezeichnen das gesamte Internet, während sich }\end{array}$ & B3.1, B3.2 & 2 \\
$\begin{array}{l}W W W, W \text { orld } W \text { ide } W e b \text { und web nur auf den } \\
\text { jüngsten Teil des Internet beziehen. }\end{array}$ & & \\
\hline $\begin{array}{l}\text { Gebrauch der Termini wechselt von Person zu } \\
\text { Person: Nur informatische Laien verwenden die } \\
\text { französischen Termini. }\end{array}$ & B3.3 & 1 \\
\hline $\begin{array}{l}\text { Toile d'araignée hat eine konkrete Bedeutung, die } \\
\text { nichts mit dem Internet zu tun hat. }\end{array}$ & B3.4 & 1 \\
\hline
\end{tabular}

Zwei Informanten betrachten die französischen Termini untereinander sowie die englischsprachigen Termini untereinander als synonym. Der Unterschied zwischen den französischen und den englischen Termini bestehe darin, dass sich die französischen Termini auf das gesamte Internet beziehen, während mit den englischen Termini nur ein Teil des Internet gemeint sei, nämlich das World Wide Web. Ein anderer Informant gibt als Unterschied den gleichen Grund an, den er bereits auf die Frage 3 nach der Synonymie zwischen e-mail/ mail und den französischen Äquivalenten angegeben hat: Nicht die Termini unterscheiden sich inhaltlich voneinander, sondern ihre Verwendungsweise sei unterschiedlich. Die französischen Termini würden tendenziell von Laien verwendet, während Fachleute die englischen Termini verwendeten. Ein weiterer Informant gibt als Unterschied an, dass toile d'araignée ('Spinnennetz') eine konkrete Bedeutung habe, die nicht mit dem Internet in Verbindung stehe.

Bei der Frage nach der persönlichen Präferenz wird noch deutlicher als bei der Frage nach dem Bekanntheitsgrad, in welch unterschiedlichem Maße die einzelnen Termini auf Akzeptanz bzw. Nicht-Akzeptanz stoßen. 
Abb. 114: Frage 18, persönliche Präferenz(en): toile d'araignée mondiale etc. (absolute Häufigkeit, Belgien)

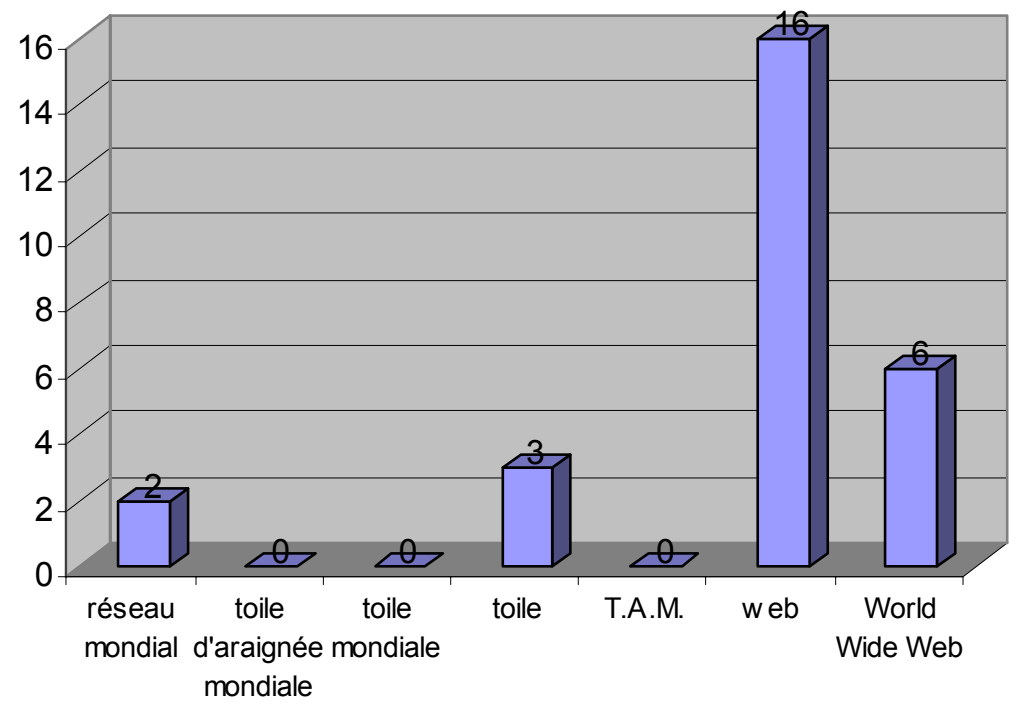

Abb. 115: Frage 18, persönliche Präferenz(en): toile d'araignée mondiale etc. (prozentuale Häufigkeit, Belgien)

\begin{tabular}{|l|r|}
\hline Termini & $\mathbf{0}$ \\
\hline Web & 94,1 \\
\hline World Wide Web & 35,3 \\
\hline Toile & 17,6 \\
\hline Réseau mondial & 11,8 \\
\hline Toile d'araignée mon- & 0,0 \\
\hline diale & \\
\hline Toile mondiale & 0,0 \\
\hline T.A.M. & 0,0 \\
\hline
\end{tabular}

16 von 17 Informanten (94,1\%) geben web als ihre persönliche Präferenz an. Mit weitem Abstand folgt an zweiter Stelle mit sechs Stimmen (35,3\%) das engl. World Wide Web. Diese beiden Termini bleiben folglich im Vergleich zur Frage 15 nach dem Bekanntheitsgrad an erster Stelle, allerdings fällt der Terminus World Wide $W e b$ bei der Frage nach der Präferenz weit hinter der kürzeren englischsprachigen Form web zurück. Die französische Bezeichnung toile folgt mit drei Stimmen $(17,6 \%)$ an dritter Stelle. Das Testwort réseau mondial erhält zwei Stimmen (11,8\%), die übrigen Termini werden von niemandem als persönliche Präferenz ausgewählt. Bezüglich des eigenen Sprachgebrauchs verteilen sich die Termini wie folgt auf die Informanten: 
Abb. 116: Frage 19, eigener Sprachgebrauch: toile d'araignée mondiale etc. (Belgien)

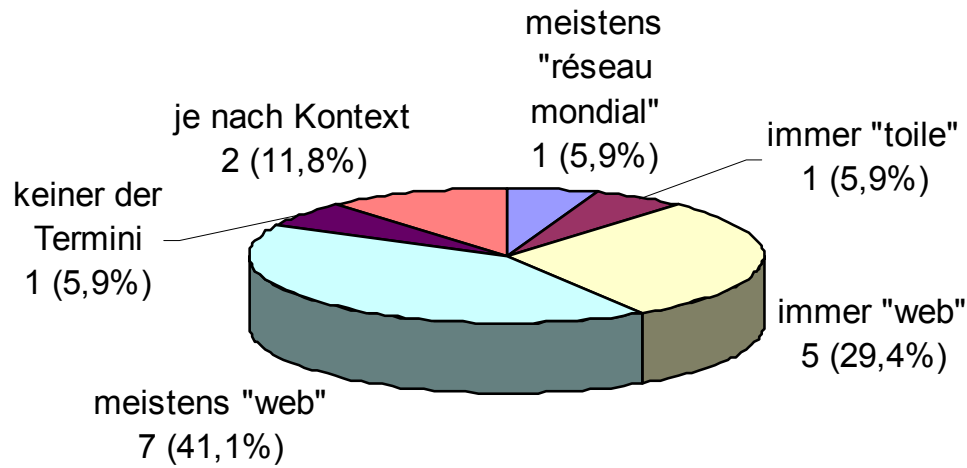

Zunächst fällt auf, dass World Wide Web, das sowohl in Frage 15 (Bekanntheitsgrad) als auch in Frage 18 (persönliche Präferenz) an zweiter Stelle gestanden hat, in Bezug auf den eigenen Sprachgebrauch nicht mehr auftaucht. Web bleibt in der Gunst der Informanten nach wie vor an erster Stelle: Sieben Informanten (41,1\%) geben an meistens web zu verwenden, fünf Informanten (29,4\%) geben an immer web zu verwenden. Zusammen ergibt eine Gebrauchsfrequenz von 70,5\% für web. Ein Informant (5,9\%) gibt an, meistens réseau mondial, ein anderer, immer toile zu verwenden. Zwei Informanten $(11,8 \%)$ entscheiden in Abhängigkeit vom Kontext. Ein Informant gibt an keinen der vorgegebenen Termini zu verwenden.

Bezüglich der Gebrauchsfrequenz lassen sich die Termini wie folgt den drei Klassen zuweisen: Web fällt mit einer Gebrauchsfrequenz von mehr als $70 \%$ in die Klasse A und gilt damit nicht nur hinsichtlich seines Bekanntheitsgrades, sondern auch hinsichtlich seines Gebrauchs als sicher etabliert. Keiner der Termini weist eine mittlere Gebrauchsfrequenz auf. Toile und réseau mondial werden nur selten gebraucht und laufen Gefahr, sich nicht zu etablieren. Dies ist bereits für toile d'araignée mondiale sowie für toile mondiale der Fall, die von keinem der Informanten verwendet werden.

Die Auswertung der Frage 20 mit der Bewertung der französischen Neologismen entfällt, da nur ein Informant für résean mondial und einer für toile plädiert. Zwölf Informanten verwenden meistens oder immer web. Daher werden in der folgenden Tabelle die Gründe aufgezeigt, weshalb die Informanten web den anderen Termini vorziehen. 
Abb. 117: Frage 21, Gründe für die Bevorzugung des englischsprachigen Terminus web (Belgien)

\begin{tabular}{|c|c|c|c|}
\hline Nr. & Begründung & $\begin{array}{l}\text { Absolute } \\
\text { Häufigkeit }\end{array}$ & $\begin{array}{l}\text { Prozentuale } \\
\text { Häufigkeit }\end{array}$ \\
\hline 1 & $\begin{array}{l}\text { - Le terme anglais est plus internatio- } \\
\text { nal. } \\
\text { - Presque tout le monde utilise le } \\
\text { terme anglais. }\end{array}$ & 9 & $\begin{array}{r}75,0 \\
75,0\end{array}$ \\
\hline 2 & $\begin{array}{l}\text { - En utilisant le terme anglais, je suis } \\
\text { sûr(e) d'être compris(e). } \\
\text { - Je me suis déjà habitué(e) à utiliser le } \\
\text { terme anglais. } \\
\text { - Le terme anglais est plus bref. }\end{array}$ & 8 & $\begin{array}{l}66,7 \\
66,7 \\
66,7\end{array}$ \\
\hline 3 & $\begin{array}{l}\text { - La signification des termes français } \\
\text { ne correspond pas à celle du terme } \\
\text { anglais. } \\
\text { - Les formulations des termes français } \\
\text { sont trop compliquées. }\end{array}$ & 3 & 25,0 \\
\hline 4 & $\begin{array}{l}\text { - Les connotations des termes français } \\
\text { ne correspondent pas aux connota- } \\
\text { tions qui sont liées au terme anglais. } \\
\text { - Les termes français ne sont pas assez } \\
\text { connus. }\end{array}$ & 2 & 16,7 \\
\hline 5 & $\begin{array}{l}\text { - Il n'est pas possible de créer des } \\
\text { termes dérivés (du type: logiciel, pro- } \\
\text { giciel, ludiciel). } \\
\text { - La signification des termes français } \\
\text { n'est pas claire. } \\
\text { - Les termes français ne sont pas assez } \\
\text { proches du terme anglais. }\end{array}$ & 1 & 8,3 \\
\hline 6 & $\begin{array}{l}\text { Autre : } \\
\text { Internet }\end{array}$ & 1 & 8,3 \\
\hline
\end{tabular}

Neun von zwölf Informanten (75\%) geben als Gründe für die Verwendung von web an, dass dieser Terminus internationaler als die französischen und weit verbreitet sei. Jeweils acht Informanten (66,7\%) nennen als Gründe die Sicherheit, verstanden zu werden, die Gewöhnung an den englischsprachigen Terminus sowie seine Kürze. Ein Informant nennt unter „Autre“ den Terminus Internet, der ja, wie sich bei der Frage 17 nach den Bedeutungsunterschieden gezeigt hat, von einigen Informanten mit dem franz. toile d'araignée mondiale und seinen kürzeren Formen gleichgesetzt wird. 
Der in 5.3.1 formulierten Arbeitshypothese „Toile wird aufgrund seiner Kürze erheblich öfter gebraucht als die alternativ möglichen französischen Neologismen toile d'araignée mondiale und toile mondiale. Populärer als toile ist jedoch der Anglizismus web" kann nur teilweise zugestimmt werden. In der Tat ist toile mit einem Bekanntheitsgrad von $70,6 \%$ wesentlich verbreiteter als toile mondiale $(17,6 \%)$ und toile d'araignée mondiale (5,9\%). Allerdings gibt bei der Frage 19 nach dem eigenen Sprachgebrauch nur ein Informant an, immer toile zu verwenden. Die meisten Informanten stimmen für web. Außer toile erhält bezüglich seiner Verwendung nur das Testwort réseau mondial eine Stimme. Insofern stimmt es zwar, dass toile häufiger verwendet wird als seine beiden längeren Entsprechungen. Allerdings reicht eine Stimme nicht aus, um die Hypothese zu verifizieren oder zu widerlegen. Insbesondere in diesem Fall wird deutlich, dass 17 Informanten nicht genügen, um ein aussagekräftiges Ergebnis erzielen zu können. Um diesem Teil der Arbeitshypothese wirklich nachgehen zu können, wäre eine größere Stichprobe nötig gewesen. Als unumstritten kann jedoch die Tatsache gelten, dass web weitaus häufiger verwendet wird als jedes der französischen Äquivalente, toile eingeschlossen.

\subsubsection{Die Termini causette, bavardage, conversation électronique und chat}

Die Frage nach dem Bekanntheitsgrad der Termini causette, bavardage, conversation électronique und chat wurde wie folgt beantwortet:

Abb. 118: Frage 22, Bekanntheitsgrad der Termini causette, bavardage, conversation électronique und chat (absolute Häufigkeit, Belgien)

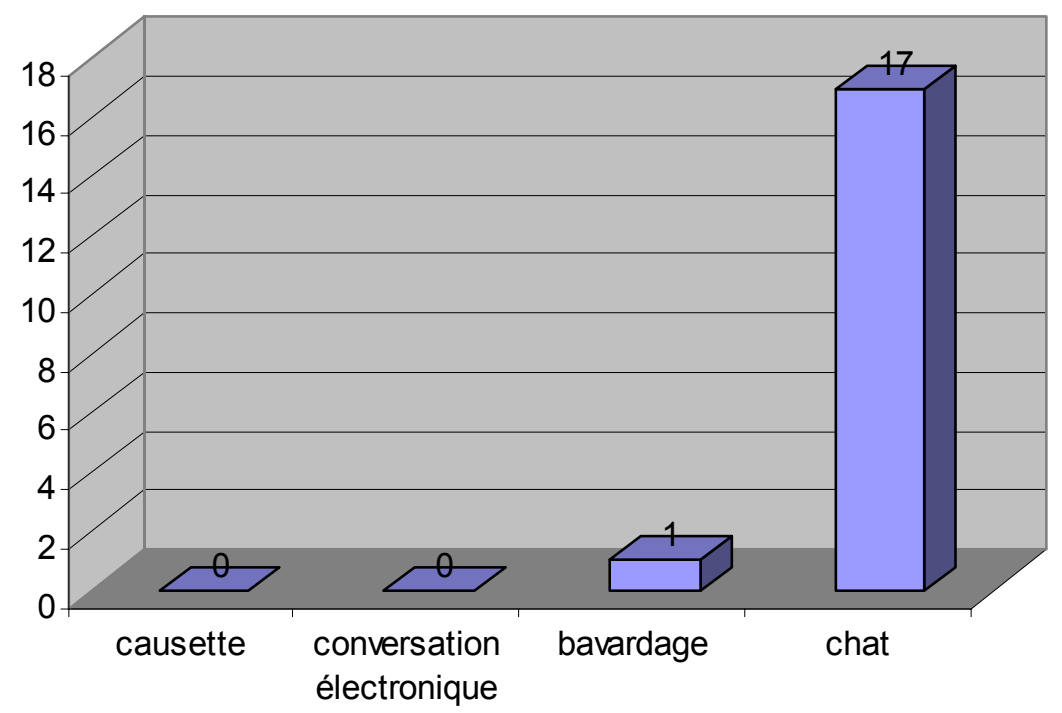


Abb. 119: Frage 22, Bekanntheitsgrad der Termini causette, bavardage, conversation électronique und chat (prozentuale Häufigkeit, Belgien)

\begin{tabular}{|l|r|}
\hline Termini & $\mathbf{\%}$ \\
\hline Chat & 100,0 \\
\hline Bavardage & 5,9 \\
\hline Causette & 0,0 \\
\hline Conversation électronique & 0,0
\end{tabular}

Alle 17 Informanten kennen chat, nur ein Informant kennt zusätzlich das französische Äquivalent bavardage. Die Ergebnisse sind so eindeutig, dass es sich in diesem Fall nicht lohnt, das Schema von Gasquet/Villebrun $(1994,117)$ zu bemühen.

Obwohl nur ein Informant bavardage und keiner causette oder conversation électronique kennt, stimmen die Informanten bei der Frage nach der Synonymie der Termini weitgehend dafür, dass sie synonym seien:

Abb. 120: Frage 23, Synonymie der Termini causette, bavardage und chat (Belgien)

\begin{tabular}{|l|r|r|} 
& \multicolumn{1}{|c|}{$\begin{array}{l}\text { Absolute } \\
\text { Häufigkeit }\end{array}$} & $\begin{array}{l}\text { Häufigkeit } \\
\text { in \% }\end{array}$ \\
\hline Synonym & 11 & 64,7 \\
\hline $\begin{array}{l}\text { Bedeutungs- } \\
\text { unterschied }\end{array}$ & 3 & 17,65 \\
\hline $\begin{array}{l}\text { Termini un- } \\
\text { bekannt / } \\
\text { Weiß nicht. }\end{array}$ & 3 & 17,65 \\
\hline Insgesamt & 17 & 100,0 \\
\hline
\end{tabular}

Elf Informanten betrachten die Termini als synonym, drei wissen es nicht bzw. geben an nicht alle Termini zu kennen. Die Antworten der drei Informanten, die einen Bedeutungsunterschied ausmachen, sind nicht sonderlich aussagekräftig: Ein Informant gibt keine Begründung. Ein anderer Informant beruft sich wie auch bezüglich der Lexemgruppen e-mail/ mail etc. und web etc. darauf, dass Laien eher die französischen, Fachleute eher die englischsprachigen Termini verwenden. Der dritte Informant, der einen Bedeutungsunterschied ausmacht, begründet diesen wie folgt: „Pour moi, seul le mot chat fait référence à l'IRC [Internet Relay Chat] et aux conversations électroniques. Bien entendu, je ne suis pas Français, :-) Les petits Belges sont plus anglophiles." Dieser Kommentar nimmt Bezug darauf, dass sich einzig der Terminus chat auf die Unterhaltung im Internet beziehe. Das bedeutet zugleich, dass sich die Termini bavardage und causette auf jede Form von Gesprächen beziehen. Außerdem spielt der Informant in selbstironischer Weise darauf an, dass die Verwendung des englischen Terminus sicherlich auf die gröBere Anglophilie der Belgier zurückzuführen sei. 
Wie bereits in 9.1.4 bestätigt wurde, kann bei der Integration eines Fremdwortes in eine andere Sprache eine Monosemierung stattfinden, d.h. von dem ursprünglich mehrdeutigen Wort wird zusammen mit der Bezeichnung nur eine Bedeutung entliehen. Chat wird im angelsächsischen Sprachraum keineswegs nur für die Konversation im Internet verwendet, sondern auch für die alltägliche Kommunikation, z.B. auf der Straße (Face-to-Face-Kommunikation). Der Informant, der angibt, dass sich chat seiner Meinung nach nur auf den IRC beziehe, bestätigt einmal mehr die Annahme, dass bei der Entlehnung von chat ins Französische eine Monosemierung stattgefunden habe.

Bei der Frage nach der persönlichen Präferenz ergibt sich ein ähnliches Bild wie bei der Frage nach dem Bekanntheitsgrad:

Abb. 121: Frage 25, persönliche Präferenz(en): causette, bavardage, conversation électronique, chat (absolute Häufigkeit, Belgien)

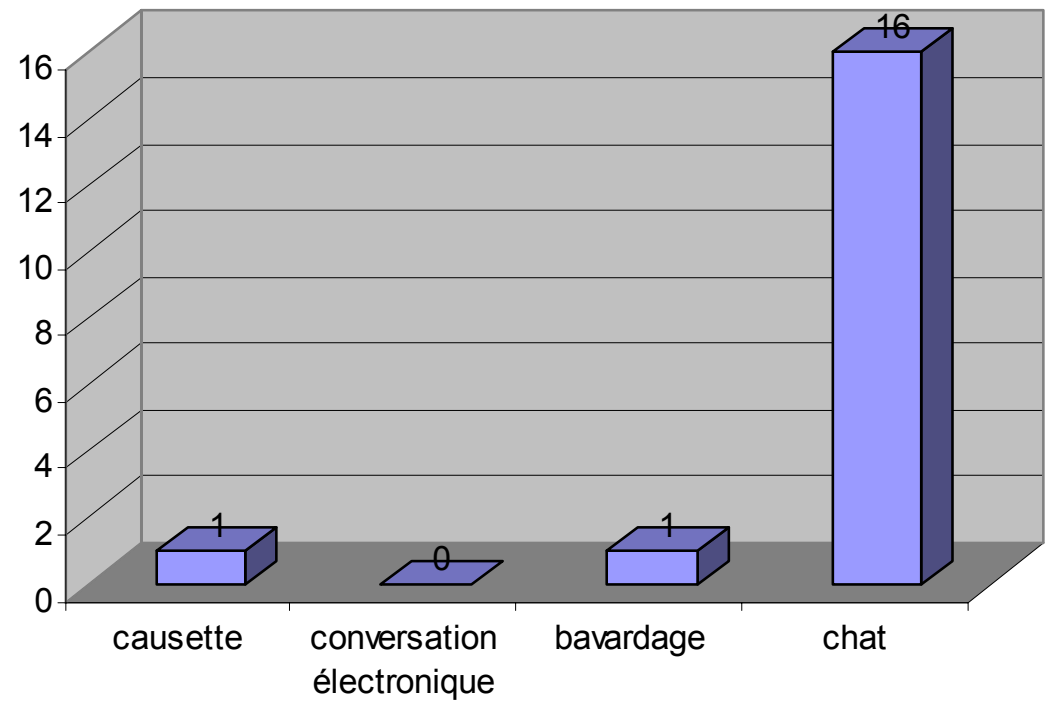

Abb. 122: Frage 25, persönliche Präferenz(en): causette, bavardage, conversation électronique, chat (prozentuale Häufigkeit, Belgien)

\begin{tabular}{|l|r|}
\hline Termini & $\mathbf{\%}$ \\
\hline Chat & 94,1 \\
\hline Bavardage & 5,9 \\
\hline Causette & 5,9 \\
\hline Conversation électronique & 0,0 \\
\hline
\end{tabular}

Aus der Datenbank wird ersichtlich, dass 16 Informanten für chat gestimmt haben und nur ein Informant zwei Präferenzen angegeben hat, nämlich franz. causette und bavardage. Wenngleich es sich bei diesem Informanten um einen Einzelfall handelt, dessen Votum sich nur geringfügig auf das Gesamtergebnis auswirkt, soll sein 
Antwortverhalten bezüglich der Fragen des ersten Fragebogenmoduls etwas genauer betrachtet werden, da es sich deutlich von den Antworten der anderen Informanten abhebt. Dieser Informant bevorzugt auch in anderen Fällen die französische Terminologie, z.B. gibt er auch page d'accueil und page d'introduction als seine persönlichen Präferenzen an (s.o.). Allerdings verwendet er nicht konsequent die französischen Termini: In Frage 5 hat er angegeben meistens engl. e-mail zu verwenden. Dafür gibt er bei den Fragen 12, 19, 26, 33 und 40 an, jeweils die französischen Neologismen zu verwenden, nämlich meistens franz. page d'accueil, meistens franz. réseau mondial, meistens franz. bavardage, meistens franz. pirate und meistens franz. fournisseur d'accès. Offensichtlich handelt es sich bei diesem Informanten um einen Verfechter der französischen Terminologie. Wie sehr dieser Informant für die französischen Termini plädiert, ist auch der Tatsache zu entnehmen, dass er den Terminus causette nach eigenen Angaben nicht kennt (Frage 22), ihn aber in Frage 25 als eine seiner Präferenzen angibt. Dieser Informant ist zwar nur ein Einzelfall, zeigt aber, dass es auch unter den belgischen Informanten, die sich teilweise selbst als anglophil bezeichnen, Personen gibt, die sich um eine konsequente Verwendung der französischen Termini bemühen oder zumindest angeben dies zu tun.

Erwartungsgemäß schlägt sich die hohe Präferenz von engl. chat auch in der Frage 26 nach dem eigenen Sprachgebrauch nieder:

Abb. 123: Frage 26, eigener Sprachgebrauch: causette, bavardage, conversation électronique, chat (Belgien)

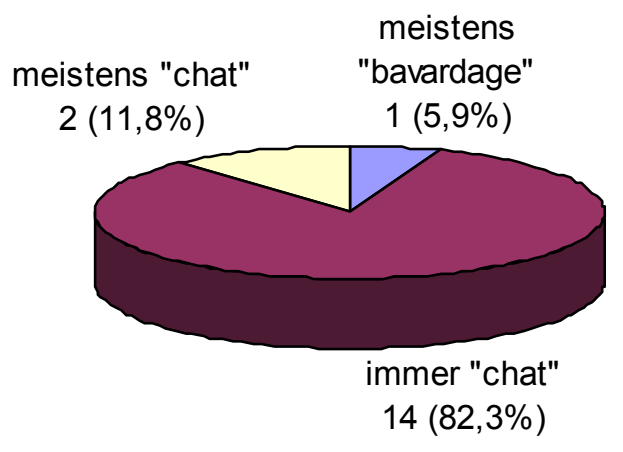

14 Informanten (82,3\%) geben an immer chat zu verwenden, zwei Informanten $(11,8 \%)$ verwenden nach eigenen Angaben meistens chat. Der Informant, der in der letzten Frage als Präferenzen die Termini causette und bavardage angegeben hat, verwendet nach eigenen Angaben meistens bavardage. 
Chat weist mit einer Gebrauchsfrequenz von über 90\% einen hohen Etablierungsgrad auf. Alle anderen Termini haben sich nicht etabliert. Der Informant, der mit Ausnahme von e-mail generell für die Verwendung der französischen Termini plädiert, dürfte eher die Ausnahme darstellen, vereint jedoch bei insgesamt nur 17 Informanten einen Prozentsatz von 5,9 auf sich.

Da 16 von 17 Informanten immer oder meistens chat verwenden, wird auf eine Auswertung der Frage 27 verzichtet. Im Folgenden werden die Gründe dargestellt, die nach Ansicht der Informanten für die Verwendung von chat sprechen.

\begin{tabular}{|c|c|c|c|}
\hline Nr. & Begründung & $\begin{array}{l}\text { Absolute } \\
\text { Häufigkeit }\end{array}$ & $\begin{array}{l}\text { Prozentuale } \\
\text { Häufigkeit }\end{array}$ \\
\hline 1 & $\begin{array}{l}\text { En utilisant le terme anglais, je suis sûr(e) } \\
\text { d'être compris(e). }\end{array}$ & 12 & 80,0 \\
\hline 2 & $\begin{array}{l}\text { Presque tout le monde utilise le terme } \\
\text { anglais. }\end{array}$ & 11 & 73,3 \\
\hline 3 & Le terme anglais est plus bref. & 9 & 60,0 \\
\hline 4 & $\begin{array}{l}\text { - Je me suis déjà habitué(e) à utiliser le } \\
\text { terme anglais. } \\
\text { - } \quad \text { Le terme anglais est plus international. }\end{array}$ & 8 & $\begin{array}{l}53,3 \\
53,3\end{array}$ \\
\hline 5 & $\begin{array}{l}\text { Les termes français ne sont pas assez } \\
\text { connus. }\end{array}$ & 6 & 40,0 \\
\hline 6 & Je ne connais pas les termes français. & 4 & 26,7 \\
\hline 7 & $\begin{array}{l}\text { - La signification des termes français } \\
\text { n'est pas claire. } \\
\text { - La signification des termes français ne } \\
\text { correspond pas à celle du terme } \\
\text { anglais. }\end{array}$ & 2 & $\begin{array}{l}13,3 \\
13,3\end{array}$ \\
\hline 8 & $\begin{array}{l}\text { - Il n'est pas possible de créer des ter- } \\
\text { mes dérivés (du type: logiciel, progi- } \\
\text { ciel, ludiciel). } \\
\text { - Les formulations des termes français } \\
\text { sont trop compliquées. } \\
\text { - Les termes français ne sont pas assez } \\
\text { proches du terme anglais. } \\
\text { - Il y a trop d'équivalents français pour } \\
\text { un seul terme anglais. } \\
\text { - Je n'aime pas suivre les propositions } \\
\text { officielles. }\end{array}$ & 1 & $\begin{array}{l}6,7 \\
6,7 \\
6,7 \\
6,7\end{array}$ \\
\hline 9 & $\begin{array}{l}\text { Autre : } \\
\text { - J'utilise également le terme discussion! }\end{array}$ & 1 & 6,7 \\
\hline
\end{tabular}


An erster Stelle steht mit zwölf von 16 Stimmen (80\%) die Sicherheit, bei Verwendung des englischsprachigen Terminus verstanden zu werden. Mit elf Stimmen $(73,3 \%)$ folgt an zweiter Stelle die hohe Verbreitung von chat. An dritter Stelle folgt seine Kürze (neun Informanten, 60\%). An vierter Position werden mit je acht Stimmen (53,3\%) die Gewöhnung an den englischsprachigen Terminus sowie seine Internationalität aufgeführt. Ein Informant - es ist nicht derjenige, der causette und bavardage bevorzugt und meistens bavardage verwendet - schreibt, dass er auch den Terminus discussion verwende. Sicherlich spielt die Situation einen nicht zu unterschätzenden Einfluss, ob chat oder ein französischer Terminus wie bavardage oder discussion verwendet wird.

Die Hypothese, dass chat aufgrund seiner Kürze und der doppeldeutigen französischen Äquivalente häufiger verwendet werde als die französischen Neologismen causette und bavardage, kann anhand der Ergebnisse verifiziert werden. Allerdings begünstigen nicht nur die Kürze des englischsprachigen Terminus und die Doppeldeutigkeit der französischen Neologismen ${ }^{2}$ die Verwendung von engl. chat, sondern auch andere Faktoren wie z.B. die weite Verbreitung dieser Bezeichnung und damit einhergehend die Sicherheit, dass man bei Verwendung von chat auch am ehesten verstanden wird (s. Frage 28).

\subsubsection{Die Termini pirate, fouineur und cracker}

Der fünfte Fragenkomplex des ersten Moduls hat die Termini pirate, fouineur und cracker zum Gegenstand.

\footnotetext{
2 Für das Argument der Doppeldeutigkeit der französischen Termini spricht die Aussage eines Informanten auf die Frage nach dem Bedeutungsunterschied zwischen franz. bavardage/causette und engl. chat. Dieser Informant hat darauf verwiesen, dass sich nur chat auf den Internet-Kontext beziehe. Diese Aussage impliziert, dass der Informant die französischen Termini für doppeldeutig hält, da sie sowohl das Face-to-Face-Gespräch als auch Plaudereien im virtuellen Kontext bezeichnen.
} 
Abb. 125: Frage 29, Bekanntheitsgrad der Termini pirate, fouineur und cracker (absolute Häufigkeit, Belgien)

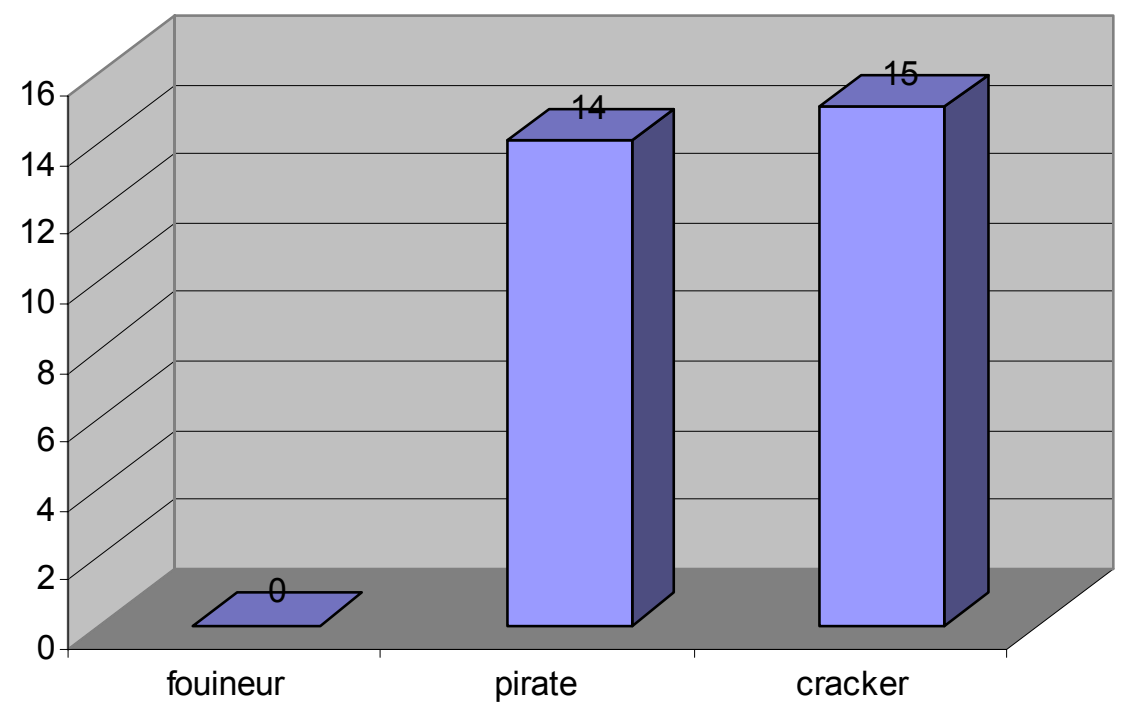

Abb. 126: Frage 29, Bekanntheitsgrad der Termini pirate, fouineur und cracker (prozentuale Häufigkeit, Belgien)

\begin{tabular}{|l|r|}
\hline Termini & $\mathbf{\%}$ \\
\hline Cracker & 88,2 \\
\hline Pirate & 82,4 \\
\hline Fonineur & 0,0 \\
\hline
\end{tabular}

Weder cracker noch pirate sind allen Befragten bekannt. Den englischsprachigen Terminus cracker kennen 15 von 17 Informanten (88,2\%), die französische Bezeichnung pirate ist 14 Informanten (82,4\%) bekannt. Das Testwort fouineur wird von niemandem als bekannt angegeben. Damit fallen beide Termini, cracker und pirate, in die zweite Kategorie des von Gasquet/Villebrun (1994, 117) entworfenen Schemas (Termini, die 80-100\% der Befragten bekannt sind) und gelten damit als sicher etabliert.

Die Frage nach der Synonymie wird eindeutig beantwortet: 
Abb. 127: Frage 30, Synonymie der Termini pirate und cracker (Belgien)

\begin{tabular}{|c|c|c|}
\hline & $\begin{array}{l}\text { Absolute } \\
\text { Häufigkeit }\end{array}$ & $\begin{array}{l}\text { Prozen- } \\
\text { tuale } \\
\text { Häufigkeit }\end{array}$ \\
\hline Synonym & 15 & 88,2 \\
\hline $\begin{array}{l}\text { Bedeutungs- } \\
\text { unterschied }\end{array}$ & 0 & 0 \\
\hline $\begin{array}{l}\text { Termini un- } \\
\text { bekannt / } \\
\text { Weiß nicht. }\end{array}$ & 2 & 11,8 \\
\hline Insgesamt & 17 & 100,0 \\
\hline
\end{tabular}

15 Informanten $(88,2 \%)$ schätzen die Termini als synonym ein, keiner der Befragten stellt einen Bedeutungsunterschied fest. Zwei Informanten geben an die Antwort nicht zu wissen bzw. verweisen darauf, dass ihnen nicht alle Termini bekannt seien.

Auf die Frage nach den persönlichen Präferenzen ergibt sich bezüglich der Termini cracker und pirate ein recht ausgeglichenes Bild:

Abb. 128: Frage 32, persönliche Präferenz(en): pirate, fouineur, cracker (absolute Häufigkeit, Belgien)

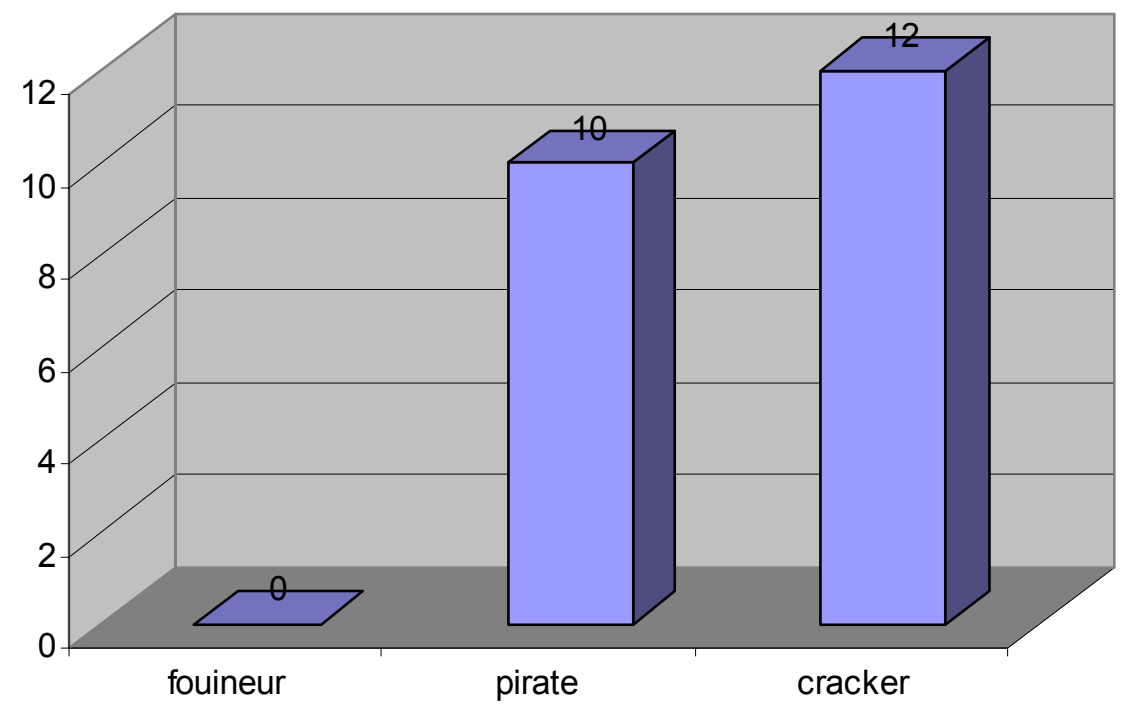


Abb. 129: Frage 32, persönliche Präferenz(en): pirate, fouineur, cracker (prozentuale Häufigkeit, Belgien)

\begin{tabular}{|l|r|}
\hline Termini & $\mathbf{\%}$ \\
\hline Cracker & 70,6 \\
\hline Pirate & 58,8 \\
\hline Fouineur & 0,0 \\
\hline
\end{tabular}

Bei der Frage nach den persönlichen Präferenzen liegt cracker wiederum vor dem französischen Terminus pirate. Der Abstand zwischen beiden Termini hat sich jedoch im Vergleich zu Frage 29 (Bekanntheitsgrad) um eine Stimme vergrößert. Wie man an den absoluten Zahlen erkennen kann, geben fünf Informanten ihr Votum für beide Termini ab, zwölf Informanten entscheiden sich jeweils für einen der Termini. Das relativ ausgeglichene Verhältnis zwischen dem englischsprachigen und dem französischen Terminus setzt sich auch in der nächsten Frage fort.

Abb. 130: Frage 33, eigener Sprachgebrauch: pirate, fouineur, cracker (Belgien)

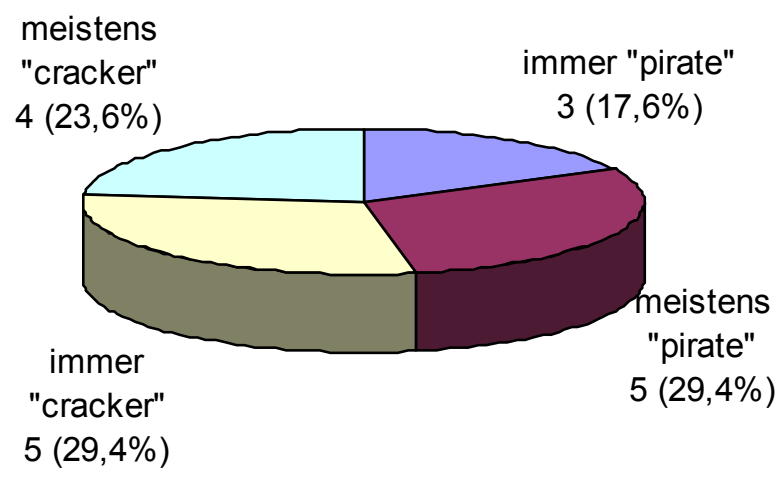

Neun Informanten (53\%) geben an meistens oder immer cracker zu verwenden. Acht Informanten (47\%) verwenden nach eigenen Angaben meistens oder immer pirate. Damit liegen beide Termini bezüglich der Gebrauchsfrequenz im mittleren Bereich und können als etabliert gelten.

Aufgrund des ausgeglichenen Verhältnisses zwischen beiden Termini wird sowohl die Frage 34 nach der Bewertung des französischen Terminus als auch die Frage 35 nach den Gründen, die für cracker sprechen, ausgewertet. 
Abb. 131: Frage 34, Bewertung des französischen (Internet-) Neologismus pirate (Belgien)

\begin{tabular}{l|l|l|} 
Kriterium & $\begin{array}{l}\text { Skalenendpunkte im } \\
\text { Fragebogen }\end{array}$ & \multicolumn{1}{|c}{$\begin{array}{l}\text { Durchschnittlicher } \\
\text { Akzeptanzwert }\end{array}$} \\
\hline $\begin{array}{l}\text { Bekanntheit (Bekanntheit } \\
\text { vs. Unbekanntheit) }\end{array}$ & $\begin{array}{l}\text { connu-inconnu } \\
1-5\end{array}$ & 1,63 \\
\hline $\begin{array}{l}\text { Schönheit (Schönheit vs. } \\
\text { Hässlichkeit) }\end{array}$ & $\begin{array}{l}\text { beau-laid } \\
1-5\end{array}$ & 2,83 \\
\hline $\begin{array}{l}\text { Verständlichkeit (Ver- } \\
\text { ständlichkeit vs. Unver- } \\
\text { ständlichkeit) }\end{array}$ & $\begin{array}{l}\text { comprébensible - in- } \\
\text { compréhensible } \\
1-5\end{array}$ & 1,71 \\
\hline $\begin{array}{l}\text { Nützlichkeit (Nützlichkeit } \\
\text { vs. Nutzlosigkeit) }\end{array}$ & $\begin{array}{l}\text { utile-inutile } \\
1-5\end{array}$ & 2,20 \\
\hline $\begin{array}{l}\text { Adäquatheit (Adäquatheit } \\
\text { vs. Inadäquatheit) }\end{array}$ & $\begin{array}{l}\text { adéquat-inapproprié } \\
1-5\end{array}$ & 2,00 \\
\hline $\begin{array}{l}\text { Etabliertheit (Altbestand } \\
\text { des Lexikons vs. Neuheit) }\end{array}$ & $\begin{array}{l}\text { établi-nouveau } \\
1-5\end{array}$ & 1,57 \\
\hline $\begin{array}{l}\text { Natürlichkeit (Normalität } \\
\text { vs. Künstlichkeit) }\end{array}$ & $\begin{array}{l}\text { normal-artificiel } \\
1-5\end{array}$ & 1,80 \\
\hline $\begin{array}{l}\text { Komplexität (Einfachheit } \\
\text { vs. Kompliziertheit) }\end{array}$ & $\begin{array}{l}\text { simple - complexe } \\
1-5\end{array}$ & 1,57 \\
\hline $\begin{array}{l}\text { Korrektheit (Korrektheit } \\
\text { vs. Unkorrektheit) }\end{array}$ & $\begin{array}{l}\text { correct-incorrect } \\
1-5\end{array}$ & 2,14 \\
\hline
\end{tabular}

Am besten schneidet pirate mit einem Wert von jeweils 1,57 auf der Likert-Skala bezüglich der Eigenschaften Etabliertheit und Komplexität ab. Pirate gilt somit in erster Linie als etabliert und einfach. Knapp dahinter folgen die Kriterien Bekanntheit, Verständlichkeit und Natürlichkeit, die alle einen Wert erzielen, der besser als 2,0 ist. Am schlechtesten schneidet der französische Terminus bezüglich seiner ästhetischen Qualitäten ab. Hier erreicht er nur den Wert 2,83 und liegt damit bereits recht nah am neutralen Wert 3,0. Als durchschnittlicher Wert aus allen neun Einzelwerten ergibt sich 1,94. Damit schneidet pirate im Sprecherurteil nicht ganz so gut ab wie page d'accueil mit dem Votum 1,72, liegt aber immer noch im positiven Bereich.

Für die Verwendung des englischen cracker sprechen nach Einschätzung der neun Informanten, die diese Frage beantwortet haben, die folgenden Gründe: 


\begin{tabular}{|c|c|c|c|}
\hline Nr. & Begründung & $\begin{array}{r}\text { Absolute } \\
\text { Häufigkeit }\end{array}$ & $\begin{array}{r}\text { Prozentuale } \\
\text { Häufigkeit }\end{array}$ \\
\hline 1 & $\begin{array}{l}\text { - En utilisant le terme anglais, je suis } \\
\text { sûr(e) d'être compris(e). } \\
\text { - Je me suis déjà habitué(e) à utiliser le } \\
\text { terme anglais. } \\
\text { - Le terme anglais est plus internatio- } \\
\text { nal. }\end{array}$ & 6 & $\begin{array}{l}66,7 \\
66,7 \\
66,7\end{array}$ \\
\hline 2 & $\begin{array}{l}\text { Presque tout le monde utilise le terme } \\
\text { anglais. }\end{array}$ & 5 & 55,6 \\
\hline 3 & $\begin{array}{l}\text { La signification des termes français n'est } \\
\text { pas claire. }\end{array}$ & 3 & 33,3 \\
\hline 4 & $\begin{array}{l}\text { - Il n'est pas possible de créer des ter- } \\
\text { mes dérivés (du type: logiciel, progi- } \\
\text { ciel, ludiciel). } \\
\text { - La signification des termes français ne } \\
\text { correspond pas à celle du terme } \\
\text { anglais. } \\
\text { Les connotations des termes français } \\
\text { ne correspondent pas aux connota- } \\
\text { tions qui sont liées au terme anglais. }\end{array}$ & 2 & 22,2 \\
\hline 5 & $\begin{array}{l}\text { Les termes français ne sont pas assez } \\
\text { proches du terme anglais. }\end{array}$ & 1 & 11,1 \\
\hline
\end{tabular}

An erster Stelle mit je sechs von neun Stimmen stehen a) die Sicherheit, bei Verwendung von cracker verstanden zu werden, b) die Gewöhnung an den Terminus und c) seine Internationalität. Es folgt an zweiter Stelle mit fünf Stimmen (55,6\%) die weite Verbreitung des englischsprachigen Terminus.

Der Hypothese, dass cracker aufgrund seiner langen Existenz als Computer-Terminus einen höheren Bekanntheits- und Verwendungsgrad aufweisen wird als pirate, kann nicht ohne weiteres zugestimmt werden. Beide Termini werden nahezu gleichermaßen von den Informanten gekannt, bevorzugt und verwendet. Möglicherweise könnte eine größere Stichprobe aufzeigen, ob sich bei belgischen Informatikern doch eine Tendenz zur Bevorzugung und häufigeren Verwendung eines der beiden Termini feststellen ließe. 


\subsubsection{Die Termini fournisseur d'accès, pourvoyeur d'accès und (access) provider}

Die folgenden Fragen widmen sich der sechsten und letzten Lexemgruppe fournisseur d'accès, pourvoyeur d'accès und (access) provider. Die Frage nach dem Bekanntheitsgrad dieser Termini wurde wie folgt beantwortet:

Abb. 133: Frage 36, Bekanntheitsgrad der Termini fournisseur d'accès, pourvoyeur d'accès und (access) provider (absolute Häufigkeit, Belgien)

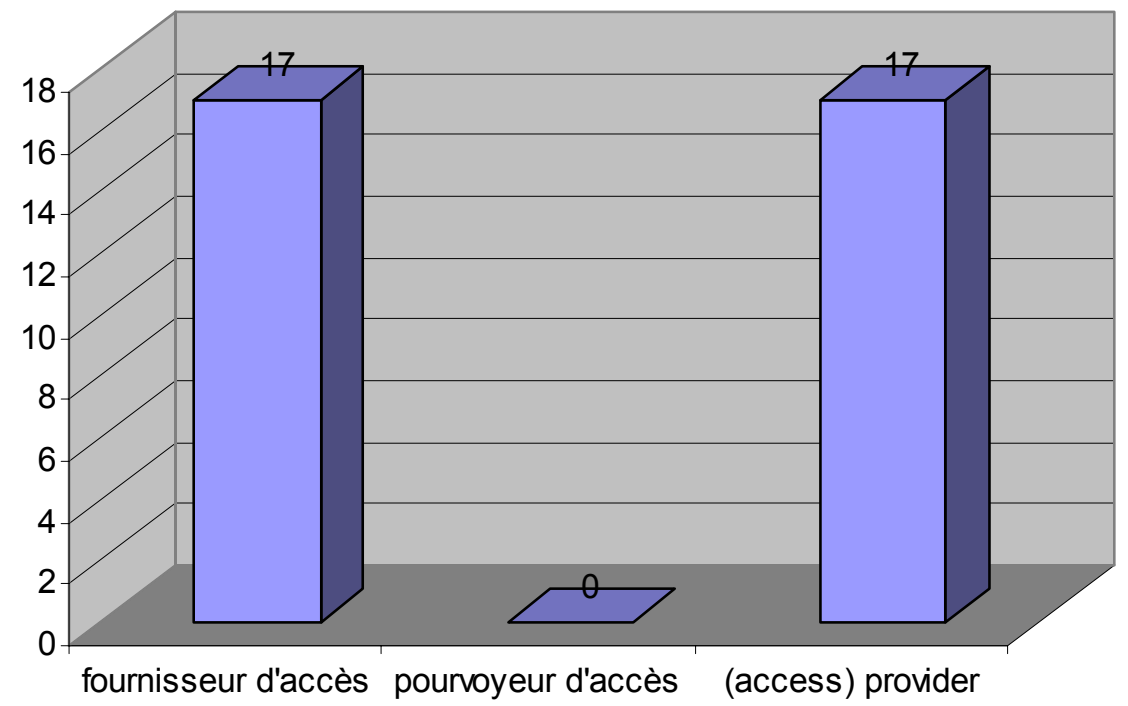

Abb. 134: Frage 36, Bekanntheitsgrad der Termini fournisseur d'accès, pourvoyeur d'accès und (access) provider (prozentuale Häufigkeit, Belgien)

\begin{tabular}{|l|r|}
\hline Termini & $\mathbf{0}$ \\
\hline (Access) provider & 100,0 \\
\hline Fournisseur d'accès & 100,0 \\
\hline Pourvoyeur d'accès & 0,0 \\
\hline
\end{tabular}

Beide Termini, engl. (access) provider und franz. fournisseur d'accès, sind allen Informanten bekannt. Das seltene Testwort pourvoyeur d'accès wird von keinem der Informanten als bekannt angegeben. Somit können bezüglich der passiven Akzeptanz (access) provider und fournisseur d'accès als 100\% \% etabliert gelten.

Auch die Frage 37 nach der Synonymie der Termini bringt ein eindeutiges Ergebnis: Alle 17 Informanten schätzen die beiden Termini als synonym ein.

Die identische Bewertung bezüglich des Bekanntheitsgrades der Termini fournisseur d'accès und (access) provider setzt sich bei der Frage nach den persönlichen Präferenzen fort: 
Abb. 135: Frage 39, persönliche Präferenz(en): fournisseur d'accès, pourvoyeur d'accès, (access) provider (absolute Häufigkeit, Belgien)

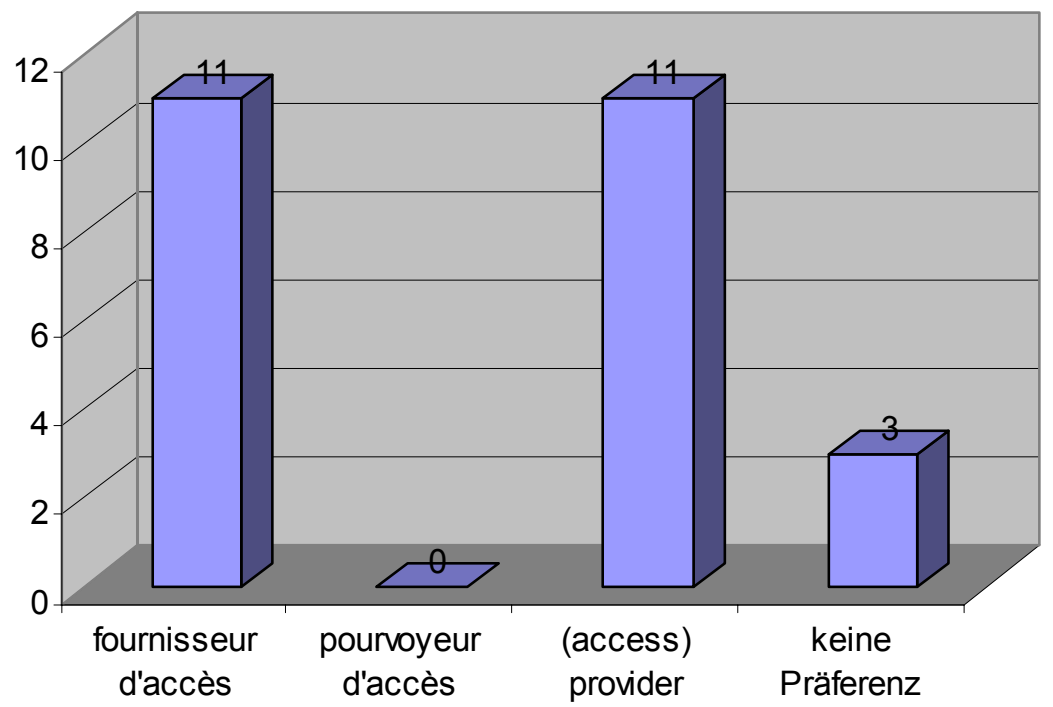

Abb. 136: Frage 39, persönliche Präferenz(en): fournisseur d'accès, pourvoyeur d'accès, (access) provider (prozentuale Häufigkeit, Belgien)

\begin{tabular}{|l|r|}
\hline Termini & $\mathbf{0}$ \\
\hline (Access) provider & 64,7 \\
\hline Fournisseur d'accès & 64,7 \\
\hline Pourvoyeur d'accès & 0,0 \\
\hline Keine Präferenz & 17,6 \\
\hline
\end{tabular}

Auch die Antworten auf die Frage nach der persönlichen Präferenz zeigen, dass beide Termini im Akzeptanzvotum gleich abschneiden. Acht Sprecher geben an sowohl (access) provider als auch fournisseur d'accès zu bevorzugen, sechs Informanten entscheiden sich für je einen der beiden Termini, und drei Informanten geben an keine Präferenz zu haben. Da pourvoyeur d'accès den Informanten gänzlich unbekannt ist, ist davon auszugehen, dass die drei Informanten, die keine Präferenz angegeben haben, beide Termini, (access) provider und fournisseur d'accès, gleichrangig bewerten.

Erst die Frage nach dem eigenen Sprachgebrauch ergibt eine leichte Bevorzugung des französischen Terminus: 


\begin{abstract}
Abb. 137: Frage 40, eigener Sprachgebrauch: foumisseur d'accès, pourvoyeur d'accès, (access) provider (Belgien)
\end{abstract}

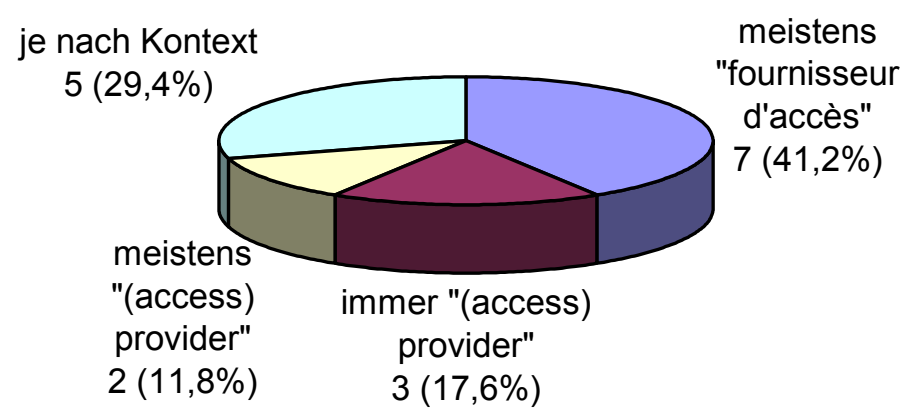

Sieben Informanten (41,2\%) verwenden meistens fournisseur d'accès, fünf (29,4\%) meistens oder immer (access) provider. Fünf Informanten entscheiden je nach Kontext. Damit weisen beide Termini bezüglich der Gebrauchsfrequenz einen mittleren Etablierungsgrad auf. Der Vorsprung des französischen vor dem englischsprachigen Terminus ist allerdings so knapp, dass auch hier die Ergebnisse mit Vorsicht zu interpretieren sind. Es ist aufgrund von nur zwei Stimmen Vorsprung nicht unbedingt davon auszugehen, dass bei einer größeren Stichprobe immer noch der französische Terminus vor dem englischsprachigen liegen würde. Dafür, dass die Gebrauchsfrequenz ziemlich ausgeglichen sein wird, spricht bereits die Auswertung der Fragen 36 und 39 nach dem Bekanntheitsgrad und der persönlichen Präferenz. Hinzu kommt, dass keiner der Informanten angegeben hat immer den französischen Terminus zu verwenden, was darauf schließen lässt, dass alle Informanten, die mehrheitlich fournisseur d'accès verwenden, ebenfalls - wenn auch seltener - den englischen Terminus gebrauchen. Diese Überlegung wird auch durch die verhältnismäßig hohe Anzahl an Informanten gestützt, die je nach dem Kontext den einen oder den anderen Terminus wählen.

Analog zum Lexempaar pirate/cracker werden im Folgenden beide Fragen, 41 und 42 , ausgewertet. 
Abb. 138: Frage 41, Bewertung des französischen Neologismus fournisseur d'accès (Belgien)

\begin{tabular}{l|l|l|}
\hline Kriterium & $\begin{array}{l}\text { Skalenendpunkte im } \\
\text { Fragebogen }\end{array}$ & \multicolumn{1}{|c|}{$\begin{array}{l}\text { Durchschnittlicher } \\
\text { Akzeptanzwert }\end{array}$} \\
\hline $\begin{array}{l}\text { Bekanntheit (Bekanntheit } \\
\text { vs. Unbekanntheit) }\end{array}$ & $\begin{array}{l}\text { connu - inconnu } \\
1-5\end{array}$ & 1,57 \\
\hline $\begin{array}{l}\text { Schönheit (Schönheit vs. } \\
\text { Hässlichkeit) }\end{array}$ & $\begin{array}{l}\text { beau - laid } \\
1-5\end{array}$ & 2,86 \\
\hline $\begin{array}{l}\text { Verständlichkeit (Ver- } \\
\text { ständlichkeit vs. Unver- } \\
\text { ständlichkeit) }\end{array}$ & $\begin{array}{l}\text { compréhensible - in- } \\
\text { compréhensible }\end{array}$ & 1,43 \\
\hline $\begin{array}{l}\text { Nützlichkeit (Nützlichkeit } \\
\text { vs. Nutzlosigkeit) }\end{array}$ & $\begin{array}{l}\text { utile }- \text { inutile } \\
1-5\end{array}$ & 2,50 \\
\hline $\begin{array}{l}\text { Adäquatheit (Adäquatheit } \\
\text { vs. Inadäquatheit) }\end{array}$ & $\begin{array}{l}\text { adéquat-inapproprié } \\
1-5\end{array}$ & 1,43 \\
\hline $\begin{array}{l}\text { Etabliertheit (Altbestand } \\
\text { des Lexikons vs. Neuheit) }\end{array}$ & $\begin{array}{l}\text { établi-nouveau } \\
1-5\end{array}$ & 2,14 \\
\hline $\begin{array}{l}\text { Natürlichkeit (Normalität } \\
\text { vs. Künstlichkeit) }\end{array}$ & $\begin{array}{l}\text { normal-artificiel } \\
1-5\end{array}$ & 2,29 \\
\hline $\begin{array}{l}\text { Komplexität (Einfachheit } \\
\text { vs. Kompliziertheit) }\end{array}$ & $\begin{array}{l}\text { simple - complexe } \\
1-5\end{array}$ & 1,57 \\
\hline $\begin{array}{l}\text { Korrektheit (Korrektheit } \\
\text { vs. Unkorrektheit) }\end{array}$ & $\begin{array}{l}\text { correct-incorrect } \\
1-5\end{array}$ & 1,43 \\
\hline
\end{tabular}

Die sieben Informanten, die nach eigenen Angaben meistens den Terminus fournisseur d'accès verwenden, haben ihn bezüglich seiner Verständlichkeit, Adäquatheit und Korrektheit besonders günstig bewertet (jeweils 1,43). Mit einem Wert von 2,86 schneidet fournisseur d'accès (analog zur Bewertung von page d'accueil und pirate) bezüglich seiner ästhetischen Qualitäten am schlechtesten ab. Er erhält einen durchschnittlichen Akzeptanzwert von 1,91. Damit schneidet er etwas besser als pirate $(1,94) \mathrm{ab}$, aber nicht so gut wie page d'accueil $(1,72)$.

Die fünf Informanten, die angeben meistens oder immer den englischsprachigen Terminus zu verwenden, begründen ihre Entscheidung mit folgenden Argumenten: 


\begin{tabular}{|c|c|c|c|}
\hline Nr. & Begründung & $\begin{array}{l}\text { Absolute } \\
\text { Häufigkeit }\end{array}$ & $\begin{array}{l}\text { Prozentuale } \\
\text { Häufigkeit }\end{array}$ \\
\hline 1 & Presque tout le monde utilise le terme anglais. & 4 & 80,0 \\
\hline 2 & $\begin{array}{l}\text { - } \quad \text { En utilisant le terme anglais, je suis sûr(e) } \\
\text { d'être compris(e). } \\
\text { - } \quad \text { Le terme anglais est plus bref. } \\
\text { - } \quad \text { Le terme anglais est plus international. }\end{array}$ & $\begin{array}{l}3 \\
3\end{array}$ & $\begin{array}{l}60,0 \\
60,0 \\
60,0\end{array}$ \\
\hline 3 & $\begin{array}{l}\text { Je me suis déjà habitué(e) à utiliser le terme } \\
\text { anglais. }\end{array}$ & 2 & 40,0 \\
\hline 4 & $\begin{array}{l}\text { - Il n'est pas possible de créer des termes } \\
\text { dérivés (du type: logiciel, progiciel, ludi- } \\
\text { ciel). } \\
\text { - La signification des termes français n'est } \\
\text { pas claire. } \\
\text { - La signification des termes français ne } \\
\text { correspond pas à celle du terme anglais. } \\
\text { - Les formulations des termes français sont } \\
\text { trop compliquées. }\end{array}$ & 1 & $\begin{array}{l}20,0 \\
20,0 \\
20,0\end{array}$ \\
\hline 5 & $\begin{array}{l}\text { Autre : } \\
\text { J'essaie de choisir le mot qui convient à mon } \\
\text { interlocuteur. }\end{array}$ & 1 & 20,0 \\
\hline
\end{tabular}

Vier von fünf Informanten begründen ihre Entscheidung für (access) provider mit dem hohen Verbreitungsgrad dieses Terminus. Je drei Informanten berufen sich auf a) die Sicherheit, bei Verwendung des englischsprachigen Terminus verstanden zu werden, b) die Kürze und c) die Internationalität des Terminus. Zwei Informanten führen an, sich an den Gebrauch des englischen Terminus gewöhnt zu haben. Die unter „Autre“ gegebene Antwort, dass die Wahl des Terminus vom Gesprächspartner abhänge, passt zu der hohen Quote an Informanten, die sich je nach Kontext für einen der Termini entscheiden.

Der Hypothese, dass der Neologismus fournisseur d'accès einen höheren Akzeptanzwert erhalten wird als der entsprechende Anglizismus (access) provider, kann nur eingeschränkt zugestimmt werden. Zwar hat sich bei der Frage 40 nach dem eigenen Sprachgebrauch eine leichte Mehrheit für den französischen Terminus ergeben, jedoch war die Stimmenverteilung bei der Frage nach der Bekanntheit der Termini sowie bei der Frage nach der persönlichen Präferenz so ausgeglichen, dass einzig der Wert für die aktive Akzeptanz von fournisseur d'accès etwas höher ist als der Wert für den entsprechenden Anglizismus. Beide Termini erhalten insgesamt ein nahezu identisches Akzeptanzvotum. Für eine Verifizierung dieser 
Hypothese in Bezug auf belgische Informatiker wäre eine größere Stichprobe nötig.

\subsubsection{Zusammenfassung und Schlussfolgerungen}

Die englischsprachigen Termini e-mail und mail werden häufiger verwendet als ihre französischen Äquivalente. Das trifft auch auf engl. homepage, web und chat zu. Bezüglich der Lexempaare cracker/pirate und fournisseur d'accès/(access) provider ist die Gebrauchsfrequenz beider Termini recht ausgeglichen, einmal gibt es einen leichten Vorsprung für den englischen, einmal für den französischen Terminus.

Es wurde weiterhin festgestellt, dass der Bekanntheitsgrad der französischen Termini sehr unterschiedlich ist. Weniger als die Hälfte der Befragten kennt die französischen Termini message électronique, messagerie électronique, toile mondiale, toile d'araignée mondiale, bavardage. Kein Informant kennt T.A.M. oder causette. Demgegenüber sind franz. courrier électronique, pirate, page d'accueil und fournisseur d'accès jeweils über $80 \%$ der Informanten bekannt. Dies verdeutlicht die folgende Abbildung:

Abb. 140: Bekanntheits- und Etablierungsgrad aller französischen und englischsprachigen Termini in \% (Belgien)

\begin{tabular}{|c|c|c|c|}
\hline \multicolumn{3}{|c|}{ Bekanntheitsgrad der Termini } & \multirow{2}{*}{$\begin{array}{l}\text { Etablierungs- } \\
\text { grad }\end{array}$} \\
\hline & $\begin{array}{l}\text { Französische Neolo- } \\
\text { gismen }\end{array}$ & $\begin{array}{l}\text { Englischsprachige } \\
\text { Termini }\end{array}$ & \\
\hline $100 \%$ & fournisseur d'accès & $\begin{array}{l}\text { (access) provider, chat, } \\
\text { homepage, mail, web }\end{array}$ & $\begin{array}{l}100 \% \text { ige Etablie- } \\
\text { rung }\end{array}$ \\
\hline $90-99,9 \%$ & page d'accueil & World Wide Web & \multirow{2}{*}{$\begin{array}{l}\text { sicherer Etablie- } \\
\text { rungsgrad }\end{array}$} \\
\hline $80-89,9 \%$ & $\begin{array}{l}\text { courrier électronique, } \\
\text { pirate }\end{array}$ & cracker, e-mail & \\
\hline $70-79,9 \%$ & courriel, toile & -- & \multirow{3}{*}{$\begin{array}{l}\text { unsicherer } \\
\text { Etablierungsgrad }\end{array}$} \\
\hline $60-69,9 \%$ & -- & -- & \\
\hline $50-59,9 \%$ & mél & -- & \\
\hline $40-49,9 \%$ & -- & -- & \multirow{4}{*}{$\begin{array}{l}\text { schwacher } \\
\text { Etablierungsgrad }\end{array}$} \\
\hline $30-39,9 \%$ & message électronique & -- & \\
\hline $20-29,9 \%$ & messagerie électronique & -- & \\
\hline $\begin{array}{l}\text { Weniger } \\
\text { als } 20 \%\end{array}$ & $\begin{array}{l}\text { bavardage, toile d'araignée } \\
\text { mondiale, toile mondiale }\end{array}$ & -- & \\
\hline $0 \%$ & causette, T.A.M. & -- & keine Etablierung \\
\hline
\end{tabular}

Die in 5.3.1 formulierte Hypothese, die befragten Informatiker würden die Internet-Termini (mit Ausnahme der Testwörter) mehrheitlich als bekannt angeben, kann aufgrund dieses Ergebnisses bestätigt werden. Allerdings fällt auf, dass die englischen Termini wesentlich verbreiteter sind als die französischen Termini, von 
denen sieben Termini weniger als 50\% der Befragten bekannt sind. Dass viele der französischen Termini relativ unbekannt sind, lässt darauf schließen, dass diese in Gesprächen oder Texten kaum auftreten. Alle englischsprachigen Termini hingegen sind mehr als 80\% der Informanten bekannt, woraus im Umkehrschluss abgeleitet werden kann, dass sie in (fachlichen) Gesprächen und Texten häufig vorkommen.

Oftmals werden die Termini nicht für synonym gehalten, z.B. wird messagerie électronique von einigen Informanten anders definiert als die übrigen Lexeme. Auch toile d'araignée mondiale wird mitunter als Bezeichnung für das gesamte Internet und nicht nur für einen Teil, nämlich das World Wide Web, verstanden. Cracker und pirate sowie (access) provider und fournisseur d'accès werden hingegen durchgängig als synonym betrachtet. Das Ergebnis bezüglich der Synonymie fällt für die französische wie belgische Terminologiekommission, deren Aufgabe es ja sein sollte, eindeutige Entsprechungen zu finden, nicht unbedingt zufriedenstellend aus. Es ist an der Zeit, einige Änderungen in der Terminologiedatenbank vorzunehmen und manche der Termini neu zu definieren. Beispielsweise hat sich chat gegenüber allen französischen Äquivalenten durchgesetzt. Diesem Tatbestand wurde in der belgischen Datenbank bereits insofern Rechnung getragen, als dieser Terminus und sämtliche Ersetzungsvorschläge gänzlich aus der offiziellen Informatik-Terminologie entfernt wurden. Aufgrund der geringen finanziellen Mittel, die für die belgische Terminologiearbeit zur Verfügung stehen, ist vorerst jedoch nicht davon auszugehen, dass die Belgier sich in der Terminologie erheblich von den Vorschlägen der französischen Terminologiekommissionen entfernen werden.

Als Gründe für die Verwendung der englischsprachigen Termini e-mail/mail, homepage, web, chat, cracker und (access) provider werden vor allem die Sicherheit, bei Verwendung der englischen Termini verstanden zu werden, die große nationale und internationale Verbreitung des Terminus, die Gewöhnung an diesen Terminus sowie seine Kürze genannt. Wichtig ist den befragten Informatikern neben persönlichen Motiven wie der Gewöhnung an den Anglizismus, dass (fachliche) Gespräche nicht durch eine möglicherweise unklare oder Verwirrung stiftende Terminologie belastet werden, die die Verständigung beeinträchtigen kann.

Zuletzt bleibt im Rahmen dieser Zusammenfassung noch die Klärung der Hypothese, die persönliche Präferenz stimme nicht prinzipiell mit dem eigenen aktiven Sprachgebrauch überein. Im Falle der belgischen Informanten sind die Parallelen zwischen der persönlichen Präferenz und dem eigenen Sprachgebrauch evident: In vier Fällen weist das von den meisten Informanten als Präferenz angegebene Wort (e-mail, web, chat, cracker) zugleich die höchste Gebrauchsfrequenz auf. Die Termini page d'accueil und homepage bzw. fournisseur d'accès und (access) provider werden gleichermaßen präferiert, homepage dann aber etwas häufiger als page d'accueil und fournisseur d'accès etwas häufiger als (access) provider verwendet. In Bezug auf die ermittelten Ergebnisse muss der Hypothese somit widersprochen werden. Prinzipiell stimmen die Präferenzen und der Sprachgebrauch überein, allerdings gibt es kleinere Abweichungen. Es kommt jedoch nicht vor, dass ein Wort häufig verwendet wird, ohne zuvor häufig als Präferenz angegeben worden zu sein. 


\subsection{Zweites Fragebogenmodul: Kenntnis und Akzeptanz der aktuellen Sprachpolitik}

\subsubsection{Auswertung der Fragen 44-49}

Die sechs Fragen des zweiten Fragebogenmoduls wurden an die belgische Situation angepasst.

In der ersten Frage des zweiten Fragebogenmoduls werden die Informanten gefragt, ob sie die aktuelle belgische Sprachpolitik kennen.

Abb. 141: Frage 44, Kenntnis der aktuellen Sprachpolitik (Belgien)

\begin{tabular}{|l|r|r|}
\hline & $\begin{array}{l}\text { Absolute } \\
\text { Häufigkeit }\end{array}$ & $\begin{array}{l}\text { Prozentuale } \\
\text { Häufigkeit }\end{array}$ \\
\hline Oui. & 0 & 0,0 \\
\hline Oui, j'en ai entendu parler. & 3 & 17,6 \\
\hline Non. & 14 & 82,4 \\
\hline Je ne sais pas. & 0 & 0,0 \\
\hline Insgesamt & 17 & 100,0 \\
\hline
\end{tabular}

In Belgien hat es kein der französischen Loi Bas-Lauriol oder der Loi Toubon vergleichbares Sprachgesetz gegeben. Das Dekret Spaak hat nicht die Reichweite der französischen Sprachgesetze und liegt zudem zeitlich ziemlich weit zurück (1976). Auch andere Verordnungen wie das 1991 zu Etikettierungen, Gebrauchsanweisungen und Garantieurkunden verabschiedete Gesetz erreichen bei weitem nicht den Stellenwert, den die Loi Toubon für Frankreich hat (vgl. 3.3.1). Entsprechend fällt auch das Ergebnis aus: 14 von 17 Informanten sind über die aktuelle belgische Sprachpolitik nicht informiert, nur drei Informanten geben an bereits davon gehört zu haben.

In Frage 45 wurden die Informanten aufgefordert die belgische Sprachpolitik zu beurteilen.

Abb. 142: Frage 45, Beurteilung der aktuellen Sprachpolitik (Belgien)

\begin{tabular}{|l|r|r|}
\hline & $\begin{array}{l}\text { Absolute } \\
\text { Häufigkeit }\end{array}$ & $\begin{array}{l}\text { Prozentuale } \\
\text { Häufigkeit }\end{array}$ \\
\hline Absolument nécessaire. & 1 & 5,9 \\
\hline Souhaitable. & 8 & 47,05 \\
\hline Inutile. & 8 & 47,05 \\
\hline Insgesamt & 17 & 100,0 \\
\hline
\end{tabular}

Das Verhältnis zwischen Befürwortung und Ablehnung sprachpolitischer Maßnahmen zum Schutz der Sprache vor Anglizismen ist sehr ausgeglichen. Neun Informanten (ca. 53\%) sprechen sich dafür, acht (ca. 47\%) dagegen aus. In diesem Fall wäre es interessant, eine größere Gruppe an Informanten zu befragen, um zu 
sehen, ob sich bei einer größeren Stichprobe eine Tendenz in die eine oder andere Richtung ergibt.

Aufgrund der hier dargestellten Daten zeichnet sich eine leichte Befürwortung sprachpolitischer Maßnahmen ab. Eine gegenläufige Tendenz ist bezüglich der Bewertung von Terminologielisten zu konstatieren.

\section{Abb. 143: Frage 46, Beurteilung der Terminologielisten (Belgien)}

\begin{tabular}{|l|r|r|}
\hline & $\begin{array}{l}\text { Absolute } \\
\text { Häufigkeit }\end{array}$ & $\begin{array}{l}\text { Prozentuale } \\
\text { Häufigkeit }\end{array}$ \\
\hline Utiles. & 2 & 11,8 \\
\hline Souhaitables. & 1 & 5,9 \\
\hline Pas assez connues. & 2 & 11,8 \\
\hline Inutiles. & 9 & 52,9 \\
\hline Je ne les connais pas. & 3 & 17,6 \\
\hline Insgesamt & 17 & 100,0 \\
\hline
\end{tabular}

Nur drei Informanten (17,7\%) stehen den Terminologielisten positiv gegenüber und beurteilen sie als nützlich bzw. wünschenswert. Zwei Informanten (11,8\%) halten die Terminologielisten nicht für bekannt genug. Neun Informanten, etwas mehr als die Hälfte der Befragten (52,9\%), halten die Terminologielisten für überflüssig. Drei Informanten $(17,6 \%)$ geben an sie nicht zu kennen.

Danach wurden die Informanten gefragt, ob sie die Terminologielisten befolgen:

Abb. 144: Frage 47, Befolgen der Terminologielisten (Belgien)

\begin{tabular}{|l|r|r|}
\hline & $\begin{array}{l}\text { Absolute } \\
\text { Häufigkeit }\end{array}$ & $\begin{array}{l}\text { Prozentuale } \\
\text { Häufigkeit }\end{array}$ \\
\hline Oui. & 1 & 5,9 \\
\hline Non. & 8 & 47,1 \\
\hline Partiellement. & 4 & 23,5 \\
\hline Je ne les connais pas. & 4 & 23,5 \\
\hline Insgesamt & 17 & 100,0 \\
\hline
\end{tabular}

Nur ein Informant gibt an die Terminologielisten konsequent zu befolgen. Vier Informanten (23,5\%) befolgen die Terminologielisten eigenen Aussagen zufolge teilweise. Acht Informanten und damit knapp die Hälfte der Befragten (47,1\%) geben an diese nie zu befolgen. Vier Informanten (23,5\%) geben an diese nicht zu kennen. Insgesamt stehen den fünf Informanten, die eigenen Angaben zufolge die Terminologielisten zumindest teilweise befolgen, acht Informanten gegenüber, die angeben diese nicht zu befolgen. Somit überwiegt die Ablehnung gegenüber einer Befolgung dieser Listen, was auch nicht erstaunt, da mehr als die Hälfte der Befragten in der vorangegangenen Frage bekundet hat die Listen für überflüssig zu halten. 
Da bereits in Frage 46 zwei Informanten darauf hingewiesen haben, dass die Terminologielisten nicht bekannt genug seien, und drei Informanten sie nach eigenen Angaben nicht kennen, ist es nicht verwunderlich, dass auch in dieser Frage vier Informanten $(23,5 \%)$ meinen die Listen nicht zu kennen.

Wie sieht es mit der offiziellen belgischen Internet-Terminologie aus, die im Rahmen der Informatik-Terminologie veröffentlicht ist?

Abb. 145: Frage 48, Kenntnis der offiziellen Internet-Terminologie (Belgien)

\begin{tabular}{|l|r|r|}
\hline Oui, je la connais un peu. & $\begin{array}{l}\text { Absolute } \\
\text { Häufigkeit }\end{array}$ & $\begin{array}{l}\text { Prozentuale } \\
\text { Häufigkeit }\end{array}$ \\
\hline J'en ai déjà entendu parler. & 2 & 11,8 \\
\hline Non, pas du tout. & 3 & 17,6 \\
\hline Insgesamt & 12 & 70,6 \\
\hline
\end{tabular}

Nur zwei von 17 Informanten geben an die offizielle Internet-Terminologie ein wenig zu kennen. Drei Informanten haben bereits davon gehört. Den fünf Informanten $(29,4 \%)$, die die Internet-Terminologie ein wenig kennen oder von ihr gehört haben, stehen zwölf Informanten (70,6\%) gegenüber, denen sie völlig unbekannt ist. $\mathrm{Zu}$ diesen zwölf Informanten gehört interessanterweise auch der Informant, der im ersten Fragebogenmodul (10.1) mehrfach angegeben hat einen der französischen Termini zu verwenden, z.B. bavardage anstelle von chat. Somit steht seine Bevorzugung der französischen Terminologie nicht im Zusammenhang mit der Kenntnis und Befolgung der offiziellen Terminologie, sondern er tut es aus anderen Motiven. Da nirgends nach den Gründen für die Verwendung der französischen Termini gefragt wurde, kann nur gemutmaßt werden. Möglicherweise gefallen diesem Informanten einfach die französischen Termini besser. Ebenso wäre denkbar, dass er prinzipiell die französischen Termini verwendet, um auf diese Weise bewusst die Anglizismen zu vermeiden.

Die beiden Informanten, die die Internet-Terminologie ein wenig kennen, erklären in der folgenden Frage 49, in der nach der Befolgung dieser Terminologie gefragt wird, sie niemals zu verwenden.

Ein Blick in die Datenbank zeigt, dass einer der beiden Informanten auf die Fragen nach dem eigenen Sprachgebrauch im ersten Fragebogenmodul in der Tat nur die englischen Termini angegeben hat. Der andere Informant hat bei der entsprechenden Frage in vier Fällen einen englischen Terminus und in zwei Fällen einen französischen Terminus angegeben, nämlich pirate und fournisseur d'accès. Dies zeigt, dass dem zweiten Informanten nicht bewusst ist, dass diese beiden französischen Termini der offiziellen Terminologie angehören. 


\subsubsection{Auswertung der länderspezifischen Hypothesen}

Abschließend wird auf die in 5.3.3 formulierten länderspezifischen Hypothesen zur Kenntnis und Akzeptanz sprachpolitischer Maßnahmen eingegangen. In der ersten Hypothese zu den frankophonen Belgiern wird davon ausgegangen, dass die Mehrheit der befragten Belgier sprachpolitische Maßnahmen zur Eindämmung der Anglizismen befürwortet. Diese Hypothese wurde im Wesentlichen aus den Ergebnisse von Garsous Umfrage (1991, vgl. 2.3.3.2.4) abgeleitet, der zufolge $70 \%$ der befragten Belgier sprachpolitische Maßnahmen des Staates und 50\% sogar die Erarbeitung konkreter Sprachschutzgesetze befürworten.

Aufgrund der geringen Anzahl an Informanten und des recht ausgeglichenen Ergebnisses zwischen Befürwortung (ca. 53\%) und Ablehnung (ca. 47\%) sprachpolitischer Maßnahmen kann diese Hypothese weder bestätigt noch abgelehnt werden. Eine größere Stichprobe wäre nötig, um eindeutige Tendenzen in die eine oder andere Richtung feststellen zu können.

Die zweite Hypothese lautet: „Im Vergleich zum Bekanntheitsgrad der offiziellen französischen Internet-Terminologie in Frankreich fällt der Bekanntheitsgrad der im Internet abrufbaren belgischen Internet-Terminologieliste niedriger aus."

Bei der Formulierung dieser Hypothese wurde bereits darauf hingewiesen, dass die belgische Internet-Terminologie nur über eine Datenbank einzusehen ist, nicht aber z.B. in Form gedruckter Broschüren veröffentlicht wurde. Die Auswertung der Frage 48 hat gezeigt, dass 29,4\% der belgischen Informanten die InternetTerminologie ein wenig kennen bzw. von ihr gehört haben, während mehr als die Hälfte der französischen Informanten (54,8\%) die Internet-Terminologie teilweise kennt oder zumindest von ihr gehört hat. Insofern kann die Hypothese bestätigt werden, dass der Bekanntheitsgrad der französischen Internet-Terminologie bei französischen Informatikern über dem der belgischen Internet-Terminologie bei belgischen Informatikern liegt.

\subsection{Drittes Fragebogenmodul: Auswertung der Kommen- tare zur Sprachpolitik und Terminologiearbeit}

Die Auswertung der Kommentare der belgischen Informanten erfolgt analog zu der Auswertung der Kommentare der französischen Informanten (vgl. 9.3).

Mehr als die Hälfte, nämlich zehn der insgesamt 17 belgischen Informanten, hat einen Kommentar zur belgischen Sprachpolitik bzw. Terminologiearbeit verfasst.

Bei der Auswertung der Kommentare wurden vier große Kategorien gebildet:

1. Befürwortung der Sprachpolitik,

2. Ablehnung der Sprachpolitik,

3. Pro \& contra Sprachpolitik,

4. Ablehnung der Terminologiearbeit. 
Während es zur Sprachpolitik sowohl Pro- als auch Contraargumente gibt, fehlen Argumente, die auf positive Aspekte der Terminologiearbeit Bezug nehmen³. Bezüglich der Tabellengestaltung gilt das Gleiche, was bereits in 9.3 ausgeführt wurde. Die in der jeweils rechten Tabellenspalte vorgenommene nachträgliche Quantifizierung der Argumente ist im Vergleich zu den Inhalten der Argumente sekundär. Die Quantifizierung ist vielmehr eine Hilfestellung, um die Argumente ordnen zu können, zeigt aber auch, welche Argumente von jeweils wie vielen Informanten angeführt wurden. Die Auflistung der einzelnen Argumente innerhalb einer Tabelle erfolgt in der Reihenfolge der Häufigkeit, in der sie genannt wurden. Bei gleicher Anzahl an Nennungen werden die Argumente alphabetisch geordnet. Die erste Tabelle zeigt das einzige Argument auf, das zur Befürwortung sprachpolitischer Maßnahmen angeführt wurde:

Abb. 146: Argumente für die Befürwortung der Sprachpolitik (Belgien)

\section{Befürwortung der Sprachpolitik}

\section{Kategorie}

Sprachpolitik ist zu befürworten, riskiert aber, ins

Lächerliche abzurutschen.

\section{Informanten}

B10
Anzahl

1

Ein Informant befürwortet Sprachpolitik mit dem einschränkenden Zusatz, dass sie oftmals drohe, ins Lächerliche abzurutschen. Demgegenüber gibt es mehrere Punkte, die bezüglich der Sprachpolitik kritisiert werden:

\section{Abb. 147: Argumente für die Ablehnung der Sprachpolitik (Belgien)}

\section{Ablehnung der Sprachpolitik}

\begin{tabular}{|c|c|c|}
\hline Kategorie & Informanten & Anzahl \\
\hline $\begin{array}{l}\text { Anstelle von Sprachpolitik, die sich gegen } \\
\text { Anglizismen richtet, soll die passive Kenntnis von } \\
\text { Fremdsprachen gefördert werden. }\end{array}$ & B9 & 1 \\
\hline Die französische Sprachpolitik ist chauvinistisch. & B5 & 1 \\
\hline Sprachpolitik ist ergebnislos. & B5 & 1 \\
\hline Sprachpolitik ist lächerlich. & B5 & 1 \\
\hline Sprachpolitik ist protektionistisch. & B5 & 1 \\
\hline Sprachpolitik ist überflüssig. & B5 & 1 \\
\hline
\end{tabular}

Ein Informant spricht sich gegen eine Sprachpolitik aus, die sich gegen Anglizismen richte, und befürwortet vielmehr die Förderung von Fremdsprachenkenntnissen. Ein anderer Informant nennt gleich eine Fülle von Adjektiven, die seiner Meinung nach auf sprachpolitische Maßnahmen generell und auf die französische Sprachpolitik speziell zutreffen.

${ }^{3}$ Alle Kommentare der belgischen Informanten sind im Anhang 15.5.2.2 vollständig nachzulesen. 
Ein Argument konnte weder eindeutig der sprachpolitische Maßnahmen befürwortenden noch der entsprechende Maßnahmen ablehnenden Seite zugeordnet werden:

Abb. 148: Argumente pro \& contra Sprachpolitik (Belgien)

\section{Pro \& contra Sprachpolitik}

\begin{tabular}{|l|l|r|}
\hline Kategorie & Informanten & Anzahl \\
\hline Sprachpolitik ist nicht bekannt genug. & B3 & 1
\end{tabular}

Das Argument mangelnder Bekanntheit war eine der Antwortoptionen bei der Frage 46 (Beurteilung der Terminologielisten) im zweiten Fragebogenmodul. Diese Antwortoption hat den Informanten sicherlich beeinflusst und ihn diesbezüglich zum Nachdenken angeregt. Er bemängelt, dass Sprachpolitik nicht bekannt genug sei, was bezogen auf die belgische Situation zweifelsohne stimmt. Im Gegensatz zur Loi Toubon in Frankreich haben in Belgien die innerhalb der einzelnen Sprachgemeinschaften getroffenen Regelungen kein großes Gewicht (vgl. 3.3.1).

In keinem der Kommentare wird die Terminologiearbeit befürwortet, es werden jedoch diverse Argumente aufgeführt, die nach Ansicht der befragten Informatiker dagegen sprechen.

Abb. 149: Argumente für die Ablehnung der Terminologiearbeit (Belgien)

\section{Ablehnung der Terminologiearbeit}

\begin{tabular}{|c|c|c|}
\hline Kategorie & Informanten & Anzahl \\
\hline $\begin{array}{l}\text { Kommunikation: } \\
\text { Englisch ist die dominierende Sprache und die } \\
\text { lingua franca im Bereich der neuen Technologien wie } \\
\text { Informatik/Internet. } \\
\text { Die Verwendung der englischen Terminologie er- } \\
\text { leichtert die Kommunikation weltweit und unter } \\
\text { frankophonen Sprechern. }\end{array}$ & $\begin{array}{l}\text { B4, B7, B8, } \\
\text { B9 }\end{array}$ & 4 \\
\hline $\begin{array}{l}\text { Französische Termini kommen häufig zu spät, } \\
\text { wenn sich die englischen Termini etabliert und die } \\
\text { Sprecher sich an diese gewöhnt haben. }\end{array}$ & B1, B6 & 2 \\
\hline $\begin{array}{l}\text { Französische Terminologie ist lächerlich, wenn es } \\
\text { sich bei den Neologismen lediglich um Französisie- } \\
\text { rungen der Anglizismen handelt, wie bei den } \\
\text { französischen Neologismen cédérom und mél für } \\
\text { engl. } C D \text {-ROM und e-mail. }\end{array}$ & B2, B10 & 2 \\
\hline $\begin{array}{l}\text { Anstatt neue Wörter zu schaffen, sollten nur die } \\
\text { bekannten Wörter verwendet werden. }\end{array}$ & B2 & 1 \\
\hline Entlehnung ist ein natürlicher Prozess. & B8 & 1 \\
\hline Französische Neologismen sind häufig lächerlich. & B1 & 1 \\
\hline
\end{tabular}




\begin{tabular}{l|l|l|}
$\begin{array}{l}\text { Französische Neologismen sind häufig künstlich. } \\
\begin{array}{l}\text { Französische Neologismen sind mitunter überflüs- } \\
\text { sig. }\end{array}\end{array}$ & B2 & 1 \\
$\begin{array}{l}\text { Sprache lebt und verändert sich, dieser Prozess ist } \\
\text { durch Terminologiearbeit nicht zu stoppen. }\end{array}$ & B8 & 1 \\
\end{tabular}

Insgesamt werden neun Argumente angeführt, die gegen die Terminologiearbeit sprechen. Am häufigsten wird auf die Bedeutung der englischen Sprache in der Kommunikation im Bereich der neuen Technologien hingewiesen: Englisch sei die in diesem Bereich am weitesten verbreitete Sprache, außerdem erleichtere die Verwendung der englischen Termini die Kommunikation. Dieses Argument hebt einer der Teilnehmer der Befragung in einer persönlichen E-Mail hervor, die er als Reaktion auf die Erinnerung an die Umfrage in den vier Diskussionsforen zu den Programmiersprachen Perl, Java, C++ und C verfasst hat:

Bonjour,

$[\ldots]$

Tous les informaticiens qui travaillent dans le développement d'applications comprennent parfaitement l'anglais technique: c'est absolument indispensable.

Auparavant, on exigeait la connaissance passive.

Maintenant, je constate que les jeunes utilisent activement la communication écrite en anglais.

Parfois même, certains cours sont donnés en anglais...pour les aider à maîtriser la langue.

On peut évidemment franciser, mais ceci n’intéresse que les enseignants.

Les élèves et leurs patrons préfèrent la connaissance de l'anglais technique, qui est d'ailleurs une langue assez simple.

Ceci est mon opinion personnelle. J'ai commencé en informatique vers 1967 et à l'aube de la pension, j'ai appris encore un langage de plus: Java. Les meilleurs ouvrages didactiques sont écrits en français...mais les références techniques sont évidemment américaines. Sans connaissance de l'anglais je n'avancerais pas.

Même un outil génial comme Copernic cache son origine française. Tout est publié en anglais.

$[\ldots]$ 
(persönliche Mitteilung eines belgischen Teilnehmers vom 19. August 20024).

Anhand der Informationen, die in dieser E-Mail gegeben werden, wird deutlich, dass die Beherrschung und Verwendung der englischen Sprache in der Informatik-Branche unvermeidlich ist. Auch wenn einige gute Lehrbücher auf Französisch verfasst sind, greifen diese Bücher auf amerikanische Quellen zurück. Ganz offensichtlich werden Anfänger in der Informatik-Branche über in englischer Sprache gehaltene Kurse nach und nach an das Englische herangeführt, da die Kenntnis dieser Sprache als lingua franca im Bereich der Informatik unverzichtbar ist.

Aus den in Abbildung 149 ausgewerteten Kommentaren wird ersichtlich, dass die Informanten durchaus eigene Standpunkte zur Sprachpolitik und Terminologiearbeit vertreten, die sie argumentativ belegen können. Zudem haben die Informanten offensichtlich am Ende der Umfrage auch das Bedürfnis verspürt, ihren Standpunkt deutlich zu machen, denn bei einer Umfrage, für die mind. 20 Minuten benötigt werden, wenn selbst formulierte Textantworten gegeben werden, ist ein zusätzlicher abschließender Kommentar keineswegs selbstverständlich. Die Tatsache, dass zehn von 17 Informanten einen kritischen Kommentar verfasst haben, zeigt sowohl ihr Interesse an der Thematik als auch das Bewusstsein dafür, dass es bezüglich der Sprachpolitik und Terminologiearbeit noch einiges zu verbessern und zu diskutieren gibt.

\footnotetext{
${ }^{4}$ Die in dieser E-Mail enthaltenen Fehler in Orthografie und Interpunktion sind verbessert worden. In einer weiteren E-Mail vom 20. August 2002 schreibt der gleiche Informant:

„[...] Ma firme belge n'est pas du tout internationale (on est spécialisé en législation sociale) et pourtant il apparaît deux phénomènes:

- les jeunes informaticiens ont leur langue maternelle + l'anglais. C'est ainsi qu'un flamand et un francophone discutent en anglais!

- notre direction générale a uniformisé les dénominations de fonction en anglais (account manager, area director...).

Pour les différences entre France et Belgique, je sais par exemple que les trains qui circulent sous la Manche sont conduits par des Belges, car la connaissance des langues étrangères est plus répandue qu'en France. Il y a certainement une différence entre un petit pays qui doit s'ouvrir à l'extérieur et un grand pays qui se referme sur sa propre langue."

Der Informant weist nicht nur auf die Rolle des Englischen in der nationalen Kommunikation hin, z.B. in belgischen Unternehmen mit Beschäftigten verschiedener Muttersprachen, sondern auch neben der Kritik an den seiner Meinung nach mangelnden Fremdsprachenkenntnissen der Franzosen - darauf, dass sich ein kleines Land sprachlich nicht von anderen Staaten abschotten dürfe. Beide Argumente belegen zwei der vier von Klinkenberg (2000, 704f., vgl. 2.3.3.3) vorgebrachten Thesen (These 2: Belgien habe dem wirtschaftlichen Einfluss der USA weniger Widerstand entgegengebracht als Frankreich. Insbesondere für ein Industrieland wie Belgien, das durch seinen Handel mit dem Ausland lebe, sei das Englische als Wirtschaftssprache unabdingbar; These 4: Das Englische diene in Belgien mitunter als Sprache des Kompromisses in der Verständigung zwischen den beiden großen Sprechergruppen und sei häufig die gemeinsame Sprache in großen Unternehmen).
} 


\subsection{Zusammenfassung}

Von den sechs im ersten Fragebogenmodul getesteten Lexempaaren erhalten bezüglich des eigenen Sprachgebrauchs in einem Fall der französische Terminus, fournisseur d'accès, und in vier Fällen die Anglizismen (mail/ e-mail, homepage, web, chat) das höhere Akzeptanzvotum. Bezüglich des Lexempaares franz. pirate vs. engl. cracker lässt sich keine eindeutige Tendenz angeben. Dieses Ergebnis bestätigt die von einem der Informanten angesprochene höhere Anglophilie der Belgier im Vergleich zu ihren französischen Nachbarn (vgl. 10.1.4). Die Wahl der englischen Termini einzig mit der größeren Anglophilie begründen zu wollen, greift jedoch zu kurz. Die von den belgischen Informanten am häufigsten genannten Gründe, die für die Verwendung der Anglizismen e-mail/mail, homepage, web, chat, pirate und (access) provider sprechen, zeigen, dass vor allem pragmatische Aspekte die Entscheidung für die englischen Termini lenken:

- der hohe Verbreitungsgrad des englischsprachigen Terminus,

- die Gewöhnung an den englischsprachigen Terminus,

- die Sicherheit, bei Verwendung des englischsprachigen Terminus verstanden zu werden,

- die Kürze des englischsprachigen Terminus und

- seine internationale Verwendung.

Zwei der Argumente beziehen sich allein auf die hohe nationale und internationale Verbreitung und Verwendung der Termini, ein weiteres Argument unmittelbar auf die Kommunikation (Sicherheit, verstanden zu werden). Die Entscheidung der frankophonen belgischen Informatiker lässt sich zu großen Teilen auf die auch beruflich erforderte Notwendigkeit einer unmissverständlichen und über Sprachgrenzen hinausreichenden Kommunikation zurückführen. Es spielen aber auch persönliche Gründe eine Rolle, wie die Gewöhnung an den englischsprachigen Terminus. Die französischen Termini verbreiten sich - nicht nur über den offiziellen Weg der Terminologielisten - zu spät, wenn sich die englischen Termini bereits etabliert und im Bewusstsein der Sprecher verankert haben.

Weiterhin wurde festgestellt, dass nicht alle Termini innerhalb der jeweiligen Lexemgruppen als synonym betrachtet werden. Unterschiede werden insbesondere zwischen messagerie électronique und den Äquivalenten für engl. e-mail, zwischen engl. homepage und franz. page d'accueil sowie zwischen engl. World Wide Web/web und toile d'araignée mondiale (und den kürzeren Entsprechungen) festgestellt. Im Sinne einer erfolgreichen Terminologiearbeit ist es allerdings von größter Wichtigkeit, dass die französischen Äquivalente mit den Anglizismen semantisch übereinstimmen und für Klarheit anstatt für Verwirrung und Unsicherheit sorgen. Werden die Anglizismen und ihre Ersatzwörter nicht als semantisch gleichwertig betrachtet oder sind sie den Sprechern in ihren Bedeutungen unklar, ist damit auch ihr Gebrauch schnell zum Scheitern verurteilt.

Im zweiten Fragebogenmodul ging es um die Kenntnis und Akzeptanz der Sprachpolitik und Terminologielisten. Die überwiegende Mehrheit der belgischen 
Informanten ist nicht über die Existenz einer belgischen Sprachpolitik informiert. Das Verhältnis zwischen Befürwortung und Ablehnung sprachpolitischer Maßnahmen zur Eindämmung des Anglizismeneinflusses kann als ausgeglichen bezeichnet werden. Die Terminologielisten werden jedoch von einer knappen Mehrheit abgelehnt. Zwölf Informanten (70,6\%) der 17 Informanten kennen die offizielle belgische Internet-Terminologie überhaupt nicht. An diesen Ergebnissen wird zum einen deutlich, dass in Belgien ein großer Informationsbedarf über die geltenden sprachpolitischen Entscheidungen herrscht. Zwar wird im Unterschied zu Frankreich nicht viel Geld in diese Maßnahmen investiert; wenn sie jedoch von der Bevölkerung nicht zur Kenntnis genommen werden, sind auch diese vergleichsweise geringen Summen schlecht investiert. Zum anderen kann eine gewisse Anglophilie, die vielleicht besser mit Toleranz gegenüber Fremdwörtern bezeichnet werden sollte, nicht geleugnet werden. Hierbei darf allerdings der berufliche Hintergrund der Informanten nicht außer Acht gelassen werden. Die englischen Entlehnungen sind nach Ansicht der befragten Informatiker für eine störungsfreie Kommunikation unabdingbar. Dies ist auch der Tenor der Kommentare, die sich gegen die Terminologiearbeit richten. Es ist aufgrund der häufig unzureichenden Qualität der französischen Ersatzwörter äußerst fraglich, ob die Informanten aufgrund terminologischer Vorschläge oder gar Vorschriften mehr französische Termini verwenden würden, auch wenn sie von diesen in Kenntnis gesetzt wären.

Bezüglich der belgischen Informanten muss des Weiteren die besondere Situation der Zweisprachigkeit berücksichtigt werden: Gerade in Brüssel ist von Unternehmen auszugehen, in denen Beschäftigte mit unterschiedlichen Muttersprachen $\operatorname{arbeiten}^{5}$. In einem mehrsprachigen Kontext hat eine einheitliche englische Terminologie einen ganz anderen Stellenwert als in einem Staat mit nur einer Amtssprache wie Frankreich, noch dazu, wenn es sich um ein verhältnismäßig kleines Land handelt, das auch in wirtschaftlicher Hinsicht auf die Kooperation mit anderen Staaten angewiesen ist (vgl. 2.3.3.3). Von einer ,réaction allergique contre l'anglais“, wie Swiggers (1993, 25; vgl. 2.3.3.3) sie bei den frankophonen Belgiern vermutet, kann am Ende dieses Kapitels zumindest bezüglich der befragten belgischen Informatiker keine Rede mehr sein.

\footnotetext{
5 Acht der 17 belgischen Informanten leben in Brüssel (vgl. 15.4.2) und sind z.T. sicherlich mit dieser Situation konfrontiert.
} 


\section{Auswertung der WWW-Befragung: die franzö- sischsprachige Schweiz}

In diesem Kapitel werden die Fragebögen der 19 schweizerischen Informatiker ausgewertet, die an der Befragung teilgenommen und den Fragebogen vollständig ausgefüllt haben. Bezüglich der Übertragbarkeit der Ergebnisse auf alle schweizerischen Informatiker gelten die am Anfang der Kapitel 9 und 10 getroffenen Einschränkungen.

Bei der Auswertung der Fragebögen der frankophonen Schweizer wird der Chronologie des Fragebogens gefolgt. Zunächst werden in 11.1 die Fragen zu den sechs ausgewählten Lexemgruppen des ersten Fragebogenmoduls ausgewertet und mit den in 5.3.1 formulierten Hypothesen verglichen. 11.2 widmet sich der Auswertung des zweiten Fragebogenmoduls, d.h. den Fragen zur Kenntnis und Akzeptanz der schweizerischen Sprachpolitik und (Internet-)Terminologie sowie der französischen Sprachpolitik. Am Ende dieses Abschnittes werden auch die in 5.3.3.3 formulierten Hypothesen mit den Ergebnissen des zweiten Fragebogenmoduls in Beziehung gesetzt. In 11.3 werden die Kommentare zur Sprachpolitik und Terminologiearbeit ausgewertet. Aufgrund der nur geringen Anzahl an schweizerischen Informanten und der ungünstigen Datenlage ${ }^{1}$ wird wie auch in

\footnotetext{
${ }^{1}$ Zwei von 19 Informanten sind weiblich, 17 männlich. Zwölf Informanten sind unter, sieben über 30 Jahre alt, nur ein Informant hat anstelle eines Abiturs eine maturité professionnelle, alle anderen haben das Abitur und z.T. darüber hinaus ein abgeschlossenes Studium. Auch bezüglich der Englischkenntnisse ist es nicht möglich, zwei Gruppen einander gegenüberzustellen, da nur zwei Informanten angegeben haben, über geringe Englischkenntnisse zu verfügen. Alle anderen verfügen über mittlere bis gute Englischkenntnisse. Nur zwei Informanten nutzen den E-Mail-Dienst und das World Wide Web weniger als drei Jahre, 17 länger als drei Jahre. Es wäre höchstens möglich, eine Korrelation bezüglich Alter und Sprachgebrauch vorzunehmen: Zwölf Informanten der jüngeren Altersklasse stehen sieben Informanten der älteren Altersklasse gegenüber. Eine ausführliche Über-
} 
Kapitel 10 auf eine Korrelation zwischen den biosozialen Daten und dem Sprachgebrauch bzw. den Einstellungen zur Sprachpolitik und Terminologiearbeit verzichtet.

\subsection{Erstes Fragebogenmodul: Auswertung der sechs aus- gewählten Lexemgruppen}

Bezüglich der Methodik der Auswertung gelten die in Kapitel 9 (bes. 9.1.1) gegebenen Hinweise.

\subsubsection{Die Termini courrier électronique, message électronique, mél, courriel, messagerie électronique, lettre électronique, e-mail und mail}

Der erste Fragenkomplex befasst sich mit engl. e-mail bzw. mail und seinen französischen Äquivalenten.

Abb. 150: Frage 1, Bekanntheitsgrad der Termini courrier électronique, message électronique, mél, courriel, messagerie électronique, lettre électronique, e-mail und mail (absolute Häufigkeit, Schweiz)

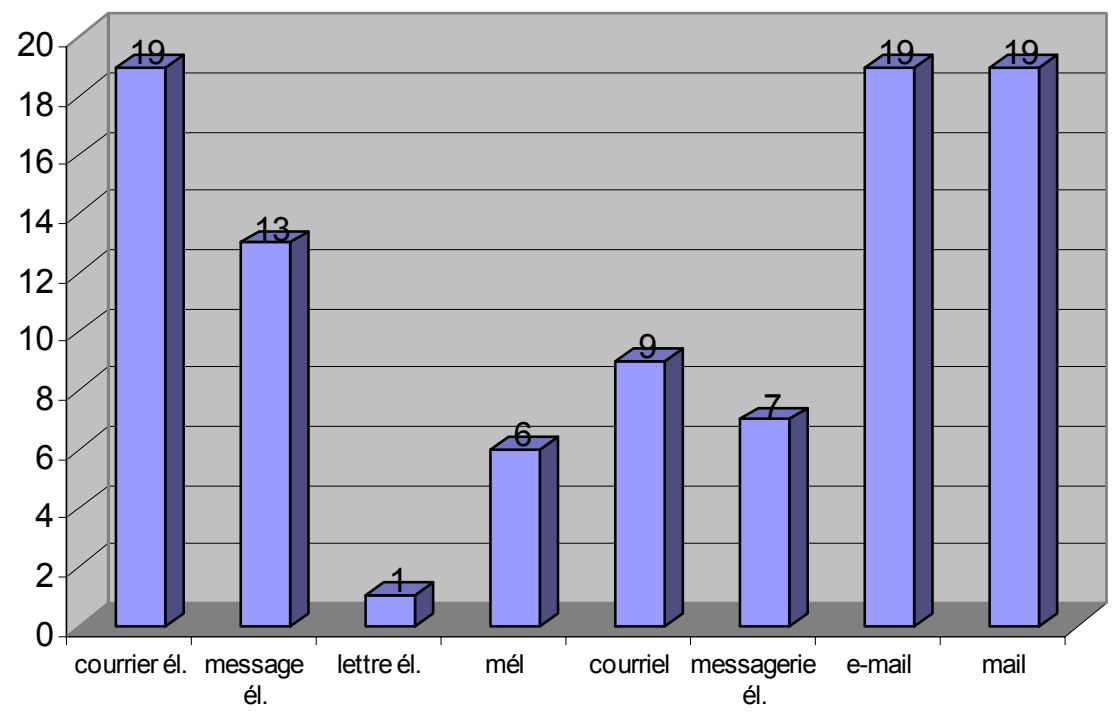

prüfung bezüglich dieses Zusammenhanges ist jedoch bereits in 9.4 .2 mit einer Datenmenge erfolgt, die besser geeignet ist, um aus den Ergebnissen brauchbare Schlussfolgerungen ableiten zu können. 
Abb. 151: Frage 1, Bekanntheitsgrad der Termini courrier électronique, message électronique, mél, courriel, messagerie électronique, lettre électronique, e-mail und mail (prozentuale Häufigkeit, Schweiz)

\begin{tabular}{|l|r|}
\hline Termini & $\mathbf{\%}$ \\
\hline Courrier électronique & 100,0 \\
\hline E-mail & 100,0 \\
\hline Mail & 100,0 \\
\hline Message électronique & 76,5 \\
\hline Courriel & 47,4 \\
\hline Messagerie électronique & 36,8 \\
\hline Mél & 31,6 \\
\hline Lettre électronique & 5,3 \\
\hline
\end{tabular}

Alle 19 befragten schweizerischen Informatiker kennen die beiden englischsprachigen Termini e-mail und mail sowie franz. courrier électronique. Es folgt mit einem Bekanntheitsgrad von 76,5\% franz. message électronique. Der Bekanntheitsgrad der Termini courriel, messagerie électronique und mél liegt zwischen 50\% und 30\%. Das Testwort lettre électronique gibt nur ein Informant als bekannt an.

Nach den vier von Gasquet/Villebrun (1994, 117) vorgeschlagenen Kategorien, um den Etablierungs- bzw. Bekanntheitsgrad von Termini zu bestimmen (vgl. 9.1.1), gelten e-mail, mail und courrier électronique bei den schweizerischen Informatikern als 100\%ig sicher etabliert. Sicher etablieren konnte sich der Terminus message électronique. Unsicher ist, ob sich courriel, messagerie électronique und mél etablieren konnten oder sich in Zukunft noch etablieren werden. Um dies mit Sicherheit sagen zu können, bedarf es einer diachronen Sichtweise, d.h. konkret einer weiteren, späteren Studie, die den Bekanntheitsgrad dieser Termini nochmals testet.

Die Frage, ob die aufgelisteten Termini synoym seien, wurde wie folgt beantwortet:

Abb. 152: Frage 2, Synonymie der Termini courrier électronique, message électronique, mél, courriel, messagerie électronique, e-mail und mail (Schweiz)

\begin{tabular}{|c|c|c|}
\hline & $\begin{array}{l}\text { Absolute } \\
\text { Häufigkeit }\end{array}$ & $\begin{array}{l}\text { Prozen- } \\
\text { tuale } \\
\text { Häufigkeit }\end{array}$ \\
\hline Synonym & 15 & 78,9 \\
\hline $\begin{array}{l}\text { Bedeutungs- } \\
\text { unterschied }\end{array}$ & 3 & 15,8 \\
\hline $\begin{array}{l}\text { Termini } \\
\text { unbekannt / } \\
\text { Weiß nicht. }\end{array}$ & 1 & 5,3 \\
\hline Insgesamt & 19 & 100,0 \\
\hline
\end{tabular}


Die meisten Informanten halten die Termini für synonym (78,9\%). Drei Informanten $(15,8 \%)$ stellen einen Bedeutungsunterschied fest, den sie wie folgt begründen:

Abb. 153: Frage 3, Bedeutungsunterschiede zwischen courrier électronique, message électronique, mél, courriel, messagerie électronique, e-mail und mail (Schweiz)

\section{Kategorie}

Bedeutungsunterschied zwischen messagerie électronique und den anderen Termini (message électronique, courrier électronique, courriel, mél, e-mail und mail): messagerie électronique ist das System (wie MS Outlook oder Netscape Messenger), die anderen Termini sind die einzelnen Nachrichten, die über das System übermittelt werden.

Message électronique hat eine allgemeinere $\mathrm{Be}-$ deutung als die anderen Termini (courrier électronique, courriel, mél, e-mail, mail) und bezieht sich auf jede Form von elektronisch übermittelten Nachrichten (z.B. auch Nachrichten im Usenet oder Chatraum).

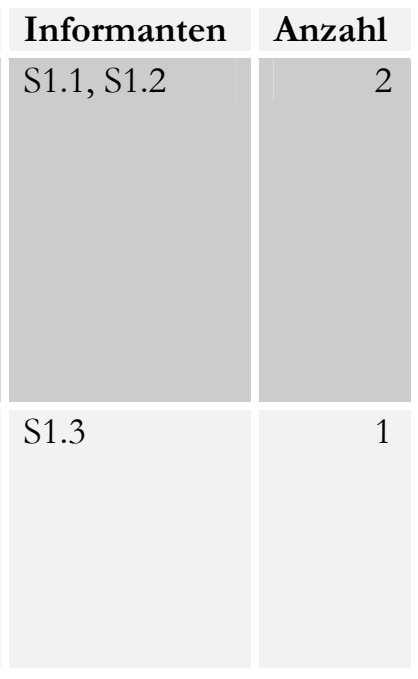

Die Frage nach den persönlichen Präferenzen ergibt eine sehr klare Verteilung:

Abb. 154: Frage 4, persönliche Präferenz(en): courrier électronique etc. (absolute Häufigkeit, Schweiz)

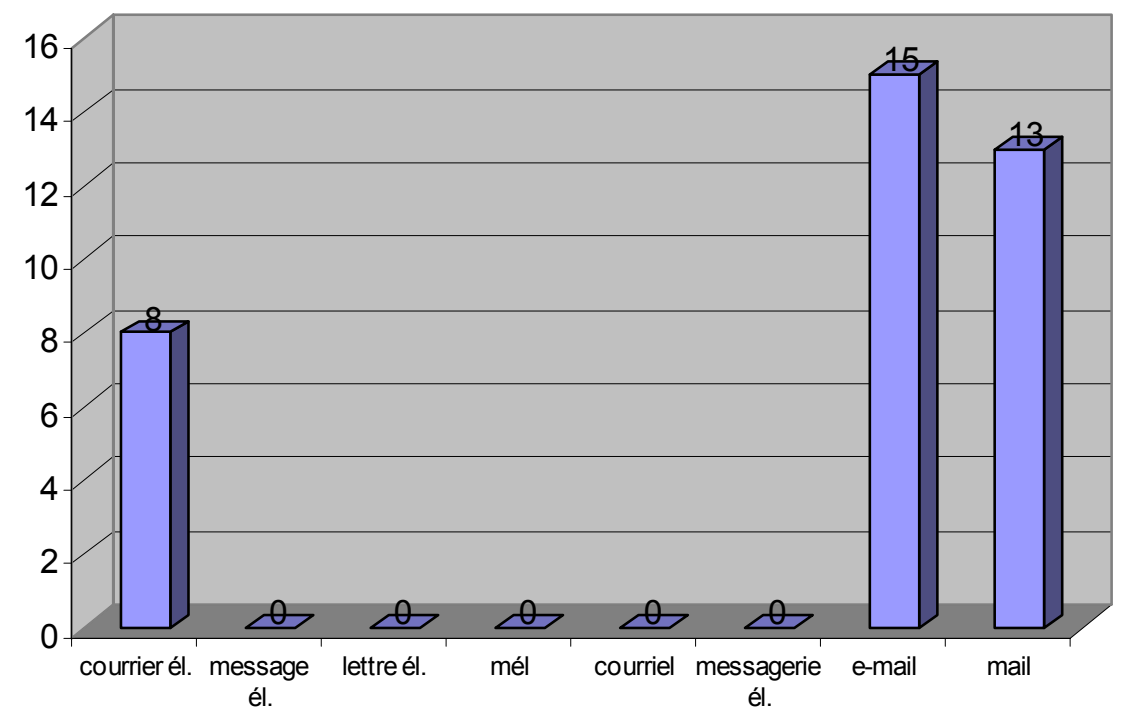


Abb. 155: Frage 4, persönliche Präferenz(en): courrier électronique etc. (prozentuale Häufigkeit, Schweiz)

\begin{tabular}{|l|r|}
\hline Termini & $\mathbf{\%}$ \\
\hline E-mail & 78,9 \\
\hline Mail & 68,4 \\
\hline Courrier électronique & 42,1 \\
\hline Courriel & 0,0 \\
\hline Mél & 0,0 \\
\hline Message électronique & 0,0 \\
\hline Messagerie électronique & 0,0 \\
\hline Lettre électronique & 0,0 \\
\hline
\end{tabular}

Während bei der Frage nach der Bekanntheit noch drei Termini bei 100\% liegen (e-mail, mail und courrier électronique) und alle anderen Termini Werte erhalten, die zwischen 5,3\% und 76,5\% liegen, ergibt sich bei dieser Frage ein ganz anderes Bild. Die einzigen Termini, die als Präferenzen angegeben werden, sind die drei Termini, die in der ersten Frage von 100\% der Informanten als bekannt angegeben wurden. Alle anderen Termini erhalten bei dieser Frage keine Stimmen. Bei den drei Termini mail, mail und courrier électronique ist eine deutliche Tendenz zur Bevorzugung der beiden englischsprachigen Termini zu erkennen. E-mail wird von 15, mail von 13 Informanten als Präferenz angegeben (78,9\% und 68,4\%). Courrier électronique folgt mit einigem Abstand und erhält nur acht Stimmen (42,1\%).

Bei der folgenden Frage nach dem eigenen Sprachgebrauch verschwindet der französische Terminus gänzlich: 


\section{Abb. 156: Frage 5, eigener Sprachgebrauch (courrier électronique etc.) (Schweiz)}

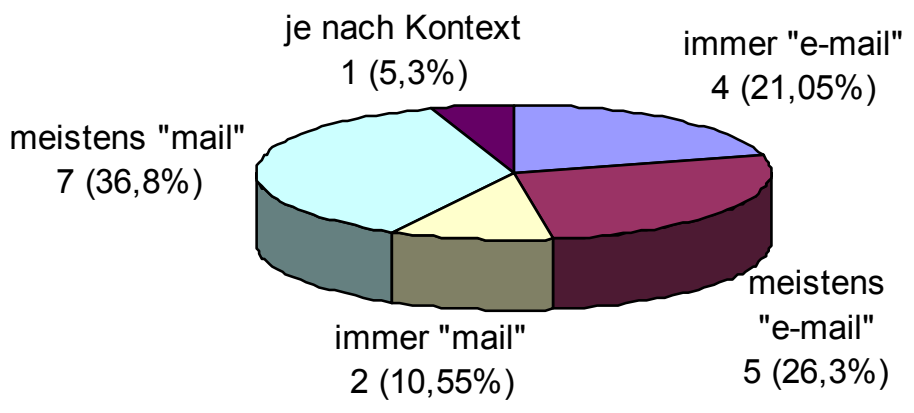

Keiner der schweizerischen Informanten und damit auch keiner der acht Informanten, die in Frage 4 courrier électronique als eine ihrer Präferenzen genannt haben, gibt an einen der französischen Termini mehrheitlich oder immer zu verwenden. Demgegenüber erklären acht Informanten (47,35\%) meistens oder immer e-mail $\mathrm{zu}$ verwenden. Ebenso viele Informanten stimmen für den Gebrauch von mail. Ein Informant (5,3\%) entscheidet je nach Kontext.

Im Unterschied zum Bekanntheitsgrad lässt sich die Gebrauchsfrequenz in Anlehnung an die Studie Thoirons in drei Kategorien unterteilen (vgl. 4.3.1; 9.1.1). In Bezug auf die Termini mail und e-mail ist dieses Schema kaum anzuwenden, da diese beiden Termini von den Informanten als ein Wort mit seiner Kurzform betrachtet werden ${ }^{2}$. Aus den Zahlenwerten lässt sich für beide Termini ein mittlerer Etablierungsgrad entnehmen, da sich die Informanten für einen der beiden Termini entscheiden mussten. Hätte bei der Auswahl nur einer dieser beiden Termini zur Verfügung gestanden, hätte dieser vermutlich eine über $90 \%$ ige Gebrauchsfrequenz erhalten. Insofern kann festgestellt werden, dass beide Termini eine hohe Gebrauchsfrequenz aufweisen.

Da mit Ausnahme des einen Informanten, der je nach Kontext entscheidet, alle Befragten angeben meistens oder immer e-mail bzw. mail zu verwenden, entfällt die Auswertung der Frage 6 mit der Bewertung des jeweiligen französischen Terminus. In Frage 7 wurde nach den Gründen für den Gebrauch von e-mail bzw. mail gefragt. Als Gründe für die Bevorzugung der Anglizismen werden genannt:

\footnotetext{
2 Auf den zwischen mail und e-mail bestehenden Unterschied machen nur wenige der befragten französischen Informatiker (vgl. 9.1.1) und keiner der befragten Schweizer aufmerksam. Üblicherweise werden die beiden Termini im Sprachgebrauch aus sprachökonomischen Gründen synonym verwendet.
} 
Abb. 157: Frage 7, Gründe für die Bevorzugung der englischsprachigen Termini email und mail (Schweiz)

\begin{tabular}{|c|c|c|c|}
\hline Nr. & Begründung & $\begin{array}{l}\text { Absolute } \\
\text { Häufigkeit }\end{array}$ & $\begin{array}{l}\text { Prozentuale } \\
\text { Häufigkeit }\end{array}$ \\
\hline 1 & $\begin{array}{l}\text { Je me suis déjà habitué(e) à utiliser le } \\
\text { terme anglais. }\end{array}$ & 12 & 66,7 \\
\hline 2 & $\begin{array}{l}\text { Presque tout le monde utilise le terme } \\
\text { anglais. }\end{array}$ & 9 & 50,0 \\
\hline 3 & $\begin{array}{ll}\text { - } & \text { Le terme anglais est plus bref. } \\
\text { - } & \text { Le terme anglais est plus international. }\end{array}$ & $\begin{array}{l}7 \\
7\end{array}$ & $\begin{array}{l}38,9 \\
38,9\end{array}$ \\
\hline 4 & $\begin{array}{l}\text { - Les termes français ne sont pas assez } \\
\text { connus. } \\
\text { - En utilisant le terme anglais, je suis } \\
\text { sûr(e) d'être compris(e). }\end{array}$ & 6 & $\begin{array}{l}33,3 \\
33,3\end{array}$ \\
\hline 5 & $\begin{array}{l}\text { - Les formulations des termes français } \\
\text { sont trop compliquées. } \\
\text { - Il y a trop d'équivalents français pour } \\
\text { un seul terme anglais. }\end{array}$ & 4 & $\begin{array}{l}22,2 \\
22,2\end{array}$ \\
\hline 6 & $\begin{array}{l}\text { Les connotations des termes français ne } \\
\text { correspondent pas aux connotations qui } \\
\text { sont liées au terme anglais. }\end{array}$ & 3 & 16,7 \\
\hline 7 & $\begin{array}{l}\text { - La signification des termes français } \\
\text { n’est pas claire. } \\
\text { - La signification des termes français ne } \\
\text { correspond pas à celle du terme } \\
\text { anglais. } \\
\text { - Pour paraître compétent, il faut se } \\
\text { servir de la terminologie anglaise. } \\
\text { - Je n'aime pas suivre les propositions } \\
\text { officielles. } \\
\text { - Je ne sais pas. }\end{array}$ & 1 & $\begin{array}{l}5,6 \\
5,6 \\
5,6 \\
5,6 \\
5,6\end{array}$ \\
\hline 8 & $\begin{array}{l}\text { Autre : } \\
\text { - Les pseudo-traductions en français } \\
\text { donnent des mots vilains. } \\
\text { - } \quad \text { Les termes français ont mis trop de } \\
\text { temps à apparaître. Il ne s'agit donc } \\
\text { pas d'une < erreur de français > à } \\
\text { proprement parler mais d'une habi- } \\
\text { tude bien implantée dans les esprits } \\
\text { des utilisateurs d'Internet. }\end{array}$ & 2 & 11,1 \\
\hline
\end{tabular}


Zwölf der 18 Informanten, die diese Frage beantwortet haben, argumentieren, dass sie sich bereits an den englischsprachigen Terminus gewöhnt hätten. Dieses Argument wird in dem zweiten unter „Autre“ formulierten Kommentar vertieft. Am zweithäufigsten wird als Begründung für den Gebrauch eines der Anglizismen darauf hingewiesen, dass der englischsprachige Terminus am weitesten verbreitet sei. An dritter Stelle wird mit seiner Kürze und Internationalität argumentiert, zwei Gründe, die immerhin noch von mehr als einem Drittel der Informanten angegeben werden. Interessant sind die beiden unter „Autre“ formulierten Kommentare: Während im ersten Kommentar die französischen Äquivalente als Pseudoübersetzungen und als hässlich charakterisiert werden, wird im zweiten Kommentar den Termini selbst jegliches Verschulden an ihrer mangelnden Akzeptanz abgesprochen: Nicht die Termini seien fehlerhaft, sondern ihr Erscheinen habe so lange gedauert, dass sich die Sprachbenutzer in der Zwischenzeit an die englischen Termini gewöhnt hätten. Bei dieser Frage wird besonders deutlich, dass es zwar eine hohe Übereinstimmung bezüglich der Motive für den Gebrauch der Anglizismen gibt, nämlich die Gewöhnung, ihre Internationalität und Kürze, dass aber die Einstellungen zu den Ersatzwörtern selbst stark divergieren zwischen einer positiven Grundhaltung und einer generellen Ablehnung. Dies wird auch bei der Auswertung der Kommentare in 11.3 deutlich werden.

Der in 5.3.1 aufgestellten Arbeitshypothese, dass die Termini e-mail und mail häufiger verwendet werden als franz. message électronique, messagerie électronique, courrier électronique und mél, kann aufgrund der Datenlage zugestimmt werden. Zwar sind den Befragten viele der französischen Termini bekannt, doch bezüglich des eigenen Sprachgebrauchs werden nur die Anglizismen e-mail und mail genannt.

\subsubsection{Die Termini page d'accueil, page d'introduction und home- page}

Die Fragen 8 bis 14 widmen sich dem französischen Neologismus page d'accueil, dem Anglizismus homepage sowie dem Testwort page d'introduction. 
Abb. 158: Frage 8, Bekanntheitsgrad der Termini page d'accueil, page d'introduction und homepage (absolute Häufigkeit, Schweiz)

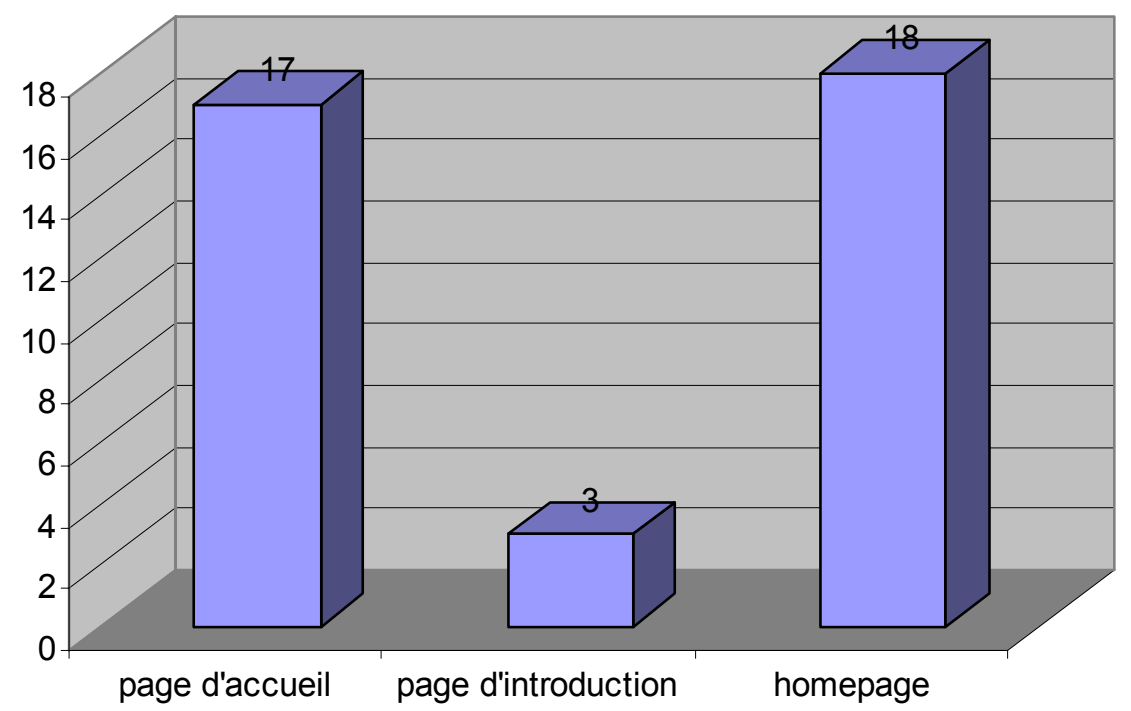

Abb. 159: Frage 8, Bekanntheitsgrad der Termini page d'accueil, page d'introduction und homepage (prozentuale Häufigkeit, Schweiz)

\begin{tabular}{|l|r|}
\hline Termini & \% \\
\hline Homepage & 94,7 \\
\hline Page d'accueil & 89,5 \\
\hline Page d'introduction & 15,8 \\
\hline
\end{tabular}

18 von 19 Informanten geben an engl. homepage zu kennen. Den französischen Terminus page d'accueil kennen 17 von 19 Informanten. Drei Informanten kennen nach eigenen Angaben auch das Testwort page d'introduction. Nach den von Gasquet/Villebrun $(1994,117)$ aufgestellten Kategorien fallen die beiden Termini bomepage und page d'accueil in die zweite Kategorie: Termini, die 80-100\% der Befragten bekannt sind. Somit gelten sie bezüglich des Bekanntheitsgrades als sicher etabliert.

Die Auswertung der Frage nach der Synonymie ergibt folgendes Bild:

Abb. 160: Frage 9, Synonymie der Termini page d'accueil und homepage (Schweiz)

\begin{tabular}{|l|r|r|} 
& $\begin{array}{l}\text { Absolute } \\
\text { Häufigkeit }\end{array}$ & $\begin{array}{l}\text { Prozentuale } \\
\text { Häufigkeit }\end{array}$ \\
\hline $\begin{array}{l}\text { Synonym } \\
\text { Bedeutungs- } \\
\text { unterschied }\end{array}$ & 14 & 73,7 \\
\hline \begin{tabular}{l} 
Insgesamt \\
\hline
\end{tabular} & 5 & 26,3 \\
\hline
\end{tabular}


14 Informanten $(73,7 \%)$ halten die Termini für synonym, fünf Informanten $(26,3 \%)$ stellen einen Bedeutungsunterschied fest.

Abb. 161: Frage 10, Bedeutungsunterschiede zwischen page d'accueil und homepage (Schweiz)

\begin{tabular}{l|l|r|}
\hline Kategorie & Informanten & Anzahl \\
\hline $\begin{array}{l}\text { Als page d'accueil wird die erste Seite als Hauptseite } \\
\text { eines Internetangebots bezeichnet, auf der sich auch }\end{array}$ & S2.1, S2.3, & 4 \\
$\begin{array}{l}\text { der Index befindet. Homepage wird als Bezeichnung } \\
\text { für private Internetseiten verwendet. }\end{array}$ & \\
\hline $\begin{array}{l}\text { Homepage bezeichnet das gesamte Internetangebot, } \\
\text { während page d'accueil nur die erste Seite eines }\end{array}$ & S2.1, S2.2 \\
$\begin{array}{l}\text { Internetauftritts bezeichnet. } \\
\text { S }\end{array}$ & \\
\hline
\end{tabular}

Von den fünf Informanten, die die Termini nicht als synonym erachten, weist ein Informant (S2.1) auf zwei Bedeutungsunterschiede hin. Insgesamt besteht - trotz der beiden unterschiedlichen Begründungen - unter den Informanten, die sich zu dieser Frage geäußert haben, Einigkeit darin, dass page d'accueil nur die erste Seite eines Internetangebots bezeichne. Bezüglich der Bedeutung von homepage werden zwei unterschiedliche Definitionen gegeben.

Die Frage nach der Präferenz der Termini ergibt keine schwerwiegenden Veränderungen im Vergleich zur Frage nach dem Bekanntheitsgrad:

Abb. 162: Frage 11, persönliche Präferenz(en): page d'accueil, page d'introduction, homepage (absolute Häufigkeit, Schweiz)

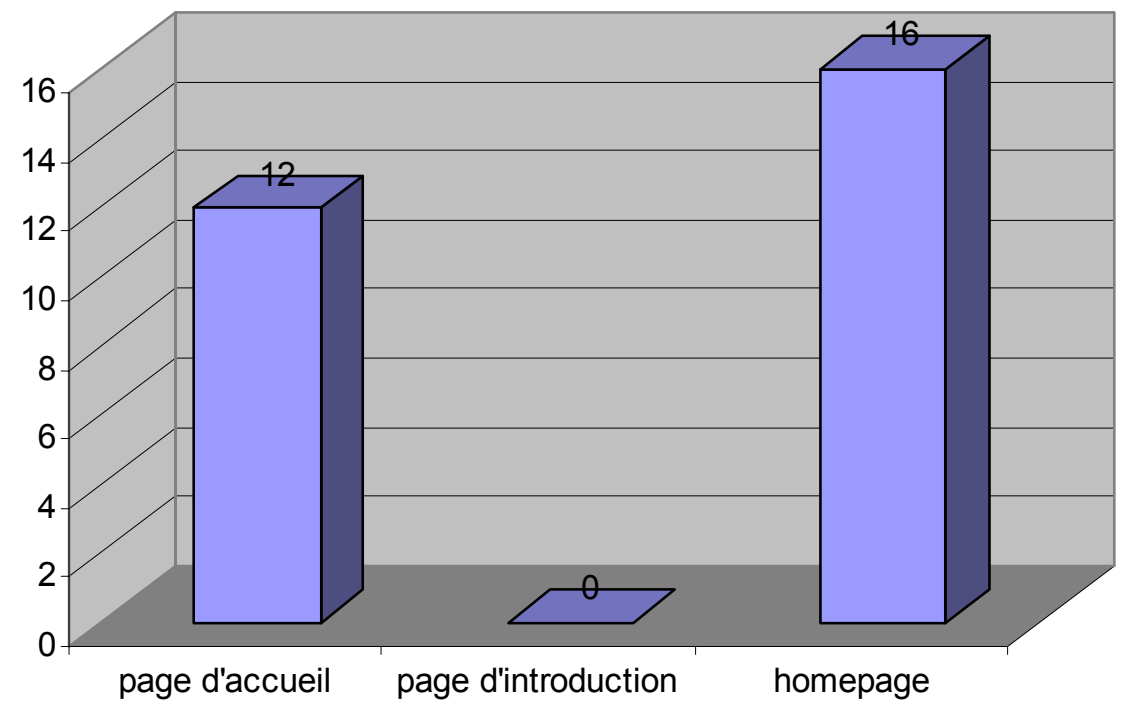


Abb. 163: Frage 11, persönliche Präferenz(en): page d'accueil, page d'introduction, homepage (prozentuale Häufigkeit, Schweiz)

\begin{tabular}{|l|r|}
\hline Termini & $\mathbf{\%}$ \\
\hline Homepage & 84,2 \\
\hline Page d'accueil & 63,2 \\
\hline Page d'introduction & 0,0 \\
\hline
\end{tabular}

Auffällig ist bei diesem Ergebnis nur, dass sich der Abstand zwischen homepage und page d'accueil etwas vergrößert. Einige der Informanten haben beide Termini als ihre Präferenz angegeben, was auch damit zusammenhängen kann, dass die beiden Termini von einigen Informanten nicht als synonym erachtet werden und deswegen von ihnen vermutlich auch - je nach Aussageabsicht - beide verwendet werden. Insgesamt ist der englischsprachige Terminus etwas beliebter als der französische.

Abb. 164: Frage 12, eigener Sprachgebrauch: page d'accueil, page d'introduction, homepage (Schweiz)

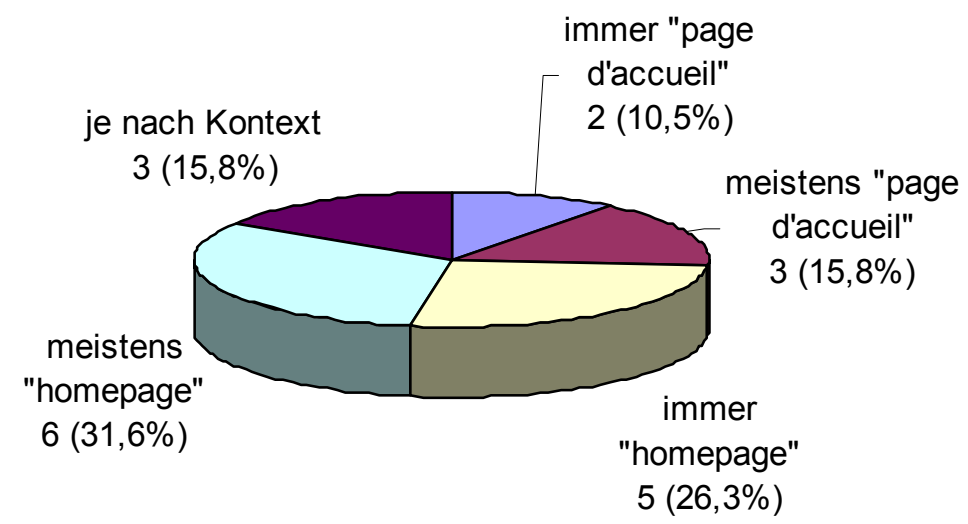

Bei der Frage nach dem eigenen Sprachgebrauch vergrößert sich der Abstand zwischen dem englischen und dem französischen Terminus wiederum um einige Prozentpunkte. Fünf Informanten (26,3\%) geben an meistens oder immer page d'accueil zu verwenden. Elf Informanten (57,9\%) geben an meistens oder immer homepage zu verwenden. Während die beiden Termini bezüglich des Bekanntheitsgrades nur um 5,2\% voneinander differierten und bezüglich der persönlichen Präferenzen um 21\%, beträgt die Differenz zwischen page d'accueil und homepage bei der Frage nach der aktiven Akzeptanz 31,6 Prozentpunkte. Einschränkend zu diesem Ergebnis muss hinzugefügt werden, dass einige der Informanten mögli- 
cherweise deshalb für homepage plädieren, weil sie diesen Terminus als semantisch weiter auffassen als page d'accueil, die sich für viele Informanten nur auf die erste Internetseite eines entsprechenden Angebots bezieht.

Werden die Ergebnisse auf die drei Klassen zur Beurteilung der Gebrauchsfrequenz übertragen, kann homepage als mittelmäßig etabliert gelten (Klasse B: Gebrauchsfrequenz von 70-30\%) und page d'accueil als nur schwach etabliert (Klasse C: Gebrauchsfrequenz unter 30\%; vgl. Rouges-Martinez 1992, 125f.). Drei Informanten haben bei der Frage nach dem eigenen Sprachgebrauch angegeben je nach Kontext zu entscheiden, was sowohl auf die Situationsadäquatheit bzw. den Adressaten als auch auf die von einigen angemerkten semantischen Unterschiede zurückzuführen sein kann.

Da nur fünf Informanten nach eigenen Angaben meistens oder immer page d'accueil verwenden, ist es wenig sinnvoll, für diese geringe Fallzahl eine Tabelle bezüglich der Bewertung des Terminus page d'accueil zu erstellen. Je geringer die Anzahl an Informanten, desto höher ist auch die Wahrscheinlichkeit, dass z.B. ein Terminus durchgehend den Wert 1 erhält, ohne dass sich auch mal eine schlechtere Bewertung darunter befindet, die insgesamt den Durchschnittswert etwas herunterzieht ${ }^{3}$. Insofern ist die Auswertung dieser Frage bei einer so geringen Anzahl an Stimmen nicht aussagekräftig.

Eine klare Mehrheit hat sich hingegen für die Verwendung des englischen Terminus ergeben. Die folgende Tabelle zeigt die Gründe, die nach Ansicht der Befragten für die Verwendung des engl. homepage sprechen.

\footnotetext{
${ }^{3}$ Dieses Faktum spiegelt sich in den Bewertungen wider: Alle fünf Informanten haben page d'accueil bezüglich der Kriterien Verständlichkeit, Natürlichkeit und Einfachheit den besten Wert (1) gegeben. Werden die Werte aller neun Kriterien zusammengenommen und ein Durchschnittswert gebildet, ergibt sich ein Wert von 1,42. Es ist davon auszugehen, dass dieser Wert bei einer größeren Stichprobe deutlich nach unten korrigiert werden müsste.
} 
Abb. 165: Frage 14, Gründe für die Bevorzugung des englischsprachigen Terminus homepage (Schweiz)

\begin{tabular}{|c|c|c|c|}
\hline $\begin{array}{l}\mathbf{N} \\
\text { r. }\end{array}$ & Begründung & $\begin{array}{l}\text { Absolute } \\
\text { Häufigkeit }\end{array}$ & $\begin{array}{l}\text { Prozentuale } \\
\text { Häufigkeit }\end{array}$ \\
\hline 1 & $\begin{array}{l}\text { Je me suis déjà habitué(e) à utiliser le terme } \\
\text { anglais. }\end{array}$ & 8 & 72,7 \\
\hline 2 & Le terme anglais est plus international. & 6 & 54,5 \\
\hline 3 & $\begin{array}{l}\text { - Le terme anglais est plus bref. } \\
\text { - En utilisant le terme anglais, je suis } \\
\text { sûr(e) d'être compris(e). }\end{array}$ & $\begin{array}{l}4 \\
4\end{array}$ & $\begin{array}{l}36,4 \\
36,4\end{array}$ \\
\hline 4 & $\begin{array}{l}\text { - Il y a trop d'équivalents français pour } \\
\text { un seul terme anglais. } \\
\text { - Presque tout le monde utilise le terme } \\
\text { anglais. }\end{array}$ & 3 & $\begin{array}{l}27,3 \\
27,3\end{array}$ \\
\hline 5 & $\begin{array}{l}\text { - Les termes français ne sont pas assez } \\
\text { proches du terme anglais. } \\
\text { - Les termes français ne sont pas assez } \\
\text { connus. }\end{array}$ & 2 & $\begin{array}{l}18,2 \\
18,2\end{array}$ \\
\hline 6 & $\begin{array}{l}\text { - La signification des termes français } \\
\text { n'est pas claire. } \\
\text { - Les formulations des termes français } \\
\text { sont trop compliquées. } \\
\text { - Les connotations des termes français } \\
\text { ne correspondent pas aux connota- } \\
\text { tions qui sont liées au terme anglais. }\end{array}$ & 1 & 9,1 \\
\hline
\end{tabular}

Acht von elf Informanten (72,7\%) begründen die Wahl des Anglizismus mit der Gewöhnung an bomepage. Das Argument der Internationalität von homepage führen sechs Informanten (54,5\%) an. Die Kürze und die Sicherheit, bei Verwendung des englischsprachigen Terminus verstanden zu werden, rangieren an dritter Position und werden von jeweils $36,4 \%$ der Informanten angeführt. Die Gründe, die am häufigsten für die Verwendung von homepage genannt werden, stimmen weitgehend mit denen überein, die für e-mail/ mail angeführt wurden. Es fällt auf, dass vor allem die Gewöhnung an die englischsprachigen Termini ausschlaggebend ist, weniger das Argument, dass der oder die französischen Termini nicht bekannt genug seien.

Der in 5.3.1 aufgestellten Hypothese, dass page d'accueil einen höheren Akzeptanzwert erhalte als der entsprechende Anglizismus bomepage, kann nach Auswertung der Fragen 8-12 nicht zugestimmt werden. Bezogen auf die schweizerischen Informanten weisen zwar beide Termini einen hohen Bekanntheitsgrad auf (pas- 
sive Akzeptanz), bezogen auf den eigenen Sprachgebrauch (aktive Akzeptanz) liegt homepage jedoch weit vor dem französischen Neologismus.

\subsubsection{Die Termini toile d'araignée mondiale, toile mondiale, toile, T.A.M., réseau mondial, World Wide Web und web}

Die dritte Lexemgruppe, der im Fragebogen überprüft wird, besteht aus engl. World Wide Web bzw. web und seinen französischen Äquivalenten.

Abb. 166: Frage 15, Bekanntheitsgrad der Termini toile d'araignée mondiale, toile mondiale, toile, T.A.M., réseau mondial, World Wide Web und web (absolute Häufigkeit, Schweiz)

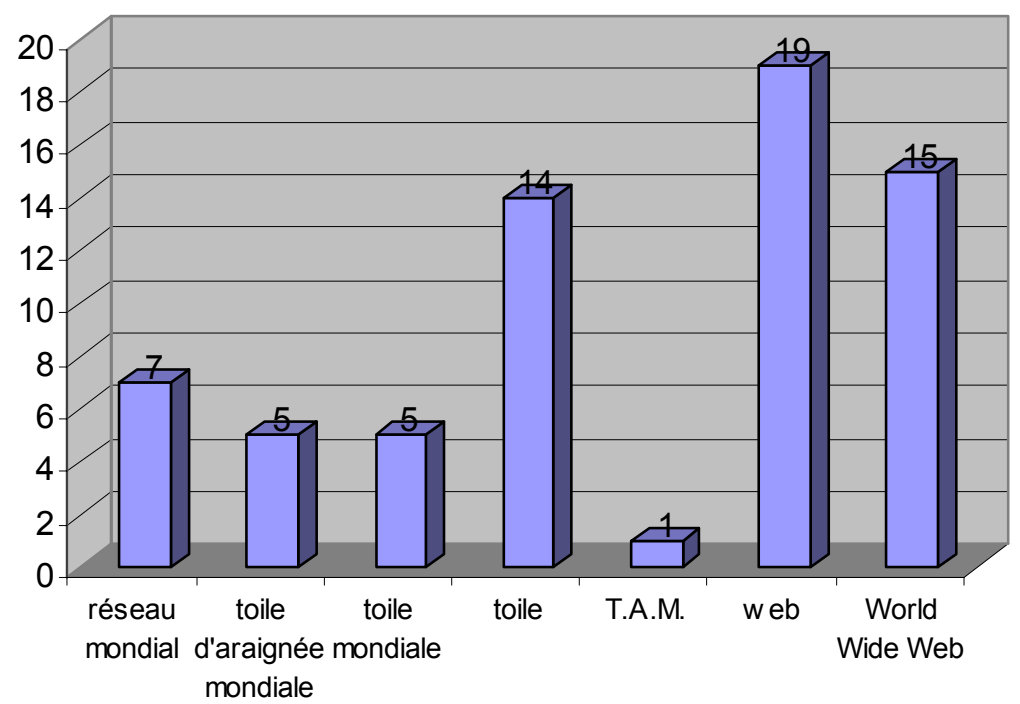

Abb. 167: Frage 15, Bekanntheitsgrad der Termini toile d'araignée mondiale, toile mondiale, toile, T.A.M., réseau mondial, World Wide Web und web (prozentuale Häufigkeit, Schweiz)

\begin{tabular}{|l|r|}
\hline Termini & $\mathbf{\%}$ \\
\hline Web & 100,0 \\
\hline World Wide Web & 78,9 \\
\hline Toile & 73,7 \\
\hline Réseau mondial & 36,8 \\
\hline Toile d'araignée mondiale & 26,3 \\
\hline Toile mondiale & 26,3 \\
\hline T.A.M. & 5,3 \\
\hline
\end{tabular}

Alle Befragten kennen engl. web. An zweiter Stelle folgt mit einem Bekanntheitsgrad von 78,9\% das engl. World Wide Web. Knapp hinter World Wide Web folgt der 
französische Terminus toile, der 73,7\% der Informanten bekannt ist. 36,8\% der Informanten geben réseau mondial als bekannt an. Die Neologismen toile d'araignée mondiale und toile mondiale sind jeweils 26,3\% der Informanten bekannt. Nur ein Informant kennt das Kurzwort T.A.M.

Bezogen auf die von Gasquet/Villebrun (1994, 117) aufgestellten Kategorien zum Bekanntheitsgrad bedeutet dies eine 100\%ige Etablierung des Anglizismus web, eine relativ sichere Etablierung von World Wide Web und toile und eine unsichere bis äußerst schwache Etablierung der übrigen französischen Termini.

Die Frage, ob die Termini synonym seien, wird wie folgt beantwortet:

Abb. 168: Frage 16, Synonymie der Termini toile d'araignée mondiale, toile mondiale, toile, T.A.M., World Wide Web und web (Schweiz)

\begin{tabular}{|l|r|r|}
\hline & $\begin{array}{l}\text { Absolute } \\
\text { Häufigkeit }\end{array}$ & $\begin{array}{l}\text { Prozentuale } \\
\text { Häufigkeit }\end{array}$ \\
\hline Synonym & 15 & 78,9 \\
\hline $\begin{array}{l}\text { Bedeutungs- } \\
\text { unterschied }\end{array}$ & 1 & 5,3 \\
\hline $\begin{array}{l}\text { Termini } \\
\text { unbekannt / } \\
\text { Weiß nicht. }\end{array}$ & 3 & 15,8 \\
\hline Insgesamt & 19 & 100,0 \\
\hline
\end{tabular}

Die Mehrheit der Informanten hält die Termini für synonym (78,9\%). Drei Informanten enthalten sich einer diesbezüglichen Aussage. Ein Informant stimmt für einen Bedeutungsunterschied, begründet diesen jedoch nicht.

Die Frage nach den persönlichen Präferenzen führt dazu, dass sich die Differenz zwischen web und den anderen Termini vergrößert. 
Abb. 169: Frage 18, persönliche Präferenz(en): toile d'araignée mondiale etc. (absolute Häufigkeit, Schweiz)

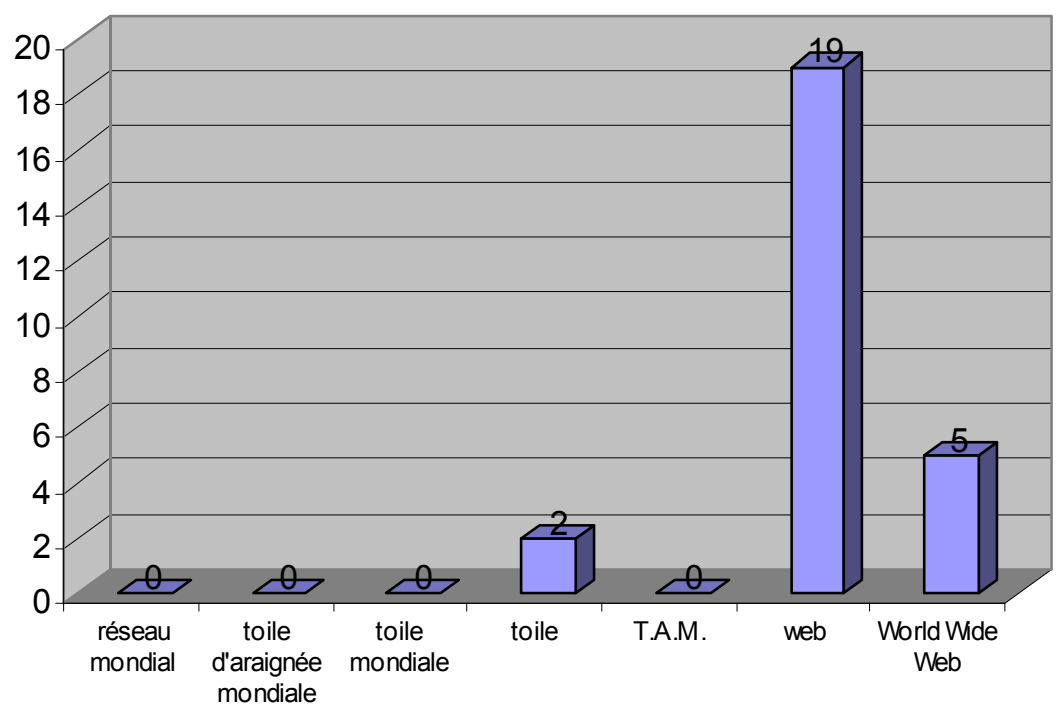

Abb. 170: Frage 18, persönliche Präferenz(en): toile d'araignée mondiale etc. (prozentuale Häufigkeit, Schweiz)

\begin{tabular}{|l|r|}
\hline Termini & $\mathbf{\%}$ \\
\hline Web & 100,0 \\
\hline World Wide Web & 26,3 \\
\hline Toile & 10,5 \\
\hline Réseau mondial & 0,0 \\
\hline Toile d'araignée mondiale & 0,0 \\
\hline Toile mondiale & 0,0 \\
\hline T.A.M. & 0,0 \\
\hline
\end{tabular}

Alle Befragten geben web als ihre persönliche Präferenz an. Einer der 19 Informanten nennt statt zwei Präferenzen drei, nämlich web, World Wide Web und toile. Fünf Informanten nennen neben web noch je eine zweite Präferenz, nämlich einmal toile und viermal $W$ orld Wide Web.

Unter den Antworten auf die Frage nach dem eigenen Sprachgebrauch tauchen die bei der Frage nach den Präferenzen genannten Termini toile und World Wide Web nicht mehr auf. 
Abb. 171: Frage 19, eigener Sprachgebrauch: toile d'araignée mondiale etc. (Schweiz)

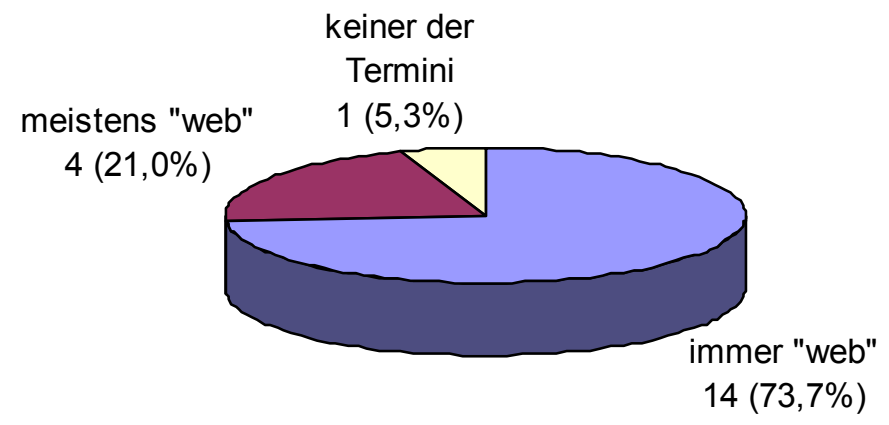

Mit Ausnahme eines Informanten, der keinen der angegebenen Termini verwendet, geben alle Informanten an immer oder meistens web zu verwenden (94,7\%). $14(73,3 \%)$ dieser 18 Informanten verwenden dabei immer, vier (21\%) meistens den Terminus web. Mit einer Gebrauchsfrequenz von über 90\% kann dem Terminus web somit auch bezüglich der aktiven Akzeptanz ein sehr hoher Etablierungsgrad bescheinigt werden.

Da keiner der Informanten angibt, einen der französischen Neologismen zu verwenden, entfällt die Auswertung der Frage 20.

Folgende Gründe werden für die Verwendung des englischsprachigen Terminus web genannt: 
Abb. 172: Frage 21, Gründe für die Bevorzugung des englischsprachigen Terminus web (Schweiz)

\section{Nr. Begründung}

\section{Absolute Prozentuale Häufigkeit Häufigkeit}

\begin{tabular}{|c|c|c|c|}
\hline 1 & $\begin{array}{l}\text { Je me suis déjà habitué(e) à utiliser le } \\
\text { terme anglais. }\end{array}$ & 14 & 77,8 \\
\hline 2 & $\begin{array}{l}\text { - } \quad \text { Le terme anglais est plus bref. } \\
\text { - Presque tout le monde utilise le terme } \\
\text { anglais. }\end{array}$ & $\begin{array}{l}7 \\
7\end{array}$ & $\begin{array}{l}38,9 \\
38,9\end{array}$ \\
\hline 3 & Le terme anglais est plus international. & 6 & 33,3 \\
\hline 4 & $\begin{array}{l}\text { En utilisant le terme anglais, je suis sûr(e) } \\
\text { d'être compris(e). }\end{array}$ & 4 & 22,2 \\
\hline 5 & $\begin{array}{l}\text { - Les formulations des termes français } \\
\text { sont trop compliquées. } \\
\text { - } \quad \text { Les termes français ne sont pas assez } \\
\text { proches du terme anglais. } \\
\text { - Les termes français ne sont pas assez } \\
\text { connus. }\end{array}$ & 3 & $\begin{array}{l}16,7 \\
16,7 \\
16,7\end{array}$ \\
\hline 6 & $\begin{array}{l}\text { - Les connotations des termes français } \\
\text { ne correspondent pas aux } \\
\text { connotations qui sont liées au terme } \\
\text { anglais. } \\
\text { - Il y a trop d'équivalents français pour } \\
\text { un seul terme anglais. }\end{array}$ & 2 & 11,1 \\
\hline 7 & $\begin{array}{l}\text { - Je ne connais pas les termes français. } \\
\text { - La signification des termes français } \\
\text { n'est pas claire. } \\
\text { - Il n'est pas possible de créer des } \\
\text { termes dérivés (du type: logiciel, } \\
\text { progiciel, ludiciel). }\end{array}$ & $\begin{array}{l}1 \\
1\end{array}$ & $\begin{array}{l}5,6 \\
5,6\end{array}$ \\
\hline 8 & $\begin{array}{l}\text { Autre : } \\
\text { Ils sont assez moches vos mots français. }\end{array}$ & 1 & 5,6 \\
\hline
\end{tabular}

Von den 18 Informanten, die diese Frage beantwortet haben, begründen 14 Informanten (77,8\%) ihre Entscheidung mit der Gewöhnung an den englischsprachigen Terminus. Es folgen an zweiter Stelle mit je sieben Stimmen (38,9\%) die Argumente der Kürze und der weiten Verbreitung von web. An dritter Stelle steht seine Internationalität. Ein Informant verweist darauf, dass er die französischen Termini ziemlich hässlich finde, woraus abzuleiten ist, dass er der Verwendung der französischen Termini nicht generell abgeneigt ist, jedoch die Termini seinen ästhetischen Ansprüchen genügen müssen. Es ist festzustellen, dass sich die für 
mail/ e-mail, homepage und web an den obersten Positionen stehenden Begründungen gleichen.

Der Hypothese, dass toile aufgrund seiner Kürze erheblich öfter gebraucht wird als die alternativ möglichen französischen Neologismen toile d'araignée mondiale und toile mondiale, kann aufgrund der Ergebnisse nicht zugestimmt werden. Hierbei ist selbstverständlich zu bedenken, dass bei einer umfassenderen Stichprobe auch die Wahrscheinlichkeit größer ist, dass einige Informanten sich für einen der französischen Termini entscheiden. Bezüglich der 19 befragten Schweizer ist dies jedoch nicht der Fall, weder toile noch toile d'araignée mondiale und toile mondiale werden von ihnen aktiv verwendet. Allerdings ist hinsichtlich des Bekanntheitsgrades ein Unterschied spürbar: Toile ist mit einem Bekanntheitsgrad von 73,7\% wesentlich bekannter als seine Äquivalente toile d'araignée mondiale und toile mondiale mit einem Bekanntheitsgrad von jeweils 26,3\%. Der populärste aller Termini ist web, in diesem Punkt kann die Hypothese bestätigt werden.

\subsubsection{Die Termini causette, bavardage, conversation électronique und chat}

Der vierte Fragenkomplex hat die Termini causette, bavardage, conversation électronique und chat zum Gegenstand. Im Unterschied zu vorangegangenen drei Lexemgruppen sind die französischen Neologismen kaum bekannt:

Abb. 173: Frage 22, Bekanntheitsgrad der Termini causette, bavardage, conversation électronique und chat (absolute Häufigkeit, Schweiz)

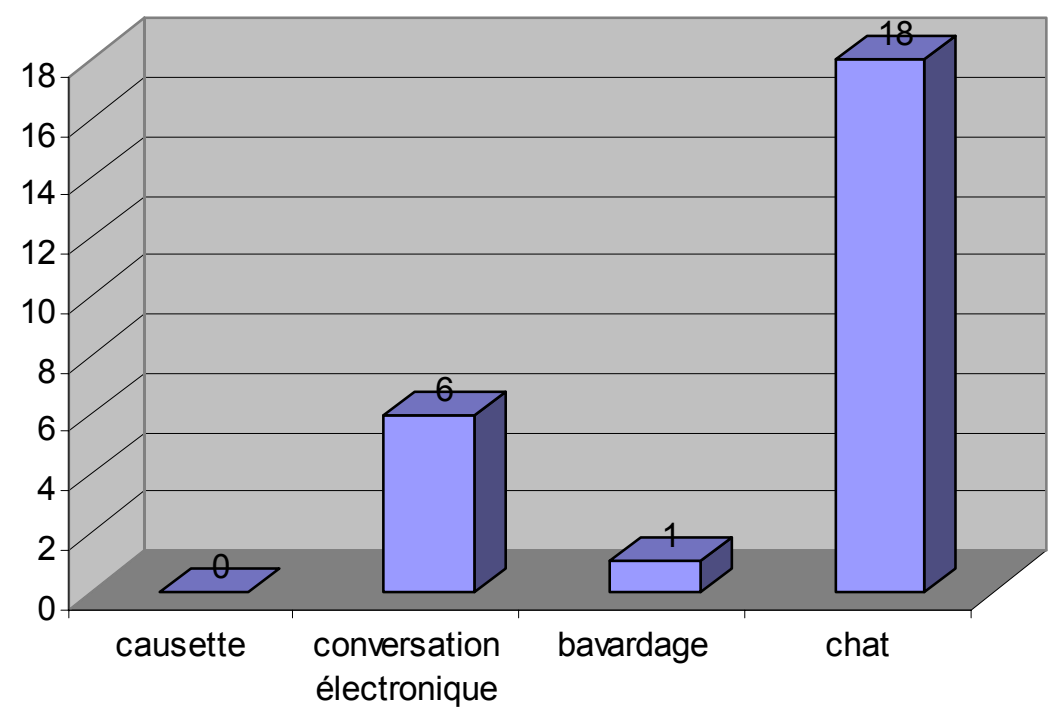


Abb. 174: Frage 22, Bekanntheitsgrad der Termini causette, bavardage, conversation électronique und chat (prozentuale Häufigkeit, Schweiz)

\begin{tabular}{|l|r|}
\hline Termini & $\mathbf{\%}$ \\
\hline Chat & 94,7 \\
\hline Conversation électronique & 31,6 \\
\hline Bavardage & 5,3 \\
\hline Causette & 0,0 \\
\hline
\end{tabular}

18 von 19 Informanten kennen den englischen Terminus chat. 31,6\% der Befragten geben an das Testwort conversation électronique zu kennen, das zwar existiert, jedoch weder in einem der Untersuchungsländer Bestandteil der offiziellen Terminologie noch auf französischsprachigen Internetseiten - andere Medien wurden nicht getestet - sehr verbreitet ist. Ein Informant (5,3\%) kennt bavardage, niemand gibt an, causette zu kennen.

Im Hinblick auf den Etablierungsgrad bedeutet dieses Ergebnis, dass nur der englische Terminus sicher etabliert ist. Die Termini conversation électronique und bavardage sind schwach bzw. sehr schwach etabliert. Causette konnte sich bei den befragten Informatikern nicht durchsetzen.

Abb. 175: Frage 23, Synonymie der Termini causette, bavardage und chat (Schweiz)

\begin{tabular}{|l|r|r|} 
& $\begin{array}{l}\text { Absolute } \\
\text { Häufigkeit }\end{array}$ & $\begin{array}{l}\text { Prozentuale } \\
\text { Häufigkeit }\end{array}$ \\
\hline Synonym & 13 & 68,4 \\
\hline $\begin{array}{l}\text { Bedeutungs- } \\
\text { unterschied }\end{array}$ & 2 & 10,5 \\
\hline $\begin{array}{l}\text { Termini un- } \\
\text { bekannt / } \\
\text { Weiß nicht. }\end{array}$ & 4 & 21,1 \\
\hline Insgesamt & 19 & 100,0 \\
\hline
\end{tabular}

13 Informanten $(68,4 \%)$ halten die Termini für synonym, vier enthalten sich einer Angabe, und zwei Informanten (10,5\%) stellen einen Bedeutungsunterschied fest. 


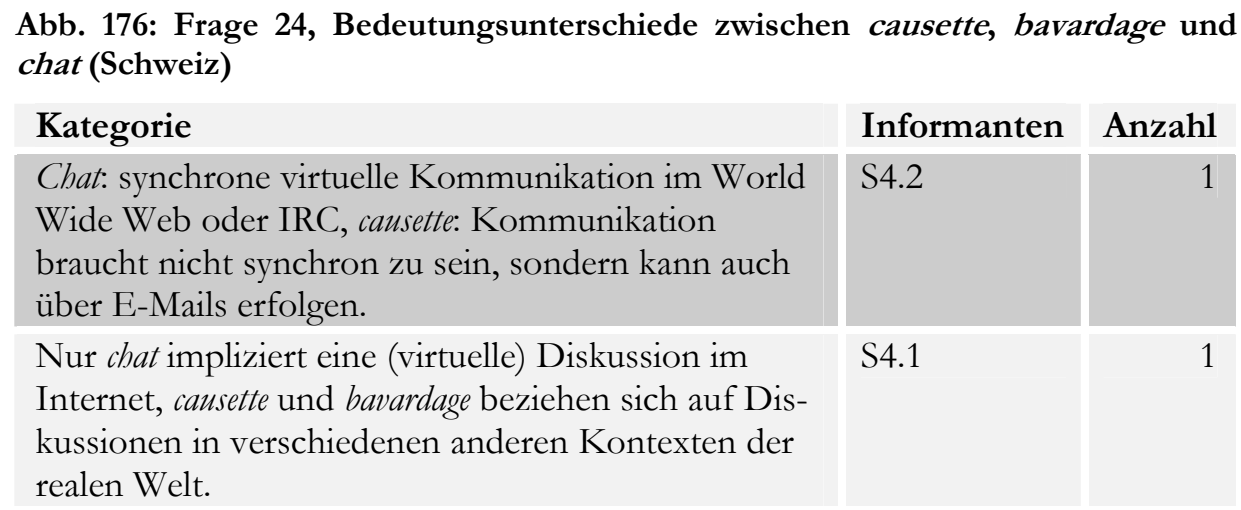

Ein Informant macht darauf aufmerksam, dass chat die synchrone Kommunikation im World Wide Web oder im IRC bezeichne, während der Terminus causette nicht unbedingt impliziere, dass die Kommunikation synchron sei, sondern sie wie in E-Mails oder in Diskussionsforen auch zeitversetzt stattfinden könne. Der andere der beiden Informanten, die einen Bedeutungsunterschied zwischen den Termini feststellen, weist darauf hin, dass nur chat im Unterschied zu causette und bavardage die virtuelle Kommunikation (im World Wide Web oder IRC) bezeichne, während die beiden französischen Termini die alltagssprachliche Kommunikation in der realen Welt bezeichneten. Hier wird die Bedeutung des ursprünglichen Terminus außer Acht gelassen; denn chat bezieht sich im anglophonen Sprachraum sowohl auf die virtuelle als auch auf die reale Kommunikation. Somit liegt die Vermutung nahe, dass bei der Entlehnung des Anglizismus insofern eine Bedeutungsreduzierung stattgefunden hat, als chat im nicht-englischsprachigen Raum ausschließlich mit der Internet-Kommunikation in Verbindung gebracht wird. Zwar macht nur einer von 19 Informanten auf diesen Punkt aufmerksam, aber es ist davon auszugehen, dass die meisten Leute bei gezieltem Nachfragen angeben würden, dass chat nur für die Kommunikation im Internet verwendet werde. Interessant ist ferner, dass ein Informant auch die Bezeichnung causette dem Kontext Internet zuordnet, was von den bisherigen Aussagen der Befragten abweicht. Wie auch in einigen der vorangehenden Fälle, vergrößert sich bei der Frage nach den persönlichen Präferenzen die Distanz zwischen dem englischen und dem französischen Terminus: 
Abb. 177: Frage 25, persönliche Präferenz(en): causette, bavardage, conversation électronique, chat (absolute Häufigkeit, Schweiz)

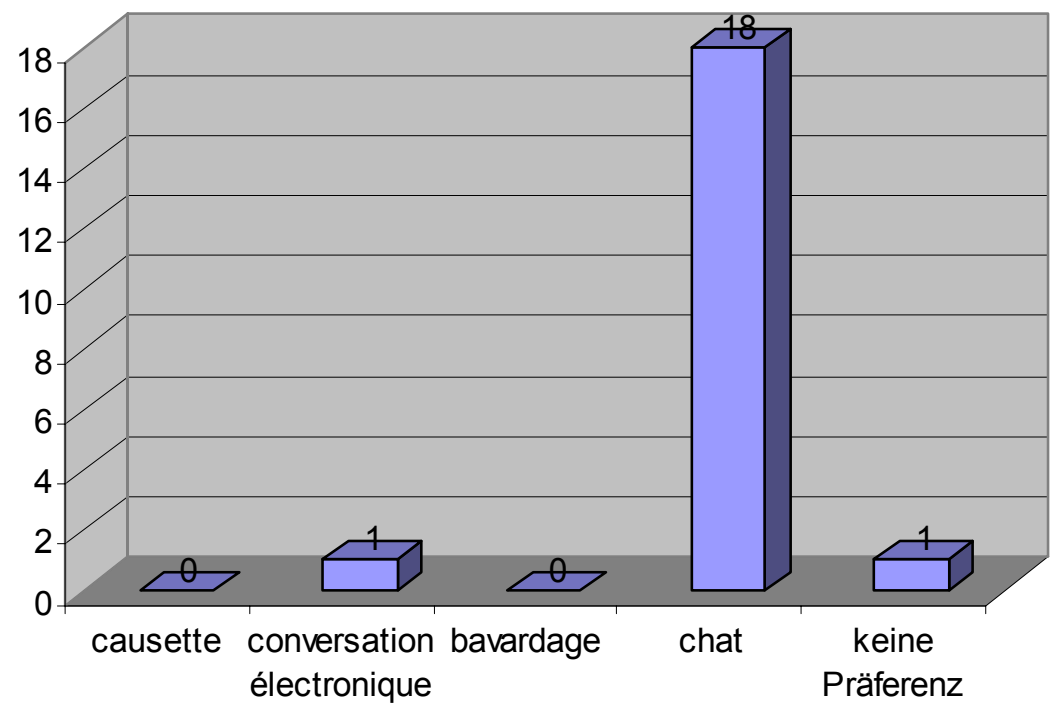

Abb. 178: Frage 25, persönliche Präferenz(en): causette, bavardage, conversation électronique, chat (prozentuale Häufigkeit, Schweiz)

\begin{tabular}{|l|r|}
\hline Termini & $\mathbf{\%}$ \\
\hline Chat & 94,7 \\
\hline Conversation électronique & 5,3 \\
\hline Bavardage & 0,0 \\
\hline Causette & 0,0 \\
\hline Keine Präferenz & 5,3 \\
\hline
\end{tabular}

18 von 19 Informanten geben chat als persönliche Präferenz an, wobei einer dieser 18 Informanten zugleich angegeben hat eigentlich keine Präferenz zu haben. Während die beiden französischen Termini in Frage 22 (Bekanntheitsgrad) sechs bzw. eine Stimme erhalten haben, stimmt bei der Frage 25 nach der persönlichen Präferenz nur noch ein Informant für einen der französischen Termini, nämlich für conversation électronique. Dieser Informant ist auch der einzige, der in der nächsten Frage angibt einen der französischen Termini zu verwenden: 
Abb. 179: Frage 26, eigener Sprachgebrauch: causette, bavardage, conversation électronique, chat (Schweiz)

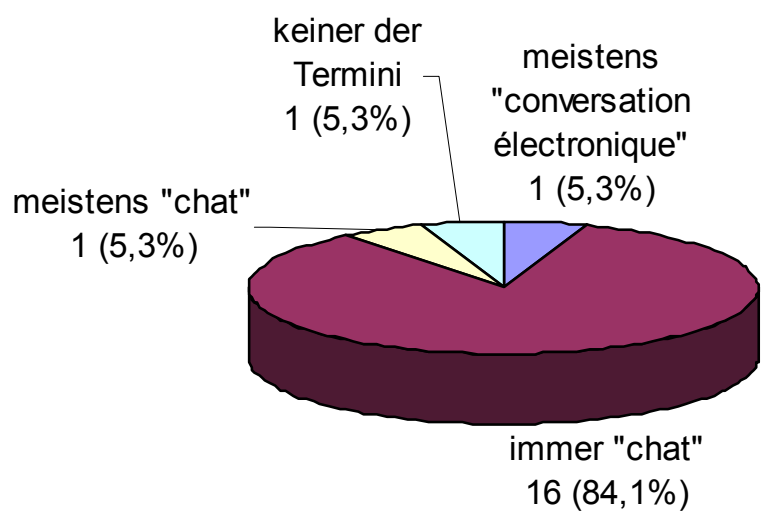

Mit Ausnahme dieses einen Informanten, der angibt meistens conversation électronique zu verwenden, und eines weiteren, der nach eigenen Angaben gar keinen der Termini benutzt, plädieren alle Informanten für die Verwendung von chat. 16 von 19 Informanten geben an diesen Terminus immer zu verwenden, ein Informant verwendet ihn meistens. Mit einer Gebrauchsfrequenz von insgesamt 89,4\% kann dem englischen Terminus chat eine sehr gute Etablierung bescheinigt werden, während sich die französischen Termini nicht haben etablieren können.

Da 17 von 19 Informanten für die Verwendung von chat plädieren, entfällt auch hier die Tabelle zur Bewertung der französischsprachigen Neologismen.

Frage 28 ermittelt wiederum die Gründe, die für chat und gegen die französischen Termini sprechen. 
Abb. 180: Frage 28, Gründe für die Bevorzugung des englischsprachigen Terminus chat (Schweiz)

\begin{tabular}{|c|c|c|c|}
\hline Nr. & Begründung & $\begin{array}{l}\text { Absolute } \\
\text { Häufigkeit }\end{array}$ & $\begin{array}{l}\text { Prozentuale } \\
\text { Häufigkeit }\end{array}$ \\
\hline 1 & $\begin{array}{l}\text { Je me suis déjà habitué(e) à utiliser le } \\
\text { terme anglais. }\end{array}$ & 11 & 64,7 \\
\hline 2 & $\begin{array}{l}\text { - En utilisant le terme anglais, je suis } \\
\text { sûr(e) d'être compris(e). } \\
\text { - } \quad \text { La signification des termes français } \\
\text { n'est pas claire. } \\
\text { - } \quad \text { Le terme anglais est plus bref. } \\
\text { - } \quad \text { Presque tout le monde utilise le terme } \\
\text { anglais. }\end{array}$ & $\begin{array}{l}5 \\
5\end{array}$ & $\begin{array}{r}29,4 \\
29,4 \\
29,4 \\
29,4\end{array}$ \\
\hline 3 & $\begin{array}{l}\text { - Le terme anglais est plus international. } \\
\text { - Les termes français ne sont pas assez } \\
\text { connus. }\end{array}$ & $\begin{array}{l}4 \\
4\end{array}$ & $\begin{array}{l}23,5 \\
23,5\end{array}$ \\
\hline 4 & $\begin{array}{l}\text { - Je ne connais pas les termes français. } \\
\text { - } \quad \text { Il y a trop d'équivalents français pour } \\
\text { un seul terme anglais. }\end{array}$ & $\begin{array}{l}3 \\
3\end{array}$ & $\begin{array}{l}17,6 \\
17,6\end{array}$ \\
\hline 5 & $\begin{array}{l}\text { - Il n’est pas possible de créer des } \\
\text { termes dérivés (du type: logiciel, } \\
\text { progiciel, ludiciel). } \\
\text { - Pour paraître compétent, il faut se } \\
\text { servir de la terminologie anglaise. }\end{array}$ & 1 & 5,9 \\
\hline 6 & $\begin{array}{l}\text { Autre: } \\
\text { Encore une fois, causette, ça ne sonne pas } \\
\text { très bien. }\end{array}$ & 1 & 5,9 \\
\hline
\end{tabular}

Als Hauptgrund wird die Gewöhnung an den englischsprachigen Terminus genannt (64,7\%). Erst mit weitem Abstand hinter diesem Motiv folgen mit jeweils fünf von 17 möglichen Stimmen (29,4\%) die Gründe a) Sicherheit, bei Verwendung des englischsprachigen Terminus verstanden zu werden, b) unklare Bedeutung der französischen Termini, c) Kürze von chat und d) weite Verbreitung von chat. Der Informant, der darauf verweist, dass franz. causette nicht sonderlich gut klinge, ist übrigens nicht identisch mit demjenigen, der bei den Gründen für die Bevorzugung von web angegeben hat, dass die französischen Wörter ziemlich hässlich seien. Somit ist in Bezug auf mehrere Informanten festzustellen, dass für sie auch die ästhetischen Qualitäten eines Wortes von Bedeutung sind und einen Einfluss darauf haben, ob sie es verwenden oder nicht. Ferner verdeutlich der am dritthäufigsten genannten Grund, dass in diesem Fall die französischen Termini 
auch vermieden werden, weil ihre Bedeutung vielen Informanten nicht ganz klar ist.

Die in 5.3.1 formulierte Hypothese „Chat wird aufgrund seiner Kürze und aufgrund der doppeldeutigen französischen Äquivalente häufiger verwendet als die französischen Neologismen causette und bavardage kann nicht in Gänze bestätigt werden. Unumstritten ist, dass chat weitaus häufiger als die französischen Äquivalente verwendet wird. Die Kürze des Terminus ist allerdings nicht so ausschlaggebend wie die Gewöhnung an diesen. Ob die Ablehnung der französischen Äquivalente auf ihre Doppeldeutigkeit zurückzuführen ist, nämlich dass sie sich sowohl auf den realen als auch auf den virtuellen Kontext beziehen (sollen), ist jedoch fraglich. Allerdings verweist fast ein Drittel der Befragten auf die unklare Bedeutung der Termini; es scheint also vielmehr eine Unsicherheit in Bezug auf die Bedeutungen vorzuliegen als ein Bewusstsein für die Doppeldeutigkeit der Termini, wofür auch die in Frage 24 aufgeführten Bedeutungsunterschiede sprechen.

\subsubsection{Die Termini pirate, fouineur und cracker}

Die Lexeme pirate und cracker sind fast gleichermaßen bekannt:

Abb. 181: Frage 29, Bekanntheitsgrad der Termini pirate, fouineur und cracker (Schweiz)

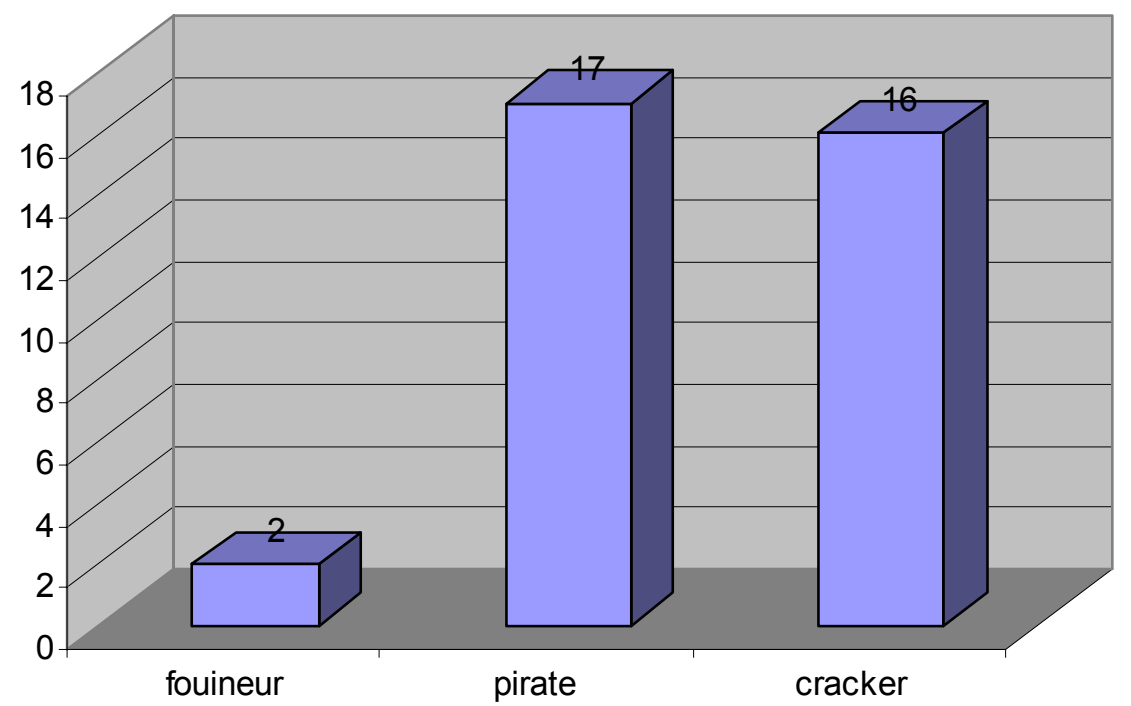

Abb. 182: Frage 29, Bekanntheitsgrad der Termini pirate, fouineur und cracker (prozentuale Häufigkeit, Schweiz)

\begin{tabular}{|l|r|}
\hline Termini & $\mathbf{\%}$ \\
\hline Pirate & 89,5 \\
\hline Cracker & 84,2 \\
\hline Fouineur & 10,5 \\
\hline
\end{tabular}


Der französische Terminus pirate ist mit einem Bekanntheitsgrad von 89,5\% etwas bekannter als sein englisches Pendant cracker (84,2\%). Das Testwort fouineur, das eine etwas andere Bedeutung hat, kennen zwei Informanten (10,5\%). Nach der Einteilung von Gasquet/Villebrun $(1994,117)$ haben sich somit sowohl pirate als auch cracker bezüglich ihrer passiven Akzeptanz sicher etablieren können.

Die Frage nach der Synonymie der Termini pirate und cracker wird wie folgt beantwortet:

Abb. 183: Frage 30, Synonymie der Termini pirate und cracker (Schweiz)

\begin{tabular}{|l|r|r|} 
& $\begin{array}{l}\text { Absolute } \\
\text { Häufigkeit }\end{array}$ & $\begin{array}{l}\text { Prozentuale } \\
\text { Häufigkeit }\end{array}$ \\
\hline Synonym & 16 & 84,2 \\
\hline $\begin{array}{l}\text { Bedeutungs- } \\
\text { unterschied }\end{array}$ & 1 & 5,3 \\
\hline $\begin{array}{l}\text { Termini } \\
\text { unbekannt / } \\
\text { Weiß nicht. }\end{array}$ & 2 & 10,5 \\
\hline Insgesamt & 19 & 100,0 \\
\hline
\end{tabular}

16 Informanten $(84,2 \%)$ halten die Termini für synonym, zwei enthalten sich einer verbindlichen Aussage, und ein Informant konstatiert einen Bedeutungsunterschied, den er wie folgt begründet: „Un pirate n'est pas forcément lié à Internet (pirate maritime, pirate de l'air, etc.). Un cracker indique précisément qu'il s'agit d'un pirate informatique." Es wird somit bemängelt, dass pirate zu allgemein sei und sich nicht unbedingt nur auf einen Hacker im Computerbereich beziehe, sondern auch auf den Meeren oder in der Luft zu finden sei. Cracker hingegen wird als eindeutig (monosem) angesehen.

Die Frage nach den persönlichen Präferenzen wird wie folgt beantwortet: 
Abb. 184: Frage 32, persönliche Präferenz(en): pirate, fouineur, cracker (Schweiz)

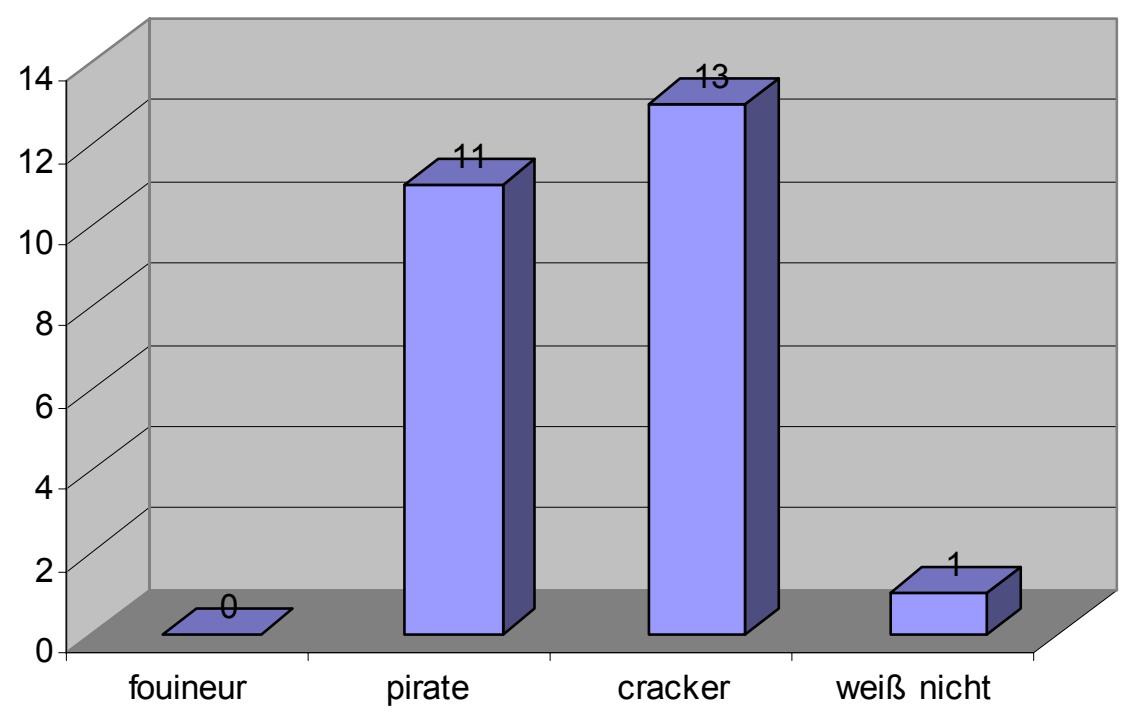

Abb. 185: Frage 32, persönliche Präferenz(en): pirate, fouineur, cracker (prozentuale Häufigkeit, Schweiz)

\begin{tabular}{|l|r|}
\hline Termini & \% \\
\hline Cracker & 68,4 \\
\hline Pirate & 57,9 \\
\hline Fouineur & 0,0 \\
\hline Weiß nicht & 5,2 \\
\hline
\end{tabular}

13 von 19 Informanten (68,4\%) ziehen cracker vor, elf pirate. Unter diesen 13 Informanten befinden sich sechs Informanten, die beide Termini als persönliche Präferenz angegeben haben. Damit ist der Unterschied zwischen der passiven Akzeptanz und der persönlichen Präferenz der Informanten nur minimal. Das ausgeglichene Bild ändert sich etwas bei der Frage nach dem eigenen Sprachgebrauch: 


\section{Abb. 186: Frage 33, eigener Sprachgebrauch: pirate, fouineur, cracker (Schweiz)}

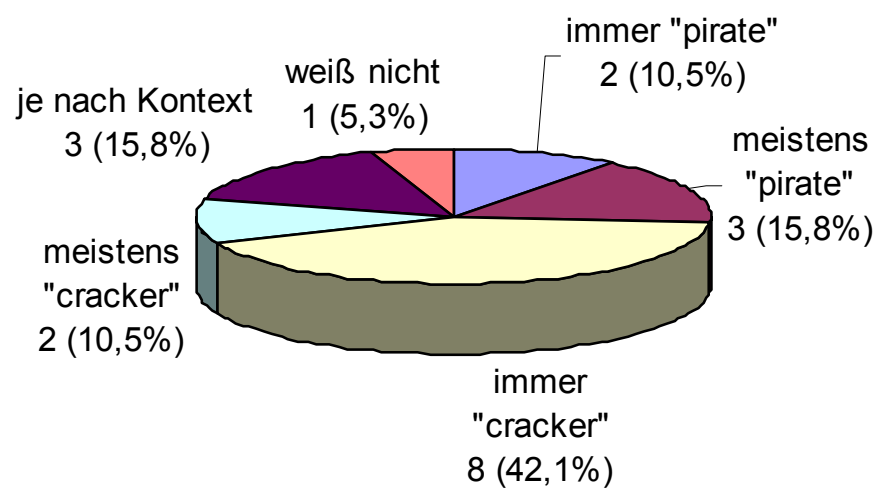

Obwohl sowohl der englische als auch der französische Terminus ein recht hohes Votum bezüglich ihrer Bekanntheit und Präferenz erhalten, wird hinsichtlich des eigenen Sprachgebrauchs der englische Terminus vorgezogen. Zehn Informanten $(52,6 \%)$ geben an immer oder meistens cracker zu verwenden. Demgegenüber verwenden nur fünf Informanten (26,3\%) nach eigenen Angaben meistens oder immer pirate. Drei Informanten entscheiden sich je nach Kontext für den englischen oder den französischen Terminus. Von diesen Prozentwerten ausgehend, hat sich cracker bezüglich der Gebrauchsfrequenz besser etablieren können als sein französisches Pendant.

Wie auch bezüglich des französischen Terminus page d'accueil ist es bei nur fünf abgegebenen Bewertungen für pirate wenig aussagekräftig, eine ausführliche Auswertung des semantischen Differentials vorzunehmen. Die Ergebnisse lassen sich dahingehend zusammenfassen, dass der Terminus pirate nicht so positiv bewertet wird wie page d'accueil. Pirate erhält ein durchschnittliches Akzeptanzvotum von 2,03, wobei der Terminus bezüglich seiner ästhetischen Qualitäten mit einem durchschnittlichen Wert von 2,75 am schlechtesten abschneidet.

Da mehrheitlich für den Anglizismus plädiert wurde, werden im Folgenden die Gründe für die Bevorzugung dieses Terminus genannt. 


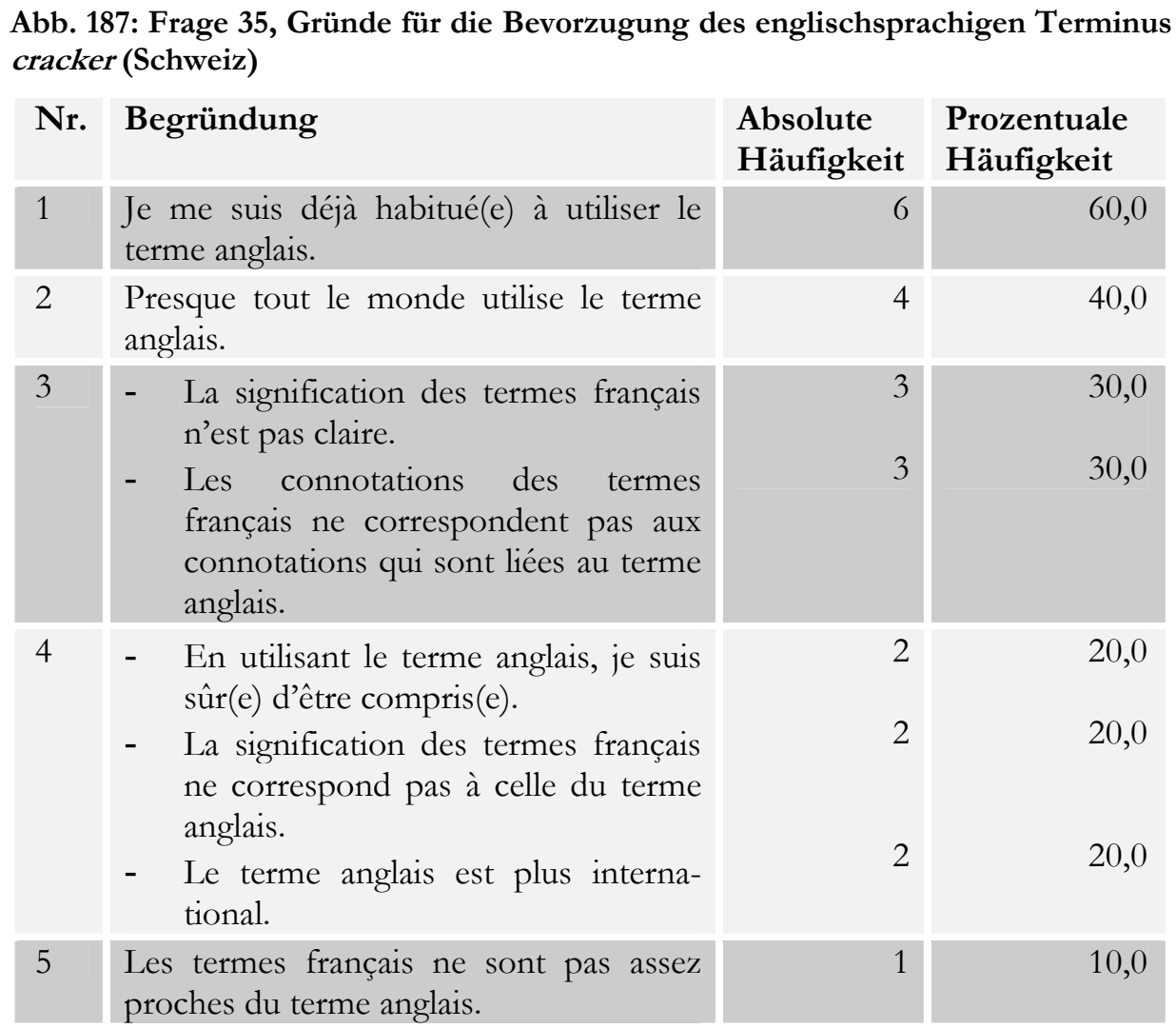

Am häufigsten wird von den zehn Informanten, die immer oder meistens cracker verwenden, die Gewöhnung an den englischsprachigen Terminus genannt. An zweiter Stelle folgt die weite Verbreitung des Terminus. An dritthäufigsten wird erklärt, dass die Bedeutung der französischen Termini nicht klar sei und dass die Konnotationen der französischen Termini nicht den Konnotationen entsprechen, die mit dem englischsprachigen Terminus verbunden seien. Der Grund dafür, dass die Informanten die Bedeutung der französischen Termini nicht als klar erachten, muss sich nicht automatisch nur auf pirate, sondern kann sich auch auf den französischen Terminus fouineur beziehen. Die Begründung bezüglich der unterschiedlichen Konnotationen ist jedoch eher auf pirate bezogen, mit dem viele wahrscheinlich in erster Linie einen Seeräuber oder Luftpiraten, aber keinen Datenräuber assoziieren.

Der Hypothese, dass cracker aufgrund seiner langen Existenz als Computer-Terminus einen höheren Bekanntheits- und Verwendungsgrad aufweist als pirate, kann zugestimmt werden, sofern eine entsprechende Aussage überhaupt bei einer so geringen Datenmenge möglich ist. Die Mehrheit der für cracker stimmenden Informanten verweist darauf, dass sie sich bereits an den englischen Terminus 
gewöhnt haben, was eindeutig dafür spricht, dass cracker bereits lange Zeit vor dem Aufkommen eines französischen Äquivalentes gebräuchlich war.

\subsubsection{Die Termini fournisseur d'accès, pourvoyeur d'accès und (access) provider}

Die sechste und letzte Lexemgruppe bezieht sich auf die Termini fournisseur d'accès und (access) provider sowie auf das Testwort pourvoyeur d'accès.

Abb. 188: Frage 36, Bekanntheitsgrad der Termini fournisseur d'accès, pourvoyeur d'accès und (access) provider (Schweiz)

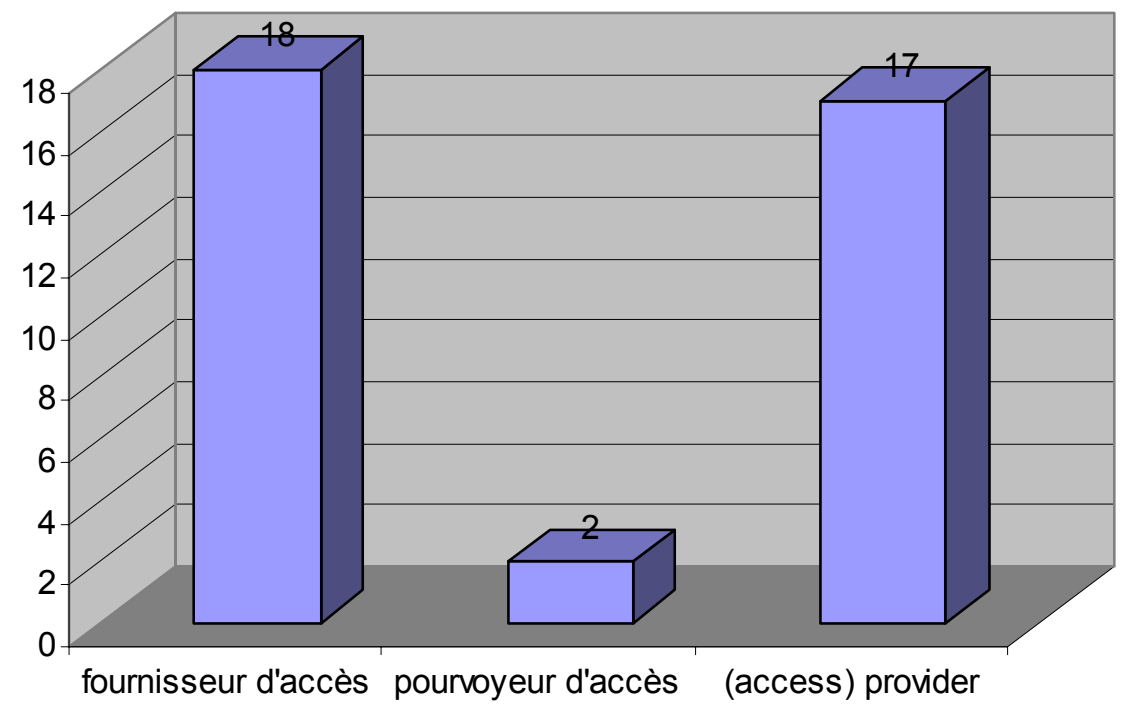

Abb. 189: Frage 36, Bekanntheitsgrad der Termini fournisseur d'accès, pourvoyeur d'accès und (access) provider (prozentuale Häufigkeit, Schweiz)

\begin{tabular}{|l|r|}
\hline Termini & $\mathbf{0}$ \\
\hline Fournisseur d'accès & 94,7 \\
\hline (Access) provider & 89,5 \\
\hline Pourvoyeur d'accès & 10,5 \\
\hline
\end{tabular}

Sowohl der französische als auch der englische Terminus sind sehr bekannt. Beide können mit einem Bekanntheitsgrad von knapp 90\% bzw. mehr als 90\% als etabliert gelten. Nur zwei von 19 Informanten geben an das überaus seltene Testwort pourvoyeur d'accès zu kennen.

Bei der nächsten Frage sprechen sich 18 Informanten (94,7\%) dafür aus, dass die Termini synonym seien, ein Informant (5,3\%) enthält sich einer verbindlichen Aussage, indem er erklärt, es nicht zu wissen bzw. nicht alle Termini zu kennen. Entsprechend dieser Ergebnisse entfällt auch die Auswertung der Frage 38 nach den Bedeutungsunterschieden zwischen fournisseur d'accès und (access) provider. 
Bezüglich der persönlichen Präferenzen liegen die beiden Termini fournisseur d'accès und (access) provider immer noch recht eng beieinander:

Abb. 190: Frage 39, persönliche Präferenz(en): fournisseur d'accès, pourvoyeur d'accès, (access) provider (Schweiz)

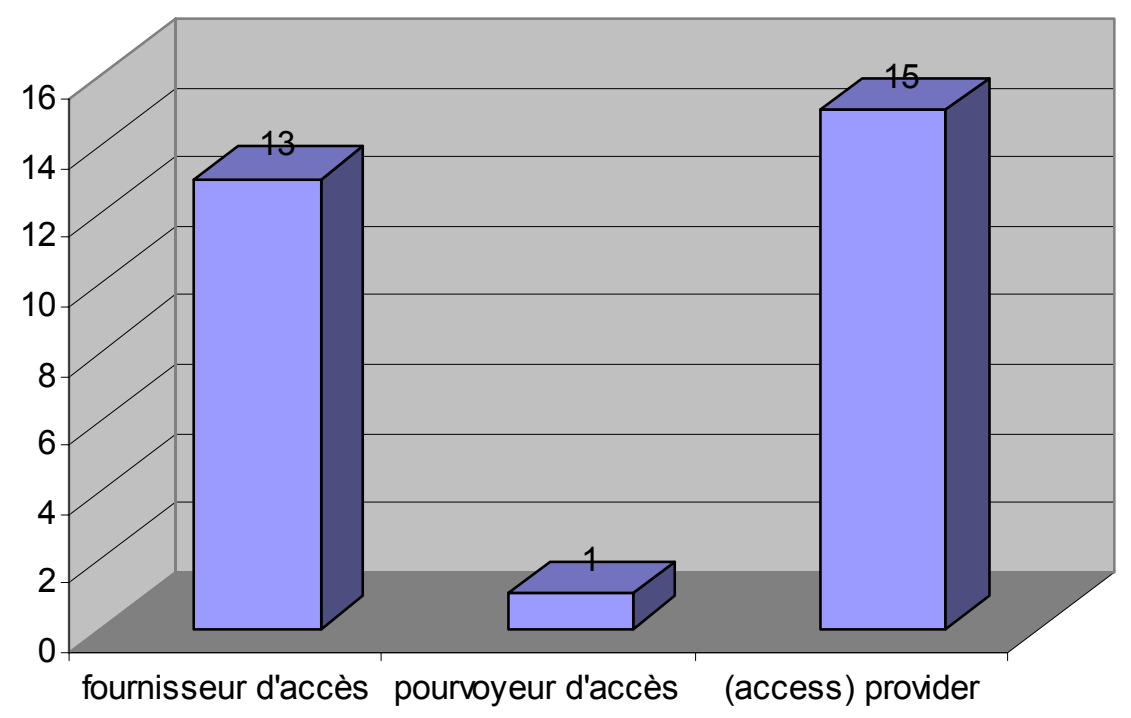

Abb. 191: Frage 39, persönliche Präferenz(en): fournisseur d'accès, pourvoyeur d'accès, (access) provider (prozentuale Häufigkeit, Schweiz)

\begin{tabular}{|l|r|}
\hline Termini & $\mathbf{0}$ \\
\hline (Access) provider & 78,9 \\
\hline Fournisseur d'accès & 68,4 \\
\hline Pourvoyeur d'accès & 5,3 \\
\hline
\end{tabular}

Obwohl der englische Terminus nicht so bekannt ist wie sein französisches Pendant (s. Frage 36), ist (access) provider etwas beliebter. 78,9\% der Befragten plädieren für (access) provider, zwei Informanten weniger (68,4\%) für fournisseur d'accès. An der hohen Anzahl an Stimmen ist ersichtlich, dass viele Informanten sowohl den englischen als auch den französischen Terminus bevorzugen.

Bei der Frage nach dem eigenen Sprachgebrauch vergrößert sich der Abstand zwischen dem englischen und dem französischen Terminus: 
Abb. 192: Frage 40, eigener Sprachgebrauch: fournisseur d'accès, pourvoyeur d'accès, (access) provider (Schweiz)

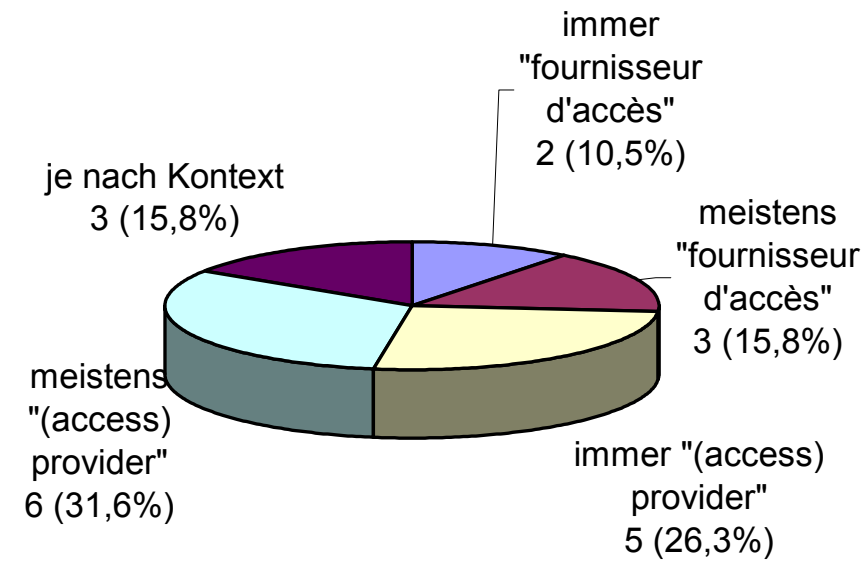

Ähnlich wie bei franz. page d'accueil und engl. homepage sind zwar beide Termini sehr bekannt und erhalten beide recht hohe Werte bezüglich der Präferenz, doch hinsichtlich des Gebrauchs wird der englische Terminus favorisiert. Elf Informanten $(57,9 \%)$ geben an meistens oder immer (access) provider zu verwenden, fünf Informanten $(26,3 \%)$ plädieren für die Verwendung des französischen Terminus. Drei Informanten entscheiden je nach Kontext, ob sie den englischen oder den französischen Terminus verwenden. Somit kann der englische Terminus bezüglich seiner Gebrauchsfrequenz als etwas etablierter gelten als sein französisches Äquivalent.

Dem französischen Terminus fournisseur d'accès geben die fünf Informanten, die für seine Verwendung gestimmt haben, ein durchschnittliches Akzeptanzvotum von 2,42, insbesondere im Hinblick auf seine ästhetischen Qualitäten schneidet fournisseur d'accès mit einem Wert von 3,8 extrem schlecht ab. Aufgrund der geringen Fallzahl dürfen diese Werte allerdings keinen Anspruch auf Repräsentativität erheben. Für verlässliche Daten wäre eine umfangreiche Stichprobe nötig (vgl. Fußnote 3).

Im Folgenden werden die Gründe angegeben, weshalb engl. (access) provider dem französischen Terminus vorgezogen wird. 
Abb. 193: Frage 35, Gründe für die Bevorzugung des englischsprachigen Terminus (access) provider (Schweiz)

\begin{tabular}{|c|c|c|c|}
\hline Nr. & Begründung & $\begin{array}{l}\text { Absolute } \\
\text { Häufigkeit }\end{array}$ & $\begin{array}{l}\text { Prozentuale } \\
\text { Häufigkeit }\end{array}$ \\
\hline 1 & $\begin{array}{l}\text { Je me suis déjà habitué(e) à utiliser le } \\
\text { terme anglais. }\end{array}$ & 7 & 65,6 \\
\hline 2 & Le terme anglais est plus international. & 4 & 36,4 \\
\hline 3 & $\begin{array}{l}\text { - En utilisant le terme anglais, je suis } \\
\text { sûr(e) d'être compris(e). } \\
\text { - Le terme anglais est plus bref. } \\
\text { - } \quad \text { Presque tout le monde utilise le } \\
\text { terme anglais. }\end{array}$ & $\begin{array}{l}3 \\
3\end{array}$ & $\begin{array}{l}27,3 \\
27,3 \\
27,3\end{array}$ \\
\hline 4 & $\begin{array}{l}\text { - Je ne connais pas les termes français. } \\
\text { - Les termes français ne sont pas } \\
\text { assez connus. } \\
\text { - Je n'aime pas suivre les propositions } \\
\text { officielles. }\end{array}$ & $\begin{array}{l}1 \\
1\end{array}$ & $\begin{array}{l}9,1 \\
9,1 \\
9,1\end{array}$ \\
\hline 5 & $\begin{array}{l}\text { Autre : } \\
\text { Pourvoyeur d'accès, laissez-moi rire! }\end{array}$ & 1 & 9,1 \\
\hline
\end{tabular}

Von den elf Informanten, die diese Frage beantwortet haben, geben sieben Informanten (65,6\%) die Gewöhnung an den Terminus als Grund für die Verwendung von (access) provider an. An zweiter Stelle steht die Internationalität des englischsprachigen Terminus (36,4\%). An dritter Stelle werden die Gründe a) Sicherheit, verstanden zu werden, b) Kürze des Terminus ${ }^{4}$ und c) weite Verbreitung genannt. Ein Informant macht in seinem Kommentar deutlich, dass er nichts von dem Testwort pourvoyeur d'accès halte und dieses lächerlich finde.

Der Hypothese, dass fournisseur d'accès einen höheren Akzeptanzwert erhalten wird als sein Pendant (access) provider, kann nicht zugestimmt werden. Bezüglich der passiven Akzeptanz (Bekanntheitsgrad) liegen beide Termini eng beieinander, jedoch bei der Frage nach dem eigenen Sprachgebrauch wird der englische dem französischen Terminus vorgezogen.

\subsubsection{Zusammenfassung und Schlussfolgerungen}

Die Anglizismen mail/e-mail, homepage, web, chat, cracker und (access) provider werden deutlich häufiger als ihre französischen Äquivalente verwendet. Als Gründe werden v.a. angeführt:

1. die Gewöhnung an den englischsprachigen Terminus,

2. der hohe Verbreitungsgrad des englischsprachigen Terminus,

3. die Kürze des englischsprachigen Terminus,

\footnotetext{
${ }^{4}$ Es wird vermutlich meistens von provider und nicht von access provider gesprochen.
} 
4. die Sicherheit, bei Verwendung des englischsprachigen Terminus verstanden zu werden,

5. seine internationale Verwendung und

6. die unklare Bedeutung der französischen Termini.

Bei ausnahmslos allen Anglizismen wurde die Gewöhnung an den englischsprachigen Terminus als erster Grund genannt. Da dieser Grund zwar auch von den befragten Franzosen und Belgiern häufig angegeben wurde, aber nur jeweils ein Mal an erster Stelle stand, drängt sich hier die Frage auf, warum der Faktor Gewöhnung für die befragten Schweizer so ausschlaggebend für die Wahl des Anglizismus ist. Mit dem Faktor Gewöhnung geht die Tatsache einher, dass sich die französischen Termini erst sehr spät verbreiten, wenn sich die Anglizismen bereits etabliert haben. Es ist jedoch nur schwer nachvollziehbar, warum sich die französischen Termini in der Schweiz später als in Belgien und Frankreich verbreiten, zumal in der Schweiz häufig auch französische Medien bezogen werden. Möglicherweise halten die schweizerischen Informanten ihre eigenen Gewohnheiten einfach für wichtiger als die anderen von ihnen genannten Vorteile, die die Verwendung des englischsprachigen Terminus mit sich bringen kann. Die anderen Gründe, die für die Verwendung der Anglizismen angeführt werden, beziehen sich größtenteils auf die nationale und internationale Kommunikation, die nach Ansicht der Informanten durch die Verwendung der weit verbreiteten englischen Termini am wenigsten beeinträchtigt werde.

Bezüglich der Synonymie der Termini wird auf die unterschiedliche Bedeutung von messagerie électronique im Vergleich zu den anderen Termini hingewiesen. Homepage wird mitunter im Unterschied zu page d'accueil als private Internetseite verstanden. Interessant ist jeweils eine Begründung, die zum Unterschied zwischen franz. causette/bavardage und engl. chat sowie zum Unterschied zwischen franz. pirate und engl. cracker angeführt wird: Die französischen Termini werden jeweils als semantisch weiter empfunden, da sie auch Gegebenheiten der realen Welt bezeichneten (ungezwungene Face-to-Face-Konversation, Meeres- und Luftpiraterie), während sich chat und cracker nur auf das Internet bezögen. Folglich werden die englischsprachigen Termini im Unterschied zu den französischen Termini als eindeutig betrachtet, während die französischen Termini unterschiedliche Bedeutungen in der realen Welt und in der Welt des Internet hätten. Die englischsprachigen Termini, die ursprünglich auch mehrdeutig sind, werden somit bei ihrer Entlehnung ins Französische monosemiert und beziehen sich damit für die Mehrzahl der befragten frankophonen Sprecher nur noch auf den Internetbereich.

Auffällig ist des Weiteren, dass viele Informanten oftmals beide Termini, den Anglizismus und den französischen Neologismus, als persönliche Präferenz angeben; bezüglich des eigenen Sprachgebrauchs liegt jedoch der Anglizismus immer mit weitem Abstand vor dem französischen Terminus. Neben dem oben genannten Argument der Gewöhnung an den englischsprachigen Terminus dürfte der Grund für dieses Ergebnis auch im ästhetischen Bereich zu suchen sein. Mehrfach wurde von den Informanten darauf hingewiesen, dass sie den Anglizismus bevorzugen, weil sie die französischen Termini als hässlich empfinden. Die Aussagen 
der Informanten bestätigen auch die Feststellung Helfrichs (1993), der zufolge auch dem Neologismus inhärente Qualitäten einen Einfluss auf das Akzeptanzurteil hätten:

„Somit ist die Akzeptanz oder Nicht-Akzeptanz von Neologismen weniger unmittelbar vom Bildungstyp abhängig als von bestimmten Qualitäten des Wortbildungsproduktes, so beispielsweise seiner Gebräuchlichkeit, Bekanntheit bzw. Fremdheit, Korrektheit, Adäquatheit oder Abstraktheit, Nützlichkeit etc.“ (Helfrich 1993, 183).

Da bezüglich der persönlichen Präferenz der englische Terminus stets etwas besser abschneidet als sein französisches Ersatzwort, muss der in 5.3.1 formulierten Hypothese widersprochen werden, der zufolge die persönliche Präferenz nicht prinzipiell mit dem eigenen aktiven Sprachgebrauch übereinstimmt. Allerdings hat die Frage nach dem eigenen Sprachgebrauch die Differenz zwischen dem englischsprachigen und dem französischen Terminus jeweils verstärkt. Der Vergleich der Fragen nach der Präferenz und dem eigenen Sprachgebrauch macht auch deutlich, dass es nicht möglich ist, von dem mitunter recht hohen Präferenzvotum der französischen Termini darauf zu schließen, dass sie von den schweizerischen Informatikern auch aktiv verwendet werden.

Um der ebenfalls in 5.3.1 formulierten Hypothese nachzugehen, dass die Mehrheit der Termini von den befragten Informatikern als bekannt angegeben wird, wird wie in Kapitel 9 und 10 verfahren. Mit Ausnahme der Testwörter werden alle Termini in eine Tabelle eingetragen, damit auf einen Blick ersichtlich wird, wie viele und welche Termini sich bezüglich ihres Bekanntheitsgrades bei den schweizerischen Informatikern etablieren konnten. 
Abb. 194: Bekanntheits- und Etablierungsgrad aller französischen und englischsprachigen Termini in \% (Schweiz)

\begin{tabular}{|c|c|c|c|}
\hline \multicolumn{3}{|c|}{ Bekanntheitsgrad der Termini } & \multirow[t]{2}{*}{ Etablierungsgrad } \\
\hline & $\begin{array}{l}\text { Französische } \\
\text { Neologismen }\end{array}$ & $\begin{array}{l}\text { Englischsprachige } \\
\text { Termini }\end{array}$ & \\
\hline $100 \%$ & courrier électronique & e-mail, mail, web & $\begin{array}{l}100 \% \text { ige Etablie- } \\
\text { rung }\end{array}$ \\
\hline $90-99,9 \%$ & fournisseur d'accès & chat, homepage & \multirow{2}{*}{$\begin{array}{l}\text { sicherer Etablie- } \\
\text { rungsgrad }\end{array}$} \\
\hline $80-89,9 \%$ & page d'accueil, pirate & $\begin{array}{l}\text { (access) provider, } \\
\text { cracker }\end{array}$ & \\
\hline $70-79,9 \%$ & message électronique, toile & World Wide Web & \multirow{3}{*}{$\begin{array}{l}\text { unsicherer Etablie- } \\
\text { rungsgrad }\end{array}$} \\
\hline $60-69,9 \%$ & -- & -- & \\
\hline $50-59,9 \%$ & -- & -- & \\
\hline $40-49,9 \%$ & courriel & -- & \multirow{4}{*}{$\begin{array}{l}\text { schwacher Etablie- } \\
\text { rungsgrad }\end{array}$} \\
\hline $30-39,9 \%$ & $\begin{array}{l}\text { messagerie électronique, } \\
\text { mél }\end{array}$ & -- & \\
\hline $20-29,9 \%$ & $\begin{array}{l}\text { toile d'araignée mondiale, } \\
\text { toile mondiale }\end{array}$ & -- & \\
\hline $\begin{array}{l}\text { Weniger } \\
\text { als } 20 \%\end{array}$ & bavardage, T.A.M. & -- & \\
\hline $0 \%$ & causette & -- & keine Etablierung \\
\hline
\end{tabular}

Alle englischsprachigen Termini sind mindestens 70\% der Befragten bekannt. Bei den französischen Termini wird das gesamte Spektrum von 100\%iger Bekanntheit (courrier électronique) bis zu vollkommener Unbekanntheit (causette) abgedeckt. Nur sechs der insgesamt 14 französischen Termini sind mehr als 50\% der Befragten bekannt. Der Hypothese kann somit nur bezüglich der englischsprachigen, nicht aber bezüglich der französischen Termini zugestimmt werden.

\subsection{Zweites Fragebogenmodul: Kenntnis und Akzeptanz der aktuellen Sprachpolitik und Terminologiearbeit}

\subsubsection{Auswertung der Fragen 44-48}

Die Fragen des zweiten Fragebogenmoduls weichen etwas von den Fragen ab, die zur französischen bzw. zur belgischen Sprachpolitik gestellt wurden. Da es in der Schweiz keine der französischen oder belgischen Sprachpolitik vergleichbaren Gesetze oder Dekrete zum Schutz der französischen Sprache vor Anglizismen gibt, wurde auf die Frage nach der Kenntnis entsprechender Maßnahmen verzichtet. Um jedoch zu ermitteln, wie die Schweizer entsprechenden Maßnahmen gegenüber stehen, wurde danach gefragt, wie sie eine entsprechende Politik beurteilen: 
Abb. 195: Frage 44, Beurteilung der aktuellen Sprachpolitik (Schweiz)

\begin{tabular}{|l|r|r|}
\hline & $\begin{array}{l}\text { Absolute } \\
\text { Häufigkeit }\end{array}$ & $\begin{array}{l}\text { Prozentuale } \\
\text { Häufigkeit }\end{array}$ \\
\hline Absolument nécessaire. & 2 & 10,5 \\
\hline Souhaitable. & 3 & 15,8 \\
\hline Inutile. & 14 & 73,7 \\
\hline Insgesamt & 19 & 100,0 \\
\hline
\end{tabular}

Sprachpolitische Maßnahmen werden von den befragten Schweizern mehrheitlich abgelehnt. 73,7\% halten sprachpolitische Maßnahmen für unnötig, nur 10,5\% für unbedingt nötig und 15,8\% für wünschenswert.

Da es in der Schweiz zwar Terminologiearbeit gibt, jedoch keine Terminologielisten $\mathrm{zu}$ verschiedenen Wortfeldern wie in Frankreich verabschiedet oder eine Terminologiedatenbank wie in Belgien geschaffen wurden, entfallen die Fragen nach der Kenntnis und Akzeptanz entsprechender Terminologielisten.

Die Frage, ob die schweizerische Internet-Terminologie bekannt sei, wurde wie folgt beantwortet:

Abb. 196: Frage 45, Kenntnis der offiziellen Internet-Terminologie (Schweiz)

\begin{tabular}{|l|r|r|}
\hline Oui, je la connais bien. & $\begin{array}{l}\text { Absolute } \\
\text { Häufigkeit }\end{array}$ & $\begin{array}{l}\text { Prozentuale } \\
\text { Häufigkeit }\end{array}$ \\
\hline Oui, je la connais un peu. & 0 & 0,0 \\
\hline J'en ai déjà entendu parler. & 2 & 10,5 \\
\hline Non, pas du tout. & 2 & 10,5 \\
\hline Insgesamt & 15 & 79,0 \\
\hline
\end{tabular}

Zwei Informanten (10,5\%) geben an die schweizerische Internet-Terminologie ein wenig zu kennen, und ebenfalls zwei Informanten (10,5\%) geben an bereits davon gehört zu haben. Der Mehrheit der Befragten (79\%) ist die Internet-Terminologie jedoch gänzlich unbekannt. Nur die beiden Informanten, die die schweizerische Internet-Terminologie ein wenig kennen, wurden zur folgenden Frage 46 weitergeleitet, in der ermittelt wurde, ob sie diese auch verwenden. Die Frage nach dem Gebrauch der offiziellen Internet-Terminologie beantworteten beide Informanten mit ,weiß nicht“.

Da den frankophonen Schweizern häufig eine Orientierung an Paris und dem dortigen Sprachgebrauch nachgesagt wird, wurden alle schweizerischen Informanten gefragt, ob sie die französische Sprachpolitik zum Schutz der Sprache vor Anglizismen kennen. 
Abb. 197: Frage 47, Kenntnis der aktuellen französischen Sprachplanung (Schweiz)

\begin{tabular}{|l|r|r|}
\hline & $\begin{array}{l}\text { Absolute } \\
\text { Häufigkeit }\end{array}$ & $\begin{array}{l}\text { Prozentuale } \\
\text { Häufigkeit }\end{array}$ \\
\hline Oui. & 3 & 15,8 \\
\hline Oui, j’en ai déjà entendu parler. & 9 & 47,4 \\
\hline Non. & 7 & 36,8 \\
\hline Je ne sais pas. & 0 & 0,0 \\
\hline Insgesamt & 19 & 100,0 \\
\hline
\end{tabular}

Mehr als die Hälfte der Befragten (zwölf Informanten, 63,2\%) gibt an, die französische Sprachpolitik zu kennen oder zumindest von ihr gehört zu haben. Sieben Informanten $(36,8 \%)$ geben an sie nicht zu kennen. Die zwölf Informanten, die angegeben haben die französische Sprachpolitik zu kennen bzw. davon gehört zu haben, wurden zur nächsten Frage weitergeleitet.

Abb. 198: Frage 48, Befolgen der französischen Sprachplanung

\begin{tabular}{|l|r|r|}
\hline & $\begin{array}{l}\text { Absolute } \\
\text { Häufigkeit }\end{array}$ & $\begin{array}{l}\text { Prozentuale } \\
\text { Häufigkeit }\end{array}$ \\
\hline Oui. & 0 & 0,0 \\
\hline Partiellement. & 1 & 8,3 \\
\hline Plutôt non. & 2 & 16,7 \\
\hline Pas du tout. & 9 & 75,0 \\
\hline Je ne sais pas. & 0 & 0,0 \\
\hline Insgesamt & 12 & 100,0 \\
\hline
\end{tabular}

Auf die Frage, ob sie sich nach der französischen Sprachpolitik richten würden, antworten elf der zwölf Informanten $(91,7 \%)$ mit nein bzw. eher nein. Nur ein Informant gibt an, sich teilweise nach der französischen Sprachpolitik zu richten. Dieses Ergebnis unterstützt die Ausführungen und Studienergebnisse (v.a. von Cichon 1998) in 2.3.4.2.1 bis 2.3.4.2.3. Von dem Zwiespalt allerdings, sich einerseits Frankreich anpassen zu wollen und andererseits auf sprachliche und kulturelle Eigenständigkeit zu drängen, ist anhand dieser Ergebnisse nichts zu merken. Viele der befragten Schweizer sind zwar über die französische Sprachpolitik informiert. Sie geben aber mehrheitlich an sich nicht nach dieser zu richten. Inwiefern dieses eigene Normenbewusstsein mit der 1992 gegründeten Délégation à la langue française (DLF) in Zusammenhang steht, kann im Rahmen dieser Studie nicht geklärt werden.

\subsubsection{Auswertung der länderspezifischen Hypothesen}

Nun werden die beiden in 5.3.3.3 formulierten Hypothesen zur Kenntnis und Akzeptanz der Sprach- und Terminologiearbeit in der Schweiz überprüft. 
Die erste Hypothese lautet: „Die Anzahl der Romands, die sprachpolitische Vorschriften begrüßen, ist geringer als die der Franzosen und frankophonen Belgier.“ In 2.3.4.1 wurde erwähnt, dass die Schweizer in Sprachfragen als recht tolerant gelten, solange sie sich nicht in ihrem Recht bedroht fühlen, sich in ihrer Muttersprache verständigen zu können. Außerdem spricht für diese Hypothese, dass die Schweizer, ähnlich wie die Deutschen, mit sprachpolitischen Vorschriften, die das Korpus betreffen, wenige bis gar keine Erfahrungen haben. In Frage 44 wurde festgestellt, dass nur fünf von 19 Informanten (26,3\%) sprachpolitische Maßnahmen für nötig bzw. wünschenswert halten. Diesem recht geringen Prozentsatz an Befürwortern stehen auf Seiten der französischen Informanten 58\% an Befürwortern gegenüber. Von den befragten Belgiern beurteilen neun von 17 Informanten $(53 \%)$ sprachpolitische Maßnahmen als notwendig bzw. wünschenswert. Von jeweils etwas mehr als der Hälfte der französischen und belgischen Befragten, aber nur von einem Viertel der schweizerischen Befragten werden sprachpolitische Maßnahmen somit befürwortet. Insofern kann die Hypothese bestätigt werden, dass sprachpolitische Maßnahmen von den befragten schweizerischen Informatikern weniger befürwortet werden als von den französischen und belgischen Informanten.

Bezüglich des zweiten Fragebogenmoduls wurde eine weitere Hypothese genannt. Diese bezieht sich auf die Kenntnis der Internet-Terminologie und lautet: „Die schweizerische (Internet-)Terminologieliste ist nur wenigen Informanten bekannt." Diese Hypothese wurde v.a. daraus abgeleitet, dass die schweizerische Terminologieliste 1. nicht über Printmedien publik gemacht wird und 2. im World Wide Web nicht so leicht zu finden ist wie die französische oder die belgische Informatik-Terminologie. Da nur vier von 19 Informanten (21\%) erklären, die schweizerische Internet-Terminologie etwas zu kennen bzw. von ihrer Existenz gehört zu haben, kann auch diese Hypothese bestätigt werden.

\subsection{Drittes Fragebogenmodul: Auswertung der Kommen- tare zur Sprachpolitik und Terminologiearbeit}

Die Auswertung der Kommentare der schweizerischen Informanten erfolgt ana$\log$ zu der Auswertung der Kommentare der französischen und belgischen Informanten (vgl. 9.3 und 10.3).

Zwölf der insgesamt 19 schweizerischen Informanten, also mehr als die Hälfte der Befragten, haben einen Kommentar zur Sprachpolitik bzw. Terminologiearbeit verfasst.

Zur Auswertung wurden die Kommentare in einzelne Argumente aufgeteilt, wie in 9.3 beschrieben ${ }^{5}$. Anschließend wurden drei große Kategorien gebildet, denen die einzelnen Argumente zugeordnet wurden: 5 Alle Kommentare der schweizerischen Informanten sind im Anhang 15.5.2.3 vollständig nachzu-
lesen. 
1. Befürwortung der Sprachpolitik,

2. Ablehnung der Sprachpolitik und

3. Ablehnung der Terminologiearbeit.

Im Unterschied zu den Kategorien, die für die Kommentare der französischen Informanten gebildet wurden, werden von keinem der schweizerischen Informanten Kommentare formuliert, die für die Terminologiearbeit sprechen. Jeder der drei genannten Kategorien entspricht im Folgenden eine Tabelle. Es geht in den Tabellen weniger um die (nachträgliche) Quantifizierung der Argumente als vielmehr um die Inhalte der Argumente selbst. Die Quantifizierung ist vielmehr eine Folge der Notwendigkeit, die Argumente in eine Reihenfolge bringen zu müssen. Die Reihenfolge richtet sich nach der Häufigkeit der Nennungen. Bei gleicher Anzahl an Nennungen werden die Argumente alphabetisch geordnet.

Die erste Tabelle zeigt die beiden Argumente auf, die nach Ansicht der befragten schweizerischen Informatiker für sprachpolitische Maßnahmen sprechen.

Abb. 199: Argumente für die Befürwortung der Sprachpolitik (Schweiz)

\section{Befürwortung der Sprachpolitik}

\begin{tabular}{l|l|r|}
\hline $\begin{array}{l}\text { Kategorie } \\
\begin{array}{l}\text { Sprachpolitik ist zu befürworten, riskiert aber, } \\
\text { ins Lächerliche abzurutschen. }\end{array}\end{array}$ & S9 & Anzahl \\
\hline $\begin{array}{l}\text { Uneingeschränkte Befürwortung der } \\
\text { Sprachpolitik zum Schutz der französischen } \\
\text { Sprache. }\end{array}$ & S8 & 1 \\
\hline
\end{tabular}

In den zwölf ausgewerteten Kommentaren wird nur ein Argument aufgeführt, das sich gegen sprachpolitische Maßnahmen richtet:

Abb. 200: Argumente für die Ablehnung der Sprachpolitik (Schweiz)

\section{Ablehnung der Sprachpolitik}

Kategorie

Anstelle von Sprachpolitik, die sich gegen

Anglizismen richtet, soll die Kenntnis von

Fremdsprachen gefördert werden.

\section{Informanten Anzahl}

S12

In diesem Fall wird die Lösung eventueller (Sprach-)Konflikte weniger in der Verabschiedung sprachpolitischer Regelungen gesehen, sondern nach Ansicht des entsprechenden Informanten sollte vielmehr die Kenntnis von Fremdsprachen gefördert werden.

Während in keinem der ausgewerteten Kommentare Argumente zur Befürwortung der Terminologiearbeit genannt werden, können den Kommentaren insgesamt acht Argumente entnommen werden, die gegen eine Terminologiearbeit sprechen. 
Abb. 201: Argumente für die Ablehnung der Terminologiearbeit (Schweiz)

\section{Ablehnung der Terminologiearbeit}

\begin{tabular}{|c|c|c|}
\hline Kategorie & Informanten & Anzahl \\
\hline $\begin{array}{l}\text { Kommunikation: } \\
\text { Englisch ist die dominierende Sprache und die } \\
\text { lingua franca im Bereich der neuen Technologien } \\
\text { wie Informatik/Internet. } \\
\text { Die Verwendung der englischen Terminologie } \\
\text { erleichtert die Kommunikation weltweit und } \\
\text { unter frankophonen Sprechern. }\end{array}$ & $\begin{array}{l}\text { S1, S3, S4, } \\
\text { S10, S11, S12 }\end{array}$ & 6 \\
\hline $\begin{array}{l}\text { Französische Terminologie ist lächerlich, wenn } \\
\text { es sich bei den Neologismen lediglich um } \\
\text { Französisierungen der Anglizismen handelt, wie } \\
\text { bei den französischen Neologismen cédérom und } \\
\text { mél für engl. CD-ROM und e-mail. }\end{array}$ & S6, S9, S12 & 3 \\
\hline $\begin{array}{l}\text { Sprachgebrauch darf nicht durch den Staat } \\
\text { vorgeschrieben werden, sondern der Gebrauch } \\
\text { soll über die Termini entscheiden } \\
\text { („Darwinismus“). }\end{array}$ & $\mathrm{S} 2, \mathrm{~S} 10$ & 2 \\
\hline $\begin{array}{l}\text { Anglizismen sind meistens präziser und } \\
\text { passender als die französischen Neologismen. }\end{array}$ & S7 & 1 \\
\hline $\begin{array}{l}\text { Anstatt neue Wörter zu schaffen, sollten nur die } \\
\text { bekannten englischen Wörter verwendet } \\
\text { werden. }\end{array}$ & S6 & 1 \\
\hline $\begin{array}{l}\text { Die englischsprachigen Termini sind von den } \\
\text { Benutzern geschaffen worden. }\end{array}$ & S7 & 1 \\
\hline $\begin{array}{l}\text { Französische Neologismen sind überflüssig und } \\
\text { lächerlich für den Bereich der neuen } \\
\text { Technologien wie Informatik. }\end{array}$ & S6 & 1 \\
\hline $\begin{array}{l}\text { Sprache lebt und verändert sich, dieser Prozess } \\
\text { ist durch Terminologiearbeit nicht zu stoppen. }\end{array}$ & S5 & 1 \\
\hline
\end{tabular}

Das am häufigsten genannte Argument bezieht sich auf die nationale und internationale Kommunikation, die nach Meinung vieler Informanten durch die Verwendung nationaler Termini erschwert würde.

\subsection{Zusammenfassung}

Insgesamt haben 19 frankophone Informatiker aus der Schweiz den Fragebogen vollständig ausgefüllt. Von allen Lexemen der im ersten Fragebogenmodul überprüften sechs Lexemgruppen erhalten jeweils die englischsprachigen Termini das 
höhere Akzeptanzvotum. Als Begründung wird stets an erster Stelle die Gewöhnung an den englischsprachigen Terminus genannt. Erst danach wird auf die große nationale und internationale Verbreitung des englischsprachigen Terminus verwiesen, was mit der Sicherheit einhergehe, bei Verwendung der Anglizismen verstanden zu werden. Die frei formulierten Argumente wiederum verweisen auch auf die mangelnden ästhetischen Qualitäten der französischen Termini. Zudem konnte in der Zusammenfassung (11.1.7) herausgearbeitet werden, dass mehr als die Hälfte der französischen Termini weitestgehend unbekannt ist. Möglicherweise gibt es einen Zusammenhang zwischen der mangelnden Bekanntheit der französischen Neologismen und der Bevorzugung der englischsprachigen Termini. Es ist möglich, dass die französischen Termini sich später in der Schweiz verbreitet haben als in den beiden anderen frankophonen Untersuchungsländern, was erklären würde, wieso für die Verwendung der Anglizismen stets das Argument der Gewöhnung angeführt wurde.

Im zweiten Fragebogenmodul ging es um die Kenntnis und Akzeptanz sprachpolitischer Eingriffe und der Terminologielisten. Die Mehrheit der Informanten hält sprachpolitische Maßnahmen zum Schutz der französischen Sprache für unnötig. Nur vier von 19 Informanten geben an die schweizerische Internet-Terminologie ein wenig zu kennen bzw. von ihrer Existenz zu wissen, 15 (79\%) kennen sie nicht. Die französische Sprachpolitik ist mehr als der Hälfte der befragten Schweizer ein Begriff. Es fällt auf, dass viele Informanten zwar über die französische Sprachpolitik informiert sind, zugleich aber jegliche auf Anglizismen bezogene sprachpolitische Regelungen ablehnen. Dies lässt sich zum einen darauf zurückführen, dass politische Eingriffe in die französische Sprache in der Schweiz keine Tradition haben, zum anderen auf den schlechten Ruf, den die französische Sprachpolitik im Ausland genießt (vgl. z.B. 4.4.2.3). Die Ergebnisse lassen nicht auf eine ausgeprägte Frankreichorientierung der befragten Informatiker schließen, wie in anderen, im zweiten Kapitel vorgestellten Studien herausgearbeitet wurde.

Von der im dritten Fragebogenteil angebotenen Möglichkeit, einen Kommentar zur Sprachpolitik bzw. Terminologiearbeit zu verfassen, machten die Informanten mehrheitlich Gebrauch, was zeigt, wie sehr sie das Thema interessiert bzw. sie die Umfrage zum Nachdenken angeregt hat. Die meisten Argumente beziehen sich auf die Terminologiearbeit, die durchweg negativ bewertet wird. Vor allem wird die nationale Terminologie als Hindernis für die problemlose nationale und internationale Kommunikation gesehen, die ohnehin im Bereich der Informatik und neuen Technologien auf Englisch ablaufe.

Aufgrund der negativen Haltung der schweizerischen Informatiker zu staatlichen Eingriffen in die französische Sprache und zu einer französischsprachigen Terminologie und aufgrund der mehrheitlichen Verwendung der englischsprachigen Termini dürfte es in der Schweiz schwierig sein, französische Termini auf offiziellem Wege durchzusetzen. Es wäre in diesem Sinne nicht ratsam (und würde kaum auf Akzeptanz stoßen), in der Schweiz Sprachpolitik nach französischem Vorbild zu betreiben. 


\section{Vergleich der Ergebnisse: Frankreich, Belgien und die Schweiz}

In den Kapiteln 9, 10 und 11 stand die länderspezifische Auswertung der Ergebnisse im Zentrum. Außerdem wurden anhand der Ergebnisse die in 5.3.1, 5.3.2 und 5.3.3 formulierten Arbeitshypothesen überprüft.

In diesem Kapitel werden die Akzeptanz der ausgewählten Internet-Lexeme und die Einstellungen zur Sprachpolitik bzw. Terminologiearbeit zwischen den drei Untersuchungsländern verglichen.

Es wurde bereits am Anfang von Kapitel 9 darauf hingewiesen, dass sich die Ergebnisse der Fragebögen aufgrund des Verfahrens der Teilnehmerrekrutierung nur bedingt auf die Gesamtheit der Informatikerinnen und Informatiker des Untersuchungslandes übertragen lassen. Auch bezüglich der Gegenüberstellung der Ergebnisse sind einige Einschränkungen zu machen.

Es ergibt sich aus den jeweiligen Bevölkerungszahlen, dass die Anzahl der französischen Informatiker über der der befragten Belgier und Schweizer liegen muss. Nach amtlichen Statistiken wurde die französische Bevölkerung Anfang 2002 auf 59.344.025 Franzosen geschätzt (vgl. Institut National de la Statistique et des Études Économiques (INSEE), http://www.insee.fr/). Für Belgien ist von 3,4 Millionen Wallonen auszugehen. Hinzu kommen die in Brüssel lebenden frankophonen Belgier, so dass in Belgien knapp 4,2 Millionen Frankophone leben (vgl. 2.3.3.1). In der Schweiz leben ca. 1,49 Millionen frankophone Sprecher (vgl. Kap. 2, Fußnote 59). Diese Verteilung legt es nahe, dass der Großteil der Informanten aus Frankreich und die Minderheit aus Belgien und der Schweiz kommen werden. Entsprechend sind 124 Fragebögen von französischen, 17 von belgischen und 19 von schweizerischen Informatikern ausgewertet worden. Das Verhältnis zwischen der Anzahl belgischer und schweizerischer Teilnehmer hat sich sogar umgekehrt: 
Obwohl es mehr frankophone Belgier als Schweizer gibt, haben mehr Informatiker aus der Schweiz als aus Belgien an der WWW-Befragung teilgenommen. Dies könnte auf eine höhere Internet- bzw. Diskussionsforenaktivität oder aber auf ein höheres Interesse der schweizerischen Informatiker an der Thematik der Befragung zurückzuführen sein ${ }^{1}$. Trotz der relativ kleinen Stichprobe für Belgien und die Schweiz ist eine Gegenüberstellung der Daten sinnvoll. Schließlich hatten die Informatiker aus Belgien und der Schweiz, die in einem der genannten Diskussionsforen aktiv waren, die gleichen Möglichkeiten, an der WWW-Umfrage teilzunehmen wie die französischen Informatiker. Es gibt daher trotz der geringen Fallzahlen keinen Anlass, von einer verzerrten Stichprobe auszugehen.

Aufgrund der geringen Fallzahlen für Belgien und die Schweiz ist allerdings bei der vergleichenden Interpretation der Daten besondere Vorsicht geboten. Generell ist es problematisch, verschiedene Gruppen oder Kategorien zu vergleichen, wenn sie zahlenmäßig sehr verschieden sind. Deshalb wurde im 9. Kapitel nur ein einziges Merkmal, das Alter, mit der Akzeptanz der Neologismen und den Einstellungen zur Sprachpolitik und Terminologiearbeit korreliert. Die Frage, ob es Parallelen oder Differenzen zwischen den drei Untersuchungsländern gibt, ist jedoch aufgrund der Konzeption dieser Arbeit und des dafür erstellten WWWFragebogens so zentral, dass ein Vergleich trotz möglicher statistischer Einwände vorgenommen wird.

Da mit dieser Studie ein neues Untersuchungsfeld ergründet wird, für das zwar Hypothesen formuliert wurden, aber noch keine gesicherten Daten aus anderen Studien vorliegen, kann und soll das Ziel dieser Studie nicht sein, für die drei Untersuchungsländer repräsentative Ergebnisse aufzuzeigen. Vielmehr wird davon ausgegangen, dass sich aus der Gegenüberstellung der länderspezifischen Daten Tendenzen zum Etablierungsgrad der ausgewählten Internet-Termini sowie zur Einstellung der befragten Informatiker gegenüber der Sprachpolitik und Terminologiearbeit ableiten lassen.

Bei der Gegenüberstellung wird analog zu den Auswertungskapiteln 9, 10 und 11 vorgegangen.

\subsection{Erstes Fragebogenmodul: Auswertung der sechs aus- gewählten Lexemgruppen}

Es werden aus jeder der sechs Lexemgruppen die Ergebnisse der Fragen nach dem Bekanntheitsgrad, den Bedeutungsunterschieden, dem eigenen Sprachgebrauch sowie der Bewertung des französischen Neologismus bzw. die für die Bevorzugung des englischsprachigen Terminus vorgebrachten Argumente verglichen.

\footnotetext{
${ }^{1}$ Es lässt sich leider nicht feststellen, ob tatsächlich mehr Schweizer als Belgier von der Umfrage Kenntnis erlangt haben, was für eine größere Diskussionsforenaktivität sprechen würde, oder ob mehr Belgier die Ankündigung gelesen haben, dann aber nicht teilgenommen haben, was für ein größeres Interesse der schweizerischen Informatiker an der Thematik der Umfrage sprechen würde.
} 
Auf den Vergleich der Fragen nach der Synonymie (Fragen 2, 9, 16, 23, 30 und 37) wird in diesem Kapitel verzichtet, wichtig erscheinen vielmehr die angeführten Bedeutungsunterschiede. Da die Auswertung der Frage nach der persönlichen Präferenz in den Kapiteln 9 bis 11 gezeigt hat, dass bei der Frage nach dem eigenen Sprachgebrauch in der Regel der- oder diejenigen Termini angegeben werden, der oder die die meisten Stimmen bezüglich der persönlichen Präferenz(en) auf sich vereint hatte/n, wird im Folgenden auf die ländervergleichende Auswertung der Fragen nach der Präferenz (Fragen 11, 18, 25, 32 und 39) verzichtet.

\subsubsection{Die Termini courrier électronique, message électronique, mél, courriel, messagerie électronique, lettre électronique, e-mail und mail}

Aufgrund der sehr ungleichen Zahlenverhältnisse ist es sinnvoll, nur die prozentualen Häufigkeiten miteinander zu vergleichen. Da die Stichprobe für die belgischen und schweizerischen Informatiker kleiner als für die französischen Informatiker ausfällt, entspricht im Falle der Belgier und Schweizer ein einziges Votum bereits einem Wert von ca. fünf Prozent. Die Schwankungen sind somit bei einer kleineren Stichprobe immer größer als bei einer umfassenderen Stichprobe.

Hinsichtlich des Bekanntheitsgrades der Termini der ersten Lexemgruppe ergibt sich im Ländervergleich die folgende Verteilung:

Abb. 202: Frage 1, Bekanntheitsgrad der Termini courrier électronique, message électronique, mél, courriel, messagerie électronique, lettre électronique, e-mail und mail (relative Häufigkeiten, Ländervergleich)

\begin{tabular}{|l|r|r|r|}
\hline Termini & Frankreich in \% & Belgien in \% & Schweiz in \% \\
\hline E-mail & 99,2 & 82,4 & 100,0 \\
\hline Mail & 97,6 & 100,0 & 100,0 \\
\hline Courrier électronique & 96,0 & 88,2 & 100,0 \\
\hline Mél & 78,2 & 52,9 & 31,6 \\
\hline Courriel & 77,4 & 70,6 & 47,4 \\
\hline Message électronique & 63,0 & 35,3 & 76,5 \\
\hline $\begin{array}{l}\text { Messagerie électro- } \\
\text { nique }\end{array}$ & 50,8 & 29,4 & 36,8 \\
\hline Lettre électronique & & & 5,3 \\
\hline
\end{tabular}

Keiner der Termini wird von allen Informanten aller drei Länder zugleich zu 100\% gekannt. Da die Reihenfolge des Bekanntheitsgrades der Termini nicht in allen drei Ländern gleich ist, kann in dieser Tabelle keine für alle drei Länder gültige Reihenfolge angegeben werden. Die in der linken Spalte stehenden Termini werden daher nach den Daten der französischen Informanten geordnet.

Bezüglich der drei Termini e-mail, mail und courrier électronique liegen die Ergebnisse für Frankreich, Belgien und die Schweiz relativ dicht beieinander, alle drei Termini weisen einen Bekanntheitsgrad auf, der zwischen 82,4\% und 100\% liegt. Bezüglich 
des Kurzwortes mél lassen sich erhebliche Unterschiede konstatieren: In Frankreich kennen 78,2\% der Befragten mél, in Belgien sind es mit 52,9\% nur noch etwas mehr als die Hälfte der Informanten, in der Schweiz mit 31,6\% nur ca. ein Drittel der Informanten. Dieses Ergebnis lässt darauf schließen, dass es sich bei diesem Kurzwort um eine Bezeichnung handelt, die sich außerhalb der französischen Landesgrenzen kaum hat durchsetzen können. Courriel erhält in Frankreich $(77,4 \%)$ und in Belgien (70,6\%) relativ ähnliche Werte, von den schweizerischen Informanten erklärt jedoch nur knapp die Hälfte der Befragten (47,4\%), diesen Terminus zu kennen. Die Werte von message électronique weisen Parallelen zwischen Frankreich und der Schweiz auf (Bekanntheitsgrad von 63\% bzw. 76,5\%), in Belgien ist dieser Terminus nur ca. einem Drittel der Informanten bekannt. Messagerie électronique ist in Frankreich mit 50,8\% etwas bekannter als in den beiden Nachbarländern (29,4\% bzw. 36,8\%), was darauf zurückgeführt werden kann, dass es den Terminus messagerie électronique bereits im Minitel-System gegeben hat. Das Testwort lettre électronique wird in allen drei Untersuchungsländern von weniger als $10 \%$ der Befragten als bekannt angegeben.

Allen drei Befragungsländern ist gemeinsam, dass engl. e-mail und mail sowie franz. courrier électronique einen sehr hohen Bekanntheitsgrad aufweisen. Bei den anderen französischen Termini schwankt der Bekanntheitsgrad je nach Land. Generell sind die französischen Termini, mit Ausnahme von message électronique, in Frankreich immer bekannter als in den beiden anderen Ländern.

Welche Begründungen am häufigsten bei der Frage nach den Bedeutungsunterschieden angeführt wurden, zeigt die folgende Tabelle:

Abb. 203: Frage 3, Bedeutungsunterschiede zwischen courrier électronique, message électronique, mél, courriel, messagerie électronique, e-mail und mail (absolute Häufigkeiten, Ländervergleich)

\section{Kategorie}

Bedeutungsunterschied zwischen messagerie
électronique und den anderen Termini (mes-
sage électronique, courrier électronique, courriel,
mél, e-mail und mail).

Message électronique ist allgemeiner als die anderen Termini (courrier électronique, courriel, mél, e-mail, mail).

\section{Anzahl der Nennungen}

Frankreich Belgien Schweiz

49

4

2

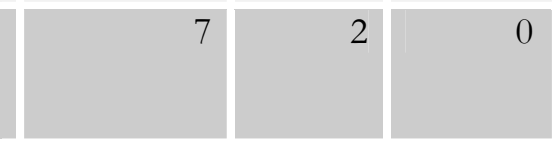

Die Parallelen sind evident. 49 der 63 Franzosen, die einen Bedeutungsunterschied feststellen, weisen auf den Bedeutungsunterschied zwischen messagerie électronique einerseits und den übrigen Termini andererseits hin. Messagerie électronique wird dabei von den meisten Informanten als das System verstanden, mit dessen Hilfe die einzelnen Nachrichten, die durch die übrigen Termini bezeichnet werden, empfangen und versendet werden können. Auf diesen Unterschied weisen auch 
die meisten Belgier hin: Vier der neun Belgier und zwei der drei Schweizer, die einen Bedeutungsunterschied feststellen, geben ebenfalls diese Begründung.

Es folgt mit sieben Stimmen bei den französischen und zwei Stimmen bei den belgischen Informatikern die Angabe, message électronique sei allgemeiner als die übrigen Termini.

Relative Einigkeit herrscht auch bezüglich des eigenen Sprachgebrauchs:

Abb. 204: Frage 5, eigener Sprachgebrauch: courrier électronique etc. (relative Häufigkeiten, Ländervergleich)

\begin{tabular}{|c|c|c|c|}
\hline Kategorien & $\begin{array}{l}\text { Frankreich in } \\
\%\end{array}$ & Belgien in \% & $\begin{array}{l}\text { Schweiz in } \\
\%\end{array}$ \\
\hline Meistens/immer mail & 54,8 & 41,1 & 47,4 \\
\hline Meistens/immer $e$-mail & 29,9 & 53,0 & 47,4 \\
\hline Meistens courrier électronique & 4,0 & 0,0 & 0,0 \\
\hline Meistens/immer mél & 2,4 & 5,9 & 0,0 \\
\hline Meistens message électronique & 1,6 & 0,0 & 0,0 \\
\hline Meistens courriel & 0,8 & 0,0 & 0,0 \\
\hline Je nach Kontext & 6,5 & 0,0 & 5,3 \\
\hline Insgesamt & 100,0 & 100,0 & 100,0 \\
\hline
\end{tabular}

Die englischen Termini e-mail und mail werden in allen drei Ländern am häufigsten verwendet: 84,7\% der französischen, 94,1\% der belgischen und 94,8\% der schweizerischen Informanten plädieren für den Gebrauch von e-mail oder mail. Es ist nicht sinnvoll, die weiteren Angaben zu den anderen Termini zu vergleichen, $\mathrm{da}$ in Belgien z.B. nur ein einziger Informant angibt, mél zu bevorzugen, dieser aber einem prozentualen Wert von 5,9\% entspricht, während die vier Prozent der französischen Informatiker, die angeben meistens courrier électronique zu verwenden, bereits fünf Informanten entsprechen. Die Auswertung der Frage nach der Bewertung der französischen Termini (Frage 6) entfällt aufgrund dieses Ergebnisses in diesem Kapitel ebenso, wie sie sich auch in den Kapiteln 9, 10 und 11 als hinfällig erwiesen hat.

Es folgt daher die Auswertung der Frage 7 nach den Gründen für die Bevorzugung von engl. mail bzw. e-mail.

Von den französischen Informanten wurden die folgenden drei Gründe am häufigsten angeführt:

- Kürze,

- Gewöhnung und

- Sicherheit, verstanden zu werden.

Bei den belgischen Informanten standen die

- Kürze,

- weite Verbreitung,

- Sicherheit, verstanden zu werden, und 
- Internationalität

an erster Stelle.

Die Informanten aus der Schweiz nannten am häufigsten die Argumente

- Gewöhnung,

- weite Verbreitung,

- Kürze und

- Internationalität.

Bezüglich der Gründe, die nach Meinung der Informanten für den Gebrauch von mail bzw. e-mail sprechen, zeigen sich - wie auch bezüglich der aktiven Akzeptanz - deutliche Parallelen zwischen den Befragten der drei Untersuchungsländer.

\subsubsection{Die Termini page d'accueil, page d'introduction und home- page}

Bezüglich des Bekanntheitsgrades der Termini page d'accueil, page d'introduction und homepage zeigen sich zwischen den drei Untersuchungsländern leichte Differenzen:

Abb. 205: Frage 8, Bekanntheitsgrad der Termini page d'accueil, page d'introduction und homepage (relative Häufigkeiten, Ländervergleich)

\begin{tabular}{|l|r|r|r|}
\hline Termini & Frankreich in \% & Belgien in \% & Schweiz in \% \\
\hline Page d'accueil & 98,4 & 94,1 & 89,5 \\
\hline Homepage & 91,1 & 100,0 & 94,7 \\
\hline Page d'introduction & 15,3 & 11,8 & 15,8 \\
\hline
\end{tabular}

Nur in Frankreich ist page d'accueil bekannter als das englische Äquivalent homepage. In Belgien und der Schweiz ist der englische Terminus bekannter als der französische. Insgesamt sind beide Termini in allen drei Ländern mit einem Prozentsatz von minimal $89,5 \%$ und maximal 100\% als sehr bekannt und damit sicher etabliert einzustufen. Das Testwort page d'introduction, das in keinem der drei Länder zur offiziellen Terminologie gehört, geben jeweils zwischen 11,8 und 15,8\% der Informanten als bekannt an.

Auf die Frage nach den Bedeutungsunterschieden zwischen engl. homepage und franz. page d'accueil wird in Frankreich (23 von 25 Stimmen) und in der Schweiz (vier von fünf Stimmen) mehrheitlich darauf verwiesen, dass homepage eine private Internetseite bezeichne, während mit page d'accueil die erste Seite eines Internetangebots gemeint sei, der Index. Auch einer der beiden Belgier, die einen Bedeutungsunterschied feststellen, nennt dieses Argument. Außerdem wird von einem Belgier und zwei Schweizern homepage als das gesamte Internetangebot und page d'accueil als die erste Seite dieses Angebots verstanden.

Während sowohl franz. page d'accueil als auch engl. homepage unter den befragten Informatikern einen hohen Bekanntheitsgrad aufweisen, gibt es bei der Frage nach dem eigenen Sprachgebrauch eindeutige Tendenzen zugunsten des einen oder des anderen Terminus. 
Abb. 206: Frage 12, eigener Sprachgebrauch: page d'accueil, page d'introduction, homepage (Ländervergleich)

\begin{tabular}{|l|r|r|r|}
\hline Termini & Frankreich in \% & Belgien in \% & Schweiz in \% \\
\hline $\begin{array}{l}\text { Meistens/immer bome- } \\
\text { page }\end{array}$ & 17,7 & 58,8 & 57,9 \\
\hline $\begin{array}{l}\text { Meistens/immer page } \\
\text { d'accueil }\end{array}$ & 68,6 & 35,3 & 26,3 \\
\hline $\begin{array}{l}\text { Meistens/immer page } \\
\text { d'introduction }\end{array}$ & 0,0 & 0,0 & 0,0 \\
\hline $\begin{array}{l}\text { Je nach Kontext } \\
\text { Keiner der Termini }\end{array}$ & 12,9 & 5,9 & 15,8 \\
\hline Insgesamt & 0,8 & 0,0 & 0,0 \\
\hline
\end{tabular}

Die französischen Informanten stimmen mehrheitlich (68,6\%) für die Verwendung von page d'accueil, während die belgischen und schweizerischen Informanten mehrheitlich für homepage plädieren.

Der Terminus page d'accueil wird von den französischen Informanten mit einem durchschnittlichen Wert von 1,56 besser bewertet als von den Belgiern, die ihm einen Wert von 1,72 zuweisen. Am besten beurteilen ihn die Schweizer mit 1,42, aber dieser Wert würde bei einer größeren Stichprobe sicherlich nach unten korrigiert werden müssen. Von den französischen und belgischen Befragten wird page d'accueil bezüglich seiner ästhetischen Qualitäten mit Werten von 2,26 bzw. 2,50 am schlechtesten beurteilt.

Die häufigsten Gründe, die von den Belgiern zugunsten des englischen Terminus angeführt werden, sind:

- die Sicherheit, verstanden zu werden,

- die Kürze,

- die weite Verbreitung und

- die Gewöhnung.

Bei den Schweizern sind es entsprechend:

- die Gewöhnung,

- die Internationalität,

- die Kürze und

- die Sicherheit, verstanden zu werden.

Die von den Belgiern und Schweizern angeführten Gründe für die Verwendung des Anglizismus sind identisch, lediglich die Rangfolge ist unterschiedlich. Dieses Phänomen war auch schon bezüglich der für e-mail/mail angeführten Argumente zu beobachten. 


\subsubsection{Die Termini toile d'araignée mondiale, toile mondiale, toile, T.A.M., réseau mondial, World Wide Web und web}

Bei der nächsten Lexemgruppe sollte wieder eine große Auswahl an Termini hinsichtlich ihrer Bekanntheit bewertet werden.

Abb. 207: Frage 15, Bekanntheitsgrad der Termini toile d'araignée mondiale, toile mondiale, toile, T.A.M., réseau mondial, World Wide Web und web (relative Häufigkeiten, Ländervergleich)

\begin{tabular}{|l|r|r|r|}
\hline Termini & Frankreich in \% & Belgien in \% & Schweiz in \% \\
\hline Web & 98,4 & 100,0 & 100,0 \\
\hline World Wide Web & 92,7 & 94,1 & 78,9 \\
\hline Toile & 79,8 & 70,6 & 73,7 \\
\hline Réseau mondial & 56,5 & 47,1 & 36,8 \\
\hline $\begin{array}{l}\text { Toile d'araignée } \\
\text { mondiale }\end{array}$ & 29,8 & 5,9 & 26,3 \\
\hline $\begin{array}{l}\text { Toile mondiale } \\
\text { T.A.M. }\end{array}$ & 29,8 & 17,6 & 26,3 \\
\hline $\begin{array}{l}\text { Termini } \\
\text { kannt }\end{array}$ & 1,6 & 0,0 & 5,3 \\
\hline
\end{tabular}

In allen drei Untersuchungsländern ist web der bekannteste Terminus, jeweils gefolgt von World Wide Web und toile. Diese drei Termini werden von jeweils mindestens $70 \%$ der Befragten als bekannt angegeben. An vierter Stelle folgt das Testwort réseau mondial. 29,8 bzw. 26,3\% der befragten Franzosen und Schweizer kennen toile d'araignée mondiale und toile mondiale. Nur 5,9\% der befragten Belgier, d.h. ein einziger von 17 Informanten, kennt toile d'araignée mondiale, aber 17,6\% der befragten Belgier kennen das etwas kürzere toile mondiale. Das Kurzwort T.A.M. rangiert am unteren Skalenende und ist jeweils weniger als 10\% der Informanten aller drei Untersuchungsländer bekannt.

Neben der in 12.1.1 erwähnten Tatsache, dass jede Stimme eines Informanten aus Belgien und der Schweiz ein im Vergleich zu den französischen Informanten höheres Gewicht erhält, sinkt auch mit der Anzahl der Informanten, die den Fragebogen ausfüllen, die Wahrscheinlichkeit, dass ein Terminus von keinem der Informanten als bekannt angegeben wird. Das bedeutet, dass sicherlich auch unter den belgischen Informatikern bei einer größeren Stichprobe ein oder mehrere Informanten gewesen wären, die T.A.M. als bekannt angegeben hätten, und es damit nicht bei einem Wert von $0,0 \%$ geblieben wäre.

Auf die Frage nach den Bedeutungsunterschieden gibt der einzige schweizerische Informant, der einen Bedeutungsunterschied feststellt, keine Antwort. Daher können bezüglich des Bedeutungsunterschiedes nur die Aussagen der französischen und belgischen Informanten verglichen werden. Am häufigsten wurde sowohl von den französischen als auch von den belgischen Informanten darauf hingewiesen, dass toile d'araignée mondiale, toile mondiale, T.A.M. und toile das gesamte 
Internet bezeichneten, während sich World Wide Web und web nur auf den auf httpund https-Protokollen basierenden Teil des Internet bezögen (elf von 13 und zwei von vier Informanten).

Bei der Frage nach dem eigenen Sprachgebrauch liegt in allen drei Ländern der englischsprachige Terminus web weit vor seinen Äquivalenten:

\begin{tabular}{|c|c|c|c|}
\hline Termini & Frankreich in \% & Belgien in \% & Schweiz in $\%$ \\
\hline Meistens/immer web & 87,1 & 70,5 & 94,7 \\
\hline Meistens/immer toile & 2,4 & 5,9 & 0,0 \\
\hline $\begin{array}{l}\text { Meistens/immer réseau } \\
\text { mondial }\end{array}$ & 0,8 & 5,9 & 0,0 \\
\hline $\begin{array}{l}\text { Meistens/immer World } \\
\text { Wide Web }\end{array}$ & 2,4 & 0,0 & 0,0 \\
\hline Je nach Kontext & 1,6 & 11,8 & 0,0 \\
\hline Keiner der Termini & 4,9 & 5,9 & 5,3 \\
\hline Weiß nicht & 0,8 & 0,0 & 0,0 \\
\hline Insgesamt & 100,0 & 100,0 & 100,0 \\
\hline
\end{tabular}

87,1\% der befragten Franzosen, 70,5\% der befragten Belgier und 94,7\% der befragten Schweizer geben an meistens oder immer web zu verwenden. Gelegentlich werden auch toile, réseau mondial oder World Wide Web genannt. Termini wie toile d'araignée mondiale oder toile mondiale werden von keinem der befragten Informanten verwendet.

Aufgrund dieses eindeutigen Votums für den englischsprachigen Terminus web bzw. bei den französischen Informanten auch für World Wide Web werden im Folgenden die Gründe aufgeführt, die nach Aussagen der Informanten für die Verwendung dieser Termini sprechen:

Von den französischen Informatikern werden vor allem die Kürze, die Gewöhnung, die weite Verbreitung, die Sicherheit, verstanden zu werden, sowie die Internationalität des englischsprachigen Terminus genannt. Bei den belgischen Informanten stehen die weite Verbreitung des Terminus, seine Internationalität, seine Kürze, die Sicherheit, verstanden zu werden, und die Gewöhnung an den Terminus web an vorderster Stelle. Die befragten Schweizer nennen vor allem die Gewöhnung an den Terminus web, seine Kürze, seine weite Verbreitung sowie seine Internationalität. Wiederum ähneln sich die vorgebrachten Argumente. Allerdings wechselt das erste Argument bei den französischen und belgischen Informatikern je nach Terminus, während die schweizerischen Informanten immer an erster Stelle auf die Gewöhnung verweisen. 


\subsubsection{Die Termini causette, bavardage, conversation électronique und chat}

Der vierte Fragenkomplex des ersten Fragebogenmoduls widmet sich den Termini causette, bavardage und chat sowie dem Testwort conversation électronique.

Abb. 209: Frage 22, Bekanntheitsgrad der Termini causette, bavardage, conversation électronique und chat (relative Häufigkeiten, Ländervergleich)

\begin{tabular}{|l|r|r|r|}
\hline Termini & Frankreich in \% & Belgien in \% & Schweiz in \% \\
\hline Chat & 99,2 & 100,0 & 94,7 \\
\hline Bavardage & 21,8 & 5,9 & 5,3 \\
\hline Conversation électronique & 11,3 & 0,0 & 31,6 \\
\hline Causette & 4,8 & 0,0 & 0,0 \\
\hline
\end{tabular}

Es fällt auf, dass nahezu alle Befragten den englischsprachigen Terminus chat kennen, jedoch nur verhältnismäßig wenige einen oder mehrere der drei französischen Termini. Da das Testwort conversation électronique von fast einem Drittel der befragten Schweizer als bekannt angegeben wird, liegt der Schluss nahe, dass es in der Schweiz häufiger verwendet wird als in Frankreich oder Belgien, wo es nur $11,3 \%$ der Informanten bzw. keinem Informanten bekannt ist. Der französische Terminus bavardage, der mittlerweile in keinem der drei Untersuchungsländer mehr zur offiziellen Terminologie gehört, weist einen jeweils höheren Bekanntheitsgrad auf als causette, das in Frankreich das einzige offizielle Ersatzwort für engl. chat darstellt. Causette ist weder den belgischen noch den schweizerischen Informanten bekannt.

Jeweils weniger als 20\% der Informanten stellen einen Bedeutungsunterschied zwischen chat, bavardage und causette fest. Hierbei wird übereinstimmend von acht Franzosen, einem Belgier und einem Schweizer darauf hingewiesen, dass sich chat nur auf die synchrone Kommunikation im Internet (IRC) beziehe, während causette und bavardage auch für Diskussionen in verschiedenen Kontexten der realen Welt verwendet würden.

Einigkeit herrscht auch bezüglich des eigenen Sprachgebrauchs: 
Abb. 210: Frage 26, eigener Sprachgebrauch: causette, bavardage, conversation électronique, chat (Ländervergleich)

\begin{tabular}{|l|r|r|r|}
\hline Termini & Frankreich in \% & Belgien in \% & Schweiz in \% \\
\hline $\begin{array}{l}\text { Meistens/immer chat } \\
\begin{array}{l}\text { Meistens/immer bavar- } \\
\text { dage }\end{array}\end{array}$ & 90,4 & 94,1 & 89,4 \\
\hline $\begin{array}{l}\text { Meistens/immer cau- } \\
\text { sette }\end{array}$ & 0,8 & 5,9 & 0,0 \\
\hline $\begin{array}{l}\text { Meistens conversation } \\
\text { électronique }\end{array}$ & 0,0 & 0,0 & 0,0 \\
\hline Keiner der Termini & & 0,0 & 5,3 \\
\hline $\begin{array}{l}\text { Je nach Kontext } \\
\text { Weiß nicht }\end{array}$ & 5,6 & 0,0 & 5,3 \\
\hline Insgesamt & 2,4 & 0,0 & 0,0 \\
\hline
\end{tabular}

Ähnlich wie bei web und seinen Äquivalenten wird von den aufgeführten Termini eindeutig das engl. chat bevorzugt. 90,4\% der befragten französischen, $94,1 \%$ der befragten belgischen und $89,4 \%$ der befragten schweizerischen Informatiker geben an meistens oder immer chat zu verwenden. Jeweils ein Franzose und ein Belgier verwenden nach eigenen Angaben bavardage, ein Schweizer conversation électronique. Das offizielle Ersatzwort causette wird von keinem der befragten Franzosen, Belgier oder Schweizer mehrheitlich oder immer verwendet.

Die Gründe, die für chat sprechen, sind nach Ansicht der französischen Informatiker die Gewöhnung an diesen Terminus, seine weite Verbreitung, seine Kürze und die Sicherheit, bei seiner Verwendung verstanden zu werden. Die befragten Belgier nennen am häufigsten die Sicherheit, bei der Verwendung des Terminus chat verstanden zu werden, seine weite Verbreitung, seine Kürze, die Gewöhnung an diesen Terminus und seine Internationalität. Bei den befragten Schweizern wird mit großem Abstand vor allen anderen Gründen die Gewöhnung an chat hervorgehoben. Sowohl bei den französischen als auch bei den schweizerischen Informatikern steht somit die Gewöhnung an den englischsprachigen Terminus an erster Stelle.

\subsubsection{Die Termini pirate, fouineur und cracker}

Der Bekanntheitsgrad der Termini franz. pirate und engl. cracker ist in allen drei Untersuchungsländern fast identisch: 
Abb. 211: Frage 29, Bekanntheitsgrad der Termini pirate, fouineur und cracker (relative Häufigkeiten, Ländervergleich)

\begin{tabular}{|l|r|r|r|}
\hline Termini & Frankreich in \% & Belgien in \% & Schweiz in \% \\
\hline Pirate & 97,6 & 82,4 & 89,5 \\
\hline Cracker & 90,3 & 88,2 & 84,2 \\
\hline Fonineur & 7,3 & 0,0 & 10,5 \\
\hline
\end{tabular}

In Frankreich und der Schweiz ist der französische Terminus etwas bekannter als sein englischsprachiges Pendant. In Belgien ist cracker etwas bekannter als franz. pirate. Nur sehr wenige Informanten geben das Testwort fouineur als bekannt an, das ebenfalls Bestandteil der offiziellen französischen und belgischen Terminologie ist, wenngleich es einen etwas anderen Inhalt als pirate bzw. cracker hat.

Nur ein französischer und ein schweizerischer Informant konstatieren einen Bedeutungsunterschied zwischen pirate und cracker. Beide Informanten geben als Begründung an, dass sich cracker nur auf den informatischen Kontext bzw. das Internet beziehe, wohingegen pirate ohne den Zusatz ,informatique“ semantisch weiter gefasst sei, z.B. auch ein „pirate maritime“ oder ein „pirate de l'air" sein könne. Hier wird die Parallele zu chat deutlich: Nur die englische Bezeichnung beziehe sich nach Ansicht der Informanten, die einen Bedeutungsunterschied feststellen, eindeutig auf Gegebenheiten im Internet, nicht aber auf Sachverhalte oder Gegenstände in der realen Welt. In diesem Kontext ist das Schlagwort der Monosemierung im Zuge der Entlehnung zu nennen.

Die Frage nach dem eigenen Sprachgebrauch ergibt keine eindeutigen Tendenzen zugunsten des einen oder anderen Terminus:

Abb. 212: Frage 33, eigener Sprachgebrauch: pirate, fouineur, cracker (Ländervergleich)

\begin{tabular}{|l|r|r|r|}
\hline Termini & Frankreich in \% & Belgien in \% & Schweiz in \% \\
\hline Meistens/immer cracker & 32,3 & 53,0 & 52,6 \\
\hline Meistens/immer pirate & 48,4 & 47,0 & 26,3 \\
\hline Je nach Kontext & 15,3 & 0,0 & 15,8 \\
\hline Keiner der Termini & 1,6 & 0,0 & 0,0 \\
\hline Weiß nicht & 2,4 & 0,0 & 5,3 \\
\hline Insgesamt & 100,0 & 100,0 & 100,0 \\
\hline
\end{tabular}

In Frankreich wird der französische Terminus leicht bevorzugt (48,4\% gegenüber $32,3 \%$ ), relativ viele Informanten entscheiden aber auch nach dem Kontext $(15,3 \%)$. In Belgien fällt die Entscheidung zwischen dem englischen und dem französischen Terminus nahezu unentschieden aus mit einer knappen Mehrheit von einem Informanten zugunsten des englischen Terminus. Bei den schweizerischen Informanten entscheidet die Mehrheit für die Verwendung von cracker $(52,6 \%)$, nur 26,3\% stimmen für den Gebrauch von pirate. Aber auch bei den 
schweizerischen Informatikern entscheiden drei Informanten $(15,8 \%)$ nach dem Kontext.

Von den befragten französischen Informatikern erhält der Terminus pirate ein hohes Akzeptanzvotum mit einem durchschnittlichen Wert von 1,61. Die belgischen Informanten bewerten pirate etwas schlechter als die französischen Informanten. Pirate erhält von ihnen einen durchschnittlichen Akzeptanzwert von 1,94 und liegt damit immer noch eindeutig im positiven Bereich. In beiden Untersuchungsländern wird der französische Neologismus bezüglich seiner ästhetischen Qualitäten am negativsten beurteilt (2,35 bzw. 2,83).

Als Gründe für die Verwendung von engl. cracker sprechen aus Sicht der französischen Informatiker:

- die Sicherheit, bei seiner Verwendung verstanden zu werden,

- die Gewöhnung an diesen Terminus,

- seine Internationalität,

- $\quad$ seine weite Verbreitung und

- die fehlende Übereinstimmung der Konnotationen der französischen und englischen Termini.

Die belgischen Informanten führen annähernd die gleichen Argumente an:

- die Sicherheit, bei der Verwendung von cracker verstanden zu werden,

- die Gewöhnung an diesen Terminus,

- seine Internationalität,

- $\quad$ seine weite Verbreitung und

- die unklare Bedeutung der französischen Termini.

Ein wiederum ähnliches Bild ergeben die von den schweizerischen Informatikern angeführten Argumente:

- die Gewöhnung an cracker,

- seine weite Verbreitung,

- die unklare Bedeutung der französischen Termini und

- die fehlende Übereinstimmung der Konnotationen der französischen und englischen Termini.

Es fällt auf, dass dieses Mal ein weiteres Argument zu den sonst üblicherweise an erster Stelle genannten hinzutritt, nämlich das Argument, die Konnotationen der französischen und englischen Termini stimmten nicht überein. Es ist davon auszugehen, dass hierbei auf den Unterschied zwischen cracker, das sich nach Ansicht der Informanten nur auf die „Computerpiraterie“ beschränke, und pirate, das auch andere Formen der Piraterie in der realen Welt einschließe, angespielt wird. Möglich, wenngleich weniger wahrscheinlich, wäre aber auch, dass die Informanten noch das Testwort fouineur im Gedächtnis haben und sich bezüglich der Konnotationen darauf beziehen. 


\subsubsection{Die Termini fournisseur d'accès, pourvoyeur d'accès und (access) provider}

Wie auch bezüglich des Lexempaares engl. cracker und franz. pirate liegen bei der Frage nach dem Bekanntheitsgrad von fournisseur d'accès, pourvoyeur d'accès und (access) provider der französische Terminus fournisseur d'accès und sein englischsprachiges Äquivalent (access) provider dicht beieinander.

Abb. 213: Frage 36, Bekanntheitsgrad der Termini fournisseur d'accès, pourvoyeur d'accès und (access) provider (Ländervergleich)

\begin{tabular}{|l|r|r|r|}
\hline Termini & Frankreich in \% & Belgien in \% & Schweiz in \% \\
\hline Fournisseur d'accès & 99,2 & 100,0 & 94,7 \\
\hline (Access) provider & 91,9 & 100,0 & 89,5 \\
\hline Pourvoyeur d'accès & 8,1 & 0,0 & 10,5 \\
\hline
\end{tabular}

Bei den französischen und schweizerischen Informatikern ist der französische Terminus jeweils etwas bekannter als der Anglizismus. Alle befragten Belgier erklären, sowohl fournisseur d'accès als auch (access) provider zu kennen. Das äußerst seltene Testwort pourvoyeur d'accès kennen nur wenige Informanten.

Keiner der Informanten stellt zwischen den beiden Termini fournisseur d'accès und (access) provider einen Bedeutungsunterschied fest. Aus diesem Grund entfällt die Auswertung der entsprechenden Frage.

Bei der Frage nach dem eigenen Sprachgebrauch zeigen sich länderspezifische Unterschiede:

Abb. 214: Frage 40, eigener Sprachgebrauch: fournisseur d'accès, pourvoyeur d'accès, (access) provider (Ländervergleich)

\begin{tabular}{|l|r|r|r|}
\hline Termini & Frankreich in \% & Belgien in \% & Schweiz in \% \\
\hline $\begin{array}{l}\text { Meistens/immer four- } \\
\text { nisseur d'accès }\end{array}$ & 71,8 & 41,2 & 26,3 \\
\hline $\begin{array}{l}\text { Meistens/immer } \\
\text { (access) provider }\end{array}$ & 19,3 & 29,4 & 57,9 \\
\hline $\begin{array}{l}\text { Meistens/immer } \\
\text { pourvoyeur d'accès }\end{array}$ & 0,8 & 0,0 & 0,0 \\
\hline Keiner der Termini & 0,8 & 0,0 & 0,0 \\
\hline Je nach Kontext & 7,3 & 29,4 & 15,8 \\
\hline Insgesamt & 100,0 & 100,0 & 100,0 \\
\hline
\end{tabular}

$71,8 \%$ der befragten französischen Informatiker geben an meistens oder immer den französischen Terminus zu verwenden, nur 19,3\% plädieren für den englischsprachigen Terminus. Bei den befragten Belgiern ergibt sich eine leichte Mehrheit für den französischen Terminus (41,2\% gegenüber 29,4\%); hier ist mit 29,4\% der Teil der Informanten groß, die sich in Abhängigkeit vom Kontext für den französischen oder englischen Terminus entscheiden. 57,9\% der befragten Schweizer 
erklären, meistens oder immer den englischen Terminus zu verwenden. 26,3\% plädieren für den französischen Terminus, und 15,8\% entscheiden je nach Kontext. Hinsichtlich des Sprachgebrauchs wird insbesondere der Unterschied zwischen den befragten Franzosen und Schweizern deutlich: Die französischen Informatiker ziehen den französischen, die schweizerischen Informatiker den englischen Terminus vor.

Der französische Terminus fournisseur d'accès erhält von den französischen Informanten, die für seinen Gebrauch gestimmt haben, ein durchschnittliches Akzeptanzvotum von 1,77. Die belgischen Informatikern beurteilen fournisseur d'accès mit einem durchschnittlichen Wert von 1,91 etwas schlechter, wenngleich immer noch im positiv. Im Vergleich dazu schneidet der französische Neologismus mit einem Wert von 2,42 bei den schweizerischen Informatikern relativ schlecht ab. Sowohl von den französischen als auch von den belgischen und schweizerischen Informanten wird der Terminus bezüglich seiner ästhetischen Qualitäten mit einem Wert von 2,61, 2,86 bzw. 3,8 am schlechtesten bewertet. Am positivsten schätzen ihn die französischen und belgischen Informanten bezüglich seiner Adäquatheit mit 1,36 bzw. 1,43 ein, bei den schweizerischen Informanten wird seine Korrektheit am positivsten bewertet $(1,0)$.

Die belgischen und schweizerischen Informanten, die nach eigenen Angaben meistens oder immer (access) provider verwenden, nennen dafür folgende Gründe:

- Weite Verbreitung,

- Kürze,

- die Sicherheit, verstanden zu werden,

- Internationalität und

- Gewöhnung

bei den belgischen Informanten;

- Gewöhnung,

- Internationalität,

- Kürze,

- weite Verbreitung und

- Sicherheit, verstanden zu werden,

bei den befragten Schweizern.

Die genannten Argumente sind - wie fast immer - die gleichen, nur wechselt bei den Franzosen und Belgier die Reihenfolge der Gründe. Bei den befragten Schweizern steht wiederum die Gewohnheit an erster Stelle.

\subsubsection{Zusammenfassung und Schlussfolgerungen}

In den Unterkapiteln 12.1.1 bis 12.1.6 wurden der Bekanntheitsgrad, die festgestellten Bedeutungsunterschiede, der Sprachgebrauch, die Bewertung des französischen Neologismus und die Gründe, die für die Verwendung des englischen Terminus/der englischen Termini sprechen, hinsichtlich länderübergreifender Gemeinsamkeiten oder Differenzen verglichen. 
Die Ergebnisse, die die Testwörter erzielt haben, werden in dieser Zusammenfassung ausgeklammert.

Es wurde beim Vergleich der Ergebnisse der drei Länder deutlich, dass es bezüglich der Kenntnis der Termini, der festgestellten Bedeutungsunterschiede, der Bewertung der französischen Termini und der Gründe für die Bevorzugung des Anglizismus/der Anglizismen viele Parallelen zwischen den Informanten aus Frankreich, Belgien und der Schweiz gibt.

Einen Überblick über die Übereinstimmungen bezüglich des Bekanntheitsgrades aller ausgewählten französischen und englischsprachigen Termini gibt die folgende Tabelle: 
Abb. 215: Bekanntheits- und Etablierungsgrad aller französischen und englischsprachigen Termini in \% (Ländervergleich)

\begin{tabular}{|c|c|c|c|c|c|c|c|}
\hline \multicolumn{7}{|c|}{ Bekanntheitsgrad der Termini } & \multirow[t]{2}{*}{$\begin{array}{l}\text { Etablie- } \\
\text { rungs- } \\
\text { grad }\end{array}$} \\
\hline & \multicolumn{3}{|c|}{ Französische Neologismen } & \multicolumn{3}{|c|}{ Englischsprachige Termini } & \\
\hline & $\begin{array}{l}\text { Frank- } \\
\text { reich }\end{array}$ & Belgien & Schweiz & Frankreich & Belgien & Schweiz & \\
\hline $100 \%$ & -- & $\begin{array}{l}\text { fournisseur } \\
\text { d'accès }\end{array}$ & $\begin{array}{l}\text { courrier } \\
\text { électronique }\end{array}$ & -- & $\begin{array}{l}\text { (access) pro- } \\
\text { vider, chat, } \\
\text { homepage, } \\
\text { mail, web }\end{array}$ & $\begin{array}{l}\text { e-mail, mail, } \\
\text { web }\end{array}$ & $\begin{array}{l}100 \% \text { ige } \\
\text { Etablie- } \\
\text { rung }\end{array}$ \\
\hline $\begin{array}{l}90- \\
99,9 \%\end{array}$ & $\begin{array}{l}\text { courrier } \\
\text { électronique, } \\
\text { fournisseur } \\
\text { d'accès, page } \\
\text { d'accueil, } \\
\text { pirate }\end{array}$ & $\begin{array}{l}\text { page } \\
\text { d'accueil }\end{array}$ & $\begin{array}{l}\text { fournisseur } \\
\text { d'accès }\end{array}$ & $\begin{array}{l}\text { (access) pro- } \\
\text { vider, chat, } \\
\text { cracker, e-mail, } \\
\text { homepage, mail, } \\
\text { web, World } \\
\text { Wide Web }\end{array}$ & $\begin{array}{l}\text { World Wide } \\
\text { Web }\end{array}$ & $\begin{array}{l}\text { chat, } \\
\text { homepage }\end{array}$ & $\begin{array}{l}\text { sicherer } \\
\text { Etablie- } \\
\text { rungs- } \\
\text { grad }\end{array}$ \\
\hline $\begin{array}{l}80- \\
89,9 \%\end{array}$ & -- & $\begin{array}{l}\text { courrier } \\
\text { électronique, } \\
\text { pirate }\end{array}$ & $\begin{array}{l}\text { page d'ac- } \\
\text { cueil, pirate }\end{array}$ & -- & $\begin{array}{l}\text { cracker, } \\
\text { e-mail }\end{array}$ & $\begin{array}{l}\text { (access) pro- } \\
\text { vider, } \\
\text { cracker }\end{array}$ & \\
\hline $\begin{array}{l}70- \\
79,9 \%\end{array}$ & $\begin{array}{l}\text { courriel, mél, } \\
\text { toile }\end{array}$ & courriel, toile & $\begin{array}{l}\text { message élec- } \\
\text { tronique, } \\
\text { toile }\end{array}$ & -- & -- & $\begin{array}{l}\text { World Wide } \\
\text { Web }\end{array}$ & \multirow{3}{*}{$\begin{array}{l}\text { unsiche- } \\
\text { rer } \\
\text { Etablie- } \\
\text { rungs- } \\
\text { grad }\end{array}$} \\
\hline $\begin{array}{l}60- \\
69,9 \%\end{array}$ & $\begin{array}{l}\text { message } \\
\text { électronique }\end{array}$ & -- & -- & -- & -- & -- & \\
\hline $\begin{array}{l}50- \\
59,9 \%\end{array}$ & $\begin{array}{l}\text { messagerie } \\
\text { électronique }\end{array}$ & mél & -- & -- & -- & -- & \\
\hline $\begin{array}{l}40- \\
49,9 \%\end{array}$ & -- & -- & courriel & -- & -- & -- & \multirow{4}{*}{$\begin{array}{l}\text { schwa- } \\
\text { cher } \\
\text { Etablie- } \\
\text { rungs- } \\
\text { grad }\end{array}$} \\
\hline $\begin{array}{l}30- \\
39,9 \%\end{array}$ & -- & $\begin{array}{l}\text { message } \\
\text { électronique }\end{array}$ & $\begin{array}{l}\text { messagerie } \\
\text { électronique, } \\
\text { mél }\end{array}$ & -- & -- & -- & \\
\hline $\begin{array}{l}20- \\
29,9 \%\end{array}$ & $\begin{array}{l}\text { bavardage, } \\
\text { toile } \\
\text { d'araignée } \\
\text { mondiale, } \\
\text { toile mon- } \\
\text { diale }\end{array}$ & $\begin{array}{l}\text { messagerie } \\
\text { électronique }\end{array}$ & $\begin{array}{l}\text { toile } \\
\text { d'araignée } \\
\text { mondiale, } \\
\text { toile mon- } \\
\text { diale }\end{array}$ & -- & -- & -- & \\
\hline $\begin{array}{l}\text { weni- } \\
\text { ger als } \\
20 \%\end{array}$ & $\begin{array}{l}\text { causette, } \\
\text { T.A.M. }\end{array}$ & $\begin{array}{l}\text { bavardage, } \\
\text { causette, } \\
\text { T.A.M., } \\
\text { toile } \\
\text { d'araignée } \\
\text { mondiale, } \\
\text { toile mon- } \\
\text { diale }\end{array}$ & $\begin{array}{l}\text { bavardage, } \\
\text { causette, } \\
\text { T.A.M. }\end{array}$ & -- & -- & -- & \\
\hline
\end{tabular}

Die Abbildung zum Bekanntheits- und Etablierungsgrad der ausgewählten Termini zeigt deutlich, dass Termini wie toile d'araignée mondiale, toile mondiale, T.A.M., bavardage und causette, die offiziellen Ersatzwörter zu engl. web/World Wide Web und chat, sich in keinem der drei Untersuchungsländer haben etablieren können. Hingegen sind alle englischen Termini mindestens 70\% aller Befragten bekannt. Daraus lässt sich ableiten, dass in allen drei Ländern die Anglizismen wesentlich 
weiter verbreitet sind als die französischen Neologismen. Es fällt aber auch auf, dass es weniger Anglizismen als französische Neologismen gibt.

In allen drei Ländern sind die französischen Termini courrier électronique, fournisseur d'accès, page d'accueil und pirate am bekanntesten. Vor allem mél und messagerie électronique sind in Frankreich wesentlich bekannter als in Belgien und der Schweiz.

In Frankreich behaupten sich bezüglich des aktiven Sprachgebrauchs drei französische Neologismen gegen die Anglizismen, page d'accueil, pirate und fournisseur d'accès. In Belgien setzt sich nur fournisseur d'accès gegen die Anglizismen durch, pirate hat immerhin noch einen geringen Vorsprung vor cracker. Ansonsten setzen sich die vier Anglizismen mail/e-mail, homepage, web, chat durch. In der Schweiz werden durchgehend die Anglizismen verwendet, obwohl Termini wie courrier électronique und fournisseur d'accès auch in der Schweiz einen hohen Bekanntheitsgrad aufweisen.

Die Gründe, die auf die Frage nach der Bevorzugung des englischsprachigen Terminus genannt wurden, sind ziemlich ähnlich und unterliegen von Terminus zu Terminus nur leichten Schwankungen. Es wird, wenn die Begründungen für alle Anglizismen zusammengefasst werden, sowohl von französischer als auch von schweizerischer Seite an erster Stelle das Argument der Gewöhnung an den englischsprachigen Terminus angeführt, wobei dieses Argument bei den Schweizern in allen Fällen an erster Stelle steht. Dann folgen bei den französischen Informanten die Sicherheit, verstanden zu werden, die Kürze, die weite Verbreitung und die Internationalität des Anglizismus. Bei den schweizerischen Informatikern sind es entsprechend die Kürze, die Internationalität, die weite Verbreitung und die Sicherheit, bei Verwendung des Anglizismus verstanden zu werden. In Belgien steht die Sicherheit, verstanden zu werden, an erster Stelle, dann erst folgen die weite Verbreitung des Anglizismus, die Gewöhnung, die Internationalität und seine Kürze. Es fällt auf, dass bei den Belgiern Argumente im Vordergrund stehen, die die Kommunikation betreffen. Dies dürfte nicht zuletzt darauf zurückzuführen sein, dass acht von 17 Informanten im zweisprachigen Brüssel leben, während die anderen Informanten weniger Kontakte zu Angehörigen anderer Sprachgemeinschaften haben dürften. Bei den Franzosen und Schweizern steht mit der Gewöhnung an den Anglizismus ein persönliches Argument an erster Stelle.

Es ist deutlich geworden, dass die staatlichen Terminologiekommissionen, in diesem Fall die französische Informatik-Kommission, die belgische Expertengruppe, die für die Entscheidung über die Annahme der französischen Terminologie zuständig ist, und die schweizerische Arbeitsgruppe nicht immer Rücksicht auf die Sprachgewohnheiten der Bevölkerung nehmen. Werden englische Termini entgegen dem Trend zur Verwendung der internationalen Termini durch nationale Bildungen ersetzt, ist deren Akzeptanz in keiner Weise gewährleistet. Insbesondere in Belgien und der Schweiz ist die Tendenz ausgeprägt, die englischen Termini zu verwenden, während in Frankreich auch häufig die französische Terminologie verwendet wird. Ein Indiz, dass die belgische Terminologiekommission versucht, den tatsächlichen Sprachgebrauch stärker zu berücksichtigen, ist darin 
zu sehen, dass Termini wie chat, die mit den entsprechenden französischen Äquivalenten im Jahre 2001 noch Bestandteil der offiziellen Informatik-Terminologie waren, im Jahre 2002 aus der Datenbank entfernt worden sind. Dies könnte darauf hindeuten, dass die Terminologiekommission dem Faktum Rechnung getragen hat, dass sich inzwischen chat so weit verbreitet hat, dass jedes französische Ersatzwort hier 1. zu spät kommt und 2. nur zusätzliche Verwirrung stiften würde.

Die Untersuchungsergebnisse haben ferner gezeigt, dass sich eine 1:1-Übersetzung des englischen Terminus ins Französische nicht automatisch in den Untersuchungsländern durchsetzt, auch wenn der französische Neologismus kurz ist: Franz. toile setzt sich nicht gegen web durch, franz. bavardage und causette setzen sich nicht gegen chat durch. Insofern kann nicht sicher davon ausgegangen werden, dass sich die Termini, deren Etablierung in 5.2.1 unter Kategorie 4 (Eindeutige 1:1-Übersetzung) als recht wahrscheinlich angenommen wurde, auch wirklich durchgesetzt haben. Daher müsste in weiteren Akzeptanzstudien auch überprüft werden, bei welchen der in der Kategorie 4 enthaltenen Lexempaaren sich der französische Terminus und bei welchen sich der englische Terminus durchsetzt ${ }^{2}$. Weiterhin hat der Ländervergleich gezeigt, dass von den Ergebnissen, die für französische Informanten festgestellt wurden, keineswegs auf andere frankophone Länder geschlossen werden darf und kann. Es ist durchaus möglich, dass sich ein französischer Neologismus in Frankreich etabliert hat - Bsp. page d'accueil - in Belgien und/oder der Schweiz aber die entsprechenden englischsprachigen Termini bevorzugt werden. Auch zwischen Belgien und der Schweiz gibt es noch Unterschiede, die Schweizer verwenden konsequent mehrheitlich die Anglizismen. Der Verschiedenheit der Akzeptanz in unterschiedlichen frankophonen Staaten wurde in der bisherigen linguistischen Forschung - mit Ausnahme von Vergleichen zwischen Québec und Frankreich - keine Rechnung getragen.

Auch muss der in 5.2.3.2 geäußerten Hypothese, dass die Akzeptanz in erster Linie von den Termini und ihrer Verbreitung selbst abhänge, aufgrund der Ergebnisse widersprochen werden: Die Kenntnis der Termini und vor allem ihr Gebrauch werden in hohem Maße durch die Länderzugehörigkeit bestimmt. Offensichtlich ist in Ländern, in denen es mehr als eine Nationalsprache gibt, das Bedürfnis nach der Verwendung einer internationalen Terminologie höher als in einem offiziell einsprachigen Land wie Frankreich.

Die Frage, ob generell der englische oder französische Terminus vorgezogen wird, lässt sich nicht allgemein beantworten, sondern muss von Fall zu Fall entschieden werden. Sicher ist nur, dass diese Entscheidung auf Seiten der Sprecher (und somit im Sprachgebrauch) und nicht auf Seiten der Terminologiekommissionen liegt, die zwar vorschlagen, nicht aber maßgeblich beeinflussen können: „Un walkman restera ainsi un walkman, quoi qu'en pensent les commissions de ter-

\footnotetext{
${ }^{2}$ Es handelt sich bei den in die Kategorie 4 eingeordneten Termini um die folgenden Lexempaare: engl.: backbone - franz.: dorsale, engl.: bookmark - franz.: signet, engl.: frame - franz:: cadre, engl.: gateway - franz.: passerelle, engl.: thread - franz.: fil (de la discussion) und engl.: window - franz.: fenêtre.
} 
minologie, tant que le français de la rue n'aura pas décidé de le remplacer par un baladeur [...]“ (Calvet 1989, 34).

Aufgrund dieser Erkenntnisse ist die Aussage, die Goosse am Ende seines Buches La néologie française aujourd'hui (1975) trifft, auch heute noch gültig. Die Macht des usage der Sprachgemeinschaft im Neologismusprozess dürfe auf keinen Fall unterschätzt werden:

„Il me reste à réaffirmer la force prépondérante de l'usage: là où il a choisi définitivement, même s'il a mal choisi, le théoricien n'a plus qu'à se taire. L'usage a toujours raison, même quand il a tort" (Goosse 1975, 72).

\subsection{Zweites Fragebogenmodul: Kenntnis und Akzeptanz der aktuellen Sprachpolitik und Terminologiearbeit}

Die Fragen im zweiten Fragebogenmodul sind je nach Land etwas unterschiedlich formuliert worden. Die Sprachpolitik der frankophonen Belgier orientiert sich am französischen Vorbild und ähnelt in mancher Hinsicht auch der des französischen Staates (vgl. 3.3.1). Allerdings treten in Belgien Gesetze zum Schutz der französischen Sprache und terminologische Aktivitäten hinter anderen Problemen zurück wie der Tatsache, dass es zunächst zwischen den drei belgischen Sprachgemeinschaften den Sprachenfrieden und die entsprechenden Rechte zu wahren gilt. Entsprechend ähneln sich die Fragen des zweiten Fragebogenmoduls für die französischen und belgischen Informanten sehr.

Die in der Schweiz betriebene Sprachpolitik unterscheidet sich in mancherlei Hinsicht von der der Franzosen und Belgier. Insofern weichen die Fragen des zweiten Fragebogenmoduls oftmals von denen ab, die den französischen und belgischen Informanten vorgelegt wurden.

Die Frage nach der Kenntnis der aktuellen Sprachpolitik ihres Landes wurde nur den französischen und belgischen Informanten gestellt:

Abb. 216: Frage 44, Kenntnis der aktuellen Sprachpolitik (Ländervergleich: Frankreich und Belgien)

\begin{tabular}{|l|r|r|}
\hline & Frankreich in \% & Belgien in \% \\
\hline Oui. & 24,2 & 0,0 \\
\hline Oui, j'en ai entendu parler. & 54,0 & 17,6 \\
\hline Non. & 21,0 & 82,4 \\
\hline Je ne sais pas. & 0,8 & 0,0 \\
\hline Insgesamt & 100,0 & 100,0 \\
\hline
\end{tabular}

Während 78,2\% der befragten Franzosen erklären, zumindest von der Sprachpolitik (insbesondere der Loi Toubon) gehört zu haben, geben dies nur 17,6\% der Belgier in Bezug auf die belgische Sprachpolitik an. Hingegen kennen 82,4\% der 
befragten Belgier die aktuelle belgische Sprachpolitik zum Schutz der französischen Sprache vor Anglizismen nach eigenen Aussagen nicht.

$\mathrm{Da}$ es in der Schweiz keinerlei staatliche Maßnahmen gibt, um den Anglizismeneinfluss einzudämmen und für viele Westschweizer eine starke Frankreichorientierung angenommen wird (vgl. besonders 2.3.4.2.2), wurden die schweizerischen Informanten nach der Kenntnis der französischen Sprachpolitik gefragt:

Abb. 217: Frage 47, Kenntnis der aktuellen französischen Sprachpolitik (Schweiz)

\section{Schweiz in \%}

\begin{tabular}{|l|r|}
\hline Oui. & 15,8 \\
\hline Oui, j'en ai entendu parler. & 47,4 \\
\hline Non. & 36,8 \\
\hline Je ne sais pas. & 0,0 \\
\hline Insgesamt & 100,0 \\
\hline
\end{tabular}

Mehr als die Hälfte $(63,2 \%)$ der befragten Schweizer gibt an, die französische Sprachpolitik zu kennen bzw. von ihr gehört zu haben. 36,8\% geben an die französische Sprachpolitik zum Schutz der Sprache vor Anglizismen nicht zu kennen. Die Bekanntheit der französischen Sprachpolitik fällt im eigenen Land mit 78,2\% nur um 15\% höher als im Nachbarland, der Schweiz, aus. Daraus lässt sich zumindest folgern, dass entweder die schweizerischen Medien über die Situation im Nachbarland berichten oder aber die Westschweizer durch die Rezeption französischer Medien über die französische Sprachpolitik informiert worden sind.

Die Frage nach der Beurteilung der aktuellen Sprachpolitik bzw. nach der generellen Beurteilung einer Politik zum Schutz der Sprache vor Anglizismen wurde von den befragten Franzosen, Belgiern und Schweizern wie folgt beantwortet:

Abb. 218: Frage 45, Beurteilung der aktuellen Sprachpolitik (Ländervergleich: Frankreich, Belgien und Schweiz)

\begin{tabular}{|c|c|c|c|}
\hline & Frankreich in \% & Belgien in \% & Schweiz in \% \\
\hline $\begin{array}{l}\text { Absolument néces- } \\
\text { saire. }\end{array}$ & 5,6 & 5,9 & 10,5 \\
\hline Souhaitable. & 52,4 & 47,05 & 15,8 \\
\hline Inutile. & 37,9 & 47,05 & 73,7 \\
\hline Je ne sais pas. & 4,1 & 0,0 & 0,0 \\
\hline Insgesamt & 100,0 & 100,0 & 100,0 \\
\hline
\end{tabular}

Nur ein geringer Prozentsatz der befragten Informatiker (5,6\%, 5,9\% bzw. 10,5\%) hält Sprachpolitik für unbedingt notwendig. 52,4\% der Franzosen und 47,05\% der Belgier, also jeweils ca. die Hälfte, halten Sprachpolitik für wünschenswert. Von den befragten Schweizern hingegen halten nur 15,8\% sprachpolitische Maßnahmen für wünschenswert, und 73,7\% lehnen sie ab. Von den französischen Informatikern lehnen nur 37,9\% sprachpolitische Maßnahmen ab. Bei den Belgiern ist 
das Verhältnis zwischen Befürwortung und Ablehnung sprachpolitischer Maßnahmen sehr ausgeglichen: Ca. 53\% stehen ihr positiv gegenüber, ca. 47\% lehnen sie $a b$.

Das Ergebnis lässt darauf schließen, dass es einen Zusammenhang zwischen sprachpolitischer Tradition und den diesbezüglichen Einstellungen gibt: Es wäre zu vermuten, dass sprachpolitische Maßnahmen zum Schutz der französischen Sprache in der Schweiz vor allem deshalb abgelehnt werden, weil sie in der Schweiz keine Tradition haben. In Belgien haben sprachpolitische Maßnahmen, um das Verhältnis zwischen frankophonen und niederländischsprachigen Belgiern zu regeln, seit dem 19. Jahrhundert Tradition, Maßnahmen zum Schutz der französischen Sprache vor Anglizismen gibt es seit 1976. Die Hälfte der befragten Belgier befürwortet Maßnahmen zum Schutz der französischen Sprache, die andere Hälfte lehnt sie ab. In Frankreich blickt Sprachpolitik bekanntermaßen auf die längste Tradition zurück. Hier wird Sprachpolitik mehrheitlich befürwortet. Die Ergebnisse legen zwar die Annahme nahe, dass es eine Parallele zwischen der sprachpolitischen Tradition und den entsprechenden Einstellungen gibt, diese Annahme kann an dieser Stelle allerdings nicht bewiesen werden. Die ausgeprägte Ablehnung der schweizerischen Informanten könnte auch damit zu erklären sein, dass die Schweizer, die ja mehrheitlich von der aktuellen französischen Sprachpolitik wissen, sie als nutzlos und gescheitert betrachten und entsprechende Maßnahmen daher für jedes andere Land sowie für ihr eigenes ebenfalls ablehnen.

Bei der folgenden Frage geht es um die Beurteilung der Terminologielisten in Frankreich und Belgien. Da es in der Schweiz keine eigens für die französischsprachigen Schweizer verfassten Terminologielisten im Stil der französischen und belgischen Terminologiearbeit gibt und die Terminologieliste der Schweizerischen Eidgenossenschaft in dieser Hinsicht einen Sonderfall darstellt, entfiel die entsprechende Frage für die schweizerischen Informanten.

\section{Abb. 219: Frage 46, Beurteilung der Terminologielisten (Ländervergleich: Frank- reich und Belgien)}

\begin{tabular}{|l|r|r|}
\hline & Frankreich in \% & Belgien in \% \\
\hline Utiles. & 8,1 & 11,8 \\
\hline Souhaitables. & 12,1 & 5,9 \\
\hline Pas assez connues. & 30,6 & 11,8 \\
\hline Inutiles. & 33,9 & 52,9 \\
\hline Je ne les connais pas. & 11,3 & 17,6 \\
\hline Rien/Je ne sais pas. & 4,0 & 0,0 \\
\hline Insgesamt & 100,0 & 100,0 \\
\hline
\end{tabular}

20,2\% der befragten Franzosen und 17,7\% der befragten Belgier halten die Terminologielisten für nützlich oder wünschenswert. Vor allem die französischen Informanten bemängeln, dass die Listen nicht bekannt genug seien. 52,9\% der Belgier, aber nur 33,9\% der Franzosen bewerten die Terminologielisten als über- 
flüssig. Aus diesem Ergebnis lassen sich keine eindeutigen Schlussfolgerungen ableiten. Es ist allerdings zu erkennen, dass die Belgier den Terminologielisten tendenziell etwas ablehnender gegenüberstehen als die befragten Franzosen. Auch dieses Faktum lässt sich möglicherweise auf die in Belgien erst seit kurzer Zeit konsequent betriebene Terminologiearbeit zurückführen.

Auf die Frage, ob sie die Terminologielisten befolgen, antworteten die französischen und belgischen Informatiker wie folgt:

Abb. 220: Frage 47, Befolgen der Terminologielisten (Ländervergleich: Frankreich und Belgien)

\begin{tabular}{|l|r|r|}
\hline & Frankreich in \% & Belgien in \% \\
\hline Oui. & 2,4 & 5,9 \\
\hline Non. & 42,0 & 47,1 \\
\hline Partiellement. & 38,7 & 23,5 \\
\hline Je ne les connais pas. & 16,1 & 23,5 \\
\hline Je ne sais pas. & 0,8 & 0,0 \\
\hline Insgesamt & 100,0 & 100,0 \\
\hline
\end{tabular}

Nur 2,4\% der befragten Franzosen und 5,9\% der befragten Belgier geben an die Terminologievorschläge in jedem Fall zu befolgen. Demgegenüber lehnen dies $42 \%$ bzw. $47,1 \%$ konsequent ab. Relativ hoch ist bei den französischen Informanten mit 38,7\% der Anteil derer, die die Terminologielisten nach eigenen Angaben teilweise befolgen. Bei den Belgiern sind dies entsprechend 23,5\%. Ebenfalls ein Viertel der befragten Belgier (23,5\%) gibt an, die Terminologielisten nicht zu kennen. Insgesamt ist der Anteil der Belgier, die die Terminologielisten nach eigenen Aussagen befolgen, geringer als der Anteil der Franzosen, oder umgekehrt formuliert ist die Ablehnung der Terminologielisten bei den befragten Belgier etwas höher als bei den befragten Franzosen. Auch hier wäre wieder die diachrone Sichtweise interessant: Würde die Ablehnung der Belgier sinken, wenn die belgische Terminologiearbeit auf eine längere Tradition zurückblicken kann, also in zehn oder zwanzig Jahren? Oder ist der Grund für die höhere Ablehnung vielmehr darin zu sehen, dass die belgische Terminologiearbeit weitgehend unbekannt ist?

Die Frage nach der Kenntnis der offiziellen Internet-Terminologie wurde den Informanten aller drei Länder gestellt. 
Abb. 221: Frage 48, Kenntnis der offiziellen Internet-Terminologie (Ländervergleich: Frankreich, Belgien und Schweiz)

\begin{tabular}{|c|c|c|c|}
\hline & $\begin{array}{l}\text { Frankreich } \\
\text { in } \%\end{array}$ & $\begin{array}{l}\text { Belgien } \\
\text { in } \%\end{array}$ & $\begin{array}{l}\text { Schweiz } \\
\text { in } \%\end{array}$ \\
\hline Oui, je les connais bien. & 0,0 & 0,0 & 0,0 \\
\hline Oui, je les/la connais un peu. & 16,1 & 11,8 & 10,5 \\
\hline $\begin{array}{l}\text { Oui, mais je connais seulement la } \\
\text { liste de } 1999 \text {. }\end{array}$ & 0,8 & -- & -- \\
\hline $\begin{array}{l}\text { Oui, mais je connais seulement la } \\
\text { liste de } 2000 \text {. }\end{array}$ & 0,0 & -- & -- \\
\hline J'en ai déjà entendu parler. & 37,9 & 17,6 & 10,5 \\
\hline Non, pas du tout. & 42,8 & 70,6 & 79,0 \\
\hline Je ne sais pas. & 2,4 & 0,0 & 0,0 \\
\hline Insgesamt & 100,0 & 100,0 & 100,0 \\
\hline
\end{tabular}

Es fällt auf, dass die belgische und die schweizerische Internet-Terminologie wesentlich unbekannter sind als die französische. 70,6\% bzw. 79\% der befragten Belgier und Schweizer, aber nur 42,8\% der befragten Franzosen geben an die Internet-Terminologie nicht zu kennen. Kein einziger Informant behauptet, die offizielle Internet-Terminologie gut zu kennen. 54,8\% der Franzosen, 29,4\% und $21 \%$ der Schweizer kennen die Internet-Terminologie ein wenig oder wissen zumindest von ihrer Existenz.

Die Tatsache, dass die französische Internet-Terminologie bekannter als die belgische und schweizerische ist, lässt sich sicherlich auf mehrere Faktoren zurückführen: Zum einen wird die französische Bevölkerung über sprachpolitische Maßnahmen in Frankreich generell schneller und ausführlicher durch die Medien in Kenntnis gesetzt als die Belgier und Schweizer. Zum anderen gibt es für die französische Internet-Terminologie im Unterschied zur belgischen oder schweizerischen Terminologieliste andere Publikationsformen als nur die Internet-Publikation. Die Versäumnisse liegen somit in allen drei Ländern, um auf das von Haugen entworfene Modell der Sprachplanung zurückzukommen, vor allem in Phase 3 und 4 (vgl. 3.1.3), nämlich in der unzureichenden Verbreitung der Ergebnisse der Sprachplanung, d.h. konkret in der mangelnden Verbreitung der Terminologielisten. Einschränkend ist für die Schweiz anzumerken, dass die Terminologielisten eigentlich ausschließlich für die Kommunikation zwischen Bürger und Behörde konzipiert sind. Darüber hinaus können sie keinen Verbindlichkeitsanspruch erheben, da in der Schweiz der rechtliche Rahmen für derartige Maßnahmen fehlt.

Die letzte Frage, die nur denjenigen Informanten gestellt wurde, die angegeben haben die Internet-Terminologie ein wenig zu kennen, bezieht sich auf den Gebrauch der Internet-Terminologie. 
Abb. 222: Frage 49, Gebrauch der offiziellen Internet-Terminologie (Ländervergleich: Frankreich, Belgien und Schweiz)

\begin{tabular}{|l|r|r|r|}
\hline & Frankreich in \% & Belgien in \% & Schweiz in \% \\
\hline Non, jamais. & 23,8 & 100,0 & 100,0 \\
\hline Partiellement. & 71,4 & 0,0 & 0,0 \\
\hline Je ne sais pas. & 4,8 & 0,0 & 0,0 \\
\hline Insgesamt & 100,0 & 100,0 & 100,0 \\
\hline
\end{tabular}

Bei den Belgiern und Schweizern haben ohnehin nur jeweils zwei Informanten angegeben die offizielle Terminologie ein wenig zu kennen. Sie befolgen nach eigenen Aussagen die offizielle Terminologie generell nicht. Von den französischen Informanten, denen diese Frage gestellt wurde, geben 71,4\% an die Internet-Terminologie partiell zu verwenden. Demgegenüber lehnen nur 23,8\% ihre Verwendung kategorisch ab. In Frankreich stößt die Internet-Terminologie auf eine spürbar höhere Akzeptanz als in den beiden Nachbarländern. Dies ist sicherlich neben der längeren sprachpolitischen Tradition auch auf die bessere Verbreitung der Terminologielisten zurückzuführen. Die höhere Akzeptanz der französischen Terminologielisten und der französischen Termini insgesamt schlägt sich auch in den Ergebnissen des ersten Fragebogenmoduls nieder, wie in 12.1 gezeigt werden konnte.

Insofern kann der in 4.4.2 zitierten und auf Frankreich bezogenen These Sokols (2001, 206f.), dass eine Kluft bestehe zwischen der Befürwortung der Sprachpolitik einerseits und der Beachtung ihrer Inhalte, nur teilweise zugestimmt werden. Die Mehrheit der befragten französischen Informatiker (78,2\%), aber nur 17,6\% der belgischen Informatiker sind über die Existenz einer staatlichen Sprachpolitik informiert. 71,4\% der Franzosen, die die Terminologielisten kennen, geben an sie teilweise zu befolgen, in Belgien befolgt sie nach eigenen Angaben niemand. In Frankreich ist somit die Kluft nicht sehr groß zwischen dem Wissen um eine Sprachpolitik bzw. dem Wissen um die Existenz der Internet-Terminologie und ihrer zumindest partiellen Befolgung, wobei es sich bei den Fragebogendaten lediglich um eine Selbsteinschätzung der Informanten handelt. Von einem „kollektive[n] Aufsehen“, dass die Publikation der Terminologielisten (bezogen auf Frankreich) errege, kann aufgrund dieser Ergebnisse jedoch kaum die Rede sein, sonst müsste ein höherer Prozentsatz an Informanten über die Existenz der Internet-Terminologie Bescheid wissen.

\subsection{Drittes Fragebogenmodul: Auswertung der Kommen- tare zur Sprachpolitik und Terminologiearbeit}

Jeweils mehr als die Hälfte der befragten Franzosen, Belgier und Schweizer haben einen Kommentar zur Sprachpolitik und/oder Terminologiearbeit verfasst, näm- 
lich 73 der 124 französischen, zehn der 17 belgischen und zwölf der 19 schweizerischen Informanten.

Wie die Kommentare analysiert und ausgewertet wurden, wurde ausführlich in 9.3 beschrieben. Von den insgesamt sechs großen Kategorien

1. Befürwortung der Sprachpolitik,

2. Ablehnung der Sprachpolitik,

3. Pro \& contra Sprachpolitik,

4. Befürwortung der Terminologiearbeit,

5. Ablehnung der Terminologiearbeit und

6. Pro \& contra Terminologiearbeit,

die anhand der Kommentare der französischen Informatiker gebildet wurden, konnten die Kommentare der belgischen und schweizerischen Informatiker auch jeweils drei dieser Kategorien zugeordnet werden. So ergaben sich als Schnittpunkte die Kategorien

1. Befürwortung der Sprachpolitik

2. Ablehnung der Sprachpolitik

3. Ablehnung der Terminologiearbeit.

Insgesamt richten sich die meisten der von den befragten Informatikern aller drei Länder vorgebrachten Argumente gegen die Terminologiearbeit. Für sprachpolitische Maßnahmen werden jeweils positive und negative Aspekte angeführt, wobei die Anzahl der gegen sprachpolitische Maßnahmen gerichteten Argumente die der befürwortenden Argumente leicht übersteigt. Während die Terminologiearbeit in keinem der von den belgischen und schweizerischen Informanten formulierten Kommentare befürwortet wird, führen die französischen Informanten auch einige Argumente an, die für die Terminologiearbeit sprechen.

Nach Ländern aufgeteilt bedeutet dies: Aus den Kommentaren der französischen Informanten konnten fünf Argumente isoliert werden, die für die französische Sprachpolitik sprechen, sieben sprechen dagegen. Bezüglich der Terminologiearbeit werden insgesamt sechs positive Aspekte aufgeführt; es werden aber auch 19 verschiedene Argumente genannt, die die negativen Aspekte der Terminologiearbeit hervorheben. Nur ein einziges Argument eines belgischen Informatikers befürwortet sprachpolitische Maßnahmen, die negativen Argumente überwiegen zahlenmäßig. Es wird kein Argument zugunsten der Terminologiearbeit vorgebracht, jedoch neun Argumente gegen Terminologiearbeit. Unter den von den schweizerischen Informatikern genannten Argumenten sprechen zwei Argumente für, eines gegen Sprachpolitik. Aus den Kommentaren der schweizerischen Informatiker konnten acht Argumente isoliert werden, die sich gegen Terminologiearbeit richten. In keinem der Kommentare wird ein positiver Aspekt der Terminologiearbeit angesprochen.

Es ist an dieser Stelle unnötig, alle in den Kommentaren enthaltenen Argumente aufzugreifen, da diese bereits in 9.3, 10.3 und 11.3 ausführlich erläutert wurden. Der Schwerpunkt wird daher im Folgenden auf die Schnittstellen in der Argumentation gelegt, d.h. auf die Parallelen zwischen den Ländern. Es wird aber auch darauf hingewiesen, wenn ein Argument, das von Vertretern eines Landes am 
häufigsten genannt wurde, von den Informanten der anderen Länder gar nicht erwähnt wird.

\section{Befürwortung der Sprachpolitik}

Bezüglich der ersten Kategorie, der Befürwortung der Sprachpolitik, wurde von je einem Franzosen, einem Belgier und einem Schweizer das Argument genannt, dass Sprachpolitik zu befürworten sei, jedoch riskiere, ins Lächerliche abzurutschen. Je ein Franzose und ein Belgier äußern auch ihre uneingeschränkte Befürwortung der Sprachpolitik zum Schutz der französischen Sprache. Am häufigsten führen die französischen Informanten das Argument an, Sprachpolitik sei notwendig, wünschenswert und nützlich, sollte aber nur in Maßen vollzogen werden. Dieses Argument wird hingegen von keinem der belgischen oder schweizerischen Informanten angesprochen.

\section{Ablebnung der Sprachpolitik}

Im Rahmen der Argumente, die gegen sprachpolitische Maßnahmen vorgebracht wurden, wiesen sechs der französischen Informanten darauf hin, dass sich die natürliche Sprachentwicklung durch sprachpolitische Maßnahmen nicht aufhalten lasse. Dieses Argument wird von je einem Informatiker aus Belgien und der Schweiz im Zusammenhang mit der Terminologiearbeit vorgebracht (s.u.). Drei Franzosen und ein Belgier schätzen sprachpolitische Maßnahmen als überflüssig ein. Ebenso gibt es Übereinstimmungen zwischen Franzosen und Belgiern: Informanten beider Länder weisen darauf hin, dass Sprachpolitik lächerlich sei. Jeweils ein Belgier und ein Schweizer argumentieren, dass anstelle einer Sprachpolitik, die sich gegen Anglizismen richtet, die Kenntnis von Fremdsprachen gefördert werden sollte. In eine ähnliche Richtung - allerdings bezogen auf die verbesserte Kenntnis der Muttersprache, nicht von Fremdsprachen - weist das Argument, das von insgesamt drei französischen Informatikern angeführt wird: Anstelle von sprachpolitischen Maßnahmen sollten vielmehr die französische Sprachkultur und die Beherrschung der französischen Sprache gefördert werden.

\section{Befürwortung der Terminologiearbeit}

Sieben französische Informatiker befürworten nach eigenen Angaben eine Terminologiearbeit, allerdings nur unter bestimmten Umständen. Sie erachten Terminologiearbeit nur dann als sinnvoll, wenn die erarbeiteten französischen Termini kurz, präzise und ästhetisch befriedigend sind sowie den Sinn des englischen Terminus korrekt wiedergeben. Während die Kürze, die Präzision und die Korrektheit des Sinns intersubjektiv nachprüfbar sind, dürfte es schwierig sein, Termini zu finden, die für alle Sprecher in ästhetischer Hinsicht akzeptabel sind. Es hat sich bei der Bewertung der französischen Neologismen gezeigt, dass der Wert bezüglich der ästhetischen Qualitäten eines Terminus stets der schlechteste oder einer der schlechtesten war. Die ästhetische Qualität eines französischen Neologismus ist den Sprechern jedoch wichtig. Mitunter wurde bei den Gründen, die nach Ansicht der Informanten die Verwendung des Anglizismus begünstigen, 
darauf verwiesen, dass die französischen Termini hässlich seien und auch aus diesem Grund die englischen Termini verwendet würden.

Wie oben bereits erwähnt, enthält keiner der von den belgischen und schweizerischen Informanten formulierten Kommentare Argumente, die für die Terminologiearbeit sprechen.

\section{Ablehnung der Terminologiearbeit}

Die meisten Kommentare enthalten Argumente, die gegen die Terminologiearbeit sprechen. Von den französischen Informanten wurde am häufigsten (19 Informanten) argumentiert, dass eine französische Terminologie in den Fällen lächerlich sei, wenn es sich bei den Neologismen lediglich um Französisierungen der Anglizismen handele (Bsp. cédérom und mél für engl. CD-ROM und e-mail). Dieses Argument wurde auch von zwei Belgiern und drei Schweizern zum Ausdruck gebracht. Das bei den französischen Informatikern mit 16 Stimmen an zweiter Stelle stehende Argument, französische Neologismen seien häufig lächerlich, insbesondere weil sie zu spät kämen, wenn sich die englischen Termini bereits etabliert und sich die Sprecher an diese gewöhnt hätten, wird auch von zwei Belgiern angeführt. Zwölf französische Informanten und zwei Schweizer lehnen es ab, dass der Staat den Sprachgebrauch festschreibe, und sprechen sich dafür aus, dass einzig der Sprachgebrauch selbst über die Termini entscheiden solle („Darwinismus").

Die belgischen und schweizerischen Informanten führen am häufigsten Kommunikationsprobleme an, die sich aus der Verwendung französischer Termini ergeben können (vier Belgier und sechs Schweizer). Aber auch zehn Franzosen nennen dieses Argument: Englisch sei die dominierende Sprache und zugleich die lingua franca im Bereich der neuen Technologien wie Informatik/Internet. Daher erleichtere die Verwendung der englischen Terminologie die Kommunikation weltweit und unter frankophonen Sprechern.

Das Argument, Sprache lebe und verändere sich und dieser Prozess sei auch durch Terminologiearbeit nicht zu stoppen, wird von sieben Franzosen, einem Belgier und einem Schweizer genannt. Je ein Belgier und ein Schweizer sprechen sich dafür aus, nur die bekannten Termini zu verwenden, anstatt neue Termini zu schaffen.

Es fällt auf, dass die von den belgischen und schweizerischen Informanten formulierten Kommentare stärker den Aspekt der nationalen und internationalen Kommunikation in den Vordergrund rücken, als dies in den Kommentaren der französischen Informanten zum Ausdruck kommt. Es ist naheliegend, dass Kommunikationsprobleme eher von Informanten gesehen werden, die in einem Land mit mehr als einer offiziellen Landessprache leben, als von Informanten, die in einem einsprachigen Land leben. Allerdings hat sich auch bei der Auswertung der von den französischen Informatikern formulierten Kommentare gezeigt, dass die Beherrschung der englischen Sprache im Bereich der neuen Technologien als unumgänglich betrachtet wird. Es ist anhand der Untersuchungsergebnisse nahe- 
liegend, dass eine erfolgreiche Terminologiearbeit in erster Linie auf die Erleichterung der Kommunikation abzielen sollte. Das Ziel der eingesetzten Terminologiekommissionen darf nicht ausschließlich darin bestehen, durch die Erarbeitung einer nationalen (französischen) Terminologie ein Maximum an Anglizismen auszumerzen und damit eine Terminologie zu schaffen, die weit von den Bedürfnissen und dem Sprachgebrauch der Sprachbenutzer entfernt ist. Wie die für die Verwendung der Anglizismen angeführten Argumente sowie die Kommentare zur Terminologiearbeit gezeigt haben, dominiert bei den befragten Informanten der Wunsch, mit möglichst nur der einen Bezeichnung, an die man sich inzwischen gewöhnt habe, sowohl mit Personen der eigenen Nationalität bzw. Sprachgemeinschaft als auch mit Personen anderer Nationalitäten bzw. Sprachgemeinschaften (sowie mit informatischen Laien als auch Fachleuten) auf unmissverständliche Weise kommunizieren können. In diesem Sinne ist es fraglich, inwieweit die Erarbeitung nationaler Terminologien im Bereich der neuen Technologien, in denen Englisch ohnehin die lingua franca geworden ist, überhaupt noch sinnvoll ist. Auf die Wichtigkeit der nationalen und internationalen Kommunikation verweist auch Fugger (1983b, 136), wenn er schreibt:

„Denn eine Sprache dient der Kommunikation, und wenn eine Sprachplanung notwendig sein sollte, dann nur mit dem Ziel, die gegenseitige Verständigung zu erleichtern. Gegenseitig heißt hierbei einerseits, daß die Sprachbenutzer ein und derselben Sprache sich bestmöglich verstehen sollen, andererseits aber auch, daß die Sprachbenutzer verschiedener Sprachen sich optimal verstehen."

Dieses Ziel könne nach Fugger nur dadurch erreicht werden, dass eine Sprache für internationale Lexeme offengehalten werde und nur diejenigen Lexeme ausgemerzt werden, die tatsächlich eine Kommunikationsbarriere darstellen (vgl. ebd.). Die meisten Kommunikationsprobleme werden nach Ansicht der im Sommer 2002 befragten Informatiker aber genau dadurch hervorgerufen, dass nationale Termini verwendet würden, die die Verständigung nicht mehr ohne weiteres gewährleisteten.

Im Übrigen spricht nichts dagegen, dass sowohl der englische als auch der französische Terminus beibehalten werden. Im Falle des Lexempaares page d'accueil/ homepage wurde sogar von vielen Informanten eine Bedeutungsdifferenzierung vorgenommen, so dass nun beide Termini ihre Daseinsberechtigung dadurch haben, dass sie jeweils unterschiedliche Sachverhalte bezeichnen.

\subsection{Zusammenfassung}

Ziel der WWW-Befragung und des Ländervergleichs konnte es nicht sein, statistisch unanfechtbare repräsentative Daten zu erhalten. Vielmehr musste sich die Untersuchung darauf beschränken, Tendenzen aufzuzeigen. Trotz der mit 17 bzw. 19 befragten Informatikern geringen Fallzahlen für Belgien und die Schweiz wird 
davon ausgegangen, dass die Gegenüberstellung der Daten der drei Untersuchungsländer Hinweise auf Parallelen und Differenzen gibt.

Bezüglich des Bekanntheitsgrades der Internet-Termini lassen sich viele Parallelen zwischen den Untersuchungsländern feststellen. Die Termini, die bei den französischen Informatikern den höchsten Bekanntheitsgrad erhalten, sind meistens auch unter den befragten Belgiern und Schweizern am bekanntesten. Allerdings gibt es auch Termini wie messagerie électronique und mél, die zwar in Frankreich, nicht aber in Belgien und der Schweiz sonderlich verbreitet sind. Entscheidend dürfte für die Verbreitung der Termini der Einfluss der Medien sein, bei den Informatikern insbesondere der Einfluss der Fachliteratur. Offensichtlich werden in den französischen Lehr- und Fachbüchern mehr französische Termini verwendet als in Belgien oder der Schweiz.

Das Gefühl für die Synonymie der Termini bzw. die Begründungen bezüglich der Bedeutungsunterschiede, die von den Informanten der drei Untersuchungsländer gegeben werden, fallen recht einheitlich aus. Bezüglich des eigenen Sprachgebrauchs verwenden die französischen Informanten drei französische und drei englische Termini mehrheitlich, bei den belgischen Informanten sind es zwei französische und vier englische Termini. Die schweizerischen Informatiker plädieren jeweils für den Anglizismus, in keinem Fall wird ein französischer Neologismus häufiger als ein Anglizismus verwendet. Für die Verwendung der englischsprachigen Termini werden von den Informanten aller drei Untersuchungsländer fünf Gründe am häufigsten aufgeführt. In alphabetischer Reihenfolge sind dies:

- Gewöhnung an den englischsprachigen Terminus,

- Internationalität des englischsprachigen Terminus,

- Kürze des englischsprachigen Terminus,

- Sicherheit, bei Verwendung des englischsprachigen Terminus verstanden zu werden, und

- $\quad$ weite Verbreitung des englischsprachigen Terminus.

Während die Belgier häufiger pragmatische Gründe heranziehen wie v.a. die durch den Einsatz von Anglizismen erleichterte Kommunikation, nennen die schweizerischen Informanten durchgehend als erstes Argument die Gewöhnung an den englischsprachigen Terminus. Im Kapitel zu den belgischen Informanten wurde bereits festgestellt, dass acht der befragten Belgier in Brüssel leben und damit im Berufsleben höchstwahrscheinlich mit Angehörigen der niederländischen Sprachgemeinschaft konfrontiert werden. Insofern ist es naheliegend, dass für sie eher die Probleme präsent sind, die durch die Verwendung nationaler Terminologien hervorgerufen werden. Allerdings ist auch bei den zehn schweizerischen Informanten, die in Genf leben, davon auszugehen, dass sie dort an der Universität oder im Berufsleben auf Deutschschweizer treffen und daher am unkompliziertesten mithilfe der englischen Terminologie kommunizieren können.

In 12.2 wurde ermittelt, inwiefern sich die Kenntnis und die Akzeptanz der Sprachpolitik und Terminologiearbeit zwischen den befragten Informatikern der drei Länder unterscheiden. Die belgische Sprachpolitik ist wesentlich unbekannter 
als die französische. Sprachpolitische Maßnahmen werden von den Franzosen eher positiv beurteilt, bei den belgischen Informanten gleichen sich die Stimmen für und wider entsprechende Maßnahmen in etwa aus, bei den schweizerischen Informanten überwiegt die Ablehnung entsprechender Maßnahmen. Die französische Internet-Terminologie ist wesentlich bekannter als die entsprechende belgische und schweizerische Terminologie. Dieses Ergebnis dürfte neben der längeren Tradition, die Sprachpolitik in Frankreich genießt, in erster Linie auf die Arbeit der DGLFLF und der französischen Terminologie-Kommission sowie auf den höheren Etat für terminologische Maßnahmen zurückzuführen sein, denn im Unterschied zu Belgien und der Schweiz werden die Terminologielisten nicht nur über das Internet verbreitet, sondern auch in gedruckter Form.

In den Kommentaren zur Sprachpolitik und Terminologiearbeit, die in 12.3 ausgewertet wurden, werden sowohl Argumente für als auch gegen sprachpolitische Maßnahmen angeführt. Insgesamt überwiegen die Argumente, die sich gegen Terminologiearbeit richten. Vor allem von den Belgiern und Schweizern wird darauf hingewiesen, dass eine nationale (französische) Terminologie die Kommunikation erschwere. Manche der französischen Neologismen werden als lächerlich erachtet. Oftmals wird moniert, die Ersatzwörter kämen zu spät, wenn sich die Anglizismen bereits etabliert hätten. Außerdem hat die Auswertung der Kommentare in den Kapiteln 9,10 und 11 gezeigt, wie stark auch das berufliche Umfeld bzw. die Notwendigkeit länder- und sprachenübergreifender Kommunikation den Wunsch nach einer internationalen Terminologie und die Verwendung der englischsprachigen Termini fördert. Die Staatsangehörigkeit und das (berufliche) Umfeld haben somit einen entscheidenden Einfluss auf die Wortkenntnis und den Sprachgebrauch. Es wäre interessant zu vergleichen, ob interessierte Laien eher die französischen oder eher die englischen Termini kennen, aber diese Frage kann im Rahmen dieser Studie leider nur aufgeworfen werden.

Die Ergebnisse des Vergleichs bestätigen die These Dierickx (1997, 313; vgl. 2.3.3.3), die davon ausgeht, dass die Reaktionen der Belgier auf den angloamerikanischen Einfluss weniger heftig ausfallen als die der Franzosen. Die aktive Akzeptanz der englischen Termini ist bei den belgischen Informatikern ausgeprägter als bei den französischen Informatikern. Noch geringer als in Belgien ist der Widerstand gegen Anglizismen allerdings in der Schweiz. Bei den belgischen und schweizerischen Informatikern dürfte die ausgeprägte Akzeptanz für Anglizismen neben ihrem beruflichen Hintergrund auch in ihrer spezifischen Situation begründet liegen, dem häufigen Kontakt mit Mitgliedern anderer Sprachgemeinschaften. Durch den Umstand, in einem mehrsprachigen Land zu leben, sind die belgischen und schweizerischen Informatiker mehr noch als französische Informatiker mit der Notwendigkeit konfrontiert, Kommunikationsprobleme möglichst gering zu halten, wenn nicht gar zu umgehen.

Es kann davon ausgegangen werden, dass Studien, die z.B. mit einem nicht fachlich spezifizierten Publikum durchgeführt werden, zu anderen Ergebnissen führen und die Akzeptanz für französische Neologismen entsprechend höher ausfällt als bei den befragten Informatikern. 


\subsection{Exkurs: Sprachpolitik und Internet-Terminologie in Spanien, Deutschland und Italien}

Technischer Fortschritt bringt Bezeichnungsbedürfnisse und infolgedessen neue Termini mit sich. Im Rahmen der Globalisierung wachsen die Wahrscheinlichkeit und das Bedürfnis, dass sich die Benennung neuer Sachverhalte nicht nur einzelsprachlich und völlig isoliert von anderen Sprachen vollzieht, sondern es länderübergreifende Gemeinsamkeiten und Schnittpunkte gibt, die sog. Internationalismen. Neben der Einsicht in die Notwendigkeit internationaler Bezeichnungen vor allem bei den betroffenen Berufsgruppen - gibt es auf staatlicher Seite mitunter das Bedürfnis, die Anzahl an internationalen (meist angloamerikanischen) Termini durch entsprechende sprachpolitische oder terminologische Maßnahmen einzugrenzen.

Gegenwärtig sind auch in anderen Ländern als in Frankreich und Belgien sprachpflegerische Aktivitäten nach französischem Vorbild spürbar. Anglizismen sind z.B. auch in Spanien ein Problem, und die Dominanz des Englischen in den Bereichen Wirtschaft und Technik löst immer wieder Diskussionen aus (vgl. Brumme 1992, 392). Der Kampf gegen das espanglis ist jedoch in Spanien nicht so institutionalisiert wie in Frankreich, obwohl auch dort bereits mehrfach ein der Loi Bas-Lauriol bzw. der Loi Toubon vergleichbares Gesetz gefordert wurde (vgl. Braselmann 2002d, 325; Braselmann/Hinger 1999, 287; Lebsanft 1997, 99-108). Anstelle von staatlich verordneter Sprachpflege übernehmen in Spanien die Libros de estilo der Tageszeitungen sprachpflegerische Tätigkeiten, zu denen auch die Frage gehört, wie mit Fremdwörtern umgegangen werden kann. Aber auch andere Stellen bemühen sich um die Sprachpflege insbesondere im Bereich der Anglizismen. So gibt es auch in Spanien Vorschläge zur Ersetzung von Internet-Anglizismen. Hier ist der Glosario básico inglés-español para usuarios de Internet zu nennen, der von der Asociación de Técnicos de Informática publiziert wird und neben der Druckfassung auch im Internet einsehbar ist (vgl. Fernández Calvo 2001). Engl. e-mail wird durch span. mensaje (de correo) electrónico, durch mensatrón oder durch emilio wiedergegeben. Ebenso taucht aber auch der Internationalismus email in der Spalte mit den spanischen Termini auf (Fernández Calvo 2001, 53f.). Für das engl. home page wird span. página inicial oder página raíz vorgeschlagen. Im Unterschied dazu wird engl. personal page mit página personal übersetzt (ebd., 55). Für engl. cracker bzw. hacker wird als spanisches Äquivalent pirata vorgeschlagen, der Vorgang wird mit pirateo bezeichnet (ebd., 55).

Auch in Deutschland wird in den letzten Jahren vielfach über Denglisch oder Engleutsch diskutiert, ohne dass jedoch ein entsprechendes Gesetz verabschiedet wurde. Anfang des Jahres 2001 forderte der damalige Berliner Innensenator Eckhart Werthebach, vielen auch scherzhaft als Mr. Valuestream bekannt, ein entsprechendes Sprachschutzgesetz und erhörte damit vor allem die Forderungen des Vereins Deutsche Sprache e.V., der sich seit 1997 massiv gegen die Verwendung sog. ,,überflüssiger“ Anglizismen einsetzt und selbst Listen mit Ersatzvorschlägen erstellt hat (vgl. Braselmann 2002, 207; Molitor 2001, 80-83). Wie utopisch ein derartiges Gesetz für Deutschland ist, braucht wohl nicht näher erläutert zu wer- 
den. In den Ersatzwortlisten, die inzwischen zu einem Glossar zusammengefügt wurden, finden sich selbstverständlich auch viele Vorschläge, wie Internet-Anglizismen durch deutsche Bezeichnungen wiedergegeben werden könnten; inwieweit diese praktikabel sind, möge jeder selbst entscheiden (vgl. http://vdsev.de/denglisch/).

Eine Studie, in der die deutsche und die französische Computersprache im Kontext weiterer europäischer Sprachen verglichen werden, bietet Zimmer (1998). Huber/Cheval $(1998,169)$ vergleichen die deutsche mit der französischen Internet-Terminologie und stellen fest, dass es im Französischen weniger Anglizismen gibt als im Deutschen. Da die relative Anglizismenhäufigkeit im Deutschen unabhängig von der Medienart höher ist als im Französischen, wie auch Plümer (2000, 274) als Ergebnis ihrer Studie festhält, kann davon ausgegangen werden, dass diese Unterschiede unmittelbare Folge der französischen Sprachpolitik sind. Während im Deutschen z.B. der Anglizismus Computer verwendet wird, wird im Französischen hierfür der eigensprachliche Ausdruck ordinateur verwendet. Auch fällt auf, dass Fremdwörter oftmals an die französische Sprache angepasst werden (engl. server $>$ franz. serveur, engl. bug $>$ franz. bogue), während dies im Hinblick auf die deutsche Sprache selten passiert und die Anglizismen meist grafisch und phonetisch unverändert übernommen werden.

In Italien gibt es zwar wie in Frankreich und Spanien eine Akademie - und vereinzelt unternehmen auch private Initiativen wie die Vereinigung „Bella Lingua“ etwas gegen den Einfluss des Angloamerikanischen -, jedoch rangiert Italien bezüglich seiner sprachpflegerischen und sprachpolitischen Aktivitäten weit hinter Frankreich und Spanien. Die staatlichen sprachpflegerischen Bemühungen konzentrieren sich in erster Linie auf die sog. „Italianisierung“, d.h. die weitere Verbreitung des Italienischen auf Kosten der einzelnen Dialekte (vgl. Braselmann 2002c, 37; 2002d, 327f. $)^{3}$. Zwar gab es unter dem Faschismus im Jahre 1941 eine erste Liste mit Ersatzwörtern für Xenismen, diese wurde jedoch mit dem Ende des Faschismus ungültig. Seitdem gibt es keine entsprechenden staatlichen Maßnahmen mehr, die sich auf die Reinheit des Wortschatzes richten (vgl. Krefeld 1988, 315), obwohl besonders seit Mitte des 20. Jahrhunderts der angloamerikanische Einfluss in allen Lebensbereichen deutlich spürbar wird. Bei der Frage, inwieweit es gerechtfertigt ist, analog zum franglais, espanglis oder Denglisch auch von einem italiese zu sprechen, gibt Windisch (ebd., 119, 139) Entwarnung: Der Anteil an Anglizismen in Zeitungstexten sei mit einem Durchschnittswert von drei Anglizismen vergleichbar niedrig. Auch für die mit Anglizismen durchsetzte Computersprache wurde bereits ein entsprechender Terminus gefunden, das sog. computerese (vgl. Vittoz Canuto 2001, 183).

\footnotetext{
${ }^{3}$ Braselmann (2002d, 328) gibt eine einleuchtende Erklärung dafür, warum in Italien kaum gegen Anglizismen vorgegangen wird: „Ein weiterer Grund für die italienische Souveränität Englischem gegenüber liegt ohne Frage in der deskriptiven Grundhaltung nicht nur der Akademie, die sprachwissenschaftlich arbeitet, sondern auch der laienlinguistischen Haltung. Normfragen werden aus der Perspektive der Mehrheit der Sprachbenutzer entschieden, und zwar der gegenwärtigen, nicht der vergangenen."
} 
Vittoz Canuto (2001) stellt bei ihrer Untersuchung ausgewählter französischer und italienischer Zeitungen und Zeitschriften (erschienen zwischen November 1999 und August 2000) im Hinblick auf die Unterschiede zwischen der französischen und der italienischen Internet-Terminologie fest, dass Frankreich die Tendenz hat, Fremdwörter an das eigene System anzupassen, und zudem häufig viele französischsprachige Varianten für einen Begriff bietet. In Italien dagegen sei es üblich, den Anglizismus zu übernehmen bzw. diesen durch einen einzigen italienischen Neologismus zu ersetzen, der sich meistens nicht durch Anpassung ergibt. Beispiele aus der Internet-Terminologie finden sich in Cortelazzos Neologismenliste (vgl. Cortelazzo 1997/1998, o.S.):

chat line loc.f. linea telefonica che permette di mettere in comunicazione più persone per conversazioni di vario genere [1993-94] ${ }^{4}$,

E-mail sf. sistema di scambio di messaggi scritti attraverso una rete telematica [1995],

messaggeria sf. in una rete telematica, servizio che gli utenti possono utilizzare per scambiarsi messaggi di vario genere [1993-94],

hackeraggio $s m$. pirateria informatica [1993-94] und

provider $\mathrm{sm}$. società commerciale che fornisce il collegamento a Internet [1996].

Wie gezeigt wurde, sind das Phänomen des Anglizismus und dessen Kritik keineswegs nur auf das Französische beschränkt. Auch andere Sprachgemeinschaften reagieren mit Widerstand auf den angloamerikanischen Einfluss, jedoch nicht so vehement und letztendlich auch nicht so erfolgreich wie Frankreich. Das Französische blickt unter den europäischen Kultursprachen auf die längste Tradition zurück, Fremdwörter zu bekämpfen.

Ein Desiderat stellt derzeit ein Vergleich der Internet-Termini zwischen verschiedenen (romanischen) Sprachen dar, so wie es Blank (1995) im Hinblick auf den Computerwortschatz vorgenommen hat und Bruns (2001) für die russische, englische, französische und deutsche Internet-Terminologie ${ }^{5}$. Vor allem das Italienische gilt im Unterschied zu anderen romanischen Sprachen als ausgesprochen ,anglophil“ (vgl. Blank 1995, 54). Dennoch hebt Blank (1995, 63) am Ende seines Aufsatzes hervor, dass das Computervokabular in den von ihm untersuchten fünf Sprachen (Deutsch, Französisch, Italienisch, Portugiesisch und Spanisch) trotz der französischen Sonderrolle relativ homogen sei.

\footnotetext{
${ }^{4}$ Der Terminus chat line bezieht sich im Rahmen dieser Liste nur auf den Bereich des Telefons, nicht des Internet.

${ }^{5}$ Die Parallelen zwischen den vier Sprachen werden insbesondere bei den Internationalismen deutlich (vgl. Bruns 2001, 121).
} 


\section{Schluss}

\subsection{Ergebnisse und Ausblick}

Abschließend sollen die wichtigsten Untersuchungsergebnisse zusammengefasst und die Grenzen der Arbeit deutlich gemacht werden.

Mittels einer WWW-Umfrage, die in den Monaten Juli und August 2002 in neun Diskussionsforen zu den Bereichen Informatik und Internet angekündigt wurde, konnten die Einstellungen frankophoner Informatiker aus Frankreich, Belgien und der Schweiz zu sechs ausgewählten Internet-Anglizismen (mail/e-mail, homepage, World Wide Web/web, chat, cracker und (access) provider) sowie ihren offiziellen französischen Entsprechungen ermittelt werden.

Nicht alle offiziellen französischen Neologismen werden von den französischsprachigen Informanten als bekannt angegeben. Während Termini wie courrier électronique, page d'accueil, pirate und fournisseur d'accès einen Bekanntheitsgrad zwischen 80 und 100\% aufweisen, sind andere Termini wie messagerie électronique, toile d'araignée mondiale, bavardage und causette weniger als der Hälfte der Sprecher bekannt. Die englischen Termini mail/e-mail, homepage, web, chat, cracker und (access) provider sind durchgehend mindestens $80 \%$ der befragten Informatiker bekannt.

In Frankreich werden in drei Fällen häufiger die französischen und in drei Fällen häufiger die englischsprachigen Termini verwendet. In Belgien und v.a. der Schweiz werden tendenziell häufiger die englischen als die französischen InternetTermini verwendet. So plädieren die befragten Belgier für zwei französische und vier englischsprachige Termini, die schweizerischen Informatiker verwenden mehrheitlich nur die Anglizismen. Dies wird in erster Linie darauf zurückgeführt, dass sich die belgischen und schweizerischen Informanten auch im eigenen Land 
mit Angehörigen anderer Sprachgemeinschaften verständigen müssen und daher lieber die internationale, unmissverständlichere Terminologie verwenden.

Die Feststellung Helfrichs (1993, 292), dass eine offenkundige Diskrepanz zwischen der Produktion und Diffusion sowie ein Spannungsverhältnis zwischen der Produktion und Akzeptanz von Neologismen im Französischen bestehe, lässt sich auch auf die französische Internet-Terminologie übertragen. Bei den untersuchten französischen Internet-Termini fällt vor allem die Diskrepanz zwischen ihrem hohen Bekanntheitsgrad und ihrem geringen Verwendungsgrad auf, d.h. zwischen passiver und aktiver Akzeptanz. Diese Diskrepanz ist - wie gezeigt werden konnte - in Belgien und der Schweiz ausgeprägter als in Frankreich, wo häufiger französische Termini verwendet werden als in den beiden Nachbarländern. Insofern kann Helfrichs (ebd.) Aussage zugestimmt werden, dass sich das Überangebot an Neologismen durch den Sprachgebrauch regele.

Anhand der sechs ausgewählten Lexemgruppen wird deutlich, dass es sehr wohl möglich ist, neue französische Termini zu schaffen, die auch außerhalb Frankreichs bekannt sind und auf Akzeptanz stoßen. Die Entscheidung für oder gegen einen Terminus ist das Resultat einer Verquickung sehr vieler Faktoren, so dass keinerlei Pauschalurteile vom Typ „In Frankreich werden in vielen Fällen die französischen Neologismen, in der Schweiz generell die Anglizismen bevorzugt" möglich sind, sondern die Akzeptanz jeweils am Einzelfall zu prüfen ist. Generell wird die Entscheidung für oder gegen einen französischen Terminus von verschiedenen Faktoren beeinflusst. Dies sind v.a.:

- beruflicher Hintergrund der Informanten (Informatiker verwenden aus Gründen der vereinfachten nationalen und internationalen Kommunikation bevorzugt die angloamerikanischen Termini),

- Nationalität der Informanten (Belgier und Schweizer verwenden häufiger die angloamerikanischen Termini, um Kommunikationsprobleme mit Sprechern anderer Nationalsprachen zu vermeiden),

- bestimmte, mit der Verwendung der englischsprachigen Termini verbundene Vorteile (Sicherheit, bei ihrer Verwendung verstanden zu werden, ihre nationale und internationale Verbreitung, ihre Kürze) und

- persönliche Gründe wie Gewöhnung an den Terminus (die englischsprachigen Termini gibt es i.d.R. vor den nationalen Termini, so dass die Sprecher aus Gewohnheit die englische Terminologie beibehalten).

Des Weiteren wurde bei der WWW-Befragung nach der Kenntnis und Bewertung der Sprachpolitik und Terminologiearbeit gefragt. Während die französische Sprachpolitik sowohl im eigenen Land als auch in der Westschweiz sehr bekannt ist, sind die Belgier kaum über die belgische Sprachpolitik informiert. Sprachpolitische Maßnahmen werden von den französischen Informanten mehrheitlich befürwortet und von den schweizerischen Informanten mehrheitlich abgelehnt. Bei den belgischen Informanten ist das Verhältnis zwischen Akzeptanz und Ablehnung entsprechender Maßnahmen recht ausgeglichen. Es ist davon auszugehen, dass die Akzeptanz staatlicher Maßnahmen zum Schutz einer Sprache durch die Bevölkerung steigt, wenn entsprechende Regelungen auf eine längere 
Tradition zurückblicken. Entsprechend stoßen auch die Terminologielisten in Frankreich, wo Sprachpolitik eine lange Tradition hat, auf eine höhere Akzeptanz als in Belgien. Hinzu kommt, dass die frankophonen Belgier und Schweizer oftmals die Bedrohung durch Anglizismen als weniger gravierend empfinden als die Angst, gegenüber Sprechern der anderen Nationalsprachen benachteiligt zu werden. Die französische Internet-Terminologie ist wesentlich bekannter als die belgische und die schweizerische, was v.a. auf die bessere Verbreitung der Terminologielisten (auf verschiedenen Internetseiten und in gedruckten Broschüren) zurückzuführen ist.

Mit der vorliegenden Arbeit wurde insofern das Ziel verfolgt, in einem bisher vernachlässigten Bereich zu forschen, als die bislang durchgeführten Studien sich fast ausschließlich auf die französische Sprachpolitik und Terminologiearbeit beziehen, die Situation in anderen frankophonen Ländern (mit Ausnahme von Québec, vgl. 3.3.4) jedoch weitgehend außer Acht gelassen wurde. Die Auswertung der WWW-Befragung hat deutlich gemacht, dass Erkenntnisse, die bezüglich der Akzeptanz bestimmter Termini oder bezüglich der Einstellungen zur Sprachpolitik und Terminologiearbeit in Frankreich gewonnen werden, nicht einfach auf andere frankophone Staaten übertragbar sind. Daher lohnt sich durchaus auch die separate Erforschung der Situation in anderen frankophonen Ländern bzw. Regionen. Bezüglich eines Vergleichs zwischen der passiven und aktiven Akzeptanz, aber auch zwischen den Einstellungen zu Sprachpolitik und Terminologiearbeit in Frankreich, dem französischsprachigen Teil Belgiens und der französischsprachigen Schweiz macht diese Arbeit einen Anfang, indem sie Parallelen und Differenzen aufzeigt. Weitere, vergleichend angelegte Akzeptanzstudien zwischen frankophonen Ländern sowie zwischen verschiedenen romanischen Ländern sind wünschenswert. Auch ist nicht absehbar, inwiefern sich die Aussagen von Spezialisten - den befragten Informatikern - auf die Gesamtbevölkerung übertragen lassen. Um Aussagen zur Akzeptanz der Internet-Termini in breiteren Bevölkerungsschichten machen zu können, wäre eine weitere Studie nötig.

Es empfiehlt sich, die in den Kapiteln 9 bis 12 präsentierten Ergebnisse kritisch zu betrachten. Diese Studie kann keine repräsentativen Ergebnisse liefern. Außerdem ist die Personengruppe, die befragt wurde, sehr eingegrenzt. Jede empirisch angelegte Arbeit stößt in mehrfacher Hinsicht an ihre spezifischen Grenzen, was jedoch nicht von Nachteil sein muss. Fast immer ergeben sich genau aus diesen Unzulänglichkeiten oder Lücken Impulse zu weiterer Forschung. Von daher sind die folgenden Punkte als Anregungen für die weitere Diskussion gedacht:

\section{Verallgemeinerbare Aussagen/Übertragbarkeit der Daten}

Die WWW-Befragung richtete sich ausschließlich an Spezialisten, nämlich an Informatiker und Personen, die im Internetbereich beschäftigt sind. Es haben zudem nur diejenigen Informatiker von der Studie Kenntnis erhalten, die im Juli bzw. August 2002 die Beiträge in einem der neun in 8.1.2 genannten Diskussionsforen verfolgt haben. Hierbei handelt es sich vorwiegend um Männer, die zwischen 20 und 40 Jahre alt sind (und vermutlich auch tatsächlich den größten An- 
teil der Informatiker stellen). Da nur Informatiker gefragt wurden, können auch nur zu dieser Personengruppe Aussagen getroffen werden. Es ist somit nicht möglich, die Ergebnisse dieser Studie auf die gesamte Bevölkerung zu übertragen und beispielsweise davon auszugehen, dass die hier getesteten Termini jedem Franzosen, frankophonen Belgier oder Schweizer mit einer ca. 80-90\%igen Wahrscheinlichkeit bekannt sind. Die Ergebnisse einer Fragebogenstudie differieren je nach Frageformulierung, je nach Zielgruppe und diversen anderen Einflussfaktoren.

Weiterhin wird die Übertragbarkeit der Daten aufgrund der Anzahl an Informanten eingeschränkt. Eine Gesamtteilnehmerzahl von 160 Teilnehmer ist zwar im Hinblick auf die stark eingegrenzte Zielgruppe und die Art der Teilnehmerrekrutierung beachtlich, allerdings sind Aussagen, die wie im Fall der befragten belgischen und schweizerischen Informatiker aus einer Stichprobe von 17 bzw. 19 Vertretern bestehen, nur bedingt gültig und übertragbar.

\section{Einflüsse der Frageformulierung und der Situation}

Die Ergebnisse jeder Fragebogenstudie hängen in mehr oder weniger ausgeprägtem Maße von der Art und Weise der Frageformulierung ab. Trotz entsprechender Bemühungen und Tests, die Fragen möglichst neutral zu formulieren, sind Einflüsse von der Art der Frageformulierung auf die Wahl der Antworten nicht auszuschließen.

Die Erforschung, inwiefern der situative Kontext die Verwendung der Termini beeinflusst, kann die Untersuchung zur Internet-Terminologie nicht leisten. Es ist davon auszugehen, dass Sprachbenutzer mitunter in ihrer Wortwahl variieren, je nachdem, ob sie das betreffende Wort in einer informellen oder formellen Kommunikationssituation oder in einem geschriebenen oder gesprochenen Text verwenden (wollen). Hinzu kommt noch die Unterscheidung zwischen beruflichem und privatem Kontext, denn viele der befragten Informatiker weisen darauf hin, dass gerade im fachlichen Kontext die Kommunikation durch die Verwendung der englischen Terminologie wesentlich vereinfacht werde. In diesem Bereich können die befragten Informatiker davon ausgehen, dass die englischen Termini sicher verstanden werden, während interessierte Laien nicht unbedingt mit der englischen Terminologie und Sprache vertraut sein müssen. Dem situativen Kontext wird in empirischen Studien bislang nur äußerst selten Rechnung getragen. Die Tatsache, dass viele Informanten angegeben haben, bei der Wahl für den englischsprachigen oder französischen Terminus je nach Kontext zu entscheiden, lässt darauf schließen, dass der Kontext die Wahl bestimmter Termini wie das gesamte Sprach- und Gesprächsverhalten entscheidend beeinflusst.

\section{Ehrlichkeit der Informanten}

Trotz verschiedener Plausibilitätskontrollen im Vor- und Nachfeld der Befragung ist es nicht auszuschließen, dass manche der gegebenen Antworten nicht der Wahrheit entsprechen. Bei Fragebogenstudien, die mit subjektiven Daten arbeiten, muss generell auf die Ehrlichkeit der Informanten vertraut werden. 


\section{Korrelationen zwischen biosozialen Daten und Einstellungen}

Aufgrund der Datenlage war es nicht möglich, das Geschlecht, das Bildungsniveau, die Englischkenntnisse oder die Dauer der Internetnutzung mit dem Sprachgebrauch oder den Einstellungen zu korrelieren, um zu ermitteln, inwiefern die genannten Faktoren die Akzeptanz von Lexemen und die Einstellungen zur Sprachpolitik bzw. die Kenntnis sprachpolitischer Maßnahmen beeinflussen. Lediglich das Alter konnte bei den französischen Informatikern mit dem Sprachgebrauch und den Einstellungen korreliert werden (vgl. 9.4). Um detaillierte Auskunft darüber zu erhalten, inwiefern personenspezifische Eigenschaften sprachliches Verhalten und Spracheinstellungen beeinflussen, wären weitere Untersuchungen nötig.

\section{Aussagen zu zukünftigem Sprachverbalten}

Auch mit den Methoden der empirischen Sozialforschung ist es schwierig, Prognosen zu zukünftigem Sprachverhalten zu treffen. Aus den vorliegenden Ergebnissen zum Hier und Jetzt kann nicht zuverlässig geschlossen werden, ob Termini, die bei den im Sommer 2002 befragten Informatikern auf eine hohe Akzeptanz gestoßen sind, in einer späteren Studie in gleicher Weise bewertet würden. In vielerlei Hinsicht wäre es interessant, ähnlich gelagerte Studien in einigen Jahren durchzuführen, um auch Aussagen auf der diachronen (evolutiven) Ebene treffen zu können.

Trotz der Einschränkungen, die bezüglich der Methodik der WWW-Befragung und der erhaltenen Ergebnisse angeführt wurden, ist festzustellen, dass sich diese Umfrage-Methode bewährt hat. Insbesondere für die Befragung eines sehr spezifischen Publikums wie der hier befragten französischsprachigen Informatiker ist die Methode geeignet, da die gewünschte Zielgruppe über das Internet problemlos zu erreichen ist.

Die Studie hat trotz der zu treffenden Einschränkungen aufschlussreiche Ergebnisse gebracht und gezeigt, welche neuen Forschungsperspektiven sich durch den Einsatz des neuen Forschungsinstrumentes, der WWW-Befragung, ergeben. 


\subsection{Résumé et perspectives}

Au moyen d'un questionnaire en ligne proposé dans neuf forums de discussion concentrant l'informatique et l'Internet entre juillet et août 2002, ce travail a permis d'étudier la perception que des informaticiens francophones de France, de Belgique et de Suisse ont de six anglicismes (mail/e-mail, homepage, World Wide Web/web, chat, cracker et (access) provider) et de leurs équivalents officiels français du domaine Internet.

Les informaticiens francophones indiquent ne pas connaître tous les néologismes français officiels. Alors que des termes comme courrier électronique, page d'accueil, pirate et fournisseur d'accès sont connus par 80\% jusqu'à 100\% des informateurs, moins de la moitié de ceux-ci connaissent des termes comme messagerie électronique, toile d'araignée mondiale, bavardage et causette. Les termes anglais de mail/ e-mail, homepage, web, chat, cracker et (access) provider sont quant à eux tous connus par au moins $80 \%$ des informaticiens interrogés.

En France, dans trois cas sur six, c'est le terme français qui est utilisé de préférence et dans le même nombre de cas le terme anglais. En Belgique et plus encore en Suisse, la tendance est d'utiliser les anglicismes plus que les termes français pour l'Internet: les Belges interrogés plébiscitent deux termes français contre quatre anglais, et les Suisses n'utilisent en grande majorité que les anglicismes. Ceci s'explique en premier lieu par le fait que les informateurs belges et suisses sont confrontés dans leur propre pays à d'autres communautés linguistiques et donc utilisent de préférence des termes internationaux compréhensibles par tous.

Helfrich $(1993,292)$ constate qu'il existe un écart flagrant entre la production et la diffusion ainsi qu'entre la production et l'acceptation des néologismes français, un écart que montre aussi la terminologie de l'Internet. Ce qui frappe dans le cas de la terminologie française de l'Internet, c'est l'écart entre le degré de connaissance relativement élevé et le degré très restreint d'utilisation, c'est-à-dire entre l'acceptation passive et l'acceptation active des termes français. Comme le montrent les résultats de l'enquête, cet écart est plus grand en Belgique et en Suisse qu'en France, où les termes français sont plus fréquemment utilisés que dans les pays voisins. En ce sens, on peut affirmer avec Helfrich (ebd.) que l'utilisation réelle régule le surplus de néologismes créés.

Les six groupes de lexèmes choisis montrent clairement qu'il est possible de créer des nouveaux termes français qui soient connus, acceptés et utilisés aussi hors de France. Le choix pour ou contre un terme nouveau est déterminé par un ensemble de facteurs, ce qui rend impossible tout jugement global du type „En France, on utilise dans la plupart des cas les néologismes français, alors qu'en Suisse on préfère en général les anglicismes“. Il faut au contraire tester l'acceptation de chacun des termes en particulier. Plusieurs facteurs influencent le choix pour ou contre un terme français, en particulier: 
- la situation et l'environnement professionnel des informateurs (les informaticiens utilisent plus volontiers les termes anglo-américains pour des raisons de facilitation de la communication nationale et internationale),

- la nationalité (Belges et Suisses utilisent de préférence les termes anglo-américains, afin d'éviter des problèmes de communication avec les autres communautés linguistiques nationales),

- certains avantages des termes anglo-américains, liés à leur utilisation (certitude d'être compris, les termes sont fortement répandus au niveau national et international, leur brièveté), et enfin,

- des raisons personnelles comme par exemple l'habitude (les termes anglais existent en règle générale avant leurs équivalents nationaux, de sorte que les sujets conservent la terminologie anglaise).

L'enquête menée en ligne cherchait d'autre part à découvrir si les informateurs connaissaient la politique linguistique et terminologique et comment ils la jugeaient. Alors que la politique linguistique française est bien connue en France et en Suisse romande, les Belges ne sont guère au courant de la politique linguistique belge. Les mesures linguistiques sont en général bien acceptées par les Français et plutôt rejetées par les Suisses. Le taux des mesures comparables belges qui sont rejetées et de celles qui sont acceptées est plus ou moins égal. On peut supposer que l'acceptation de mesures officielles pour la protection d'une langue est d'autant plus grande que cette protection a déjà une longue tradition. Ainsi, les listes terminologiques sont mieux acceptées en France, où la politique linguistique possède une longue tradition, qu'en Belgique. À cela s'ajoute que les Belges et les Suisses francophones ont moins peur des anglicismes comme une menace pour leur langue que d'être défavorisés face aux autres communautés linguistiques nationales. La terminologie de l'Internet officielle française est largement plus connue que celles de Belgique et de Suisse, ce qui s'explique entre autres par le fait que les listes officielles sont répandues (sur des sites Internet et dans des brochures publiées).

Le présent travail poursuit le but d'éclairer un domaine négligé par la recherche. En effet, les différentes études menées jusqu'ici se concentrent uniquement sur la politique linguistique et les efforts terminologiques de la France, négligeant les autres pays francophones (à l'exception du Québec, cf. 3.3.4). Les résultats de l'enquête ont pourtant montré que les résultats des recherches menées en France concernant l'acceptation et l'utilisation de certains termes ou la perception du travail linguistique et terminologique officiel, ne peuvent pas être étendus sans autre aux autres pays francophones, de sorte que des recherches approfondies concernant les autres pays ou régions francophones sont nécessaires. Le présent travail propose une première comparaison de l'acceptation passive et active de néologismes français ainsi que la perception de la politique linguistique et du travail terminologique officiel en France et dans les parties francophones de la Belgique et de la Suisse. Il met en évidence des parallèles mais aussi des différences, rendant ainsi des études semblables sur les autres pays francophones et sur les pays de langue romane, plus qu'intéressantes: nécessaires. Il faut aussi remarquer 
que les résultats de ce travail représentent l'opinion de spécialistes - les informaticiens interrogés - qui n'est pas nécessairement celle de la population en général. L'acceptation de la terminologie de l'Internet dans la population reste en effet à étudier.

Les résultats présentés dans les chapitres 9 à 12 doivent être pris avec précautions. Cette étude ne saurait en effet livrer des résultats représentatifs. Le nombre d'informateurs est relativement restreint. Toute étude empirique se trouve limitée par sa propre spécificité. Ceci n'est pourtant forcément un désavantage, car ce sont souvent précisément ces faiblesses qui servent de moteur à d'autres recherches. C'est en ce sens que les points présentés ci-dessous sont à comprendre, comme des idées à discuter.

\section{Possibilité de généraliser les résultats}

L'enquête en ligne s'adressait uniquement à des spécialistes, c'est-à-dire à des informaticiens et à des personnes travaillant dans le domaine de l'Internet. Parmi ceux-ci, seuls les informaticiens ayant participé à l'un des neufs forums de discussion nommés en 8.1.2 entre juillet et août 2002 ont eu connaissance de cette enquête. Il s'agit avant tout d'hommes entre 20 et 40 ans (ce qui correspond probablement en effet à la majorité des informaticiens). Puisque seuls des informaticiens ont été interrogés, les résultats ne s'appliquent qu'à ce groupe de personnes en particulier. Il n'est ainsi pas possible d'étendre ces résultats au reste de la population et par exemple d'affirmer qu'avec une probabilité de 80 à $90 \%$ tous les Français, Belges et Suisses connaissent les termes proposés ici. Les résultats d'un questionnaire changent en effet en fonction de la formulation des questions, du groupe d'informateurs et d'autres facteurs.

De plus, le nombre même d'informateurs limite la généralisation des résultats. S’il est vrai qu'au vu du type très précis d'informateurs ainsi que du mode de recrutement, le nombre de 160 participations est remarquable, les résultats concernant les informaticiens belges et suisses, représentés par seulement 17 et 19 personnes, ne sont valables qu'avec restriction et ne peuvent être généralisés qu'avec prudence.

\section{Influence de la formulation des questions et de la situation}

Les résultats de tout questionnaire sont toujours plus ou moins fortement influencés par la manière dans laquelle sont posées les questions. Malgré les tentatives et les tests pour formuler le présent questionnaire de manière neutre, il n'est pas à exclure que la formulation des questions ait eu une influence sur le choix des réponses.

L'influence que la situation contextuelle peut avoir sur l'utilisation des termes proposés ne peut quant à elle être étudiée à travers ce type d'enquête en ligne. Il semble évident que les sujets parlant choisissent un terme en fonction du contexte dans lequel ce mot est utilisé, s'il s'agit d'une situation formelle ou informelle, orale ou écrite. À cela s'ajoute la différence entre un contexte professionnel ou un contexte privé, comme l'indiquent plusieurs informaticiens constatant que l'utilisation des termes anglais facilite la communication professionnelle. Les 
informaticiens savent en effet que dans le domaine professionnel, la terminologie et la langue anglaise sont comprises de tous, alors que ce n'est pas forcement le cas des personnes qui s'adonnent à l'informatique par loisir. Rares sont les études empiriques qui prennent en compte la situation de communication réelle. Pourtant, le fait que les informateurs indiquent d'eux-mêmes qu'ils choisissent le terme anglais ou français selon le contexte, montre que le contexte est un facteur déterminant pour le choix d'un terme comme pour l'utilisation de la langue et le comportement dialogique en général.

\section{Honnêteté des informateurs}

Malgré divers tests menés avant et après le questionnaire, il n'est pas exclu que certaines réponses fournies ne soient pas complètement vraies. Pour les enquêtes par questionnaire basées sur des données subjectives, force est de faire confiance à l'honnêteté et à la véracité des informateurs.

\section{Corrélations entre particularités socio-biologiques et les réponses fournies}

À cause du manque d'informations concrètes, il n'a pas été possible de faire des liens entre le sexe, le niveau de formation, les connaissances en langue anglaise et la durée d'utilisation de l'Internet d'une part et l'utilisation et la perception de la langue d'autre part, de sorte que l'influence que les premiers facteurs mentionnés peuvent avoir sur l'acceptation des lexèmes ou sur l'opinion des informateurs concernant la politique linguistique, ne peut être mesurée. Seul un rapport entre l'âge des informaticiens français interrogés et leur utilisation et position face à la langue a pu être établi (cf. 9.4). D’autres études sont nécessaires pour établir dans quelle mesure et comment les spécificités personnelles influencent le comportement linguistique et la perception de la langue en général.

\section{Conjecture sur l'évolution du comportement linguistique}

Même avec les méthodes de recherche sociale empiriques, il reste difficile de faire des pronostics sur l'évolution du comportement linguistique. À partir des résultats présentés qui concernent l' «ici et maintenant », il n'est pas possible de prédire de manière certaine si les termes plébiscités par les informaticiens interrogés en 2002 obtiendront la même acceptation lors d'une enquête postérieure. Ainsi, il serait à bien des égards intéressant de mener des études semblables dans les années à venir, entre autres choses pour découvrir et étudier le niveau diachronique (évolutif).

Malgré les limites et problèmes tant la technique d'enquête que des résultats obtenus, il faut souligner que la méthode de l'enquête en ligne a fait ses preuves. En particulier lorsqu'il s'agit d'interroger un groupe bien défini, dans le cas présent des informaticiens francophones, cette méthode se recommande particulièrement, car elle permet de contacter sans problème le groupe visé à travers l'Internet.

La présente enquête a donc d'une part apporté des résultats probants et enrichissants malgré les quelques restrictions, et d'autre part dessiné des nouvelles 
perspectives pour la recherche à travers l'utilisation d'un nouvel instrument, l'enquête en ligne. 


\section{Bibliografie}

Abraham, Werner, Terminologie zur neueren Linguistik, Tübingen, Niemeyer, ${ }^{2} 1988$.

Académie française, Mises en garde, propositions, équivalences, publiées par l'Académie française, du 5 novembre 1964 au 6 avril 1967, Paris, Firmin-Didot et Cie, 1967.

ACNielsen eRatings.com, Internetnutzung im Juli. Große Wachstumschancen für den weltweiten PC-Markt: 459 Millionen Menschen weltweit sind online, http://www.|acnielsen.at/at/news/press/2001_08_31_211340/FULLTEXT.PDF1, August 2001.

Afi-Pythagore Médiation Communication, La fête de l'internet, http://www.feteinternet.fr, 2003.

Ager, Denis, Language policy in Britain and France. The processes of policy, London/New York, Cassell, 1996.

Agheyisi, Rebecca/Fishman, Joshua A.: „Language Attitude Studies. A Brief Survey of Methodological Approaches“, in: Anthropological Linguistics 12 (1970), 137-157.

Ahlers, Christian/Holtus, Günter, „Lassen sich Anglizismen verbieten? Zum Wortschatz der Informatik in der fachbezogenen Presse Frankreichs", in: Wagener, Peter (ed.), Sprachformen. Deutsch und Niederdeutsch in europäischen Bezügen. Festschrift für Dieter Stellmacher zum 60. Geburtstag, Stuttgart, Steiner, 1999, 297-310.

\footnotetext{
1 Zur Trennung von Internetadressen wird das von Runkehl/Siever (2001, 111f.) vorgeschlagene System verwendet. Entweder wird ein senkrechter Strich $(\mid)$ mit einem nachstehenden Trennstrich als Umbruchzeichen verwendet (da der senkrechte Strich kein Bestandteil einer URL sein kann), oder aber ein in der URL enthaltener Bindestrich fungiert als Trennzeichen. Die Internet-Adressen wurden im Oktober 2003 überprüft und waren zu diesem Zeitpunkt, sofern nicht anders angegeben, noch aktuell.
} 
Albert, Ruth/Koster, Cor J., Empirie in Linguistike und Sprachlehrforschung. Ein methodologisches Arbeitsbuch, Tübingen, Narr, 2002.

Albrecht, Jörn, „Sprachbewertung/Évaluation de la langue“, in: Holtus/Metzeltin/Schmitt 2001, 526-540.

Altwegg, Jürg, „Statt Airbag soll es künftig heißen: Aufblasbarer Sack. Blick in französische Zeitschriften: Ein Handbuch der ,offiziellen Begriffe', die Politik der Frankophonie und das Gatt", in: Frankfurter Allgemeine Zeitung (FAZ) vom 16. April 1994, 30

Ammon, Ulrich/Dittmar, Norbert/Mattheier, Klaus J., (edd.), An international bandbook of the science of language and society $=$ Soziolinguistik: Ein internationales Handbuch zur Wissenschaft von Sprache und Gesellschaft (= Handbücher zur Sprach- und Kommunikationswissenschaft, 3.1), 1. Halbband, Berlin/New York, de Gruyter, 1987.

Ammon, Ulrich/Dittmar, Norbert/Mattheier, Klaus J., (edd.), An international handbook of the science of language and society = Soziolinguistik: Ein internationales Handbuch zur Wissenschaft von Sprache und Gesellschaft (= Handbücher zur Sprach- und Kommunikationswissenschaft, 3.2), 2. Halbband, Berlin/New York, de Gruyter, 1988.

Ammon, Ulrich/Hellinger, Marlis (edd.), Status change of languages, Berlin/New York, de Gruyter, 1991.

Andrianne, René, „Belgicismes et canadianismes: pertinence et définition“, in: Cabiers de L'Institut de Linguistique de Louvain 10 (1984), 5-16.

Andrianne, René, „Das Französische und der Dialekt in Belgien: Spannungen und Interdependenz", in: Dahmen et al. 1992, 116-129.

Anis, Jacques, Texte et ordinateur. L'écriture réinventée?, Paris/Bruxelles, De Boeck \& Larcier, 1998.

Anis, Jacques (ed.), Parlez-vous texto? Guide des nouveaux langages du réseau, Paris, Le cherche midi éditeur, 2001.

Antoine, Gérald/Cerquiglini, Bernard (edd.), Histoire de la langue française 19452000, Paris, CNRS Éditions, 2000.

Antos, Gerd, Laien-Linguistik: Studien zu Sprach- und Kommunikationsproblemen im Alltag; am Beispiel von Sprachratgebern und Kommunikationstrainings, Tübingen, Niemeyer, 1996.

Apothéloz, Denis, „Attitudes linguistiques: Esquisse d'une typologie“, in: Travaux neuchâtelois de linguistique 4 (1982), 87-92.

Apothéloz, Denis/Bysaeth, Léo, „Attitudes linguistiques: Résultats d'une enquête“, in: Travaux neuchâtelois de linguistique 2 (1981), 69-90.

Arbeitsgemeinschaft Informationsgesellschaft (Universität Köln), Tips und Tricks zur Erstellung von Fragebögen im Internet, http://infosoc.uni-koeln.de/|wwwpretest/tips_zu_formulierungen.html, o.J. 
Arbeitsgruppe der Schweizerischen Konferenz der Kantonalen Erziehungsdirektoren (EDK) für ein Gesamtsprachenkonzept für das Lehren und Lernen von modernen Sprachen in der Schweiz (Basel), Sprachenkonzept Schweiz, http://131.152.151.1/sprachenkonzept/, http://www.romsem.unibas.|ch/sprachenkonzept, 2003.

Arbeitskreis Deutscher Markt- und Sozialforschungsinstitute (ADM) et al., Richtlinie für Online-Befragungen, Oktober 2000 (Download unter: http://|www.adm-ev.de/, 2003).

Arbeitskreis Deutscher Markt- und Sozialforschungsinstitute e.V. (ADM) et al., Standards zur Qualitätssicherung für Online-Befragungen (Ausgabe Mai 2001) (Download unter: http://www.adm-ev.de/, 2003).

Arntz, Reiner, Das vielsprachige Europa. Eine Herausforderung für Sprachpolitik und Sprachplanung, Hildesheim, Universitätsbibliothek, 1998.

Arntz, Reiner/Picht, Heribert, Einführung in die Terminologiearbeit, Hildesheim/Zürich/New York, Olms, ${ }^{2} 1991$.

Arquint, Jachen Curdin, „Stationen der Standardisierung“, in: Bickel/Schläpfer 2000, 240-267.

Association des Informaticiens de Langue Française (AILF), Terminologie, http:/ | www.ailf.net/projet/terminol.htm, 2002.

Auger, Pierre, „Implantabilité et acceptabilité terminologiques: les aspects linguistiques d'une socioterminologie de la langue du travail“, in: Terminologies nouvelles 12 (1994), 47-57.

Ausseil, David, The best of Internet en France, Brüssel, Best of Publishing, 1998.

Baggioni, Daniel, „La notion d'insécurité linguistique chez Labov et la sociolinguistique co-variationniste et ses précurseurs littéraires“, in: Bavoux 1996, 1332.

Baggioni, Daniel/Breton, Roland, „Communauté(s) linguistique(s), espace(s) francophone(s) et réseaux de communication: le problème de la délimitation d'un/des ensemble(s) dans la ,francophonie", in: Robillard/Beniamino 1996, 887-901.

Bagola, Beatrice, „Das Sprachbewußtsein in Quebec“, in: Haßler, Gerda/Niederehe, Hans-Josef (edd.), Geschichte des Sprachbewußtseins in romanischen Ländern, Münster, Nodus Publikationen, 2000, 251-264.

Baker, Colin R., Attitudes and languages, Clevedon (UK), Multilingual Matters, 1992.

Bal, Willy, „Le wallon“, in: Dahmen et al. 1992, 136-145.

Bal, Willy/Doppagne, Albert/Goosse, André, Belgicismes. Inventaire des particularités lexicales du français en Belgique, Louvain-la Neuve, Duculot, 1994.

Bally, Charles, La crise du français. Notre langue maternelle à l'école, Neuchâtel/Paris, Delachaux \& Nestlé, 1930.

Bamert, Thomas/Heidingsfelder, Martin, „Designeffekte in Online-Umfragen“, in: Theobald/Dreyer/Starsetzki 2001, 165-178.

Bandilla, Wolfgang/Hauptmanns, Peter, „Internetbasierte Umfragen als Datenerhebungstechnik für die empirische Sozialforschung?“, in: ZUMA Nachrichten 43 (1998), 36-53. 
Batinic, Bernad, WWW-Fragebogen-Generator (WFG), http://www.psychol.unigiessen.de/ $\sim$ Batinic/tools/wfg.zip ( $=$ kostenloser Download des Programms), o.J.

Batinic, Bernad, „How to make an internet based survey?“, in: Bandilla, Wolfgang/Faulbaum, Frank Faulbaum (edd.), SoftStat'97. Advances in statistical software 6, Stuttgart, Lucius \& Lucius, 1997, 125-132.

Batinic, Bernad, Fragebogenuntersuchungen im Internet, Aachen, Shaker, 2001.

Batinic, Bernad/Puhle, Birgit/Moser, Klaus, „Der WWW-Fragebogen-Generator (WFG)“, in: Batinic et al. 1999, 93-102.

Batinic, Bernad/Werner, Andreas/Gräf, Lorenz/Bandilla Wolfgang, Online Research - Methoden, Anwendungen und Ergebnisse, Göttingen, Hogrefe, 1999.

Bauer, Roland, „Anglizismen im Französischen - am Beispiel fachsprachlicher Akronyme aus Werbetexten französischer EDV-Firmen“, in: Fachsprache 12, $1 / 2$ (1990), 36-50.

Bauvois, Cécile, „Locuteur masqué“, in Moreau 1997a, $202 \mathrm{f}$.

Bavoux, Claudine (ed.), Français régionaux et insécurité linguistique. Approches lexicographiques, interactionnelles et textuelles. Actes de la deuxième table ronde du Moufia, 23-25 septembre 1994, Paris/Saint-Denis (Université de la Réunion), L'Harmattan, 1996.

Baylon, Christian, Sociolinguistique: Société, langue et discours, Paris, Nathan, 21996.

Bécherel, Danièle, „A propos des solutions de remplacements des anglicismes“, in: La Linguistique 17, 2 (1981), 119-131.

Beck, Klaus/Glotz, Peter/Vogelsang, Gregor, Die Zukunft des Internet: Internationale Delphi-Befragung zur Entwicklung der Online-Kommunikation, Konstanz, UVKVerlag, 2000.

Beinke, Christiane, Der Mythos franglais. Zur Frage der Akzeptanz von Angloamerikanismen im zeitgenössischen Französisch - mit einem kurzen Ausblick auf die Anglizismen-Diskussion in Dänemark, Franfurt am Main et al., Lang, 1990.

Beinke, Christiane, „Tomatine statt ketchup. Ein Weg zum reinen Französisch?“, in: Trabant 1995a, 79-90.

Bengtsson, Sverker, La défense organisée de la langue française. Étude sur l'activité de quelques organismes qui depuis 1937 ont pris pour tâche de veiller à la correction et à la pureté de la langue française, Uppsala, Almqvist \& Wiksell, 1968.

Benoît, Joseph, Belgicismes ou les vices de langage et de prononciation les plus communs en Belgique, Anvers, 1857.

Bessé, Bruno de, „Terminology Committees in France: Balance and Perspectives“, in: Sager, Juan C. (ed.), Standardization of Nomenclature, The Hague/Paris/New York, Mouton, 1980, 43-49.

Bessé, Bruno de, „L'État terminologue: peut mieux faire“, in: Terminologie et traduction 1 (1990), 87-100.

Bickel, Hans/Schläpfer, Robert (edd.), Die viersprachige Schweiæ, Aarau/Frankfurt am Main/Salzburg, Sauerländer, 22000. 
Bidard, R., „Le Commissarait général de la langue française et les commissions ministérielles de terminologie“, in: Défense de la langue française 143 (1988), 18-20.

Bildungsdirektion des Kantons Zürich, Schulprojekt 21, http://www.volksschul|amt.ch, 2003.

Blampain, Daniel/Goosse, André/Klinkenberg, Jean-Marie/Wilmet, Marc (edd.), Le français de Belgique. Une langue, une communauté, Bruxelles/Louvain-laNeuve, Duculot, 1997.

Blank, Andreas, „Lexikalische Entlehnung - Sprachwandel - Sprachvergleich: Beispiele aus dem Computer-Wortschatz", in: Schmitt, Christian/Schweickard, Wolfgang (edd.), Die romanischen Sprachen im Vergleich. Akten der gleichnamigen Sektion des Potsdamer Romanistentages (27.30.9.1993) / XXIII. Romanistentag in Potsdam, Bonn, Romanistischer Verlag, 1995, 38-69.

Bochmann, Klaus, „Theorie und Methoden der Sprachpolitik und ihrer Analyse“, in: Bochmann 1993, 3-62.

Borg, Ingwer/Staufenbiel, Thomas, Theorien und Methoden der Skalierung, Bern et al., Huber, 31997.

Bosnjak, Michael/Batinic, Bernad, „Determinanten der Teilnahmebereitschaft an internet-basierten Fragebogenuntersuchungen am Beispiel E-Mail“", in: Batinic et al. 1999, 145-157.

Bourdieu, Pierre, Ce que parler veut dire. L’économie des échanges linguistiques, Paris, Fayard, 1993.

Bourhis, Richard Y., „Language policies and language attitudes: le monde de la Francophonie“", in: Bouchard Ryan, Ellen/Giles, Howard (edd.), Attitudes towards language variation, Social and applied contexts, London, Edward Arnold, 1982, 34-62.

Bourhis, Richard Y, „Language attitudes and self-reports of french-english language usage in Québec", in: Journal of multilingual and multicultural development 4, $2 / 3$ (1983), 163-179.

Bourhis, Richard Y., „The Charter of the French Language and Cross-Cultural Communication in Montreal“, in: Bourhis, Richard Y. (ed.), Conflict and Language Planning in Quebec, Clevedon (Avon, Angleterre), Multilingual Matters Ltd., 1984, 174-204.

Bourhis, Richard Y. (ed.), French-English langugage issues in Canada, Berlin/New York, de Gruyter, 1994.

Bradac, James J./Cargile, Aaron C./Hallett, Jennifer S., „Language Attitudes: Retrospect, Conspect, and Prospect", in: Giles, Howard/Robinson, W. Peter (edd.), The New Handbook of Language and Social Psychology, Chichester (UK) et al., Wiley \& Sons Ltd., 2001, 137-155.

Brand, Guy/Kuypers, Jean-Pierre, Lexique des néologismes Internet, 1995-1997, http://www-chimie.u-strasbg.fr/membres/GB/Lexique.html, Revisionsdatum: 04. Juli 1997. 
Braselmann, Petra, „Sprachkontakt - Kulturkontakt. Angloamerikanische Sprache und Kultur als transglossisches Phänomen in der Romania“, in: Iliescu, Maria, et al. (edd.), Ladinia et Romania. Festschrift für Guntram A. Plangg zum 65. Geburtstag, Vigo di Fassa, Istitut Cultural Ladin, 445-465.

Braselmann, Petra, Sprachpolitik und Sprachbewusstsein in Frankereich beute, Tübingen, Niemeyer, 1999 (= 1999a).

Braselmann, Petra, „Sprachkontakt und Sprachgesetzgebung: Sprachbewusstsein und Sprachpolitik in Frankreich“, in: Ohnheiser/Kienpointner/Kalb 1999, 267-280 (= 1999b).

Braselmann, Petra/Hinger, Barbara, „Sprach(en)politik und Sprachpflege in Spanien“, in: Ohnheiser/Kienpointner/Kalb 1999, 281-296.

Braselmann, Petra, „Reinheitsgebot für die Sprache. Kampf den Anglizismen?““, in: Frankfurter Allgemeine Zeitung (FAZ) vom 11. April 2000, B2 (Beilage „Frankreich“), 2.

Braselmann, Petra, „Institutionelle Sprachlenkung in Frankreich: neue Wege“, in: Haßler, Gerda (ed.), Texte und Institutionen in der Geschichte der französischen Sprache, Bonn, Romanistischer Verlag, 2001, 165-187.

Braselmann, Petra, „Deutsche Sprachpflege à la française’? Die französische Sprachpolitik im Spiegel der deutschen Presse“, in: Muttersprache 4 (2002), 289-308 (= 2002a).

Braselmann, Petra, „Anglizismen“, in: Kolboom/Kotschi/Reichel 2002, 204-208 $(=2002 \mathrm{~b})$.

Braselmann, Petra, „Sprachpolitik in der Romania“, in: Deutscher Akademischer Austauschdienst (DAAD, ed.; Red. Werner Roggausch), Dokumentation der Tagungsbeiträge. Germanistentreffen Deutschland - Argentinien - Brasilien - Chile - Kolumbien - Kuba - Mexiko - Venezuela. São Paulo, 8.-12-10.2001. Bonn, DAAD, 2002, 23-42 (= 2002c).

Braselmann, Petra, „Englisch in der Romania“, in: Hoberg, Rudolf (ed.), Deutsch Englisch- Europäisch. Impulse für eine neue Sprachpolitik, Mannheim et al., Dudenverlag, 2002, 298-332 (= 2002d).

Brasseur, Léon, Comment ,est-ce que' nous, causons' le français et le wallon, et comment ,qu'on devrait le faire, Liège, 1939.

Braun, Peter, „Internationalismen - Gleiche Wortschätze in europäischen Sprachen“, in: Braun/Schaeder/Volmert 1990, 13-33.

Braun, Peter/Schaeder, Burkhard/Volmert, Johannes (edd.), Internationalismen: Studien zur interlingualen Lexikologie und Lexikographie, Tübingen, Niemeyer, 1990.

Brekle, Herbert E., „Volkslinguistik': ein Gegenstand der Sprachwissenschaft bzw. ihrer Historiographie?"،, in: Januschek, Franz (ed.), Politische Sprachwissenschaft. Zur Analyse von Sprache als kultureller Praxis, Opladen, Westdeutscher Verlag, 1985, 145-156.

Broglie, Gabriel de, L'enrichissement de la langue française. Conférence donnée par M. Gabriel de Broglie de l'Académie Française, Président de la Commission générale de terminologie et de néologieau Congrès de la Fédération inter- 
nationale des professeurs de français à Rio de Janeiro, le 5 juin 2001, http://www.culture.gouv.fr/culture/dglf/terminologie/CONFEREN | CE\%20RIO\%20DE\%20JANEIRO.html, 2001.

Broglie, Gabriel de, Recommandation à propos de l'usage du préfixe ,e-'et de ses équivalents possibles en français, http://www.culture.fr/culture/dglf/terminologie/e_version_3.htm, 2002.

Brumme, Jenny, „Spanisch: Sprachbewertung/Lingüistica y valoración“, in: Holtus, Günter/Metzeltin, Michael/Schmitt, Christian (edd.), Lexikon der Romanistischen Linguistik (LRL), vol. VI, 1: Aragonesisch/Navarresisch, Spanisch, Asturianisch/Leonesisch, Tübingen, Niemeyer, 1992, 379-396.

Bruns, Thomas, Russische Internet-Terminologie. Unter vergleichender Berücksichtigung des Französischen und Deutschen, Frankfurt am Main et al., Lang, 2001.

Bundesamt für Statistik (BFS)/Office fédéral de la statistique (OFS), Recensement fédéral de la population 2000: Progression du français - Meilleure intégration des étrangers (= Pressemitteilung vom 19. Dezember 2002), http://www.|statistik.admin.ch/news/pm/0351-0213-10.pdf, 2002.

Bureau de normalisation du Québec (BNQ), Bienvenue au BNQ, http://www.|criq.qc.ca/bnq/francais/index.html, o.J.

Burr, Isolde, „Aspekte französischer Sprachlenkung im ausgehenden 20. Jahrhundert", in: Stein 2000, 117-156.

Bußmann, Hadumod (ed.), Lexikon der Sprachwissenschaft, Stuttgart, Kröner, ${ }^{32002 .}$

Butterworth, Joan, „Attitudes to franglais in Orléans 1969“, in: Nelde, Peter H. (ed.), Sprachkontakt und Sprachkonflikt $=$ Languages in contact and conflict $=$ Langues en contact et en conflit = Taalcontact en taalconflict, Wiesbaden, Steiner, 1980, 125-130.

Butzke-Rudzynski, Martina, Soziokulturelle und sprachenpolitische Aspekte der Francophonie am Beispiel Marokko, Bochum, Brockmeyer, 1992.

Cajolet-Laganière, Hélène/Martel, Pierre, La qualité de la langue au Québec, Québec, Institut québécois de recherche sur la culture, 1995.

Calvet, Louis-Jean, „Match de tennis ou jeu de paume?“, in: Le français dans le monde 227 (1989), 33-34.

Calvet, Louis-Jean, La guerre des langues et les politiques linguistiques, Paris, Hachette, 21999.

Candel, Danielle, „Néologie et terminologie: activité et réflexions“, in: Terminologie nouvelles 20 (1999), 44-53.

Carstensen, Broder, Englische Einflïsse auf die deutsche Sprache nach 1945, Heidelberg, Winter, 1965.

Carstensen, Broder, „Zur Intensität und Rezeption des englischen Einflusses“, in: Braun, Peter (ed.), Fremdwort-Diskussion, München, Fink, 1979, 321-326.

Cartier, Alice, „Connaissance et usage d'anglicismes par des français de Paris“, in: La Linguistique 13 (1977), 55-84.

Cassen, Bernard, „Parler français ou la ,langue des maittres’?“, in: Le Monde diplomatique vom April 1994, 32, http://www.monde-diplomatique.fr/|1994/04/CASSEN/400.html. 
Centre de Recherches et d'Études en Terminologie, Termatique et Aménagement des Langues (CRETTAL), Dictionnaire panlatin des termes de base de l'informatique. Version 2.05, http://www.realiter.net/microinf/_BDT0.|HTM\#Sommaire, http://www.realiter.net/microinf/CDICO32.HTM\#, 1996.

Centre international pour le développement de l'inforoute en français (CIDIF, Nouveau Brunswick, Canada), Vocabulaire de l'inforoute, http://www.|naviguer.org/vocabulaire/, 1996-2001.

Chansou, Michel, Recherche sur la planification linguistique en français contemporain. Le Comité d'étude des termes français et l'emprunt linguistique, Paris, Université Paris-Nord, 1981.

Chansou, Michel, „Étude d'implantation des arrêtés de terminologie. Domaines: Audiovisuel et publicité“ (Januar 1993), in: Depecker 1997a, 133-233.

Chansou, Michel, „Évaluation d'une action de politique linguistique. Les travaux de la Commission ministérielle de terminologie de l'audiovisuel et de la publicitéc, in: Terminologies nouvelles 12 (1994), 107-111.

Chansou, Michel, „Les politiques de la langue et la législation linguistique en France (1966-1994)“, in: Mots 52 (1997), 23-35.

Chomsky, Noam, Aspekte der Syntax-Theorie, Frankfurt am Main, Suhrkamp, 1969.

Christian, Donna, „Language planning: the view from linguistics“, in: Newmeyer, Frederick J. (ed.), Linguistics: The Cambridge Survey, vol. 4: Language: The Socio-cultural Context, Cambridge (UK), Cambridge University Press, 1988, 193-209.

Christmann, Hans Helmut, „Das Französische der Gegenwart: zu seiner Norm und seiner ,défense“", in: Wunderli, Peter/Müller, Wulf (edd.), Romanica bistorica et Romania hodierna. Festschrift für Olaf Deutschmann, Frankfurt am Main et al., Lang, 1982, 259-281.

Christmann, Hans Helmut, „Sprachpolitik und Sprachpflege im Frankreich der 80er Jahre: défense, illustration, diffusion“, in: Barrera-Vidal, Albert/Kleineidam, Hartmut/Raupach, Manfred (edd.), Französische Sprachlehre und ,bon usage'. Festschrift für Hans-Wilhelm Klein zum 75. Geburtstag, München, Hueber, 1986, 15-31.

Cichon, Peter, Spracherziehung in der Diglossiesituation: Zum Sprachbewußtsein von Okzitanischlehrern, Wien, VWGOe, 1988.

Cichon, Peter, Sprachbewusstsein und Sprachhandeln: Romands im Umgang mit Deutschschweizern, Wien, Braumüller, 1998.

Commissariat général de la langue française (ed.), Répertoire des organisations et associations francophones, Paris, La Documentation Française, 1984.

Commissariat général de la langue française, Guide des mots nouveaux (ouvrage réalisé par Loïc Depecker et Alain Pagès), Paris, Nathan, 1985.

Commission générale de terminologie et de néologie, Enrichissement de la langue française, Vocabulaire de l'internet, Paris, Délégation générale à la langue française, 2000 (=2000a). 
Commission générale de terminologie et de néologie, Le Répertoire terminologique 2000 publié an Journal officiel, http://www.culture.fr/culture/dglf/termi |nologie/repertoireJO220900/A2200006.htm, 2000 (= 2000b).

Commission générale de terminologie et de néologie, Le Répertoire terminologique 2000, http://www.culture.fr/culture/dglf/terminologie/repertoire |JO220900/accueil.htm, 2000 (= 2000c).

Commission générale de terminologie et de néologie, Répertoire terminologique (Révision des listes antérieurement publiées), Édition 2000, http://www.culture.|$\mathrm{fr} /$ culture/dglf/terminologie/repertoireJO220900/A2200002.htm, 2000 $(=2000 \mathrm{~d})$.

Commission générale de terminologie et de néologie, Enrichissement de la langue française, Vocabulaire de l'internet et de l'informatique, Termes et définitions publiés au Journal officiel, Paris, Délégation générale à la langue française, 2001 (Recueil actualisé des termes officialisés en France dans des domaines proches : informatique, internet et télécommunications).

Commission générale de terminologie et de néologie, „Listes de termes, expressions et définitions adoptés et publiés au Journal officiel de la République française, http://www.culture.fr/culture/dglf/cogeter/publications-jo.|htm, o.J. (= o.J.).

Commission spécialisée de terminologie et de néologie de l'informatique et des composants électroniques (CSTIC), La CSTIC propose les termes français pour l'informatique et l'internet. Communiqué, http://www-rocq.inria.fr/qui/|Philippe.Deschamp/CSTIC/presse1999.html, September 1999.

„Comptes rendus des débats“, in: Terminologies nouvelles 11 (1994), 73-76.

Conférence intercantonal de l'instruction publique de la Suisse romande et du Tessin, Glossaire des patois de la Suisse romande (GPSR), http://www.|ciip.ch/ciip/pages/navigation_entetes/som_gpsr.htm, o.J.

Conseil de l'Europe, Charte européenne des langues régionales ou minoritaires/European Charter for Regional or Minority Languages (Situation au 11/09/00), http:// |conventions.coe.int $/$ treaty $/ \mathrm{fr} /$ searchsig.asp? $\mathrm{NT}=148 \& \mathrm{CM}=8 \& \mathrm{DF}=11 / 0$ 9/00, 2000.

Cooper, Robert L., Language Planning and Social Change, Cambridge (UK), Cambridge University Press, 1989.

Corbeil, Jean-Claude, L'aménagement linguistique au Québec, http://www.olf.gouv.|qc.ca/ressources/sociolinguistique/amenagement/loubier_4.pdf, o.J. (= o.J.a).

Corbeil, Jean-Claude, „La politique linguistique québécoise“, Québec, Office québécois de la langue française, http://www.olf.gouv.qc.ca/ressources/|sociolinguistique/amenagement/loubier_5.pdf, o.J. (= o.J.b).

Cormier, Monique C./St-Pierre, Paul, „Language planning and terminology: The case of Quebec", in: International journal of Dravidian linguistics 25 (1996), 8695.

Cortelazzo, Michele A., Annali del Lessico Contemporaneo Italiano (ALCI): Neologismi 1993-1996, http://www.maldura.unipd.it/alci/public_html/, 1997-1998. 
Cosquer, Catherine, „Terminologie d'internet“, in: La Banque des Mots 51 (1996), 89-114.

Coulmas, Florian, Sprache und Staat. Studien zur Sprachplanung, Berlin/New York, de Gruyter, 1985.

Crystal, David, Language and the Internet, Cambridge (UK), Cambridge University Press, 2001.

Dahmen, Wolfgang, et al. (edd.), Germanisch und Romanisch in Belgien und Luxemburg. Romanistisches Kolloquium VI, Tübingen, Narr, 1992.

Daoust, Denise/Maurais, Jacques, „L'aménagement linguistique“, in: Maurais 1987a, 5-46.

De la Guérivière, Jean, „L’anglomanie bruxelloise“, in: Le Monde vom 04. Mai 1994, 10.

De LaBarre, François Poulain, Essai des remarques particulières sur la langue françoise pour la ville de Genève, Genf, 1691.

De Pietro, Jean-François, „Francophone ou romand? Qualité de la langue et identité linguistique en situation minoritaire“, in: Éloy 1995, 223-250.

De Pietro, Jean-François/Matthey, Marinette, „Comme Suisses romands, on emploie déjà tellement de germanismes sans s'en rendre compte...'. Entre insécurité et identité linguistiques: le cas du français à Neuchâtel (Suisse)“, in: Cabiers de l'Institut de Linguistique de Louvain 19, 3/4 (1993), 121-136.

Défense du français. Bulletin édité par la section suisse de l'Union internationale des journalistes et de la presse de la langue française.

Délégation à la langue française (DLF), Un pôle de réflexion sur la langue française en Suisse, http://www.ciip.ch/pages/DLF/dlf.htm, o.J.

Délégation générale à la langue française (DGLF), Dictionnaire des termes officiels, Paris, Éditions du Journal officiel, 1994 (= 1994a).

Délégation générale à la langue française (DGLF), Résultats du sondage réalisé par la SOFRES sur l'attitude des Français à l'égard de la politique de la langue française (1994), http://www.culture.fr/culture/dglf/politique-langue/sondage. |htm, 1994 (= 1994b).

Délégation générale à la langue française (DGLF), Termes relatifs au courrier électronique (Journal officiel du 2 décembre 1997), http://www.culture.fr/|culture/dglf/cogeter/2-12-97-mel.htm, 1997.

Délégation générale à la langue française (DGLF), Vocabulaire de l'informatique et de linternet (Journal officiel du 16 mars 1999), http://www.culture.|$\mathrm{fr} /$ culture/dglf/cogeter/16-03-99-internet-listes.html, 1999.

Délégation générale à la langue française (DGLF), Vocabulaire de l'internet (Journal officiel du 1 septembre 2000), http://www.culture.fr/culture/dglf/cogeter/19-00-internet.htm, 2000 (= DGLF 2000a).

Délégation générale à la langue française (DGLF), Répertoire terminologique (Révision des listes antérieurement publiées, Édition 2000, Journal officiel du 22.9.00) Paris, Journaux officiels, 2000 (= DGLF 2000b). 
Délégation générale à la langue française et aux langues de France (DGLFLF), Vocabulaire de l'internet (Journal officiel du 08 décembre 2002), http://|www.culture.fr/culture/dglf/cogeter/08-12-02-internet.htm, 2002.

Délégation générale à la langue française et aux langues de France (DGLFLF), Le rôle de la Délégation générale à la langue française et aux langues de France, http://www.culture.fr/culture/dglf/politique-langue/dglf-role.htm, o.J. $(=$ o.J.a).

Délégation générale à la langue française et aux langues de France (DGLFLF), Les travaux, http://www.culture.gouv.fr/culture/dglf/terminologie/les-tra|vaux.html, o.J. (= o.J.b).

Délégation générale à la langue française et aux langues de France (DGLFLF), Liste des commissions spécialisées de terminologie et de néologie, http://www.culture.fr/culture/dglf/terminologie/List-commis-termi |no.html, o.J. (= o.J.c).

Délégation générale à la langue française et aux langues de France (DGLFLF), La base de données CRITER, http://www.culture.fr/culture/dglf/termi|nologie/base-donnees.html (= o.J.d).

Délégation générale à la langue française et aux langues de France (DGLFLF), Des ressources sur la toile pour les traducteurs et les terminologues, http://www.|culture.gouv.fr/culture/dglf/traduction/Accueil.htm, o.J. (= o.J.e).

Délégation générale à la langue française et aux langues de France (DGLFLF), La francophonie en chiffres, http://www.culture.fr/culture/dglf/politiquelangue/franco-chiffre-2000.html, o.J. (= o.J.f).

Deniau, Xavier, La francophonie, Paris, Presses Universitaires de France, ${ }^{4} 1998$.

Depecker, Loïc (ed., avec la collaboration de Gina Mamavi), La mesure des mots. Cinq études d'implantation terminologique, Rouen, Publications de l'Université de Rouen, 1997 (= 1997a).

Depecker, Loïc, „Introduction“, in: Depecker 1997a, VII-XXXVII (= 1997b).

Depecker, Loïc, La politique terminologique en France, http://lilla2.unice.fr/labo_fr/|Coll\&Ouv/Colloques/termino96/loic.htm, 1997 (= 1997c).

Depecker, Loïc, „Quelques aspects des vocabulaires spécialisés de la fin du XX ${ }^{\mathrm{e}}$ siècle: entre créativité lexicale et parallélisation sur l'anglais“, in: La Banque des Mots 60 (2000), 103-134.

Depecker, Loïc, L'invention de la langue, Le choix des mots nouveaux, Paris, Larousse/ Armand Colin, 2001 (=2001a).

Depecker, Loïc, „Les vocabulaires spécialisés: Nouvelles perspectives d'aménagement" in: Pruvost, Jean (ed.), Les dictionnaires de langue française. Dictionnaires d'apprentissage - Dictionnaires spécialisés de la langue - Dictionnaires de spécialité, Paris, Champion, 2001, 225-229 (=2001b).

Deprez, Kas/Persoons, Yves, „Attitude“, in: Ammon/Dittmar/Mattheier 1987, 125-132.

Deumert, Andrea, „Language Planning: Models“, in: Mesthrie, Rajend (ed.), Concise encyclopedia of sociolinguistics, Amsterdam et al., Elsevier, 2001, 644-647.

„Die Ächtung der Sprachsünde“, in: Frankfurter Rundschau vom 06. Mai 1994, 3. 
Dieckmann, Walther, „Sprachlenkung/Sprachkritik“, in: Althaus, Hans Peter/Henne, Helmut/Wiegand, Herbert Ernst (edd.), Lexikon der germanistischen Linguistik, Tübingen, Niemeyer, ${ }^{21980, ~ 508-515 . ~}$

Diekmann, Andreas, Empirische Sozialforschung: Grundlagen, Methoden, Anwendungen, Reinbek bei Hamburg, Rowohlt, ${ }^{9} 2002$.

Dierickx, Jean, „Le français et l’anglais“, in: Blampain et al. 1997, 307-318.

Dillman, Don A., Mail and Internet Surveys. The Tailored Design Method, New York et al., Wiley \& Sons, ${ }^{2} 2000$.

Doise, Willem/Sinclair, Anne/Bourhis, Richard Y., „Evaluation of accent convergence and divergence in cooperative and competitive inter-group situations“, in: British Journal of Social and Clinical Psychology 15 (1976), 247-257.

Doppagne, Albert, Belgicismes de bon aloi, Bruxelles, Office du bon langage, 1979.

Doppagne, Albert/Hanse, Joseph/Bourgeois-Gielen, Hélène, Chasse aux belgicismes, Bruxelles, Office du bon langage, 1971.

Doppagne, Albert/Hanse, Joseph/Bourgeois-Gielen, Hélène, Nouvelle chasse aux belgicismes, Bruxelles, Plisnier, 1974 (Édition revue, Bruxelles, Plisnier, 1995).

Doppagne, Albert/Lenoble-Pinson, Michèle, Le français à la sauce anglaise. Lexique des termes anglais et américains relevés en une année dans un grand quotidien bruxellois en 1979, Bruxelles, Commission française de la culture, 1982.

Dubois, Jean, et al., Dictionnaire de linguistique, Paris, Larousse, 1994.

Dupuy, Gérard, „La françoise parlure“, in: Libération vom 13. April 1994, 3.

Durand, Charles, La langue française: atout ou obstacle? Réalisme économique, communication et francophonie au XXIe siècle, Toulouse, Presses Universitaires du Mirail, 1997.

Edl, Elisabeth/Matz, Wolfgang, „Restez cool! Frankophone FremdsprachenFurchtsamkeit“, in: Frankfurter Rundschau vom 11. März 1994, 8

Eimeren, Birgit van/Gerhard, Heinz, „ARD/ZDF-Online-Studie 2000: Gebrauchswert entscheidet über Internetnutzung“, in: Media Pespektiven 8 (2000), 338-349, URL: http://www.das-erste.de/studie/.

Eimeren, Birgit van/Gerhard, Heinz/Frees, Beate, „ARD/ZDF-Online-Studie 2001: Internetnutzung stark zweckgebunden“, in: Media Pespektiven 8 (2001), 382-397, URL: http://www.das-erste.de/studie/.

Eimeren, Birgit van/Gerhard, Heinz/Frees, Beate, „Entwicklung der Online-Nutzung in Deutschland: Mehr Routine, weniger Entdeckerfreude“, in: Media Pespektiven 8 (2002), 346-362, URL: http://www.das-erste.de/studie/.

Éloy, Jean-Michel, „L'insécurité en français monolithique ou quel est le salaire de la peur?“, in: Cahiers de l'Institut de Linguistique de Louvain 19, 3/4 (1993), 95-108.

Éloy, Jean-Michel, „La langue française, objet de politique linguistique“, in: French Review 67 (1994), 403-413.

Éloy, Jean-Michel (ed.), La qualité de la langue? Le cas du français, Paris, Champion, 1995. 
Éloy, Jean-Michel, „AAménagement' ou ,politique’ linguistique?“, in: Mots 52 (1997), 7-22.

Erfurt, Jürgen, „Sprachpolitik in Belgien“, in: Dahmen et al. 1992, 3-27.

Étiemble, René, Parlez-vous franglais?, Paris, Gallimard, 31991.

Falter, Christina, „Sprachgesetzgebung in Frankreich“, in: Sprachreport 4 (1991), 13.

Fantapié, Alain/Brulé, Marcel (edd.), Dictionnaire des néologismes officiels. Tous les mots nouveaux, avec en annexe l'ensemble des textes législatifs et réglementaires sur la langue française, Paris, FRANTERM, 1984.

Fasold, Ralph W., „Language Attitudes“, in: Fasold, Ralph W. (ed.), Introduction to sociolinguistics, Oxford/New York, Blackwell, 1984, 147-179.

Fernández Calvo, Rafael, Glosario básico inglés-español para usuarios de Internet. Con vocabulario español-inglés, Barcelona, Asociación de Técnicos de Informática, 42001, URL: http://www.ati.es/novatica/glointv2.html.

Feyry, Monique, „Les commissions ministérielles de terminologie. Observations générales", in: La Banque des Mots 5 (1973), 47-74.

Fichier français de Berne, Berne (en cours d'élaboration depuis 1959). Fichier sur le bon usage, destiné aux traducteurs et aux rédacteurs. Organisme privé fondé en 1959.

Figge, Udo, „Fachsprache und maschinelle Übersetzung“, in: Dahmen, Wolfgang, et al., Technische Sprache und Technolekte in der Romania. Romanistisches Kolloquium II, Tübingen, Narr, 1989, 302-314.

Fischer, Johann, Die Einstellung der Sprecher zu ibrer Sprache. Okizitanisch und Bündnerromanisch im Vergleich, Veitshöchheim bei Würzburg, Lehmann, 1993.

Fischer, Mathilde, Sprachbewußtsein in Paris. Eine empirische Untersuchung, Wien/ Köln/Graz, Böhlau, 1988.

Fishbein, Martin/Ajzen, Icek, Belief, attitude, intention and behaviour. An introduction to theory and research, California, Addison-Wesley, 1975.

Fortin, Jean-Marie, „Le processus de francisation de la langue du travail au Qué-

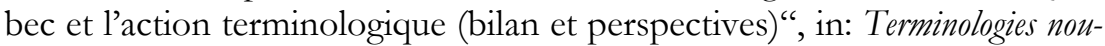
velles 9 (1993), 22-31.

Fortin, Jean-Marie, „L'Internet, le Grand dictionnaire terminologique et la mutation des pratiques terminologiques“, in: Terminogramme 84/85 (1998), 26-29.

Francard, Michel, „Insécurité linguistique en situation de diglossie. Le cas de l'Ardenne belge", in: Revue québécoise de linguistique théorique et appliquée 8, 2 (1989), 133-163.

Francard, Michel (avec la collaboration de Joëlle Lambert et Françoise Masuy), L'insécurité linguistique en Communauté française de Belgique, Bruxelles, Service de la langue française, 1993 (= 1993a).

Francard, Michel (ed., avec la collaboration de Geneviève Geron et Régine Wilmet), L'insécurité linguistique dans les communautés francophones périphériques. Actes du colloque de Louvain-la-Neuve, 10-12 novembre 1993, 2 vol., Louvain-la-Neuve, Peeters, 1993 (= Cahiers de l'Institut de Linguistique de Louvain 19, 3/4) (=1993b). 
Francard, Michel, „Trop proches pour ne pas être différents. Profils de l'insécurité linguistique dans la Communauté française de Belgique“, in: Francard 1993b, vol. 1, 61-70 (= 1993c).

Francard, Michel, „Entre Romania et Germania: la Belgique francophone“, in: Robillard/Beniamino 1993, 317-336 (= 1993d).

Francard, Michel, „Des francophones en quête de légitimité. Perceptions de la langue française dans la Communauté française de Belgique", in: MassartPiérard, Françoise (ed.), La langue: vecteur d'organisation internationale, Louvain-la-Neuve, Academia, 1993, 39-46 (= 1993e).

Francard, Michel, „Insécurité linguistique“, in: Moreau 1997a, 170-176 (= 1997a).

Francard, Michel, „Légitimité linguistique“, in: Moreau 1997a, 201-202 (= 1997b).

Francard, Michel, „La légitimité linguistique passe-t-elle par la reconnaissance du statut de variété ,nationale’? Le cas de la communauté française WallonieBruxelles“, in: Revue québécoise de linguistique 26,2 (1998), 13-23.

Francoeur, Aline, „Compte rendu: Depecker, Loïc (dir.) (1997): La mesure des mots. Cing études d'implantation terminologique, Rouen, Publications de l'Université de Rouen, xxxvii + 528p.“, in: Meta 43,2 (1998), URL: http://www.|erudit.org/revue/meta/1998/v43/n2/index.html.

„Französisch per Gesetz geschützt. Parlament billigt Vorlage von Kulturminister Toubon", in: Frankfurter Rundschau vom 06. Mai 1994, 7.

Frey, Brigitte, Die Académie Française und ibre Stellung zu anderen Sprachpflegeinstitutionen, Bonn, Romanistischer Verlag, 2000.

Friedrichs, Jürgen, Methoden empirischer Sozialforschung, Opladen, Westdeutscher Verlag, ${ }^{141990 .}$

Fuchs, Gabriela/Werlen, Iwar, Bilinguisme à Biel-Bienne. Enquête dans le cadre du baromètre du bilinguisme biennois 1998, Berne, Centre universitaire de recherche sur le plurilinguisme, 1999 [dt.: Zweisprachigkeit in Biel-Bienne, Untersuchung im Rahmen des Bieler Bilinguismus-Barometers 1998].

Fugger, Bernd, „Les Français et les arrêtés ministériels. Étude sur l’impact de la loi linguistique dans l'est de la France“, Teil 1 in: La Banque des Mots 18 (1979), 157-170, Teil 2 in: La Banque des Mots 25 (1983), 52-62 (= 1983a).

Fugger, Bernd, „Die Einstellung der Franzosen zur französischen Sprachpolitik“, in: Stimm 1980, 58-78.

Fugger, Bernd, „Sprachentwicklung - Sprachbeeinflussung - Sprachbewußtsein. Eine soziolinguistische Untersuchung zur französischen Sprachpolitik“, in: Fachsprache 3 (1983), 128-137 (=1983b).

Fugger, Bernd, „Die französische Sprachpolitik im internationalen Sprachkontakt", in: Französisch heute 18, 3 (1987), 231-247.

FUNREDES/Unión Latina, El lugar de las lenguas latinas en Internet/Il poste delle lingue latine in Internet/Lugar das linguas latinas na Internet/Locul limbilor latine pe Internet (Realizado entre agosto 2000 y junio 2001. Publicado: 1/08/2001. Derechos de autor y de explotación (C), 2000-2001, Funredes, Unión Latina. Con el apoyo de la Délégation générale à la langue française), http://www.unilat.org/dtil/LI/index.htm, 2001. 
Gadeib, Andrea, „Ansprüche und Entwicklung eines Systems zur Befragung über das World Wide Web“, in: Batinic et al. 1999, 103-111.

Gahlen, Dorothee/Geisel, Birgit, Französische Sprachpolitik und Sprachbewußtsein in Senegal, Frankfurt am Main et al., Lang, 1999.

Gardner, Robert C./Lambert, Wallace E., Attitudes and Motivation in Second-Language Learning, Rowley (Massachusetts), Newbury House, 1972.

Garsou, Martine, L’image de la langue française, Bruxelles, Service de la langue française, 1991.

Garsou, Martine, „La promotion du français en Communauté française de Belgique“, in: Blampain et al. 1997, 459-481.

Gasquet, Evelyne/Villebrun, Isabelle, ,, Observation de faits d'implantation terminologique en métallurgie“, in: Terminologies nouvelles 12 (1994), 114-122.

Gaudin, François, „Enquête sur l'impact des arrêtés terminologiques auprès de magistrats“" in: La Banque des Mots 42 (1991), 59-66.

Gaudin, François/Guespin, Louis, „Étude d'implantation des arrêtés de terminologie. Domaine: Génie génétique“ (1993), in: Depecker 1997a, 1-45.

Gauthier, François/Leclerc, Jacques/Maurais, Jacques [pour l'] Office de la langue française, Langues et constitutions. Recueil des clauses linguistiques des constitutions du monde, Québec, Publications du Québec/Paris, Conseil international de la langue française, 1993.

Gebhardt, Karl, „Sprachlenkung und Sprachpflege im heutigen Frankreich: Zum Problem des ,franglais"“, in: Die Neueren Sprachen 80 (1981), 18-34.

Gediga, Günther, Skalierung: Eine Einführung in die Methodik zur Entwicklung von Testund Meßinstrumenten in den Verhaltenswissenschaften, Münster, LIT, 1998.

Genouvrier, Émile, Naître en français, Paris, Larousse, 1986.

Giles, Howard/Hewstone, Miles/Ball, Peter, „Language attitudes in multilingual settings: Prologue with priorities“, in: Journal of Multilingual and Multicultural Development 4(2,3) (1983), 81-100.

Giles, Howard/Hewstone, Miles/Ryan, Ellen B./Johnson, Patricia, „Research on Language Attitudes“, in: Ammon/Dittmar/Mattheier 1987, 585-597.

Gladischefski, Anke/Lieber, Maria Gesina, „La féminisation des noms de métier et des titres au Canada francophone: une comparaison avec la France, la Suisse et la Belgique“, in: Kolboom, Ingo/Lieber, Maria/Reichel, Edward (edd.), Le Québec: Sociétés et Cultures. Les Enjeux d'une Francophonie lointaine, Dresden et al., Dresden University Press, 1998, 275-292.

Global Reach, Global Internet Statistics (by Language), http://glreach.com/globstats, Revisionsdatum: 30. September 2003.

Glück, Helmut (ed.), Metzler-Lexikon Sprache, Stuttgart, Metzler, 22000.

Goebl, Hans/Nelde, Peter H./Zdenek, Starý (edd.), Kontaktlinguistik. Ein internationales Handbuch zeitgenössischer Forschung $=$ Contact linguistics $=$ Linguistique de contact (= Handbücher zur Sprach- und Kommunikationswissenschaft, vol. 12.1), 1. Halbband, Berlin/New York, de Gruyter, 1996.

Goebl, Hans/Nelde, Peter H./Zdenek, Starý (edd.), Kontaktlinguistik. Ein internationales Handbuch zeitgenössischer Forschung $=$ Contact linguistics $=$ Linguistique de 
contact ( $=$ Handbücher zur Sprach- und Kommunikationswissenschaft, vol. 12.2), 2. Halbband, Berlin/New York, de Gruyter, 1997.

Goosse, André, La néologie française aujourd'bui. Observations et réflexions, Paris, Conseil International de la langue française (CILF), 1975.

Goosse, André, „La notion de qualité de la langue française en Belgique“, in: Éloy 1995, 269-284.

Görtz, Barbara, Untersuchung zur Diskussion über das Thema Sprachverfall im Fin-deSiècle, Frankfurt am Main et al., Lang, 1990.

Gouadec, Daniel, „Étude d'implantation des arrêtés de terminologie. Domaine: Informatique“ (1993), in: Depecker 1997a, 235-493.

Gouadec, Daniel, „Implantation des termes officiels de l'informatique. Attestations, francisation, normalisation, assimilation“, in: Terminologies nouvelles 12 (1994), 141-147.

Goudaillier, Jean-Pierre, „A nouveau les puristes contre la langue“, in: La Linguistique 13, 2 (1977), 85-98.

Goudaillier, Jean-Pierre, „Sprache und Macht: Wie ein Gesetz in Frankreich die Sprache reinigen will", in: Dialect 6, 1 (1982), 28-51.

Goudaillier, Jean-Pierre, „De la nécessité des enquêtes linguistiques pour le travail des commissions de terminologie" in: Meta 32, 3 (1987), 361-365.

Gräf, Lorenz, „Optimierung von WWW-Umfragen: Das Online Pretest-Studio“, in: Batinic et al. 1999, 159-177.

Gräf, Lorenz/Heidingsfelder, Martin, „Bessere Datenqualität bei WWW-Umfragen - Erfahrungen aus einem Methodenexperiment mit dem InternetRogator", in: Batinic et al. 1999, 113-126.

Greule, Albrecht, „Theorie und Praxis der germanistischen Sprachpflege“, in: Muttersprache 92 (1982), 265-292.

Greule, Albrecht/Ahlvers-Liebel, Elisabeth, Germanistische Sprachpflege: Geschichte, Praxis und Zielsetrung, Darmstadt, Wissenschaftliche Buchgesellschaft, 1986.

Grevisse, Maurice, Le Bon Usage: Grammaire française, refondue par André Goosse, Paris/Gembloux, Duculot, 131993.

Gröschel, Bernhard, Sprachnorm, Sprachplanung und Sprachpflege: Bibliographie theoretischer Arbeiten aus Linguistik und Nachbarwissenschaften, Münster, Institut für Allgemeine Sprachwissenschaft, Universität, 1982.

Gsteiger, Fredy, o.T., in: Die Zeit 29 vom 15. Juli 1994, 26 (= 1994a).

Gsteiger, Fredy, im Interview mit Claude Hagège, „Wenn Franzosen Fremdwörter benutzen, gilt kein Pardon: Ihnen droht Prison. Mariannes Sprachpolizei“, in: Die Zeit 29 vom 15. Juli 1994, 26 (= 1994b).

Guespin, Louis/Marcellesi, Jean-Baptiste, „Pour la glottopolitique“, in: Languages 21 (1986), 5-35.

Gueunier, Nicole „Représentations linguistiques“, in: Moreau 1997a, 246-252.

Gueunier, Nicole/Genouvrier, Émile/Khomsi, Abdelhamid, Les Français devant la norme. Contribution à une étude de la norme du français parlé, Paris, Champion, 1978. 
Guilbert, Louis, La créativité lexicale, Paris, Larousse, 1975.

Guilford, Jonathon, „Les attitudes des jeunes français à propos des emprunts à l'anglais“, in: La Linguistique 33, 2 (1997), 117-135.

Haarmann, Harald, „Sprache und Prestige. Sprachtheoretische Parameter zur Formalisierung einer zentralen Beziehung“, in: Zeitschrift für romanische Philologie 106, 1/2 (1990), 1-21 (= 1990a).

Haarmann, Harald, „Language Planning in the Light of a General Theory of Language - a Methodological Framework“", in: International Journal of the Sociology of Language 86 (1990), 103-126 (= 1990b).

Haarmann, Harald, „Wie kann man das Sprachprestige in eine Theorie der Sprachplanung einbetten?", in: Spillner 1990, 41-44 (= 1990c).

Haas, Rainer, Französische Sprachengesetzgebung und europäische Integration, Berlin, Duncker \& Humblot, 1991.

Hadacek, Catherine, Le suisse romand tel qu'on le parle. Lexique romand-français, Lausanne, Favre, 1983.

Hagège, Claude, Le français et les siècles, Paris, Jacob, 1987.

Hagège, Claude, Le français, histoire d'un combat, Paris, Hagège, 1996.

Hahn, Dorothea, „Parlez français - oder zahlen! Gesetz über den Gebrauch der französischen Sprache“, in: Die Tageszeitung (TAZ) vom 28. Februar 1994, 20.

Hall, Robert A., Leave your language alone!, Ithaca (New York), Linguistica, 1950 [2. Auflage: Hall, R.A., Linguistics and your language, Garden City (New York), Anchor Books, 1950].

Hanimann, Joseph, „Französisch staubsaugen. Wie die Pariser Regierung die Sprache reinhält", in: Frankfurter Allgemeinen Zeitung (FAZ) vom 28. Februar 1994, 33.

Hanse, Joseph, „Consultations grammaticales et lexicologiques“, in: Les Études Classiques (1939), 496-511.

Hanse, Joseph, Dictionnaire des difficultés grammaticales et lexicologiques, Paris/Bruxelles, Baude, 1949.

Hanse, Joseph, „Autour du „Bon usage', in: Bulletin de l'Académie Royale de Langue et de Littérature Françaises 67 (1989), 313-327.

Hanse, Joseph/Blampain, Daniel, Nouveau dictionnaire des difficultés du français moderne, Bruxelles, De Boeck Duculot, ${ }^{4} 2000$.

Hauck, Werner, „Die Amtssprachen der Schweiz. Anspruch und Wirklichkeit“, in: Born, Joachim/Stickel, Gerhard (edd.), Deutsch als Verkehrssprache in Europa, Berlin/New York, de Gruyter, 1993, 147-163 (= Institut für deutsche Sprache. Jahrbuch 1992).

Hauck, Werner, „Demokratiefähige Gesetzessprache trotz Globalisierung. Erfahrungen aus dem Alltag eines staatlichen Sprachdienstes“, in: Wilss 2000, 192-215.

Haugen, Einar, Language Conflict and Language Planning, the Case of Modern Norwegian, Cambridge, Harvard University Press, 1966. 
Haugen, Einar, „Language Planning in Modern Norway“, in: Anthropological Linguistics 1, 3 (1959), 8-21 [wieder abgedruckt in Fishman, Joshua A. (ed.), Readings in the Sociology of Language, La Haye, Mouton, 1968, 673-687].

Haugen, Einar, „The Implementation of Corpus Planning: Theory and Practice“, in: Cobarrubias, Juan/Fishman, Joshua A. (edd.), Progress in Language Planning: International Perspectives, La Haye, Mouton, 1983, 269-289.

Haugen, Einar, „Language planning“, in: Ammon/Dittmar/Mattheier 1987, 626637.

Hauptmanns, Peter, „Grenzen und Chancen von quantitativen Befragungen mit Hilfe des Internet“, in: Batinic et al. 1999, 21-38.

Hausmann, Franz Josef, „Les dictionnaires du français hors de France“, in: Boisvert, Lionel/Poirier, Claude/Verreault, Claude (edd.), La lexicographie québécoise. Bilan et perspectives. Actes du colloque organisé par l'équipe du Trésor de la langue française au Québec et tenu à l'Université Laval les 11 und 12 avril 1985, Québec, Les Presses de l’Université Laval, 1986, 3-21 $(=1986 a)$.

Hausmann, Franz Josef, „The influence of the English language on French“, in: Viereck, Wolfgang/Bald, Wolf-Dietrich (edd.), English in contact with other languages, Budapest, Akademiai Kiado, 1986, 79-105 (= 1986b).

Helfrich, Uta, Neologismen auf dem Prüfstand. Ein Modell zur Ermittlung der Akzeptanz. französischer Neologismen, Wilhelmsfeld, Egert, 1993.

Helfrich, Uta, „Konservativ vs. innovatorisch: Geschlechtsspezifisches Akzeptanzverhalten gegenüber Neologismen im Französischen“, in: Dahmen, Wolfgang, et al. (edd.), Sprache und Geschlecht in der Romania. Romanistisches Kolloquium X, Tübingen, Narr, 1997, 223-239.

Hellinger, Marlis/Ammon, Ulrich (edd.), Contrastive sociolinguistics, Berlin/New York, de Gruyter, 1996.

Herberg, Dieter, „Neologismen der Neunzigerjahre“, in: Stickel, Gerhard (ed.), Neues und Fremdes im deutschen Wortschatr. Aktueller lexikalischer Wandel, Berlin/New York, de Gruyter, 2001, 89-104 (= Institut für Deutsche Sprache, Jahrbuch 2000).

Hoenigswald, Henry, „A proposal for the study of folk-linguistics“, in: Bright, William O. (ed.), Sociolinguistics. Proceedings of the UCLA Sociolinguistics Conference, 1964, The Hague/Paris, Mouton, 31975, 16-26.

Hoerkens, Waltraud, Die Renaissance der französischen Sprache in Quebec, Bonn, Romanistischer Verlag, 1998.

Högstedt, Helena, Belgicismes. Une étude de belgicismes lexicaux dans la presse quotidienne belge, http://hem.passagen.se/nenan/uppsatsen.html, 1998.

Holtus, Günter, „Der Beitrag der belgischen Sprachwissenschaft zur Normierung des Französischen“, in: Dahmen et al. 1992, 46-63.

Holtus, Günter, „Sprachwandel - retrospektiv und prospektiv betrachtet. Einführende Bemerkungen zur Sprachprognostik am Beispiel des Italienischen“, in: Holtus, Günter/Radtke, Edgar (edd.), Sprachprognostik und das „ita- 
liano di domani“. Prospettive per una linguistica „prognostica“, Tübingen, Narr, 1994, 7-19.

Holtus, Günter/Metzeltin, Michael/Schmitt, Christian (edd.), Lexikon der Romanistischen Linguistik (LRL), vol. V.1: Französisch, Tübingen, Niemeyer, 1990.

Holtus, Günter/Metzeltin, Michael/Schmitt, Christian (edd.), Lexikon der Romanistischen Linguistik (LRL), vol. I,2: Methodologie (Sprache in der Gesellschaft/Sprache und Klassifikation/Datensammlung und -verarbeitung), Tübingen, Niemeyer, 2001.

Hoppe, Danielle, Aussprache und sozialer Status. Eine empirische Untersuchung zur französischen Gegenwartssprache, Kronberg/Taunus, Scriptor, 1976.

Huber, Herbert/Cheval, Mireille, „Internet, comment s’y retrouver? Quelques aspects d'une terminologie en constante évolution (français - allemand)“, in: Lebende Sprachen 4 (1998), 169-172.

Humbley, John, „Le purisme dans les dictionnaires de l'informatique ,grand public"“, in: Cabiers de Lexicologie 56-57 (1990), 241-253.

Humbley, John, „Paramètres d'observation de l'aménagement de la langue“, in: Labrie 1997, 155-162.

Humbley, John, „La terminologie“, in: Antoine/Cerquiglini 2000, 315-338.

Institut de Dialectologie de l'Université de Neuchâtel, Les projets de recherche de l'Institut de Dialectologie, http://www.unine.ch/dialectologie/ |recherche.html, o.J.

Jahr, Ernst H., „Sociolinguistics: Minorities and sociolinguistics“, in: Bright, William O. (ed.), International encyclopedia of linguistics, vol. 4, New York, Oxford University Press, 1992, 12-15.

Januschek, Franz, Arbeit an Sprache: Konzept für die Empirie einer politischen Sprachwissenschaft, Opladen, Westdeutscher Verlag, 1986.

Jäpel, Werner, Die Qualität alternativer Rating-Formen und ibre Einflußgrößßen, Regensburg, Universität, 1985.

Juhász, János, „Versuch einer konstruktiven Kritik von Sprachpflege. Prinzipien und Probleme“, in: Besch, Werner, et al. (edd.), Festschrift für Siegfried Grosse zum 60. Geburtstag, Göppingen, Kümmerle, 1984, 63-94.

Juhász, János, „Der Stellenwert der Sprachkultur in der modernen Gesellschaft. Ökologische Aufgaben der Linguistik“, in: Wimmer, Rainer (ed.), Sprachkultur, Düsseldorf, Schwann, 1985, 33-54 (= Jahrbuch 1984 des Instituts für deutsche Sprache).

Kaase, Max (ed.)/Deutsche Forschungsgemeinschaft, Qualitätskriterien der Umfrageforschung: Denkschrift = Quality criteria for survey research, Berlin, Akademie Verlag, 1999.

Kasper, Christine, „Wallonisch als Regionalsprache in Belgien“, in: Cichon, Peter/Czernilofsky, Barbara (edd.), Mehrsprachigkeit als gesellschaftliche Herausforderung. Sprachenpolitik in romanischsprachigen Ländern, Wien, Edition Praesens, 2001, 31-46. 
Kattenbusch, Dieter, „Computervermittelte Kommunikation in der Romania im Spannungsfeld zwischen Mündlichkeit und Schriftlichkeit“, in: Heinemann, Sabine/Bernhard, Gerald/Kattenbusch, Dieter (edd.), Roma et Romania. Festschrift für Gerbard Ernst zum 65. Geburtstag, Tübingen, Niemeyer, 2002.

Katz, Daniel, „The functional approach to the study of attitudes“, in: Public Opinion Quarterly 24 (1960), 163-204.

Klare, Johannes, „Sprachpolitik, Sprachkultur und Sprachpflege in Frankreich gestern und heute“, in: Scharnhorst, Jürgen (ed.), Sprachkultur und Sprachgeschichte: Herausbildung und Förderung von Sprachbewusstsein und wissenschaftlicher Sprachpflege in Europa, Frankfurt am Main et al., Lang, 1999, 13-45.

Klein, Jean-René/Lienart, Nathalie/Ostyn, Stéphane, „L'anglicisme et la presse. Enquête et analyse à travers quatre quotidiens français et belges“, in: Revue de Linguistique Romane 61 (1997), 337-360.

Kleineidam, Hartmut, „Sprachverbreitungspolitik in Frankreich“, in: Spillner 1990, 51-55.

Klinkenberg, Jean-Marie, „La crise des langues en Belgique“, in: Maurais 1985a, 93-145.

Klinkenberg, Jean-Marie, „Préface“, in: Francard 1993b, 5-7.

Klinkenberg, Jean-Marie, „Les arts de la langue“, in: Blampain et al. 1997, 401413.

Klinkenberg, Jean-Marie, „Le français en Belgique“, in: Antoine/Cerquiglini 2000, 701-718.

Klinkenberg, Jean-Marie, La langue et le citoyen, Paris, Presses Universitaires de France, 2001.

Kloss, Heinz, Research Possibilities on Group Bilingualism: A Report, Québec, Centre international de recherche sur le bilingualisme, Presses de l'Université Laval, 1969.

Knapp, Frank/Heidingsfelder, Martin, „Drop-Out-Analyse: Wirkungen des Untersuchungsdesigns“, in: Reips et al. 1999, Kurzfassung unter: http://www.gor.de/tband99/pdfs/i_p/knapp_ad.pdf, http://www.psy|ma.com/info/veroeff_drop.htm.

Knecht, Pierre, „Le français en Suisse romande: aspects linguistiques et sociolinguistiques", in: Valdman, Albert (ed.), Le français hors de France, Paris, Champion, 1979, 249-258.

Knecht, Pierre, „La Suisse romande: aspects d'un paysage francophone conservateur", in: Robillard/Beniamino 1996, 759-770.

Knecht, Pierre, „Préface“, in: Thibault 1997, 9-15.

Knecht, Pierre, „Die französischsprachige Schweiz“, in: Bickel/Schläpfer 2000, 139-176 (= 2000a).

Knecht, Pierre, „Le français en Suisse Romande“, in: Antoine/Cerquiglini 2000, $719-727$ (= 2000b).

Knecht, Pierre/Py, Bernard, „Suisse romande“, in: Goebl/Nelde/Starý 1997, 1862-1870. 
Knecht, Pierre/Rubattel, Christian, „À propos de la dimension sociolinguistique du français en Suisse romande“, in: Le Français Moderne 52, 3/4 (1984), 138-150.

Knecht, Pierre/Rubattel, Christian, „Problèmes sociolinguistiques en Suisse romande“, in: Werlen, Iwar (ed.), Probleme der schweizerischen Dialektologie/Problèmes de la dialectologie suisse, Fribourg, Éditions universitaires, 1985, 141-157.

Kolboom, Ingo/Kotschi, Thomas/Reichel, Edward (edd.), Handbuch Französisch. Sprache-Literatur-Kultur-Gesellschaft. Für Studium, Lehre, Praxis, Berlin, Schmidt, 2002.

Kolde, Gottfried, Sprachkontakte in gemischtsprachigen Städten: Vergleichende Untersuchungen über Voraussetzungen und Formen sprachlicher Interaktion verschiedensprachiger Jugendlicher in den Schweizer Städten Biel/Bienne und Fribourg/Freiburg i. Ue., Wiesbaden, Steiner, 1981.

Kolde, Gottfried/Näf, Anton, „Die Westschweiz“, in: Hinderling, Robert/Eichinger, Ludwig M. (edd.), Handbuch der mitteleuropäischen Sprachminderheiten, Tübingen, Narr, 1996, 385-412.

Koschnick, Wolfgang J., FOCUS-Lexikon für Mediaplanung, Markt und Mediaforschung, http://medialine.focus.de/PM1D/PM1DB/PM1DBF/pm1dbf.|htm, o.J.

Kramer, Johannes, „Deutsch als Publikationssprache und vielsprachige Romanistik - ein Ärgernis in der internationalen Wissenschaftslandschaft?“", in: Lieber, Maria/Wentzlaff-Eggebert, Harald (edd.), Deutschsprachige Romanistik - für wen?, Heidelberg, Synchron Wissenschaftsverlag der Autoren, 2002, 13-27.

Krefeld, Thomas, „Italienisch: Sprachbewertung/Giudizi sulla lingua“, in: Holtus, Günter/ Metzeltin, Michael/Schmitt, Christian (edd.), Lexikon der Romanistischen Linguistik (LRL), vol. IV: Italienisch, Korsisch, Sardisch, Tübingen, Niemeyer, 1988, 312-326.

Kremnitz, Georg, „La sociolinguistique dans les États français et espagnol“, in: Dittmar, Norbert/Schlieben-Lange, Brigitte (edd.), Die Soziolinguistik in den romanischsprachigen Ländern/La sociolinguistique dans les pays de langue romane, Tübingen, Narr, 1982, 13-28.

Kremnitz, Georg, Gesellschaftliche Mehrsprachigkeit. Institutionelle, gesellschaftliche und individuelle Aspekte. Ein einführender Überblick, Wien, Braumüller, 21994.

Kremnitz, Georg, ,Sprache und Politik/Langue et politique, a) Sprache und Gesetzgebung/ Aménagement linguistique“, in: Holtus/Metzeltin/Schmitt 2001, 492-500.

Kunze, Klaus, Die Netikette, http://www.uni-leipzig.de/netz/netikett.htm, Erstellungsdatum: 10. Mai 2000.

L'association suisse des journalistes de langue française, Défense du français, http://www.francophonie.ch/, 2003. 
Laboratoire de Linguistique Informatique (LLI), Rapport 1993-1996, Paris, http://www-lli.univ-paris13.fr/, Revisionsdatum: 12. Dezember 2002 (= 2002a).

Laboratoire de Linguistique Informatique (LLI), Rapport 1997-2000, Paris, http://www-lli.univ-paris13.fr/, Revisionsdatum: 12. Dezember 2002 (= 2002b).

Labov, William, The social stratification of English in New York, Washington, D.C., Center for Applied Linguistics, 1966.

Labov, William, Sociolinguistic Patterns, Philadelphia, University of Pennsylvania Press, 1972.

Labov, William, Sprache im sozialen Kontext. Beschreibung und Erkelärung struktureller und sozialer Bedeutungen von Sprachvariation, vol. 1, herausgegeben von Norbert Dittmar und Bert-Olaf Rieck, Königstein/Taunus, Scriptor, 1976.

Labov, William, Sprache im sozialen Kontext, Beschreibung und Erkelärung struktureller und sozialer Bedeutungen von Sprachvariation, vol. 2, herausgegeben von Norbert Dittmar und Bert-Olaf Rieck, Königstein/Taunus, Scriptor, 1978.

Labrie, Normand, „The Role of Pressure Groups in the Change of the Status of French in Québec since 1960“, in: Ammon/Hellinger 1991, 17-42.

Labrie, Normand, „Politique linguistique“, in: Goebl/Nelde/Starý 1996, 826-833.

Labrie, Normand (ed.), Études récentes en linguistique de contact, Bonn, Dümmler, 1997.

Labrie, Normand/Nelde, Peter Hans, „L'aménagement linguistique dans la communauté européenne“, in: Carton, Fernand/Delefosse, J.M. Odéric (edd.), Les langues dans l'Europe de demain, Paris, Presses de la Sorbonne nouvelle, 1994, 117-127.

Lafontaine, Dominique, Le parti pris des mots. Normes et attitudes linguistiques, Bruxelles, Mardaga, 1986.

Lafontaine, Dominique, Les mots et les Belges. Enquête sociolinguistique à Liège, Charleroi, Bruxelles, Bruxelles, Communauté française, Service de la langue française, 1991.

Lafontaine, Dominique, Performances en lecture et contexte éducatif. Enquête internationale auprès d'élèves de 9 et 14 ans, Bruxelles, De Boeck, 1996.

Lafontaine, Dominique, „Les attitudes et les représentations linguistiques“, in: Blampain et al. 1997, 381-390.

Lagerqvist, Hans, Introduction au français hors de France. Manuel pour l'étude des variétés belge, suisse, nord-américaine, maghrébine et négro-africaine de la langue française, Aalborg, Aalborg University Press, 2001.

Lagueux, Paul-André, „La part des emprunts à l'anglais dans la création néologique en France et au Québec“, in: Pergnier 1988a, 91-111.

Lambert, Wallace E., „A social psychology of bilingualism“, in: Journal of Social Issues 23 (1967), 91-109.

Lambert, Wallace E., et al., „Evaluational reactions to spoken languages“, in: Journal of Abnormal and Social Psychology 60 (1960), 44-51. 
Langenbacher, Jutta, „Normative Lexikologie. Die ,Communiqués de mise en garde' der Académie française (1964-1978) und ihre Rezeption in den französischen Wörterbüchern der Gegenwart", in: Stimm 1980, 79-95.

LaPiere, Richard T., „Attitudes versus actions“, in: Social Forces 13 (1934), 230-237.

Laporte, Pierre-Etienne, „Aspects historiques et politiques de la question de la qualité de la langue: le cas du français québécois,“ in: Éloy 1995, 205-222.

Lazare, Françoise, „Les nouveaux mots pour le dire. Sous les assauts de la globalisation et du vocabulaire anglais-américain des nouvelles technologies, une autre façon de parler et d'écrire émerge, où se dissout la langue de Molière“, in: Le Monde vom 17. November 2000, 26.

Le Droit de comprendre, La langue française dans tous ses états. Rapport des associations (Paris, janvier 1999), http://persoweb.francenet.fr/ languefr/ddc/|rapportlfddc.htm, o.J.

Le Guilly-Wallis, Anne, „Étude de cas: l'impact des arrêtés de terminologie sur l'informaticien français“, in: Terminologie et traduction 1 (1991), 117-142.

Lebouc, Georges, Le belge dans tous ses états. Dictionnaire de belgicismes, grammaire et prononciation, Paris, Bonneton, 1998.

Lebsanft, Franz, Spanische Sprachkultur. Studien zur Bewertung und Pflege des öffentlichen Sprachgebrauchs im heutigen Spanien, Tübingen, Niemeyer, 1997.

Lebsanft, Franz, „,Lingüística popular’ y cultivo del idioma en Internet. Los resultados de una encuesta a participantes de la lista de correo ,Apuntes"“, in: Español Actual (Arco/Libros) 72 (1999), 47-57 [erschienen 2001].

Leclerc, Jacques, „La politique linguistique du français“, in: L'aménagement linguistique dans le monde, http://www.tlfq.ulaval.ca/axl/, Revisionsdatum: 2002.

Le Culturactif Suisse, Situation juridique du romanche. Niveau fédéral/Rechtsstellung des Rätoromanischen. Bundesebene, http://www.culturactif.ch/vieculturelle/|suisse5.htm, o.J.

Ledegen, Gudrun, „Maîtrise de la norme et sécurité/insécurité linguistiques chez les étudiants francophones“, in: Le français aujourd'bui 124 (1998), 43-51.

Le Droit de comprendre, Notre mission, http://persoweb.francenet.fr/|languefr/ddc/, o.J.

Lefevre, J., „Dialect and regional identification in Belgium: The case of Wallonia“, in: International Journal of the Sociology of Language 15 (1978), 47-51.

Lefevre, J., „Nationalisme linguistique et identification linguistique: Le cas de Belgique“, in: International Journal of the Sociology of Language 20 (1979), 37-58.

Lemeur, André/Depecker, Loïc, „Balnéo: un projet de réseau informatique pour la veille néologique“, in: Terminologies nouvelles 14 (1995), 48-53 [in englischer Fassung: Lemeur, André/Depecker, Loïc, „Balnéo: A Computer Network Project for ,Neological Watch', in: Galinski, Christian, et al. (edd.), Terminology and knowledge engineering. Proceedings/TKE '96, Fourth International Congress on Terminology and Knowledge Engineering, 26 28 August 1996, Vienna, Austria, Frankfurt am Main, Indeks-Verlag, 1996, 159-165]. 
Lenoble-Pinson, Michèle, „208 fiches lexicales d',Anglicismes“, in: Questions de français vivant (1984-1987 et 1989-1992).

Lenoble-Pinson, Michèle, „Fiches lexicales d',Anglicismes"“, in: Francité. Revue de la Maison de la Francité (1993-1996).

Lenoble-Pinson, Michèle, „Grandeur et misère du plurilinguisme en Belgique“, in: Labrie 1997, 240-249.

Lenoble-Pinson, Michèle, Anglicismes et substituts français, Paris/Louvaine-la-Neuve, Duculot, 1991.

Lerat, Pierre, „Französisch: Sprachbewertung/Évaluation de la langue“, in: Holtus/Metzeltin/Schmitt 1990, 392-401.

Lerat, Pierre/Sourioux, Jean-Louis, „Les définitions de noms dans un arrêté ministériel français de terminologie“", in: Centre d'études du lexique, La Définition, Paris, Larousse, 1990, 262-270.

Link Everything Online (LEO, Informatik der Technischen Universität München), English-German-Dictionary, http://dict.leo.org/, (C) LEO Dictionary Team 1995-2003.

Lorey, Barbara, „Mr. Allgood kämpft gegen Hollywood. Hüter der französischen Sprache: Kulturminister Jacques Toubon versucht, aus Jack Langs Schatten zu treten“, in: Die Welt vom 04. Juli 1994, 8.

Loubier, Christiane, L'aménagement linguistique. Fondements de l'aménagement linguistique, http://www.olf.gouv.qc.ca/ressources/sociolinguistique/amenagement |/loubier_1.pdf, o.J. (= o.J.a).

Loubier, Christiane, Politiques linguistiques et droit linguistique, http://www.olf.|gouv.qc.ca/ressources/sociolinguistique/amenagement/loubier_2.pdf, o.J. (= o.J.b).

Lüdi, Georges, „Multilingualism through migration: A comparison of internal and external migrant communities in Switzerland“, in: Hellinger/Ammon 1996, 103-133.

Maas, Utz, Sprachpolitik und politische Sprachwissenschaft. Sieben Studien, Frankfurt am Main, Suhrkamp, 1989.

Maison de la Francité, Législation linguistique en Belgique, http://www.|maisondelafrancite.be $/$ francite $/$ ?page $=$ services $/$ legislations\&rubrique $=\mid-$ services (= o.J.a).

Maison de la Francité, Cercle de qualité du français dynamique, http://www.maison |delafrancite.be $/$ francite $/$ ?page $=$ services $/$ cqfd\&rubrique $=$ services, o.J. $\quad(=$ o.J.b)

Marcellesi, Christiane, Approche synchronique du vocabulaire de l'informatique (3e génération), Nanterre, Université de Paris X, 1971.

Marcellesi, Christiane, „Le langage des techniciens de l'informatique: quelques aspects de leur vocabulaire écrit et oral“", in: Langue Française 17 (1973), 5971.

Markhof, Wolfgang, Renaissance oder Substitution? Eine soziolinguistische Untersuchung zur Stellung des Okzitanischen im Département Cantal, Genève, Droz, 1987. 
Martel, Pierre/Cajolet-Laganière, Hélène, Le Français québécois: Usage, standard et aménagement, Québec, Institut Québécois de Recherche sur la Culture, 1996.

Martin, André, „Théorie de la diffusion des innovations et implantation terminologique (II)“, in: Terminologies nouvelles 11 (1994), 33-39.

Martin, André, „Quelques aspects d'une problématique de l'implantation terminologique: le cas de la terminologie officielle de l'éducation au Québec", in: Terminologies nouvelles 16 (1997), 86-94.

Martinet, André, Le français sans fard, Paris, Presses Universitaires de France, ${ }^{2} 1974$.

Massion, François, Dictionnaire de belgicismes, 2 vol., vol. 1: A-K, vol. 2: L-Z, Frankfurt am Main et al., Lang, 1987.

Mauderer, Michael, „Zum Französischen in der kanadischen Provinz Québec. Bemerkungen zu einigen ausgewählten Fragen der Frankophonie“, in: französisch beute 1 (1994), 44-60.

Maurais, Jacques (ed.), La crise des langues, Québec, Conseil de la langue française/Paris, Robert, 1985 (=1985a).

Maurais, Jacques, „La crise du français au Québec“, in: Maurais 1985a, 39-83 (= 1985b).

Maurais, Jacques (ed.), Politique et aménagement linguistiques, Québec, Conseil de la langue française, 1987 (= 1987a).

Maurais, Jacques, „L'expérience québécoise d'aménagement linguistique“, in: Maurais 1987a, 359-416 (= 1987b).

Maurais, Jacques, „État de la recherche sur la description de la francophonie au Québec“, in: Robillard/Beniamino 1993, 79-99.

Mayntz, Renate/Holm, Kurt/Hübner, Peter, Einführung in die Methoden der empirischen Soziologie, Opladen, Westdeutscher Verlag, ${ }^{5} 1978$.

Meisenburg, Trudel, Die soziale Rolle des Okzitanischen in einer kleinen Gemeinde im Languedoc (Lacaune/Tarn), Tübingen, Niemeyer, 1985.

Ministère des Affaires Étrangères, IXème Sommet de la Francophonie. Beyrouth 2002, http://www.sommet2001.org, 2002.

Ministère des Affaires Étrangères, Le français dans le monde. Carte du monde francophone, http://www.france.diplomatie.fr/francophonie/francais/carte. |html, o.J. (= o.J.a).

Ministère des Affaires Étrangères, „Mémoire" de la Francophonie. Historique des sommets, http://www.france.diplomatie.fr/francophonie/memoire/som |mets.html, o.J. (= o.J.b).

„Mireille statt Guns N’ Roses“, in: Der Spiegel 20 (1994), 168-172.

Molitor, Eva, „Sprachpolitik nach französischem Vorbild für Deutschland? Ein Sprachschutzgesetz für die deutsche Sprache? (Teil 1)“, in: Göttinger Beiträge zur Sprachwissenschaft 6 (2001), 63-107.

Molitor, Eva, „Sprachpolitik nach französischem Vorbild für Deutschland? Ergebnisse einer Umfrage unter deutschsprachigen Informanten zu den Anglizismen des Wortfeldes Internet (Teil 2)“, in: Göttinger Beiträge zur Sprachwissenschaft 7 (2002), 65-88. 
Molitor, Eva, „Appelons un chat un chat. Zur Akzeptanz der französischsprachigen Internet-Terminologie bei frankophonen Studierenden“, in: Dahmen et al., Englisch und Romanisch. Romanistisches Kolloquium XVII, Tübingen, Narr (im Druck).

Moreau, Marie-Louise (ed.), Sociolinguistique. Concepts de base, Sprimont, Mardaga, 1997 (= 1997a).

Moreau, Marie-Louise, „Le bon français de Belgique. D’un divorce entre norme et discours sur la norme“, in: Blampain et al. 1997, 391-399 (= 1997b).

Moreau, Marie Louise, „Conclusions“, in: Moreau/Brichard/Dupal 1999, 37-41.

Moreau, Marie Louise/Brichard, Huguette, „Français et Belges: des fluidités verbales différentes? Des données objectives aux représentations subjectives“, in: Moreau/Brichard/ Dupal 1999, 12-18.

Moreau, Marie Louise/Brichard, Huguette/Dupal, Claude, Les belges et la norme. Analyse d'un complexe linguistique, Bruxelles, Duculot/Service de la langue française, 1999.

Mortureux, Marie-Françoise, La lexicologie: entre la langue et le discours, Paris, SEDES, 1997.

Morvan, Pierre (ed.), Dictionnaire de l'informatique, Paris, Larousse, 1996.

Moser, Hugo, Sprache - Freiheit oder Lenkung? Zum Verhältnis von Sprachnorm, Sprachwandel, Sprachpflege. Rede anläßlich der feierlichen Überreichung des Konrad-Duden-Preises der Stadt Mannheim durch den Herrn Oberbürgermeister am 19. April 1964, Mannheim, Bibliographisches Institut, 1967.

Müller, Bodo, Das Franæösische der Gegenwart. Varietäten, Strukturen, Tendenzen, Heidelberg, Winter, 1975.

Munzi, Ulderico, „In nome della libertà d'espressione il consiglio costituzionale sancisce il permesso di usare le parole straniere. La Francia dice ,oui' all'inglese. Liberata da Bastiglia lessicale: via la legge che proibiva ,weekend' et ,topless"“, in: Corriere della sera vom 31. Juli 1994, 6.

Murcia, Colette/Joly, Hubert, „Néologie“, in: La Banque des Mots 61 (2001), $57-$ 119.

Murray, Heather/Wegmüller, Ursula/Khan, Fayaz Ali, L'anglais en Suisse. Rapport de recherche, http://www.bbw.admin.ch/html/pages/services/publikatio|nen/bildung/english-f.pdf, Bern, Institut für Sprachwissenschaft, 2001.

Naguschewski, Dirk, „Zur Bedeutung und Rezeption eines Sprachgesetzes: Die Loi 118 du 2 Thermidor, l'an II de la République française“, in: Zeitschrift für romanische Philologie 118, 1 (2002), 35-50.

Nelde, Peter H./Weber, Peter J., „Les trois identités linguistiques en Belgique des particularismes culturels?"،, in: Haarmann, Harald (ed.), Europäische Identität und Sprachenvielfalt, Tübingen, Niemeyer, 1995, 88-95.

„Néologie coopérative 1999“, in: La Banque des Mots 58 (1999), 51-106.

„Néologie coopérative 2000“, in: La Banque des Mots 59 (2000), 28-51.

Nemeth, Thomas, „[Conseils d'utilisation] fr.misc.bavardages.linux“, in: fr.misc.bavardages.linux/fr.usenet.reponses vom 02. August 2002. 
Networds: Langenscheidt KG/sueddeutsche.de GmbH, Networds. Das Internet-Wörterbuch, http://www.networds.de, http://www.langenscheidt.de/, 19972003 [auch als Buch erhältlich: Herda, Susanne/Fischer, Jürgen, Langenscheidts Internet-Wörterbuch Englisch - Deutsch 2000, Berlin et al., Langenscheidt, $\left.{ }^{2} 2000\right]$.

Neuland, Eva, „Sprachgefühl, Spracheinstellungen, Sprachbewußtsein. Zur Relevanz ,subjektiver Faktoren' für Sprachvariation und Sprachwandel“, in: Mattheier, Klaus J., et al. (edd.), Vielfalt des Deutschen. Festschrift für Werner Besch, Frankfurt am Main et al., Lang, 1993, 723-747.

Neumann-Holzschuh, Ingrid, „Zwischen bon usage und plurizentrischer Sprachkultur. Zum Stand der sprachnormativen Diskussion in Frankreich und Québec“, in: Rostocker Beiträge zur Sprachwissenschaft 1 (1995), 195-210.

Nicollier, Alain, Dictionnaire des mots suisses de la langue française, Genève, Éditions GVA SA, 1990.

„Niederlage für französische Puristen. Verfassungsrat hebt Sprachgesetz teilweise auf. Verbot von Fremdwörtern verstößt gegen Recht auf freie Meinungsäußerung“", in: Süddeutsche Zeitung vom 01. August 1994, 6.

Nierveze, Sylvain, „[Conseils d'utilisation] fr.comp.lang.general“, in: fr.comp.|lang.general/ fr.usenet.reponses vom 02. August 2002.

Nierveze, Sylvain, „[Conseils d'utilisation] fr.comp.lang.perl“, in: fr.comp.|lang.perl/ fr.usenet.reponses vom 02. August 2002.

Nierveze, Sylvain, „[Conseils d'utilisation] fr.comp.lang.c $++“$, in: fr.comp.|lang.c ++ / fr.usenet.reponses, vom 02. August 2002.

Nierveze, Sylvain, „[Conseils d'utilisation] fr.comp.lang.c“, in: fr.comp.|lang.c/fr.usenet.reponses vom 02. August 2002.

Office québécois de la langue française, Comité d'officialisation linguistique, http://|www.olf.gouv.qc.ca/ressources/bibliotheque/officialisation/membres. |html, Québec, Gouvernement du Québec, 2002 (= 2002a), Revisionsdatum: 16. Juni 2003.

Office québécois de la langue française, Politique de l'officialisation linguistique, http://www.olf.gouv.qc.ca/ressources/bibliotheque/officialisation/offi |cialisation.html, Québec, Gouvernement du Québec, 2002 (= 2002b), Revisionsdatum: 16. Juni 2003.

Office québécois de la langue française, Vocabulaire d'Internet - Banque de terminologie du Québec, http://www.olf.gouv.qc.ca/ressources/bibliotheque/diction |naires/Internet/Index/, Québec, Gouvernement du Québec, 2002 (= 2002c), Revisionsdatum: 01. Oktober 2003.

Ohnheiser, Ingeborg/Kienpointner, Manfred/Kalb, Helmut (edd.), Sprachen in Europa: Sprachsituation und Sprachpolitik in europäischen Ländern, Innsbruck, Institut für Sprachwissenschaft der Universität, 1999.

Oleffe, Michel, „Une entreprise face à la langue. Le cas d'IBM Belgique“, in: Terminologies nouvelles 11 (1994), 23-25.

Oppenheim, Abraham N., Questionnaire Design, Interviewing and Attitude Measurement, London/New York, Pinter Publishers, 1992. 
Osgood, Charles E./Suci, George J./Tannenbaum, Percy H., The Measurement of Meaning, Urbana, University of Illinois Press, 1957.

Otman, Gabriel, „La terminologie et la qualité de la connaissance“, in: Éloy 1995, 305-325.

Otman, Gabriel, „Le vocabulaire de l'informatique et des technologies de l'information et de la communication", in: Antoine/Cerquiglini 2000, 371-396.

Pacquot, Annette, „Revendication linguistique et identité culturelle: données d'enquête et réflexions sur la conscience linguistique et les jugements métalinguistiques au Québec“, in: Martel, Claude (ed.), Les Français et leurs langues. Colloque tenu à Montpellier les 5, 6 et 7 septembre 1988, Aix, Université de Provence, 1991, 99-106.

Paltridge, John/Giles, Howard, „Attitudes towards speakers of regional accents of french: Effects of regionality, age and sex of listeners", in: Linguistische Berichte 90 (1984), 71-85.

„Parigi contro l'inglese/l'inglesese. Multe a chi ne abusa“, in: Corriere della sera vom 24. Februar 1994, 8.

Pellisier, Laurent, „[Conseils d'utilisation] fr.comp.lang.java“, in: fr.comp.lang.|java/ fr.usenet.reponses vom 02. August 2002.

Pergnier, Maurice (ed.), Le français en contact avec l'anglais (en hommage à Jean Darbelnet, Préface de Danica Seleskovitch), Paris, L'Information grammaticale/Didier-Érudition, 1988 (= 1988a).

Pergnier, Maurice, „À propos des emprunts du français à l'anglais“, in: Pergnier 1988a, 113-117 (= 1988b).

Pergnier, Maurice, Les anglicismes: Danger ou enrichissement pour la langue française?, Paris, Presses Universitaires de France, 1989.

Péroncel-Hugoz, Jean-Pierre, „Selon le projet de loi adopté par le conseil des ministres: L'emploi du français serait obligatoire pour ,toute inscription ou annonce' dans un lieu public", in: Le Monde vom 25. Februar 1994, 14 (= 1994a).

Péroncel-Hugoz, Jean-Pierre, „Le projet de loi linguistique“, in: Le Monde vom 10. März 1994, 20 (= 1994b).

Péroncel-Hugoz, Jean-Pierre, „Les députés adoptent le projet de loi Toubon relatif à l'emploi de la langue française“, in: Le Monde vom 03./04. Juli 1994, 7 $(=1994 \mathrm{c})$.

Petit, Gérard, „Internet et terminologie“, in: Anis, Jacques (ed.), Internet, communication et langue française, Paris, Hermès Science Publications, 1999, 157-180.

Pfitzner, Jürgen, Der Anglizismus im Deutschen. Ein Beitrag zur Bestimmung seiner stilistischen Funktion in der heutigen Pressesprache, Stuttgart, Metzler, 1978.

Pichard, Alain, La romandie n'existe pas. Six portraits politiques: Fribourg, Genève, Jura, Neuchâtel, V alais, Vaud, Lausanne, Éditions 24Heures, 1978.

Pidoux, Edmont, Le langage des Romands, Lausanne, Ensemble, 1984.

Pierrehumbert, William, Dictionnaire historique du parler neuchâtelois et suisse romand, Neuchâtel, Attinger, 1926. 
Piron, Maurice, „Les belgicismes lexicaux. Essai d’inventaire“, in: Mélanges de linguistique francaise et de philosophie et littérature méridionale offerts à Paul Imbs, 1973, 295-304.

Plenel, Edwy, „Langue vivante, puissance défunte. Défensif, le projet de loi sur l'emploi du français exprime la nostalgie d'une gloire perdue“, in: Le Monde vom 04. Mai 1994, 1, 10.

Plümer, Nicole, Anglizismus - Purismus - sprachliche Identität. Eine Untersuchung zu den Anglizismen in der deutschen und französischen Mediensprache, Frankfurt am Main et al., Lang, 2000.

Pochon, Charles F., „Rappel: Problèmes de traduction“, in: Domaine Public 1395 vom 20. August 1999, URL: http://www.domainepublic.ch/archives/|Pochon_Charles_F___Rappel__Problemes_de_tradu_.html.

Pohl, Jacques, „Le statalisme“, in: Travaux de linguistique et de littérature 22, 1 (1984), 251-264.

Pöll, Bernhard, Franæösisch außerbalb Frankreichs. Geschichte, Status und Profil regionaler und nationaler V arietäten, Tübingen, Niemeyer, 1998.

Pöll, Bernhard, Francophonies périphériques. Histoire, statut et profil des principales variétés $d u$ français hors de France (Traduit de l'allemand par Christian Ollivier, en collaboration avec l'auteur. Préface de François Gadet), Paris, L'Harmattan, 2001.

Porst, Rolf, „Im Vorfeld der Befragung: Planung, Fragebogenentwicklung, Pretesting", in: ZUMA-Arbeitsbericht 2 (1998), URL: http://www.gesis.org/ | Publikationen/Berichte/ZUMA_Arbeitsberichte/98/98_02abs.htm.

Portail fédéral (Belgien), La Belgique. Population: Statistiques, http://www.|belgium.be/, 2003.

Prüfer, Peter/Rexroth, Margrit, „Verfahren zur Evaluation von Survey-Fragen: Ein Überblick“, in: ZUMA-Nachrichten 39, Jg. 20 (1996), 95-116, URL: http://www.gesis.org/Publikationen/Berichte/ZUMA_Arbeitsberich |te/96/96_05abs.htm.

Prüfer, Peter/Rexroth, Margrit, „Zwei-Phasen-Pretesting“, in ZUMA-Arbeitsbericht 8 (2000), 1-21, URL: http://www.gesis.org/Publikationen/Berichte/ |ZUMA_Arbeitsberichte/00/00_08abs.htm.

Quasthoff, Uta, Soziales Vorurteil und Kommunikation. Eine sprachwissenschaftliche Analyse des Stereotyps: ein interdisziplinärer Versuch im Bereich von Linguistik, Sozialwissenschaft und Psychologie, Frankfurt am Main, Athenäum-Fischer, 1973.

Reinart, Sylvia, Terminologie und Einzelsprache. Vergleichende Untersuchung zu einzelsprachlichen Besonderheiten der fachsprachlichen Lexik mit Schwerpunket auf dem Sprachenpaar Deutsch-Französisch, Frankfurt am Main et al., Lang, 1993.

Reips, Ulf-Dietrich, et al. (edd.), Current Internet Science - Trends Techniques, results / Aktuelle Online Forschung - Trends, Techniken, Ergebnisse. Proceedings of the 3rd German Online Research conference, Zürich, 1999, URL: http://dgof.de/tband99/.

Renonciat, Manon/Cours de Stéphane Cottin, Bilan du PAGSI, http://www.|droitconstit.org/pagsi.html, o.J. 
„Répertoire des institutions et associations“, in: Francité. Revue de la Maison de la Francité 27 (2000), URL: http://www.synec-doc.be/francite/rev27/|repert.html.

Réseau International de Néologie et de Terminologie (Rint), Qu'est-ce que le Rint?, http://www.rint.org/1questceque.htm, o.J. (= o.J.a).

Réseau International de Néologie et de Terminologie (Rint), Revue ,Terminologies nouvelles', http://www.rint.org/3Revue.htm, o.J. (= o.J.b).

Réseau international francophone d'aménagement linguistique (Rifal), Produits, ressources, http://www.rifal.org/2_outils.html, o.J.

Réseau panlatin de terminologie (Realiter), Qu'est-ce que Realiter?, http://www.|realiter.net/fr/presentacion.htm, Revisionsdatum: 20. November 2002 (= 2002a).

Réseau panlatin de terminologie (Realiter), Règlement. Réseau panlatin de terminologie (Realiter), http://www.realiter.net/fr/reglamento.htm, Revisionsdatum: 20. November 2002 (=2002b).

Réseau panlatin de terminologie (Realiter), Activités, http://www.realiter.net/fr/|actividades.htm, Revisionsdatum: 20. November 2002 (= 2002c).

Réseau panlatin de terminologie (Realiter), Membres/Miembros/Membros/Membri/Membri, http://www.realiter.net/miembros/miembros.htm, Revisionsdatum: 20. November 2002 (=2002d).

Rey, Alain, „Le Grand Robert est une fenêtre sur la culture“ [Propos recueillis par V alérie Plomb], Amazon.com, Inc., (C) 1996-2003, http://www.amazon.|$\mathrm{fr} / \mathrm{exec} / \mathrm{obidos} / \mathrm{tg} /$ feature/-/195461/171-8135834-0377030, 2001.

Rey-Debove, Josette/Gagnon, Gilberte, Dictionnaire des anglicismes. Les mots anglais et américains en français, Paris, Le Robert, ${ }^{2} 1988$.

Robert, Paul, Le nouveau Petit Robert. Dictionnaire alphabétique et analogique de la langue française, Texte remanié et amplifié sous la direction de Josette Rey-Debove et Alain Rey, Paris, Dictionnaires Le Robert, 2000.

Robillard, Didier de, „Le concept d'insécurité linguistique: à la recherche d'un mode d'emploi“, in: Bavoux, Claudine (ed.), Français régionaux et insécurité linguistique. Approches lexicographiques, interactionnelles et textuelles. Actes de la deuxième table ronde du Moufia, 23-25 septembre 1994, Paris/Saint-Denis (Université de la Réunion), L'Harmattan, 1996, 55-76.

Robillard, Didier de, „Normalisation“, in: Moreau 1997a, 214-215.

Robillard, Didier de, „Planification“, in: Moreau 1997a, $228 \mathrm{f}$.

Robillard, Didier de, „Politique linguistique“, in: Moreau 1997a, $229 f$.

Robillard, Didier de, The French-Speaking World: a tentative typology to get a better understanding of language contact and cultural impact", in: Stein 2000, 65-86.

Robillard, Didier de/Beniamino, Michel, Le français dans l'espace francophone. Description linguistique et sociolinguistique de la francophonie, vol. 1, Paris, Champion, 1993. 
Robillard, Didier de/Beniamino, Michel, Le français dans l'espace francophone. Description linguistique et sociolinguistique de la francophonie, vol. 2, Paris, Champion, 1996.

Rogator Software AG, Software für Online Befragung - Online Marktforschung - Survey Software, http:/ / www.rogator.de, 2002.

Rogge, Waltraud, Aspekte des Sprachwissens von Schülern im Bereich der französisch-okzitanischen Diglossie: Ergebnisse einer empirischen Untersuchung in Albi, Bédarieux, Mende und Montpellier, Trier, Wissenschaftlicher Verlag, 1987.

Rosenberg, Milton J./Hovland, Carl I., „Cognitive, affective, and behavioral components of attitudes“, in: Rosenberg, Milton J., et al. (edd.), Attitude organization and change. An analysis of consistency among attitude components, New Haven, Yale University Press, 1960, 1-14.

Rouges-Martinez, Josiane, „Étude d'implantation des arrêtés de terminologie. Domaine: Télédétection aérospatiale“ (Dezember 1992), in: Depecker 1997a, 97-132.

Rouges-Martinez, Josiane/Fossat, Jean-Louis, „Implantation terminologique en télédétection aérospatiale: méthodologie et mesure“, in: Terminologies nouvelles 12 (1994), 123-135.

Rousseau, Louis-Jean, „Rifal“, in: Terminologies nouvelles 21 (2000), 2-4.

Rubattel, Christian, „Une crise du français en Suisse romande?“،, in: Maurais 1985a, 85-91.

Rubin, Joan/Jernudd, Björn H. (edd.), Can Language Be Planned? Sociolinguistic Theory and Practice for Developing Nations, Honolulu, The University Press of Hawaii, 1971.

Runkehl, Jens/Schlobinski, Peter/Siever, Torsten, Sprache und Kommunikation im Internet, Hannover, 1998, http://www.websprache.uni-hannover.de/|networx/docs/einstieg.htm [Erstveröffentlichung in: Muttersprache 2 (1998), 97-109].

Runkehl, Jens/Siever, Torsten, Das Zitat im Internet. Ein Electronic Style Guide zum Publizieren, Bibliographieren und Zitieren, Hannover, Revonnah, 32001.

Ryan, Ellen Bouchard/Giles, Howard (edd.), Attitudes towards Language V ariations, London, Arnold, 1982.

Sachs, F., La défense de la Francophonie et de la Langue Française sur Internet, Paris, Université Paris III, http://perso.club-internet.fr/fsachs/memoire.html, September 1998.

Sarcher, Walburga Christine, Über Ideal und Wirklichkeit der Frankophonie: Eine Untersuchung zum Verhältnis und zur sprachlichen Zusammenarbeit zwischen Quebec und Frankreich, Bochum, Brockmeyer, 1994.

Sarter, Heidemarie, „Sprachbewußtsein im Wandel“, in: Asholt, Wolfgang/Thoma, Heinz (edd.), Frankreich. Ein unverstandener Nachbar (19451990), Bonn, Romanistischer Verlag, 1990, 197-223.

Schaeder, Burkhard, ,Versuch einer theoretischen Grundlegung der Internationalismen-Forschung“, in: Braun/Schaeder/Volmert 1990, 34-46. 
Schaetzen, Caroline de, „Diachronie et libéralisme en terminologie“, in: La Banque des Mots 45 (1993), 33-39.

Schafroth, Elmar, „Feminine Berufsbezeichnungen in Kanada und Frankreich“, in: Zeitschrift der Gesellschaft für Kanada-Studien 12 (1992), 109-125.

Schafroth, Elmar, „Kontrastive Betrachtung von Anglizismen im Französischen Frankreichs und Kanadas. Aspekte der Bewertung, Integration und lexikographischen Beschreibung“", in: Rainer-Olaf Schultze (ed.), Aus der Werkstatt der Augsburger Kanadistik, Analysen, Berichte, Dokumentation, Bochum, Brockmeyer, 1996, 35-56.

Scherfer, Peter, Untersuchungen zum Sprachbewußtsein der Patois-Sprecher in der FrancheComté, Tübingen, Narr, 1983.

Schlieben-Lange, Brigitte, „Metasprache und Metakommunikation. Zur Überführung eines sprachphilosophischen Problems in die Sprachtheorie und in die sprachwissenschaftliche Forschungspraxis“, in: Schlieben-Lange, Brigitte (ed.), Sprachtheorie, Hamburg, Hoffmann und Campe, 1975, 189-204.

Schlieben-Lange, Brigitte, Soziolinguistik. Eine Einführung, Stuttgart/Berlin/Köln, Kohlhammer, ${ }^{3} 1991$.

Schlobinski, Peter, Empirische Sprachwissenschaft, Opladen, Westdeutscher Verlag, 1996.

Schmitt, Christian, „Sprachplanung und Sprachlenkung im Französischen der Gegenwart", in: Rattunde, Eckhard (ed.), Sprachnorm(en) im Fremdsprachenunterricht, Frankfurt am Main et al, Diesterweg, 1979.

Schmitt, Christian, „Französisch: Sprache und Gesetzgebung/Législation linguistique a) Frankreich/France“, in: Holtus/Metzeltin/Schmitt 1990, 354-379 (= 1990a).

Schmitt, Christian, „Französisch: Sprache und Gesetzgebung/Législation linguistique b) Frankophonie/Francophonie“, in: Holtus/Metzeltin/Schmitt 1990, 379391 (= 1990b).

Schmitt, Christian, „Frankophonie I. Der Begriff der Frankophonie/Francophonie I. Le concept de francophonie“, in: Holtus/Metzeltin/Schmitt 1990, 686-703 (= 1990c).

Schmitt, Christian, „Das Fremde als Staatsaffäre: bebdo Langage, télélangage und MÉDIAS \& langage“, in: Trabant 1995a, 91-117.

Schmitt, Christian, „Sprachpflege und Sprachreinigung“،, in: Goebl/Nelde/Zdenek 1996, 871-880.

Schmitt, Christian, „Sprachkultur und Sprachpflege in Frankreich“, in: Greule, Albrecht/ Lebsanft, Franz (edd.), Europäische Sprachkultur und Sprachpflege, Tübingen, Narr, 1998, 215-243.

Schmitt, Christian, „Französisch als funktionale Weltsprache“, in: Wilss 2000, 50 74.

Schoeni, Gilbert/Bronckart, Jean-Paul/Perrenoud, Philippe (edd.), La langue française est-elle gouvernable? Normes et activités langagières, Neuchâtel/Paris, Delachaux \& Niestlé, 1988. 
Schwarze, Christoph, Sprachschwierigkeiten, Sprachpflege, Sprachbewußtsein. Das Phänomen der ,chronique de langage", Konstanz, Universität, 1977.

Sektion Terminologie der Bundeskanzlei/Section de terminologie de l'administration fédérale suisse, TERMDAT (Terminologiedatenbank der Bundesverwaltung), Leitfaden für die Erarbeitung von Datenbankeinträgen, auf Deutsch: http://www.admin.ch/ch/i/bk/termdat/d/termdat/red guide_d.pdf (70 S.), auf Französisch: http://www.admin.ch/ch/i/bk/|termdat/f/termdat/redguide_f.pdf (69 S.), Januar 2002.

Sektion Terminologie der Schweizerischen Bundeskanzlei/Section de terminologie de l'administration fédérale suisse, Activités terminologiques: La terminologie à l'Administration fédérale, http://www.admin.ch/ch/i/bk/termdat/|$\mathrm{f} /$ tworking/about.htm, o.J.

Service de la langue française du Ministère de la Communauté française de Belgique, Bienvenue à la banque de données terminologique du Service de la langue française du Ministère de la Communauté française de Belgique, http:/ /www.cfwb.|be/franca/bd/bienvenu.htm, Revisionsdatum: 05. September 2003.

Service de la langue française du Ministère de la Communauté française de Belgique, Pour la promotion de la langue française: Huit grandes actions pour une politique de la langue française, http://www.cfwb.be/franca/pg009.htm, o.J. (= o.J.a).

Service de la langue française du Ministère de la Communauté française de Belgique, L'enrichissement de la langue française: Néologie et terminologie, http://www.cfwb.be/franca/pg011.htm, o.J. (= o.J.b).

Service de la langue française du Ministère de la Communauté française de Belgique, Le Conseil supérieur de la langue française, http://www.cfwb.be/|franca/pg006.htm, o.J. (= o.J.c).

Service de la langue française du Ministère de la Communauté française de Belgique, La charte de la langue française adoptée le 21 juin 1989, http://www.cfwb.be/franca/publicat/pg007.htm, o.J. (= o.J.d).

Service de la langue française du Ministère de la Communauté française de Belgique, Le décret du 12 juillet 1978 sur la défense de la langue française, http://www.cfwb.be/franca/publicat/pg008.htm, o.J. (= o.J.e).

Service de la langue française du Ministère de la Communauté française de Belgique, Banque de données terminologique, http://www.cfwb.be/franca/ |bd/bd.htm, o.J. (= o.J.f), Revisionsdatum: 05. September 2003.

Service de la langue française du Ministère de la Communauté française de Belgique, Les cabiers du Rifal ont succédé à Terminologies nouvelles, http://www.cfwb.be/franca/termin/liste.htm, o.J. (= o.J.g).

Service de la langue française du Ministère de la Communauté française de Belgique, Format des fiches terminologiques, http://www.cfwb.be/franca/|bd/format.htm, o.J. (= o.J.h).

Settekorn, Wolfgang, Sprachnorm und Sprachnormierung in Frankreich. Einführung in die begrifflichen, bistorischen und materiellen Grundlagen, Tübingen, Niemeyer, 1988. 
Siegele, Ludwig, „Zeitliches aus Frankreich. Linguistically correct“, in: Die Zeit vom 27. Mai 1994, 39.

Singy, Pascal, L’image du français en Suisse romande. Une enquête sociolinguistique en Pays de V aud [Préface de William Labov], Paris, L'Harmattan, 1997.

Sittek, Dietmar (unter Mitarbeit von Christian Wenz), Das Internet-Lexikon: Begriffe, Abkürzungen, Slang - enträtselt und erläutert, München, Deutscher Taschenbuch-Verlag/Beck, 1997.

Smit, Ute, A new English for a new South Africa? Language attitudes, language planning and education, Wien, Braumüller, 1996.

Sokol, Monika, Französische Sprachwissenschaft. Eine Einführung mit thematischem Reader, Tübingen, Narr, 2001.

Solèr, Clau, „Rätoromanische Schweiz“, in: Goebl/Nelde/Starý 1997, 1879-1886.

Söll, Ludwig, „Die Krise der französischen Sprache - Realität oder Illusion?“, in: Hausmann, Franz Josef (ed.), Die französische Sprache von heute, Darmstadt, Wissenschaftliche Buchgesellschaft, 1983, 270-285.

Spillner, Bernd (ed.), Sprache und Politik, Frankfurt am Main et al., Lang, 1990.

Spintig, Susanne, „Online-Research - Akzeptanz und Verbreitung: Abstract“, in: Reips et al. 1999.

Stahlberg, Dagmar/Frey, Dieter, „Einstellungen: Struktur, Messung und Funktion“, in: Stroebe, Wolfgang/Hewstone, Miles/Stephenson, Geoffrey M. (edd.), Sozialpsychologie. Eine Einführung, Berlin et al., Springer, 31996, 219252.

Starsetzki, Thomas, „Rekrutierungsformen und ihre Einsatzbereiche“, in: Theobald, Axel/Dreyer, Marcus/Starsetzki, Thomas (edd.), Online-Marktforschung. Theoretische Grundlagen und praktische Erfahrungen, Wiesbaden, Gabler, 2001, 41-53.

Stein, Peter (ed.), Frankophone Sprachvarietäten. Variétés linguistiques francophones. Hommage à Daniel Baggioni de la part de ses „dalons“, Tübingen, Stauffenburg, 2000.

Stier, Winfried, Empirische Forschungsmethoden, Berlin et al., Springer, 1996.

Stimm, Helmut (ed.), Zur Geschichte des gesprochenen Französisch und zur Sprachlenkung im Gegenwartsfranzösischen. Beiträge des Saarbrücker Romanistentages 1979, Wiesbaden, Steiner, 1980.

Stosberg, Manfred, „Klassische Ansätze in der Einstellungsmessung“, in: Petermann, Franz (ed.), Einstellungsmessung - Einstellungsforschung, Göttingen/Toronto/Zürich, Hogrefe, 1980, 99-116.

Straßner, Björn, Die Wirksamkeit offizieller Sprachpolitik in Frankreich: Kenntnis und Akzeptanz, Kiel, Universität, 1997.

Stroh, Cornelia, Sprachkontakt und Sprachbewußtsein. Eine soziolinguistische Studie am Beispiel Ost-Lothringens, Tübingen, Narr, 1993.

Swiggers, Pierre, „L'insécurité linguistique: Du complexe (problématique) à la complexité du problème", in: Cabiers de l'Institut de Linguistique de Louvain 19, 3/4 (1993), 19-29. 
Szulmajster-Celnikier, Anne, „La politique de la langue en France“, in: Linguistique 32, 2 (1996), 35-63.

Taylor Nelson Sofres, Les attitudes des Français à l'égard de la science, http://www.|sofres.com/etudes/pol/140201_science1_r.htm, 2000.

Taylor Nelson Sofres Interactive, Global eCommerce Report (the GER), Juni 2002, http://www.tnsofres.com/ger2002/ (kostenloser Download der Studie als Power-Point-Präsentation möglich).

Theobald, Axel, Das World Wide Web als Befragungsinstrument, Wiesbaden, Gabler, $2000(=2000 \mathrm{a})$.

Theobald, Axel, „Marktforschung im Internet“, in: Bliemel, Friedhelm/Fassott, Georg/Theobald, Axel (edd.), Electronic Commerce. Herausforderungen - Anwendungen - Perspektiven, Wiesbaden, Gabler, ${ }^{32000,}$ 297-314 (= 2000b).

Thibault, André (ed., sous la direction de Pierre Knecht), Dictionnaire suisse romand. Particularités lexicales du français contemporain. Une contribution au Trésor des vocabulaires francophones, Carouge-Genève, Éditions Zoé, 1997.

Thibault, André, „Légitimité linguistique des français nationaux hors de France: le cas du Français de Suisse romande“, in: Revue québécoise de linguistique 26,2 (1998), 25-42.

Thogmartin, Clyde, „The Public Impact of Terminological Planning in France“, in: The French Review 64, 6 (1991), 1000-1006.

Thoiron, Philippe/Iwaz, Jean/Zaouche, Nadine, „Étude d'implantation des arrêtés de terminologie. Domaines: santé et médecine“ (1993), in: Depecker 1997a, 47-95.

Thoiron, Philippe/Iwaz, Jean/Zaouche, Nadine, „Résultats de l'enquête d'implantation des termes de santé et de médecine“, in: Terminologies nouvelles 12 (1994), 77-103.

Toubon, Jacques, „L'esprit des langues“, in: Le Monde vom 24. Februar 1994, 2 [wieder abgedruckt in Trabant 1995a, 199-201] (= 1994a).

Toubon, Jacques, „La langue de tous“, in: Le Monde vom 04. August 1994, 16 [wieder abgedruckt in Trabant 1995a, 209-212] (= 1994b).

Trabant, Jürgen (ed.), Die Herausforderung durch die fremde Sprache. Das Beispiel der Verteidigung des Französischen, Berlin, Akademie-Verlag, 1995 (= 1995a).

Trabant, Jürgen, „Zur Einführung: Fremde Sprachen in Babel und Paris“, in: Trabant 1995a, 7-16 (= 1995b).

Trabant, Jürgen, „Die Sprache der Freiheit und ihre Freunde“, in: Trabant 1995a, 175-191 (= 1995c).

Trabant, Jürgen, „Französische Sprachpolitik - ein Modell für Deutschland?“, in: Akademie-Journal 2 (2001), 10-14.

Trabant, Jürgen, „Die politische und kulturelle Bedeutung des Französischen“, in Kolboom/Kotschi/Reichel 2002, 128-136.

Trescases, Pierre, Le franglais vingt ans après, Montréal/Toronto, Guérin, 1982.

Truchot, Claude (ed.), Le plurilinguisme européen, Paris, Champion, 1994 (= Truchot 1994a). 
Truchot, Claude, „La France, l'anglais, le français et l'Europe“, in: Sociolinguistica 8 (1994) (English only? in Europa, in Europe, en Europe, hrsg. von Ulrich Ammon), 15-25 (= Truchot 1994b).

UDT (Amt für Technische Überwachung, Warschau, Polen)/Informationsbüro Deutschland, Gesetz, über die polnische Sprache vom 07. Oktober 1999, http://www.udt.de/Gesetz.htm, 1999.

Utz, Sonja, „Untersuchungsformen in MUDs“, in: Batinic et al. 1999, 305-318.

Vandermeeren, Sonja, „Language attitudes on either side of the linguistic frontier: A sociolinguistic survey in the Voeren/Fouron-area and in Old Belgium North“, in: Hellinger/Ammon 1996, 157-172.

„Verfassungsrat gegen staatliche Zwangsterminologie. Korrektur am französischen Sprachgesetz“, in: Neue Zürcher Zeitung vom 03. August 1994, 4.

Vittoz Canuto, Marie-Berthe, „Le lexique des technologies de l'information et de la communication et son intégration en français et en italien. Quelques réflexions“, in: Cabiers de Lexicologie 78, 1 (2001), 177-197.

Wahl, Jürgen, „Frankreichs Sprachschützer kollidierten mit den Idealen von 1789. Gescheitert, Monsieur Allgood!‘, in: Rheinischer Merkur vom 05. August 1994, 2.

Walter, Henriette, „Le lexique de l'informatique et l'emprise de l'anglais“, in: La Linguistique 33, 2 (1997), 45-59.

Walter, Henriette, Honni soit qui mal y pense ou l'incroyable histoire de l'amour entre le français et l'anglais, Paris, Laffont, 2001.

Warnant, Léon, Dictionnaire de la prononciation française dans sa norme actuelle, Paris/Gembloux, Duculot, ${ }^{4} 1987$.

Webster's $2001=$ Random House Webster's advanced English dictionary, edited by Gerard M. Dalgish, New York, Random House, 2001.

Welche Sprachen sollen die Schülerinnen und Schüler während der obligatorischen Schulzeit lernen? Bericht einer von der Kommission für allgemeine Bildung eingesetzten Expertengruppe ,Gesamtsprachenkonzept' an die Schweizerische Konferenz der kantonalen Erziehungsdirektoren (Bern), http://131.|152.151.1/sprachenkonzept/, http:/ /www.romsem.unibas.ch/sprachen |konzept, 15. Juli 1998.

Welt-Nachrichtendienst, „Frankreichs Sprachhüter müssen ,Franglais’ dulden“, in: Die Welt vom 01. August 1994, 3.

Werlen, Erika, Studien zur Datenerhebung in der Dialektologie, Stuttgart, Steiner, 1984.

Wernert, Bernadette, „[Conseils d'utilisation] fr.soc.internet“, in: fr.soc.internet/ fr.usenet.reponses vom 02. August 2002.

Wiley, Terrence G., „Language planing and policy“, in: Lee McKay, Sandra/Hornberger, Nancy H. (edd.), Sociolinguistics and Language Teaching, Cambridge (UK) et al., Cambridge University Press, 1996, 103-147.

Willems, Dominique, „Le français en Flandre“, in: Blampain et al. 1997, 259-272.

Willemyns, Roland, „Belgium“, in: Ammon/Dittmar/Mattheier 1988, 1254-1258.

Willemyns, Roland, „Linguistic Legislation and Prestige Shift“, in: Ammon/Hellinger 1991, 3-16. 
Willemyns, Roland, „Language borders in northern France and in Belgium: A contrastive analysis“, in: Hellinger/Ammon 1996, 229-249.

Willemyns, Roland, „Niederländisch - Französisch“, in: Goebl/Nelde/Starý 1997, 1123-1129.

Wilmet, Marc, „Le français de Belgique: fiction ou réalité, in: Labeau, Emmanuelle (ed.), France - Belgique: des frères-ennemis de la langue de chez nous?, Sainte-Foy (Québec), Centre International de Recherche en Aménagement Linguistique, 2000, 7-24.

Wilss, Wolfram (ed.), Weltgesellschaft, Weltverkehrssprache, Weltkultur. Globalisierung vs. Fragmentierung. Akten eines Symposiums in der Europäischen Akademie Otzenhausen/Saarland vom 11.-13.06.1999, Tübingen, Stauffenburg, 2000.

Windisch, Rudolf, „Anglizismen im Italienischen“, in: Schmidt-Radefeldt, Jürgen/Windisch, Rudolf (edd.), Sprachgebrauch und diasystematische Beschreibung romanischer Sprachen, Rostock, Universität, Philosophische Fakultät, 1999, 115-150.

Windisch, Uli, La Suisse. Clichés, délire, réalité, Lausanne, L’Age d’Homme, 1998.

Windisch, Uli, et al., Les relations quotidiennes entre Romands et Suisse allemands: Les cantons bilingues de Fribourg et $d u$ Valais, 2. vol., Lausanne, Payot, 1992 [deutsch: Alltagsbeziehungen zwischen Romands und Deutschschweizern. Am Beispiel der zweisprachigen Kantone Freiburg und Wallis, 2 vol., Basel et al., Helbing und Lichtenhahn, 1994].

Winkelmann, Otto, „Französisch: Sprachnormierung und Standardsprache/Norme et standard", in: Holtus/Metzeltin/Schmitt 1990, 334-353.

Wistinghausen, Christian von, Das Gesetz über die Polnische Sprache vom 7. Oktober 1999, http://www.zanthier.de/aktuell/ges_poln.html, 1999.

Wolf, Heinz Jürgen, „Das Französische in Belgien“, in: Dahmen et al. 1992, 101115.

Wunderli, Peter, „Destruktion eines Mythos: Die viersprachige Schweiz“, in: Akademie-Journal 2 (2001), 15-19.

Wynants, Armel, „Traduction et terminologie dans la gestion du multilinguisme en Belgique“, in: Terminologies nouvelles 9 (1993), 48-53.

Yaguello, Marina, Catalogue des idées reçes sur la langue, Paris, Seuil, 1988.

Yaguello, Marina, „Quand l'Académie s'en mél, elle s'emmêle!“, in: ead., Petits faits de langue, Paris, Seuil, 1998, 140-142.

Zentrale Sprachdienste der Schweizerischen Bundeskanzlei/Services linguistiques centraux de l'administration fédérale suisse, Bienvenue sur le site des anglicismes de l'administration fédérale, http://www.admin.ch/ch/f/bk/sp/|anglicismes/anglicismes-fr-1.html, o.J. (= o.J.a).

Zentrale Sprachdienste der Schweizerischen Bundeskanzlei/Services linguistiques centraux de l'administration fédérale suisse, Anglicismes dans l'administration fédérale. Liste des termes recensés (index des termes anglais et des autres emprunts), http://www.admin.ch/ch/f/bk/sp/anglicismes/anglicismes-fr-2.html, o.J. (= o.J.b). 
Zentrale Sprachdienste der Schweizerischen Bundeskanzlei/Services linguistiques centraux de l'administration fédérale suisse, Anglicismes : vos questions et contributions, http://www.admin.ch/ch/f/bk/sp/anglicismes/anglicismesfr-3.html, o.J. (= o.J.c).

Zentrale Sprachdienste der Schweizerischen Bundeskanzlei/Services linguistiques centraux de l'administration fédérale suisse, Recommandations relatives au traitement des anglicismes au sein de l'administration fédérale, http://www.ad|min.ch/ch/f/bk/sp/anglicismes/anglicismes-fr-6.html\#confederation, o.J. (= o.J.d).

Zimmer, Dieter E., Deutsch und anders - die Sprache im Modernisierungsfieber, Reinbek bei Hamburg, Rowohlt, 1998. 


\section{Anhang}

\subsection{Internetseiten zur WWW-Umfrage}

\subsubsection{Eingangsseite der WWW-Umfrage}

Die Eingangsseite der WWW-Umfrage enthielt den nachfolgend abgedruckten Text:

\section{La terminologie d'Internet}

Bienvenue au questionnaire en ligne sur la terminologie française d'Internet!

Cette enquête anonyme est destinée à toute personne résidante en France, Belgique ou Suisse.

Pour remplir le questionnaire (questions à choix multiples), vous aurez besoin d'environ une quinzaine de minutes.

\begin{tabular}{|l|l||}
\hline L'objectift & $\begin{array}{l}\text { À l'aide de ce questionnaire, j’aimerais étudier } \\
\text { 1. le degré d'implantation de la terminologie française et la diffusion de } \\
\text { la terminologie anglaise } \\
\text { 2. vos réactions face à la politique linguistique actuelle concernant les } \\
\text { anglicismes. }\end{array}$ \\
\hline
\end{tabular}




\begin{tabular}{|c|c|}
\hline $\begin{array}{l}\text { Le contenu du ques- } \\
\text { tionnaire }\end{array}$ & $\begin{array}{l}\text { Le questionnaire contient trois parties : } \\
\text { 1. six termes que vous devez juger (c'est la partie la plus } \\
\text { longue - ne pas se décourager!) } \\
\text { 2. six questions concernant vos réactions face à la } \\
\text { politique } \\
\text { linguistique (c'est rapide!) } \\
\text { 3. quelques données personnelles qui sont bien entendu } \\
\text { traitées confidentiellement (c'est rapide!). }\end{array}$ \\
\hline Demande & $\begin{array}{l}\text { Je vous prie de ne participer à cette enquête qu'une seule } \\
\text { fois, et d'être aussi honnête et objectif que possible. }\end{array}$ \\
\hline $\begin{array}{l}\text { Informations } \\
\text { supplémentaires }\end{array}$ & $\begin{array}{l}\text { Pour avoir des informations supplémentaires sur le } \\
\text { questionnaire, veuillez cliquer ici. }\end{array}$ \\
\hline
\end{tabular}

\section{Au questionnaire}

\subsubsection{Internetseite mit weiterführenden Informationen}

Auf eine andere Internetseite mit dem nachfolgend abgedruckten Text gelangten die Informanten, wenn sie auf der Eingangsseite angeklickt haben, dass sie mehr Informationen wünschen.

\section{La terminologie d'Internet}

\section{Une sorte de «FAQ » concernant le questionnaire}

\section{Qui dirige cette enquête? $[\ldots]$}

2. Pourquoi s'adresser uniquement aux personnes travaillant dans les secteurs de l'informatique et d'Internet?

a) Pour mener une enquête, il vaut mieux se restreindre à un groupe limité qu'on aimerait interviewer. Comme le média que j'utilise pour cette enquête est Internet et que le sujet concerne sa terminologie, je préfère m’adresser aux spécialistes dans ce domaine.

b) Dans les années 1988-1991 une autre linguiste a mené des interviews auprès des informaticiens. J'aimerais pouvoir comparer les résultats qu'elle a obtenus il y a plus de 10 ans avec les miens.

c) De plus, ce sont avant tout les informaticiens et les personnes qui travaillent dans les deux secteurs indiqués qui sont concernés par la terminologie officielle. 
3. Pourquoi le questionnaire s'adresse-t-il aux Français, Belges et Suisses, mais non aux Québécois qui disposent également d'une terminologie française d'Internet?

Il est vrai que l'Office de la langue française présente sur son site un lexique d'Internet très élaboré. Mais en comparant les expressions proposées au Québec avec les expressions proposées en France, en Belgique et en Suisse, le vocabulaire québécois montre de grandes différences.

Par exemple : dans les pays francophones européens, les états proposent uniquement « page d'accueil » pour remplacer le terme anglais « homepage » tandis qu'au Québec, les deux termes « page d'ouverture » et « page d'accueil » sont officiellement proposés. Un autre exemple : en France, en Belgique et en Suisse il n'existe que le terme «fournisseur d'accès » pour remplacer l'anglicisme « (access) provider » tandis que l'Office de la langue française (Québec) offre trois solutions possibles : a) «fournisseur de services Internet », b) « prestataire de services Internet » et c) «fournisseur Internet ». Un dernier exemple : pour l'anglais « webmaster ", les états français, belge et suisse proposent le terme français " administrateur de site » tandis qu'au Québec, l'équivalent offert est « webmestre ».

\section{En quoi consiste exactement le questionnaire?}

Le questionnaire se compose de trois parties :

Dans la première partie, vous serez prié(e) d'indiquer, pour six mots de la terminologie d'Internet française, belge et suisse, quels termes proposés dans le questionnaire (anglicismes et néologismes officiels)

a) vous connaissez et

b) vous utilisez.

Vous êtes aussi prié(e) de donner les raisons de votre choix (plusieurs possibilités de réponse sont offertes).

Dans la deuxième partie, qui est différente selon le pays dans lequel vous vivez, il s'agit de juger la politique linguistique officielle par rapport aux anglicismes, c'està-dire d'indiquer

a) si les mesures prises par le gouvernement de votre pays face aux anglicismes vous sont connues,

b) si vous les considérez comme efficaces et

c) si vous les suivez ou non.

Il ne s'agit en aucun cas de tester vos connaissances, mais d'évaluer le succès ou l'échec de la politique linguistique officielle!

Moins les listes de termes officiels sont connues et moins la politique linguistique est acceptée, plus les États devraient faire un effort pour la diffusion de leurs travaux ou pour persuader la population de la nécessité de leurs actions.

Une troisième partie vous demande d'indiquer votre sexe, votre profession, la région dans laquelle vous vivez etc., pour mieux pouvoir évaluer les questionnaires. 


\section{Comment faire pour être informé(e) des résultats?}

$[\ldots]$

\section{Qui a élaboré la terminologie en France, en Belgique et en Suisse?}

Pour éviter toute anticipation sur le déroulement de l'enquête, vous l'apprendrez à la fin du questionnaire!

7. Comment puis-je poser d'autres questions ou faire des commentaires sur le questionnaire?

$[\ldots]$

\subsubsection{Endseite der WWW-Umfrage}

Direkt nach Abschluss der Befragung öffnete sich eine Internetseite mit folgendem Inhalt:

\section{La terminologie d'Internet}

\section{Merci beaucoup d'avoir participé à cette enquête !}

Si vous voulez être informé(e) des résultats de cette enquête, veuillez. m'envoyer un e-mail/message électronique : emolito1@gwdg.de

Il suffit de mettre sous objet «ENQUETE».

Votre adresse électronique sera transmise par courrier électronique et donc enregistrée séparément des données du questionnaire.

Votre adresse ne sera pas transmise à d'autres personnes et uniquement utilisée pour vous communiquer les résultats.

Pour ceux et celles qui ont lu les «FAQ »: Il manquait encore la réponse à la sixième question :

Qui a élaboré la terminologie en France, en Belgique et en Suisse?

En France, il y a des commissions de terminologie depuis 1970.

Le vocabulaire d'Internet a été élaboré en 1999 par la « commission spécialisée de terminologie et de néologie de l'informatique et des composants électroniques » (CSTIC) qui est entre autre soutenue par la commission des télécommunications (CSTNT). Le 1er septembre 2000 une deuxième liste de terminologie d'Internet est sortie, une troisième est en préparation.

Pour des informations ultérieures veuillez consulter la rubrique «Vocabulaire et terminologie » sur le site de la Délégation générale à la langue française et aux langues de France (DGLFLF) ou le site de la CSTIC. 
En Belgique, il existe depuis quelques années une commission d'experts pour le champ de la terminologie qui examinent si les termes proposés par l'État français peuvent être repris en Belgique. En principe, les termes des arrêtés français sont acceptés pour la Belgique. Des exceptions sont prévues lorsque ce terme n'a qu'une implantation médiocre ou nulle dans la Communauté française de Belgique. La terminologie belge peut être consultée sur le site du Service de la langue française de la Communauté française de Belgique. En cliquant ici vous arrivez directement sur la page : «Banque de données terminologique ».

En Suisse, il n'y a pas de système de commissions terminologiques analogues. Mais pour la terminologie d'Internet, exceptionellement, il y a un groupe d'experts de la Chancellerie fédérale qui travaille sur une terminologie d'Internet trilingue : allemand, français et italien. Pour voir la terminologie d'Internet suisse veuillez cliquer ici. ${ }^{1}$

\subsection{Ankündigung des Fragebogens in den ausgewählten Diskussionsforen (Juli/August 2002)}

\subsubsection{Ankündigung des Fragebogens}

Mit dem folgenden Text wurde die WWW-Umfrage im Forum fr.comp.divers angekündigt:

[Betreff] Enquête sur la terminologie française, belge et suisse d'Internet

„Bonjour,

je suis linguiste allemande.

Je m'adresse à vous pour vous demander de participer à une enquête universitaire. Cette enquête en ligne que vous trouvez à l'adresse suivante

[...]

s'adresse à tous les Français, Belges et Suisses de langue maternelle française qui travaillent dans le secteur de l'informatique et/ou d'Internet y compris bien sur les professeurs/enseignants d'informatique (désolée pour les Québécois et autres francophones, mais leur situation ne rentre pas dans le cadre de l'étude).

\footnotetext{
1 Die angegebenen Adressen verweisen auf die Eingangsseite der DGLFLF (http://www.culture.fr/culture/dglf), der CSTIC (http://www.ensmp.fr/industrie/igic/cstic/), auf die Datenbank des belgischen Service de la langue française (http://www.cfwb.be/franca/bd/bd.htm) und auf die schweizerische Anglizismenliste (http://www.admin.ch/ch/f/bk/sp/anglicis |mes/anglicismes-fr-1.html).
} 
Sur Internet, il y a beaucoup d'anglicismes pour lesquels en France, en Belgique et en Suisse (mais aussi au Québec) des équivalents français ont été proposés. Cette enquête a pour but d'évaluer le succès des efforts officiels pour règlementer la terminologie. Le questionnaire vise à mesurer premièrement le degré d'implantation de six termes de la terminologie officielle française, belge et suisse d'Internet et deuxièmement les réactions générales envers une politique linguistique combattant les anglicismes.

Ce questionnaire sera naturellement anonyme et les données ne seront utilisées que dans le cadre de cette recherche. La participation au questionnaire est basé sur le volontariat. Vous m'aideriez beaucoup en remplissant ce questionnaire.

A titre de remerciement, tous les participants auront la possibilité de recevoir les résultats de l'enquête dès qu'elle sera terminée.

Pour des informations supplémentaires et pour remplir le questionnaire en ligne, qui vous prendra environ quinze minutes, veuillez-vous rendre au site indiqué plus haut. L'étude se poursuit jusqu'à fin août.

Je vous remercie d'avance de l'aide que vous apporterez à cette étude.

$[\ldots]^{\text {‘ }}$

Der Ankündigungstext für die weiteren acht Diskussionsforen ist identisch mit diesem Text, wurde allerdings um das folgende PS ergänzt:

„PS : Pardonnez-moi d'être hors sujet, mais je ne vois pas d'autre possibilité pour demander à mon groupe cible (informaticiens et personnes travaillant dans le secteur d'Internet) que de le faire dans un groupe de spécialistes."

\subsubsection{Erinnerungsschreiben (2. Erhebungswelle)}

Nach jeweils vier bis fünf Tagen wurde eine E-Mail an die Foren geschickt, in der den bisherigen Teilnehmern für ihre Mitarbeit gedankt wurde und alle übrigen potenziellen Teilnehmer darauf hingewiesen wurden, dass die Umfrage noch bis Ende August 2002 laufe:

„Bonjour, 
Merci beaucoup à tous qui ont déjà participé à l'enquête [...] ! Ceux qui ont demandé à être informés des résultats les auront bien entendu au mois de septembre.

J'aimerais bien rappeler aux autres participants de ce forum que l'étude ne se poursuit que jusqu'à fin août. Vous êtes invités d'y participer - cela m’aiderait vraiment énormément !

Le questionnaire en ligne que vous trouvez à l'adresse [...] s'adresse à tous les Français, Belges et Suisses de langue maternelle française qui travaillent dans le secteur de l'informatique et/ou d'Internet y compris bien sûr les professeurs/enseignants/étudiants d'informatique.

Merci d'avance! $[\ldots]^{\text {“ }}$

\subsection{Der Fragebogen}

Die grafische Umsetzung des Fragebogens, so wie er sich im Rahmen der WWWBefragung präsentierte, wird an dieser Stelle nicht berücksichtigt. Es erfolgt die chronologische Aufzählung aller Fragen (Filter werden in eckigen Klammern angegeben).

Première partie

\section{[Seite 1]}

1. Pour entrer en contact avec quelqu'un on peut lui envoyer un/une courrier électronique / message électronique / lettre électronique / mél / courriel / messagerie électronique / e-mail / mail.

Choisissez les mots que vous connaissez !

(Il ne s'agit pas de ce que vous comprenez, mais bien de ce que vous avez déjà entendu.)

Je connais

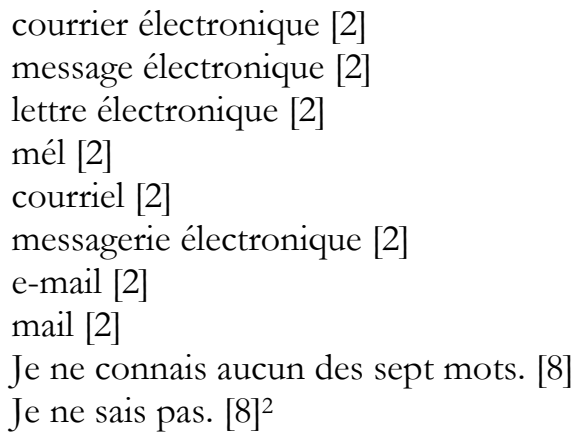

2 Je nach gewählter Antwortoption werden die Informanten zur zweiten bzw. zur achten Frage weitergeleitet. Entsprechend sind auch die folgenden Filterangaben, d.h. die Nummern in den 


\section{[Seite 2]}

2. Les mots courrier électronique, message électronique, mél, courriel, messagerie électronique, email et mail sont-ils synonymes ou non?

Choisissez une seule case !

Synonymes (même sens). [4]

- Non, ils ont un sens différent. [3]

- Je ne connais pas tous les mots./Je ne sais pas. [4]

\section{[Seite 3]}

3. Veuillez préciser en quoi consiste la différence de signification!

$<$ Textfeld $>$

\section{[Seite 4]}

4. Quelle(s) expression(s) préférez-vous ?

Choisissez deux cases au maximum !

Je préfère

$$
\begin{array}{ll}
\text { - } & \text { courrier électronique } \\
\text { - } & \text { lettre électronique } \\
\text { - } & \text { mél } \\
\text { - } & \text { courriel } \\
\text { - } & \text { messagerie électronique } \\
\text { - } & \text { e-mail } \\
\text { - } \quad \text { mail } \\
\text { - Je n'ai pas de préférence. } \\
\text { - Je ne sais pas. }
\end{array}
$$

5. Laquelle des expressions suivantes utilisez-vous?

J'utilise

toujours courrier électronique [6]

dans la majorité des cas courrier électronique [6]

toujours message électronique [6]

dans la majorité des cas message électronique [6]

toujours lettre électronique [6]

dans la majorité des cas lettre électronique [6]

toujours mél [6]

dans la majorité des cas mél [6]

toujours courriel [6]

dans la majorité des cas courriel [6]

toujours messagerie électronique [6]

eckigen Klammern zu verstehen: Sie verweisen jeweils auf die Fragennummer. Sind hinter den Antwortoptionen keine Filter angegeben, werden die Befragten unabhängig ihrer Antworten zur nächsten Frage weitergeleitet. 
- dans la majorité des cas messagerie électronique [6]

- toujours e-mail [7]

- dans la majorité des cas e-mail [7]

- toujours mail [7]

- dans la majorité des cas mail [7]

- Aucun des termes proposés. [8]

- Je décide toujours selon le contexte. [8]

- Je ne sais pas. [8]

\section{[Seite 5]}

6. Caractérisez le mot français que vous avez choisi dans la dernière question !

Si vous avez oublié le mot que vous avez choisi dans la dernière question, appuyez sur la touche retour de votre navigateur!

Explications pour remplir cette question:

Vous devez juger le mot que vous avez choisi dans la dernière question, c'est-àdire : courrier électronique, message électronique, lettre électronique, mél ou courriel d'après les critères 'connu/inconnu', 'beau/laid', 'compréhensible/incompréhensible' etc. !

C'est-à-dire, dans ce type de questions, il y a dans chaque ligne deux pôles extrêmes qui sont définis par les deux adjectifs que vous voyez à gauche et à droite.

Les deux cases extérieures - la première et la cinquième - signifient donc que vous acceptez complètement les adjectifs donnés. La deuxième case (vers l'intérieur) de chacun des côtés signifie que vous approuvez en grande partie l'adjectif proposé.

La case du milieu est neutre.

Exemple pour la première ligne (les cases sont numérotées de gauche à droite) :

1. connu, 2. plutôt connu, 3. ni connu ni inconnu, 4. plutôt inconnu, 5. inconnu.

Si vous ne savez pas comment adapter une paire d'adjectifs au mot donné, choisissez la réponse 'Je ne sais pas.'

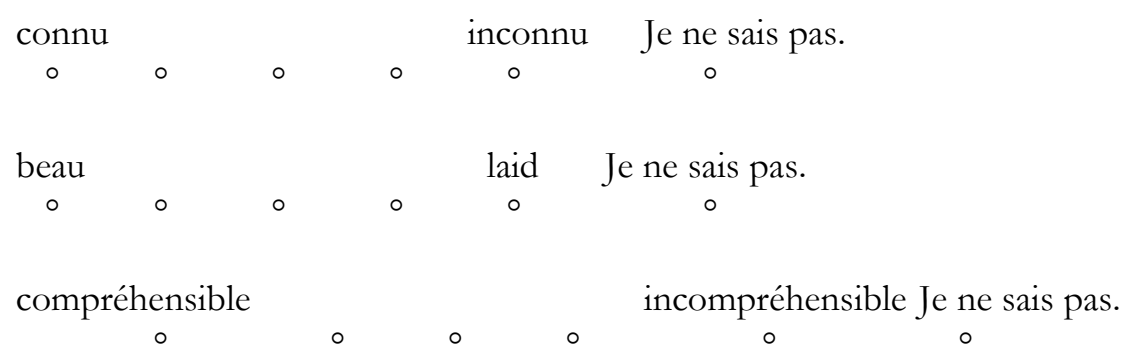

utile inutile Je ne sais pas. 


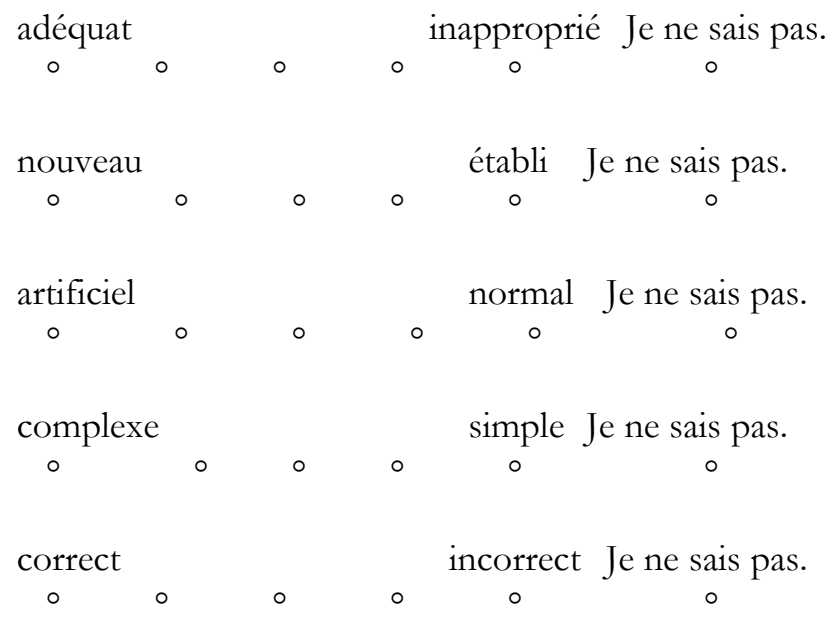

[8]

\section{[Seite 6]}

7. Pourquoi préférez-vous utiliser dans ce cas l'anglicisme plutôt que les termes français?

Choisissez la ou les cases pertinentes !

Si vous avez oublié le mot que vous avez choisi dans la dernière question, appuyez sur la touche retour de votre navigateur!

Je ne connais pas les termes français.

La signification des termes français n'est pas claire.

Il n’est pas possible de créer des termes dérivés (du type : logiciel, progiciel, ludiciel).

La signification des termes français ne correspond pas à celle du terme anglais.

Les formulations des termes français sont trop compliquées.

Le terme anglais est plus bref.

Les termes français ne sont pas assez proches du terme anglais.

Les connotations des termes français ne correspondent pas aux connotations qui sont liées au terme anglais.

Il y a trop d'équivalents français pour un seul terme anglais.

Les néologismes français ne sont pas assez connus.

Presque tout le monde utilise le terme anglais.

En utilisant le terme anglais, je suis sûr(e) d'être compris(e).

Je me suis déjà habitué(e) à utiliser le terme anglais et je ne veux pas changer mes habitudes.

Le terme anglais est plus international.

Pour paraître compétent, il faut se servir de la terminologie anglaise.

Je n'aime pas suivre les propositions officielles.

Autre (veuillez préciser) : <Textfeld $>$

Je ne sais pas. 


\section{[Seite 7]}

8. Une page d'accueil / page d'introduction / homepage contient en général le sommaire $\mathrm{du}$ site web, avec des liens hypertexte vers les différentes rubriques.

Choisissez les mots que vous connaissez !

(Il ne s'agit pas de ce que vous comprenez, mais bien de ce que vous avez déjà entendu.)

Je connais

- $\quad$ page d'accueil [9]

- page d'introduction [9]

- homepage [9]

- Je ne connais aucun des trois mots. [15]

Je ne sais pas. [15]

\section{[Seite 8]}

9. Les mots page d'accueil et homepage sont-ils synonymes ou non?

Synonymes (même sens). [11]

- Non, ils ont un sens différent. [10]

- Je ne connais pas tous les mots./Je ne sais pas. [11]

\section{[Seite 9]}

10. Veuillez préciser en quoi consiste la différence de signification!

$<$ Textfeld $>$

\section{[Seite 10]}

11. Quelle(s) expression(s) préférez-vous?

Choisissez deux cases au maximum !

Je préfère

$$
\begin{aligned}
& \text { page d'accueil } \\
& \text { page d'introduction } \\
& \text { homepage } \\
& \text { Je n'ai pas de préférence. } \\
& \text { Je ne sais pas. }
\end{aligned}
$$

12. Laquelle des expressions suivantes utilisez-vous?

J'utilise

$$
\text { toujours page d'accueil [13] }
$$

dans la majorité des cas page d'accueil [13]

toujours page d'introduction [13]

dans la majorité des cas page d'introduction [13]

toujours homepage [14]

dans la majorité des cas homepage [14]

Aucun des termes proposés. [15]

Je décide toujours selon le contexte [15] 
Je ne sais pas. [15]

\section{[Seite 11]}

13. Caractérisez le mot français que vous avez choisi dans la dernière question!

s. Frage $6^{3}[15]$

\section{[Seite 12]}

14. Pourquoi préférez-vous utiliser dans ce cas l'anglicisme plutôt que les termes français?

s. Frage 7

\section{[Seite 13]}

15. Le / La réseau mondial / toile d'araignée mondiale / toile mondiale / toile / T.A.M. / web / World Wide Web comprend une série de ressources (Gopher, FTP, http, telnet, Usenet, Wais, etc.) accessibles avec un navigateur.

Choisissez les mots que vous connaissez !

(Il ne s'agit pas de ce que vous comprenez, mais bien de ce que vous avez déjà entendu.)

Je connais

réseau mondial [16]

toile d'araignée mondiale [16]

toile mondiale [16]

toile [16]

T.A.M. [16]

web [16]

World Wide Web [16]

- Je ne connais aucun des mots. [22]

Je ne sais pas. [22]

\section{[Seite 14]}

16. Les mots toile d'araignée moniale, toile mondiale, toile, T.A.M., web et World Wide Web sont-ils synonymes ou non?

- Synonymes (même sens). [18]

- $\quad$ Non, ils ont un sens différent. [17]

- Je ne connais pas tous les mots./Je ne sais pas. [18]

\section{[Seite 15]}

17. Veuillez préciser en quoi consiste la différence de signification!

$<$ Textfeld $>$

\footnotetext{
${ }^{3}$ Frage 13 ist bis auf eine Ausnahme mit Frage 6 identisch: In den Erklärungen zur Frage werden jedes Mal diejenigen französischen Termini aufgezählt, die zur Bewertung zur Verfügung stehen, in diesem Fall page d'accueil oder page d'introduction. Dies gilt auch für die Fragen 20, 27, 34 und 41.
} 
[Seite 16]

18. Quelle(s) expression(s) préférez-vous ?

Choisissez deux cases au maximum!

Je préfère

réseau mondial

- toile d'araignée mondiale

- toile mondiale

- toile

- T.A.M.

- web

- $\quad$ World Wide Web

- Je n'ai pas de préférence. Je ne sais pas.

19. Laquelle des expressions suivantes utilisez-vous ?

J'utilise

toujours réseau mondial [20]

dans la majorité des cas réseau mondial [20]

toujours toile d'araignée mondiale [20]

dans la majorité des cas toile d'araignée mondiale [20]

toujours toile mondiale [20]

dans la majorité des cas toile mondiale [20]

toujours toile [20]

dans la majorité des cas toile [20]

toujours T.A.M. [20]

dans la majorité des cas T.A.M. [20]

toujours web [21]

dans la majorité des cas web [21]

toujours World Wide Web [21]

dans la majorité des cas World Wide Web [21]

- Aucun des termes proposés. [22]

- Je décide toujours selon le contexte. [22]

- Je ne sais pas. [22]

[Seite 17]

20. Caractérisez le mot français que vous avez choisi dans la dernière question!

s. Frage 6 [22]

[Seite 18]

21. Pourquoi préférez-vous utiliser dans ce cas l'anglicisme plutôt que les termes français?

s. Frage 7 


\section{[Seite 19]}

22. Une conversation typique sur la toile, dans l'espace-temps virtuel, s'appelle causette / conversation électronique / bavardage / chat.

Choisissez les mots que vous connaissez!

(Il ne s'agit pas de ce que vous comprenez, mais bien de ce que vous avez déjà entendu.)

Je connais

- causette [23]

- conversation électronique [23]

- bavardage [23]

- conversation électronique [23]

- chat [23]

- Je ne connais aucun des mots. [29]

- Je ne sais pas. [29]

\section{[Seite 20]}

23. Les mots causette, bavardage et chat sont-ils synonymes ou non?

- Synonymes (même sens). [25]

- Non, ils ont un sens différent. [24]

- Je ne connais pas tous les mots./Je ne sais pas. [25]

\section{[Seite 21]}

24. Veuillez préciser en quoi consiste la différence de signification! $<$ Textfeld $>$

\section{[Seite 22]}

25. Quelle(s) expression(s) préférez-vous?

Choisissez deux cases au maximum!

Je préfère

- causette

- conversation électronique

- bavardage

- chat

- Je n'ai pas de préférence.

- Je ne sais pas. 
26. Laquelle des expressions suivantes utilisez-vous?

J'utilise

toujours causette [27]

dans la majorité des cas causette [27]

toujours conversation électronique [27]

dans la majorité des cas conversation électronique [27]

toujours bavardage [27]

dans la majorité des cas bavardage [27]

toujours chat [28]

dans la majorité des cas chat [28]

Aucun des termes proposés. [29]

Je décide toujours selon le contexte. [29]

Je ne sais pas. [29]

[Seite 23]

27. Caractérisez le mot français que vous avez choisi dans la dernière question!

s. Frage 6 [29]

\section{[Seite 24]}

28. Pourquoi préférez-vous utiliser dans ce cas l'anglicisme plutôt que les termes français?

s. Frage 7

\section{[Seite 25]}

29. Un individu cherchant à s'introduire dans un réseau ou un système informatique protégé, soit pour prouver sa vulnérabilité, soit pour voler des données, s'appelle fouineur / pirate / cracker.

Choisissez les mots que vous connaissez!

(Il ne s'agit pas de ce que vous comprenez, mais bien de ce que vous avez déjà entendu.)

Je connais

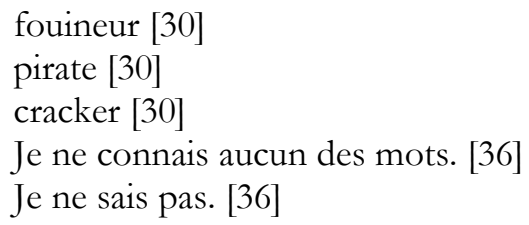

\section{[Seite 26]}

30. Les mots pirate et cracker sont-ils synonymes ou non?

Synonymes (même sens). [32]

Non, ils ont un sens différent. [31]

- Je ne connais pas tous les mots./Je ne sais pas. [32] 
[Seite 27]

31. Veuillez préciser en quoi consiste la différence de signification!

$<$ Textfeld $>$

\section{[Seite 28]}

32. Quelle(s) expression(s) préférez-vous ?

Choisissez deux cases au maximum !

Je préfère

- fouineur

- pirate

- cracker

- Je n'ai pas de préférence.

- Je ne sais pas.

33. Laquelle des expressions suivantes utilisez-vous ?

J'utilise

toujours fouineur [34]

dans la majorité des cas fouineur [34]

toujours pirate [34]

dans la majorité des cas pirate [34]

toujours cracker [35]

dans la majorité des cas cracker [35]

Aucun des termes proposés. [36]

- Je décide toujours selon le contexte. [36]

Je ne sais pas. [36]

[Seite 29]

34. Caractérisez le mot français que vous avez choisi dans la dernière question!

s. Frage $6[36]$

\section{[Seite 30]}

35. Pourquoi préférez-vous utiliser dans ce cas l'anglicisme plutôt que les termes français?

s. Frage 7 


\section{[Seite 31]}

36. Le fournisseur d'accès / pourvoyeur d'accès / (access) provider peut être soit un opérateur comme France Télécom (Wanadoo), soit une grande société spécialisée comme Compuserve ou America Online.

Choisissez les mots que vous connaissez!

(Il ne s'agit pas de ce que vous comprenez, mais bien de ce que vous avez déjà entendu.)

Je connais

- fournisseur d'accès [37]

- pourvoyeur d'accès [37]

- (access) provider [37]

- Je ne connais aucun des mots. [43] Je ne sais pas. [43]

\section{[Seite 32]}

37. Les mots fournisseur d'accès et (access) provider mots sont-ils synonymes ou non ? Synonymes (même sens). [39]

- Non, ils ont un sens différent. [38]

- Je ne connais pas tous les mots./Je ne sais pas. [39]

\section{[Seite 33]}

38. Veuillez préciser en quoi consiste la différence de signification!

$<$ Textfeld $>$

\section{[Seite 34]}

39. Quelle(s) expression(s) préférez-vous ?

Choisissez deux cases au maximum!

Je préfère
fournisseur d'accès
pourvoyeur d'accès
(access) provider
- Je n'ai pas de préférence.

- Je ne sais pas.

40. Laquelle des expressions suivantes utilisez-vous ?

J'utilise

toujours fournisseur d'accès [41]

dans la majorité des cas fournisseur d'accès [41]

toujours pourvoyeur d'accès [41]

dans la majorité des cas pourvoyeur d'accès [41]

toujours (access) provider [42]

dans la majorité des cas (access) provider [42]

Aucun des termes proposés. [43]

Je décide toujours selon le contexte. [43] 
Je ne sais pas. [43]

\section{[Seite 35]}

41. Caractérisez le mot français que vous avez choisi dans la dernière question! s. Frage 6 [43]

\section{[Seite 36]}

42. Pourquoi préférez-vous utiliser dans ce cas l'anglicisme plutôt que les termes français?

s. Frage 7 [43]

[Ende des 1. Fragebogenteils]

[Seite 37]

43. Pour continuer avec les dernières questions, veuillez indiquer le pays où vous habitez :

En France

En Belgique

En Suisse

Dans un autre pays francophone

Deuxième Partie : La Politique linguistique française ${ }^{4}$

\section{[Seite 38]}

44. Êtes-vous informé(e) sur la politique linguistique actuelle, particulièrement sur la loi Toubon?

Oui.

Oui, j’en ai entendu parler.

Non.

- Je ne sais pas.

\footnotetext{
${ }^{4}$ Der jeweils zweite Teil für die Belgier und Schweizer ist analog aufgebaut. Die Fragen zur belgischen Sprachpolitik lauten: Êtes-vous informé(e) sur la planification de la langue pour la protéger des anglicismes en Belgique?, Comment jugez-vous une planification de la langue pour la protéger des anglicismes ?, Comment trouvez-vous les listes de terminologie qui sont actuellement publiées dans la Banque de données terminologique du Service de la langue française (par ex.: vocabulaire de l'économie et des finances, de l'informatique, du sport - exemple pour le langage du sport : on ne doit plus employer penalty, mais tir au but) ?, Vous conformez-vous aux dispositions des listes de terminologie ?, Connaissez-vous la terminologie officielle belge de l'informatique qui a été publiée dans la Banque de données terminologique du Service de la langue française ? [Filter, wie beim Teil zu Frankreich], Utilisez-vous la terminologie d'informatique (y compris la terminologie d'Internet) qui a été publiée dans la Banque de données terminologique du Service de la langue française ?

Die Fragen zur schweizerischen Sprachpolitik lauten: Comment jugez-vous une planification de la langue pour la protéger des anglicismes ?, Connaissez-vous la terminologie française de l'Internet qui a été créée par un groupe de travail terminologique suisse et publié sur le site de la Chancellerie fédérale ? [Filter], Utilisez-vous la terminologie officielle suisse de l'Internet? ?, Êtes-vous informé(e) de la planification linguistique instaurée par l'État français pour protéger la langue des anglicismes?, [Filter], Vous conformez-vous à la planification de la langue de l'État français pour protéger la langue des anglicismes?
} 
45. Comment jugez-vous une planification de la langue pour la protéger des anglicismes?

Absolument nécessaire.

Souhaitable (C'est bien s'il y en ait une, mais ce n'est pas indispensable).

Inutile.

- Je ne sais pas.

46. Comment trouvez-vous les listes de terminologie (par ex. : vocabulaire de l'économie et des finances, de l'informatique, du sport qui contiennent des tables d'équivalences d'anglicismes et de termes français - exemple pour le langage du sport : on ne doit plus employer penalty, mais tir au but. Ces listes ont été publiées entre autre au Journal officiel)?

Utiles.

Souhaitables.

- Pas assez connues.

- Inutiles.

- Je ne les connais pas.

- $\quad$ Rien/Je ne sais pas.

47. Vous conformez-vous aux dispositions des listes de terminologie?

Oui.

- Non.

- Partiellement.

- Je ne les connais pas.

- Je ne sais pas.

48. Connaissez-vous les listes de terminologie officielle de l'Internet (publiée entre autre au Journal officiel du 16 mars 1999 et du 1er septembre 2000 et sur le site de la Délégation générale à la langue française et aux langues de France (DGLFLF)) ?

Oui, je les connais bien. [49]

Oui, je les connais un peu. [49]

Oui, mais je connais seulement la liste de 1999. [49]

Oui, mais je connais seulement la liste de 2000. [49]

- J'en ai déjà entendu parler, mais je ne connais aucune des deux. [50]

- Non, pas du tout. [50]

- Je ne sais pas. [50]

\section{[Seite 39]}

49. Utilisez-vous la terminologie d'Internet officielle (du 16 mars 1999 et du $1^{\text {er }}$ septembre 2000)?

Oui, toujours. [50]

Non, jamais. [50]

Partiellement. [50]

Je ne sais pas. [50] 
[Ende des 2. Fragebogenteils]

Troisième partie : Pour mieux vous connaître

\section{[Seite 40]}

50. Sexe :

Masculin.

Féminin.

51. Âge :

Moins de 20 ans.

21-30 ans.

31-40 ans.

41-50 ans.

51-60 ans.

Plus de 60 ans.

52. Situation professionnelle :

Salarié(e) ou fonctionnaire : Agriculteur

Salarié(e) ou fonctionnaire : Armée, police, gendarmerie

Salarié(e) ou fonctionnaire : Artisan, commercant et assimilé

Salarié(e) ou fonctionnaire : Chef d'entreprise

Salarié(e) ou fonctionnaire : Cadre et professions intellectuelles supérieures

Salarié(e) ou fonctionnaire : Employé

Salarié(e) ou fonctionnaire : Instituteur, enseignant et assimilé

Salarié(e) ou fonctionnaire : Journaliste

Salarié(e) ou fonctionnaire : Ouvrier

Salarié(e) ou fonctionnaire : Professions artistiques et du spectacle

Salarié(e) ou fonctionnaire : Technicien, contremaittre, agent de maitrise

Salarié(e) ou fonctionnaire : Autre

Étudiant(e) : Université, Grande École

Étudiant(e) : Collège, Lycée

Profession libérale : Activité de conseil

Profession libérale : Avocat et professions associées

Profession libérale : Journaliste

Profession libérale : Professions artistiques et du spectacle

Profession libérale : Santé et professions associées

Demandeur d'emploi

Femme (homme) au foyer

Retraité(e)

Autre

53. Veuillez préciser la profession exercée : $<$ Textfeld $>$ 
54. Niveau d'études actuel :

\begin{tabular}{|c|c|c|}
\hline [für Frankreich] & [für Belgien] & [für die Schweiq] \\
\hline $\begin{array}{ll}- & \text { Primaire } \\
- & \mathrm{BEPC} \\
- & \mathrm{BEP} / \mathrm{CAP} \\
- & \mathrm{Bac} \text { et équivalent } \\
- & \mathrm{Bac}+2 \\
- & \mathrm{Bac}+3,+4 \\
- & \mathrm{Bac}+5 \text { et plus }\end{array}$ & $\begin{array}{l}\text { École primaire } \\
\text { École } \\
\text { professionnelle / } \\
\text { École technique } \\
\text { Baccalauréat / } \\
\text { Diplôme de } \\
\text { l'Enseignement } \\
\text { Supérieur } \\
\text { Candidature } \\
\text { Licence } \\
\text { Doctorat }\end{array}$ & $\begin{array}{l}\text { - École obligatoire } \\
\text { - } \quad \text { Maturité } \\
\text { professionnelle } \\
\text { Maturité } \\
\text { Baccalauréat et } \\
\text { équivalent } \\
\text { - } \begin{array}{l}\text { Demi-licence } \\
\text { - }\end{array} \text { Licence } \\
\text { - } \quad \text { Doctorat }\end{array}$ \\
\hline
\end{tabular}

55. Pays de naissance :

France (y compris DOM-TOM)

- Belgique

- Suisse

- Canada

- $\quad$ Autre (veuillez préciser) : $<$ Textfeld $>$

56. Langue(s) maternelle(s) :

Allemand

Anglais

Flamand/Néerlandais

Français

Italien

Autre (veuillez préciser) : <Textfeld $>$ 
57. Domicile :

\begin{tabular}{|c|c|c|}
\hline [für Frankreich] & [für Belgien] & [für die Schweiq] \\
\hline $\begin{array}{l}\text { Paris, Ile de France } \\
\text { Nord-Ouest (Bretagne, Basse- } \\
\text { Normandie, Centre, Haute- } \\
\text { Normandie, Pays de la Loire) } \\
\text { Nord-Est (Alsace, Bourgogne, } \\
\text { Champagne-Ardenne, Franche- } \\
\text { Comté, Lorraine, Nord-Pas-de- } \\
\text { Calais, Picardie) } \\
\text { Sud-Est (Auvergne, Corse, } \\
\text { Languedoc-Roussillon, } \\
\text { Provence-Alpes-Côte d'Azur, } \\
\text { Rhône-Alpes) } \\
\text { Sud-Ouest (Aquitaine, } \\
\text { Limousin, Midi-Pyrénées, } \\
\text { Poitou-Charentes } \\
\text { DOM-TOM (Guadeloupe, } \\
\text { Guyane, Martinique, Réunion) }\end{array}$ & $\begin{array}{ll}\text { - } & \text { Bruxelles } \\
\text { - } & \text { Liège } \\
\text { - } & \text { Namur } \\
\text { - } & \text { Hainaut } \\
\text { - } & \text { Luxemburg } \\
\text { - } & \text { Brabant }\end{array}$ & $\begin{array}{ll}\text { - } & \text { Berne } \\
\text { - } & \text { Fribourg } \\
\text { - } & \text { Genève } \\
\text { - } & \text { Jura } \\
\text { - } & \text { Neuchâtel } \\
\text { - } & \text { Valais } \\
\text { - } & \text { Vaud }\end{array}$ \\
\hline
\end{tabular}

58. Connaissances en anglais :

Aucune.

Très rudimentaires (à l'oral et à l'écrit).

Seulement bien à l'écrit.

Seulement bien à l'oral.

Bonnes connaissances (à l'écrit et à l'oral).

Je ne sais pas.

59. Depuis quand utilisez-vous les services fournis par l'Internet?

\begin{tabular}{|l|l|l|}
$\begin{array}{l}\text { Message électro- } \\
\text { nique / E-mail }\end{array}$ & $\begin{array}{l}\text { T.A.M. / WWW } \\
\text { (Web) }\end{array}$ & $\begin{array}{l}\text { Forums / News- } \\
\text { groups (Usenet) }\end{array}$ \\
\hline $\begin{array}{l}\text { Pas du tout } \\
\text { Moins d'un an }\end{array}$ & Pas du tout & Pas du tout \\
\hline Moins de trois ans & Moins de trois ans & Moins d'un an \\
\hline $\begin{array}{l}\text { Plus de trois ans } \\
\text { Je ne sais pas }\end{array}$ & Plus de trois ans & Plus de trois ans \\
\hline
\end{tabular}

Vous pouvez noter ici ce que vous pensez de la politique linguistique (terminologie)!

$<$ Textfeld $>$ 
Avez-vous des suggestions ou des remarques à faire concernant ce questionnaire? $<$ Textfeld $>$

[Ende des Fragebogens]

\subsection{Biosoziale Daten (3. Fragebogenmodul)}

\subsubsection{Berufe der Informanten}

Die folgenden sechs Tabellen zeigen die Berufsgruppen und die präzisen Berufsbezeichnungen für die französischen, belgischen und schweizerischen Informanten. Sie sind nach der Häufigkeit der Nennungen geordnet, bei gleicher Anzahl an Nennungen alphabetisch.

Abb. 223: Berufsgruppen der französischen Informanten

\begin{tabular}{|c|c|c|}
\hline Kategorie & $\begin{array}{l}\text { Absolute } \\
\text { Häufigkeit }\end{array}$ & $\begin{array}{l}\text { Prozentuale } \\
\text { Häufigkeit }\end{array}$ \\
\hline $\begin{array}{l}\text { Salarié(e) ou fonctionnaire : } \\
\text { Cadre et professions intellec- } \\
\text { tuelles supérieures }\end{array}$ & 59 & 47,6 \\
\hline $\begin{array}{l}\text { Étudiant(e) : Université, Grande } \\
\text { École }\end{array}$ & 28 & 22,6 \\
\hline $\begin{array}{l}\text { Salarié(e) ou fonctionnaire : } \\
\text { Employé }\end{array}$ & 9 & 7,3 \\
\hline $\begin{array}{l}\text { Salarié(e) ou fonctionnaire : } \\
\text { Technicien, contremaître, agent } \\
\text { de maîtrise }\end{array}$ & 9 & 7,3 \\
\hline $\begin{array}{l}\text { Salarié(e) ou fonctionnaire : } \\
\text { Instituteur, enseignant et assimilé }\end{array}$ & 5 & 4,0 \\
\hline $\begin{array}{l}\text { Profession libérale : Activité de } \\
\text { conseil }\end{array}$ & 4 & 3,2 \\
\hline $\begin{array}{l}\text { Salarié(e) ou fonctionnaire : Chef } \\
\text { d'entreprise }\end{array}$ & 3 & 2,4 \\
\hline $\begin{array}{l}\text { Salarié(e) ou fonctionnaire : } \\
\text { Autre }\end{array}$ & 2 & 1,6 \\
\hline $\begin{array}{l}\text { Profession libérale : Professions } \\
\text { artistiques et du spectacle }\end{array}$ & 1 & 0,8 \\
\hline Retraité(e) & 1 & 0,8 \\
\hline Autre & 3 & 2,4 \\
\hline Insgesamt & 124 & 100,0 \\
\hline
\end{tabular}


Abb. 224: Genaue Berufsbezeichnungen der französischen Informanten

\begin{tabular}{|c|c|c|}
\hline Kategorie & $\begin{array}{l}\text { Absolute } \\
\text { Häufigkeit }\end{array}$ & $\begin{array}{l}\text { Prozentuale } \\
\text { Häufigkeit }\end{array}$ \\
\hline $\begin{array}{l}\text { Ingénieur } \\
\text { Ingénieur en informatique (17) } \\
\text { Ingénieur (ohne Präzisierung) (3) } \\
\text { Ingénieur système (3) } \\
\text { Ingénieur Télécom (2) } \\
\text { Ingénieur d'étude (1) } \\
\text { Ingénieur recherche/développement (3) } \\
\text { Ingénieur sécurité informatique (1) } \\
\text { Ingénieur dans un Centre de Recherche } \\
\text { (1) } \\
\text { En stage ingénieur développement (1) }\end{array}$ & 32 & 26,2 \\
\hline Informaticien & 14 & 11,3 \\
\hline $\begin{array}{l}\text { Étudiant } \\
\text { Étudiant (ohne Präzisierung) (5) } \\
\text { Étudiant(e) en école d'ingénieur (en } \\
\text { informatique) (4) } \\
\text { Étudiant en informatique/NTIC (2) } \\
\text { Étudiant en physique (1) }\end{array}$ & 12 & 9,7 \\
\hline $\begin{array}{l}\text { Analyste } \\
\text { Analyste-programmeur (6) } \\
\text { Analyste de l'informatique (1) } \\
\text { Analyste-développeur (1) }\end{array}$ & 8 & 6,4 \\
\hline Développeur & 5 & 4,0 \\
\hline Chef de projet (informatique) & 4 & 3,2 \\
\hline $\begin{array}{l}\text { Enseignant } \\
\text { Enseignant-chercheur (2) } \\
\text { Enseignant à l’Université (1) } \\
\text { Faciliteur d'accès aux nouvelles } \\
\text { technologies (1) }\end{array}$ & 4 & 3,2 \\
\hline $\begin{array}{l}\text { Consultant } \\
\text { Consultant en informatique (1) } \\
\text { Consultant en sécurité informatique (1) } \\
\text { Consultant logiciels libres et réseaux (1) }\end{array}$ & 3 & 2,4 \\
\hline Doctorand (en informatique) & 3 & 2,4 \\
\hline Bioinformaticien(ne) & 2 & 1,6 \\
\hline $\begin{array}{l}\text { Chef d'entreprise } \\
\text { Chef d'entreprise (ohne Präzisierung) (1) } \\
\text { Président Directeur Général d'une Société } \\
\text { de Services et d'Ingéniérie (1) }\end{array}$ & 2 & 1,6 \\
\hline Programmeur & 2 & 1,6 \\
\hline
\end{tabular}


Responsable

Responsable Editorial Internet dans une banque (1)

Responsable informatique (1)

\section{Support et soutien technique (employé)}

Technicien

Technicien systèmes \& réseaux (1)

Technicien informatique (1)

\begin{tabular}{|l|r|r|}
\hline Administrateur système & 1 & 0,8 \\
\hline Animateur informatique & 1 & 0,8 \\
\hline Attachée de production & 1 & 0,8 \\
\hline Cadre SNCF & 1 & 0,8 \\
\hline Chargé de cours & 1 & 0,8 \\
\hline Électronicien & 1 & 0,8 \\
\hline Formateur / Concepteur de formation & 1 & 0,8 \\
\hline Haut fonctionnaire (fonction publique & 1 & 0,8 \\
\hline internationale) & & \\
\hline Infographie, maintenance & 1 & 0,8 \\
\hline Keine Angabe & 18 & 14,4 \\
\hline Insgesamt & 124 & 100,0 \\
\hline
\end{tabular}

\section{Abb. 225: Berufsgruppen der belgischen Informanten}

\section{Kategorie}

Salarié(e) ou fonctionnaire :

Cadre et professions intellectuelles supérieures

Salarié(e) ou fonctionnaire :

Employé

Étudiant(e) : Université,

Grande École

Salarié(e) ou fonctionnaire :

Armée, police, gendarmerie

Salarié(e) ou fonctionnaire :

Instituteur, enseignant et assimilé

Salarié(e) ou fonctionnaire :

Autre

Insgesamt
Absolute Prozentuale

Häufigkeit Häufigkeit

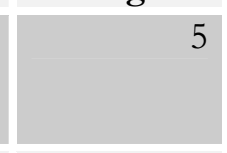

5

29,4

4

23,5

1

5,9

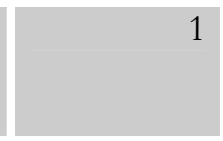

5,9

5,9
0,8

0,8

0,8

0,8

0,8

0,8

0,8 
Abb. 226: Genaue Berufsbezeichnungen der belgischen Informanten

\begin{tabular}{|l|r|r|}
\hline Kategorie & $\begin{array}{l}\text { Absolute } \\
\text { Häufigkeit }\end{array}$ & $\begin{array}{l}\text { Prozentuale } \\
\text { Häufigkeit }\end{array}$ \\
\hline Étudiant en informatique & 4 & 23,5 \\
\hline Informaticien & 4 & 23,5 \\
\hline Analyste-programmeur & 3 & 17,6 \\
\hline $\begin{array}{l}\text { Technicien } \\
\text { dans un bureau technique (1) } \\
\text { en bactériologie (1) }\end{array}$ & 2 & 11,8 \\
\hline $\begin{array}{l}\text { Employé } \\
\text { dans une Société d'IT (1) } \\
\text { aux Services Communaux (1) }\end{array}$ & & \\
\hline Actuaire & 2 & 11,8 \\
\hline Ingénieur & & \\
\hline Insgesamt & 1 & 5,9 \\
\hline
\end{tabular}

Abb. 227: Berufsgruppen der schweizerischen Informanten

\section{Kategorie}

Salarié(e) ou fonctionnaire :

Cadre et professions intellec-

tuelles supérieures

Étudiant(e) : Université, Grande École

Salarié(e) ou fonctionnaire :

Instituteur, enseignant et assimilé

Salarié(e) ou fonctionnaire :

Employé

Salarié(e) ou fonctionnaire :

Technicien, contremaittre, agent de maîtrise

Profession libérale : Activité de conseil

\section{Autre}

Insgesamt

\section{Absolute Prozentuale Häufigkeit Häufigkeit}

\begin{tabular}{|r|r|}
\hline 6 & 31,6 \\
\hline 4 & 21,0 \\
\hline 3 & 15,8 \\
\hline 2 & 10,5 \\
\hline 1 & 5,3 \\
\hline & \\
\hline 1 & 5,3 \\
\hline 2 & 10,5 \\
\hline 19 & 100,0 \\
\hline
\end{tabular}


Abb. 228: Genaue Berufsbezeichnungen der schweizerischen Informanten

\begin{tabular}{|c|c|c|}
\hline Kategorie & $\begin{array}{l}\text { Absolute } \\
\text { Häufigkeit }\end{array}$ & $\begin{array}{l}\text { Prozentuale } \\
\text { Häufigkeit }\end{array}$ \\
\hline $\begin{array}{l}\text { Étudiant } \\
\text { Étudiant en informatique (3) } \\
\text { Étudiant (ohne Präzisierung) (1) }\end{array}$ & 4 & 21,0 \\
\hline $\begin{array}{l}\text { Enseignant(e) } \\
\text { Enseignant d'informatique (1) } \\
\text { Enseignant en secondaire (1) } \\
\text { Enseignante (1) }\end{array}$ & 3 & 15,7 \\
\hline $\begin{array}{l}\text { Ingénieur } \\
\text { Ingénieur Système Unix (1) } \\
\text { Ingénieur Télécom (1) } \\
\text { Ingénieur logiciel (1) }\end{array}$ & 3 & 15,7 \\
\hline Informaticien & 2 & 10,5 \\
\hline Analyste-programmeur & 1 & 5,3 \\
\hline $\begin{array}{l}\text { Consultant en Technologies de } \\
\text { l'Enseignement }\end{array}$ & 1 & 5,3 \\
\hline Employé de commerce & 1 & 5,3 \\
\hline Internet Content Manager & 1 & 5,3 \\
\hline Technicien & 1 & 5,3 \\
\hline Web Developper & 1 & 5,3 \\
\hline Webpublisher & 1 & 5,3 \\
\hline Insgesamt & 19 & 100,0 \\
\hline
\end{tabular}

\subsubsection{Wohnsitz der Informanten}

Die Einteilung Frankreichs erfolgte analog zur Verteilung der internen französischen Vorwahlen für die einzelnen Zonen. Es gibt sechs verschiedene Vorwahlen für sechs verschiedene Zonen: „1“ für den Großraum Paris, „2“ für den Nordwesten, „,“ für den Nordosten, „4“ für den Südosten, „5“ für den Südwesten und „6“ für die überseeischen französischen Gebiete. Die Regionen Frankreichs verteilen sich wie folgt auf die sechs Zonen:

1. Paris, Ile de France,

2. Nordwesten: Bretagne, Basse-normandie, Centre, Haute-normandie, Pays de la Loire,

3. Nordosten: Alsace, Bourgogne, Champagne-Ardenne, Franche-Comté, Lorraine, nord-Pas-de-Calais, Picardie,

4. Südosten: Auvergne, Corse, Languedoc-Roussillon, Provence-Alpes-Côte d'Azur, Rhône-Alpes,

5. Südwesten: Aquitaine, Limousin, Midi-Pyrénées, Poitou-Charentes, 
6. DOM-TOM: Guadeloupe, Guyane, Martinique, Réunion, Polynésie Française, Nouvelle Calédonie, Wallis \& Futuna.

Abb. 229: Wohnsitz der französischen Informanten

\begin{tabular}{|l|r|r|}
\hline Kategorie & $\begin{array}{l}\text { Absolute } \\
\text { Häufigkeit }\end{array}$ & $\begin{array}{l}\text { Prozentuale } \\
\text { Häufigkeit }\end{array}$ \\
\hline Paris & 69 & 55,6 \\
\hline Nordwesten & 13 & 10,4 \\
\hline Nordosten & 20 & 16,1 \\
\hline Südosten & 16 & 12,9 \\
\hline Südwesten & 0 & 0,0 \\
\hline DOM-TOM & 0 & 0,0 \\
\hline Anderes & 6 & 4,8 \\
\hline Finnland (2) & & \\
\hline Deutschland (1) & & \\
\hline Québec (1) & & \\
\hline wroßbritannien (1) & & 0,0 \\
\hline Keine Angabe & & 100,0 \\
\hline Insgesamt
\end{tabular}

Für Belgien wurden als Kategorien Brüssel sowie die fünf französischsprachigen Provinzen (Wallonien) zur Auswahl gestellt:

1. Bruxelles,

2. Liège,

3. Namur,

4. Hainaut,

5. Luxemburg,

6. Brabant. 
Abb. 230: Wohnsitz der belgischen Informanten

\begin{tabular}{|l|r|r|}
\hline Kategorie & $\begin{array}{l}\text { Absolute } \\
\text { Häufigkeit }\end{array}$ & $\begin{array}{l}\text { Prozentuale } \\
\text { Häufigkeit }\end{array}$ \\
\hline Brüssel & 8 & 47,1 \\
\hline Lüttich & 1 & 5,9 \\
\hline Namur & 1 & 5,9 \\
\hline Hainaut & 2 & 11,7 \\
\hline Luxemburg & 1 & 5,9 \\
\hline Brabant & 1 & 5,9 \\
\hline Andere & 3 & 17,6 \\
\hline Gand (Flandern) (1) & & \\
\hline Marchin (zwischen & & \\
\hline Namur und Lüttich) (1) & & \\
Flämisch-Brabant (1) & & 100,0 \\
\hline Insgesamt & 17 & \\
\hline
\end{tabular}

Die französischsprachige Schweiz wurde entsprechend in die französischsprachigen Kantone unterteilt:

1. Berne,

2. Fribourg,

3. Genève,

4. Jura,

5. Neuchâtel,

6. Valais,

7. Vaud.

Abb. 231: Wohnsitz der schweizerischen Informanten

\begin{tabular}{|l|r|r|}
\hline Kategorie & $\begin{array}{l}\text { Absolute } \\
\text { Häufigkeit }\end{array}$ & $\begin{array}{l}\text { Prozentuale } \\
\text { Häufigkeit }\end{array}$ \\
\hline Bern & 0 & 0,0 \\
\hline Freiburg & 0 & 0,0 \\
\hline Genf & 10 & 52,6 \\
\hline Jura & 1 & 5,3 \\
\hline Neuenburg & 2 & 10,5 \\
\hline Wallis & 1 & 5,3 \\
\hline Waadt & 5 & 26,3 \\
\hline Insgesamt & 19 & 100,0 \\
\hline
\end{tabular}




\subsection{Textantworten (2. Fragebogenmodul)}

Die zitierten Antworten und Kommentare sind orthografisch und grammatisch an die Standardsprache angepasst worden. Mitunter wird die korrekte syntaktische Form in eckigen Klammern vermerkt, um nicht zu sehr in den ursprünglichen, oft sehr informellen Charakter des Textes einzugreifen. Ebenso befinden sich mitunter in den eckigen Klammern inhaltliche Ergänzungen oder die Auflösung von Akronymen, um die Aussagen verständlicher zu machen. Werden internetspezifische Akronyme nicht aufgelöst, sind sie im Abkürzungsverzeichnis und/oder Glossar zu finden.

Vielfach werden die Aussagen mit Beispielen für französische oder englische Terminologie illustriert. In diesen Fällen wurden die Termini einheitlich kursiv gesetzt, um sie vom restlichen Text hervorzuheben.

\subsubsection{Fragen 3, 10, 17, 24, 31 und 38 nach dem Bedeutungsunter- schied}

Die Textantworten sind im Folgenden in alphabetischer Reihenfolge aufgeführt. Die den jeweiligen Antworten vorangestellte Ziffer-Zahlen-Kombination entspricht den in den Tabellen der Kapitel 9, 10 und 11 aufgeführten Ziffer-ZahlenKombinationen.

\subsubsection{Frankreich}

15.5.1.1.1 Frage 3: Bedeutungsunterschiede zwischen courrier électronique / message électronique / mél / courriel / messagerie électronique / e-mail / mail (Frankreich)

F1.1 C'est l'effet et la cause. Par exemple: un mail est envoyé grâce à une messagerie électronique.

F1.2 Certains, comme messagerie électronique, se rapportent plus au processus qu'au message lui-même. J'ai plutôt vu lettre électronique employé comme une diffusion d'un message destiné à plusieurs personnes sans attente de réponse.

F1.3 Certains désignent le message (en tant qu'objet), d'autres désignent un système ou un principe de fonctionnement. Enfin, certains ne veulent rien dire.

F1.4 Certains désignent un service (messagerie) alors que d'autres désignent l'élément du service, à savoir le courrier (lettre) électronique en lui-même (le document).

F1.5 Certains termes désignent les messages (le contenu). D’autres termes désignent les messages (au sens large). Enfin, d'autres encore désignent les moyens de s'échanger des messages (les serveurs et le réseau).

F1.6 Courrier électronique et les autres indiquent un message, messagerie indique un outil. 


\section{F1.7 Courrier électronique: E-mail}

Message électronique : Traduction de E-Mail en français

Mél: contraction de Message Électronique

Courriel: francisation de E-mail

Messagerie électronique : Système (serveurs de messageries, réseau et logiciels clients de messagerie) dédié à l'expédition et la réception de messages électroniques

E-mail: Courrier électronique

Mail: courrier en anglais

En conclusion, seule messagerie électronique comporte un sens de nature différente. Tous les autres termes peuvent être apparentés.

F1.8 Courrier électronique $=$ mél $=$ courriel $=e-$ mail $=$ mail

Message électronique : plus général (ICQ ...)

Messagerie électronique : le logiciel qui gère ça.

F1.9 Courrier électronique, message électronique, mél, courriel, e-mail et mail sont des [synonymes] (à mettre en relation avec une lettre classique).

Messagerie électronique est le service de façon plus générale (à mettre en relation avec le courrier).

On dit (selon moi) *un* courrier électronique, mais *la* messagerie électronique.

F1.10 Différence entre message (e-mai) et service (messagerie électronique).

F1.11 Email = electronic mail

Mail $=$ 'slow' mail

F1.12 Entre courrier et message : on ne peut pas considérer l'envoi d'un email (ou courrier) comme l'envoi d'un message (= sous-entendant de la messagerie instantanée comme ICQ, MSN ...).

F1.13 Il eût été utile de rappeler les différents mots sur cette page. Je ne me rappelle que de messagerie électronique et de courrier électronique. Le premier désigne l'intégralité du système permettant l'échange de courriels (qui est, à mon sens, le meilleur mot francophone pour e-maì) alors que le second ne désigne qu'un unique message.

F1.14 L'expression messagerie électronique est un intrus. En effet, un message électronique n'est pas la messagerie électronique. Une lettre n'est pas une boîte aux lettres ...

F1.15 La messagerie électronique contient des emails.

F1.16 La messagerie électronique concerne à mon sens toute l'infrastructure (client/serveur/protocoles d'achange) tandis que le reste exprime le message + adresse du correspondant. 
F1.17 La messagerie électronique désigne l'application en général. Les autres mots peuvent aussi désigner un message donné.

F1.18 La messagerie électronique est un service. Un email (ou mél ou courriel, etc. ...) est ce que l'on pourrait considérer comme l'objet de ce service.

F1.19 La messagerie électronique, contrairement à tous les autres mots, désigne à mon sens l'ensemble du système qui permet de recevoir et d'envoyer des mails.

F1.20 La notion de message électronique est plus vaste que l'email, il peut s'agir de messages envoyés par messagerie instantanée de type ICQ, MSN ou AIM.

F1.21 La notion de messagerie électronique concerne plus, à mon sens, les éléments logiciels et/ou matériels permettant l'échange de e-mail/courriel.

F1.22 Les messages électroniques peuvent désigner également les messages postés sur USENET. Le courrier faisant plus référence à ce qui va arriver dans la boîte aux lettres. Et pour être exact, mail partout sauf en France désigne le snail mail : c'est-àdire le bon vieux courrier timbré. Et malgré la tendance que l'on a à écrire mail, email serait plus correct.

F1.23 Mail: courrier 'classique'.

Messagerie électronique: terme générique qui ne désigne pas le message en lui-même.

Les autres mots sont synonymes.

F1.24 Messagerie électronique $=$ Outlook.

Message électronique, e-mail, ... = le message en lui-même.

F1.25 Message électronique $=$ e-mail $=$ mail $=\ldots=$ le message (toutes les infos - objet, destinataire, corps, ...).

Messagerie électronique $=$ le principe.

F1.26 Message électronique à mon sens est plus large. Il ne fonctionne pas forcément sur le même protocole.

Mail, mél, e-mail, courrier électronique, courriel sont synonymes en ce sens qu'ils impliquent tous le protocole SMTP.

Messagerie électronique implique plus l'infrastructure ; le système de transport et le serveur de messagerie.

F1.27 Message et messagerie ne veulent pas dire la même chose !

F1.28 Message électronique est plus général que les autres termes. 
F1.29 Message électronique peut s'appliquer à n'importe quel autre protocole capable de permettre la diffusion d'une information (un beeper de poche délivre un message électronique). Disons que c'est un terme extrêmement générique comparé à courrier électronique, ce dernier précisant bien de quoi on parle.

F1.30 Message, messagerie électronique ... concernent plus particulièrement le réseau interne d'une entreprise.

F1.31 Message n'est pas synonyme de messagerie!

F1.32 Messagerie correspond à l'endroit où sont stockés les messages.

F1.33 Messagerie électronique = l'ensemble du système (logiciels, protocoles, paramètres, données ...).

Message électronique (ou EMail) = un élément ponctuel de cet ensemble.

F1.34 Messagerie électronique : c'est l'outil pour écrire le mail. Le mail, lui, est le courrier en lui-même.

F1.35 Messagerie électronique : il s'agit de l'application qui gère les messages électroniques.

F1.36 Messagerie électronique : signifie le système de courrier électronique en général, et non UN courrier en particulier, contrairement aux autres termes.

F1.37 Messagerie électronique : Système qui permet l'envoi et la réception de mails. Je n’ai jamais entendu quelqu'un dire « je vais envoyer une messagerie électronique ».

F1.38 Messagerie électronique $=$ outil de messagerie qui génère des messages. Les autres sont des messages générés par un tel outil.

F1.39 Messagerie électronique $=$ système de messagerie .

F1.40 Messagerie électronique correspond plus à une boîte aux lettres.

Message électronique, mail, ... correspond plus au courrier.

F1.41 Messagerie électronique désigne l'outil, la fonction. Le reste désigne le courrier lui-même.

F1.42 Messagerie électronique désigne plutôt un ensemble des messages électroniques / méls / e-mails / mails / courriels ...

F1.43 Messagerie électronique est l'instrument ... Il s'agit du support ou du logiciel de messagerie ... 
F1.44 Messagerie électronique est le système de gestion des émails, pas l'email lui-même.

F1.45 Messagerie électronique n'a pour moi rien à faire dans cette catégorie (c'est un logiciel pour envoyer des email, pas un email).

F1.46 Messagerie électronique ne s'applique pas à un message mais au serveur chargé de réceptionner les messages. Mél ne peut en aucun cas être utilisé pour désigner un message. Il ne peut être utilisé qu'en tant qu'abréviation dans un document pour désigner l'adresse électronique d'une personne. Les autres termes sont plus ou moins synonymes.

F1.47 Messagerie électronique : 'lieu' qui recoit les e-mails.

Mél, email, mail: le message lui-même.

F1.48 On peut envoyer un message électronique, e-mail, courriel, mail, mél sur une messagerie électronique et non le contraire par exemple ...

F1.49 Par exemple, mail veut dire simplement courrier alors que e-mail signifie courrier électronique.

F1.50 Pour consulter mes mails/messages électroniques/mél/etc., j’utilise ma messagerie électronique. Pour moi, la messagerie électronique (ou logiciel de messagerie) désigne donc le logiciel de rapatriement des messages, tandis que les autres termes désignent le courrier lui-même. À noter que mél et courriel se trouvent de plus en plus dans les magazines et que leur utilisation, qui m'horripilait il y a encore peu de temps, se développe.

F1.51 Selon moi, la messagerie électronique, c'est là où on envoie les courriers électroniques, messages électroniques, courriels, e-mails et mails.

F1.52 Tous pareils, sauf messagerie électronique qui désigne la fonctionnalité et non un message ou un courrier en particulier.

F1.53 Un courrier électronique -> mail SMTP.

Messagerie électronique -> possibilité d'autres choses ...

F1.54 Un message et une messagerie, ce n'est pas la même chose.

F1.55 Un message n'est pas la même chose qu'une messagerie ...

F1.56 Une adresse de messagerie électronique $=e$-mail, mail, etc.

F1.57 Une messagerie contient des courriers mais n'en est pas un. 
F1.58 Une messagerie électronique est plutôt comprise dans le sens 'logiciel de messagerie' ou alors 'boîte aux lettres'. Dans ce sens alors elle contient des messages électroniques.

F1.59 Une messagerie électronique est pour moi un conteneur qui contient le reste. Ex : dans ma messagerie électronique, je stocke/reçois des emails.

F1.60 Une messagerie est differente d'un message.

\subsection{Frage 10: Bedeutungsunterschiede zwischen page d'accueil / homepage} (Frankreich)

F2.1 Dans homepage, je dirais qu'il y a la notion de 'page perso' et pas uniquement de 'page d'accueil/sommaire'5.

F2.2 En français, l'utilisation de homepage correspond plus souvent à une page personnelle, bien qu'en anglais, la page d'accueil soit appellée homepage.

F2.3 Home page a le sens supplémentaire de 'page personnelle' d'un utilisateur.

F2.4 Home page désigne plus un site personnel entier, alors que page d'accueil désigne plus la premiere page d'un site.

F2.5 Home page se définit comme 'page maison', dans le sens 'site personnel', alors que la page d'accueil est la page de présentation (principale) du site.

F2.6 Home page signifie pour moi 'page personnelle', pas 'page d'introduction/accueil'.

F2.7 Homepage : page perso dans le sens 'site perso'. Page d'accueil: l'index que l'on voit lorsque l'on arrive normalement sur le site, la page principale.

F2.8 Homepage $=$ page perso. Page d'accueil $=$ première page d'un site Web.

F2.9 J'ai la sensation que homepage est plus réservé aux particuliers ... Je me trompe peut-être.

F2.10 Je désigne une homepage comme étant plus une page personnelle tandis qu'une page d'accueil est plutôt générique et impersonnelle.

F2.11 Je dirais que homepage correspond plus à une page de démarrage qu'à une page d'accueil.

\footnotetext{
${ }^{5}$ Page perso ist die weit verbreitete umgangssprachliche Abkürzung für page personnelle.
} 
F2.12 Je traduirais home page par page personnelle (site perso), page d'acceuil n'étant que la première page d'un site (index).

F2.13 La homepage est l'endroit où l'individu lambda expose au monde ébahi sa vie passionante, alors que la page d'accueil (index) permet d'accéder aux principales rubriques d'un site.

F2.14 Le mot homepage est plus utilisé pour une page personnelle alors qu'une page d'accueil concerne tous les sites y compris commerciaux.

F2.15 Page d'acceuil: premiere page d'un site (index.html).

Homepage : page personnelle d'un internaute.

F2.16 - Page d'accueil : première page d'un site web, celle regroupant tous les liens internes à un site, et éventuellement un texte d'accueil.

- Homepage : connotation 'page personnelle', a plus un sens de type de 'site' (my homepage on wich are photos of my pets and my family). => par opposition à un site commercial, de réalisation professionnelle. D'ailleurs, le mot home de homepage veut tout dire ...

F2.17 Page d'accueil = page par défaut du navigateur.

Homepage $=$ page perso.

F2.18 Page d'accueil différente de page d'introduction car la page d'accueil est la première pour accéder, alors que la page d'introduction est la première page d'un thème à l'intérieur d'un site.

F2.19 Page d'accenil est la première page d'un site. Alors que homepage est le nom d'un site fait par un particulier.

F2.20 Page d'accueil est la première page du site, home page est une page personelle (style cv [curriculum vitae], ou familial).

F2.21 Pour moi, le terme d'homepage fais plus référence à une page personnelle, page d'accueil fait plus professionnel.

F2.22 Pour moi, home page = page personnelle. C'est-à-dire 'page d'accueil d'un site personnel', voire le site personnel tout entier.

F2.23 Pour moi, page d'accueil est la première page d'un site. Une homepage est une page ou un site qui raconte l'histoire de ma vie, de mon chat et de ma famille;)

F2.24 Une homepage a, pour moi, un sens plus personnel. Je parlerais de page d'accueil d'un projet et de la homepage d'une connaissance. 
F2.25 Une page d'accueil peut être sur n'importe quel site. Homepage : site personnel uniquement.

15.5.1.1.3 Frage 17: Bedeutungsunterschiede zwischen toile d'araignée mondiale / toile mondiale / toile / T.A.M. / web / World Wide Web (Frankreich)

F3.1 Il y a, il me semble, une erreur extrêmement courante :

- La toile ou ses dérivés (toile mondiale, ...), désignent bien l'organisation physique du réseau qu'utilise internet, en forme de toile.

- Le $W W W$ (World Wide $W e b$ ) désigne quant à lui UNE ressource de la toile : le World Wide Web. Le web, www ... n'est qu'un élément (web, ftp, mail, telnet, news, gopher, sont tant de services différents utilisant l'internet ...).

F3.2 Le web (et d'autre mots que j'ai oubliés) désigne un type d'accès spécifique (via les protocoles http et https) alors que la toile (et d'autres mots équivalents) désigne Internet (un réseau de réseaux d'ordinateurs).

F3.3 Le web et le world wide web désignent [...] le réseau que représente internet mais en le limitant à un support (le protocole http). Alors que la toile désigne plus le réseau internet au sens large du terme sans pour autant le restreindre à une utilisation.

F3.4 Le web et le world wide web sont souvent assimilés à la simple consultation de page reposant sur le protocole http, c'est l'usage et le contexte qui décident l'emploi ... Réseau mondial implique la notion d'interconnexion de machines reposant sur l'IP. On peut dire que le wmw (couche applicative) est au-dessus d'internet (IP).

F3.5 Le web ne contient que ce qui à rapport avec http. Le ftp et compagnie, ce n'est pas la même chose. Cela dit, la différence n'est pas très nette non plus.

F3.6 Les termes Web et World Wide Web sont spécifiques au protocole http alors que les autres désignent le réseaux interconnectant les machines.

F3.7 Toile d'araignée mondiale: traduction littérale de $W W W$.

Toile mondiale : raccourci de toile d'araignée mondiale.

Toile : plusieurs sens (dont celui de peinture artistique).

T.A.M. : connais pas.

Web: toile d'araignée en anglais.

World Wide Web : réseau de sites accessibles par le protocole http sur Internet.

La connotation du mot web sonne faux une fois traduit en français.

F3.8 Toile mondiale et dérivés : Internet.

World Wide $W e b$ : le $W e b$, la partie d'Internet accessible par le protocole HTTP, avec un navigateur, etc. ... 
F3.9 Un réseau n'est pas forcément le $W W W$, et le $W W W$ est un réseau parmi d'autres. D'autre part, toile d'araignée est une expression imagée, alors que la locution réseau mondial est plus explicite.

F3.10 Web = une partie SEULEMENT de Internet.

F3.11 Web est un protocole, toile est un réseau.

F3.12 Web et world wide web ne caractérisent pas un réseau mais un protocole (http).

F3.13 Web signifie tout ce qui touche au protocole HTTP (pour moi) tandis que World Wide Web fait plutôt référence à l'ensemble des services. C'est une image imprécise de ma part, j'en suis conscient.

\subsection{Frage 24: Bedeutungsunterschiede zwischen causette / bavardage / chat} (Frankreich)

F4.1 Bavardage et causette ne signifient pas qu'on parle à distance. Le terme anglais non plus d'ailleurs mais c'est peut-être pour ça qu'il y a besoin d'un nouveau mot : chat.

F4.2 Bavardage et causette ne sont pour moi en rien associés à quoi que ce soit sur le Net!!! (jamais rencontrés en 8 ans de travail professionnel dans le secteur et de surf intensif)

F4.3 Bavardage n’est pas chat. Chat est beaucoup plus précis.

F4.4 Causette, bavardage : discussion, quelque soit le contexte.

Chat : discussion sur Internet.

F4.5 Causette : dans le monde réel ; chat: conversation virtuelle, généralement sur le web ou IRC, proche du temps réel ; bavardage : dans le monde réel, ou éventuellement une conversation par e-mail ou sur les groupes de discussion.

F4.6 Causette est une petite discussion entre des personnes qui se voient vraiment. Bavardage est une petite discussion qui ne doit pas avoir lieu entre des personnes qui se voient vraiment. Chat est une discussion en direct sur le web.

F4.7 Causette et bavardage pour moi n’ont rien de spécifique au web, ils sont utilisés pour qualifier une conversation à la cafet [caféteria], mais pas sur internet. Alors que le chat n'existe que sur le net, et permet de converser avec de complets étrangers sans s'en soucier.

F4.8 Causette et bavardage sont plus susceptibles d'être associés à d'autres moyens de communication (telephone, e-mail, etc.). 
F4.9 Causette s'utilise dans un dialogue où l'on voit les personnes devant soi.

F4.10 Chat correctement prononcé dans une conversation en français identifie immédiatement le contexte électronique, alors que bavardage ...

F4.11 Chat est électronique, les autres pas obligatoirement.

F4.12 Conversation électronique est plus large et n'implique pas forcément la notion d'interactivité (même si le terme conversation l'est plus que conversation [électronique]). On peut par exemple converser avec des personnes sur usenet (newsgroup, forum de discussion).

F4.13 Jamais utilisé causette dans le contexte Internet, par contre, pour moi qui participe à un groupe USENET de bavardage, le chat (IRC) est très différent. Le bavardage sur USENET est asynchrone et le chat synchrone.

F4.14 Je n'ai jamais entendu les autres [causette et bavardage], et ils me paraissent ambigus.

F4.15 Je ne connais que chat!

F4.16 La version française des mots rentre plus dans le cadre d'une conversation courante (dans la rue, pas sur internet).

F4.17 Le chat est plus complet, permet plus qu'une discussion.

F4.18 Les termes français (causette, bavardage) ne dénotent pas pour moi une conversation écrite.

F4.19 Seul chat est typique pour internet, les autres peuvent être employés dans un autre contexte.

15.5.1.1.5 Frage 31: Bedeutungsunterschiede zwischen pirate / cracker (Frankreich) Cracker $=$ pirate informatique. Pirate $=$ sens plus large.

\subsubsection{Belgien}

15.5.1.2.1 Frage 3: Bedeutungsunterschiede zwischen courrier électronique / message électronique / mél / courriel / messagerie électronique / e-mail / mail (Belgien)

B1.1 Ben, cela reflète le type de personne qui les utilise, exemple : celui qui dira mél sera une personne qui ne connaît pas beaucoup l'informatique et/ou qui vient de débarquer dans ce monde, tandis que les personnes qui sont dans ce domaine tout le temps, vont utiliser une grande partie du temps les termes anglais. Enfin, je peux me tromper évidemment. 
B1.2 Ils sont tous équivalents sauf messagerie électronique qui est l'outil en général.

B1.3 Je comprends message électronique au sens large. Je comprends e-mail, courriel et mél comme étant des messages électroniques échangé via internet et le protocole SMTP. Je crois savoir que courriel est un terme canadien alors que mél est français (voir académie).

B1.4 La différence se situe en langue anglaise, il est vrai qu'en français, ils sont tous utilisés dans le même sens ... Mais pour moi : mail $=$ courrier et $e$-mail $=$ courrier électronique. Différent donc.

B1.5 Le mail/ email est le document qu'on envoie, tandis que la messagerie électronique est l'outil qui permet d'envoyer ce mail.

B1.6 Messagerie électronique : le système de transmission du courrier ou du message électronique. Le courrier électronique (mél, email, courriel) sont les documents électroniques émis dans le cadre de l'utilisation d'un logiciel de courrier; tandis que le message électronique me semble plus adapté au document électronique transmis dans le cadre de la participation au forum (ou usenet). À moins que je ne me trompe ... [...]

B1.7 Messagerie électronique reprend le système permettant d'envoyer un message électronique, un mail, un courriel...

B1.8 Tous sont synonymes exceptés pour messagerie électronique qui a un sens plus large.

\subsection{Frage 10: Bedeutungsunterschiede zwischen page d'accueil / homepage} (Belgien)

B2.1 À mon humble avis, homepage fait plus souvent référence au site entier. Page d'accueil désigne la première page du site. On dira : "va voir ma homepage » pour dire « va voir mon site ». Par contre, on dira «va voir la page d'accueil de mon site » mais plus rarement.

B2.2 Ici par exemple, la définition varie légèrement. Une page d'accueil peut être une page d'accueil pour n'importe quoi (disons un logiciel par exemple) tandis que homepage, cela a plus le sens d'une page personelle d'un utilisateur.

15.5.1.2.3 Frage 17: Bedeutungsunterschiede zwischen toile d'araignée mondiale / toile mondiale / toile / T.A.M. / web / World Wide Web (Belgien)

B3.1 La toile ou la toile d'araignée sont une analogie à la structure du réseau internet. 
B3.2 Le web et le world wide web ne concernent que la partie la plus récente d'Internet. La toile se réfère plutôt à une interconnection de réseaux utilisant aussi bien FTP que Gopher, Usenet, Wais, ... qu'Internet.

B3.3 Même raison que précédemment, ce sont des termes que certaines personnes qui ne sont pas dans 'le milieu' utilisent, mais qui pour moi ne veulent pas dire la même chose ... bon, maintenant, comme la justification est chaque fois la même, je vais mettre cfr précédent:)

B3.4 Pourquoi toile d'araignée? Je ne vois de fils de soie nulle part.

15.5.1.2.4 Frage 24: Bedeutungsunterschiede zwischen causette / bavardage / chat (Belgien)

B4.1 Cfr précédent.

B4.2 Pour moi, seul le mot chat fait référence à l'IRC et aux conversations électroniques. Bien entendu, je ne suis pas Français, :-) Les petits Belges sont plus anglophiles.

\subsubsection{Schweiz.}

15.5.1.3.1 Frage 3: Bedeutungsunterschiede zwischen courrier électronique / message électronique / mél / courriel / messagerie électronique / e-mail / mail (Schweiz)

S1.1 Courrier électronique, message électronique, mél, courriel, e-mail et mail : = le message en lui même.

Messagerie électronique : Le logiciel servant à envoyer des messages.

S1.2 Message électronique désigne la 'lettre' qui est envoyée. Messagerie électronique désigne le système de 'postage'.

S1.3 Message électronique peut être un message style ICQ et non un e-mail.

\subsection{Frage 10: Bedeutungsunterschiede zwischen page d'accueil / homepage} (Schweiz)

S2.1 Homepage peut signifier l'ensemble du site internet personnel (et non un site commercial ou industriel) tandis que page d'accueil est la page de bienvenue (en principe la première page du site).

S2.2 Il me semble que page d'accueil est la première page d'un site, alors que j'utiliserais homepage pour parler d'un site de manière plus générale (« regarde sur ma homepage », alors que l'information ne se trouve peut-être pas sur la première page du site en question). 
S2.3 La page d'accueil est la première page d'un site. Il en va de même pour la homepage. Mais en parlant de home page on parle aussi de site personnel.

S2.4 Page d'accueil = page d'introduction.

Homepage $=$ le site en entier d'une personne amatrice.

S2.5 Page d'accueil = page de démarrage d'un site.

Homepage $=$ page privée, site personnel.

15.5.1.3.3 Frage 24: Bedeutungsunterschiede zwischen causette / bavardage / chat (Schweiz)

S4.1 Causette : petite conversation

Bavardage: conversation sans importance

Chat : conversation par voie électronique.

S4.2 Chat implique un dialogue en direct. Causette peut-être un échange de mails.

15.5.1.3.4 Frage 31: Bedeutungsunterschiede zwischen pirate / cracker (Schweiz) Un pirate n'est pas forcément lié à Internet (pirate maritime, pirate de l'air, etc.). Un cracker indique précisément qu'il s'agit d'un pirate informatique.

\subsubsection{Kritik zur aktuellen Sprachpolitik (3. Fragebogenmodul)}

Die Kommentare sind in der Reihenfolge des Eintreffens der Fragebögen aufgeführt. Die den einzelnen Kommentaren vorangestellte Ziffer-Zahlen-Kombination entspricht den in den Tabellen der Kapitel 9, 10 und 11 aufgeführten ZifferZahlen-Kombinationen.

\subsubsection{Frankreich}

F1: Elle [la terminologie] arrive beaucoup trop souvent TROP TARD, après que les habitudes aient largement consacré l'usage de mots ou expressions courantes. De plus, elle génère des néologismes qui frisent souvent le ridicule (mél, cédérom, ...). Inversement, quand elle est suffisamment à l'avant-garde de la technique, et cohérente avec l'existant, elle peut donner de très bons résultats (p.ex. le mot logiciel, adopté sans problème par les communautés francophones, en particulier grâce à l'existence de son antonyme matériel).

De plus, elle doit faciliter la tâche des utilisateurs. Si un mot anglais, court, universellement compris et prononcé par tout le monde, existe déjà, à quoi bon se compliquer la vie en créant un nouveau terme qui ne sera compris et utilisé que par quelques pédants.

F2: Le Web est un système à l'échelle mondiale et il me semble que la communication doit se faire dans un langage compris de tous, tout en laissant à chaque nation la possibilité de l'adapter à ses besoins propres. 
F3: Elle doit sérieusement prendre en compte l'origine et la finalité d'un mot avant de vouloir le franciser, car vouloir le faire pour un mot issu de l'informatique, alors que c'est les États-Unis qui tiennent les racines, est vain et ridicule.

F4: Ce n'est pas forcément une mauvaise chose, mais elle peut facilement sombrer dans le ridicule.

F5: Souhaitée, mais sans en faire un cheval de bataille !

F6: La politique linguistique (loi Toubon), bien que partie d'un bon sentiment et animé d'une volonté légitime de préserver un français correct, n'a d'interêt que si la langue française est entretenue hors des frontières.

Il fut une époque où le français était la langue privilégiée dans la haute société ... S'il était possible d'introduire plus massivement des 'francismes' dans la langue anglaise, on pourrait sans nul doute sauver ce qui reste de notre pauvre babillage, hélas déjà bien éraflé par une éducation toujours plus destructrive ...

F7: Bien pour les notions déjà existantes, ridicules et isolationniste lorsqu'il s'agit de nouvelles technologies pour lesquelles toutes les langues doivent créer de nouveaux mots.

F8: Je trouve ça contraire à la volonté de l'ouverture sur le monde. En faisant ça, la France ne fait que se fermer.

F9: C'est une nécessité, mais elle doit rester souple et intelligente, ne pas devenir l'obsession de banir du français tout ce qui est « estranger».

F10: Je vote [OUI] aux processus darwiniens pour la sélection des néologismes liés aux nouveautés ...

F11: Mise en place par des personnes ne connaissant absolument pas les domaines dont ils veulent déterminer la manière de communiquer.

F12: Il est inutile à l'heure de la mondialisation de chercher des termes équivalents en français alors que tout le monde utilise les termes anglais et que finalement, tout le monde se comprend ainsi. Par contre, ça me parait intéressant de développer pour des termes peu usités mais qui vont le devenir.

F13: Ça me fait énormément rire !!! Les termes anglais sont déjà entrés dans le langage courant français et il faudrait maintenant changer de manière de parler ?? S'il doit y avoir une traduction française des termes informatiques, elle doit être faite avant que le terme anglais [ne] soit passé dans le language courant et non pas après par pseudo-nationalisme à 2 euros!! 
F14: Très et trop laborieuse. Utiliser par principe le mot étranger me semble aussi stupide que d'utiliser par principe ou zèle une terminologie française douteuse.

F15: Inutile et même souvent ridicule à cause des termes choisis.

F16: Ridicule pour les termes informatiques.

F17: La plupart des termes proposés à la traduction sont ridicules. Par exemple, cédérom ne veut rien dire alors que CDROM veut dire compact disc read only memory ...

F18: Trop peu connue, et souvent trop en retard par rapport aux avancées technologiques ... Et puis, pourquoi chercher à innover quand d'autres ont déjà créé : pourquoi vouloir imposer mél ou navigateur quand les Québécois utilisent les très jolis courriel et butineur (ou fureteur)?

F19: Autant il est nécéssaire de ne pas laisser l'anglais s'introduire dans toutes les phrases, autant il est ridicule d'inventer des mots (cédérom, mél) pour s'en protéger.

F20: Beaucoup de termes sont assez mal choisis. Mél est maladroit alors que le courriel québécois était beaucoup plus élégant. De même, la traduction stricte de $W e b$ en toile n'est pas très heureuse. Ces créations de termes donnent l'impression d'avoir été réalisées à la va-vite sans prendre en compte la réalité du terrain ...

F21: Aux résultats variés ! Certaines traductions ont un grand succès, voire n'ont pas d'équivalent en anglais : logiciel, ordinateur ... D'autres sont un échec. Difficile de savoir pourquoi!

F22: J'aime bien utiliser le français pour m'exprimer au sujet d'Internet et des techniques du réseau (et pas technologies). Mais ce n'est pas toujours évident, ni toujours gracieux. De plus, utiliser le mot anglais permet à des francophones de comprendre que je parle d'informatique. Exemple, quand j'utilise le mot log à la place de journal système. Les gens n'ont pas besoin d'attendre que j'ai prononcé le mot système ou de se poser des questions quand je dis journal, ils ont tout de suite compris de quoi je parle quand je dis log. Ça facilite la discussion et c'est pour cela que c'est utilisé, malheureusement.

F23: Nos chers académiciens manquent d'humour et de logique. Les termes anglais techniques comme rail, wagon, tunnel ou packed boat se sont imposés sans qu'on y trouve tellement à redire. L'essentiel, à mon humble avis, est de franciser l'orthographe quand elle est illisible ou trop complexe (baby -> bébé, packed boat -> paquebot, roasted beef -> rosbiff. Dans «l'ivresse des providers » de Catherine Dufour, on trouve nimel.

On voit parfois écrit nionzes au lieu de news. Je parie que ces termes farfelus ont plus de chance de s'imposer que les propositions officielles. 
F24: Je suis d'accord pour défendre la langue française, mais pas au détriment de la signification des mots. Remplacer mail par mél n'apporte rien de plus et au contraire élimine l'étymologie première. Idem pour bug et bogue. Je pense que nous devrions nous inspirer des Québécois qui n'essayent pas de 'singer' la prononciation anglaise mais de proposer un nouveau terme français ayant une signification ou un lien direct avec le sujet. Je préfère de loin parler de courriel plutôt que de mél. On y retrouve aisément les notions de message électronique.

F25: Les termes «inventés » par l'administration n'ont pas de légitimité ce qui ne permet par leur utilisation.

F26: Je trouve que si certains termes sont mieux, la plupart du temps la méthode de transporter l'anglais presque littéralement est idiote.

F27: [...] Je ne vais pas dire que je suis un fervent défenseur de la langue française, étant le premier à utiliser des termes anglais lorsque je les trouve mieux adaptés ou plus compréhensibles, mais je suis un amoureux de ma langue maternelle dès lors qu'elle sort du domaine informatique! Je ne suis certainement pas le mieux placé pour en juger, mais il me semble que le vocabulaire nouveau ne peut trouver sa place que s'il est adapté et répond à certains critères d'esthétisme. Pour ma part, les mots comme mél ne me donnent pas envie de les employer, alors qu'il m'arrive de prendre plaisir à passer pour un extraterrestre en employant du vocabulaire inusité depuis 2 siècles : peut-être est-ce là une façon de me démarquer de la génération $\mathrm{McDo}$ lorsqu'un malin me parle un peu trop 'hi-tech'. Et puis passé un petit temps d'adaptation, ça ne choque plus et les gens rentrent dans le jeu sans même s'en apercevoir, pour peu que le terme soit adapté (imagé, pour qu'ils puissent se rappeler de sa signification) et agréable à entendre. À mon humble avis, il suffirait d'un peu d'imagination pour que la langue anglaise perde de son attrait. Mais j'avoue que ce ne sont certainement pas l'Académie Française et les lois Toubon qui m’imposeront leur vocabulaire tant que celui-ci restera aussi insipide [...].

F28: Je trouve inutile de vouloir localiser certains termes techniques. Leur définition au sein du grand public n'apporte pas grand chose, et le choc et la confusion entrainée lors de l'arrivée de ces gens sur l'internet ne peut que gêner ces gens ou les rendre confus. Par ailleurs, l'internet nivelle les langages. Le simple fait de regarder une conversation IRC entre jeunes entre 15 et 25 ans montre bien à quelle vitesse l'évolution de la langue «technologique » s'oriente vers l'anglais. Ceci dit pour qu'une langue soit vivante il faut que ses utilisateurs en soient les maitres et une francisation des termes anglais par les utilisateurs eux-mêmes (sans commission qui tranche) est une bonne chose et toute imposition de vocabulaire par une instance étatique est vaine. C'est pour cela que les directives «Toubon» sont inadéquates. 
F29: Son utilité et sa visibilité seraient améliorées si elle ne se calquait pas directement sur l'anglais. Elle ressemble aujourd'hui plus à une médiocre imitation de l'anglais qu'à du français. Le Québec a fait des choix plus imaginatifs et heureux avec des mots comme courriel, par exemple. Pourquoi avoir une terminologie française s'il ne doit s'agir que d'un anglais mal (ré-)écrit?

F30: Elle semble ridicule aux yeux des professionnels qui se sont habitués aux termes anglo-saxons, et les traductions sont parfois inexactes (ce qui les rend encore plus ridicules).

F31: Ça complique la vie pour pas grand chose, on s'éloigne du sens originel (que veut dire mél ????) et ça nous éloigne encore plus de la langue européenne/mondiale.

F32: Démarche souhaitable, mais les propositions devraient aller dans le sens de l'usage établi, quand c'est le cas, et accepter les anglicismes. Ainsi mail est de loin préférable à e-mail, et plus facile à utiliser que mél ou message et plus connu que courriel. En informatique, il est très difficile de se faire comprendre sans utiliser d'anglicismes même quand un terme français existe, plus agréable et parfaitement approprié.

L'effort doit venir des communiquants : journaliste, écrivain, radio, télévision, etc. : loi Toubon :-).

F33: Franchement, je ne suis pas sûr qu'elle soit valable. Les gens découvrent de nouvelles technologies avec des noms qui ont une connotation magique car totalement inconnus (net, chat, news, surf sur le web). Les obliger à parler français (mél, courriel et autres abbérations, attention, je ne dis pas que toutes les traductions sont mauvaises, mais certaines sont ridicules) n'est pas la solution, car cela perd les gens qui s'initient à l'informatique (ceux qui connaissent et qui parlent couramment n'ont alors pas les mêmes mots ce qui pose des problèmes de compréhension).

F34: C'est difficile de changer ses habitudes ...

F35: Les termes proposés en français sont souvent ridicules. D'autre part, Internet étant par définition très international, il est normal qu'il y ait unification de la terminologie.

F36: Je pense que les termes choisis par les Québécois sont souvent soit plus pertinents, soit plus courts que ceux retenus pour la France (Ex.: Mél ne veut rien dire et sort de nulle part contrairement à courriel, idem pour des termes comme pourriel).

F37: Traductions pas toujours heureuses (par exemple, mél n'est qu'une piètre imitation phonétique de mail, je préfère courriel qui est bien plus esthétique). 
F38: Elle est ridicule !!! Ça me fait bien rire.

F39: Ne vous prenez pas trop la tête avec ça. Le verlan ça marche très bien, c'est typiquement français, et tout le monde connaît. Ce sera difficile d'imposer quelque chose qui ne vienne pas de la population elle-même. Les choses changent, en fonction des gens, c'est ce qui fait l'identité de celui-ci [gemeint ist vermutlich: de la population]. Mais imposer une langue, c'est nier l'évolution naturelle de la culture du peuple. Proposez si vous voulez, mais c'est pas la peine de dépenser trop d'énergie pour ça. [...]

F40: C'est une bonne chose.

F41: Totalement inutile. Elle suit une évolution de la langue.

Elle est particulièrement inutile dans un contexte technique international où l'utilisation des mots anglais s'est établie jusqu'à 10 ans avant qu'elle ne passe dans la vie quotidienne et qu'elle fasse l'objet d'une mention dans le journal officiel.

C'est d'autant plus inutile que dans un contexte technique vous êtes amenés à échanger des informations qui ont, en général, comme source des pays anglophones et que jusqu'à preuve du contraire, l'anglais reste la langue de référence de communication inter-culture ... Si vous ne connaissez que le mot français vous ferez une traduction plus ou moins littérale qui n'aura aucun sens pour une personne d'une autre culture ... et peut être même possiblement de la même culture. Par exemple, la notion de 'deadlock' en programmation a son équivalent français comme 'étreinte fatale'. Faire un discours de ce genre vous garantit à coup sûr de ne pas être compris de votre auditoire même francophone ...

Au lieu de se poser la question des anglicismes, on ferait plutôt mieux de se poser la question de savoir pourquoi les pays concernés n'ont aucune influence dans ce domaine ...

F42: Ça doit passer en douceur.

F43: C'est une bonne initiative. Mais il ne faut pas la rendre obligatoire. Surtout que certains mots sont assez ridicules (je pense surtout à cédérom).

F44: La loi n'a que peu d'impact sur l'usage, à moins de s'y rallier ...

F45: Ça ne sert à rien.

F46: Je pense que l'évolution des langues est affaire d'usage et pas de législation. Pour protéger une langue il faut développer la culture littéraire et le goût des mots. Tout 'protectionisme' de vocabulaire me semble voué à l'échec.

F47: embrouillante 
F48: Trop souvent n'importe quoi. À se demander ce que vient faire une cosse de chataigne dans un programme.

F49: Je pense qu'elle rajoute en complexité et rend plus ésotérique encore l'apprentissage de l'informatique. Avoir 15000 mots pour désigner une chose ne fait pas vraiment avancer les choses et rajoute en confusion pour les personnes qui ne savent plus à quel saint se vouer.

F50: Inutile, voire nuisible. Toutes les langues se sont toujours auto-régulées et stabilisées. La langue française a été dominante jadis en Europe, tout comme le latin dans l'antiquité ... Et les journaux et livres anglo-saxons contiennent de nombreux termes français également, sans que cela choque qui que ce soit. Vouloir défendre la langue, c'est s'attaquer aux effets et non à la cause, qui, elle, vaut le coup d'y travailler : c'est notre économie qu'il faut protéger !!!

F51: C'est bien d'avoir une équivalence des termes anglais-français, tant que l'on n'en abuse pas : par exemple, l'équivalent de virus (paru au Journal Officiel) est Fragment infectieux de code nécessitant un programme hôte (sans commentaires :-)).

F52: Je suis assez habitué aux termes anglais, qui me conviennent bien la plupart du temps.

Je les préfère en général aux termes français lorsque je juge ceux-ci trop artificiels. Créer un néologisme en français juste pour remplacer un terme anglais me semble absurde.

Néanmoins, dans certains cas lorsque le mot français existe déjà et correspond bien au sens du terme anglais, j'utilise le terme français.

F53: Pourquoi pas protéger la langue française ? Mais laissez le choix aux gens d'utiliser ce qu'ils veulent!

F54: Il est vrai que 'proteger' le français n’est pas forcément une mauvaise chose, mais il ne faut pas perdre de vue que c'est une langue qui évolue et qui va continuer à s'enrichir.

Avant de vouloir absolument faire barrière à l'anglicisme, il faudrait déjà penser à enseigner correctement le français afin que les gens évitent de faire 50 fautes dans une phrase.

De plus, il faut aussi éviter de faire n'importe quoi sous prétexte de franciser tous les termes anglophones ... je pense par exemple à CDRom en anglais qui donne CédéRom en français. Cela n’a pas de sens !!!! Il faut arrêter le délire !!!

F55: Je pense qu'il est inutile (surtout à l'heure d'internet) d'employer des artifices juridiques pour tenter de remplacer des termes qui se sont imposés de facto. Personnellement, je trouve qu'utiliser le terme de Hacker pour pirate électronique est un enrichissement de la langue, dans la mesure où on n'utilise pas hackers pour dési- 
gner les défunts corsaires ... En plus, ça ne nuit pas à la compréhension, qu'on en soit content ou non, la langue informatique [hier: l'anglais] est la langue internationale. À partir de là, il vaut mieux la maîtriser et je ne vois pas l'intérêt de créer un nouveau mot pour ne pas utiliser celui qui existe déjà dans d'autres langues. À mon avis, il vaudrait mieux se protéger du colonialisme anglo-saxon en matière de politique, économies, informations, art ... Après tout, nos ancêtres ont communiqué entre nations à l'aide du latin pendant des décennies, ça n'a pas empêché le français de survivre et le latin de mourir ... Si nos politiques veulent protéger le français, qu'ils s'attachent à parrainer la création de traducteur surpuissant capable de traduire décemment et dans des temps de réponse adéquat tout texte, y compris scientifique. Et il vaut mieux prévenir que guérir, entendre jet de coin [für engl. corner] me fait bien rire ... La tradition est une invention moderne, avec un peu de recul, on se rend compte que traditionnellement, nos ancêtres évoluaient ... Alors qu'on en ressort causerie d'un placard poussiéreux pour remplacer chat je ris. Mais il faut bien reconnaitre que je ris moins que quand j'entend chat au lieu de tchat, tiens, ça serait une traduction sensée ...

F56: Pas de volonté à trouver des termes simples, concrets et utiles.

F57: Perte de temps si les termes choisis ne sont pas immédiatement compréhensibles et agréables à utiliser.

F58: Trouver des termes français pour désigner des anglicismes, est en soi une idée honorable, mais il y a d'une part la difficulté de trouver des termes simples, courts et concis à utiliser, d'autant plus qu'ils auront, d'autre part, à remplacer des termes anglais souvent simples déjà mémorisés dans les esprits.

Bref, il vaudrait mieux se préoccuper que la France notamment reprenne son esprit d'initiative technologique comme elle l'a eu auparavant, de manière à ce que les nouveaux termes soient dés le départ français, puis traduits, aussi simples que ça puisse paraître.

F59: La conversion anglais- $>$ français est bien faite, mais les mots ainsi créés vont mal dans une discussion, car trop longs. Les mots français ne sont pas assez brefs.

F60: Tant que les principales avancées technologiques seront faites par des entreprises anglophones, il me semble inutile de vouloir traduire à tout prix les termes techniques liés à ces technologies.

F61: Bof ... le français est une langue vivante, laissons le vivre, et que le meilleur terme gagne ... qu'il s'agisse de l'anglicisme ou du 'francocisme' ...

F62: Tout d'abord, il est nécessaire que les « autorités compétentes » élaborent des terminologies françaises adaptées aux nouvelles technologies. Il faut en effet qu'un utilisateur francophone puisse utiliser sa langue pour communiquer sur ces sujets. 
Toutefois, je ne crois pas qu'une politique « répressive» soit de mise : c'est l'usage qui doit décider. Le français est, j’ose espérer, encore une langue vivante. Elle peut très bien s'accomoder de l'incorporation de mots d'origine étrangère, comme ce fut le cas depuis des siècles. La dérive que l'on peut observer sur des mots intégrés depuis longtemps dans le langage se produira sur les mots d'origine plus récente (liés aux nouvelles technologies ou non d'ailleurs). Mais ce processus est lent, et j'ai l'impression que certains linguistes ont été, eux aussi, pris au piège de l'Internet: ils croient que, parce que c'est une technologie en évolution rapide, le langage qui lui est associé devrait faire de même, ce qui est à mon sens une absurdité.

J'ai confiance en les francophones pour maintenir cette langue active !

F63: Il y en a une?

F64: Les termes conseillés sont souvent « ridicules » ou peu connus.

F65: Les langues évoluent toutes seules. Il est bon de donner des équivalents officiels, mais le peuple décide de ce qu'il utilise et fait autorité. Ensuite, l'académie doit se prononcer si l'anglicisme éventuel n'en est plus un et fait partie de la langue courante ...

F66: Un mot qui sonne mal à l'oreille, qui est laid quand il est écrit est rarement employé. Typiquement cédérom est une infamie. CD veut dire Compact Disc, nous avions déjà Disque Compact qui était largement employé. Il aurait peut-être plus fallu chercher du côté $D C$ que cédé. Les termes qui se sont imposés naturellement : ordinateur, moniteur, clavier, souris, enceintes, carte mère, processeur, disque dur, lecteur de disquette, carte réseau, carte graphique, carte son, serveur, ... sont utilisés couramment. Par contre, chez moi, je suis désolé de devoir toujours utiliser un switch, un bub, et un scanner.

Plutôt que de sortir des listes de termes lorsque un mot est déjà utilisé par des milliers de gens, il vaudrait peut-être mieux suivre l'avancée technologique et proposer des équivalents naturels, même s'ils sont phonétiquement différents de l'original. Cédérom est une tentative malhabile pour imposer un terme francisé à consonnance identique à ce que les gens utilisaient déjà.

Et puis franchement, c'est un faux problème. Les Québécois utilisent largement plus de termes anglais que les Français. Ok, nous avons des parkings, et jouons au football, alors que eux ont remplacés les pins par des épinglettes. D’un autre côté, demandez à un Québécois de parler informatique ou automobile. Sa voiture aura un windshield, un engine, etc. ... alors qu'en France, nous utilisons couramment les pare-brises et les moteurs.

Que les terminologues suivent les groupes de discussion de la hiérarchie «fr », et ils découvrirons vite les termes qui doivent être francisés.

F67: L'intention est louable, mais il vaut mieux traduire le sens plutôt que de proposer parfois des 'traductions' phonétiques, comme pour bogue (bug) et mél (mail). 
Dans le cas du mail, la traduction courriel est à peu près correcte. Pour bug elle est à mon avis catastrophique.

F68: Je pense que nous devons conserver notre belle langue ... Mais de la rendre ridicule avec des traductions à $2 €$ !!! Je suis partisan d'utiliser des termes français, mais qui doivent avoir un sens français, non pas une traduction littérale du terme anglais. Genre mail $=>$ mél, www $=>$ la toile d'araigné mondiale $\ldots$

F69: Utiles, mais souvent les termes sont trop compliqués et/ou trop longs par rapport à l'anglais.

F70: En règle générale, il est souhaitable d'avoir une francisation des termes, mais la traduction en courriel ou mél me paraît difficile à avaler ... Et puis, quand on utilise certains termes français, on observe une tendance à la moquerie un peu justifiée. Par contre, des termes comme courrier électronique, liste de diffusion sont plus facilement acceptés. L'erreur est certainement de noter email dans les logiciels et les pages ouaib (euh ...) en français.

F71: Quelque peu ridicule sur certains termes tel que mél!

F72: Je suis étudiant en électronique et informatique. Dans ces deux domaines, l'influence de la langue anglaise est très présente. Étant français, j'essaie d'utiliser des expressions françaises à la place des anglicismes. Oralement, j'utilise les anglicismes car plus courts à prononcer, mais à l'écrit, j'utilise les expressions françaises (courrier électronique au lieu de e-maih). Je pense [que] l'utilisation des anglicismes est un abus lorsque des expressions françaises existent. Par exemple, on entend souvent parler de work package qui signifie simplement une fiche de tâches. Pourquoi n'utilise-t-on pas cette dernière?

Voici une petite anecdote qui m'a fait sauter au plafond. Un président d'un grand groupe français d'électronique était invité au journal télévisé et a utilisé le mot outsourcer. Ce mot n'existe pas et est une pure invention et un abus intolérable. Les mots externaliser ou sous-traiter sont français et conviennent parfaitement.

Concernant l'informatique, je n'aime pas les inventions comme courriel, mél, bogue des ministres. Une langue est vivante, subit diverses influences et elle évolue au fil du temps (sinon c'est une langue morte). Il ne s'agit pas de les refouler, mais j'aimerais que les gens fassent l'effort d'utiliser le français le plus possible.

Des expressions françaises existent, mais elles sont peut être trop longues. Pourquoi ne pas utiliser dysfonctionnement à la place de bug ou bogue ? Pourquoi ne pas utiliser courrier électronique à la place de mail ou courriel?

Les informaticiens utilisent les mots anglais peut-être par paresse. Je pense que la plupart des expressions anglaises peuvent être remplacées par un équivalent en français. Mais un informaticien qui s'acharnerait à remplacer les mots anglais par du français passerait pour un conservateur. Je ne pense pas que la sauvegarde du français soit un combat d'arrière-garde. Mais il est de plus en plus difficile ... 
F73: Il est difficile d'imposer des changements d'usage; il serait souhaitable par contre d'aller au devant des évolutions en proposant rapidement des termes français clairs.

\subsubsection{Belgien}

B1: Elle est trop tardive. Les termes anglais ont eu le temps de s'enraciner. Exemple, Aquaplaning est connu de tout le monde, aquaplanage fait sourire. Faute de rapidité, le 'verbe' chatter est de plus en plus utilisé.

B2: La majorité des nouvelles expressions proposées sont artificielles, inutiles et se contentent de franciser l'orthographe de certains mots tout en en maintenant la pronociation. On atteint l'absurde avec cédérom qui est la transcription d'un acronyme. Pourquoi créér un mot inutile comme mél alors qu'on a déjà courrier que tout le monde comprend? Je ne veux même pas parler des écluses et butineurs dont peu de gens doivent savoir de quoi il s'agit.

B3: J'ignorais totalement qu'il y avait une politique de cette sorte en Belgique !

B4: Hum, c'est inutile, l'informatique étant déjà un domaine très complexe, il faut qu'on utilise un language commun pour communiquer avec les autres de ce domaine, essayez de sortir les mots cédérom, mél, toile, etc. à un type qui est mordu d'informatique, il va vous regarder de travers :).

B5: Élitiste, prétentieuse, chauvine (France), souvent ridicule et inutile, protectionniste, vaine.

B6: Les linguistes devraient être plus rapides, il est évident qu'à l'heure actuelle, ils ont toujours une guerre de retard par rapport à l'implémentation de la terminologie anglaise.

B7: En Belgique, nous n'avons pas ce problème. Comme il y a des francophones et néerlandophones, on opte systématiquement pour les termes anglais. Les instances européennes et internationales font que c'est aussi l'anglais qui prédomine dans l'informatique.

B8: C'est beaucoup plus simple lorsque l'on utilise les anglicismes. Je ne crois pas qu'il soit bon de vouloir traduire tous les termes. La langue française évolue et s'adapte ... elle a toujours été constituée de termes provenant d'autres langues (latin, grec, anglais, ...).

B9: Totalement inutile. Il faut un dictionnaire pour traduire courriel. Favorisez la connaissance passive des autres langues, à défaut d'une connaissance active. Regardez le comportement des professionnels! Les mots anglais sont des «codes » qui ont une signification précise et dont la valeur est d'être compris par les autres professionnels. 
B10: Il est important de protéger la langue française, mais certaines propositions ne sont pas toujours heureuses ... Par exemple, mél ne protège en rien la langue française, car on pense immédiatement à mail ...

\subsubsection{Schweiz.}

S1: Je trouve le sujet de votre étude très intéressant. Je suis un amoureux inconditionnel de la langue française, je la trouve belle, riche, variée, douce, mais dans le domaine technologique, je pense que la terminologie anglaise est plus adaptée, permet un discours international et le fait d'essayer à tout prix de traduire certains mots amène l'individu à confondre. Je suis pour une unité de dialogue dans le domaine informatique, alors arrêtons la chasse aux sorcières!

S2: La meilleure solution est de laisser faire l'usage.

S3: Il n'est pas nécessaire de vouloir absolument protéger une langue d'une autre. En effet, plus les termes techniques sont universels, plus la facilité d'assimilation sera aisée. Si on n'apprend que des mots français, on ne pourra plus en parler avec des étrangers.

S4: Le but est d'être compris sans équivoque ou quiproquos. Franciser un terme pour soit-disant protéger une langue risque forcément de créer des malentendus, car il faudra implicitement se mettre d'accord sur le sens traduit du mot.

S5: On s'en fout. De toute façon, une langue évolue de manière incontrolée, c'est de l'ordre de l'utopie que de vouloir [en] influencer son évolution, en particulier sous un prétexte aussi conservateur...

S6: Je trouve cela relativement stupide d'essayer de 'franciser' certains termes. Ils sont tellement utilisés, pourquoi vouloir les changer?

Je trouve qu'il serait plus simple et bien meilleur 'd'intégrer' ces mots dans le dictionnaire.

Le groupe qui s'occupe de franciser les termes, il a que ça à faire ? Comment peuton perdre du temps sur quelque chose d'inutile comme cela?

Et encore, s'il veut vraiment le faire, pitié, [qu'il] crée des noms qui ont de 'la classe' ! Car bon, courriel ou mél, c'est pas terrible ... e-lettre à la limite serait pas mal ... Au fait, Internet, vous le traduisez aussi ? Réseaux interconnectés, Interrés ? Soit vous traduisez tout, soit rien!

Enfin, ça m'a fait quand même bien rigoler, le pourvoyeur d'accès! [...]

S7: Je suis un fervent partisant des termes anglais, bien que je pense utile de connaître les termes français au cas où l'on devrait avoir affaire à une personne les utilisant. L'avantage des termes anglais est qu'ils sont déjà très précis et bien adaptés aux situations rencontrées sur Internet, ayant la plupart du temps créés par les utilisateurs eux-mêmes. 
S8: Contrairement au Québec, la Suisse n'a pas de politique de protection de la langue française (dans les faits). Les anglicismes envahissent de plus en plus notre quotidien et je trouve cela dommage.

S9: Je trouve que l'idée de protéger un peu le langage français est une bonne chose. Cependant, des termes ridicules sont apparus, des dérivés du genre : cédérom, courriel ... . C'est pour cela que je préfère toujours utiliser les termes anglais.

S10: On ne fixe pas une langue par une loi ... de plus dans un cadre de travail bilingue (ou même multilingue) il est plus simple de choisir des documents (et donc des termes) anglais que d'utiliser des termes qui ne seront pas compris par tout le monde (savez-vous ce qu'est un Speichersta[p]pelzeiger? Mais vous connaissez les stack pointers).

S11: Pour moi qui suis suisse, cette politique fait que je comprends moins bien les messages dans les newsgroups francophones qu'auparavant, suite à l'introduction des termes francisés. Je préfère de plus en plus lire les news en anglais.

S12: Perte de temps ... l'anglais est 'la langue internationale' donc celle du Net. Les pires [néologismes français] sont du genre cédé : phonétiques anglaises écrites à la française. Je crois qu'en Suisse, nous ne sommes pas attachés vraiment au français, nous sommes habitués au mélange des langues. On ne peut pas survivre sans une ou plusieures langues étrangères.

\subsection{Präsenz verschiedener Sprachen im Internet}

Abb. 232: Präsenz verschiedener Sprachen im Internet

\begin{tabular}{|c|c|c|c|}
\hline \multicolumn{4}{|c|}{ Les langues sur l'internet } \\
\hline & Septembre 1998 & Août 2000 & Juin 2001 \\
\hline ANGLAIS & $75,00 \%$ & $60,00 \%$ & $52,00 \%$ \\
\hline ESPAGNOL & $2,53 \%$ & $4,85 \%$ & $5,69 \%$ \\
\hline FRANÇAIS & $2,81 \%$ & $4,39 \%$ & $4,61 \%$ \\
\hline ITALIEN & $1,50 \%$ & $2,77 \%$ & $3,06 \%$ \\
\hline PORTUGAIS & $0,82 \%$ & $1,97 \%$ & $2,81 \%$ \\
\hline ROUMAIN & $0,15 \%$ & $0,19 \%$ & $0,17 \%$ \\
\hline ALLEMAND & Non recensé & $6,30 \%$ & $6,97 \%$ \\
\hline \hline
\end{tabular}

(vgl. Bericht der DGLFLF von 2001, Kap. X.; FUNREDES/Unión Latina 2001, o.S.) 
Die Prozentangaben beziehen sich auf die Sprachen, in denen die Internetseiten verfasst sind. Das bedeutet, dass im September 1998 75\% aller Internetseiten auf englisch publiziert waren, während im Juni 2001 nur noch ca. die Hälfte, 52\%, auf englisch verfasst waren.

\subsection{Glossar der verwendeten Internet-Termini}

In diesem Glossar befinden sich die Definitionen aller im Rahmen der Arbeit auftretenden wichtigen Internet-Termini. Es wurde darauf verzichtet, alle $53 \mathrm{im}$ Rahmen der Terminologieliste vom 16. März 1999 publizierten Termini in die folgende Tabelle aufzunehmen. Vielmehr sind die im Fragebogen enthaltenen Internationalismen aufgenommen worden sowie diejenigen Termini, die im Laufe der Arbeit verwendet und/oder von den Informanten in ihren Antworten und Kommentaren genannt worden sind.

\section{Abb. 233: Glossar der verwendeten Internet-Termini}

\begin{tabular}{|c|c|}
\hline $\begin{array}{l}\text { Internatio- } \\
\text { nalismus }\end{array}$ & Definition \\
\hline $\begin{array}{l}\text { (access) } \\
\text { provider }\end{array}$ & $\begin{array}{l}\text { „Anbieter eines Internet-Zugangs. Dabei sind die Preise und } \\
\text { Service-Leistungen von Provider zu Provider verschieden. } \\
\text { Grundsätzlich unterscheidet man in kommerzielle Provider [...] } \\
\text { und nicht-kommerzielle Anbieter [... “ (Sittek 1997, 137f.). }\end{array}$ \\
\hline AIM & $\begin{array}{l}\text { AOL Instant Messenger } \\
\text { dt.: AOL Internet-Telegramm } \\
\text { „Der auf das Internet ausgeweitete Instant-Messaging-Service } \\
{[\ldots . .] \text { von AOL [...]“ (Networds 1997-2002, o.S.). }}\end{array}$ \\
\hline ASCII & $\begin{array}{l}\text { American Standard Code for Information Interchange } \\
\text { „7-Bit-Zeichensatz, der von praktisch jedem Computerherstel- } \\
\text { ler unterstützt wird, um Buchstaben, Zahlen und Sonderzei- } \\
\text { chen darzustellen. Dateien, die ausschließlich im ASCII-Text- } \\
\text { format erzeugt wurden, enthalten keinerlei Gestaltung } \\
\text { und/oder Schriftarten, aber sie können von jedem Computer } \\
\text { gelesen und dargestellt werden“ (Networds 1997-2002, o.S.). }\end{array}$ \\
\hline ASCII art & $\begin{array}{l}\text { dt.: ASCII-Kunst } \\
\text { „Grafik oder Zeichnung, die ausschließlich aus ASCII-Zeichen } \\
\text { zusammengesetzt ist. Hauptsächlich vorkommend als Be- } \\
\text { standteil langer und überladener Signaturen [...] im Usenet“" } \\
\text { (Networds 1997-2002, o.S.). }\end{array}$ \\
\hline
\end{tabular}


Banner

„Bezeichnung für Mitteilungen, die bei der Ausführung bestimmter Programm-Operationen auf dem Bildschirm erscheinen und entsprechende Informationen vermitteln. Bestimmte Programme blenden beim Start z. B. ein Login-Banner [...] ein, das den Status der Einwahl anzeigt. Mittlerweile wird die Bezeichnung vor allem für die Werbeflächen auf Webseiten (ad banner) benutzt [...]“ (Networds 1997-2002, o.S.).

CGI

Common Gateway Interface

„Standardisierte Programmierschnittstelle zum Datenaustausch zwischen Browser [...] und Programmen auf dem Webserver [...]. Diese Programme sind überwiegend in PERL geschrieben und dienen hauptsächlich der Auswertung von HTML-Formularen [...] “" (Networds 1997-2002, o.S.).

chat

„Im Kontext Internet bedeutet Chat, eine Unterhaltung in Echtzeit mit anderen per Computer zu führen. Es wird eine Nachricht abgeschickt[,] und innerhalb kürzester Zeit erhält die betreffende Person diese Nachricht. Der Empfänger wiederum antwortet sofort, und es entsteht eine Konversation per Tastatur, vergleichbar einem Telefongespräch [...]“ (Sittek 1997, 56f.).

Cookie

cracker

cross posting dt.: Keks

„Kleine Textdatei, die von einer besuchten Webseite [...] in einem vom Browser [...] dafür vorgesehenen Verzeichnis auf der Festplatte des Users [...] erzeugt wird. Eine solche Datei protokolliert die Aktivitäten des Users in der besuchten Webseite [...]“ (Networds 1997-2002, o.S.).

„Jemand, der unbefugt in Computersysteme wie Internet-Server [...] oder Bankenrechner eindringt und dort Änderungen am Programmcode vornimmt. Manchmal ist auch jemand gemeint, der Computerspiele oder andere Programme, knackt', um aus einer Shareware [...] eine Vollversion zu machen, z. B. wenn diese zeitbegrenzt oder per Registrierungscode freigeschaltet ist. Im Gegensatz zu Hackern [...] handeln Cracker in der Regel eigennützig oder gegen Bezahlung im Auftrag“ (Networds 1997-2002, o.S.).

\section{dt.: Streusendung}

„Das Verbreiten ein- und derselben Nachricht in verschiedenen Diskussionsforen [...]; entspricht nicht dem Internet-Verhaltenskodex (netiquette), da es die Newsgroups [...] unnötig anfüllt. Also eine wirksame Methode, sich in der Internet-Gemeinde unbeliebt zu machen“ (Networds 1997-2002, o.S.). 
e-mail dt.: elektronische Post, E-Mail

„Methode, Nachrichten per Computer zu verschicken anstelle der traditionellen Briefpost auf dem Überlandweg (vgl. snail mail). Eine der wichtigsten und populärsten Errungenschaften der computergestützten Kommunikation. Über E-Mail können nicht nur Texte, sondern auch Daten aller Art verschickt werden; vgl. attachment. Laut Duden ,die' E-Mail, besonders in Süddeutschland und Österreich auch ,das’ E-Mail"“ (Networds 1997-2002, o.S.).

FAQ

ftp frequently asked questions

„Oft auch Plural FAQs = häufig gestellte Fragen: Um das mehrmalige Beantworten immer wieder gestellter Fragen zu vermeiden, werden diese Fragen von Mailbox-, Webseiten- und Newsgroup-Betreibern [...] gesammelt und entsprechende Antworten auf der betreffenden Site [...] zur Verfügung gestellt" (Networds 1997-2002, o.S.).

File Transfer Protocol

dt.: Dateiübertragungsprotokoll

„Technischer Kommunikationsstandard, der die Dateiübertragung via Internet regelt." FTP bezeichnet aber auch Programme, die Dateien nach dem FTP-Protokoll übertragen und empfangen“" (Networds 1997-2002, o.S.).

gopher

dt.: Beutelratte

„Inoffizieller Vorgänger des WWW (World Wide Web) und der erste Versuch, die immense Datenfülle des Internets zu strukturieren. Gopher bietet Zugang auf textbasierte Informationen, ist menügesteuert und im Gegensatz zum WWW mit seinen Hyperlinks [...] hierarchisch gegliedert. Man kann also nicht nach Belieben von einer Seite zur anderen springen, sondern muss stets zum Ausgangspunkt zurück, um von dort eine andere Abzweigung in der Baumstruktur zu nehmen; veraltendes System, dem das grafisch ausgerichtete WWW den Rang abgelaufen hat [...]“" (Networds 1997-2002, o.S.). 


\begin{abstract}
hacker „Computer-Enthusiast, der sein Können und Wissen u. a. dazu nutzt, unbefugt in geschlossene Computersysteme einzudringen. Je nach Sichtweise wird mit der Bezeichnung ,Hacker' nicht in jedem Fall eine Kritik, sondern oft auch Bewunderung ausgedrückt. Entstanden ist die Verbindung von ,to hack' (u. a. einen Streich spielen oder ein Problem auf die Schnelle lösen) und Computern am MIT, als sich die Mitglieder des Eisenbahnclubs zu Beginn der Sechzigerjahre auf den Institutsrechner stürzten. Unter den ersten Hacks waren die gelungenen Versuche, dem Großrechner Melodien zu entlocken. Hacker selbst grenzen sich betont von so genannten Cybervandalen [...] und Crackern [...] ab. Wegen häufiger begrifflicher Verwaschung in der Vergangenheit wird das Wortpaar , hacker cracker' zunehmend von den Begriffen ,white hat -- black hat' [...] abgelöst [...]“ (Networds 1997-2002, o.S.).
\end{abstract}

homepage

dt.: Startseite, Homepage

„Eine Homepage ist die erste Seite einer Website. Die Homepage bezeichnet eine Seite, auf der sich ein Internet-User mit seinen Personalien wie Photo, Hobbies, persönlichen Links und Möglichkeit, ihm eine E-Mail zu schicken, vorstellt. Firmen stellen sich und in einem Überblick ihre Dienstleistungen oder Produkte auf dieser ersten Seite vor [... ““ (Sittek 1997, 118).

Hypertext Transfer/Transmission Protocol

„Eines von vielen Internet-Protokollen [...], das für die Übertragung und Verknüpfung von Webseiten [...] zuständig ist“" (Networds 1997-2002, o.S.).

https

Hypertext Transfer Protocol Secure dt.: sicheres Hypertext-Übertragungsprotokoll „Auf SSL beruhendes, besonders sicheres HTTP-Protokoll [...] zur Datenübertragung im World Wide Web“ (Networds 19972002, o.S.).

Hyperlink dt.: Hyper(text)-Verbindung

„Üblicherweise blaufarbige und blau unterstrichene Wörter im Fließtext von Webseiten [...], die man anklicken kann und die einen Querverweis auf bzw. Absprungspunkt zu einer anderen Adresse (URL) im WWW darstellen. In jedem HTML-Dokument lassen sich beliebig viele Hyperlinks zu anderen Seiten unterbringen [...] " (vgl. Networds 1997-2002, o.S.). 


\begin{tabular}{|c|c|}
\hline ICQ & $\begin{array}{l}\text { I Seek You } \\
\text { „Ein von der Firma Mirabilis entwickeltes Instant-Messaging- } \\
\text { Programm [...]. Es wird für die direkte Kommunikation mit } \\
\text { einem anderen Teilnehmer via E-Mail }[\ldots] \text { oder Chat }[. . .] \text { ver- } \\
\text { wendet, aber auch für Computerspiele oder um Dateien auszu- } \\
\text { tauschen. [....“ (vgl. Networds } 1997-2002 \text {, o.S.). }\end{array}$ \\
\hline IP & 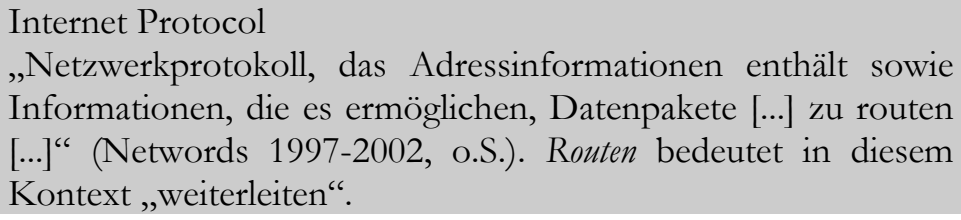 \\
\hline IRC & $\begin{array}{l}\text { Internet Relay Chat } \\
\text { „Internet-Dienstart, die es den Usern [...] ermöglicht, über alle } \\
\text { Grenzen hinweg über die Computertastatur in Echtzeit [...] } \\
\text { miteinander zu, chatten’ [...]“ (Networds 1997-2002, o.S.). } \\
\text { S. chat }\end{array}$ \\
\hline
\end{tabular}

Mailingliste „Per E-Mail [...] ausgetauschte Liste mit Diskussionsbeiträgen / mailing list zu einem bestimmten Thema. Nach Anmeldung bei dem auf der jeweiligen Liste genannten, list server' erhält man automatisch eine Kopie der laufenden E-Mail-Korrespondenz zu dem gewünschten Thema in den eigenen Briefkasten [...] geschickt [... $]^{\text {“ }}$ (Networds 1997-2002, o.S.).

Netiquette „Verhaltenskodex der Online-Gemeinschaft [...], der den Umgang der Teilnehmer miteinander beim Versenden von E-Mails [...], im Internet Relay Chat (IRC) und in den Newsgroups [...] regelt.

So ist z. B. alles verpönt, was dem Empfänger einer Nachricht zu viel Speicherplatz und/oder Zeitaufwand zumutet: Streusendungen (cross posting), Werbung, tausendmal gestellte Fragen (anstatt die FAQ anzusehen), aufgebauschte Darstellungen (ASCII art) statt kurzer Signaturen [...]“" (Networds 1997-2002, o.S.).

news / newsgroup
„Eine Art öffentliches schwarzes Brett zum Nachrichtenaustausch -- ein von einem Thema bestimmter Bereich im Usenet, bestehend aus Artikeln, die von den Teilnehmern verfasst wurden. Die Anzahl dieser Art virtueller Diskussionsgruppen ist enorm“ (Networds 1997-2002, o.S.). 


peer to peer
/ peer-to-
peer net-
work
pop up
window

Provider

SMTP

Telnet

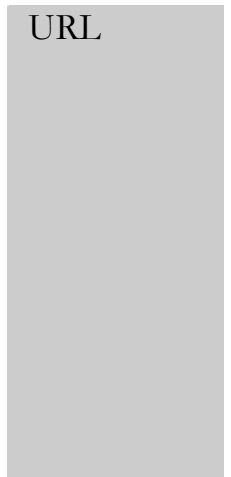

Usenet dt.: Gleich-zu-Gleich-Netzwerk

„Nicht-hierarchisches Netz [...], in dem die verbundenen Rechner stets gleichberechtigten Zugriff auf die anderen Rechner des Netzes haben. Jeder ans Netz angeschlossene Rechner kann sowohl die Funktion eines Servers als auch die eines Clients [...] wahrnehmen; vgl. Morpheus, Gnutella“" (vgl. Networds 19972002, o.S.).

\section{dt.: Pop-up-Fenster}

„Fenster, das angezeigt wird, sobald eine Option durch Mausklick, Rollover [...], sprach- oder zeitgesteuert ausgewählt ist. Im Internet wird diese Technik bislang vor allem zu Werbezwecken eingesetzt [...]“ (Networds 1997-2002, o.S.).

\section{s. (access) provider}

\section{Simple Mail Transfer Protocol}

dt.: Einfaches Postübertragungsprotokoll

„Teil der TCP/IP-Protokollfamilie [...], der die Übertragung von E-Mails [...] zwischen Computern regelt" (Networds 19972002, o.S.).

„Kategorie von Programmen, die ähnlich einem Terminal-Programm [...] dem User [...] direkten Zugriff auf einen anderen Computer im Internet ermöglichen. Wenn man die entsprechenden Zugriffsrechte auf diesen Rechner hat, kann man aus der Ferne Programme starten, Dateien bearbeiten oder auch hinauf- und herunterladen [...]“ (Networds 1997-2002, o.S.).

\section{Uniform Resource Locator \\ dt.: einheitlicher Quellenlokalisierer}

„Bezeichnung für die gesamte Adresse [...] einer Internet-Seite. Sie besteht aus einem Dienstpräfix für die Art, mit der man zugreift (z. B. http:// für WWW-Adressen [...] oder ftp:// bei FTP-Zugang), einem Server-Namen [...], der wiederum aus dem Namen des Servers und seiner Domain [...] besteht (z. B. www.langenscheidt.de), und dem Namen des Dokuments [...], der noch durch eine Pfadangabe [...] ergänzt sein kann. Laut Duden ,die' URL, selten ,der' URL“" (Networds 1997-2002, o.S.).

„Eigenständiges Netzwerk [...] innerhalb des Internets, das sich in tausende, thematisch sortierte Unterbereiche, so genannte Newsgroups [...], teilt. Hier werden Neuigkeiten und Dateien ausgetauscht, es wird diskutiert, philosophiert und bei technischen Problemen Hilfestellung geleistet. Wie im Internet üblich, ist das Usenet dezentral angelegt, d. h. es ist keine Zensur und kaum eine Kontrolle möglich" (Networds 1997-2002, o.S.). 


\section{World Wide dt.: Weltweites Netz}

Web / web / WWW

„Auf Hypertext [...] basierendes Informations- und Quellensystem für das Internet und der am schnellsten wachsende Teil des Internets; wurde 1989 im Schweizer Forschungslabor CERN von Robert Cailliau und Tim Berners-Lee [...] entwickelt [...]“ (Networds 1997-2002, o.S.).

\subsection{Internetadressen}

\subsubsection{Belgien}

Cercle de qualité du français dynamique (C.Q.F.D.), auf der Seite des Maison de la Francité unter „Services permanents“

Institut National des Statistiques: http:/ / www.statbel.fgov.be

Le décret du 12 juillet 1978 sur la défense de la langue française: http://www.|cfwb.be/franca/publicat/pg008.htm

Maison de la Francité: http://www.maisondelafrancite.be/francite/

Portail fédéral: http://www.belgium.be/

Service de la langue française: http://www.cfwb.be/franca/index.htm

\subsubsection{Frankophonie}

Agence Universitaire de la Francophonie (AUF, früher: AUPELF/UREF): http:/ / www.auf.org

Agence Intergouvernementale de la Francophonie (AIF): http://www.agence.|francophonie.org, http://agence.francophonie.org

Conseil international de la langue française (CILF): http:/ / www.cilf.org/)

Frankophoniegipfel im Internet: http://www.france.diplomatie.fr/|francophonie/memoire/sommets.html, http://www.sommet2001.org

Ministère des Affaires Étrangères, Stichwort „Francophonie“: http://www.|france.diplomatie.fr/francophonie/index.html

Réseau international francophone d'aménagement linguistique (Rifal): http://www.|rifal.org/

Réseau International de Néologie et de Terminologie (Rint): http:/ / www.rint.org

Réseau international des observatoires francophones de l'inforoute et du traitement informatique des langues (Riofil): http:/ /www.riofil.net/

Réseau panlatin de terminologie (Realiter): http:/ /www.realiter.net/

\subsubsection{Frankreich}

Académie française: http:/ / www.academie-francaise.fr

Actions pour promouvoir le français des affaires (APFA, Association placée sous le patronage de la Délégation générale à la langue française et aux langues de France): http://www.presse-francophone.org/apfa/sommaire.htm Amazon France (Internetbuchhandlung), (C) 1996-2003: http://www.amazon.fr 
Association Française de Normalisation (AFNOR): http://www.afnor.fr/|Portail/portail.asp

Association des informaticiens de langue française (AILF): http:/ /www.ailf.net/

Avenir de la langue française: http:/ / persoweb.francenet.fr/ languefr/alf

Centre National de la recherche scientifique (C.N.R.S.): http://www.cnrs.fr/|accueil.html

Courrier Sud - Association Francophone des Professionnels de l'Aéronautique (gegründet: 23. Juni 20006): http:/ / courriersud.free.fr/index.htm

Comité d'étude des termes médicaux français (CETMF) [keine eigene Internetseite]

Commission Spécialisée de Terminologie et de Néologie de l'Information et des Composants Électroniques (CSTIC): http://www.ensmp.fr/industrie/igic/cstic/, http://|www-rocq.inria.fr/qui/Philippe.Deschamp/CSTIC/presse1999.html.

Défense de la langue française (DLF): http:/ / www.langue-francaise.org/

Délégation générale à la langue française et aux langues de France (DGLFLF): http://www.culture.fr/culture/dglf/

Fête de l'Internet: http:/ /www.fete-internet.asso.fr/

Index of / pub/ usenet/control/ fr/: ftp:/ / ftp.isc.org/pub/usenet/control/fr/

Institut National de la Statistique et des Études Économiques (INSEE): http://www.insee.fr/

Journal officiel: http:/ /www.journal-officiel.gouv.fr

Laboratoire de Linguistique Informatique (LLI): http:/ / www-lli.univ-paris13.fr/

Légifrance, l'essentiel du droit français: http:/ / www.legifrance.gouv.fr

Le Droit de comprendre (DDC): http://persoweb.francenet.fr/ languefr/ddc

Liste des groupes fr: http://www.fr.net/news-fr/liste.html

Ministère des Affaires Étrangères (Frankreich): http:/ / www.france.diplomatie.fr

Taylor Nelson Sofres (Frankreich): http://www.sofres.com

\subsubsection{Québec}

Bureau de la traduction, „Termium“: http:/ /www.termium.com/site/francais/ |index.html

Bureau de normalisation du Québec (BNQ): http://www.criq.qc.ca/bnq/|francais/index.html

Centre international pour le développement de l'inforoute en français (CIDIF): http:/ / www.naviguer.org/vocabulaire/

„Dictionnaire de l'internaute (commerce électronique, infographie, informatique, internet, micro-informatique, multimédia, réseautique, sécurité informatique, technologies de l'information, télécommunications)“", IBM (Kanada): http:/ /www.can.ibm.com/francais/dico/

Grand dictionnaire terminologique: http://www.granddictionnaire.com

Office québécois de la langue française (OLF): http:/ / www.olf.gouv.qc.ca/

${ }^{6}$ Courrier Sud ergibt sich aus dem Zusammenschluss $\operatorname{der}$ Association internationale des navigants de langue française (AISLF, gegründet 1976) und der Association des Contrôleurs de la Navigation Aérienne Francophone (ACNAF, gegründet im April 2000). 
Vocabulaire d'Internet (Banque de terminologie du Québec), http://|www.olf.gouv.qc.ca/ressources/bibliotheque/dictionnaires/Internet/Index/

\subsubsection{Schweiz}

Arbeitsgruppe der EDK (Schweizerische Konferenz der kantonalen Erziehungsdirektoren) für ein Gesamtsprachenkonzept für das Lehren und Lernen von modernen Sprachen in der Schweiz: http://www.romsem.unibas. |ch/sprachenkonzept/

Behörden der Schweizerischen Eidgenossenschaft: http://www.admin.ch/|$\mathrm{ch} /$

Bildungsdirektion des Kantons Zürich, „Schulprojekt 21“, http://www.|schulprojekt21.ch

Bundesamt für Statistik (BFS)/Office fédéral de la statistique (OFS), Neuchâtel: http://www.statistik.admin.ch/

Défense du français. Bulletin édité par la section suisse de l'Union internationale des journalistes et de la presse de la langue française: http://www.francolphonie.ch/ddf/ddf.htm.

Délégation à la langue française (DLF): http://www.ciip.ch/pages/DLF/dlf.htm Institut de dialectologie de l'Université de Neuchâtel: http://www.unine.|ch/dialectologie/

L'association suisse des journalistes de langue française: http://www.francophonie.ch/.

Lia Rumantscha: http:/ /www.liarumantscha.ch

Section de terminologie/Sektion Terminologie der Bundeskanzlei (Schweizerische Bundesverwaltung): http://www.admin.ch/ch/i/bk/termdat/f/index.htm Situation juridique du romanche/Rechtsstellung des Rätoromanischen (Schweiz): http://www.culturactif.ch/vieculturelle/suisse5.htm

\subsubsection{Diverses}

Gesellschaft für wissenschaftliche Datenverarbeitung mbH Göttingen (GWDG): http://www.gwdg.de

Globalpark - Software und Consulting für Online-Marktforschung: Online-Panel und Online-Umfragen: http://www.globalpark.de/

Internetadressen zum polnischen Sprachgesetz: http://www.udt.de/Gesetz.htm, http://www.zanthier.de/aktuell/ges_poln.html

Link Everything Online (LEO), „English-German-Dictionary“, Informatik der Technischen Universität München, C LEO Dictionary Team 1995-2002, http:/ / dict.leo.org/

Mailgate Web Server v.4.5, Rom (Copyright (C) 1996-2000 Dario Centofanti - (C) 2000-2002 Mailgate Srl), http://www.mailgate.org/.

MOOSE: http://www.globalpark.de/online_tools/moose/

Networds: http://www.networds.de

Union latine: http://www.unilat.org/

Verein Deutsche Sprache: http://vds-ev.de/ 


\subsubsection{Gesetzestexte (Frankreich)}

Décision $\mathrm{n}^{\circ} 94-345$ du Conseil constitutionnel du 29 juillet 1994: http://www.culture.fr/culture/dglf/lois/sommaire_loi.htm

Loi no 94-665 du 4 août 1994 relative à l'emploi de la langue française: http://www.culture.fr/culture/dglf/lois/sommaire_loi.htm

Décret du 3 mars 1995 pris pour l'application de la loi du 4 août 1994 relative à l'emploi de la langue française: http://www.culture.fr/culture/dglf/lois/ | sommaire_loi.htm

Circulaire du 19 mars 1996 concernant l'application de la loi du 4 août 1994 relative à l'emploi de la langue française: http://www.culture.fr/culture/|dglf/lois/sommaire_loi.htm

Circulaire du 15 mai 1996 relative à la communication, à l'information et à la documentation des services de l'Etat sur les nouveaux réseaux de télécommunication: http://www.adminet.com/jo/PRMX9601516C.html

Décret no 96-602 du 3 juillet 1996 relatif à l'enrichissement de la langue française: http://www.culture.fr/culture/dglf/terminologie/journal-off-5-7-96.|html, http://www.culture.fr:8895/decret030796.html

Arrêté du 5 août 1997 portant création de la commission spécialisée de terminologie et de néologie de l'informatique et des composants électroniques: http://www.admi.net/jo/ECO19700424A.html, http://www.adminet.com/jo/EC0197004254.html

Décret du 1er juillet 1998 modifiant le décret du 3 mars 1995 et pris pour l'application, dans le domaine des transports internationaux, de la loi du 4 août 1994 relative à l'emploi de la langue française: http://www.culture.fr/ |culture/dglf/lois/sommaire_loi.htm

Circulaire du 28 septembre 1999 concernant l'application, dans le domaine des transports, des dispositions des articles 3 et 4 de la loi no $94-665$ du 4 août 1994 relative à l'emploi de la langue française: http://www.culture.fr/|culture/dglf/lois/sommaire_loi.htm

Arrêté du 18 décembre 2000 portant nomination à la commission générale de terminologie et de néologie: http://admi.net/jo/20001229/MCCG0000|783A.html

Arrêté du 11 janvier 2001 portant nomination du président de la Commission générale de terminologie et de néologie: http://admi.net/jo/20010112/|PRMX0104596A.html

Arrêté du 27 mars 2001 portant création d'une commission spécialisée de terminologie et de néologie au ministère de la jeunesse et des sports: http://admi.net/jo/20010401/MJSK0170008A.html

Arrêté du 25 juin 2001 portant renouvellement de l'agrément d'associations de défense de la langue française: http://www.culture.fr/culture/dglf/lois/|sommaire_loi.htm

Circulaire du 20 septembre 2001 relative à l'application de l'article 2 de la loi du 4 août 1994 relative à l'emploi de la langue française: http://www.cul|- 
ture.fr/culture/dglf/lois/sommaire_loi.htm, http://www.adminet.com/jo/20011027/MCCG0100589C.html

Arrêté du 9 janvier 2002 portant nomination à la commission spécialisée de terminologie et de néologie de l'informatique et des composants électroniques: http://admi.net/jo/20020129/ECOI0100708A.html

\subsubsection{Terminologielisten und -datenbanken}

Anglicismes dans l'administration fédérale, Liste des termes recensés (Schweiz): http://www.admin.ch/ch/f/bk/sp/anglicismes/anglicismes-fr2.html

Banque de données terminologique du Service de la langue française du Ministère de la Communauté française de Belgique: http://www.|cfwb.be/franca/bd/bd.htm

CRITER (Frankreich): http://www.culture.fr/culture/dglf/terminolo gie/base-donnees.html

Dictionnaire panlatin des termes de base de l'informatique: http:/ /www.realiter.net/microinf/_BDT0.HTM\#Sommaire

EURODICAUTOM (European Terminology Database): http://europa.eu. |int/eurodicautom/login.jsp

Liste des termes, expressions et définitions du vocabulaire de l'informatique publiés au Journal officiel de la République française (en application du décret n 96-602 du 3 juillet 1996 relatif à l'enrichissement de la langue française) Journal Officiel du 10 octobre 1998: http://www.culture.fr/culture/dglf/|cogeter/10-10-98-3.htm).

Liste des termes, expressions et définitions adoptés et publiés au Journal officiel de la République française: Vocabulaire de l'internet (En application du décret $n^{\circ}$ 96-602 du 3 juillet 1996 relatif à l'enrichissement de la langue française), Journal Officiel du 1 septembre 2000: http://www.culture.fr/|culture/dglf/cogeter/1-9-00-internet.htm

Internet-Terminologie (Schweiz): http://www.admin.ch/ch/f/bk/sp/angli cismes/anglicismes-fr-2.html

Répertoire terminologique 2000 (Frankreich): http://www.culture.fr/|culture/dglf/terminologie/repertoireJO220900/accueil.htm

Banque de données terminologique (Belgien): http://www.cfwb.be/franca/ |bd/bd.htm, http://www.cfwb.be/franca/bd/bienvenu.htm

Vocabulaire de l'informatique et de l'internet, Journal officiel du 16 mars 1999: http:/ / www.culture.fr/culture/dglf/cogeter/16-03-99-internet.html

Vocabulaire d'Internet (Banque de terminologie du Québec), http://www.olf.|gouv.qc.ca/ressources/bibliotheque/dictionnaires/Internet/Index/

\subsubsection{Jahresberichte der DGLF/DGLFLF und der Commission générale de terminologie et de néologie}

15.8.9.1 Die Jabresberichte der DGLF/DGLFLF

Alle Berichte der DGLF/DGLFLF auf einen Blick (1996-2002):

http://www.culture.fr/culture/dglf/rapport/Liste_des_rapports.htm 
Die Adressen der einzelnen Berichte:

DGLF 1996: http://www.culture.fr/culture/dglf/rapport/1996/sommaire.htm

DGLF 1997: http://www.culture.fr/culture/dglf/rapport/1997/sommaire.htm DGLF 1998: http://www.culture.fr/culture/dglf/rapport/1998/rapport98-1.htm

DGLF 1999: http://www.culture.fr/culture/dglf/rapport/1999/sommaire.html

DGLF 2000: http://www.culture.fr/culture/dglf/rapport/2000/accueil.htm

DGLFLF 2001: http://www.culture.fr/culture/dglf/rapport/2001/accueil.htm

DGLFLF 2002: http://www.culture.fr/culture/dglf/rapport/2002/index.htm

DGLFLF 2003: http://www.culture.gouv.fr/culture/dglf/rapport/2003/index. |htm

15.8.9.2 Die Jahresberichte der Commission générale de terminologie et de néologie

COGETER 1998: http://www.culture.fr/culture/dglf/rapport/rap-act-98/rapannu-termino.html

COGETER 1999: http://www.culture.fr/culture/dglf/rapport/rap-act99/Annexe1-sommaire.html

COGETER 2000: (nicht im Anhang des DGLF-Berichts)

COGETER 2001: http://www.culture.gouv.fr/culture/dglf/cogeter/Rapport|2001/sommaire.htm

COGETER 2002: http://www.culture.gouv.fr/culture/dglf/cogeter/rapport2002/rapport-2002.rtf 


\subsection{Abbildungsverzeichnis}

Abb. 1: $\quad$ Direkte und indirekte Erhebungsverfahren in der linguis- 16

Abb. 2: $\quad$ Zusammensetzung der Informatik-Kommission 1997-2001 108 und 2002-2005/2006

Abb. 3: $\quad$ Beteiligung der Öffentlichkeit an der Terminologiearbeit der 113 CSTIC

Abb. 4: Die Internet-Terminologie in Frankreich, Belgien, der

Schweiz und Québec: 21 Termini und Definitionen

Abb. 5: Die sechs ausgewählten Internet-Termini und ihre fran-

zösischen Äquivalente

Abb. 6: Die offizielle Terminologieliste zum Vokabular des Internet vom 16. März 1999

Abb. 7: $\quad$ Schema zur Bestimmung der Wortbildung bei Ersatzwörtern

216

Abb. 8: Analyse der ausgewählten französischsprachigen Internet-

Termini

Abb. 9: $\quad$ Vor- und Nachteile von WWW-Befragungen

251

Abb. 10: Die Lexeme des ersten Fragebogenmoduls (inkl. der Testwörter)

Abb. 11: Geschlecht der Informanten (absolute Häufigkeit)

286

Abb. 12: Geschlecht der Informanten (prozentuale Häufigkeit) 286

Abb. 13: Alter der Informanten (Frankreich) 287

Abb. 14: Alter der Informanten (Belgien) 288

Abb. 15: Alter der Informanten (Schweiz) 288

Abb. 16: Höchster Bildungsabschluss der französischen Informanten 290

Abb. 17: Höchster Bildungsabschluss der belgischen Informanten 291

Abb. 18: Höchster Bildungsabschluss der schweizerischen Infor- 291

Abb. 19: Geburtsort der französischen Informanten 292

Abb. 20: Geburtsort der belgischen Informanten 292

Abb. 21: Geburtsort der schweizerischen Informanten 292

Abb. 22: Muttersprache(n) der französischen Informanten 293

Abb. 23: Englischkenntnisse der französischen Informanten 294

Abb. 24: Englischkenntnisse der belgischen Informanten 295

Abb. 25: Englischkenntnisse der schweizerischen Informanten 295

Abb. 26: Internetnutzung der französischen Informanten 297

Abb. 27: Internetnutzung der belgischen Informanten 298

Abb. 28: Internetnutzung der schweizerischen Informanten 298

Abb. 29: $\quad$ Frage 1, Bekanntheitsgrad der Termini courrier électronique, $\quad 302$ message électronique, mél, courriel, messagerie électronique, lettre électronique, e-mail und mail (absolute Häufigkeit, Frankreich) 
Abb. 30: $\quad$ Frage 1, Bekanntheitsgrad der Termini courrier électronique, message électronique, mél, courriel, messagerie électronique, lettre électronique, e-mail und mail (prozentuale Häufigkeit, Frankreich)

Abb. 31: $\quad$ Frage 2, Synonymie der Termini courrier électronique, message électronique, mél, courriel, messagerie électronique, e-mail und mail (Frankreich)

Abb. 32: $\quad$ Frage 3, Bedeutungsunterschiede zwischen courrier électronique, 304 message électronique, mél, courriel, messagerie électronique, e-mail und mail (Frankreich)

Abb. 33: $\quad$ Frage 4, persönliche Präferenz(en): courrier électronique etc. (absoute Häufigkeit, Frankreich)

Abb. 34: $\quad$ Frage 4, persönliche Präferenz(en): courrier électronique etc. (prozentuale Häufigkeit, Frankreich)

Abb. 35: Frage 5, eigener Sprachgebrauch: courrier électronique etc. (Frankreich)

Abb. 36: Frage 7, Gründe für die Bevorzugung der englischsprachigen Termini e-mail und mail (Frankreich)

Abb. 37: $\quad$ Frage 8, Bekanntheitsgrad der Termini page d'accueil, page d'introduction und homepage (absolute Häufigkeit, Frankreich)

Abb. 38: $\quad$ Frage 8, Bekanntheitsgrad der Termini page d'accueil, page

d'introduction und homepage (prozentuale Häufigkeit, Frankreich)

Abb. 39: $\quad$ Frage 9, Synonymie der Termini page d'accueil und homepage (Frankreich)

Abb. 40: $\quad$ Frage 10, Bedeutungsunterschiede zwischen page d'accueil und bomepage (Frankreich)

Abb. 41: Frage 11, persönliche Präferenz(en): page d'accueil, page d'introduction, homepage (absolute Häufigkeit, Frankreich)

Abb. 42: Frage 11, persönliche Präferenz(en): page d'accueil, page d'introduction, homepage (prozentuale Häufigkeit, Frankreich)

Abb. 43: $\quad$ Frage 12, eigener Sprachgebrauch: page d'accueil, page d'introduction, homepage (Frankreich)

Abb. 44: $\quad$ Frage 13, Bewertung des französischen Neologismus page d'accueil (Frankreich)

Abb. 45: $\quad$ Frage 15, Bekanntheitsgrad der Termini toile d'araignée mondiale, 321 toile mondiale, toile, T.A.M., réseau mondial, World Wide Web und web (absolute Häufigkeit, Frankreich)

Abb. 46: Frage 15, Bekanntheitsgrad der Termini toile d'araignée mondiale, 322 toile mondiale, toile, T.A.M., réseau mondial, World Wide Web und web (prozentuale Häufigkeit, Frankreich)

Abb. 47: Frage 16, Synonymie der Termini toile d'araignée mondiale, toile 323 mondiale, toile, T.A.M., World Wide Web und web (Frankreich) 
Abb. 48: $\quad$ Frage 17, Bedeutungsunterschiede zwischen toile d'araignée mondiale, toile mondiale, toile, T.A.M., World Wide Web und web (Frankreich)

Abb. 49: $\quad$ Frage 18, persönliche Präferenz(en): toile d'araignée mondiale etc. 324 (absolute Häufigkeit, Frankreich)

Abb. 50: $\quad$ Frage 18, persönliche Präferenz(en): toile d'araignée mondiale etc. 325 (absolute Häufigkeit, Frankreich)

Abb. 51: $\quad$ Frage 19, eigener Sprachgebrauch: toile d'araignée mondiale etc. 326 (Frankreich)

Abb. 52: $\quad$ Frage 21, Gründe für die Bevorzugung der englischsprachigen Termini web und World Wide Web (Frankreich)

Abb. 53: Frage 22, Bekanntheitsgrad der Termini causette, bavardage, conversation électronique und chat (absolute Häufigkeit, Frankreich)

Abb. 54: $\quad$ Frage 22, Bekanntheitsgrad der Termini causette, bavardage, conversation électronique und chat (prozentuale Häufigkeit, Frankreich)

Abb. 55: Frage 23, Synonymie der Termini causette, bavardage und chat (Frankreich)

Abb. 56: Frage 24, Bedeutungsunterschiede zwischen causette, bavardage und chat (Frankreich)

Abb. 57: $\quad$ Frage 25, persönliche Präferenz(en): causette, bavardage, conversation électronique, chat (absolute Häufigkeit, Frankreich)

Abb. 58: Frage 25, persönliche Präferenz(en): causette, bavardage, conversation électronique, chat (prozentuale Häufigkeit, Frankreich)

Abb. 59: Frage 26, eigener Sprachgebrauch: causette, bavardage, conversation électronique, chat (Frankreich)

Abb. 60: Frage 28, Gründe für die Bevorzugung des englischsprachigen Terminus chat (Frankreich)

Abb. 61: $\quad$ Frage 29, Bekanntheitsgrad der Termini pirate, fouineur und cracker (absolute Häufigkeit, Frankreich)

Abb. 62: $\quad$ Frage 29, Bekanntheitsgrad der Termini pirate, fouineur und 336 cracker (prozentuale Häufigkeit, Frankreich)

Abb. 63: Frage 30, Synonymie der Termini pirate und cracker 337 (Frankreich)

Abb. 64: Frage 32, persönliche Präferenz(en): pirate, fouineur, cracker (absolute Häufigkeit, Frankreich)

Abb. 65: Frage 32, persönliche Präferenz(en): pirate, fouineur, cracker (prozentuale Häufigkeit, Frankreich)

Abb. 66: Frage 33, eigener Sprachgebrauch: pirate, fouineur, cracker (Frankreich)

Abb. 67: Frage 34, Bewertung des französischen (Internet-) Neologismus pirate (Frankreich) 
Abb. 68: Frage 35, Gründe für die Bevorzugung des englischspra-

chigen Terminus cracker (Frankreich)

Abb. 69: Frage 36, Bekanntheitsgrad der Termini fournisseur d'accès,

pourvoyeur d'accès und (access) provider (absolute Häufigkeit,

Frankreich)

Abb. 70: Frage 36, Bekanntheitsgrad der Termini fournisseur d'accès,

pourvoyeur d'accès und (access) provider (prozentuale Häufigkeit,

Frankreich)

Abb. 71: $\quad$ Frage 37, Synonymie der Termini fournisseur d'accès und (access)

342 provider (Frankreich)

Abb. 72: Frage 39, persönliche Präferenz(en): fournisseur d'accès,

pourvoyeur d'accès, (access) provider (absolute Häufigkeit,

Frankreich)

Abb. 73: Frage 39, persönliche Präferenz(en): fournisseur d'accès,

pourvoyeur d'accès, (access) provider (prozentuale Häufigkeit, Frankreich)

Abb. 74: Frage 40, eigener Sprachgebrauch: fournisseur d'accès, pourvoyeur

d'accès, (access) provider (Frankreich)

Abb. 75: Frage 41, Bewertung des französischen Neologismus fournisseur d'accès (Frankreich)

Abb. 76: Bekanntheits- und Etablierungsgrad aller französischen und englischsprachigen Termini in \% (Frankreich)

Abb. 77: Frage 44, Kenntnis der aktuellen Sprachpolitik (Frankreich)

Abb. 78: Frage 45, Beurteilung der aktuellen Sprachpolitik (Frankreich) 351

Abb. 79: $\quad$ Frage 46, Beurteilung der Terminologielisten (Frankreich) 352

Abb. 80: Frage 47, Befolgen der Terminologielisten (Frankreich) 352

Abb. 81: $\quad$ Frage 48, Kenntnis der offiziellen Internet-Terminologie $\quad 354$ (Frankreich)

Abb. 82: $\quad$ Frage 49, Gebrauch der offiziellen Internet-Terminologie 355 (Frankreich)

Abb. 83: Argumente für die Befürwortung der Sprachpolitik (Frankreich)

Abb. 84: Argumente für die Ablehnung der Sprachpolitik (Frankreich) 360

Abb. 85: Argumente pro \& contra Terminologiearbeit (Frankreich) 360

Abb. 86: Argumente für die Befürwortung der Terminologiearbeit $\quad 361$ (Frankreich)

Abb. 87: Argumente für die Ablehnung der Terminologiearbeit 362 (Frankreich)

Abb. 88: Argumente pro \& contra Terminologiearbeit (Frankreich) 367

Abb. 89: $\quad$ Kreuztabelle: Korrelation zwischen Alter und Einstellung 371 (Kenntnis der aktuellen Sprachpolitik)

Abb. 90: Kreuztabelle: Korrelation zwischen Alter und Einstellung $\quad 372$ (Beurteilung der aktuellen Sprachpolitik) 
Abb. 91: Kreuztabelle: Korrelation zwischen Alter und Einstellung 373 (Beurteilung der Terminologielisten)

Abb. 92: Kreuztabelle: Korrelation zwischen Alter und Einstellung $\quad 374$ (Befolgen der Terminologielisten)

Abb. 93: Frage 1, Bekanntheitsgrad der Termini courrier électronique, 380 message électronique, mél, courriel, messagerie électronique, lettre électronique, e-mail und mail (absolute Häufigkeit, Belgien)

Abb. 94: Frage 1, Bekanntheitsgrad der Termini courrier électronique, 381 message électronique, mél, courriel, messagerie électronique, lettre électronique, e-mail und mail (prozentuale Häufigkeit, Belgien)

Abb. 95: $\quad$ Frage 2, Synonymie der Termini courrier électronique, message 382 électronique, mél, courriel, messagerie électronique, e-mail und mail (Belgien)

Abb. 96: Frage 3, Bedeutungsunterschiede zwischen courrier électronique, 382 message électronique, mél, courriel, messagerie électronique, e-mail und mail (Belgien)

Abb. 97: $\quad$ Frage 4, persönliche Präferenz(en): courrier électronique etc. (absolute Häufigkeit, Belgien)

Abb. 98: $\quad$ Frage 4, persönliche Präferenz(en): courrier électronique etc. (prozentuale Häufigkeit, Belgien)

Abb. 99: Frage 5, eigener Sprachgebrauch: courrier électronique etc. (Belgien)

Abb. 100: Frage 7, Gründe für die Bevorzugung der englischsprachigen 386 Termini e-mail und mail (Belgien)

Abb. 101: Frage 8, Bekanntheitsgrad der Termini page d'accueil, page d'introduction und homepage (absolute Häufigkeit, Belgien)

Abb. 102: Frage 8, Bekanntheitsgrad der Termini page d'accueil, page d'introduction und homepage (prozentuale Häufigkeit, Belgien)

Abb. 103: Frage 9, Synonymie der Termini page d'accueil und homepage (Belgien)

Abb. 104: Frage 10, Bedeutungsunterschiede zwischen page d'accueil und bomepage (Belgien)

Abb. 105: Frage 11, persönliche Präferenz(en): page d'accueil, page d'introduction, homepage (absolute Häufigkeit, Belgien)

Abb. 106: Frage 11, persönliche Präferenz(en): page d'accueil, page d'introduction, homepage (prozentuale Häufigkeit, Belgien)

Abb. 107: Frage 12, eigener Sprachgebrauch: page d'accueil etc. (Belgien)

Abb. 108: Frage 13, Bewertung des französischen Neologismus page d'accueil (Belgien)

Abb. 109: Frage 14, Gründe für die Bevorzugung des englischsprachigen Terminus homepage (Belgien)

Abb. 110: Frage 15, Bekanntheitsgrad der Termini toile d'araignée mondiale, 394 toile mondiale, toile, T.A.M., réseau mondial, World Wide Web und web (absolute Häufigkeit, Belgien) 
Abb. 111: Frage 15, Bekanntheitsgrad der Termini toile d'araignée mondiale, 395 toile mondiale, toile, T.A.M., réseau mondial, World Wide Web und web (prozentuale Häufigkeit, Belgien)

Abb. 112: Frage 16, Synonymie der Termini toile d'araignée mondiale, toile mondiale, toile, T.A.M., World Wide Web und web (Belgien)

Abb. 113: Frage 17, Bedeutungsunterschiede zwischen toile d'araignée 395 mondiale, toile mondiale, toile, T.A.M., World Wide Web und web (Belgien)

Abb. 114: Frage 18, persönliche Präferenz(en): toile d'araignée mondiale etc. 397 (absolute Häufigkeit, Belgien)

Abb. 115: Frage 18, persönliche Präferenz(en): toile d'araignée mondiale etc. 397 (prozentuale Häufigkeit, Belgien)

Abb. 116: Frage 19, eigener Sprachgebrauch: toile d'araignée mondiale etc. 398 (Belgien)

Abb. 117: Frage 21, Gründe für die Bevorzugung des englischspra399 chigen Terminus web (Belgien)

Abb. 118: Frage 22, Bekanntheitsgrad der Termini causette, bavardage, 400 conversation électronique und chat (absolute Häufigkeit, Belgien)

Abb. 119: Frage 22, Bekanntheitsgrad der Termini causette, bavardage, conversation électronique und chat (prozentuale Häufigkeit, Belgien)

Abb. 120: Frage 23, Synonymie der Termini causette, bavardage und chat (Belgien)

Abb. 121: Frage 25, persönliche Präferenz(en): causette, bavardage, conversation électronique, chat (absolute Häufigkeit, Belgien)

Abb. 122: Frage 25, persönliche Präferenz(en): causette, bavardage, 396 conversation électronique, chat (prozentuale Häufigkeit, Belgien)

Abb. 123: Frage 26, eigener Sprachgebrauch: causette, bavardage, conversation électronique, chat (Belgien)

Abb. 124: Frage 28, Gründe für die Bevorzugung des englischsprachigen Terminus chat (Belgien)

Abb. 125: Frage 29, Bekanntheitsgrad der Termini pirate, fouineur und 406 cracker (absolute Häufigkeit, Belgien)

Abb. 126: Frage 29, Bekanntheitsgrad der Termini pirate, fouineur und 406 cracker (prozentuale Häufigkeit, Belgien)

Abb. 127: Frage 30, Synonymie der Termini pirate und cracker (Belgien) 407

Abb. 128: Frage 32, persönliche Präferenz(en): pirate, fouineur, cracker $\quad 407$ (absolute Häufigkeit, Belgien)

Abb. 129: Frage 32, persönliche Präferenz(en): pirate, fouineur, cracker 408 (prozentuale Häufigkeit, Belgien)

Abb. 130: Frage 33, eigener Sprachgebrauch: pirate, fouineur, cracker 408 (Belgien)

Abb. 131: Frage 34, Bewertung des französischen (Internet-) Neo- 409 logismus pirate (Belgien) 
Abb. 132: Frage 35, Gründe für die Bevorzugung des englischsprachigen Terminus cracker (Belgien)

Abb. 133: Frage 36, Bekanntheitsgrad der Termini fournisseur d'accès, pourvoyeur d'accès und (access) provider (absolute Häufigkeit, Belgien)

Abb. 134: Frage 36, Bekanntheitsgrad der Termini fournisseur d'accès, pourvoyeur d'accès und (access) provider (prozentuale Häufigkeit, Belgien)

Abb. 135: Frage 39, persönliche Präferenz(en): fournisseur d'accès, pourvoyeur d'accès, (access) provider (absolute Häufigkeit, Belgien)

Abb. 136: Frage 39, persönliche Präferenz(en): fournisseur d'accès, pourvoyeur d'accès, (access) provider (prozentuale Häufigkeit, Belgien)

Abb. 137: Frage 40, eigener Sprachgebrauch: fournisseur d'accès, pourvoyeur d'accès, (access) provider (Belgien)

Abb. 138: Frage 41, Bewertung des französischen Neologismus fournisseur d'accès (Belgien)

Abb. 139: Frage 42, Gründe für die Bevorzugung des englischsprachigen Terminus (access) provider (Belgien)

Abb. 140: Bekanntheits- und Etablierungsgrad aller französischen und englischsprachigen Termini in \% (Belgien)

Abb. 141: Frage 44, Kenntnis der aktuellen Sprachpolitik (Belgien)

Abb. 142: Frage 45, Beurteilung der aktuellen Sprachpolitik (Belgien) 418

Abb. 143: Frage 46, Beurteilung der Terminologielisten (Belgien)

Abb. 144: Frage 47, Befolgen der Terminologielisten (Belgien)

Abb. 145: Frage 48, Kenntnis der offiziellen Internet-Terminologie

Abb. 146: Argumente für die Befürwortung der Sprachpolitik (Belgien)

Abb. 147: Argumente für die Ablehnung der Sprachpolitik (Belgien) 422

Abb. 148: Argumente pro \& contra Sprachpolitik (Belgien)

Abb. 149: Argumente für die Ablehnung der Terminologiearbeit (Belgien)

Abb. 150: Frage 1, Bekanntheitsgrad der Termini courrier électronique, message électronique, mél, courriel, messagerie électronique, lettre électronique, e-mail und mail (absolute Häufigkeit, Schweiz)

Abb. 151: Frage 1, Bekanntheitsgrad der Termini courrier électronique, 430 message électronique, mél, courriel, messagerie électronique, lettre électronique, e-mail und mail (prozentuale Häufigkeit, Schweiz)

Abb. 152: Frage 2, Synonymie der Termini courrier électronique, message électronique, mél, courriel, messagerie électronique, e-mail und mail (Schweiz)

Abb. 153: Frage 3, Bedeutungsunterschiede zwischen courrier électronique, message électronique, mél, courriel, messagerie électronique, e-mail und mail (Schweiz) 
Abb. 154: Frage 4, persönliche Präferenz(en): courrier électronique etc.

431

(absolute Häufigkeit, Schweiz)

Abb. 155: Frage 4, persönliche Präferenz(en): courrier électronique etc.

(prozentuale Häufigkeit, Schweiz)

Abb. 156: Frage 5, eigener Sprachgebrauch (courrier électronique etc.)

(Schweiz)

Abb. 157: Frage 7, Gründe für die Bevorzugung der englischsprachigen 434

Termini e-mail und mail (Schweiz)

Abb. 158: Frage 8, Bekanntheitsgrad der Termini page d'accueil, page

436

d'introduction und homepage (absolute Häufigkeit, Schweiz)

Abb. 159: Frage 8, Bekanntheitsgrad der Termini page d'accueil, page

d'introduction und homepage (prozentuale Häufigkeit, Schweiz)

Abb. 160: Frage 9, Synonymie der Termini page d'accueil und homepage (Schweiz)

Abb. 161: Frage 10, Bedeutungsunterschiede zwischen page d'accueil und homepage (Schweiz)

Abb. 162: Frage 11, persönliche Präferenz(en): page d'accueil, page

d'introduction, homepage (absolute Häufigkeit, Schweiz)

Abb. 163: Frage 11, persönliche Präferenz(en): page d'accueil, page

d'introduction, homepage (prozentuale Häufigkeit, Schweiz)

Abb. 164: Frage 12, eigener Sprachgebrauch: page d'accueil, page

d'introduction, bomepage (Schweiz)

Abb. 165: Frage 14, Gründe für die Bevorzugung des englischsprachigen Terminus homepage (Schweiz)

Abb. 166: Frage 15, Bekanntheitsgrad der Termini toile d'araignée mondiale, 441 toile mondiale, toile, T.A.M., réseau mondial, World Wide Web und web (absolute Häufigkeit, Schweiz)

Abb. 167: Frage 15, Bekanntheitsgrad der Termini toile d'araignée mondiale, 441 toile mondiale, toile, T.A.M., réseau mondial, World Wide Web und web (prozentuale Häufigkeit, Schweiz)

Abb. 168: Frage 16, Synonymie der Termini toile d'araignée mondiale, toile 442 mondiale, toile, T.A.M., World Wide Web und web (Schweiz)

Abb. 169: Frage 18, persönliche Präferenz(en): toile d'araignée mondiale etc. 443 (absolute Häufigkeit, Schweiz)

Abb. 170: Frage 18, persönliche Präferenz(en): toile d'araignée mondiale etc. 443 (prozentuale Häufigkeit, Schweiz)

Abb. 171: Frage 19, eigener Sprachgebrauch: toile d'araignée mondiale etc. 444 (Schweiz)

Abb. 172: Frage 21, Gründe für die Bevorzugung des englischspra445 chigen Terminus web (Schweiz)

Abb. 173: Frage 22, Bekanntheitsgrad der Termini causette, bavardage, 446 conversation électronique und chat (absolute Häufigkeit, Schweiz) 
Abb. 174: Frage 22, Bekanntheitsgrad der Termini causette, bavardage, conversation électronique und chat (prozentuale Häufigkeit, Schweiz)

Abb. 175: Frage 23, Synonymie der Termini causette, bavardage und chat (Schweiz)

Abb. 176: Frage 24, Bedeutungsunterschiede zwischen causette, bavardage und chat (Schweiz)

Abb. 177: Frage 25, persönliche Präferenz(en): causette, bavardage, conversation électronique, chat (absolute Häufigkeit, Schweiz)

Abb. 178: Frage 25, persönliche Präferenz(en): causette, bavardage, conversation électronique, chat (prozentuale Häufigkeit, Schweiz)

Abb. 179: Frage 26, eigener Sprachgebrauch: causette, bavardage, conversation électronique, chat (Schweiz)

Abb. 180: Frage 28, Gründe für die Bevorzugung des englischsprachigen Terminus chat (Schweiz)

Abb. 181: Frage 29, Bekanntheitsgrad der Termini pirate, fouineur und 452 cracker (Schweiz)

Abb. 182: Frage 29, Bekanntheitsgrad der Termini pirate, fouineur und cracker (prozentuale Häufigkeit, Schweiz)

Abb. 183: Frage 30, Synonymie der Termini pirate und cracker (Schweiz)

Abb. 184: Frage 32, persönliche Präferenz(en): pirate, fouineur, cracker (Schweiz)

Abb. 185: Frage 32, persönliche Präferenz(en): pirate, fouineur, cracker (prozentuale Häufigkeit, Schweiz)

Abb. 186: Frage 33, eigener Sprachgebrauch: pirate, fouineur, cracker 455 (Schweiz)

Abb. 187: Frage 35, Gründe für die Bevorzugung des englischsprachigen Terminus cracker (Schweiz)

Abb. 188: Frage 36, Bekanntheitsgrad der Termini fournisseur d'accès, pourvoyeur d'accès und (access) provider (Schweiz)

Abb. 189: Frage 36, Bekanntheitsgrad der Termini fournisseur d'accès, pourvoyeur d'accès und (access) provider (prozentuale Häufigkeit, Schweiz)

Abb. 190: Frage 39, persönliche Präferenz(en): fournisseur d'accès, pourvoyeur d'accès, (access) provider (Schweiz)

Abb. 191: Frage 39, persönliche Präferenz(en): fournisseur d'accès, 458 pourvoyeur d'accès, (access) provider (prozentuale Häufigkeit, Schweiz)

Abb. 192: Frage 40, eigener Sprachgebrauch: fournisseur d'accès, pourvoyeur d'accès, (access) provider (Schweiz)

Abb. 193: Frage 35, Gründe für die Bevorzugung des englischsprachigen Terminus (access) provider (Schweiz)

Abb. 194: Bekanntheits- und Etablierungsgrad aller französischen und englischsprachigen Termini in \% (Schweiz) 
Abb. 195: $\quad$ Frage 44, Beurteilung der aktuellen Sprachpolitik (Schweiz) 464

Abb. 196: Frage 45, Kenntnis der offiziellen Internet-Terminologie $\quad 464$ (Schweiz)

Abb. 197: Frage 47, Kenntnis der aktuellen französischen Sprach- 465 planung (Schweiz)

Abb. 198: Frage 48, Befolgen der französischen Sprachplanung 465

Abb. 199: Argumente für die Befürwortung der Sprachpolitik (Schweiz) 467

Abb. 200: Argumente für die Ablehnung der Sprachpolitik (Schweiz) 467

Abb. 201: Argumente für die Ablehnung der Terminologiearbeit 468 (Schweiz)

Abb. 202: $\quad$ Frage 1, Bekanntheitsgrad der Termini courrier électronique, $\quad 472$ message électronique, mél, courriel, messagerie électronique, lettre électronique, e-mail und mail (relative Häufigkeiten, Ländervergleich)

Abb. 203: Frage 3, Bedeutungsunterschiede zwischen courrier électronique, message électronique, mél, courriel, messagerie électronique, e-mail und mail (absolute Häufigkeiten, Ländervergleich)

Abb. 204: Frage 5, eigener Sprachgebrauch: courrier électronique etc. (relative Häufigkeiten, Ländervergleich)

Abb. 205: Frage 8, Bekanntheitsgrad der Termini page d'accueil, page

d'introduction und homepage (relative Häufigkeiten, Ländervergleich)

Abb. 206: Frage 12, eigener Sprachgebrauch: page d'accueil, page

d'introduction, homepage (Ländervergleich)

Abb. 207: Frage 15, Bekanntheitsgrad der Termini toile d'araignée mondiale, 477 toile mondiale, toile, T.A.M., réseau mondial, World Wide Web und web (relative Häufigkeiten, Ländervergleich)

Abb. 208: Frage 19, eigener Sprachgebrauch: toile d'araignée mondiale etc. (Ländervergleich)

Abb. 209: Frage 22, Bekanntheitsgrad der Termini causette, bavardage, conversation électronique und chat (relative Häufigkeiten, Ländervergleich)

Abb. 210: Frage 26, eigener Sprachgebrauch: causette, bavardage, con480 versation électronique, chat (Ländervergleich)

Abb. 211: Frage 29, Bekanntheitsgrad der Termini pirate, fouineur und cracker (relative Häufigkeiten, Ländervergleich)

Abb. 212: Frage 33, eigener Sprachgebrauch: pirate, fouineur, cracker (Ländervergleich)

Abb. 213: Frage 36, Bekanntheitsgrad der Termini fournisseur d'accès, 478 pourvoyeur d'accès und (access) provider (Ländervergleich)

Abb. 214: Frage 40, eigener Sprachgebrauch: fournisseur d'accès, pourvoyeur d'accès, (access) provider (Ländervergleich)

Abb. 215: Bekanntheits- und Etablierungsgrad aller französischen und englischsprachigen Termini in \% (Ländervergleich) 
Abb. 216: Frage 44, Kenntnis der aktuellen Sprachpolitik (Ländervergleich: Frankreich und Belgien)

Abb. 217: Frage 47, Kenntnis der aktuellen französischen Sprachpolitik 490 (Schweiz)

Abb. 218: Frage 45, Beurteilung der aktuellen Sprachpolitik (Ländervergleich: Frankreich, Belgien und Schweiz)

Abb. 219: Frage 46, Beurteilung der Terminologielisten (Ländervergleich: Frankreich und Belgien)

Abb. 220: Frage 47, Befolgen der Terminologielisten (Ländervergleich: 492 Frankreich und Belgien)

Abb. 221: Frage 48, Kenntnis der offiziellen Internet-Terminologie 493 (Ländervergleich: Frankreich, Belgien und Schweiz)

Abb. 222: Frage 49, Gebrauch der offiziellen Internet-Terminologie 494 (Ländervergleich: Frankreich, Belgien und Schweiz)

Abb. 223: Berufsgruppen der französischen Informanten 574

Abb. 224: Genaue Berufsbezeichnungen der französischen Informanten 575

Abb. 225: Berufsgruppen der belgischen Informanten 576

Abb. 226: Genaue Berufsbezeichnungen der belgischen Informanten $\quad 577$

Abb. 227: Berufsgruppen der schweizerischen Informanten 577

Abb. 228: Genaue Berufsbezeichnungen der schweizerischen In- $\quad 578$ formanten

Abb. 229: Wohnsitz der französischen Informanten 579

Abb. 230: Wohnsitz der belgischen Informanten 580

Abb. 231: Wohnsitz der schweizerischen Informanten 580

Abb. 232: Präsenz verschiedener Sprachen im Internet 605

Abb. 233: Glossar der verwendeten Internet-Termini 606 


\subsection{Sachindex}

Dieser Sachindex ist kapitelbezogen.

Abbruchquote 7.1.1.2

abréviation (s. Kurzwort)

Abstraktheit 11.1.7

Académie des enfants 3.2.2

Académie des sciences 3.2.2

Académie française 2.3.2, 2.3.4.2.3, 3.1.2, 3.2.1, 3.2.2, 3.2.3.2, 3.2.4.2, $3.2 .5,3.3 .2,4.2,9.1 .1$

accent aigu 5.2.3.2

Accord du 22 mars 1999 3.3.1

ACCT 3.3.2, 3.3.3

Adaptation, ausdrucksseitig 5.2.3.1

Adäquatheit 4.3.1, 8.1.2.1, 9.1.2, 9.1.5, 9.1.6, 10.1.2, 10.1.5, 10.1.6, 11.1.2, 11.1.7, 12.1.6

Adjektiv 2.2, 3.3.4, 4.4.1, 5.2.3.1, 7.1.2.1, 10.3

-, bipolar 7.1.2.1

Adressat 1.1, 4.5, 5.1, 6.3.1, 7.1.2, 11.1.2

AFAL 3.2.3.1

affektiv (s. Einstellungsdimension)

AFNOR 3.2.2, 3.2.5, 3.3.3, 15.8.3

AFTERM 3.2.2

AGULF 3.2.2

AIF 3.3.3.1, 15.8.2

AILF 3.2.2, 3.2.5, 14, 15.8.3

AISLF 3.2.2, 15.8.3

Akademie 2.3.2, 2.3.4.2.3, 3.2.2, 3.3.2, 12.5

Akronym 4.2, 5.2, 5.2.1, 5.2.3.1, 5.2.3.2, $5.4,9.1 .3,9.1 .4,9.3,14,15.5$

Akzent 2.3.2, 2.3.3.2.2, 2.3.3.2.4, 2.3.3.4, 2.3.4.2.4, 5.2.1

Akzeptanz

-, aktiv 4.3, 4.3.1, 4.3.3, 5.3.1, 7.1.2.1, 8.1.1, 9.1.1, 9.1.2, 9.1.3, 9.1.4, 9.1.5, 9.1.6, 9.1.7, 9.2.1, 9.2.2, 9.5, 10.1.1,

10.1.2, 10.1.6, 10.1.7, 11.1.2, 11.1.3, 11.1.7, 12.1.1, 12.4, 13

-, passiv 4.3, 4.3.1, 4.3.3, 8.1.1, 9.1.1, 9.1.2, 9.1.3, 9.1.4, 9.1.5, 9.1.6, 9.1.7, 9.2.1, 9.2.2, 9.5, 10.1.6, 10.3, 11.1.2, 11.1.5, 11.1.6, 13

Akzeptanzmodell 4.3, 4.3.1

Akzeptanzvotum 9.1.2, 9.5, 10.1.2, 10.1.6, 10.4, 11.1.5, 11.1.6, 11.4, 12.1.5, 12.1.6

Akzeptanzwert 2.3.4.2.4, 2.3.4.4, 5.3.1, $9.1 .2,9.1 .5,9.1 .6,9.4 .2,10.1 .2$, 10.1.5, 10.1.6, 11.1.2, 11.1.6, 12.1.5

ALF 3.2.2, 3.2.3.1

Allgemeinsprache (s. Gemeinsprache)

Allgemeinverständlichkeit (s. Verständlichkeit)

Alltagskommunikation 4.4.1

Alter 2.1, 2.2, 2.3.3.2.2, 2.3.3.2.4, 2.3.4.2.2, 4.3.1, 5.1, 5.3, 5.3.2, 6.3.1, 7.1.2.3, 8.2, 8.2.2, 9.3, 9.4, 9.4.2, 9.4.2.1, 9.4.2.2, 9.5, 11, 12

Amtsfranzösisch (Schweiz, s. français fédéral)

Amtssprache 2.3.1, 2.3.4.1, 2.3.4.2.1, 3.2, 10.4

Anglizismendebatte 3.2.1, 4.3, Anglizismeneinfluss 4.2, 10.4, 12.2 Anglizismenquote 2.3.3.3, 4, 4.2, 4.4.1 Anglizismenwörterbuch 2.1, 2.3.2 Anglizismus 1.1, 2.1, 2.3.1, 2.3.2, 2.3.3.2.3, 2.3.3.3, 2.3.3.4, 2.3.4.2.1, 2.3.4.2.3, 2.3.4.2.4, 2.3.4.3, 2.3.4.4, 2.4, 3.1.2, 3.1.3, 3.2, 3.2.1, 3.2.2, 3.2.3.1, 3.2.4.1, 3.2.4.2, 3.2.6, 3.3.1, 3.3.2, 3.3.4, 4, 4.2, 4.3, 4.3.1, 4.3.2, 4.3.3, 4.4.1, 4.4.2.3, 4.5, 5.1, 5.2, 5.2.1, 5.2.3.1, 5.2.3.2, 5.3.1, 5.3.2, 5.3.3.2, 5.4, 7.1.2, 7.1.2.1, 7.1.2.2, 
8.2, 8.2.8, 8.2.9, 9.1.1, 9.1.2, 9.1.3, 9.1.6, 9.1.7, 9.2.1, 9.3, 9.4.1, 9.4.2.1, 9.4.5, 9.4.6, 9.5, 10.1.1, 10.1.2, 10.1.3, 10.1.6, 10.1.7, 10.2.1, 10.2.2, 10.3, 10.4, 11.1.1, 11.1.2, 11.1.3, 11.1.4, 11.1.5, 11.1.7, 11.2.1, 11.3, 11.4, 12.1.2, 12.1.6, 12.1.7, 12.2, $12.3,12.4,12.5,13$

(anglo-)amerikanisch 2.2, 2.3.1, 2.3.2, 2.3.3.3, 3, 3.1.3, 3.2.1, 3.2.2, 3.3.2,

3.3.4, 4.4.1, 4.4.2.3, 5.1, 5.2.1, 5.2.3.1, 5.2.3.2, 5.3.2, 9.1.4, 9.3, 9.4.1, 10.1.2, 12.4, 12.5, 13

(Anglo-)Amerikanismus 1.1, 2.3.2, 2.3.3.3, 3.1.2, 3.2.1, 3.2.2, 3.2.7, 4.4.1, 5.1

anglophil 4.3.1, 10.1.4, 12.5, 15.5.1.2.4

Anglophilie 10.1.4, 10.4

Anglophobie 2.3.3.3

Antiamerikanismus 2.3.3.3, 3.1.2, 3.2.1 Antwortmöglichkeit (s. Antwortoption) Antwortoption 2.2, 6.3.2, 7.1.1.2, 7.1.2, 7.1.2.1, 7.2.2, 7.3, 9.1.1, 9.1.5, 9.2.1, $9.3,10.3,15.3$

APFA 3.2.2, 15.8.3

Archaismus 4.3, 4.3.1

arrêté (s. Erlass)

Assimilierung 4.3.2, 9.1.7

Association Force Ouvrière Consommateurs 3.2.3.1

Assoziationen 5.1, 7.1.2.1

Ästhetik 1.1, 2.3.4.3, 9.1.6

ästhetisch 2.3.2, 2.3.4.3, 4.3.1, 4.4.1, 5.2.1, 7.1.1.3, 7.1.2.1, 8.2, 8.2.6, 9.1.1, 9.1.2, 9.1.5, 9.3, 9.5, 10.1.2, 10.1.5, 10.1.6, 11.1.3, 11.1.4, 11.1.5, 11.1.6, 11.1.7, 11.4, 12.1.2, 12.1.5, 12.1.6, 12.3

Ausgangssprache 5.2.3.1

Aussageabsicht 9.1.2, 11.1.2

Aussprache 2.2, 2.3.2, 4.3.1, 5.1, 5.2.1, 5.2.3.2, 5.3.2

-, pseudoenglisch 5.2.3.2, 5.3.1, 9.1.1, 10.1.1
Aussprachegewohnheit (s. Gewohnheit)

Aussprachewörterbuch 2.3.3.2.3

Auswertung, qualitativ 2.2, 7.1.1.2

Auswertung, quantitativ 2.2, 7.1.1.2

autochthon (s. Bildung, autochthon)

Balnéo 3.3.3.1

Banque de données terminologique (Belgien) 3.3.1, 3.3.2, 15.3, 15.8.8

Bearbeitungszeit (s. Fragebogen)

Bedeutungsänderung 9.1.1

Bedeutungsäquivalenz (s. Synonymie)

Bedeutungsdifferenzierung 12.3

Bedeutungserweiterung 5.2.1

bedeutungsgleich (s. synonym)

Bedeutungsgleichheit (s. Synonymie)

Bedeutungsreduzierung 11.1.4

Bedeutungsunterschied 7.1.2, 7.2.1.2, 9.1, 9.1.1, 9.1.2, 9.1.3, 9.1.4, 9.1.5, 9.1.6, 9.1.7, 9.5, 10.1.1, 10.1.2, 10.1.3, 10.1.4, 10.1.5, 10.1.6, 11.1.1, 11.1.2, 11.1.3, 11.1.4, 11.1.5, 11.1.6, 12.1, 12.1.1, 12.1.2, 12.1.3, 12.1.4, 12.1.5, 12.1.6, 12.1.7, 12.4, 15.5.1, 15.5.1.1.1, 15.5.1.1.2, 15.5.1.1.3, 15.5.1.1.4, 15.5.1.1.5, 15.5.1.2.1, 15.5.1.2.2, 15.5.1.2.3, 15.5.1.2.4, 15.5.1.3.1, 15.5.1.3.2, 15.5.1.3.3, 15.5.1.3.4

Bedeutungsvielfalt 9.1.1, 9.1.7

Befragung

- Ankündigung (s. Fragebogen)

- mündliche Befragung 2.2, 2.4, 4.3, 4.3.1

- Online-Befragung 1.2, 2.2, 6, 6.1, 6.2, 6.3.1, 6.3.2, 6.4, 6.5, 9

- Papier-Bleistift-Befragung 6, 6.3.2, 7

- schriftliche Befragung 2.2, 2.4, 4.3,

$$
6.1,6.2,6.3 .1,7
$$


- WWW-Befragung 1.1, 1.2, 1.3, 2.2, 3.3.4, 4.3, 4.3.1, 4.3.2, 4.3.3, 4.4.2, $4.5,5,5.2 .2,5.3 .3 .3,5.4,6,6.1,6.2$, 6.3, 6.3.1, 6.3.2, 6.4, 6.5, 7, 7.1.1, 7.1.2, 7.1.3, 8, 8.1, 9, 9.3, 9.4.2.2, 10, $11,12,12.4,13,15.3$

behavioristisch 2.1

Behörden der Schweizerischen Eidgenossenschaft (s. Bundeskanzlei, schweizerisch)

Bekanntheitsgrad 3.2.4.1, 3.3.4, 4.3, 4.3.1, 4.3.3, 4.5, 5.2, 5.2.2, 5.3.3.2, 5.4, 6.1, 7.1.2, 9.1.1, 9.1.2, 9.1.3, 9.1.4, 9.1.5, 9.1.6, 9.1.7, 9.2.1, 9.5, 10.1.1, 10.1.2, 10.1.3, 10.1.4, 10.1.5, 10.1.6, 10.1.7, 10.2.2, 11.1.1, 11.1.2, 11.1.3, 11.1.4, 11.1.5, 11.1.6, 11.1.7, 12.1, 12.1.1, 12.1.2, 12.1.3, 12.1.4, 12.1.5, 12.1.6, 12.1.7, 12.4, 13

Belgizismus 2.3.3.2.2, 2.3.3.2.3, 2.3.3.2.4, 2.3.3.4, 2.3.4.2.1, 2.3.4.2.3, 3.3 .1

Bella Lingua 12.5

Benutzungsfrequenz (s. Gebrauchsfrequenz)

Beobachtung, teilnehmend 2.2, 2.3.4.2.2, 6.1

Beobachtungsverfahren 2.2

Bevölkerungsschicht 1.3, 3.2.4.2, 3.2.6, 4.3.3., 6.1, 7.1.2.1, 9.1.1, 13

Bezeichnungsbedürfnis 3.3.3.1, 4.1, 5.1, 12.5

Bildung, autochthon 4.1, 5.1

Bildungstyp 4.3.1, 5.1, 5.2.1, 5.2.3.1, 5.2.3.2, 11.1.7

Bilinguismus 9.3

bon goût 3.2.1

bon usage (guter Sprachgebrauch)

2.3.2, 2.4, 3.2.1

Bon Usage (Grevisse) 2.3.3.2.3

BSI 3.3.3

Bulletin officiel du Ministère de l'Éducation nationale 3.2.3.2, 3.2.4.1
Bundesbehörden, schweizerisch (s. Bundeskanzlei, schweizerisch)

Bundeskanzlei, schweizerisch 1.1, 2.3.4.1, 2.3.4.2.1, 3.3.2, 3.3.3, 3.3.3.2, 3.3.4, 3.3.5, 5.3.3.3, 12.2, 15.8 .5

Bundesverwaltung, schweizerisch (s. Bundeskanzlei, schweizerisch) bündnerromanisch 2.3.2, 2.3.4.1

Centre de dialectologie et de français régional (Schweiz) 2.3.4.2.3

Centre d'étude du français moderne et contemporain (Frankreich) 3.2.2

Cercle de presse Richelieu (Frankreich) 3.2.1

CETMF (Frankreich) 3.2.2

Chancellerie fédérale de Berne (s. Bundeskanzlei, schweizerisch)

Charte de la langue française (Belgien) 3.3.1

Charte de la langue française (Québec) 2.3.1

Charte européenne des langues régionales ou minoritaires 3.1 .2

Checkbox 7.1.1.2, 7.1.2

CIDIF (Québec) 3.2.5, 15.8.4

CILF (Frankreich) 2.3.1, 3.2.1, 3.2.4.2, 3.2.5, 15.8.2

circulaire 3.2.3.1, 15.8.7

clarté 2.3.2, 3.2.1, 3.2.3.2, 3.3.2, 4.4.1

CMT (Frankreich) 3.1.3, 3.2.2, 3.2.3.2, 3.2.4.2, 3.2.5, 3.2.7, 4.4.1

CNRS (Frankreich) 3.2.2, 3.2.5, 3.3.3.2, 4.3, 15.8 .3

codification 3.1.1, 3.1.3

Comité consultatif de la langue française (Frankreich) 3.2.1

Comité consultatif du langage scientifique (Frankreich) 3.2.1

Comité d'étude des termes techniques français (Frankreich) 3.2.1, 3.2.2, 3.2 .5 
Comité interministériel pour les affaires francophones 3.3.3

Comités expérimentaux de terminologie (Belgien) 3.3.1

Commissariat général de la langue française (Frankreich) 3.2.1, 3.2.2

Commission de défense de la langue française en matière d'informatique (Frankreich) 3.2.5

Commission de terminologie de l'éducation (Québec) 4

Commission générale de terminologie (Frankreich) 3.2.1, 3.2.3.2

Commission générale de terminologie et de néologie (Frankreich) 3.1.3, 3.2.1, 3.2.2, 3.2.3.1, 3.2.3.2, 3.2.4.1, 3.2.4.2, 3.2.5, 3.2.6, 3.2.7, 3.3, 3.3.1, 3.3.2, 4.3, 4.4.1, 5.1, 9.1.1, 15.8.7, 15.8.9, 15.8.9.2

Communauté française de Belgique 1.1, 2.3.1, 2.3.3.1, 2.3.3.2.3, 3.3.1, 3.3.3, 3.3.3.1, 3.3.3.2, 3.3.5, 15.2.3, 15.8 .8

communiqué de mises en garde 3.2.2, 4.2

Conseil de la Communauté (Belgien) 3.3.1

Conseil de la langue française (Belgien) 3.3.1

Conseil supérieur de la langue française (Belgien) 3.3.1

Conseil Supérieur de la langue française (Frankreich) 3.2.1

Conseils d'utilisation (s. Diskussionsforum)

C.Q.F.D. (Belgien) 3.3.1, 15.8.1

créativité lexicale 4.1, 9.3

CRITER (Frankreich) 3.2.4.1, 3.2.4.2, 3.2.6, 3.2.7, 3.3.4, 15.8 .8

CST (Frankreich) 3.2.3.2, 3.2.4.2, 3.2.6

CSTIC (Frankreich) 3.2.5, 3.3.4, 4.3.2, 15.2.3,15.8.3, 9.3

CTN (Frankreich) 3.2.2
Datenbank (Terminologie-Datenbank)

1.1, 2.3.4.2.1, 3.2.2, 3.2.4.2, 3.2.5,

3.2.6, 3.2.7, 3.3.1, 3.3.2, 3.3.3.1,

3.3.4, 3.3.5, 4.3.1, 5.3.3.2, 5.3.3.3,

6.3.2, 7.1.2.2, 9.1.2, 9.2.1, 9.3,

10.1.2, 10.1.4, 10.1.7, 10.2.1, 10.2.2,

11.2.1, 12.1.7, 15.2.3, 15.8.8

DDC (Frankreich) 3.2.3.1

décret (s. Dekret)

décret Spaak (Belgien) 2.3.3.2.4, 3.3.1, 5.3.3.2, 10.2.1, 15.8.1

Défense du français (Schweiz)

2.3.4.2.1, 15.8.5

Dekret 1.1, 2.3.3.1, 3.1.4, 3.2.2, 3.2.3, 3.2.3.1, 3.2.3.2, 3.2.4.2, 3.2.5, 3.2.7, 3.3.1, 3.3.2, 3.3.4, 4.3, 4.3.1, 4.4.1, 9.3, 11.2.1, 15.8.7, 15.8.8

Denglisch 12.5

Derivation 4.3.1, 5.1, 9.1.5

Derivationsmorphem 5.1

Determinans 5.2.3.1

Determinativkompositum 3.3.4, 5.1, 5.2.1, 5.2.3.1, 9.1.2

Determinatum 5.2.3.1

DGCCRF (Frankreich) 3.2.3.1

DGLFLF (Frankreich) 1.1, 2.3.1, 3.1.2,

3.1.3, 3.2.1, 3.2.3.1, 3.2.3.2, 3.2.4.1,

3.2.4.2, 3.2.5, 3.2.6, 4.3, 4.3.3, 4.4.2.1,

5.3.3.1, 12.4, 15.2.3, 15.3, 15.6, 15.8.3,

15.8.9, 15.8.9.1

diachron (diachronisch) 4.3.1, 4.3.3, 4.4.1, 11.1.1, 12.2, 13

Dialektsprecher 2.1, 2.3.2

Dictionnaire de l'internaute 3.2.5, 15.8 .4

Dictionnaire de la langue française (Littré) 2.3.4.2.3

Dictionnaire des néologismes officiels 3.2.2, 4.3.1

Dictionnaire panlatin des termes de base de l'informatique 3.3.3.2, 15.8 .8 
Diskussionsforum 1.2, 3.3.4, 5.2.1, 5.2.3.2, 6.2, 6.4, 8.1.1, 8.1.2.2, 8.1.2.3, 8.1.2.4, 8.1.2.5, 8.1.2.6, 8.1.2.7, 8.1.2.8, 8.1.2.9

- Conseils d'utilisation 5.2.1, 8.1.2.1, 8.1.2.2, 8.1.2.3, 8.1.2.4, 8.1.2.5, 8.1.2.6, 8.1.2.7, 8.1.2.8, 8.1.2.9

Distanznorm 4.4.2

DLF (Frankreich) 3.2.1, 3.2.2, 3.2.3.1, 15.8.3

DLF (Schweiz) 2.3.4.2.3, 2.3.4.3, 3.3.5, 11.2.1, 15.8.5

DOM-TOM 2.3.1, 8.2.5, 15.3, 15.4.2

Doppeldeutigkeit 10.1.4, 11.1.4

Drop-down-Menü 7.1.1.2, 7.1.2

DSR (Schweiz) 2.3.4.2.3, 2.3.4.4

Durchschnittsleser 5.3.1

Durchschnittssprecher 5.3.1

Edikt von Villers-Cotterêts 3.2 eindeutig (s. monosem)

Einfachheit, sprachlich 4.3.1, 5.1, 5.2.1, 9.1.2, 9.1.5, 9.1.6, 10.1.2, 10.1.5, 10.1.6, 11.1.2

Eingängigkeit 5.1, 5.2.1

Einsilbigkeit 5.1

Einsprachigkeit 2.3.3.1, 2.3.4.1, 3.1.2

Einstellungsdimension

-, affektiv 2.1, 2.2, 2.3.2, 2.4, 5.3.1, 7.1.2, 7.1.2.1, 8.2

-, ästhetisch-affektiv 7.1.2.1

-, instrumental-kognitiv 7.1.2.1

-, kognitiv 2.1, 2.4, 7.1.2, 9.2.1

-, konativ 2.1, 2.4, 7.1.2

elaboration 3.1.1, 3.1.3

élégance 3.2.1

elterliches Vorbild 2.1

Engleutsch 12.5

Entlehnung 2.3.4.2.1, 3.3.2, 4.1, 5.2.3.1, 5.2.3.2, 9.1.1, 9.3, 10.1.4, 10.3, 10.4, 11.1.4, 11.1.7, 12.1.5

Entwicklung

-, semantisch 9.1.2
-, sprachlich 3.1.1, 4.3.1, 4.2.2, 5.3.3.1,

9.3, 13

-, terminologisch 9.1 .2

episprachlich 2.1, 4.2, 4.3.1

Erhebungswellen 8.1.1

Erlass 1.1, 3.2.2, 3.2.3.1, 3.2.3.2, 3.2.4.1, 3.2.4.2, 3.2.5, 3.2.6, 3.3.1, 4.1, 4.3, 4.3.1, 4.3.2, 4.3.3, 4.4.1, 4.4.2, 4.4.2.3, 4.5, 5.1, 5.2.1, 5.2.3.2, 5.3.2, 5.3.3.1, 7.1.2, 9.1.1, 9.1.4, 9.1.5, $9.2 .1,9.2 .2$

Erlernbarkeit 2.3.4.3

Ersatzwortbildung 4.4.1

Ersatzwortfindung 3.2.6, 9.5

Ersatzwortliste 12.5

Erwünschtheit, sozial 2.2

espanglis 12.5

Etablierungsgrad 1.1, 2.3.4.3, 3.3.4, 4, 4.2, 4.3, 4.3.1, 4.3.3, 4.5, 9, 9.1.2, 9.1.3, 9.1.6, 9.1.7, 10.1.1, 10.1.2, 10.1.4, 10.1.6, 10.1.7, 11.1.1, 11.1.3, 11.1.4, 11.1.7, 12, 12.1.7

EURODICAUTOM 2.3.4.2.1, 3.3.2, 3.3.5, 15.8 .8

Face-to-Face-Gespräch (s. Gespräch)

Fachkommission (s. CMT, CST)

Fachsprache 3.2.5, 4.2, 4.4.1, 4.5, 5.1, 5.2.2, 5.2.3.1, 8.2.7

Fachterminologie 3.2.4.1, 3.3.2, 4.3.1, 5.1, 8.2, 9.5

Faktoren

-, akzeptanzbegünstigend (s. akzeptanzfördernd)

-, akzeptanzfördernd 3.1.3, 5, 5.1, 5.2.1

-, akzeptanzhemmend 5, 5.1

-, außersprachlich 3.1.3, 4.5, 5, 5.4

-, interpersonal 2.1, 2.2, 5.1

-, persönlich 2.1, 2.2, 2.3.3.1, 5.1, 5.3, 5.3.2, 5.3.3.1, 7.1.2.3, 9.1.7, 9.5, 10.1.7, 10.4, 11.1.7, 13

-, situativ 2.1, 2.2, 4.3, 4.5, 5.1, 9.1.7, 13

Faktorenanalyse 9.1.2 
Feminisierung der Berufs- und anderer Bezeichnungen 2.3.1, 4.4.1

Fête de l'Internet 3.2.4.1

Fichier français de Berne 2.3.4.2.1

Frage

-, offen 2.2, 6.1, 7.1.1.2, 7.1.2, 7.1.2.1, 7.3

-, geschlossen 2.2, 6.1, 7.1.1.2, 7.1.2, 7.1.2.1, 7.1.2.2, 7.3

Fragebogen

- Ankündigung 1.2, 6.1, 6.2, 6.3.1, 6.3.2, 6.4, 7.1.1.4, 7.1.2.1, 8.1.1, 8.2, $8.3,9,12,15.2,15.2 .1$

- Anschreiben 6, 6.3.1, 6.4, 6.5, 7.2.2, 8.1.1, 8.2.3

- Bearbeitungszeit 5.2, 7.2.2, 8.1.1

- einteiliger Fragebogen 7, 7.1.1.1, 7.1.2

- elektronischer Fragebogen 6, 6.3.1, 6.3.2, 6.5, 7.1.1.3

- Fragebogengenerator 7.1.1, 7.1.1.1, 7.1.1.3, 7.1.2

- mehrteiliger Fragebogen 7, 7.1.1.1, 7.1 .2

- Rücklauf 5.2, 6.3.1, 6.3.2, 6.4, 7.1.1.3, 8.1.1, 8.3

français fédéral 2.3.4.2.1, 2.3.4.4

français régional 2.3.4.2.2, 2.3.4.2.3

Francité (s. auch Maison de la Francité) 2.3.1, 3.3.1, 15.8.1

franglais 2.3.2, 2.3.4.3, 3.2.1, 3.2.3.1, 3.3.1, 4.3, 4.3.1, 4.4.1, 4.4.2.3, 4.5, $5.2 .1,9.1 .4,12.5$

Frankophonie 1.1, 2.1, 2.3, 2.3.1, 2.3.4.2.1, 2.3.4.2.2, 2.4, 3.1.2, 3.2.1, 3.2.2, 3.2.3.1, 3.2.7, 3.3, 3.3.1, 3.3.2, 3.3.3, 4.4.2, 4.4.2.1, 4.4.2.3, 15.8 .2 franricain 3.2.1

FRANTERM 3.2.2, 3.2.7

Französische Revolution 2.3.2, 3.1.2 französisieren 3.1.4, 3.2.4.1, 4.3.2, 5.1, 5.2.1, 5.2.3.2, 9.3

Französisierung 4.3.2, 4.4.1, 5.2.1, 9.1.1, 9.3, 10.3, 11.3, 12.3

Fremdeinschätzung 2.3.2
Fremdheit 11.1.7

Fremdsprache 2.1, 2.3.1, 2.3.3.3, 2.3.4.3, 2.3.4.4, 8.2, 10.3, 12.3

Fremdwort 4.1, 4.4.1, 5.1, 5.2.3.1, 5.2.3.2, 9.1.7, 10.1.4, 12.5

Fremdwortbekämpfung 3.2.1

Fremdwortdiskussion 3.2.1

Fremdwortgebrauch 3.3.1, 9.3

Funktion, motivational 2.1

Gebersprache 9.1.7

Gebräuchlichkeit 4.3.1, 5.1, 11.1.7

Gebrauchsfrequenz 4.3.1, 4.3.2, 9.1.1,

9.1.2, 9.1.3, 9.1.4, 9.1.5, 10.1.1, 10.1.3, 10.1.4, 10.1.5, 10.1.6, 10.1.7, 11.1.1, 11.1.2, 11.1.3, 11.1.4, 11.1.5, 11.1.6

Gemeinsprache 2.3.3.3, 3.1.1, 4.3, 4.3.1, 4.4.1, 4.4.2.2, 4.5, 5.2, 5.2.2, 5.2.3.2, 7.1 .2

generationsspezifisch 5.3.2, 9.4.2, 9.4.2.1, 9.4.2.2, 9.5

génie de la langue 3.2.1

Germanismus 2.3.4.2.1, 2.3.4.2.4, 2.3.4.4, 5.2

Gesamtsprachenkonzept, schweizerisch 2.3.4.3, 2.3.4.4, 15.8.5

Gesamtwortlaut (s. Vollform)

Gesetze (Sprachgesetze) 1.1, 2.1, 2.3.1, 2.3.3.1, 2.3.3.2.3, 2.3.3.2.4, 2.3.3.3, 2.3.4.3, 3.1.2, 3.1.3, 3.1.4, 3.2, 3.2.1, 3.2.2, 3.2.3.1, 3.2.7, 3.3, 3.3.1, 3.3.2, 4, 4.4.1, 4.4.2.1, 4.4.2.2, 4.4.2.3, 4.5, 5.1, 5.3.3.2, 5.3.3.3, 7.1.2.2, 9.2.1, 9.4.2.2, 10.2.1, 10.2.2, 11.2.1, 12.2, 15.8.7

Gespräch, Face-to-Face 5.2.3.2, 9.1.4, 9.1.7, 10.1.4, 11.1.7

Gesprächspartner 10.1.2, 10.1.6

Gewohnheiten

- akustische Gewohnheiten 5.1

- artikulatorische Gewohnheiten 5.1

- Aussprachegewohnheiten 5.2.3.2

- Schreibgewohnheiten 4.4.2.1 
- Sprechgewohnheiten 4.4.2.1, 5.1

Gewöhnung 5.1, 5.2.3.2, 9.1.1, 9.1.2, 9.1.3, 9.1.4, 9.1.5, 9.1.6, 9.1.7, 9.5, 10.1.1, 10.1.2, 10.1.3, 10.1.4, 10.1.5, 10.1.7, 10.4, 11.1.1, 11.1.2, 11.1.3, 11.1.4, 11.1.5, 11.1.6, 11.1.7, 11.4, 12.1.1, 12.1.2, 12.1.3, 12.1.4, 12.1.5, 12.1.6, 12.1.7, 12.4, 13

Globalisierung 4.4.1, 9.3, 12.5

Glosario básico inglés-español para usuarios de Internet 12.5

GPSR 2.3.4.2.3

Grafie 5.2.1, 5.2.2, 5.2.3.2, 9.3

Grammatik 2.3.3.2.3, 2.3.4.2.2, 3.1.2, 3.1.3

Grand Robert 5.2.1

Guide des mots nouveaux 3.2.2

Handeln, sprachlich 4.4.1, 5.1

Harmonisierung 3.2.3.2

Haut Comité de la langue française 3.2.1, 3.2.2, 3.2.7

Haut Comité pour la défense et l'expansion de la langue française 3.2.1, 3.2.2

Haut Conseil de la francophonie 3.2.1, 3.3.3

Helvetismus 2.3.4.2.1, 2.3.4.2.2, 2.3.4.2.3

Hybridbildung 5.2.1

Idealnorm 2.3.2, 3.2.1

Identität 2.3.2, 2.3.3.1, 2.3.3.2, 2.3.3.2.2, 2.3.3.2.3, 2.3.3.4, 2.3.4, 2.3.4.2.2, 2.3.4.2.3, 2.3.4.2.4, 3.2.1

IEC 3.3.3

implementation 3.1 .3

INaLF 3.2.2, 3.3.3.2, 4.3

Informatik-Kommission (s. CSTIC)

Initiale 5.2, 5.2.1, 5.2.3.1

insécurité linguistique (s. Unsicherheit, sprachlich)

INSEE 3.2.5, 12, 15.8.3

Integrationsgrad 4.4.1
Internationalismus 3.3.2, 3.3.4, 4.4.1, $5.1,12.5$

Introspektion 2.1

Intuition 2.1

Inventaire ressources terminologiques 3.3.3.1

Inventaire terminotique 3.3.3.1

IRANOR 3.3.3

ISO 3.3 .3

Italianisierung 12.5

Italianismus 3.2.1

italiese 12.5

Journal officiel (JO) 3.2.2, 3.2.3.2, 3.2.4.1, 3.2.4.2, 3.2.5, 3.3.1, 3.3.2, 3.3.4, 4.2, 4.2.2, 4.3.1, 4.3.3, 9.3, $15.3,15.8 .3,15.8 .8$

Kode 3.1.2

kognitiv (s. Einstellungsdimension) Kommission zur Feminisierung der Berufs- und anderer Bezeichnungen 4.4.1

Kommunikationsbarriere 4.4.1, 9.3, 12.3

Kommunikationsniveau 4.3.1

Kommunikationspartner 4.4.1

Kommunikationsprobleme 3.1.1, 9.3, $12.3,12.4,13$

Kommunikationssituation

-, formell 4.3.3, 7.1.2.1, 13

-, informell 4.3.3, 7.1.2.1, 13

Kommunikationstyp 4.3.2

Komplexität, sprachlich 5.2.1, 9.1.2, 9.1.5, 9.1.6, 10.1.2, 10.1.5, 10.1.6

Kompositum (s. Determinativkompositum)

konativ (s. Einstellungsdimension)

Konnotation 5.1, 5.2.3.2, 7.1.2.1, 9.1.3, $9.1 .5,10.1 .1,11.1 .5,12.1 .5$

Kontaktlinguistik 3.1.2

Kontamination 4.4.1 
Korpus 2.3.3.3, 3.1.2, 3.3.1, 4.2, 4.3, 4.3.1, 4.3.2, 4.3.3, 4.4.1, 4.5, 5.2, 5.2.2, 7.1.2, 11.2.2

Korpusplanung 2.3.3.2.2, 3.1.2, 3.1.4, 5.3.3.3

Korrektheit, sprachlich 2.3.2, 4.3.1, 9.1.2, 9.1.5, 9.1.6, 10.1.2, 10.1.5, 10.1.6, 11.1.7, 12.1.6, 12.3

Krise des Französischen 2.3.3.2.3, 3.2.1, 3.3.1

Kulturimperialismus 4.4.2.2

Kürze (eines Wortes) 5.1, 5.2.1, 5.2.3.2, 5.3.1, 9.1.1, 9.1.2, 9.1.3, 9.1.4, 9.1.6, 9.1.7, 9.5, 10.1.1, 10.1.3, 10.1.4, 10.1.6, 10.1.7, 10.4, 11.1.1, 11.1.2, 11.1.3, 11.1.4, 11.1.6, 11.1.7, 12.1.1, 12.1.2, 12.1.3, 12.1.4, 12.1.6, 12.1.7, $12.3,12.4,13$

kurzsilbig 9.1.7

Kurzwort 3.3.4, 5.2, 5.2.1, 5.2.3.1, 5.2.3.2, 9.1.1, 9.1.3, 9.1.7, 10.1.1, 10.1.3, 11.1.3, 12.1.1, 12.1.3

La Banque des Mots 3.2.1, 3.2.4.2, 3.2.5

Laboratoire d'Ingéniérie Linguistique et de Linguistique Appliquée 3.3.3.2

Laienlinguistik 2.1

laienlinguistisch 12.5

Landessprache 2.3.1, 2.3.4.2.3, 2.3.4.3, 3.3.2, 4.4.2.3, 12.3

Länge (der Termini) 3.3.2, 5.2.1, 5.2.3.2, 5.4, 7.1.2.1, 9.1.3, 10.1.3 langue commune (s. Gemeinsprache)

Latinismus 4.3, 4.3.1

Lehnbedeutung 5.2.3.1

Lehngut 3.2.2

Lehngut

-, äußeres 5.2.3.1

-, inneres 5.2.3.1

Lehnschöpfung 5.2.3.1

Lehnübersetzung 4.1, 5.2.3.1

Lehnübertragung 5.2.3.1

Lehnwort 2.3.2, 5.1, 9.3
Les cahiers du Rifal 3.3.3.1

Lexem 2.3.2, 2.3.3.2.3, 2.3.4.2.4, 3.2.2, 4.2, 4.3, 4.3.1, 4.4.1, 5.2.3.2, 7.1.2, 7.1.2.1, 9.1, 9.1.1, 9.1.5, 9.1.7, 10.1.1, 10.1.7, 11.1.5, 11.4, 12, 12.3, 13

Lexemimportation 5.2.3.1

Léxico Panlatino de Terminologia do Ambiente 3.3.3.2

Lexik (Wortgut, Wortschatz) 1.1, 2.3.2, 2.3.3.2.3, 2.3.3.3, 2.3.4.2.1, 2.3.4.2.2, 2.3.4.2.3, 2.3.4.3.1, 3, 3.1.2, 3.1.3, 3.1.4, 3.2.2, 3.2.3.1, 3.2.5, 3.3, 3.3.1, 3.3.2, 4.4.1, 4.3.1, 4.3.2, 4.3.3, 4.4.1, 4.5, 5.1, 5.3.2, 8.2.2, 9.4.1, 9.4.6, 12.5

Lexikograf 3.2.5, 4.4.1, 9.3

Lexikografie 2.3.4.2.3, 3.2.2

Lexikologe 2.3.3.2.3, 9.3

Lexikologie 2.3.3.2.3

Lexikon 3.1.2, 3.3.3.2, 4.1, 4.2, 9.1.2, 9.1.5, 9.1.6, 10.1.2, 10.1.5, 10.1 .6

Lexique des néologismes Internet 3.2.5

Lexique des termes de base de

l'informatique 3.3.3.2

Lexique panlatin d'Internet 3.3.3.2

lingua franca (s. auch Verkehrssprache) $2.4,9.3,10.3,11.3,12.3$

LLI 3.2.2, 15.8.3

Loi $118 \mathrm{du} 2$ Thermidor 3.2.1

Loi Deixonne 3.1.2

Loi du 14 juillet 1991 (Belgien) 3.3.1

Loi Toubon 2.1, 3.1.2, 3.1.3, 3.2.1, 3.2.2, 3.2.3, 3.2.3.1, 3.3.1, 3.3.2, 4.3, 4.4.1, 4.4.2, 4.4.2.1, 4.4.2.3, 5.3.3.1, 5.3.3.2, 9.2.1, 9.2.2, 9.4.2.2, 9.3, $12.2,12.5,15.3,15.5 .2 .1$

Lokalkolorit 5.1

Loyalität, sprachlich 2.3.2, 2.3.4.2.2, 2.3.4.2.4

Maison de la Francité 3.3.1, 15.8.1

Majuskel 2.3.1, 5.2, 5.2.1

Markt, sprachlich 5.1, 9.3 
matched-guise-Technik 2.2, 2.3.2, 2.3.4.2.2, 6

Mehrdeutigkeit 3.1.1, 4.3.2

Mehrfachnennung 7.1.2, 7.1.2.1

mehrsprachig 2.1, 2.3.3.2, 2.3.4.1, 3.1.2, 3.3.2, 3.3.3.2, 8.2.8, 10.4, 12.4

Mehrsprachigkeit 2.3.3.2.3, 2.3.4.1, 2.3.4.3, 3.2.1

Mentalist 2.1

mentalistisch 2.1, 2.4

Metaphorik (s. Tiermetaphorik)

metaphorisch 5.1, 5.2.1, 5.2.3.1, 5.2.3.2, 9.3

Metasprache 2.1

metasprachlich 2.1, 2.3.2, 4.2, 4.3.1, 9.2.1

Methoden

-, direkt 2.1

-, indirekt 2.1

Minderheitensprache 2.1, 2.3.1, 2.3.2, 3.1 .2

Minderwertigkeit(sgefühl) 2.3.3.2.2, 2.3.3.2.3, 2.3.4.2.4

Minderwertigkeitskomplex 2.3.3.2.2, 2.3.3.2.3

Ministère de l'Éducation nationale (Frankreich) 2.3.2, 3.2.2, 3.2.3.2, 3.2.4.1

Ministère de la Culture et de la Francophonie (Frankreich) 4.4.2.1

Missverständnis 7.1.2.1, 9.1.1, 9.3

Moniteur belge 2.3.3.1, 3.3.1

monolexematisch 5.2.3.1

monosem 3.1.1, 3.2.5, 5.1, 5.2.1, 5.2.3.1, 5.2.3.2, 5.4, 9.1.3, 9.1.5, 9.1.7, 11.1.5, 11.1.7, 12.1.5, 12.1.7

Monosemie 4.3.1, 9.1.1, 9.1.4, 9.1.7

Monosemierung 10.1.4, 12.1.5

Morphem 4.4.1 (s. auch Derivationsmorphem)

morphologisch 2.3.2, 4.1, 4.3, 4.3.1, 4.4.1, 5.1, 5.2.1, 5.2.3.1, 5.2.3.2, 5.4 morpho-phonologisch 5.2.3.2

Morphosyntax 3.1.3
Motiviertheit, semantisch 5.1

Multiple Choice 7.1.1.2, 7.1.2.1, 7.1.2.2

Mundart 2.3.2, 2.3.4.2.2, 3.1.2

Muttersprache 2.3.1, 2.3.3.1, 2.3.4.1, 2.3.4.2.3, 3.3.2, 4.3.1, 4.4.1, 4.4.2.1, 5.3.3.3, 7.1.2.3, 8.2, 8.2.6, 8.2.7, 8.3, $9.3,10.3,10.4,11.2 .2,12.3$

Muttersprachler 2.1, 2.3.1, 2.3.2. 2.3.4.2.1, 3.1.3, 5.2.1, 5.2.3.2, 8.2, 8.2 .6

Nationalsprache 2.3.2, 2.3.3.1, 2.3.3.2.1, 2.3.3.2.2, 2.3.4.1, 2.3.4.3, 2.3.4.4, 3.2.1, 3.3.2, 12.1.7, 13

Natürlichkeit 9.1.2, 9.1.5, 9.1.6, 10.1.2, 10.1.5, 10.1.6, 11.1.2

Nehmersprache 9.1.7

néo-français 4.4 .1

Neologie 1.1, 3.2.1, 3.2.6

Netiquette 8.1.1

Neuschöpfung 5.2.3.1

Nicht-Muttersprachler 3.1.3, 9.1.1, 9.1 .2

Norm, sprachlich 2.1, 2.3.1, 2.3.2, 2.3.3.2.2, 2.3.3.2.3, 2.3.4.2.1, 2.3.4.3, 3.1.1, 3.1.2, 3.1.3, 3.1.4, 3.2.1, 3.2.2, 4.1, 4.4.2, 5.1, 5.3.3.1, 9.2.1

Normalität, sprachlich 4.3.1, 9.1.2, 9.1.5, 9.1.6, 10.1.2, 10.1.5, 10.1.6

Normenbewusstsein (s. Sprachnormenbewusstsein)

Normfragen 12.5

Notwendigkeit (eines Neologismus) 3.2.3.2

Notwendigkeit (von Terminologie) 4.3.1

Nützlichkeit 1.1, 2.3.4.3, 4.3.1, 9.1.2, 9.1.5, 9.1.6, 10.1.2, 10.1.5, 10.1.6, 11.1.7

Office de la langue française (Frankreich) 3.2.2

Office du vocabulaire français 3.2.1, 3.2 .2 
Office québécois de la langue française 3.2.2, 3.3.1, 3.3.3, 3.3.3.1, 3.3.4, $9.1 .5,15.1 .2,15.8 .4$

Okzitanisch 2.3.1, 2.3.2

Online-Befragung (s. Befragung)

onomasiologisch 4.2, 5.2.1

Organisationen, nichtstaatlich 2.3.1, 2.3.3.2.4

Organisationen, staatlich 2.3.1, 2.3.3.2.4

Orthografie 2.3.1, 2.3.4.2.3, 3.1.2, 3.1.3, 10.3

Orthografiereform 2.1, 2.3.1, 2.3.4.2.3, 3.3.2, 5.3.3.3

OVF 3.2.1, 3.2.2

PAGSI 3.2.5

Papier-Fragebogen (s. Befragung)

Paradigmenbildung 5.1

Patois 2.3.2, 2.3.4.2.3, 3.1.2

Personalitätsprinzip 2.3.3.1

Petit Robert 2.3.1, 2.3.3.2.3, 2.3.3.3, 4, $5.1,5.2 .1,5.2 .3 .2$

Phonetik 3.1.3

Phonetiker 2.3.3.2.3

phonetisch 2.3.2, 2.3.3.2, 3.2.5, 5.1, 5.2.1, 5.2.3.1, 5.2.3.2, 5.4, 9.1.1, 12.5, 15.5.2.1, 15.5.2.3

phonetisch-phonologisch 2.3.2

Phonologie 3.1.3

phonologisch 2.3.4.2.2

physiologische Messungen 2.1, 2.2, 2.4

Planbarkeit von Sprache(n) 3.1.2

planification de la langue (s. Sprachplanung)

planification linguistique (s. Sprachplanung)

Polaritätenprofil (s. semantisches Differential)

Polysemie 5.2.3.1, 5.2.3.2

Präfix

- e- 3.2.5, 5.2.3.1

- yber- 3.2 .5

- télé- 3.2 .5
Präfixoid $e-3.3 .2$

Prager Schule 3.1.1

präskriptiv 2.1, 2.3.3.2.3, 3.1.1, 3.1.3, 3.3.3.1, 4.4.2.2

Pressesprache 2.3.3.2.2, 2.3.3.3

Prestige 2.1, 2.3.2, 2.3.3.1, 2.3.3.2.1, 2.3.3.2.2, 2.3.3.4, 2.3.4.2.2, 2.3.4.2.4, 2.3.4.3, 2.3.4.4, 3.1.1, 3.2.1, 3.2.3.1, 5.3 .1

Pretest 1.3, 2.2, 5.2, 7, 7.1.1.3, 7.1.2.1, $7.2,7.2 .1,7.2 .2,7.3,9.1 .1$

Prognose 3.1.3, 4.3.1, 4.3.3, 5, 5.1, $5.2 .3,5.2 .3 .2,5.3 .1,5.4,9.1 .7,13$

prognostisch 2.1, 5.2.1

prognostizieren 2.1, 4.4.1, 8.2.1

Pseudoanglizismus 5.2.3.1

Pseudoenglisch (s. Aussprache, pseudoenglisch)

Pseudoübersetzung 11.1.1

Pull-down-Menü (s. Dop-down-Menü)

pureté 3.2.1, 7.1.2

Purismus 2.3.3.2.3, 2.3.4.2.1, 3.2.1, 9.3

Purist 2.3.3.2.3, 3.2.1, 4.4.2.3

puristisch 2.3.2, 2.3.3.2.3, 2.3.4.2.1, 3.2.1, 9.4 .2

Questions du français vivant 3.3.1

Radio-Button 7.1.1.2

Rätoromane 2.3.4.1

rätoromanisch 2.3.4.1, 3.3.2, 15.8 .5

Realiter 3.3.3, 3.3.3.2, 3.3.5, 15.8.2

Rechtschreibreform (s. Orthografiereform)

Regionalismus 2.3.1, 2.3.4.2.1, 2.3.4.2.4, 2.3.4.4

Regionalsprache 2.1, 2.3.3.1, 2.3.3.2.4, 2.3.3.4, 2.3.4.2.4, 3.1.2

Reinheit, sprachlich (s. Sprachreinheit)

Répertoire des institutions et associations (Belgien) 3.3.1

Répertoire des organisations et associations francophones 3.2.1 
Répertoire terminologique 2000 3.2.2, 3.2.3.2, 3.2.4.2, 3.2.6, 3.2.7, 15.8 .8

Repräsentation 2.1, 2.3.1, 2.3.4.3

Repräsentativität 1.1, 2.2, 6.3.1, 6.3.2, 6.5, 8.2, 9.3, 11.1.6,

Rifal 3.3.3, 3.3.3.1, 3.3.3.2, 3.3.5, 15.8 .2

Rint 3.3.1, 3.3.3, 3.3.3.1, 3.3.5, 15.8.2

Romand(s) 2.3.4.1, 2.3.4.2.2, 2.3.4.2.3, 2.3.4.2.4, 2.3.4.3, 2.3.4.4, 3.3.2,

5.3.3.3, 7.1.2.2, 11.2.2

Romandie 2.3.4, 2.3.4.1, 2.3.4.2.1, 2.3.4.2.2, 2.3.4.2.3, 2.3.4.2.4, 3.3.5

Röstigraben 2.3.4.2.2

Rücklauf (s. Fragebogen)

Ruhe, sprachlich (quiétude linguistique) 2.3.3.2.1, 2.3.3.2.2, 2.3.3.3

Rumantsch grischun 2.3.4.1

Rumpfwort 5.2

sanktionieren 9.2.2

Sanktion 2.1, 3.3.1, 5.3.3.1

Scheinentlehnung 5.2.3.1

Schlüsselreiz (politisch und historisch) 2.1, 3.1.2

Schönheit, sprachlich 9.1.2, 9.1.5, 9.1.6, 10.1.2, 10.1.5, 10.1.6

Schreibpraxis 4.3.1

Secrétariat d'État à la francophonie 3.3 .3

Secrétariat d'État du Canada 3.3.3

sécurité linguistique (s. Sicherheit, sprachlich)

Selbstbewusstsein, sprachlich 2.3.1, 2.3.4.2.2, 2.3.4.2.4

Selbsteinschätzung 2.2, 2.3.2, 2.3.4.2.4, 2.3.4.3, 2.4, 8.2.8, 9.1.1, 9.2.1, 12.2

Selbstschutz (der Sprache) 9.2.2

Selectfeld (s. Drop-down-Menü)

selection 3.1.3

Semaine de la langue française et de la francophonie 3.2.4.1

Semantik 5.2.1, 9.1.2 semantisch 2.3.2, 4.1, 4.3, 4.3.1, 4.3.2,

5.1, 5.2.1, 5.2.3.1, 5.2.3.2, 7.1.2,

7.1.2.1, 9.1.2, 10.1.1, 10.1.3, 10.4,

11.1.2, 11.1.5, 11.1.7, 12.1.5

semantisches Differential 2.1, 2.2,

2.3.4.3, 4.3, 4.3.1, 5.2.1, 7.1.2,

7.1.2.1, 7.2.2, 8.2.6, 9.1.2, 9.1.3,

$9.4 .2,9.4 .2 .1,10.1 .2,11.1 .5$

semasiologisch 4.2

Service de la Francophonie (Schweiz)

3.3.2

Service de la langue française (Belgien)

1.1, 3.3.1, 3.3.3, 3.3.3.1, 3.3.3.2,

3.3.4, 3.3.5, 15.2.3, 15.3, 15.8.1,

15.8 .8

Service de néologie et terminologie

(SNT) 3.2.2

Service de terminologie multilingue

(Schweiz) 3.3.2

Service Général des Lettres et du Livre

(Belgien) 3.3.1

Sicherheit, sprachlich 2.3.2, 2.3.3.2.1,

2.3.3.2.2, 2.3.3.2.3, 2.3.4.2.4, 2.4, 5.3

Sigle 4.2, 4.3.2, 4.4.1, 9.1.7

Silbe 5.2.1, 5.2.3.2

-, geschlossen 5.2.3.2

-, offen 5.2.3.2

Skala

- Ein-Item-Rating-Skala 2.2

- Likert-Skala 2.2, 7.1.1.2, 7.1.2.1, 9.1.2, 9.1.7, 10.1.2, 10.1.5

- Thurston-Skala 2.2

- Thurston\&Chave-Skala 2.2

- Rating-Skala 7.1.2.1

- Skalogramm 2.2

Snobismus 2.3.2, 2.3.3.3, 4.3.2, 5.1

snobistisch 5.3.2

SNT 3.2.2

SOFRES 1.1, 2.3.2, 3.2.3.1, 4.4.2.1, 6.3.1, 15.8.3

Soziolinguist 3.1.1, 3.1.3

Soziolinguistik 2.1, 2.3.2, 3.1.1, 5.3.2, 6, 9.4 
Sprachakademie (s. Académie française, Akademie)

Sprachaustausch 4.4.1

Sprachbeherrschung 2.3.4.2.4

Sprachbewertung 2.3.2, 4.3.1, 9.4.2

Sprachbewusstsein 2.1, 2.3.1, 2.3.2, 2.3.3.2, 2.3.3.3, 2.3.4.2.3, 2.4, 4.4.1, 5.2.3.1

Sprachchronik 2.1, 2.3.2, 2.3.4.2.1

Sprache

-, geschrieben 4.3.3, 4.4.2.1, 9.3, 13

-, gesprochen 4.3.3, 4.4.1, 4.4.2.1, 9.3, 13

Sprachenfreiheit 2.3.4.1

Sprachenfrieden 2.3.4.1, 12.2

Sprachenplanung 3.1.2

Sprachenpolitik 3.1.1

Sprachentwicklung (s. Sprachwandel)

Sprachevolution (s. Sprachwandel)

Sprachfragen 2.3.2, 2.3.4.2.1, 2.3.4.2.3, 5.3.3.1, 5.3.3.3, 9.2.1, 11.2.2

Sprachgefühl 2.1, 2.3.1

Sprachgemeinschaft 1.1, 2.1, 2.3.3.1, 2.3.3.3, 2.3.3.4, 2.3.4.1, 2.3.4.2.4, 2.3.4.3, 2.4, 3.1.1, 3.1.3, 3.3.1, 4.4.1, 5.1, 10.3, 12.1.7, 12.2, 12.3, 12.4, $12.5,13$

Sprachgesetz 1.1, 2.3.1, 2.3.3.2.3, 2.3.3.2.4, 3.1.2, 3.1.3, 3.1.4, 3.2, 3.2.2, 3.2.3.1, 3.2.7, 3.3, 3.3.1, 3.3.2, 4, 4.3, 4.3.1, 4.4.1, 4.4.2.1, 4.4.2.3, 4.5, 7.1.2, 9.2.1, 9.4.2.2, 10.2.1, 12.5, 15.8 .6

Sprachgesetzgebung 3.2.2, 4.4.1

Sprachgrenze 2.3.3.1, 2.3.3.3, 2.3.4.1, 10.4

Sprachgruppe 2.1, 2.3.3.1, 2.3.4.3

Sprachkompetenz 2.3.3.2.2, 2.3.4.2.4, 2.4, 3.1.1

Sprachkonflikt 2.3.3.3, 2.3.4.1, 3.1.2

Sprachkontakt 2.1, 2.3.2, 2.3.3.2, 2.3.4.1, 2.3.4.2.2, 3.1.2, 3.3.2, 8.2.7

Sprachkultur 2.3.1, 3.1.1, 9.3, 12.3
Sprachlenkung 2.3.4.2.2, 2.3.4.2.3, 3.1.1, 5.3.2, 5.3.3.1

Sprachnormenbewusstsein 2.3.3.2, 2.3.3.2.3, 11.2.1

Sprachnormierung 3.1.1

Sprachökonomie 9.1.7

Sprachpflege 1.1, 1.2, 2.1, 2.3.3.2, 2.4, 3, 3.1.1, 3.1.2, 3.1.4, 3.2, 3.2.1, 3.2.3.1, 3.2.3.2, 3.2.4.1, 3.2.6, 3.3.2, 4.3.2, 9.2.2, 12.5

Sprachpflegegesellschaft (s. Sprachpflegeinstitution)

Sprachpflegeinstitution 2.3.1, 2.3.3.2.4, 2.3.4.2.3, 3.1.1, 3.1.2, 3.2.1, 3.2.3.1, 3.2.4.1, 3.2.7, 3.3.1, 3.3.2, 3.3.5, 4.3.2, 4.4.1, 5.3.3.3, 7.1.2

Sprachpflegeorganisation (s. Sprachpflegeinstitution)

Sprachpflegeprozess 1.1

sprachpflegerisch 2.3.3.3, 2.3.4.2.1, 3, 3.1.1, 3.2.1, 3.2.4.1, 12.5

Sprachplanung 1.3, 3, 3.1.1, 3.1.2, 3.1.3, 3.1.4, 3.2.2, 3.3.5, 4.2, 4.3.1, 4.4.1, 7.1.2, 9.2.1, 11.2.1, 12.2, 12.3

Sprachprobleme 3.1.1

Sprachprognostik (s. auch Prognose)

4.3.1

sprachpuristisch (s. puristisch)

Sprachregelung (sprachpolitische Regelung) 1.1, 2.3.1, 2.3.3.1, 2.3.3.2.4, 2.3.3.4, 2.3.4.1, 2.3.4.2.1, 2.3.4.3, 2.3.4.4, 3.1.2, 3.1.3, 3.2.3.1, 3.2.7, 3.3.1, 4.3.2, 4.3.3, 4.4.2.2, 5.1, 7.1.2.2, 10.3, 11.3, 11.4, 13

Sprachreinheit 2.3.2, 2.3.4.2.2, 2.3.4.2.3, 3.2.1, 12.5

Sprachreinigung 3.1.2

Sprachschutz 4.3.2

Sprachschutzgesetz 4.4.2.3, 10.2.2, 12.5

Sprachsoziologie 3.1.1

Sprachtradition, lokal 2.3.4.2.1, 2.3.4.2.2

Sprachverbreitungspolitik 3.1.2 
Sprachverhalten 2.2, 2.3.4.2.1, 2.3.4.2.2, 3.1.3, 4.3.1, 4.4.1, 5.1, 5.3, 5.3.2, 5.4, 8.2.1, 9.2.1, 9.4, 9.4.2.1, 9.5, 13

Sprachverwendung 3.1.1, 3.1.4, 4.4.2, 5.2.3.2, 9.1.1, 9.1.6

Sprachwahl 2.1, 2.3.4.1, 2.3.4.3

Sprachwandel 3.1.2, 3.1.3, 4.1, 4.3.1, 5.3.3.1, 9.3, 12.3

Sprachwissen 2.1

Sprachwissenschaft, politisch 3.1.1

Sprechergruppe 2.3.1, 2.3.3.3, 2.3.4.2.2, 2.4, 3.1.3, 5.3.3, 10.3

Sprecherurteil 10.1.5

Standarderhaltung 3.1.1

Statalismus 2.3.3.2.2, 2.3.3.2.4, 2.3.4.2.1

Status von Sprachen oder Varietäten 2.1, 2.3.1, 2.3.3.1, 2.3.3.2.1, 2.3.4.1, 3.2.1, 3.3.1, 3.3.2, 5.3.3.3

Statusplanung 2.3.3.2.2, 2.3.3.3, 3.1.2, 3.1.3, 3.1.4

Stereotyp 2.1

Stichprobe 4.3, 6.1, 6.2, 6.3.1, 6.5, 8.2, 10.1.3, 10.1.5, 10.1.6, 10.2.1, 10.2.2, 11.1.2, 11.1.3, 11.1.6, 12, 12.1.1, 12.1.2, 12.1.3, 13

Strukturalismus, amerikanisch 3.1.2

Substantiv 3.3.4, 5.2.1, 5.2.3.1, 5.2.3.2

Substitution 2.3.2, 4.3.1, 5.2.1

Suffigierung 5.2.3.2

Suffix 5.2.1

Symbol 5.2.1, 5.2.3.2, 9.1.1

synonym 2.1 , 3.1.1, 3.3.1, 3.3.4, 4.4.1,

5.1, 7.1.2, 7.1.2.1, 9.1.1, 9.1.2, 9.1.3, 9.1.4, 9.1.5, 9.1.6, 9.1.7, 9.5, 10.1.1, 10.1.2, 10.1.3, 10.1.4, 10.1.5, 10.1.6, 10.1.7, 11.1.1, 11.1.2, 11.1.3, 11.1.4, 11.1.5, 11.1.6, 15.3, 15.5.1.1.1, 15.5.1.2.1

Synonym 3.2.5, 3.3.1, 3.3.4, 4.3.1, 5.2.1, 5.2.3.2, 9.1.1, 9.1.2, 9.1.3, 9.1.4, 9.1.5, 9.1.6, 10.1.1, 10.1.2, 10.1.3, 10.1.4, 10.1.5, 10.1.6, 11.1.1, 11.1.2, 11.1.3, 11.1.4, 11.1.5, 11.1.6
Synonymie 7.1.2.1 9.1, 9.1.1, 9.1.2, 9.1.3, 9.1.4, 9.1.5, 9.1.6, 9.1.7, 9.5, $10,10.1 .1,10.1 .2,10.1 .3,10.1 .4$, 10.1.5, 10.1.6, 10.1.7, 11.1.1, 11.1.2, 11.1.3, 11.1.4, 11.1.5, 11.1.6, 11.1.7, $12.2,12.4$

Syntagma 5.2.3.1

Systemadäquatheit 3.2.3.2

systemlinguistisch 4.4 .1

Taula de formants cultes 3.3.3.2

TERMDAT 3.3.2

terminografisch 9.3

Terminologie-Datenbank (s. Datenbank)

Terminologiearbeit 1.1, 1.3, 2.3.1, 3, 3.1.3, 3.1.4, 3.2, 3.2.1, 3.2.2, 3.2.3.1, 3.2.3.2, 3.2.4.1, 3.2.5, 3.2.6, 3.2.7, 3.3, 3.3.1, 3.3.2, 3.3.3, 3.3.3.1, 3.3.3.2, 3.3.4, 3.3.5, 4, 4.2, 4.3, 4.3.1, 4.4, 4.4.1, 4.5, 5.2.3.2, 5.3, 5.3.3, 7.1.2, 7.3, 9, 9.1.1, 9.1.7, 9.2, 9.2.1, 9.2.2, 9.3, 9.4.1, 9.4.2.2, 9.4.5, 9.5, $10,10.1 .7,10.2,10.3,10.4,11,11.2$, 11.2.1, 11.2.2, 11.3, 11.4, 12, 12.2, $12.3,12.4,13$

Terminologiebildung 3.3, 4.3.1, 4.3.2, 9.3

Terminologieerlass 1.1, 3.2.2, 3.2.3.2, 3.2.4.1, 3.2.4.2, 3.2.5, 3.3.1, 4.3, 4.3.1, 4.3.2, 4.3.3, 4.5, 5.3.3.1, 7.1.2, $9.2 .1,9.2 .2$

Terminologiekommission 1.3, 2.3.2, 3.1.3, 3.1.4, 3.2.1, 3.2.2, 3.2.3.2, 3.2.4.2, 3.2.5, 3.2.7, 3.3.1, 3.3.2, 3.3.3.1, 3.3.4, 3.3.5, 4.1, 4.2, 4.3, 4.3.1, 4.3.2, 4.4.1, 4.4.2.1, 4.4.2.2, 5.1, 5.2.3.1, 5.2.3.2, 5.3.3.1, 8.2.9, 9.1.2, 9.1.3, 9.2.2, 9.3, 9.5, 10.1.2, 10.1.7, 12.1.7, 12.3 
Terminologieliste (s. auch Ersatzwortliste) 2.3.3.2.3, 2.3.4.2.3, 3.1.3, 3.2.2, 3.2.3.1, 3.2.3.2, 3.2.4.1, 3.2.4.2, 3.2.5, 3.2.6, 3.2.7, 3.3.1, 3.3.2, 3.3.3.2, 3.3.4, 3.3.5, 4.1, 4.3, 4.3.1, 4.3.2, 4.3.3, 4.4.1, 5, 5.1, 5.2, 5.2.1, 5.3, 5.3.2, 5.3.3.1, 5.3.3.2, 5.4, 7.1.2.1, 7.1.2.2, 8.2.9, 9.1.1, 9.2.1, 9.2.2, 9.3, 9.4.1, 9.4.2.2, 9.4.4, 9.5, 10.2.1, 10.2.2, 10.3, 10.4, 11.2.1, 11.2.2, 11.4, 12.2, 12.4, 13, 15.7, 15.8 .8

Terminologienormierung 4.3.2

Terminologieplanung 1.1, 2.3.4.2.3, 3, 3.1.2, 3.1.3, 3.1.4, 3.2, 3.2.1, 3.2.2, 3.2.3.2, 3.2.4.1, 3.2.7, 3.3.1, 3.3.3.1, 4.3, 4.3.3, 4.4.1, 7.1.2, 8.1.1

Terminologies nouvelles 3.3.3.1, 4.3, 4.3.1

terminologisch 1.1, 2.3.2, 3.1.1, 3.2.2, 3.2.7, 3.3.3, 3.3.3.1, 3.3.5, 4, 4.4.1, 9.1.2, 9.1.7, 9.3, 9.4.2.2, 9.5, 10.4, $12.2,12.4,12.5$

Territorialitätsprinzip 2.3.3.1, 2.3.3.2.1, 2.3.4.1, 2.3.4.4

Textlinguistik 2.3.2

Textsorte 1.2, 4.3.1, 4.3.2, 4.3.3, 4.5

Tiermetaphorik 5.2.3.1

Übersetzung 2.3.4.2.1, 3.2.3.1, 3.2.5, 3.2.6, 4.1, 4.3.2, 5.1, 5.2.1, 5.2.3.1, 5.4, 7.1.2.1, 9.1.1, 9.1.3, 9.1.7, 9.3, 11.1.1, 12.1.7

Union Latine 1.1, 3.3.3.1, 3.3.3.2, 15.8.6

universalité 2.3.2, 3.2.1

Unsicherheit, sprachlich 2.1, 2.3.1, 2.3.2, 2.3.3.2, 2.3.3.2.2, 2.3.3.2.3, 2.3.3.3, 2.3.3.4, 2.3.4.2.2, 2.3.4.2.4, 2.3.4.4, 2.4, 4.4.1, 5.3, 9.3

Unterbegriff 3.3.1, 5.2.1, 5.4

Unterdrückung, sprachlich 2.3.3.2.1, 2.3.4.1, 2.3.4.2.2, 3.1.3
Unverständlichkeit 9.1.2, 9.1.5, 9.1.6, 10.1.2, 10.1.5, 10.1.6

Ursprungswort 3.2.4.2, 4.4.1, 5.1, 5.2.1, 5.2.3.1, 5.2.3.2, 9.1.2, 9.3

Usine Nouvelle 2.3.2

Variation 2.1, 2.3.2, 3.1.2

Varietät 2.1, 2.3.1, 2.3.2, 2.3.3.1, 2.3.3.2, 2.3.3.2.2, 2.3.3.2.3, 2.3.3.2.4, 2.3.3.4, 2.3.4.2.2, 2.3.4.2.3, 2.3.4.2.4, 2.3.4.4, $3.1 .2,3.1 .3,3.3 .5,4.1,5.1$

Verb 3.3.4, 5.2.1, 5.2.3.2, 9.1.4

Verein Deutsche Sprache e.V. 12.5

Verfahren

-, reaktiv 2.2

-, nicht-reaktiv 2.2

Verhaltensabsicht 2.1

Verhaltensdisposition 2.1, 2.4

Verhaltensprädiktor 2.1

Verhaltensbeobachtung 2.2, 2.4

Verkehrssprache (s. auch lingua franca) 2.3.1, 2.3.3.4, 2.3.4.3, 2.3.4.4, 4.3.2, 8.2.8, 9.1.7, 9.4.5

Verständigung 2.3.3.3, 3.1.2, 4.4.1, 9.3, $10.1 .7,10.3,12.3$

verständlich 4.4.1, 5.2.1, 7.1.1.3, 7.2.2, 9.1.2, 9.1.4, 15.5

Verständlichkeit 2.3.4.3, 3.2.2, 3.2.3.2, 4.3.1, 7.1.1.3, 7.2.1, 7.2.2, 7.3, 9.1.2, 9.1.5, 9.1.6, 10.1.2

verständnisfördernd 5.1

Verstehensprozess 5.1

Verteidigung (des Französischen) 2.3.1, 2.3.3.2.4, 2.3.4.2.3, 3.1.2, 3.2.1, 3.2.2, 3.2.3.1, 3.2.7, 3.3.1, 4.4.2.1, 5.3.3.2

Verwaltungssprache 2.3.1, 2.3.3.1, 4.3.1

Verwendungshäufigkeit 9.1.2, 9.1.5

Vokabular 1.1, 2.3.2, 3.2.2, 3.2.5, 3.3.1, 3.3.2, 4.3, 4.3.1, 4.3.2, 4.4.2.3, 4.5, 5.1, 5.2, 5.2.1, 5.2.3.2, 5.3.2, 9.1.2, 12.5

Volkslinguistik 2.1

Vollform 5.2.1, 5.2.3.1, 5.2.3.2, 9.1.3 
Vorstellungen von Sprache 2.1, 2.3.3.2, 2.3.3.4, 3.2.1, 4.3.2

Weltgeltung (des Französischen) 4.4.2.2

Wirtschaftssprache 2.3.3.3, 3.2.1, 10.3

Wortalternativentest 4.3.1

Wortbildung 5.1, 5.4

Wortbildungsmuster 4.4.1

Wortbildungsprodukt 11.1.7

Wortbildungsregel 4.1, 4.4.1, 5.2.3.1

Wortbildungsschema 5, 5.2.3.1, 5.4

Wortbildungsverfahren 4.3.1, 9.1.2

Wörterbuch (dictionnaire) 2.1, 2.3.2,

2.3.3.2.2, 2.3.3.2.3, 2.3.3.3, 2.3.4.2.3, 2.3.4.4, 3.2.1, 3.2.4.1, 3.2.5, 3.3.3.1, 3.3.3.2, 4.2, 4.3.1, 4.3.2, 4.3.3, 4.4.2.1, 4.4.2.3, 4.5, 5.2.1, 15.5.2.2, 15.5.2.3, 15.8.4, 15.8 .8 (s. auch Anglizismenwörterbuch)

Wortfeld 1.3, 3.3.1, 3.3.2, 3.3.3.2, 3.3.5, 4.3.1, 4.4.1, 5.2, 5.2.1, 5.2.3.1, 5.4, $9.1 .5,9.2 .1,11.2 .1$
Wortgut (s. Lexik/Lexikon)

Wortkenntnis 5.3.1, 12.4

Wortkürzung (s. Kurzwort)

Wortliste (s. Terminologieliste)

Wortschatz (s. Lexik/Lexikon)

Wortstamm 5.1

Wortverwendung 5.3.1

Wortwahl 4.4.2.3, 13

Wortzusammensetzung (s. Determinativkompositum)

WWW-Befragung (s. Befragung)

Xenismus (s. Fremdwort)

Zielsprache 5.1, 5.2.3.1

Zwei-Phasen-Pretesting 7.2.1

zweisprachig 2.3.3.1, 2.3.3.2.4, 2.3.3.4, 2.3.4.1, 2.3.4.2.2, 3.3.2, 4.2, 8.2.6, 12.1.7

Zweisprachigkeit 2.3.4.1, 10.4 